Social Problems 


\section{Social Problems}

\section{Continuity and Change}

[Author removed at request of original publisher]

UNIVERSITY OF MINNESOTA LIBRARIES PUBLISHING EDITION, 2015. THIS EDITION ADAPTED FROM A WORK ORIGINALLY PRODUCED IN 2010 BY A PUBLISHER WHO HAS REQUESTED THAT IT NOT RECEIVE ATTRIBUTION.

MINNEAPOLIS, MN 


\section{() (1) $\circledast(0$}

Social Problems by University of Minnesota is licensed under a Creative Commons Attribution-NonCommercial-ShareAlike 4.0 International License, except where otherwise noted. 



\section{Contents}

Chapter 1: Understanding Social Problems

1.1 What Is a Social Problem?

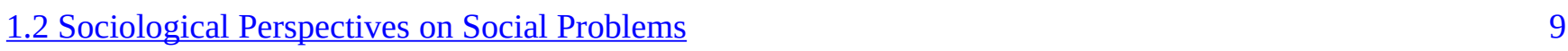

$\begin{array}{lr}1.3 \text { Continuity and Change in Social Problems } & 21\end{array}$

$\begin{array}{lr}\text { 1.4 Doing Research on Social Problems } & 25\end{array}$

$\begin{array}{lr}1.5 \text { End-of-Chapter Material } & 30\end{array}$

Chapter 2: Poverty

2.1 The Measurement and Extent of Poverty 33

$\begin{array}{ll}2.2 \text { Who the Poor Are: Social Patterns of Poverty } & 37\end{array}$

$\begin{array}{lr}2.3 \text { Explaining Poverty } & 46\end{array}$

$\begin{array}{ll}2.4 \text { The Consequences of Poverty } & 57\end{array}$

$\begin{array}{ll}2.5 \text { Global Poverty } & 64\end{array}$

$\begin{array}{lr}2.6 \text { Reducing Poverty } & 78\end{array}$

$\begin{array}{lr}2.7 \text { End-of-Chapter Material } & 83\end{array}$

Chapter 3: Racial and Ethnic Inequality

3.1 Racial and Ethnic Inequality: A Historical Prelude $\quad 87$

$\begin{array}{ll}3.2 \text { The Meaning of Race and Ethnicity } & 90\end{array}$

$\begin{array}{lr}3.3 \text { Prejudice } & 96\end{array}$

$\begin{array}{lr}3.4 \text { Discrimination } & 107\end{array}$

$\begin{array}{lr}\text { 3.5 Dimensions of Racial and Ethnic Inequality } & 118\end{array}$

$\begin{array}{ll}3.6 \text { Explaining Racial and Ethnic Inequality } & 124\end{array}$

3.7 Reducing Racial and Ethnic Inequality 129

3.8 End-of-Chapter Material 135

Chapter 4: Gender Inequality

4.1 Understanding Sex and Gender $\quad 138$

4.2 Feminism and Sexism 152

4.3 Dimensions of Gender Inequality 156

$\begin{array}{ll}\text { 4.4 Violence against Women: Rape and Sexual Assault } & 171\end{array}$

$\begin{array}{ll}\text { 4.5 The Benefits and Costs of Being Male } & 177\end{array}$ 


\section{Chapter 5: Sexual Orientation and Inequality}

$\begin{array}{lr}5.1 \text { Understanding Sexual Orientation } & 187\end{array}$

$\begin{array}{lr}5.2 \text { Public Attitudes about Sexual Orientation } & 198\end{array}$

$\begin{array}{lr}5.3 \text { Inequality Based on Sexual Orientation } & 208\end{array}$

$\begin{array}{ll}5.4 \text { Improving the Lives of the LGBT Community } & 222\end{array}$

$\begin{array}{lr}5.5 \text { End-of-Chapter Material } & 224\end{array}$

\section{Chapter 6: Aging and Ageism}

6.1 The Concept and Experience of Aging $\quad 227$

$\begin{array}{lr}6.2 \text { Perspectives on Aging } & 230\end{array}$

6.3 Life Expectancy and the Graying of Society 233

$\begin{array}{ll}\text { 6.4 Biological and Psychological Aspects of Aging } & 239\end{array}$

$\begin{array}{lr}6.5 \text { Problems Facing Older Americans } & 245\end{array}$

$\begin{array}{ll}\text { 6.6 Reducing Ageism and Helping Older Americans } & 260\end{array}$

$\begin{array}{lr}6.7 \text { End-of-Chapter Material } & 263\end{array}$

\section{Chapter 7: Alcohol and Other Drugs}

$\begin{array}{ll}7.1 \text { Drug Use in History } & 266\end{array}$

$\begin{array}{lr}7.2 \text { Drugs and Drug Use Today } & 272\end{array}$

7.3 Social Patterning of Drug Use 293

$\begin{array}{lr}7.4 \text { Explaining Drug Use } & 300\end{array}$

$\begin{array}{ll}7.5 \text { Drug Policy and the War on Illegal Drugs } & 307\end{array}$

7.6 Addressing the Drug Problem and Reducing Drug Use 316

$\begin{array}{lr}7.7 \text { End-of-Chapter Material } & 320\end{array}$

Chapter 8: Crime and Criminal Justice

$\begin{array}{ll}\text { 8.1 The Problem of Crime } & 322\end{array}$

$\begin{array}{lr}\text { 8.2 Types of Crime } & 328\end{array}$

$\begin{array}{ll}8.3 \text { Who Commits Crime? } & 337\end{array}$

8.4 Explaining Crime $\quad 343$

$\begin{array}{ll}\text { 8.5 The Criminal Justice System } & 354\end{array}$

$\begin{array}{ll}\text { 8.6 Reducing Crime } & 363\end{array}$

$\begin{array}{ll}\text { 8.7 End-of-Chapter Material } & 368\end{array}$ 
Chapter 9: Sexual Behavior

9.1 An Overview of Heterosexuality $\quad 371$

$\begin{array}{lr}9.2 \text { Teenage Sex and Pregnancy } & 380\end{array}$

$\begin{array}{ll}9.3 \text { Abortion } & 391\end{array}$

9.4 Prostitution 404

$\begin{array}{ll}9.5 \text { Pornography } & 415\end{array}$

$\begin{array}{ll}9.6 \text { End-of-Chapter Material } & 421\end{array}$

Chapter 10: The Changing Family

10.1 Overview of the Family $\quad 426$

10.2 Sociological Perspectives on the Family $\quad 434$

10.3 Changes and Problems in American Families $\quad 439$

$\begin{array}{ll}10.4 \text { Families in the Future } & 459\end{array}$

10.5 End-of-Chapter Material $\quad 462$

Chapter 11: Schools and Education

11.1 An Overview of Education in the United States $\quad 466$

$\begin{array}{ll}\text { 11.2 Sociological Perspectives on Education } & 477\end{array}$

11.3 Issues and Problems in Elementary and Secondary Education $\quad 484$

11.4 Issues and Problems in Higher Education $\quad 498$

$\begin{array}{ll}11.5 \text { Improving Schools and Education } & 506\end{array}$

$\begin{array}{lr}11.6 \text { End-of-Chapter Material } & 511\end{array}$

Chapter 12: Work and the Economy

$\begin{array}{ll}12.1 \text { Overview of the Economy } & 514\end{array}$

12.2 Sociological Perspectives on Work and the Economy 523

$\begin{array}{ll}12.3 \text { Problems in Work and the Economy } & 529\end{array}$

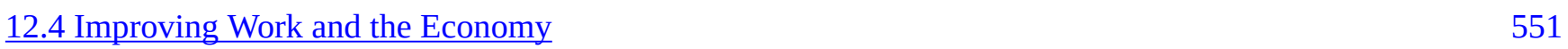

12.5 End-of-Chapter Material $\quad 555$

Chapter 13: Health and Health Care

13.1 Sociological Perspectives on Health and Health Care $\quad 558$

13.2 Global Aspects of Health and Health Care 565

$\begin{array}{ll}\text { 13.3 Problems of Health in the United States } & 571\end{array}$

13.4 Problems of Health Care in the United States $\quad 587$

\begin{tabular}{ll}
13.5 Improving Health and Health Care & 598 \\
\hline
\end{tabular}

13.6 End-of-Chapter Material $\quad 603$ 


\section{Chapter 14: Urban and Rural Problems}

14.1 A Brief History of Urbanization $\quad 606$

$\begin{array}{ll}\text { 14.2 Sociological Perspectives on Urbanization } & 614\end{array}$

$\begin{array}{ll}\text { 14.3 Problems of Urban Life } & 621\end{array}$

14.4 Problems of Rural Life $\quad 636$

$\begin{array}{ll}14.5 \text { Improving Urban and Rural Life } & 641\end{array}$

14.6 End-of-Chapter Material $\quad 643$

Chapter 15: Population and the Environment

15.1 Sociological Perspectives on Population and the Environment $\quad 645$

$\begin{array}{ll}15.2 \text { Population } & 649\end{array}$

$\begin{array}{lr}15.3 \text { The Environment } & 670\end{array}$

15.4 Addressing Population Problems and Improving the Environment $\quad 690$

15.5 End-of-Chapter Material $\quad 694$

Chapter 16: War and Terrorism

16.1 Sociological Perspectives on War and Terrorism $\quad 699$

$\begin{array}{ll}16.2 \mathrm{War} & 705\end{array}$

$\begin{array}{lr}16.3 \text { Terrorism } & 728\end{array}$

$\begin{array}{ll}\text { 16.4 Preventing War and Stopping Terrorism } & 736\end{array}$

$\begin{array}{lr}16.5 \text { End-of-Chapter Material } & 740\end{array}$

$\begin{array}{lr}\text { Supplementary materials } & 742\end{array}$ 


\section{Publisher Information}

Social Problems: Continuity and Change is adapted from a work produced and distributed under a Creative Commons license (CC BYNC-SA) in 2010 by a publisher who has requested that they and the original author not receive attribution. This

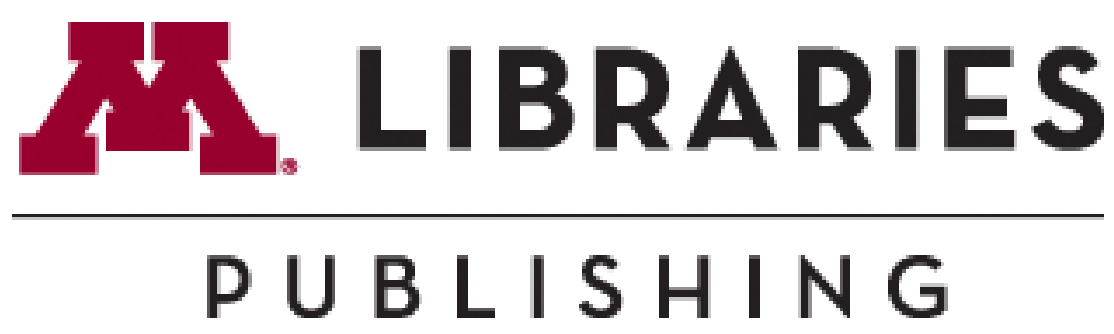
adapted edition is produced by the University of Minnesota Libraries Publishing through the eLearning Support Initiative.

This adaptation has reformatted the original text, and replaced some images and figures to make the resulting whole more shareable. This adaptation has not significantly altered or updated the original 2010 text. This work is made available under the terms of a Creative Commons Attribution-NonCommercial-ShareAlike license.

For questions about this textbook please contact textbookuse@umn.edu 


\section{Chapter 1: Understanding Social Problems}

1.1 What Is a Social Problem?

1.2 Sociological Perspectives on Social Problems

1.3 Continuity and Change in Social Problems

1.4 Doing Research on Social Problems

1.5 End-of-Chapter Material 


\subsection{What Is a Social Problem?}

\section{Learning Objectives}

1. Define "social problem."

2. Explain the objective and subjective components of the definition of a social problem.

3. Understand the social constructionist view of social problems.

4. List the stages of the natural history of social problems.

A social problem is any condition or behavior that has negative consequences for large numbers of people and that is generally recognized as a condition or behavior that needs to be addressed. This definition has both an objective component and a subjective component.

The objective component is this: For any condition or behavior to be considered a social problem, it must have negative consequences for large numbers of people, as each chapter of this book discusses. How do we know if a social problem has negative consequences? Reasonable people can and do disagree on whether such consequences exist and, if so, on their extent and seriousness, but ordinarily a body of data accumulates-from work by academic researchers, government agencies, and other sources-that strongly points to extensive and serious consequences. The reasons for these consequences are often hotly debated, and sometimes, as we shall see in certain chapters in this book, sometimes the very existence of these consequences is disputed. A current example is climate change: Although the overwhelming majority of climate scientists say that climate change (changes in the earth's climate due to the buildup of greenhouse gases in the atmosphere) is real and serious, fewer than twothirds of Americans (64 percent) in a 2011 poll said they “think that global warming is happening”(Leiserowitz, et. al., 2011).

This type of dispute points to the subjective component of the definition of social problems: There must be a perception that a condition or behavior needs to be addressed for it to be considered a social problem. This component lies at the heart of the social constructionist view of social problems (Rubington \& Weinberg, 2010). In this view, many types of negative conditions and behaviors exist. Many of these are considered sufficiently negative to acquire the status of a social problem; some do not receive this consideration and thus do not become a social problem; and some become considered a social problem only if citizens, policymakers, or other parties call attention to the condition or behavior. 


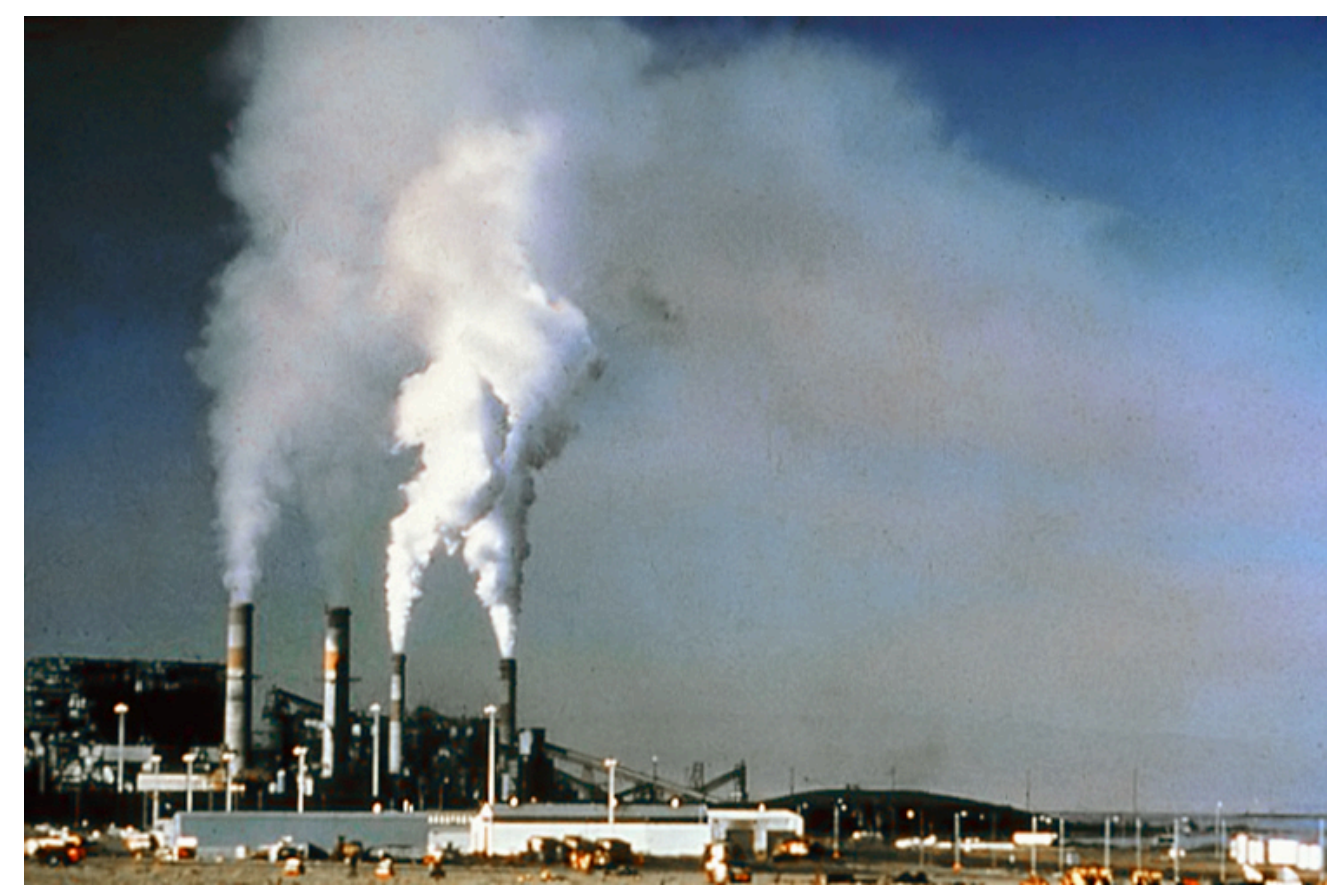

Sometimes disputes occur over whether a particular condition or behavior has negative consequences and is thus a social problem. A current example is climate change: although almost all climate scientists think climate change is real and serious, more than one-third of the American public thinks that climate change is not happening.

Wikimedia Commons - public domain.

The history of attention given to rape and sexual assault in the United States before and after the 1970s provides an example of this latter situation. These acts of sexual violence against women have probably occurred from the beginning of humanity and certainly were very common in the United States before the 1970s. Although men were sometimes arrested and prosecuted for rape and sexual assault, sexual violence was otherwise ignored by legal policymakers and received little attention in college textbooks and the news media, and many people thought that rape and sexual assault were just something that happened (Allison \& Wrightsman, 1993). Thus although sexual violence existed, it was not considered a social problem. When the contemporary women's movement began in the late 1970s, it soon focused on rape and sexual assault as serious crimes and as manifestations of women's inequality. Thanks to this focus, rape and sexual assault eventually entered the public consciousness, views of these crimes began to change, and legal policymakers began to give them more attention. In short, sexual violence against women became a social problem. 


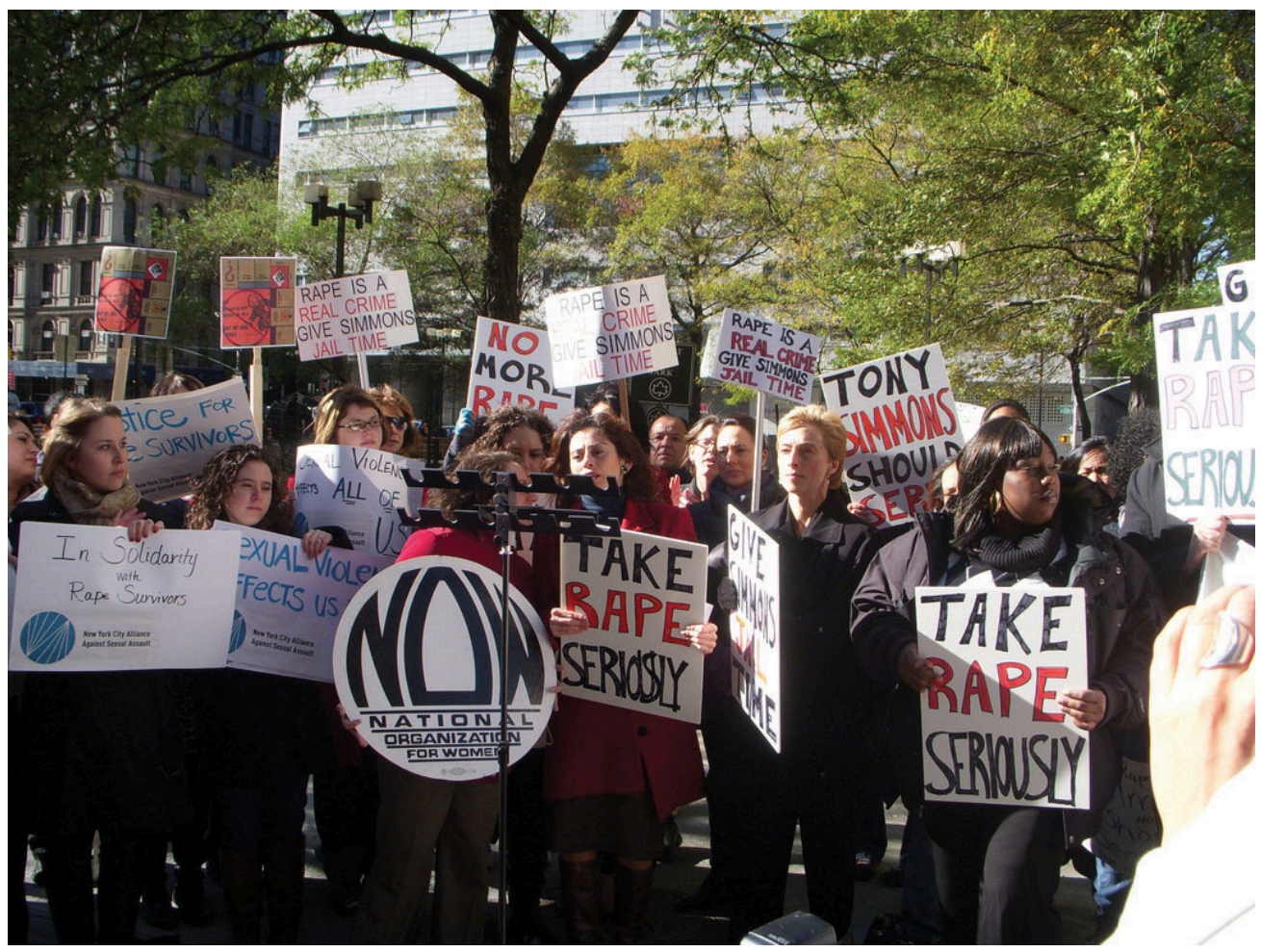

Before the 1970s, rape and sexual assault certainly existed and were very common, but they were generally ignored and not considered a social problem. When the contemporary women's movement arose during the 1970s, it focused on sexual violence against women and turned this behavior into a social problem.

Women's e News - Placards at the Rally To Take Rape Seriously - CC BY 2.0.

The social constructionist view raises an interesting question: When is a social problem a social problem? According to some sociologists who adopt this view, negative conditions and behaviors are not a social problem unless they are recognized as such by policymakers, large numbers of lay citizens, or other segments of our society; these sociologists would thus say that rape and sexual assault before the 1970s were not a social problem because our society as a whole paid them little attention. Other sociologists say that negative conditions and behaviors should be considered a social problem even if they receive little or no attention; these sociologists would thus say that rape and sexual assault before the 1970s were a social problem.

This type of debate is probably akin to the age-old question: If a tree falls in a forest and no one is there to hear it, is a sound made? As such, it is not easy to answer, but it does reinforce one of the key beliefs of the social constructionist view: Perception matters at least as much as reality, and sometimes more so. In line with this belief, social constructionism emphasizes that citizens, interest groups, policymakers, and other parties often compete to influence popular perceptions of many types of conditions and behaviors. They try to influence news media coverage and popular views of the nature and extent of any negative consequences that may be occurring, the reasons underlying the condition or behavior in question, and possible solutions to the problem. 


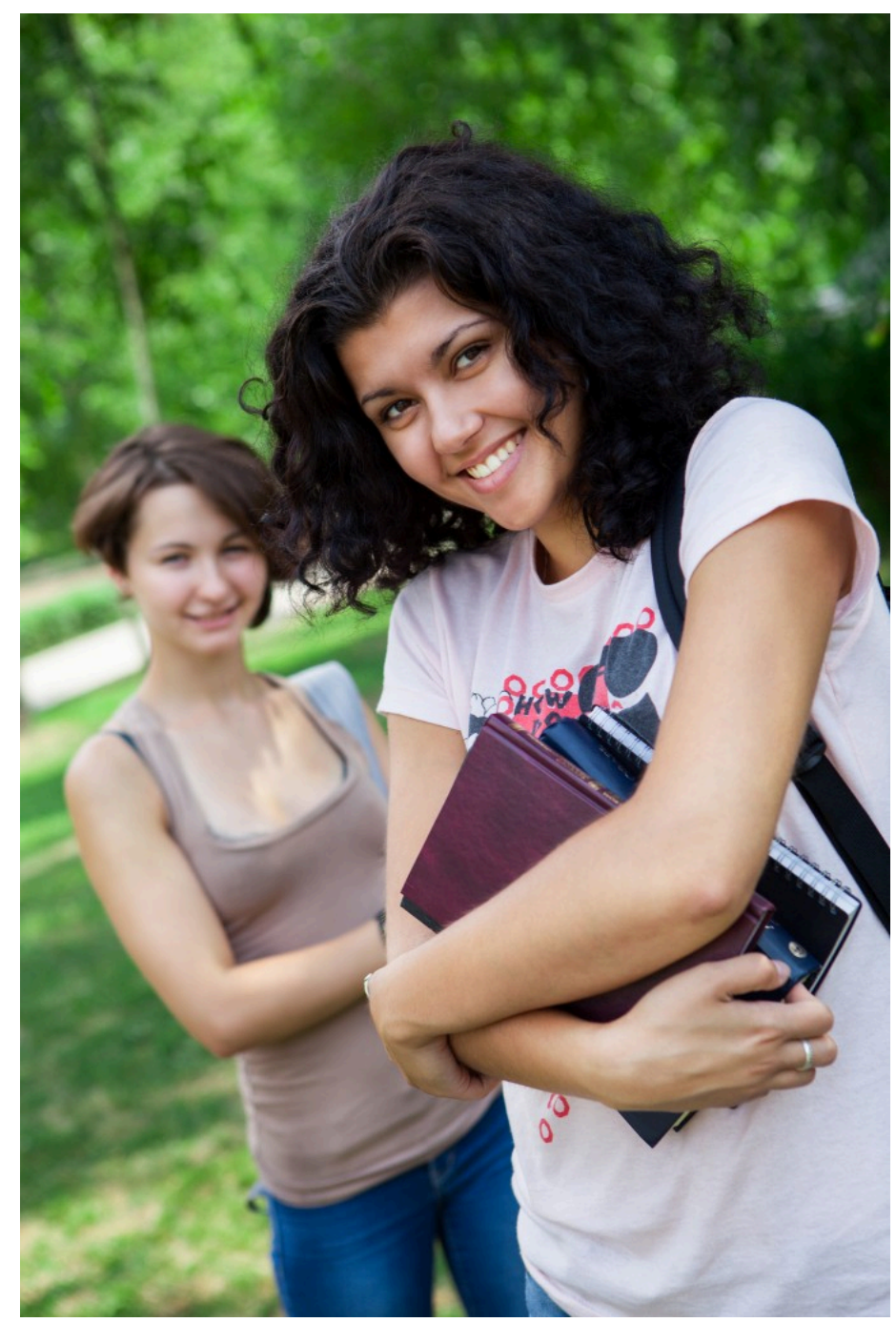

Sometimes a condition or behavior becomes a social problem even if there is little or no basis for this perception. A historical example involves women in college. During the late 1800s, medical authorities and other experts warned women not to go to college for two reasons: they feared that the stress of college would disrupt women's menstrual cycles, and they thought that women would not do well on exams while they were menstruating.

CollegeDegrees360 - College Girls - CC BY-SA 2.0.

Social constructionism's emphasis on perception has a provocative implication: Just as a condition or behavior may not be considered a social problem even if there is strong basis for this perception, so may a condition or behavior be considered a social problem even if there is little or no basis for this perception. The "issue" of women in college provides a historical example of this latter possibility. In the late 1800s, leading physicians and medical researchers in the United States wrote journal articles, textbooks, and newspaper columns in which they warned women not to go to college. The reason? They feared that the stress of college would disrupt women's menstrual cycles, and they also feared that women would not do well in exams during "that time of the month" (Ehrenreich \& English, 2005)! We now know better, of course, but the sexist beliefs of these writers turned the idea of women going to college into a social problem and helped to reinforce restrictions by colleges and universities on the admission of women. 
In a related dynamic, various parties can distort certain aspects of a social problem that does exist: politicians can give speeches, the news media can use scary headlines and heavy coverage to capture readers' or viewers' interest, businesses can use advertising and influence news coverage. News media coverage of violent crime provides many examples of this dynamic (Robinson, 2011; Surette, 2011). The news media overdramatize violent crime, which is far less common than property crime like burglary and larceny, by featuring so many stories about it, and this coverage contributes to public fear of crime. Media stories about violent crime also tend to be more common when the accused offender is black and the victim is white and when the offender is a juvenile. This type of coverage is thought to heighten the public's prejudice toward African Americans and to contribute to negative views about teenagers.

\section{The Natural History of a Social Problem}

We have just discussed some of the difficulties in defining a social problem and the fact that various parties often try to influence public perceptions of social problems. These issues aside, most social problems go through a natural history consisting of several stages of their development (Spector \& Kitsuse, 2001).

\section{Stage 1: Emergence and Claims Making}

A social problem emerges when a social entity (such as a social change group, the news media, or influential politicians) begins to call attention to a condition or behavior that it perceives to be undesirable and in need of remedy. As part of this process, it tries to influence public perceptions of the problem, the reasons for it, and possible solutions to it. Because the social entity is making claims about all these matters, this aspect of Stage 1 is termed the claims-making process. Not all efforts to turn a condition or behavior into a social problem succeed, and if they do not succeed, a social problem does not emerge. Because of the resources they have or do not have, some social entities are more likely than others to succeed at this stage. A few ordinary individuals have little influence in the public sphere, but masses of individuals who engage in protest or other political activity have greater ability to help a social problem emerge. Because politicians have the ear of the news media and other types of influence, their views about social problems are often very influential. Most studies of this stage of a social problem focus on the efforts of social change groups and the larger social movement to which they may belong, as most social problems begin with bottom-up efforts from such groups. 


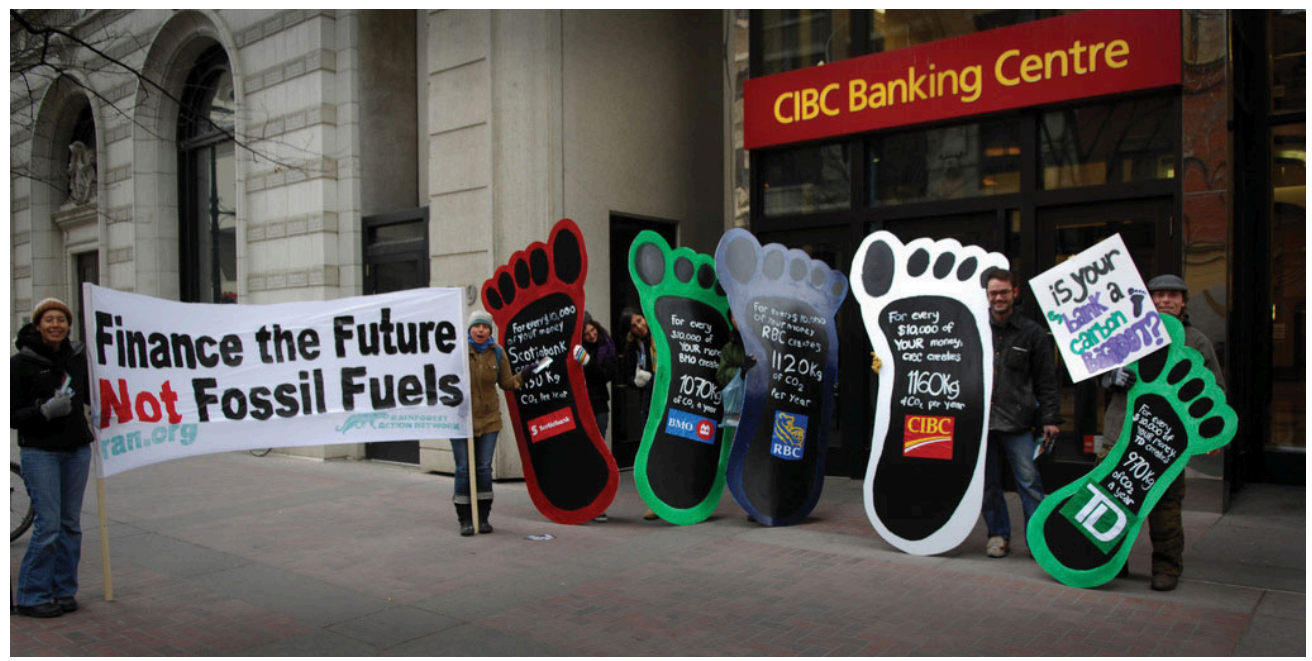

A social problem emerges when a social change group successfully calls attention to a condition or behavior that it considers serious. Protests like the one depicted here have raised the environmental consciousness of Americans and helped put pressure on businesses to be environmentally responsible.

ItzaFineDay - Financing Climate Change - CC BY 2.0.

\section{Stage 2: Legitimacy}

Once a social group succeeds in turning a condition or behavior into a social problem, it usually tries to persuade the government (local, state, and/or federal) to take some action—spending and policymaking — to address the problem. As part of this effort, it tries to convince the government that its claims about the problem are legitimate - that they make sense and are supported by empirical (research-based) evidence. To the extent that the group succeeds in convincing the government of the legitimacy of its claims, government action is that much more likely to occur.

\section{Stage 3: Renewed Claims Making}

Even if government action does occur, social change groups often conclude that the action is too limited in goals or scope to be able to successfully address the social problem. If they reach this conclusion, they often decide to press their demands anew. They do so by reasserting their claims and by criticizing the official response they have received from the government or other established interests, such as big businesses. This stage may involve a fair amount of tension between the social change groups and these targets of their claims.

\section{Stage 4: Development of Alternative Strategies}

Despite the renewed claims making, social change groups often conclude that the government and established interests are not responding adequately to their claims. Although the groups may continue to press their claims, 
they nonetheless realize that these claims may fail to win an adequate response from established interests. This realization leads them to develop their own strategies for addressing the social problem.

\section{Key Takeaways}

- The definition of a social problem has both an objective component and a subjective component. The objective component involves empirical evidence of the negative consequences of a social condition or behavior, while the subjective component involves the perception that the condition or behavior is indeed a problem that needs to be addressed.

- The social constructionist view emphasizes that a condition or behavior does not become a social problem unless there is a perception that it should be considered a social problem.

- The natural history of a social problem consists of four stages: emergence and claims making, legitimacy, renewed claims making, and alternative strategies.

\section{For Your Review}

1. What do you think is the most important social problem facing our nation right now? Explain your answer.

2. Do you agree with the social constructionist view that a negative social condition or behavior is not a social problem unless there is a perception that it should be considered a social problem? Why or why not?

\section{References}

Allison, J. A., \& Wrightsman, L. S. (1993). Rape: The misunderstood crime. Thousand Oaks, CA: Sage Publications.

Ehrenreich, B., \& English, D. (2005). For her own good: Two centuries of the experts' advice to women (2nd ed.). New York, NY: Anchor Books.

Leiserowitz, A., Maibach, E., Roser-Renouf, C., \& Smith, N. (2011). Climate change in the American mind: Americans' global warming beliefs and attitudes in May 2011. New Haven, CT: Yale Project on Climate Change Communication.

Robinson, M. B. (2011). Media coverage of crime and criminal justice. Durham, NC: Carolina Academic Press.

Rubington, E., \& Weinberg, M. S. (2010). The study of social problems: Seven perspectives (7th ed.). New York, NY: Oxford University Press.

Spector, M., \& Kitsuse, J. I. (2001). Constructing social problems. New Brunswick, NJ: Transaction.

Surette, R. (2011). Media, crime, and criminal justice: Images, realities, and policies (4th ed.). Belmont, CA: Wadsworth. 


\subsection{Sociological Perspectives on Social Problems}

\section{Learning Objectives}

1. Define the sociological imagination.

2. Explain what is meant by the blaming-the-victim belief.

3. Summarize the most important beliefs and assumptions of functionalism and conflict theory.

4. Summarize the most important beliefs and assumptions of symbolic interactionism and exchange theory.

The sociological understanding of social problems rests heavily on the concept of the sociological imagination. We discuss this concept in some detail before turning to various theoretical perspectives that provide a further context for understanding social problems.

\section{The Sociological Imagination}

Many individuals experience one or more social problems personally. For example, many people are poor and unemployed, many are in poor health, and many have family problems, drink too much alcohol, or commit crime. When we hear about these individuals, it is easy to think that their problems are theirs alone, and that they and other individuals with the same problems are entirely to blame for their difficulties.

Sociology takes a different approach, as it stresses that individual problems are often rooted in problems stemming from aspects of society itself. This key insight informed C. Wright Mills's (1959) (Mills, 1959) classic distinction between personal troubles and public issues. Personal troubles refer to a problem affecting individuals that the affected individual, as well as other members of society, typically blame on the individual's own personal and moral failings. Examples include such different problems as eating disorders, divorce, and unemployment. Public issues, whose source lies in the social structure and culture of a society, refer to social problems affecting many individuals. Problems in society thus help account for problems that individuals experience. Mills felt that many problems ordinarily considered private troubles are best understood as public issues, and he coined the term sociological imagination to refer to the ability to appreciate the structural basis for individual problems.

To illustrate Mills's viewpoint, let's use our sociological imaginations to understand some contemporary social problems. We will start with unemployment, which Mills himself discussed. If only a few people were unemployed, Mills wrote, we could reasonably explain their unemployment by saying they were lazy, lacked good work habits, and so forth. If so, their unemployment would be their own personal trouble. But when millions of people are out of work, unemployment is best understood as a public issue because, as Mills (Mills, 1959) put it, "the very structure of opportunities has collapsed. Both the correct statement of the problem and the range of 
possible solutions require us to consider the economic and political institutions of the society, and not merely the personal situation and character of a scatter of individuals.”

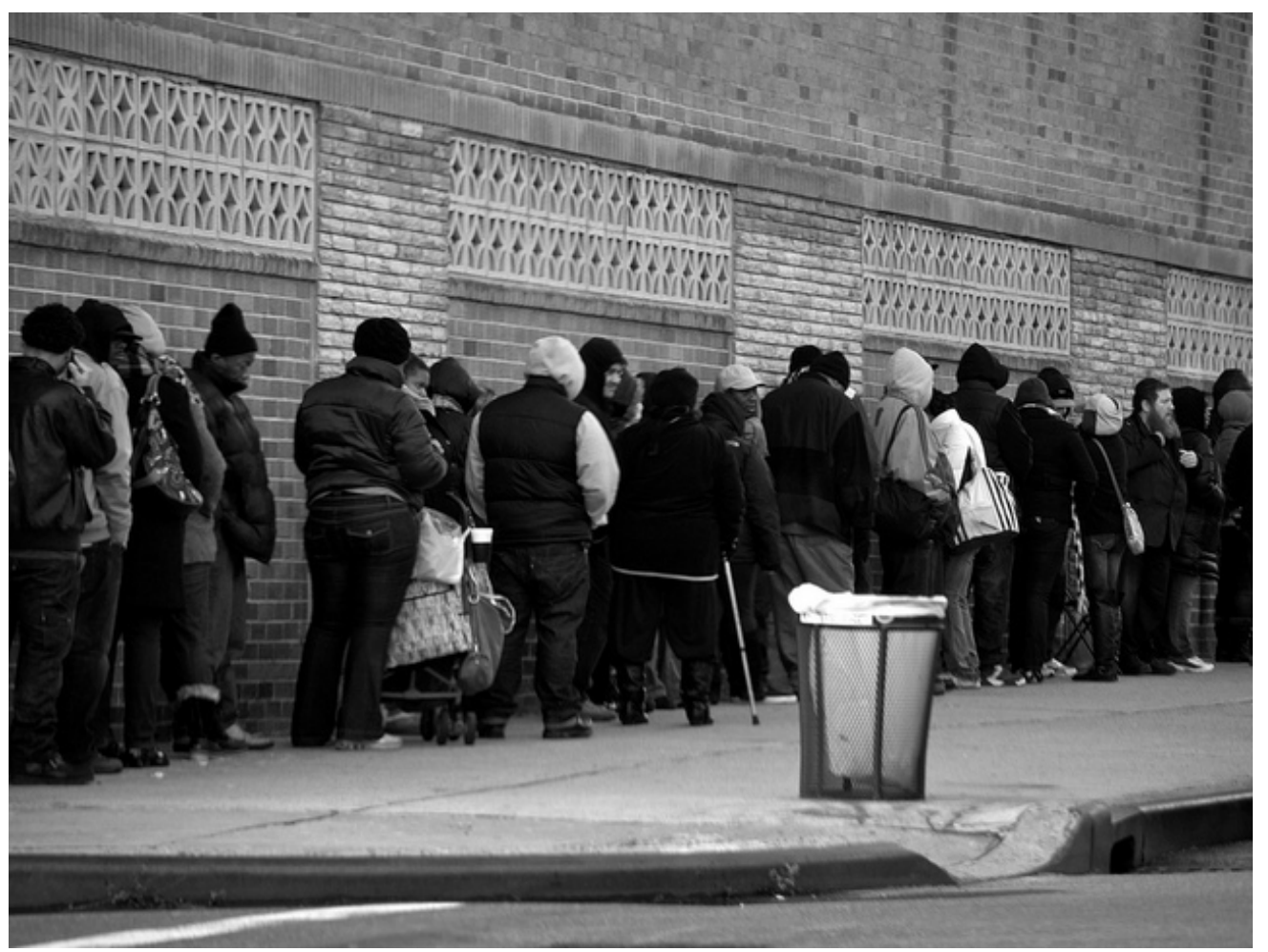

When only a few people are out of work, it is fair to say that their unemployment is their personal trouble. However, when millions of people are out of work, as has been true since the economic downturn began in 2008, this massive unemployment is more accurately viewed as a public issue. As such, its causes lie not in the unemployed individuals but rather in our society's economic and social systems.

Rawle C. Jackman - The line of hope... - CC BY-NC-ND 2.0.

The high US unemployment rate stemming from the severe economic downturn that began in 2008 provides a telling example of the point Mills was making. Millions of people lost their jobs through no fault of their own. While some individuals are undoubtedly unemployed because they are lazy or lack good work habits, a more structural explanation focusing on lack of opportunity is needed to explain why so many people were out of work. If so, unemployment is best understood as a public issue rather than a personal trouble.

Another social problem is eating disorders. We usually consider a person's eating disorder to be a personal trouble that stems from a lack of control, low self-esteem, or another personal problem. This explanation may be OK as far as it goes, but it does not help us understand why so many people have the personal problems that lead to eating disorders. Perhaps more important, this belief also neglects the larger social and cultural forces that help explain such disorders. For example, most Americans with eating disorders are women, not men. This gender difference forces us to ask what it is about being a woman in American society that makes eating disorders so much more common. To begin to answer this question, we need to look to the standard of beauty for women that emphasizes a slender body (Boyd, et. al., 2011). If this cultural standard did not exist, far fewer American women would suffer from eating disorders than do now. Because it does exist, even if every girl and woman with an eating disorder 
were cured, others would take their places unless we could somehow change this standard. Viewed in this way, eating disorders are best understood as a public issue, not just as a personal trouble.

Picking up on Mills’s insights, William Ryan (1976) (Ryan, 1976) pointed out that Americans typically think that social problems such as poverty and unemployment stem from personal failings of the people experiencing these problems, not from structural problems in the larger society. Using Mills's terms, Americans tend to think of social problems as personal troubles rather than public issues. As Ryan put it, they tend to believe in blaming the victim rather than blaming the system.

To help us understand a blaming-the-victim ideology, let's consider why poor children in urban areas often learn very little in their schools. According to Ryan, a blaming-the-victim approach would say the children's parents do not care about their learning, fail to teach them good study habits, and do not encourage them to take school seriously. This type of explanation, he wrote, may apply to some parents, but it ignores a much more important reason: the sad shape of America's urban schools, which, he said, are overcrowded, decrepit structures housing old textbooks and out-of-date equipment. To improve the schooling of children in urban areas, he wrote, we must improve the schools themselves and not just try to "improve” the parents.

As this example suggests, a blaming-the-victim approach points to solutions to social problems such as poverty and illiteracy that are very different from those suggested by a more structural approach that blames the system. If we blame the victim, we would spend our limited dollars to address the personal failings of individuals who suffer from poverty, illiteracy, poor health, eating disorders, and other difficulties. If instead we blame the system, we would focus our attention on the various social conditions (decrepit schools, cultural standards of female beauty, and the like) that account for these difficulties. A sociological understanding suggests that the latter approach is ultimately needed to help us deal successfully with the social problems facing us today.

\section{Theoretical Perspectives}

Three theoretical perspectives guide sociological thinking on social problems: functionalist theory, conflict theory, and symbolic interactionist theory. These perspectives look at the same social problems, but they do so in different ways. Their views taken together offer a fuller understanding of social problems than any of the views can offer alone. Table 1.1 "Theory Snapshot" summarizes the three perspectives.

Table 1.1 Theory Snapshot 


\begin{tabular}{|l|l|l|}
\hline $\begin{array}{l}\text { Theoretical } \\
\text { perspective }\end{array}$ & Major assumptions & Views of social problems \\
\hline Functionalism & $\begin{array}{l}\text { Social stability is necessary for a strong society, and } \\
\text { adequate socialization and social integration are } \\
\text { necessary for social stability. Society's social institutions } \\
\text { perform important functions to help ensure social } \\
\text { stability. Slow social change is desirable, but rapid social } \\
\text { change threatens social order. }\end{array}$ & $\begin{array}{l}\text { Social problems weaken a society's stability } \\
\text { but do not reflect fundamental faults in how } \\
\text { the society is structured. Solutions to social } \\
\text { problems should take the form of gradual } \\
\text { social reform rather than sudden and } \\
\text { far-reaching change. Despite their negative } \\
\text { effects, social problems often also serve } \\
\text { important functions for society. }\end{array}$ \\
\hline $\begin{array}{l}\text { Conflict } \\
\text { theory }\end{array}$ & $\begin{array}{l}\text { Society is characterized by pervasive inequality based on } \\
\text { social class, race, gender, and other factors. Far-reaching } \\
\text { social change is needed to reduce or eliminate social } \\
\text { inequality and to create an egalitarian society. }\end{array}$ & $\begin{array}{l}\text { Social problems arise from fundamental faults } \\
\text { in the structure of a society and both reflect } \\
\text { and reinforce inequalities based on social } \\
\text { class, race, gender, and other dimensions. } \\
\text { Successful solutions to social problems must } \\
\text { involve far-reaching change in the structure of } \\
\text { society. }\end{array}$ \\
\hline $\begin{array}{l}\text { Symbolic } \\
\text { interactionism }\end{array}$ & $\begin{array}{l}\text { People construct their roles as they interact; they do not } \\
\text { merely learn the roles that society has set out for them. } \\
\text { As this interaction occurs, individuals negotiate their } \\
\text { definitions of the situations in which they find } \\
\text { themselves and socially construct the reality of these } \\
\text { situations. In so doing, they rely heavily on symbols } \\
\text { such as words and gestures to reach a shared } \\
\text { understanding of their interaction. }\end{array}$ & $\begin{array}{l}\text { Social problems arise from the interaction of } \\
\text { individuals. People who engage in socially } \\
\text { problematic behaviors often learn these } \\
\text { behaviors from other people. Individuals also } \\
\text { learn their perceptions of social problems } \\
\text { from other people. }\end{array}$ \\
\hline
\end{tabular}

\section{Functionalism}

Functionalism, also known as the functionalist theory or perspective, arose out of two great revolutions of the eighteenth and nineteenth centuries. The first was the French Revolution of 1789, whose intense violence and bloody terror shook Europe to its core. The aristocracy throughout Europe feared that revolution would spread to their own lands, and intellectuals feared that social order was crumbling.

The Industrial Revolution of the nineteenth century reinforced these concerns. Starting first in Europe and then in the United States, the Industrial Revolution led to many changes, including the rise and growth of cities as people left their farms to live near factories. As the cities grew, people lived in increasingly poor, crowded, and decrepit conditions, and crime was rampant. Here was additional evidence, if European intellectuals needed it, of the breakdown of social order.

In response, the intellectuals began to write that a strong society, as exemplified by strong social bonds and rules and effective socialization, was needed to prevent social order from disintegrating. Without a strong society and effective socialization, they warned, social order breaks down, and violence and other signs of social disorder result.

This general framework reached fruition in the writings of Émile Durkheim (1858-1917), a French scholar largely responsible for the sociological perspective, as we now know it. Adopting the conservative intellectuals' view of the need for a strong society, Durkheim felt that human beings have desires that result in chaos unless society limits them (Durkheim, 1952). It does so, he wrote, through two related social mechanisms: socialization 
and social integration. Socialization helps us learn society's rules and the need to cooperate, as people end up generally agreeing on important norms and values, while social integration, or our ties to other people and to social institutions such as religion and the family, helps socialize us and integrate us into society and reinforce our respect for its rules.

Today's functionalist perspective arises out of Durkheim's work and that of other conservative intellectuals of the nineteenth century. It uses the human body as a model for understanding society. In the human body, our various organs and other body parts serve important functions for the ongoing health and stability of our body. Our eyes help us see, our ears help us hear, our heart circulates our blood, and so forth. Just as we can understand the body by describing and understanding the functions that its parts serve for its health and stability, so can we understand society by describing and understanding the functions that its parts—or, more accurately, its social institutions — serve for the ongoing health and stability of society. Thus functionalism emphasizes the importance of social institutions such as the family, religion, and education for producing a stable society.

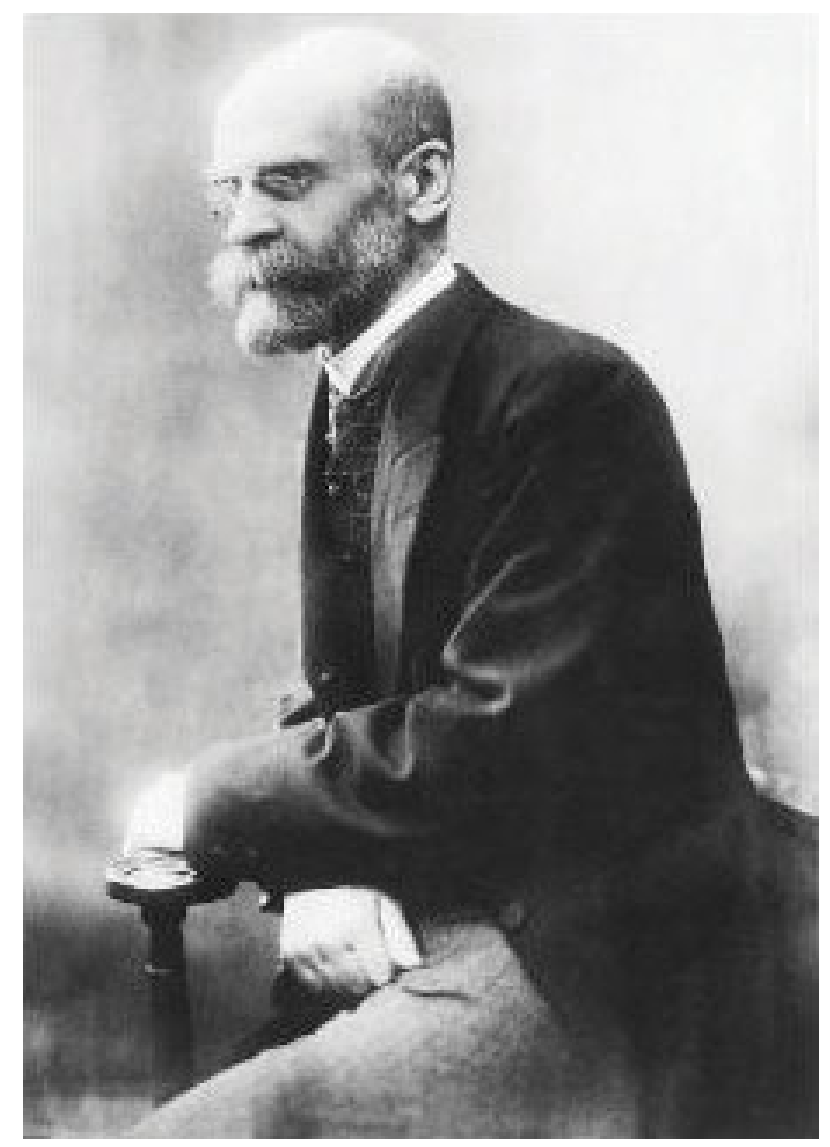

Émile Durkheim was a founder of sociology and is largely credited with developing the functionalist perspective.

Marxists.org - public domain.

Similar to the view of the conservative intellectuals from which it grew, functionalism is skeptical of rapid social change and other major social upheaval. The analogy to the human body helps us understand this skepticism. In our bodies, any sudden, rapid change is a sign of danger to our health. If we break a bone in one of our legs, we have trouble walking; if we lose sight in both our eyes, we can no longer see. Slow changes, such as the growth 
of our hair and our nails, are fine and even normal, but sudden changes like those just described are obviously troublesome. By analogy, sudden and rapid changes in society and its social institutions are troublesome according to the functionalist perspective. If the human body evolved to its present form and functions because these made sense from an evolutionary perspective, so did society evolve to its present form and functions because these made sense. Any sudden change in society thus threatens its stability and future.

As these comments might suggest, functionalism views social problems as arising from society's natural evolution. When a social problem does occur, it might threaten a society's stability, but it does not mean that fundamental flaws in the society exist. Accordingly, gradual social reform should be all that is needed to address the social problem.

Functionalism even suggests that social problems must be functional in some ways for society, because otherwise these problems would not continue. This is certainly a controversial suggestion, but it is true that many social problems do serve important functions for our society. For example, crime is a major social problem, but it is also good for the economy because it creates hundreds of thousands of jobs in law enforcement, courts and corrections, home security, and other sectors of the economy whose major role is to deal with crime. If crime disappeared, many people would be out of work! Similarly, poverty is also a major social problem, but one function that poverty serves is that poor people do jobs that otherwise might not get done because other people would not want to do them (Gans, 1972). Like crime, poverty also provides employment for people across the nation, such as those who work in social service agencies that help poor people.

\section{Conflict Theory}

In many ways, conflict theory is the opposite of functionalism but ironically also grew out of the Industrial Revolution, thanks largely to Karl Marx (1818-1883) and his collaborator, Friedrich Engels (1820-1895). Whereas conservative intellectuals feared the mass violence resulting from industrialization, Marx and Engels deplored the conditions they felt were responsible for the mass violence and the capitalist society they felt was responsible for these conditions. Instead of fearing the breakdown of social order that mass violence represented, they felt that revolutionary violence was needed to eliminate capitalism and the poverty and misery they saw as its inevitable results (Marx, 1906; Marx \& Engels, 1962).

According to Marx and Engels, every society is divided into two classes based on the ownership of the means of production (tools, factories, and the like). In a capitalist society, the bourgeoisie, or ruling class, owns the means of production, while the proletariat, or working class, does not own the means of production and instead is oppressed and exploited by the bourgeoisie. This difference creates an automatic conflict of interests between the two groups. Simply put, the bourgeoisie is interested in maintaining its position at the top of society, while the proletariat's interest lies in rising up from the bottom and overthrowing the bourgeoisie to create an egalitarian society.

In a capitalist society, Marx and Engels wrote, revolution is inevitable because of structural contradictions arising from the very nature of capitalism. Because profit is the main goal of capitalism, the bourgeoisie's interest lies in maximizing profit. To do so, capitalists try to keep wages as low as possible and to spend as little money as possible on working conditions. This central fact of capitalism, said Marx and Engels, eventually prompts 
the rise of class consciousness, or an awareness of the reasons for their oppression, among workers. Their class consciousness in turn leads them to revolt against the bourgeoisie to eliminate the oppression and exploitation they suffer.

Marx and Engels' view of conflict arising from unequal positions held by members of society lies at the heart of today's conflict theory. This theory emphasizes that different groups in society have different interests stemming from their different social positions. These different interests in turn lead to different views on important social issues. Some versions of the theory root conflict in divisions based on race and ethnicity, gender, and other such differences, while other versions follow Marx and Engels in seeing conflict arising out of different positions in the economic structure. In general, however, conflict theory emphasizes that the various parts of society contribute to ongoing inequality, whereas functionalist theory, as we have seen, stresses that they contribute to the ongoing stability of society. Thus while functionalist theory emphasizes the benefits of the various parts of society for ongoing social stability, conflict theory favors social change to reduce inequality. 


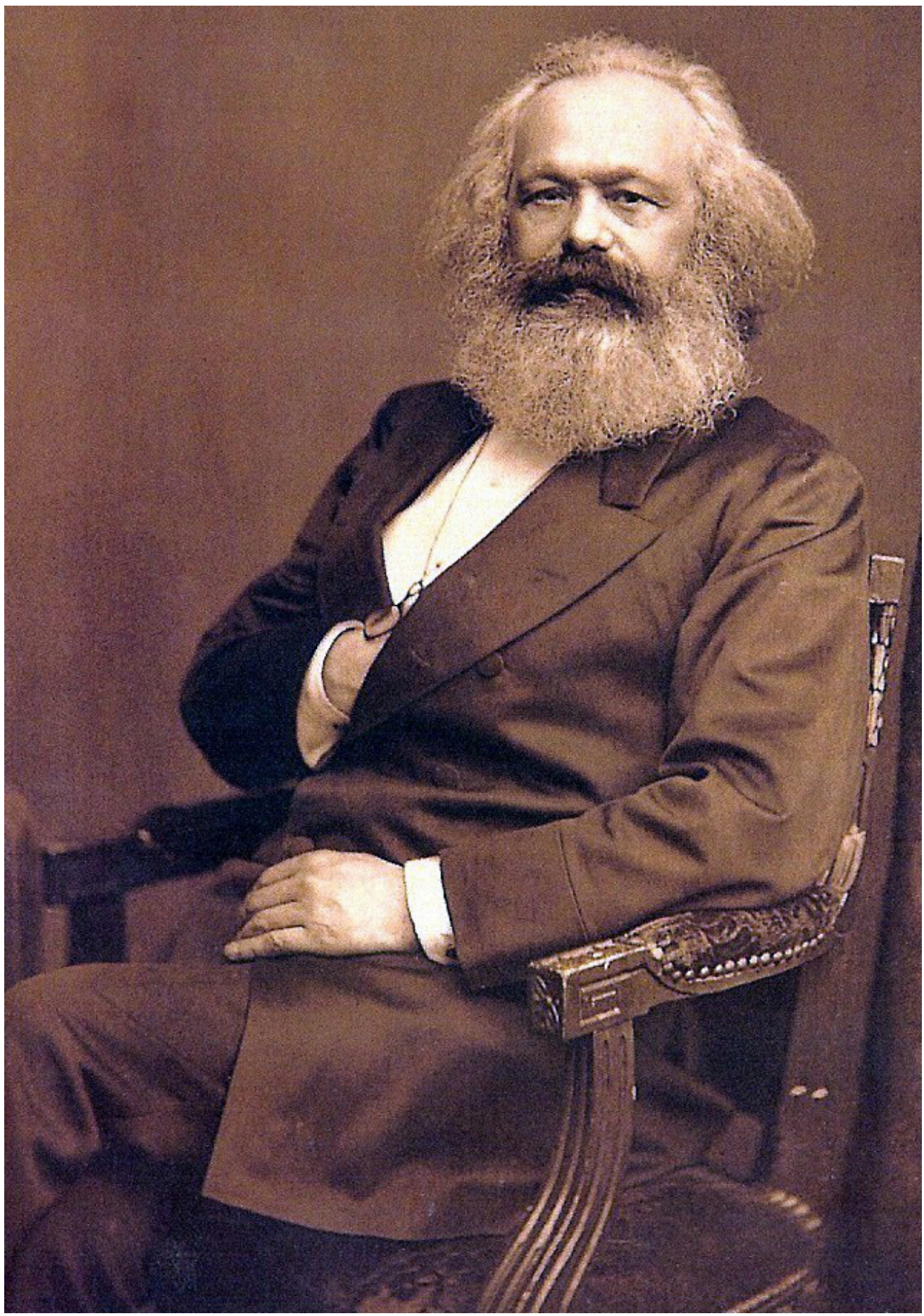

Karl Marx and his collaborator Friedrich Engels were intense critics of capitalism. Their work inspired the later development of conflict theory in sociology.

Wikimedia Commons - public domain

Feminist theory has developed in sociology and other disciplines since the 1970s and for our purposes will be considered a specific application of conflict theory. In this case, the conflict concerns gender inequality rather than the class inequality emphasized by Marx and Engels. Although many variations of feminist theory exist, they all emphasize that society is filled with gender inequality such that women are the subordinate sex in many 
dimensions of social, political, and economic life (Lorber, 2010). Liberal feminists view gender inequality as arising out of gender differences in socialization, while Marxist feminists say that this inequality is a result of the rise of capitalism, which made women dependent on men for economic support. On the other hand, radical feminists view gender inequality as present in all societies, not just capitalist ones. Several chapters in this book emphasize the perspectives of feminist sociologists and other social scientists.

Conflict theory in its various forms views social problems as arising from society's inherent inequality. Depending on which version of conflict theory is being considered, the inequality contributing to social problems is based on social class, race and ethnicity, gender, or some other dimension of society's hierarchy. Because any of these inequalities represents a fundamental flaw in society, conflict theory assumes that fundamental social change is needed to address society's many social problems.

\section{Symbolic Interactionism}

Symbolic interactionism focuses on the interaction of individuals and on how they interpret their interaction. Its roots lie in the work of early 1900s American sociologists, social psychologists, and philosophers who were interested in human consciousness and action. Herbert Blumer (1969) (Blumer, 1969), a sociologist at the University of Chicago, built on their writings to develop symbolic interactionism, a term he coined. Drawing on Blumer's work, symbolic interactionists feel that people do not merely learn the roles that society has set out for them; instead they construct these roles as they interact. As they interact, they negotiate their definitions of the situations in which they find themselves and socially construct the reality of these situations. In doing so, they rely heavily on symbols such as words and gestures to reach a shared understanding of their interaction.

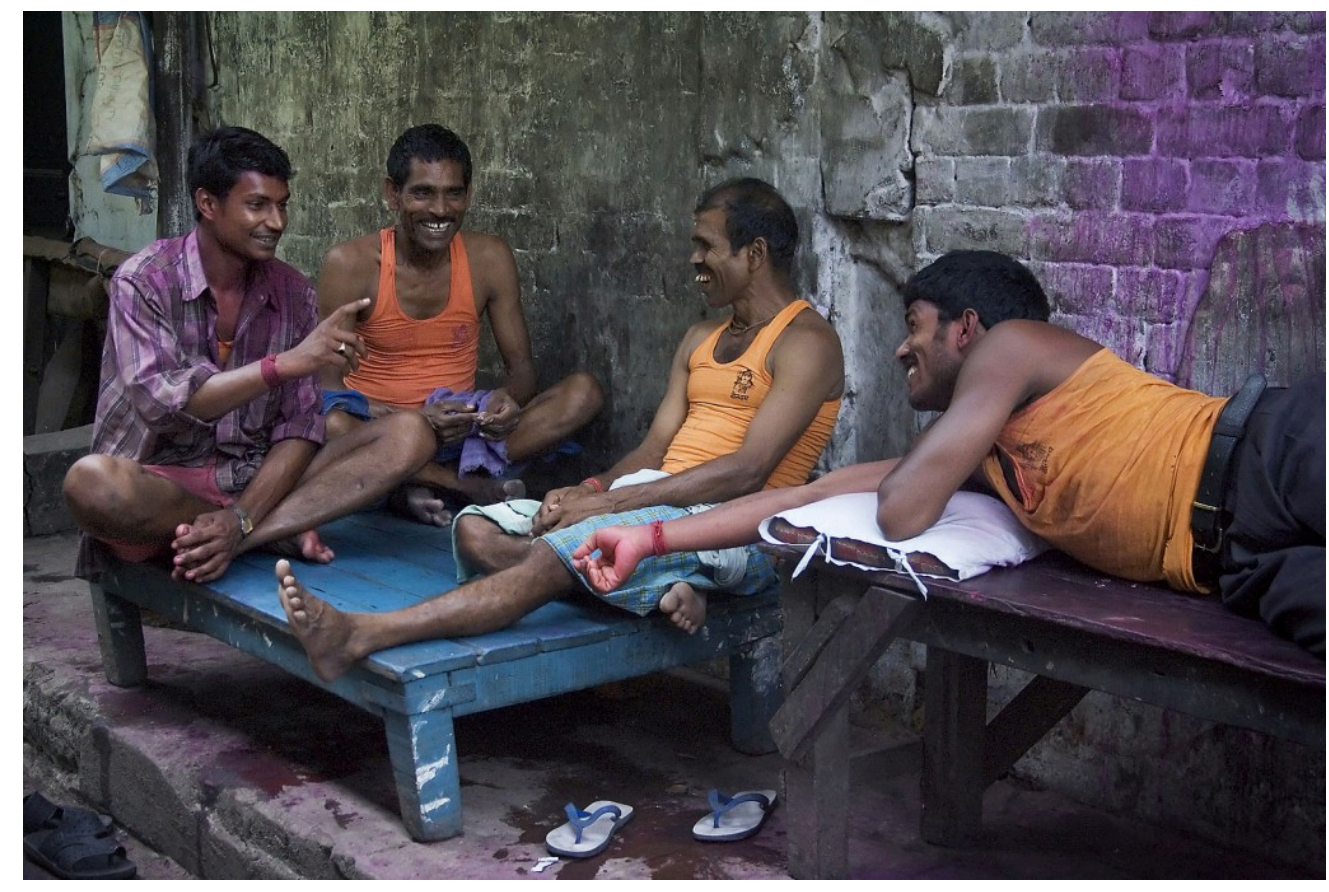

Symbolic interactionism focuses on individuals, such as the people conversing here. Sociologists favoring this approach examine how and why individuals interact and interpret the meanings of their interaction. 
Wikimedia Commons - public domain.

An example is the familiar symbol of shaking hands. In the United States and many other societies, shaking hands is a symbol of greeting and friendship. This simple act indicates that you are a nice, polite person with whom someone should feel comfortable. To reinforce this symbol's importance for understanding a bit of interaction, consider a situation where someone refuses to shake hands. This action is usually intended as a sign of dislike or as an insult, and the other person interprets it as such. Their understanding of the situation and subsequent interaction will be very different from those arising from the more typical shaking of hands. As the term symbolic interactionism implies, their understanding of this encounter arises from what they do when they interact and from their use and interpretation of the various symbols included in their interaction. According to symbolic interactionists, social order is possible because people learn what various symbols (such as shaking hands) mean and apply these meanings to different kinds of situations. If you visited a society where sticking your right hand out to greet someone was interpreted as a threatening gesture, you would quickly learn the value of common understandings of symbols.

Symbolic interactionism views social problems as arising from the interaction of individuals. This interaction matters in two important respects. First, socially problematic behaviors such as crime and drug use are often learned from our interaction with people who engage in these behaviors; we adopt their attitudes that justify committing these behaviors, and we learn any special techniques that might be needed to commit these behaviors. Second, we also learn our perceptions of a social problem from our interaction with other people, whose perceptions and beliefs influence our own perceptions and beliefs.

Because symbolic interactionism emphasizes the perception of social problems, it is closely aligned with the social constructionist view discussed earlier. Both perspectives emphasize the subjective nature of social problems. By doing so, they remind us that perceptions often matter at least as much as objective reality in determining whether a given condition or behavior rises to the level of a social problem and in the types of possible solutions that various parties might favor for a particular social problem.

\section{Applying the Three Perspectives}




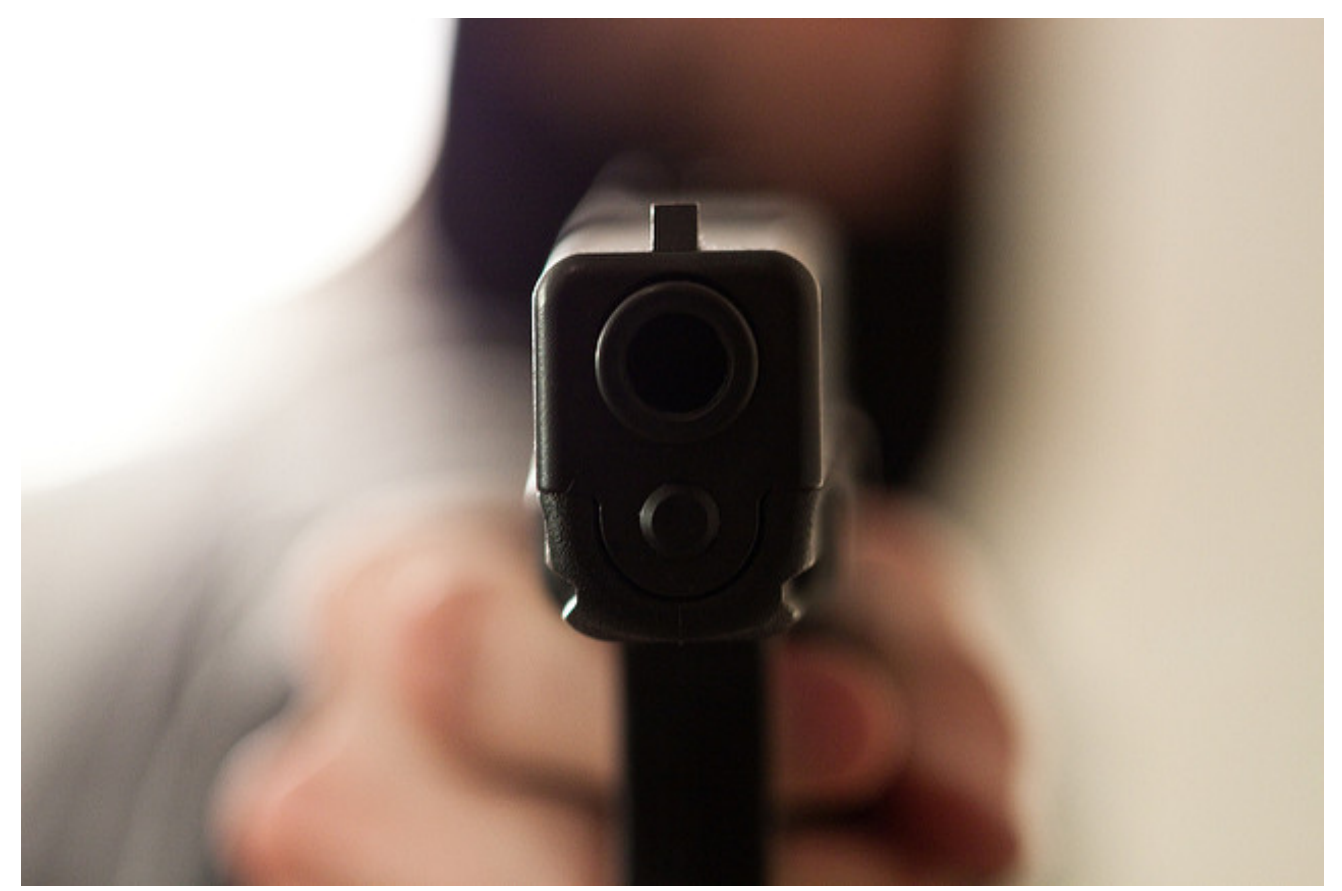

To explain armed robbery, symbolic interactionists focus on how armed robbers decide when and where to rob a victim and on how their interactions with other criminals reinforce their own criminal tendencies.

Geoffrey Fairchild - The Robbery - CC BY 2.0.

To help you further understand the different views of these three theoretical perspectives, let's see what they would probably say about armed robbery, a very serious form of crime, while recognizing that the three perspectives together provide a more comprehensive understanding of armed robbery than any one perspective provides by itself.

A functionalist approach might suggest that armed robbery actually serves positive functions for society, such as the job-creating function mentioned earlier for crime in general. It would still think that efforts should be made to reduce armed robbery, but it would also assume that far-reaching changes in our society would be neither wise nor necessary as part of the effort to reduce crime.

Conflict theory would take a very different approach to understanding armed robbery. It might note that most street criminals are poor and thus emphasize that armed robbery is the result of the despair and frustration of living in poverty and facing a lack of jobs and other opportunities for economic and social success. The roots of street crime, from the perspective of conflict theory, thus lie in society at least as much as they lie in the individuals committing such crime. To reduce armed robbery and other street crime, conflict theory would advocate farreaching changes in the economic structure of society.

For its part, symbolic interactionism would focus on how armed robbers make such decisions as when and where to rob someone and on how their interactions with other criminals reinforce their own criminal tendencies. It would also investigate how victims of armed robbery behave when confronted by a robber. To reduce armed robbery, it would advocate programs that reduce the opportunities for interaction among potential criminal offenders, for example, after-school programs that keep at-risk youths busy in "conventional” activities so that they have less time to spend with youths who might help them get into trouble. 


\section{Key Takeaways}

- According to C. Wright Mills, the sociological imagination involves the ability to recognize that private troubles are rooted in public issues and structural problems.

- Functionalism emphasizes the importance of social institutions for social stability and implies that farreaching social change will be socially harmful.

- Conflict theory emphasizes social inequality and suggests that far-reaching social change is needed to achieve a just society.

- Symbolic interactionism emphasizes the social meanings and understandings that individuals derive from their social interaction.

\section{For Your Review}

1. Select an example of a "private trouble" and explain how and why it may reflect a structural problem in society.

2. At this point in your study of social problems, which one of the three sociological theoretical perspectives sounds most appealing to you? Why?

\section{References}

Blumer, H. (1969). Symbolic interactionism: Perspective and Method. Englewood Cliffs, NJ: Prentice Hall.

Boyd, E. M., Reynolds, J. R., Tillman, K. H., \& Martin, P. Y. (2011). Adolescent girls' race/ethnic status, identities, and drive for thinness. Social Science Research, 40(2), 667-684.

Durkheim, É. (1952). Suicide (J. Spaulding \& G. Simpson, Trans.). New York, NY: Free Press. (Original work published 1897).

Gans, H. J. (1972). The positive functions of poverty. American Journal of Sociology, 78, 275-289.

Lorber, J. (2010). Gender Inequality: Feminist Theories and Politics. New York, NY: Oxford University Press.

Marx, K. (1906). Capital. New York, NY: Random House. (Original work published 1867).

Marx, K., \& Engels, F. (1962). The communist manifesto. In Marx and Engels: Selected works (Vol. 2, pp. 21-65).

Moscow, Russia: Foreign Language Publishing House. (Original work published 1848).

Mills, C. W. (1959). The sociological imagination. London, United Kingdom: Oxford University Press.

Ryan, W. (1976). Blaming the victim (Rev. ed.). New York, NY: Vintage Books. 


\subsection{Continuity and Change in Social Problems}

\section{Learning Objectives}

1. Explain what is meant by this book’s subtitle, "Continuity and Change."

2. List the three sources of changes to social problems.

3. Describe how the United States compares to other democracies regarding the seriousness of social problems.

This book's subtitle, “Continuity and Change,” conveys a theme that will guide every chapter's discussion. Social problems are, first of all, persistent. They have continued for decades and even centuries, and they show no sign of ending anytime soon. In view of social problems' long history, certainty of continuing for some time to come, and serious consequences, it is easy to feel overwhelmed when reading about them, to think that little can be done about them, and even to become a bit depressed. As a result, it is easy for students to come away from social problems courses with a rather pessimistic, “doom and gloom” outlook (Johnson, 2005).

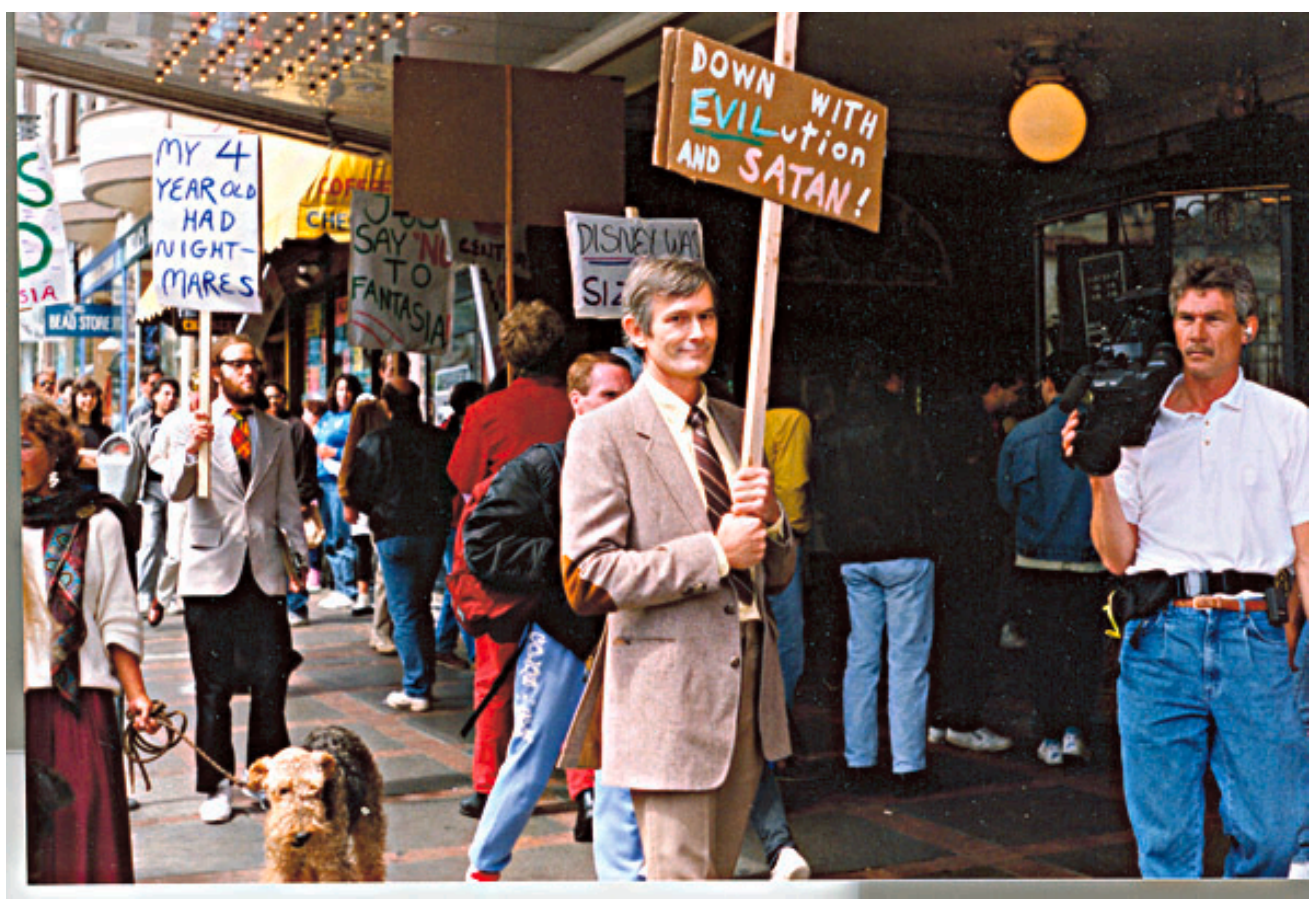

An important source of change in social problems is protest by a social change group or movement.

M 2 - Fantasia Protest, Castro Theater, 1991 - CC BY-NC-ND 2.0.

That is why this book stresses the second part of the subtitle, change. Although social problems are indeed persistent, it is also true that certain problems are less serious now than in the past. Change is possible. As just one of many examples, consider the conditions that workers face in the United States. As Chapter 12 "Work and 
the Economy" discusses, many workers today are unemployed, have low wages, or work in substandard and even dangerous workplaces. Yet they are immeasurably better off than a century ago, thanks to the US labor movement that began during the 1870s. Workers now have the eight-hour day, the minimum wage (even if many people think it is too low), the right to strike, and workplaces that are much safer than when the labor movement began. In two more examples, people of color and women have made incredible advances since the 1960s, even if, as $\underline{\text { Chapter } 3}$ "Racial and Ethnic Inequality" and Chapter 4 "Gender Inequality" discuss, they continue to experience racial and gender inequality, respectively. To repeat: Change is possible.

How does change occur? One source of change in social problems is social science theory and research. Over the decades, theory and research in sociology and the other social sciences have pointed to the reasons for social problems, to potentially successful ways of addressing them, and to actual policies that succeeded in addressing some aspect of a social problem. Accordingly, the discussion in each chapter of this book is based on sound social science theory and research, and each chapter will present examples of how the findings from sociological and other social science research have either contributed to public policy related to the chapter's social problem or have the potential of doing so.

The actions of individuals and groups may also make a difference. Many people have public-service jobs or volunteer in all sorts of activities involving a social problem: they assist at a food pantry, they help clean up a riverbank, and so forth. Others take on a more activist orientation by becoming involved in small social change groups or a larger social movement. Our nation is a better place today because of the labor movement, the Southern civil rights movement, the women's movement, the gay rights movement, the environmental movement, and other efforts too numerous to mention. According to Frances Fox Piven (2006) (Piven, 2006), a former president of the American Sociological Association, it is through such efforts that "ordinary people change America," as the subtitle of her book on this subject reads.

Sharing this view, anthropologist Margaret Mead once said, "Never doubt that a small group of thoughtful, committed citizens can change the world. Indeed, it is the only thing that ever has." Change thus is not easy, but it can and does occur. Eleanor Roosevelt (Roosevelt, 1960) recognized this when she wrote, "Surely, in the light of history, it is more intelligent to hope rather than to fear, to try rather than not to try. For one thing we know beyond all doubt: Nothing has ever been achieved by the person who says, 'It can't be done."' In the optimistic spirit of these two famous women, we will see examples throughout this book of people making a difference in their jobs, volunteer activities, and involvement in social change efforts. 


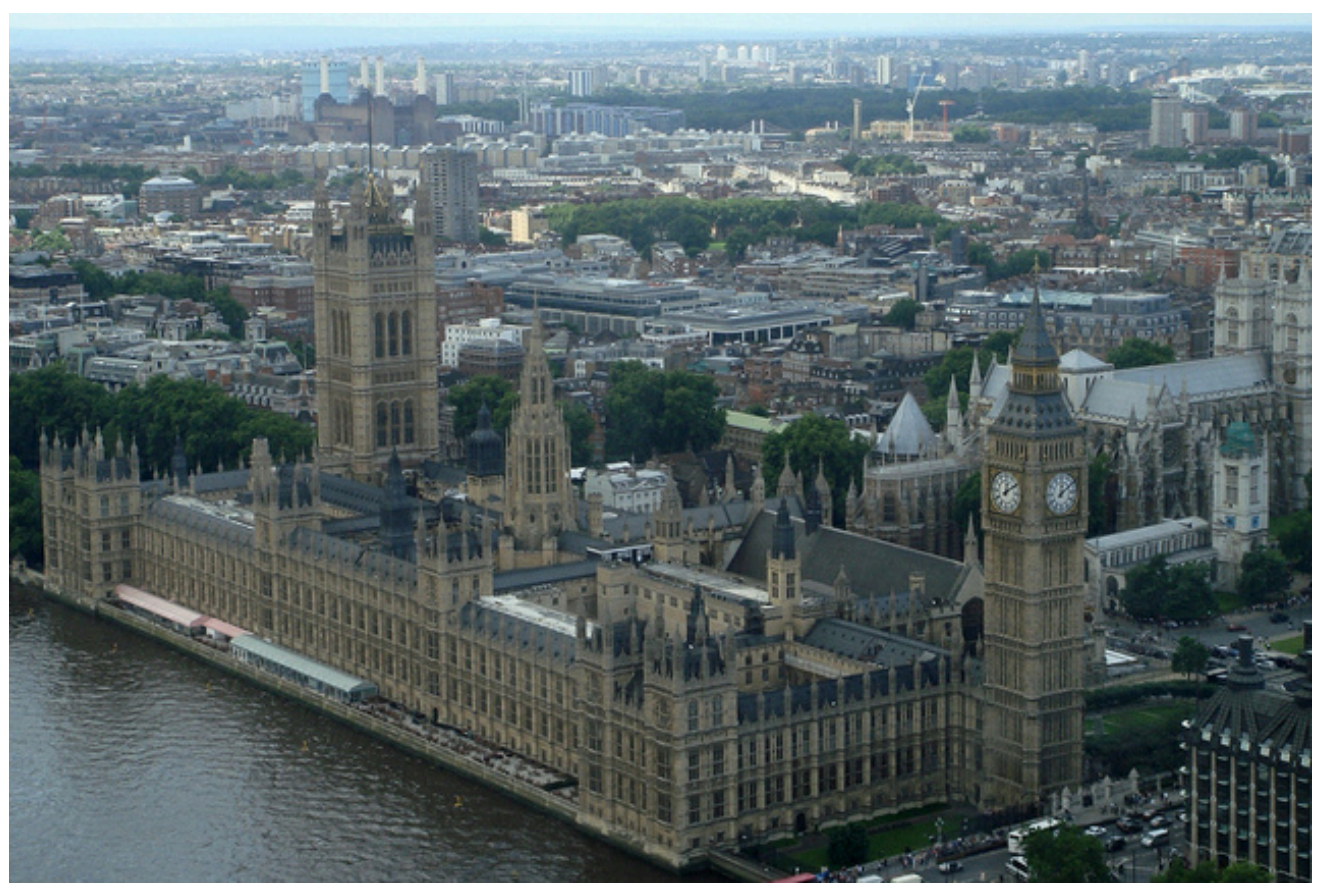

Many other democracies rank higher than the United States on poverty, health, and other social indicators. For this reason, the United

States may have much to learn from their positive examples.

Alex Loach - Houses of Parliament, London, England - CC BY-NC-ND 2.0.

Change also occurs in social problems because policymakers (elected or appointed officials and other individuals) pass laws or enact policies that successfully address a social problem. They often do so only because of the pressure of a social movement, but sometimes they have the vision to act without such pressure. It is also true that many officials fail to take action despite the pressure of a social movement, so those who do take action should be applauded. A recent example involves the governor of New York, Andrew Cuomo, who made the legalization of same-sex marriage a top priority for his state when he took office in January 2011. After the New York state legislature narrowly approved same-sex marriage six months later, Cuomo’s advocacy was widely credited for enabling this to happen (Barbaro, 2011).

A final source of change is the lessons learned from other nations' experiences with social problems. Sometimes these lessons for the United States are positive ones, as when another nation has tackled a social problem more successfully than the United States, and sometimes these lessons are negative ones, as when another nation has a more serious problem than the United States and/or has made mistakes in addressing this problem. The United States can learn from the good examples of some other nations, and it can also learn from the bad ones. For this reason, each chapter of this book discusses such examples. In this regard, the United States has much to learn from the experiences of other long-standing democracies like Canada, the nations of Western Europe, and Australia and New Zealand. Despite its great wealth, the United States ranks below most of its democratic peers on many social indicators, such as poverty, health, and so on (Holland, 2011; Russell, 2011). A major reason for this difference is that other democratic governments are far more proactive, in terms of attention and spending, than the US federal and state governments in helping their citizens. Because the United States has much to learn from their positive example, this book's chapters all discuss policies that enable other democracies to address certain social problems far more successfully than the United States has addressed them. 


\section{Key Takeaways}

- Social problems are persistent, but they have also changed over the years, and many social problems are less serious now than in the past.

- Three sources of change to social problems include social science research, the efforts of citizens acting alone or especially in social change groups, and the experiences of other nations.

\section{For Your Review}

1. Have you participated in any volunteer or other activity involving a social problem? If so, why did you do so? If not, why have you not participated in such an effort?

2. Do you share Eleanor Roosevelt's optimism that social change is possible? Why or why not?

\section{References}

Barbaro, M. (2011, June 6). Behind NY gay marriage, an unlikely mix of forces. New York Times, p. A1.

Holland, J. (2011, June 15). 9 countries that do it better: Why does Europe take better care of its people than America? AlterNet. Retrieved from http://www.alternet.org/story/151312/ 151319 countries that do it better\%151313A why does europe take better care of its people than america?page=151311.

Johnson, B. (2005). Overcoming "doom and gloom": Empowering students in courses on social problems, injustice, and inequality. Teaching Sociology, 33, 44-58.

Piven, F. F. (2006). Challenging authority: How ordinary people change America. Lanham, MD: Rowman \& Littlefield.

Roosevelt, E. (1960). You learn by living: Eleven keys for a more fulfilling life. New York, NY: Harper \& Row.

Russell, J. W. (2011). Double standard: Social policy in Europe and the United States (2nd ed.). Lanham, MD: Rowman \& Littlefield. 


\subsection{Doing Research on Social Problems}

\section{Learning Objectives}

1. List the major advantages and disadvantages of surveys, observational studies, and experiments.

2. Explain why scholars who study social problems often rely on existing data.

Sound research is an essential tool for understanding the sources, dynamics, and consequences of social problems and possible solutions to them. This section briefly describes the major ways in which sociologists gather information about social problems. Table 1.2 "Major Sociological Research Methods" summarizes the advantages and disadvantages of each method.

Table 1.2 Major Sociological Research Methods

\begin{tabular}{|l|l|l|}
\hline Method & Advantages & Disadvantages \\
\hline Survey & $\begin{array}{l}\text { Many people can be included. If given to } \\
\text { a random sample of the population, a } \\
\text { survey's results can be generalized to the } \\
\text { population. }\end{array}$ & $\begin{array}{l}\text { Large surveys are expensive and time consuming. Although } \\
\text { much information is gathered, this information is relatively } \\
\text { superficial. }\end{array}$ \\
\hline Experiments & $\begin{array}{l}\text { If random assignment is used, } \\
\text { experiments provide fairly convincing } \\
\text { data on cause and effect. }\end{array}$ & $\begin{array}{l}\text { Because experiments do not involve random samples of the } \\
\text { population and most often involve college students, their } \\
\text { results cannot readily be generalized to the population. }\end{array}$ \\
\hline $\begin{array}{l}\text { Observation } \\
\text { (field } \\
\text { research) }\end{array}$ & $\begin{array}{l}\text { Observational studies may provide rich, } \\
\text { detailed information about the people } \\
\text { who are observed. }\end{array}$ & $\begin{array}{l}\text { Because observation studies do not involve random samples of } \\
\text { the population, their results cannot readily be generalized to the } \\
\text { population. }\end{array}$ \\
\hline $\begin{array}{l}\text { Existing } \\
\text { data }\end{array}$ & $\begin{array}{l}\text { Because existing data have already been } \\
\text { gathered, the researcher does not have to } \\
\text { spend the time and money to gather data. }\end{array}$ & $\begin{array}{l}\text { The data set that is being analyzed may not contain data on all } \\
\text { the variables in which a sociologist is interested or may contain } \\
\text { data on variables that are not measured in ways the sociologist } \\
\text { prefers. }\end{array}$ \\
\hline
\end{tabular}

\section{Surveys}

The survey is the most common method by which sociologists gather their data. The Gallup poll is perhaps the most well-known example of a survey and, like all surveys, gathers its data with the help of a questionnaire that is given to a group of respondents. The Gallup poll is an example of a survey conducted by a private organization, but sociologists do their own surveys, as does the government and many organizations in addition to Gallup. Many surveys are administered to respondents who are randomly chosen and thus constitute a random sample. In a random sample, everyone in the population (whether it be the whole US population or just the population 
of a state or city, all the college students in a state or city or all the students at just one college, etc.) has the same chance of being included in the survey. The beauty of a random sample is that it allows us to generalize the results of the sample to the population from which the sample comes. This means that we can be fairly sure of the behavior and attitudes of the whole US population by knowing the behavior and attitudes of just four hundred people randomly chosen from that population.

Some surveys are face-to-face surveys, in which interviewers meet with respondents to ask them questions. This type of survey can yield much information, because interviewers typically will spend at least an hour asking their questions, and a high response rate (the percentage of all people in the sample who agree to be interviewed), which is important to be able to generalize the survey's results to the entire population. On the downside, this type of survey can be very expensive and time consuming to conduct.

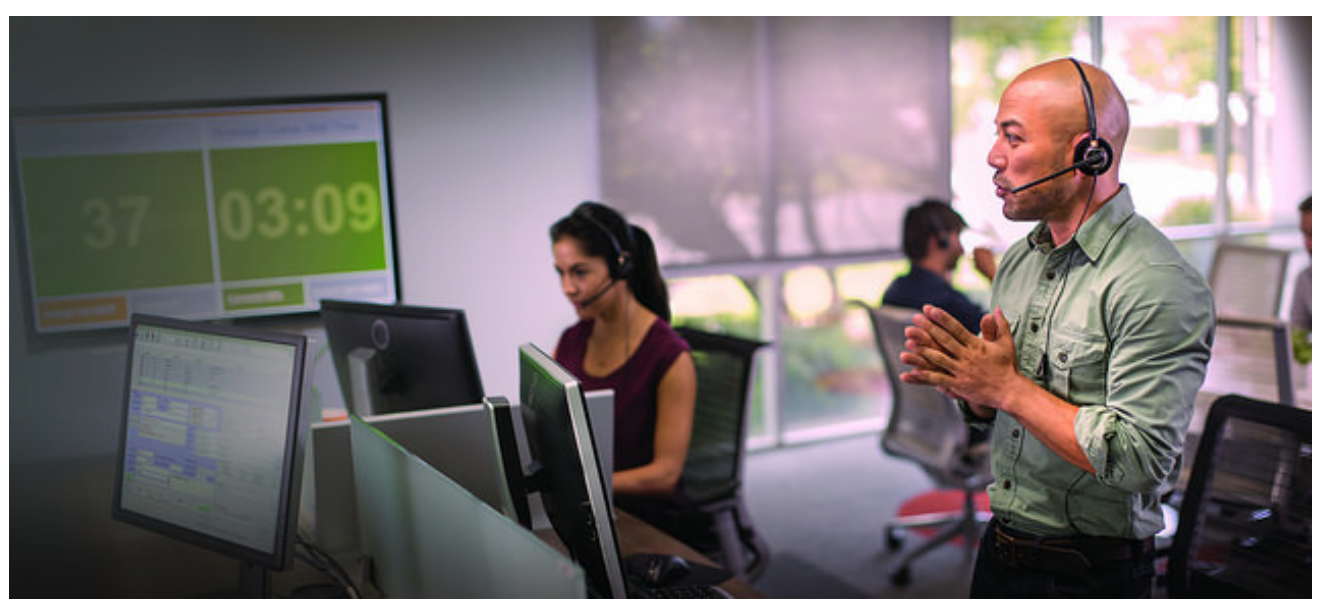

Surveys are very useful for gathering various kinds of information relevant to social problems. Advances in technology have made telephone surveys involving random-digit dialing perhaps the most popular way of conducting a survey.

plantronicsgermany - Encore520 call center man standing - CC BY-ND 2.0.

Because of these drawbacks, sociologists and other researchers have turned to telephone surveys. Most Gallup polls are conducted over the telephone. Computers do random-digit dialing, which results in a random sample of all telephone numbers being selected. Although the response rate and the number of questions asked are both lower than in face-to-face surveys (people can just hang up the phone at the outset or let their answering machine take the call), the ease and low expense of telephone surveys are making them increasingly popular. Surveys done over the Internet are also becoming more popular, as they can reach many people at very low expense. A major problem with web surveys is that their results cannot necessarily be generalized to the entire population because not everyone has access to the Internet.

Surveys are used in the study of social problems to gather information about the behavior and attitudes of people regarding one or more problems. For example, many surveys ask people about their use of alcohol, tobacco, and other drugs or about their experiences of being unemployed or in poor health. Many of the chapters in this book will present evidence gathered by surveys carried out by sociologists and other social scientists, various governmental agencies, and private research and public interest firms. 


\section{Experiments}

Experiments are the primary form of research in the natural and physical sciences, but in the social sciences they are for the most part found only in psychology. Some sociologists still use experiments, however, and they remain a powerful tool of social research.

The major advantage of experiments, whether they are done in the natural and physical sciences or in the social sciences, is that the researcher can be fairly sure of a cause-and-effect relationship because of the way the experiment is set up. Although many different experimental designs exist, the typical experiment consists of an experimental group and a control group, with subjects randomly assigned to either group. The researcher does something to the experimental group that is not done to the control group. If the two groups differ later in some variable, then it is safe to say that the condition to which the experimental group was subjected was responsible for the difference that resulted.

Most experiments take place in the laboratory, which for psychologists may be a room with a one-way mirror, but some experiments occur in the field, or in a natural setting (field experiments). In Minneapolis, Minnesota, in the early 1980s, sociologists were involved in a much-discussed field experiment sponsored by the federal government. The researchers wanted to see whether arresting men for domestic violence made it less likely that they would commit such violence again. To test this hypothesis, the researchers had police do one of the following after arriving at the scene of a domestic dispute: They either arrested the suspect, separated him from his wife or partner for several hours, or warned him to stop but did not arrest or separate him. The researchers then determined the percentage of men in each group who committed repeated domestic violence during the next six months and found that those who were arrested had the lowest rate of recidivism, or repeat offending (Sherman \& Berk, 1984). This finding led many jurisdictions across the United States to adopt a policy of mandatory arrest for domestic violence suspects. However, replications of the Minneapolis experiment in other cities found that arrest sometimes reduced recidivism for domestic violence but also sometimes increased it, depending on which city was being studied and on certain characteristics of the suspects, including whether they were employed at the time of their arrest (Sherman, 1992).

As the Minneapolis study suggests, perhaps the most important problem with experiments is that their results are not generalizable beyond the specific subjects studied. The subjects in most psychology experiments, for example, are college students, who obviously are not typical of average Americans: They are younger, more educated, and more likely to be middle class. Despite this problem, experiments in psychology and other social sciences have given us very valuable insights into the sources of attitudes and behavior. Scholars of social problems are increasingly using field experiments to study the effectiveness of various policies and programs aimed at addressing social problems. We will examine the results of several such experiments in the chapters ahead.

\section{Observational Studies}

Observational research, also called field research, is a staple of sociology. Sociologists have long gone into the field to observe people and social settings, and the result has been many rich descriptions and analyses of behavior in juvenile gangs, bars, urban street corners, and even whole communities. 
Observational studies consist of both participant observation and nonparticipant observation. Their names describe how they differ. In participant observation, the researcher is part of the group that she or he is studying, spends time with the group, and might even live with people in the group. Several classical social problems studies of this type exist, many of them involving people in urban neighborhoods (Liebow, 1967; Liebow, 1993; Whyte, 1943). In nonparticipant observation, the researcher observes a group of people but does not otherwise interact with them. If you went to your local shopping mall to observe, say, whether people walking with children looked happier than people without children, you would be engaging in nonparticipant observation.

Similar to experiments, observational studies cannot automatically be generalized to other settings or members of the population. But in many ways they provide a richer account of people's lives than surveys do, and they remain an important method of research on social problems.

\section{Existing Data}

Sometimes sociologists do not gather their own data but instead analyze existing data that someone else has gathered. The US Census Bureau, for example, gathers data on all kinds of areas relevant to the lives of Americans, and many sociologists analyze census data on such social problems as poverty, unemployment, and illness. Sociologists interested in crime and the criminal justice system may analyze data from court records, while medical sociologists often analyze data from patient records at hospitals. Analysis of existing data such as these is called secondary data analysis. Its advantage to sociologists is that someone else has already spent the time and money to gather the data. A disadvantage is that the data set being analyzed may not contain data on all the topics in which a sociologist may be interested or may contain data on topics that are not measured in ways the sociologist might prefer.

\section{The Scientific Method and Objectivity}

This section began by stressing the need for sound research in the study of social problems. But what are the elements of sound research? At a minimum, such research should follow the rules of the scientific method. As you probably learned in high school and/or college science classes, these rules-formulating hypotheses, gathering and testing data, drawing conclusions, and so forth—help guarantee that research yields the most accurate and reliable conclusions possible.

An overriding principle of the scientific method is that research should be conducted as objectively as possible. Researchers are often passionate about their work, but they must take care not to let the findings they expect and even hope to uncover affect how they do their research. This in turn means that they must not conduct their research in a manner that helps achieve the results they expect to find. Such bias can happen unconsciously, and the scientific method helps reduce the potential for this bias as much as possible.

This potential is arguably greater in the social sciences than in the natural and physical sciences. The political views of chemists and physicists typically do not affect how an experiment is performed and how the outcome of the experiment is interpreted. In contrast, researchers in the social sciences, and perhaps particularly in sociology, often have strong feelings about the topics they are studying. Their social and political beliefs may thus influence 
how they perform their research on these topics and how they interpret the results of this research. Following the scientific method helps reduce this possible influence.

\section{Key Takeaways}

- The major types of research on social problems include surveys, experiments, observational studies, and the use of existing data.

- Surveys are the most common method, and the results of surveys of random samples may be generalized to the populations from which the samples come.

- Observation studies and existing data are also common methods in social problems research. Observation studies enable the gathering of rich, detailed information, but their results cannot necessarily be generalized beyond the people studied.

- Research on social problems should follow the scientific method to yield the most accurate and objective conclusions possible.

\section{For Your Review}

1. Have you ever been a respondent or subject in any type of sociological or psychological research project? If so, how did it feel to be studied?

2. Which type of social problems research method sounds most interesting to you? Why?

\section{References}

Liebow, E. (1967). Tally’s corner. Boston, MA: Little, Brown.

Liebow, E. (1993). Tell them who I am: The lives of homeless women. New York, NY: Free Press.

Sherman, L. W., \& Berk, R. A. (1984). The specific deterrent effects of arrest for domestic assault. American Sociological Review, 49, 261-272.

Sherman, L. W. (1992). Policing domestic violence: Experiments and dilemmas. New York, NY: Free Press.

Whyte, W. F. (1943). Street corner society: The social structure of an Italian slum. Chicago, IL: University of Chicago Press. 


\subsection{End-of-Chapter Material}

\section{Summary}

1. Some sociologists favor the social constructionist view that negative social conditions or behaviors are not social problems unless they are generally perceived as a social problem, but other sociologists say that these conditions and behaviors are still social problems even if they are not perceived as such.

2. According to C. Wright Mills, the sociological imagination involves the ability to realize that personal troubles are rooted in problems in the larger social structure. The sociological imagination thus supports a blaming-the-system view over a blaming-the-victim view.

3. Social problems have existed for decades or even centuries, but many of these have also lessened in their seriousness over time, and change in the future is indeed possible.

4. Several theoretical perspectives in sociology exist. Functionalism emphasizes the functions that social institutions serve to ensure the ongoing stability of society, while conflict theory focuses on the conflict among different racial, ethnic, social class, and other groups and emphasizes how social institutions help ensure inequality. Symbolic interactionism focuses on how individuals interpret the meanings of the situations in which they find themselves. 


\section{Chapter 2: Poverty}

\section{Social Problems in the News}

"Survey: More US Kids Go to School Hungry,” the headline said. As the US economy continued to struggle, a nationwide survey of 638 public school teachers in grades K-8 conducted for Share Our Strength, a nonprofit organization working to end childhood hunger, found alarming evidence of children coming to school with empty stomachs. More than two-thirds of the teachers said they had students who "regularly come to school too hungry to learn-some having had no dinner the night before," according to the news article. More than 60 percent of the teachers said the problem had worsened during the past year, and more than 40 percent called it a "serious" problem. Many of the teachers said they spent their own money to buy food for their students. As an elementary school teacher explained, "I've had lots of students come to school—not just one or two-who put their heads down and cry because they haven't eaten since lunch yesterday” (United Press International, 2011).

The United States is one of the richest nations in the world. Many Americans live in luxury or at least are comfortably well-off. Yet, as this poignant news story of childhood hunger reminds us, many Americans also live in poverty or near poverty. This chapter explains why poverty exists and why the US poverty rate is so high, and it discusses the devastating consequences of poverty for the millions of Americans who live in or near poverty. It also examines poverty in the poorest nations of the world and outlines efforts for reducing poverty in the United States and these nations.

Although this chapter will paint a disturbing picture of poverty, there is still cause for hope. As we shall see, the "war on poverty" that began in the United States during the 1960s dramatically reduced poverty. Inspired by books with titles like The Other America: Poverty in the United States (Harrington, 1962) and In the Midst of Plenty: The Poor in America (Bagdikian, 1964) that described the plight of the poor in heartbreaking detail, the federal government established various funding programs and other policies that greatly lowered the poverty rate in less than a decade (Schwartz, 1984). Since the 1960s and 1970s, however, the United States has cut back on these programs, and the poor are no longer on the national agenda. Other wealthy democracies provide much more funding and many more services for their poor than does the United States, and their poverty rates are much lower than ours.

Still, the history of the war on poverty and the experience of these other nations both demonstrate that US poverty can be reduced with appropriate policies and programs. If the United States were to go back to the future by remembering its earlier war on poverty and by learning from other Western democracies, it could again lower poverty and help millions of Americans lead better, healthier, and more productive lives.

But why should we care about poverty in the first place? As this chapter discusses, many politicians and much of the public blame the poor for being poor, and they oppose increasing federal spending to help the poor and even want to reduce such spending. As poverty expert Mark R. Rank (Rank, 2011) summarizes this way of thinking, “All too often we view poverty as someone else's problem.” Rank says this unsympathetic view is shortsighted because, as he puts it, "poverty affects us all” (Rank, 2011). This is true, he explains, for at least two reasons. 
First, the United States spends much more money than it needs to because of the consequences of poverty. Poor people experience worse health, family problems, higher crime rates, and many other problems, all of which our nation spends billions of dollars annually to address. In fact, childhood poverty has been estimated to cost the US economy an estimated $\$ 500$ billion annually because of the problems it leads to, including unemployment, low-paid employment, higher crime rates, and physical and mental health problems (Eckholm, 2007). If the US poverty rate were no higher than that of other democracies, billions of tax dollars and other resources would be saved.

Second, the majority of Americans can actually expect to be poor or near poor at some point in their lives, with about 75 percent of Americans in the 20-75 age range living in poverty or near poverty for at least one year in their lives. As Rank (Rank, 2011) observes, most Americans "will find ourselves below the poverty line and using a social safety net program at some point.” Because poverty costs the United States so much money and because so many people experience poverty, says Rank, everyone should want the United States to do everything possible to reduce poverty.

Sociologist John Iceland (Iceland, 2006) adds two additional reasons for why everyone should care about poverty and want it reduced. First, a high rate of poverty impairs our nation's economic progress: When a large number of people cannot afford to purchase goods and services, economic growth is more difficult to achieve. Second, poverty produces crime and other social problems that affect people across the socioeconomic ladder. Reductions in poverty would help not only the poor but also people who are not poor.

We begin our examination of poverty by discussing how poverty is measured and how much poverty exists.

\section{References}

Bagdikian, B. H. (1964). In the midst of plenty: The poor in America. Boston, MA: Beacon Press.

Eckholm, E. (2007, January 25). Childhood poverty is found to portend high adult costs. New York Times, p. A19.

Harrington, M. (1962). The other America: Poverty in the United States. New York, NY: Macmillan.

Iceland, J. (2006). Poverty in America: A handbook. Berkeley, CA: University of California Press.

Rank, M. R. (2011). Rethinking American poverty. Contexts, 10(Spring), 16-21.

Schwartz, J. E. (1984, June 18). The war we won: How the great society defeated poverty. The New Republic, 18-19.

United Press International. (2011, February 23). Survey: More U.S. kids go to school hungry. UPI.com. Retrieved from http://www.upi.com/Health_News/2011/2002/2023/Survey-More-US-kids-go-to-school-hungry/ UPI-20871298510763/. 


\subsection{The Measurement and Extent of Poverty}

\section{Learning Objectives}

1. Understand how official poverty in the United States is measured.

2. Describe problems in the measurement of official poverty.

3. Describe the extent of official poverty.

When US officials became concerned about poverty during the 1960s, they quickly realized they needed to find out how much poverty we had. To do so, a measure of official poverty, or a poverty line, was needed. A government economist, Mollie Orshanky, first calculated this line in 1963 by multiplying the cost of a very minimal diet by three, as a 1955 government study had determined that the typical American family spent onethird of its income on food. Thus a family whose cash income is lower than three times the cost of a very minimal diet is considered officially poor.

This way of calculating the official poverty line has not changed since 1963. It is thus out of date for many reasons. For example, many expenses, such as heat and electricity, child care, transportation, and health care, now occupy a greater percentage of the typical family's budget than was true in 1963. In addition, this official measure ignores a family's noncash income from benefits such as food stamps and tax credits. As a national measure, the poverty line also fails to take into account regional differences in the cost of living. All these problems make the official measurement of poverty highly suspect. As one poverty expert observes, “The official measure no longer corresponds to reality. It doesn't get either side of the equation right-how much the poor have or how much they need. No one really trusts the data” (DeParle, et. al., 2011). We'll return to this issue shortly. 


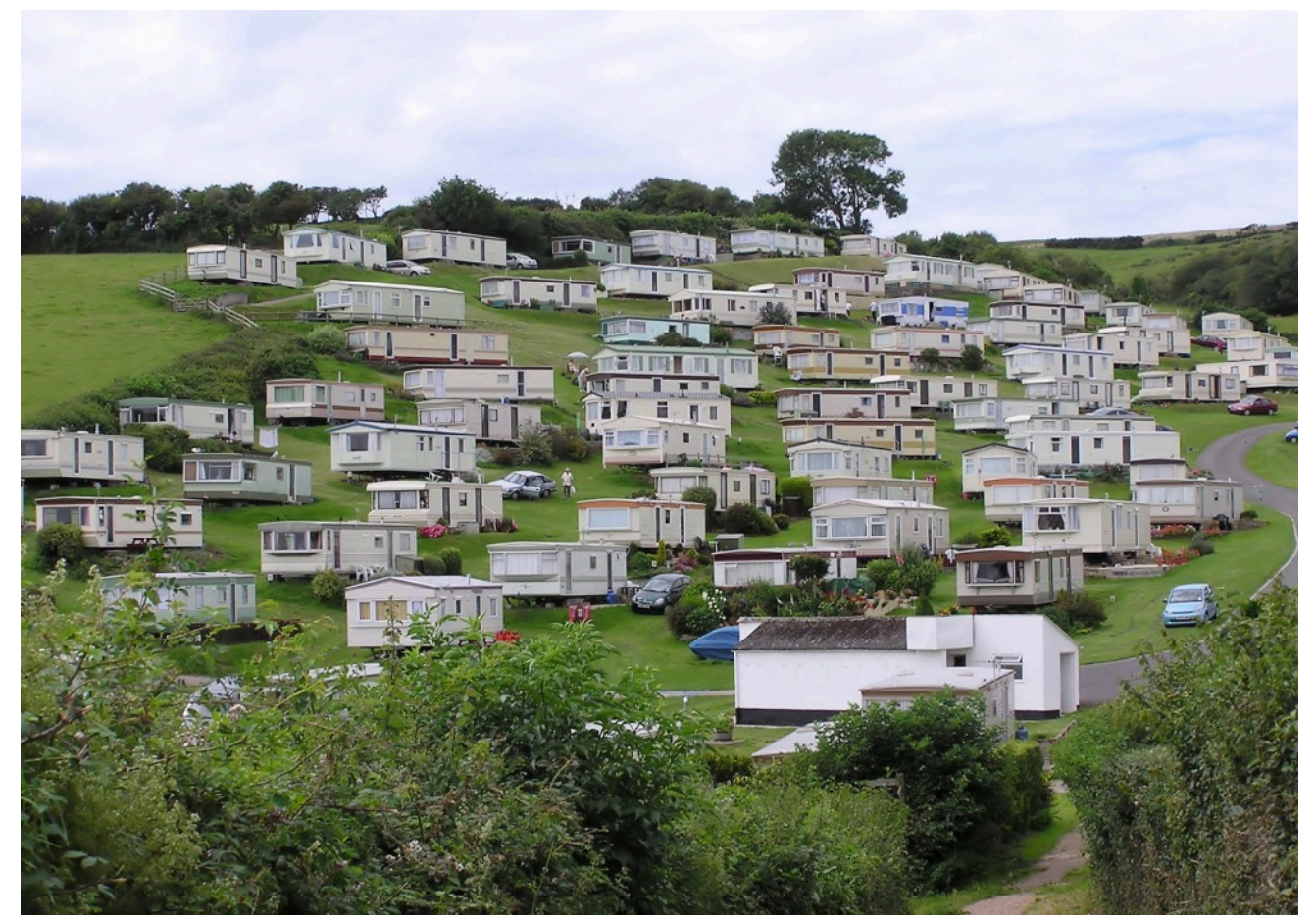

The measure of official poverty began in 1963 and stipulates that a family whose income is lower than three times the cost of a

minimal diet is considered officially poor. This measure has not changed since 1963 even though family expenses have risen greatly in many areas.

Wikimedia Commons - public domain.

The poverty line is adjusted annually for inflation and takes into account the number of people in a family: The larger the family size, the higher the poverty line. In 2010, the poverty line for a nonfarm family of four (two adults, two children) was $\$ 22,213$. A four-person family earning even one more dollar than $\$ 22,213$ in 2010 was not officially poor, even though its "extra" income hardly lifted it out of dire economic straits. Poverty experts have calculated a no-frills budget that enables a family to meet its basic needs in food, clothing, shelter, and so forth; this budget is about twice the poverty line. Families with incomes between the poverty line and twice the poverty line (or twice poverty) are barely making ends meet, but they are not considered officially poor. When we talk here about the poverty level, then, keep in mind that we are talking only about official poverty and that there are many families and individuals living in near poverty who have trouble meeting their basic needs, especially when they face unusually high medical expenses, motor vehicle expenses, or the like. For this reason, many analysts think families need incomes twice as high as the federal poverty level just to get by (Wright, et. al., 2011). They thus use twice-poverty data (i.e., family incomes below twice the poverty line) to provide a more accurate understanding of how many Americans face serious financial difficulties, even if they are not living in official poverty.

\section{The Extent of Poverty}

With this caveat in mind, how many Americans are poor? The US Census Bureau gives us some answers that use the traditional, official measure of poverty developed in 1963. In 2010, 15.1 percent of the US population, or 46.2 million Americans, lived in official poverty (DeNavas-Walt, et. al., 2011). This percentage represented a decline 
from the early 1990s but was higher than 2000 and even higher than the rate in the late 1960s (see Figure 2.1 "US Poverty, 1959-2010"). If we were winning the war on poverty in the 1960s (notice the sharp drop in the 1960s in Figure 2.1 "US Poverty, 1959-2010”), since then poverty has fought us to a standstill.

Figure 2.1 US Poverty, 1959-2010

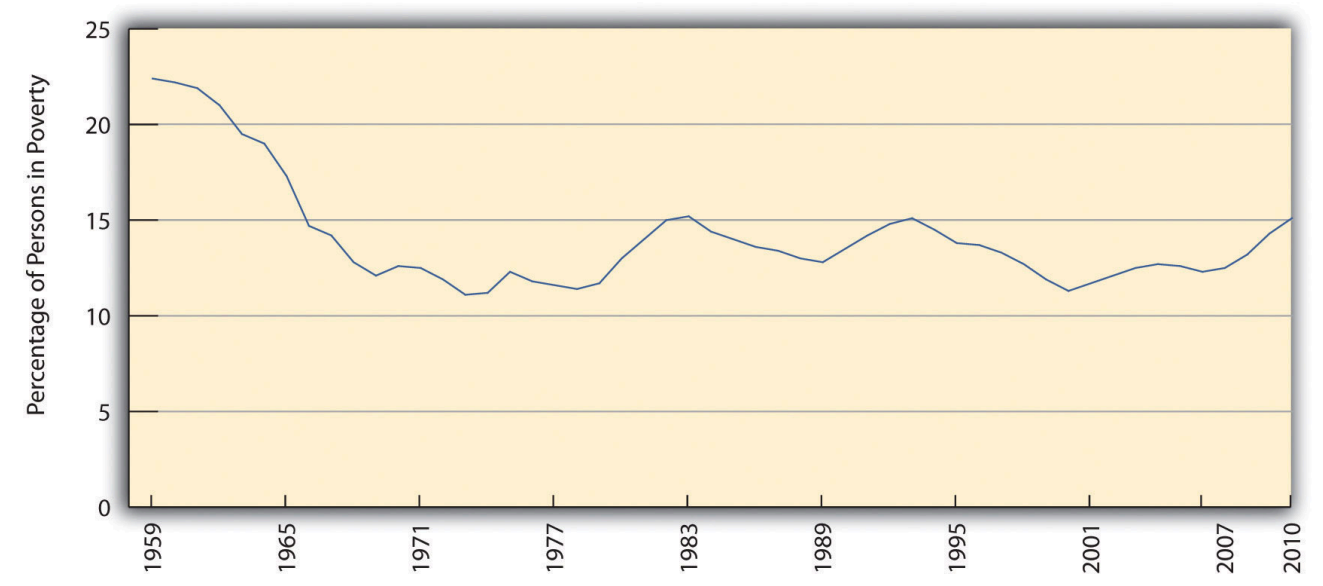

Source: Data from US Census Bureau. (2011). Historical poverty tables: People. Retrieved from http://www.census.gov/hhes/www/poverty/data/historical/people.html.

Another way of understanding the extent of poverty is to consider episodic poverty, defined by the Census Bureau as being poor for at least two consecutive months in some time period. From 2004 to 2007, the last years for which data are available, almost one-third of the US public, equal to about 95 million people, were poor for at least two consecutive months, although only 2.2 percent were poor for all three years (DeNavas-Walt, et al., 2010). As these figures indicate, people go into and out of poverty, but even those who go out of it do not usually move very far from it. And as we have seen, the majority of Americans can expect to experience poverty or near poverty at some point in their lives.

The problems in the official poverty measure that were noted earlier have led the Census Bureau to develop a Supplemental Poverty Measure. This measure takes into account the many family expenses in addition to food; it also takes into account geographic differences in the cost of living, taxes paid and tax credits received, and the provision of food stamps, Medicaid, and certain other kinds of government aid. This new measure yields an estimate of poverty that is higher than the rather simplistic official poverty measure that, as noted earlier, is based solely on the size of a family and the cost of food and the amount of a family's cash income. According to this new measure, the 2010 poverty rate was 16.0 percent, equal to 49.1 million Americans (Short, 2011). Because the official poverty measure identified 46.2 million people as poor, the new, more accurate measure increased the number of poor people in the United States by almost 3 million. Without the help of Social Security, food stamps, and other federal programs, at least 25 million additional people would be classified as poor (Sherman, 2011). These programs thus are essential in keeping many people above the poverty level, even if they still have trouble making ends meet and even though the poverty rate remains unacceptably high.

A final figure is worth noting. Recall that many poverty experts think that twice-poverty data - the percentage and number of people living in families with incomes below twice the official poverty level—are a better gauge than the official poverty level of the actual extent of poverty, broadly defined, in the United States. Using the twicepoverty threshold, about one-third of the US population, or more than 100 million Americans, live in poverty or 
near poverty (Pereyra, 2011). Those in near poverty are just one crisis-losing a job or sustaining a serious illness or injury—away from poverty. Twice-poverty data paint a very discouraging picture.

\section{Key Takeaways}

- The official poverty rate is based on the size of a family and a minimal food budget; this measure underestimates the true extent of poverty.

- The official poverty rate in 2010 was 15.1 percent, equal to more than 46 million Americans.

- About one-third of the US population, or more than 100 million Americans, have incomes no higher than twice the poverty line.

\section{For Your Review}

1. Write a short essay that summarizes the problems by which the official poverty rate is determined.

2. Sit down with some classmates and estimate what a family of four (two parents, two young children) in your area would have to pay annually for food, clothing, shelter, energy, and other necessities of life. What figure do you end up with? How does this sum of money compare with the official poverty line of \$22,213 in 2010 for a family of four?

\section{References}

DeNavas-Walt, C., Proctor, B. D., \& Smith, J. C. (2011). Income, poverty, and health insurance coverage in the United States: 2010 (Current Population Reports, P60-239). Washington, DC: US Census Bureau.

DeParle, J., Gebeloff, R., \& Tavernise, S. (2011, November 4). Bleak portrait of poverty is off the mark, experts say. New York Times, p. A1.

Pereyra, L. (2011). Half in Ten campaign criticizes House Republican funding proposal. Washington, DC: Center for American Progress.

Sherman, A. (2011). Despite deep recession and high unemployment, government efforts_including the Recovery Act-prevented poverty from rising in 2009, new census data show. Washington, DC: Center on Budget and Policy Priorities.

Short, K. (2011). The research supplemental poverty measure: 2010 (Current Population Reports, P60-241). Washington, DC: US Census Bureau.

Wright, V. R., Chau, M., \& Aratani, Y. (2011). Who are America's poor children? The official story. New York, NY: National Center for Children in Poverty. 


\subsection{Who the Poor Are: Social Patterns of Poverty}

\section{Learning Objectives}

1. Describe racial/ethnic differences in the poverty rate.

2. Discuss how family structure is related to the poverty rate.

3. Explain what poverty and labor force participation data imply about the belief that many poor people lack the motivation to work.

Who are the poor? Although the official poverty rate in 2010 was 15.1 percent, this rate differs by the important sociodemographic characteristics of race/ethnicity, gender, and age, and it also differs by region of the nation and by family structure. The poverty rate differences based on these variables are critical to understanding the nature and social patterning of poverty in the United States. We look at each of these variables in turn with 2010 census data (DeNavas-Walt, et, al., 2011).

\section{Race/Ethnicity}

Here is a quick quiz; please circle the correct answer.

- Most poor people in the United States are

1. Black/African American

2. Latino

3. Native American

4. Asian

5. White

What did you circle? If you are like the majority of people who answer a similar question in public opinion surveys, you would have circled a. Black/African American. When Americans think about poor people, they tend to picture African Americans (White, 2007). This popular image is thought to reduce the public's sympathy for poor people and to lead them to oppose increased government aid for the poor. The public's views on these matters are, in turn, thought to play a key role in government poverty policy. It is thus essential for the public to have an accurate understanding of the racial/ethnic patterning of poverty. 


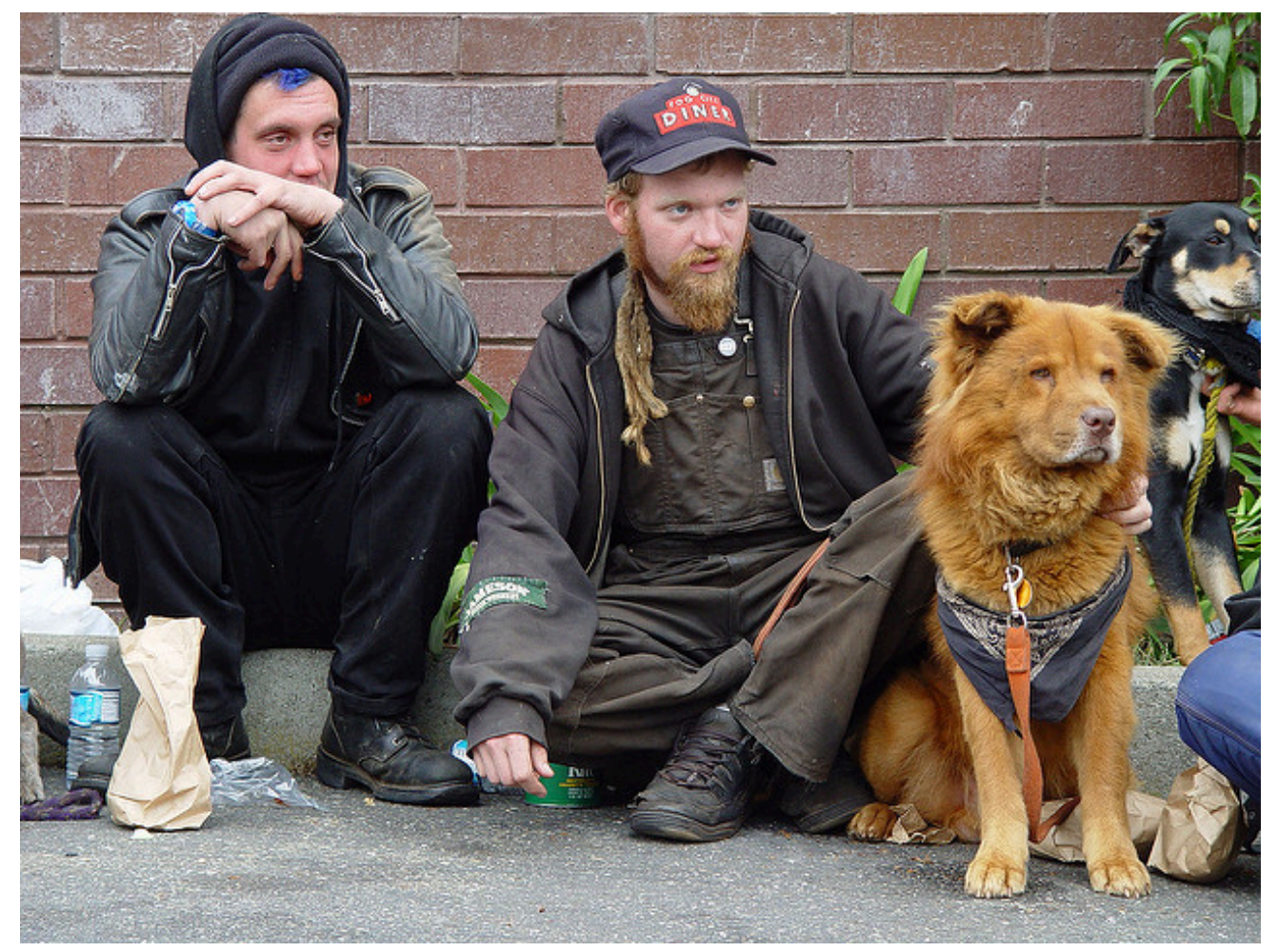

The most typical poor people in the United States are non-Latino whites. These individuals comprise 42.4 percent of all poor Americans.

Franco Folini - $\underline{\text { Homeless guys with dogs }}$ - CC BY-SA 2.0.

Unfortunately, the public's racial image of poor people is mistaken, as census data reveal that the most typical poor person is white (non-Latino). To be more precise, 42.4 percent of poor people are white (non-Latino), 28.7 percent are Latino, 23.1 percent are black, and 3.7 percent are Asian (see Figure 2.2 "Racial and Ethnic Composition of the Poor, 2010 (Percentage of Poor Persons Who Belong to Each Group)”). As these figures show, non-Latino whites certainly comprise the greatest number of the American poor. Turning these percentages into numbers, they account for 19.6 million of the 46.2 million poor Americans.

It is also true, though, that race and ethnicity affect the chances of being poor. While only 9.9 percent of nonLatino whites are poor, 27.4 percent of African Americans, 12.1 percent of Asians, and 26.6 percent of Latinos (who may be of any race) are poor (see Figure 2.3 "Race, Ethnicity, and Poverty, 2010 (Percentage of Each Group That Is Poor)”). Thus African Americans and Latinos are almost three times as likely as non-Latino whites to be poor. (Because there are so many non-Latino whites in the United States, the greatest number of poor people are non-Latino white, even if the percentage of whites who are poor is relatively low.) The higher poverty rates of people of color are so striking and important that they have been termed the "colors of poverty" (Lin \& Harris, 2008). 


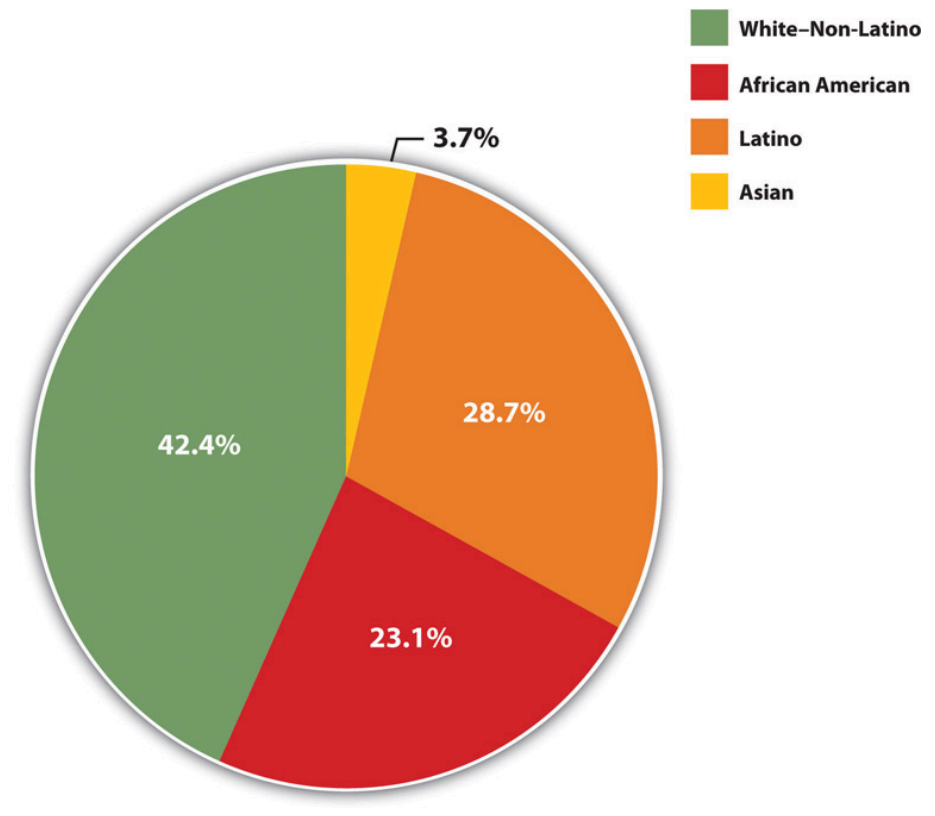

Source: Data from DeNavas-Walt, C., Proctor, B. D., \& Smith, J. C. (2011). Income, poverty, and health insurance coverage in the United States: 2010 (Current Population Report P60-239). Washington, DC: US Census Bureau.

Figure 2.3 Race, Ethnicity, and Poverty, 2010 (Percentage of Each Group That Is Poor)

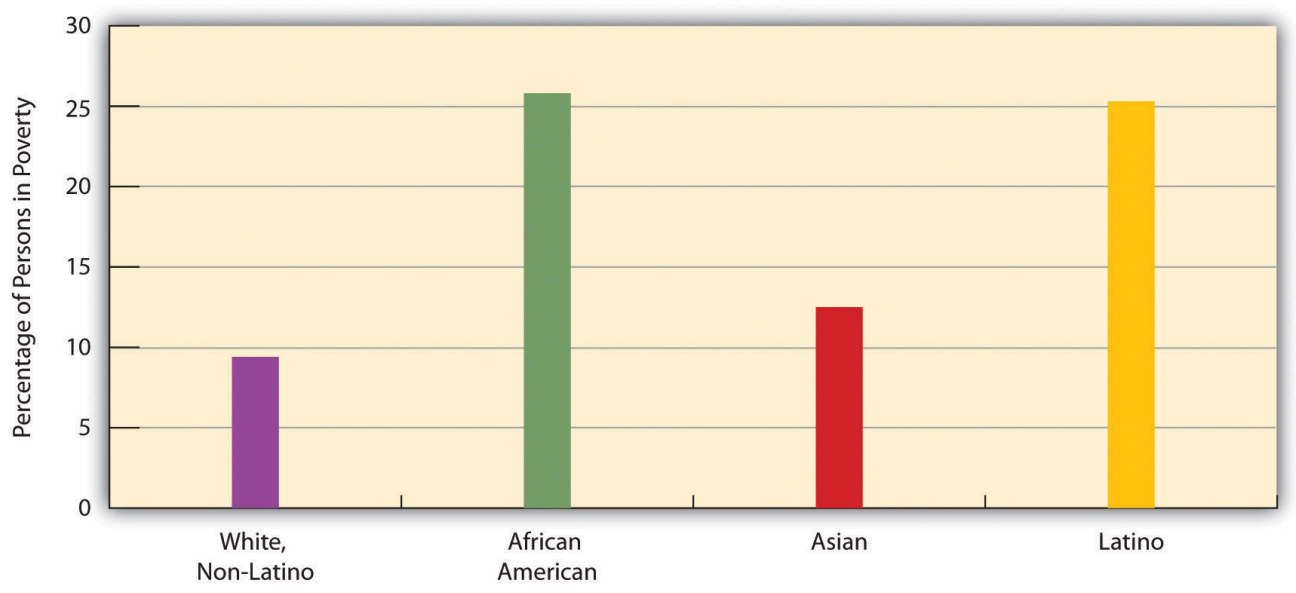

Source: Data from DeNavas-Walt, C., Proctor, B. D., \& Smith, J. C. (2011). Income, poverty, and health insurance coverage in the United States: 2010 (Current Population Report P60-239). Washington, DC: US Census Bureau.

\section{Gender}

One thing that many women know all too well is that women are more likely than men to be poor. According to 
the census, 16.2 percent of all females live in poverty, compared to only 14.0 percent of all males. These figures translate to a large gender gap in the actual number of poor people, as 25.2 million women and girls live in poverty, compared to only 21.0 million men and boys, for a difference of 4.2 million people. The high rate of female poverty is called the feminization of poverty (Iceland, 2006). We will see additional evidence of this pattern when we look at the section on family structure that follows.

\section{Age}

Turning to age, at any one time 22 percent of children under age 18 are poor (amounting to 16.4 million children), a figure that rises to about 39 percent of African American children and 35 percent of Latino children. About 37 percent of all children live in poverty for at least one year before turning 18 (Ratcliffe \& McKernan, 2010). The poverty rate for US children is the highest of all wealthy democracies and in fact is 1.5 to 9 times greater than the corresponding rates in Canada and Western Europe (Mishel, et. al., 2009). As high as the US childhood poverty rate is, twice-poverty data again paint an even more discouraging picture. Children living in families with incomes below twice the official poverty level are called low-income children, and their families are called low-income families. Almost 44 percent of American children, or some 32.5 million kids, live in such families (Addy \& Wright, 2012). Almost two-thirds of African American children and Latino children live in low-income families. 


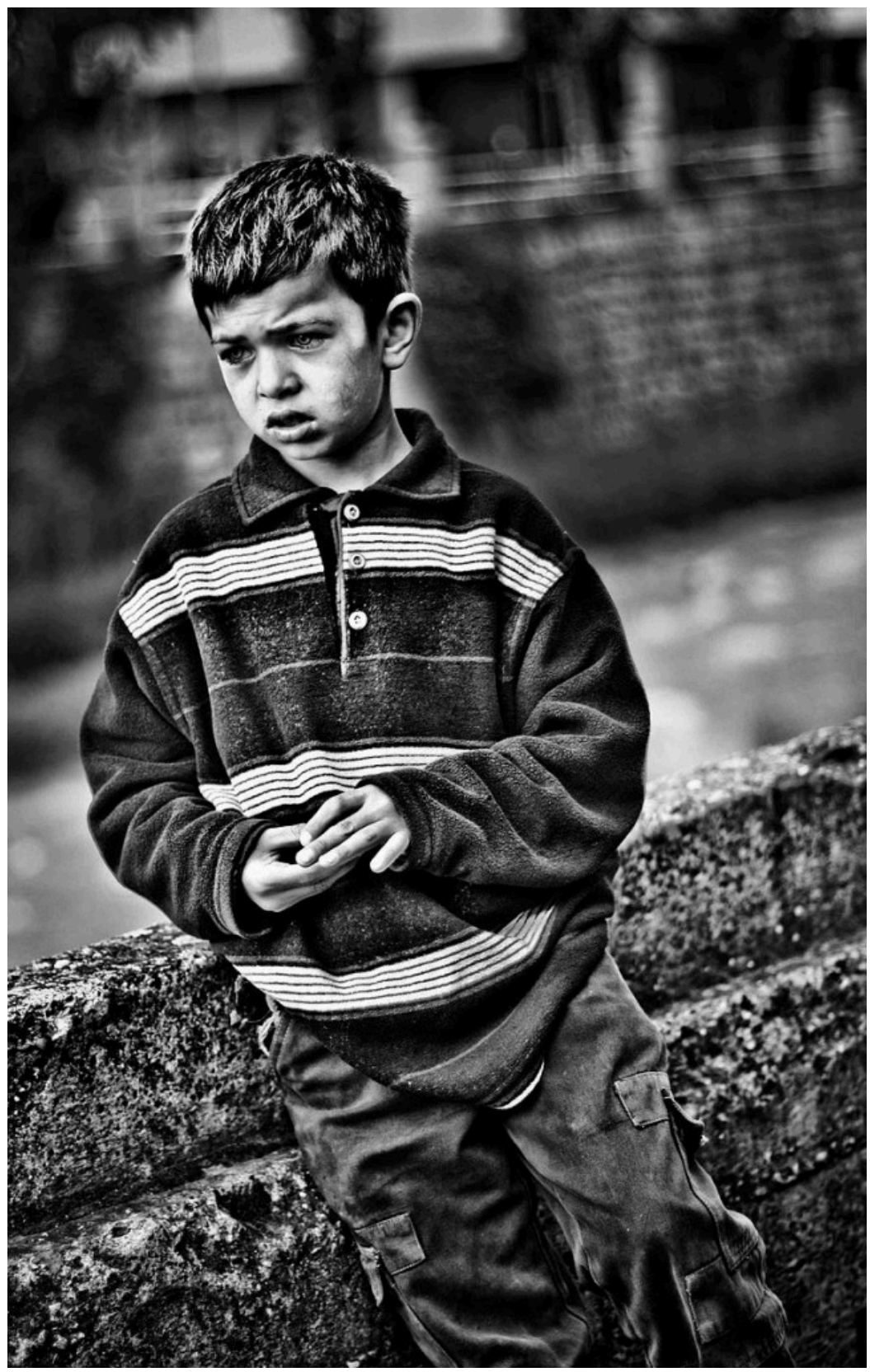

The poverty rate for US children is the highest in the Western world.

Wikimedia Commons - CC BY-SA 3.0.

At the other end of the age distribution, 9 percent of people aged 65 or older are poor (amounting to about 3.5 million seniors). Turning around these age figures, almost 36 percent of all poor people in the United States are children, and almost 8 percent of the poor are 65 or older. Thus more than 43.4 percent of Americans living in poverty are children or the elderly. 


\section{Region}

Poverty rates differ around the country. Some states have higher poverty rates than other states, and some counties within a state are poorer than other counties within that state. A basic way of understanding geographical differences in poverty is to examine the poverty rates of the four major regions of the nation. When we do this, the South is the poorest region, with a poverty rate of 16.9 percent. The West is next (15.3 percent), followed by the Midwest (13.9 percent) and then the Northeast (12.8 percent). The South's high poverty rate is thought to be an important reason for the high rate of illnesses and other health problems it experiences compared to the other regions (Ramshaw, 2011).

\section{Family Structure}

There are many types of family structures, including a married couple living with their children; an unmarried couple living with one or more children; a household with children headed by only one parent, usually a woman; a household with two adults and no children; and a household with only one adult living alone. Across the nation, poverty rates differ from one type of family structure to another.

Not surprisingly, poverty rates are higher in families with one adult than in those with two adults (because they often are bringing in two incomes), and, in one-adult families, they are higher in families headed by a woman than in those headed by a man (because women generally have lower incomes than men). Of all families headed by just a woman, 31.6 percent live in poverty, compared to only 15.8 percent of families headed by just a man. In contrast, only 6.2 percent of families headed by a married couple live in poverty (see Figure 2.4 "Family Structure and Poverty Rate (Percentage of Each Type of Structure That Lives in Poverty)"). The figure for female-headed families provides additional evidence for the feminization of poverty concept introduced earlier.

Figure 2.4 Family Structure and Poverty Rate (Percentage of Each Type of Structure That Lives in Poverty)

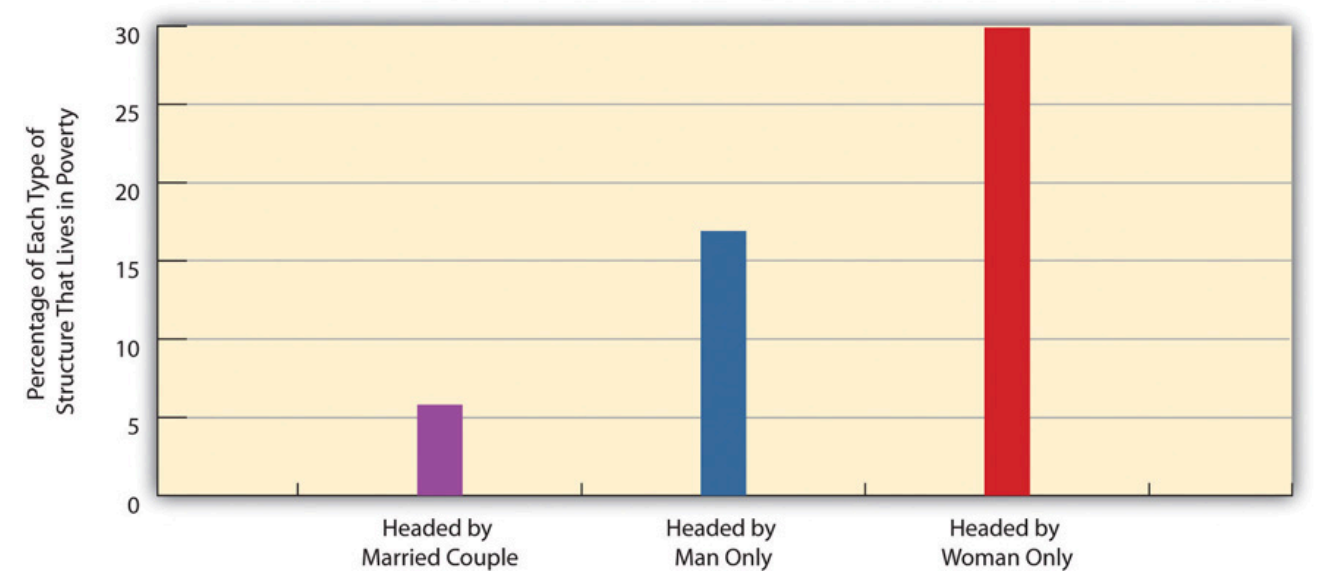

Source: Data from DeNavas-Walt, C., Proctor, B. D., \& Smith, J. C. (2011). Income, poverty, and health insurance coverage in the United States: 2010 (Current Population Report P60-239). Washington, DC: US Census Bureau. 
We saw earlier that 22 percent of American children are poor. This figure varies according to the type of family structure in which the children live. Whereas only 11.6 percent of children residing with married parents live in poverty, 46.9 percent of those living with only their mother live in poverty. This latter figure rises to 53.3 percent for African American children and 57.0 percent for Latino children (US Census Bureau, 2012). Yet regardless of their race or ethnicity, children living just with their mothers are at particularly great risk of living in poverty.

\section{Labor Force Status}

As this chapter discusses later, many Americans think the poor are lazy and lack the motivation to work and, as is often said, "really could work if they wanted to." However, government data on the poor show that most poor people are, in fact, either working, unemployed but looking for work, or unable to work because of their age or health. Table 2.1 "Poverty and Labor Force Participation, 2010" shows the relevant data. We discuss these numbers in some detail because of their importance, so please follow along carefully.

Table 2.1 Poverty and Labor Force Participation, 2010

\begin{tabular}{|l|l|}
\hline Total number of poor people & $46,180,000$ \\
\hline Number of poor people under age 18 & $16,401,000$ \\
\hline Number of poor people ages 65 and older & $3,521,000$ \\
\hline Number of poor people ages 18-64 & $26,258,000$ \\
\hline Number of poor people ages 18-64 who were: \\
\hline Working full- or part-time & $9,053,000$ \\
\hline Unemployed but looking for work & $3,616,000$ \\
\hline Disabled & $4,247,000$ \\
\hline In the armed forces & 77,000 \\
\hline Able-bodied but not in the labor force & $9,254,000$ \\
\hline
\end{tabular}

Source: Data from US Census Bureau. (2010). Current population survey (CPS) table creator. Retrieved from http://www.census.gov/cps/data/ cpstablecreator.html.

Let's examine this table to see the story it tells. Of the roughly 46.2 million poor people, almost 20 million were either under age 18 or at least 65. Because of their ages, we would not expect them to be working. Of the remaining 26.3 million poor adults ages 18-64, almost 17 million, or about two-thirds, fell into one of these categories: (a) they worked full-time or part-time, (b) they were unemployed but looking for work during a year of very high unemployment due to the nation's faltering economy, (c) they did not work because of a disability, 
or (d) they were in the armed forces. Subtracting all these adults leaves about 9.3 million able-bodied people ages $18-64$.

Doing some arithmetic, we thus see that almost 37 million of the 46.2 million poor people we started with, or 80 percent, with were either working or unemployed but looking for work, too young or too old to work, disabled, or in the armed forces. It would thus be inaccurate to describe the vast majority of the poor as lazy and lacking the motivation to work.

What about the 9.3 million able-bodied poor people who are ages 18-64 but not in the labor force, who compose only 20 percent of the poor to begin with? Most of them were either taking care of small children or elderly parents or other relatives, retired for health reasons, or in school (US Census Bureau, 2012); some also left the labor force out of frustration and did not look for work (and thus were not counted officially as unemployed). Taking all these numbers and categories into account, it turns out that the percentage of poor people who "really could work if they wanted to" is rather miniscule, and the common belief that they "really could work if they wanted to" is nothing more than a myth.

\section{People Making a Difference}

Feeding “Motel Kids” Near Disneyland

Just blocks from Disneyland in Anaheim, California, more than 1,000 families live in cheap motels frequently used by drug dealers and prostitutes. Because they cannot afford the deposit for an apartment, the motels are their only alternative to homelessness. As Bruno Serato, a local Italian restaurant owner, observed, "Some people are stuck, they have no money. They need to live in that room. They've lost everything they have. They have no other choice. No choice."

Serato learned about these families back in 2005, when he saw a boy at the local Boys \& Girls Club eating a bag of potato chips as his only food for dinner. He was told that the boy lived with his family in a motel and that the Boys \& Girls Club had a "motel kids" program that drove children in vans after school to their motels. Although the children got free breakfast and lunch at school, they often went hungry at night. Serato soon began serving pasta dinners to some seventy children at the club every evening, a number that had grown by spring 2011 to almost three hundred children nightly. Serato also pays to have the children transported to the club for their dinners, and he estimates that the food and transportation cost him about $\$ 2,000$ monthly. His program had served more than 300,000 pasta dinners to motel kids by 2011.

Two of the children who eat Serato's pasta are Carlos and Anthony Gomez, 12, who live in a motel room with the other members of their family. Their father was grateful for the pasta: "I no longer worry as much, about them [coming home] and there being no food. I know that they eat over there at [the] Boys \& Girls Club."

Bruno Serato is merely happy to be helping out. “They’re customers,” he explains. "My favorite customers” (Toner, 2011).

For more information about Bruno Serato’s efforts, visit his charity site at www.thecaterinasclub.org.

\section{Key Takeaways}

- Although people of color have higher poverty rates than non-Latino whites, the most typical poor person in the United States is non-Latino white. 
- The US childhood poverty rate is the highest of all Western democracies.

- Labor force participation data indicate that the belief that poor people lack motivation to work is in fact a myth.

\section{For Your Review}

1. Why do you think the majority of Americans assume poor people lack the motivation to work?

2. Explain to a friend how labor force participation data indicate that it is inaccurate to think that poor people lack the motivation to work.

\section{References}

Addy, S., \& Wright, V. R. (2012). Basic facts about low-income children, 2010. New York, NY: National Center for Children in Poverty.

DeNavas-Walt, C., Proctor, B. D., \& Smith, J. C. (2011). Income, poverty, and health insurance coverage in the United States: 2010 (Current Population Reports, P60-298). Washington, DC: US Census Bureau.

Iceland, J. (2006). Poverty in America: A handbook. Berkeley, CA: University of California Press.

Lin, A. C., \& Harris, D. R. (Eds.). (2008). The colors of poverty: Why racial and ethnic disparities persist. New York, NY: Russell Sage Foundation.

Mishel, L., Bernstein, J., \& Shierholz, H. (2009). The state of working America 2008/2009. Ithaca, NY: ILR Press. Ramshaw, E. (2011, July 10). Major health problems linked to poverty. New York Times, p. A21.

Ratcliffe, C., \& McKernan, S.-M. (2010). Childhood poverty persistence: Facts and consequences. Washington, DC: Urban Institute Press.

Toner, K. (2011, March 24). Making sure “motel kids” don’t go hungry. CNN. Retrieved from http://www.cnn.com/2011/LIVING/03/24/cnnheroes.serato.motel.kids/index.html.

US Census Bureau . (2012). Poverty. Washington, DC: Author. Retrieved from http://www.census.gov/hhes/ www/cpstables/032011/pov/new02 100.htm.

US Census Bureau. (2012). Current population survey. 2012 annual social and economic supplement. Washington, DC: Author.

White, J. A. (2007). The hollow and the ghetto: Space, race, and the politics of poverty. Politics \& Gender, 3, 271-280. 


\subsection{Explaining Poverty}

\section{Learning Objectives}

1. Describe the assumptions of the functionalist and conflict views of stratification and of poverty.

2. Explain the focus of symbolic interactionist work on poverty.

3. Understand the difference between the individualist and structural explanations of poverty.

Why does poverty exist, and why and how do poor people end up being poor? The sociological perspectives introduced in Chapter 1 "Understanding Social Problems" provide some possible answers to these questions through their attempt to explain why American society is stratified - that is, why it has a range of wealth ranging from the extremely wealthy to the extremely poor. We review what these perspectives say generally about social stratification (rankings of people based on wealth and other resources a society values) before turning to explanations focusing specifically on poverty.

In general, the functionalist perspective and conflict perspective both try to explain why social stratification exists and endures, while the symbolic interactionist perspective discusses the differences that stratification produces for everyday interaction. Table 2.2 "Theory Snapshot" summarizes these three approaches.

Table 2.2 Theory Snapshot

\begin{tabular}{|l|l|}
\hline $\begin{array}{l}\text { Theoretical } \\
\text { perspective }\end{array}$ & Major assumptions \\
\hline Functionalism & $\begin{array}{l}\text { Stratification is necessary to induce people with special intelligence, knowledge, and skills to enter the } \\
\text { most important occupations. For this reason, stratification is necessary and inevitable. }\end{array}$ \\
\hline $\begin{array}{l}\text { Conflict } \\
\text { theory }\end{array}$ & $\begin{array}{l}\text { Stratification results from lack of opportunity and from discrimination and prejudice against the poor, } \\
\text { women, and people of color. It is neither necessary nor inevitable. }\end{array}$ \\
\hline $\begin{array}{l}\text { Symbolic } \\
\text { interactionism }\end{array}$ & Stratification affects people's beliefs, lifestyles, daily interaction, and conceptions of themselves. \\
\hline
\end{tabular}

\section{The Functionalist View}

As discussed in Chapter 1 "Understanding Social Problems", functionalist theory assumes that society's structures and processes exist because they serve important functions for society's stability and continuity. In line with this view, functionalist theorists in sociology assume that stratification exists because it also serves important functions for society. This explanation was developed more than sixty years ago by Kingsley Davis and Wilbert Moore 
(Davis \& Moore, 1945) in the form of several logical assumptions that imply stratification is both necessary and inevitable. When applied to American society, their assumptions would be as follows:

1. Some jobs are more important than other jobs. For example, the job of a brain surgeon is more important than the job of shoe shining.

2. Some jobs require more skills and knowledge than other jobs. To stay with our example, it takes more skills and knowledge to perform brain surgery than to shine shoes.

3. Relatively few people have the ability to acquire the skills and knowledge that are needed to do these important, highly skilled jobs. Most of us would be able to do a decent job of shining shoes, but very few of us would be able to become brain surgeons.

4. To encourage the people with the skills and knowledge to do the important, highly skilled jobs, society must promise them higher incomes or other rewards. If this is true, some people

automatically end up higher in society’s ranking system than others, and stratification is thus necessary and inevitable.

To illustrate their assumptions, say we have a society where shining shoes and doing brain surgery both give us incomes of $\$ 150,000$ per year. (This example is very hypothetical, but please keep reading.) If you decide to shine shoes, you can begin making this money at age 16, but if you decide to become a brain surgeon, you will not start making this same amount until about age 35, as you must first go to college and medical school and then acquire several more years of medical training. While you have spent nineteen additional years beyond age 16 getting this education and training and taking out tens of thousands of dollars in student loans, you could have spent those years shining shoes and making $\$ 150,000$ a year, or $\$ 2.85$ million overall. Which job would you choose? 


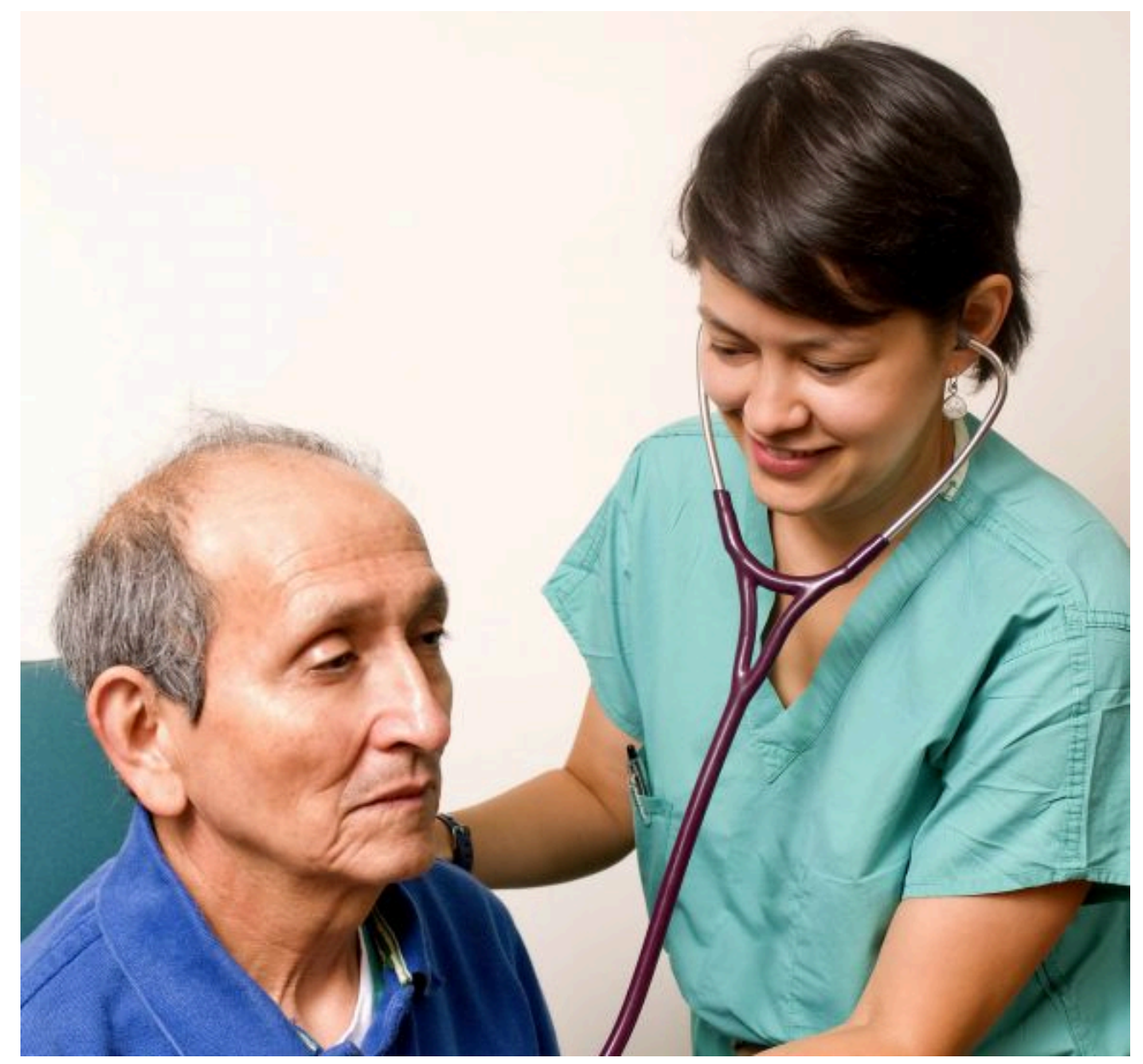

Functional theory argues that the promise of very high incomes is necessary to encourage talented people to pursue important careers such as surgery. If physicians and shoe shiners made the same high income, would enough people decide to become physicians?

Public Domain Images - CC0 public domain.

As this example suggests, many people might not choose to become brain surgeons unless considerable financial and other rewards awaited them. By extension, we might not have enough people filling society's important jobs unless they know they will be similarly rewarded. If this is true, we must have stratification. And if we must have stratification, then that means some people will have much less money than other people. If stratification is inevitable, then, poverty is also inevitable. The functionalist view further implies that if people are poor, it is because they do not have the ability to acquire the skills and knowledge necessary for the important, high-paying jobs.

The functionalist view sounds very logical, but a few years after Davis and Moore published their theory, other sociologists pointed out some serious problems in their argument (Tumin, 1953; Wrong, 1959).

First, it is difficult to compare the importance of many types of jobs. For example, which is more important, doing brain surgery or mining coal? Although you might be tempted to answer with brain surgery, if no coal were mined then much of our society could not function. In another example, which job is more important, attorney or professor? (Be careful how you answer this one!) 
Second, the functionalist explanation implies that the most important jobs have the highest incomes and the least important jobs the lowest incomes, but many examples, including the ones just mentioned, counter this view. Coal miners make much less money than physicians, and professors, for better or worse, earn much less on the average than lawyers. A professional athlete making millions of dollars a year earns many times the income of the president of the United States, but who is more important to the nation? Elementary school teachers do a very important job in our society, but their salaries are much lower than those of sports agents, advertising executives, and many other people whose jobs are far less essential.

Third, the functionalist view assumes that people move up the economic ladder based on their abilities, skills, knowledge, and, more generally, their merit. This implies that if they do not move up the ladder, they lack the necessary merit. However, this view ignores the fact that much of our stratification stems from lack of equal opportunity. As later chapters in this book discuss, because of their race, ethnicity, gender, and class standing at birth, some people have less opportunity than others to acquire the skills and training they need to fill the types of jobs addressed by the functionalist approach.

Finally, the functionalist explanation might make sense up to a point, but it does not justify the extremes of wealth and poverty found in the United States and other nations. Even if we do have to promise higher incomes to get enough people to become physicians, does that mean we also need the amount of poverty we have? Do CEOs of corporations really need to make millions of dollars per year to get enough qualified people to become CEOs? Do people take on a position as CEO or other high-paying job at least partly because of the challenge, working conditions, and other positive aspects they offer? The functionalist view does not answer these questions adequately.

One other line of functionalist thinking focuses more directly on poverty than generally on stratification. This particular functionalist view provocatively argues that poverty exists because it serves certain positive functions for our society. These functions include the following: (1) poor people do the work that other people do not want to do; (2) the programs that help poor people provide a lot of jobs for the people employed by the programs; (3) the poor purchase goods, such as day-old bread and used clothing, that other people do not wish to purchase, and thus extend the economic value of these goods; and (4) the poor provide jobs for doctors, lawyers, teachers, and other professionals who may not be competent enough to be employed in positions catering to wealthier patients, clients, students, and so forth (Gans, 1972). Because poverty serves all these functions and more, according to this argument, the middle and upper classes have a vested interested in neglecting poverty to help ensure its continued existence.

\section{The Conflict View}




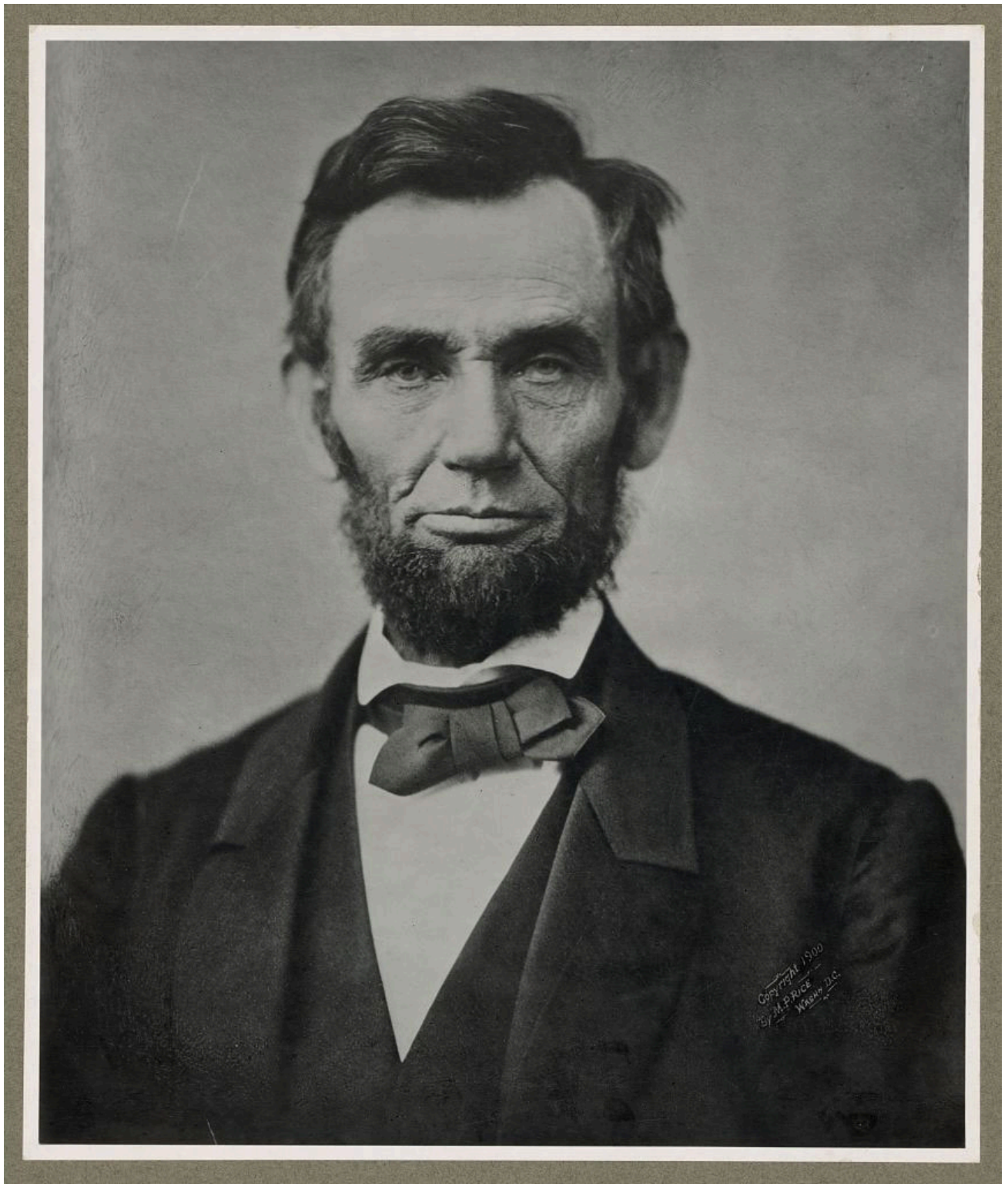

Because he was born in a log cabin and later became president, Abraham Lincoln's life epitomizes the American Dream, which is the belief that people born into poverty can become successful through hard work. The popularity of this belief leads many Americans to blame poor people for their poverty.

\section{US Library of Congress - public domain.}

Conflict theory's explanation of stratification draws on Karl Marx's view of class societies and incorporates the critique of the functionalist view just discussed. Many different explanations grounded in conflict theory exist, but they all assume that stratification stems from a fundamental conflict between the needs and interests of the powerful, or "haves," in society and those of the weak, or "have-nots" (Kerbo, 2012). The former take advantage of their position at the top of society to stay at the top, even if it means oppressing those at the bottom. At a minimum, they can heavily influence the law, the media, and other institutions in a way that maintains society's class structure.

In general, conflict theory attributes stratification and thus poverty to lack of opportunity from discrimination and 
prejudice against the poor, women, and people of color. In this regard, it reflects one of the early critiques of the functionalist view that the previous section outlined. To reiterate an earlier point, several of the remaining chapters of this book discuss the various obstacles that make it difficult for the poor, women, and people of color in the United States to move up the socioeconomic ladder and to otherwise enjoy healthy and productive lives.

\section{Symbolic Interactionism}

Consistent with its micro orientation, symbolic interactionism tries to understand stratification and thus poverty by looking at people's interaction and understandings in their daily lives. Unlike the functionalist and conflict views, it does not try to explain why we have stratification in the first place. Rather, it examines the differences that stratification makes for people’s lifestyles and their interaction with other people.

Many detailed, insightful sociological books on the lives of the urban and rural poor reflect the symbolic interactionist perspective (Anderson, 1999; C. M. Duncan, 2000; Liebow, 1993; Rank, 1994). These books focus on different people in different places, but they all make very clear that the poor often lead lives of quiet desperation and must find ways of coping with the fact of being poor. In these books, the consequences of poverty discussed later in this chapter acquire a human face, and readers learn in great detail what it is like to live in poverty on a daily basis.

Some classic journalistic accounts by authors not trained in the social sciences also present eloquent descriptions of poor people’s lives (Bagdikian, 1964; Harrington, 1962). Writing in this tradition, a newspaper columnist who grew up in poverty recently recalled, "I know the feel of thick calluses on the bottom of shoeless feet. I know the bite of the cold breeze that slithers through a drafty house. I know the weight of constant worry over not having enough to fill a belly or fight an illness...Poverty is brutal, consuming and unforgiving. It strikes at the soul” (Blow, 2011).

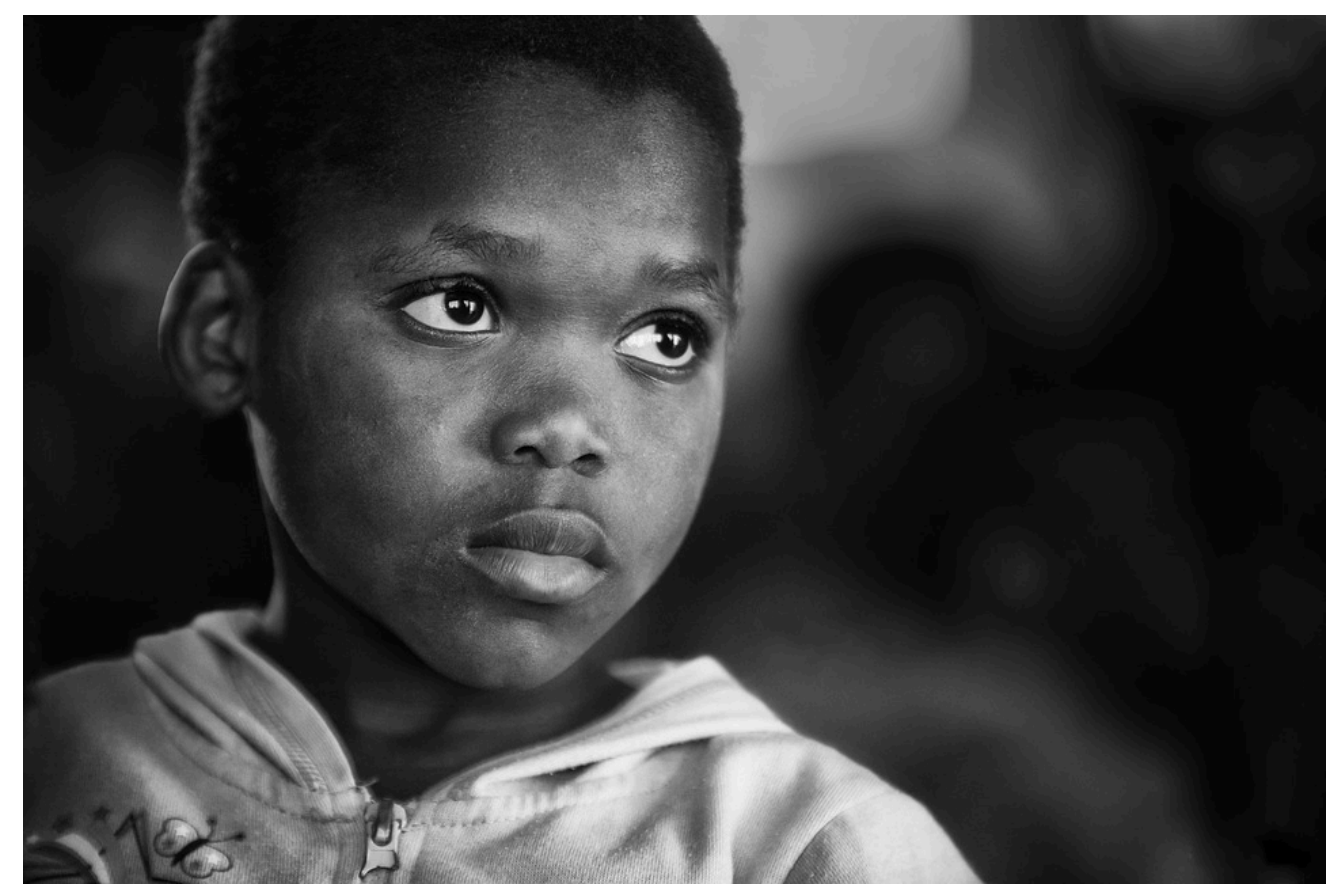


Sociological accounts of the poor provide a vivid portrait of what it is like to live in poverty on a daily basis.

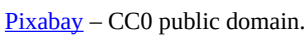

On a more lighthearted note, examples of the symbolic interactionist framework are also seen in the many literary works and films that portray the difficulties that the rich and poor have in interacting on the relatively few occasions when they do interact. For example, in the film Pretty Woman, Richard Gere plays a rich businessman who hires a prostitute, played by Julia Roberts, to accompany him to swank parties and other affairs. Roberts has to buy a new wardrobe and learn how to dine and behave in these social settings, and much of the film's humor and poignancy come from her awkwardness in learning the lifestyle of the rich.

\section{Specific Explanations of Poverty}

The functionalist and conflict views focus broadly on social stratification but only indirectly on poverty. When poverty finally attracted national attention during the 1960s, scholars began to try specifically to understand why poor people become poor and remain poor. Two competing explanations developed, with the basic debate turning on whether poverty arises from problems either within the poor themselves or in the society in which they live (Rank, 2011). The first type of explanation follows logically from the functional theory of stratification and may be considered an individualistic explanation. The second type of explanation follows from conflict theory and is a structural explanation that focuses on problems in American society that produce poverty. Table 2.3 "Explanations of Poverty" summarizes these explanations.

Table 2.3 Explanations of Poverty

\begin{tabular}{|l|l|}
\hline Explanation & Major assumptions \\
\hline Individualistic & $\begin{array}{l}\text { Poverty results from the fact that poor people lack the motivation to work and have certain beliefs and } \\
\text { values that contribute to their poverty. }\end{array}$ \\
\hline Structural & Poverty results from problems in society that lead to a lack of opportunity and a lack of jobs. \\
\hline
\end{tabular}

It is critical to determine which explanation makes more sense because, as sociologist Theresa C. Davidson (Davidson, 2009) observes, "beliefs about the causes of poverty shape attitudes toward the poor." To be more precise, the particular explanation that people favor affects their view of government efforts to help the poor. Those who attribute poverty to problems in the larger society are much more likely than those who attribute it to deficiencies among the poor to believe that the government should do more to help the poor (Bradley \& Cole, 2002). The explanation for poverty we favor presumably affects the amount of sympathy we have for the poor, and our sympathy, or lack of sympathy, in turn affects our views about the government's role in helping the poor. With this backdrop in mind, what do the individualistic and structural explanations of poverty say?

\section{Individualistic Explanation}

According to the individualistic explanation, the poor have personal problems and deficiencies that are responsible 
for their poverty. In the past, the poor were thought to be biologically inferior, a view that has not entirely faded, but today the much more common belief is that they lack the ambition and motivation to work hard and to achieve success. According to survey evidence, the majority of Americans share this belief (Davidson, 2009). A more sophisticated version of this type of explanation is called the culture of poverty theory (Banfield, 1974; Lewis, 1966; Murray, 2012). According to this theory, the poor generally have beliefs and values that differ from those of the nonpoor and that doom them to continued poverty. For example, they are said to be impulsive and to live for the present rather than the future.

Regardless of which version one might hold, the individualistic explanation is a blaming-the-victim approach (see Chapter 1 "Understanding Social Problems"). Critics say this explanation ignores discrimination and other problems in American society and exaggerates the degree to which the poor and nonpoor do in fact hold different values (Ehrenreich, 2012; Holland, 2011; Schmidt, 2012). Regarding the latter point, they note that poor employed adults work more hours per week than wealthier adults and that poor parents interviewed in surveys value education for their children at least as much as wealthier parents. These and other similarities in values and beliefs lead critics of the individualistic explanation to conclude that poor people's poverty cannot reasonably be said to result from a culture of poverty.

\section{Structural Explanation}

According to the second, structural explanation, which is a blaming-the-system approach, US poverty stems from problems in American society that lead to a lack of equal opportunity and a lack of jobs. These problems include (a) racial, ethnic, gender, and age discrimination; (b) lack of good schooling and adequate health care; and (c) structural changes in the American economic system, such as the departure of manufacturing companies from American cities in the 1980s and 1990s that led to the loss of thousands of jobs. These problems help create a vicious cycle of poverty in which children of the poor are often fated to end up in poverty or near poverty themselves as adults.

As Rank (Rank, 2011) summarizes this view, “American poverty is largely the result of failings at the economic and political levels, rather than at the individual level...In contrast to [the individualistic] perspective, the basic problem lies in a shortage of viable opportunities for all Americans.” Rank points out that the US economy during the past few decades has created more low-paying and part-time jobs and jobs without benefits, meaning that Americans increasingly find themselves in jobs that barely lift them out of poverty, if at all. Sociologist Fred Block and colleagues share this critique of the individualistic perspective: "Most of our policies incorrectly assume that people can avoid or overcome poverty through hard work alone. Yet this assumption ignores the realities of our failing urban schools, increasing employment insecurities, and the lack of affordable housing, health care, and child care. It ignores the fact that the American Dream is rapidly becoming unattainable for an increasing number of Americans, whether employed or not” (Block, et. al., 2006).

Most sociologists favor the structural explanation. As later chapters in this book document, racial and ethnic discrimination, lack of adequate schooling and health care, and other problems make it difficult to rise out of poverty. On the other hand, some ethnographic research supports the individualistic explanation by showing that the poor do have certain values and follow certain practices that augment their plight (Small, et. al., 2010). For example, the poor have higher rates of cigarette smoking (34 percent of people with annual incomes between 
$\$ 6,000$ and $\$ 11,999$ smoke, compared to only 13 percent of those with incomes $\$ 90,000$ or greater [Goszkowski, 2008]), which helps cause them to have more serious health problems.

Adopting an integrated perspective, some researchers say these values and practices are ultimately the result of poverty itself (Small et, al., 2010). These scholars concede a culture of poverty does exist, but they also say it exists because it helps the poor cope daily with the structural effects of being poor. If these effects lead to a culture of poverty, they add, poverty then becomes self-perpetuating. If poverty is both cultural and structural in origin, these scholars say, efforts to improve the lives of people in the "other America" must involve increased structural opportunities for the poor and changes in some of their values and practices.

\section{Key Takeaways}

- According to the functionalist view, stratification is a necessary and inevitable consequence of the need to use the promise of financial reward to encourage talented people to pursue important jobs and careers.

- According to conflict theory, stratification results from lack of opportunity and discrimination against the poor and people of color.

- According to symbolic interactionism, social class affects how people interact in everyday life and how they view certain aspects of the social world.

- The individualistic view attributes poverty to individual failings of poor people themselves, while the structural view attributes poverty to problems in the larger society.

\section{For Your Review}

1. In explaining poverty in the United States, which view, individualist or structural, makes more sense to you? Why?

2. Suppose you could wave a magic wand and invent a society where everyone had about the same income no matter which job he or she performed. Do you think it would be difficult to persuade enough people to become physicians or to pursue other important careers? Explain your answer.

\section{References}

Anderson, E. (1999). Code of the street: Decency, violence, and the moral life of the inner city. New York, NY: W. W. Norton.

Bagdikian, B. H. (1964). In the midst of plenty: The poor in America. Boston, MA: Beacon Press.

Banfield, E. C. (1974). The unheavenly city revisited. Boston, MA: Little, Brown.

Block, F., Korteweg, A. C., \& Woodward, K. (2006). The compassion gap in American poverty policy. Contexts, 5(2), 14-20. 
Blow, C. M. (2011, June 25). Them that's not shall lose. New York Times, p. A19.

Bradley, C., \& Cole, D. J. (2002). Causal attributions and the significance of self-efficacy in predicting solutions to poverty. Sociological Focus, 35, 381-396.

Davidson, T. C. (2009). Attributions for poverty among college students: The impact of service-learning and religiosity. College Student Journal, 43, 136-144.

Davis, K., \& Moore, W. (1945). Some principles of stratification. American Sociological Review, 10, $242-249$.

Duncan, C. M. (2000). Worlds apart: Why poverty persists in rural America. New Haven, CT: Yale University Press.

Ehrenreich, B. (2012, March 15). What “other America”? Salon.com. Retrieved from http://www.salon.com/2012/ $\underline{03 / 15 / \text { the truth about the poor/. }}$

Gans, H. J. (1972). The positive functions of poverty. American Journal of Sociology, 78, 275-289.

Goszkowski, R. (2008). Among Americans, smoking decreases as income increases. Retrieved from http://www.gallup.com/poll/105550/among-americans-smoking-decreases-income-increases.aspx.

Harrington, M. (1962). The other America: Poverty in the United States. New York, NY: Macmillan.

Holland, J. (2011, July 29). Debunking the big lie right-wingers use to justify black poverty and unemployment. AlterNet. Retrieved from http://www.alternet.org/story/151830/debunking the big_lie_rightwingers use to justify black poverty and unemployment ?page=entire.

Kerbo, H. R. (2012). Social stratification and inequality. New York, NY: McGraw-Hill.

Lewis, O. (1966). The culture of poverty. Scientific American, 113, 19-25.

Liebow, E. (1993). Tell them who I am: The lives of homeless women. New York, NY: Free Press.

Murray, C. (2012). Coming apart: The state of white America, 1960-2010. New York, NY: Crown Forum.

Rank, M. R. (1994). Living on the edge: The realities of welfare in America. New York, NY: Columbia University Press.

Rank, M. R. (2011). Rethinking American poverty. Contexts, 10(Spring), 16-21.

Schmidt, P. (2012, February 12). Charles Murray, author of the "Bell Curve," steps back into the ring. The Chronicle of Higher Education. Retrieved from http://chronicle.com/article/Charles-Murray-Author-of-The/

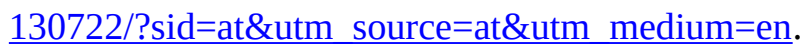

Small, M. L., Harding, D. J., \& Lamont, M. (2010). Reconsidering culture and poverty. The Annals of the American Academy of Political and Social Science, 629(May), 6-27.

Tumin, M. M. (1953). Some principles of stratification: A critical analysis. American Sociological Review, 18, 387-393. 
Wrong, D. H. (1959). The functional theory of stratification: Some neglected considerations. American Sociological Review, 24, 772-782. 


\subsection{The Consequences of Poverty}

\section{Learning Objectives}

1. Describe the family and housing problems associated with poverty.

2. Explain how poverty affects health and educational attainment.

Regardless of its causes, poverty has devastating consequences for the people who live in it. Much research conducted and/or analyzed by scholars, government agencies, and nonprofit organizations has documented the effects of poverty (and near poverty) on the lives of the poor (Lindsey, 2009; Moore, et. al., 2009; Ratcliffe \& McKernan, 2010; Sanders, 2011). Many of these studies focus on childhood poverty, and these studies make it very clear that childhood poverty has lifelong consequences. In general, poor children are more likely to be poor as adults, more likely to drop out of high school, more likely to become a teenaged parent, and more likely to have employment problems. Although only 1 percent of children who are never poor end up being poor as young adults, 32 percent of poor children become poor as young adults (Ratcliffe \& McKernan, 2010). 


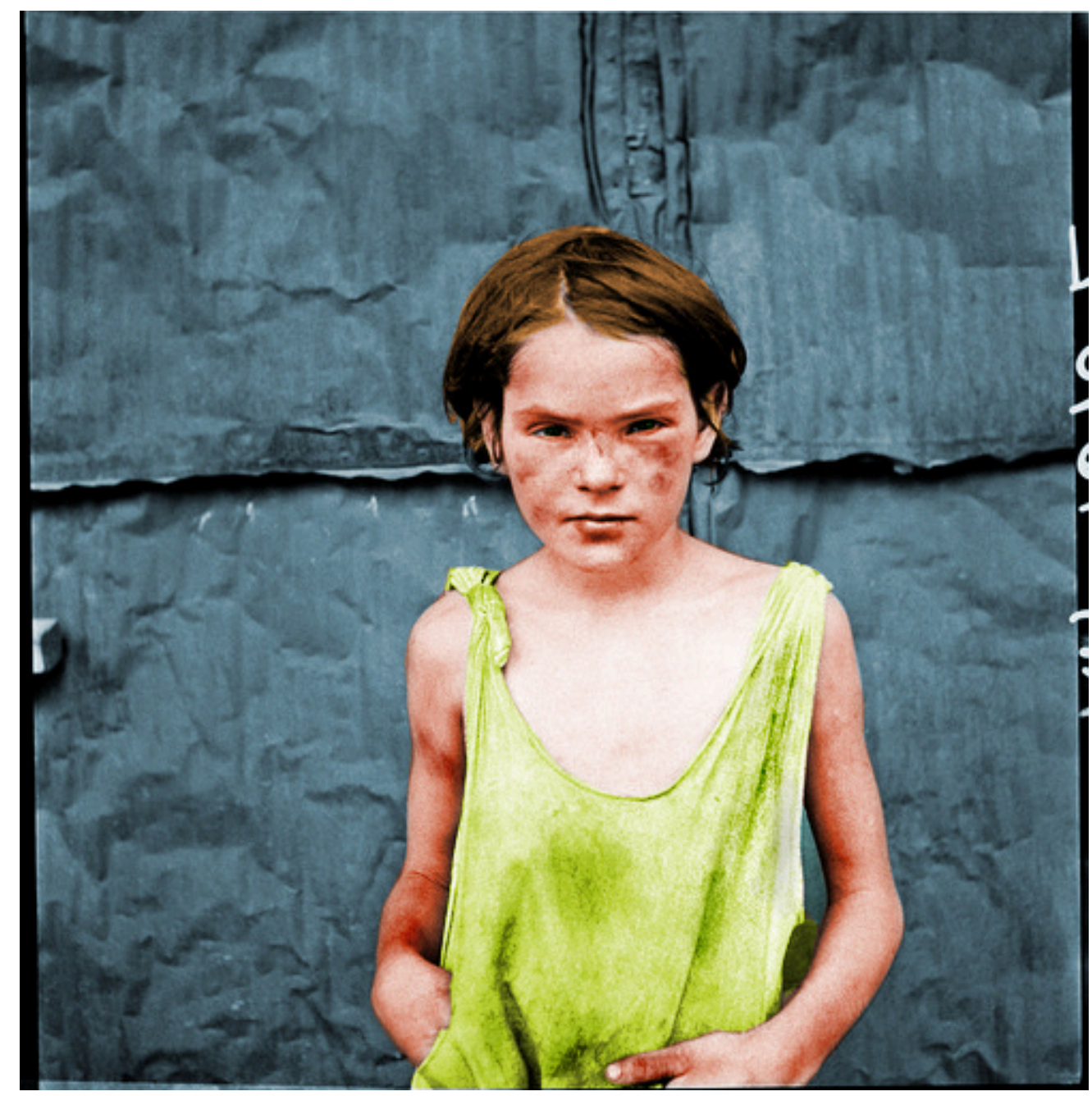

Poor children are more likely to have inadequate nutrition and to experience health, behavioral, and cognitive problems.

Kelly Short - Poverty: “Damaged Child,” Oklahoma City, OK, USA, 1936. (Colorized). - CC BY-SA 2.0.

A recent study used government data to follow children born between 1968 and 1975 until they were ages 30 to 37 (Duncan \& Magnuson, 2011). The researchers compared individuals who lived in poverty in early childhood to those whose families had incomes at least twice the poverty line in early childhood. Compared to the latter group, adults who were poor in early childhood

- had completed two fewer years of schooling on the average;

- had incomes that were less than half of those earned by adults who had wealthier childhoods;

- received \$826 more annually in food stamps on the average;

- were almost three times more likely to report being in poor health;

- $\quad$ were twice as likely to have been arrested (males only); and

- were five times as likely to have borne a child (females only).

We discuss some of the major specific consequences of poverty here and will return to them in later chapters. 


\section{Family Problems}

The poor are at greater risk for family problems, including divorce and domestic violence. As Chapter 9 "Sexual Behavior" explains, a major reason for many of the problems families experience is stress. Even in families that are not poor, running a household can cause stress, children can cause stress, and paying the bills can cause stress. Families that are poor have more stress because of their poverty, and the ordinary stresses of family life become even more intense in poor families. The various kinds of family problems thus happen more commonly in poor families than in wealthier families. Compounding this situation, when these problems occur, poor families have fewer resources than wealthier families to deal with these problems.

\section{Children and Our Future}

Getting under Children's Skin: The Biological Effects of Childhood Poverty

As the text discusses, childhood poverty often has lifelong consequences. Poor children are more likely to be poor when they become adults, and they are at greater risk for antisocial behavior when young, and for unemployment, criminal behavior, and other problems when they reach adolescence and young adulthood.

According to growing evidence, one reason poverty has these consequences is that it has certain neural effects on poor children that impair their cognitive abilities and thus their behavior and learning potential. As Greg J. Duncan and Katherine Magnuson (Duncan \& Magnuson, 2011, p. 23) observe, "Emerging research in neuroscience and developmental psychology suggests that poverty early in a child's life may be particularly harmful because the astonishingly rapid development of young children's brains leaves them sensitive (and vulnerable) to environmental conditions."

In short, poverty can change the way the brain develops in young children. The major reason for this effect is stress. Children growing up in poverty experience multiple stressful events: neighborhood crime and drug use; divorce, parental conflict, and other family problems, including abuse and neglect by their parents; parental financial problems and unemployment; physical and mental health problems of one or more family members; and so forth. Their great levels of stress in turn affect their bodies in certain harmful ways. As two poverty scholars note, "It's not just that poverty-induced stress is mentally taxing. If it's experienced early enough in childhood, it can in fact get 'under the skin' and change the way in which the body copes with the environment and the way in which the brain develops. These deep, enduring, and sometimes irreversible physiological changes are the very human price of running a high-poverty society” (Grusky \& Wimer, 2011, p. 2).

One way poverty gets “under children’s skin” is as follows (Evans, et. al., 2011). Poor children's high levels of stress produce unusually high levels of stress hormones such as cortisol and higher levels of blood pressure. Because these high levels impair their neural development, their memory and language development skills suffer. This result in turn affects their behavior and learning potential. For other physiological reasons, high levels of stress also affect the immune system, so that poor children are more likely to develop various illnesses during childhood and to have high blood pressure and other health problems when they grow older, and cause other biological changes that make poor children more likely to end up being obese and to have drug and alcohol problems.

The policy implications of the scientific research on childhood poverty are clear. As public health scholar Jack P. Shonkoff (Shonkoff, 2011) explains, "Viewing this scientific evidence within a biodevelopmental framework points to the particular importance of addressing the needs of our most disadvantaged children at the earliest ages." Duncan and Magnuson (Duncan \& Magnuson, 2011) agree that "greater policy attention should be given to remediating situations involving deep and persistent poverty occurring early in childhood.” To reduce poverty's harmful physiological effects on children, Skonkoff advocates efforts to promote strong, stable relationships among all members of poor families; to improve the quality of the home and neighborhood physical environments in which poor children grow; and to improve the nutrition of poor children. Duncan and Magnuson call for more generous income transfers to poor families with young children and note that many European democracies provide many kinds of support to such families. The recent 
scientific evidence on early childhood poverty underscores the importance of doing everything possible to reduce the harmful effects of poverty during the first few years of life.

\section{Health, Illness, and Medical Care}

The poor are also more likely to have many kinds of health problems, including infant mortality, earlier adulthood mortality, and mental illness, and they are also more likely to receive inadequate medical care. Poor children are more likely to have inadequate nutrition and, partly for this reason, to suffer health, behavioral, and cognitive problems. These problems in turn impair their ability to do well in school and land stable employment as adults, helping to ensure that poverty will persist across generations. Many poor people are uninsured or underinsured, at least until the US health-care reform legislation of 2010 takes full effect a few years from now, and many have to visit health clinics that are overcrowded and understaffed.

As Chapter 12 "Work and the Economy" discusses, it is unclear how much of poor people's worse health stems from their lack of money and lack of good health care versus their own behavior such as smoking and eating unhealthy diets. Regardless of the exact reasons, however, the fact remains that poor health is a major consequence of poverty. According to recent research, this fact means that poverty is responsible for almost 150,000 deaths annually, a figure about equal to the number of deaths from lung cancer (Bakalar, 2011).

\section{Education}

Poor children typically go to rundown schools with inadequate facilities where they receive inadequate schooling. They are much less likely than wealthier children to graduate from high school or to go to college. Their lack of education in turn restricts them and their own children to poverty, once again helping to ensure a vicious cycle of continuing poverty across generations. As Chapter 10 “The Changing Family" explains, scholars debate whether the poor school performance of poor children stems more from the inadequacy of their schools and schooling versus their own poverty. Regardless of exactly why poor children are more likely to do poorly in school and to have low educational attainment, these educational problems are another major consequence of poverty.

\section{Housing and Homelessness}

The poor are, not surprisingly, more likely to be homeless than the nonpoor but also more likely to live in dilapidated housing and unable to buy their own homes. Many poor families spend more than half their income on rent, and they tend to live in poor neighborhoods that lack job opportunities, good schools, and other features of modern life that wealthier people take for granted. The lack of adequate housing for the poor remains a major national problem. Even worse is outright homelessness. An estimated 1.6 million people, including more than 300,000 children, are homeless at least part of the year (Lee, et. al., 2010). 


\section{Crime and Victimization}

As Chapter 7 "Alcohol and Other Drugs” discusses, poor (and near poor) people account for the bulk of our street crime (homicide, robbery, burglary, etc.), and they also account for the bulk of victims of street crime. That chapter will outline several reasons for this dual connection between poverty and street crime, but they include the deep frustration and stress of living in poverty and the fact that many poor people live in high-crime neighborhoods. In such neighborhoods, children are more likely to grow up under the influence of older peers who are already in gangs or otherwise committing crime, and people of any age are more likely to become crime victims. Moreover, because poor and near-poor people are more likely to commit street crime, they also comprise most of the people arrested for street crimes, convicted of street crime, and imprisoned for street crime. Most of the more than 2 million people now in the nation's prisons and jails come from poor or near-poor backgrounds. Criminal behavior and criminal victimization, then, are other major consequences of poverty.

\section{Lessons from Other Societies}

Poverty and Poverty Policy in Other Western Democracies

To compare international poverty rates, scholars commonly use a measure of the percentage of households in a nation that receive less than half of the nation's median household income after taxes and cash transfers from the government. In data from the late 2000s, 17.3 percent of US households lived in poverty as defined by this measure. By comparison, other Western democracies had the rates depicted in the figure that follows. The average poverty rate of the nations in the figure excluding the United States is 9.5 percent. The US rate is thus almost twice as high as the average for all the other democracies.

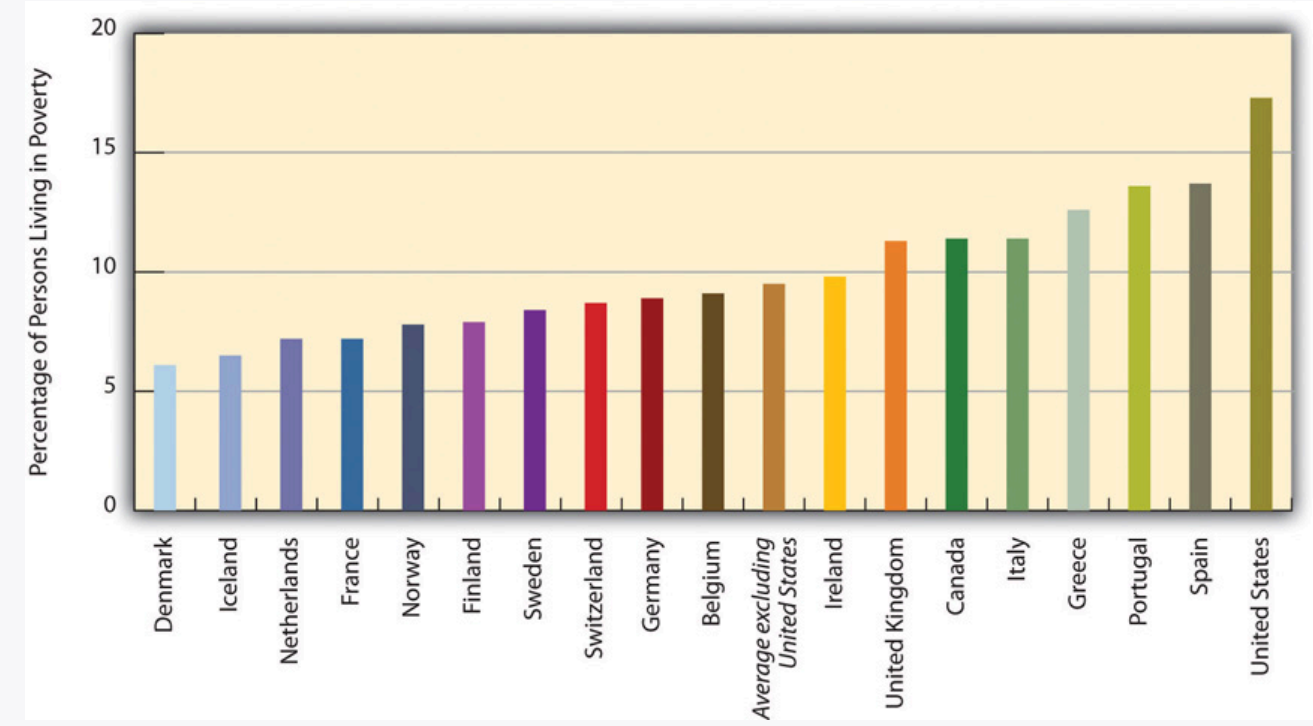

This graph illustrates the poverty rates in western democracies (i.e., the percentage of persons living with less than half of the median household income) as of the late $2000 \mathrm{~s}$

Source: Data from Organisation for Economic Co-operation and Development (OECD). (2011). Society at a glance 2011: OECD social indicators. Retrieved July 23, 2011, from http://www.oecd-ilibrary.org/sites/soc glance-2011-en/06/02/ index.html;jsessionid=erdqhbpb203ea.epsilon?contentType=\&itemId=/content/chapter/soc glance-2011-17-en\&containerItemId=/content/se.

Why is there so much more poverty in the United States than in its Western counterparts? Several differences between the United States and the other nations stand out (Brady, 2009; Russell, 2011). First, other Western nations have higher 
minimum wages and stronger labor unions than the United States has, and these lead to incomes that help push people above poverty. Second, these other nations spend a much greater proportion of their gross domestic product on social expenditures (income support and social services such as child-care subsidies and housing allowances) than does the United States. As sociologist John Iceland (Iceland, 2006) notes, "Such countries often invest heavily in both universal benefits, such as maternity leave, child care, and medical care, and in promoting work among [poor] families...The United States, in comparison with other advanced nations, lacks national health insurance, provides less publicly supported housing, and spends less on job training and job creation.” Block and colleagues agree: “These other countries all take a more comprehensive government approach to combating poverty, and they assume that it is caused by economic and structural factors rather than bad behavior” (Block et, al., 2006).

The experience of the United Kingdom provides a striking contrast between the effectiveness of the expansive approach used in other wealthy democracies and the inadequacy of the American approach. In 1994, about 30 percent of British children lived in poverty; by 2009, that figure had fallen by more than half to 12 percent. Meanwhile, the US 2009 child poverty rate, was almost 21 percent.

Britain used three strategies to reduce its child poverty rate and to help poor children and their families in other ways. First, it induced more poor parents to work through a series of new measures, including a national minimum wage higher than its US counterpart and various tax savings for low-income workers. Because of these measures, the percentage of single parents who worked rose from 45 percent in 1997 to 57 percent in 2008. Second, Britain increased child welfare benefits regardless of whether a parent worked. Third, it increased paid maternity leave from four months to nine months, implemented two weeks of paid paternity leave, established universal preschool (which both helps children's cognitive abilities and makes it easier for parents to afford to work), increased child-care aid, and made it possible for parents of young children to adjust their working hours to their parental responsibilities (Waldfogel, 2010). While the British child poverty rate fell dramatically because of these strategies, the US child poverty rate stagnated.

In short, the United States has so much more poverty than other democracies in part because it spends so much less than they do on helping the poor. The United States certainly has the wealth to follow their example, but it has chosen not to do so, and a high poverty rate is the unfortunate result. As the Nobel laureate economist Paul Krugman (2006, p. A25) summarizes this lesson, "Government truly can be a force for good. Decades of propaganda have conditioned many Americans to assume that government is always incompetent...But the [British experience has] shown that a government that seriously tries to reduce poverty can achieve a lot."

\section{Key Takeaways}

- Poor people are more likely to have several kinds of family problems, including divorce and family conflict.

- Poor people are more likely to have several kinds of health problems.

- Children growing up in poverty are less likely to graduate high school or go to college, and they are more likely to commit street crime.

\section{For Your Review}

1. Write a brief essay that summarizes the consequences of poverty.

2. Why do you think poor children are more likely to develop health problems? 


\section{References}

Bakalar, N. (2011, July 4). Researchers link deaths to social ills. New York Times, p. D5.

Block, F., Korteweg, A. C., \& Woodward, K. (2006). The compassion gap in American poverty policy. Contexts, 5(2), 14-20.

Brady, D. (2009). Rich democracies, poor people: How politics explain poverty. New York, NY: Oxford University Press.

Duncan, G. J., \& Magnuson, K. (2011, winter). The long reach of early childhood poverty. Pathways: A Magazine on Poverty, Inequality, and Social Policy, 22-27.

Evans, G. W., Brooks-Gunn, J., \& Klebanov, P. K. (2011, winter). Stressing out the poor: Chronic physiological stress and the income-achievement gap. Pathways: A Magazine on Poverty, Inequality, and Social Policy, 16-21.

Grusky, D., \& Wimer, C.(Eds.). (2011, winter). Editors’ note. Pathways: A Magazine on Poverty, Inequality, and Social Policy, 2.

Iceland, J. (2006). Poverty in America: A handbook. Berkeley, CA: University of California Press.

Krugman, P. (Krugman, 2006). Helping the poor, the British way. New York Times, p. A25.

Lee, B., Tyler, K. A., \& Wright, J. D. ( 2010). The new homelessness revisited. Annual Review of Sociology, 36, 501-521.

Lindsey, D. (2009). Child poverty and inequality: Securing a better future for America's children. New York, NY: Oxford University Press.

Moore, K. A., Redd, Z., Burkhauser, M., Mbawa, K., \& Collins, A. (2009). Children in poverty: Trends, consequences, and policy options. Washington, DC: Child Trends. Retrieved from http://www.childtrends.org/ Files//Child Trends-2009 0407 RB ChildreninPoverty.pdf.

Ratcliffe, C., \& McKernan, S.-M. (2010). Childhood poverty persistence: Facts and consequences. Washington, DC: Urban Institute Press.

Russell, J. W. ( 2011). Double standard: Social policy in Europe and the United States (2nd ed.). Lanham, MD: Rowman \& Littlefield.

Sanders, L. (2011). Neuroscience exposes pernicious effects of poverty. Science News, 179(3), 32.

Shonkoff, J. P. (2011, winter). Building a foundation for prosperity on the science of early childhood development. Pathways: A Magazine on Poverty, Inequality, and Social Policy, 10-14.

Waldfogel, J. (2010). Britain's war on poverty. New York, NY: Russell Sage Foundation. 


\subsection{Global Poverty}

\section{Learning Objectives}

1. Describe where poor nations tend to be located.

2. Explain the difference between the modernization and dependency theories of poverty.

3. List some of the consequences of global poverty.

As serious as poverty is in the United States, poverty in much of the rest of the world is beyond comprehension to the average American. Many of the world's poor live in such desperate circumstances that they would envy the lives of poor Americans. Without at all meaning to minimize the plight of the American poor, this section provides a brief look at the world's poor and at the dimensions of global poverty

\section{Global Inequality}

The world has a few very rich nations and many very poor nations, and there is an enormous gulf between these two extremes. If the world were one nation, its median annual income (at which half of the world's population is below this income and half is above it) would be only \$1,700 (Dikhanov, 2005). The richest fifth of the world's population would have three-fourths of the world's entire income, while the poorest fifth of the world's population would have only 1.5 percent of the world's income, and the poorest two-fifths would have only 5.0 percent of the world's income (Dikhanov, 2005). Reflecting this latter fact, these poorest two-fifths, or about 2 billion people, live on less than \$2 per day (United Nations Development Programme, 2009). As Figure 2.5 "Global Income Distribution (Percentage of World Income Held by Each Fifth of World Population)” illustrates, this distribution of income resembles a champagne glass. 


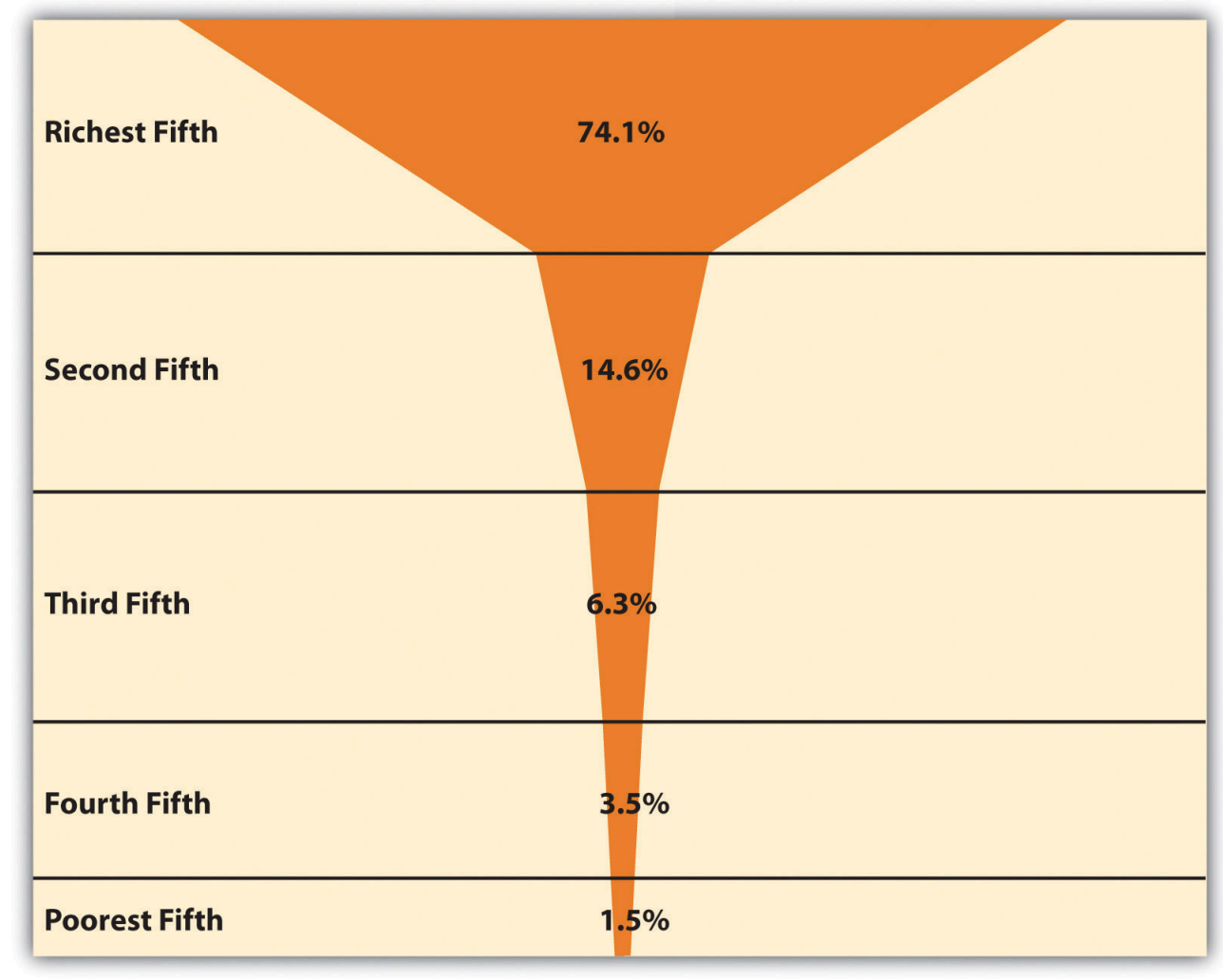

Source: Data from Dikhanov, Y. (2005). Trends in global income distribution, 1970-2000, and scenarios for 2015. New York, NY:

United Nations Development Programme.

To understand global inequality, it is helpful to classify nations into a small number of categories based on their degree of wealth or poverty, their level of industrialization and economic development, and related factors. Over the decades, scholars and international organizations such as the United Nations and the World Bank have used various classification systems, or typologies. A popular typology today simply ranks nations into groups called wealthy (or high-income) nations, middle-income nations, and poor (or low-income) nations, based on measures such as gross domestic product (GDP) per capita (the total value of a nation's goods and services divided by its population). This typology has the advantage of emphasizing the most important variable in global stratification: how much wealth a nation has. At the risk of being somewhat simplistic, the other important differences among the world's nations all stem from their degree of wealth or poverty. Figure 2.6 "Global Stratification Map” depicts these three categories of nations (with the middle category divided into upper-middle and lower-middle). As should be clear, whether a nation is wealthy, middle income, or poor is heavily related to the continent on which it is found. 


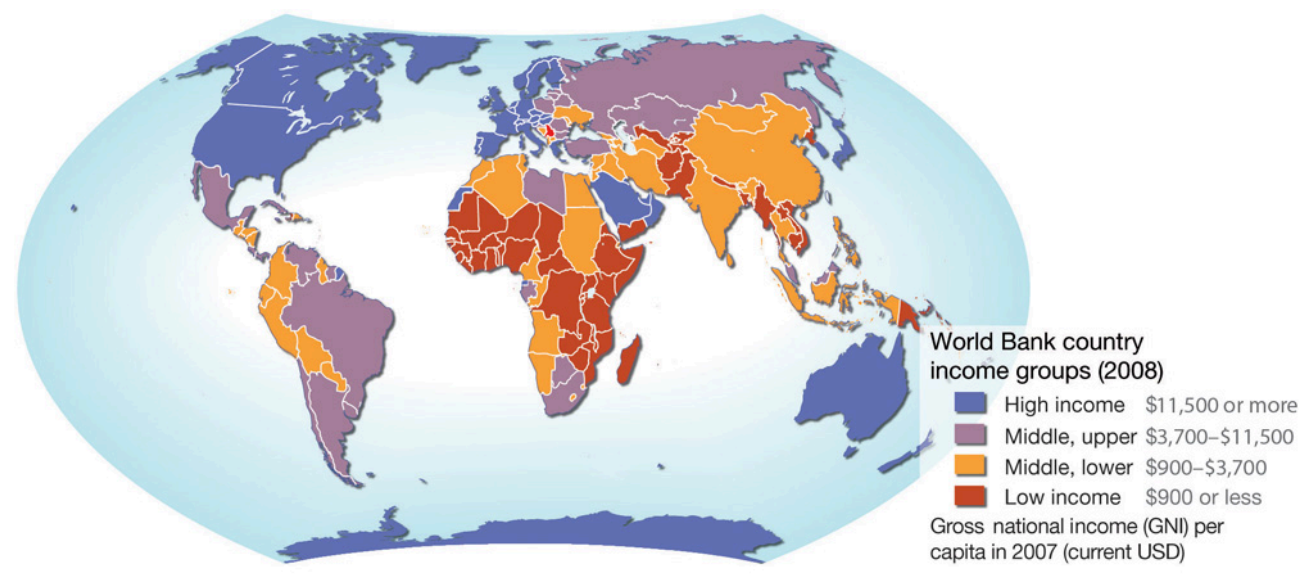

Source: Adapted from UNEP/GRID-Arendal Maps and Graphics Library. (2009).Country income groups (World Bank classification). Retrieved from http://maps.grida.no/go/graphic/country-income-groups-world-bank-classification.

\section{Measuring Global Poverty}

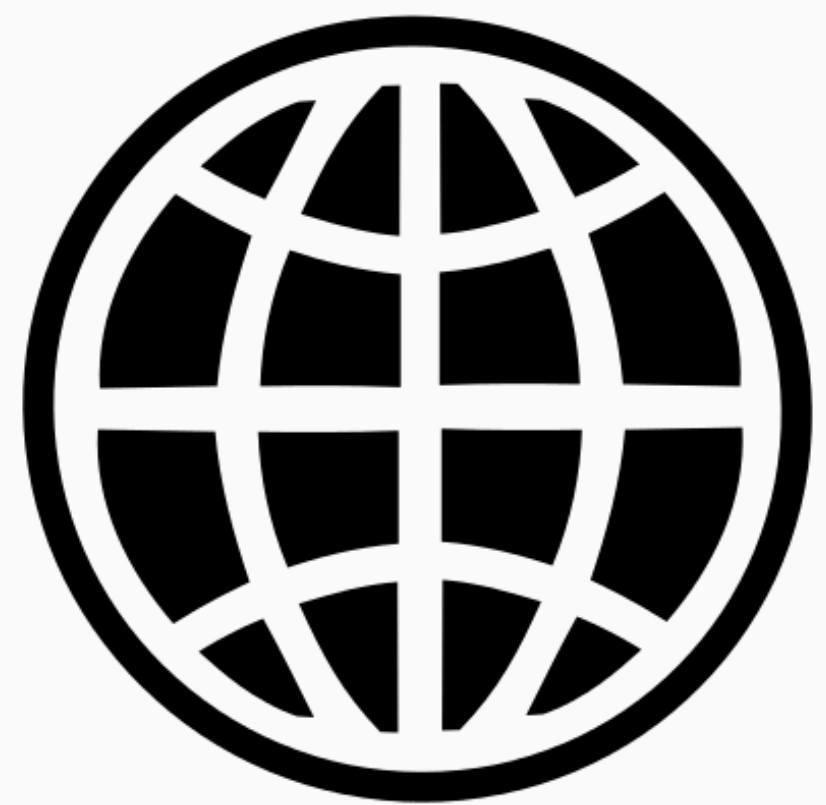

\section{THE WORLD BANK}

The World Bank has begun to emphasize vulnerability to poverty. Many people who are not officially poor have a good chance of becoming poor within a year. Strategies to prevent this from happening are a major focus of the World Bank.

Wikimedia Commons - CC BY-SA 2.0.

How do we know which nations are poor? A very common measure of global poverty was developed by the World Bank, an international institution funded by wealthy nations that provides loans, grants, and other aid to 
help poor and middle-income nations. Each year the World Bank publishes its World Development Report, which provides statistics and other information on the economic and social well-being of the globe's almost two hundred nations. The World Bank puts the official global poverty line (which is considered a measure of extreme poverty) at income under $\$ 1.25$ per person per day, which amounts to about $\$ 456$ yearly per person or $\$ 1,825$ for a family of four. According to this measure, 1.4 billion people, making up more than one-fifth of the world's population and more than one-fourth of the population of developing (poor and middle-income) nations, are poor. This level of poverty rises to 40 percent of South Asia and 51 percent of sub-Saharan Africa (Haughton \& Khandker, 2009).

In a new development, the World Bank has begun emphasizing the concept of vulnerability to poverty, which refers to a significant probability that people who are not officially poor will become poor within the next year. Determining vulnerability to poverty is important because it enables antipoverty strategies to be aimed at those most at risk for sliding into poverty, with the hope of preventing them from doing so.

Vulnerability to poverty appears widespread; in several developing nations, about one-fourth of the population is always poor, while almost one-third is vulnerable to poverty or is slipping into and out of poverty. In these nations, more than half the population is always or sometimes poor. (Haughton \& Khandker, 2009) summarize this situation: "As typically defined, vulnerability to poverty is more widespread than poverty itself. A wide swathe of society risks poverty at some point of time; put another way, in most societies, only a relatively modest portion of society may be considered as economically secure.”

\section{Explaining Global Poverty}

Explanations of global poverty parallel those of US poverty in their focus on individualistic versus structural problems. One type of explanation takes an individualistic approach by, in effect, blaming the people in the poorest nations for their own poverty, while a second explanation takes a structural approach in blaming the plight of poor nations on their treatment by the richest ones. Table 2.4 "Theory Snapshot" summarizes the two sets of explanations.

Table 2.4 Theory Snapshot

\begin{tabular}{|l|l|}
\hline Theory & Major assumptions \\
\hline $\begin{array}{l}\text { Modernization } \\
\text { theory }\end{array}$ & $\begin{array}{l}\text { Wealthy nations became wealthy because early on they were able to develop the necessary beliefs, values, } \\
\text { and practices for trade, industrialization, and rapid economic growth to occur. Poor nations remained poor } \\
\text { because they failed to develop these beliefs, values, and practices; instead, they continued to follow } \\
\text { traditional beliefs and practices that stymied industrial development and modernization. }\end{array}$ \\
\hline $\begin{array}{l}\text { Dependency } \\
\text { theory }\end{array}$ & $\begin{array}{l}\text { The poverty of poor nations stems from their colonization by European nations, which exploited the poor } \\
\text { nations' resources and either enslaved their populations or used them as cheap labor. The colonized } \\
\text { nations were thus unable to develop a professional and business class that would have enabled them to } \\
\text { enter the industrial age and to otherwise develop their economies. }\end{array}$ \\
\hline
\end{tabular}




\section{Modernization Theory}

The individualistic explanation is called modernization theory (Rostow, 1990). According to this theory, rich nations became wealthy because early on they were able to develop the "correct" beliefs, values, and practices-in short, the correct culture-for trade, industrialization, and rapid economic growth to occur. These cultural traits include a willingness to work hard, to abandon tradition in favor of new ways of thinking and doing things, and to adopt a future orientation rather than one focused on maintaining present conditions. Thus Western European nations began to emerge several centuries ago as economic powers because their populations adopted the kinds of values and practices just listed. In contrast, nations in other parts of the world never became wealthy and remain poor today because they never developed the appropriate values and practices. Instead, they continued to follow traditional beliefs and practices that stymied industrial development and modernization.

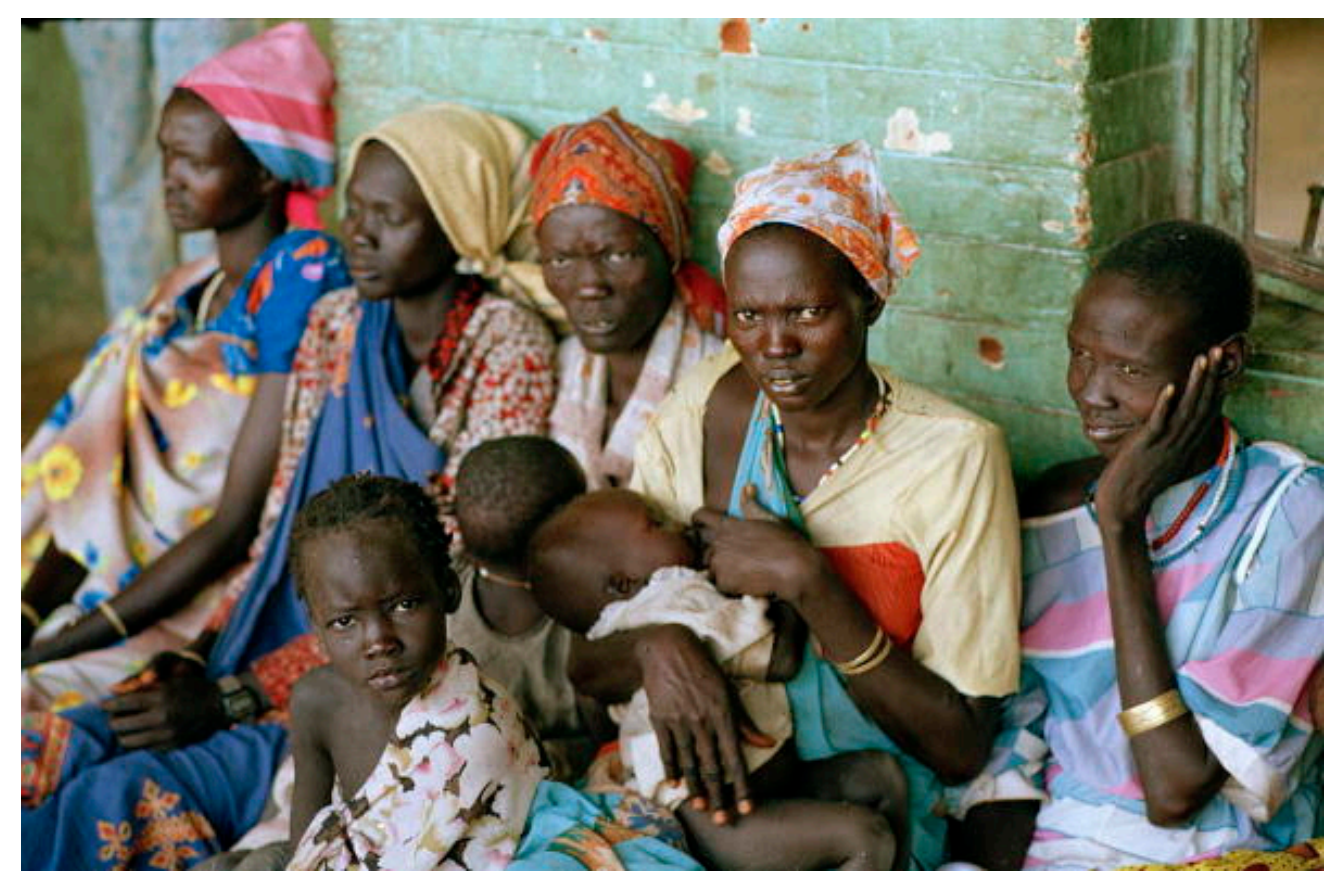

According to modernization theory, poor nations are poor because their people never developed values such as an emphasis on hard work.

United Nations Photo - OLS Brings Support to Strained Medical Services - CC BY-NC-ND 2.0.

Modernization theory has much in common with the culture of poverty theory discussed earlier. It attributes the poverty of poor nations to their failure to develop the "proper" beliefs, values, and practices necessary for economic success both at the beginning of industrialization during the nineteenth century and in the two centuries that have since transpired. Because modernization theory implies that people in poor nations do not have the talent and ability to improve their lot, it may be considered a functionalist explanation of global inequality. 


\section{Dependency Theory}

The structural explanation for global stratification is called dependency theory, which may be considered a conflict explanation of global inequality. Not surprisingly, this theory's views sharply challenge modernization theory's assumptions (Packenham, 1992). Whereas modernization theory attributes global stratification to the "wrong" cultural values and practices in poor nations, dependency theory blames global stratification on the exploitation of these nations by wealthy nations. According to this view, poor nations never got the chance to pursue economic growth because early on they were conquered and colonized by European ones. The European nations stole the poor nations' resources and either enslaved their populations or used them as cheap labor. They installed their own governments and often prevented the local populace from getting a good education. As a result, the colonized nations were unable to develop a professional and business class that would have enabled them to enter the industrial age and to otherwise develop their economies. Along the way, wealthy nations sold their own goods to colonized nations and forced them to run up enormous debt that continues to amount today.

In today's world, huge multinational corporations continue to exploit the labor and resources of the poorest nations, say dependency theorists. These corporations run sweatshops in many nations, in which workers toil in inhumane conditions at extremely low wages (Sluiter, 2009). Often the corporations work hand-in-hand with corrupt officials in the poor nations to strengthen their economic stake in the countries.

\section{Comparing the Theories}

Which makes more sense, modernization theory or dependency theory? As with many theories, both make sense to some degree, but both have their faults. Modernization theory places too much blame on poor nations for their own poverty and ignores the long history of exploitation of poor nations by rich nations and multinational corporations alike. For its part, dependency theory cannot explain why some of the poorest countries are poor even though they were never European colonies; neither can it explain why some former colonies such as Hong Kong have been able to attain enough economic growth to leave the rank of the poorest nations. Together, both theories help us understand the reasons for global stratification, but most sociologists would probably favor dependency theory because of its emphasis on structural factors in the world's historic and current economy.

\section{The Lives of the World's Poor}

Poor nations are the least industrialized and most agricultural of all the world's countries. They consist primarily of nations in Africa and parts of Asia and constitute roughly half of the world's population. Many of these nations rely heavily on one or two crops, and if weather conditions render a crop unproductive in a particular season, the nations' hungry become even hungrier. By the same token, if economic conditions reduce the price of a crop or other natural resource, the income from exports of these commodities plummets, and these already poor nations become even poorer. 


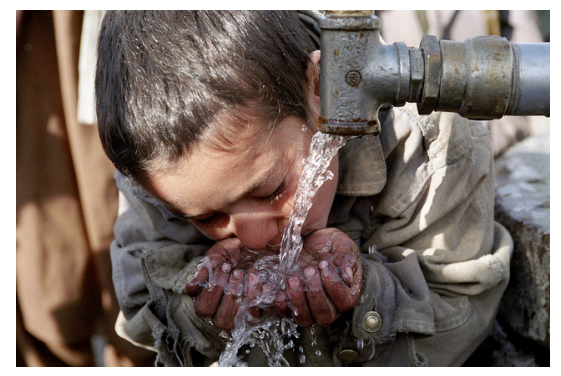

People in poor nations live in the most miserable conditions possible.

United Nations Photo - Maslakh Camp for Displaced, Afghanistan - CC BY-NC-ND 2.0.

By any standard, the more than 1.4 billion people in poor nations live a desperate existence in the most miserable conditions possible. They suffer from AIDS and other deadly diseases, live on the edge of starvation, and lack indoor plumbing, electricity, and other modern conveniences that most Americans take for granted. Most of us have seen unforgettable photos or video footage of African children with stick-thin limbs and distended stomachs reflecting severe malnutrition.

It would be nice if these images were merely fiction, but unfortunately they are far too real. AIDS, malaria, starvation, and other deadly diseases are common. Many children die before reaching adolescence, and many adults die before reaching what in the richest nations would be considered middle age. Many people in the poorest nations are illiterate, and a college education remains as foreign to them as their way of life would be to us. The images of the world's poor that we see in television news reports or in film documentaries fade quickly from our minds. Meanwhile, millions of people on our planet die every year because they do not have enough to eat, because they lack access to clean water or adequate sanitation, or because they lack access to medicine that is found in every CVS, Rite Aid, and Walgreens in the United States. We now examine some specific dimensions and consequences of global poverty.

\section{Life Expectancy}

When we look around the world, we see that global poverty is literally a matter of life and death. The clearest evidence of this fact comes from data on life expectancy, or the average number of years that a nation's citizens can be expected to live. Life expectancy certainly differs within each nation, with some people dying younger and others dying older, but poverty and related conditions affect a nation's overall life expectancy to a startling degree. 


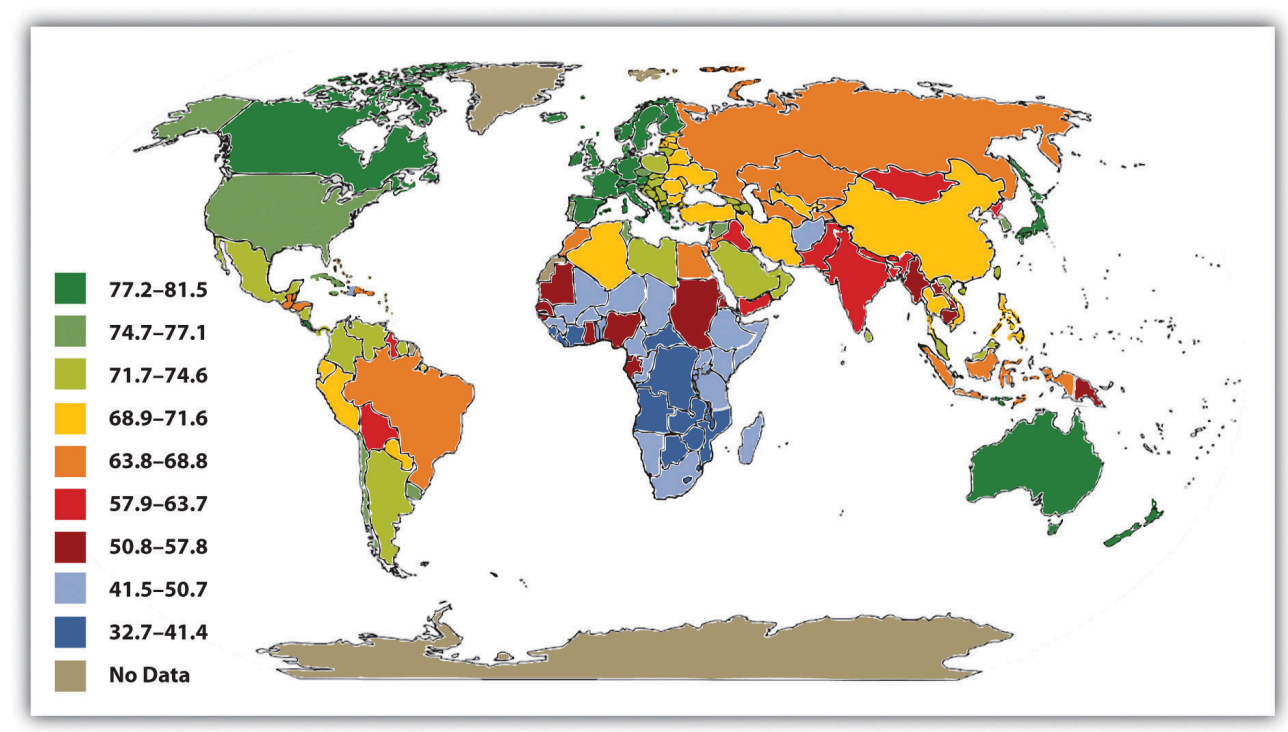

Source: Adapted from Global Education Project. (2004). Human conditions: World life expectancy map. Retrieved from http://www.theglobaleducationproject.org/earth/human-conditions.php.

A map of global life expectancy appears in Figure 2.7 “Average Life Expectancy across the Globe (Years)”. Life expectancy is highest in North America, Western Europe, and certain other regions of the world and lowest in Africa and South Asia, where life expectancy in many nations is some 30 years shorter than in other regions. Another way of visualizing the relationship between global poverty and life expectancy appears in Figure 2.8 “Global Poverty and Life Expectancy, 2006”, which depicts average life expectancy for wealthy nations, uppermiddle-income nations, lower-middle-income nations, and poor nations. Men in wealthy nations can expect to live 76 years on average, compared to only 56 in poor nations; women in wealthy nations can expect to live 82 years, compared to only 58 in poor nations. Life expectancy in poor nations is thus 20 and 24 years lower, respectively, for the two sexes.

Figure 2.8 Global Poverty and Life Expectancy, 2006

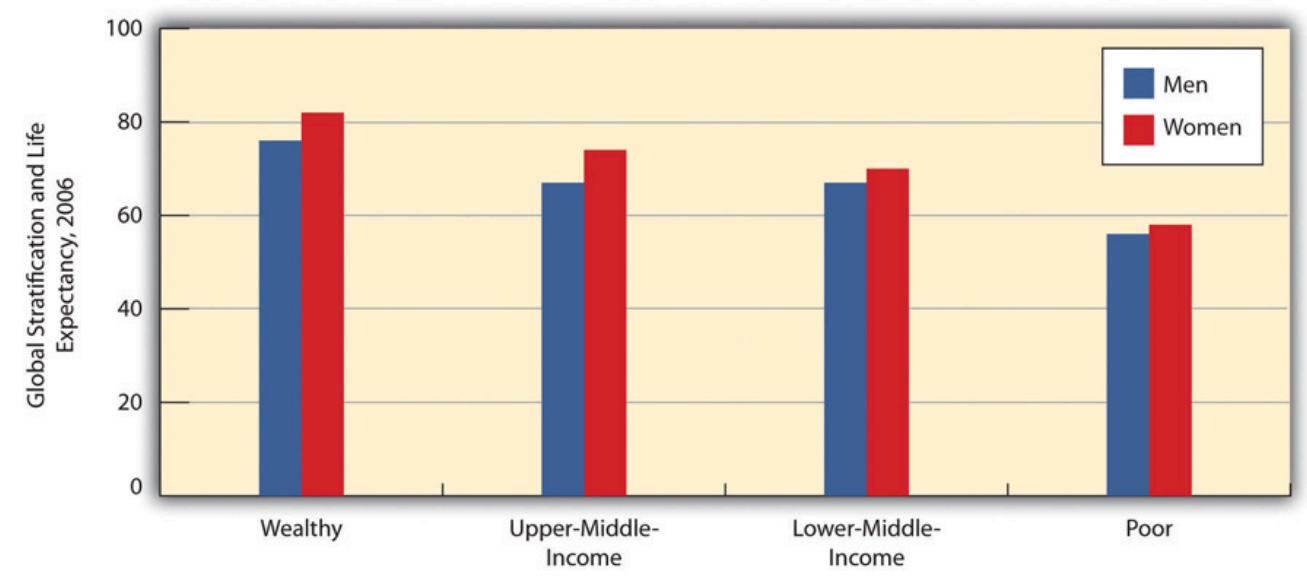

Source: Data from World Bank. (2009). World development report 2009. Washington, DC: Author. 


\section{Child Mortality}

A key contributor to life expectancy and also a significant consequence of global poverty in its own right is child mortality, the number of children who die before age 5 per 1,000 children. As Figure 2.9 "Global Poverty and Child Mortality, 2006” shows, the rate of child mortality in poor nations is 135 per 1,000 children, meaning that 13.5 percent of all children in these nations die before age 5. In a few African nations, child mortality exceeds 200 per 1,000 . In contrast, the rate in wealthy nations is only 7 per 1,000 . Children in poor nations are thus about 19 times $(13.5 \div 0.7)$ more likely to die before age 5 than children in wealthy nations.

Figure 2.9 Global Poverty and Child Mortality, 2006

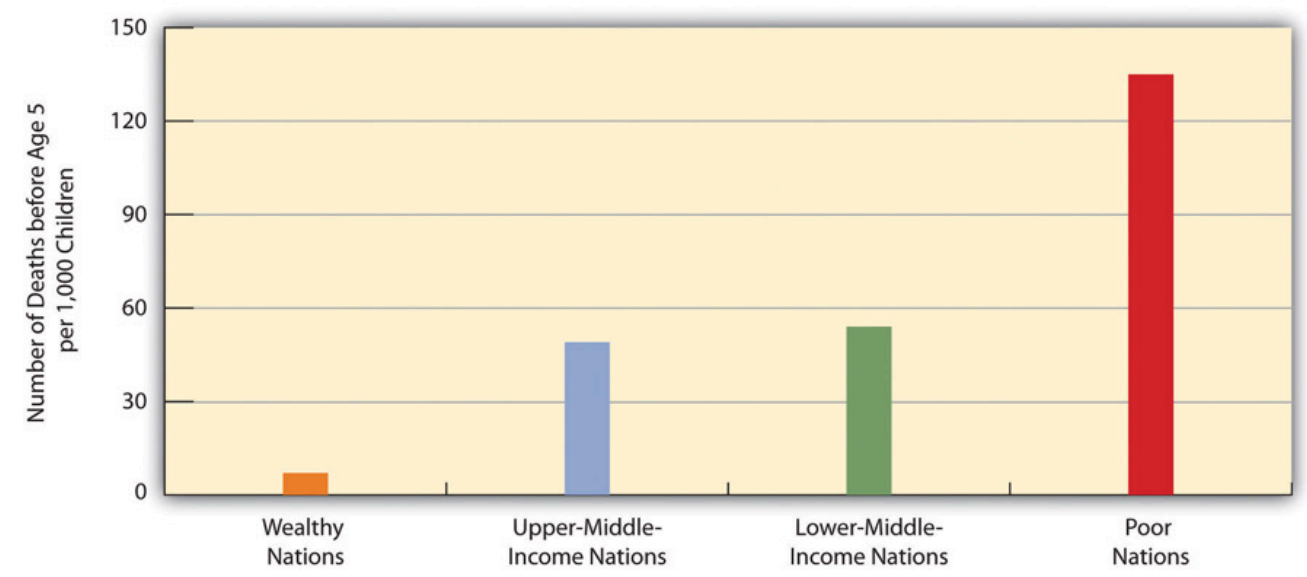

Source: Data from World Bank. (2009). World development report 2009. Washington, DC: Author.

\section{Sanitation and Clean Water}

Two other important indicators of a nation's health are access to adequate sanitation (disposal of human waste) and access to clean water. When people lack adequate sanitation and clean water, they are at much greater risk for life-threatening diarrhea, serious infectious diseases such as cholera and typhoid, and parasitic diseases such as schistosomiasis (World Health Organization, 2010). About 2.4 billion people around the world, almost all of them in poor and middle-income nations, do not have adequate sanitation, and more than 2 million, most of them children, die annually from diarrhea. More than 40 million people worldwide, almost all of them again in poor and middle-income nations, suffer from a parasitic infection caused by flatworms.

As Figure 2.10 "Global Stratification and Access to Adequate Sanitation, 2006" and Figure 2.11 "Global Stratification and Access to Clean Water, 2006” show, access to adequate sanitation and clean water is strongly related to national wealth. Poor nations are much less likely than wealthier nations to have adequate access to both sanitation and clean water. Adequate sanitation is virtually universal in wealthy nations but is available to only 38 percent of people in poor nations. Clean water is also nearly universal in wealthy nations but is available to only 67 percent of people in poor nations. 


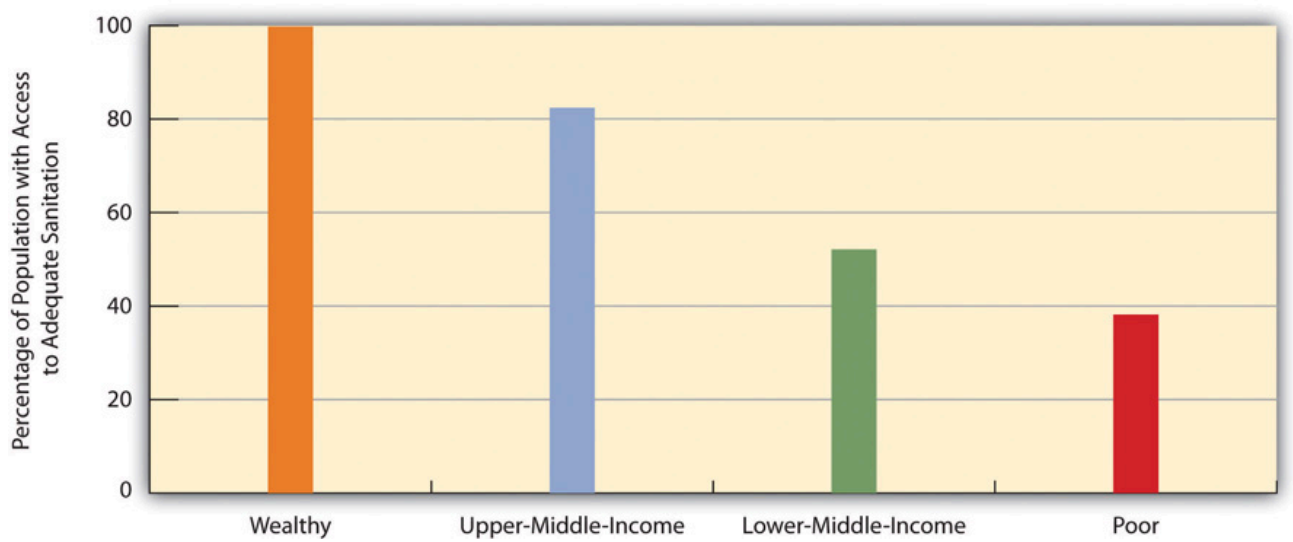

Source: Data from World Bank. (2010). Health nutrition and population statistics. Retrieved from http://databank.worldbank.org/ddp/ home.do.

Figure 2.11 Global Stratification and Access to Clean Water, 2006

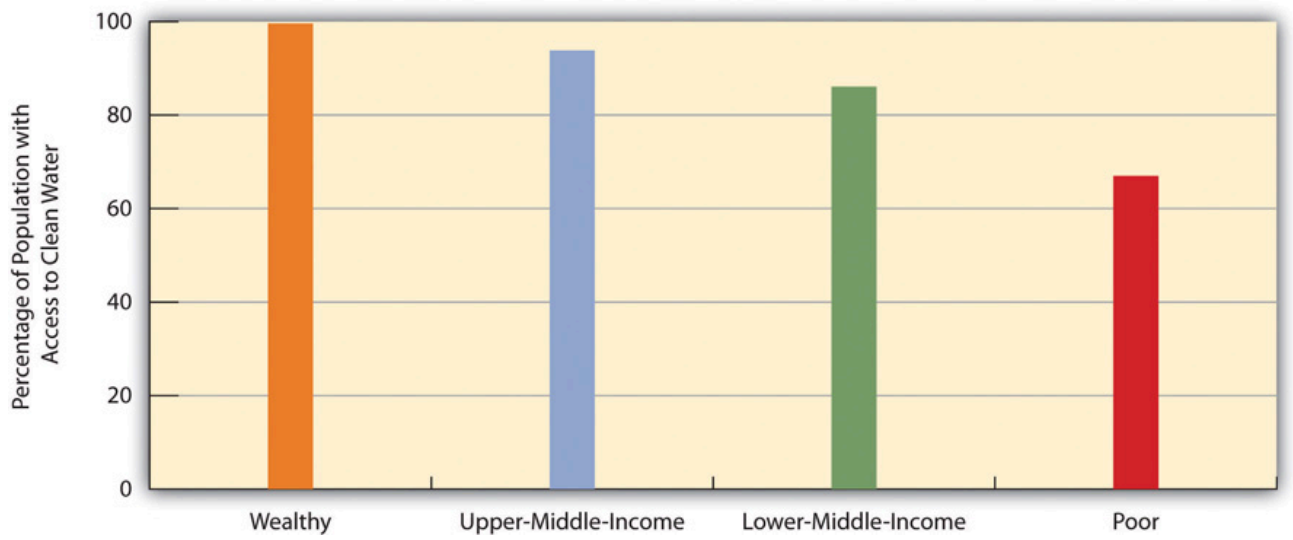

Source: Data from World Bank. (2010). Health nutrition and population statistics. Retrieved from http://databank.worldbank.org/ddp/home.do.

\section{Malnutrition}




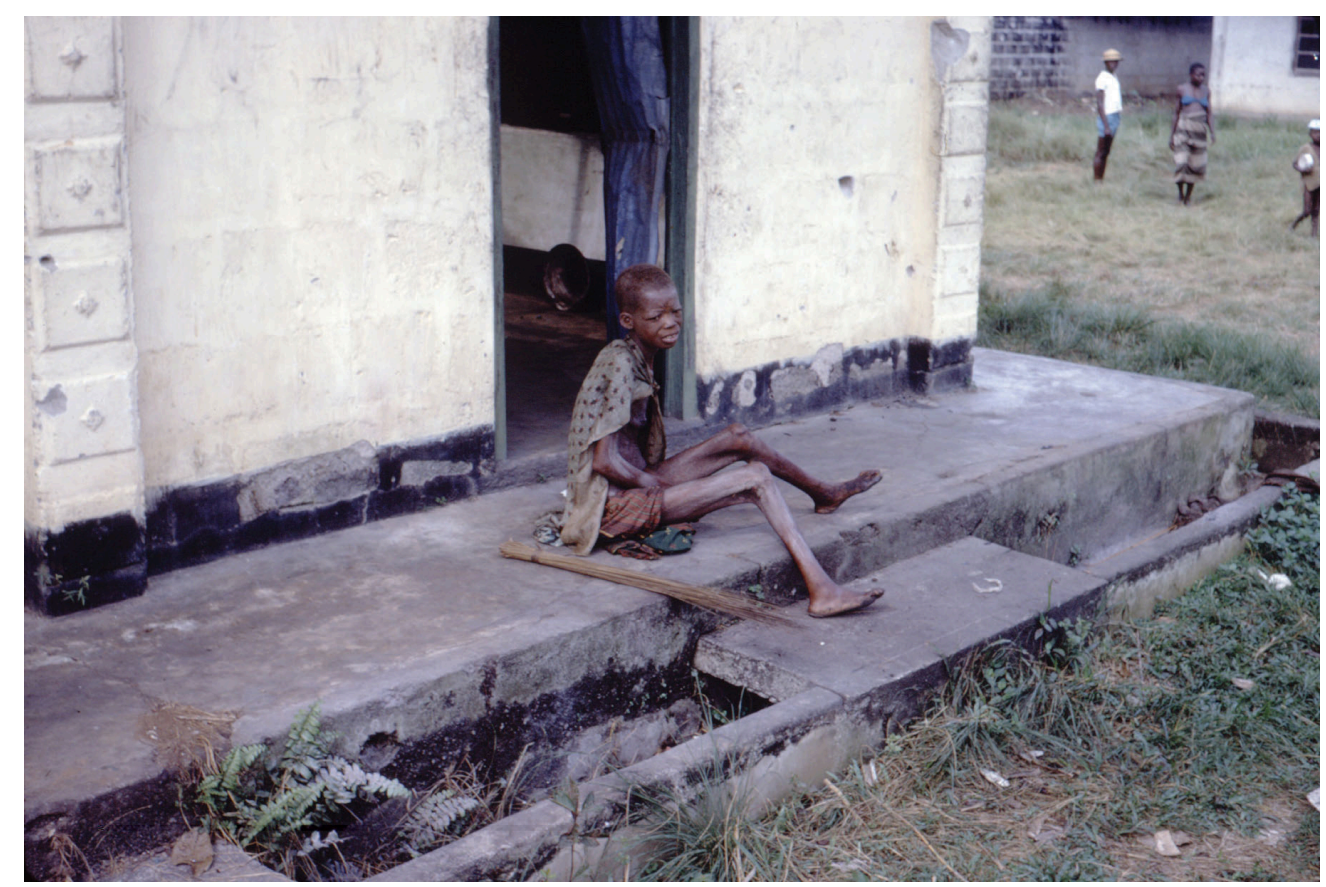

About one-fifth of the population of poor nations, about 800 million individuals, are malnourished.

Dr. Lyle Conrad at the Centers for Disease Control and Prevention- ID\# 6874 - public domain.

Another health indicator is malnutrition. This problem is caused by a lack of good food combined with infections and diseases such as diarrhea that sap the body of essential nutrients. About one-fifth of the population of poor nations, or about 800 million individuals, are malnourished; looking just at children, in developing nations more than one-fourth of children under age 5, or about 150 million altogether, are underweight. Half of all these children live in only three nations: Bangladesh, India, and Pakistan; almost half the children in these and other South Asian nations are underweight. Children who are malnourished are at much greater risk for fat and muscle loss, brain damage, blindness, and death; perhaps you have seen video footage of children in Africa or South Asia who are so starved that they look like skeletons. Not surprisingly, child malnutrition contributes heavily to the extremely high rates of child mortality that we just examined and is estimated to be responsible for more than 5 million deaths of children annually (United Nations Children’s Fund [UNICEF], 2006; World Health Organization, 2010).

\section{Adult Literacy}

Moving from the area of health, a final indicator of human development is adult literacy, the percentage of people 15 and older who can read and write a simple sentence. Once again we see that people in poor and middle-income nations are far worse off (see Figure 2.12 “Global Poverty and Adult Literacy, 2008”). In poor nations, only about 69 percent of adults 15 and older can read and write a simple sentence. The high rate of illiteracy in poor nations not only reflects their poverty but also contributes to it, as people who cannot read and write are obviously at a huge disadvantage in the labor market. 


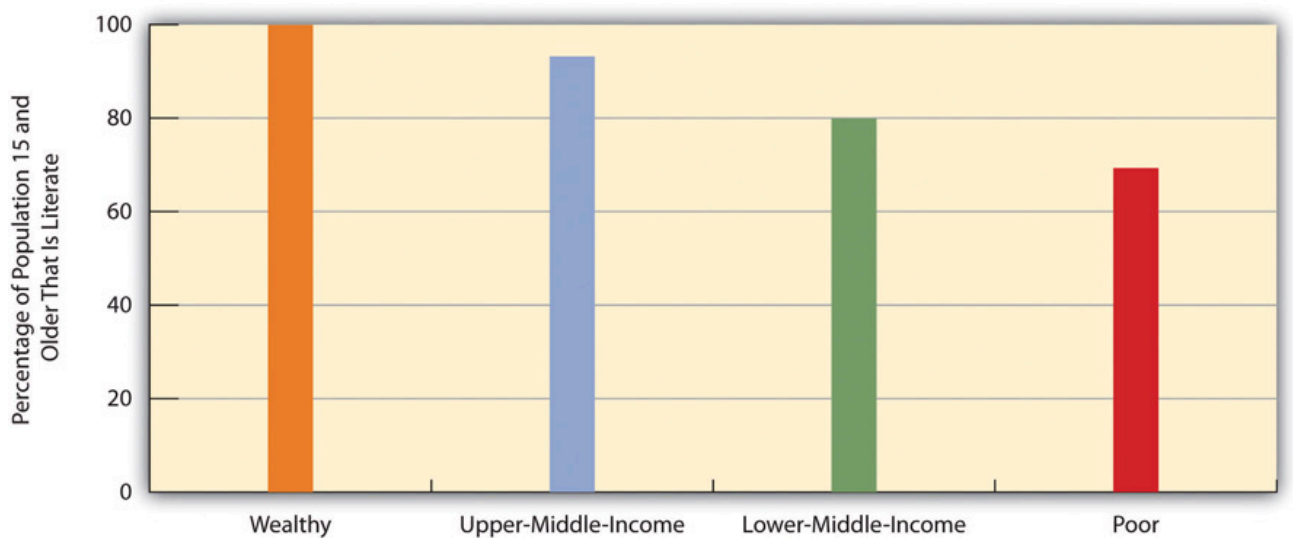

Source: Data from World Bank. (2010). Health nutrition and population statistics. Retrieved from http://databank.worldbank.org/ddp/

home.do.

\section{Applying Social Research}

\section{Unintended Consequences of Welfare Reform}

Aid to Families with Dependent Children (AFDC) was a major government program to help the poor from the 1930s to the 1960s. Under this program, states allocated federal money to provide cash payments to poor families with children. Although the program was heavily criticized for allegedly providing an incentive to poor mothers both to have more children and to not join the workforce, research studies found little or no basis for this criticism. Still, many politicians and much of the public accepted the criticism as true, and AFDC became so unpopular that it was replaced in 1997 by a new program, Temporary Assistance for Needy Families (TANF), which is still a major program today.

TANF is more restrictive in many respects than AFDC was. In particular, it limits the amount of time a poor family can receive federal funds to five years, and allows states to impose a shorter duration for funding, which many have done. In addition, it requires single parents in families receiving TANF funds to work at least thirty hours a week (or twenty hours a week if they have a child under the age of 6) and two parents to work at least thirty-five hours per week combined. In most states, going to school to obtain a degree does not count as the equivalent of working and thus does not make a parent eligible for TANF payments. Only short-term programs or workshops to develop job skills qualify.

Did welfare reform involving TANF work? Many adults formerly on AFDC found jobs, TANF payments nationwide have been much lower than AFDC payments, and many fewer families receive TANF payments than used to receive AFDC payments. All these facts lead many observers to hail TANF as a successful program. However, sociologists and other scholars who study TANF families say the numbers are misleading because poor families have in effect been excluded from TANF funding because of its strict requirements. The reduced payments and lower number of funded families indicate the failure of TANF, they say, not its success.

Several problems explain why TANF has had these unintended consequences. First, many families are poor for many more than five years, and the five-year time limit under TANF means that they receive financial help for only some of the years they live in poverty. Second, because the federal and state governments provide relatively little financial aid for child care, many parents simply cannot afford to work, and if they don't work, they lose their TANF payments. Third, jobs are certainly difficult to find, especially if, as is typical, a poor parent has relatively little education and few job skills, and if parents cannot find a job, they again lose their TANF payments. Fourth, many parents cannot work because they have physical or mental health problems or because they are taking care of a family member or friend with a health problem; these parents, too, become ineligible for TANF payments.

Sociologist Lorna Rivera put a human face to these problems in a study of fifty poor women in Boston, Massachusetts. She lived among them, interviewed them individually, and conducted focus groups. She found that TANF worsened the situation of these women for the reasons just stated, and concluded that welfare reform left these and other poor women "uneducated, underemployed, underpaid, and unable to effectively move themselves and their families forward." 
Ironically, some studies suggest that welfare reform impaired the health of black women for several reasons. Many ended up with jobs with long bus commutes and odd hours, leading to sleep deprivation and less time for medical visits. Many of these new workers also suddenly had to struggle to find affordable day care for their children. These problems are thought to have increased their stress levels and, in turn, harmed their health.

The research by social scientists on the effects of TANF reveals that the United States took a large step backward when it passed welfare reform in the 1990s. Far from reducing poverty, welfare reform only worsened it. This research underscores the need for the United States to develop better strategies for reducing poverty similar to those used by other Western democracies, as discussed in the Note 2.19 "Lessons from Other Societies" box in this chapter.

Sources: (Blitstein, 2009; Mink, 2008; Parrott \& Sherman, 2008; Rivera, 2008)

\section{Key Takeaways}

- People in poor nations live in the worst conditions possible. Deadly diseases are common, and many children die before reaching adolescence.

- According to the modernization theory, rich nations became rich because their peoples possessed certain values, beliefs, and practices that helped them become wealthy. Conversely, poor nations remained poor because their peoples did not possess these values, beliefs, and practices.

- According to the dependency theory, poor nations have remained poor because they have been exploited by rich nations and by multinational corporations.

\section{For Your Review}

1. Considering all the ways in which poor nations fare much worse than wealthy nations, which one seems to you to be the most important problem that poor nations experience? Explain your answer.

2. Which theory of global poverty, modernization or dependency, makes more sense to you? Why?

\section{References}

Blitstein, R. (2009). Weathering the storm. Miller-McCune, 2(July-August), 48-57.

Dikhanov, Y. (2005). Trends in global income distribution, 1970-2000, and scenarios for 2015. New York, NY: United Nations Development Programme.

Haughton, J., \& Khandker, S. R. (2009). Handbook on poverty and inequality. Washington, DC: World Bank.

Mink, G. (2008). TANF reauthorization and opportunity to invest in America's future. Paper presented to the ADA Economic Policy Committee. Retrieved July 25, 2011, from http://www.adaction.org/pages/issues/all-policyresolutions/social-amp-domestic/issues-brief-no.-13-welfare-reform.php. 
Packenham, R. A. (1992). The dependency movement: Scholarship and politics in development studies. Cambridge, MA: Harvard University Press.

Parrott, S., \& Sherman, A. (2008). TANF at 10: Program results are more mixed than often understood. Washington, DC: Center on Budget and Policy Priorities.

Rivera, L. (2008). Laboring to learn: Women's literacy and poverty in the post-welfare era. Urbana, IL: University of Illinois Press.

Rostow, W. W. (1990). The stages of economic growth: A non-communist manifesto (3rd ed.). New York, NY: Cambridge University Press.

Sluiter, L. (2009). Clean clothes: A global movement to end sweatshops. New York, NY: Pluto Press.

United Nations Children's Fund. (2006). Progress for children: A report card on nutrition. New York, NY: Author. United Nations Development Programme. (2009). Human development report 2009. New York, NY: Author.

World Health Organization. (2010). Children's environmental health. Retrieved from http://www.who.int/ceh/ risks/cehwater2/en/index.html.

World Health Organization. (2010). Water sanitation and health. Retrieved from http://www.who.int/ water sanitation health/diseases/malnutrition/en/. 


\subsection{Reducing Poverty}

\section{Learning Objectives}

1. Explain why the United States neglects its poor.

2. List any three potentially promising strategies to reduce US poverty.

3. Describe how to reduce global poverty from a sociological perspective.

As this chapter noted at the outset, the United States greatly reduced poverty during the 1960s through a series of programs and policies that composed the so-called war on poverty. You saw evidence of the success of the war on poverty in Figure 2.1 "US Poverty, 1959-2010", which showed that the poverty rate declined from 22.2 percent in 1960 to a low of 11.1 percent in 1973 before fluctuating from year to year and then rising since 2000. The Note 2.19 "Lessons from Other Societies" box showed that other democracies have much lower poverty rates than the United States because, as many scholars believe, they have better funded and more extensive programs to help their poor (Brady, 2009; Russell, 2011).

The lessons from the 1960s' war on poverty and the experience of other democracies are clear: It is very possible to reduce poverty if, and only if, a nation is willing to fund and implement appropriate programs and policies that address the causes of poverty and that help the poor deal with the immediate and ongoing difficulties they experience.

A major reason that the US poverty rate reached its low in 1973 and never went lower during the past four decades is that the United States retreated from its war on poverty by cutting back on the programs and services it had provided during that good war (Soss, et. al., 2007). Another major reason is that changes in the national economy during the past few decades have meant that well-paying manufacturing jobs have been replaced by low-paying service jobs with fewer benefits (Wilson, 2010). Yet this has also happened in other democracies, and their poverty rates remain lower than the US rate because, unlike the United States, they have continued to try to help their poor rather than neglect them.

Why does the United States neglect its poor? Many scholars attribute this neglect to the fact that many citizens and politicians think the poor are poor because of their own failings. As summarized by sociologist Mark R. Rank (Rank, 2011), these failings include "not working hard enough, failure to acquire sufficient skills, or just making bad decisions.” By thus blaming the poor for their fate, citizens and politicians think the poor do not deserve to have the US government help them, and so the government does not help, or at least not nearly as much as other democracies do. We have seen that the facts do not support the myth that the poor lack motivation to work, but that does not lessen the blame given the poor for being poor.

To renew the US effort to help the poor, it is essential that the actual facts about poverty become better known so that a fundamental shift in thinking about poverty and the poor can occur. Rank (Rank, 2011) says that one aspect 
of this shift must include the recognition, as noted at the beginning of this chapter, that "poverty affects us all" because it costs so many tax dollars to help the poor and because a majority of the public can expect to be poor or near poor at some point in their lives. A second aspect of this shift in thinking, adds Rank, is the recognition (following a blaming-the-system approach) that poverty stems much more from the lack of opportunity, lack of jobs, declining government help for the poor, and other structural failings of American society than from individual failings of the poor themselves. A third aspect of this shift in thinking, he concludes, is that poverty must become seen as a "moral problem” and as "an injustice of a substantial magnitude” (Rank, 2011). As he forcefully argues, "Something is seriously wrong when we find that, in a country with the most abundant resources in the world, there are children without enough to eat, families who cannot afford health care, and people sleeping on the streets for lack of shelter" (Rank, 2011). This situation, he says, must become seen as a "moral outrage” (Rank, 2011).

Sociologist Joe Soss (Soss, 2011) argues that a change in thinking is not enough for a renewed antipoverty effort to occur. What is needed, he says, is political protest and other political activity by the poor and on behalf of the poor. Soss notes that "political conflict and mass mobilization played key roles" in providing the impetus for social-welfare programs in the 1930s and 1960s in the United States, and he adds that the lower poverty rates of Western European democracies "are products of labor movements, unions, and parties that mobilized workers to demand more adequate social supports.” These twin histories lead Soss to conclude that the United States will not increase its antipoverty efforts unless a new wave of political activity by and on behalf of the poor arises. As he argues, “History suggests that major antipoverty victories can be achieved. But they won’t be achieved by good will and smart ideas alone. They'll be won politically, when people-in poor communities, in advocacy groups, in government, in the academy, and elsewhere-mobilize to advance antipoverty agendas in ways that make politics as usual untenable.”

\section{Antipoverty Programs and Policies}

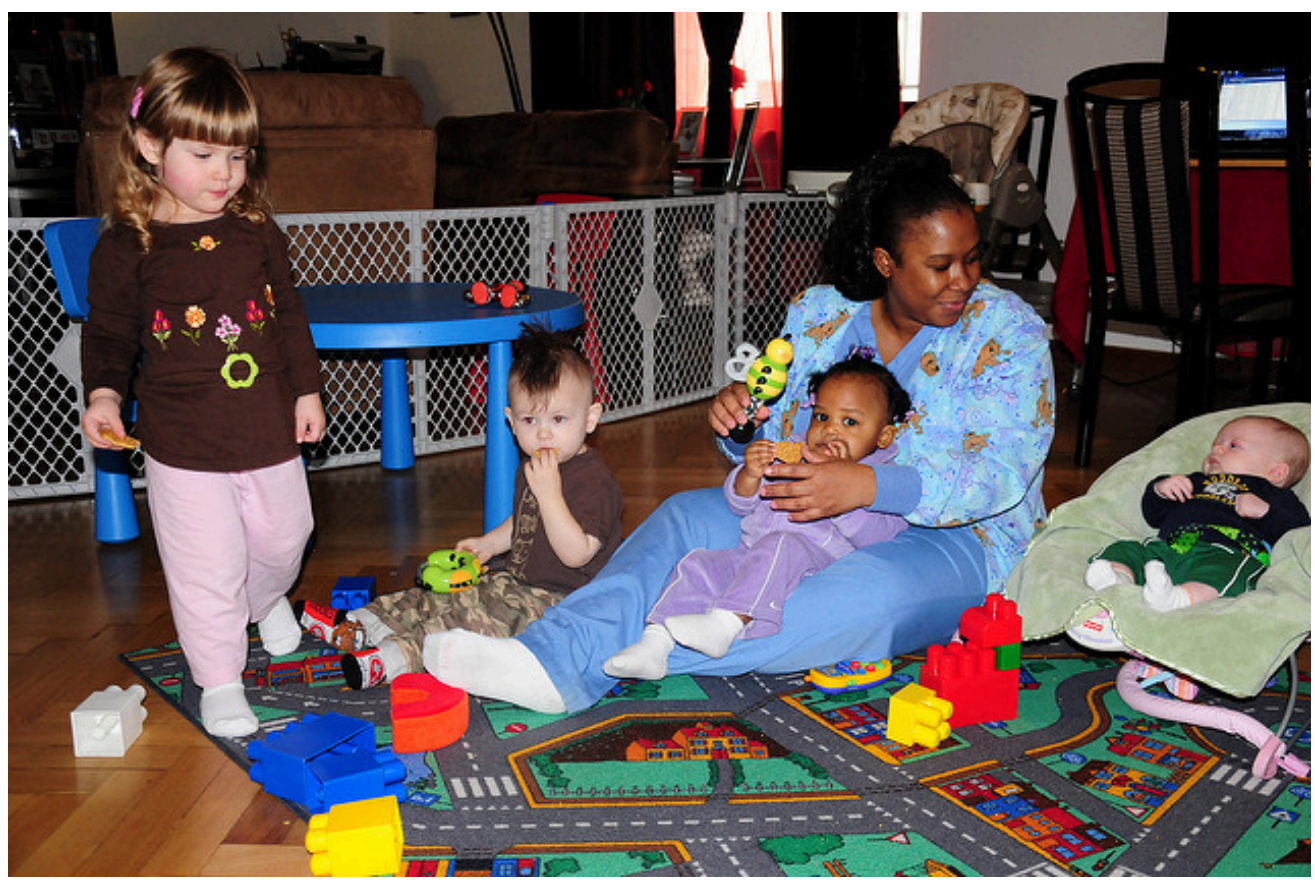


To help reduce poverty, it is essential to help poor parents pay for child care.

Herald Post - Family Child Care - CC BY-NC 2.0.

If a renewed antipoverty effort does occur for whatever reason, what types of programs and policies show promise for effectively reducing poverty? Here a sociological vision is essential. It is easy to understand why the hungry schoolchildren described in the news story that began this chapter might be going without food during a very faltering national economy. Yet a sociological understanding of poverty emphasizes its structural basis in bad times and good times alike. Poverty is rooted in social and economic problems of the larger society rather than in the lack of willpower, laziness, or other moral failings of poor individuals themselves. Individuals born into poverty suffer from a lack of opportunity from their first months up through adulthood, and poverty becomes a self-perpetuating, vicious cycle. To the extent a culture of poverty might exist, it is best seen as a logical and perhaps even inevitable outcome of, and adaptation to, the problem of being poor and not the primary force driving poverty itself.

This sort of understanding suggests that efforts to reduce poverty must address first and foremost the structural basis for poverty while not ignoring certain beliefs and practices of the poor that also make a difference. An extensive literature on poverty policy outlines many types of policies and programs that follow this dual approach (Cancian \& Danziger, 2009; Greenberg, et. al., 2007; Iceland, 2006; Lindsey, 2009; Moore et al., 2009; Rank, 2004). If these were fully adopted, funded, and implemented, as they are in many other democracies, they would offer great promise for reducing poverty. As two poverty experts recently wrote, "We are optimistic that poverty can be reduced significantly in the long term if the public and policymakers can muster the political will to pursue a range of promising antipoverty policies” (M. Cancian \& S. Danziger, 2009, p. 32). Although a full discussion of these policies is beyond the scope of this chapter, the following measures are commonly cited as holding strong potential for reducing poverty, and they are found in varying degrees in other Western democracies:

1. Adopt a national “full employment” policy for the poor, involving federally funded job training and public works programs, and increase the minimum wage so that individuals working full-time will earn enough to lift their families out of poverty.

2. Increase federal aid for the working poor, including higher earned income credits and child-care subsidies for those with children.

3. Establish well-funded early childhood intervention programs, including home visitations by trained professionals, for poor families.

4. Provide poor families with enough income to enable them to pay for food and housing.

5. Increase the supply of affordable housing.

6. Improve the schools that poor children attend and the schooling they receive and expand early childhood education programs for poor children.

7. Provide better nutrition and health services for poor families with young children.

8. Establish universal health insurance.

9. Increase Pell Grants and other financial aid for higher education. 


\section{Global Poverty}

Years of international aid to poor nations have helped them somewhat, but, as this chapter has shown, their situation remains dire. International aid experts acknowledge that efforts to achieve economic growth in poor nations have largely failed, but they disagree why this is so and what alternative strategies may prove more successful (Cohen \& Easterly, 2009). ${ }^{2}$ One very promising trend has been a switch from macro efforts focusing on infrastructure problems and on social institutions, such as the schools, to micro efforts, such as providing cash payments or small loans directly to poor people in poor nations (a practice called microfinancing) and giving them bed nets to prevent mosquito bites (Banerjee \& Duflo, 2011; Hanlon, Barrientos, \& Hulme, 2010; Karlan \& Appel, 2011). ${ }^{3}$ However, the evidence on the success of these efforts is mixed (Bennett, 2009; The Economist, 2010). ${ }^{4}$ Much more to help the world's poor certainly needs to be done.

In this regard, sociology's structural approach is in line with dependency theory and suggests that global stratification results from the history of colonialism and from continuing exploitation today of poor nations' resources by wealthy nations and multinational corporations. To the extent such exploitation exists, global poverty will lessen if and only if this exploitation lessens. A sociological approach also emphasizes the role that class, gender, and ethnic inequality play in perpetuating global poverty. For global poverty to be reduced, gender and ethnic inequality must be reduced.

Writers Nicholas D. Kristof and Sheryl WuDunn (2010) ${ }^{5}$ emphasize the need to focus efforts to reduce global poverty of women. We have already seen one reason this emphasis makes sense: women are much worse off than men in poor nations in many ways, so helping them is crucial for both economic and humanitarian reasons. An additional reason is especially illuminating: When women in poor nations acquire extra money, they typically spend it on food, clothing, and medicine, essentials for their families. However, when men in poor nations acquire extra money, they often spend it on alcohol, tobacco, and gambling. This gender difference might sound like a stereotype, but it does indicate that aid to women will help in many ways, while aid to men might be less effective and often even wasted.

\section{Key Takeaways}

- According to some sociologists, a change in thinking about poverty and the poor and political action by and on behalf of the poor are necessary for a renewed effort to help poor Americans.

- Potentially successful antipoverty programs and policies to help the US poor include expanding their employment opportunities and providing them much greater amounts of financial and other aid.

- To help people in poor nations, gender and ethnic inequality must be addressed.

2. Cohen, J., \& Easterly, W. (Eds.). (2009). What works in development? Thinking big and thinking small. Washington, DC: Brookings Institution Press.

3. Banerjee, A. V., \& Duflo, E. (2011). Poor economics: A radical rethinking of the way to fight global poverty. New York, NY: PublicAffairs; Hanlon, J., Barrientos, A., \& Hulme, D. (2010). Just give money to the poor: The development revolution from the global south. Sterling, VA: Kumarian Press; Karlan, D., \& Appel, J. (2011). More than good intentions: How a new economics is helping to solve global poverty. New York, NY: Dutton.

4. Bennett, D. (2009, September 20). Small change. The Boston Globe. Retrieved from http://www.boston.com/bostonglobe/ideas/articles/2009/09/20/ small_change does microlending actually fight_poverty/; The Economist. (2010). A better mattress. The Economist, 394(8673), 75-76.

5. Kristoff, N. D., \& WuDunn, S. (2010). Half the sky: Turning oppression into opportunity for women worldwide. New York, NY: Vintage Books. 


\section{For Your Review}

1. Write a brief essay summarizing the changes in thinking that some sociologists argue must occur before a renewed effort to reduce poverty can take place.

2. Write a brief essay summarizing any four policies or programs that could potentially lower US poverty.

\section{References}

Brady, D. (2009). Rich democracies, poor people: How politics explain poverty. New York, NY: Oxford University Press.

Cancian, M., \& Danziger, S. H. (2009). Changing poverty, changing policies. New York, NY: Russell Sage Foundation.

Greenberg, M., Dutta-Gupta, I., \& Minoff, E. (2007). From poverty to prosperity: A national strategy to cut poverty in half. Washington, DC: Center for American Progress.

Iceland, J. (2006). Poverty in America: A handbook. Berkeley, CA: University of California Press.

Lindsey, D. (2009). Child poverty and inequality: Securing a better future for America's children. New York, NY: Oxford University Press.

Moore, K. A., Redd, Z., Burkhauser, M., Mbawa, K., \& Collins, A. (2009). Children in poverty: Trends, consequences, and policy options. Washington, DC: Child Trends. Retrieved from http://www.childtrends.org/ Files//Child Trends-2009 0407 RB ChildreninPoverty.pdf.

Rank, M. R. (2004). One nation, underprivileged: Why American poverty affects us all. New York, NY: Oxford University Press.

Rank, M. R. (2011). Rethinking American poverty. Contexts, 10(Spring), 16-21.

Russell, J. W. ( 2011). Double standard: Social policy in Europe and the United States (2nd ed.). Lanham, MD: Rowman \& Littlefield.

Soss, J. (2011). The poverty fight. Contexts, 10(2), 84.

Soss, J., Hacker, J. S., \& Mettler, S. (Eds.). (2007). Remaking America: Democracy and public policy in an age of inequality. New York, NY: Russell Sage Foundation.

Wilson, W. J. (2010). More than just race: Being black and poor in the inner city. New York, NY: W. W. Norton. 


\subsection{End-of-Chapter Material}

\section{Summary}

1. Poverty statistics are misleading in at least two ways. First, the way that poverty is measured is inadequate for several reasons, and more accurate measures of poverty that have recently been developed suggest that poverty is higher than the official poverty measure indicates. Second, even if people live slightly above the poverty line, they are still living in very difficult circumstances and are having trouble making ends meet.

2. Children, people of color, the South, and single-parent families headed by women have especially high poverty rates. Despite what many Americans think, the most typical poor person is white, and most poor people who are able to work outside the home in fact do work.

3. To explain social stratification and thus poverty, functionalist theory says that stratification is necessary and inevitable because of the need to encourage people with the needed knowledge and skills to decide to pursue the careers that are most important to society. Conflict theory says stratification exists because of discrimination against, and blocked opportunities for, the have-nots of society. Symbolic interactionist theory does not try to explain why stratification and poverty exist, but it does attempt to understand the experience of being poor.

4. The individualistic explanation attributes poverty to individual failings of poor people themselves, while the structuralist explanation attributes poverty to lack of jobs and lack of opportunity in the larger society.

5. Poverty has serious consequences in many respects. Among other problems, poor children are more likely to grow up to be poor, to have health problems, to commit street crime, and to have lower levels of formal education.

6. The nations of the world differ dramatically in wealth and other resources, with the poorest nations being found in Africa and parts of Asia.

7. Global poverty has a devastating impact on the lives of hundreds of millions of people throughout the world. Poor nations have much higher rates of mortality and disease and lower rates of literacy.

8. Modernization theory attributes global poverty to the failure of poor nations to develop the necessary beliefs, values, and practices to achieve economic growth, while dependency theory attributes global poverty to the colonization and exploitation by European nations of nations in other parts of the world.

9. A sociological perspective suggests that poverty reduction in the United States and around the world can occur if the structural causes of poverty are successfully addressed.

\section{Using What You Know}

It is December 20, and you have just finished final exams. In two days, you will go home for winter break and are looking forward to a couple weeks of eating, sleeping, and seeing your high school friends. Your smartphone signals that someone has texted you. When you read the message, you see that a friend is asking you to join her in serving a holiday supper on December 23 at a food pantry just a few miles from your campus. If you do that, you will not be able to get home until two days after you had been planning to arrive, and you will miss a big high school "reunion" party set for the night of the twenty-third. What do you decide to do? Why? 


\section{What You Can Do}

To help fight poverty and the effects of poverty, you may wish to do any of the following:

1. Contribute money to a local, state, or national organization that provides various kinds of aid to the poor.

2. Volunteer at a local food pantry or homeless shelter.

3. Start a canned food or used clothing drive on your campus.

4. Write letters or send e-mails to local, state, and federal officials that encourage them to expand antipoverty programs. 


\section{Chapter 3: Racial and Ethnic Inequality}

\section{Social Problems in the News}

“Anger, Shock over Cross Burning in Calif. Community,” the headline said. This cross burning took place next to a black woman's home in Arroyo Grande, California, a small, wealthy town about 170 miles northwest of Los Angeles. The eleven-foot cross had recently been stolen from a nearby church.

This hate crime shocked residents and led a group of local ministers to issue a public statement that said in part, "Burning crosses, swastikas on synagogue walls, hateful words on mosque doors are not pranks. They are hate crimes meant to frighten and intimidate." The head of the group added, "We live in a beautiful area, but it's only beautiful if every single person feels safe conducting their lives and living here."

Four people were arrested four months later for allegedly burning the cross and charged with arson, hate crime, terrorism, and conspiracy. Arroyo Grande's mayor applauded the arrests and said in a statement, "Despite the fact that our city was shaken by this crime, it did provide an opportunity for us to become better educated on matters relating to diversity."

Sources: (Jablon, 2011; Lerner, 2011; Mann, 2011)

Cross burnings like this one recall the Ku Klux Klan era between the 1880s and 1960s, when white men dressed in white sheets and white hoods terrorized African Americans in the South and elsewhere and lynched more than 3,000 black men and women. Thankfully, that era is long gone, but as this news story reminds us, racial issues continue to trouble the United States.

In the wake of the 1960s urban riots, the so-called Kerner Commission (Kerner Commission, 1968) ${ }^{1}$ appointed by President Lyndon Johnson to study the riots famously warned, "Our nation is moving toward two societies, one black, one white-separate and unequal.” The commission blamed white racism for the riots and urged the government to provide jobs and housing for African Americans and to take steps to end racial segregation.

More than four decades later, racial inequality in the United States continues to exist and in many ways has worsened. Despite major advances by African Americans, Latinos, and other people of color during the past few decades, they continue to lag behind non-Hispanic whites in education, income, health, and other social indicators. The faltering economy since 2008 has hit people of color especially hard, and the racial wealth gap is deeper now than it was just two decades ago.

Why does racial and ethnic inequality exist? What forms does it take? What can be done about it? This chapter addresses all these questions. We shall see that, although racial and ethnic inequality has stained the United States since its beginnings, there is hope for the future as long as our nation understands the structural sources of this inequality and makes a concerted effort to reduce it. Later chapters in this book will continue to highlight various dimensions of racial and ethnic inequality. Immigration, a very relevant issue today for Latinos and Asians and the 
source of much political controversy, receives special attention in Chapter 15 "Population and the Environment"'s discussion of population problems.

\section{References}

Jablon, R. (2011, March 23). Anger, shock over cross burning in Calif. community. washingtonpost.com. Retrieved from http://www.washingtonpost.com/wp-dyn/content/article/2011/03/23/AR2011032300301.html.

Kerner Commission. (1968). Report of the National Advisory Commission on civil disorders. New York, NY: Bantam Books.

Lerner, D. (2011, July 22). Police chief says suspects wanted to "terrorize” cross burning victim. ksby.com. Retrieved from http://www.ksby.com/news/police-chief-says-suspects-wanted-to-terrorize-cross-burning-victim/.

Mann, C. (2011, March 22). Cross burning in Calif. suburb brings FBI into hate crime investigation. cbsnews.com. Retrieved from http://www.cbsnews.com/. 


\subsection{Racial and Ethnic Inequality: A Historical Prelude}

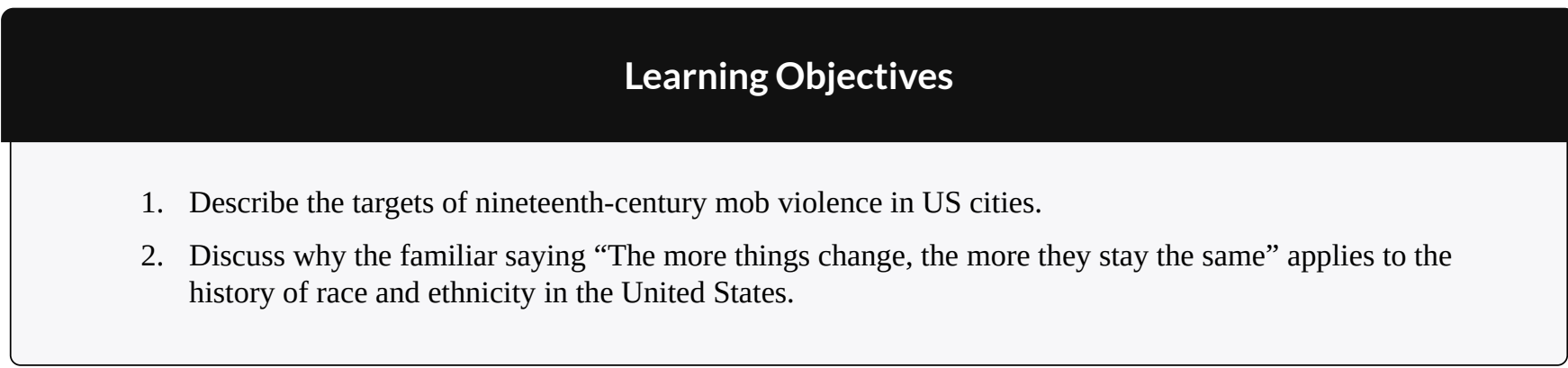

Race and ethnicity have torn at the fabric of American society ever since the time of Christopher Columbus, when an estimated 1 million Native Americans populated the eventual United States. By 1900, their numbers had dwindled to about 240,000, as tens of thousands were killed by white settlers and US troops and countless others died from disease contracted from people with European backgrounds. Scholars say this mass killing of Native Americans amounted to genocide (Brown, 2009).

African Americans also have a history of maltreatment that began during the colonial period, when Africans were forcibly transported from their homelands to be sold as slaves in the Americas. Slavery, of course, continued in the United States until the North's victory in the Civil War ended it. African Americans outside the South were not slaves but were still victims of racial prejudice. During the 1830s, white mobs attacked free African Americans in cities throughout the nation, including Philadelphia, Cincinnati, Buffalo, and Pittsburgh. The mob violence stemmed from a "deep-seated racial prejudice...in which whites saw blacks as 'something less than human"” (Brown, 1975) and continued well into the twentieth century, when white mobs attacked African Americans in several cities, with at least seven antiblack riots occurring in 1919 that left dozens dead. Meanwhile, an era of Jim Crow racism in the South led to the lynching of thousands of African Americans, segregation in all facets of life, and other kinds of abuses (Litwack, 2009). 


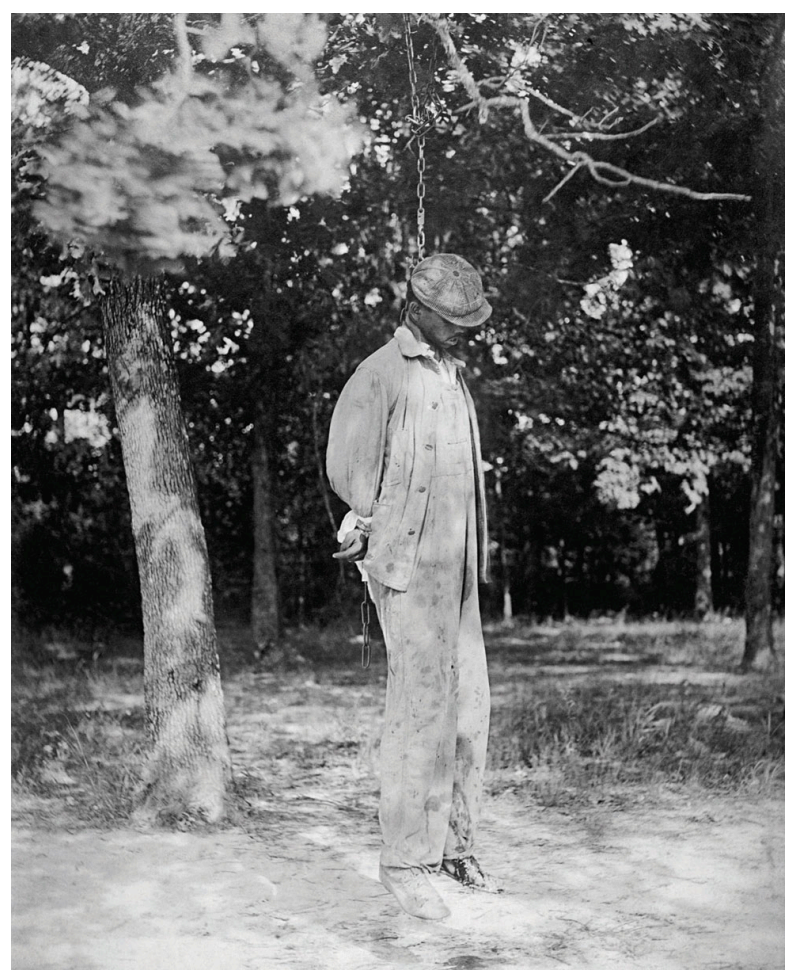

During the era of Jim Crow racism in the South, several thousand African Americans were lynched.

US Library of Congress - public domain.

African Americans were not the only targets of native-born white mobs back then (Dinnerstein \& Reimers, 2009). As immigrants from Ireland, Italy, Eastern Europe, Mexico, and Asia flooded into the United States during the nineteenth and early twentieth centuries, they, too, were beaten, denied jobs, and otherwise mistreated. During the 1850s, mobs beat and sometimes killed Catholics in cities such as Baltimore and New Orleans. During the 1870s, whites rioted against Chinese immigrants in cities in California and other states. Hundreds of Mexicans were attacked and/or lynched in California and Texas during this period.

Nazi racism in the 1930s and 1940s helped awaken Americans to the evils of prejudice in their own country. Against this backdrop, a monumental two-volume work by Swedish social scientist Gunnar Myrdal (Myrdal, 1944) attracted much attention when it was published. The book, An American Dilemma: The Negro Problem and Modern Democracy, documented the various forms of discrimination facing blacks back then. The "dilemma" referred to by the book's title was the conflict between the American democratic ideals of egalitarianism and liberty and justice for all and the harsh reality of prejudice, discrimination, and lack of equal opportunity.

The Kerner Commission's 1968 report reminded the nation that little, if anything, had been done since Myrdal's book to address this conflict. Sociologists and other social scientists have warned since then that the status of people of color has actually been worsening in many ways since this report was issued (Massey, 2007; Wilson, 2009). Evidence of this status appears in the remainder of this chapter. 


\section{Key Takeaways}

- US history is filled with violence and other maltreatment against Native Americans, blacks, and immigrants.

- Social scientists warn that the status of people of color has been worsening.

\section{For Your Review}

1. Describe why Myrdal said US race relations were an "American dilemma.”

2. How much did you learn in high school about the history of race and ethnicity in the United States? Do you think you should have learned more?

\section{References}

Brown, D. A. (2009). Bury my heart at Wounded Knee: An Indian history of the American West. New York, NY: Sterling Innovation.

Brown, R. M. (1975). Strain of violence: Historical studies of American violence and vigilantism. New York, NY: Oxford University Press.

Dinnerstein, L., \& Reimers, D. M. (2009). Ethnic Americans: A history of immigration. New York, NY: Columbia University Press.

Litwack, L. F. (2009). How free is free? The long death of Jim Crow. Cambridge, MA: Harvard University Press.

Massey, D. S. (2007). Categorically unequal: The American stratification system. New York, NY: Russell Sage Foundation.

Myrdal, G. (1944). An American dilemma: The negro problem and modern democracy. New York, NY: Harper and Brothers.

Wilson, W. J. (2009). The economic plight of inner-city black males. In E. Anderson (Ed.), Against the wall: Poor, young, black, and male (pp. 55-70). Philadelphia, PA: University of Pennsylvania Press. 


\subsection{The Meaning of Race and Ethnicity}

\section{Learning Objectives}

1. Critique the biological concept of race.

2. Discuss why race is a social construction.

3. Explain why ethnic heritages have both good and bad consequences.

To begin our understanding of racial and ethnic inequality, we first need to understand what race and ethnicity mean. These terms may seem easy to define but are much more complex than their definitions suggest.

\section{Race}

Let's start first with race, which refers to a category of people who share certain inherited physical characteristics, such as skin color, facial features, and stature. A key question about race is whether it is more of a biological category or a social category. Most people think of race in biological terms, and for more than three hundred years, or ever since white Europeans began colonizing nations filled with people of color, people have been identified as belonging to one race or another based on certain biological features.

It is certainly easy to see that people in the United States and around the world differ physically in some obvious ways. The most noticeable difference is skin tone: Some groups of people have very dark skin, while others have very light skin. Other differences also exist. Some people have very curly hair, while others have very straight hair. Some have thin lips, while others have thick lips. Some groups of people tend to be relatively tall, while others tend to be relatively short. Using such physical differences as their criteria, scientists at one point identified as many as nine races: African, American Indian or Native American, Asian, Australian Aborigine, European (more commonly called “white”), Indian, Melanesian, Micronesian, and Polynesian (Smedley, 2007).

Although people certainly do differ in these kinds of physical features, anthropologists, sociologists, and many biologists question the value of these categories and thus the value of the biological concept of race (Smedley, 2007). For one thing, we often see more physical differences within a race than between races. For example, some people we call "white" (or European), such as those with Scandinavian backgrounds, have very light skins, while others, such as those from some Eastern European backgrounds, have much darker skins. In fact, some "whites" have darker skin than some "blacks," or African Americans. Some whites have very straight hair, while others have very curly hair; some have blonde hair and blue eyes, while others have dark hair and brown eyes. Because of interracial reproduction going back to the days of slavery, African Americans also differ in the darkness of their skin and in other physical characteristics. In fact, it is estimated that at least 30 percent of African Americans have some white (i.e., European) ancestry and that at least 20 percent of whites have African or Native American 
ancestry. If clear racial differences ever existed hundreds or thousands of years ago (and many scientists doubt such differences ever existed), in today's world these differences have become increasingly blurred.

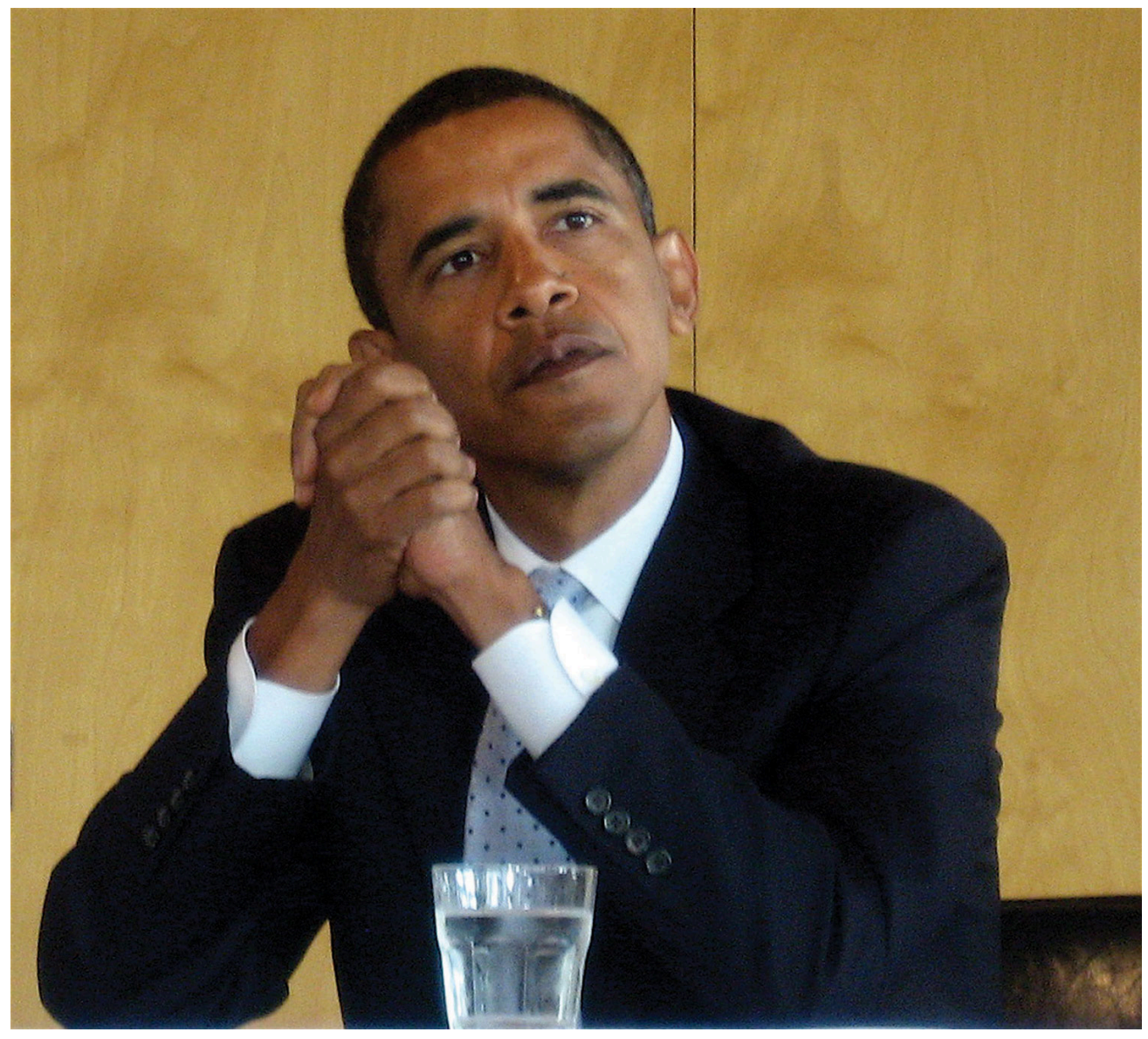

President Barack Obama had an African father and a white mother. Although his ancestry is equally black and white, Obama considers himself an African American, as do most Americans. In several Latin American nations, however, Obama would be considered white because of his white ancestry.

Steve Jurvetson - Barak Obama on the Primary - CC BY 2.0.

Another reason to question the biological concept of race is that an individual or a group of individuals is often assigned to a race arbitrarily. A century ago, for example, Irish, Italians, and Eastern European Jews who left their homelands were not regarded as white once they reached the United States but rather as a different, inferior (if unnamed) race (Painter, 2010). The belief in their inferiority helped justify the harsh treatment they suffered in their new country. Today, of course, we call people from all three backgrounds white or European.

In this context, consider someone in the United States who has a white parent and a black parent. What race is this person? American society usually calls this person black or African American, and the person may adopt this identity (as does President Barack Obama, who had a white mother and African father). But where is the logic for doing so? This person, as well as President Obama, is as much white as black in terms of parental ancestry.

Or consider someone with one white parent and another parent who is the child of one black parent and one white parent. This person thus has three white grandparents and one black grandparent. Even though this person's 
ancestry is thus 75 percent white and 25 percent black, she or he is likely to be considered black in the United States and may well adopt this racial identity. This practice reflects the traditional one-drop rule in the United States that defines someone as black if she or he has at least one drop of black blood, and that was used in the antebellum South to keep the slave population as large as possible (Staples, 2005). Yet in many Latin American nations, this person would be considered white (see Note 3.7 “Lessons from Other Societies"). With such arbitrary designations, race is more of a social category than a biological one.

\section{Lessons from Other Societies}

The Concept of Race in Brazil

As the text discusses, race was long considered a fixed, biological category, but today it is now regarded as a social construction. The experience of Brazil provides very interesting comparative evidence for this more accurate way of thinking about race.

When slaves were first brought to the Americas almost four hundred years ago, many more were taken to Brazil, where slavery was not abolished until 1888, than to the land that eventually became the United States. Brazil was then a colony of Portugal, and the Portuguese used Africans as slave labor. Just as in the United States, a good deal of interracial reproduction has occurred since those early days, much of it initially the result of rape of women slaves by their owners, and Brazil over the centuries has had many more racial intermarriages than the United States. Also like the United States, then, much of Brazil's population has multiracial ancestry. But in a significant departure from the United States, Brazil uses different criteria to consider the race to which a person belongs.

Brazil uses the term preto, or black, for people whose ancestry is solely African. It also uses the term branco, or white, to refer to people whose ancestry is both African and European. In contrast, as the text discusses, the United States commonly uses the term black or African American to refer to someone with even a small amount of African ancestry and white for someone who is thought to have solely European ancestry or at least "looks" white. If the United States were to follow Brazil's practice of reserving the term black for someone whose ancestry is solely African and the term white for someone whose ancestry is both African and European, many of the Americans commonly called "black" would no longer be considered black and instead would be considered white.

As sociologist Edward E. Telles (2006, p. 79) summarizes these differences, "[Blackness is differently understood in Brazil than in the United States. A person considered black in the United States is often not so in Brazil. Indeed, some U.S. blacks may be considered white in Brazil. Although the value given to blackness is similarly low [in both nations], who gets classified as black is not uniform." The fact that someone can count on being considered "black" in one society and not "black" in another society underscores the idea that race is best considered a social construction rather than a biological category.

Sources: Barrionuevo \& Calmes, 2011; Klein \& Luno, 2009; Telles, 2006

A third reason to question the biological concept of race comes from the field of biology itself and more specifically from the studies of genetics and human evolution. Starting with genetics, people from different races are more than 99.9 percent the same in their DNA (Begley, 2008). To turn that around, less than 0.1 percent of all DNA in our bodies accounts for the physical differences among people that we associate with racial differences. In terms of DNA, then, people with different racial backgrounds are much, much more similar than dissimilar.

Even if we acknowledge that people differ in the physical characteristics we associate with race, modern evolutionary evidence reminds us that we are all, really, of one human race. According to evolutionary theory, the human race began thousands and thousands of years ago in sub-Saharan Africa. As people migrated around the world over the millennia, natural selection took over. It favored dark skin for people living in hot, sunny climates (i.e., near the equator), because the heavy amounts of melanin that produce dark skin protect against 
severe sunburn, cancer, and other problems. By the same token, natural selection favored light skin for people who migrated farther from the equator to cooler, less sunny climates, because dark skins there would have interfered with the production of vitamin D (Stone \& Lurquin, 2007). Evolutionary evidence thus reinforces the common humanity of people who differ in the rather superficial ways associated with their appearances: We are one human species composed of people who happen to look different.

\section{Race as a Social Construction}

The reasons for doubting the biological basis for racial categories suggest that race is more of a social category than a biological one. Another way to say this is that race is a social construction, a concept that has no objective reality but rather is what people decide it is (Berger \& Luckmann, 1963). In this view, race has no real existence other than what and how people think of it.

This understanding of race is reflected in the problems, outlined earlier, in placing people with multiracial backgrounds into any one racial category. We have already mentioned the example of President Obama. As another example, golfer Tiger Woods was typically called an African American by the news media when he burst onto the golfing scene in the late 1990s, but in fact his ancestry is one-half Asian (divided evenly between Chinese and Thai), one-quarter white, one-eighth Native American, and only one-eighth African American (Leland \& Beals, 1997).

Historical examples of attempts to place people in racial categories further underscore the social constructionism of race. In the South during the time of slavery, the skin tone of slaves lightened over the years as babies were born from the union, often in the form of rape, of slave owners and other whites with slaves. As it became difficult to tell who was "black" and who was not, many court battles over people's racial identity occurred. People who were accused of having black ancestry would go to court to prove they were white in order to avoid enslavement or other problems (Staples, 1998).

Although race is a social construction, it is also true that race has real consequences because people do perceive race as something real. Even though so little of DNA accounts for the physical differences we associate with racial differences, that low amount leads us not only to classify people into different races but also to treat them differently_and, more to the point, unequally_based on their classification. Yet modern evidence shows there is little, if any, scientific basis for the racial classification that is the source of so much inequality.

\section{Ethnicity}

Because of the problems in the meaning of race, many social scientists prefer the term ethnicity in speaking of people of color and others with distinctive cultural heritages. In this context, ethnicity refers to the shared social, cultural, and historical experiences, stemming from common national or regional backgrounds, that make subgroups of a population different from one another. Similarly, an ethnic group is a subgroup of a population with a set of shared social, cultural, and historical experiences; with relatively distinctive beliefs, values, and behaviors; and with some sense of identity of belonging to the subgroup. So conceived, the terms ethnicity and ethnic group avoid the biological connotations of the terms race and racial group. 
At the same time, the importance we attach to ethnicity illustrates that it, too, is in many ways a social construction, and our ethnic membership thus has important consequences for how we are treated. In particular, history and current practice indicate that it is easy to become prejudiced against people with different ethnicities from our own. Much of the rest of this chapter looks at the prejudice and discrimination operating today in the United States against people whose ethnicity is not white and European. Around the world today, ethnic conflict continues to rear its ugly head. The 1990s and 2000s were filled with ethnic cleansing and pitched battles among ethnic groups in Eastern Europe, Africa, and elsewhere. Our ethnic heritages shape us in many ways and fill many of us with pride, but they also are the source of much conflict, prejudice, and even hatred, as the hate crime story that began this chapter so sadly reminds us.

\section{Key Takeaways}

- Sociologists think race is best considered a social construction rather than a biological category.

• "Ethnicity" and "ethnic” avoid the biological connotations of "race” and "racial."

\section{For Your Review}

1. List everyone you might know whose ancestry is biracial or multiracial. What do these individuals consider themselves to be?

2. List two or three examples that indicate race is a social construction rather than a biological category.

\section{References}

Barrionuevo, A., \& Calmes, J. (2011, March 21). President underscores similarities with Brazilians, but sidesteps one. New York Times, p. A8.

Begley, S. (2008, February 29). Race and DNA. Newsweek. Retrieved from http://www.thedailybeast.com/ newsweek/blogs/lab-notes/2008/02/29/race-and-dna.html.

Berger, P., \& Luckmann, T. (1963). The social construction of reality. New York, NY: Doubleday.

Klein, H. S., \& Luno, F. V. (2009). Slavery in Brazil. New York, NY: Cambridge University Press.

Leland, J., \& Beals, G. (1997, May 5). In living colors: Tiger Woods is the exception that rules. Newsweek, 58-60.

Painter, N. I. (2010). The history of white people. New York, NY: W. W. Norton.

Smedley, A. (2007). Race in North America: Evolution of a worldview. Boulder, CO: Westview Press.

Staples, B. (1998, November 13). The shifting meanings of “black” and “white.” New York Times, p. WK14. 
Staples, B. (2005, October 31). Why race isn’t as “black” and “white” as we think. New York Times, p. A18.

Stone, L., \& Lurquin, P. F. (2007). Genes, culture, and human evolution: A synthesis. Malden, MA: Blackwell.

Telles, E. E. (2006). Race in another America: The significance of skin color in Brazil. Princeton, NJ: Princeton University Press. 


\subsection{Prejudice}

\section{Learning Objectives}

1. Define prejudice, racism, and stereotypes.

2. Discuss the major social-psychological and sociological theories of prejudice.

3. Describe how the nature of prejudice has changed.

Prejudice and discrimination (discussed in the next section) are often confused, but the basic difference between them is this: Prejudice is the attitude, while discrimination is the behavior. More specifically, racial and ethnic prejudice refers to a set of negative attitudes, beliefs, and judgments about whole categories of people, and about individual members of those categories, because of their perceived race and/or ethnicity. A closely related concept is racism, or the belief that certain racial or ethnic groups are inferior to one's own. Prejudice and racism are often based on racial and ethnic stereotypes, or simplified, mistaken generalizations about people because of their race and/or ethnicity. While cultural and other differences do exist among the various American racial and ethnic groups, many of the views we have of such groups are unfounded and hence are stereotypes. An example of the stereotypes that white people have of other groups appears in Figure 3.1 "Perceptions by Non-Latino White Respondents of the Intelligence of White and Black Americans", in which white respondents in the General Social Survey (GSS), a recurring survey of a random sample of the US population, are less likely to think blacks are intelligent than they are to think whites are intelligent.

Figure 3.1 Perceptions by Non-Latino White Respondents of the Intelligence of White and Black Americans

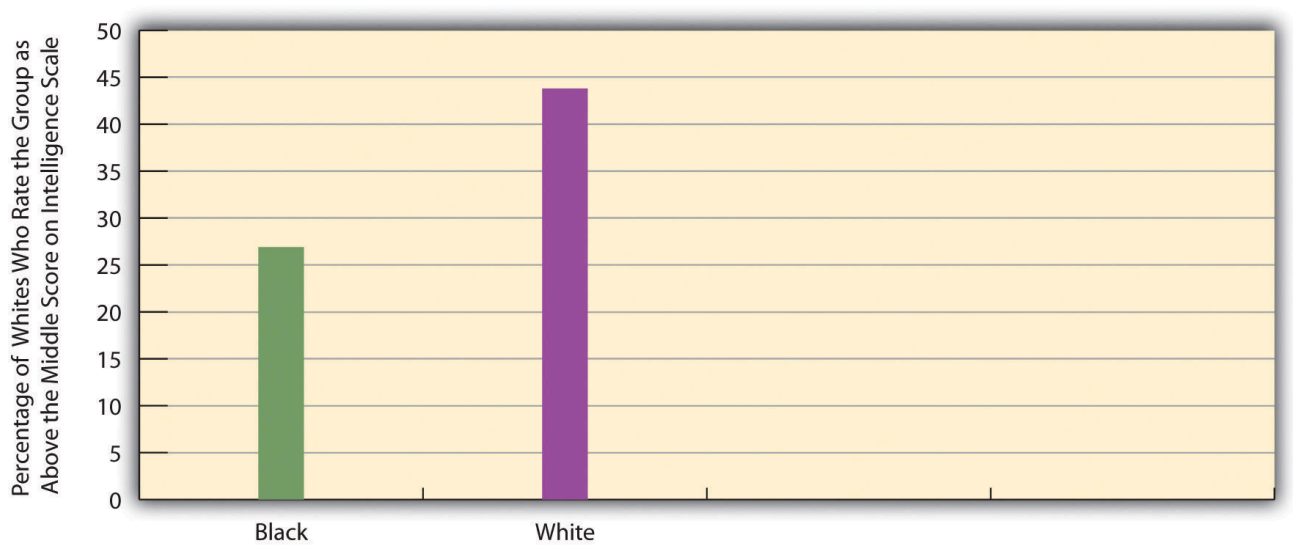

Source: Data from General Social Survey. (2010). Retrieved from http://sda.berkeley.edu/cgi-bin/hsda?harcsda+gss10. 


\section{Explaining Prejudice}

Where does racial and ethnic prejudice come from? Why are some people more prejudiced than others? Scholars have tried to answer these questions at least since the 1940s, when the horrors of Nazism were still fresh in people's minds. Theories of prejudice fall into two camps, social-psychological and sociological. We will look at social-psychological explanations first and then turn to sociological explanations. We will also discuss distorted mass media treatment of various racial and ethnic groups.

\section{Social-Psychological Explanations}

One of the first social-psychological explanations of prejudice centered on the authoritarian personality (Adorno, Frenkel-Brunswick, Levinson, \& Sanford, 1950). According to this view, authoritarian personalities develop in childhood in response to parents who practice harsh discipline. Individuals with authoritarian personalities emphasize such things as obedience to authority, a rigid adherence to rules, and low acceptance of people (outgroups) not like oneself. Many studies find strong racial and ethnic prejudice among such individuals (Sibley \& Duckitt, 2008). But whether their prejudice stems from their authoritarian personalities or instead from the fact that their parents were probably prejudiced themselves remains an important question.

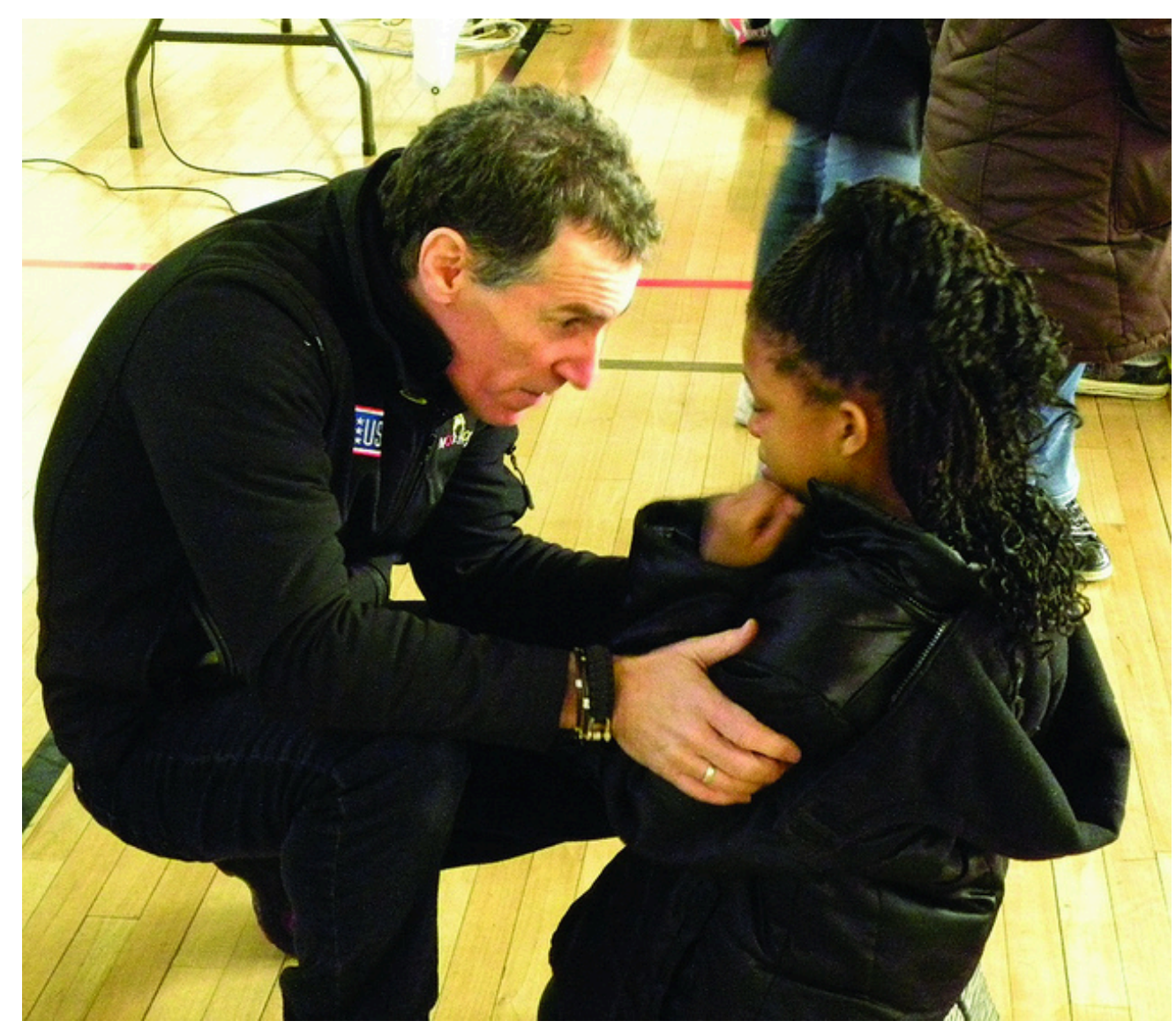


prejudice. Although many people with authoritarian personalities are prejudiced, it remains unclear whether their prejudice stems

from their personalities or from their parents' own prejudice.

Flickr - CC BY-NC-ND 2.0.

Another early and still popular social-psychological explanation is called frustration theory (or scapegoat theory) (Dollard, Doob, Miller, Mowrer, \& Sears, 1939). In this view individuals with various problems become frustrated and tend to blame their troubles on groups that are often disliked in the real world (e.g., racial, ethnic, and religious minorities). These minorities are thus scapegoats for the real sources of people's misfortunes. Several psychology experiments find that when people are frustrated, they indeed become more prejudiced. In one early experiment, college students who were purposely not given enough time to solve a puzzle were more prejudiced after the experiment than before it (Cowen, Landes, \& Schaet, 1959).

\section{Sociological Explanations}

One popular sociological explanation emphasizes conformity and socialization and is called social learning theory. In this view, people who are prejudiced are merely conforming to the culture in which they grow up, and prejudice is the result of socialization from parents, peers, the news media, and other various aspects of their culture. Supporting this view, studies have found that people tend to become more prejudiced when they move to areas where people are very prejudiced and less prejudiced when they move to locations where people are less prejudiced (Aronson, 2008). If people in the South today continue to be more prejudiced than those outside the South, as we discuss later, even though legal segregation ended more than four decades ago, the influence of their culture on their socialization may help explain these beliefs.

\section{Children and Our Future}

Growing Up as Farmworkers’ Kids

In the large agricultural fields of California work thousands of farmworkers and their families. Adults and children alike live in poor, crowded conditions and do backbreaking work in the hot sun, day after day after day.

Because their parents are migrant workers, many children attend a specific school for only a few weeks or months at most before their parents move to another field in another town or even another state. At Sherwood Elementary School in Salinas, California, in the heart of the state's agricultural sector, 97 percent of students live in or near poverty. With their Latino backgrounds, more than three-fourths do not speak English well or at all, and many of their parents cannot read or write their own language, Spanish.

At the Sherwood school, according to a news report, many students "sleep beneath carports and live in such cramped quarters that their parents take them to the local truck stop to wash up before school.” A local high school teacher said many of his students see little of their parents, who spend most of their waking hours working in the fields. "They have little brothers and sisters to take care of, maybe cook for. Yet they're supposed to turn in a 10-page paper by tomorrow? I mean, it's unreal."

These conditions have grievous consequences for California's migrant farmworker children, almost half of whom fail to complete high school. The principal of the Sherwood Elementary School said the key strategy for her faculty and school was "understanding where the students come from but also having high expectations."

The plight of farmworkers' children is just one aspect of the difficulties facing Latino children around the country. 
Thanks to reproduction and immigration, the number of Latino children nationwide has grown significantly during the past few decades: in 2009, 23 percent of US kindergarten children were Latino, compared to only 10 percent in 1989. These growing numbers underscore the need to pay attention to the health and welfare of Latino children.

Against this backdrop, it is distressing to note that their health and welfare is not very good at all. About one-third of Latino children live in poverty. The average Latino child grows up in a poor neighborhood where almost half of the residents do not speak English fluently, where the schools are substandard, and where the high school dropout and teen unemployment rates are high. A number of factors, including their ethnicity, poverty, language barriers, and the immigrant status of many of their parents, limit Latino children's access to adequate health care and various kinds of social services.

Amid all these problems, however, the situation of California's farmworker children stands out as a national embarrassment for a prosperous country like the United States. As the country struggles to end racial and ethnic inequality, it must not forget the children of Salinas who have to use a truck stop to wash up before school.

Sources: P. L. Brown, 2011; Landale, McHale, \& Booth, 2011; Tavernise, 2011

The mass media play a key role in how many people learn to be prejudiced. This type of learning happens because the media often present people of color in a negative light. By doing so, the media unwittingly reinforce the prejudice that individuals already have or even increase their prejudice (Larson, 2005). Examples of distorted media coverage abound. Even though poor people are more likely to be white than any other race or ethnicity (see Chapter 2 "Poverty"), the news media use pictures of African Americans far more often than those of whites in stories about poverty. In one study, national news magazines, such as Time and Newsweek, and television news shows portrayed African Americans in almost two-thirds of their stories on poverty, even though only about onefourth of poor people are African Americans. In the magazine stories, only 12 percent of the African Americans had a job, even though in the real world more than 40 percent of poor African Americans were working at the time the stories were written (Gilens, 1996). In a Chicago study, television news shows there depicted whites fourteen times more often in stories of good Samaritans, even though whites and African Americans live in Chicago in roughly equal numbers (Entman \& Rojecki, 2001). Many other studies find that newspaper and television stories about crime and drugs feature higher proportions of African Americans as offenders than is true in arrest statistics (Surette, 2011). Studies like these show that the news media "convey the message that black people are violent, lazy, and less civic minded” (Jackson, 1997, p. A27).

A second sociological explanation emphasizes economic and political competition and is commonly called group threat theory (Quillian, 2006). In this view, prejudice arises from competition over jobs and other resources and from disagreement over various political issues. When groups vie with each other over these matters, they often become hostile toward each other. Amid such hostility, it is easy to become prejudiced toward the group that threatens your economic or political standing. A popular version of this basic explanation is Susan Olzak's (1992) ethnic competition theory, which holds that ethnic prejudice and conflict increase when two or more ethnic groups find themselves competing for jobs, housing, and other goals.

The competition explanation is the macro equivalent of the frustration/scapegoat theory already discussed. Much of the white mob violence discussed earlier stemmed from whites' concern that the groups they attacked threatened their jobs and other aspects of their lives. Thus lynchings of African Americans in the South increased when the Southern economy worsened and decreased when the economy improved (Tolnay \& Beck, 1995). Similarly, white mob violence against Chinese immigrants in the 1870 s began after the railroad construction that employed so many Chinese immigrants slowed and the Chinese began looking for work in other industries. Whites feared that the Chinese would take jobs away from white workers and that their large supply of labor 
would drive down wages. Their assaults on the Chinese killed several people and prompted the passage by Congress of the Chinese Exclusion Act in 1882 that prohibited Chinese immigration (Dinnerstein \& Reimers, 2009).

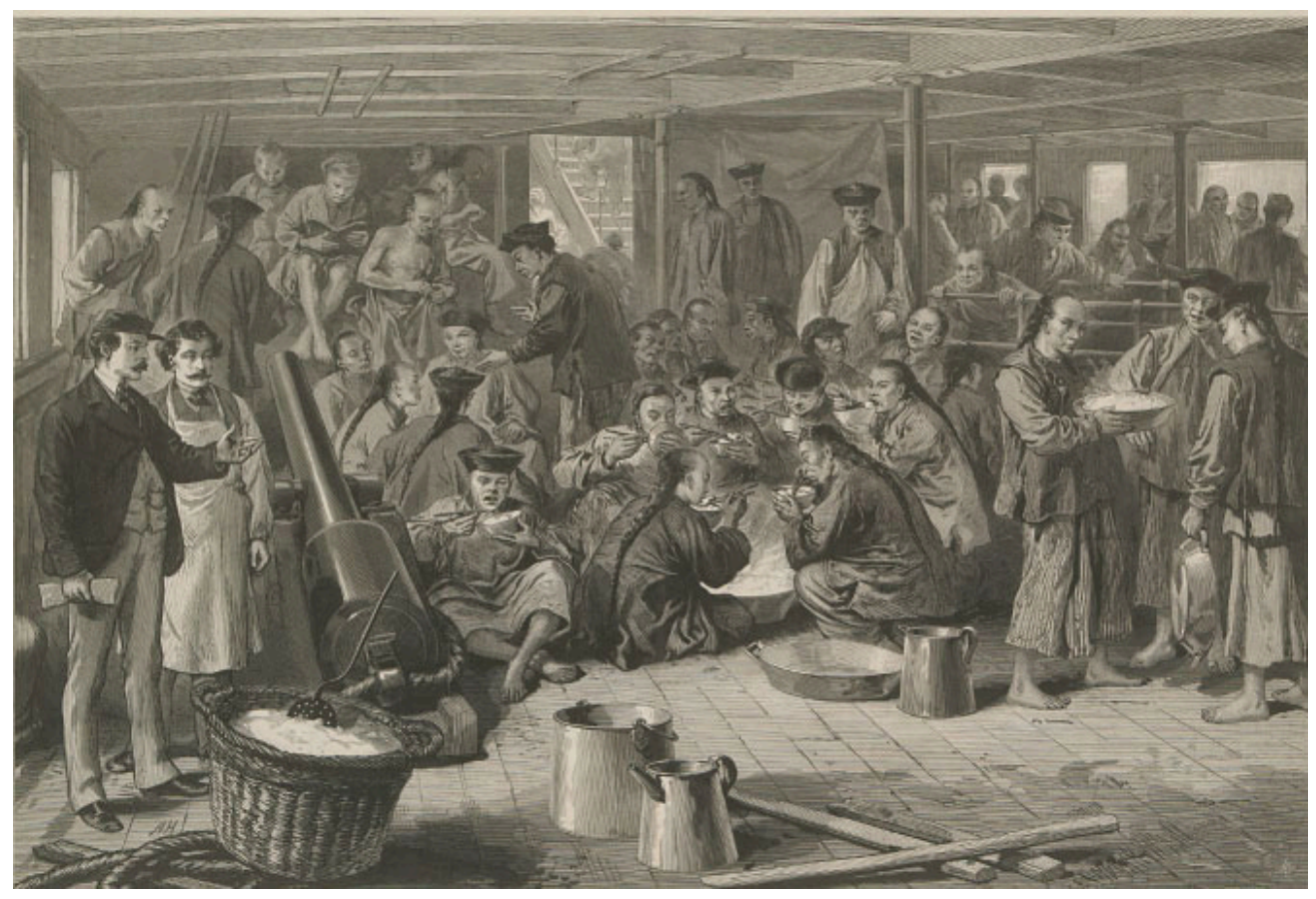

During the 1870s, whites feared that Chinese immigrants would take away their jobs. This fear led to white mob violence against the Chinese and to an act of Congress that prohibited Chinese immigration.

Wikimedia Commons - public domain.

\section{Correlates of Prejudice}

Since the 1940s, social scientists have investigated the individual correlates of racial and ethnic prejudice (Stangor, 2009). These correlates help test the theories of prejudice just presented. For example, if authoritarian personalities do produce prejudice, then people with these personalities should be more prejudiced. If frustration also produces prejudice, then people who are frustrated with aspects of their lives should also be more prejudiced. Other correlates that have been studied include age, education, gender, region of country, race, residence in integrated neighborhoods, and religiosity. We can take time here to focus on gender, education, and region of country and discuss the evidence for the racial attitudes of whites, as most studies do in view of the historic dominance of whites in the United States.

The findings on gender are rather surprising. Although women are usually thought to be more empathetic than men and thus to be less likely to be racially prejudiced, recent research indicates that the racial views of (white) women and men are in fact very similar and that the two genders are about equally prejudiced (Hughes \& Tuch, 2003). This similarity supports group threat theory, outlined earlier, in that it indicates that white women and men are responding more as whites than as women or men, respectively, in formulating their racial views. 
Findings on education and region of country are not surprising. Focusing again just on whites, less educated people are usually more racially prejudiced than better-educated people, and Southerners are usually more prejudiced than non-Southerners (Krysan, 2000). Evidence of these differences appears in Figure 3.2 "Education, Region, and Opposition by Non-Latino Whites to a Close Relative Marrying an African American", which depicts educational and regional differences in a type of racial prejudice that social scientists call social distance, or feelings about interacting with members of other races and ethnicities. The General Social Survey asks respondents how they feel about a "close relative” marrying an African American. Figure 3.2 "Education, Region, and Opposition by Non-Latino Whites to a Close Relative Marrying an African American" shows how responses by white (non-Latino) respondents to this question vary by education and by Southern residence. Whites without a high school degree are much more likely than those with more education to oppose these marriages, and whites in the South are also much more likely than their non-Southern counterparts to oppose them. To recall the sociological perspective (see Chapter 1 "Understanding Social Problems”), our social backgrounds certainly do seem to affect our attitudes.

Figure 3.2 Education, Region, and Opposition by Non-Latino Whites to a Close Relative Marrying an African American
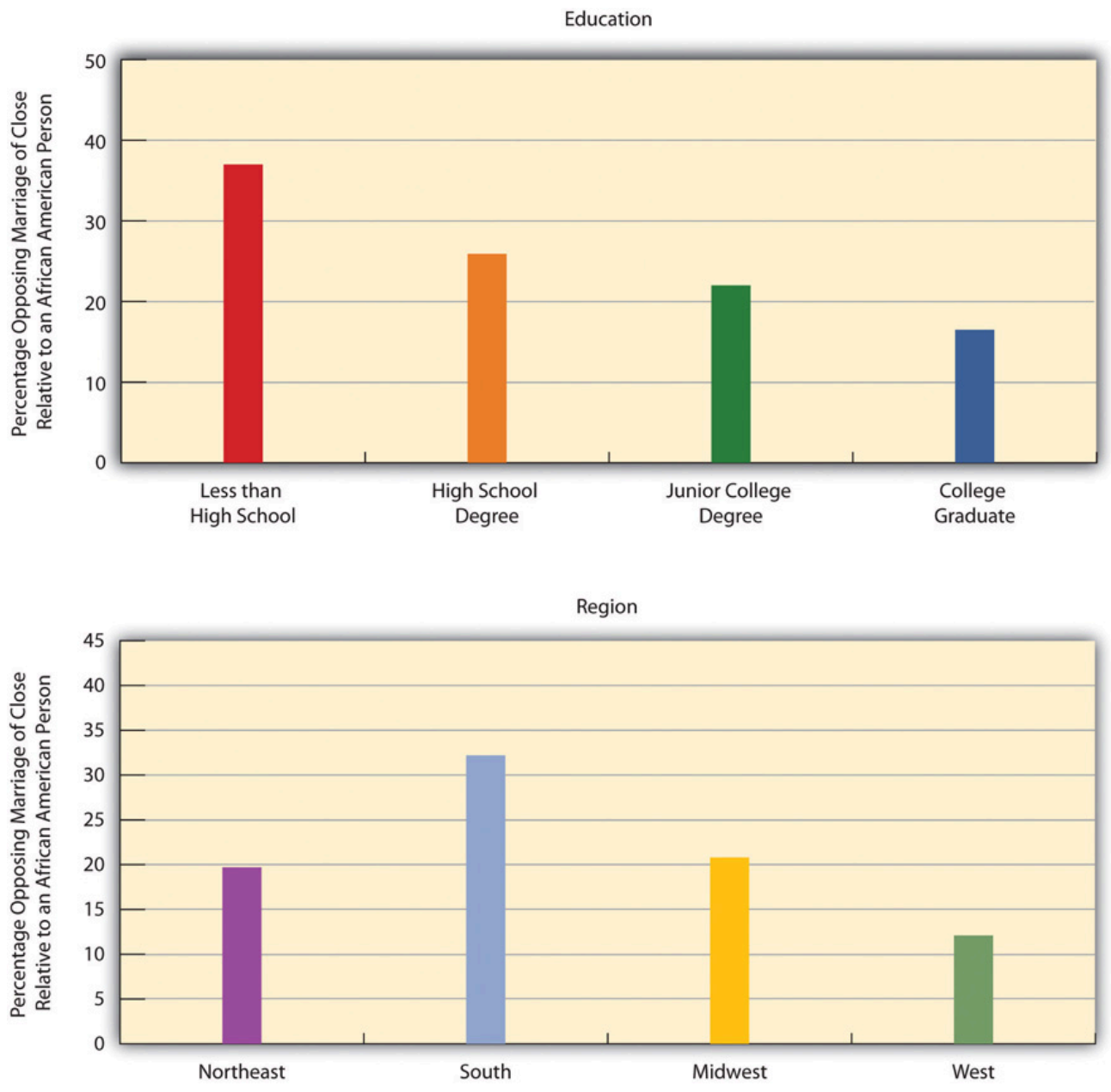

Source: Data from General Social Survey. (2010). Retrieved from http://sda.berkeley.edu/cgi-bin/hsda?harcsda+gss10. 


\section{The Changing Nature of Prejudice}

Although racial and ethnic prejudice still exists in the United States, its nature has changed during the past halfcentury. Studies of these changes focus on whites' perceptions of African Americans. Back in the 1940s and before, an era of overt Jim Crow racism (also called traditional or old-fashioned racism) prevailed, not just in the South but in the entire nation. This racism involved blatant bigotry, firm beliefs in the need for segregation, and the view that blacks were biologically inferior to whites. In the early 1940s, for example, more than half of all whites thought that blacks were less intelligent than whites, more than half favored segregation in public transportation, more than two-thirds favored segregated schools, and more than half thought whites should receive preference over blacks in employment hiring (Schuman, Steeh, Bobo, \& Krysan, 1997).

The Nazi experience and then the civil rights movement led whites to reassess their views, and Jim Crow racism gradually waned. Few whites believe today that African Americans are biologically inferior, and few favor segregation. So few whites now support segregation and other Jim Crow views that national surveys no longer include many of the questions that were asked a half-century ago.

But that does not mean that prejudice has disappeared. Many scholars say that Jim Crow racism has been replaced by a more subtle form of racial prejudice, termed laissez-faire, symbolic, or modern racism, that amounts to a "kinder, gentler, antiblack ideology" that avoids notions of biological inferiority (Bobo, Kluegel, \& Smith, 1997, p. 15; Quillian, 2006; Sears, 1988). Instead, it involves stereotypes about African Americans, a belief that their poverty is due to their cultural inferiority, and opposition to government policies to help them. Similar views exist about Latinos. In effect, this new form of prejudice blames African Americans and Latinos themselves for their low socioeconomic standing and involves such beliefs that they simply do not want to work hard.

Evidence for this modern form of prejudice is seen in Figure 3.3 "Attribution by Non-Latino Whites of Blacks' Low Socioeconomic Status to Blacks' Low Innate Intelligence and to Their Lack of Motivation to Improve”, which presents whites' responses to two General Social Survey (GSS) questions that asked, respectively, whether African Americans' low socioeconomic status is due to their lower "in-born ability to learn" or to their lack of "motivation and will power to pull themselves up out of poverty." While only 8.5 percent of whites attributed blacks' status to lower innate intelligence (reflecting the decline of Jim Crow racism), about 48 percent attributed it to their lack of motivation and willpower. Although this reason sounds "kinder" and "gentler" than a belief in blacks' biological inferiority, it is still one that blames African Americans for their low socioeconomic status.

Figure 3.3 Attribution by Non-Latino Whites of Blacks’ Low Socioeconomic Status to Blacks' Low Innate Intelligence and to Their 


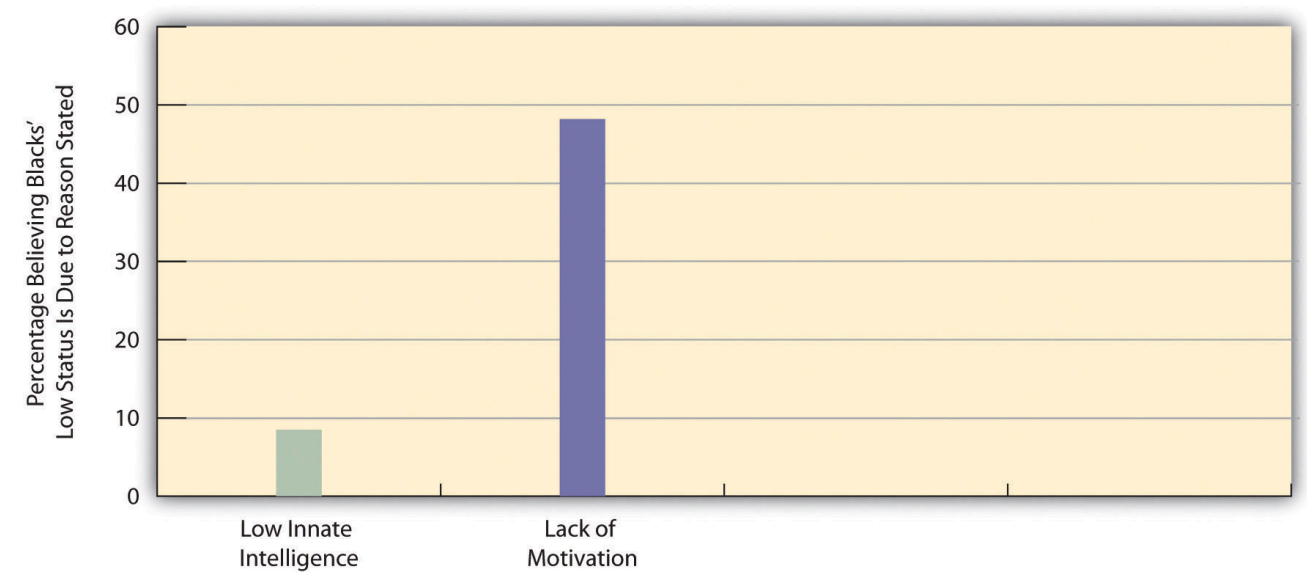

Source: Data from General Social Survey. (2010). Retrieved from http://sda.berkeley.edu/cgi-bin/hsda?harcsda+gss10.

\section{Prejudice and Public Policy Preferences}

If whites do continue to believe in racial stereotypes, say the scholars who study modern prejudice, they are that much more likely to oppose government efforts to help people of color. For example, whites who hold racial stereotypes are more likely to oppose government programs for African Americans (Quillian, 2006). We can see an example of this type of effect in Figure 3.4 "Racial Stereotyping by Non-Latino Whites and Their Opposition to Government Spending to Help African Americans", which compares two groups: whites who attribute blacks' poverty to lack of motivation, and whites who attribute blacks' poverty to discrimination. Those who cite lack of motivation are more likely than those who cite discrimination to believe the government is spending too much to help blacks.

Figure 3.4 Racial Stereotyping by Non-Latino Whites and Their Opposition to Government Spending to Help African Americans

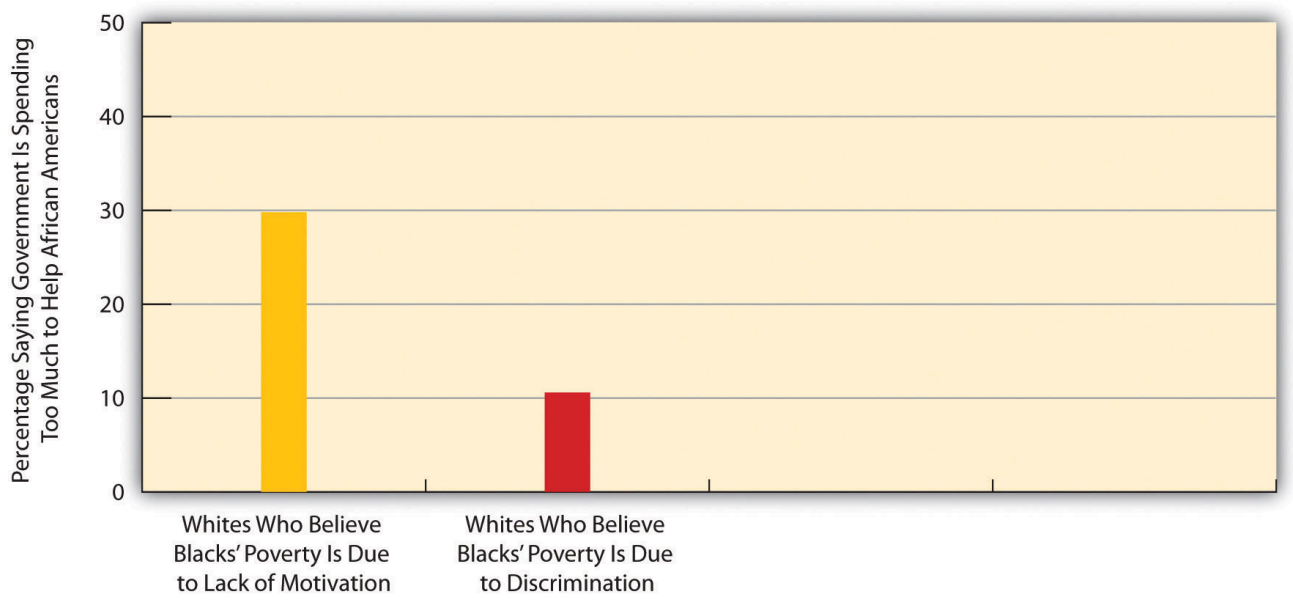

Source: Data from General Social Survey. (2010). Retrieved from http://sda.berkeley.edu/cgi-bin/hsda?harcsda+gss10. 


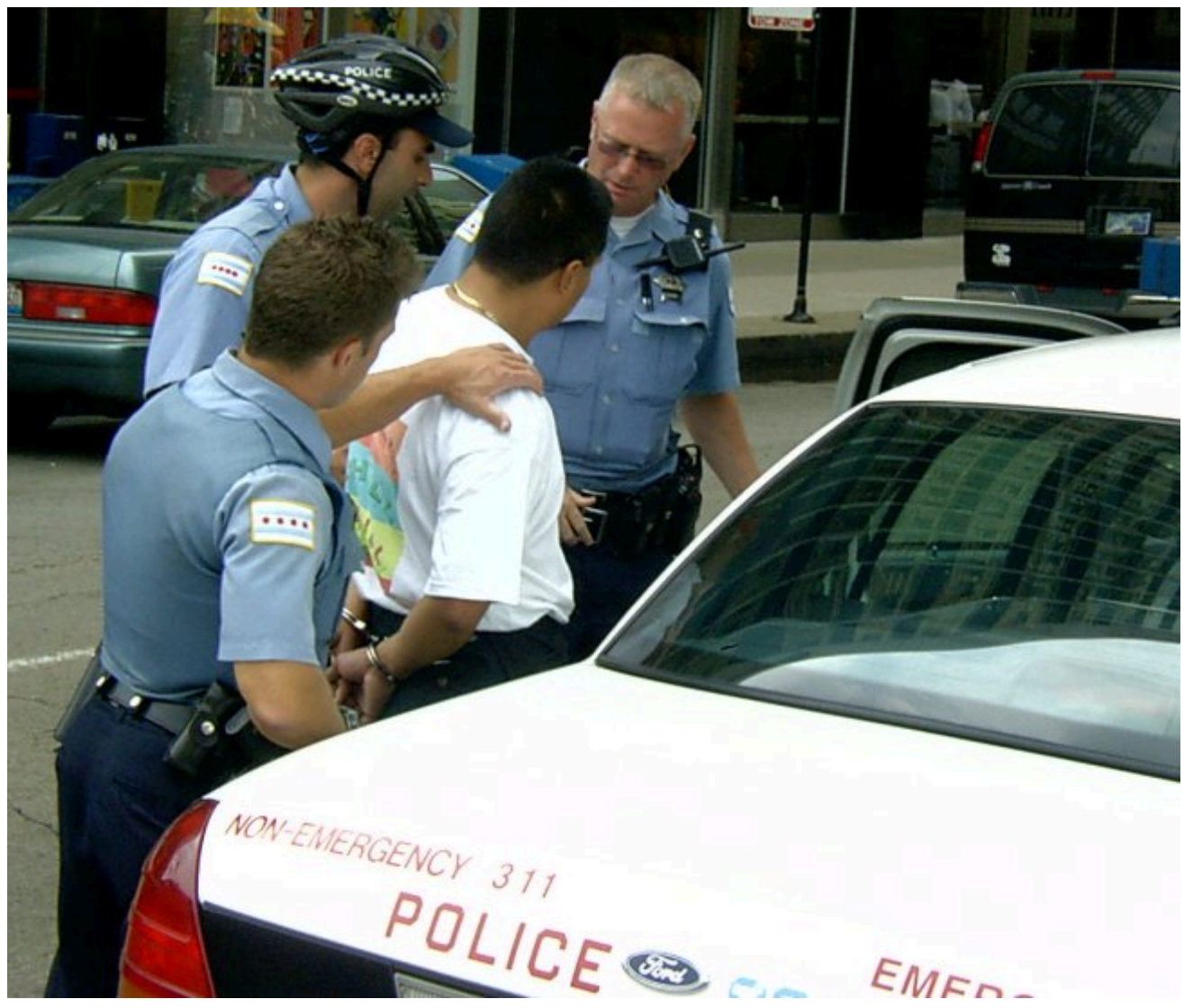

Whites who are racially prejudiced are more likely to favor harsher treatment of criminals and in particular are more likely to support the death penalty.

Wikimedia Commons - CC BY-SA 3.0.

Racial prejudice influences other public policy preferences as well. In the area of criminal justice, whites who hold racial stereotypes or hostile feelings toward African Americans are more likely to be afraid of crime, to think that the courts are not harsh enough, to support the death penalty, to want more money spent to fight crime, and to favor excessive use of force by police (Barkan \& Cohn, 2005; Unnever \& Cullen, 2010).

If racial prejudice influences views on all these issues, then these results are troubling for a democratic society like the United States. In a democracy, it is appropriate for the public to disagree on all sorts of issues, including criminal justice. For example, citizens hold many reasons for either favoring or opposing the death penalty. But is it appropriate for racial prejudice to be one of these reasons? To the extent that elected officials respond to public opinion, as they should in a democracy, and to the extent that racial prejudice affects public opinion, then racial prejudice may be influencing government policy on criminal justice and on other issues. In a democratic society, it is unacceptable for racial prejudice to have this effect.

\section{Key Takeaways}

- Social-psychological explanations of prejudice emphasize authoritarian personalities and frustration, while 
sociological explanations emphasize social learning and group threat.

- Education and region of residence are related to racial prejudice among whites; prejudice is higher among whites with lower levels of formal education and among whites living in the South.

- Jim Crow racism has been replaced by symbolic or modern racism that emphasizes the cultural inferiority of people of color.

- Racial prejudice among whites is linked to certain views they hold about public policy. Prejudice is associated with lower support among whites for governmental efforts to help people of color and with greater support for a more punitive criminal justice system.

\section{For Your Review}

1. Think about the last time you heard someone say a remark that was racially prejudiced. What was said? What was your reaction?

2. The text argues that it is inappropriate in a democratic society for racial prejudice to influence public policy. Do you agree with this argument? Why or why not?

\section{References}

Adorno, T. W., Frenkel-Brunswick, E., Levinson, D. J., \& Sanford, R. N. (1950). The authoritarian personality. New York, NY: Harper.

Aronson, E. (2008). The social animal (10th ed.). New York, NY: Worth.

Barkan, S. E., \& Cohn, S. F. (2005). Why whites favor spending more money to fight crime: The role of racial prejudice. Social Problems, 52, 300-314

Bobo, L., Kluegel, J. R., \& Smith, R. A. (1997). Laissez-faire racism: The crystallization of a kinder, gentler, antiblack ideology. In S. A. Tuch \& J. K. Martin (Eds.), Racial attitudes in the 1990s: Continuity and change (pp. 15-44). Westport, CT: Praeger.

Brown, P. L. (2011, March 13). Itinerant life weighs on farmworkers’ children. New York Times, p. A18

Cowen, E. L., Landes, J., \& Schaet, D. E. (1959). The effects of mild frustration on the expression of prejudiced attitudes. Journal of Abnormal and Social Psychology, 64, 33-38.

Dinnerstein, L., \& Reimers, D. M. (2009). Ethnic Americans: A history of immigration. New York, NY: Columbia University Press.

Dollard, J., Doob, L. W., Miller, N. E., Mowrer, O. H., \& Sears, R. R. (1939). Frustration and Aggression. New Haven, CT: Yale University Press. 
Entman, R. M., \& Rojecki, A. (2001). The black image in the white mind. Chicago, IL: University of Chicago Press.

Gilens, M. (1996). Race and poverty in America: Public misperceptions and the American news media. Public Opinion Quarterly, 60, 515-541.

Hughes, M., \& Tuch, S. A. (2003). Gender differences in whites' racial attitudes: Are women’s attitudes really more favorable? Social Psychology Quarterly, 66, 384-401.

Jackson, D. Z. (1997, December 5). Unspoken during race talk. The Boston Globe, p. A27.

Krysan, M. (2000). Prejudice, politics, and public opinion: Understanding the sources of racial policy attitudes. Annual Review of Sociology, 26, 135-168.

Landale, N. S., McHale, S., \& Booth, A. (Eds.). (2011). Growing up Hispanic: Health and development of children of immigrants. Washington, DC: Urban Institute Press.

Larson, S. G. (2005). Media \& minorities: The politics of race in news and entertainment. Lanham, MD: Rowman \& Littlefield.

Olzak, S. (1992). The dynamics of ethnic competition and conflict. Stanford, CA: Stanford University Press.

Quillian, L. (2006). New approaches to understanding racial prejudice and discrimination. Annual Review of Sociology, 32, 299-328.

Schuman, H., Steeh, C., Bobo, L., \& Krysan, M. (1997). Racial attitudes in America: Trends and interpretations (Rev. ed.). Cambridge, MA: Harvard University Press.

Sears, D. O. (1988). Symbolic racism. In P. A. Katz \& D. A. Taylor (Eds.), Eliminating racism: Profiles in controversy (pp. 53-84). New York, NY: Plenum.

Sibley, C. G., \& Duckitt, J. (2008). Personality and prejudice: A meta-analysis and theoretical review. Personality and Social Psychology Review, 12, 248-279.

Stangor, C. (2009). The study of stereotyping, prejudice, and discrimination within social psychology: A quick history of theory and research. In T. D. Nelson (Ed.), Handbook of prejudice, stereotyping, and discrimination (pp. 1-22). New York, NY: Psychology Press.

Surette, R. (2011). Media, crime, and criminal justice: Images, realities, and policies (4th ed.). Belmont, CA: Wadsworth.

Tavernise, S. (2011, February 8). Among nation’s youngest, analysis finds fewer whites. New York Times, p. A14.

Tolnay, S. E., \& Beck, E. M. (1995). A festival of violence: An analysis of southern lynchings, 1882-1930. Urbana, IL: University of Illinois Press.

Unnever, J. D., \& Cullen, F. T. (2010). The social sources of Americans' punitiveness: A test of three competing models. Criminology, 48, 99-129. 


\subsection{Discrimination}

\section{Learning Objectives}

1. Discuss Merton's views on whether prejudice and discrimination always coincide.

2. Distinguish between individual discrimination and institutional discrimination.

3. Provide two examples of institutional discrimination.

Often racial and ethnic prejudice lead to discrimination against the subordinate racial and ethnic groups in a given society. Discrimination in this context refers to the arbitrary denial of rights, privileges, and opportunities to members of these groups. The use of the word arbitrary emphasizes that these groups are being treated unequally not because of their lack of merit but because of their race and ethnicity.

Usually prejudice and discrimination go hand-in-hand, but Robert Merton (1949) stressed this is not always so. Sometimes we can be prejudiced and not discriminate, and sometimes we might not be prejudiced and still discriminate. Table 3.1 “The Relationship between Prejudice and Discrimination” illustrates his perspective. The top-left cell and bottom-right cell consist of people who behave in ways we would normally expect. The top-left one consists of “active bigots," in Merton's terminology, people who are both prejudiced and discriminatory. An example of such a person is the white owner of an apartment building who dislikes people of color and refuses to rent to them. The bottom-right cell consists of "all-weather liberals," as Merton called them, people who are neither prejudiced nor discriminatory. An example would be someone who holds no stereotypes about the various racial and ethnic groups and treats everyone the same regardless of her or his background.

Table 3.1 The Relationship between Prejudice and Discrimination

\begin{tabular}{|l|l|l|}
\hline \multicolumn{2}{|l|}{ Prejudiced? } \\
\hline & Yes & No \\
\hline Discriminates? & & \\
\hline Yes & Active bigots & Fair-weather liberals \\
\hline No & Timid bigots & All-weather liberals \\
\hline
\end{tabular}

Source: Adapted from Merton, R. K. (1949). Discrimination and the American creed. In R. M. MacIver (Ed.), Discrimination and national welfare (pp. 99-126). New York, NY: Institute for Religious Studies.

The remaining two cells of Table 3.1 “The Relationship between Prejudice and Discrimination” are the more unexpected ones. On the bottom left, we see people who are prejudiced but who nonetheless do not discriminate; Merton called them "timid bigots." An example would be white restaurant owners who do not like people of color 
but still serve them anyway because they want their business or are afraid of being sued if they do not serve them. At the top right, we see "fair-weather liberals," or people who are not prejudiced but who still discriminate. An example would be white store owners in the South during the segregation era who thought it was wrong to treat blacks worse than whites but who still refused to sell to them because they were afraid of losing white customers.

\section{Individual Discrimination}

The discussion so far has centered on individual discrimination, or discrimination that individuals practice in their daily lives, usually because they are prejudiced but sometimes even if they are not prejudiced. Individual discrimination is common, as Joe Feagin (1991), a former president of the American Sociological Association, found when he interviewed middle-class African Americans about their experiences. Many of the people he interviewed said they had been refused service, or at least received poor service, in stores or restaurants. Others said they had been harassed by the police, and even put in fear of their lives, just for being black. Feagin concluded that these examples are not just isolated incidents but rather reflect the larger racism that characterizes US society. 


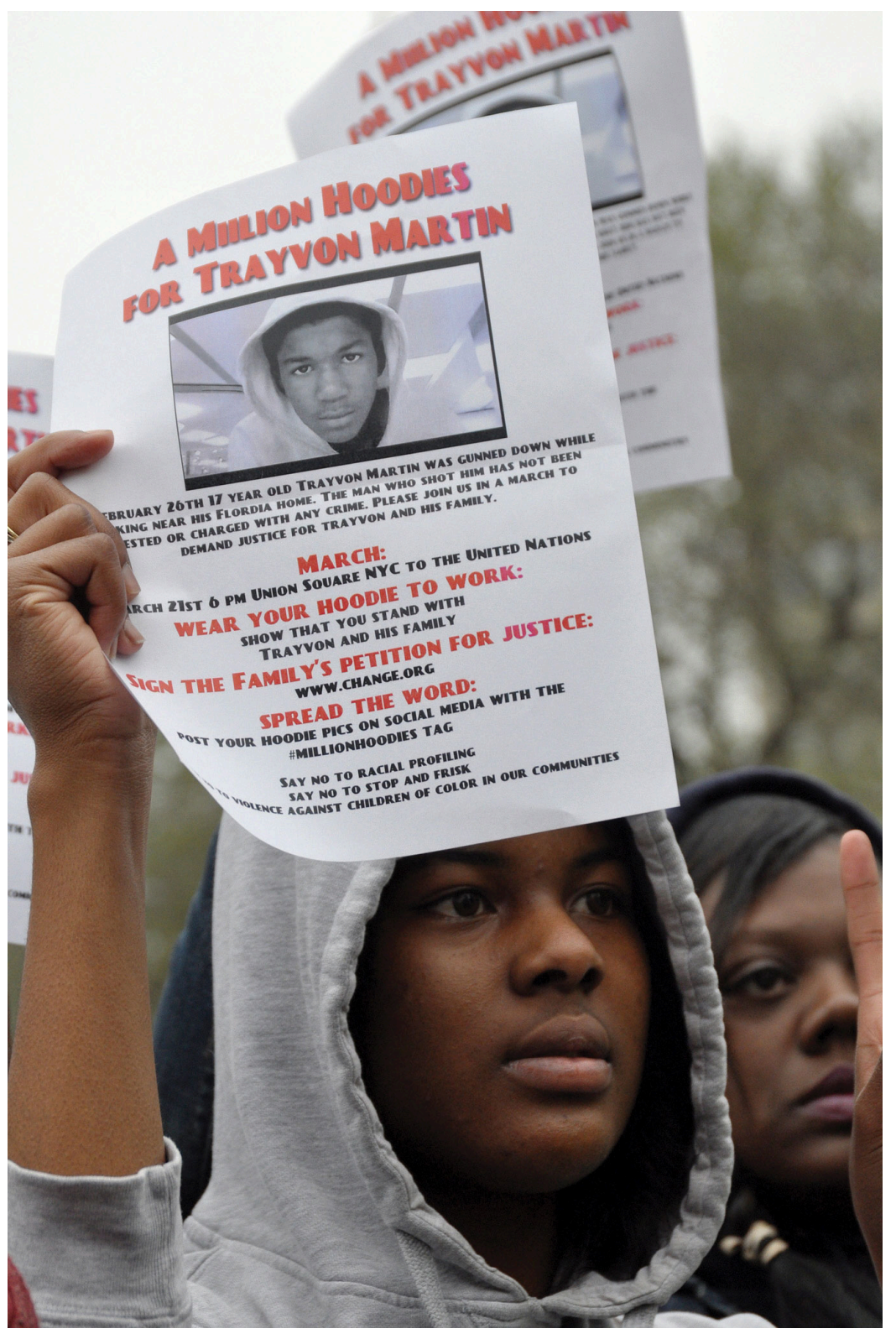

In February 2012, neighborhood watch volunteer George Zimmerman fatally shot 17-year-old Trayvon Martin as Martin was walking back from a 7-Eleven carrying some Skittles and iced tea. Critics said Zimmerman was suspicious of Martin only because Martin was black.

Michael Fleshman - Trayvon Martin Occupy March 21 - CC BY-SA 2.0. 


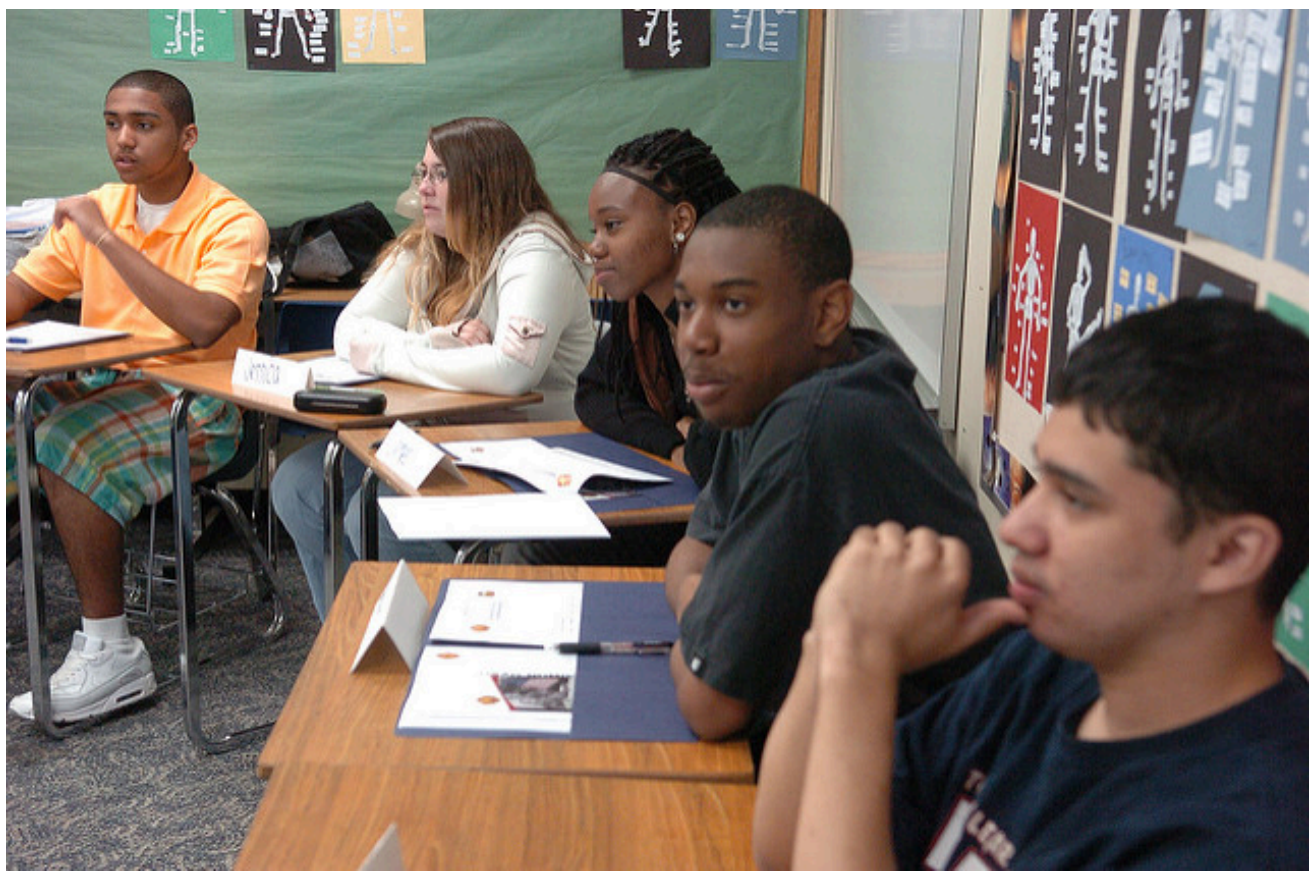

Sociologist Joe Feagin's study of middle-class African Americans found that many had been harassed by police and had otherwise experienced various kinds of racial slights.

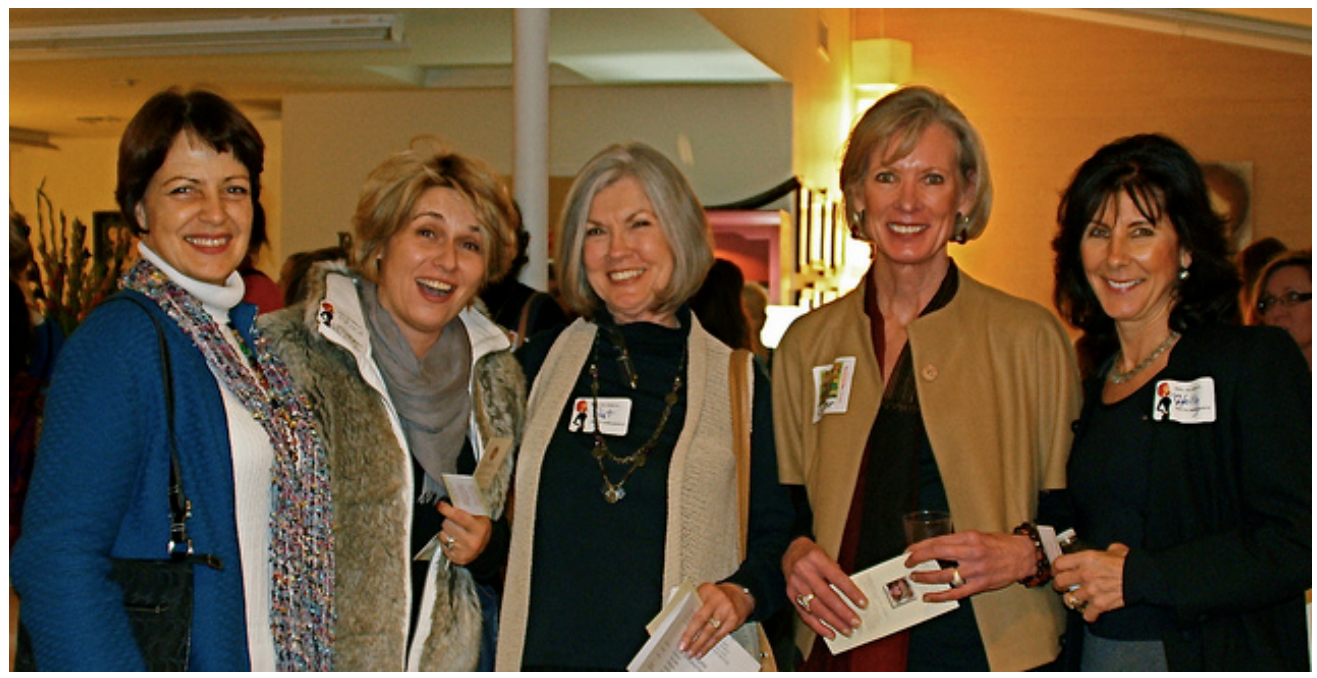

Sociologist Denise Segura found that more than 40 percent of the Mexican American women she interviewed at a public university had encountered workplace discrimination based on their ethnicity and/or gender.

To many observers, the fatal shooting of Trayvon Martin in February 2012 was a deadly example of individual discrimination. Martin, a 17-year-old African American, was walking in a gated community in Sanford, Florida, as he returned from a 7-Eleven with a bag of Skittles and some iced tea. An armed neighborhood watch 
volunteer, George Zimmerman, called 911 and said Martin looked suspicious. Although the 911 operator told Zimmerman not to approach Martin, Zimmerman did so anyway; within minutes Zimmerman shot and killed the unarmed Martin and later claimed self-defense. According to many critics of this incident, Martin's only "crime” was "walking while black." As an African American newspaper columnist observed, "For every black man in America, from the millionaire in the corner office to the mechanic in the local garage, the Trayvon Martin tragedy is personal. It could have been me or one of my sons. It could have been any of us” (Robinson, 2012).

Much individual discrimination occurs in the workplace, as sociologist Denise Segura (Segura, 1992) documented when she interviewed 152 Mexican American women working in white-collar jobs at a public university in California. More than 40 percent of the women said they had encountered workplace discrimination based on their ethnicity and/or gender, and they attributed their treatment to stereotypes held by their employers and coworkers. Along with discrimination, they were the targets of condescending comments like "I didn't know that there were any educated people in Mexico that have a graduate degree.”

\section{Institutional Discrimination}

Individual discrimination is important to address, but at least as consequential in today's world is institutional discrimination, or discrimination that pervades the practices of whole institutions, such as housing, medical care, law enforcement, employment, and education. This type of discrimination does not just affect a few isolated people of color. Instead, it affects large numbers of individuals simply because of their race or ethnicity. Sometimes institutional discrimination is also based on gender, disability, and other characteristics.

In the area of race and ethnicity, institutional discrimination often stems from prejudice, as was certainly true in the South during segregation. However, just as individuals can discriminate without being prejudiced, so can institutions when they engage in practices that seem to be racially neutral but in fact have a discriminatory effect. Individuals in institutions can also discriminate without realizing it. They make decisions that turn out, upon close inspection, to discriminate against people of color even if they did not mean to do so.

The bottom line is this: Institutions can discriminate even if they do not intend to do so. Consider height requirements for police. Before the 1970s, police forces around the United States commonly had height requirements, say five feet ten inches. As women began to want to join police forces in the 1970s, many found they were too short. The same was true for people from some racial/ethnic backgrounds, such as Latinos, whose stature is smaller on the average than that of non-Latino whites. Of course, even many white males were too short to become police officers, but the point is that even more women, and even more men of certain ethnicities, were too short.

This gender and ethnic difference is not, in and of itself, discriminatory as the law defines the term. The law allows for bona fide (good faith) physical qualifications for a job. As an example, we would all agree that someone has to be able to see to be a school bus driver; sight therefore is a bona fide requirement for this line of work. Thus even though people who are blind cannot become school bus drivers, the law does not consider such a physical requirement to be discriminatory. 


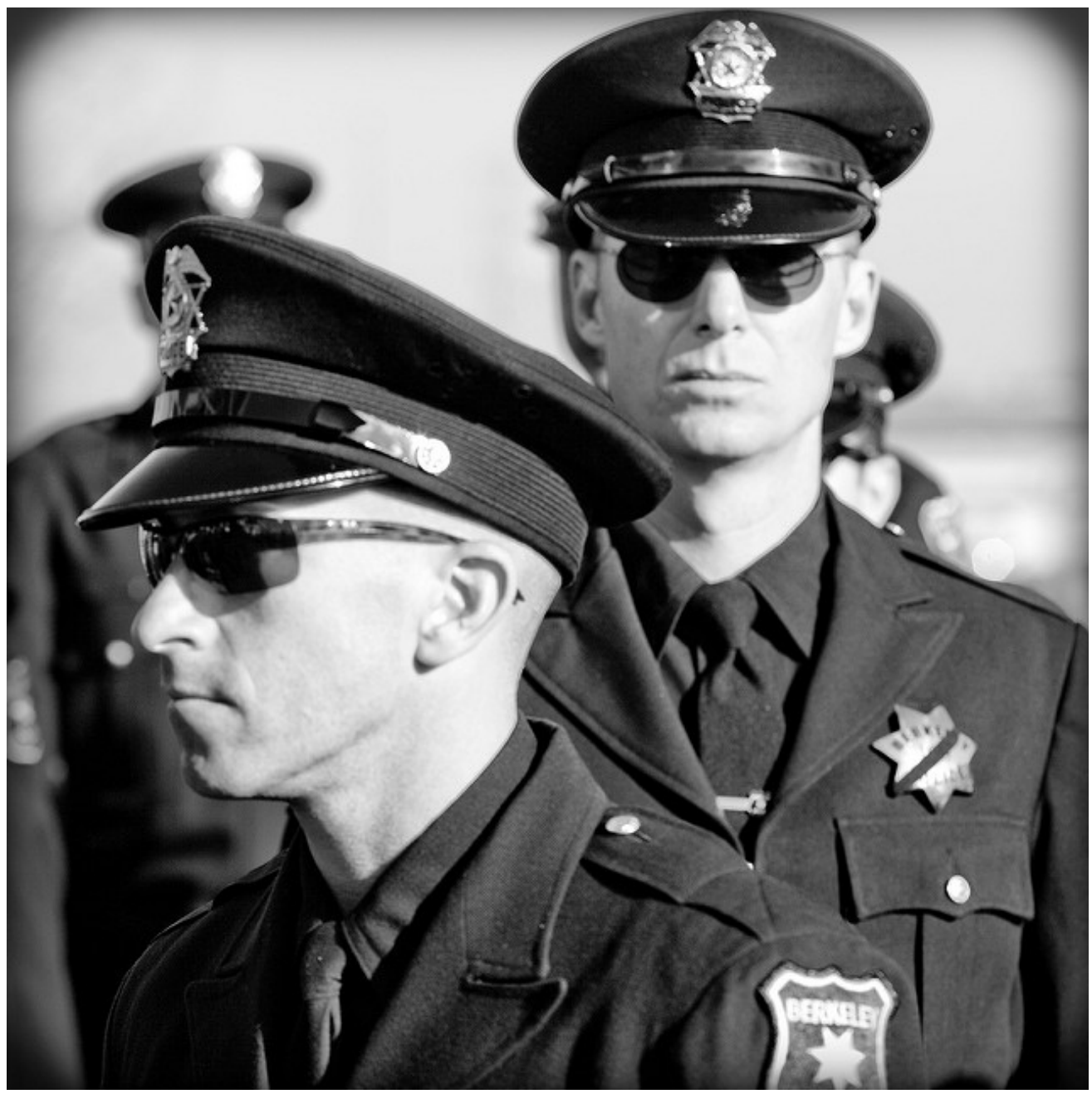

Institutional discrimination can occur even if this type of discrimination is not intended. Police forces used to have height requirements, but these were deemed by courts to discriminate against women, Latinos, and other individuals. In response, police forces lowered their height requirements.

Thomas Hawk - Oakland Police Memorial - CC BY-NC 2.0.

But were the height restrictions for police work in the early 1970s bona fide requirements? Women and members of certain ethnic groups challenged these restrictions in court and won their cases, as it was decided that there was no logical basis for the height restrictions then in effect. In short (pun intended), the courts concluded that a person did not have to be five feet ten inches to be an effective police officer. In response to these court challenges, police forces lowered their height requirements, opening the door for many more women, Latino men, and some other men to join police forces (Appier, 1998). Whether police forces back then intended their height requirements to discriminate, or whether they honestly thought their height requirements made sense, remains in dispute. Regardless of the reason, their requirements did discriminate.

Institutional discrimination affects the life chances of people of color in many aspects of life today. To illustrate this, we turn briefly to some examples of institutional discrimination that have been the subject of government investigation and scholarly research. 


\section{Health Care}

People of color have higher rates of disease and illness than whites, a fact explored further in Chapter 12 "Work and the Economy"'s treatment of health and medicine. One question that arises is why their health is worse. One possible answer involves institutional discrimination based on race and ethnicity.

Several studies use hospital records to investigate whether people of color receive optimal medical care, including coronary bypass surgery, angioplasty, and catheterization. After taking the patients' medical symptoms and needs into account, these studies find that African Americans are much less likely than whites to receive the procedures just listed. This is true when poor blacks are compared to poor whites and also when middle-class blacks are compared to middle-class whites (Smedley, Stith, \& Nelson, 2003). In a novel way of studying race and cardiac care, one study performed an experiment in which several hundred doctors viewed videos of African American and white patients, all of whom, unknown to the doctors, were actors. In the videos, each "patient" complained of identical chest pain and other symptoms. The doctors were then asked to indicate whether they thought the patient needed cardiac catheterization. The African American patients were less likely than the white patients to be recommended for this procedure (Schulman et al., 1999).

Why does discrimination like this occur? It is possible, of course, that some doctors are racists and decide that the lives of African Americans just are not worth saving, but it is far more likely that they have unconscious racial biases that somehow affect their medical judgments. Regardless of the reason, the result is the same: African Americans are less likely to receive potentially life-saving cardiac procedures simply because they are black. Institutional discrimination in health care, then, is literally a matter of life and death.

\section{Mortgages, Redlining, and Residential Segregation}

When loan officers review mortgage applications, they consider many factors, including the person's income, employment, and credit history. The law forbids them to consider race and ethnicity. Yet African Americans and Latinos are more likely than whites to have their mortgage applications declined (Blank, Venkatachalam, McNeil, \& Green, 2005). Because members of these groups tend to be poorer than whites and to have less desirable employment and credit histories, the higher rate of mortgage rejections may be appropriate, albeit unfortunate.

To control for this possibility, researchers take these factors into account and in effect compare whites, African Americans, and Latinos with similar incomes, employment, and credit histories. Some studies are purely statistical, and some involve white, African American, and Latino individuals who independently visit the same mortgage-lending institutions. Both types of studies find that African Americans and Latinos are still more likely than whites with similar qualifications to have their mortgage applications rejected (Turner et al., 2002). We will

probably never know whether loan officers are consciously basing their decisions on racial prejudice, but their practices still amount to racial and ethnic discrimination whether the loan officers are consciously prejudiced or not.

There is also evidence of banks rejecting mortgage applications for people who wish to live in certain urban, supposedly high-risk neighborhoods, and of insurance companies denying homeowner's insurance or else 
charging higher rates for homes in these same neighborhoods. Practices like these that discriminate against houses in certain neighborhoods are called redlining, and they also violate the law (Ezeala-Harrison, Glover, \& ShawJackson, 2008). Because the people affected by redlining tend to be people of color, redlining, too, is an example of institutional discrimination.

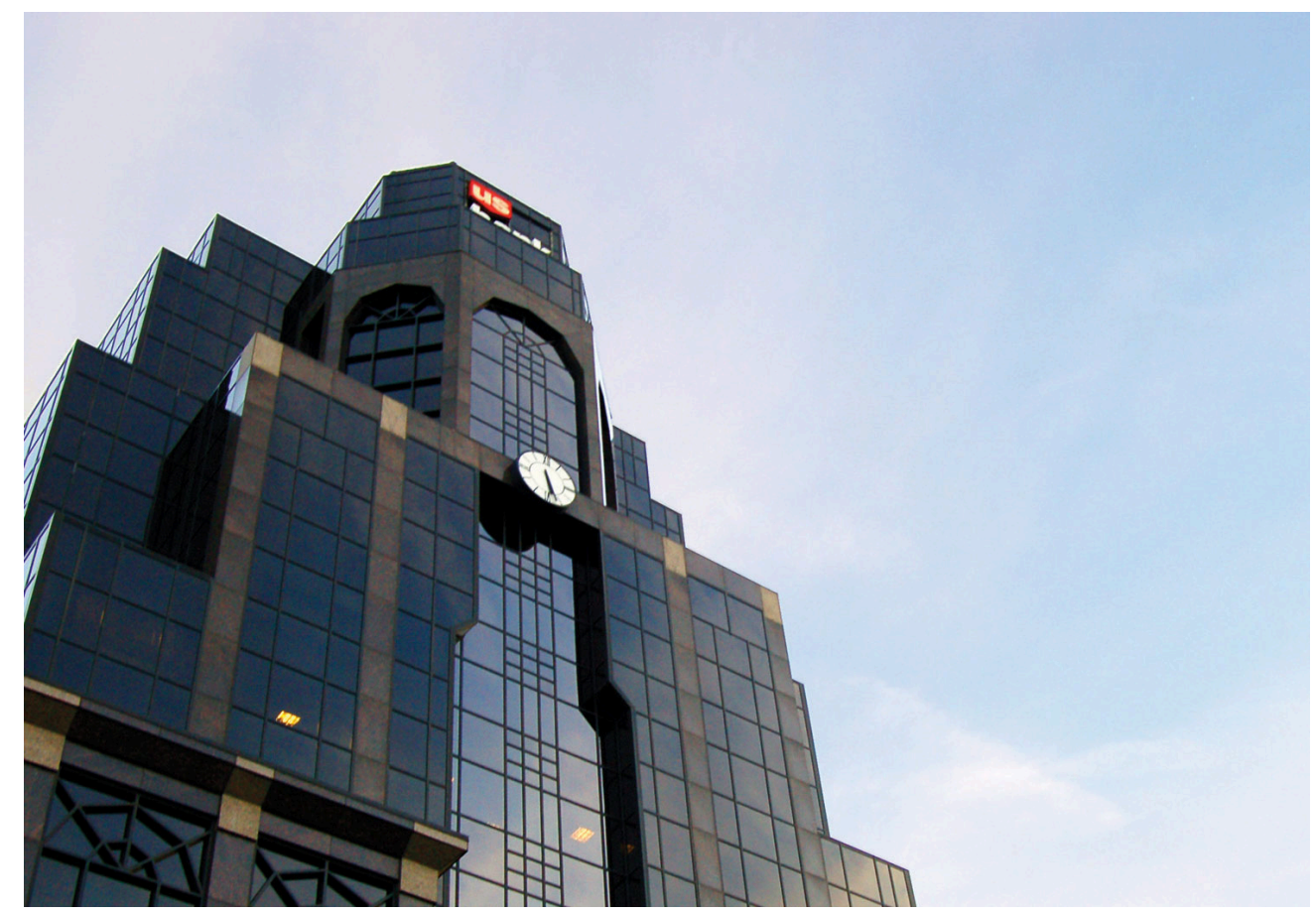

Banks have rejected mortgage applications from people who wish to live in certain urban, high-risk neighborhoods. This practice, called redlining, violates the law. Because many of the loan applicants who experience redlining are people of color, redlining is an example of institutional discrimination.

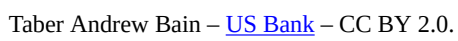

Mortgage rejections and redlining contribute to another major problem facing people of color: residential segregation. Housing segregation is illegal but is nonetheless widespread because of mortgage rejections and other processes that make it very difficult for people of color to move out of segregated neighborhoods and into unsegregated areas. African Americans in particular remain highly segregated by residence in many cities, much more so than is true for other people of color. The residential segregation of African Americans is so extensive that it has been termed hypersegregation and more generally called American apartheid (Massey \& Denton, 1993).

In addition to mortgage rejections, a pattern of subtle discrimination by realtors and homeowners makes it difficult for African Americans to find out about homes in white neighborhoods and to buy them (Pager, 2008). For example, realtors may tell African American clients that no homes are available in a particular white neighborhood, but then inform white clients of available homes. The now routine posting of housing listings on the Internet might be reducing this form of housing discrimination, but not all homes and apartments are posted, and some are simply sold by word of mouth to avoid certain people learning about them.

The hypersegregation experienced by African Americans cuts them off from the larger society, as many rarely leave their immediate neighborhoods, and results in concentrated poverty, where joblessness, crime, and other 
problems reign. For several reasons, then, residential segregation is thought to play a major role in the seriousness and persistence of African American poverty (Rothstein, 2012; Stoll, 2008).

\section{Employment Discrimination}

Title VII of the federal Civil Rights Act of 1964 banned racial discrimination in employment, including hiring, wages, and firing. However, African Americans, Latinos, and Native Americans still have much lower earnings than whites. Several factors explain this disparity, including the various structural obstacles discussed in $\underline{\text { Chapter }}$ $\underline{2}$ "Poverty"'s examination of poverty. Despite Title VII, however, an additional reason is that people of color continue to face discrimination in hiring and promotion (Hirsh \& Cha, 2008). It is again difficult to determine whether such discrimination stems from conscious prejudice or from unconscious prejudice on the part of potential employers, but it is racial discrimination nonetheless.

A now-classic field experiment documented such discrimination. Sociologist Devah Pager (2003) had young white and African American men apply independently in person for entry-level jobs. They dressed the same and reported similar levels of education and other qualifications. Some applicants also admitted having a criminal record, while other applicants reported no such record. As might be expected, applicants with a criminal record were hired at lower rates than those without a record. However, in striking evidence of racial discrimination in hiring, African American applicants without a criminal record were hired at the same low rate as the white applicants with a criminal record.

\section{Key Takeaways}

- People who practice racial or ethnic discrimination are usually also prejudiced, but not always. Some people practice discrimination without being prejudiced, and some may not practice discrimination even though they are prejudiced.

- Individual discrimination is common and can involve various kinds of racial slights. Much individual discrimination occurs in the workplace.

- Institutional discrimination often stems from prejudice, but institutions can also practice racial and ethnic discrimination when they engage in practices that seem to be racially neutral but in fact have a discriminatory effect.

\section{For Your Review}

1. If you have ever experienced individual discrimination, either as the person committing it or as the person affected by it, briefly describe what happened. How do you now feel when you reflect on this incident?

2. Do you think institutional discrimination occurs because people are purposely acting in a racially discriminatory manner? Why or why not? 


\section{References}

Appier, J. (1998). Policing women: The sexual politics of law enforcement and the LAPD. Philadelphia, PA: Temple University Press.

Blank, E. C., Venkatachalam, P., McNeil, L., \& Green, R. D. (2005). Racial discrimination in mortgage lending in Washington, DC: A mixed methods approach. The Review of Black Political Economy, 33(2), 9-30.

Ezeala-Harrison, F., Glover, G. B., \& Shaw-Jackson, J. (2008). Housing loan patterns toward minority borrowers in Mississippi: Analysis of some micro data evidence of redlining. The Review of Black Political Economy, 35(1), $43-54$.

Feagin, J. R. (1991). The continuing significance of race: Antiblack discrimination in public places. American Sociological Review, 56, 101-116.

Hirsh, C. E., \& Cha, Y. (2008). Understanding employment discrimination: A multilevel approach. Sociology Compass, 2(6), 1989-2007.

Massey, D. S., \& Denton, N. A. (1993). American apartheid: Segregation and the making of the underclass. Cambridge, MA: Harvard University Press.

Merton, R. K. (1949). Discrimination and the American creed. In R. M. MacIver (Ed.), Discrimination and national welfare (pp. 99-126). New York, NY: Institute for Religious Studies.

Pager, D. (2008). The dynamics of discrimination. In A. C. Lin \& D. R. Harris (Eds.), The colors of poverty: Why racial and ethnic disparities exist (pp. 21-51). New York, NY: Russell Sage Foundation.

Pager, D. (2003). The mark of a criminal record. American Journal of Sociology, 108, 937-975.

Robinson, E. (2012, March 23). Perils of walking while black. The Washington Post, p. A19.

Rothstein, R. (2012). Racial segregation continues, and even intensifies. Retrieved from http://www.epi.org/ publication/racial-segregation-continues-intensifies/.

Schulman, K. A., et al. (1999). The effect of race and sex on physicians' recommendations for cardiac catheterization. The New England Journal of Medicine, 340, 618-626.

Segura, D. A. (1992). Chicanas in white-collar jobs: "You have to prove yourself more.” In C. G. Ellison \& W. A. Martin (Eds.), Race and ethnic relations in the United States: Readings for the 21st century (pp. 79-88). Los Angeles, CA: Roxbury.

Smedley, B. D., Stith, A. Y., \& Nelson, A. R. (2003). Unequal treatment: Confronting racial and ethnic disparities in health care. Washington, DC: National Academies Press.

Stoll, M. A. (2008). Race, place, and poverty revisited. In A. C. Lin \& D. R. Harris (Eds.), The colors of poverty: Why racial and ethnic disparities persist (pp. 201-231). New York, NY: Russell Sage Foundation. 
117 Social Problems

Turner, M. A., Freiberg, F., Godfrey, E., Herbig, C., Levy, D. K., \& Smith, R. R. (2002). All other things being equal: A paired testing study of mortgage lending institutions. Washington, DC: Urban Institute Press. 


\subsection{Dimensions of Racial and Ethnic Inequality}

\section{Learning Objectives}

1. Describe any two manifestations of racial and ethnic inequality in the United States.

2. Explain how and why racial inequality takes a hidden toll on people of color.

3. Provide two examples of white privilege.

Racial and ethnic inequality manifests itself in all walks of life. The individual and institutional discrimination just discussed is one manifestation of this inequality. We can also see stark evidence of racial and ethnic inequality in various government statistics. Sometimes statistics lie, and sometimes they provide all too true a picture; statistics on racial and ethnic inequality fall into the latter category. Table 3.2 "Selected Indicators of Racial and Ethnic Inequality in the United States” presents data on racial and ethnic differences in income, education, and health.

Table 3.2 Selected Indicators of Racial and Ethnic Inequality in the United States

\begin{tabular}{|l|l|l|l|l|l|}
\hline & White & $\begin{array}{l}\text { African } \\
\text { American }\end{array}$ & Latino & Asian & $\begin{array}{l}\text { Native } \\
\text { American }\end{array}$ \\
\hline Median family income, 2010 (\$) & 68,818 & 39,900 & 41,102 & 76,736 & 39,664 \\
\hline Persons who are college educated, 2010 (\%) & 30.3 & 19.8 & 13.9 & 52.4 & $14.9(2008)$ \\
\hline Persons in poverty, 2010 (\%) & $\begin{array}{l}9.9 \\
\text { (non-Latino) }\end{array}$ & 27.4 & 26.6 & 12.1 & 28.4 \\
\hline $\begin{array}{l}\text { Infant mortality (number of infant deaths per 1,000 } \\
\text { births), 2006 }\end{array}$ & 5.6 & 12.9 & 5.4 & 4.6 & 8.3 \\
\hline
\end{tabular}

Sources: Data from US Census Bureau. (2012). Statistical abstract of the United States: 2012. Washington, DC: US Government Printing Office. Retrieved from http://www.census.gov/compendia/statab; US Census Bureau. (2012). American FactFinder. Retrieved from http://factfinder2.census.gov/faces/nav/jsf/pages/index.xhtml; MacDorman, M., \& Mathews, T. J. (2011). Infant Deaths-United States, 2000-2007. Morbidity and Mortality Weekly Report, 60(1), 49-51. 


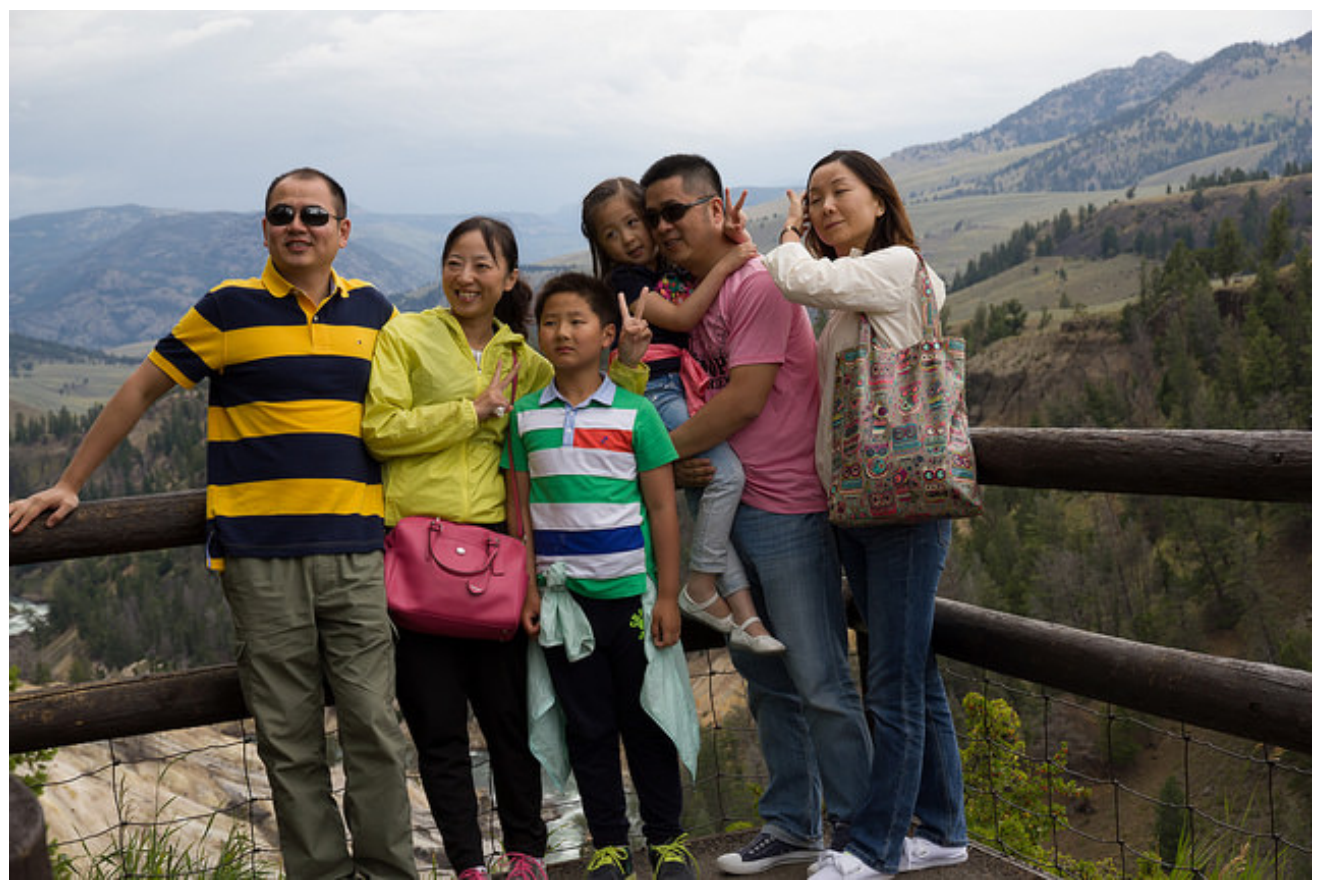

Asian Americans have higher family incomes than whites on the average. Although Asian Americans are often viewed as a "model minority," some Asians have been less able than others to achieve economic success, and stereotypes of Asians and discrimination against them remain serious problems.

LindaDee2006 - CC BY-NC-ND 2.0.

The picture presented by Table 3.2 "Selected Indicators of Racial and Ethnic Inequality in the United States" is clear: US racial and ethnic groups differ dramatically in their life chances. Compared to whites, for example, African Americans, Latinos, and Native Americans have much lower family incomes and much higher rates of poverty; they are also much less likely to have college degrees. In addition, African Americans and Native Americans have much higher infant mortality rates than whites: Black infants, for example, are more than twice as likely as white infants to die. Later chapters in this book will continue to highlight various dimensions of racial and ethnic inequality.

Although Table 3.2 "Selected Indicators of Racial and Ethnic Inequality in the United States" shows that African Americans, Latinos, and Native Americans fare much worse than whites, it presents a more complex pattern for Asian Americans. Compared to whites, Asian Americans have higher family incomes and are more likely to hold college degrees, but they also have a higher poverty rate. Thus many Asian Americans do relatively well, while others fare relatively worse, as just noted. Although Asian Americans are often viewed as a "model minority," meaning that they have achieved economic success despite not being white, some Asians have been less able than others to climb the economic ladder. Moreover, stereotypes of Asian Americans and discrimination against them remain serious problems (Chou \& Feagin, 2008). Even the overall success rate of Asian Americans obscures the fact that their occupations and incomes are often lower than would be expected from their educational attainment. They thus have to work harder for their success than whites do (Hurh \& Kim, 1999). 


\section{The Increasing Racial/Ethnic Wealth Gap}

At the beginning of this chapter, we noted that racial and ethnic inequality has existed since the beginning of the United States. We also noted that social scientists have warned that certain conditions have actually worsened for people of color since the 1960s (Hacker, 2003; Massey \& Sampson, 2009).

Recent evidence of this worsening appeared in a report by the Pew Research Center (2011). The report focused on racial disparities in wealth, which includes a family's total assets (income, savings and investments, home equity, etc.) and debts (mortgage, credit cards, etc.). The report found that the wealth gap between white households on the one hand and African American and Latino households on the other hand was much wider than just a few years earlier, thanks to the faltering US economy since 2008 that affected blacks more severely than whites.

According to the report, whites' median wealth was ten times greater than blacks' median wealth in 2007, a discouraging disparity for anyone who believes in racial equality. By 2009, however, whites' median wealth had jumped to twenty times greater than blacks' median wealth and eighteen times greater than Latinos' median wealth. White households had a median net worth of about $\$ 113,000$, while black and Latino households had a median net worth of only \$5,700 and \$6,300, respectively (see Figure 3.5 “The Racial/Ethnic Wealth Gap (Median Net Worth of Households in 2009)”). This racial and ethnic difference is the largest since the government began tracking wealth more than a quarter-century ago.

Figure 3.5 The Racial/Ethnic Wealth Gap (Median Net Worth of Households in 2009)

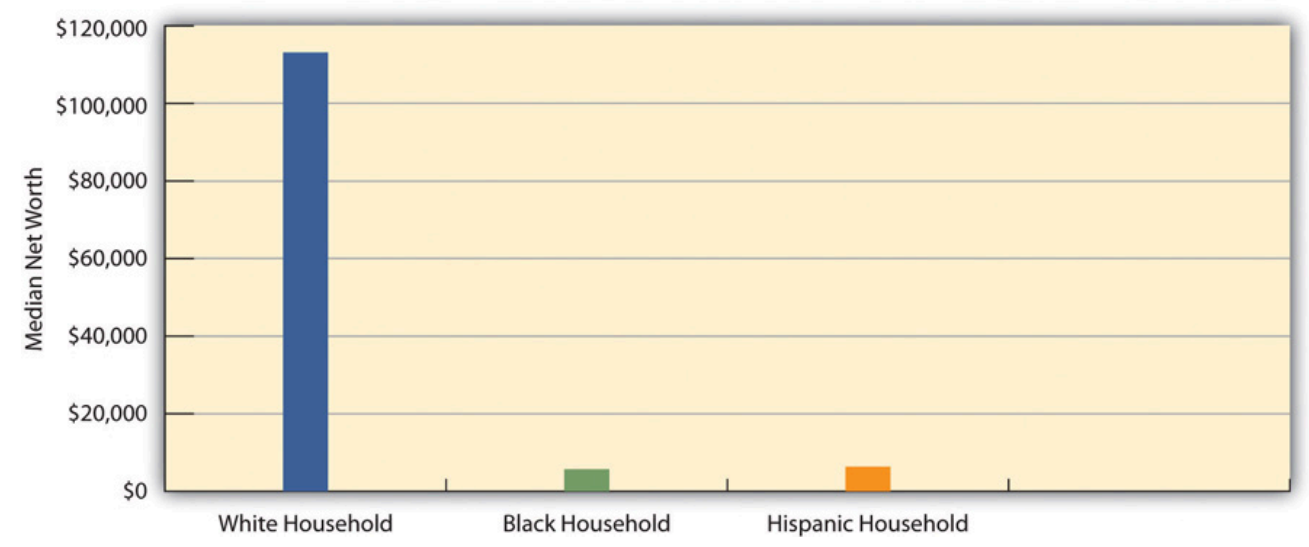

Source: Pew Research Center, 2011.

A large racial/ethnic gap also existed in the percentage of families with negative net worth-that is, those whose debts exceed their assets. One-third of black and Latino households had negative net worth, compared to only 15 percent of white households. Black and Latino households were thus more than twice as likely as white households to be in debt.

\section{The Hidden Toll of Racial and Ethnic Inequality}

An increasing amount of evidence suggests that being black in a society filled with racial prejudice, 
discrimination, and inequality takes what has been called a "hidden toll" on the lives of African Americans (Blitstein, 2009). As we shall see in later chapters, African Americans on the average have worse health than whites and die at younger ages. In fact, every year there are an additional 100,000 African American deaths than would be expected if they lived as long as whites do. Although many reasons probably explain all these disparities, scholars are increasingly concluding that the stress of being black is a major factor (Geronimus et al., 2010).

In this way of thinking, African Americans are much more likely than whites to be poor, to live in high-crime neighborhoods, and to live in crowded conditions, among many other problems. As this chapter discussed earlier, they are also more likely, whether or not they are poor, to experience racial slights, refusals to be interviewed for jobs, and other forms of discrimination in their everyday lives. All these problems mean that African Americans from their earliest ages grow up with a great deal of stress, far more than what most whites experience. This stress in turn has certain neural and physiological effects, including hypertension (high blood pressure), that impair African Americans' short-term and long-term health and that ultimately shorten their lives. These effects accumulate over time: black and white hypertension rates are equal for people in their twenties, but the black rate becomes much higher by the time people reach their forties and fifties. As a recent news article on evidence of this "hidden toll” summarized this process, “The long-term stress of living in a white-dominated society 'weathers' blacks, making them age faster than their white counterparts” (Blitstein, 2009, p. 48).

Although there is less research on other people of color, many Latinos and Native Americans also experience the various sources of stress that African Americans experience. To the extent this is true, racial and ethnic inequality also takes a hidden toll on members of these two groups. They, too, experience racial slights, live under disadvantaged conditions, and face other problems that result in high levels of stress and shorten their life spans.

\section{White Privilege: The Benefits of Being White}

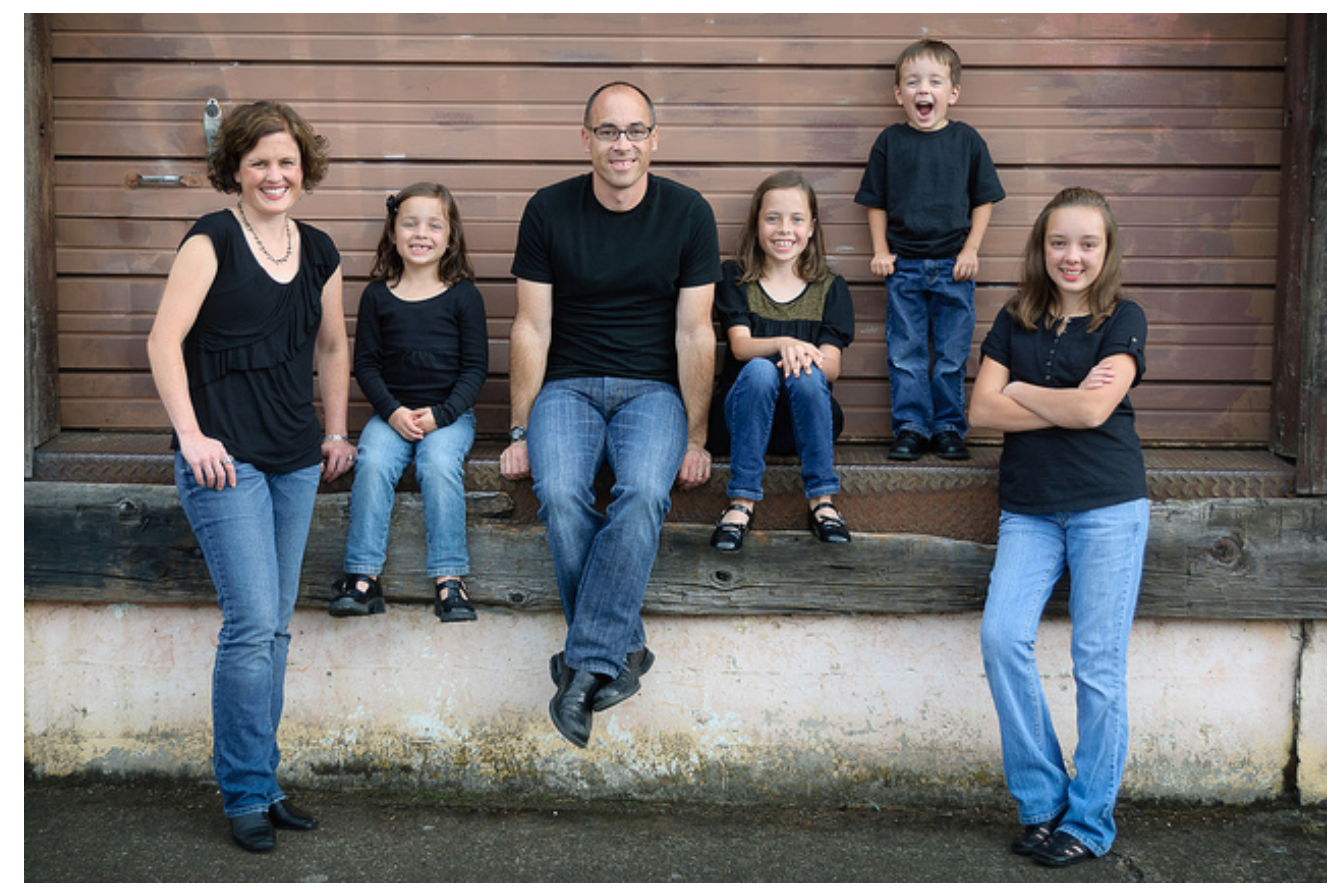


officer will stop them simply because they are white, and they also generally do not have to worry about being mistaken for a bellhop,

parking valet, or maid.

Loren Kerns - Day 73 - CC BY 2.0.

Before we leave this section, it is important to discuss the advantages that US whites enjoy in their daily lives simply because they are white. Social scientists term these advantages white privilege and say that whites benefit from being white whether or not they are aware of their advantages (McIntosh, 2007).

This chapter's discussion of the problems facing people of color points to some of these advantages. For example, whites can usually drive a car at night or walk down a street without having to fear that a police officer will stop them simply because they are white. Recalling the Trayvon Martin tragedy, they can also walk down a street without having to fear they will be confronted and possibly killed by a neighborhood watch volunteer. In addition, whites can count on being able to move into any neighborhood they desire to as long as they can afford the rent or mortgage. They generally do not have to fear being passed up for promotion simply because of their race. White students can live in college dorms without having to worry that racial slurs will be directed their way. White people in general do not have to worry about being the victims of hate crimes based on their race. They can be seated in a restaurant without having to worry that they will be served more slowly or not at all because of their skin color. If they are in a hotel, they do not have to think that someone will mistake them for a bellhop, parking valet, or maid. If they are trying to hail a taxi, they do not have to worry about the taxi driver ignoring them because the driver fears he or she will be robbed.

Social scientist Robert W. Terry (1981, p. 120) once summarized white privilege as follows: “To be white in America is not to have to think about it. Except for hard-core racial supremacists, the meaning of being white is having the choice of attending to or ignoring one's own whiteness” (emphasis in original). For people of color in the United States, it is not an exaggeration to say that race and ethnicity is a daily fact of their existence. Yet whites do not generally have to think about being white. As all of us go about our daily lives, this basic difference is one of the most important manifestations of racial and ethnic inequality in the United States.

Perhaps because whites do not have to think about being white, many studies find they tend to underestimate the degree of racial inequality in the United States by assuming that African Americans and Latinos are much better off than they really are. As one report summarized these studies' overall conclusion, "Whites tend to have a relatively rosy impression of what it means to be a black person in America. Whites are more than twice as likely as blacks to believe that the position of African Americans has improved a great deal” (Vedantam, 2008, p. A3). Because whites think African Americans and Latinos fare much better than they really do, that perception probably reduces whites' sympathy for programs designed to reduce racial and ethnic inequality.

\section{Key Takeaways}

- Compared to non-Latino whites, people of color have lower incomes, lower educational attainment, higher poverty rates, and worse health.

- Racial and ethnic inequality takes a hidden toll on people of color, as the stress they experience impairs their health and ability to achieve. 
- Whites benefit from being white, whether or not they realize it. This benefit is called white privilege.

\section{For Your Review}

1. Write a brief essay that describes important dimensions of racial and ethnic inequality in the United States.

2. If you are white, describe a time when you benefited from white privilege, whether or not you realized it at the time. If you are a person of color, describe an experience when you would have benefited if you had been white.

\section{References}

Blitstein, R. (2009). Weathering the storm. Miller-McCune, 2(July-August), 48-57.

Chou, R. S., \& Feagin, J. R. (2008). The myth of the model minority: Asian Americans facing racism. Boulder, CO: Paradigm.

Geronimus, A. T., Hicken, M., Pearson, J., Seashols, S., Brown, K., \& Cruz., T. D. (2010). Do US black women experience stress-related accelerated biological aging? Human Nature: An Interdisciplinary Biosocial Perspective, 21, 19-38.

Hacker, A. (2003). Two nations: Black and white, separate, hostile, unequal (Rev. ed.). New York, NY: Scribner.

Hurh, W. M., \& Kim, K. C. (1999). The “success” image of Asian Americans: Its validity, and its practical and theoretical implications. In C. G. Ellison \& W. A. Martin (Eds.), Race and ethnic relations in the United States (pp. 115-122). Los Angeles, CA: Roxbury.

Massey, D. S., \& Sampson, R. J. (2009). Moynihan redux: Legacies and lessons. The ANNALS of the American Academy of Political and Social Science, 621, 6-27.

McIntosh, P. (2007). White privilege and male privilege: A personal account of coming to see correspondence through work in women's studies. In M. L. Andersen \& P. H. Collins (Eds.), Race, class, and gender: An anthology (6th ed.). Belmont, CA: Wadsworth.

Pew Research Center. (2011). Twenty-to-one: Wealth gaps rise to record highs between whites, blacks and Hispanics. Washington, DC: Author.

Terry, R. W. (1981). The negative impact on white values. In B. P. Bowser \& R. G. Hunt (Eds.), Impacts of racism on white Americans (pp. 119-151). Beverly Hills, CA: Sage Publications.

Vedantam, S. (2008, March 24). Unequal perspectives on racial equality. The Washington Post, p. A3. 


\subsection{Explaining Racial and Ethnic Inequality}

\section{Learning Objectives}

1. Understand cultural explanations for racial and ethnic inequality.

2. Describe structural explanations for racial and ethnic inequality.

Why do racial and ethnic inequality exist? Why do African Americans, Latinos, Native Americans, and some Asian Americans fare worse than whites? In answering these questions, many people have some very strong opinions.

\section{Biological Inferiority}

One long-standing explanation is that blacks and other people of color are biologically inferior: They are naturally less intelligent and have other innate flaws that keep them from getting a good education and otherwise doing what needs to be done to achieve the American Dream. As discussed earlier, this racist view is no longer common today. However, whites historically used this belief to justify slavery, lynchings, the harsh treatment of Native Americans in the 1800s, and lesser forms of discrimination. In 1994, Richard J. Herrnstein and Charles Murray revived this view in their controversial book, The Bell Curve (Herrnstein \& Murray, 1994), in which they argued that the low IQ scores of African Americans, and of poor people more generally, reflect their genetic inferiority in the area of intelligence. African Americans' low innate intelligence, they said, accounts for their poverty and other problems. Although the news media gave much attention to their book, few scholars agreed with its views, and many condemned the book’s argument as a racist way of "blaming the victim” (Gould, 1994).

\section{Cultural Deficiencies}

Another explanation of racial and ethnic inequality focuses on supposed cultural deficiencies of African Americans and other people of color (Murray, 1984). These deficiencies include a failure to value hard work and, for African Americans, a lack of strong family ties, and are said to account for the poverty and other problems facing these minorities. This view echoes the culture-of-poverty argument presented in Chapter 2 "Poverty" and is certainly popular today. As we saw earlier, more than half of non-Latino whites think that blacks' poverty is due to their lack of motivation and willpower. Ironically some scholars find support for this cultural deficiency view in the experience of many Asian Americans, whose success is often attributed to their culture's emphasis on hard work, educational attainment, and strong family ties (Min, 2005). If that is true, these scholars say, then the lack of success of other people of color stems from the failure of their own cultures to value these attributes. 
How accurate is the cultural deficiency argument? Whether people of color have "deficient” cultures remains hotly debated (Bonilla-Silva, 2009). Many social scientists find little or no evidence of cultural problems in minority communities and say the belief in cultural deficiencies is an example of symbolic racism that blames the victim. Citing survey evidence, they say that poor people of color value work and education for themselves and their children at least as much as wealthier white people do (Holland, 2011; Muhammad, 2007). Yet other social scientists, including those sympathetic to the structural problems facing people of color, believe that certain cultural problems do exist, but they are careful to say that these cultural problems arise out of the structural problems. For example, Elijah Anderson (1999) wrote that a "street culture” or "oppositional culture" exists among African Americans in urban areas that contributes to high levels of violent behavior, but he emphasized that this type of culture stems from the segregation, extreme poverty, and other difficulties these citizens face in their daily lives and helps them deal with these difficulties. Thus even if cultural problems do exist, they should not obscure the fact that structural problems are responsible for the cultural ones.

\section{Structural Problems}

A third explanation for US racial and ethnic inequality is based in conflict theory and reflects the blaming-thesystem approach outlined in Chapter 1 "Understanding Social Problems". This view attributes racial and ethnic inequality to structural problems, including institutional and individual discrimination, a lack of opportunity in education and other spheres of life, and the absence of jobs that pay an adequate wage (Feagin, 2006). Segregated housing, for example, prevents African Americans from escaping the inner city and from moving to areas with greater employment opportunities. Employment discrimination keeps the salaries of people of color much lower than they would be otherwise. The schools that many children of color attend every day are typically overcrowded and underfunded. As these problems continue from one generation to the next, it becomes very difficult for people already at the bottom of the socioeconomic ladder to climb up it because of their race and ethnicity (see Note 3.33 “Applying Social Research”).

\section{Applying Social Research}

\section{The Poor Neighborhoods of Middle-Class African Americans}

In a society that values equal opportunity for all, scholars have discovered a troubling trend: African American children from middle-class families are much more likely than white children from middle-class families to move down the socioeconomic ladder by the time they become adults. In fact, almost half of all African American children born during the 1950s and 1960s to middle-class parents ended up with lower incomes than their parents by adulthood. Because these children had parents who had evidently succeeded despite all the obstacles facing them in a society filled with racial inequality, we have to assume they were raised with the values, skills, and aspirations necessary to stay in the middle class and even to rise beyond it. What, then, explains why some end up doing worse than their parents?

According to a recent study written by sociologist Patrick Sharkey for the Pew Charitable Trusts, one important answer lies in the neighborhoods in which these children are raised. Because of continuing racial segregation, many middleclass African American families find themselves having to live in poor urban neighborhoods. About half of African American children born between 1955 and 1970 to middle-class parents grew up in poor neighborhoods, but hardly any middle-class white children grew up in such neighborhoods. In Sharkey's statistical analysis, neighborhood poverty was a much more important factor than variables such as parents' education and marital status in explaining the huge racial difference in the eventual socioeconomic status of middle-class children. An additional finding of the study underscored 
the importance of neighborhood poverty for adult socioeconomic status: African American children raised in poor neighborhoods in which the poverty rate declined significantly ended up with higher incomes as adults than those raised in neighborhoods where the poverty rate did not change.

Why do poor neighborhoods have this effect? It is difficult to pinpoint the exact causes, but several probable reasons come to mind. In these neighborhoods, middle-class African American children often receive inadequate schooling at run-down schools, and they come under the influence of youths who care much less about schooling and who get into various kinds of trouble. The various problems associated with living in poor neighborhoods also likely cause a good deal of stress, which, as discussed elsewhere in this chapter, can cause health problems and impair learning ability.

Even if the exact reasons remain unclear, this study showed that poor neighborhoods make a huge difference. As a Pew official summarized the study, "We've known that neighborhood matters...but this does it in a new and powerful way. Neighborhoods become a significant drag not just on the poor, but on those who would otherwise be stable." Sociologist Sharkey added, "What surprises me is how dramatic the racial differences are in terms of the environments in which children are raised. There's this perception that after the civil rights period, families have been more able to seek out any neighborhood they choose, and that...the racial gap in neighborhoods would whittle away over time, and that hasn't happened."

Data from the 2010 Census confirm that the racial gap in neighborhoods persists. A study by sociologist John R. Logan for the Russell Sage Foundation found that African American and Latino families with incomes above \$75,000 are more likely to live in poor neighborhoods than non-Latino white families with incomes below $\$ 40,000$. More generally, Logan concluded, “The average affluent black or Hispanic household lives in a poorer neighborhood than the average lower-income white household."

One implication of this neighborhood research is clear: to help reduce African American poverty, it is important to do everything possible to improve the quality and economy of the poor neighborhoods in which many African American children, middle-class or poor, grow up.

Sources: Logan, 2011; MacGillis, 2009; Sharkey, 2009

As we assess the importance of structure versus culture in explaining why people of color have higher poverty rates, it is interesting to consider the economic experience of African Americans and Latinos since the 1990s. During that decade, the US economy thrived. Along with this thriving economy, unemployment rates for African Americans and Latinos declined and their poverty rates also declined. Since the early 2000s and especially since 2008, the US economy has faltered. Along with this faltering economy, unemployment and poverty rates for African Americans and Latinos increased.

To explain these trends, does it make sense to assume that African Americans and Latinos somehow had fewer cultural deficiencies during the 1990s and more cultural deficiencies since the early 2000s? Or does it make sense to assume that their economic success or lack of it depended on the opportunities afforded them by the US economy? Economic writer Joshua Holland (2011) provides the logical answer by attacking the idea of cultural deficiencies: "That's obviously nonsense. It was exogenous economic factors and changes in public policies, not manifestations of 'black culture' [or 'Latino culture'], that resulted in those widely varied outcomes... While economic swings this significant can be explained by economic changes and different public policies, it's simply impossible to fit them into a cultural narrative.”

\section{Key Takeaways}

- Although a belief in biological inferiority used to be an explanation for racial and ethnic inequality, this 
belief is now considered racist.

- Cultural explanations attribute racial and ethnic inequality to certain cultural deficiencies among people of color.

- Structural explanations attribute racial and ethnic inequality to problems in the larger society, including discriminatory practices and lack of opportunity.

\section{For Your Review}

1. Which of the three explanations of racial and ethnic inequality makes the most sense to you? Why?

2. Why should a belief in the biological inferiority of people of color be considered racist?

\section{References}

Anderson, E. (1999). Code of the street: Decency, violence, and the moral life of the inner city. New York, NY: W. W. Norton.

Bonilla-Silva, E. (2009). Racism without racists: Color-blind racism and the persistence of racial inequality in the United States (3rd ed.). Lanham, MD: Rowman \& Littlefield.

Feagin, J. R. (2006). Systematic racism: A theory of oppression. New York, NY: Routledge.

Gould, S. J. (1994, November 28). Curveball. The New Yorker, pp. 139-149.

Herrnstein, R. J., \& Murray, C. (1994). The bell curve: Intelligence and class structure in American life. New York, NY: Free Press.

Holland, J. (2011, July 29). Debunking the big lie right-wingers use to justify black poverty and unemployment. AlterNet. Retrieved from http://www.alternet.org/teaparty/151830/debunking the big lie rightwingers use to justify black poverty and unemployment.

Logan, J. R. (2011). Separate and unequal: The neighborhood gap for blacks, Hispanics and Asians in metropolitan America. New York, NY: US201 Project.

MacGillis, A. (2009, July 27). Neighborhoods key to future income, study finds. The Washington Post, p. A06.

Min, P. G. (Ed.). (2005). Asian Americans: Contemporary trends and issues (2nd ed.). Thousand Oaks, CA: Sage Publications.

Muhammad, K. G. (2007, December 9). White may be might, but it’s not always right. The Washington Post, p. B3. 
Murray, C. (1984). Losing ground: American social policy, 1950-1980. New York, NY: Basic Books.

Sharkey, P. (2009). Neighborhoods and the black-white mobility gap. Washington, DC: Pew Charitable Trusts. 


\subsection{Reducing Racial and Ethnic Inequality}

\section{Learning Objectives}

1. Summarize the debate over affirmative action.

2. Describe any three policies or practices that could reduce racial and ethnic inequality in the United States.

Now that we have examined race and ethnicity in the United States, what have we found? Where do we stand in the second decade of the twenty-first century? Did the historic election of Barack Obama as president in 2008 signify a new era of equality between the races, as many observers wrote, or did his election occur despite the continued existence of pervasive racial and ethnic inequality?

On the one hand, there is cause for hope. Legal segregation is gone. The vicious, "old-fashioned" racism that was so rampant in this country into the 1960s has declined dramatically since that tumultuous time. People of color have made important gains in several spheres of life, and African Americans and other people of color occupy some important elected positions in and outside the South, a feat that would have been unimaginable a generation ago. Perhaps most notably, Barack Obama has African ancestry and identifies as an African American, and on his 2008 election night people across the country wept with joy at the symbolism of his victory. Certainly progress has been made in US racial and ethnic relations.

On the other hand, there is also cause for despair. Old-fashioned racism has been replaced by a modern, symbolic racism that still blames people of color for their problems and reduces public support for government policies to deal with their problems. Institutional discrimination remains pervasive, and hate crimes, such as the cross burning that began this chapter, remain all too common. So does suspicion of people based solely on the color of their skin, as the Trayvon Martin tragedy again reminds us.

If adequately funded and implemented, several types of programs and policies show strong promise of reducing racial and ethnic inequality. We turn to these in a moment, but first let's discuss affirmative action, an issue that has aroused controversy since its inception.

\section{People Making a Difference}

College Students and the Southern Civil Rights Movement

The first chapter of this book included this famous quotation by anthropologist Margaret Mead: "Never doubt that a small group of thoughtful, committed citizens can change the world. Indeed, it is the only thing that ever has." The beginnings of the Southern civil rights movement provide an inspirational example of Mead's wisdom and remind us that young people can make a difference.

Although there had been several efforts during the 1950s by African Americans to end legal segregation in the South, 
the start of the civil rights movement is commonly thought to have begun on February 1, 1960. On that historic day, four brave African American students from the Agricultural and Technical College of North Carolina, dressed in coats and ties, sat down quietly at a segregated lunch counter in a Woolworth's store in the city of Greensboro and asked to be served. When they were refused service, they stayed until the store closed at the end of the day, and then went home. They returned the next day and were joined by some two dozen other students. They were again refused service and sat quietly the rest of the day. The next day some sixty students and other people joined them, followed by some three hundred on the fourth day. Within a week, sit-ins were occurring at lunch counters in several other towns and cities inside and outside of North Carolina. In late July, 1960, the Greensboro Woolworth's finally served African Americans, and the entire Woolworth's chain desegregated its lunch counters a day later. Although no one realized it at the time, the civil rights movement had "officially” begun thanks to the efforts of a small group of college students.

During the remaining years of the heyday of the civil rights movement, college students from the South and North joined thousands of other people in sit-ins, marches, and other activities to end legal segregation. Thousands were arrested, and at least forty-one were murdered. By risking their freedom and even their lives, they made a difference for millions of African Americans. And it all began when a small group of college students sat down at a lunch counter in Greensboro and politely refused to leave until they were served.

Sources: Branch, 1988; Southern Poverty Law Center, 2011

\section{Affirmative Action}

Affirmative action refers to special consideration for minorities and women in employment and education to compensate for the discrimination and lack of opportunities they experience in the larger society. Affirmative action programs were begun in the 1960s to provide African Americans and, later, other people of color and women access to jobs and education to make up for past discrimination. President John F. Kennedy was the first known official to use the term, when he signed an executive order in 1961 ordering federal contractors to "take affirmative action" in ensuring that applicants are hired and treated without regard to their race and national origin. Six years later, President Lyndon B. Johnson added sex to race and national origin as demographic categories for which affirmative action should be used.

Although many affirmative action programs remain in effect today, court rulings, state legislation, and other efforts have limited their number and scope. Despite this curtailment, affirmative action continues to spark much controversy, with scholars, members of the public, and elected officials all holding strong views on the issue.

One of the major court rulings just mentioned was the US Supreme Court's decision in Regents of the University of California v. Bakke, 438 US 265 (1978). Allan Bakke was a 35-year-old white man who had twice been rejected for admission into the medical school at the University of California, Davis. At the time he applied, UC-Davis had a policy of reserving sixteen seats in its entering class of one hundred for qualified people of color to make up for their underrepresentation in the medical profession. Bakke's college grades and scores on the Medical College Admission Test were higher than those of the people of color admitted to UC-Davis either time Bakke applied. He sued for admission on the grounds that his rejection amounted to reverse racial discrimination on the basis of his being white (Stefoff, 2005).

The case eventually reached the Supreme Court, which ruled 5-4 that Bakke must be admitted into the UC-Davis medical school because he had been unfairly denied admission on the basis of his race. As part of its historic but complex decision, the Court thus rejected the use of strict racial quotas in admission, as it declared that no 
applicant could be excluded based solely on the applicant's race. At the same time, however, the Court also declared that race may be used as one of the several criteria that admissions committees consider when making their decisions. For example, if an institution desires racial diversity among its students, it may use race as an admissions criterion along with other factors such as grades and test scores.

Two more recent Supreme Court cases both involved the University of Michigan: Gratz v. Bollinger, 539 US 244 (2003), which involved the university's undergraduate admissions, and Grutter v. Bollinger, 539 US 306 (2003), which involved the university's law school admissions. In Grutter the Court reaffirmed the right of institutions of higher education to take race into account in the admissions process. In Gratz, however, the Court invalidated the university's policy of awarding additional points to high school students of color as part of its use of a point system to evaluate applicants; the Court said that consideration of applicants needed to be more individualized than a point system allowed.

Drawing on these Supreme Court rulings, then, affirmative action in higher education admissions on the basis of race/ethnicity is permissible as long as it does not involve a rigid quota system and as long as it does involve an individualized way of evaluating candidates. Race may be used as one of several criteria in such an individualized evaluation process, but it must not be used as the only criterion.

\section{The Debate over Affirmative Action}

Opponents of affirmative action cite several reasons for opposing it (Connors, 2009). Affirmative action, they say, is reverse discrimination and, as such, is both illegal and immoral. The people benefiting from affirmative action are less qualified than many of the whites with whom they compete for employment and college admissions. In addition, opponents say, affirmative action implies that the people benefiting from it need extra help and thus are indeed less qualified. This implication stigmatizes the groups benefiting from affirmative action.

In response, proponents of affirmative action give several reasons for favoring it (Connors, 2009). Many say it is needed to make up not just for past discrimination and a lack of opportunities for people of color but also for ongoing discrimination and a lack of opportunity. For example, because of their social networks, whites are much better able than people of color to find out about and to get jobs (Reskin, 1998). If this is true, people of color are automatically at a disadvantage in the job market, and some form of affirmative action is needed to give them an equal chance at employment. Proponents also say that affirmative action helps add diversity to the workplace and to the campus. Many colleges, they note, give some preference to high school students who live in a distant state in order to add needed diversity to the student body; to "legacy" students-those with a parent who went to the same institution - to reinforce alumni loyalty and to motivate alumni to donate to the institution; and to athletes, musicians, and other applicants with certain specialized talents and skills. If all these forms of preferential admission make sense, proponents say, it also makes sense to take students' racial and ethnic backgrounds into account as admissions officers strive to have a diverse student body.

Proponents add that affirmative action has indeed succeeded in expanding employment and educational opportunities for people of color, and that individuals benefiting from affirmative action have generally fared well in the workplace or on the campus. In this regard research finds that African American students graduating from selective US colleges and universities after being admitted under affirmative action guidelines are slightly more 
likely than their white counterparts to obtain professional degrees and to become involved in civic affairs (Bowen \& Bok, 1998).

As this brief discussion indicates, several reasons exist for and against affirmative action. A cautious view is that affirmative action may not be perfect but that some form of it is needed to make up for past and ongoing discrimination and lack of opportunity in the workplace and on the campus. Without the extra help that affirmative action programs give disadvantaged people of color, the discrimination and other difficulties they face are certain to continue.

\section{Other Programs and Policies}

As indicated near the beginning of this chapter, one message from DNA evidence and studies of evolution is that we are all part of one human race. If we fail to recognize this lesson, we are doomed to repeat the experiences of the past, when racial and ethnic hostility overtook good reason and subjected people who happened to look different from the white majority to legal, social, and violent oppression. In the democracy that is America, we must try to do better so that there will truly be "liberty and justice for all."

As the United States attempts, however haltingly, to reduce racial and ethnic inequality, sociology has much insight to offer in its emphasis on the structural basis for this inequality. This emphasis strongly indicates that racial and ethnic inequality has much less to do with any personal faults of people of color than with the structural obstacles they face, including ongoing discrimination and lack of opportunity. Efforts aimed at such obstacles, then, are in the long run essential to reducing racial and ethnic inequality (Danziger, Reed, \& Brown, 2004; Syme, 2008; Walsh, 2011). Some of these efforts resemble those for reducing poverty discussed in Chapter 2 "Poverty", given the greater poverty of many people of color, and include the following:

1. Adopt a national "full employment” policy involving federally funded job training and public works programs.

2. Increase federal aid for the working poor, including earned income credits and child-care subsidies for those with children.

3. Establish and expand well-funded early childhood intervention programs, including home visitation by trained professionals, for poor families, as well as adolescent intervention programs, such as Upward Bound, for low-income teenagers.

4. Improve the schools that poor children attend and the schooling they receive, and expand early childhood education programs for poor children.

5. Provide better nutrition and health services for poor families with young children.

6. Strengthen efforts to reduce teenage pregnancies.

7. Strengthen affirmative action programs within the limits imposed by court rulings.

8. Strengthen legal enforcement of existing laws forbidding racial and ethnic discrimination in hiring and promotion.

9. Strengthen efforts to reduce residential segregation. 


\section{Key Takeaways}

- There is reason to be both hopeful and less hopeful in regard to the future of racial and ethnic relations and inequality in the United States.

- Affirmative action continues to be a very controversial issue. Proponents think it is necessary to compensate for past and continuing racial and ethnic discrimination and lack of opportunity, while opponents think it discriminates against qualified whites.

- A variety of policies and practices hold strong potential for reducing racial and ethnic inequality, providing they are adequately funded and successfully implemented.

\section{For Your Review}

1. How hopeful are you in regard to the future of race and ethnicity in the United States? Explain your answer.

2. Do you favor or oppose affirmative action? Why?

\section{References}

Bowen, W. G., \& Bok, D. C. (1998). The shape of the river: Long-term consequences of considering race in college and university admissions. Princeton, NJ: Princeton University Press.

Branch, T. (1988). Parting the waters: America in the King years, 1954-1963. New York, NY: Simon \& Schuster.

Connors, P. (Ed.). (2009). Affirmative action. Farmington Hills, MI: Greenhaven Press.

Danziger, S., Reed, D., \& Brown, T. N. (2004). Poverty and prosperity: Prospects for reducing racial economic disparities in the United States. Geneva, Switzerland: United Nations Research Institute for Social Development.

Reskin, B. F. (1998). Realities of affirmative action in employment. Washington, DC: American Sociological Association.

Southern Poverty Law Center. (2011). 41 lives for freedom. Retrieved from http://www.crmvet.org/mem/ 41lives.htm.

Stefoff, R. (2005). The Bakke case: Challenging affirmative action. New York, NY: Marshall Cavendish Benchmark.

Syme, S. L. (2008). Reducing racial and social-class inqualities in health: The need for a new approach. Health Affairs, 27, 456-459. 
Walsh, R. (2011). Helping or hurting: Are adolescent intervention programs minimizing racial inequality? Education \& Urban Society, 43(3), 370-395. 


\subsection{End-of-Chapter Material}

\section{Summary}

1. Racial and ethnic prejudice and discrimination have been an "American dilemma" in the United States ever since the colonial period. Slavery was only the ugliest manifestation of this dilemma. The urban riots of the 1960s led to warnings about the racial hostility and discrimination confronting African Americans and other groups, and these warnings continue down to the present.

2. Social scientists today tend to consider race more of a social category than a biological one for several reasons. Race is thus best considered a social construction and not a fixed biological category.

3. Ethnicity refers to a shared cultural heritage and is a term increasingly favored by social scientists over race. Membership in ethnic groups gives many people an important sense of identity and pride but can also lead to hostility toward people in other ethnic groups.

4. Prejudice, racism, and stereotypes all refer to negative attitudes about people based on their membership in racial or ethnic categories. Social-psychological explanations of prejudice focus on scapegoating and authoritarian personalities, while sociological explanations focus on conformity and socialization or on economic and political competition. Jim Crow racism has given way to modern or symbolic racism that considers people of color to be culturally inferior.

5. Discrimination and prejudice often go hand in hand, but not always. People can discriminate without being prejudiced, and they can be prejudiced without discriminating. Individual and institutional discrimination both continue to exist in the United States.

6. Racial and ethnic inequality in the United States is reflected in income, employment, education, and health statistics. In their daily lives, whites enjoy many privileges denied to their counterparts in other racial and ethnic groups.

7. On many issues Americans remain sharply divided along racial and ethnic lines. One of the most divisive issues is affirmative action. Its opponents view it among other things as reverse discrimination, while its proponents cite many reasons for its importance, including the need to correct past and present discrimination against racial and ethnic minorities.

\section{Using What You Know}

After graduating college, you obtain a job in a medium-sized city in the Midwest and rent an apartment in a house in a nearby town. A family with an African American father and white mother has recently moved into a house down the street. You think nothing of it, but you begin to hear some of the neighbors expressing concern that the neighborhood "has begun to change." Then one night a brick is thrown through the window of the new family's home, and around the brick is wrapped the message, “Go back to where you came from!” Since you're new to the neighborhood yourself, you don't want to make waves, but you are also shocked by this act of racial hatred. You can speak up somehow or you can stay quiet. What do you decide to do? Why? 


\section{What You Can Do}

To help reduce racial and ethnic inequality, you may wish to do any of the following:

1. Contribute money to a local, state, or national organization that tries to help youths of color at their schools, homes, or other venues.

2. Volunteer for an organization that focuses on policy issues related to race and ethnicity.

3. Volunteer for any programs at your campus that aim at enhancing the educational success of new students of color; if no such programs exist, start one. 


\section{Chapter 4: Gender Inequality}

\section{Social Problems in the News}

“\$3.2M Awarded in Harassment Suit against Ex-Judge,” the headline said. A federal jury in Houston, Texas, awarded $\$ 3.2$ million to three women, all county employees, who had accused a former judge of sexual harassment. Their suit said the judge had "hugged, groped, kissed and fondled them and had emailed them sexually explicit photographs," according to a news report, and that county officials had ignored the judge's behavior despite their knowledge of it. The judge had resigned his position three years earlier after pleading no contest to several charges of misdemeanor assault related to his physical contact with several women. His only criminal penalty was to pay a fine of less than $\$ 3,000$.

After the verdict was announced, the plaintiffs' attorney said, “I am very proud of this verdict, and hope it sends a message to all public officials that they are not above the law and should think twice before abusing power." One of the plaintiffs recalled what it was like to have been harassed by the judge: "I felt alone, I felt small, I felt like he was the most powerful man in Brazoria County. I felt like there was nothing I could do. I felt scared.” At the same time, she was encouraged by the jury's verdict and the fact that other women had come forward to speak out about the judge's behavior: "You don’t have to go through it alone. You can stand up for yourself."

Sources: Cisneros, 2011; Tolson, 2011

Thanks to the contemporary women's rights movement that began in the late 1960s, much has changed for women and men in American society during the past half-century. Still, as this news story about sexual harassment reminds us, much more still needs to be done. Despite tremendous advancements for women since the 1960s, gender inequality persists and manifests itself in many ways. This chapter examines the major forms of gender inequality and the reasons for its existence, and it outlines various steps our society should take to help ensure equality between the sexes. Our discussion begins with a critical look at the concepts of sex and gender.

\section{References}

Cisneros, C. (2011, July 15). \$3.2M settlement awarded in sexual harassment case. KTRK-TV. Retrieved from http://abclocal.go.com/ktrk/story?section=news/local\&id=8253455.

Tolson, M. (2011, July 15). \$3.2M awarded in harassment suit against ex-judge. Houston Chronicle. Retrieved from http://www.chron.com/disp/story.mpl/metropolitan/7655717.html. 


\subsection{Understanding Sex and Gender}

\section{Learning Objectives}

1. Define sex, gender, femininity, and masculinity.

2. Critically assess the evidence on biology, culture and socialization, and gender.

3. Discuss agents of gender socialization.

Although the terms sex and gender are sometimes used interchangeably and do complement each other, they nonetheless refer to different aspects of what it means to be a woman or man in any society.

$\underline{\text { Sex }}$ refers to the anatomical and other biological differences between females and males that are determined at the moment of conception and develop in the womb and throughout childhood and adolescence. Females, of course, have two X chromosomes, while males have one X chromosome and one Y chromosome. From this basic genetic difference spring other biological differences. The first to appear are the genitals that boys and girls develop in the womb and that the doctor (or midwife) and parents look for when a baby is born (assuming the baby's sex is not already known from ultrasound or other techniques) so that the momentous announcement, "It's a boy!" or "It's a girl!" can be made. The genitalia are called primary sex characteristics, while the other differences that develop during puberty are called secondary sex characteristics and stem from hormonal differences between the two sexes. Boys generally acquire deeper voices, more body hair, and more muscles from their flowing testosterone. Girls develop breasts and wider hips and begin menstruating as nature prepares them for possible pregnancy and childbirth. For better or worse, these basic biological differences between the sexes affect many people's perceptions of what it means to be female or male, as we next discuss. 


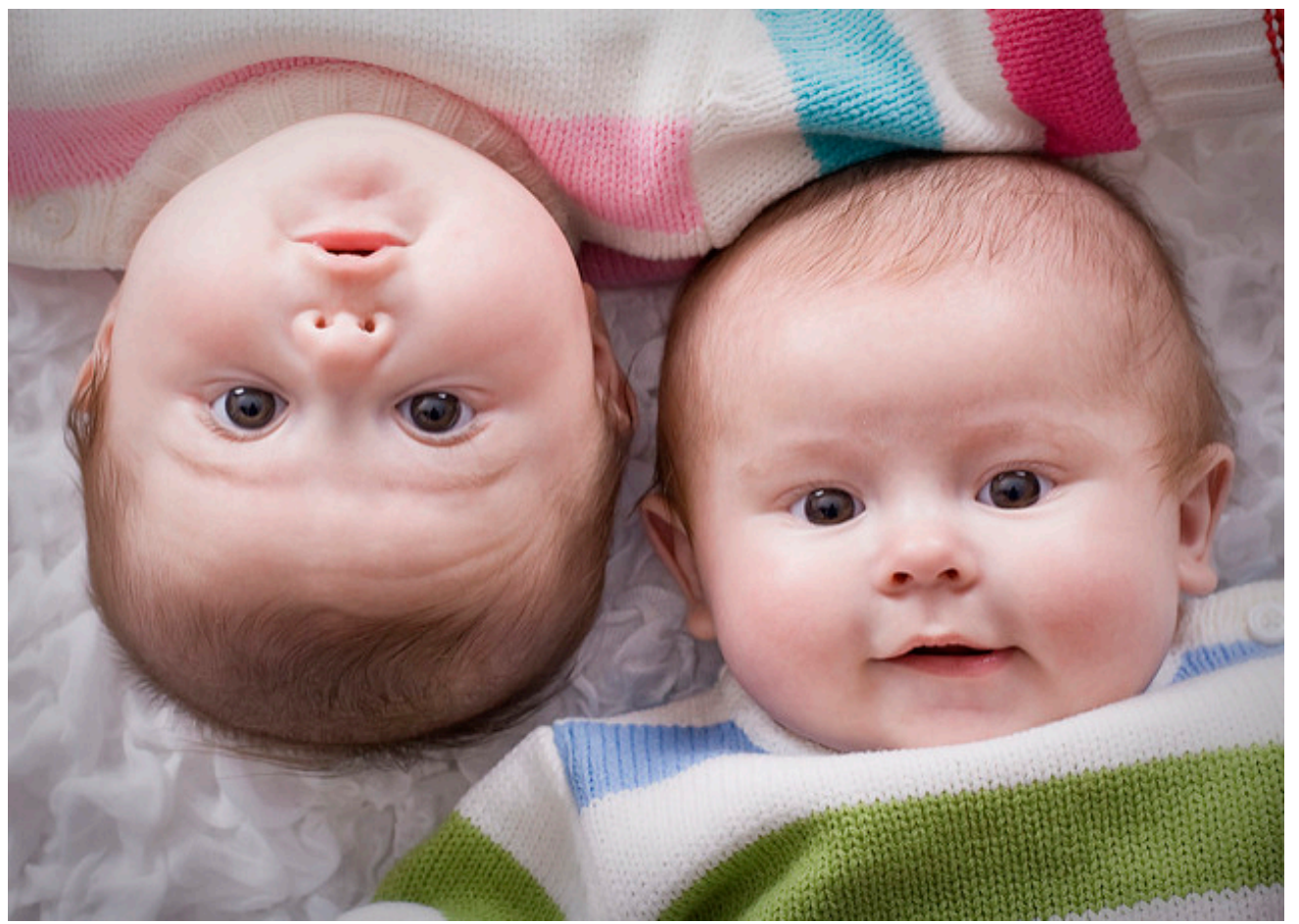

Babies are born with anatomical and other biological differences that are determined at the moment of conception. These biological differences define the baby's sex.

Abby Bischoff - CC BY-NC-ND 2.0.

\section{Gender as a Social Construction}

If sex is a biological concept, then gender is a social concept. It refers to the social and cultural differences a society assigns to people based on their (biological) sex. A related concept, gender roles, refers to a society's expectations of people's behavior and attitudes based on whether they are females or males. Understood in this way, gender, like race as discussed in Chapter 3 "Racial and Ethnic Inequality", is a social construction. How we think and behave as females and males is not etched in stone by our biology but rather is a result of how society expects us to think and behave based on what sex we are. As we grow up, we learn these expectations as we develop our gender identity, or our beliefs about ourselves as females or males.

These expectations are called femininity and masculinity. Femininity refers to the cultural expectations we have of girls and women, while masculinity refers to the expectations we have of boys and men. A familiar nursery rhyme nicely summarizes these two sets of traits: 


\footnotetext{
What are little boys made of?

Snips and snails,

And puppy dog tails,

That's what little boys are made of.

What are little girls made of?

Sugar and spice,

And everything nice,

That's what little girls are made of.
}

As this rhyme suggests, our traditional notions of femininity and masculinity indicate that we think females and males are fundamentally different from each other. In effect, we think of them as two sides of the same coin of being human. What we traditionally mean by femininity is captured in the adjectives, both positive and negative, we traditionally ascribe to women: gentle, sensitive, nurturing, delicate, graceful, cooperative, decorative, dependent, emotional, passive, and weak. Thus when we say that a girl or woman is very feminine, we have some combination of these traits in mind: she is soft, dainty, pretty, and even a bit flighty. What we traditionally mean by masculinity is captured in the adjectives, again both positive and negative, our society traditionally ascribes to men: strong, assertive, brave, active, independent, intelligent, competitive, insensitive, unemotional, and aggressive. When we say that a boy or man is very masculine, we have some combination of these traits in mind: he is tough, strong, and assertive.

These traits might sound like stereotypes of females and males in today's society, and to some extent they are, but differences between women and men in attitudes and behavior do in fact exist (Aulette \& Wittner, 2011). For example, women cry more often than men do. Men are more physically violent than women. Women take care of children more than men do. Women smile more often than men. Men curse and spit more often than women. When women talk with each other, they are more likely to talk about their personal lives than men are when they talk with each other. The two sexes even differ when they hold a cigarette (not that anyone should smoke!). When a woman holds a cigarette, she usually has the palm of her cigarette-holding hand facing upward; when a man holds a cigarette, he usually has his palm facing downward.

\section{The Development of Gender Differences}

What accounts for differences in female and male behavior and attitudes? Do the biological differences between the sexes account for these other differences? Or do these latter differences stem, as most sociologists think, from cultural expectations and from differences in the ways in which the sexes are socialized? These are critical questions, for they ask whether the differences between boys and girls and women and men stem more from biology or from society. If we think behavioral and other differences between the sexes are due primarily to their respective biological makeups, we imply that these differences are inevitable or nearly so and that any attempt to change them goes against biology and will likely fail.

For example, consider the obvious biological fact that women bear and nurse children and men do not. Couple this 
with the common view that women are also more gentle and nurturing than men, and we end up with a "biological recipe" for women to be the primary caretakers of children. Many people think this means women are therefore much better suited than men to take care of children once they are born, and that the family might be harmed if mothers work outside the home or if fathers are the primary caretakers. Figure 4.1 "Belief That Women Should Stay at Home" shows that more than one-third of the public agrees that "it is much better for everyone involved if the man is the achiever outside the home and the woman takes care of the home and family.” To the extent this belief exists, women may not want to work outside the home or, if they choose to do so, they then face difficulties from employers, family, and friends. Conversely, men may not even think about wanting to stay at home and may themselves face difficulties from employees, family, and friends if they want to do so. A belief in a strong biological basis for differences between women and men implies, then, that there is little we can or should do to change these differences. It implies that “anatomy is destiny,” and destiny is, of course, by definition inevitable.

Figure 4.1 Belief That Women Should Stay at Home

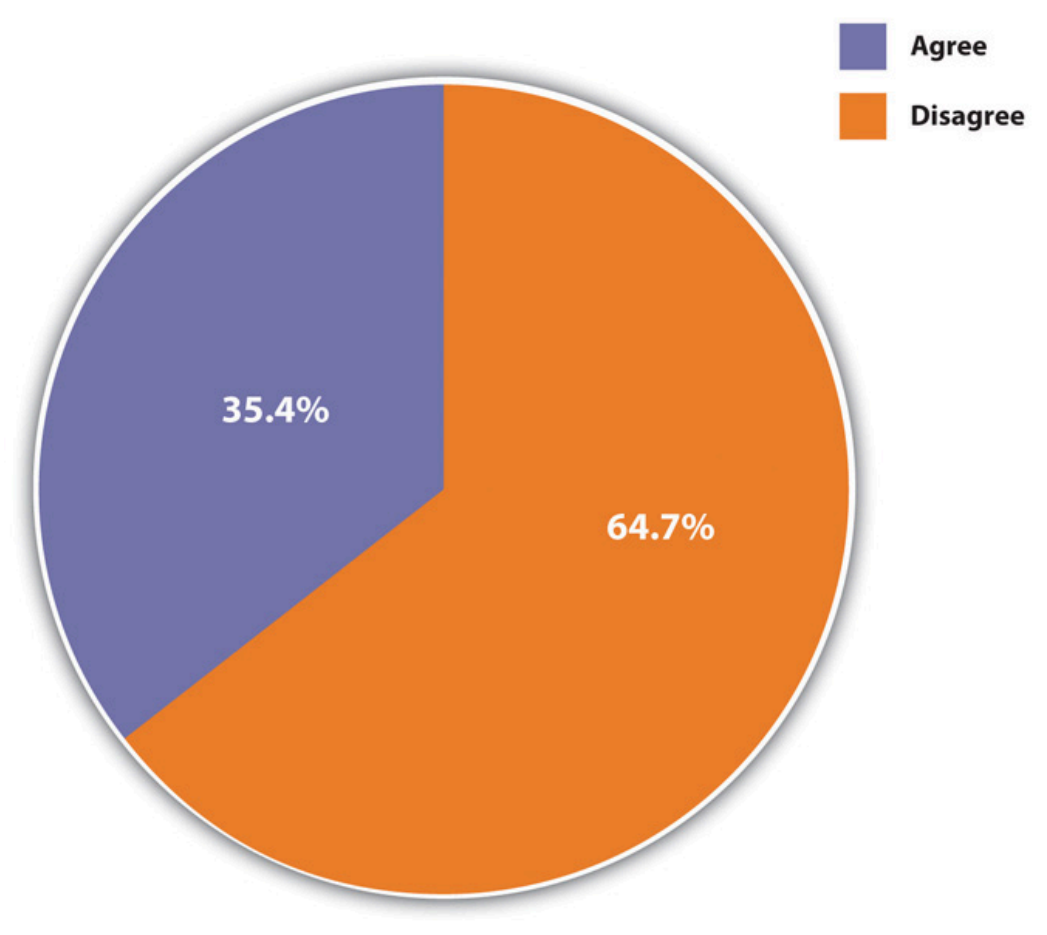

Agreement or disagreement with the statement that "it is much better for everyone involved if the man is
the achiever outside the home and the woman takes care of the home and family."
Source: Data from General Social Survey. (2010). Retrieved from http://sda.berkeley.edu/cgi-bin/
hsda?harcsda+gss10.

This implication makes it essential to understand the extent to which gender differences do, in fact, stem from biological differences between the sexes or, instead, stem from cultural and social influences. If biology is paramount, then gender differences are perhaps inevitable and the status quo will remain. If culture and social influences matter much more than biology, then gender differences can change and the status quo may give way. With this backdrop in mind, let's turn to the biological evidence for behavioral and other differences between the sexes and then examine the evidence for their social and cultural roots. 


\section{Biology and Gender}

Several biological explanations for gender roles exist, and we discuss two of the most important ones here. One explanation is from the field of evolutionary psychology (Buss, 2012) and argues an evolutionary basis for traditional gender roles.

Scholars advocating this view reason as follows (Thornhill \& Gangestad, 2008). In prehistoric societies, two major social roles existed (1) hunting or gathering food to relieve hunger, and (2) bearing and nursing children. Because only women could perform the latter role, they were also the primary caretakers for children for several years after birth. And because women were frequently pregnant, their roles as mothers confined them to the home. Meanwhile, men were better suited than women for hunting because they were stronger and quicker than women. In prehistoric societies, then, biology was indeed destiny: For biological reasons, men in effect worked outside the home (hunted), while women stayed at home with their children.

Evolutionary reasons also explain why men are more violent than women. In prehistoric times, men who were more willing to commit violence against and even kill other men would "win out" in the competition for female mates. They thus were more likely than less violent men to produce offspring, who would then carry these males' genetic violent tendencies.

If the human race evolved along these lines, evolutionary psychologists continue, natural selection favored those societies where men were stronger, braver, and more aggressive and where women were more fertile and nurturing. Such traits over the millennia became fairly instinctual, meaning that men's and women's biological natures evolved differently. Men became, by nature, more assertive, daring, and violent than women, and women became, by nature, more gentle, nurturing, and maternal than men. To the extent this is true, these scholars add, traditional gender roles for women and men make sense from an evolutionary standpoint, and attempts to change them go against the sexes' biological natures. This in turn implies that existing gender inequality must continue because it is rooted in biology. The title of a book presenting the evolutionary psychology argument summarizes this implication: "Biology at Work: Rethinking Sexual Equality” (Browne, 2002). 


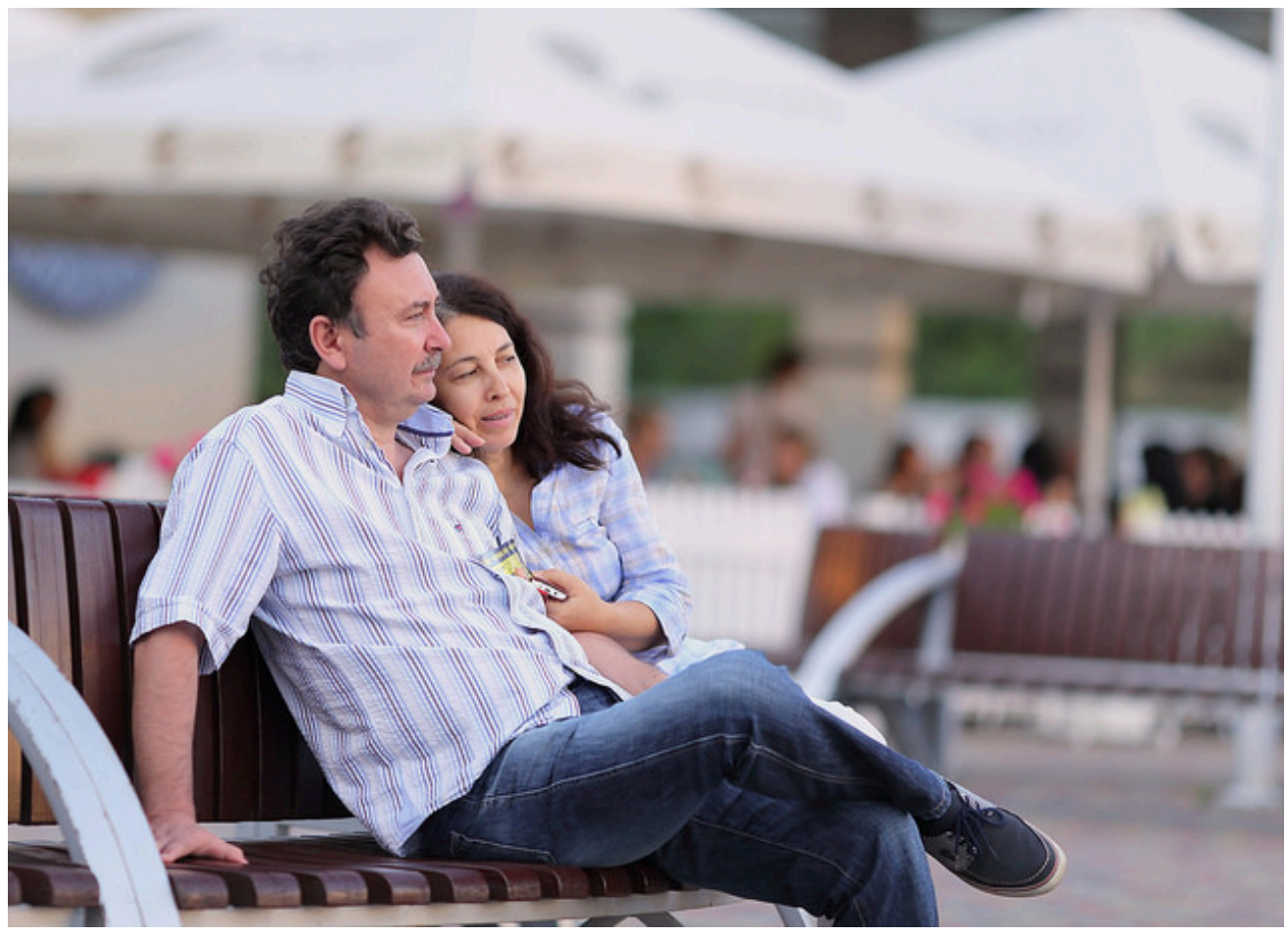

According to some evolutionary psychologists, today's gender differences in strength and physical aggression are ultimately rooted in certain evolutionary processes that spanned millennia.

Vladimir Pustovit - Couple - CC BY 2.0.

Critics challenge the evolutionary explanation on several grounds (Begley, 2009; Fine, 2011). First, much greater gender variation in behavior and attitudes existed in prehistoric times than the evolutionary explanation assumes. Second, even if biological differences did influence gender roles in prehistoric times, these differences are largely irrelevant in modern societies, in which, for example, physical strength is not necessary for survival. Third, human environments throughout the millennia have simply been too diverse to permit the simple, straightforward biological development that the evolutionary explanation assumes. Fourth, evolutionary arguments implicitly justify existing gender inequality by implying the need to confine women and men to their traditional roles.

Recent anthropological evidence also challenges the evolutionary argument that men's tendency to commit violence was biologically transmitted. This evidence instead finds that violent men have trouble finding female mates who would want them and that the female mates they find and the children they produce are often killed by rivals to the men (Begley, 2009).

A second biological explanation for traditional gender roles attributes males' higher levels of aggression to their higher levels of testosterone (Mazur, 2009). Several studies find that males with higher levels of testosterone tend to have higher levels of aggression. However, this correlation does not necessarily mean that their testosterone increased their violence; as has been found in various animal species, it is also possible that their violence increased their testosterone. Because studies of human males cannot for ethical and practical reasons manipulate their testosterone levels, the exact meaning of the results from these testosterone-aggression studies must remain unclear, according to a report by the National Academy of Sciences (Miczek, Mirsky, Carey, DeBold, \& Raine, 1994). 
Another line of research on the biological basis for sex differences in aggression involves children, including some as young as ages 1 or 2, in various situations (Card, Stucky, Sawalani, \& Little, 2008). They might be playing with each other, interacting with adults, or writing down solutions to hypothetical scenarios given to them by a researcher. In most of these studies, boys are more physically aggressive in thought or deed than girls, even at a very young age. Other studies are more experimental in nature. In one type of study, a toddler will be playing with a toy, only to have it removed by an adult. Boys typically tend to look angry and try to grab the toy back, while girls tend to just sit there and whimper. Because these gender differences in aggression are found at very young ages, researchers often say they must have some biological basis. However, critics of this line of research counter that even young children have already been socialized along gender lines (Begley, 2009; Fine, 2011), a point to which we return later in the chapter. To the extent this is true, gender differences in children's aggression may reflect socialization rather than biology.

In sum, biological evidence for gender differences certainly exists, but its interpretation remains very controversial. It must be weighed against the evidence, to which we next turn, of cultural variations in the experience of gender and of socialization differences by gender. One thing is clear: To the extent we accept biological explanations for gender, we imply that existing gender differences and gender inequality must continue to exist. As sociologist Linda L. Lindsey (2011, p. 52) notes, "Biological arguments are consistently drawn upon to justify gender inequality and the continued oppression of women.” In contrast, cultural and social explanations of gender differences and gender inequality promise some hope for change. Let's examine the evidence for these explanations.

\section{Culture and Gender}

Some of the most compelling evidence against a strong biological determination of gender roles comes from anthropologists, whose work on preindustrial societies demonstrates some striking gender variation from one culture to another. This variation underscores the impact of culture on how females and males think and behave.

Extensive evidence of this impact comes from anthropologist George Murdock (1937), who created the Standard Cross-Cultural Sample of almost two hundred preindustrial societies studied by anthropologists. Murdock found that some tasks in these societies, such as hunting and trapping, are almost always done by men, while other tasks, such as cooking and fetching water, are almost always done by women. These patterns provide evidence for the evolutionary argument presented earlier, as they probably stem from the biological differences between the sexes. Even so, there were at least some societies in which women hunted and in which men cooked and fetched water. 


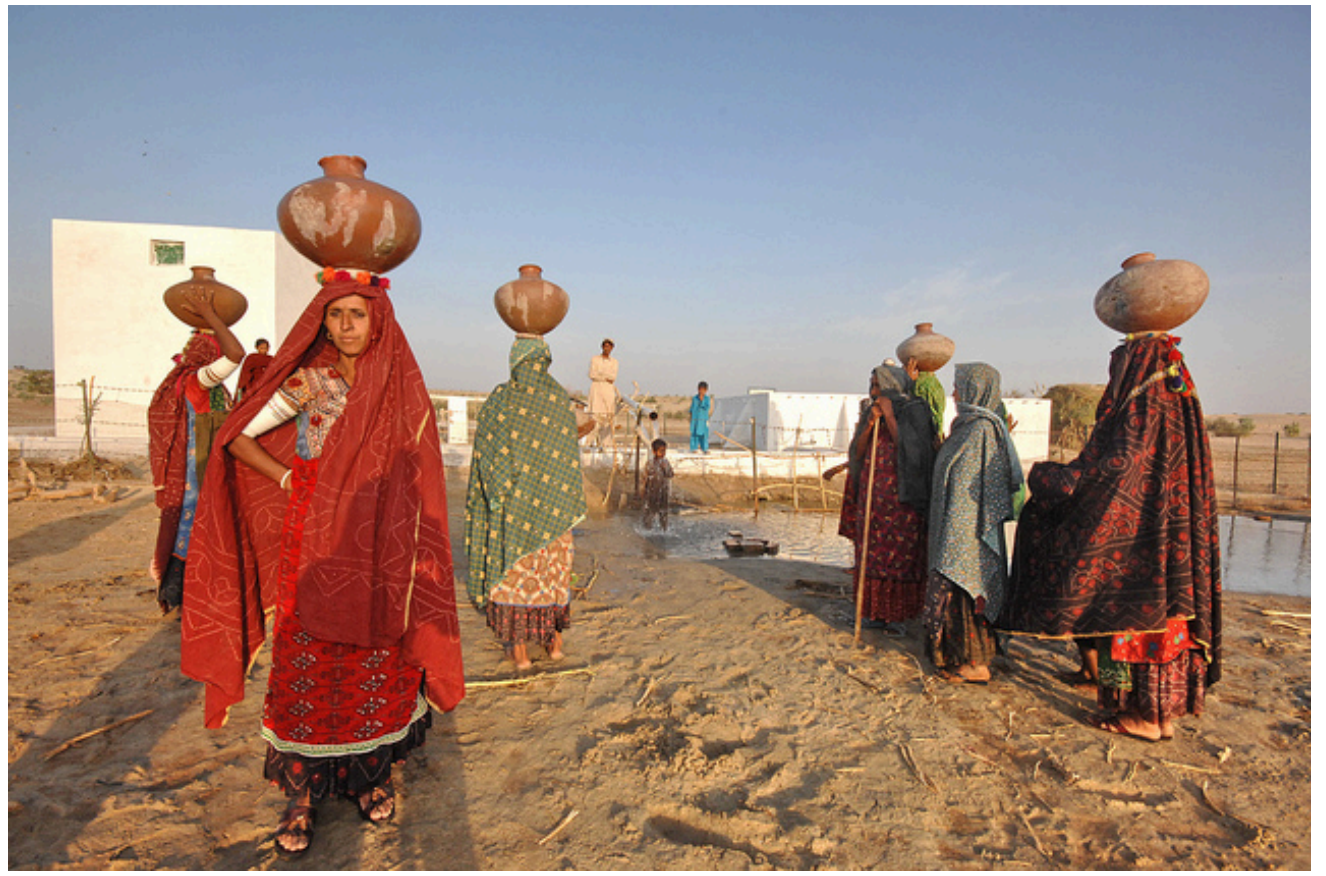

Anthropological research finds a good deal of variation in gender roles for certain tasks, including planting crops, milking, and generating fires. Other tasks, such as hunting and trapping, are typically done by men while tasks such as cooking and fetching water are typically done by women.

World Bank Photo Collection - Somo Samo village well - CC BY-NC-ND 2.0.

More important, Murdock found much greater gender variation in several of the other tasks he studied, including planting crops, milking, and generating fires. Men primarily performed these tasks in some societies, women primarily performed them in other societies, and in still other societies both sexes performed them equally. Murdock's findings illustrate how gender roles differ from one culture to another and imply they are not biologically determined.

Anthropologists continue to investigate cultural differences in gender. Some of their most interesting findings concern gender and sexuality (Brettell \& Sargent, 2009). Although all societies distinguish "femaleness" and "maleness," additional gender categories exist in some societies. The Native Americans known as the Mohave, for example, recognize four genders: a woman, a woman who acts like a man, a man, and a man who acts like a woman. In some societies, a third, intermediary gender category is recognized. Anthropologists call this category the berdache, who is usually a man who takes on a woman's role. This intermediary category combines aspects of both femininity and masculinity of the society in which it is found and is thus considered an androgynous gender. Although some people in this category are born as intersexed individuals (formerly known as hermaphrodites), meaning they have genitalia of both sexes, many are born biologically as one sex or the other but adopt an androgynous identity.

Anthropologists have found another androgynous gender composed of women warriors in thirty-three Native American groups in North America. Walter L. Williams (1997) calls these women "amazons" and notes that they dress like men and sometimes even marry women. In some tribes girls exhibit such "masculine" characteristics from childhood, while in others they may be recruited into "amazonhood.” In the Kaska Indians, for example, a married couple with too many daughters would select one to "be like a man.” When she was about 5 years of 
age, her parents would begin to dress her like a boy and have her do male tasks. Eventually she would grow up to become a hunter.

The androgynous genders found by anthropologists remind us that gender is a social construction and not just a biological fact. If culture does affect gender roles, socialization is the process through which culture has this effect. What we experience as girls and boys strongly influences how we develop as women and men in terms of behavior and attitudes. To illustrate this important dimension of gender, let's turn to the evidence on socialization.

\section{Socialization and Gender}

Socialization is the process whereby individuals learn the culture of their society. Several agents of socialization exist, including the family, peers, schools, the mass media, and religion, and all these institutions help to socialize people into their gender roles and also help them develop their gender identity (Andersen \& Hysock, 2011).

\section{The Family}

Socialization into gender roles begins in infancy, as almost from the moment of birth parents begin to socialize their children as boys or girls without even knowing it (Begley, 2009; Eliot, 2011). Parents commonly describe their infant daughters as pretty, soft, and delicate and their infant sons as strong, active, and alert, even though neutral observers find no such gender differences among infants when they do not know the infants' sex. From infancy on, parents play with and otherwise interact with their daughters and sons differently. They play more roughly with their sons — for example, by throwing them up in the air or by gently wrestling with them —and more quietly with their daughters. When their infant or toddler daughters cry, they warmly comfort them, but they tend to let their sons cry longer and to comfort them less. They give their girls dolls to play with and their boys action figures and toy guns. While these gender differences in socialization are probably smaller now than a generation

ago, they certainly continue to exist. Go into a large toy store and you will see pink aisles of dolls and cooking sets and blue aisles of action figures, toy guns, and related items.

\section{Peers}

Peer influences also encourage gender socialization. As they reach school age, children begin to play different games based on their gender. Boys tend to play sports and other competitive team games governed by inflexible rules and relatively large numbers of roles, while girls tend to play smaller, cooperative games such as hopscotch and jumping rope with fewer and more flexible rules. Although girls are much more involved in sports now than a generation ago, these gender differences in their play persist and continue to reinforce gender roles. For example, boys' games encourage them to be competitive, while girls' games encourage them to become cooperative and trusting. The patterns we see in adult males and females thus have roots in their play as young children (Lindsey, 2011) (see Note 4.13 “Children and Our Future”). 


\section{Children and Our Future}

Girls and Boys at Play

The text discusses how the types of games that girls and boys play influence their gender-role socialization. Let's take a closer look at two early sociological studies that provided important evidence for this process.

Janet Lever (1978) studied fifth-grade children in three different communities in Connecticut. She watched them play and otherwise interact in school and also had the children keep diaries of their play and games outside school. Lever found that boys' games were typically more complex than girls' games: The boys' games had a greater number of rules and more specialized roles, and they also involved more individuals playing. She attributed these differences to socialization by parents, teachers, and other adults and argued that the complexity of boys' play and games helped them to be better able than girls to learn important social skills such as dealing with rules and coordinating actions to achieve goals.

A second sociologist, Barrie Thorne (1993), studied fourth- and fifth-graders in California and Michigan. The boys tended to play team sports and other competitive games, while the girls tended to play cooperative games such as jump rope. These differences led Thorne to conclude that gender-role socialization stems not only from practices by adults but also from the children's own activities without adult involvement. When boys and girls interacted, it was often "girls against the boys" in classroom spelling contests and in games such as tag. Thorne concluded that these "us against them" contests helped the children learn that boys and girls are two different and antagonistic sexes. Boys also tended to disrupt girls' games more than the reverse and in this manner both exerted and learned dominance over females. In all these ways, children were not just the passive recipients of gender-role socialization from adults (their teachers), but they also played an active role in ensuring that such socialization occurred.

These two studies were among the first to emphasize the importance of children's play for the gender-based traits and values that girls and boys learn, which in turn affect the choices they make for careers and other matters later in life. The rise in team sports opportunities for girls in the years since Lever and Thorne did their research is a welcome development, but young children continue to play in the ways that Lever and Thorne found. The body of research on gender differences in children's play points to the need for teachers, parents, and other adults to encourage girls and boys alike to have a mixture of both competitive and cooperative games so that both sexes may develop a better balance of values that are now commonly considered to be either feminine or masculine.

\section{Schools}

School is yet another agent of gender socialization. First of all, school playgrounds provide a location for the gender-linked play activities just described to occur. Second, and perhaps more important, teachers at all levels treat their female and male students differently in subtle ways of which they are probably not aware. They tend to call on boys more often to answer questions in class and to praise them more when they give the right answer. They also give boys more feedback about their assignments and other school work (Sadker \& Sadker, 1994). At all grade levels, many textbooks and other books still portray people in gender-stereotyped ways. It is true that the newer books do less of this than older ones, but the newer books still contain some stereotypes, and the older books are still used in many schools, especially those that cannot afford to buy newer volumes.

\section{Mass Media}

Gender socialization also occurs through the mass media (Renzetti, Curran, \& Maier, 2012). On children’s 
television shows, the major characters are male. On Nickelodeon, for example, the very popular SpongeBob SquarePants is a male, as are his pet snail, Gary; his best friend, Patrick Star; their neighbor, Squidward Tentacles; and SpongeBob's employer, Eugene Crabs. Of the major characters in Bikini Bottom, only Sandy Cheeks is a female. For all its virtues, Sesame Street features Bert, Ernie, Cookie Monster, and other male characters. Most of the Muppets are males, and the main female character, Miss Piggy, depicted as vain and jealous, is hardly an admirable female role model. As for adults' prime-time television, more men than women continue to fill more major roles in weekly shows, despite notable women's roles in shows such as The Good Wife and Grey's Anatomy. Women are also often portrayed as unintelligent or frivolous individuals who are there more for their looks than for anything else. Television commercials reinforce this image. Cosmetics ads abound, suggesting not only that a major task for women is to look good but also that their sense of self-worth stems from looking good. Other commercials show women becoming ecstatic over achieving a clean floor or sparkling laundry. Judging from the world of television commercials, then, women's chief goals in life are to look good and to have a clean house. At the same time, men's chief goals, judging from many commercials, are to drink beer and drive cars.

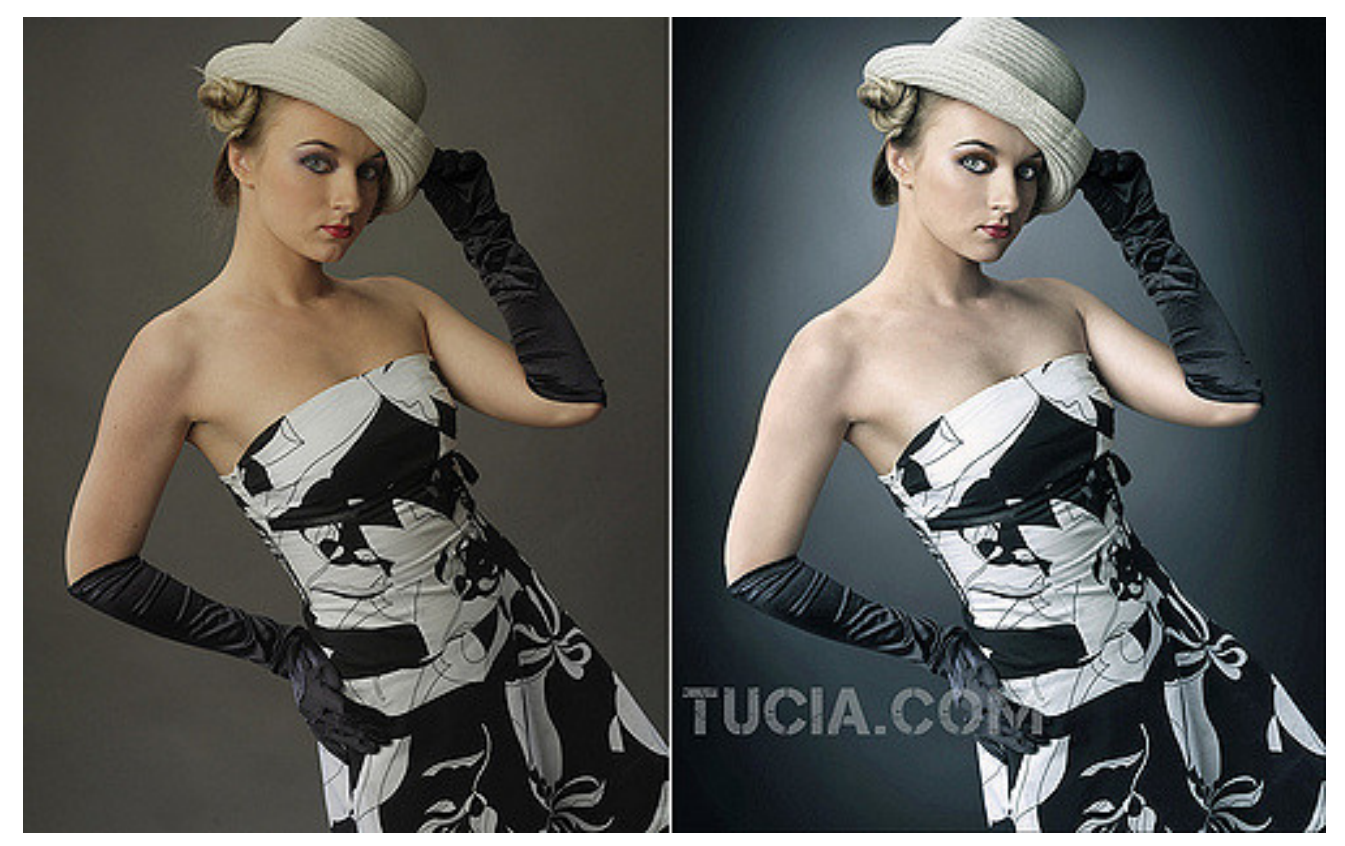

Women's magazines reinforce the view that women need to be slender and wear many cosmetics in order to be considered beautiful.

Photo Editing Services Tucia.com - Glamour /Fashion Retouching by Tucia - CC BY 2.0.

Women's and men's magazines reinforce these gender images (Hesse-Biber, 2007; Milillo, 2008). Most of the magazines intended for teenaged girls and adult women are filled with pictures of thin, beautiful models; advice on dieting; cosmetics ads; and articles on how to win and please your man. Conversely, the magazines intended for teenaged boys and men are filled with ads and articles on cars and sports, advice on how to succeed in careers and other endeavors, and pictures of thin, beautiful (and sometimes nude) women. These magazine images again suggest that women's chief goals are to look good and to please men and that men's chief goals are to succeed, win over women, and live life in the fast lane. 


\section{Religion}

Another agent of socialization, religion, also contributes to traditional gender stereotypes. Many traditional interpretations of the Bible yield the message that women are subservient to men (Tanenbaum, 2009). This message begins in Genesis, where the first human is Adam, and Eve was made from one of his ribs. The major figures in the rest of the Bible are men, and women are for the most part depicted as wives, mothers, temptresses, and prostitutes; they are praised for their roles as wives and mothers and condemned for their other roles. More generally, women are constantly depicted as the property of men. The Ten Commandments includes a neighbor's wife with his house, ox, and other objects as things not to be coveted (Exodus 20:17), and many biblical passages say explicitly that women belong to men, such as this one from the New Testament: "Wives be subject to your husbands, as to the Lord. For the husband is the head of the wife as Christ is the head of the Church. As the Church is subject to Christ, so let wives also be subject in everything to their husbands” (Ephesians 5:22-24).

Several passages in the Old Testament justify the rape and murder of women and girls. The Koran, the sacred book of Islam, also contains passages asserting the subordinate role of women (Mayer, 2009).

\section{A Final Word on the Sources of Gender}

Scholars in many fields continue to debate the relative importance of biology and of culture and socialization for how we behave and think as girls and boys and as women and men. The biological differences between females and males lead many scholars and no doubt much of the public to assume that masculinity and femininity are to a large degree biologically determined or at least influenced. In contrast, anthropologists, sociologists, and other social scientists tend to view gender as a social construction. Even if biology does matter for gender, they say, the significance of culture and socialization should not be underestimated. To the extent that gender is indeed shaped by society and culture, it is possible to change gender and to help bring about a society where both men and women have more opportunity to achieve their full potential.

\section{Key Takeaways}

- Sex is a biological concept, while gender is a social concept and refers to the social and cultural differences a society assigns to people based on their sex.

- Several biological explanations for gender roles exist, but sociologists think culture and socialization are more important sources of gender roles than biology.

- Families, schools, peers, the mass media, and religion are agents of socialization for the development of gender identity and gender roles. 


\section{For Your Review}

1. Write a short essay about one or two events you recall from your childhood that reflected or reinforced your gender socialization.

2. Do you think gender roles are due more to biology or to culture and socialization? Explain your answer.

\section{References}

Andersen, M., \& Hysock, D. (2011). Thinking about women: Sociological perspectives on sex and gender (9th ed.). Boston, MA: Allyn \& Bacon.

Aulette, J. R., \& Wittner, J. (2011). Gendered worlds (2nd ed.). New York, NY: Oxford University Press.

Begley, S. (2009, June 29). Don’t blame the caveman. Newsweek, 52-62.

Begley, S. (2009, September 14). Pink brain, blue brain: Claims of sex differences fall apart. Newsweek, 28

Brettell, C. B., \& Sargent, C. F. (Eds.). (2009). Gender in cross-cultural perspective (5th ed.). Upper Saddle River, NJ: Prentice Hall.

Browne, K. (2002). Biology at work: Rethinking sexual equality. New Brunswick, NJ: Rutgers University Press.

Buss, D. (2012). Evolutionary psychology: The new science of the mind (4th ed.). Upper Saddle River, NJ: Pearson.

Card, N. A., Stucky, B. D., Sawalani, G. M., \& Little, T. D. (2008). Direct and indirect aggression during childhood and adolescence: A meta-analytic review of gender differences, intercorrelations, and relations to maladjustment. Child Development, 79(5), 1185-1229.

Eliot, L. (2011). Pink brain, blue brain: How small differences grow into troublesome gaps—and what we can do about it. London, United Kingdom: Oneworld Publications.

Fine, C. (2011). Delusions of gender: The real science behind sex differences. New York, NY: W. W. Norton.

Hesse-Biber, S. N. (2007). The cult of thinness. New York, NY: Oxford University Press.

Lever, J. (1978). Sex differences in the complexity of children's play and games. American Sociological Review, 43, 471-483.

Lindsey, L. L. (2011). Gender roles: A sociological perspective (5th ed.). Upper Saddle River, NJ: Prentice Hall.

Mayer, A. E. (2009). Review of "Women, the Koran and international human rights law: The experience of Pakistan.” Human Rights Quarterly, 31(4), 1155-1158. 
Mazur, A. (2009). Testosterone and violence among young men. In A. Walsh \& K. M. Beaver (Eds.), Biosocial criminology: New directions in theory and research (pp. 190-204). New York, NY: Routledge.

Miczek, K. A., Mirsky, A. F., Carey, G., DeBold, J., \& Raine, A. (1994). An overview of biological influences on violent behavior. In J. Albert, J. Reiss, K. A. Miczek \& J. A. Roth (Eds.), Understanding and preventing violence: Biobehavioral influences (Vol. 2, pp. 1-20). Washington, DC: National Academy Press.

Milillo, D. (2008). Sexuality sells: A content analysis of lesbian and heterosexual women's bodies in magazine advertisements. Journal of Lesbian Studies, 12(4), 381-392.

Murdock, G. (1937). Comparative data on the division of labor by sex. Social Forces, 15, 551-553.

Renzetti, C. M., Curran, D. J., \& Maier, S. (2012). Women, men, and society. Upper Saddle River, NJ: Pearson.

Sadker, M., \& Sadker, D. (1994). Failing at fairness: How America’s schools cheat girls. New York, NY: Charles Scribner's.

Tanenbaum, L. (2009). Taking back God: American women rising up for religious equality. New York, NY: Farrar, Straus and Giroux.

Thorne, B. (1993). Gender play: Girls and boys in school. New Brunswick, NJ: Rutgers University Press.

Thornhill, R., \& Gangestad, S. W. (2008). The evolutionary biology of human female sexuality. New York, NY: Oxford University Press.

Williams, W. L. (1997). Amazons of America: Female gender variance. In C. B. Brettell \& C. F. Sargent (Eds.), Gender in cross-cultural perspective (2nd ed., pp. 202-213). Upper Saddle River, NJ: Prentice Hall. 


\subsection{Feminism and Sexism}

\section{Learning Objectives}

1. Define feminism, sexism, and patriarchy.

2. Discuss evidence for a decline in sexism.

In the national General Social Survey (GSS), slightly more than one-third of the public agrees with this statement: "It is much better for everyone involved if the man is the achiever outside the home and the woman takes care of the home and family.” Do you agree or disagree with this statement? If you are like the majority of college students, you disagree.

Today a lot of women, and some men, will say, "I'm not a feminist, but...," and then go on to add that they hold certain beliefs about women's equality and traditional gender roles that actually fall into a feminist framework. Their reluctance to self-identify as feminists underscores the negative image that feminists and feminism have but also suggests that the actual meaning of feminism may be unclear.

Feminism and sexism are generally two sides of the same coin. Feminism refers to the belief that women and men should have equal opportunities in economic, political, and social life, while sexism refers to a belief in traditional gender role stereotypes and in the inherent inequality between men and women. Sexism thus parallels the concept of racial and ethnic prejudice discussed in Chapter 3 "Racial and Ethnic Inequality". Women and people of color are both said, for biological and/or cultural reasons, to lack certain qualities for success in today's world. 


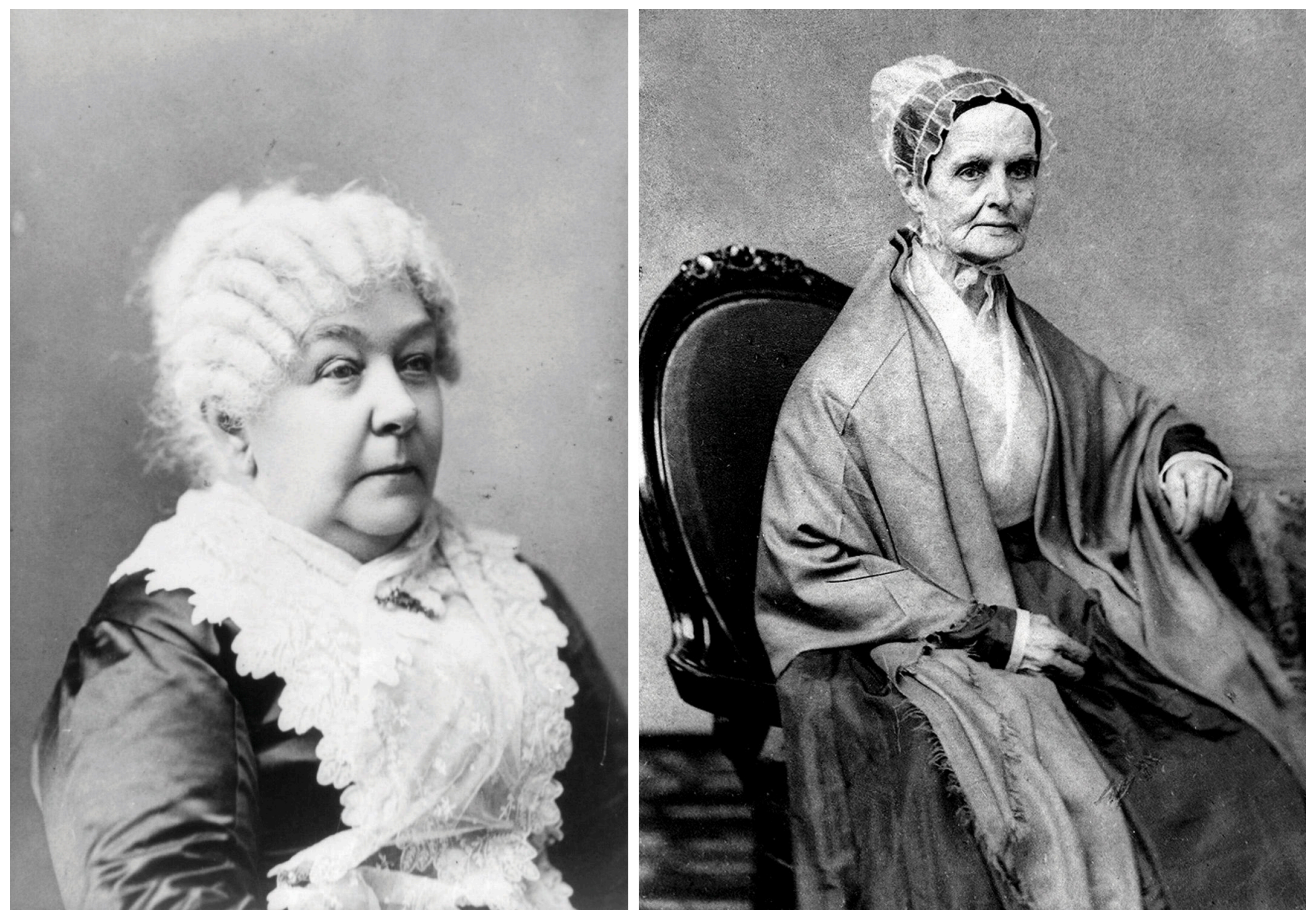

Feminism as a social movement began in the United States during the abolitionist period before the Civil War. Elizabeth Cady Stanton (left) and Lucretia Mott (right) were outspoken abolitionists who made connections between slavery and the oppression of women.

The US Library of Congress - public domain; The US Library of Congress - public domain.

Two feminist movements in US history have greatly advanced the cause of women's equality and changed views about gender. The first began during the abolitionist period, when abolitionists such as Susan B. Anthony, Lucretia Mott, and Elizabeth Cady Stanton began to see similarities between slavery and the oppression of women. This new women's movement focused on many issues but especially the right to vote, which women won in 1920. The second major feminist movement began in the late 1960s, as women active in the Southern civil rights movement turned their attention to women's rights, and it is still active today. This movement has profoundly changed public thinking and social and economic institutions, but, as we will soon see, much gender inequality remains.

Several varieties of feminism exist. Although they all share the basic idea that women and men should be equal in their opportunities in all spheres of life, they differ in other ways (Hannam, 2012). Liberal feminism believes that the equality of women can be achieved within our existing society by passing laws and reforming social, economic, and political institutions. In contrast, socialist feminism blames capitalism for women's inequality and says that true gender equality can result only if fundamental changes in social institutions, and even a socialist revolution, are achieved. Radical feminism, on the other hand, says that patriarchy (male domination) lies at the root of women's oppression and that women are oppressed even in noncapitalist societies. Patriarchy itself must be abolished, they say, if women are to become equal to men. Finally, multicultural feminism emphasizes that women of color are oppressed not only because of their gender but also because of their race and class. They thus face a triple burden that goes beyond their gender. By focusing their attention on women of color in the United States and other nations, multicultural feminists remind us that the lives of these women differ in many ways from those of the middle-class women who historically have led US feminist movements. 


\section{The Growth of Feminism and the Decline of Sexism}

What evidence is there for the impact of the contemporary women's movement on public thinking? The GSS, the Gallup poll, and other national surveys show that the public has moved away from traditional views of gender toward more modern ones. Another way of saying this is that the public has moved from sexism toward feminism.

To illustrate this, let's return to the GSS statement that it is much better for the man to achieve outside the home and for the woman to take care of home and family. Figure 4.2 "Change in Acceptance of Traditional Gender Roles in the Family, 1977-2010" shows that agreement with this statement dropped sharply during the 1970s and 1980s before leveling off afterward to slightly more than one-third of the public.

Figure 4.2 Change in Acceptance of Traditional Gender Roles in the Family, 1977-2010

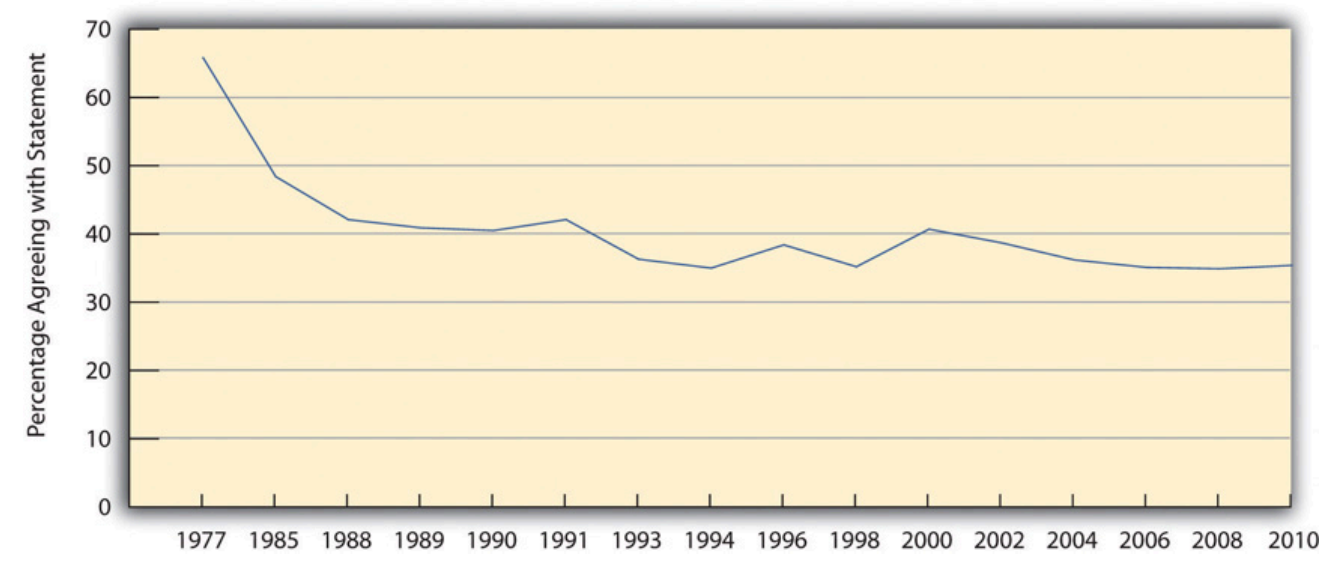

Percentage agreeing that "it is much better for everyone involved if the man is the achiever outside the home and the woman takes care of the home and family."

Source: Data from General Social Surveys. (1977-2010). Retrieved from http://sda.berkeley.edu/cgi-bin/hsda?harcsda+gss10.

Another GSS question over the years has asked whether respondents would be willing to vote for a qualified woman for president of the United States. As Figure 4.3 "Change in Willingness to Vote for a Qualified Woman for President” illustrates, this percentage rose from 74 percent in the early 1970s to a high of 96.2 percent in 2010. Although we have not yet had a woman president, despite Hillary Rodham Clinton's historic presidential primary campaign in 2007 and 2008 and Sarah Palin's presence on the Republican ticket in 2008, the survey evidence indicates the public is willing to vote for one. As demonstrated by the responses to the survey questions on women's home roles and on a woman president, traditional gender views have indeed declined. 


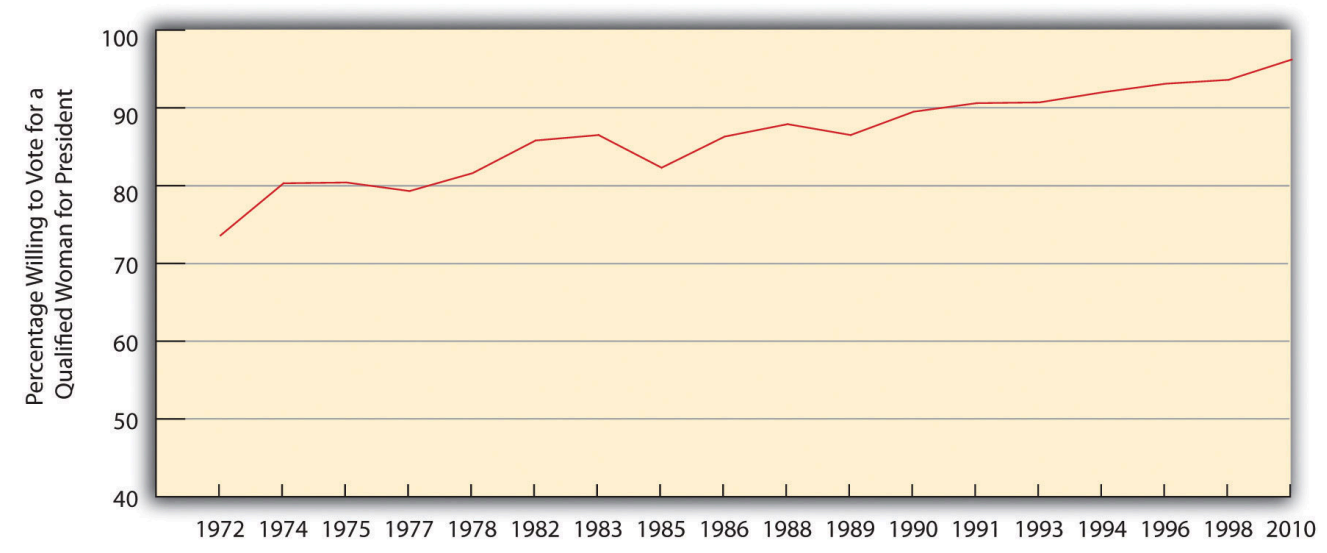

Source: Data from General Social Survey. (2010). Retrieved from http://sda.berkeley.edu/cgi-bin/hsda?harcsda+gss10.

\section{Key Takeaways}

- Feminism refers to the belief that women and men should have equal opportunities in economic, political, and social life, while sexism refers to a belief in traditional gender role stereotypes and in the inherent inequality between men and women.

- Sexist beliefs have declined in the United States since the early 1970s.

\section{For Your Review}

1. Do you consider yourself a feminist? Why or why not?

2. Think about one of your parents or of another adult much older than you. Does this person hold more traditional views about gender than you do? Explain your answer.

\section{References}

Hannam, J. (2012). Feminism. New York, NY: Pearson Longman. 


\subsection{Dimensions of Gender Inequality}

\section{Learning Objectives}

1. Summarize the status of women around the world today.

2. Understand the extent of and reasons for gender inequality in income and the workplace in the United States.

3. Understand the extent of and reasons for sexual harassment.

The primary focus of this chapter is gender inequality in the United States, but it is also important to discuss gender inequality worldwide. While American women are unequal to men in many respects, women's situation throughout much of the world is especially dire. Accordingly, we first examine the global inequality of women before turning our attention to the United States.

\section{The Global Inequality of Women}

The problem of global poverty first discussed in Chapter 2 "Poverty" is especially severe for women. Although, as Chapter 2 "Poverty" noted, more than 1.4 billion people on earth are desperately poor, their ranks include more than their fair share of women, who are estimated to make up 70 percent of the world's poor. Because women tend to be poorer than men worldwide, they are more likely than men to experience all the problems that poverty causes, including malnutrition and disease. But they also suffer additional problems. Some of these problems derive from women's physiological role of childbearing, and some arise from how they are treated simply because they are women.

Let's first look at childbearing. One of the most depressing examples of how global poverty affects women is maternal mortality, or the number of women who die during childbirth for every 100,000 live births. More than 500,000 women die worldwide annually from complications during pregnancy or childbirth. Maternal mortality usually results from one or more of the following: inadequate prenatal nutrition, disease and illness, and inferior obstetrical care, all of which are much more common in poor nations than in wealthy nations. In wealthy nations, the rate of maternal mortality is 14 per 100,000 births, but in poor nations the rate is a distressingly high 590 per 100,000 births, equivalent to almost 6 deaths for every 1,000 births. Women in poor nations are thus forty-two times more likely than those in wealthy nations to die from complications during pregnancy or childbirth (World Bank, 2012). 


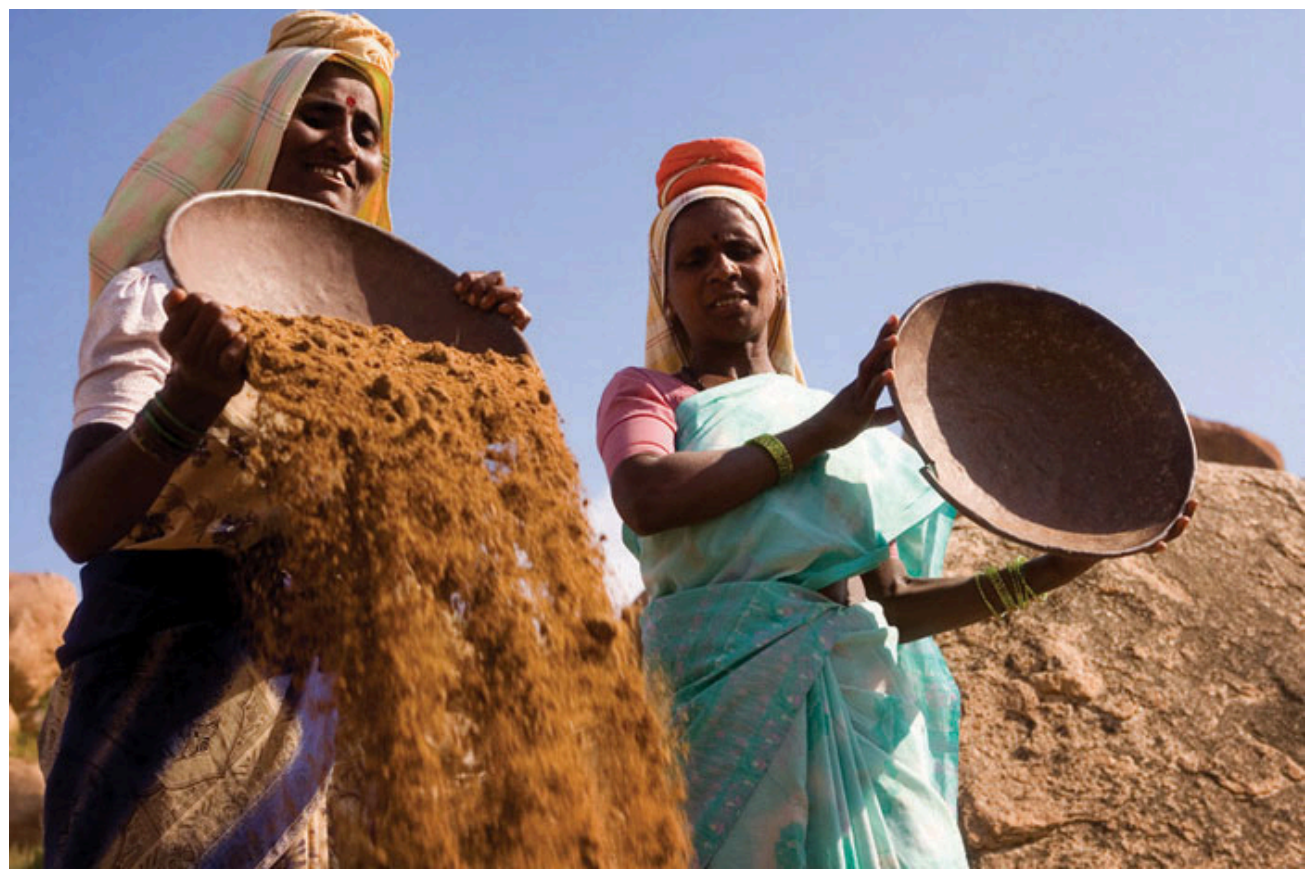

In India and Pakistan, thousands of new wives every year are murdered in dowry deaths because they have not provided their husbands a suitable amount of money and goods.

Wikimedia Commons - CC BY 2.0.

In addition to these problems, women in poor nations fare worse than men in other ways because of how they are treated as women. One manifestation of this fact is the violence they experience (World Health Organization, 2010).World Health Organization/London School of Hygiene and Tropical Medicine. (2010). Preventing intimate partner and sexual violence against women: Taking action and generating evidence. Geneva, Switzerland: Author. About one-third of women worldwide have been raped or beaten, leading Amnesty International (2004) to call violence against women "the greatest human rights scandal of our times." Although violence against women certainly occurs in wealthy nations, it is more common and extreme in poor and middle-income nations, and in nations where women's inequality (as reflected by criteria such as their labor force participation and their educational attainment) is especially high (Kaya \& Cook, 2010). More than half of women in Uganda, for example, have been physically or sexually abused (Amnesty International, 2010). Many young women in India who work outside the home have been raped by male high-school dropouts who think these women lack virtue and should be punished with rape (Polgreen, 2011). In India and Pakistan, thousands of women are killed every year in dowry deaths, in which a new wife is murdered by her husband and/or his relatives if she does not pay the groom money or goods (Kethineni \& Srinivasan, 2009). In many countries, young girls routinely have their genitals cut out, often with no anesthesia, in what has been termed female genital mutilation, a practice that is thought to affect more than 100 million girls and women across the earth and has been called an act of torture (Kristoff, 2011; Rogo, Subayi, \& Toubia, 2007).

Sex trafficking is another major problem in countries like Cambodia, India, Nepal, and Thailand, where young girls are often stolen from their parents and forced to work as prostitutes in what amounts to sexual slavery. The number of girls (and sometimes boys) under age 18 who work as sex slaves is thought to reach into the millions and to be larger than the number of African slaves during the eighteenth and nineteenth centuries (Kristoff \& WuDunn, 2010). 
Beyond violence, women in poor nations are less likely than their male counterparts to get a higher education, and girls are less likely than boys to attend primary school. Women are also less likely than men to work in jobs that pay a decent wage and to hold political office. In many poor nations, girls are less likely than boys to receive adequate medical care when they become ill and are more likely than boys to die before age 5 . In all these ways, women and girls in poor nations especially suffer.

In stark contrast, women in wealthy democratic nations fare much better than their counterparts in poor nations. In many wealthy democracies, women's status vis-à-vis men is higher than in the United States. The Note 4.23 "Lessons from Other Societies" box discusses this situation further.

\section{Lessons from Other Societies}

Women in the Nordic Nations

The United Nations Development Programme ranks nations on a “gender empowerment measure” of women's involvement in their nation's economy and political life (United Nations Development Programme, 2009). Of the 109 nations included in the measure, Sweden ranks first, followed by Norway, Finland, and Denmark. The remaining Nordic nation, Iceland, ranks eighth. The other nations in the top ten are the Netherlands, Belgium, Australia, Germany, and New Zealand. Canada ranks twelfth, and the United States ranks only eighteenth. In trying to understand why the United States ranks this low and what it might be able to do to increase its empowerment of women, the experience of the Nordic nations provides some important lessons.

The Nordic nations rank at the top of the gender empowerment measure largely because they have made a concerted effort to boost women's involvement in the business and political worlds (Sumer, Smithson, Guerreiro, \& Granlund, 2008). They are all social democratic welfare states characterized by extensive government programs and other efforts to promote full economic and gender equality.

For example, Norway's government provides day care for children and adult care for older or disabled individuals, and it also provides forty-four weeks of paid parental leave after the birth of a child. Parents can also work fewer hours without losing income until their child is 2 years of age. All these provisions mean that women are much more likely than their American counterparts to have the freedom and economic means to work outside the home, and they have taken advantage of this opportunity. As a recent analysis concluded, "It has been extremely important for women that social rights have been extended to cover such things as the caring of young children and elderly, sick and disabled members of society. In the Nordic countries, women have been more successful than elsewhere in combining their dual role as mothers and workers, and social policy arrangements are an integral part of the gender equality policy" (Kangas \& Palme, 2009, p. 565).

The lesson for the United States is clear: An important reason for the Nordic nations' high gender empowerment ranking is government policy that enables women to work outside the home if they want to do so. The experience of these nations indicates that greater gender equality might be achieved in the United States if it adopted policies similar to those found in these nations that make it easier for women to join and stay in the labor force.

\section{Gender Inequality in the United States}

We have said that the women's movement changed American life in many ways but that gender inequality persists in the United States. Let's look at examples of such inequality, much of it taking the form of institutional discrimination, which, as we saw in Chapter 3 "Racial and Ethnic Inequality", can occur even if it is not intended to happen. We start with gender inequality in income and the workplace and then move on to a few other spheres of life. 


\section{The Gender Gap in Income}

In the last few decades, women have entered the workplace in increasing numbers, partly, and for many women mostly, out of economic necessity, and partly out of desire for the sense of self-worth and other fulfillment that comes with work. In February 2012, 57.9 percent of US women aged 16 or older were in the labor force, compared to only 43.3 percent in 1970; comparable figures for men were 70.3 percent in 2012 and 79.7 percent in 1970 (Bureau of Labor Statistics, 2012). Thus while women's labor force participation continues to lag behind men's, this gender gap has narrowed. The figures just cited include women of retirement age. When we just look at younger women, labor force participation is even higher. For example, 74.7 percent of women aged 35-44 were in the labor force in 2011, compared to only 46.8 percent in 1970.

Despite the workplace gains women have made, problems persist. Perhaps the major problem is a gender gap in income. Women have earned less money than men ever since records started being kept (Reskin \& Padavic, 2002). In the United States in the early 1800s, full-time women workers in agriculture and manufacturing earned less than 38 percent of what men earned. By 1885, they were earning about 50 percent of what men earned in manufacturing jobs. As the 1980s began, full-time women workers' median weekly earnings were about 65 percent of men's. Women have narrowed the gender gap in earnings since then: Their weekly earnings now (2011) are 82.2 percent of men's among full-time workers ages 16 and older (Bureau of Labor Statistics, 2012). Still, this means that for every $\$ 10,000$ men earn, women earn only about $\$ 8,220$. To turn that around, for every $\$ 10,000$ women earn, men earn $\$ 12,156$. This gap amounts to hundreds of thousands of dollars over a lifetime of working.

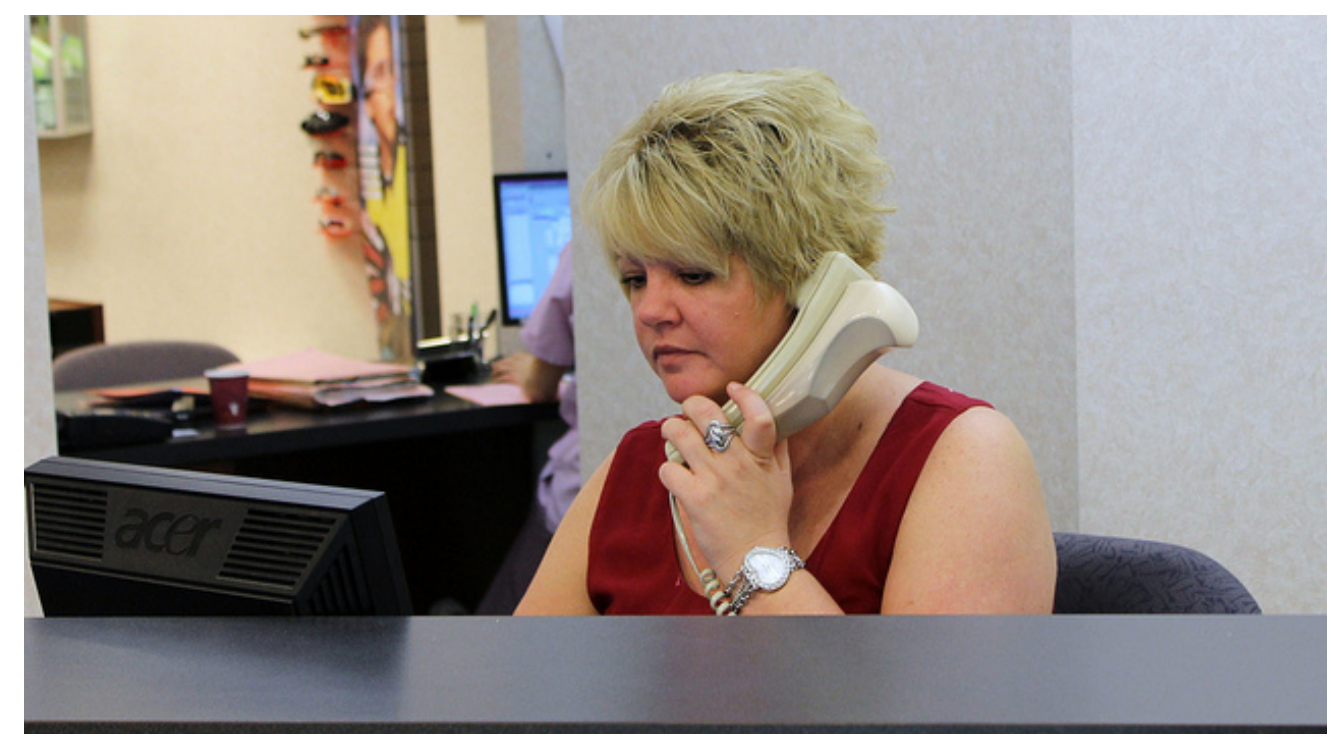

Women have earned less money than men ever since records started being kept. Women now earn about 81 percent of what men earn.

John Jacobi - receptionist answering phone at suburban eye care - CC BY 2.0.

As Table 4.1 "Median Annual Earnings of Full-Time, Year-Round Workers Aged 25-64 by Educational Attainment, 2010*” shows, this gender gap exists for all levels of education and even increases with higher levels of education. On the average, women with a bachelor's degree or higher and working full time earn almost $\$ 18,000$ less per year than their male counterparts. 
Table 4.1 Median Annual Earnings of Full-Time, Year-Round Workers Aged 25-64 by Educational Attainment, 2010*

\begin{tabular}{|l|l|l|l|l|}
\hline & $\begin{array}{l}\text { High school } \\
\text { dropout }\end{array}$ & $\begin{array}{l}\text { High school } \\
\text { degree }\end{array}$ & $\begin{array}{l}\text { Some college or associate's } \\
\text { degree }\end{array}$ & $\begin{array}{l}\text { Bachelor's degree or } \\
\text { higher }\end{array}$ \\
\hline Men & 25,272 & 36,920 & 43,940 & 69,160 \\
\hline Women & 20,176 & 28,236 & 33,176 & 51,272 \\
\hline Difference & 5,096 & 8,684 & 10,764 & 17,888 \\
\hline $\begin{array}{l}\text { Gender gap (\%; women } \\
\text { - men) }\end{array}$ & 79.8 & 76.5 & 75.5 & 74.1 \\
\hline * Median weekly earnings $\times \mathbf{5 2}$ weeks & & & \\
\hline
\end{tabular}

Source: US Department of Labor. (2011). Highlights of women's earnings in 2010. Washington, DC: Author.

What accounts for the gender gap in earnings? A major reason is sex segregation in the workplace, which accounts for up to 45 percent of the gender gap (Kelley, 2011; Reskin \& Padavic, 2002). Although women have increased their labor force participation, the workplace remains segregated by gender. Almost half of all women work in a few low-paying clerical and service (e.g., waitressing) jobs, while men work in a much greater variety of jobs, including high-paying ones. Table 4.2 "Gender Segregation in the Workplace for Selected Occupations, 2010" shows that many jobs are composed primarily of women or of men. Part of the reason for this segregation is that socialization affects what jobs young men and women choose to pursue, and part of the reason is that women and men do not want to encounter difficulties they may experience if they took a job traditionally assigned to the other sex. A third reason is that sex-segregated jobs discriminate against applicants who are not the "right" sex for that job. Employers may either consciously refuse to hire someone who is the "wrong" sex for the job or have job requirements (e.g., height requirements) and workplace rules (e.g., working at night) that unintentionally make it more difficult for women to qualify for certain jobs. Although such practices and requirements are now illegal, they still continue. The sex segregation they help create contributes to the continuing gender gap between female and male workers. Occupations dominated by women tend to have lower wages and salaries. Because women are concentrated in low-paying jobs, their earnings are much lower than men’s (Reskin \& Padavic, 2002).

This fact raises an important question: Why do women's jobs pay less than men's jobs? Is it because their jobs are not important and require few skills (recalling the functional theory of stratification discussed in Chapter 2 "Poverty")? The evidence indicates otherwise: Women's work is devalued precisely because it is women's work, and women's jobs thus pay less than men’s jobs because they are women’s jobs (Magnusson, 2009). 


\begin{tabular}{|l|l|l|}
\hline Occupation & Female workers (\%) & Male workers (\%) \\
\hline Preschool and kindergarten teachers & 97.0 & 3.0 \\
\hline Speech-language pathologists & 96.3 & 3.7 \\
\hline Secretaries and administrative assistants & 96.1 & 3.9 \\
\hline Dental hygienists & 95.1 & 4.9 \\
\hline Registered nurses & 91.1 & 8.9 \\
\hline Food servers (waiters/waitresses) & 71.1 & 29.9 \\
\hline Pharmacists & 53.0 & 47.0 \\
\hline Physicians & 32.3 & 67.7 \\
\hline Lawyers & 31.5 & 68.5 \\
\hline Dentists & 25.5 & 64.5 \\
\hline Computer software engineers & 20.9 & 79.1 \\
\hline Electricians & 1.5 & 98.5 \\
\hline Carpenters & 1.4 & 98.5 \\
\hline
\end{tabular}

Source: Data from US Census Bureau. (2012). Statistical abstract of the United States: 2012. Washington, DC: US Government Printing Office. Retrieved from http://www.census.gov/compendia/statab.

Studies of comparable worth support this argument (Levanon, England, \& Allison, 2009). Researchers rate various jobs in terms of their requirements and attributes that logically should affect the salaries they offer: the importance of the job, the degree of skill it requires, the level of responsibility it requires, the degree to which the employee must exercise independent judgment, and so forth. They then use these dimensions to determine what salary a job should offer. Some jobs might be better on some dimensions and worse on others but still end up with the same predicted salary if everything evens out. 


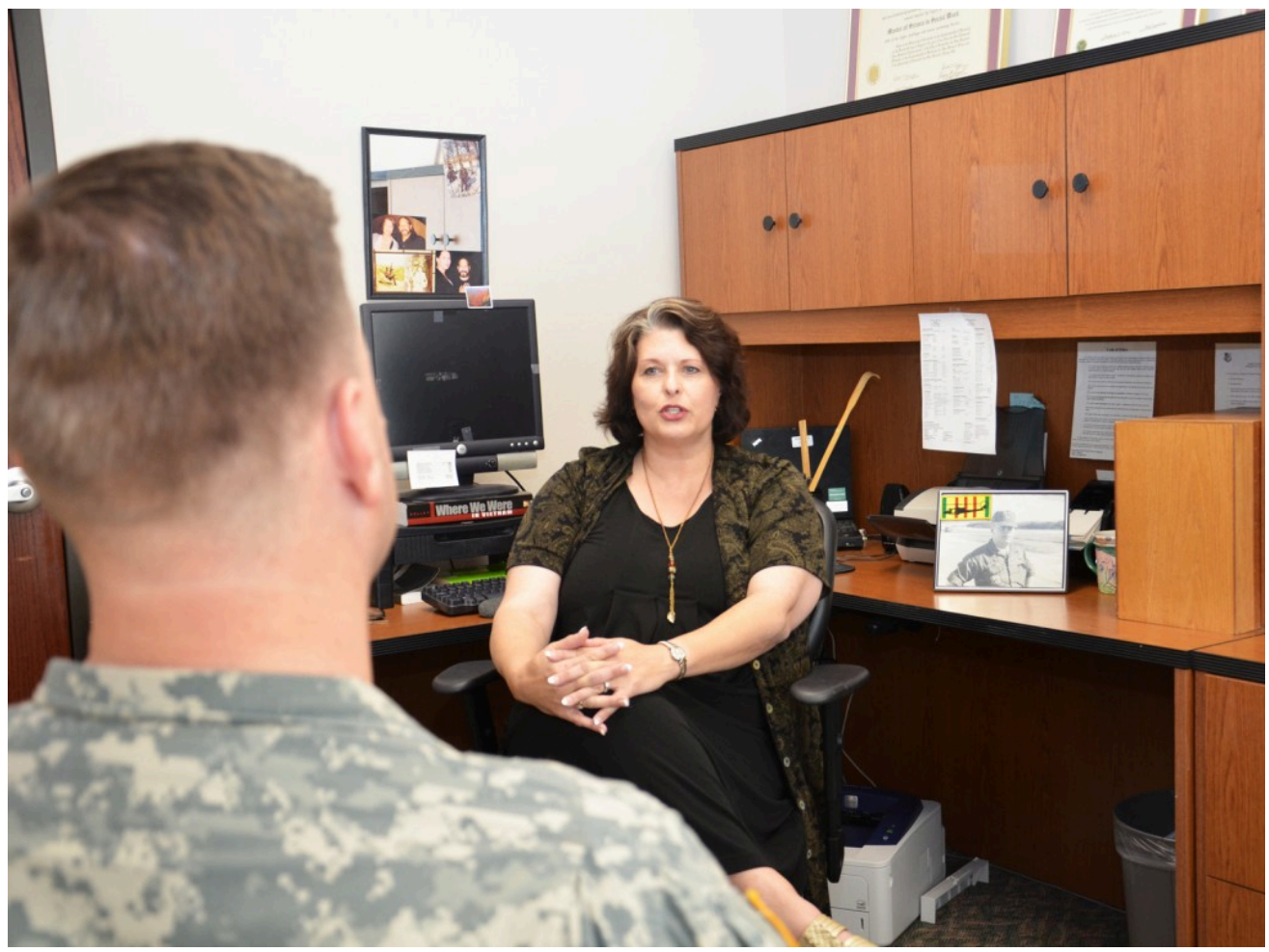

Some women's jobs pay less than men’s jobs even though their comparable worth is equal to or even higher than the men's jobs. For example, a social worker, depicted here, may earn less money than a probation officer, even though calculations based on comparable worth would predict that a social worker should earn at least as much.

Wikimedia Commons - CC BY 2.0.

When researchers make their calculations, they find that certain women's jobs pay less than men's even though their comparable worth is equal to or even higher than the men's jobs. For example, a social worker may earn less money than a probation officer, even though calculations based on comparable worth would predict that a social worker should earn at least as much. The comparable worth research demonstrates that women's jobs pay less than men's jobs of comparable worth and that the average working family would earn several thousand dollars more annually if pay scales were reevaluated based on comparable worth and women were paid more for their work.

Even when women and men work in the same jobs, women often earn less than men, and men are more likely than women to hold leadership positions in these occupations. Government data provide ready evidence of the lower incomes women receive even in the same occupations. For example, among full-time employees, female marketing and sales managers earn only 66 percent of what their male counterparts earn; female human resource managers earn only 80 percent of what their male counterparts earn; female claims adjusters earn only 77 percent; female accountants earn only 75 percent; female elementary and middle school teachers earn only 91 percent; and even female secretaries and clerical workers earn only 91 percent (US Department of Labor, 2011).

One reason for these differences, and for women's lower earnings in general, is their caregiving responsibilities (Chang, 2010). Women are more likely than men to have the major, and perhaps the sole, responsibility for taking care of children and aging parents or other adults who need care. This responsibility limits their work hours and often prompts them to drop out of the labor force. If women rejoin the labor force after their children start 
school, or join for the first time, they are already several years behind men who began working at an earlier age. Economics writer David Leonhardt (2010, p. B1) explains this dynamic: "Many more women take time off from work. Many more women work part time at some point in their careers. Many more women can't get to work early or stay late. And our economy exacts a terribly steep price for any time away from work - in both pay and promotions. People often cannot just pick up where they have left off. Entire career paths are closed off. The hit to earnings is permanent.”

We can see evidence of this "hit" when we examine the gender gap in earnings by age. This gap is relatively low for people in their early twenties, when women earn 93.8 percent of what men earn, but rises during the next two decades of age as more and more women bear and raise children (see Figure 4.4 "Gender, Age, and Median Weekly Earnings of Full-Time Employees, 2010”).

Figure 4.4 Gender, Age, and Median Weekly Earnings of Full-Time Employees, 2010

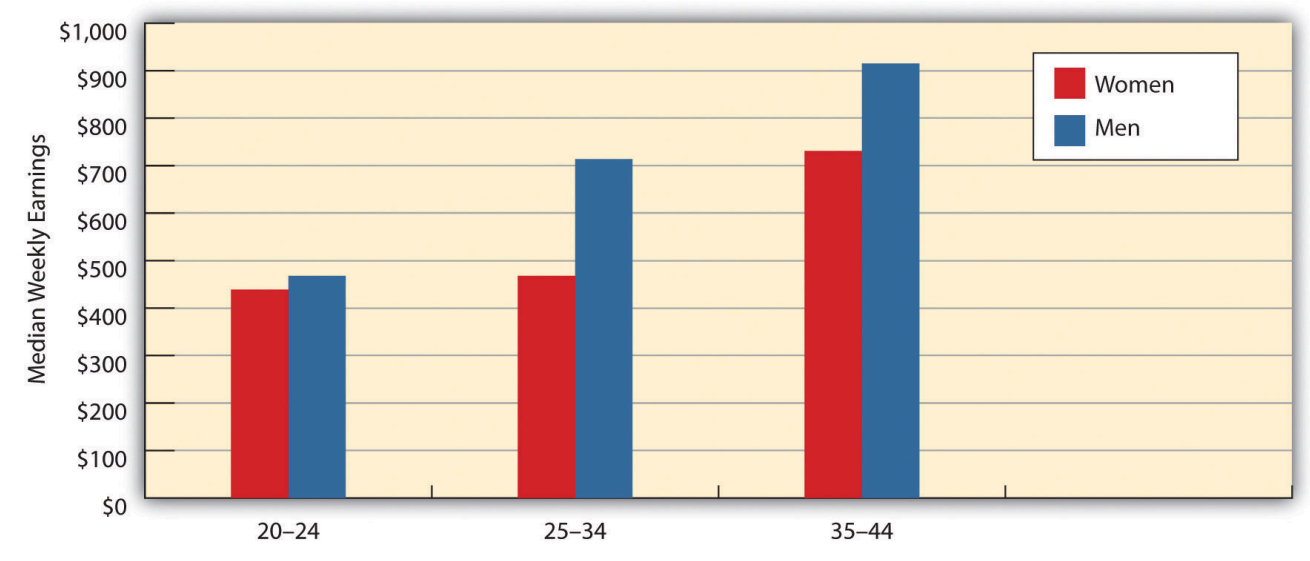

Source: U.S. Department of Labor. (2011). Highlights of Women's Earnings in 2010. Washington, DC: U.S. Department of Labor.

Still, when variables like number of years on the job, number of hours worked per week, and size of firm are taken into account, gender differences in earnings diminish but do not disappear altogether, and it is very likely that sex discrimination (conscious or unconscious) by employers accounts for much of the remaining disparity.

Some of the sex discrimination in employment reflects the existence of two related phenomena, the glass ceiling and the glass escalator. Women may be promoted in a job only to find they reach an invisible "glass ceiling" beyond which they cannot get promoted, or they may not get promoted in the first place. In the largest US corporations, women constitute only about 16 percent of the top executives, and women executives are paid much less than their male counterparts (Jenner \& Ferguson, 2009). Although these disparities stem partly from the fact that women joined the corporate ranks much more recently than men, they also reflect a glass ceiling in the corporate world that prevents qualified women from rising up above a certain level (Hymowitz, 2009). Men, on the other hand, can often ride a "glass escalator" to the top, even in female occupations. An example is seen in elementary school teaching, where principals typically rise from the ranks of teachers. Although men constitute only about 16 percent of all public elementary school teachers, they account for about 41 percent of all elementary school principals (Aud et al., 2011). 


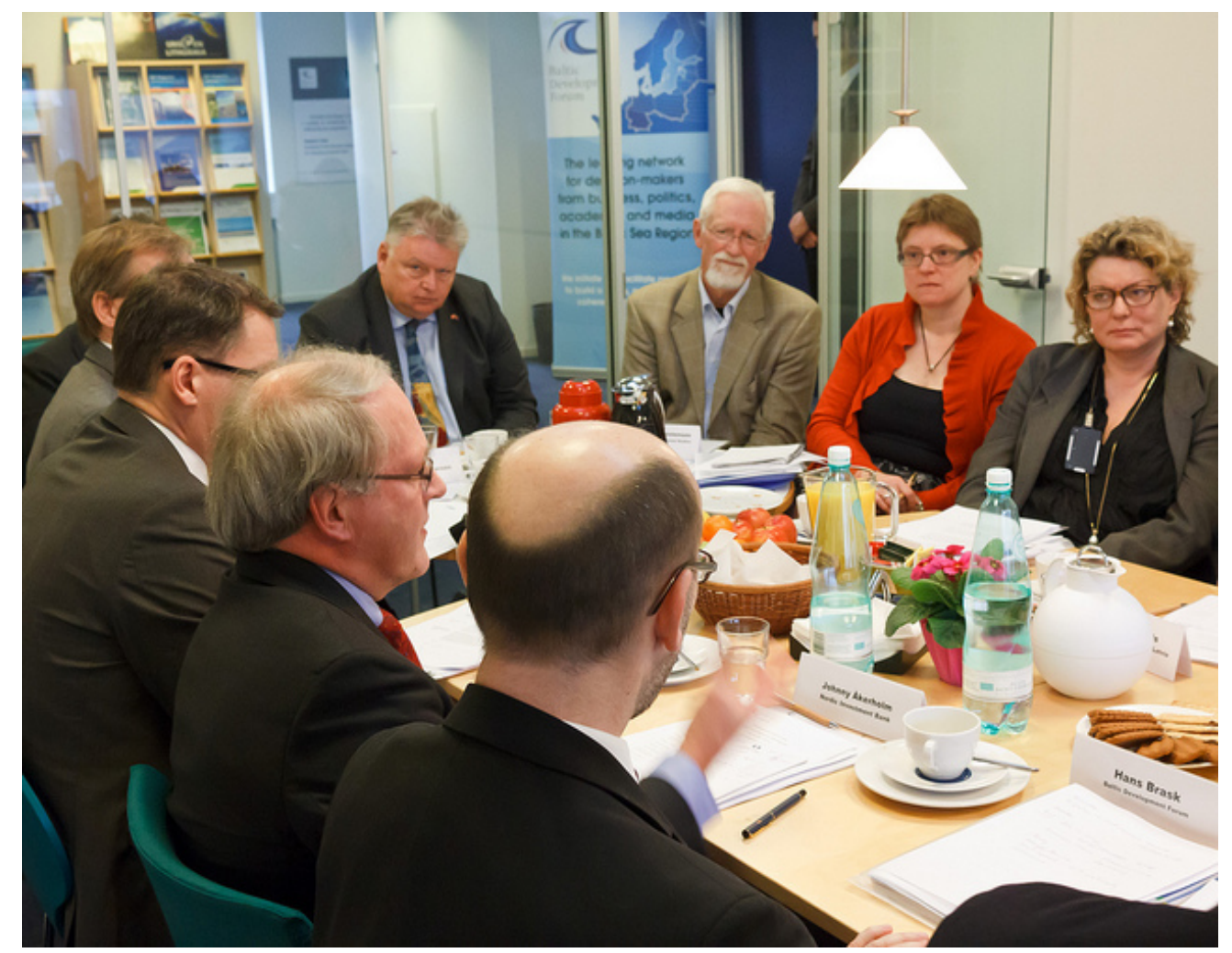

Women constitute only about 16 percent of the top executives in the largest US corporations, and women executives are paid much less than their male counterparts. These disparities reflect a "glass ceiling” that limits women’s opportunities for promotion.

Baltic Development Forum - Kristovskis meeting - CC BY 2.0.

Whatever the reasons for the gender gap in income, the fact that women make so much less than men means that female-headed families are especially likely to be poor. In 2010, almost 32 percent of these families lived in poverty, compared to only 6 percent of married-couple families (DeNavas-Walt, Proctor, \& Smith, 2011). As noted in Chapter 2 "Poverty", the term feminization of poverty refers to the fact that female-headed households are especially likely to be poor. The gendering of poverty in this manner is one of the most significant manifestations of gender inequality in the United States.

\section{Sexual Harassment}

Another workplace problem (including schools) is sexual harassment, which, as defined by federal guidelines and legal rulings and statutes, consists of unwelcome sexual advances, requests for sexual favors, or physical conduct of a sexual nature that is used as a condition of employment or promotion or that interferes with an individual's job performance and creates an intimidating or hostile environment.

Although men can be, and are, sexually harassed, women are more often the targets of sexual harassment. This gender difference exists for at least two reasons, one cultural and one structural. The cultural reason centers on the depiction of women and the socialization of men. As our discussion of the mass media and gender socialization indicated, women are still depicted in our culture as sexual objects that exist for men's pleasure. At the same time, 
our culture socializes men to be sexually assertive. These two cultural beliefs combine to make men believe that they have the right to make verbal and physical advances to women in the workplace. When these advances fall into the guidelines listed here, they become sexual harassment.

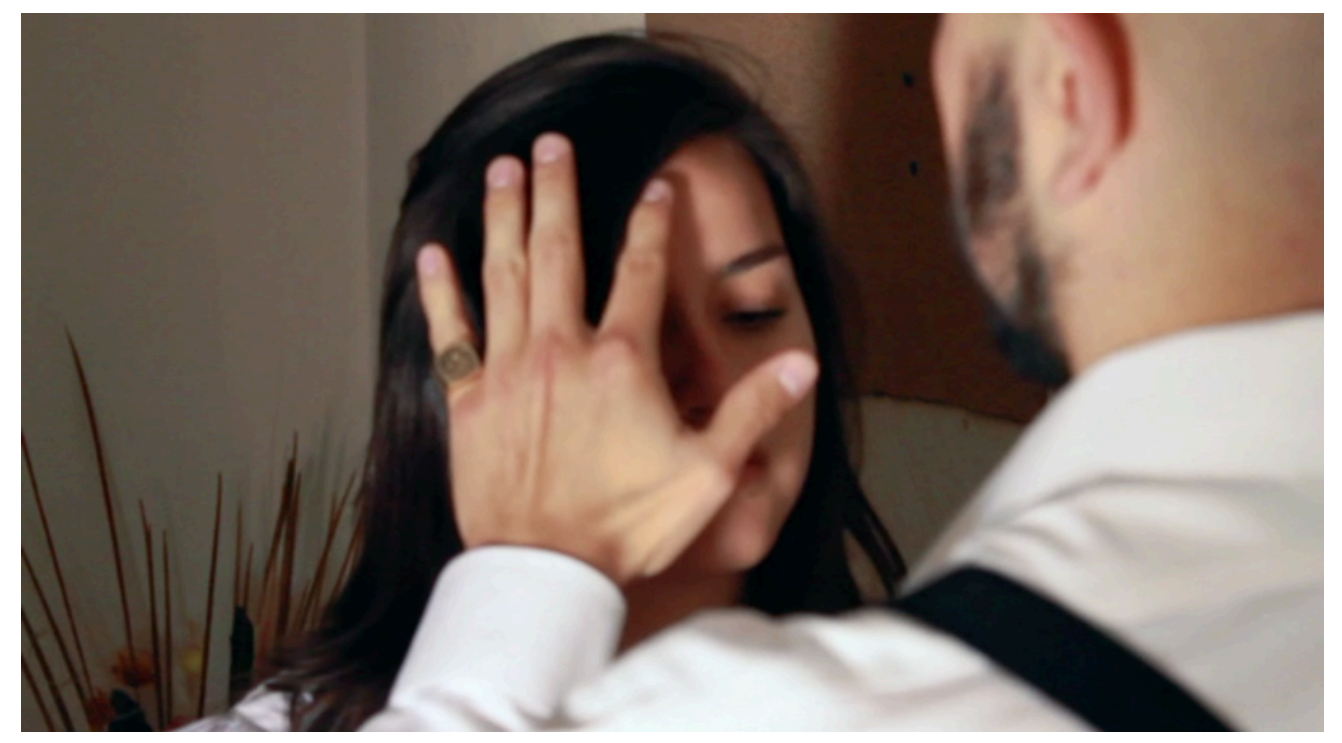

Sexual harassment in the workplace is a common experience. In surveys of women employees, up to two-thirds of respondents report

having been sexually harassed.

Wikimedia Commons - CC BY-SA 4.0.

The second reason that most targets of sexual harassment are women is more structural. Reflecting the gendered nature of the workplace and of the educational system, typically the men doing the harassment are in a position of power over the women they harass. A male boss harasses a female employee, or a male professor harasses a female student or employee. These men realize that subordinate women may find it difficult to resist their advances for fear of reprisals: A female employee may be fired or not promoted, and a female student may receive a bad grade.

How common is sexual harassment? This is difficult to determine, as the men who do the sexual harassment are not about to shout it from the rooftops, and the women who suffer it often keep quiet because of the repercussions just listed. But anonymous surveys of women employees in corporate and other settings commonly find that 40-65 percent of the respondents report being sexually harassed (Rospenda, Richman, \& Shannon, 2009). In a survey of 4,501 women physicians, 36.9 percent reported being sexually harassed either in medical school or in their practice as physicians (Frank, Brogan, \& Schiffman, 1998). In studies of college students, almost one-third of women undergraduates and about 40 percent of women graduate students report being sexually harassed by a faculty member (Clodfelter, Turner, Hartman, \& Kuhns, 2010).

Studies of people who have been sexually harassed find that they often experience various psychological problems. The Note 4.29 “Applying Social Research” box discusses this body of research further. 


\section{Applying Social Research}

The Long-Term Mental Health Consequences of Sexual Harassment

Despite the fact that sexual harassment is illegal, most women (and men) who are sexually harassed do not bring court action. Two reasons explain their decision not to sue: they fear being fired and/or they worry they will not be believed. But another reason has to do with the mental and emotional consequences of being sexually harassed. These consequences include relationship problems, a loss of self-esteem, fatigue, depression, anxiety, sleeplessness, and a feeling of powerlessness. These effects are similar to those for posttraumatic stress disorder and are considered symptoms of what has been termed sexual harassment trauma syndrome. This syndrome, and perhaps especially the feeling of powerlessness, are thought to help explain why sexual harassment victims hardly ever bring court action and otherwise often keep quiet. According to law professor Theresa Beiner, the legal system should become more aware of these psychological consequences as it deals with the important question in sexual harassment cases of whether harassment actually occurred. If a woman keeps quiet about the harassment, it is too easy for judges and juries to believe, as happens in rape cases, that the woman originally did not mind the behavior that she now says is harassment.

Should the legal system begin to make better use of social science research on sexual harassment trauma syndrome, a recent study by sociologist Jason N. Houle and colleagues provides important new evidence for legal officials to consider. The authors note two faults in prior sexual harassment research. First, most studies have focused on workers in a single occupation, such as lawyers, or in a single organization, such as a university campus, rather than in a diverse set of occupations and organizations. Second, because most studies have examined workers at only one point in time, they have been unable to study the long-term psychological consequences of sexual harassment.

To correct these deficiencies, Houle et al. analyzed data from a study of 1,010 ninth-graders in St. Paul, Minnesota, that followed them from 1988 to 2004, when they were 30 or 31 years old. The study included measures of the respondents' experience of sexual harassment at several periods over the study's sixteen-year time span (ages 14-18, 19-26, 29-30, and 30-31), their level of psychological depression, and their sociodemographic background. Focusing on depression at ages 30 or 31, the authors found that sexual harassment at ages 14-18 did not affect the chances of depression at ages 30-31, but that sexual harassment during any of the other three age periods did increase the chances of depression at ages 30-31. These results held true for both women and men who had been harassed. The authors concluded that the "effects of harassment are indeed lasting, as harassment experiences early in the career were associated with heightened depressive symptoms nearly 10 years later.”

In finding long-term effects of sexual harassment on women and men in a variety of occupations and organizational settings, Houle et al.'s study made an important contribution to our understanding of the psychological consequences of sexual harassment. Its findings underscore the need for workplaces and campuses to do everything possible to eliminate this illegal and harmful behavior and perhaps will prove useful in sexual harassment lawsuits.

Sources: Beiner, 2005; Houle, Staff, Mortimer, Uggen, \& Blackstone, 2011; Willness, Steel, \& Lee, 2007

\section{Women of Color: A Triple Burden}

Earlier we mentioned multicultural feminism, which stresses that women of color face difficulties for three reasons: their gender, their race, and, often, their social class, which is frequently near the bottom of the socioeconomic ladder. They thus face a triple burden that manifests itself in many ways.

For example, women of color experience extra income inequality. Earlier we discussed the gender gap in earnings, with women earning 82.2 percent of what men earn, but women of color face both a gender gap and a racial/ethnic gap. Table 4.3 "The Race/Ethnicity and Gender Gap in Annual Earnings for Full-Time, Year-Round Workers, 2010*” depicts this double gap for full-time workers. We see a racial/ethnic gap among both women and men, as African Americans and Latinos of either gender earn less than whites. We also see a gender gap between men and 
women, as women earn less than men within any race/ethnicity. These two gaps combine to produce an especially high gap between African American and Latina women and white men: African American women earn only about 70 percent of what white men earn, and Latina women earn only about 60 percent of what white men earn.

Table 4.3 The Race/Ethnicity and Gender Gap in Annual Earnings for Full-Time, Year-Round Workers, 2010*

\begin{tabular}{|l|l|l|}
\hline \multicolumn{2}{|c|}{ Annual earnings (\$) } & Percentage of white male earnings \\
\hline Men & & \\
\hline White (non-Hispanic) & 44,200 & - \\
\hline Black & 32,916 & 74.5 \\
\hline Latino & 26,416 & 59.8 \\
\hline Women & & \\
\hline White (non-Hispanic) & 35,568 & 80.5 \\
\hline Black & 30,784 & 69.7 \\
\hline Latina & 26,416 & 59.8 \\
\hline * Median weekly earnings $\times \mathbf{5 2}$ weeks & \\
\hline
\end{tabular}

Source: US Department of Labor. (2011). Highlights of women's earnings in 2010. Washington, DC: Author.

These differences in income mean that African American and Latina women are poorer than white women. We noted earlier that almost 32 percent of all female-headed families are poor. This figure masks race/ethnic differences among such families: 24.8 percent of families headed by non-Latina white women are poor, compared to 41.0 percent of families headed by African American women and also 44.5 percent of families headed by Latina women (DeNavas-Walt et al., 2011). While white women are poorer than white men, African American and Latina women are clearly poorer than white women.

\section{Household Inequality}

Gender inequality occurs within families and households. We will talk more about this aspect of family life in Chapter 10 "The Changing Family", but briefly discuss here one significant dimension of gender-based household inequality: housework. Someone has to do housework, and that someone is usually a woman. It takes many hours a week to clean the bathrooms, cook, shop in the grocery store, vacuum, and do everything else that needs to be done. The research evidence indicates that women married to or living with men spend two to three times as many hours per week on housework as men spend (Gupta \& Ash, 2008). This disparity holds true even when women work outside the home, leading sociologist Arlie Hochschild (Hochschild, 1989) to observe in a widely cited book that women engage in a "second shift" of unpaid work when they come home from their paying job.

The good news is that gender differences in housework time are smaller than a generation ago. The bad news is that a large gender difference remains. As one study summarized the evidence on this issue, "Women invest significantly more hours in household labor than do men despite the narrowing of gender differences in recent 
years” (Bianchi, Milkie, Sayer, \& Robinson, 2000, p. 196). In the realm of household work, then, gender inequality persists.

\section{Key Takeaways}

- Among full-time workers, women earn about 79.4 percent of men's earnings. This gender gap in earnings stems from several factors, including sex segregation in the workplace and the lower wages and salaries found in occupations that involve mostly women.

- Sexual harassment results partly from women's subordinate status in the workplace and may involve up to two-thirds of women employees.

- Women of color may face a "triple burden" of difficulties based on their gender, their race/ethnicity, and their social class.

\section{For Your Review}

1. Do you think it is fair for occupations dominated by women to have lower wages and salaries than those dominated by men? Explain your answer.

2. If you know a woman who works in a male-dominated occupation, interview her about any difficulties she might be experiencing as a result of being in this sort of situation.

\section{References}

Amnesty International. (2004). It's in our hands: Stop violence against women. Summary. London, United Kingdom: Author.

Amnesty International. (2010). "I can't afford justice": Violence against women in Uganda continues unpunished and unchecked. London, United Kingdom: Author.

Aud, S., Hussar, W., Kena, G., Bianco, K., Frohlich, L., Kemp, J., \& Tahan, K. (2011). The condition of education 2011 (NCES 2011-033). U.S. Department of Education, National Center for Education Statistics. Washington, DC: U.S. Government Printing Office. Retrieved from http://nces.ed.gov/pubs2011/2011033.pdf.

Beiner, T. (2005). Gender myths v. working realities: Using social science to reformulate sexual harassment law. New York, NY: New York University Press.

Bianchi, S. M., Milkie, M. A., Sayer, L. C., \& Robinson, J. P. (2000). Is anyone doing the housework? Trends in the gender division of household labor. Social Forces, 79(1), 191-228.

Bureau of Labor Statistics. (2012). 2012 employment and earnings online. Washington, DC: Author. Retrieved from http://www.bls.gov/opub/ee/home.htm. 
Chang, M. L. (2010). Shortchanged: Why women have less wealth and what can be done about it. New York, NY: Oxford University Press.

Clodfelter, T. A., Turner, M. G., Hartman, J. L., \& Kuhns, J. B. (2010). Sexual harassment victimization during emerging adulthood. Crime \& Delinquency, 56(3), 455-481.

DeNavas-Walt, C., Proctor, B. D., \& Smith, J. C. (2011). Income, poverty, and health insurance coverage in the United States: 2010 (Current Population Reports, P60-239). Washington, DC: US Census Bureau.

Frank, E., Brogan, D., \& Schiffman, M. (1998). Prevalence and correlates of harsssment among US women physicians. Archives of Internal Medicine, 158(4), 352-358.

Gupta, S., \& Ash, M. (2008). Whose money, whose time? A nonparametric approach to modeling time spent on housework in the United States. Feminist Economics, 14(1), 93-120.

Hochschild, A. (1989). The second shift: Working parents and the revolution at home. New York, NY: Viking.

Houle, J. N., Staff, J., Mortimer, J. T., Uggen, C., \& Blackstone, A. (2011). The impact of sexual harassment on depressive symptoms during the early occupational career. Society and Mental Health, 1, 89-105.

Hymowitz, C. (2009, May 1). For executive women, it can be lonely at the top. Forbes. Retrieved from http://www.forbes.com.

Jenner, L., \& Ferguson, R. (2009). 2008 catalyst census of women corporate officers and top earners of the FP500. New York, NY: Catalyst.

Kangas, O., \& Palme, J. (2009). Making social policy work for economic development: The Nordic experience. International Journal of Social Welfare, 18(s1), S62-S72.

Kaya, Y., \& Cook, K. J. (2010). A cross-national analysis of physical intimate partner violence against women. International Journal of Comparative Sociology, 5, 423-444.

Kelley, L. (2011, April 12). Today is equal pay day: Women still earn 77 cents to a man's dollar. AlterNet. Retrieved from http://www.alternet.org/rss/1/557442/ today_is_equal_pay_day\%557443A_women_still_earn_557477_cents_to_a_man \%557445C’s_dollar/; Reskin, B., \& Padavic, I. (2002). Women and men at work (2nd ed.). Thousand Oaks, CA: Pine Forge Press.

Kethineni, S., \& Srinivasan, M. (2009). Police handling of domestic violence cases in Tamil Nadu, India. Journal of Contemporary Criminal Justice, 25, 202-213.

Kristoff, N. D. (2011, May 12). A rite of torture for girls. New York Times, p. A29.

Kristoff, N. D., \& WuDunn, S. (2010). Half the sky: Turning oppression into opportunity for women worldwide. New York, NY: Vintage Books.

Leonhardt, D. (2010, August 4). A labor market punishing to mothers. New York Times, B1.

Levanon, A., England, P., \& Allison, P. (2009). Occupational feminization and pay: Assessing causal dynamics using 1950-2000 US census data. Social Forces, 88(2), 865-891. 
Magnusson, C. (2009). Gender, occupational prestige, and wages: A test of devaluation theory. European Sociological Review, 25(1), 87-101.

Polgreen, L. (2011, March 27). Rapes of women show clash of old and new India. New York Times, p. A8.

Reskin, B., \& Padavic, I. (2002). Women and men at work (2nd ed.). Thousand Oaks, CA: Pine Forge Press.

Rogo, K., Subayi, T., \& Toubia, N. (2007). Female genital cutting, women's health and development: The role of the World Bank. Washington, DC: Africa Region Human Development Department.

Rospenda, K. M., Richman, J. A., \& Shannon, C. A. (2009). Prevalence and mental health correlates of harassment and discrimination in the workplace: Results from a national study. Journal of Interpersonal Violence, 24(5), 819-843.

Sumer, S., Smithson, J., Guerreiro, M. D., \& Granlund, L. (2008). Becoming working mothers: Reconciling work and family at three particular workplaces in Norway, the UK, and Portugal. Community, Work \& Family, 11(4), 365-384.

United Nations Development Programme. (2009). Human development report 2009. New York, NY: Author. US Department of Labor. (2011). Highlights of women's earnings in 2010. Washington, DC: US Department of Labor.

Willness, C. R., Steel, P., \& Lee, K. (2007). A meta-analysis of the antecedents and consequences of workplace sexual harassment. Personnel Psychology, 60, 127-162.

World Bank. (2012). Data. Retrieved from http://data.worldbank.org.

World Health Organization/London School of Hygiene and Tropical Medicine. (2010). Preventing intimate partner and sexual violence against women: Taking action and generating evidence. Geneva, Switzerland: Author. 


\subsection{Violence against Women: Rape and Sexual Assault}

\section{Learning Objectives}

1. Describe the extent of rape and sexual assault.

2. Explain why rape and sexual assault occur.

Susan Griffin (1971, p. 26) began a classic essay on rape in 1971 with this startling statement: "I have never been free of the fear of rape. From a very early age I, like most women, have thought of rape as a part of my natural environment-something to be feared and prayed against like fire or lightning. I never asked why men raped; I simply thought it one of the many mysteries of human nature.”

When we consider interpersonal violence of all kinds-homicide, assault, robbery, and rape and sexual assault-men are more likely than women to be victims of violence. While true, this fact obscures another fact: Women are far more likely than men to be raped and sexually assaulted. They are also much more likely to be portrayed as victims of pornographic violence on the Internet and in videos, magazines, and other outlets. Finally, women are more likely than men to be victims of domestic violence, or violence between spouses and others with intimate relationships. The gendered nature of these acts against women distinguishes them from the violence men suffer. Violence is directed against men not because they are men per se, but because of anger, jealousy, and the sociological reasons discussed in Chapter 8 "Crime and Criminal Justice"'s treatment of deviance and crime. But rape and sexual assault, domestic violence, and pornographic violence are directed against women precisely because they are women. These acts are thus an extreme manifestation of the gender inequality women face in other areas of life. We discuss rape and sexual assault here but will leave domestic violence for Chapter 10 "The Changing Family" and pornography for Chapter 9 "Sexual Behavior".

\section{The Extent and Context of Rape and Sexual Assault}

Our knowledge about the extent and context of rape and reasons for it comes from three sources: the FBI Uniform Crime Reports (UCR) and the National Crime Victimization Survey (NCVS), both discussed in Chapter 8 "Crime and Criminal Justice”, and surveys of and interviews with women and men conducted by academic researchers. From these sources we have a fairly good if not perfect idea of how much rape occurs, the context in which it occurs, and the reasons for it. What do we know? 


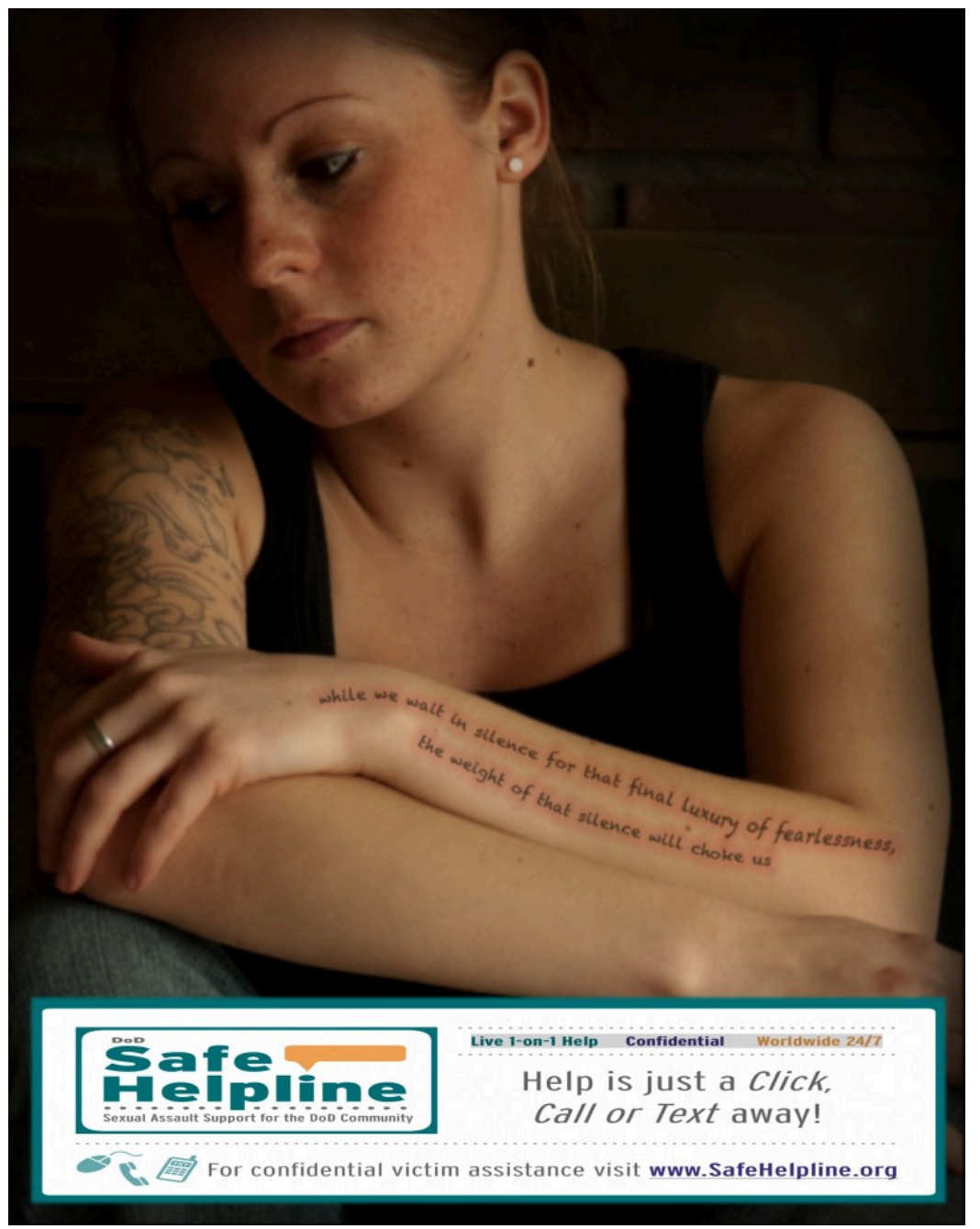

Up to one-third of US women experience a rape or sexual assault, including attempts, at least once in their lives.

Wikimedia Commons - public domain.

According to the UCR, which are compiled by the Federal Bureau of Investigation (FBI) from police reports, 88,767 reported rapes (including attempts, and defined as forced sexual intercourse) occurred in the United States in 2010 (Federal Bureau of Investigation, 2011). Because women often do not tell police they were raped, the NCVS, which involves survey interviews of thousands of people nationwide, probably yields a better estimate of rape; the NCVS also measures sexual assaults in addition to rape, while the UCR measures only rape. According to the NCVS, 188,380 rapes and sexual assaults occurred in 2010 (Truman, 2011). Other research indicates that up to one-third of US women will experience a rape or sexual assault, including attempts, at least once in their lives (Barkan, 2012). A study of a random sample of 420 Toronto women involving intensive interviews yielded an even higher figure: Two-thirds said they had experienced at least one rape or sexual assault, including attempts. The researchers, Melanie Randall and Lori Haskell (1995, p. 22), concluded that "it is more common than not for a woman to have an experience of sexual assault during their lifetime.”

Studies of college students also find a high amount of rape and sexual assault. About 20-30 percent of women students in anonymous surveys report being raped or sexually assaulted (including attempts), usually by a male 
student they knew beforehand (Fisher, Cullen, \& Turner, 2000; Gross, Winslett, Roberts, \& Gohm, 2006). Thus at a campus of 10,000 students of whom 5,000 are women, about 1,000-1,500 women will be raped or sexually assaulted over a period of four years, or about 10 per week in a four-year academic calendar. The Note 4.33 "People Making a Difference" box describes what one group of college students did to help reduce rape and sexual assault at their campus.

\section{People Making a Difference}

College Students Protest against Sexual Violence

Dickinson College is a small liberal-arts campus in the small town of Carlisle, Pennsylvania. But in the fight against sexual violence, it loomed huge in March 2011, when up to 150 students conducted a nonviolent occupation of the college's administrative building for three days to protest rape and sexual assault on their campus. While they read, ate, and slept inside the building, more than 250 other students held rallies outside, with the total number of protesters easily exceeding one-tenth of Dickinson's student enrollment. The protesters held signs that said "Stop the silence, our safety is more important than your reputation" and "I value my body, you should value my rights." One student told a reporter, "This is a pervasive problem. Almost every student will tell you they know somebody who's experienced sexual violence or have experienced it themselves."

Feeling that college officials had not done enough to help protect Dickinson's women students, the students occupying the administrative building called on the college to set up an improved emergency system for reporting sexual assaults, to revamp its judicial system's treatment of sexual assault cases, to create a sexual violence prevention program, and to develop a new sexual misconduct policy.

Rather than having police or security guards take the students from the administrative building and even arrest them, Dickinson officials negotiated with the students and finally agreed to their demands. Upon hearing this good news, the occupying students left the building on a Saturday morning, suffering from a lack of sleep and showers but cheered that they had won their demands. A college public relations official applauded the protesters, saying they "have indelibly left their mark on the college. We're all very proud of them.” On this small campus in a small town in Pennsylvania, a few hundred college students had made a difference.

Sources: Jerving, 2011; Pitz, 2011

The public image of rape is of the proverbial stranger attacking a woman in an alleyway. While such rapes do occur, most rapes actually happen between people who know each other. A wide body of research finds that 60-80 percent of all rapes and sexual assaults are committed by someone the woman knows, including husbands, exhusbands, boyfriends, and ex-boyfriends, and only 20-35 percent by strangers (Barkan, 2012). A woman is thus two to four times more likely to be raped by someone she knows than by a stranger.

In 2011, sexual assaults of hotel housekeepers made major headlines after the head of the International Monetary Fund was arrested for allegedly sexually assaulting a hotel housekeeper in New York City; the charges were later dropped because the prosecution worried about the housekeeper's credibility despite forensic evidence supporting her claim. Still, in the wake of the arrest, news stories reported that hotel housekeepers sometimes encounter male guests who commit sexual assault, make explicit comments, or expose themselves. A hotel security expert said in one news story, "These problems happen with some regularity. They're not rare, but they're not common either." A housekeeper recalled in the same story an incident when she was vacuuming when a male guest appeared: "[He] reached to try to kiss me behind my ear. I dropped my vacuum, and then he grabbed my body at the waist, and he was holding me close. It was very scary." She ran out of the room when the guest let her leave but did not call the police. A hotel workers union official said housekeepers often refused to report sexual assault and other 
incidents to the police because they were afraid they would not be believed or that they would get fired if they did so (Greenhouse, 2011, p. B1).

\section{Explaining Rape and Sexual Assault}

Sociological explanations of rape fall into cultural and structural categories similar to those presented earlier for sexual harassment. Various "rape myths" in our culture support the absurd notion that women somehow enjoy being raped, want to be raped, or are "asking for it” (Franiuk, Seefelt, \& Vandello, 2008). One of the most famous scenes in movie history occurs in the classic film Gone with the Wind, when Rhett Butler carries a struggling Scarlett O’Hara up the stairs. She is struggling because she does not want to have sex with him. The next scene shows Scarlett waking up the next morning with a satisfied, loving look on her face. The not-so-subtle message is that she enjoyed being raped (or, to be more charitable to the film, was just playing hard to get).

A related cultural belief is that women somehow ask or deserve to be raped by the way they dress or behave. If she dresses attractively or walks into a bar by herself, she wants to have sex, and if a rape occurs, well, then, what did she expect? In the award-winning film The Accused, based on a true story, actress Jodie Foster plays a woman who was raped by several men on top of a pool table in a bar. The film recounts how members of the public questioned why she was in the bar by herself if she did not want to have sex and blamed her for being raped.

A third cultural belief is that a man who is sexually active with a lot of women is a stud and thus someone admired by his male peers. Although this belief is less common in this day of AIDS and other STDs, it is still with us. A man with multiple sex partners continues to be the source of envy among many of his peers. At a minimum, men are still the ones who have to "make the first move" and then continue making more moves. There is a thin line between being sexually assertive and sexually aggressive (Kassing, Beesley, \& Frey, 2005).

These three cultural beliefs - that women enjoy being forced to have sex, that they ask or deserve to be raped, and that men should be sexually assertive or even aggressive-combine to produce a cultural recipe for rape. Although most men do not rape, the cultural beliefs and myths just described help account for the rapes that do occur. Recognizing this, the contemporary women's movement began attacking these myths back in the 1970s, and the public is much more conscious of the true nature of rape than a generation ago. That said, much of the public still accepts these cultural beliefs and myths, and prosecutors continue to find it difficult to win jury convictions in rape trials unless the woman who was raped had suffered visible injuries, had not known the man who raped her, and/or was not dressed attractively (Levine, 2006).

Structural explanations for rape emphasize the power differences between women and men similar to those outlined earlier for sexual harassment. In societies that are male dominated, rape and other violence against women is a likely outcome, as they allow men to demonstrate and maintain their power over women. Supporting this view, studies of preindustrial societies and of the fifty states of the United States find that rape is more common in societies where women have less economic and political power (Baron \& Straus, 1989; Sanday, 1981). Poverty is also a predictor of rape; although rape in the United States transcends social class boundaries, it does seem more common among poorer segments of the population than among wealthier segments, as is true for other types of violence (Truman \& Rand, 2010). Scholars think the higher rape rates among the poor stem from poor 
men trying to prove their "masculinity" by taking out their economic frustration on women (Martin, Vieraitis, \& Britto, 2006).

\section{Key Takeaways}

- Up to one-third of US women experience a rape or sexual assault, including attempts, in their lifetime.

- Rape and sexual assault result from a combination of structural and cultural factors. In states and nations where women are more unequal, rape rates tend to be higher.

\section{For Your Review}

1. What evidence and reasoning indicate that rape and sexual assault are not just the result of psychological problems affecting the men who engage in these crimes?

2. Write a brief essay in which you critically evaluate the cultural beliefs that contribute to rape and sexual assault.

\section{References}

Barkan, S. E. (2012). Criminology: A sociological understanding (5th ed.). Upper Saddle River, NJ: Prentice Hall.

Baron, L., \& Straus, M. A. (1989). Four theories of rape in American society: A state-level analysis. New Haven, CT: Yale University Press.

Federal Bureau of Investigation. (2011). Crime in the United States, 2010. Washington, DC: Author.

Fisher, B. S., Cullen, F. T., \& Turner, M. G. (2000). The sexual victimization of college women. Washington, DC: National Institute of Justice.

Franiuk, R., Seefelt, J., \& Vandello, J. (2008). Prevalence of rape myths in headlines and their effects on attitudes toward rape. Sex Roles, 58(11/12), 790-801.

Greenhouse, S. (2011, May 21). Sexual affronts a known hotel hazard. New York Times, p. B1.

Griffin, S. (1971, September). Rape: The all-American crime. Ramparts, 10, $26-35$.

Gross, A. M., Winslett, A., Roberts, M., \& Gohm, C. L. (2006). An examination of sexual violence against college women. Violence Against Women, 12, 288-300.

Jerving, S. (2011, March 4). Pennsylvania students protest against sexual violence and administrators respond. The Nation. Retrieved from http://www.thenation.com/blog/159037/pennsylvania-students-protests-againstsexual-violence-and-administrators-respond. 
Kassing, L. R., Beesley, D., \& Frey, L. L. (2005). Gender role conflict, homophobia, age, and education as predictors of male rape myth acceptance. Journal of Mental Health Counseling, 27(4), 311-328.

Levine, K. L. (2006). The intimacy discount: Prosecutorial discretion, privacy, and equality in the statuory rape caseload. Emory Law Journal, 55(4), 691-749.

Martin, K., Vieraitis, L. M., \& Britto, S. (2006). Gender equality and women's absolute status: A test of the feminist models of rape. Violence Against Women, 12, 321-339.

Pitz, M. (2011, March 6). Dickinson College to change sexual assault policy after sit-in. Pittsburgh Post-Gazette. Retrieved from http://www.post-gazette.com/pg/11065/1130102-1130454.stm.

Randall, M., \& Haskell, L. (1995). Sexual violence in women’s lives: Findings from the women's safety project, a community-based survey. Violence Against Women, 1, 6-31.

Sanday, P. R. (1981). The Socio-Cultural Context of Rape: A Cross-Cultural Study. Journal of Social Issues, 37, 5-27.

Truman, J. L., \& Rand, M. R. (2010). Criminal victimization, 2009. Washington, DC: Bureau of Justice Statistics. 


\subsection{The Benefits and Costs of Being Male}

\section{Learning Objectives}

1. List some of the benefits of being male.

2. List some of the costs of being male.

Most of the discussion so far has been about women, and with good reason: In a sexist society such as our own, women are the subordinate, unequal sex. But gender means more than female, and a few comments about men are in order.

\section{Benefits}

We have already discussed gender differences in occupations and incomes that favor men over women. In a patriarchal society, men have more wealth than women and more influence in the political and economic worlds more generally.

Men profit in other ways as well. In Chapter 3 "Racial and Ethnic Inequality", we talked about white privilege, or the advantages that whites automatically have in a racist society whether or not they realize they have these advantages. Many scholars also talk about male privilege, or the advantages that males automatically have in a patriarchal society whether or not they realize they have these advantages (McIntosh, 2007).

A few examples illustrate male privilege. Men can usually walk anywhere they want or go into any bar they want without having to worry about being raped or sexually harassed. Susan Griffin was able to write "I have never been free of the fear of rape" because she was a woman; it is no exaggeration to say that few men could write the same thing and mean it. Although some men are sexually harassed, most men can work at any job they want without having to worry about sexual harassment. Men can walk down the street without having strangers make crude remarks about their looks, dress, and sexual behavior. Men can ride the subway system in large cities without having strangers grope them, flash them, or rub their bodies against them. Men can apply for most jobs without worrying about being rejected because of their gender, or, if hired, not being promoted because of their gender. We could go on with many other examples, but the fact remains that in a patriarchal society, men automatically have advantages just because they are men, even if race/ethnicity, social class, and sexual orientation affect the degree to which they are able to enjoy these advantages. 


\section{Costs}

Yet it is also true that men pay a price for living in a patriarchy. Without trying to claim that men have it as bad as women, scholars are increasingly pointing to the problems men face in a society that promotes male domination and traditional standards of masculinity such as assertiveness, competitiveness, and toughness (Kimmel \& Messner, 2010). Socialization into masculinity is thought to underlie many of the emotional problems men experience, which stem from a combination of their emotional inexpressiveness and reluctance to admit to, and seek help for, various personal problems (Wong \& Rochlen, 2005). Sometimes these emotional problems build up and explode, as mass shootings by males at schools and elsewhere indicate, or express themselves in other ways. Compared to girls, for example, boys are much more likely to be diagnosed with emotional disorders, learning disabilities, and attention deficit disorder, and they are also more likely to commit suicide and to drop out of high school.

Men experience other problems that put themselves at a disadvantage compared to women. They commit much more violence than women do and, apart from rape and sexual assault, also suffer a much higher rate of violent victimization. They die earlier than women and are injured more often. Because men are less involved than women in child rearing, they also miss out on the joy of parenting that women are much more likely to experience.

Growing recognition of the problems males experience because of their socialization into masculinity has led to increased concern over what is happening to American boys. Citing the strong linkage between masculinity and violence, some writers urge parents to raise their sons differently in order to help our society reduce its violent behavior (Corbett, 2011). In all these respects, boys and men — and our nation as a whole — are paying a very real price for being male in a patriarchal society.

\section{Key Takeaways}

- In a patriarchal society, males automatically have certain advantages, including a general freedom from fear of being raped and sexually assaulted and from experiencing job discrimination on the basis of their gender.

- Men also suffer certain disadvantages from being male, including higher rates of injury, violence, and death and a lower likelihood of experiencing the joy that parenting often brings.

\section{For Your Review}

1. What do you think is the most important advantage, privilege, or benefit that men enjoy in the United States? Explain your answer.

2. What do you think is the most significant cost or disadvantage that men experience? Again, explain your answer. 


\section{References}

Corbett, K. (2011). Boyhoods: Rethinking masculinities. New Haven, CT: Yale University Press.

Kimmel, M. S., \& Messner, M. A. (Eds.). (2010). Men’s lives (8th ed.). Boston, MA: Allyn \& Bacon.

McIntosh, P. (2007). White privilege and male privilege: A personal account of coming to see correspondence through work in women's studies. In M. L. Andersen \& P. H. Collins (Eds.), Race, class, and gender: An anthology (6th ed.). Belmont, CA: Wadsworth.

Wong, Y. J., \& Rochlen, A. B. (2005). Demystifying men’s emotional behavior: New directions and implications for counseling and research. Psychology of Men \& Masculinity, 6, 62-72. 


\subsection{Reducing Gender Inequality}

\section{Learning Objectives}

1. Describe any three policies or programs that should help reduce gender inequality.

2. Discuss possible ways of reducing rape and sexual assault.

Gender inequality is found in varying degrees in most societies around the world, and the United States is no exception. Just as racial/ethnic stereotyping and prejudice underlie racial/ethnic inequality (see Chapter 3 "Racial and Ethnic Inequality"), so do stereotypes and false beliefs underlie gender inequality. Although these stereotypes and beliefs have weakened considerably since the 1970s thanks in large part to the contemporary women's movement, they obviously persist and hamper efforts to achieve full gender equality.

A sociological perspective reminds us that gender inequality stems from a complex mixture of cultural and structural factors that must be addressed if gender inequality is to be reduced further than it already has been since the 1970s. Despite changes during this period, children are still socialized from birth into traditional notions of femininity and masculinity, and gender-based stereotyping incorporating these notions still continues. Although people should certainly be free to pursue whatever family and career responsibilities they desire, socialization and stereotyping still combine to limit the ability of girls and boys and women and men alike to imagine less traditional possibilities. Meanwhile, structural obstacles in the workplace and elsewhere continue to keep women in a subordinate social and economic status relative to men.

To reduce gender inequality, then, a sociological perspective suggests various policies and measures to address the cultural and structural factors that help produce gender inequality. These steps might include, but are not limited to, the following:

1. Reduce socialization by parents and other adults of girls and boys into traditional gender roles.

2. Confront gender stereotyping by the popular and news media.

3. Increase public consciousness of the reasons for, extent of, and consequences of rape and sexual assault, sexual harassment, and pornography.

4. Increase enforcement of existing laws against gender-based employment discrimination and against sexual harassment.

5. Increase funding of rape-crisis centers and other services for girls and women who have been raped and/or sexually assaulted.

6. Increase government funding of high-quality day-care options to enable parents, and especially mothers, to work outside the home if they so desire, and to do so without fear that their finances or their children's well-being will be compromised. 
7. Increase mentorship and other efforts to boost the number of women in traditionally male occupations and in positions of political leadership.

As we consider how best to reduce gender inequality, the impact of the contemporary women's movement must be neither forgotten nor underestimated. Since it began in the late 1960s, the women's movement has generated important advances for women in almost every sphere of life. Brave women (and some men) challenged the status quo by calling attention to gender inequality in the workplace, education, and elsewhere, and they brought rape and sexual assault, sexual harassment, and domestic violence into the national consciousness. For gender inequality to continue to be reduced, it is essential that a strong women's movement continue to remind us of the sexism that still persists in American society and the rest of the world.

\section{Reducing Rape and Sexual Assault}

As we have seen, gender inequality also manifests itself in the form of violence against women. A sociological perspective tells us that cultural myths and economic and gender inequality help lead to rape, and that the rape problem goes far beyond a few psychopathic men who rape women. A sociological perspective thus tells us that our society cannot just stop at doing something about these men. Instead it must make more far-reaching changes by changing people's beliefs about rape and by making every effort to reduce poverty and to empower women. This last task is especially important, for, as Randall and Haskell (1995, p. 22) observed, a sociological perspective on rape "means calling into question the organization of sexual inequality in our society."

Aside from this fundamental change, other remedies, such as additional and better funded rape-crisis centers, would help women who experience rape and sexual assault. Yet even here women of color face an additional barrier. Because the antirape movement was begun by white, middle-class feminists, the rape-crisis centers they founded tended to be near where they live, such as college campuses, and not in the areas where women of color live, such as inner cities and Native American reservations. This meant that women of color who experienced sexual violence lacked the kinds of help available to their white, middle-class counterparts (Matthews, 1989), and despite some progress, this is still true today.

\section{Key Takeaways}

- Certain government efforts, including increased financial support for child care, should help reduce gender inequality.

- If gender inequality lessens, rape and sexual assault should decrease as well.

\section{For Your Review}

1. To reduce gender inequality, do you think efforts should focus more on changing socialization practices or on changing policies in the workplace and schools? Explain your answer. 
2. How hopeful are you that rape and sexual assault will decrease significantly in your lifetime?

\section{References}

Matthews, N. A. (1989). Surmounting a legacy: The expansion of racial diversity in a local anti-rape movement. Gender \& Society, 3, 518-532.

Randall, M., \& Haskell, L. (1995). Sexual violence in women’s lives: Findings from the women's safety project, a community-based survey. Violence Against Women, 1, 6-31. 


\subsection{End-of-Chapter Material}

\section{Summary}

1. Sex is a concept that refers to biological differences between females and males, while gender is a concept that refers to a society's expectations of how females and males should think and behave.

2. In understanding gender differences, scholars continue to debate the value of biological explanations. Biological explanations are provocative but ultimately imply that gender differences are inevitable and that the status quo must be maintained. In contrast, cultural and socialization explanations imply some hope for changing gender roles and for reducing gender inequality.

3. Many studies emphasize that socialization leads children in the United States to adopt the gender roles associated with femininity and masculinity. Parents view and interact with their daughters and sons differently, and children continue to learn their gender roles from their peers, schools, the mass media, and religion.

4. Feminism refers to the belief that women should be equal to men. With feminism defined in this way, many more people hold feminist beliefs than might be willing to admit to it.

5. Gender inequality in the workplace is manifested through the gender gap in earnings and through sexual harassment. Women earn only about 80 percent of what men earn. Several reasons account for this gap, including sex segregation in the workplace, women's caring roles, the devaluing of women's work, and outright sex discrimination by employers. Sexual harassment against women is quite common and stems from cultural beliefs about women's and men's roles and structural differences in the workplace in power between women and men.

6. Women of color experience a triple burden based on their gender, race/ethnicity, and social class. Even though white women earn less money and are poorer than white men, women of color earn less money and are poorer than white women.

7. Violence against women is another manifestation of gender inequality. Research shows that up to one-third of US women will be raped or sexually assaulted and that about 70-80 percent of their assailants will be men they know.

8. In a patriarchal society men enjoy privileges just for being male, whether or not they recognize these privileges. At the same time, men also experience disadvantages, including violent behavior and victimization and higher rates of certain emotional problems than those experienced by women.

\section{Using What You Know}

A friend of yours is working twenty hours per week in a local restaurant during the academic year to earn money for her tuition. She tells you that her manager has pressured her to go out on a date with him and has hinted she could be fired if she refuses. Your friend likes working there otherwise and makes good tips, but she is now dreading having to go to work. With the tight job market, she fears not being able to find other work if she quits, and she's afraid of being fired or not believed if she complains to state authorities. She asks you what she should do. What do you tell her? 


\section{What You Can Do}

To help reduce gender inequality, you may wish to do any of the following:

1. Contribute money to a local, state, or national organization that provides treatment to adolescent girls with drug, alcohol, or other problems.

2. Volunteer at a rape crisis center or for a rape hotline.

3. Start or join a group on your campus that focuses on gender issues.

4. Start or join a group on your campus or in the local community that focuses on getting middle-school girls more interested in math and the sciences. 


\section{Chapter 5: Sexual Orientation and Inequality}

\section{Social Problems in the News}

"Miami Beach to Fire Two Officers in Gay Beating at Park," the headline said. City officials in Miami Beach, Florida, announced that the city would fire two police officers accused of beating a gay man two years earlier and kicking and arresting a gay tourist who came to the man's defense. The tourist said he called 911 when he saw two officers, who were working undercover, beating the man and kicking his head. According to his account, the officers then shouted antigay slurs at him, kicked him, and arrested him on false charges. The president of Miami Beach Gay Pride welcomed the news of the impending firing. "It sets a precedent that you can't discriminate against anyone and get away with it," he said. "[The two officers] tried to cover it up and arrested the guy. It’s an abuse of power. Kudos to the city. They’ve taken it seriously.”

Source: Smiley \& Rothaus, 2011

From 1933 to 1945, Adolf Hitler's Nazi regime exterminated 6 million Jews in the Holocaust, but it also persecuted millions of other people, including gay men. Nazi officials alleged that these men harbored what they termed a "degeneracy” that threatened Germany’s “disciplined masculinity.” Calling gay men "antisocial parasites" and "enemies of the state," the Nazi government arrested more than 100,000 men for violating a law against homosexuality, although it did not arrest lesbians because it valued their child-bearing capacity. At least 5,000 gay men were imprisoned, and many more were put in mental institutions. Several hundred other gay men were castrated, and up to 15,000 were placed in concentration camps, where most died from disease, starvation, or murder. As the United States Holocaust Memorial Museum (2011) summarizes these events, "Nazi Germany did not seek to kill all homosexuals. Nevertheless, the Nazi state, through active persecution, attempted to terrorize German homosexuals into sexual and social conformity, leaving thousands dead and shattering the lives of many more.”

This terrible history reminds us that sexual orientation has often resulted in inequality of many kinds, and, in the extreme case of the Nazis, inhumane treatment that included castration, imprisonment, and death. The news story that began this chapter makes clear that sexual orientation still results in violence, even if this violence falls short of what the Nazis did. Although the gay rights movement has achieved much success, sexual orientation continues to result in other types of inequality as well. This chapter examines the many forms of inequality linked to sexual orientation today. It begins with a conceptual discussion of sexual orientation before turning to its history, explanation, types of inequality, and other matters.

\section{References}

Smiley, D. \& Rothaus, S. (2011, July 25). Miami Beach to fire two officers in gay beating at park. The Miami 
Herald. Retrieved from http://miamiherald.typepad.com/gaysouthflorida/2011/07/miami-beach-to-fire-two-copswho-beat-falsely-arrested-gay-man-at-flamingo-park.html.

United States Holocaust Memorial Museum. (2011). Nazi persecution of homosexuals 1933-1945. Retrieved August 14, 2011, from http://www.ushmm.org/museum/exhibit/online/hsx/. 


\subsection{Understanding Sexual Orientation}

\section{Learning Objectives}

1. Define sexual orientation and gender identity.

2. Describe what percentage of the US population is estimated to be LGBT.

3. Summarize the history of sexual orientation.

4. Evaluate the possible reasons for sexual orientation.

Sexual orientation refers to a person's preference for sexual relationships with individuals of the other sex (heterosexuality), one's own sex (homosexuality), or both sexes (bisexuality). The term also increasingly refers to transgender (also transgendered) individuals, those whose behavior, appearance, and/or gender identity (the personal conception of oneself as female, male, both, or neither) departs from conventional norms. Transgendered individuals include transvestites (those who dress in the clothing of the opposite sex) and transsexuals (those whose gender identity differs from their physiological sex and who sometimes undergo a sex change). A transgender woman is a person who was born biologically as a male and becomes a woman, while a transgender man is a person who was born biologically as a woman and becomes a man. As you almost certainly know, gay is the common term now used for any homosexual individual; gay men or gays is the common term used for homosexual men, while lesbian is the common term used for homosexual women. All the types of social orientation just outlined are often collectively referred to by the shorthand LGBT (lesbian/gay/bisexual/ transgender). As you almost certainly also know, the term straight is used today as a synonym for heterosexual.

\section{Counting Sexual Orientation}

We will probably never know precisely how many people are gay, lesbian, bisexual, or transgendered. One problem is conceptual. For example, what does it mean to be gay or lesbian? Does one need to actually have sexual relations with a same-sex partner to be considered gay? What if someone is attracted to same-sex partners but does not actually engage in sex with such persons? What if someone identifies as heterosexual but engages in homosexual sex for money (as in certain forms of prostitution) or for power and influence (as in much prison sex)? These conceptual problems make it difficult to determine the extent of homosexuality (Gates, 2011). 


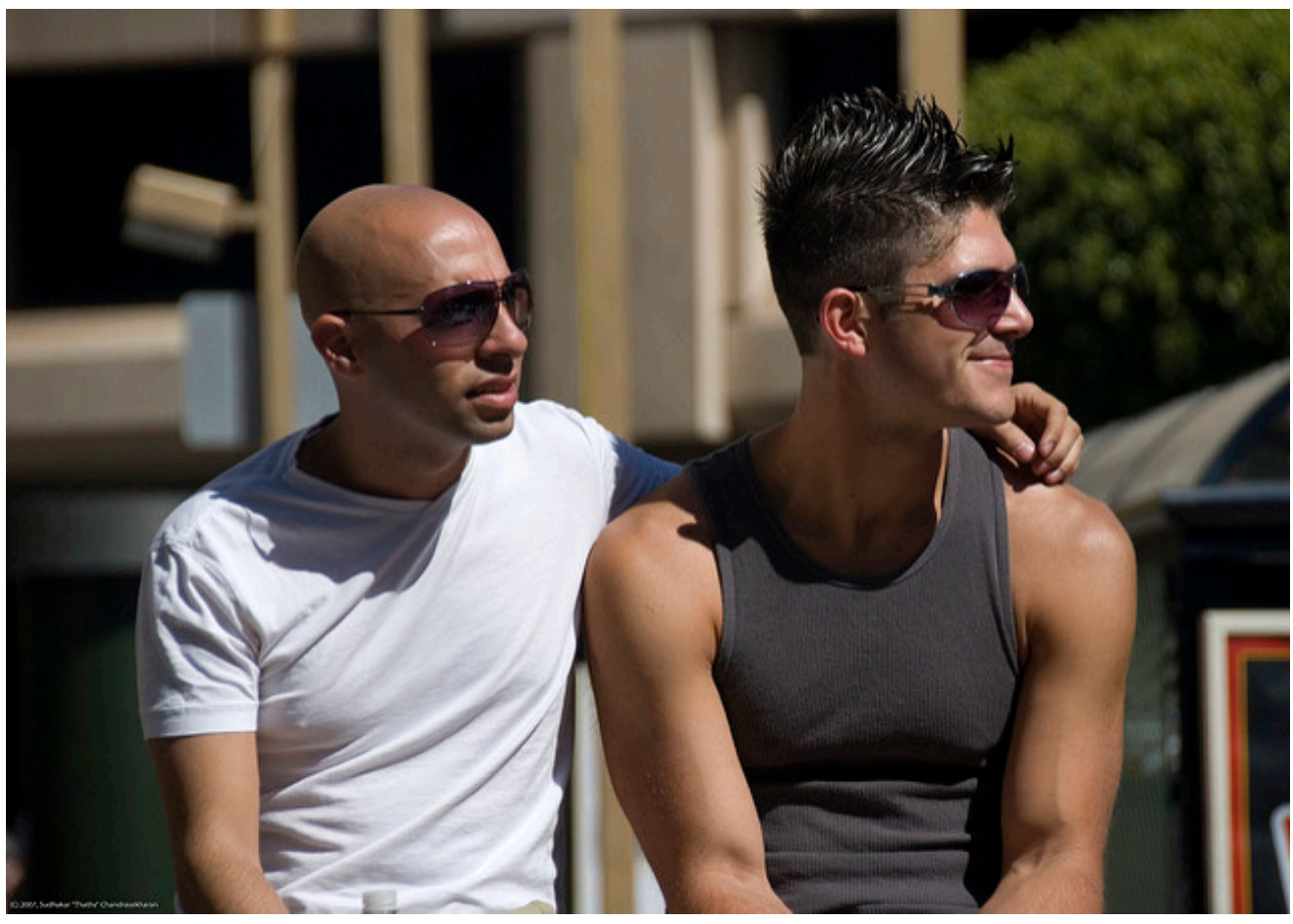

It is difficult for several reasons to know exactly how many people are LGBT.

thaths - A gay couple watching the parade - CC BY-NC 2.0.

A second problem is empirical. Even if we can settle on a definition of homosexuality, how do we then determine how many people fit this definition? For better or worse, our best evidence of the number of gays and lesbians in the United States comes from surveys that ask random samples of Americans various questions about their sexuality. Although these are anonymous surveys, some individuals may be reluctant to disclose their sexual activity and thoughts to an interviewer. Still, scholars think that estimates from these surveys are fairly accurate but also that they probably underestimate by at least a small amount the number of gays and lesbians.

During the 1940s and 1950s, sex researcher Alfred C. Kinsey carried out the first notable attempt to estimate the number of gays and lesbians (Kinsey, Pomeroy, \& Martin, 1948; Kinsey, Pomeroy, Martin, \& Gebhard, 1953). His project interviewed more than 11,000 white women and men about their sexual experiences, thoughts, and attractions, with each subject answering hundreds of questions. While most individuals had experiences and feelings that were exclusively heterosexual, a significant number had experiences and feelings that were either exclusively homosexual or both heterosexual and homosexual in varying degrees. These findings led Kinsey to reject the popular idea back then that a person is necessarily either heterosexual or homosexual (or straight or gay, to use the common modern terms). As he wrote, "It is a characteristic of the human mind that tries to dichotomize in its classification of phenomena... Sexual behavior is either normal or abnormal, socially acceptable or unacceptable, heterosexual or homosexual; and many persons do not want to believe that there are gradations in these matters from one to the other extreme” (Kinsey et al., 1953, p. 469). Perhaps Kinsey’s most significant and controversial finding was that gradations did, in fact, exist between being exclusively heterosexual on the one hand and exclusively homosexual on the other hand. To reflect these gradations, he developed the well-known Kinsey Scale, which ranks individuals on a continuum ranging from 0 (exclusively heterosexual) to 6 (exclusively homosexual). 
In terms of specific numbers, Kinsey found that (a) 37 percent of males and 13 percent of females had had at least one same-sex experience; (b) 10 percent of males had mostly homosexual experiences between the ages of 16 and 55, while up to 6 percent of females had mostly homosexual experiences between the ages of 20 and 35; (c) 4 percent of males were exclusively homosexual after adolescence began, compared to 1-3 percent of females; and (d) 46 percent of males either had engaged in both heterosexual and homosexual experiences or had been attracted to persons of both sexes, compared to 14 percent of females.

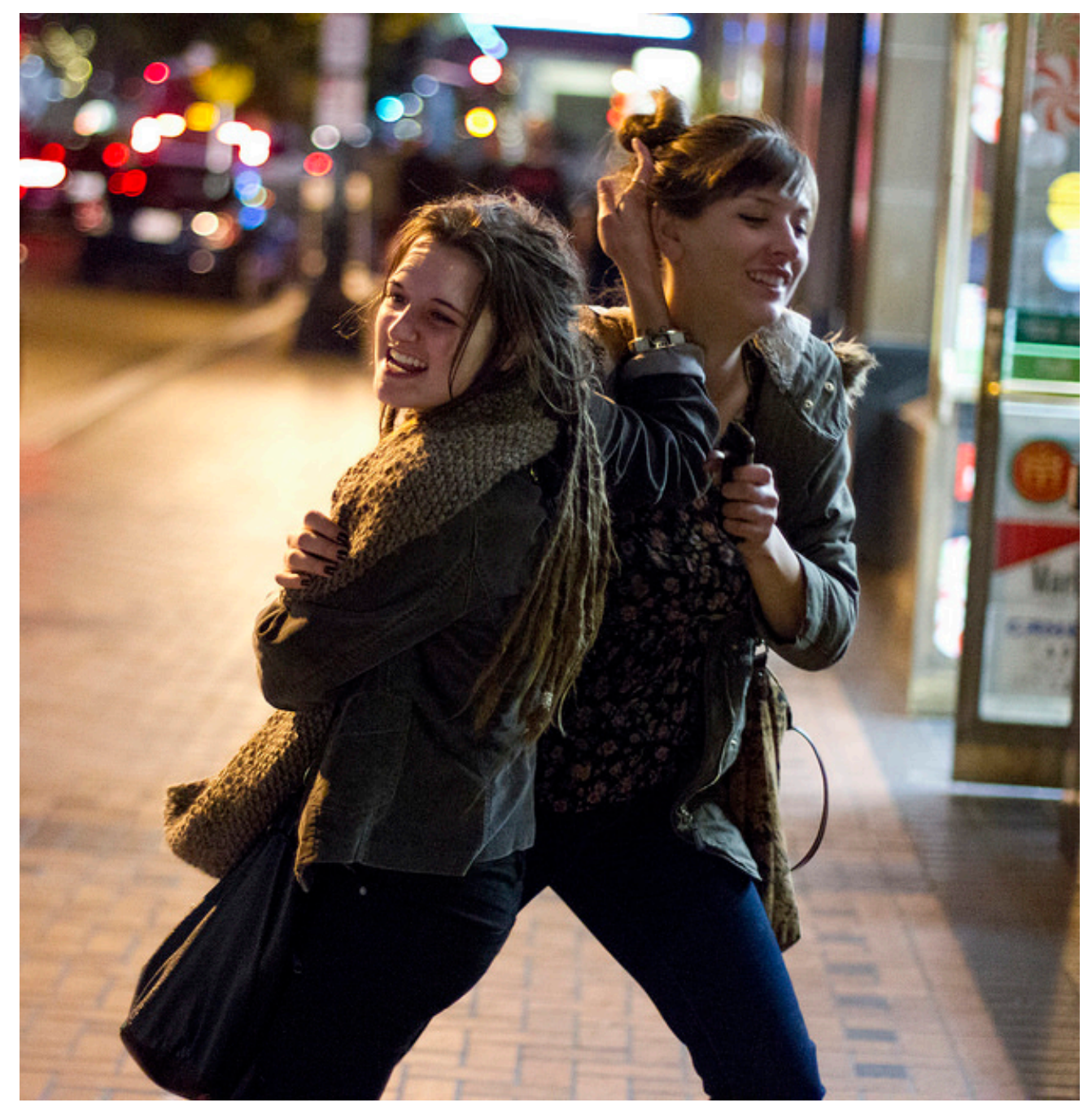

An estimated 3.8 percent of the US adult population identifies as LGBT. This figure amounts to about 9 million people.

Nathan Rupert - Crazy fun loving lesbian couple - CC BY-NC-ND 2.0.

More recent research updates Kinsey's early findings and, more important, uses nationally representative samples of Americans (which Kinsey did not use). In general, this research suggests that Kinsey overstated the numbers of Americans who have had same-sex experiences and/or attractions. A widely cited survey carried out in the early 1990s by researchers at the University of Chicago found that 2.8 percent of men and 1.4 percent of women selfidentified as gay/lesbian or bisexual, with greater percentages reporting having had sexual relations with samesex partners or being attracted to same-sex persons (see Table 5.1 "Prevalence of Homosexuality in the United States”). In the 2010 General Social Survey (GSS), 1.8 percent of men and 3.3 percent of women self-identified as gay/lesbian or bisexual. In the 2006-2008 National Survey of Family Growth (NSFG) conducted by the federal 
government (Chandra, Mosher, Copen, \& Sionean, 2011), 2.8 percent of men self-identified as gay or bisexual, compared to 4.6 percent of women (ages 18-44 for both sexes).

Table 5.1 Prevalence of Homosexuality in the United States

\begin{tabular}{|l|l|l|}
\hline Activity, attraction, or identity & Men (\%) & Women (\%) \\
\hline Find same-sex sexual relations appealing & 4.5 & 5.6 \\
\hline Attracted to people of same sex & 6.2 & 4.4 \\
\hline Identify as gay or bisexual & 2.8 & 1.4 \\
\hline At least one sex partner of same sex during past year among those sexually active & 2.7 & 1.3 \\
\hline At least one sex partner of same sex since turning 18 & 4.9 & 4.1 \\
\hline
\end{tabular}

Source: Data from Laumann, E. O., Gagnon, J. H., Michael, R. T., \& Michaels, S. (1994). The social organization of sexuality. Chicago, IL: University of Chicago Press.

These are all a lot of numbers, but demographer Gary J. Gates (2011) drew on the most recent national survey evidence to come up with the following estimates for adults 18 and older:

- 3.5 percent of Americans identify as gay, lesbian, or bisexual, and 0.3 percent are transgender; these figures add up to 3.8 percent of Americans, or 9 million people, who are LGBT.

- 3.4 percent of women and 3.6 percent of men identify as LGB.

- 66.7 percent of LGB women identify as bisexual, and 33.3 percent identify as lesbian; 33.3 percent of LGB men identify as bisexual, and 66.7 percent identify as gay. LGB women are thus twice as likely as LGB men to identify as bisexual.

- 8.2 percent of Americans, or 19 million people, have engaged in same-sex sexual behavior, with women twice as likely as men to have done so.

- 11 percent of Americans, or 25.6 million people, report having some same-sex sexual attraction, with women twice as likely as men to report such attraction.

The overall picture from these estimates is clear: Self-identified LGBT people comprise only a small percentage of the US population, but they amount to about 9 million adults and undoubtedly a significant number of adolescents. In addition, the total number of people who, regardless of their sexual orientation, have had a same-sex experience is probably at least 19 million, and the number who have had same-sex attraction is probably at least 25 million.

\section{Sexual Orientation in Historical Perspective}

Based on what is known about homosexuality in past societies, it should be no surprise that so many people in the United States identify as gay/lesbian or have had same-sex experiences. This historical record is clear: Homosexuality has existed since ancient times and in some societies has been rather common or at least fully accepted as a normal form of sexual expression. 
In the great city of Athens in ancient Greece, male homosexuality (to be more precise, sexual relations between a man and a teenaged boy and, less often, between a man and a man) was not only approved but even encouraged. According to classical scholar K. J. Dover (1989, p. 12), Athenian society "certainly regarded strong homosexual desire and emotion as normal," in part because it also generally "entertained a low opinion of the intellectual capacity and staying-power of women.” Louis Crompton (2003, p. 2), who wrote perhaps the definitive history of homosexuality, agrees that male homosexuality in ancient Greece was common and notes that "in Greek history and literature...the abundance of accounts of homosexual love overwhelms the investigator.” He adds,

Greek lyric poets sing of male love from almost the earliest fragments down to the end of classical times...Vase-painters portray scores of homoerotic scenes, hundreds of inscriptions celebrate the love of boys, and such affairs enter into the lives of a long catalogue of famous Greek statesmen, warriors, artists, and authors. Though it has often been assumed that the love of males was a fashion confined to a small intellectual elite during the age of Plato, in fact it was pervasive throughout all levels of Greek society and held an honored place in Greek culture for more than a thousand years, that is, from before 600 B.C.E. to about 400 C.E.

Male homosexuality in ancient Rome was also common and accepted as normal sexuality, but it took a different form from than in ancient Greece. Ancient Romans disapproved of sexual relations between a man and a freeborn male youth, but they approved of relations between a slave master and his youthful male slave. Sexual activity of this type was common. As Crompton (2003, p. 80) wryly notes, "Opportunities were ample for Roman masters" because slaves comprised about 40 percent of the population of ancient Rome. However, these “opportunities” are best regarded as violent domination by slave masters over their slaves.

By the time Rome fell in $476 \mathrm{CE}$, Europe had become a Christian continent. Influenced by several passages in the Bible that condemn homosexuality, Europeans considered homosexuality a sin, and their governments outlawed same-sex relations. If discovered, male homosexuals (or any men suspected of homosexuality) were vulnerable to execution for the next fourteen centuries, and many did lose their lives. During the Middle Ages, gay men and lesbians were stoned, burned at the stake, hanged, or beheaded, and otherwise abused and mistreated. Crompton (2003, p. 539) calls these atrocities a "routine of terror" and a "kaleidoscope of horrors." Hitler's persecution of gay men several centuries after the Middle Ages ended had ample precedent in European history.

In contrast to the European treatment of gay men and lesbians, China and Japan from ancient times onward viewed homosexuality much more positively in what Crompton (2003, p. 215) calls an "unselfconscious acceptance of same-sex relations." He adds that male love in Japan during the 1500s was "a national tradition—one the Japanese thought natural and meritorious” (Crompton, 2003, p. 412) and very much part of the samurai (military nobility) culture of preindustrial Japan. In China, both male and female homosexuality were seen as normal and even healthy sexual outlets. Because Confucianism, the major Chinese religion when the Common Era began, considered women inferior, it considered male friendships very important and thus may have unwittingly promoted same-sex relations among men. Various artistic and written records indicate that male homosexuality was fairly common in China over the centuries, although the exact numbers can never be known. When China began trading and otherwise communicating with Europe during the Ming dynasty, its tolerance for homosexuality shocked and disgusted Catholic missionaries and other Europeans. Some European clergy and scientists even blamed earthquakes and other natural disasters in China on this tolerance.

In addition to this body of work by historians, anthropologists have also studied same-sex relations in small, 
traditional societies. In many of these societies, homosexuality is both common and accepted as normal sexual behavior. In one overview of seventy-six societies, the authors found that almost two-thirds regarded homosexuality as "normal and socially acceptable for certain members of the community" (Ford \& Beach, 1951, p. 130). Among the Azande of East Africa, for example, young warriors live with each other and are not allowed to marry. During this time, they often have sex with younger boys. Among the Sambia of New Guinea, young males live separately from females and have same-sex relations for at least a decade. It is felt that the boys would be less masculine if they continued to live with their mothers and that the semen of older males helps young boys become strong and fierce (Edgerton, 1976).

This brief historical and anthropological overview provides ready evidence of what was said at its outset: Homosexuality has existed since ancient times and in some societies has been rather common or at least fully accepted as a normal form of sexual expression. Although Western society, influenced by the Judeo-Christian tradition, has largely condemned homosexuality since Western civilization began some 2,000 years ago, the great civilizations of ancient Greece and ancient China and Japan until the industrial age approved of homosexuality. In these civilizations, male homosexuality was fairly common, and female homosexuality was far from unknown. Same-sex relations are also fairly common in many of the societies that anthropologists have studied. Although Western societies have long considered homosexuality sinful and unnatural and more generally have viewed it very negatively, the historical and anthropological record demonstrates that same-sex relationships are far from rare. They thus must objectively be regarded as normal expressions of sexuality.

In fact, some of the most famous individuals in Western political, literary, and artistic history certainly or probably engaged in same-sex relations, either sometimes or exclusively: Alexander the Great, Hans Christian Andersen, Marie Antoinette, Aristotle, Sir Francis Bacon, James Baldwin, Leonard Bernstein, Lord Byron, Julius Caesar, Ralph Waldo Emerson, Frederick the Great, Leonardo de Vinci, Herman Melville, Michelangelo, Plato, Cole Porter, Richard the Lionhearted, Eleanor Roosevelt, Socrates, Gertrude Stein, Pyotr Tchaikovsky, Henry David Thoreau, Walt Whitman, Tennessee Williams, Oscar Wilde, and Virginia Woolf, to name just a few. Regardless or perhaps in some cases because of their sexuality, they all made great contributions to the societies in which they lived.

\section{Explaining Sexual Orientation}

We have seen that it is difficult to determine the number of people who are gay/lesbian or bisexual. It is even more difficult to determine why some people have these sexual orientations while most do not, and scholars disagree on the "causes" of sexual orientation (Engle, McFalls, Gallagher, \& Curtis, 2006; Sheldon, Pfeffer, Jayaratne, Feldbaum, \& Petty, 2007). Determining the origins of sexual orientation is not just an academic exercise. When people believe that the roots of homosexuality are biological or that gays otherwise do not choose to be gay, they are more likely to have positive or at least tolerant views of same-sex behavior. When they believe that homosexuality is instead merely a personal choice, they are more likely to disapprove of it (Sheldon et al., 2007). For this reason if for no other, it is important to know why some people are gay or bisexual while most are not.

Studies of the origins of sexual orientation focus mostly on biological factors and on social and cultural factors, and a healthy scholarly debate exists on the relative importance of these two sets of factors. 


\section{Biological Factors}

Research points to certain genetic and other biological roots of sexual orientation but is by no means conclusive. One line of research concerns genetics. Although no "gay gene" has been discovered, studies of identical twins find they are more likely to have the same sexual orientation (gay or straight) than would be expected from chance alone (Kendler, Thornton, Gilman, \& Kessler, 2000; Santtila et al., 2008). Because identical twins have the same DNA, this similarity suggests, but does not prove, a genetic basis for sexual orientation. Keep in mind, however, that any physical or behavioral trait that is totally due to genetics should show up in both twins or in neither twin. Because many identical twins do not have the same sexual orientation, this dissimilarity suggests that genetics are far from the only cause of sexual orientation, to the extent they cause it at all. Several methodological problems also cast doubt on findings from many of these twin studies. A recent review concluded that the case for a genetic cause of sexual orientation is far from proven: "Findings from genetic studies of homosexuality in humans have been confusing — contradictory at worst and tantalizing at best—with no clear, strong, compelling

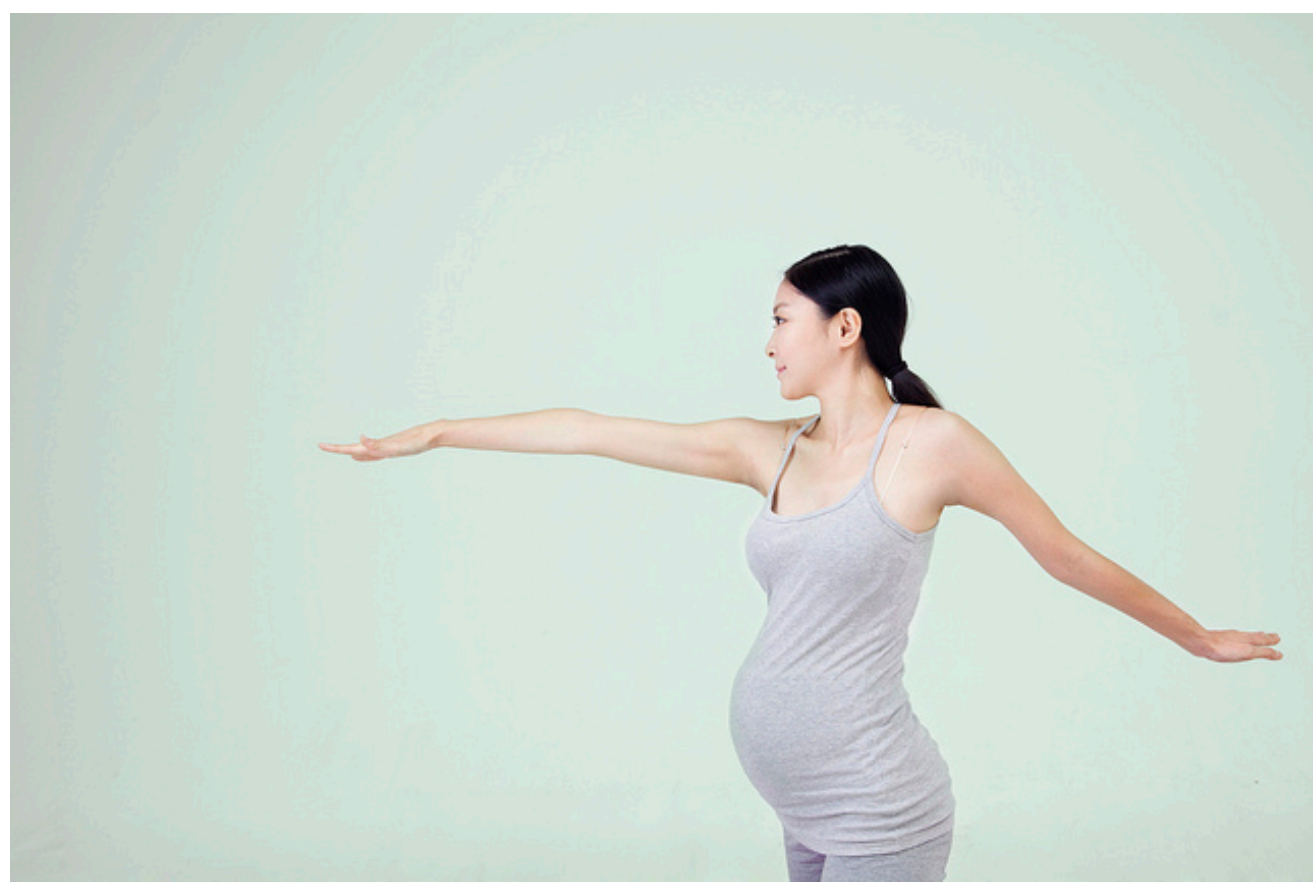

Despite scholarly speculation, sexual orientation does not appear to be affected by the level of prenatal hormones.

il-young ko - pregnant - CC BY-NC-ND 2.0.

Another line of research concerns brain anatomy, as some studies find differences in the size and structure of the hypothalamus, which controls many bodily functions, in the brains of gays versus the brains of straights (Allen \& Gorski, 1992). However, other studies find no such differences (Lasco, Jordan, Edgar, Petito, \& Byne, 2002). Complicating matters further, because sexual behavior can affect the hypothalamus (Breedlove, 1997), it is difficult to determine whether any differences that might be found reflect the influence of the hypothalamus on sexual orientation, or instead the influence of sexual orientation on the hypothalamus (Sheldon et al., 2007).

A third line of biological research concerns hormonal balance in the womb, with scientists speculating that the level of prenatal androgen affects which sexual orientation develops. Because prenatal androgen levels cannot be 
measured, studies typically measure it only indirectly in the bodies of gays and straights by comparing the lengths of certain fingers and bones that are thought to be related to prenatal androgen. Some of these studies suggest that gay men had lower levels of prenatal androgen than straight men and that lesbians had higher levels of prenatal androgen than straight women, but other studies find no evidence of this connection (Martin \& Nguyen, 2004; Mustanski, Chivers, \& Bailey, 2002). A recent review concluded that the results of the hormone studies are "often inconsistent" and that "the notion that non-heterosexual preferences may reflect [deviations from normal prenatal hormonal levels] is not supported by the available data” (Rahman, 2005, p. 1057).

\section{Social and Cultural Factors}

Sociologists usually emphasize the importance of socialization over biology for the learning of many forms of human behavior. In this view, humans are born with "blank slates" and thereafter shaped by their society and culture, and children are shaped by their parents, teachers, peers, and other aspects of their immediate social environment while they are growing up.

Given this standard sociological position, one might think that sociologists generally believe that people are gay or straight not because of their biology but because they learn to be gay or straight from their society, culture, and immediate social environment. This, in fact, was a common belief of sociologists about a generation ago (Engle et al., 2006). In a 1988 review article, two sociologists concluded that "evidence that homosexuality is a social construction [learned from society and culture] is far more powerful than the evidence for a widespread organic [biological] predisposition toward homosexual desire” (Risman \& Schwartz, 1988, p. 143). The most popular introductory sociology text of the era similarly declared, "Many people, including some homosexuals, believe that gays and lesbians are simply 'born that way.' But since we know that even heterosexuals are not 'born that way,' this explanation seems unlikely...Homosexuality, like any other sexual behavior ranging from oral sex to sadomasochism to the pursuit of brunettes, is learned” (Robertson, 1987, p. 243).

However, sociologists' views of the origins of sexual orientation have apparently changed since these passages were written. In a recent national survey of a random sample of sociologists, 22 percent said male homosexuality results from biological factors, 38 percent said it results from both biological and environmental (learning) factors, and 39 percent said it results from environmental factors (Engle et al., 2006). Thus 60 percent (= $22+38)$ thought that biology totally or partly explains male homosexuality, almost certainly a much higher figure than would have been found a generation ago had a similar survey been done.

In this regard, it is important to note that 77 percent $(=38+39)$ of the sociologists still feel that environmental factors, or socialization, matter as well. Scholars who hold this view believe that sexual orientation is partly or totally learned from one's society, culture, and immediate social environment. In this way of thinking, we learn "messages" from all these influences about whether it is OK or not OK to be sexually attracted to someone from our own sex and/or to someone from the opposite sex. If we grow up with positive messages about same-sex attraction, we are more likely to acquire this attraction. If we grow up with negative messages about same-sex attraction, we are less likely to acquire it and more likely to have heterosexual desire.

It is difficult to do the necessary type of research to test whether socialization matters in this way, but the historical and cross-cultural evidence discussed earlier provides at least some support for this process. Homosexuality was 
generally accepted in ancient Greece, ancient China, and ancient Japan, and it also seemed rather common in those societies. The same connection holds true in many of the societies that anthropologists have studied. In contrast, homosexuality was condemned in Europe from the very early part of the first millennium CE, and it seems to have been rather rare (although it is very possible that many gays hid their sexual orientation for fear of persecution and death).

So where does this leave us? What are the origins of sexual orientation? The most honest answer is that we do not yet know its origins. As we have seen, many scholars attribute sexual orientation to still unknown biological factor(s) over which individuals have no control, just as individuals do not decide whether they are left-handed or right-handed. Supporting this view, many gays say they realized they were gay during adolescence, just as straights would say they realized they were straight during their own adolescence; moreover, evidence (from toy, play, and clothing preferences) of future sexual orientation even appears during childhood (Rieger, Linsenmeier, Bailey, \& Gygax, 2008). Other scholars say that sexual orientation is at least partly influenced by cultural norms, so that individuals are more likely to identify as gay or straight and be attracted to their same sex or opposite sex depending on the cultural views of sexual orientation into which they are socialized as they grow up. At best, perhaps all we can say is that sexual orientation stems from a complex mix of biological and cultural factors that remain to be determined.

The official stance of the American Psychological Association (APA) is in line with this view. According to the APA, "There is no consensus among scientists about the exact reasons that an individual develops a heterosexual, bisexual, gay, or lesbian orientation. Although much research has examined the possible genetic, hormonal, developmental, social, and cultural influences on sexual orientation, no findings have emerged that permit scientists to conclude that sexual orientation is determined by any particular factor or factors. Many think that nature and nurture both play complex roles; most people experience little or no sense of choice about their sexual orientation” (American Psychological Association, 2008, p. 2).

Although the exact origins of sexual orientation remain unknown, the APA's last statement is perhaps the most important conclusion from research on this issue: Most people experience little or no sense of choice about their sexual orientation. Because, as mentioned earlier, people are more likely to approve of or tolerate homosexuality when they believe it is not a choice, efforts to educate the public about this research conclusion should help the public become more accepting of LGBT behavior and individuals.

\section{Key Takeaways}

- An estimated 3.8 percent, or 9 million, Americans identify as LGBT.

- Homosexuality seems to have been fairly common and very much accepted in some ancient societies as well as in many societies studied by anthropologists.

- Scholars continue to debate the extent to which sexual orientation stems more from biological factors or from social and cultural factors and the extent to which sexual orientation is a choice or not a choice. 


\section{For Your Review}

1. Do you think sexual orientation is a choice, or not? Explain your answer.

2. Write an essay that describes how your middle school and high school friends talked about sexual orientation generally and homosexuality specifically.

\section{References}

Allen, L. S., \& Gorski, R. A. (1992). Sexual orientation and the size of the anterior commissure in the human brain. PNAS, 89, 7199-7202.

American Psychological Association. (2008). Answers to your questions: For a better understanding of sexual orientation and homosexuality. Washington, DC: Author.

Breedlove, M. S. (1997). Sex on the brain. Nature, 389, 801.

Chandra, A., Mosher, W. D., Copen, C., \& Sionean, C. (2011). Sexual behavior, sexual attraction, and sexual identity in the United States: Data from the 2006-2008 national survey of family growth (National Health Statistics Reports: Number 36). Hyattsville, MD: National Center for Health Statistics. Retrieved from http://www.cdc.gov/nchs/data/nhsr/nhsr036.pdf.

Crompton, L. (2003). Homosexuality and civilization. Cambridge, MA: Belknap Press.

Dover, K. J. (1989). Greek homosexuality. Cambridge, MA: Harvard University Press.

Edgerton, R. (1976). Deviance: A cross-cultural perspective. Menlo Park, CA: Cummings Publishing.

Engle, M. J., McFalls, J. A., Jr., Gallagher, B. J., III, \& Curtis, K. (2006). The attitudes of American sociologists toward causal theories of male homosexuality. The American Sociologist, 37(1), 68-76.

Ford, C. S., \& Beach, F. A. (1951). Patterns of sexual behavior. New York: Harper and Row.

Gates, G. J. (2011). How many people are lesbian, gay, bisexual, and transgender? Los Angeles, CA: Williams Institute.

Kendler, K. S., Thornton, L. M., Gilman, S. E., \& Kessler, R. C. (2000). Sexual orientation in a US national sample of twin and nontwin sibling pairs. American Journal of Psychiatry, 157, 1843-1846.

Kinsey, A. C., Pomeroy, W. B., \& Martin, C. E. (1948). Sexual behavior in the human male. Philadelphia, PA: W. B. Saunders.

Kinsey, A. C., Pomeroy, W. B., Martin, C. E., \& Gebhard, P. H. (1953). Sexual behavior in the human female. Philadelphia, PA: W. B. Saunders. 
Lasco, M. A., Jordan, T. J., Edgar, M. A., Petito, C. K., \& Byne, W. (2002). A lack of dimporphism of sex or sexual orientation in the human anterior commissure. Brain Research, 986, 95-98.

Martin, J. T., \& Nguyen, D. H. (2004). Anthropometric analysis of homosexuals and heterosexuals: Implications for early hormone exposure. Hormones and Behavior, 45, 31-39.

Mustanski, B. S., Chivers, M. L., \& Bailey, J. M. (2002). A critical review of recent biological research on human sexual orientation. Annual Review of Sex Research, 13, 89-140.

Rahman, Q. (2005). The neurodevelopment of human sexual orientation. Neuroscience Biobehavioral Review, 29(7), 1057-1066.

Rieger, G., Linsenmeier, J. A. W., Bailey, J. M., \& Gygax, L. (2008). Sexual orientation and childhood gender nonconformity: Evidence from home videos. Developmental Psychology, 44(1), 46-58.

Risman, B., \& Schwartz, P. (1988). Sociological research on male and female homosexuality. Annual Review of Sociology, 14, 125-147.

Robertson, I. (1987). Sociology. New York, NY: Worth.

Santtila, P., Sandnabba, N. K., Harlaar, N., Varjonen, M., Alanko, K., \& Pahlen, B. v. d. (2008). Potential for homosexual response is prevalent and genetic. Biological Psychology, 77, 102-105.

Sheldon, J. P., Pfeffer, C. A., Jayaratne, T. E., Feldbaum, M., \& Petty, E. M. (2007). Beliefs about the etiology of homosexuality and about the ramifications of discovering its possible genetic origin. Journal of Homosexuality, 52(3/4), 111-150. 


\subsection{Public Attitudes about Sexual Orientation}

\section{Learning Objectives}

1. Understand the extent and correlates of heterosexism.

2. Understand the nature of public opinion on other issues related to sexual orientation.

3. Describe how views about LGBT issues have changed since a few decades ago.

As noted earlier, views about gays and lesbians have certainly been very negative over the centuries in the areas of the world, such as Europe and the Americas, that mostly follow the Judeo-Christian tradition. There is no question that the Bible condemns homosexuality, with perhaps the most quoted Biblical passages in this regard found in Leviticus:

- "Do not lie with a man as one lies with a woman; that is detestable” (Leviticus 18:22).

- "If a man lies with a man as one lies with a woman, both of them have done what is detestable. They must be put to death; their blood will be on their own heads" (Leviticus 20:13).

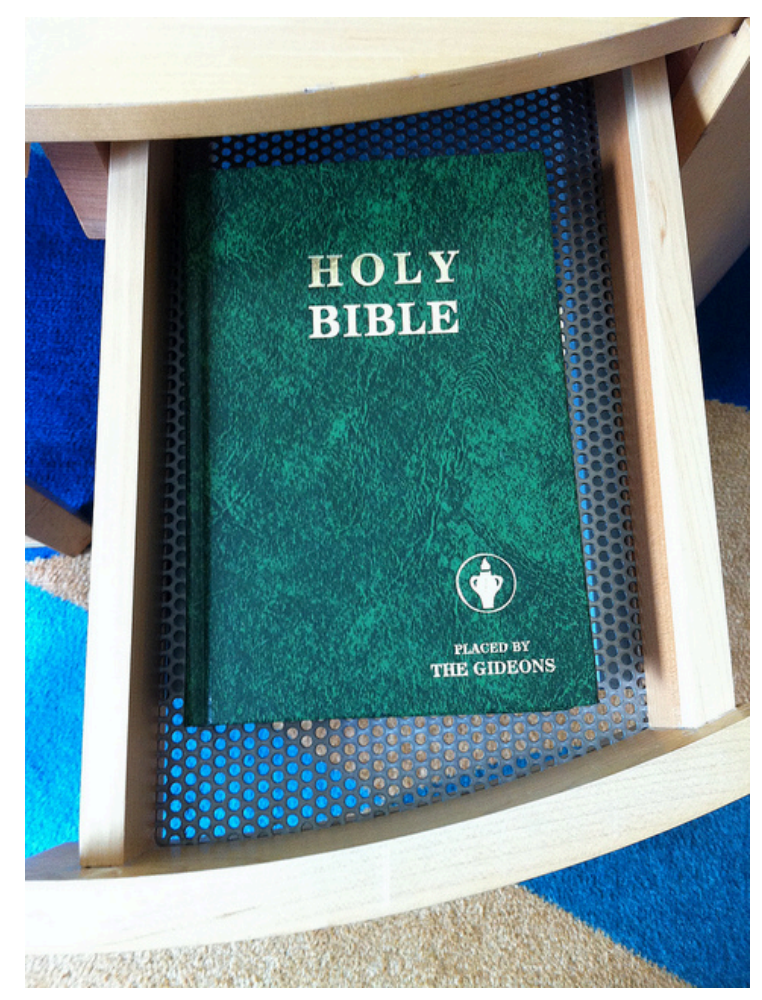

The Bible contains several passages that appear to condemn homosexuality. 
The important question, though, is to what extent these passages should be interpreted literally. Certainly very few people today believe that male homosexuals should be executed, despite what Leviticus 20:13 declares. Still, many people who condemn homosexuality cite passages like Leviticus 18:22 and Leviticus 20:13 as reasons for their negative views.

This is not a theology text, but it is appropriate to mention briefly two points that many religious scholars make about what the Bible says about homosexuality (Helminiak, 2000; Via \& Gagnon, 2003). First, English translations of the Bible's antigay passages may distort their original meanings, and various contextual studies of the Bible suggest that these passages did not, in fact, make blanket condemnations about homosexuality.

Second, and perhaps more important, most people "pick and choose" what they decide to believe from the Bible and what they decide not to believe. Although the Bible is a great source of inspiration for many people, most individuals are inconsistent when it comes to choosing which Biblical beliefs to believe and about which beliefs not to believe. For example, if someone chooses to disapprove of homosexuality because the Bible condemns it, why does this person not also choose to believe that gay men should be executed, which is precisely what Leviticus 20:13 dictates? Further, the Bible calls for many practices and specifies many penalties that even very devout people do not follow or believe. For example, most people except for devout Jews do not keep kosher, even though the Bible says that everyone should do this, and most people certainly do not believe people who commit adultery, engage in premarital sex, or work on the Sabbath should be executed, even though the Bible says that such people should be executed. Citing the inconsistency with which most people follow Biblical commands, many religious scholars say it is inappropriate to base public views about homosexuality on what the Bible says about it.

We now turn our attention to social science evidence on views about LGBT behavior and individuals. We first look at negative attitudes and then discuss a few other views.

\section{The Extent of Heterosexism in the United States}

We saw in earlier chapters that racism refers to negative views about, and practices toward, people of color, and that sexism refers to negative views about, and practices toward, women. Heterosexism is the analogous term for negative views about, and discriminatory practices toward, LGBT individuals and their sexual behavior.

There are many types of negative views about LGBT and thus many ways to measure heterosexism. The General Social Survey (GSS), given regularly to a national sample of US residents, asks whether respondents think that "sexual relations between two adults of the same sex" are always wrong, almost always wrong, sometimes wrong, or not wrong at all. In 2010, almost 46 percent of respondents said same-sex relations are "always wrong," and 43 percent responded they are "not wrong at all" (see Figure 5.1 "Opinion about "Sexual Relations between Two Adults of the Same Sex,” 2010”).

Figure 5.1 Opinion about “Sexual Relations between Two Adults of the Same Sex,” 2010 


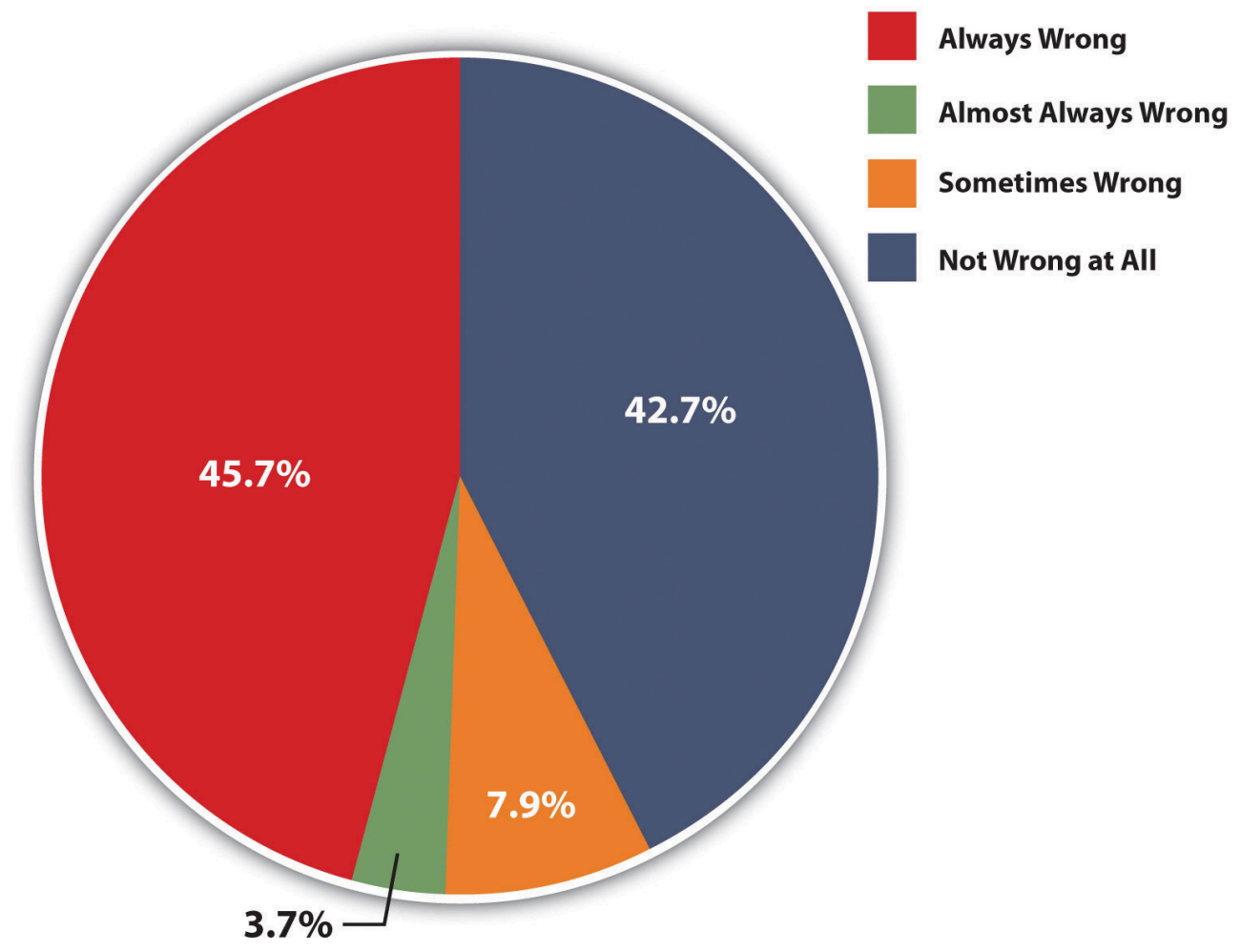

Source: Data from General Social Survey. (2010). Retrieved from http://sda.berkeley.edu/cgi-bin/hsda?harcsda+gss10.

As another way of measuring heterosexism, the Gallup poll asks whether "gay or lesbian relations" are "morally acceptable or morally wrong” (Gallup, 2011). In 2011, 56 percent of Gallup respondents answered "morally acceptable," while 39 percent replied "morally wrong."

Although Figure 5.1 "Opinion about "Sexual Relations between Two Adults of the Same Sex," 2010" shows that 57.3 percent of Americans $(=45.7+3.7+7.9)$ think that same-sex relations are at least sometimes wrong, public views regarding LGBT have notably become more positive over the past few decades. We can see evidence of this trend in Figure 5.2 "Changes in Opinion about "Sexual Relations between Two Adults of the Same Sex," 1973-2010”, which shows that the percentage of GSS respondents who say same-sex relations are "always wrong” has dropped considerably since the GSS first asked this question in 1973, while the percentage who respond "not wrong at all” has risen considerably, with both these changes occurring since the early 1990s. 


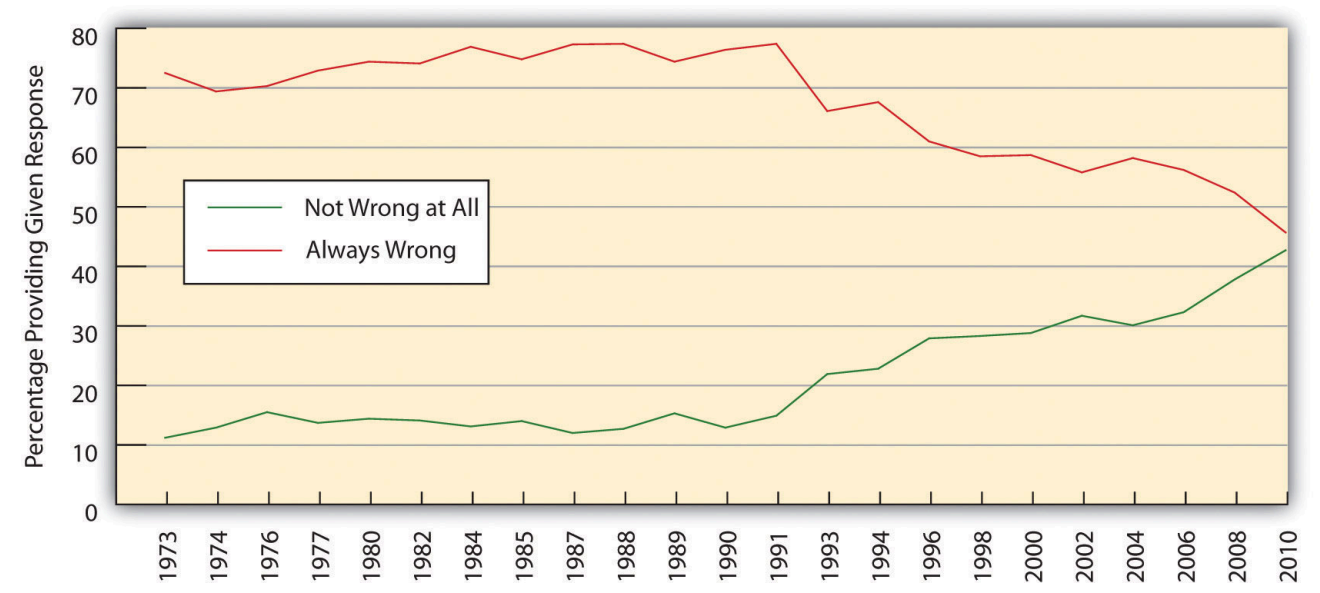

Source: Data from General Social Surveys. (1973-2010). Retrieved from http://sda.berkeley.edu/cgi-bin/hsda?harcsda+gss10.

Trends in Gallup data confirm that public views regarding homosexuality have become more positive in recent times. Recall that 56 percent of Gallup respondents in 2011 called same-sex relations "morally acceptable," while 39 percent replied "morally wrong." Ten years earlier, these percentages were 40 percent and 53 percent, respectively, representing a marked shift in public opinion in just a decade.

\section{Correlates of Heterosexism}

Scholars have investigated the sociodemographic factors that predict heterosexist attitudes. Reflecting the sociological axiom that our social backgrounds influence our attitudes and behavior, several aspects of our social backgrounds influence views about gays and lesbians. Among the most influential of these factors are gender, age, education, region of residence, and religion. We can illustrate each of these influences with the GSS question on whether same-sex relations are wrong, using the response "always wrong” as a measure of heterosexism.

- Gender. Men are somewhat more heterosexist than women (see part a of Figure 5.3 "Correlates of Heterosexism (Percentage Saying That Same-Sex Relations Are “Always Wrong”)”).

- Age. Older people are considerably more heterosexist than younger people (see part $\mathbf{b}$ of Figure 5.3 “Correlates of Heterosexism (Percentage Saying That Same-Sex Relations Are “Always Wrong”)”).

- Education. Less educated people are considerably more heterosexist than more educated people (see part c of Figure 5.3 "Correlates of Heterosexism (Percentage Saying That Same-Sex Relations Are "Always Wrong”)").

- Region of residence. Southerners are more heterosexist than non-Southerners (see part d of Figure 5.3 "Correlates of Heterosexism (Percentage Saying That Same-Sex Relations Are “Always Wrong”)”).

- Religion. Religious people are considerably more heterosexist than less religious people (see part $\mathbf{e}$ of Figure 5.3 "Correlates of Heterosexism (Percentage Saying That Same-Sex Relations Are "Always Wrong”)”). 


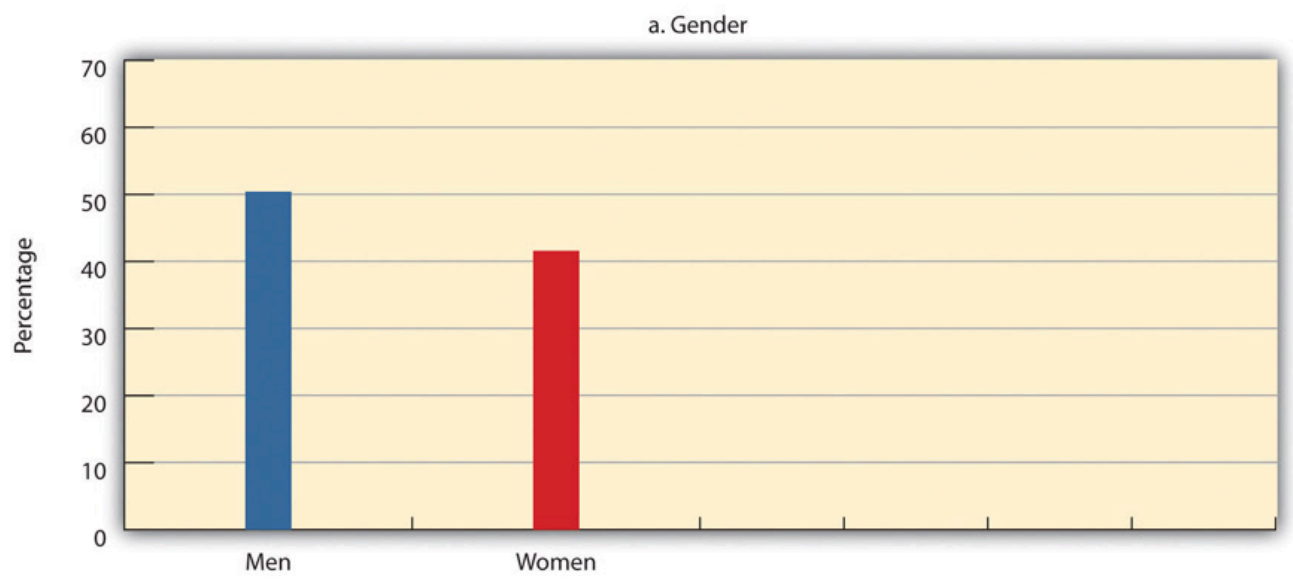

b. Age

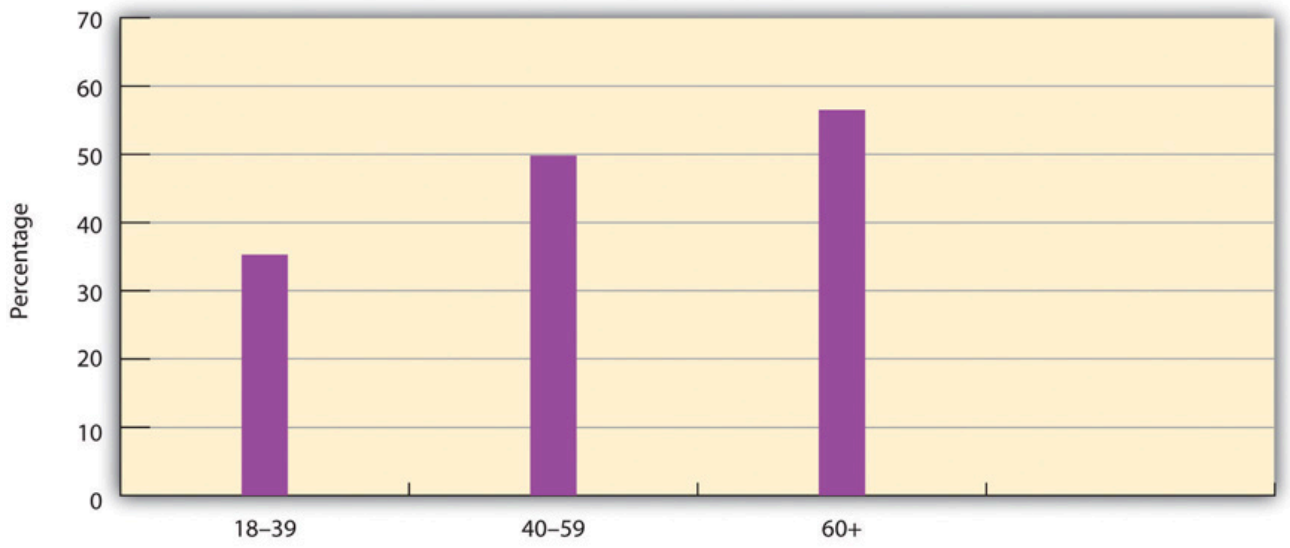

c. Education

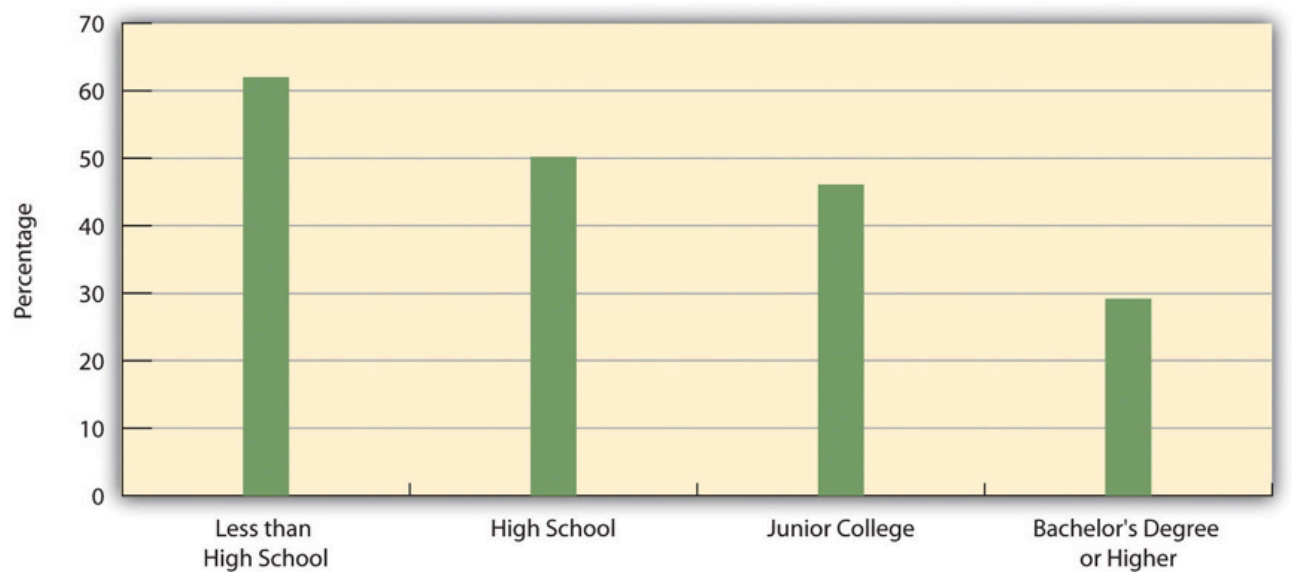



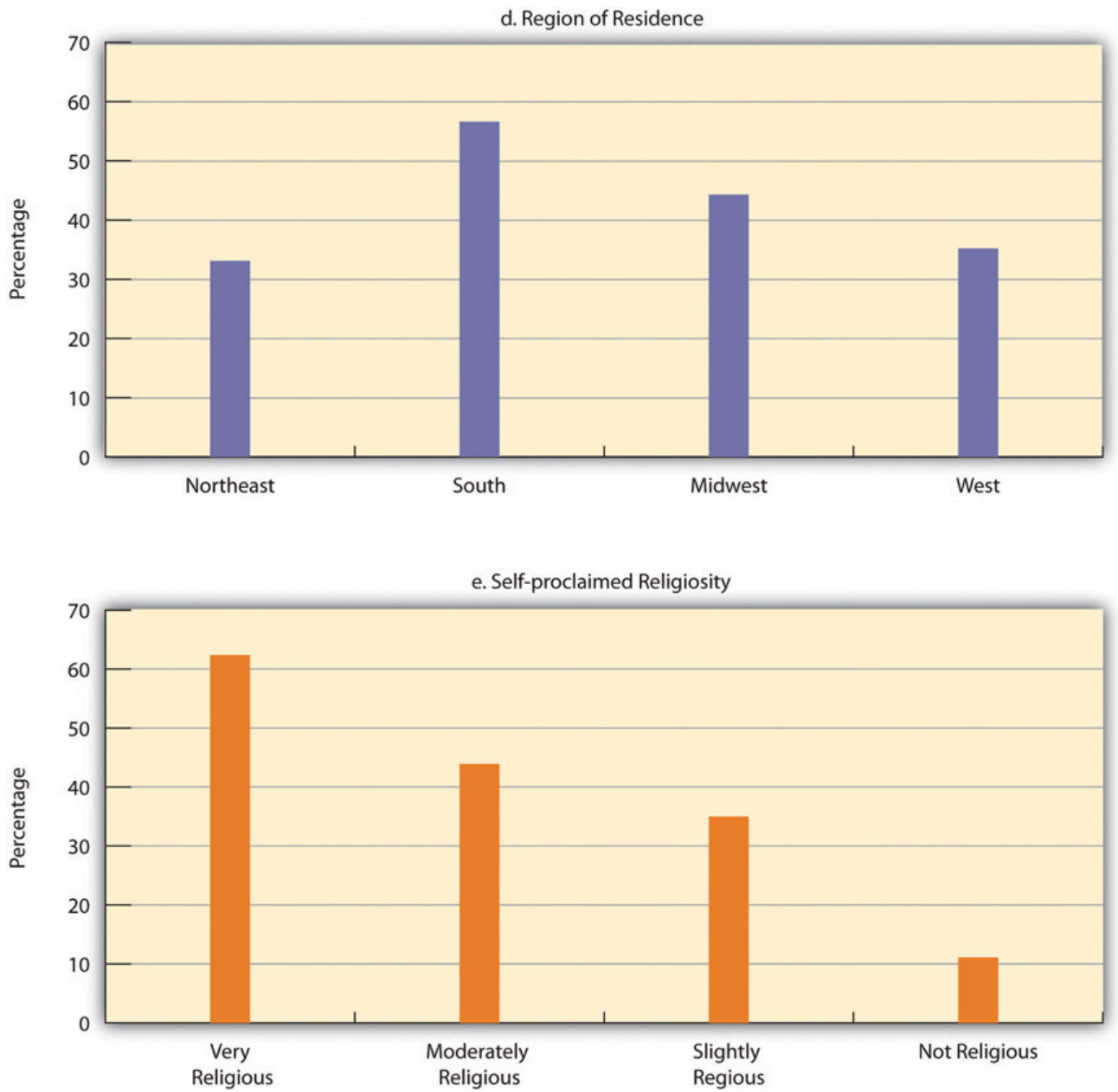

Source: Data from General Social Survey. (2010). Retrieved from http://sda.berkeley.edu/cgi-bin/hsda?harcsda+gss10.

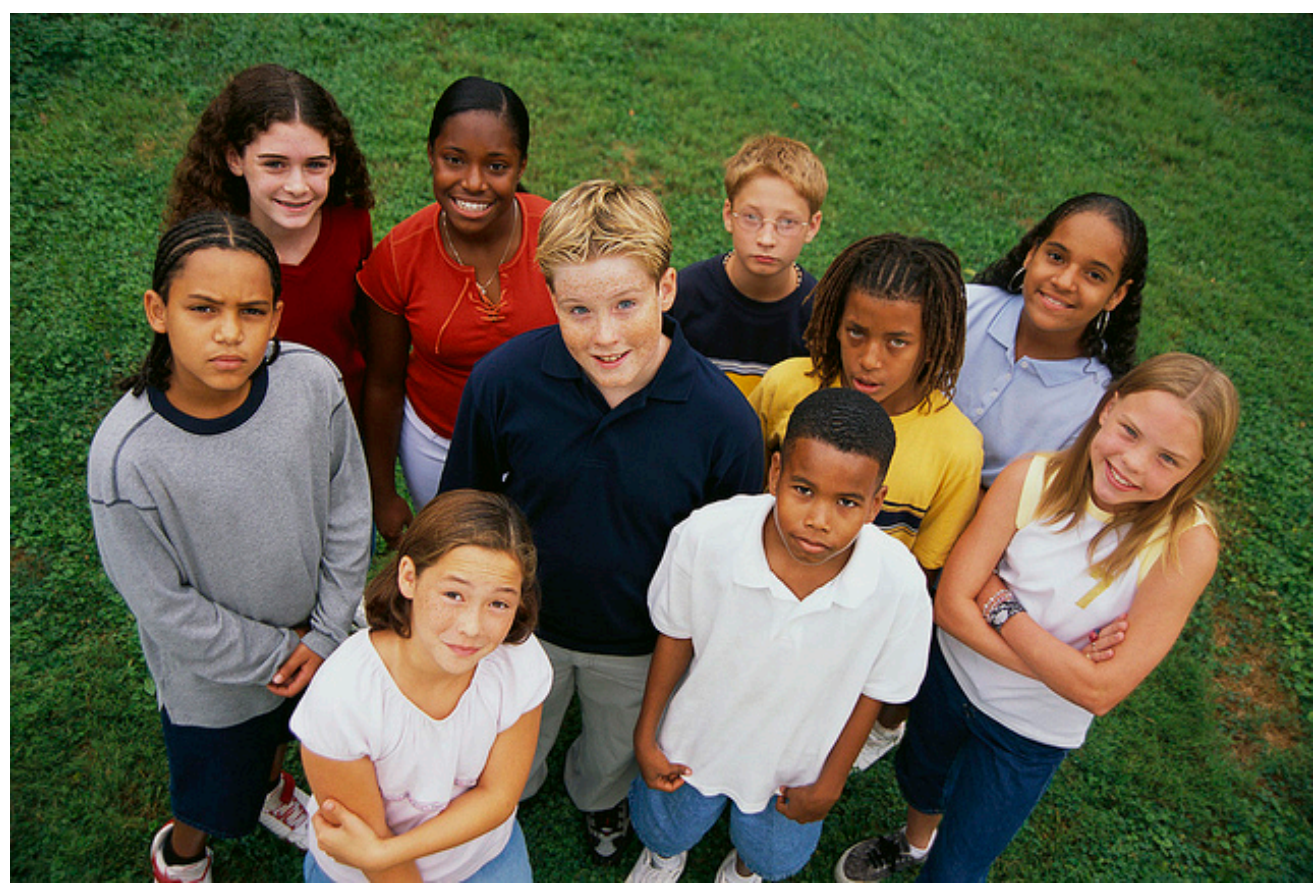


Because young people are especially likely to be accepting of homosexuality, attitudes about LGBT issues should continue to improve

as the older population passes away.

hepingting - $\underline{\mathrm{CB} 106492}-\mathrm{CC}$ BY-SA 2.0 .

The age difference in heterosexism is perhaps particularly interesting. Many studies find that young people-those younger than 30-are especially accepting of homosexuality and of same-sex marriage. As older people, who have more negative views, pass away, it is likely that public opinion as a whole will become more accepting of homosexuality and issues related to it. Scholars think this trend will further the legalization of same-sex marriage and the establishment of other laws and policies that will reduce the discrimination and inequality that the LGBT community experiences (Gelman, Lax, \& Phillips, 2010).

\section{Opinion on the Origins of Sexual Orientation}

Earlier we discussed scholarly research on the origins of sexual orientation. In this regard, it is interesting to note that the US public is rather split over the issue of whether sexual orientation is in-born or instead the result of environmental factors, and also over the closely related issue of whether it is something people are able to choose. A 2011 Gallup poll asked, "In your view, is being gay or lesbian something a person is born with, or due to factors such as upbringing and environment?” (Jones, 2011). Forty percent of respondents replied that sexual orientation is in-born, while 42 percent said it stems from upbringing and/or environment. The 40 percent in-born figure represented a sharp increase from the 13 percent figure that Gallup obtained when it first asked this question in 1977. A 2010 CBS News poll, asked, "Do you think being homosexual is something people choose to be, or do you think it is something they cannot change?” (CBS News, 2010). About 36 percent of respondents replied that homosexuality is a choice, while 51 percent said it is something that cannot be changed, with the remainder saying they did not know or providing no answer. The 51 percent "cannot change” figure represented an increase from the 43 percent figure that CBS News obtained when it first asked this question in 1993.

\section{Other Views}

The next section discusses several issues that demonstrate inequality based on sexual orientation. Because these issues are so controversial, public opinion polls have included many questions about them. We examine public views on some of these issues in this section.

A first issue is same-sex marriage. The 2010 GSS asked whether respondents agree that "homosexual couples should have the right to marry one another": 53.3 percent of respondents who expressed an opinion agreed with this statement, and 46.7 percent disagreed, indicating a slight majority in favor of legalizing same-sex marriage (SDA, 2010). In 2011, an ABC News/Washington Post poll asked about same-sex marriage in a slightly different way: "Do you think it should be legal or illegal for gay and lesbian couples to get married?” A majority, 51 percent, of respondents replied "legal," and 45 percent replied "illegal” (Langer, 2011). Although only bare majorities now favor legalizing same-sex marriage, public views on this issue have become much more positive in recent years. We can see dramatic evidence of this trend in Figure 5.4 "Changes in Opinion about Same-Sex Marriage, 1988-2010 (Percentage Agreeing That Same-Sex Couples Should Have the Right to Marry; Those 
Expressing No Opinion Excluded from Analysis)", which shows that the percentage agreeing with the GSS question on the right of same-sex couples to marry has risen considerably during the past quarter-century.

Figure 5.4 Changes in Opinion about Same-Sex Marriage, 1988-2010 (Percentage Agreeing That Same-Sex Couples Should Have the Right to Marry; Those Expressing No Opinion Excluded from Analysis)

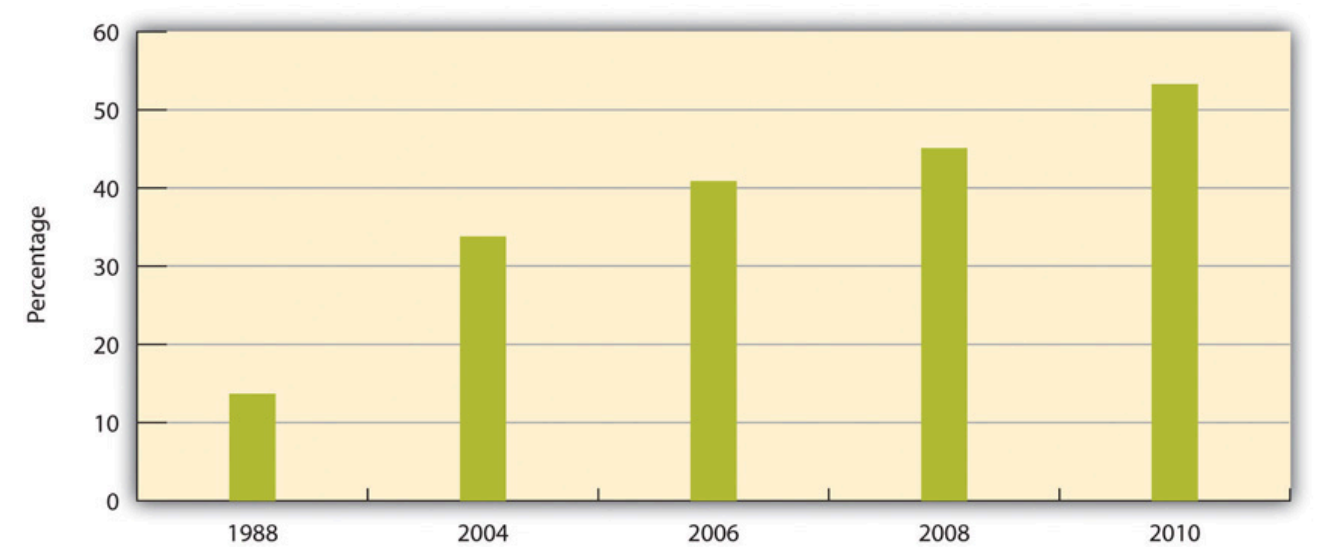

Source: Data from General Social Surveys. (1988-2010). Retrieved from http://sda.berkeley.edu/cgi-bin/hsda?harcsda+gss10.

In a related topic, public opinion about same-sex couples as parents has also become more favorable in recent years. In 2007, 50 percent of the public said that the increasing number of same-sex couples raising children was “a bad thing” for society. By 2011, this figure had declined to 35 percent, a remarkable decrease in just four years (Pew Research Center, 2011).

A second LGBT issue that has aroused public debate involves the right of gays and lesbians to serve in the military, which we discuss further later in this chapter. A 2010 ABC News/Washington Post poll asked whether "gays and lesbians who do not publicly disclose their sexual orientation should be allowed to serve in the military" (Mokrzycki, 2010). About 83 percent of respondents replied they "should be allowed," up considerably from the 63 percent figure that this poll obtained when it first asked this question in 1993 (Saad, 2008).

A third issue involves the right of gays and lesbians to be free from job discrimination based on their sexual orientation, as federal law does not prohibit such discrimination. A 2008 Gallup poll asked whether "homosexuals should or should not have equal rights in terms of job opportunities." About 89 percent of respondents replied that there "should be" such rights, and only 8 percent said there "should not be" such rights. The 89 percent figure represented a large increase from the 56 percent figure that Gallup obtained in 1977 when Gallup first asked this question.

\section{Two Brief Conclusions on Public Attitudes}

We have had limited space to discuss public views on LGBT topics, but two brief conclusions are apparent from the discussion. First, although the public remains sharply divided on various LGBT issues and much of the public remains heterosexist, views about LGBT behavior and certain rights of the LGBT community have become markedly more positive in recent decades. This trend matches what we saw in earlier chapters regarding views 
concerning people of color and women. The United States has without question become less racist, less sexist, and less heterosexist since the 1970s.

Second, certain aspects of people's sociodemographic backgrounds influence the extent to which they do, or do not, hold heterosexist attitudes. This conclusion is not surprising, as sociology has long since demonstrated that social backgrounds influence many types of attitudes and behaviors, but the influence we saw earlier of sociodemographic factors on heterosexism was striking nonetheless. These factors would no doubt also be relevant for understanding differences in views on other LGBT issues. As you think about your own views, perhaps you can recognize why you might hold these views based on your gender, age, education, and other aspects of your social background.

\section{Key Takeaways}

- Views about LGBT behavior have improved markedly since a generation ago. More than half the US public now supports same-sex marriage.

- Males, older people, the less educated, Southerners, and the more religious exhibit higher levels of heterosexism than their counterparts.

\section{For Your Review}

1. Reread this section and indicate how you would have responded to every survey question discussed in the section. Drawing on the discussion of correlates of heterosexism, explain how knowing about these correlates helps you understand why you hold your own views.

2. Why do you think public opinion about LGBT behavior and issues has become more positive during the past few decades?

\section{References}

CBS News. (2010, June 9). CBS News poll: Views of gays and lesbians. Retrieved from http://www.cbsnews.com/htdocs/pdf/poll gays lesbians 060910.pdf.

Gallup. (2011). Gay and lesbian rights. Gallup. Retrieved September 4, 2011, from http://www.gallup.com/poll/ 1651/gay-lesbian-rights.aspx.

Gelman, A., Lax, J., \& Phillips, J. (2010, August 22). Over time, a gay marriage groundswell. New York Times, p. WK3.

Helminiak, D. A. (2000). What the Bible really says about homosexuality. Tajique, NM: Alamo Square Press. 
Jones, Jeffrey M. (2011). Support for legal gay relations hits new high. Retrieved from http://www.gallup.com/ poll/147785/Support-Legal-Gay-Relations-Hits-New-High.aspx.

Langer, Gary. (2011). Support for gay marriage reaches a milestone. Retrieved from http://abcnews.go.com/ Politics/support-gay-marriage-reaches-milestone-half-americans-support/story?id=13159608\#.T66 kp9YtQp.

Mokrzycki, Mike. (2010). Support for gays in the military crosses ideological, party lines. Retrieved from http://abcnews.go.com/PollingUnit/poll-support-gays-military-crosses-ideological-party-lines/ story?id=9811516\#.T67A659YtQo.

Pew Research Center. (2011). 35\%—Disapprove of gay and lesbian couples raising children. Retrieved from http://pewresearch.org/databank/dailynumber/?NumberID=1253.

Saad, Lydia. (2008). Americans evenly divided on morality of homosexuality. Retrieved from http://www.gallup.com/poll/108115/americans-evenly-divided-morality-homosexuality.aspx.

SDA. (2010). GSS 1972-2010 cumulative datafile. Retrieved from http://sda.berkeley.edu/cgi-bin/ hsda?harcsda+gss10.

Via, D. O., \& Gagnon, R. A. J. (2003). Homosexuality and the Bible: Two views. Minneapolis, MN: Fortress Press. 


\subsection{Inequality Based on Sexual Orientation}

\section{Learning Objectives}

1. Understand the behavioral, psychological, and health effects of bullying and other mistreatment of the LGBT community.

2. Evaluate the arguments for and against same-sex marriage.

3. Provide three examples of heterosexual privilege.

Until just a decade ago, individuals who engaged in consensual same-sex relations could be arrested in many states for violating so-called sodomy laws. The US Supreme Court, which had upheld such laws in 1986, finally outlawed them in 2003 in Lawrence v. Texas, 539 US 558, by a 6-3 vote. The majority opinion of the court declared that individuals have a constitutional right under the Fourteenth Amendment to engage in consensual, private sexual activity.

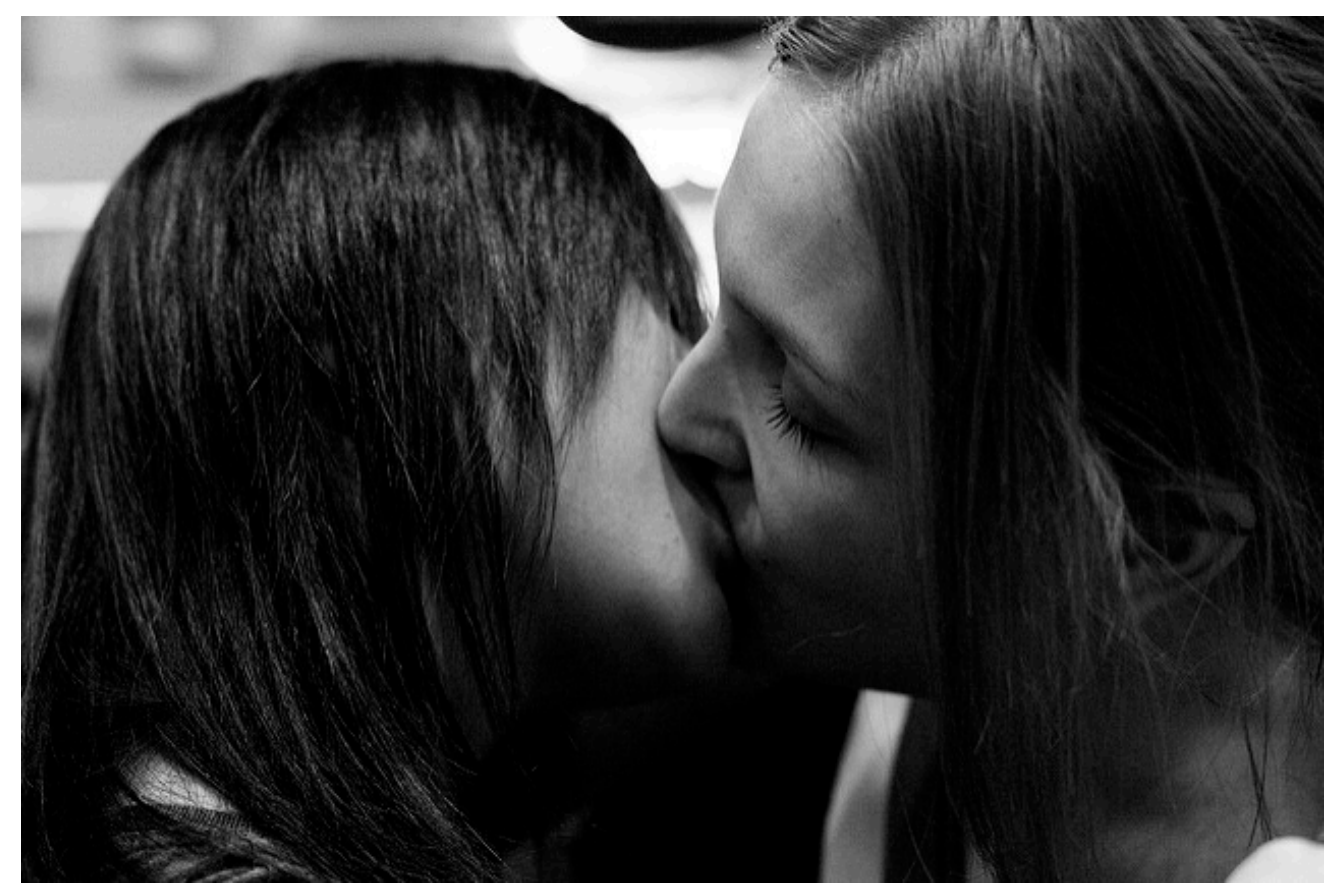

Until the Supreme Court's Lawrence v. Texas ruling just a decade ago, individuals who engaged in consensual same-sex relations could be arrested in many states.

philippe leroyer - Kiss In (08) - CC BY-NC-ND 2.0.

Despite this landmark ruling, the LGBT community continues to experience many types of problems. In this regard, sexual orientation is a significant source of social inequality, just as race/ethnicity, gender, and social 
class are sources of social inequality. We examine manifestations of inequality based on sexual orientation in this section.

\section{Bullying and Violence}

The news story that began this chapter concerned the reported beatings of two gay men. Bullying and violence against adolescents and adults thought or known to be gay or lesbian constitute perhaps the most serious manifestation of inequality based on sexual orientation. According to the Federal Bureau of Investigation (2011), 1,277 hate crimes (violence and/or property destruction) against gays and lesbians occurred in 2010, although this number is very likely an underestimate because many hate crime victims do not report their victimization to the police. An estimated 25 percent of gay men have been physically or sexually assaulted because of their sexual orientation (Egan, 2010), and some have been murdered. Matthew Shepard was one of these victims. He was a student at the University of Wyoming in October 1998 when he was kidnapped by two young men who tortured him, tied him to a fence, and left him to die. When found almost a day later, he was in a coma, and he died a few days later. Shepard's murder prompted headlines around the country and is credited with winning public sympathy for the problems experienced by the LGBT community (Loffreda, 2001).

Gay teenagers and straight teenagers thought to be gay are very often the targets of taunting, bullying, physical assault, and other abuse in schools and elsewhere (Denizet-Lewis, 2009). Survey evidence indicates that 85 percent of LGBT students report being verbally harassed at school, and 40 percent report being verbally harassed; 72 percent report hearing antigay slurs frequently or often at school; 61 percent feel unsafe at school, with 30 percent missing at least one day of school in the past month for fear of their safety; and 17 percent are physically assaulted to the point they need medical attention (Kosciw, Greytak, Diaz, \& Bartkiewicz, 2010).

The bullying, violence, and other mistreatment experienced by gay teens have significant educational and mental health effects. The most serious consequence is suicide, as a series of suicides by gay teens in fall 2010 reminded the nation. During that period, three male teenagers in California, Indiana, and Texas killed themselves after reportedly being victims of antigay bullying, and a male college student also killed himself after his roommate broadcast a live video of the student making out with another male (Talbot, 2010).

In other effects, LGBT teens are much more likely than their straight peers to skip school; to do poorly in their studies; to drop out of school; and to experience depression, anxiety, and low self-esteem (Mental Health America, 2011). These mental health problems tend to last at least into their twenties (Russell, Ryan, Toomey, Diaz, \& Sanchez, 2011). According to a 2011 report by the Centers for Disease Control and Prevention (CDC), LGBT teens are also much more likely to engage in risky and/or unhealthy behaviors such as using tobacco, alcohol, and other drugs, having unprotected sex, and even not using a seatbelt (Kann et al., 2011). Commenting on the report, a CDC official said, "This report should be a wake-up call. We are very concerned that these students face such dramatic disparities for so many different health risks” (Melnick, 2011).

Ironically, despite the bullying and other mistreatment that LBGT teens receive at school, they are much more likely to be disciplined for misconduct than straight students accused of similar misconduct. This disparity is greater for girls than for boys. The reasons for the disparity remain unknown but may stem from unconscious bias against gays and lesbians by school officials. As a scholar in educational psychology observed, "To me, it 
is saying there is some kind of internal bias that adults are not aware of that is impacting the punishment of this group” (St. George, 2010).

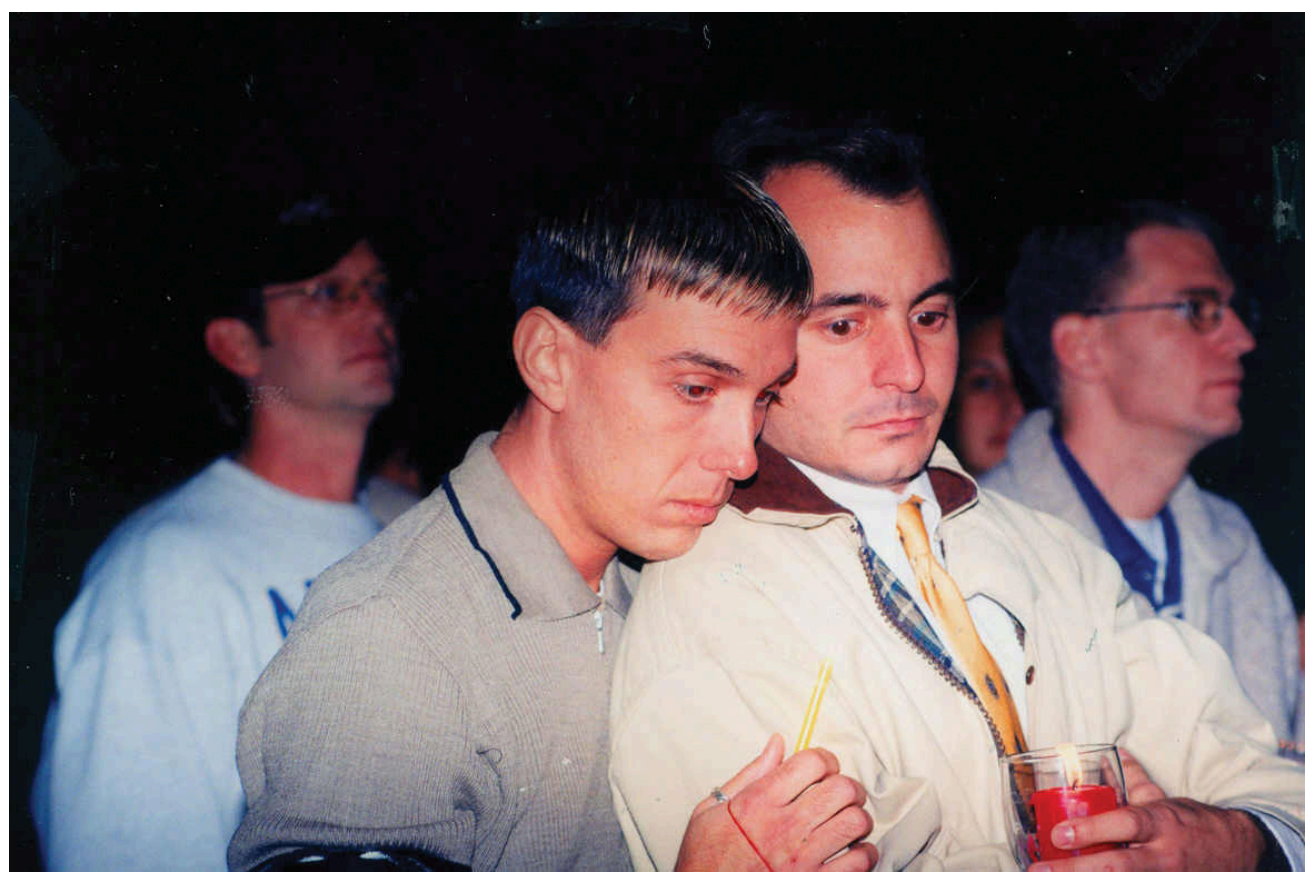

This candlelight vigil honored the memory of Matthew Shepard, a gay college student, who was tortured, tied, to a fence, and left to die in Wyoming in 1998. He was in a coma when he was found and died a few days later.

\section{Children and Our Future}

The Homeless Status of LGBT Teens

Many LGBT teens are taunted, bullied, and otherwise mistreated at school. As the text discusses, this mistreatment affects their school performance and psychological well-being, and some even drop out of school as a result. We often think of the home as a haven from the realities of life, but the lives of many gay teens are often no better at home. If they come out (disclose their sexual orientation) to their parents, one or both parents often reject them. Sometimes they kick their teen out of the home, and sometimes the teen leaves because the home environment has become intolerable. Regardless of the reason, a large number of LGBT teens become homeless. They may be living in the streets, but they may also be living with a friend, at a homeless shelter, or at some other venue. But the bottom line is that they are not living at home with a parent.

The actual number of homeless LGBT teens will probably never be known, but a study in Massachusetts of more than 6,300 high school students was the first to estimate the prevalence of their homelessness using a representative sample. The study found that 25 percent of gay or lesbian teens and 15 percent of bisexual teens are homeless in the state, compared to only 3 percent of heterosexual teens. Fewer than 5 percent of the students in the study identified themselves as LGB, but they accounted for 19 percent of all the homeless students who were surveyed. Regardless of their sexual orientation, some homeless teens live with a parent or guardian, but the study found that homeless LGBT teens were more likely than their heterosexual counterparts to be living without a parent.

Being homeless adds to the problems that many LGBT teens already experience. Regardless of sexual orientation, homeless people of all ages are at greater risk for victimization by robbers and other offenders, hunger, substance abuse, and mental health problems. 
The study noted that LGBT teen homelessness may be higher in other states because attitudes about LGBT status are more favorable in Massachusetts than in many other states. Because the study was administered to high school students, it may have undercounted LGBT teens, who are more likely to be absent from school.

These methodological limitations should not obscure the central message of the study as summarized by one of its authors: "The high risk of homelessness among sexual minority teens is a serious problem requiring immediate attention. These teens face enormous risks and all types of obstacles to succeeding in school and are in need of a great deal of assistance.”

Sources: Connolly, 2011; Corliss, Goodenow, Nichols, \& Austin, 2011

\section{Employment Discrimination}

Federal law prohibits employment discrimination based on race, nationality, sex, or religion. Notice that this list does not include sexual orientation. It is entirely legal under federal law for employers to refuse to hire LGBT individuals or those perceived as LGBT, to fire an employee who is openly LGBT or perceived as LGBT, or to refuse to promote such an employee. Twenty-one states do prohibit employment discrimination based on sexual orientation, but that leaves twenty-nine states that do not prohibit such discrimination. Employers in these states are entirely free to refuse to hire, fire, or refuse to promote LGBT people (openly LGBT or perceived as LGBT) as they see fit. In addition, only fifteen states prohibit employment discrimination based on gender identity (transgender), which leaves thirty-five states in which employers may practice such discrimination (Human Rights Campaign, 2011).

The Employment Non-Discrimination Act (ENDA), which would prohibit job discrimination based on sexual orientation or gender identity, has been proposed in Congress but has not come close to passing. In response to the absence of legal protection for LGBT employees, many companies have instituted their own policies. As of March 2011, 87 percent of the Fortune 500 companies, the largest 500 corporations in the United States, had policies prohibiting sexual orientation discrimination, and 46 percent had policies prohibiting gender identity discrimination (Human Rights Campaign, 2011).

National survey evidence shows that many LGBT people have, in fact, experienced workplace discrimination (Sears \& Mallory, 2011). In the 2008 GSS, 27.1 percent of LGB respondents said they had been verbally harassed at work during the past five years, and 7.1 percent said they had been either fired or not hired during the same period (SDA, 2008). In other surveys that are not based on nationally representative samples, the percentage of LGB respondents who report workplace harassment or discrimination exceeds the GSS's figures. Not surprisingly, more than one-third of LGB employees say they conceal their sexual orientation in their workplace. Transgender people appear to experience more employment problems than LGB people, as 78 percent of transgender respondents in one study reported some form of workplace harassment or discrimination. Scholars have also conducted field experiments in which they send out resumes or job applicants to prospective employers. The resumes are identical except that some mention the applicant is LGB, while the others do not indicate sexual orientation. The job applicants similarly either say they are LGB or do not say this. The LGB resumes and applicants are less likely than their non-LGB counterparts to receive a positive response from prospective employers. 
LGBT people who experience workplace harassment and discrimination suffer in other ways as well (Sears \& Mallory, 2011). Compared to LGBT employees who do not experience these problems, they are more likely to have various mental health issues, to be less satisfied with their jobs, and to have more absences from work.

\section{Applying Social Research}

How Well Do the Children of Same-Sex Couples Fare?

Many opponents of same-sex marriage claim that children are better off if they are raised by both a mother and a father and that children of same-sex couples fare worse as a result. As the National Organization for Marriage (National Organization for Marriage, 2011) states, "Two men might each be a good father, but neither can be a mom. The ideal for children is the love of their own mom and dad. No same-sex couple can provide that.”

Addressing this contention, social scientists have studied the children of same-sex couples and compared them to the children of heterosexual parents. Although it is difficult to have random, representative samples of same-sex couples' children, a growing number of studies find that these children fare at least as well psychologically and in other respects as heterosexual couples' children.

Perhaps the most notable published paper in this area appeared in the American Sociological Review, the preeminent sociology journal, in 2001. The authors, Judith Stacey and Timothy J. Biblarz, reviewed almost two dozen studies that had been done of same-sex couples' children. All these studies yielded the central conclusion that the psychological well-being of these children is no worse than that of heterosexual couples' children. As the authors summarized this conclusion and its policy implications, "Because every relevant study to date shows that parental sexual orientation per se has no measurable effect on the quality of parent-child relationships or on children's mental health or social adjustment, there is no evidentiary basis for considering parental sexual orientation in decisions about children's 'best interest."”

Biblarz and Stacey returned to this issue in a 2010 article in the Journal of Marriage and the Family, the preeminent journal in its field. This time they reviewed almost three dozen studies published since 1990 that compared the children of same-sex couples (most of them lesbian parents) to those of heterosexual couples. They again found that the psychological well-being and social adjustment of same-sex couples' children was at least as high as those of heterosexual couples' children, and they even found some evidence that children of lesbian couples fare better in some respects than those of heterosexual couples. Although the authors acknowledged that two parents are generally better for children than one parent, they concluded that the sexual orientation of the parents makes no difference overall. As they summarized the body of research on this issue: "Research consistently has demonstrated that despite prejudice and discrimination children raised by lesbians develop as well as their peers. Across the standard panoply of measures, studies find far more similarities than differences among children with lesbian and heterosexual parents, and the rare differences mainly favor the former."

This body of research, then, contributes in important ways to the national debate on same-sex marriage. If children of same-sex couples indeed fare well, as the available evidence indicates, concern about these children's welfare should play no part in this debate.

\section{Same-Sex Marriage}

Same-sex marriage has been one of the most controversial social issues in recent years. Nearly 650,000 samesex couples live together in the United States (Gates, 2012). Many of them would like to marry, but most are not permitted by law to marry. In May 2012, President Obama endorsed same-sex marriage. 


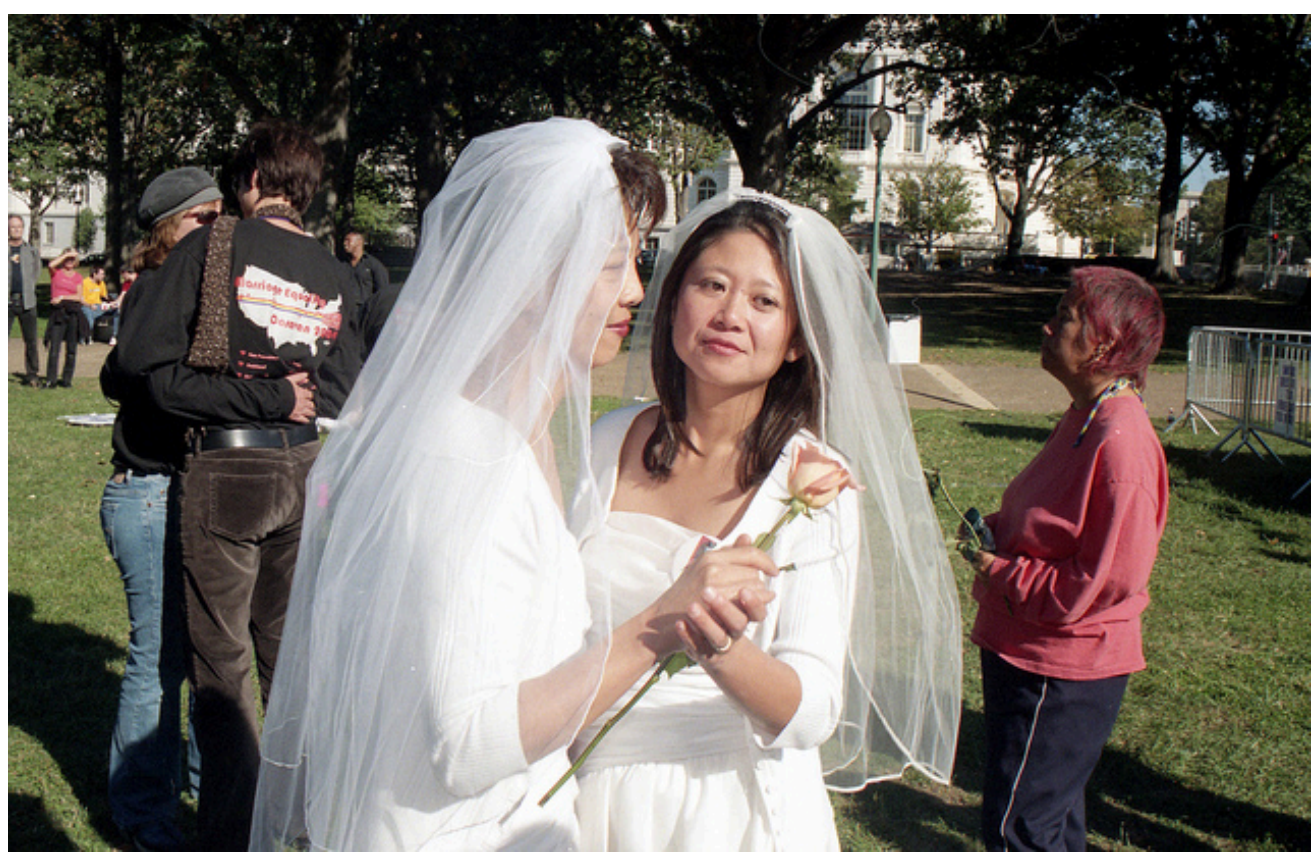

The issue of same-sex marriage has aroused much controversy in recent years. As of June 2012, same-sex couples could marry in only seven states and the District of Columbia.

Elvert Barnes - 70a Marriage Equality US Capitol - CC BY-SA 2.0.

We saw earlier that a narrow margin of Americans now favors the right of same-sex couples to marry, and that public opinion in favor of same-sex marriage has increased greatly in recent times. As of June 2012, same-sex marriage was legal in seven states (Connecticut, Iowa, Maryland, Massachusetts, New Hampshire, New York, Vermont, and Washington) and the District of Columbia. Nine other states permitted same-sex couples to form civil unions or domestic partnerships, which provide some or many of the various legal benefits that married spouses enjoy. In the remaining thirty-five states, same-sex couples may not legally marry or form civil unions or domestic partnerships. The federal Defense of Marriage Act (DOMA), passed in 1996 (and under legal dispute at the time of this writing), prohibits federal recognition of same-sex marriage. This means that even when same-sex couples legally marry because their state allows them to, they do not enjoy the various federal tax, inheritance, and other benefits that married couples enjoy. Most of the states that do not allow same-sex marriage also have laws that prohibit recognition of same-sex marriages performed in the states that allow them.

Arguments against same-sex marriage. Opponents of same-sex marriage make at least three central points (Emrich, 2009; National Organization for Marriage, 2011). First, and in no particular order, marriage is intended to procreate the species, and same-sex couples cannot reproduce. Second, the children that same-sex couples do have through adoption or artificial means experience various psychological problems because their parents are gay or lesbian and/or because they do not have both a father and a mother. Third, allowing gays and lesbians to marry would undermine the institution of marriage.

Arguments for same-sex marriage. In reply, proponents of same-sex marriage make their own points (Barkan, Marks, \& Milardo, 2009; Human Rights Campaign, 2009). First, many heterosexual couples are allowed to marry even though they will not have children, either because they are not able to have them, because they do not wish to have them, or because they are beyond childbearing age. Second, studies show that children of same-sex couples 
are at least as psychologically healthy as the children of opposite-sex couples (see Note 5.12 "Children and Our Future”). Third, there is no evidence that legalizing same-sex marriage has weakened the institution of marriage in the few states and other nations that have legalized it (see Note 5.14 "Lessons from Other Societies").

\section{Lessons from Other Societies}

Same-Sex Marriage in the Netherlands

At the time of this writing, same-sex marriage was legal in ten nations: Argentina, Belgium, Canada, Iceland, the Netherlands, Norway, Portugal, Spain, South Africa, and Sweden. All these nations have legalized it since 2001, when the Netherlands became the first country to do so. Because more than a decade has passed since this notable event, it is informative to examine how, if at all, legalization has affected the lives of gays and lesbians and the institution of marriage itself in the Netherlands.

One thing is clear: There is no evidence that the institution of marriage in the Netherlands has in any respect become weaker because same-sex couples have been allowed to marry since 2001. Heterosexual couples continue to marry, and the institution appears at least as strong as it was before 2001. It also seems clear that same-sex marriages are working and that same-sex married couples' unions are accepted as normal features of contemporary Dutch life. As Vera Bergkamp, a gay rights leader in the Netherlands said, "Gay marriage is Holland's best export because we have shown that it is possible."

In an interesting development, same-sex couples have not exactly rushed to marry. There was an initial spurt in 2001, and many such couples have married since. However, the Dutch government estimates that only 20 percent of same-sex couples have married compared to 80 percent of heterosexual couples.

Three reasons may account for this disparity. First, there is less pressure from family and friends for same-sex couples to marry than for heterosexual couples to marry. As Bergkamp put it, "For heterosexuals, it's normal when you're in a steady relationship for more than a year, that a lot of people start asking, 'well when are you getting married?' With two women or two men you don't get that yet.” Second, fewer same-sex couples than heterosexual couples decide to marry in order to have children. Third, gays and lesbians in the Netherlands are thought to be somewhat more individualistic than their heterosexual counterparts.

The same-sex couples who have married in the Netherlands seem happy to have done so, at least according to anecdotal evidence. As one same-sex spouse reflected on her marriage, “It was a huge step. For me it was incredible...I'd been to my brother's wedding and my sister's wedding and their spouses were welcomed into the family. Now finally I was able to have my family take my partner in. The moment we got married there was a switch, she was now one of us.”

The experience of the Netherlands is mirrored in the other nine nations that have legalized same-sex marriage. Legalization seems to be working from all accounts, and the institution of marriage seems to be thriving at least as well as in other nations. As the first openly gay member of the Dutch parliament who played a key role in legalization wryly described its outcome, "Heterosexual couples did not turn away from the institution of marriage, and nor did the world isolate my country. After the Netherlands acted, civilization as we know it didn't end.” As the United States continues to debate same-sex marriage, it has much to learn from the Netherlands and the other nations that have legalized this form of marriage.

Sources: Ames, 2011; Badgett, 2009; Dittrich, 2011

Although the children of same-sex couples fare at least as well as those of heterosexual couples, it is still difficult in many states for same-sex couples to adopt a child. Two states at the time of this writing, Mississippi and Utah, prohibit adoptions by same-sex couples, but half of the other states make it very difficult for these adoptions to occur (Tavernise, 2011). For example, in some states social workers are required to prefer married heterosexual couples over same-sex couples in adoption decisions. Moreover, several states require that a couple must be married to be adopted; in these states, a single gay or lesbian may adopt, but not a same-sex couple. Still, adoptions 
by same-sex couples have become more numerous in recent years because of the number of children waiting for adoption and because public opinion about gays and lesbians has become more favorable.

\section{Costs of the Illegality of Same-Sex Marriage}

Marriage provides many legal rights, benefits, and responsibilities for the two spouses. Because same-sex couples are not allowed to marry in most states and, even if they do marry, are currently denied federal recognition of their marriage, they suffer materially in numerous ways. In fact, there are more than 1,000 federal rights that heterosexual married couples receive that no married same-sex couple is allowed to receive (Shell, 2011).

We have space here to list only a few of the many costs that the illegality of same-sex marriage imposes on samesex couples who cannot marry and on the same-sex couples whose marriages are not federally recognized (Human Rights Campaign, 2009):

- Spouses have visitation rights if one of them is hospitalized as well as the right to make medical decisions if one spouse is unable to do so; same-sex couples do not have these visitation rights.

- Same-sex couples cannot file joint federal tax returns or joint state tax returns (in the states that do not recognize same-sex marriage), potentially costing each couple thousands of dollars every year in taxes they would not have to pay if they were able to file jointly.

- Spouses receive Social Security survivor benefits averaging more than \$5,500 annually when a spouse dies; same-sex couples do not receive these benefits.

- Many employers who provide health insurance coverage for the spouse of an employee do not provide this coverage for a same-sex partner; when they do provide this coverage, the employee must pay taxes on the value of the coverage.

- When a spouse dies, the surviving spouse inherits the deceased spouse's property without paying estate taxes; the surviving partner of a same-sex couple must pay estate taxes.

Notice that many of these costs are economic. It is difficult to estimate the exact economic costs of the illegality of same-sex marriage, but one analysis estimated that these costs can range from $\$ 41,000$ to as much as $\$ 467,000$ over the lifetime of a same-sex couple, depending on their income, state of residence, and many other factors (Bernard \& Leber, 2009).

\section{Military Service}

LGBT individuals traditionally were not permitted to serve in the US military. If they remained in the closet (hid evidence of their sexual orientation), of course, they could serve with impunity, but many gays and lesbians in the military were given dishonorable discharges when their sexual orientation was discovered. Those who successfully remained in the closet lived under continual fear that their sexual orientation would become known and they would be ousted from the military. 
As a presidential candidate in 1992, Bill Clinton said he would end the ban on LGBT people in the military. After his election, his intention to do so was met with fierce opposition by military leaders, much of the Congress, and considerable public opinion. As a compromise, in 1993 the government established the so-called don't-ask, don'ttell (DADT) policy. DADT protected members of the military from being asked about their sexual orientation, but it also stipulated that they would be discharged from the military if they made statements or engaged in behavior that indicated an LGBT orientation. Because DADT continued the military ban on LGBT people, proponents of allowing them to serve in the military opposed the policy and continued to call for the elimination of any restrictions regarding sexual orientation for military service.

In response to a lawsuit, a federal judge in 2010 ruled that DADT was unconstitutional. Meanwhile, Barack Obama had also called for the repeal of DADT, both as a presidential candidate and then as president. In late 2010, Congress passed legislation repealing DADT, and President Obama signed the legislation, which took effect in September 2011. Official discrimination against gays and lesbians in the military has thus ended, and they may now serve openly in the nation's armed forces. It remains to be seen, however, whether they will be able to serve without facing negative experiences such as verbal and physical abuse.

\section{Physical and Mental Health}

It is well known that HIV (human immunodeficiency virus) and AIDS (acquired immunodeficiency syndrome) racked the LGBT community beginning in the 1980s. Many gays and lesbians eventually died from AIDS-related complications, and HIV and AIDS remain serious illnesses for gays and straights alike. An estimated 1.2 million Americans now have HIV, and about 35,000 have AIDS. Almost 50,000 Americans are diagnosed with HIV annually, and more than half of these new cases are men who have had sex with other men. Fortunately, HIV can now be controlled fairly well by appropriate medical treatment (Centers for Disease Control and Prevention, 2011).

It is less well known that LGBT adults have higher rates than straight adults of other physical health problems and also of mental health problems (Frost, Lehavot, \& Meyer, 2011; Institute of Medicine, 2011). These problems are thought to stem from the stress that the LGBT community experiences from living in a society in which they frequently encounter verbal and physical harassment, job discrimination, a need for some to conceal their sexual identity, and lack of equal treatment arising from the illegality of same-sex marriage. We saw earlier that LGBT secondary school students experience various kinds of educational and mental health issues because of the mistreatment they encounter. By the time LGBT individuals reach their adult years, the various stressors they have experienced at least since adolescence have begun to take a toll on their physical and mental health. 


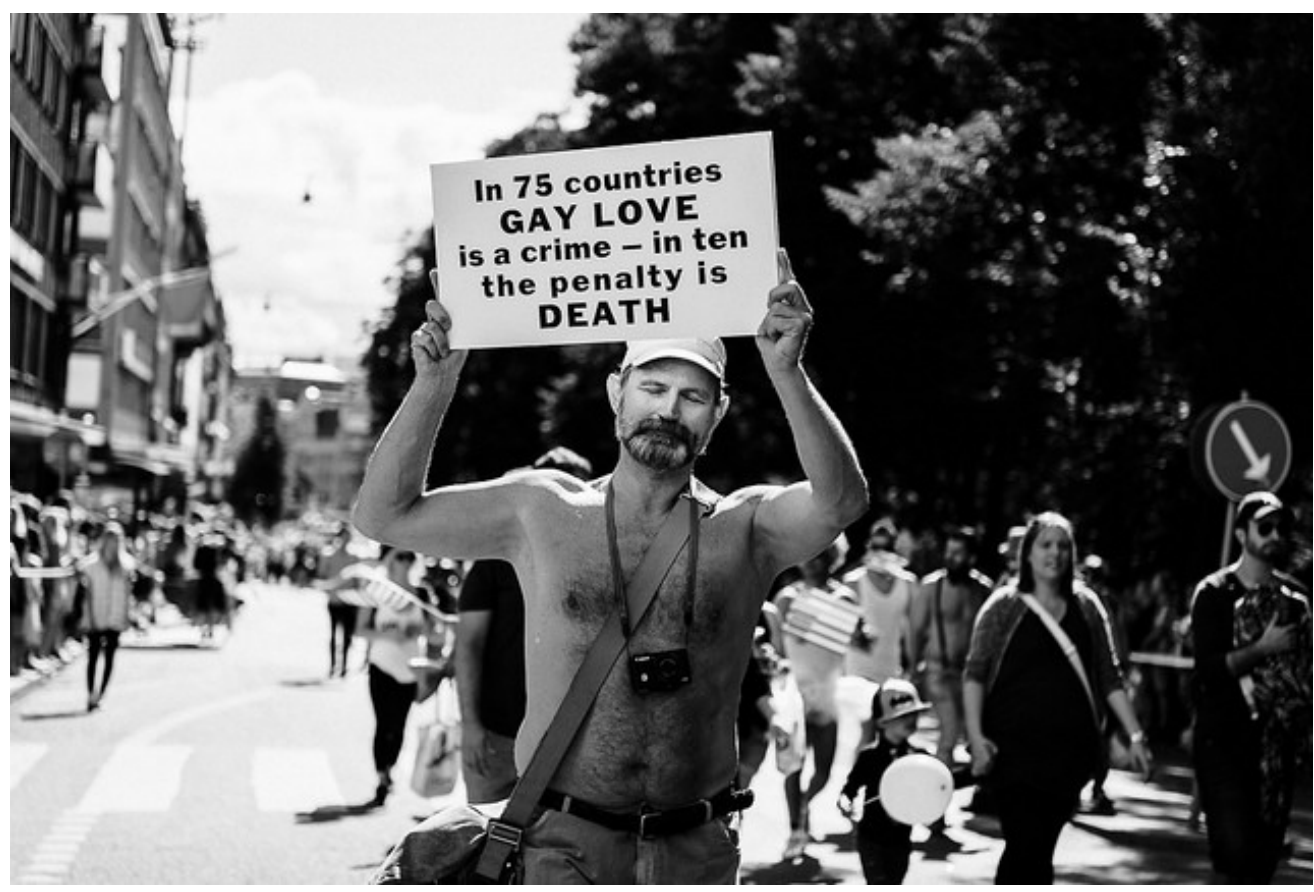

The stress of being LGBT in a society that disapproves of this sexual orientation is thought to account for the greater likelihood of LGBT people to have physical and mental health problems.

Patrik Nygren - LGBT rights - CC BY-SA 2.0.

Because stress is thought to compromise immune systems, LGBT individuals on the average have lower immune functioning and lower perceived physical health than straight individuals. Because stress impairs mental health, they are also more likely to have higher rates of depression, loneliness, low self-esteem, and other psychiatric and psychological problems, including a tendency to attempt suicide (Sears \& Mallory, 2011). Among all LGBT individuals, those who have experienced greater levels of stress related to their sexual orientation have higher levels of physical and mental health problems than those who have experienced lower levels of stress. It is important to keep in mind that these various physical and mental health problems do not stem from an LGBT sexual orientation in and of itself, but rather from the experience of living as an LGBT individual in a homophobic (disliking LGBT behavior and individuals) society.

Despite the health problems that LGBT people experience, medical students do not learn very much about these problems. A recent survey of medical school deans found that one-third of medical schools provide no clinical training about these health issues, and that students in the medical schools that do provide training still receive only an average of five hours of training (Obedin-Maliver et al., 2011). The senior author of the study commented on its findings, "It's great that a lot of schools are starting to teach these topics. But the conversation needs to go deeper. We heard from the deans that a lot of these important LGBT health topics are completely off the radar screens of many medical schools” (White, 2011).

\section{Heterosexual Privilege}

In earlier chapters, we discussed the related concepts of white privilege and male privilege. To recall, simply 
because they are white, whites can go through their daily lives without worrying about or experiencing the many kinds of subtle and not-so-subtle negative events that people of color experience. Moreover, simply because they are male, men can go through their daily lives without worrying about or experiencing the many kinds of subtle and not-so-subtle negative events that women experience. Whether or not they are conscious of it, therefore, whites and men are automatically privileged compared to people of color and women, respectively.

An analogous concept exists in the study of sexual orientation and inequality. This concept is heterosexual privilege, which refers to the many advantages that heterosexuals (or people perceived as heterosexuals) enjoy simply because their sexual orientation is not LGBT. There are many such advantages, and we have space to list only a few:

- Heterosexuals can be out day or night or at school or workplaces without fearing that they will be verbally harassed or physically attacked because of their sexuality or that they will hear jokes about their sexuality.

- Heterosexuals do not have to worry about not being hired for a job, about being fired, or not being promoted because of their sexuality.

- Heterosexuals can legally marry everywhere in the United States and receive all the federal, state, and other benefits that married couples receive.

- Heterosexuals can express a reasonable amount of affection (holding hands, kissing, etc.) in public without fearing negative reactions from onlookers.

- Heterosexuals do not have to worry about being asked why they prefer opposite-sex relations, being criticized for choosing their sexual orientation, or being urged to change their sexual orientation.

- Heterosexual parents do not have to worry about anyone questioning their fitness as parents because of their sexuality.

- Heterosexuals do not have to feel the need to conceal their sexual orientation.

- Heterosexuals do not have to worry about being accused of trying to "push" their sexuality onto other people.

\section{People Making a Difference}

Improving the Family Lives of LGBT Youth

Many organizations and agencies around the country aim to improve the lives of LGBT teens. One of them is the Family Acceptance Project (FAP) at San Francisco State University, which focuses on the family problems that LGBT teens often experience. According to its website, FAP is "the only community research, intervention, education and policy initiative that works to decrease major health and related risks for [LGBT] youth, such as suicide, substance abuse, HIV and homelessness - in the context of their families. We use a research-based, culturally grounded approach to help ethnically, socially and religiously diverse families decrease rejection and increase support for their LGBT children.”

To accomplish its mission, FAP engages in two types of activities: research and family support services. In the research area, FAP has published some pioneering studies of the effects of school victimization and of family rejection and acceptance on the physical and mental health of LGBT teens during their adolescence and into their early adulthood. In the family support services area, FAP provides confidential advice, information, and counseling to families with one or 
more LGBT children or adolescents, and it also has produced various educational materials for these families and for professionals who deal with LGBT issues. At the time of this writing, FAP was producing several documentary videos featuring LGBT youth talking about their family situations and other aspects of their lives. Its support services and written materials are available in English, Spanish, and Cantonese.

Through its pioneering efforts, the Family Acceptance Project is one of many organizations making a difference in the lives of LGBT youth. For further information about FAP, visit http://familyproject.sfsu.edu.

\section{Key Takeaways}

- Bullying, taunting, and violence are significant problems for the LGBT community.

- LGBT people are at greater risk for behavioral and physical and mental health problems because of the many negative experiences they encounter.

- Federal law does not protect LGBT individuals from employment discrimination.

- The children of same-sex couples fare at least as well as children of heterosexual couples.

\section{For Your Review}

1. Do you know anyone who has ever been bullied and taunted for being LGBT or for being perceived as LGBT? If so, describe what happened.

2. Write a brief essay in which you summarize the debate over same-sex marriage, provide your own view, and justify your view.

\section{References}

Ames, P. (2011, April 20). Dutch gays don’t take advantage of opportunity to marry. GlobalPost. Retrieved from http://www.globalpost.com/dispatch/news/regions/europe/benelux/110419/netherlands-gay-rights-same-sexmarriage.

Badgett, M. V. L. (2009). When gay people get married: What happens when societies legalize same-sex marriage. New York, NY: New York University Press.

Barkan, S., Marks, S., \& Milardo, R. (2009, September 22). Same-sex couples are families, too. Bangor Daily News. Retrieved from http://www.bangordailynews.com/detail/121751.html.

Bernard, T. S., \& Leber, R. (2009, October 3). The high price of being a gay couple. New York Times, p. A1.

Centers for Disease Control and Prevention. (2011). Basic information about HIV and AIDS. Retrieved Septembr 6, 2011, from http://www.cdc.gov/hiv/topics/basic/index.htm. 
Connolly, C. (2011, July 21). 1 in 4 gay/lesbian high school students are homeless. EurekaAlert. Retrieved September 8, 2011, from http://www.eurekalert.org/pub releases/2011-07/chb-1i4072111.php.

Corliss, H. L., Goodenow, C. S., Nichols, L., \& Austin, S. B. (2011). High burden of homelessness among sexualminority adolescents: Findings from a representative Massachusetts high school sample. American Journal of Public Health, 101, 1683-1689.

Denizet-Lewis, B. (2009, September 27). Coming out in middle school. New York Times Magazine, p. MM36ff.

Dittrich, B. O. (2011, April 17). Gay marriage’s diamond anniversary: After the Netherlands acted, civilization as we know it didn't end. Los Angeles Times. Retrieved from http://articles.latimes.com/2011/apr/17/opinion/la-oedittrich-gay-marriage-20110417.

Egan, P. J. (2010, spring). Within reach: Reducing LGBT inequality in the age of Obama. Pathways: A Magazine on Poverty, Inequality, and Social Policy, 22-25.

Emrich, B. (2009, September 2). Same-sex marriage would be harmful to society. Bangor Daily News. Retrieved from http://bangordailynews.com/2009/2009/2001/opinion/samesex-marriage-would-be-harmful-to-society/.

Federal Bureau of Investigation. (2011). Crime in the United States, 2010. Washington, DC: Author.

Frost, D. M., Lehavot, K., \& Meyer, I. H. (2011). Minority stress and physical health among sexual minorities. Los Angeles, CA: Williams Institute.

Gates, G. J. (2012). Same-Sex Couples in Census 2010: Race and Ethnicity. Williams Institute. Retrieved May 29, 2012, from http://williamsinstitute.law.ucla.edu/wp-content/uploads/Gates-CouplesRaceEthnicityApril-2012.pdf.

Human Rights Campaign. (2009). Answers to questions about marriage equality. Washington, DC: Human Rights Campaign.

Human Rights Campaign. (2011). Laws: Employment non-discrimination act. Retrieved September 5, 2011, from http://www.hrc.org/.

Institute of Medicine. (2011). The health of lesbian, gay, bisexual, and transgender people: Building a foundation for better understanding. Washington, DC: National Academies Press.

Kann, L., Olsen, E. O. M., McManus, T., Kinchen, S., Chyen, D., Harris, W. A., et al. (2011). Sexual Identity, Sex of Sexual Contacts, and Health-Risk Behaviors Among Students in Grades 9-12-Youth Risk Behavior Surveillance, Selected Sites, United States, 2001-2009. Morbidity and Mortality Weekly Report, 60(June 10), $1-133$.

Kosciw, J. G., Greytak, E. A., Diaz, E. M., \& Bartkiewicz, M. J. (2010). The 2009 national school climate survey: The experiences of lesbian, gay, bisexual and transgender youth in our nation's schools. New York, NY: Gay, Lesbian and Straight Education Network.

Loffreda, B. (2001). Losing Matt Shepard: Life and politics in the aftermath of anti-gay murder. New York, NY: Columbia University Press. 
Melnick, M. (2011, June 6). CDC: Why gay and bisexual teens are more likely to risk their health. Time. Retrieved from $\quad$ http://healthland.time.com/2011/2006/2006/cdc-gay-and-bisexual-teens-are-more-likely-to-risk-theirhealth/.

Mental Health America. (2011). Bullying and gay youth. Retrieved from http://www.nmha.org/ index.cfm?objectid=CA866DCF-1372-4D20-C8EB26EEB30B9982.

National Organization for Marriage. (2011). Marriage talking points. Retrieved September 5, 2011, from http://www.nationformarriage.org/site/c.omL2KeN0LzH/b.4475595/k.566A/Marriage Talking_Points.htm.

National Organization for Marriage. (2011). Same-sex marriage: Answering the toughest questions. Retrieved September 8, 2011, from http:/www.nationformarriage.org/site/c.omL2KeN0LzH/b.4475595/k.566A/ Marriage_Talking_Points.htm.

Obedin-Maliver, J., Goldsmith, E. S., Stewart, L., White, W., Tran, E., Brenman, S., et al. (2011). Lesbian, gay, bisexual, and transgender-related content in undergraduate medical education. JAMA, 306(9), 971-977.

Russell, S. T., Ryan, C., Toomey, R. B., Diaz, R. M., \& Sanchez, J. (2011). Lesbian, gay, bisexual, and transgender adolescent school victimization: implications for young adult health and adjustment. Journal of School Health, 81(5), 223-230.

SDA. (2008). GSS 1972-2010 cumulative datafile. Retrieved from http://sda.berkeley.edu/cgi-bin/ hsda?harcsda+gss10.

Sears, B., \& Mallory, C. (2011). Documented evidence of employment discrimination \& its effects on LGBT people. Los Angeles, LA: Williams Institute.

Shell, A. (2011, July 22). Legal gay marriage doesn’t end money headaches. USA Today. Retrieved from http://www.usatoday.com/money/perfi/index.

St. George, D. (2010, December 6). Gay and lesbian teens are punished more at school, by police, study says. The Washington Post. Retrieved from http://www.washingtonpost.com/wp-dyn/content/article/2010/12/06/ AR2010120600035.html.

Talbot, M. (2010, October 25). Pride and prejudice. The New Yorker. Retrieved from http://www.newyorker.com. Tavernise, S. (2011, July 14). Adoptions rise by same-sex couples, despite legal barriers. New York Times , p. A11. White, T. (2011). LGBT health issues not being taught at medical schools, Stanford study finds. EurekaAlert. Retrieved September 7, 2011, from http://www.eurekalert.org/pub releases/2011-09/sumc-lhi083111.php. 


\subsection{Improving the Lives of the LGBT Community}

\section{Learning Objective}

1. Understand which measures show promise of reducing inequality based on sexual orientation.

The inequality arising from sexual orientation stems from long-standing and deep-rooted prejudice against nonheterosexual attraction and behavior and against the many people whose sexual orientation is not heterosexual. We have seen in this chapter that attitudes about and related to same-sex sexuality have become markedly more positive since a generation ago. Reflecting this trend, the number of openly gay elected officials and candidates for office has increased greatly since a generation ago, and the sexual orientation of candidates appears to be a nonissue in many areas of the nation (Page, 2011). In a 2011 Gallup poll, two-thirds of Americans said they would vote for a gay candidate for president, up from only one-fourth of Americans in 1978 (Page, 2011). Also in 2011, the US Senate confirmed the nomination of the first openly gay man for a federal judgeship (Milbank, 2011). To paraphrase the slogan of a nationwide campaign aimed at helping gay teens deal with bullying and other mistreatment, it is getting better.

Much of this improvement must be credited to the gay rights movement that is popularly thought to have begun in June 1969 in New York City after police raided a gay bar called the Stonewall Inn and arrested several people inside. A crowd of several hundred people gathered and rioted in protest that night and the next night. The gay rights movement had begun.

Despite the advances this movement has made and despite the improvement in public attitudes about LGBT issues, we have seen in this chapter that LGBT people continue to experience many types of inequality and other problems. As with inequality based on race and/or ethnicity, social class, and gender, there is much work still to be done to reduce inequality based on sexual orientation.

For such inequality to be reduced, it is certainly essential that heterosexuals do everything possible in their daily lives to avoid any form of mistreatment of LGBT individuals and to treat them as they would treat any heterosexual. Beyond this, certain other measures should help address LGBT inequality. These measures might include, but are not limited to, the following:

1. Parents should make clear to their children that all sexual orientations are equally valid. Parents whose child happens to be LGBT should love that child at least as much as they would love a heterosexual child.

2. School programs should continue and strengthen their efforts to provide students a positive environment in regard to sexual orientation and to educate them about LGBT issues. Bullying and other harassment of LGBT students must not be tolerated. In 2011, California became the first state to require the teaching of gay and lesbian history; other states should follow this example. 
3. Federal law should prohibit employment discrimination against LGBT people, and same-sex marriages should become legal throughout the United States. In the meantime, new legislation should provide same-sex couples the same rights, responsibilities, and benefits that heterosexual married couples have.

4. Police should continue to educate themselves about LGBT issues and should strengthen their efforts to ensure that physical attacks on LGBT people are treated at least as seriously as attacks on heterosexual people are treated.

\section{Key Takeaways}

- Although the gay rights movement has made significant advances, many types of inequality based on sexual orientation continue to exist.

- Several measures should be begun or continued to reduce inequality based on sexual orientation.

\section{For Your Review}

1. Is there a gay rights advocacy group on your campus? If so, what is your opinion of it?

2. How do you think parents should react if their teenaged daughter or son comes out to them? Explain your answer.

\section{References}

Milbank, D. (2011, July 18). In a “quiet moment," gay judge makes history. The Washington Post. Retrieved from http://www.washingtonpost.com/.

Page, S. (2011, July 20). Gay candidates gain acceptance. USA Today. Retrieved from http://www.usatoday.com/ news/politics/index. 


\subsection{End-of-Chapter Material}

\section{Summary}

1. Sexual orientation refers to a person's preference for sexual relationships with individuals of the other sex, one's own sex, or both sexes. The term also increasingly refers to transgender individuals, whose behavior, appearance, and/or gender identity departs from conventional norms.

2. According to national survey evidence, almost 4 percent of American adults identify as LGBT (lesbian/gay/ bisexual/transgender), a figure equivalent to 9 million adults. Almost 20 million have engaged in same-sex relations.

3. Male homosexuality in ancient Greece and Rome seems to have been accepted and rather common, but Europe, the Americas, and other areas influenced by the Judeo-Christian tradition have long viewed homosexuality very negatively. In many societies studied by anthropologists, homosexuality is rather common and considered a normal form of sexuality.

4. Scholars continue to debate whether sexual orientation is more the result of biological factors or social and cultural factors. Related to this debate, the public is fairly split over the issue of whether sexual orientation is a choice or something over which people have no control.

5. Heterosexism in the United States is higher among men than among women, among older people than younger people, among the less educated than among the more highly educated, among Southerners than among non-Southerners, and among more religious people than among less religious people. Levels of heterosexism have declined markedly since a generation ago.

6. Sexual orientation is a significant source of inequality. LGBT individuals experience bullying, taunting, and violence; they may experience employment discrimination; and they are not allowed to marry in most states. Because of the stress of living as LGBT, they are at greater risk than heterosexuals for several types of physical and mental health problems.

\section{Using What You Know}

You're working in a medium-sized office and generally like your coworkers. However, occasionally you hear them make jokes about gays and lesbians. You never laugh at these jokes, but neither have you ever said anything critical about them. Your conscience is bothering you, but you also know that if you tell your supervisor or coworkers that their joking makes you feel uncomfortable, they may get angry with you and even stop talking to you. What do you decide to do?

\section{What You Can Do}

To help reduce inequality based on sexual orientation, you may wish to do any of the following: 
1. Start or join an LGBT advocacy group on your campus.

2. Write a letter to the editor in favor of same-sex marriage.

3. Urge your US Senators and Representative to pass legislation prohibiting employment discrimination on the basis of sexual orientation.

4. Work for a social service agency in your local community that focuses on the needs of LGBT teens. 


\section{Chapter 6: Aging and Ageism}

\section{Social Problems in the News}

"Still Working: Economy Forcing Retirees to Re-enter Workforce," the headline said. The story featured four seniors, ranging in age from 66 to their eighties, in southern California who had retired several years ago but were now trying to get back into the labor force. Because of the faltering economy and rising costs, they were having trouble affording their retirement. They were also having trouble finding a job, in part because they lacked the computer skills that are virtually a necessity in today's world to find and perform a job. One of the unemployed seniors was a retired warehouse worker who did not know how to fill out a job application online. He said, “To say I have computer skills—no, I don't. But I can learn. I will do anything to get work.” An official in California's Office on Aging indicated that employers who hire older people would be happy they did so: "You know the person's going to come in and you know they're going to accomplish something while they're there. And, they are a wellspring of knowledge.”

Source: Barkas, 2011

The number of older Americans is growing rapidly. As this news story suggests, they have much to contribute to our society. Yet they also encounter various problems because of their advanced age. We appreciate our elderly but also consider them something of a burden. We also hold unfortunate stereotypes of them and seemingly view old age as something to be shunned. Television commercials and other advertisements extol the virtues of staying young by "washing away the gray" and by removing all facial wrinkles. In our youth-obsessed culture, older people seem to be second-class citizens. This chapter discusses views about aging and the ways in which old age is a source of inequality.

\section{References}

Barkas, S. (2011, September 5). Still working: Economy forcing retirees to re-enter workforce. The Desert Sun. Retrieved from http://www.mydesert.com. 


\subsection{The Concept and Experience of Aging}

\section{Learning Objectives}

1. Define social gerontology.

2. Distinguish biological aging, psychological aging, and social aging.

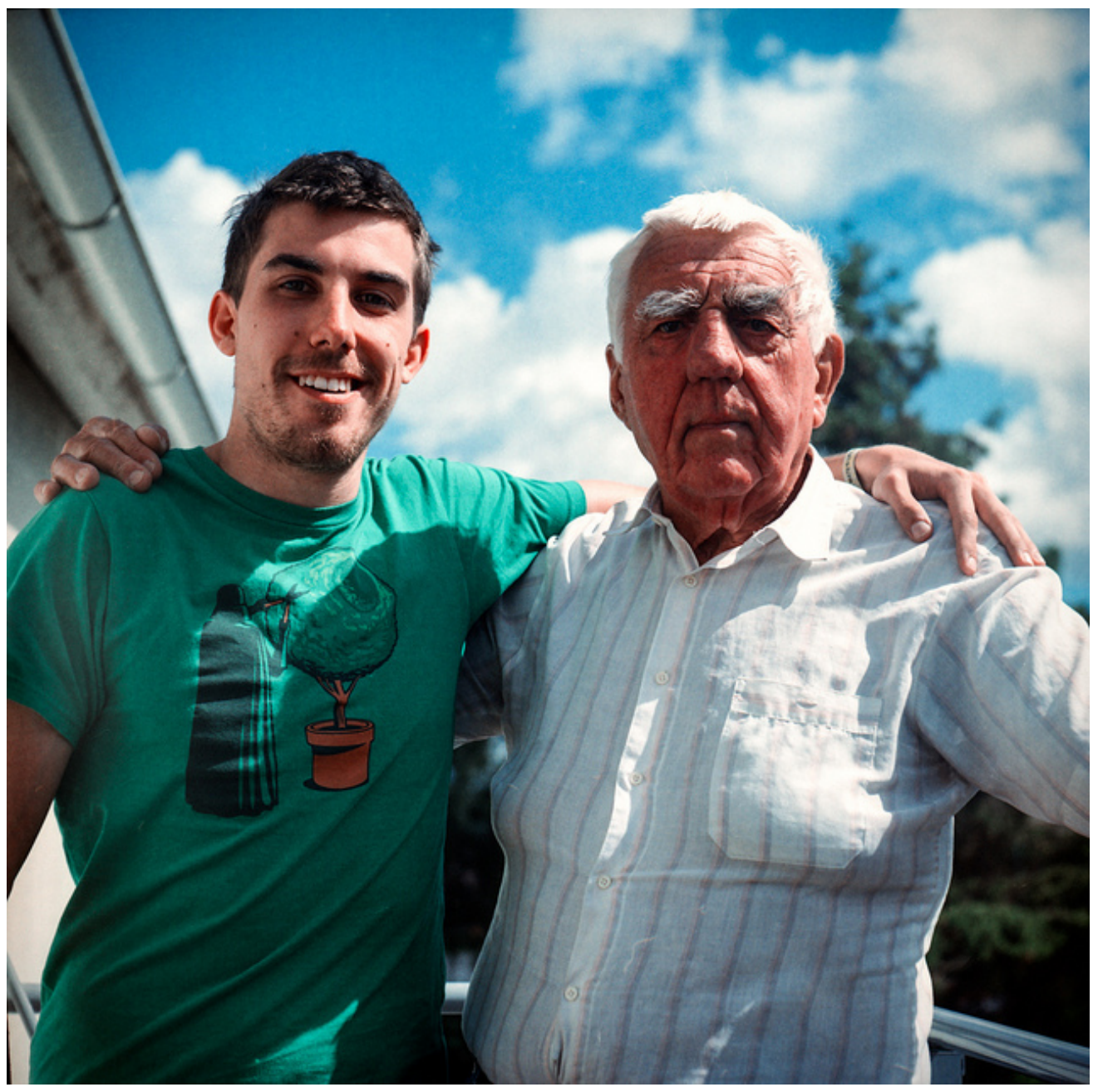

Because we all want to live into old age, the study of age and aging helps us understand something about ourselves and a stage in the life course we all hope to reach.

Carl Nenzén Lovén - Grandpa - CC BY 2.0.

Here is why you should want to know about aging and the problems older people face: You will be old someday. At least you will be old if you do not die prematurely from an accident, cancer, a heart attack, some other medical 
problem, murder, or suicide. Although we do not often think about aging when we are in our late teens and early twenties, one of our major goals in life is to become old. By studying age and aging and becoming familiar with some of the problems facing the elderly now and in the future, we are really studying something about ourselves and a stage in the life course we all hope to reach.

The study of aging is so important and popular that it has its own name, gerontology. Social gerontology is the study of the social aspects of aging (Novak, 2012). The scholars who study aging are called gerontologists. The people they study go by several names, most commonly "older people," "elders," and "the elderly." The latter term is usually reserved for those 65 or older, while "older people" and "elders" often include people in their fifties as well as those 60 or older.

\section{Dimensions of Aging}

Age and aging have four dimensions. The dimension most of us think of is chronological age, defined as the number of years since someone was born. A second dimension is biological aging, which refers to the physical changes that "slow us down" as we get into our middle and older years. For example, our arteries might clog up, or problems with our lungs might make it more difficult for us to breathe. A third dimension, psychological aging, refers to the psychological changes, including those involving mental functioning and personality, that occur as we age. Gerontologists emphasize that chronological age is not always the same thing as biological or psychological age. Some people who are 65, for example, can look and act much younger than some who are 50.

The fourth dimension of aging is social. Social aging refers to changes in a person's roles and relationships, both within their networks of relatives and friends and in formal organizations such as the workplace and houses of worship. Although social aging can differ from one individual to another, it is also profoundly influenced by the perception of aging that is part of a society's culture. If a society views aging positively, the social aging experienced by individuals in that society will be more positive and enjoyable than in a society that views aging negatively. As we shall see, though, the perception of aging in the United States is not very positive, with important consequences for our older citizens.

\section{Key Takeaways}

- The study of the elderly and aging helps us understand problems in a state of the life course we all hope to reach.

- Biological aging refers to the physical changes that accompany the aging process, while psychological aging refers to the psychological changes that occur.

- Social aging refers to the changes in a person's roles and relationships as the person ages. 


\section{For Your Review}

1. Think about an older person whom you know. To what extent has this person experienced psychological aging? To what extent has this person experienced social aging?

2. The text states that the perception of aging in the United States is not very positive. What do you think accounts for this?

\section{References}

Novak, M. (2012). Issues in aging (3rd ed.). Upper Saddle River, NJ: Pearson. 


\subsection{Perspectives on Aging}

\section{Learning Objectives}

1. State the assumptions of disengagement, activity, and conflict theories of aging.

2. Critically assess these three theories.

Recall that social aging refers to changes in people's roles and relationships in a society as they age. Social gerontologists have tried to explain how and why the aging process in the United States and other societies occurs. Their various explanations, summarized in Table 6.1 "Theory Snapshot", help us understand patterns of social aging. They fall roughly into either the functionalist, social interactionist, or conflict approaches discussed in Chapter 1 "Understanding Social Problems".

Table 6.1 Theory Snapshot

\begin{tabular}{|l|l|}
\hline $\begin{array}{l}\text { Theoretical } \\
\text { perspective }\end{array}$ & Major assumptions \\
\hline $\begin{array}{l}\text { Disengagement } \\
\text { theory }\end{array}$ & $\begin{array}{l}\text { To enable younger people to assume important roles, a society must encourage its older people to } \\
\text { disengage from their previous roles and to take on roles more appropriate to their physical and mental } \\
\text { decline. This theory is considered a functionalist explanation of the aging process. }\end{array}$ \\
\hline Activity theory & $\begin{array}{l}\text { Older people benefit themselves and their society if they continue to be active. Their positive perceptions } \\
\text { of the aging process are crucial to their ability to remain active. This theory is considered an } \\
\text { interactionist explanation of the aging process. }\end{array}$ \\
\hline Conflict theory & $\begin{array}{l}\text { Older people experience age-based prejudice and discrimination. Inequalities among the aged exist along } \\
\text { the lines of gender, race/ethnicity, and social class. This theory falls into the more general conflict theory } \\
\text { of society. }\end{array}$ \\
\hline
\end{tabular}

One of the first explanations was called disengagement theory (Cumming \& Henry, 1961). This approach assumed that all societies must find ways for older people's authority to give way to younger people. A society thus encourages its elderly to disengage from their previous roles and to take on roles more appropriate to their physical and mental decline. In this way, a society effects a smooth transition of its elderly into a new, more sedentary lifestyle and ensures that their previous roles will be undertaken by a younger generation that is presumably more able to carry out these roles. Because disengagement theory assumes that social aging preserves a society's stability and that a society needs to ensure that disengagement occurs, it is often considered a functionalist explanation of the aging process.

A critical problem with this theory was that it assumes that older people are no longer capable of adequately performing their previous roles. However, older people in many societies continue to perform their previous roles quite well. In fact, society may suffer if its elderly do disengage, as it loses their insight and wisdom. It is also true that many elders cannot afford to disengage from their previous roles; if they leave their jobs, they are also leaving 
needed sources of income, as the opening news story discussed, and if they leave their jobs and other roles, they also reduce their social interaction and the benefits it brings.

Today most social gerontologists prefer activity theory, which assumes that older people benefit both themselves and their society if they remain active and try to continue to perform the roles they had before they aged (Choi \& Kim, 2011). As they perform their roles, their perception of the situations they are in is crucial to their perception of their aging and thus to their self-esteem and other aspects of their psychological well-being. Because activity theory focuses on the individual and her or his perception of the aging process, it is often considered a social interactionist explanation of social aging.

One criticism of activity theory is that it overestimates the ability of the elderly to maintain their level of activity: Although some elders can remain active, others cannot. Another criticism is that activity theory is too much of an individualistic approach, as it overlooks the barriers many societies place to successful aging. Some elders are less able to remain active because of their poverty, gender, and social class, as these and other structural conditions may adversely affect their physical and mental health. Activity theory overlooks these conditions.

Explanations of aging grounded in conflict theory put these conditions at the forefront of their analyses. A conflict theory of aging, then, emphasizes the impact of ageism, or negative views about old age and prejudice and discrimination against the elderly (Novak, 2012). According to this view, older workers are devalued because they are no longer economically productive and because their higher salaries (because of their job seniority), health benefits, and other costs drive down capitalist profits. Conflict theory also emphasizes inequality among the aged along gender, race/ethnicity, and social class lines. Reflecting these inequalities in the larger society, some elders are quite wealthy, but others are very poor.

One criticism of conflict theory is that it blames ageism on modern, capitalist economies. However, negative views of the elderly also exist to some extent in modern, socialist societies and in preindustrial societies. Capitalism may make these views more negative, but such views can exist even in societies that are not capitalistic.

\section{Key Takeaways}

- Disengagement theory assumes that all societies must find ways for older people's authority to give way to younger people. A society thus encourages its elderly to disengage from their previous roles and to take on roles more appropriate to their physical and mental decline.

- Activity theory assumes that older people will benefit both themselves and their society if they remain active and try to continue to perform the roles they had before they aged.

\section{For Your Review}

1. Which theory of aging—disengagement theory, activity theory, or conflict theory—makes the most sense to you? Why? 


\section{References}

Choi, N. G., \& Kim, J. (2011). The effect of time volunteering and charitable donations in later life on psychological wellbeing. Ageing \& Society, 31(4), 590-610.

Cumming, E., \& Henry, W. E. (1961). Growing old: The process of disengagement. New York, NY: Basic Books. Novak, M. (2012). Issues in aging (3rd ed.). Upper Saddle River, NJ: Pearson. 


\subsection{Life Expectancy and the Graying of Society}

\section{Learning Objectives}

1. Describe the differences in life expectancy around the world.

2. List the potential problems associated with the growing proportion of older individuals in poor nations.

3. Explain the evidence for inequality in US life expectancy.

When we look historically and cross-culturally, we see that old age is a relative term, since few people in preindustrial times or in poor countries today reach the age range that most Americans would consider to be old, say 65 or older. When we compare contemporary societies, we find that life expectancy, or the average age to which people can be expected to live, varies dramatically across the world. As Figure 6.1 "Average Life Expectancy across the Globe (Years)" illustrates, life expectancy in North America, most of Europe, and Australia averages 75 years or more, while life expectancy in most of Africa averages less than 60 years (Population Reference Bureau, 2011).

Figure 6.1 Average Life Expectancy across the Globe (Years)

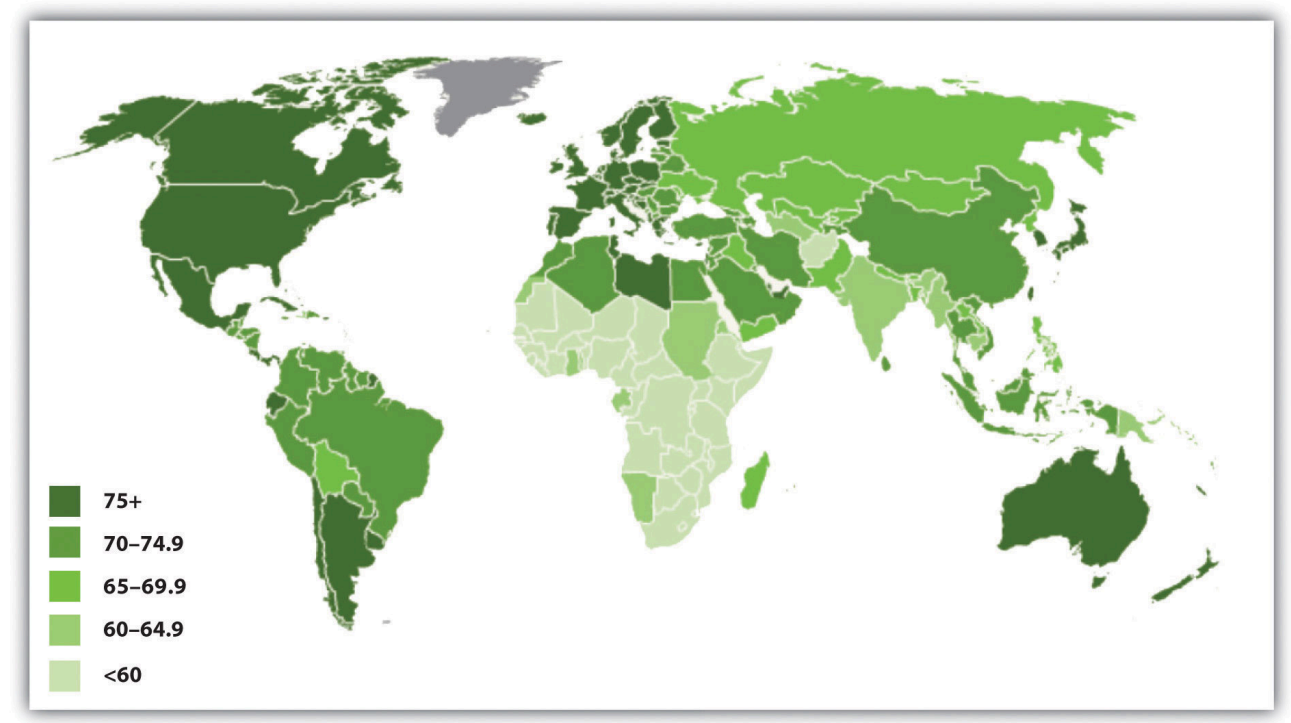

Source: Adapted from Population Reference Bureau. (2011). The world at 7 billion: World population data sheet: Life expectancy.

Retrieved from http://www.prb.org/publications/datasheets/2011/world-population-data-sheet/world-map.aspx\#/map/lifeexp.

What accounts for these large disparities? The major factor is the wealth or poverty of a nation, as the wealthiest nations have much longer life expectancies than the poorest ones. This is true because, as Chapter 2 "Poverty" noted, the poorest nations by definition have little money and few other resources. They suffer from hunger, AIDS, and other diseases, and they lack indoor plumbing and other modern conveniences found in almost every home in 
the wealthiest nations. As a result, they have high rates of infant and childhood mortality, and many people who make it past childhood die prematurely from disease, starvation, and other problems.

These differences mean that few people in these societies reach the age of 65 that Western nations commonly mark as the beginning of old age. Figure 6.2 "Percentage of Population Aged 65 or Older, 2011" depicts the percentage of each nation's population that is 65 or older. Not surprisingly, the nations of Africa have very low numbers of people 65 or older. In Uganda, for example, only 3 percent of the population is at least 65, compared to 13 percent of Americans and 20-21 percent of Germans and Italians.

Figure 6.2 Percentage of Population Aged 65 or Older, 2011

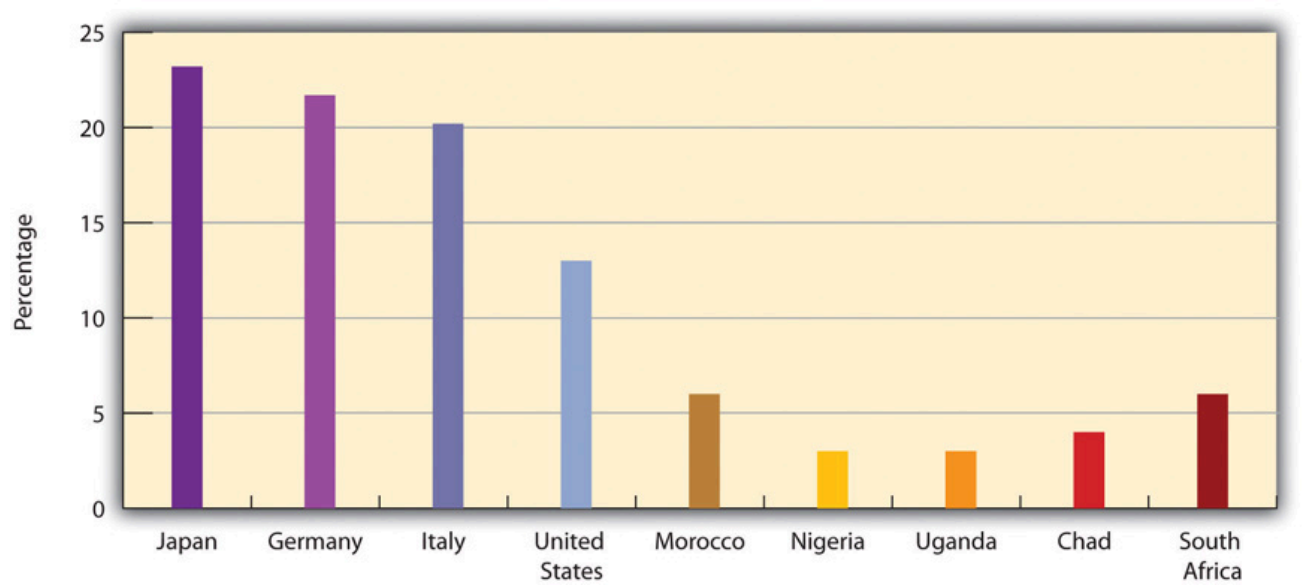

Source: Adapted from Population Reference Bureau. (2011). 2011 world population data sheet. Washington, DC: Author. Retrieved from http://www.prb.org/pdf11/ 2011population-data-sheet_eng.pdf.

Despite these international disparities, life expectancy overall has been increasing around the world. It was only 46 years worldwide in the early 1950s but was 69 in 2009 and is expected to reach about 75 by 2050 (Population Reference Bureau, 2011). This means that the number of people 65 or older is growing rapidly; they are expected to reach almost 1.5 billion worldwide by 2050, three times their number today and five times their number just twenty years ago (United Nations Population Division, 2011). Despite international differences in life expectancy and the elderly percentage of the population, the world as a whole is decidedly "graying," with important implications for the cost and quality of elder care and other issues. 


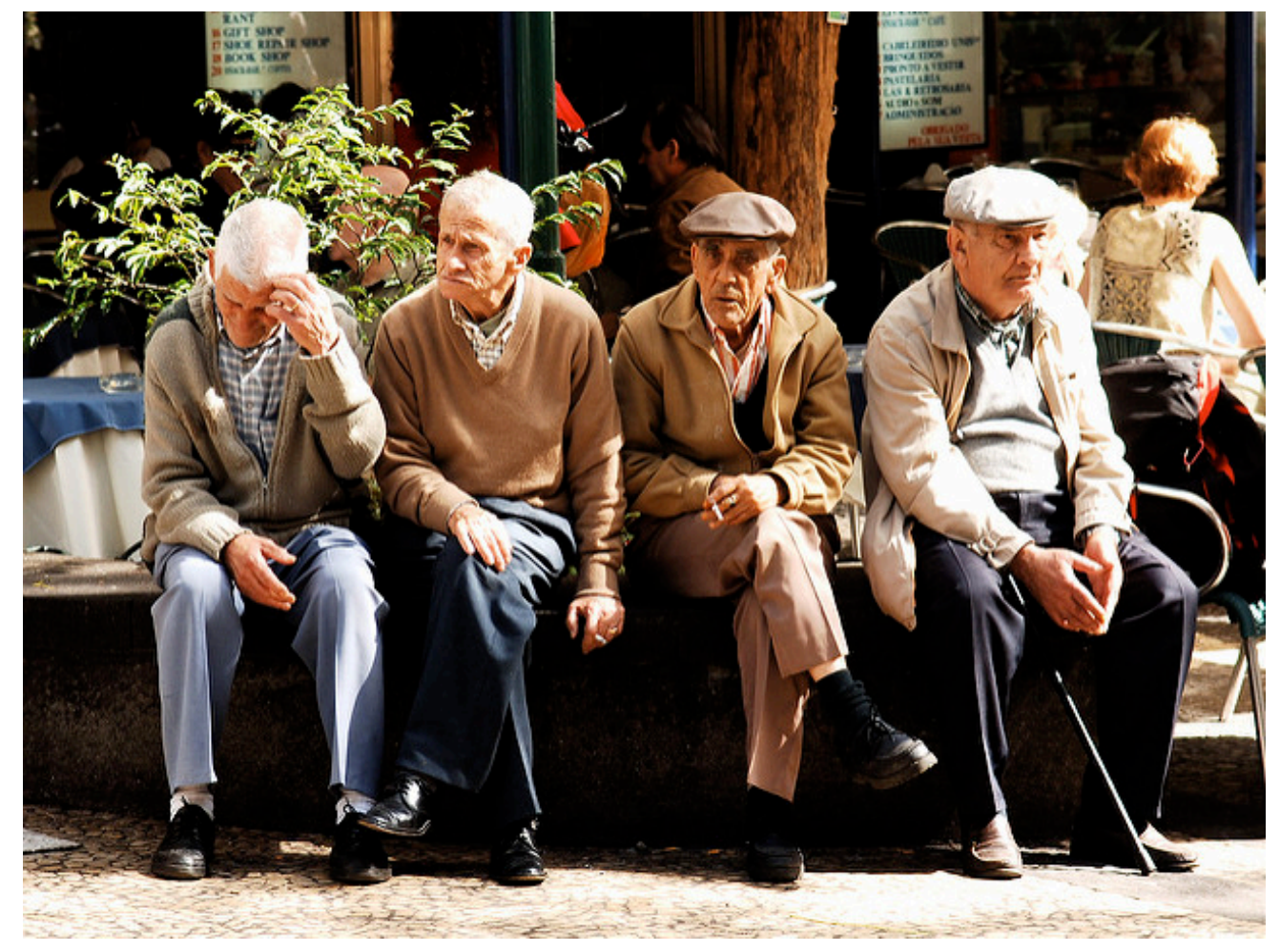

Older people now constitute 15 percent of the combined population of wealthy nations, but they will account for 26 percent by 2050 .

Pedro Ribeiro Simões - Warming the bones - CC BY 2.0.

As life expectancy rises in poor nations, these nations will experience special problems (Hayutin, 2007). One problem will involve paying for the increased health care that older people in these nations will require. Because these nations are so poor, they will face even greater problems than the industrial world in paying for such care and for other programs and services their older citizens will need. Another problem stems from the fact that many poor nations are beginning or continuing to industrialize and urbanize. As they do so, traditional family patterns, including respect for the elderly and the continuation of their roles and influence, may weaken. One reason for this is that urban families have smaller dwelling units in which to accommodate their elderly relatives and lack any land onto which they can build new housing. Families in poor nations will thus find it increasingly difficult to accommodate their elders.

\section{Life Expectancy in the United States}

Life expectancy has been increasing in the United States along with the rest of the world (see Figure 6.3 "Changes in US Life Expectancy at Birth, 1900-2010”). It rose rapidly in the first half of the twentieth century and has increased steadily since then. From a low of 47.3 years in 1900, it rose to about 71 years in 1970 and 77 years in 2000 and to more than 78 years in 2010. Americans born in 2010 will thus be expected to live about 31 years longer than those born a century earlier. 


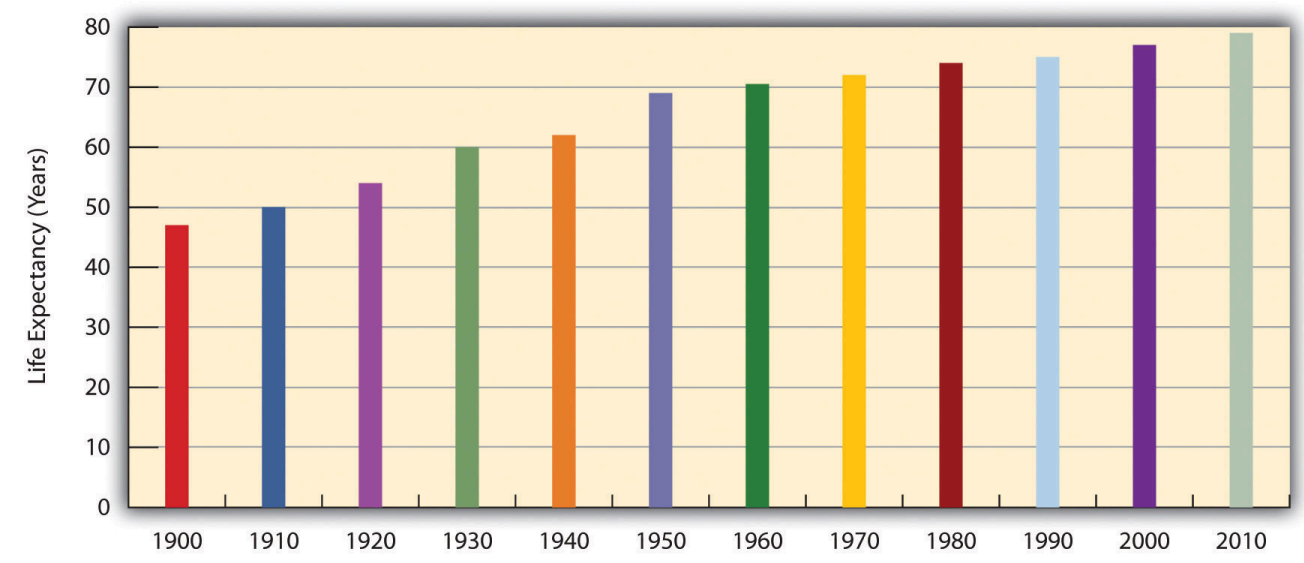

Sources: Data from Arias, E. (2010). United States life tables, 2006. National Vital Statistics Reports, 58(21), 1-40.

During the next few decades, the numbers of the elderly will increase rapidly thanks to the large baby boom generation born after World War II (from 1946 to 1964) that is now entering its mid-sixties. Figure 6.4 "Past and Projected Percentage of US Population Aged 65 or Older, 1900-2050” shows the rapid rise of older Americans (65 or older) as a percentage of the population that is expected to occur. Elders numbered about 3.1 million in 1900 (4.1 percent of the population), number about 40 million today, and are expected to reach 89 million by 2050 (20.2 percent of the population). The large increase in older Americans overall has been called the graying of America and will have important repercussions for elderly care and other aspects of old age in the United States, as we discuss later.

Figure 6.4 Past and Projected Percentage of US Population Aged 65 or Older, 1900-2050

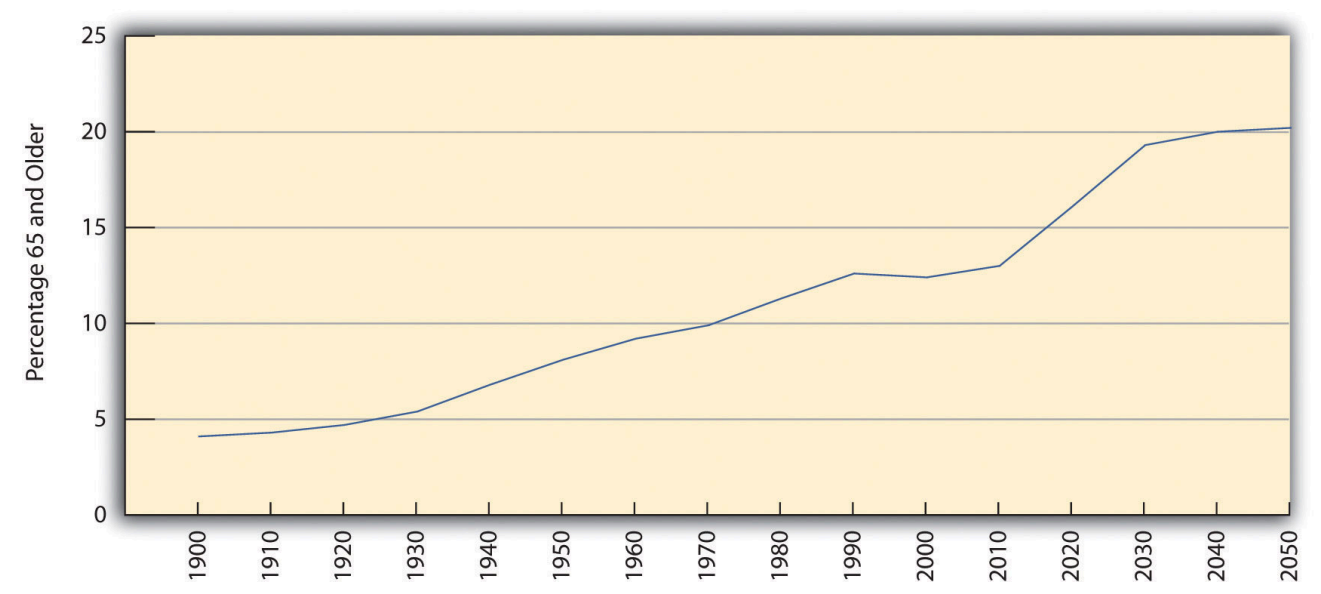

Source: Data from Administration on Aging. (n.d.). Projected future growth of the older population by age: 1900-2050. Retrieved from http://www.aoa.gov/AoARoot/Aging_Statistics/future_growth/future_growth.aspx.

\section{Inequality in Life Expectancy}

We have seen that inequality in life expectancy exists around the world, with life expectancy lower in poor 
nations than in wealthy nations. Inequality in life expectancy also exists within a given society along gender, race/ ethnicity, and social class lines.

For gender, the inequality is in favor of women, who for both biological and social reasons outlive men across the globe. In the United States, for example, girls born in 2007 could expect to live 80.4 years on the average, but boys only 75.4 years.

In most countries, race and ethnicity combine with social class to produce longer life expectancies for the (wealthier) dominant race, which in the Western world is almost always white. The United States again reflects this international phenomenon: Whites born in 2007 could expect to live 78.4 years on the average, but African Americans only 73.6 years. In fact, gender and race combine in the United States to put African American males at a particular disadvantage, as they can expect to live only 70.0 years (see Figure 6.5 "Sex, Race, and Life Expectancy for US Residents Born in 2007”). The average African American male will die almost 11 years earlier than the average white woman.

Figure 6.5 Sex, Race, and Life Expectancy for US Residents Born in 2007

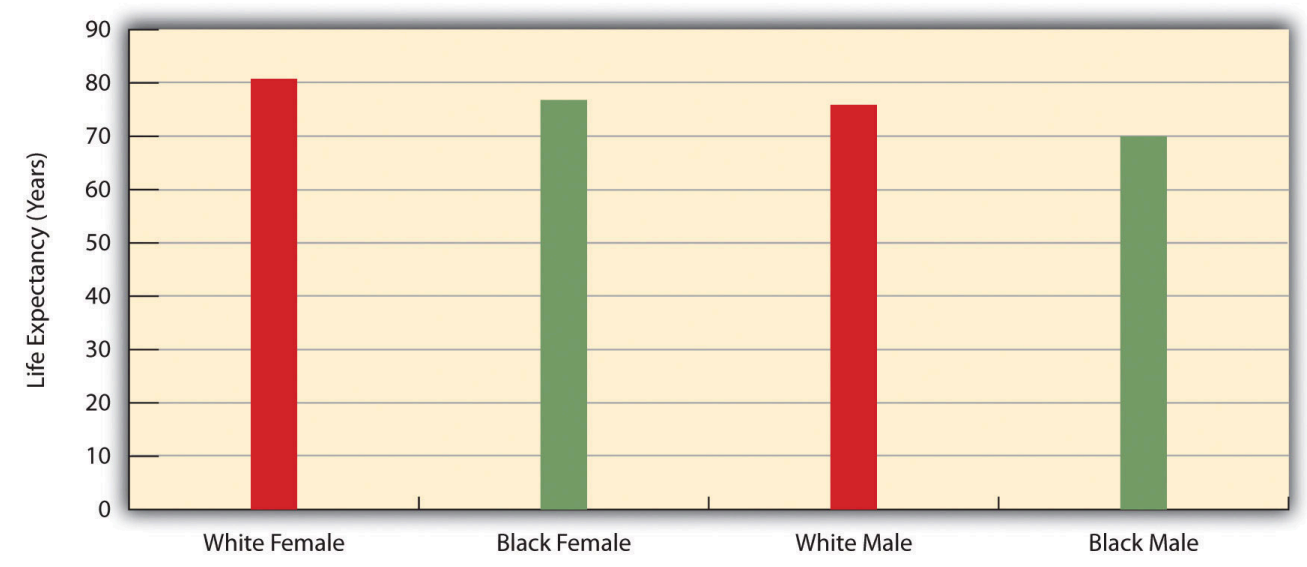

Source: Data from National Center for Health Statistics, US Department of Health and Human Services. (2010). Health, United States, 2010, with special feature on death and dying. Retrieved from http://www.cdc.gov/nchs/data/hus/hus10.pdf.

\section{Key Takeaways}

- Life expectancy differs widely around the world and is much higher in wealthy nations than in poor nations.

- Life expectancy has also been increasing around the world, including in the United States, and the increasing number of older people in the decades ahead will pose several serious challenges.

- Inequality in life expectancy exists within a given society along gender, race/ethnicity, and social class lines.

\section{For Your Review}

1. As our nation and the world both "gray," what do you think is the most important problem that will stem 
from the increasing number of older people?

2. Write a short essay in which you discuss the problems that an elderly person you know, perhaps a grandparent, has experienced related to being older.

\section{References}

Hayutin, A. M. (2007). Graying of the global population. Public Policy \& Aging Report, 17(4), 12-17.

Population Reference Bureau. (2011). 2011 world population data sheet. Washington, DC: Author.

United Nations Population Division. (2011). World population prospects: The 2010 revision. New York, NY: Author. 


\subsection{Biological and Psychological Aspects of Aging}

\section{Learning Objectives}

1. Describe any four biological changes associated with aging.

2. List any three steps that individuals can try to undertake to achieve successful aging.

Like many other societies, the United States has a mixed view of aging and older people. While we generally appreciate our elderly, we have a culture oriented toward youth, as evidenced by the abundance of television characters in their twenties and lack of those in their older years. As individuals, we do our best not to look old, as the many ads for wrinkle creams and products to darken gray hair attest. Moreover, when we think of the elderly, negative images often come to mind. We often think of someone who has been slowed by age both physically and mentally. She or he may have trouble walking up steps, picking up heavy grocery bags, standing up straight, or remembering recent events. The term senile often comes to mind, and phrases like "doddering old fool," "geezer," and other disparaging remarks sprinkle our language when we talk about them. Meanwhile, despite some improvement, the elderly are often portrayed in stereotypical ways on television and in movies (Lee, Carpenter, \& Meyers, 2007).

How true is this negative image? What do we know of physical and psychological changes among the elderly? How much of what we think we know about aging and the elderly is a myth, and how much is reality? Gerontologists have paid special attention to answering these questions (Novak, 2012).

Biological changes certainly occur as we age. The first signs are probably in our appearance. Our hair begins to turn gray, our (male) hairlines recede, and a few wrinkles set in. The internal changes that often accompany aging are more consequential, among them being that (a) fat replaces lean body mass, and many people gain weight; (b) bone and muscle loss occur; (c) lungs lose their ability to take in air, and our respiratory efficiency declines; (d) the functions of the cardiovascular and renal (kidney) systems decline; (e) the number of brain cells declines, as does brain mass overall; and (f) vision and hearing decline. Cognitive and psychological changes also occur. Learning and memory begin declining after people reach their seventies; depression and other mental and/ or emotional disorders can set in; and dementia, including Alzheimer’s disease, can occur. 


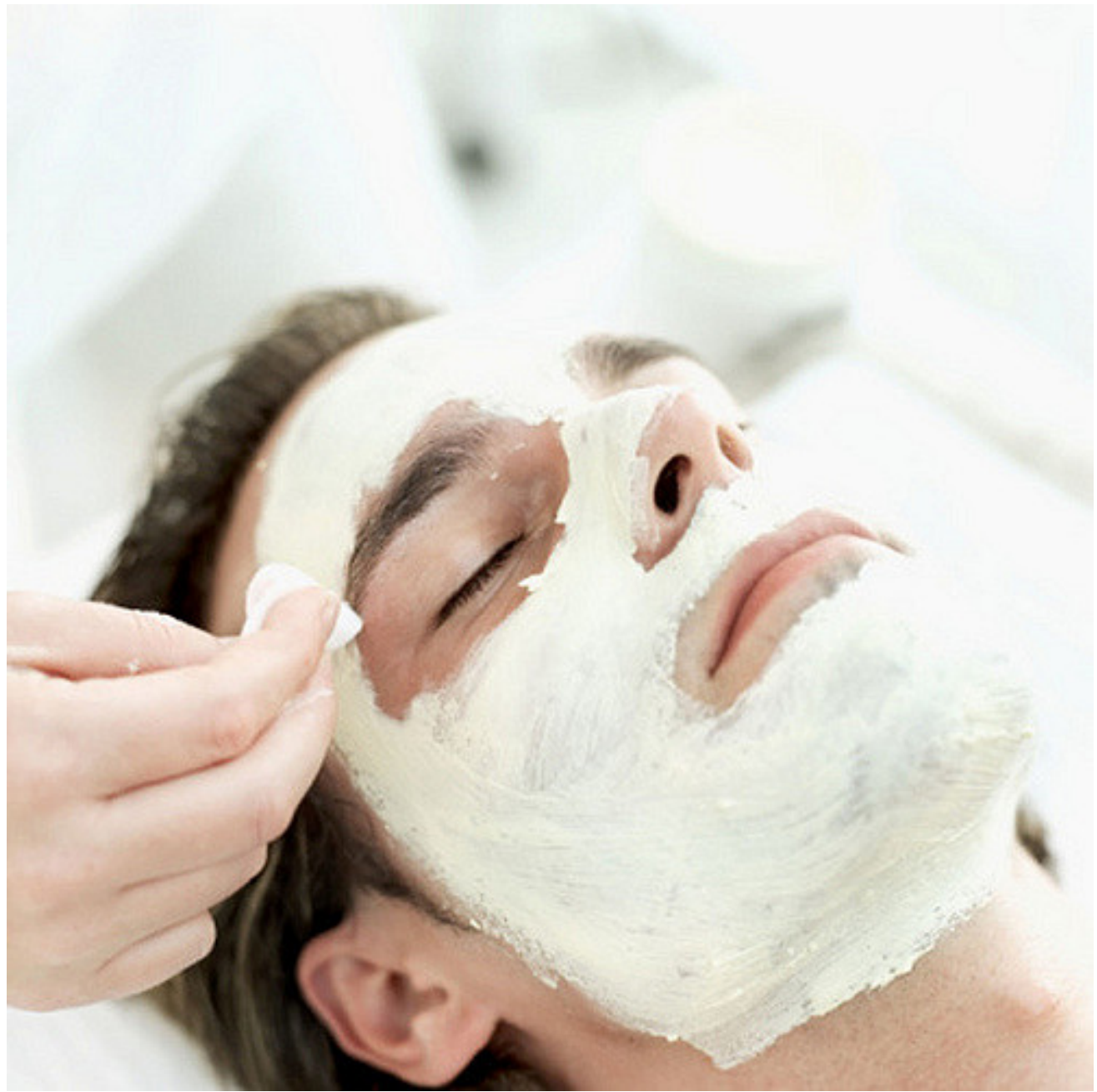

Because our society values youthfulness, many people try to do their best not to look old.

FoundryParkInn - Men’s Facial - CC BY-NC-ND 2.0.

All these conditions yield statistics such as follows: about half of people 65 or older have arthritis or high blood pressure; almost one-fifth have coronary heart disease; more than one-fifth have diabetes; and about 60 percent of women in their seventies have osteoporosis (Centers for Disease Control and Prevention \& The Merck Company Foundation, 2007; Crawthorne, 2008).

Still, the nature and extent of all these changes vary widely among older people. Some individuals are frail at 65, while others remain vigorous well into their seventies and beyond. People can be "old" at 60 or even 50, while others can be "young” at 80. Many elders are no longer able to work, but others remain in the labor force. All in all, then, most older people do not fit the doddering image myth and can still live a satisfying and productive life (Rowe et al., 2010).

\section{Enhancing Vitality for Successful Aging}

To what extent are the effects of biological and psychological aging the inevitable results of chronological aging? 
Gerontologists are still trying to understand what causes these effects, and their explanations center on such things as a declining immune system, the slowing of cellular replication, and other processes that need not concern us here.

One thing is clear: We can all take several steps to help us age better, because what we do as we enter our older years matters much more than genetics (Centers for Disease Control and Prevention \& The Merck Company Foundation, 2007; Crawthorne, 2008). To the extent this is true, the effects of biological and psychological aging are not necessarily inevitable, and "successful aging" is possible. The steps highlighted in the gerontological literature are by now almost a cliché, but regular exercise, good nutrition, and stress reduction stand at the top of most gerontologists' recommendations for continued vitality in later life. In fact, Americans live about ten years less than an average set of genes should let them live because they do not exercise enough and because they eat inadequate diets.

Research by social gerontologists suggests at least two additional steps older people can take if they want "successful aging." The first is involvement in informal, personal networks of friends, neighbors, and relatives. The importance of such networks is one of the most thoroughly documented in the social gerontological literature (Binstock \& George, 2006) (see Note 6.23 “Applying Social Research”). Networks enhance successful aging for at least two reasons. First, they provide practical support, such as help buying groceries and visiting the doctor, to the elderly who need it. Second, they help older people maintain their self-esteem, meet their desire for friendships, and satisfy other emotional needs.

\section{Children and Our Future}

\section{Grandparents Raising Grandchildren}

An increasing number of grandparents are raising their grandchildren. Almost 6 million children, or about 8 percent of all children, live in a household headed by a grandparent, up from 4.5 million in 2000. Grandparents are the sole caregiver for almost 3 million of these children because the child's parents are absent for several reasons: The parents may have died, they may be in jail or prison or have been unable to deal with substance abuse, a child may have been removed from a parent because of parental abuse, or a child may have been abandoned.

In the remaining households where a parent is present, grandparents (usually the grandmother) are still the primary caregivers or at least play a major role in raising the child; the same is true of many grandparents who live near their grown child's home. In today's faltering economy, many grandparents are also helping their children out with the expenses of raising their grandchild and running a home. As a family expert with AARP explained, "Grandparents have become the family safety net, and I don't see that changing any time soon. While they will continue to enjoy their traditional roles, including spending on gifts for grandchildren, I see them increasingly paying for the extras that parents are struggling to keep up with—sports, camps, tutoring or other educational needs, such as music lessons.”

Estella Hyde, 65, and her husband live near Erie, Pennsylvania. They began raising their granddaughter, who started college in fall 2011, when she was one-year-old after her mother said she did not want to raise her. Ms. Hyde called for more government assistance for people in her situation: "It never happens in a happy situation where a son or daughter comes and says, 'I need you to raise a child for me.' We were very lucky, we were able to financially take care of her and support her. But many grandparent caregivers need other sources of assistance."

Many grandparents consider the caregiving and financial support they provide for a grandchild to be both a joy and a privilege. But as their numbers grow, many such grandparents are also finding their involvement to also be somewhat of a physical and/or financial burden. As their numbers continue to grow, it will be important for the federal and state governments to provide them the assistance that Estella Hyde advocated.

Sources: Whitley \& Kelley, 2007; Yen, 2011 
A second step for successful aging suggested by scholarly research is religious involvement (Moberg, 2008), which enhances psychological well-being for at least two reasons. As people worship in a congregation, they interact with other congregants and, as just noted, enhance their social support networks. Moreover, as they practice their religious faith, they reduce their stress and can cope better with personal troubles. For both these reasons, attendance at religious services and the practice of prayer are thought to enhance psychological wellbeing among older people. Some elders cannot attend religious services regularly because they have health problems or are no longer able to drive a car. But prayer and other private devotional activities remain significant for many of them. To the extent that religion makes a difference for elders' well-being, health-care facilities and congregations should do what they can to enable older adults to attend religious services and to otherwise practice their religious faith.

\section{Applying Social Research}

Friendships and Successful Aging

As the text discusses, social networks improve the lives of older Americans by providing both practical and emotional support. Early research on social networks and aging focused more on relatives than on friends. Rebecca G. Adams, former president of the Southern Sociological Society, was one of the first sociologists to emphasize the role that friends can also play in the lives of the elderly. She interviewed seventy older women who lived in a Chicago suburb and asked them many questions about the extent and quality of their friendships.

In one of her most important findings, Adams discovered that the women reported receiving more help from friends than other researchers had assumed was the case. The women were somewhat reluctant to ask friends for help but did so when family members were not available and when they would not overly inconvenience the friends whom they asked for help. Adams also found that "secondary" friendships-those involving friends that a woman spent time with but with whom she was not especially close-were more likely than "primary" friendships (very close friendships) to contribute to her interviewees' psychological well-being, as these friendships enabled the women to meet new people, to become involved in new activities, and thus to be engaged with the larger society. This finding led Adams to conclude that one should not underestimate how important friends are to older people, particularly to the elderly without family. Friends are an important source of companionship and possibly a more important source of service support than most of the current literature suggests.

Adams also asked the women about their friendships with men. The seventy women she interviewed reported 670 friendships, of which only 3.6 percent were with men. (About 91 percent were with other women, and 6 percent were with couples.) Although prior research had assumed that the number of these friendships is small because there are so few unmarried elderly men compared to the number of unmarried elderly women, Adams discovered from her interviews some additional reasons. Her respondents interpreted any friendship with a man as a courting or romantic friendship, which they thought would be viewed negatively by their children and by their peers. Adopting a traditional gender-role orientation, they also expected any man they might marry to be able to protect them physically and financially. Yet they also realized that any elderly man they might know would be very likely unable to do so. For all these reasons, they shied away from friendships with men.

Work by Adams and other social scientists on the friendships and other aspects of the social support systems for older Americans has contributed greatly to our understanding of the components of successful aging. Practically speaking, it points to the need for programs and other activities to make it easier for the elderly to develop and maintain friendships with both sexes to improve their ability to meet both their practical and emotional needs.

Sources: Adams, 1985, 1986; Roscow, 1967 


\section{Key Takeaways}

- Certain biological, cognitive, and psychological changes occur as people age. These changes reinforce the negative view of the elderly, but this view nonetheless reflects stereotypes and myths about aging and the elderly.

- Regular exercise, good nutrition, stress reduction, involvement in personal networks, and religious involvement all enhance successful aging.

\section{For Your Review}

1. Do you think the negative view of older people that is often found in our society is an unfair stereotype, or do you think there is actually some truth to this stereotype? Explain your answer.

2. Referring back to Chapter 1 “Understanding Social Problems"'s discussion of Émile Durkheim, how does research that documents the importance of personal networks for successful aging reflect Durkheim’s insights?

\section{References}

Adams, R. G. (1985). People would talk: Normative barriers to cross-sex friendships for elderly women. The Gerontologist, 25, 605-611.

Adams, R. G. (1986). Secondary friendship networks and psychological well-being among elderly women. Activities, Adaptation, and Aging, 8, 59-72.

Binstock, R. H., \& George, L. K. (Eds.). (2006). Handbook of aging and the social sciences (6th ed.). Boston: Academic Press.

Centers for Disease Control and Prevention \& The Merck Company Foundation. (2007). The state of aging and health in America 2007. Whitehouse Station, NJ: Merck Company Foundation.

Crawthorne, A. (2008). Elderly poverty: The challenge before us. Washington, DC: Center for American Progress.

Lee, M. M., Carpenter, B., \& Meyers, L. S. (2007). Representations of older adults in television advertisements. Journal of Aging Studies, 21(1), 23-30.

Moberg, D. O. (2008). Spirituality and aging: Research and implications. Journal of Religion, Spirituality \& Aging, 20, 95-134.

Novak, M. (2012). Issues in aging (3rd ed.). Upper Saddle River, NJ: Pearson.

Roscow, I. (1967). Social integration of the aged. New York, NY: Free Press. 
Rowe, J. W., Berkman, L. F., Binstock, R., Boersch-Supan, A., Cacioppo, J., Carsternsen, L., et al. (2010). Policies and politics for an aging America. Contexts, 9(1), 22-27.

Whitley, D. M., \& Kelley, S. J. (2007). Grandparents raising grandchildren: A call to action. Washington, DC: Administration for Children and Families.

Yen, H. (2011, August 25). Grandparents play a bigger role in child-rearing. Associated Press. Retrieved from http://www.huffingtonpost.com/2011/08/26/grandparents-play-a-bigge n 937945.html. 


\subsection{Problems Facing Older Americans}

\section{Learning Objectives}

1. Present a brief sociodemographic profile of the US elderly.

2. Discuss the several problems experienced by the US elderly.

3. Describe how the social attitudes of older Americans generally differ from those of younger Americans.

We now turn our attention to older people in the United States. We first sketch a demographic profile of our elderly and then examine some of the problems they face because of their age and because of ageism.

\section{Who Are the Elderly?}

Table 6.2 "Demographic Composition of the Elderly, 2010" presents the demographic composition of Americans aged 65 or older. Slightly more than half the elderly are 65-74 years of age, and about 57 percent are female, reflecting males' shorter life spans as discussed earlier. About 80 percent of the elderly are non-Latino whites, compared to about 66 percent in the population as a whole; 8.6 percent are African American, compared to about 13 percent of the population; and 7.0 percent are Latino, compared to 15 percent of the population. The greater proportion of whites among the elderly and lower proportions of African Americans and Latinos reflects these groups' life expectancy differences discussed earlier and also their differences in birth rates.

Table 6.2 Demographic Composition of the Elderly, 2010 


\begin{tabular}{|c|c|}
\hline \multicolumn{2}{|l|}{ Age } \\
\hline 65-74 years & $52.3 \%$ \\
\hline 75-84 years & $33.4 \%$ \\
\hline 85 years and over & $14.3 \%$ \\
\hline \multicolumn{2}{|l|}{ Gender } \\
\hline Female & $56.9 \%$ \\
\hline Male & $43.1 \%$ \\
\hline \multicolumn{2}{|l|}{ Race and/or ethnicity* } \\
\hline White, non-Latino & $80.1 \%$ \\
\hline African American & $8.6 \%$ \\
\hline Latino & $7.0 \%$ \\
\hline Asian/Pacific Islander & $3.5 \%$ \\
\hline Amer. Ind., Esk., Aleut. & $0.6 \%$ \\
\hline Two or more races & $0.7 \%$ \\
\hline Living in poverty & $9.0 \%$ \\
\hline \multicolumn{2}{|l|}{ Marital status } \\
\hline Married & $57.6 \%$ \\
\hline Widowed & $28.1 \%$ \\
\hline Divorced & $10.0 \%$ \\
\hline Never married & $4.3 \%$ \\
\hline \multicolumn{2}{|c|}{ Years of school completed } \\
\hline $0-8$ years & $10.2 \%$ \\
\hline $1-3$ years of high school & $10.3 \%$ \\
\hline High school graduate & $36.4 \%$ \\
\hline $1-3$ years of college & $20.6 \%$ \\
\hline College graduate & $22.5 \%$ \\
\hline \multicolumn{2}{|l|}{ Labor force participation } \\
\hline Employed & $16.2 \%$ \\
\hline Unemployed & $1.2 \%$ \\
\hline Not in labor force & $82.6 \%$ \\
\hline \multicolumn{2}{|l|}{ Household income* } \\
\hline * 2009 data & \\
\hline
\end{tabular}




\begin{tabular}{|l|l|}
\hline Under $\$ 15,000$ & $18.8 \%$ \\
\hline$\$ 15,000-\$ 24,999$ & $20.7 \%$ \\
\hline$\$ 25,000-\$ 34,999$ & $15.4 \%$ \\
\hline$\$ 35,000-49,999$ & $15.1 \%$ \\
\hline$\$ 50,000-\$ 74,999$ & $14.2 \%$ \\
\hline$\$ 75,000-\$ 99,999$ & $6.5 \%$ \\
\hline$\$ 100,000$ and over & $9.4 \%$ \\
\hline$* 2009$ data & \\
\hline
\end{tabular}

Source: Data from US Census Bureau. (2012). Statistical abstract of the United States: 2012. Washington, DC: US Government Printing Office. Retrieved from http://www.census.gov/compendia/statab.

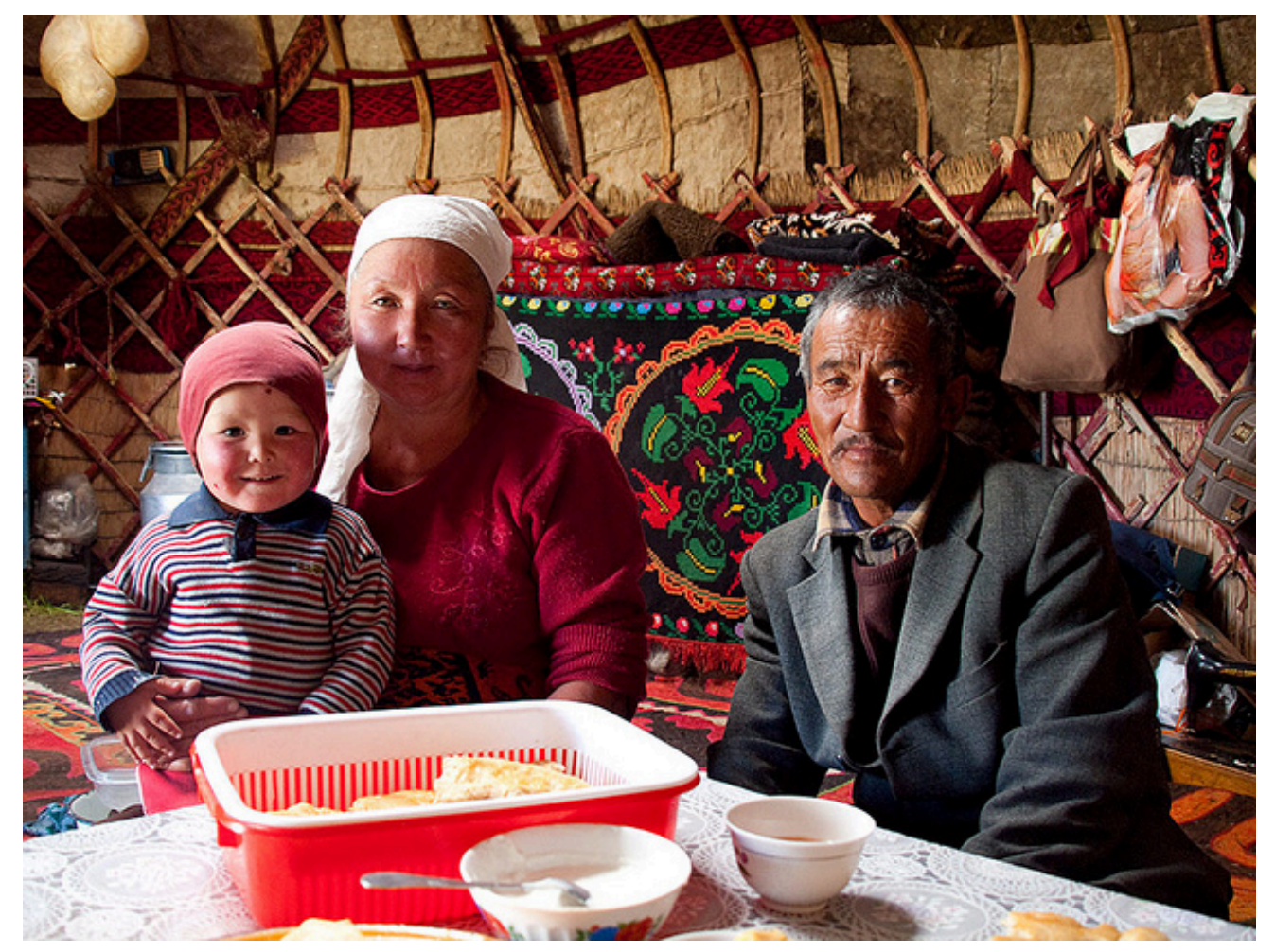

The lower proportions of African Americans and Latinos among the elderly partly reflect these groups' lower life expectancies.

Evgeni Zotov - Grandparents - CC BY-NC-ND 2.0.

The percentage of elders living in poverty is 9.0, compared to 15.1 percent of the entire population. Although most elders have fixed incomes, the fact that their family size is usually one or two means that they are less likely than younger people to live in poverty. In fact, today's elderly are financially much better off than their grandparents were, thanks to Social Security, Medicare (the federal health insurance program for older Americans), pensions, and their own assets. We will revisit the health and financial security of elders a little later.

Turning to education, about 22 percent of the elderly are college graduates, compared to about 29 percent of the 
population as a whole. This difference reflects the fact that few people went to college when today's elderly were in their late teens and early twenties. However, it is still true that today's elders are better educated than any previous generation of elders. Future generations of the elderly will be even better educated than those now.

While most elders are retired and no longer in the labor force, about 16 percent do continue to work (see Table 6.2 "Demographic Composition of the Elderly, 2010"). These seniors tend to be in good health and to find their jobs psychologically satisfying. Compared to younger workers, they miss fewer days of work for health or other reasons and are less likely to quit their jobs for other opportunities (Sears, 2009).

Although we emphasized earlier that many older Americans do not fit the negative image with which they are portrayed, it is still true that they face special problems because of their age and life circumstances and because of ageism. We discuss some of these here.

\section{Physical and Mental Health}

Perhaps the problem that comes most readily to mind is health, or, to be more precise, poor health. It is true that many older people remain in good health and are fully able to function mentally and physically (Rowe et al., 2010). Still, the biological and psychological effects of aging do lead to greater physical and mental health problems among the elderly than in younger age groups, as we briefly discussed earlier. These problems are reflected in responses to the General Social Survey (GSS) question, "Would you say your own health, in general, is excellent, good, fair, or poor?” Figure 6.6 “Age and Self-Reported Health” shows that the elderly are more likely than the nonelderly to report that their health is only fair or poor.

Figure 6.6 Age and Self-Reported Health

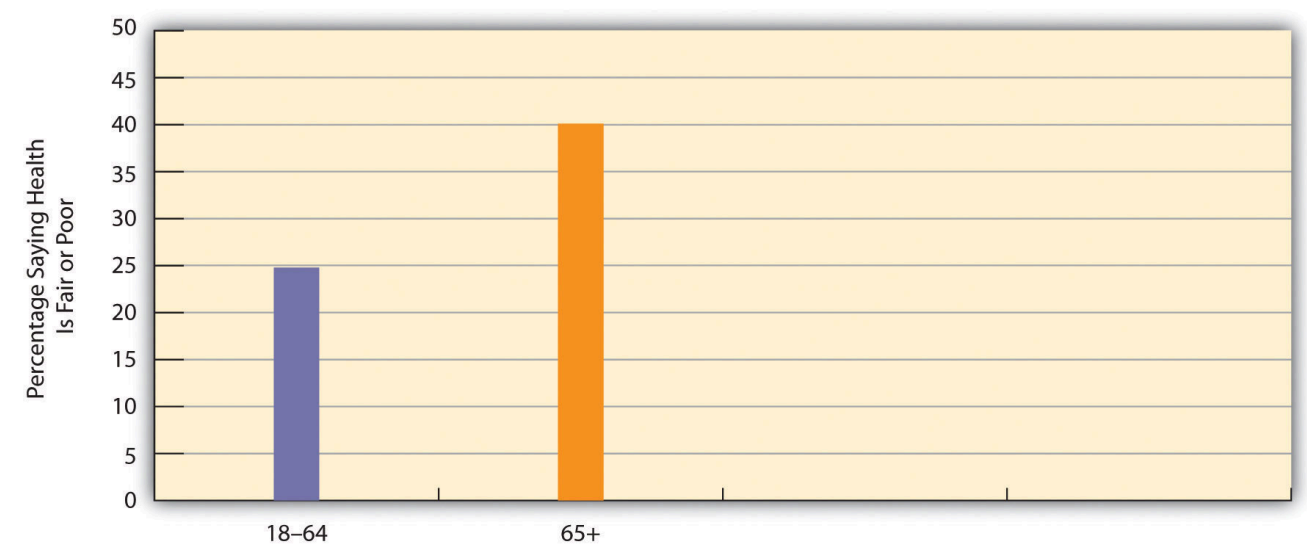

Source: Data from General Social Survey. (2010). Retrieved from http://sda.berkeley.edu/cgi-bin/hsda?harcsda+gss10.

The elderly's perception of their own health is supported by government estimates of chronic health conditions for older Americans. Of all people aged 65 or older not living in a nursing home or other institution, almost 50 percent have arthritis, 56 percent have high blood pressure, 32 percent have heart disease, 35 percent have hearing loss, 18 percent have vision problems, and 19 percent have diabetes (these numbers add up to more than 100 percent as people may have several health conditions) (Federal Interagency Forum on Aging-Related Statistics, 2010). These rates are much higher than those for younger age groups. 
The elderly also suffer from dementia, including Alzheimer's disease, which affects almost 13 percent of people 65 or older (Alzheimer's Association, 2009). Another mental health problem is depression, which affects almost 15 percent of people 65 or older. Because of mental or physical disability, about two-thirds of all people 65 or older need help with at least one “daily living” activity, such as preparing a meal (Federal Interagency Forum on Aging-Related Statistics, 2010).

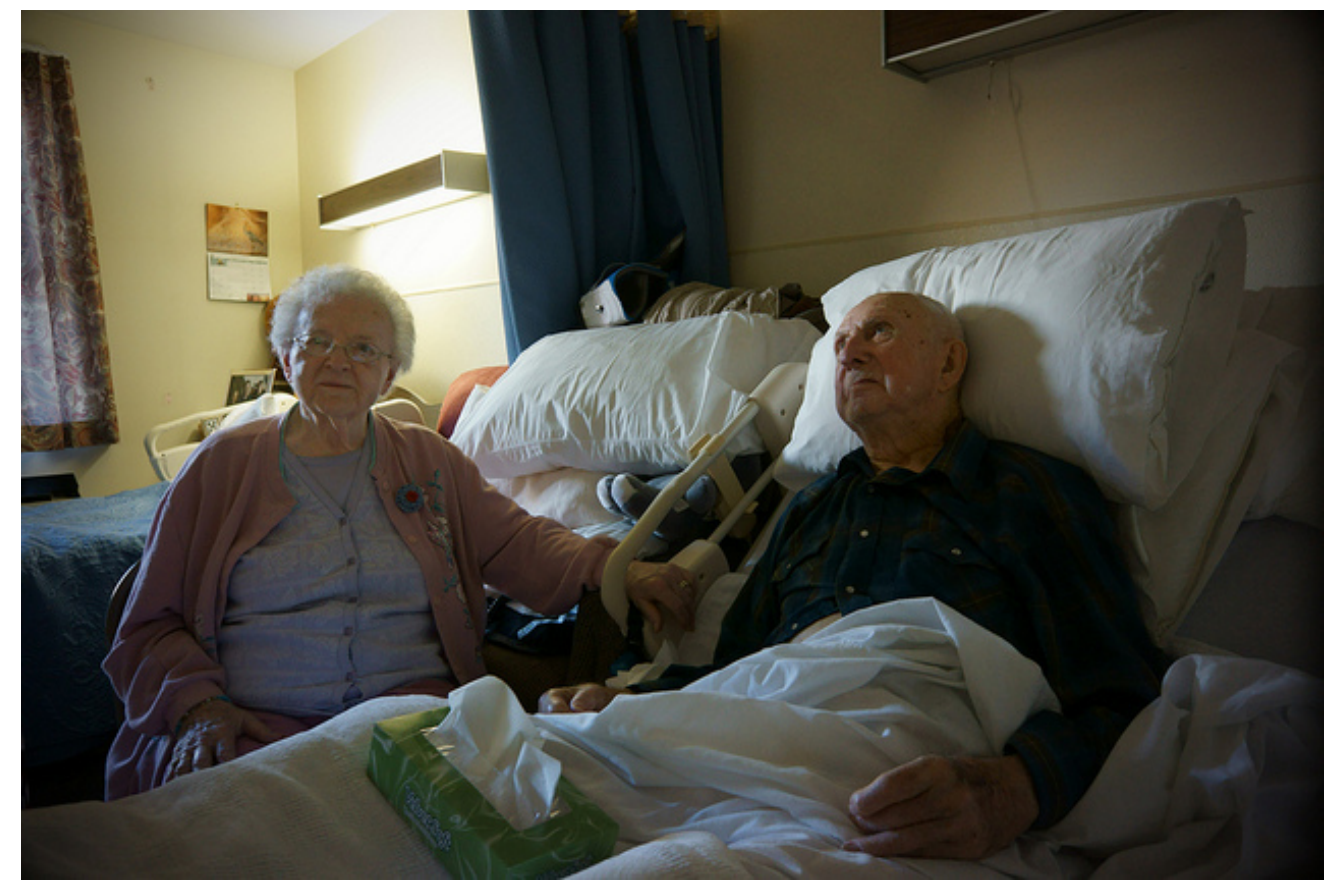

Older people visit the doctor and hospital more often than younger people. Partly for this reason, adequate health care for the elderly

is of major importance.

Ted Van Pelt - The Coopers - CC BY 2.0.

If the elderly have more health problems, then adequate care for them is of major importance. They visit the doctor and hospital more often than their middle-aged counterparts. Medicare covers about one-half of their health-care costs; this is a substantial amount of coverage but still forces many seniors to pay thousands of dollars annually themselves. Some physicians and other health-care providers do not accept Medicare "assignment," meaning that the patient must pay an even higher amount. Moreover, Medicare pays little or nothing for long-term care in nursing homes and other institutions and for mental health services. All these factors mean that older Americans can still face high medical expenses or at least pay high premiums for private health insurance.

In addition, Medicare costs have risen rapidly along with other health-care costs. Medicare expenditures soared from about \$37 billion in 1980 to more than \$500 billion today (see Figure 6.7 "Medicare Expenditures, 1980-2010”). As the population continues to age and as health-care costs continue to rise, Medicare expenses will continue to rise as well, making it increasingly difficult to find the money to finance Medicare.

Figure 6.7 Medicare Expenditures, 1980-2010 


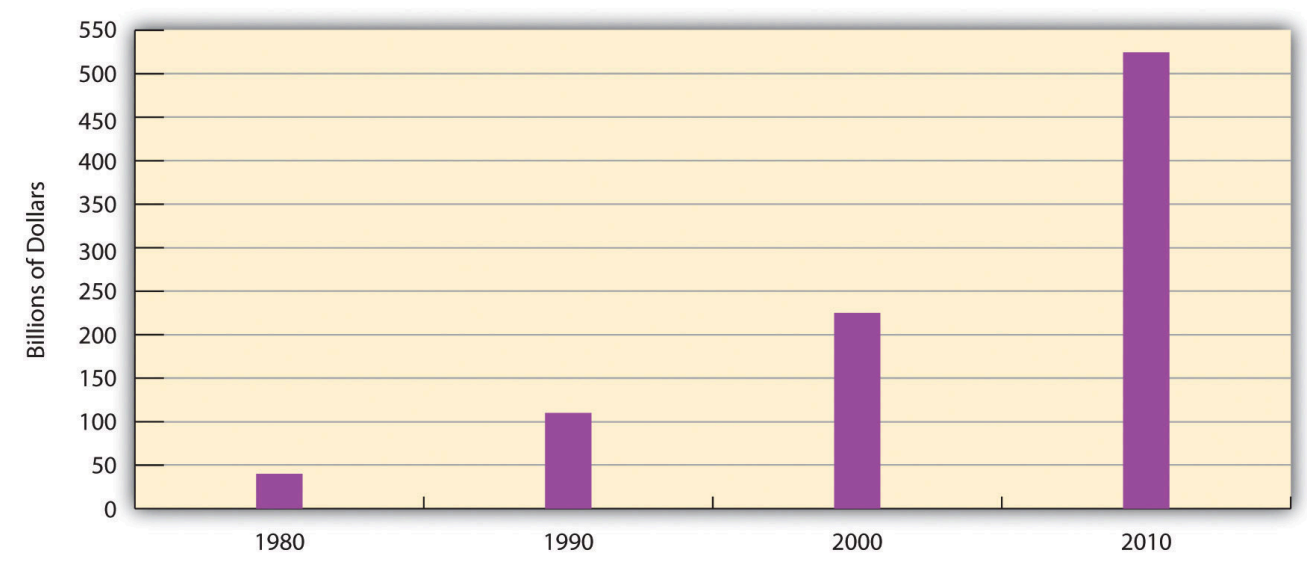

Source: Data from Centers for Medicare and Medicaid Services. (n.d.). National health expenditure data. Retrieved from http://www.hhs.gov.

\section{Nursing Home Care}

While most older Americans live by themselves or with their families, a small minority live in group settings. A growing type of group setting is the continuous care retirement community, a setting of private rooms, apartments, and/or condominiums that offers medical and practical care to those who need it. In some such communities, residents eat their meals together, while in others they cook for themselves. Usually these communities offer above-average recreational facilities and can be very expensive, as some require a lifetime contract or at least monthly fees that can run into the thousands of dollars.

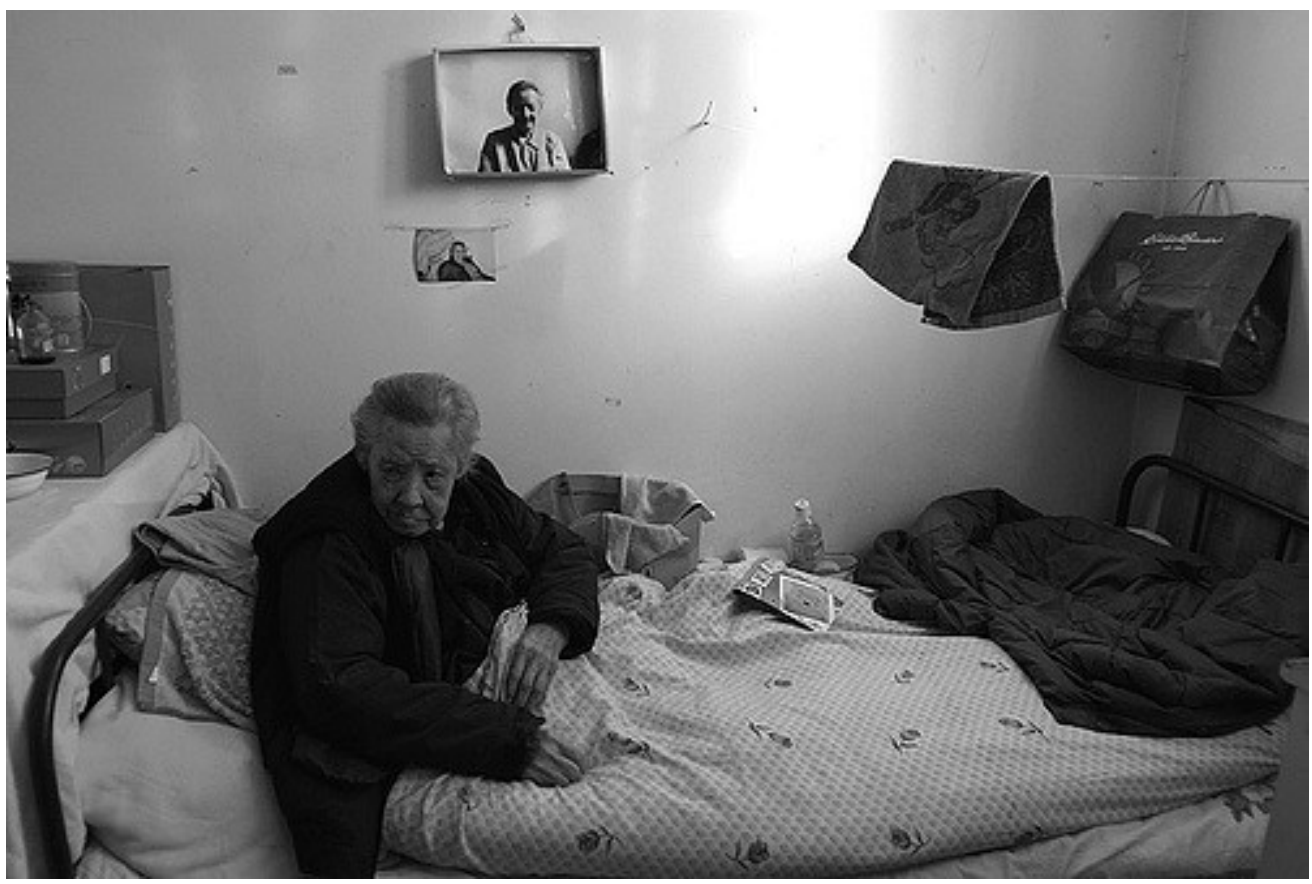

Nursing homes are often understaffed to save costs and are also generally not subject to outside inspection. These conditions help contribute to the neglect of nursing home residents. 
Sheila - Christian Nursing Home - CC BY-NC-ND 2.0.

For elders who need high-level medical care or practical support, nursing homes are the primary option. About 16,100 nursing homes exist, and 3.9 percent of Americans 65 or older live in them (Federal Interagency Forum on Aging-Related Statistics, 2010). About three-fourths of all nursing home residents are women. Almost all residents receive assistance in bathing and showering, 80 percent receive help in using the bathroom, and onethird receive help in eating.

As noted earlier, Medicare does not pay for long-term institutional care for most older Americans. Because nursing home care costs at least $\$ 70,000$ yearly, residents can quickly use up all their assets and then, ironically, become eligible for payments from Medicaid, the federal insurance program for people with low incomes.

If one problem of nursing homes is their expense, another problem is the quality of care they provide. Because their residents are typically in poor physical and/or mental health, their care must be the best possible, as they can do little to help themselves if their care is substandard. As more people enter nursing homes in the years ahead, the quality of nursing home care will become even more important. Yet there is much evidence that nursing home care is often substandard and is replete with neglect and abuse (DeHart, Webb, \& Cornman, 2009).

\section{Financial Security and Employment}

Earlier we noted that the elderly are less likely than younger age groups to live in poverty and that their financial status is much better than that of previous generations of older people. One reason for this is Social Security: If Social Security did not exist, the poverty rate of the elderly would be 45 percent, or five times higher than the actual rate (Kerby, 2012). Without Social Security, then, nearly half of all people 65 or older would be living in official poverty, and this rate would be even much higher for older women and older persons of color. However, this brief summary of their economic well-being obscures some underlying problems (Carr, 2010; Crawthorne, 2008).

First, recall Chapter 2 "Poverty"'s discussion of episodic poverty, which refers to the drifting of many people into and out of poverty as their jobs and other circumstances change. Once they become poor, older people are more likely than younger ones to stay poor, as younger people have more job and other opportunities to move out of poverty. Recall also that the official poverty rate obscures the fact that many people live just above it and are "near poor.” This is especially true of the elderly, who, if hit by large medical bills or other expenses, can hardly afford to pay them.

Second, the extent of older Americans' poverty varies by sociodemographic factors and is much worse for some groups than for others (Carr, 2010). Older women, for example, are more likely than older men to live in poverty for at least two reasons. Because women earn less than men and are more likely to take time off from work during their careers, they have lower monthly Social Security benefits than men and smaller pensions from their employers. As well, women outlive men and thus use up their savings. Racial and ethnic disparities also exist among the elderly, reflecting poverty disparities in the entire population, as older people of color are much more likely than older whites to live in poverty (Carr, 2010). Among women 65 and older, 9 percent of whites live in poverty, compared to 27 percent of African Americans, 12 percent of Asians, and 21 percent of Hispanics. 


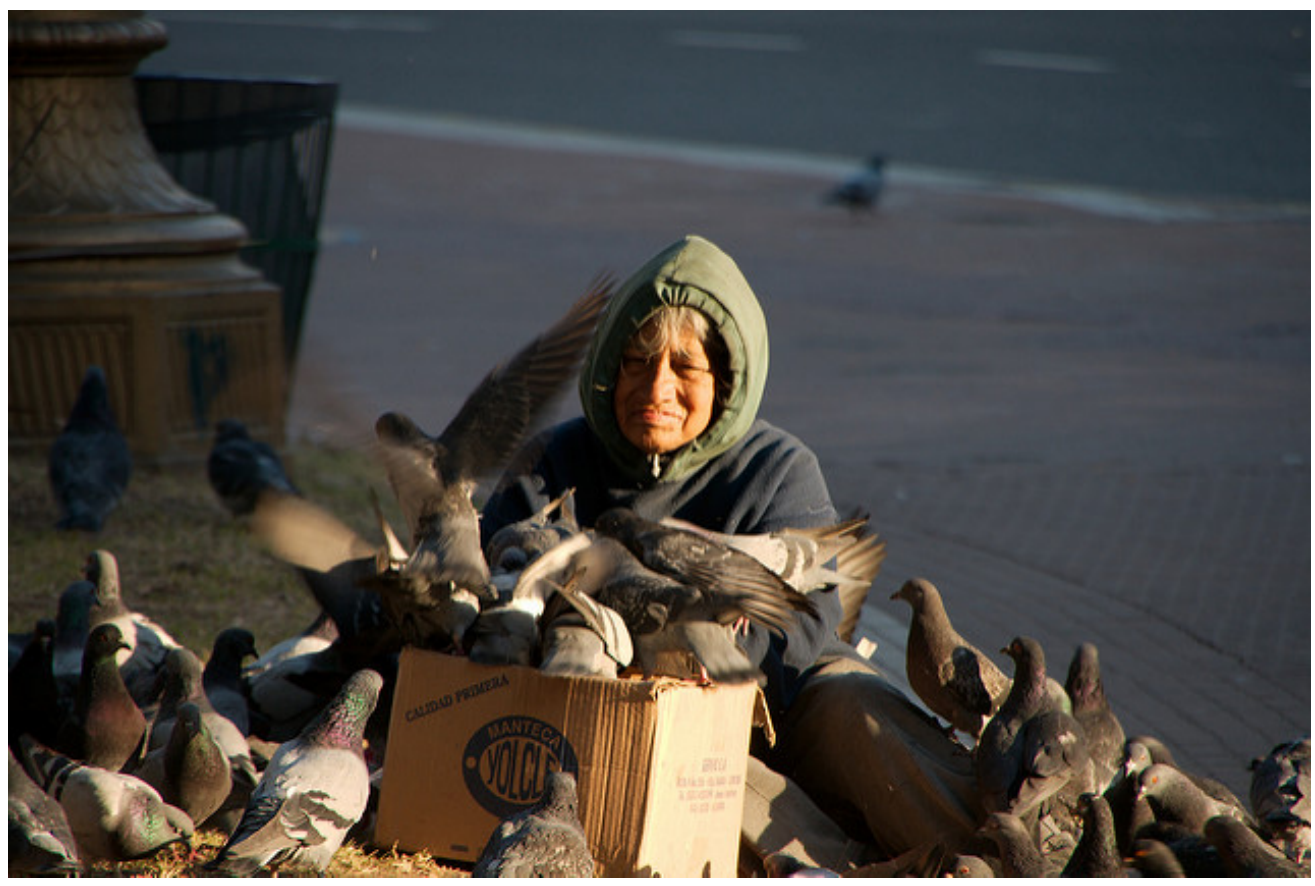

Older women are more likely than older men to live in poverty.

Christian Haugen - Old woman feeding the pigeon - CC BY 2.0.

Third, monthly Social Security benefits are tied to people's earnings before retirement; the higher the earnings, the higher the monthly benefit. Thus a paradox occurs: People who earn low wages will get lower Social Security benefits after they retire, even though they need higher benefits to make up for their lower earnings. In this manner, the income inequality that exists before retirement continues to exist after it.

This paradox reflects a wider problem involving Social Security. However helpful it might be in aiding older Americans, the aid it provides lags far behind comparable programs in other wealthy Western nations (see Note 6.27 "Lessons from Other Societies"). Social Security payments are low enough that almost one-third of the elderly who receive no other income assistance live in official poverty. For all these reasons, Social Security is certainly beneficial for many older Americans, but it remains inadequate compared to what other nations provide.

\section{Lessons from Other Societies}

Aging Policy and Programs in the Netherlands and Sweden

A few years ago, AARP assessed quality-of-life issues for older people and the larger society in sixteen wealthy democracies (the nations of North America and Western Europe, along with Australia and Japan). Each nation was rated (on a scale of $1-5$, with 5 being the highest score) on seventeen criteria, including life expectancy, health care for the elderly, pension coverage, and age-discrimination laws. Of the sixteen nations, the Netherlands ranked first, with a total score of 64, while Italy ranked last, with a score of 48; the United States was thirteenth, with a score of 50. Despite its immense wealth, then, the United States lagged behind most other democracies. Because a "perfect" score would have been $85(17 \times 5)$, even the Netherlands fell short of an ideal quality of life as measured by the AARP indicators.

Why did the United States not rank higher? The experience of the Netherlands and Sweden, both of which have longer life expectancies than the United States, points to some possible answers. In the Netherlands, everyone at age 65 
receives a full pension that does not depend on how much money they earned while they were working, and everyone thus gets the same amount. This amount is larger than the average American gets, because Social Security does depend on earnings and many people earned fairly low amounts during their working years. As a result, Dutch elderly are much less likely than their American counterparts to be poor. The Dutch elderly (and also the nonelderly) have generous government insurance for medical problems and for nursing home care; this financial help is much higher than older Americans obtain through Medicare.

As one example, the AARP article mentioned an elderly Dutch woman who had cancer surgery and thirty-two chemotherapy treatments, for which she paid nothing. In the United States, the chemotherapy treatments would have cost at least $\$ 30,000$. Medicare would have covered only 80 percent of this amount, leaving a patient to pay $\$ 6,000$.

The Netherlands also helps its elderly in other ways. One example is that about one-fourth of that nation's elderly receive regular government-subsidized home visits by health-care professionals and/or housekeepers; this practice enables the elderly to remain independent and avoid having to enter a nursing home. In another example, the elderly also receive seven days of free riding on the nation's rail system.

Sweden has a home-care visitation program that is similar to the Netherlands’ program. Many elderly are visited twice a day by a care assistant who helps them bathe and dress in the morning and go to bed at night. The care assistant also regularly cleans their residence and takes them out for exercise. The Swedish government pays about 80 percent of the costs of this assistance and subsidizes the remaining cost for elderly who cannot afford it. Like the Netherlands' program, Sweden's program helps the elderly to remain independent and live at home rather than enter a nursing institution.

Compared to the United States, then, other democracies generally provide their elderly less expensive or free health care, greater financial support during their retirement, and home visits by health-care professionals and other assistants. In these and other ways, these other governments encourage "active aging." Adoption of similar policies in the United States would improve the lives of older Americans and perhaps prolong their life spans.

Sources: Edwards, 2004; Hartlapp \& Schmid, 2008; Ney, 2005

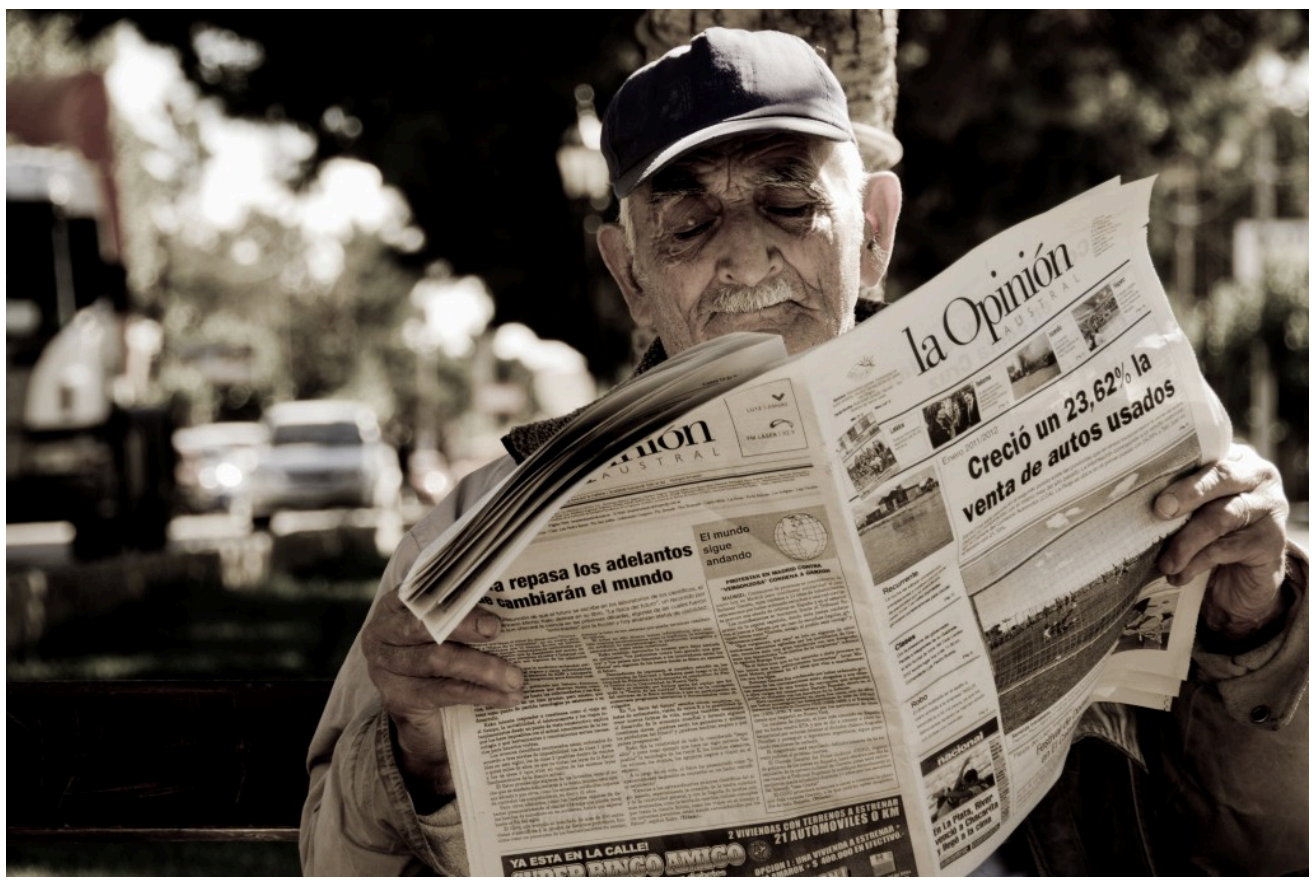

Older people who want to work may have trouble finding employment because of age discrimination and other factors. 


\section{Workplace Ageism}

Older Americans also face problems in employment. Recall that about 16 percent of seniors remain employed. Other elders may wish to work but are retired or unemployed because several obstacles make it difficult for them to find jobs. First, many workplaces do not permit the part-time working arrangements that many seniors favor. Second, and as the opening news story indicated, the rise in high-tech jobs means that older workers would need to be retrained for many of today's jobs, and few retraining programs exist. Third, although federal law prohibits age discrimination in employment, it exists anyway, as employers do not think older people are "up to" the job, even though the evidence indicates they are good, productive workers (Berger, 2009; Roscigno, 2010). Finally, earnings above a certain level reduce Social Security benefits before full retirement age, leading some older people to avoid working at all or to at least limit their hours. All these obstacles lead seniors to drop out of the labor force or to remain unemployed (Gallo, Brand, Teng, Leo-Summers, \& Byers, 2009).

Age discrimination in the workplace merits some further discussion. According to sociologist Vincent J. Roscigno (2010), survey evidence suggests that more than half of older workers have experienced or observed age discrimination in the workplace, and more than 80 percent of older workers have experienced or observed jokes, disrespect, or other prejudicial comments about old age. Roscigno notes that workplace ageism receives little news media attention and has also been neglected by social scientists. This is so despite the related facts that ageism in the workplace is common and that the older people who experience this discrimination suffer financial loss and emotional problems. Roscigno (2010, p. 17) interviewed several victims of age discrimination and later wrote, "Many conveyed fear of defaulting on mortgages or being unable to pay for their children's college after being pushed out of their jobs. Others expressed anger and insecurity over the loss of affordable health insurance or pension benefits...Just as prevalent and somewhat surprising to me in these discussions were the less-tangible, yet deeper social-psychological and emotional costs that social science research has established for racial discrimination or sexual harassment, for instance, but are only now being considered in relation to older workers."

One of the people Roscigno interviewed was a maintenance worker who was laid off after more than two decades of working for his employer. This worker was both hurt and angry. "They now don't want to pay me my pension," he said. "I was a good worker for them and always did everything they asked. I went out of my way to help train people and make everything run smoothly, so everybody was happy and it was a good place to work. And now this is what I get, like I never really mattered to them. It’s just not right” (Roscigno, 2010, p. 17).

\section{Bereavement and Social Isolation}

"We all need someone we can lean on," as a famous Rolling Stones song goes. Most older Americans do have adequate social support networks, which, as we saw earlier, are important for their well-being. However, a significant minority of elders live alone and do not see friends and relatives as often as they wish. Bereavement takes a toll, as elders who might have been married for many years suddenly find themselves living alone. Here a gender difference again exists. Because women outlive men and are generally younger than their husbands, they are three times more likely than men (42 percent compared to 13 percent) to be widowed and thus much more likely to live alone (see Table 6.3 “Living Arrangements of Noninstitutionalized Older Americans, 2010"). 


\begin{tabular}{|l|l|l|}
\hline & Men (\%) & Women (\%) \\
\hline Living alone & 19 & 41 \\
\hline Living with spouse & 70 & 37 \\
\hline Other arrangement & 11 & 21 \\
\hline
\end{tabular}

Source: Data from Administration on Aging. (2011). A profile of older Americans: 2011. Retrieved from http://www.aoa.gov/aoaroot/ aging_statistics/Profile/2011/docs/2011profile.pdf.

Many elders have at least one adult child living within driving distance, and such children are an invaluable resource. At the same time, however, some elders have no children, because either they have outlived their children or they never had any. As baby boomers begin reaching their older years, more of them will have no children because they were more likely than previous generations to not marry and/or to not have children if they did marry. Baby boomers thus face a relative lack of children to help them when they enter their "old-old" years (Leland, 2010).

Bereavement is always a difficult experience, but because so many elders lose a spouse, it is a particular problem in their lives. The grief that usually follows bereavement can last several years and, if it becomes extreme, can involve anxiety, depression, guilt, loneliness, and other problems. Of all these problems, loneliness is perhaps the most common and the most difficult to overcome.

\section{Elder Abuse}

Some seniors fall prey to their own relatives who commit elder abuse against them. Such abuse involves one or more of the following: physical or sexual violence, psychological or emotional abuse, neglect of care, or financial exploitation (Novak, 2012). Accurate data are hard to come by since few elders report their abuse, but estimates say that at least 10 percent of older Americans have suffered at least one form of abuse, amounting to hundreds of thousands of cases annually. However, few of these cases come to the attention of the police or other authorities (National Center on Elder Abuse, 2010).

Although we may never know the actual extent of elder abuse, it poses a serious health problem for the elders who are physically, sexually, and/or psychologically abused or neglected, and it may even raise their chances of dying. One study of more than 2,800 elders found that those who were abused or neglected were three times more likely than those who were not mistreated to die during the next thirteen years. This difference was found even after injury and chronic illness were taken into account (Horn, 1998).

A major reason for elder abuse seems to be stress. The adult children and other relatives who care for elders often find it an exhausting, emotionally trying experience, especially if the person they are helping needs extensive help with daily activities. Faced with this stress, elders' caregivers can easily snap and take out their frustrations with physical violence, emotional abuse, or neglect of care. 


\section{Senior Power: Older Americans as a Political Force}

Older Americans often hold strong views on issues that affect them directly, such as Medicare and Social Security. In turn, politicians often work to win the older vote and shape their political stances accordingly.

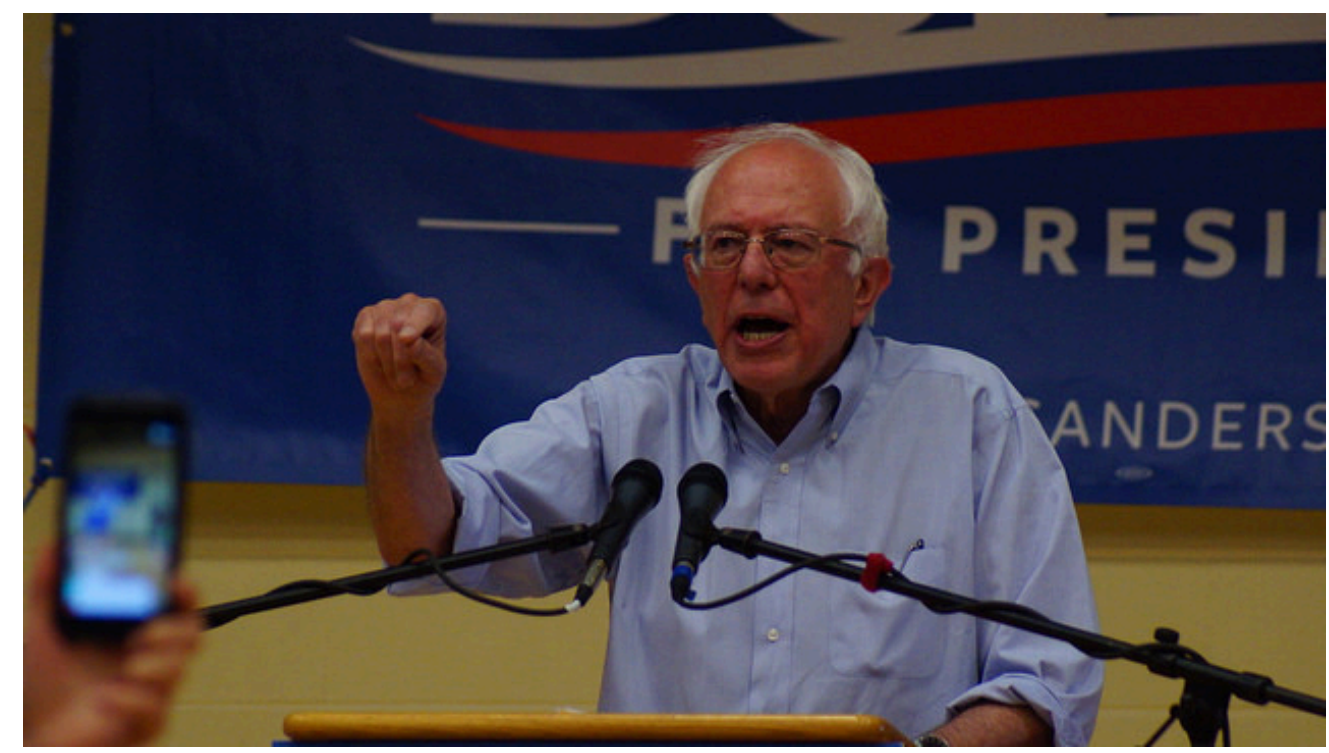

During the past few decades, older people have become more active politically on their own behalf.

Marc Nozell - Bernie Sanders - CC BY-NC 2.0.

To help address all the problems discussed in the preceding pages, several organizations have been established since the 1980s to act as interest groups in the political arena on behalf of older Americans (Walker, 2006). One of the most influential groups is the American Association of Retired Persons (AARP), which is open to people 50 or older. AARP provides travel and other discounts to its members and lobbies Congress and other groups extensively on elderly issues. Its membership numbers about 40 million, or 40 percent of the over-50 population. Some critics say AARP focuses too much on its largely middle-class membership's self-interests instead of working for more far-reaching economic changes that might benefit the older poor; others say its efforts on Medicare, Social Security, and other issues do benefit the elderly from all walks of life. This controversy aside, AARP is an influential force in the political arena because of its numbers and resources.

A very different type of political organization of the elderly was the Gray Panthers, founded by the late Maggie Kuhn in 1970 (Kuhn, Long, \& Quinn, 1991). Although this group has been less newsworthy since Kuhn’s death in 1995, at its height it had some eighty-five local chapters across the nation and 70,000 members and supporters. A more activist organization than AARP and other lobbying groups for the elderly, the Gray Panthers took more liberal stances. For example, it urged the establishment of a national health-care service and programs to increase affordable housing for the elderly.

As older Americans have engaged the political process on their own behalf, critics have charged that programs for the elderly are too costly to the nation, that the elderly are better off than groups like AARP claim, and that new programs for the elderly will take even more money from younger generations and leave them insufficient 
funds for their own retirement many years from now. Their criticism, which began during the 1980s, is termed the generational equity argument (Williamson, McNamara, \& Howling, 2003).

Advocates for the elderly say the generational equity critics exaggerate the financial well-being of older Americans and neglect the fact that many older Americans, especially women and those of color, are poor or near poor and thus need additional government aid. Anything we can do now to help the aged, they continue, will also help future generations of the elderly. As Lenard W. Kaye (1994, p. 346) observed in an early critique of the generational equity movement, "In the long run, all of us can expect to live into extended old age, barring an unexpected fatal illness or accident. To do injustice to our current generation of elders, by means of policy change, can only come back to haunt us as each and every one of us-children, young families, and working people-move toward the latter stages of the life course.”

\section{People Making a Difference}

\section{College Students Helping Senior Citizens}

After Hurricane Irene swept up the East Coast in August 2011, many towns and cities faced severe flooding. One of these towns was Cranford, New Jersey, just southwest of Newark. Streets and hundreds of homes flooded, and many residents' belongings were ruined.

Union County College, which has campuses in Cranford and a few other towns, came to Cranford residents' aid. As the college president explained in late August, "Many of the town's residents are senior citizens. Even though the fall term won't begin until Sept. 1, we've still got a number of strong men and women on campus to help residents clear out their basements and help move whatever people needed moved."

Led by the dean of college life, a dozen or so students went house-to-house on a Cranford street that experienced the worst flooding to aid the town's senior citizens and younger ones as well. The dean later recalled, "Everyone we met was just so happy to see us there helping out. Sometimes they had plenty of work for us. Other times, they just smiled and said they were glad to know we cared."

A news report summarized the impact of the students' assistance: “In the coming weeks and months, Cranford residents will be able to recover what their town lost to Irene. But they may never forget the damage Irene caused, nor are they likely to forget how Union County College's students came to help them in their time of need.” At a time of crisis, the staff and students of Union County College in the small town of Cranford, New Jersey, made a big difference in the lives of Cranford's senior citizens and younger residents alike.

Source: Cranford Chronicle, 2011

\section{Key Takeaways}

- The US elderly experience several health problems, including arthritis, high blood pressure, heart disease, hearing loss, vision problems, diabetes, and dementia.

- Nursing home care in the United States is very expensive and often substandard; neglect and abuse of nursing home residents is fairly common.

- Despite help from Social Security, many older Americans face problems of financial security.

- It is difficult to determine the actual extent of elder abuse, but elder abuse often has serious consequences for the health and lives of older Americans. 
- During the last few decades, older Americans have been active in the political process on their own behalf and today are an important political force in the United States.

\section{For Your Review}

1. What do you think is the worst or most serious problem facing the US elderly? Explain your answer.

2. The text suggests that the lives of the US elderly would be improved if the United States were to adopt some of the policies and practices that other nations have for their elderly. Explain why you agree or disagree with this suggestion.

\section{References}

Alzheimer’s Association. (2009). 2009 Alzheimer’s disease facts and figures. Chicago, IL: Author.

Berger, E. D. (2009). Managing age discrimination: An examination of the techniques used when seeking employment. The Gerontologist, 49(3), 317-332.

Carr, D. (2010). Golden years? Poverty among older Americans. Contexts, 9(1), 62-63.

Cranford Chronicle. (2011, August 31). County College students help Cranford residents cleanup. Cranford Chronicle. Retrieved from http://www.nj.com/cranford/index.ssf/2011/2008/ county college students help c.html.

Crawthorne, A. (2008). Elderly poverty: The challenge before us. Washington, DC: Center for American Progress.

DeHart, D., Webb, J., \& Cornman, C. (2009). Prevention of elder mistreatment in nursing homes: Competencies for direct-care staff. Journal of Elder Abuse \& Neglect, 21(4), 360-378.

Edwards, M. (2007). As Good As It Gets: What Country Takes the Best Care of Its Older Citizens? In D. S. Eitzen (Ed.), Solutions to Social Problems: Lessons from Other Societies (4th ed., pp. 76-85). Boston, MA: Allyn \& Bacon.

Federal Interagency Forum on Aging-Related Statistics. (2010). Older Americans 2010: Key indicators of wellbeing. Washington, DC: US Goverment Printing Office.

Gallo, W. T., Brand, J. E., Teng, H.-M., Leo-Summers, L., \& Byers, A. L. (2009). Differential impact of involuntary job loss on physical disability among older workers: Does predisposition matter? Research on Aging, 31(3), 345-360.

Hartlapp, M., \& Schmid, G. (2008). Labour market policy for “active ageing” in Europe: Expanding the options for retirement transitions. Journal of Social Policy, 37(3), 409-431. 
Horn, D. (1998, August 17). Bad news on elder abuse. Time, p. 82.

Kaye, L. W. (1994). Generational equity: Pitting young against old. In J. Robert B. Enright (Ed.), Perspectives in social gerontology (pp. 343-347). Boston, MA: Allyn and Bacon.

Kerby, S. (2012). Debunking poverty myths and racial stereotypes. Washington, DC: Center for American Progress.

Kuhn, M., Long, C., \& Quinn, L. (1991). No stone unturned: The life and times of Maggie Kuhn. New York, NY: Ballantine Books.

Leland, J. (2010, April 25). A graying population, a graying work force. New York Times, p. A14.

National Center on Elder Abuse. (2010). Why should I care about elder abuse? Washington, DC: Author.

Ney, S. (2005). Active aging policy in Europe: Between path dependency and path departure. Ageing International, 30, 325-342.

Novak, M. (2012). Issues in aging (3rd ed.). Upper Saddle River, NJ: Pearson.

Roscigno, V. J. (2010). Ageism in the American workplace. Contexts, 9(1), 16-21.

Rowe, J. W., Berkman, L. F., Binstock, R., Boersch-Supan, A., Cacioppo, J., Carsternsen, L., et al. (2010). Policies and politics for an aging America. Contexts, 9(1), 22-27.

Sears, D. (2009, September 6). Myths busted on older workers' job performance. TheLadders. Retrieved from http://www.career-line.com/job-search-news/myths-busted-on-older-workers-job-performance/.

Walker, A. (2006). Aging and politics: An international perspective. In R. H. Binstock \& L. K. George (Eds.), Handbook of aging and the social sciences (6th ed., pp. 338-358). New York, NY: Academic Press.

Williamson, J. B., McNamara, T. K., \& Howling, S. A. (2003). Generational equity, generational interdependence, and the framing of the debate over social security reform. Journal of Sociology and Social Welfare, 30(3), 3-14. 


\subsection{Reducing Ageism and Helping Older Americans}

\section{Learning Objectives}

1. Understand the contradictory impulses that make it difficult to predict the future for older Americans.

2. Discuss any two programs or policies that should help address some of the problems facing older Americans.

We have seen some contradictory impulses that make it difficult to predict the status of older Americans in the decades ahead. On the one hand, the large number of baby boomers will combine with increasing longevity to swell the ranks of the elderly; this process has already begun and will accelerate during the coming years. The inevitable jump in the size of the aged population may strain Social Security, Medicare, and other programs for the aged. On the other hand, the baby boomer generation will reach its old age as a much better educated and more healthy and wealthy group than any previous generation. It will likely participate in the labor force, politics, and other arenas more than previous generations of elders and, as has been true for some time, exert a good deal of influence on national political and cultural affairs.

Although this sounds like a rosier picture, several concerns remain. Despite the relative affluence of the baby boomers, segments of the group, especially among women and people of color, remain mired in poverty, and these segments will continue to be once they reach their older years. Moreover, the relative health of the baby boomers means that they will outlive previous generations of the aged. Yet as more of them reach the ranks of the "oldold," they will become frailer and require care from health-care professionals and organizations and from social support networks. As noted earlier, some may not have children and will be in even more need of help.

Although older Americans fare much better than their counterparts in poor nations, they fare not nearly as well as their counterparts in other wealthy democracies, which generally provide many more extensive and better-funded programs and services for their elderly. Older Americans also continue to confront stereotypes and prejudicial attitudes that add to the burden many of them already face from the biological process of aging.

A sociological understanding of aging and ageism reminds us that many of the problems that older Americans face are ultimately rooted not in their chronological age but rather in the stereotypes about them and in the lack of adequate social programs like those found throughout other Western nations. This understanding also reminds us that the older Americans who face the most severe problems of health, health care, and financial security are women and people of color and that their more severe problems reflect the many inequalities they have experienced throughout the life course, long before they reached their older years. These inequalities accumulate over the years to leave them especially vulnerable when they finally arrive into their sixties.

With this understanding, it becomes clear that efforts to improve the lives of older Americans must focus on providing them with more numerous and more extensive social services and programming of many kinds and on reducing the stereotypes and prejudicial attitudes that many Americans hold of older people. Possibilities 
involving improved social services and programming might be drawn from the example provided by other Western nations and include the following (Rowe et al., 2010; Uhlenberg, 2009):

1. An expansion of Social Security to provide a much more comfortable life for all older Americans, regardless of their earnings history, and thus regardless of their gender and race/ethnicity.

2. An expansion of Medicare and other health aid for older Americans to match the level of health-care assistance provided by many other Western nations. In one particular area that needs attention, Medicare pays for nursing home care only after nursing home patients use up most of their own assets, leaving a patient's spouse with severe financial problems. Other Western nations pay for nursing home care from the outset, and the United States should adopt this practice.

3. The establishment of more flexible work hours, job-sharing arrangements, and other policies that would enhance the ability of older people to work part-time or full-time.

4. Increase paid and volunteer opportunities for older adults to help take care of young children and adolescents, especially those who are poor or otherwise disadvantaged, in schools and other settings, creating a win-win situation for both the older adults and the children.

5. As with stereotypical and prejudicial views based on gender and on race/ethnicity, greater educational efforts should be launched to reduce stereotyping and prejudicial attitudes based on aging. Like sexism and racism, ageism has no place in a nation like the United States, which has historically promised equality and equal opportunity for all.

Beyond all these measures, aging scholars emphasize the need to help future older populations by investing in younger people. As a group of several scholars has noted, "Many of the key determinants of successful aging are cumulative, occurring throughout the lifetime and, importantly, starting in early childhood. The people who will turn 65 between 2050 and 2070 have already been born. If we want to promote their health and well-being into old age, we need to begin now, when they are infants and children. Childhood and early adolescent experiences leave a footprint for many functions in older age. Failing to invest in education and health throughout childhood and young adulthood is short-sighted” (Rowe et al., 2010, p. 24).

\section{Key Takeaways}

- Although the number of older Americans will be increasing in the years ahead, the baby boomers who are now reaching old age will be better educated and wealthier than older Americans of past generations.

- Efforts to help older Americans would benefit from relying on the models practiced by other Western democracies.

\section{For Your Review}

1. What do you think is the most important action the United States should take to help older Americans?

2. Does it make sense for the United States to follow the example of other democracies as it tries to help older 
Americans, or is the United States different enough from these nations that it does not make sense to do so? Explain your answer.

\section{References}

Rowe, J. W., Berkman, L. F., Binstock, R., Boersch-Supan, A., Cacioppo, J., Carsternsen, L., et al. (2010). Policies and politics for an aging America. Contexts, 9(1), 22-27.

Uhlenberg, P. (2009). Children in an aging society. Journal of Gerontology Series B: Psychological Sciences and Social Sciences, 64B(4), 489-496. 


\subsection{End-of-Chapter Material}

\section{Summary}

1. Gerontology is the study of aging. Gerontologists study the biological, psychological, and social dimensions of aging. Social gerontologists focus on social aging and distinguish several dimensions of aging, which refers to changes in people's roles and relationships as they age.

2. The perception and experience of aging vary from one society to another and within a given society over time.

3. Sociological explanations of aging include disengagement theory, activity theory, and conflict theory. Disengagement theory emphasizes the need of society to disengage its elders from their previous roles to pave the way for a younger and presumably more able generation to take over those roles. In contrast, activity theory assumes that elders need to remain active to enhance their physical and mental health. Conflict theory emphasizes ageism, or discrimination and prejudice against the elderly, and the structural barriers society poses to elders' economic and other aspects of overall well-being.

4. Life expectancy differs dramatically around the world and within the United States, where it's lower for men and lower for people of color. Because life expectancy has increased, people are living longer, resulting in a "graying of society." In the United States, the imminent entrance of the baby boom generation into its older years will further fuel a large rise in the number of older Americans. This graying of society may strain traditional economic and medical programs for their care and affect views of aging and the elderly.

5. Although aging involves several physiological and psychological changes, negative stereotypes of aging and the elderly exaggerate the extent and impact of these changes. Proper exercise, nutrition, and stress reduction can minimize the effects of aging, as can religious involvement and informal social support networks.

6. As a diverse group, older Americans differ greatly in terms of wealth and poverty, education, health, and other dimensions. They face several problems because of their age, including illness and disability, financial security, employment obstacles, and elder abuse. For several reasons, older Americans generally hold more conservative views on social and moral issues. At the same time, groups working on behalf of older Americans in the political arena have succeeded in bringing elder issues to the attention of public officials and political parties.

7. As the ranks of older Americans swell in the years ahead, elders will be better educated and wealthier than their predecessors, but their sheer numbers may impose considerable strain on social institutions. Already there are signs of perceived conflict between the needs of the elderly and those of younger generations. However, advocates for older Americans believe that efforts to help elders now will in the long run help younger Americans when they finally reach their old age.

\section{Using What You Know}

It is about twenty years from now, and a close friend of yours is facing a difficult decision. Her mother is in failing health and might have the onset of dementia. It has become increasingly apparent that she can no longer live alone, and your friend is trying to decide whether to have her mother come live with her, to arrange for in-home care for her, or to place her into residential care. What advice do you give to your friend? 


\section{What You Can Do}

To help reduce inequality based on aging and ageism and the problems facing older people, you may wish to do any of the following:

1. Volunteer at a senior citizens' center, residential care facility, or nursing home.

2. Write a letter to the editor about media stereotypes about older people.

3. Start a group on your campus to educate students about the problems facing senior citizens. 


\section{Chapter 7: Alcohol and Other Drugs}

\section{Social Problems in the News}

“Why Do College Students Love Getting Wasted?” the headline asked. Ohio University sociologist Thomas Vander Ven, author of a recent book on college drinking, was interviewed for this news story and had several answers to this question. First, drinking helps lessen college students' anxieties about their courses, social relationships, and other matters. Second, it helps them have a good time and develop close friendships, including perhaps a romantic or sexual partner. Third, and perhaps most important, they drink because it's fun. He also noted that when students get drunk, the other students who take care of them learn something about adult responsibility.

Vander Ven said that when students drink, “They’re more likely to say and do things that they normally wouldn't do-show affection to their peers, get angry at them, get more emboldened to sing and dance and take risks and act crazy and there's a ton of laughing that goes on. It creates this world of adventure. It creates war stories. It creates bonding rituals." He added, "When things go wrong — the getting sick, the getting arrested, the getting upset—it gives them an opportunity to care for one another, to deliver social support. So you've got young adults who, for the first time, are taking care of a sick person, staying up all night with them, consoling them when they're upset. It's an opportunity for them to try on adult roles.”

Source: Rogers, 2011

This news story points to two central facts that are often forgotten in discussions about alcohol and other drugs. First, because of a combination of physiological, psychological, and social factors, drugs make us feel good. Second, because drugs make us feel good, many people want to use them, come hell or high water. To acknowledge these two basic facts is not meant to excuse the use of alcohol and other drugs, which cause serious individual and societal problems. But it is meant to indicate why the United States and other nations have found it so difficult to deal with drug use.

This difficulty in turn points to the need to understand why people use alcohol and other drugs, including the influence of our sociodemographic backgrounds on the likelihood of using them. This chapter examines these and other aspects of drug use before turning to the important issue of social and political policy regarding drug use.

\section{References}

Rogers, T. (2011, August 28). Why do college students love getting wasted? Salon.com. Retrieved from http://www.salon.com/life/education/?story=/mwt/feature/2011/2008/2028/college drinking interview. 


\subsection{Drug Use in History}

\section{Learning Objectives}

1. Discuss the presence of drugs in ancient times.

2. Summarize the use of drugs in the United States during the nineteenth century.

3. Explain the racial basis for decisions to ban opium, cocaine, and marijuana in the United States.

Shakespeare once wrote that "what's past is prologue.” This familiar phrase means that what happened in the past provides a context for, and can help to understand and predict, the future. To the extent that the past is prologue, the history of drug use provides a sobering lesson: Drug use has been common since ancient times and has been common in almost every society. As a recent book on drug policy states, "People have used chemicals to alter their state of mind since before there were written records” (Kleiman, Caulkins, \& Hawken, 2011, p. xviii). If past is indeed prologue, then it is no surprise that drug use remains common in contemporary nations despite considerable efforts to reduce it.

One manifestation of the long history of drug use is that humans have used mind-altering plants since prehistoric times. "Early humans discovered that eating some plants gave a feeling of relaxation, happiness, drowsiness, or peace," one scholar writes. "Some gave a feeling of increased energy, alertness, and stamina. And some caused strange sensations, terrifying visions, or a profoundly different awareness” (Gahlinger, 2004, p. 5).

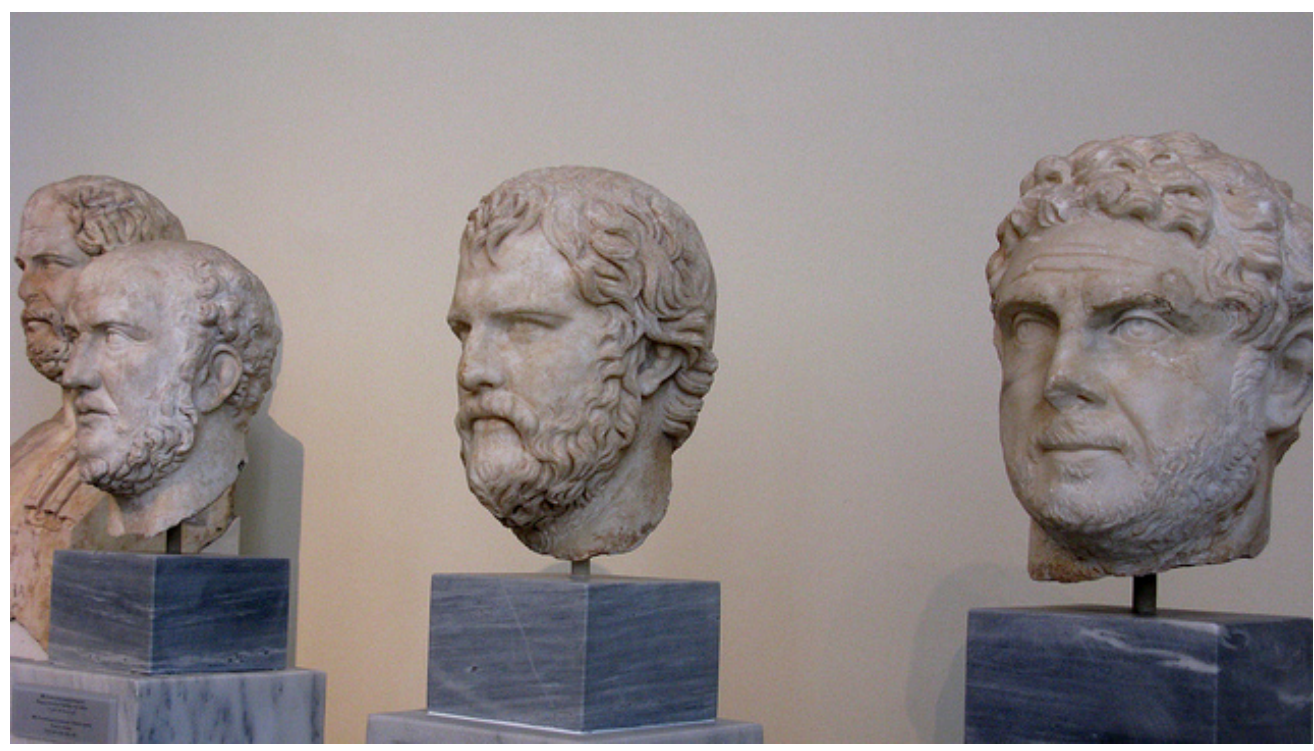

Ancient Greeks drank poppy juice, which contained opium, around 300 BCE. Use of other drugs was also common in ancient times.

Tilemahos Efthimiadis - National Archaeological Museum, Athens, Greece - CC BY 2.0. 
Examples of drug use thousands of years ago abound (Escohotado, 2010; Faupel, Horowitz, \& Weaver, 2010; Goodman, Sherratt, \& Lovejoy, 2007). Mead, an alcoholic drink made from fermented honey, was first used about 8000 BCE, and beer and berry wines were first used about 6000 BCE. The ancient Sumerians used opium starting about 5000 BCE. Ancient Egypt used alcohol in 3500 BCE, while ancient China used cannabis (the source of marijuana) around 3000 BCE. Ancient people in what is now Switzerland ate poppy seeds (the source of opium) in 2500 BCE. Coca leaves (the source of cocaine) have been chewed for thousands of years. Folk medicines made from plants and herbs have also been used since ancient times. People in ancient Palestine drank wine in 350 BCE. Ancient Greeks drank poppy juice in 300 BCE. In about the same period, South American tribes used a hallucinogen called cohoba, made from mimosa beans. The Chinese and other Asians were using opium regularly by 1000 CE. Native Americans used tobacco before being discovered by Columbus in 1492. The use of various drugs has also been common in the many societies that anthropologists have studied (Durant \& Thakker, 2003; Page \& Singer, 2010).

Sociologist Erich Goode (2008, p. 176) summarizes the history of drug use as follows: "Humans have been ingesting drugs for thousands of years. And throughout recorded time, significant numbers of nearly every society on earth have used one or more drugs to achieve certain desired physical or mental states. Drug use comes close to being a universal, both worldwide and throughout history.”

\section{Drug Use in US History}

This history of drug use includes the United States, where past is again prologue. During the colonial era, tobacco was a major crop in Virginia and other colonies thanks to slave labor. After being processed, it was commonly used by colonists and also exported to Europe in great quantities (Gately, 2001). From the earliest colonial days, alcohol was another drug used in great quantities, as "Americans were drinkers right from the start” (Genzlinger, 2011, p. C1). The Mayflower, the celebrated ship that brought the first Puritans to what eventually became the United States, was filled with barrels of beer. In colonial New England, rum manufacturing was a major industry, and rum drinking was common. During the early 1770s, New England had more than 140 rum distilleries, and rum consumption in the colonies averaged 7.5 million gallons annually. This massive drinking has led one author to call rum "the real spirit of 1776" (Williams, 2006). Rum was also a major export to Europe and elsewhere. In addition to rum, colonists routinely drank beer and hard cider.

During the nineteenth century, Americans began to use drugs other than alcohol in great quantities. One popular drug was coffee. Before the Civil War, Americans who drank coffee had to buy green (unroasted) coffee beans in bulk and roast their own coffee. Then in 1865, John Arbuckle, a Pittsburgh grocer, began selling roasted coffee inside a new invention - the paper bag. His bagged coffee was an instant hit across the nation, other coffee manufacturers followed suit, and coffee use by Americans greatly increased.

Alcohol also remained a very popular drug, and use of this drug during the 1800s was probably greater than during colonial America. Two reasons help account for this trend (Faupel et al., 2010). One reason was the western frontier. As the nation moved west, many of the explorers and settlers who led the way were men who were unmarried or, if married, men who had left their families behind. To put it mildly, they drank a lot, fought a lot, and gambled a lot. A second reason was that many Irish immigrants came to the United States during a great wave of immigration that began in the mid-nineteenth century. Although it might sound like a stereotype, the Irish drank a 
lot of alcohol back in their homeland, and they continued to do so once they reached the United States. Regardless of who was drinking, heavy alcohol use contributed greatly to poverty, to physical assaults and homicides, and to domestic violence and other family problems.

Three other popular drugs in this era were opium, cocaine, and marijuana. Use of these drugs was so common that nineteenth-century America has been called a “dope fiend's paradise” (Brecher, 1973). A brief discussion of these drugs' histories will underscore the widespread use of drugs in the American past and also racial issues that arose when laws were passed to ban these drugs (Musto, 1999).

\section{Opium}

During the decades before and after the Civil War, the use of opium was extremely common (Goode, 2012). Beyond making people feel good, opium is an effective painkiller and cough suppressant. Accordingly, it was a staple in many patent medicines, elixirs and tonics, sold back then in apothecaries, general stores, and other venues. Large numbers of people from all social backgrounds used these opium-laced medicines for problems such as depression, headaches, menstrual cramps, and toothaches. It is not much of an exaggeration to say that the United States was a nation of opium users during this period; an estimated 500,000 Americans were addicted to opium by the end of the century. As anthropologist Robert B. Edgerton (1976, pp. 57-58) summarizes the situation, "The use of opium was widespread in all segments of American society. Children were calmed with opium derivatives, women used many popular patent medicines which were liberally larded with opiates, and 'opium dens' were probably present in all cities and most towns as well.”

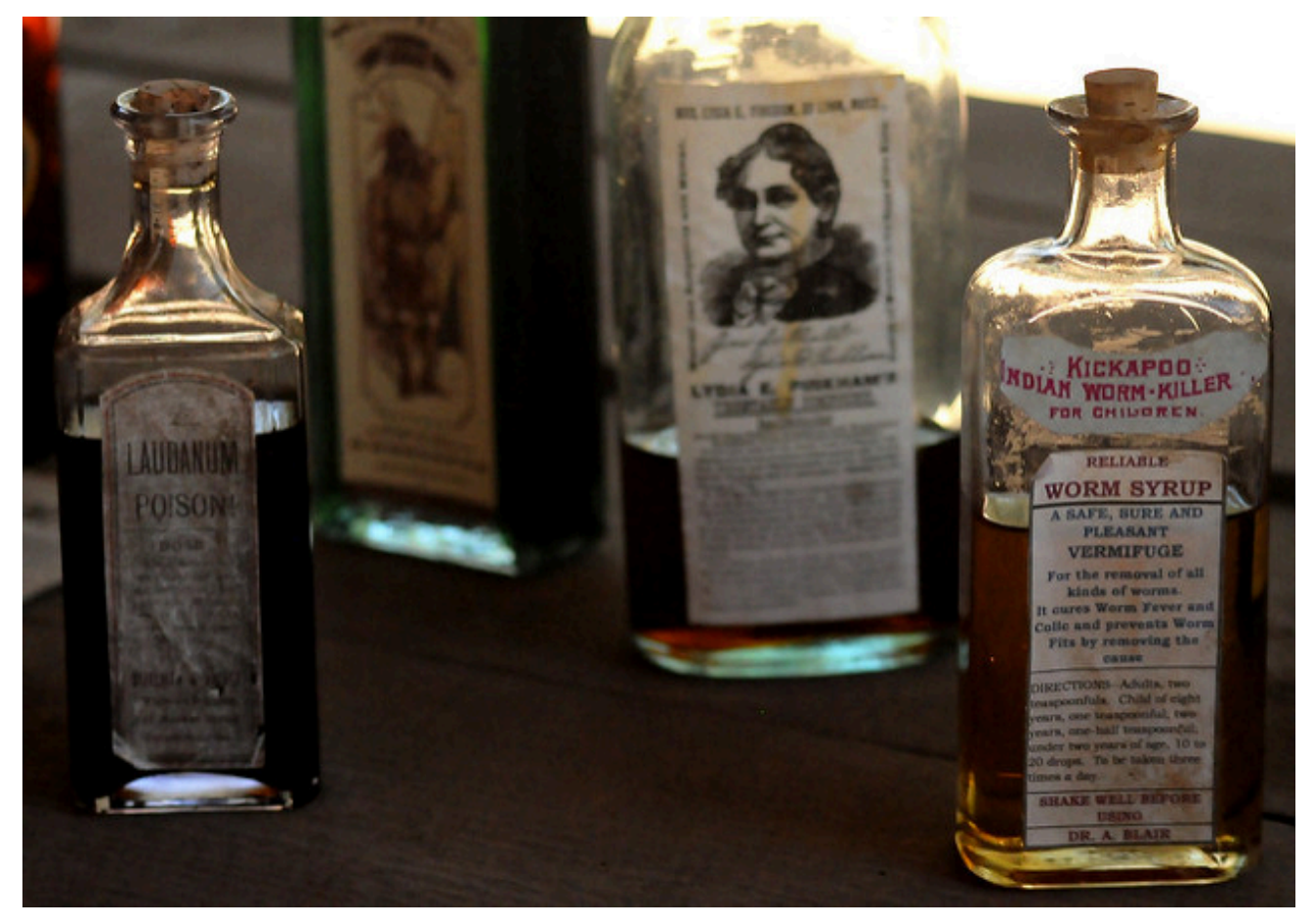

Opium was a common ingredient in nineteenth-century tonics and elixirs that were sold widely to the public.

camarelius - DSC 5554 rot cr alt - CC BY-NC 2.0. 
Attendance at opium dens (the equivalent of today's bar or tavern, with opium the drug of choice rather than alcohol) was a popular activity for the Chinese immigrants who began coming to the United States during the 1850s to help build the nation's railroads and perform other jobs. White workers feared their growing numbers as a threat to their jobs, and racial prejudice against the Chinese increased. Politicians, labor unions, and other parties began to focus on the Chinese habit of smoking opium at opium dens and warned that the Chinese were kidnapping little white children, taking them to the opium dens, and turning them into "opium fiends." This campaign had two effects: it increased prejudice against the Chinese, and it increased public concern about opium. This rising concern led San Francisco in 1875 to become the first locality to ban opium dens. Other California cities did the same, and the state itself banned opium dens in 1881. Three decades later, the federal government banned the manufacture, sale, and use of opium (except for use with a physician's prescription) when it passed the Harrison Narcotics Act in 1914.

\section{Cocaine}

Cocaine was another drug that was very popular in the nineteenth century, beginning in the 1880s, thanks in part to enthusiastic claims by Sigmund Freud and American physicians that cocaine could help relieve asthma, depression, hay fever, sexual impotence, toothache pain, and a host of other problems. Like opium, cocaine was a popular ingredient in the many patent medicines that people bought at various stores, and the US Army SurgeonGeneral advocated its medical use. It was a major ingredient in a new beverage introduced in 1886, Coca-Cola, which became an instant hit because people naturally felt so good when they drank Coke! During the next two decades, however, concern grew about cocaine's effects. Some of this concern was fueled by the absurd belief that African Americans who used cocaine became extra strong, dangerous, and even invulnerable to bullets. Cocaine was heavily taxed by the 1914 Harrison Narcotics Act and later banned.

\section{Marijuana}

A third legal drug during the late nineteenth century was marijuana. It joined opium and cocaine in being a common ingredient in patent medicines, and it was a popular drug for problems like migraine headaches, menstrual cramps, and toothache pain. After the Mexican Revolution of 1910, Mexicans moved to the United States in increased numbers and brought with them their habit of marijuana use. Whites feared that Mexicans would take their jobs, and, similar to what happened with opium and Chinese immigrants during the 1870s, began to charge that Mexicans who used marijuana would become violent and more likely to rape and murder innocent white victims. This racially prejudiced claim increased concern about marijuana and helped lead to the federal Marijuana Tax Act of 1937 that banned its use.

This brief history shows that drug use has been part of the American culture ever since the nation began. If past is prologue, it should come as no surprise that drugs remain part of the American culture today, and it should also come as no surprise that efforts to reduce or eliminate drug use often meet with much resistance and little success. As the United States continues to try to deal with drug use, these basic facts must not be forgotten. 


\section{Key Takeaways}

- Drug use has been common since ancient times.

- Alcohol was widely drunk in colonial America. During the latter nineteenth century, opium, marijuana, and cocaine were legal drugs that were also widely used.

- Racial prejudice played an important role in decisions during the late nineteenth century and early twentieth century to ban opium, marijuana, and cocaine.

\section{For Your Review}

1. Were you surprised to read that mind-altering drug use has been common since ancient times? Why or why not?

2. Were you surprised to read that racial prejudice helped lead to bans on opium, marijuana, and cocaine? Why or why not?

\section{References}

Brecher, E. M. (1973). Licit and illicit drugs. Boston, MA: Little, Brown.

Durant, R., \& Thakker, J. (2003). Substance use and abuse: Cultural and historical perspectives. Thousand Oaks, CA: Sage Publications.

Edgerton, R. (1976). Deviance: A cross-cultural perspective. Menlo Park, CA: Cummings.

Escohotado, A. (2010). The general history of drugs (G. W. Robinette, Trans.). Valparasio, Chile: Graffiti Milante Press.

Faupel, C. E., Horowitz, A. M., \& Weaver., G. S. (2010). The sociology of American drug use. New York, NY: Oxford University Press.

Gahlinger, P. (2004). Illegal drugs: A complete guide to their history, chemistry, use, and abuse. New York, NY: Penguin.

Gately, I. (2001). Tobacco: The story of how tobacco seduced the world. New York, NY: Grove Press.

Genzlinger, N. (2011, October 1). Bellying up to the time when America went dry. New York Times, p. C1.

Goode, E. (2008). Deviant behavior (8th ed.). Upper Saddle River, NJ: Prentice Hall.

Goode, E. (2012). Drugs in American society (8th ed.). New York, NY: McGraw-Hill. 
Goodman, J., Sherratt, A., \& Lovejoy, P. E. (Eds.). (2007). Consuming habits: Drugs in history and anthropology (2nd ed.). New York, NY: Routledge.

Kleiman, M. A. R., Caulkins, J. P., \& Hawken, A. (2011). Drugs and drug policy: What everyone needs to know. New York, NY: Oxford University Press.

Musto, D. F. (1999). The American disease: Origins of narcotic control (3rd ed.). New York, NY: Oxford University Press.

Page, B., \& Singer, M. (2010). Comprehending drug use: Ethnographic Research at the social margins. New Brunswick, NJ: Rutgers University Press.

Williams, I. (2006). Rum: a social and sociable history of the real spirit of 1776. New York, NY: Nation Books. 


\subsection{Drugs and Drug Use Today}

\section{Learning Objectives}

1. Summarize the different types of drugs.

2. Explain the various harms caused by alcohol and tobacco.

3. Understand the effects of marijuana, cocaine, and other illegal drugs.

A drug may be defined as any substance other than food that, when taken into the body, affects the structure and/or functioning of the body. Defined this way, many common substances contain drugs or are drugs: coffee, No-Doz, and other products to keep us alert; aspirin, acetaminophen, ibuprofen, and other pain relievers; Tums, Rolaids, and other products that reduce heartburn; Metamucil and other products that reduce constipation; Robitussin, Sudafed, and other cold medicines; and so forth. If you have ever used one of these products, you are technically a drug user, however silly that might sound.

Many prescription drugs also certainly exist: Prozac and other antidepressants; Valium and other tranquilizers; Lipitor and other cholesterol drugs; Yasmin, Yaz and other birth control pills; Viagra and other products that relieve erectile dysfunction; and so forth. Sales of these prescription drugs amount to tens of billions of dollars annually.

The following substances are also drugs: alcohol, ecstasy, cocaine, heroin, marijuana, LSD, methamphetamine, PCP, and tobacco. Much has been written about these drugs, and we will discuss them further later in this section. But note that two of these drugs, alcohol and tobacco, are legal after a certain age, while the remaining drugs are illegal.

One of the problems in deciding how to think about and deal with drugs is that this distinction between legal drugs and illegal drugs has no logical basis. It makes sense to assume that the illegal drugs should be the ones that are the most dangerous and cause the most physical and social harm, but that is not true. Rather, alcohol and tobacco cause the most harm even though they are legal. As Kleiman et al. (2011, p. xviii) note about alcohol, "When we read that one in twelve adults suffers from a substance abuse disorder or that 8 million children are living with an addicted parent, it is important to remember that alcohol abuse drives those numbers to a much greater extent than does dependence on illegal drugs.” Tobacco kills about 435,000 Americans annually by causing premature death, and alcohol kills about 85,000 annually through its effects on the liver and other body organs (Mokdad, Marks, Stroup, \& Gerberding, 2004).

Putting these numbers together, some 520,000 Americans die annually from alcohol and tobacco use. Meanwhile, the physiological effects of all illegal drugs combined kill an estimated 17,000 Americans annually (Mokdad et al., 2004), a number that is only just above the number of annual deaths $(16,500)$ from nonsteroidal inflammatory drugs (NSAIDs) such as aspirin and ibuprofen (Frech \& Go, 2009). Figure 7.1 "Annual Deaths from Legal and 
Illegal Drugs” depicts the huge difference between deaths from alcohol and tobacco as legal drugs and from illegal drugs.

Figure 7.1 Annual Deaths from Legal and Illegal Drugs

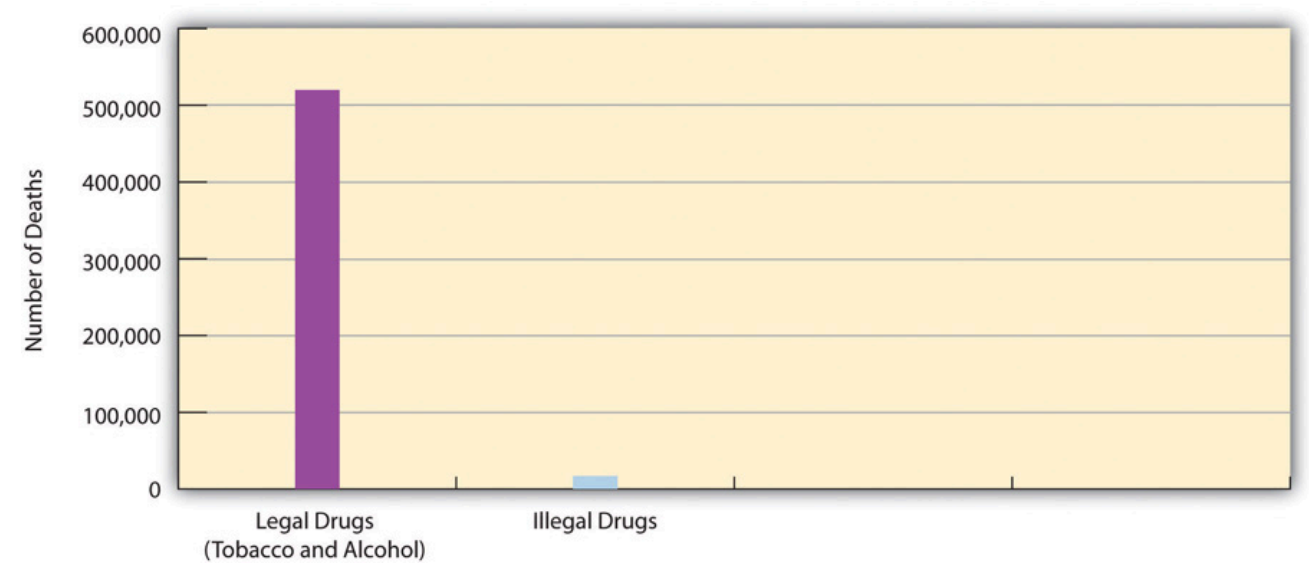

Source: Mokdad, A. H., Marks, J. S., Stroup, D. F., \& Gerberding, J. L. (2004). Actual causes of death in the United States, 2000.

Journal of the American Medical Association, 291(10), 1238-1245.

We return to the issue of the relative harm of legal and illegal drugs toward the end of the chapter when we discuss drug policy. In the meantime, keep in mind two related facts: (1) all drugs can be dangerous, and (2) some drugs are much more dangerous than others. Two aspirins are safe to take, but a bottle of aspirin can kill someone. Two cups of coffee a day are fine, but drinking many cups a day can cause anxiety, insomnia, and headaches. One drink of alcohol is safe to take, but several drinks in a short time amount to binge drinking, and long-term use of alcohol can kill someone. One snort of cocaine is usually safe, but even one snort can result in a sudden fatal heart attack, and long-term use often has serious health consequences.

\section{Types of Drugs}

Drugs are commonly classified into certain categories according to their physiological effects. All drugs may make us feel good, but they do so in different ways. Because some drugs are much more potent than other drugs, there is much variation within each category. Partly because many drugs have multiple effects, many different classifications of drugs exist. A common classification includes the following categories: depressants, hallucinogens, marijuana, narcotics, and stimulants.

\section{Depressants}

Depressants slow down the activity of the central nervous system. Depending on the specific drug, they help induce drowsiness and relaxation, and they can reduce anxiety and pain. Several types of depressants exist. Analgesics reduce pain and include over-the-counter products such as aspirin, acetaminophen (the major ingredient in Tylenol), and ibuprofen (the major ingredient in Advil and Motrin), and many prescription medicines that contain acetaminophen. Sedatives help people relax and include alcohol, barbiturates, and sleep medicines 
such as Sominex and Tylenol PM (both over-the-counter) and Ambien and Valium (both prescription). Large doses of depressants may lead to physical dependence and sometimes death.

\section{Hallucinogens}

Hallucinogens are mind-altering drugs that cause delusions or hallucinations. Their ranks include ecstasy, LSD, mescaline, and PCP. Many people who use a hallucinogen report that the mind-altering effects of the drug provide them a truly wonderful experience, but many also find the effects to be troubling at best and horrible and terrifying at worst. Long-term effects include hallucinations that occur without any drug use preceding them.

\section{Marijuana}

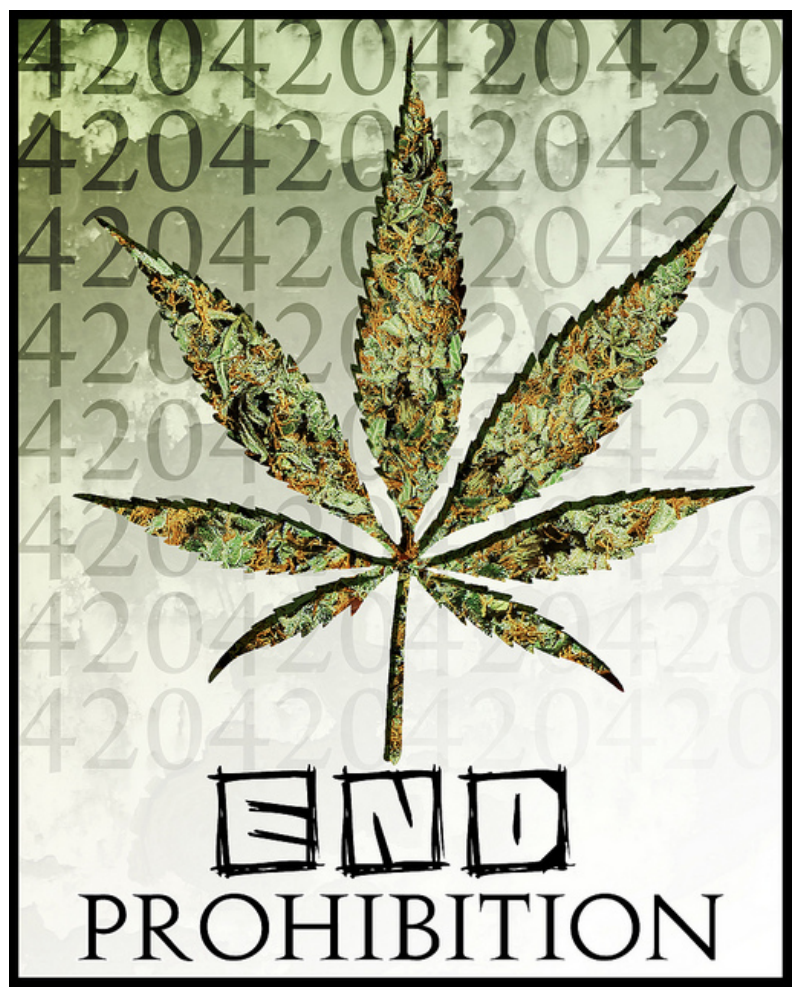

Marijuana is by far the most popular illegal drug in the United States.

Modern Scribe Photography - Maryjane 4-20-2010 (420) - CC BY-ND 2.0.

Because marijuana's effects do not fit neatly into any other category of drug, marijuana (along with its close cousin, hashish) is often considered to be its own category. As we will see later, it is by far the most popular illegal drug in the United States. Its effects include distortion of time and space, euphoria, hunger, increased sensory perception, and relaxation. 


\section{Narcotics}

Narcotics are sometimes classified under depressants because they slow down the central nervous system, but they are often still considered as their own category. They are highly effective at relieving pain and are a common substance in prescription medicines for severe pain. By definition, all narcotics are derived from opium, either in its natural form or in a synthesized form. Examples of narcotics include codeine, heroin, methadone, and morphine. In addition to relieving pain, narcotics may induce drowsiness, euphoria, and relaxation. Although narcotics do not damage bodily organs, they are very physically addictive, and high doses can be fatal.

\section{Stimulants}

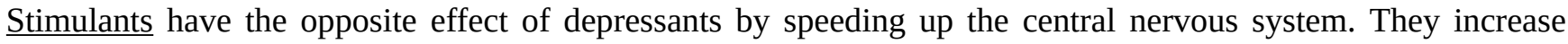
alertness and energy and can produce euphoria or anxiety. Some are legal and some are illegal, and many very different drugs are all considered stimulants: caffeine, cocaine, methamphetamine and other amphetamines, nicotine (tobacco), and Ritalin. Stimulants can be very physically addictive, and nicotine is thought to be more addictive than heroin. While caffeine is very safe as long as someone does not have too many cups of coffee daily, many other stimulants may have dangerous short-term or long-term side effects on the cardiovascular system.

Not all drugs can be discussed in one chapter. In choosing which drugs to discuss in a book on social problems, it makes sense to discuss the drugs that probably concern Americans the most. We thus focus in the remainder of this section mostly on alcohol, tobacco, marijuana, cocaine, and heroin.

\section{Legal Drugs}

As noted earlier, alcohol and tobacco (nicotine) are two legal drugs that are very common and that together kill hundreds of thousands of Americans annually. According to national survey evidence collected by the Substance Abuse and Mental Health Services Administration (SAMHSA) of the federal government, most people 12 and older (as well as many younger than 18) have tried alcohol, and over half the public drinks currently (defined as having had at least one drink in the past month). While many people have tried tobacco, only slightly more than one-fourth of the public uses it currently (at least once during the past month). Table 7.1 "Prevalence of Alcohol and Tobacco Use, Ages 12 and Older, 2010*” summarizes the prevalence of alcohol and nicotine use. Translating some of these percentages into actual numbers, almost 70 million Americans are current tobacco users (mostly by smoking cigarettes), and 131 million are current alcohol users.

Table 7.1 Prevalence of Alcohol and Tobacco Use, Ages 12 and Older, 2010* 


\begin{tabular}{|l|l|l|l|}
\hline & Lifetime & Past year & Past month \\
\hline Alcohol & 82.5 & 66.4 & 51.8 \\
\hline Tobacco & 68.7 & 32.8 & 27.4 \\
\hline
\end{tabular}

\section{* Percentage using in designated time period}

Source: Substance Abuse and Mental Health Services Administration. (2011). Results from the 2010 national survey on drug use and health: Summary of national findings. Rockville, MD: Author.

With this backdrop, we now discuss these two legal but very harmful drugs in greater detail.

\section{Alcohol}

Moderate alcohol use (more than one drink per day for an adult female and two drinks per day for an adult male) is relatively safe for most people and may even have health benefits (Harvard School of Public Health, 2012). The problem is that many people drink much more than moderately. As the Harvard School of Public Health (2012) explains, "If all drinkers limited themselves to a single drink a day, we probably wouldn't need as many cardiologists, liver specialists, mental health professionals, and substance abuse counselors. But not everyone who likes to drink alcohol stops at just one. While most people drink in moderation, some don’t.”

SAMHSA survey data show the extent of such problem drinking, as its survey measures both binge drinking (five or more drinks on the same occasion—within two hours of each other—on at least one day in the past month) and heavy drinking (binge drinking on at least five days in the past month). Table 7.2 "Prevalence of Binge and Heavy Alcohol Use, 2010*” presents the relevant data for people 12 and older and also for those aged 18-20, the customary age for people in their first two years of college.

Table 7.2 Prevalence of Binge and Heavy Alcohol Use, 2010*

\begin{tabular}{|l|l|l|}
\hline & Ages 12 and older & Ages 18-20 \\
\hline Binge use & 23.1 & 33.3 \\
\hline Heavy use & 6.7 & 11.3 \\
\hline * Percentage engaging in alcohol use \\
\hline
\end{tabular}

Source: Substance Abuse and Mental Health Services Administration. (2011). Results from the 2010 national survey on drug use and health: Summary of national findings. Rockville, MD: Author.

As Table 7.2 "Prevalence of Binge and Heavy Alcohol Use, 2010*" indicates, almost one-fourth of all people 12 and older and one-third of those aged 18-20 engage in binge drinking, while almost 7 percent and about 11 percent, respectively, engage in heavy drinking. The figures for those 12 and older translate to almost 59 million binge drinkers and 17 million heavy drinkers. These numbers show that tens of millions of people abuse alcohol annually and underscore the problem of dealing with problem drinking. 
The amount of alcohol consumed annually by occasional, moderate, and heavy drinkers is staggering. The relevant data appear in Table 7.3 "Alcohol Consumption in the United States, 2010". Americans drink 7.6 billion gallons of alcohol annually, equivalent to 126 billion standard drinks. This number of drinks works out to 496 drinks per person annually for the 12 and older population and 748 drinks per person for the 12 and older population that drinks at all. Keep in mind that this is just an average. The heavy drinkers identified in Table 7.2 "Prevalence of Binge and Heavy Alcohol Use, 2010*” have many more than 748 drinks every year, while light drinkers have only a relative handful of drinks.

Table 7.3 Alcohol Consumption in the United States, 2010

\begin{tabular}{|l|l|l|}
\hline & Number of gallons & Equivalent number of standard drinks* \\
\hline Beer & 6.4 billion & 68.2 billion \\
\hline Wine & 713.2 million & 18.3 billion \\
\hline Spirits & 463.1 million & 39.5 billion \\
\hline Total & 7.6 billion & 126.0 billion \\
\hline * one drink $=\mathbf{1 2}$ ounces of beer, $\mathbf{5}$ ounces of wine, or $\mathbf{1 . 5}$ ounces of spirits \\
\hline
\end{tabular}

Source: Beer Institute. (2011). Brewers almanac, 2011. Washington, DC: Author.

\section{The Drinking Culture and the Alcohol Industry}

As noted earlier, alcohol has a long history in the United States and an even longer history in much of the rest of the world. When we think about the tens of millions of Americans who drink at least occasionally, the ads for beer and wine and hard liquor that appear regularly in the popular media, and the thousands of bars and related venues across the country, it is certainly no exaggeration to say that we have a drinking culture.

Once upon a time, the federal and state governments tried to eliminate this culture. We are speaking, of course, about Prohibition. The passage of the Eighteenth Amendment to the US Constitution in January 1919 banned the manufacture, sale, and transportation of alcohol; the ban took effect a year later. For reasons we will discuss later, the ban was eventually deemed a failure, and the passage of the Twenty-First Amendment in 1933 repealed the Eighteenth Amendment. The manufacture, sale, and transportation of alcohol became legal once again.

Alcohol manufacturing and sales are a major industry worldwide today. Several alcohol companies rank among the largest corporations in the world as well as in the United States (Jernigan, 2009). US alcohol sales amount to about $\$ 160$ billion annually, and they rose by 20 percent in the 2010-2011 period during the faltering economy (Smith, 2011). The amount of money the public spends on alcohol equals 12.5 percent of what it spends on food (US Department of Agriculture, 2011). The alcohol industry provides about 2 million jobs annually, more than $\$ 40$ billion in wages, and more than $\$ 50$ billion in taxes, and it contributes more than $\$ 160$ billion to the annual national economy (Distilled Spirits Council of the United States, 2011). All these figures show that the alcohol industry plays a significant role in the US economy. 
Despite this role, if the United States does indeed have a drinking culture, the alcohol industry bears a major share of the responsibility. As the American Medical Association (2004) has stated,

Like the tobacco industry, the alcohol industry produces a legal, widely consumed drug; is dominated by relatively few producers; and utilizes a powerful combination of advertising dollars, savvy marketing, political campaign contributions, and sophisticated lobbying tactics to create and maintain an environment favorable to its economic and political interests. It requires the recruitment of new, youthful drinkers to maintain and build its customer base...As a chemical that affects our bodies, alcohol is a powerful drug resulting in more premature deaths and illnesses than all illicit drugs combined. Yet the industry has shaped public opinion and forced government to treat it not as a drug but as a cultural artifact, a valued legal commodity, almost a food, even a necessity of life.

As just one example of how the alcohol industry promotes its "powerful drug," the headline of a recent news article declared that the "alcohol companies go online to lure young drinkers" (Gardner, 2010). According to the report, alcohol companies are increasingly using Facebook and other social media to persuade young people to buy and drink their products. Not surprisingly, many of these young targets turn out to be under the legal drinking age of 21 because they are easily able to gain access to alcohol sites. This problem led a public health professor to observe, "Close to 5,000 people under the age of 21 die of alcohol overuse each year. Virtual worlds show all of the appeal and none of the consequences of alcohol use and undercut efforts to reduce the incidence of underage drinking. At this point, alcohol companies appear limited only by their imaginations and pocketbooks" (Gardner, 2010).

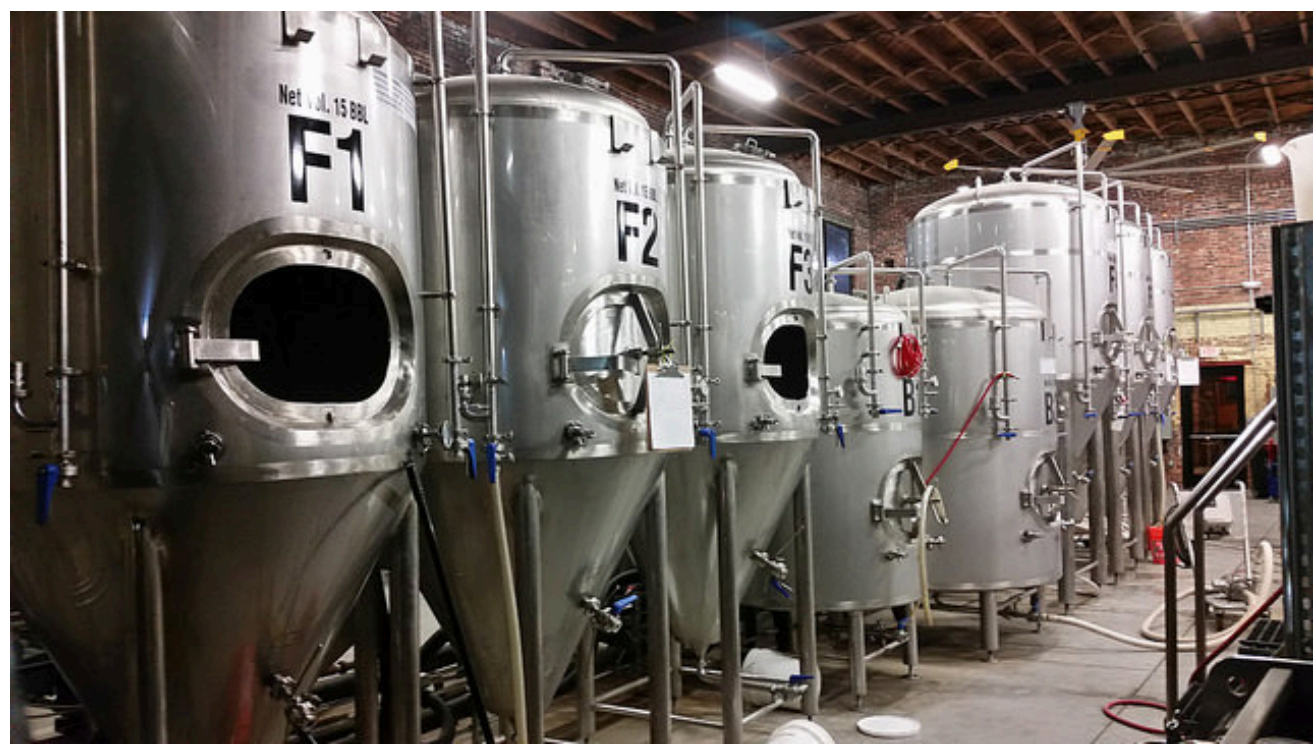

The alcohol industry is a major part of the US and worldwide economies and provides about 2 million jobs annually in the United States.

amateur photography by michel - Aardwolf Brewing Company - CC BY 2.0. 


\section{Consequences of Alcohol Abuse}

Despite alcohol's immense popularity, the fact remains that more than 18 million Americans abuse it (Harvard School of Public Health, 2012). This heavy rate of abuse means that alcohol has serious personal and social consequences. One set of consequences involves personal health. We noted earlier that alcohol abuse is responsible for about 85,000 deaths annually through the physiological damage it does. Heavy alcohol use can destroy the liver, increase blood pressure, weaken the heart and immune system, and cause sexual dysfunction. It can lead to neurological problems and also raises the risk of incurring several kinds of cancer. Binge drinking can cause serious immediate health problems because it may lead to someone overdosing on alcohol. About 800,000 adults are hospitalized every year for alcohol overdoses, and tens of thousands more are hospitalized because they have consumed alcohol along with prescription narcotic pain medications, a combination that can be deadly (National Institutes of Health, 2011).

In addition to these health problems, alcohol use is responsible for more than 16,000 traffic fatalities annually, and it plays an important role in violent crime (Felson, Teasdale, \& Burchfield, 2008). As almost anyone with an alcoholic family member can attest, alcohol abuse can also cause many problems for families, including domestic violence and divorce and the stress that results from having to deal with someone's alcoholism on a daily basis. (The Note 7.13 "Children and Our Future” box discusses the impact of parental alcoholism on children.) Alcohol abuse costs the United States more than \$185 billion each year in medical expenses, lost earnings because of alcohol-related illness or premature death, lost earnings by victims of violent crime, and alcohol-caused traffic accidents (Harvard School of Public Health, 2012).

\section{Children and Our Future}

\section{Children of Alcoholics}

As with so many social problems, one of the saddest consequences of alcohol abuse involves children. About one-fifth of children have lived with an alcoholic parent or other adult. Whether because alcoholism is partly inherited or because children tend to use their parents as role models, children of alcoholics are four times more likely than children of nonalcoholics to become alcoholics themselves by the time they reach adulthood.

Because living with an alcoholic parent is often both chaotic and unpredictable, it is no surprise that children of alcoholics often experience a great deal of stress and other difficulties that may also account for their greater tendency to become alcoholics. Compared to other children, they are more likely to be neglected and/or abused by their parents, and they are also more likely to miss school, have lower grades, and engage in disruptive behavior. In addition, they are at great risk for eating disorders and substance abuse other than alcohol abuse. The stress they experience can also harm their neurological development and immune system and put them at greater risk for different kinds of illness and disease. Children of alcoholics are also at greater risk for several kinds of psychological and emotional problems. These include (1) guilt, because they may blame themselves for their parent's drinking; (2) anxiety, because they worry about their parent's health and may see their parents arguing and fighting; (3) embarrassment that leads them not to invite friends over to visit nor to ask another adult for help; (4) lack of trust in other people, because they have learned not to trust their alcoholic parent; and (5) anger, confusion, and depression.

One special problem that children of alcoholics face is that they are "forced into adulthood." They often find themselves having to care for younger siblings and even for their alcoholic parent. By taking on such a heavy responsibility, they in effect become adults at too tender an age. This responsibility weighs on them and helps account for the psychological and emotional difficulties they often experience.

Mental health professionals strongly advise that children of alcoholics receive counseling and other kinds of support to 
help them deal with their family experiences. Group support programs for teenaged children may be very helpful. Perhaps the best known such program is Alateen, which also services teenagers who want help dealing with an alcoholic friend. Teenagers at Alateen meetings share their experiences, learn how to deal with the special difficulties that stem from having a relative or friend with an alcohol problem, and provide emotional support for each other. One important message they learn from Alateen is that they are in no way responsible for the alcoholism of their parent, other relative, or friend.

Alateen has helped many young people, as this testimonial from "Lizzy" attests: “Alateen has helped me a lot over the years...From the day I went to my first meeting, the door to my happiness was flung open. With the help of the Alateen Group Sponsors and my fellow teens, my life has become what I always wanted it to be. My goal for success in the program was fulfilled. I have been given a second chance at life and I have Alateen to thank for that.”

Young children and teenagers are resilient, but children of alcoholics have to be especially resilient. Programs like Alateen help give them a second chance.

Sources: Alateen, 2011; American Academy of Child and Adolescent Psychiatry, 2006; James, 2008

\section{College Students}

Alcohol abuse is also a problem on college and university campuses across the United States. Based on the SAMHSA survey evidence discussed earlier, full-time college students ages 18-22 drink more often and more heavily than their peers who are not in college (Substance Abuse and Mental Health Services Administration, 2008). Among full-time college students ages 18-20, who are all too young to drink legally, about 40 percent have engaged in binge drinking in the past month, and 17 percent have engaged in heavy drinking as defined earlier. Binge drinking on and off campus is so common that binge drinkers consume 91 percent of all the alcohol that college students drink.

Binge drinking by college students has many serious consequences (Center for Science in the Public Interest, 2008; National Center on Addiction and Substance Abuse, 2007). The following are consequences with approximate figures:

- Binge drinkers are much more likely than other students to miss class, get poor grades, be injured, have unprotected sex, and to drive after drinking.

- Six hundred thousand college students suffer alcohol-related injuries (from motor vehicle crashes and other accidents) each year, and 1,700 die from these injuries.

- Thirty thousand college students need medical attention annually to treat alcohol overdosing.

- Seven hundred thousand students are assaulted annually by a student who has been drinking, and three hundred students die from these assaults.

- Students who attend colleges with high rates of binge drinking are more likely to experience sleep disruption, property damage, and physical and sexual assaults than those who attend colleges with low rates of binge drinking. 


\section{Tobacco and Nicotine}

Nicotine, the major drug in tobacco, is another legal but very dangerous drug. As we saw earlier, its use kills four times as many people every year as those killed by alcohol use. Tobacco is a slow poison. If it were not already a legal drug used by millions, and a company had just manufactured cigarettes for the first time, the Food and Drug Administration would never approve this product. Fortunately for tobacco companies, nicotine does not distort perception the way that alcohol and many other psychoactive drugs do. Someone smoking or otherwise using tobacco can safely drive a car, operate machinery, and so forth, and someone "under the influence" of tobacco does not become violent.

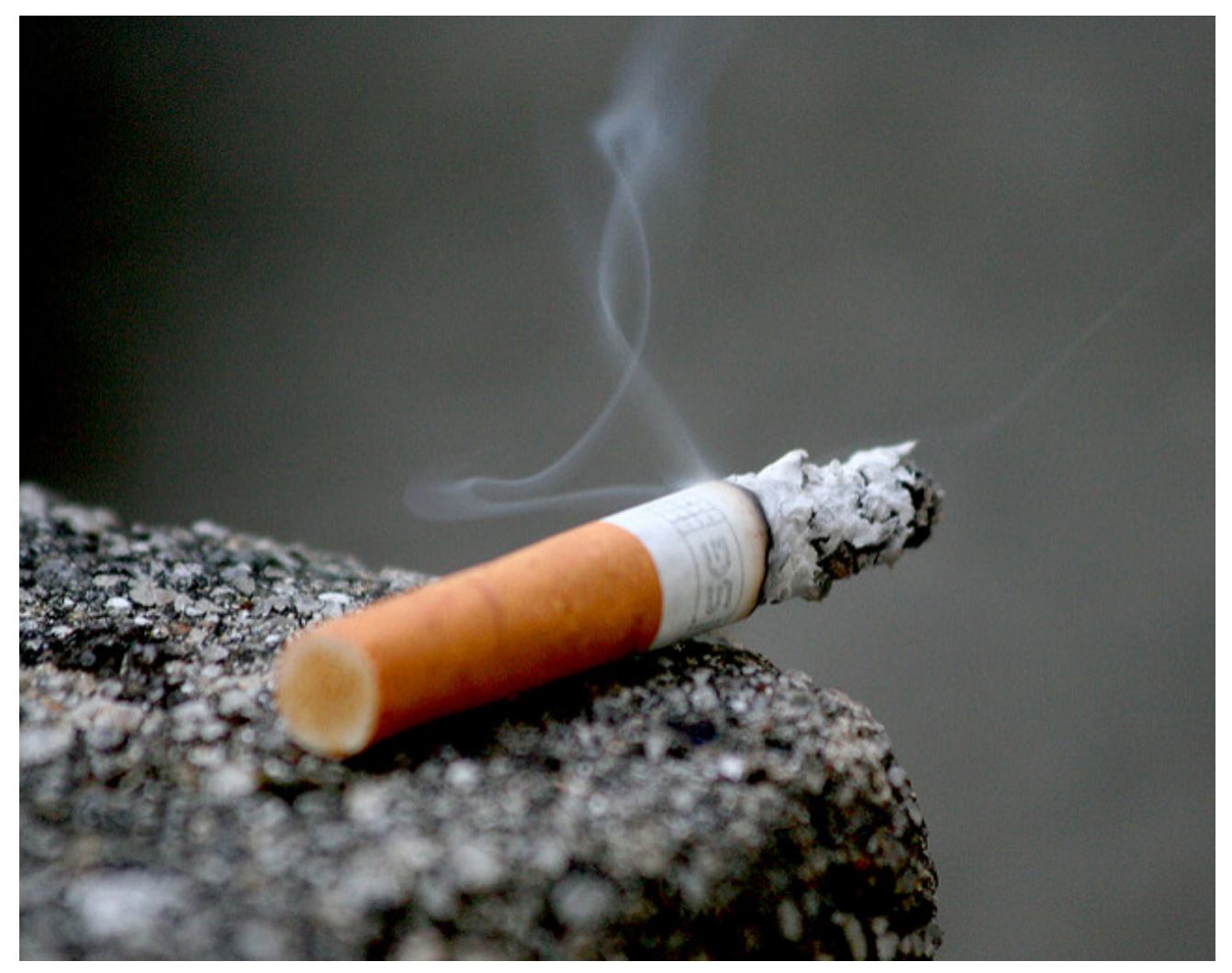

Tobacco is a slow poison. If it were a new drug, it would not be approved for public consumption.

Raul Lieberwirth - $\underline{\text { cigarette }}$ - CC BY-NC-ND 2.0.

If you have ever watched any number of pre-1970s movies or television shows like "Mad Men" that portray life back then, you know that the United States used to have a tobacco culture the way it now has an alcohol culture. Many, many people smoked cigarettes, and a large number smoked cigars or pipes. This particular drug culture began to abate in the 1970s after much evidence mounted about the deaths and other serious health effects of tobacco use and especially about the dangers of second-hand smoke. Whereas college students a generation ago often sat in smoke-filled classrooms and Americans generally sat in smoke-filled restaurants and other venues, today most Americans can count on being in enclosed public spaces in which smoking is banned.

Even so, we have already seen that more than one-fourth of Americans 12 and older, or some 70 million people, are still current users (past month) of tobacco. Almost one-fifth of American adults (18 and older), or 45.3 million 
adults, smoke cigarettes daily or occasionally (King, Dube, Kaufmann, Shaw, \& Pechacek, 2011). Thanks to the greater knowledge about tobacco's health effects, public education campaigns about these effects, heavy taxes on cigarettes, and changing attitudes about tobacco, these numbers represent a significant decline from a generation ago.

Tobacco use causes more preventable death and illness in the United States than any other cause of death; if no one used tobacco, the more than 400,000 tobacco-related deaths each year would not occur. As we think about tobacco, this startling statistic needs to be kept in mind: About half of all cigarette smokers will one day die from a premature death caused by a smoking-related illness (King et al., 2011). To repeat what was said just earlier, nicotine is a slow poison.

Tobacco kills in several ways. Smoking causes 80-90 percent of all lung cancers, and it greatly increases the risk of emphysema and other lung disease, coronary heart disease, and stroke. In addition to lung cancer, tobacco use also causes several other cancers, including bladder cancer, cervical cancer, esophageal cancer, stomach cancer, and throat cancer. Women who smoke are at greater risk for lower bone density and hip fracture when they get older.

The economics of tobacco use are also worth knowing. Americans spend about $\$ 90$ billion annually on tobacco products, with most of this amount spent on cigarettes (Centers for Disease Control and Prevention, 2011). They purchase more than 300 billion cigarettes annually, with most of the cigarettes sold by three companies. Cigarette smoking is estimated to cost almost $\$ 200$ billion annually in medical expenses and lost economic productivity. This works out to a national economic loss of about $\$ 10.50$ for every pack of cigarettes that is sold.

One interesting and very important fact about the economics of cigarette smoking is what happens when the cost of cigarettes is increased. Most smokers begin their deadly habit during adolescence or young adulthood. Because this is a period of their lives when they do not have much money, increases in the cost of cigarettes are particularly useful in persuading some of these young people not to buy cigarettes. Government data indicate that every 10 percent increase in the price of cigarettes reduces cigarette consumption among young people by 4 percent (Centers for Disease Control and Prevention, 2011). A similar but smaller effect occurs among older smokers.

Earlier we said that the alcohol industry plays a major role in the amount of drinking that occurs in the United States. The same is true of the tobacco industry and smoking. This industry spends about $\$ 15$ billion annually—or an average of \$41 million daily - in advertising, sponsorship of public events, and other activities to promote its deadly product, and for many years hid or distorted data about the deadly effects of cigarette smoking (Brandt, 2009). Because of funding cutbacks during the recent faltering economy, the states have reduced their media campaigns and other efforts aimed at reducing smoking. This reduction, combined with the tobacco industry's huge promotional spending, leads one public health professor to lament, "The tobacco companies are winning the battle” (Martin, 2011).

\section{Illegal Drugs}

The SAMHSA survey also gathers data from its thousands of respondents about illegal drug use. Table 7.4 
"Prevalence of Illegal Drug Use, Ages 12 and Older, 2010*” presents these data for several illegal drugs and shows that use of these drugs is far from rare.

Table 7.4 Prevalence of Illegal Drug Use, Ages 12 and Older, 2010*

\begin{tabular}{|l|l|l|l|}
\hline & Lifetime & Past year & Past month \\
\hline Any illegal drug & 47.1 & 15.3 & 8.9 \\
\hline Illegal drug other than marijuana & 30.0 & 8.1 & 3.6 \\
\hline Marijuana/hashish & 41.9 & 11.5 & 6.9 \\
\hline Cocaine/crack & 14.7 & 1.8 & 0.6 \\
\hline Hallucinogens & 14.8 & 1.8 & 0.5 \\
\hline Heroin & 1.6 & 0.2 & 0.1 \\
\hline Stimulants & 8.5 & 1.1 & 0.4 \\
\hline Nonmedical use of prescription-type drugs† & 20.4 & 6.3 & 2.7 \\
\hline * Percentage using in designated time period & & \\
\hline † Includes stimulants & & & \\
\hline
\end{tabular}

Source: Substance Abuse and Mental Health Services Administration. (2011). Results from the 2010 national survey on drug use and health: Summary of national findings. Rockville, MD: Author.

The following figure from Table 7.5 "Prevalence of Illegal Drug Use, Ages 18-20, 2010*” is striking: 47.1 percent of all Americans ages 12 and older have used an illegal drug at least once in their lifetimes. This percentage translates to almost 120 million people. In terms of lifetime use, the single most popular illegal drug is easily marijuana, but 30 percent of Americans, or 76 million people, have used an illegal drug other than marijuana. Almost 15 percent, or more than 37 million people, have used cocaine/crack or hallucinogens, and more than 20 percent, or almost 52 million people, have used prescription drugs illegally. These percentages and the numbers of people associated with them all indicate that lifetime illegal drug use in the United States is widespread.

Despite this fact, most public health experts are primarily concerned with current (past month) illegal drug use. The percentages for past-month (and also past-year) use in Table 7.5 "Prevalence of Illegal Drug Use, Ages 18-20, 2010*” are noticeably smaller than those for lifetime use. They indicate that most people who have used illegal drugs in their lifetimes are no longer using them, or at least have not used them in the past year or past month. Most of these lifetime users tried their illegal drug once, twice, or a few times and then stopped using it, and some may have used it more often but then stopped. In any event, it is the current, past-month users who raise the most concern for our society in general and for the public health and legal communities and other sectors of our society that deal with illegal drug use and its effects.

In looking at current illegal drug use, we see that 8.9 percent of the public falls into this category. This percentage translates to almost 23 million Americans, no small number by any means. Their favorite illegal drug is marijuana (and hashish), but 3.6 percent, or 9 million people, have used an illegal drug other than marijuana in the past month. These users favor prescription drugs used for nonmedical reasons. Despite the publicity that cocaine/crack 
still receives, less than 1 percent of the public has used it in the past month, and less than 2 percent has used it in the past year. These small percentages, though, still translate to 1.5 million people and 5.5 million people, respectively.

The percentages in Table 7.4 "Prevalence of Illegal Drug Use, Ages 12 and Older, 2010*” underestimate the problem of illegal drug use in at least two respects. First, the SAMHSA survey does not include people whose illegal drug use is especially high: the homeless, runaway teenagers, jail and prison inmates, and youths in detention centers. Second, and conversely, the SAMHSA survey includes people whose illegal drug use is relatively low-namely, young adolescents and people in their middle age and older years. For this reason, it is instructive to examine the prevalence of illegal drug use among the people who are in their "prime" ages for it: those who are 18-20 years old. Accordingly, Table 7.5 "Prevalence of Illegal Drug Use, Ages 18-20, 2010*” presents the appropriate figures for Americans in this age group.

Table 7.5 Prevalence of Illegal Drug Use, Ages 18-20, 2010*

\begin{tabular}{|l|l|l|l|}
\hline & Lifetime & Past year & Past month \\
\hline Any illegal drug & 52.8 & 37.7 & 23.1 \\
\hline Illegal drug other than marijuana & 31.2 & 19.1 & 8.0 \\
\hline Marijuana/hashish & 46.4 & 32.7 & 20.3 \\
\hline Cocaine/crack & 8.5 & 4.1 & 1.2 \\
\hline Hallucinogens & 14.1 & 7.9 & 2.3 \\
\hline Heroin & 1.6 & 0.5 & 0.2 \\
\hline Stimulants & 7.8 & 3.9 & 1.3 \\
\hline Nonmedical use of prescription-type drugs $\dagger$ & 24.5 & 14.5 & 5.9 \\
\hline * Percentage using in designated time period & & \\
\hline \\
† Includes stimulants & & & \\
\hline
\end{tabular}

Source: Substance Abuse and Mental Health Services Administration. (2011). Results from the 2010 national survey on drug use and health: Summary of national findings. Rockville, MD: Author.

Take a moment to compare the percentages in Table 7.5 "Prevalence of Illegal Drug Use, Ages 18-20, 2010*" for ages 18-20 to the percentages in Table 7.4 "Prevalence of Illegal Drug Use, Ages 12 and Older, 2010*” for ages 12 and older. When you do this, you will see that past-year and past-month illegal drug use is generally much higher for people ages 18-20 than for everyone 12 and older. More than one-third of the 18-20 age group have used an illegal drug in the past year, and almost one-fourth are current users, having used an illegal drug in the past month. As with the 12 and older population, their drug of choice is clearly marijuana, with nonmedical use of prescription-type drugs a distant second.

This last statement is important to keep in mind. In terms of percentages, the major illegal drug is marijuana. Very low percentages of Americans use other illegal drugs when we consider current use and past-year use, although a greater number have experimented with other illegal drugs in their lifetimes. As we have seen, however, the low 
percentages for the other illegal drugs still translate into millions of Americans who are current users of illegal drugs other than marijuana. It is also true that drugs like heroin and cocaine/crack are used more heavily in large cities than in smaller cities and towns and rural areas. Although these drugs are only rarely used nationwide, they are a particular problem in large urban areas.

With this backdrop in mind, we now discuss a few illegal drugs in further detail.

\section{Marijuana}

As we have seen, marijuana is easily the most widely used illegal drug in the United States. The percentages for marijuana use in Table 7.4 "Prevalence of Illegal Drug Use, Ages 12 and Older, 2010*” translate to 106 million people who have ever used marijuana, 29 million people who used it in the past year, and 17 million people who used it in the past month (current users). As Table 7.5 "Prevalence of Illegal Drug Use, Ages 18-20, 2010*” showed, marijuana use is especially high among young people: One-third of people ages 18-20 have used marijuana in the past year, and one-fifth are current users.

Marijuana use can cause several problems (National Institute on Drug Abuse, 2010). Marijuana distorts perception, impairs coordination, and can cause short-term memory loss, and people who are high from marijuana may be unable to safely drive a motor vehicle or operate machinery. In addition, regular pot smokers are at risk for respiratory problems, though not lung cancer. Chronic marijuana use is also associated with absence from school and the workplace and with social relationship problems, although it is difficult to determine whether marijuana is causing these effects or whether the association exists because someone with personal problems begins using marijuana regularly.

Despite these problems, marijuana is almost certainly the most benign illegal drug in terms of health and social consequences, and it is also much more benign than either alcohol or tobacco (Drug Policy Alliance, 2011; Faupel et al., 2010). As noted earlier, these latter two drugs kill about 520,000 Americans annually. In contrast, marijuana has probably never killed anyone, and its use has not been associated with any cancers. Alcohol use is a risk factor for violent behavior, but marijuana use is a risk factor for mellow behavior; if everyone who now uses alcohol instead smoked marijuana, our violent crime rate would probably drop significantly! Despite some popular beliefs, marijuana is generally not physiologically addictive, it does not reduce ambition and motivation, and it does not act as a "gateway drug" that leads to the use of more dangerous drugs (Hanson, Venturelli, \& Fleckenstein, 2012). A review of the evidence on marijuana summarized research findings as follows: "Studies of long-term marijuana smokers do not produce gross or major clinical, psychiatric, psychological, or social difference between users and nonusers, or between heavier and lighter users” (Goode, 2008, p. 247).

While not entirely safe, then, marijuana is much safer, both on an individual basis and on a societal basis, than either alcohol or tobacco. Even so, it remains an illegal drug. This fact underscores our earlier observation that the legality or illegality of drugs has no logical basis. If the personal and social harm caused by a drug determined whether it is legal or not, then it would be logical for marijuana to be legal and for alcohol or tobacco to be illegal.

For better or worse, though, the millions of marijuana users have broken the law. In most states, marijuana possession is a crime punishable by a jail or prison term that depends on the amount of marijuana involved. Fourteen states (Alaska, California, Colorado, Connecticut, Maine, Massachusetts, Minnesota, Mississippi, 
Nebraska, Nevada, New York, North Carolina, Ohio, Oregon) have decriminalized simple possession of small amounts of marijuana: They treat possession as a minor offense similar to a traffic violation and punish it with only a small fine. Most of these states decriminalized the drug in the 1970s after a national commission with members appointed by the US Congress and by President Richard Nixon recommended taking this action. There is no evidence that marijuana use in these states increased compared to use in the states that have not decriminalized marijuana (Beckett \& Herbert, 2008). In fact, marijuana use in the nation declined sharply in the 1980s, the first decade after decriminalization began, both in the states that decriminalized pot possession and in the states that did not decriminalize it.

\section{Cocaine}

Cocaine produces a high that is considered more pleasurable than that for any other drug. According to sociologist Erich Goode (2008, p. 288), “Cocaine’s principal effects are exhilaration, elation, and euphoria-voluptuous, joyous feelings accompanied by a sense of grandiosity.” As a stimulant, cocaine also increases energy, alertness, and a sense of self-confidence. It is not physiologically addictive, but it is considered psychologically addictive: The high it produces is so pleasurable that some users find they need to keep using it.

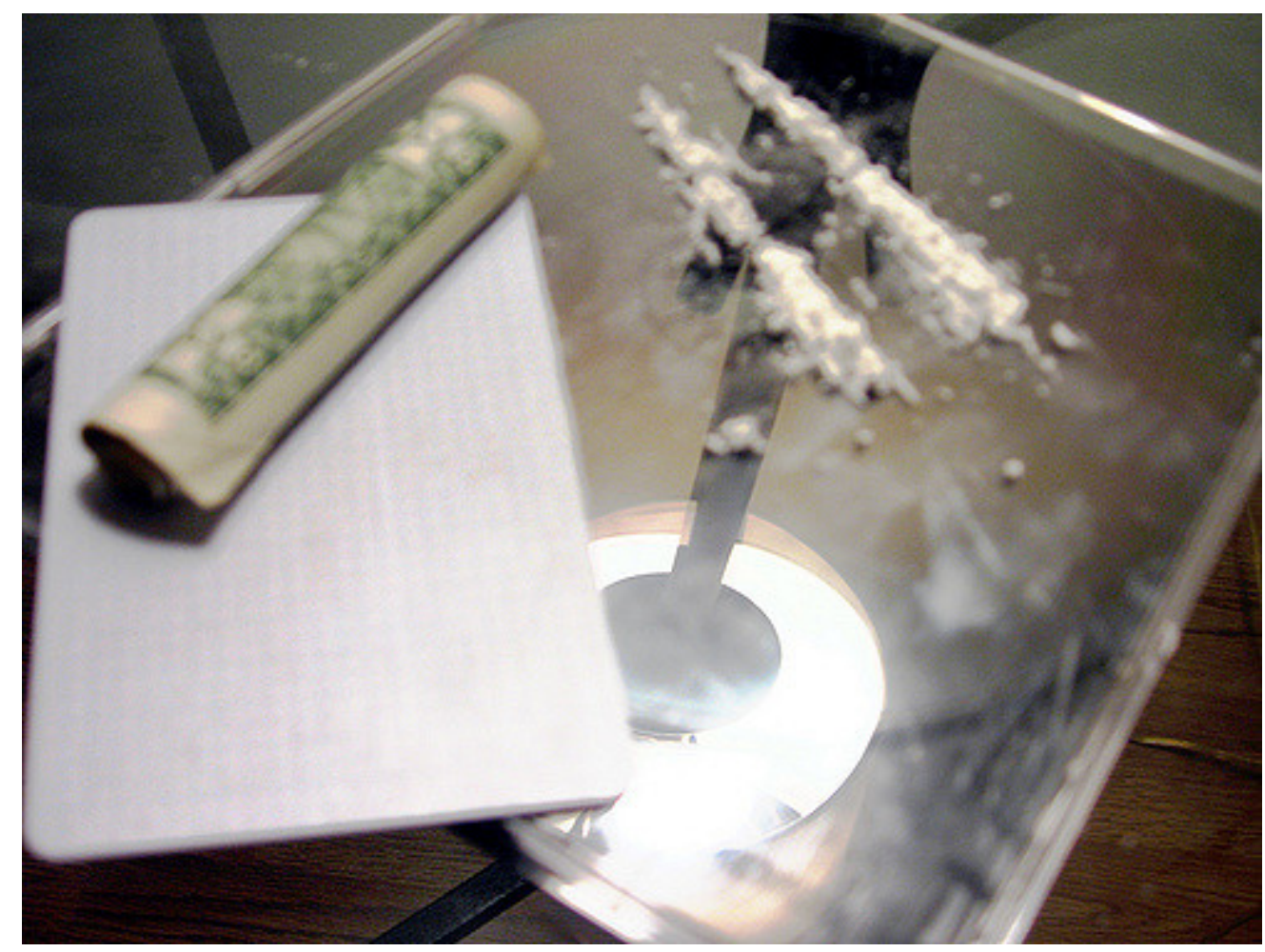

Cocaine is a particularly addictive drug because of the high degree of pleasurable feelings it causes.

Nightlife of Revelry - $\underline{\text { Cocaine }}$ - CC BY 2.0.

Cocaine is made from coca plants grown in South America. It most often appears in a powdered form that is sniffed (or, to use the more common term for this method, snorted). The high it produces takes some time to occur but may last up to thirty minutes once it does arrive. A more potent form, crack cocaine (or, more commonly, 
crack), is made by heating a mixture of powdered cocaine, baking soda, and water. A user then heats the mixture that remains and breathes in the vapors that result. Crack produces an immediate, intense high and is a relatively inexpensive drug. These features made crack a very popular drug when it was first introduced into US cities in the 1980s (Faupel et al. 2010). Street gangs fought each other to control its distribution and sale, much as organized crime gangs fought each other over alcohol distribution and sale during Prohibition.

Cocaine and crack use has declined since the 1970s and 1980s, but, as Table 7.5 "Prevalence of Illegal Drug Use, Ages 18-20, 2010*” showed, almost 15 percent of the public has used cocaine at least once; this number translates to some 37 million Americans. Still, past-year use is only 1.8 percent, and past-month (current) use is only 0.6 percent. Cocaine use thus must be considered rare in percentage terms. At the same time, these percentages translate to 4.5 million and 1.5 million Americans, respectively. These are not small numbers. Moreover, past-year and past-month cocaine use is higher among young people, as Table 7.5 "Prevalence of Illegal Drug Use, Ages

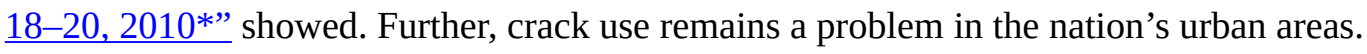

In terms of health risks, cocaine is a much more dangerous drug than marijuana. As a stimulant, cocaine speeds up the central nervous system. Because it does so much more intensely than most other stimulants, its use poses special dangers for the cardiovascular system (National Institute on Drug Abuse, 2011). In particular, it can disrupt the heart's normal rhythm and cause ventricular fibrillations, and it can speed up the heart and raise blood pressure. An overdose of cocaine can thus be deadly, and long-term use produces an increased risk of stroke, seizure, and heart disease. Because cocaine also constricts blood vessels in the brain, long-term use raises the risk of attention deficit, memory loss, and other cognitive problems. Long-term abuse has also caused panic attacks, paranoia, and even psychosis.

\section{Heroin}

Heroin is derived from opium (and more immediately from morphine, an opium derivative) and is almost certainly the most notorious opiate. It was one of the popular opiate drugs that, as discussed earlier, were used so widely during the late nineteenth century. Heroin was first marketed as a painkiller and cough suppressant by the company that makes Bayer aspirin. As the United States became more concerned about opium use, Bayer Laboratories discontinued heroin marketing in 1910, and heroin, like other opiates, was banned under the 1914 Harrison Narcotic Act.

Although Table 7.4 "Prevalence of Illegal Drug Use, Ages 12 and Older, 2010*” shows that its use is minuscule in percentage terms, these percentages translate to 600,000 people who have used heroin in the past year, and 240,000 who have used in the past month. Because these users are concentrated in the nation's large cities, heroin, like crack, is a special problem for these areas.

Like other narcotics, heroin use produces a feeling of euphoria. After it is injected, "the user feels a flash, a rush, which has been described as an intense, voluptuous, orgasmlike sensation. Following this is the feeling of wellbeing, tranquility, ease, and calm, the sensation that everything in the user's life is just fine. Tensions, worries, problems, the rough edges of life-all seem simply to melt away” (Goode, 2008, pp. 308-309).

Although heroin use is uncommon, it continues to capture the public's concern more than perhaps any other illegal drug. As sociologist Goode (2008, pp. 307-308) has observed, 
For decades, it was the most feared, the most dreaded, the "hardest" drug; heroin has virtually defined the drug problem. In spite of being somewhat overshadowed since the mid-1980s by cocaine, and specifically crack, heroin probably remains the single substance the American public is most likely to point to as an example of a dangerous drug. Until recently, disapproval of any level of heroin use was greater than for any other drug. And, until recently, heroin addicts were the most stigmatized of all drug users. Heroin is the epitome of the illicit street drug. Its association in the public mind with street crime, even today, is probably stronger than for any other drug. The stereotype of the junkie is that he or she is by nature a lowlife, an outcast, a "deviant," a dweller in the underworld, an unsavory, untrustworthy character to be avoided at any cost.

Users typically take heroin into their body by injecting it into a vein. This mode of administration is undoubtedly a major reason for the public's very negative image of heroin users. Indeed, the image of a heroin addict "shooting up" is one that has appeared in many movies and television shows past and present. Many heroin addicts share their needles, a practice that increases their risk of contracting HIV and hepatitis.

The public's image and concern about heroin is partly deserved in some ways and partly undeserved in other ways. Like other opiates, heroin is extremely physiologically addictive, although not as addictive as nicotine. But also like other opiates, heroin does not damage body organs. The emaciated look we often associate with heroin users stems not from the drug itself but from the low-caliber lifestyles that heroin addicts tend to live and their decisions to spend the little money they have on heroin rather than on food and a healthier lifestyle. An overdose of heroin can certainly kill, just as overdoses of other drugs can kill. One reason heroin overdoses occur is that heroin users cannot know for sure the purity of the heroin they buy illegally and thus may inject an unsafe dose to get high.

\section{Prescription Drug Abuse}

Table 7.4 "Prevalence of Illegal Drug Use, Ages 12 and Older, 2010*" showed that about one-fifth of Americans have used prescription drugs for nonmedical purposes. This type of use is illegal. It constitutes the most widespread illegal drug use other than marijuana use and has grown in recent years, especially among adolescents. The prescription drugs that are most often abused are those containing narcotics, tranquilizers, and stimulants; two of the most common brands that are abused are OxyContin and Vicodin. Because prescription drugs are beneficial for so many people even if they are abused, our nation faces a special difficulty in dealing with the abuse of these drugs. As the head of the National Institute on Drug Abuse explains, "The challenges we face are much more complex because we need to address the needs of patients in pain, while protecting those at risk for substance use disorders” (Zuger, 2011, p. D1). Thus according to a news report, “These drugs must be somehow legal and illegal, encouraged yet discouraged, tightly regulated yet easily available” (Zuger, 2011, p. D1). 


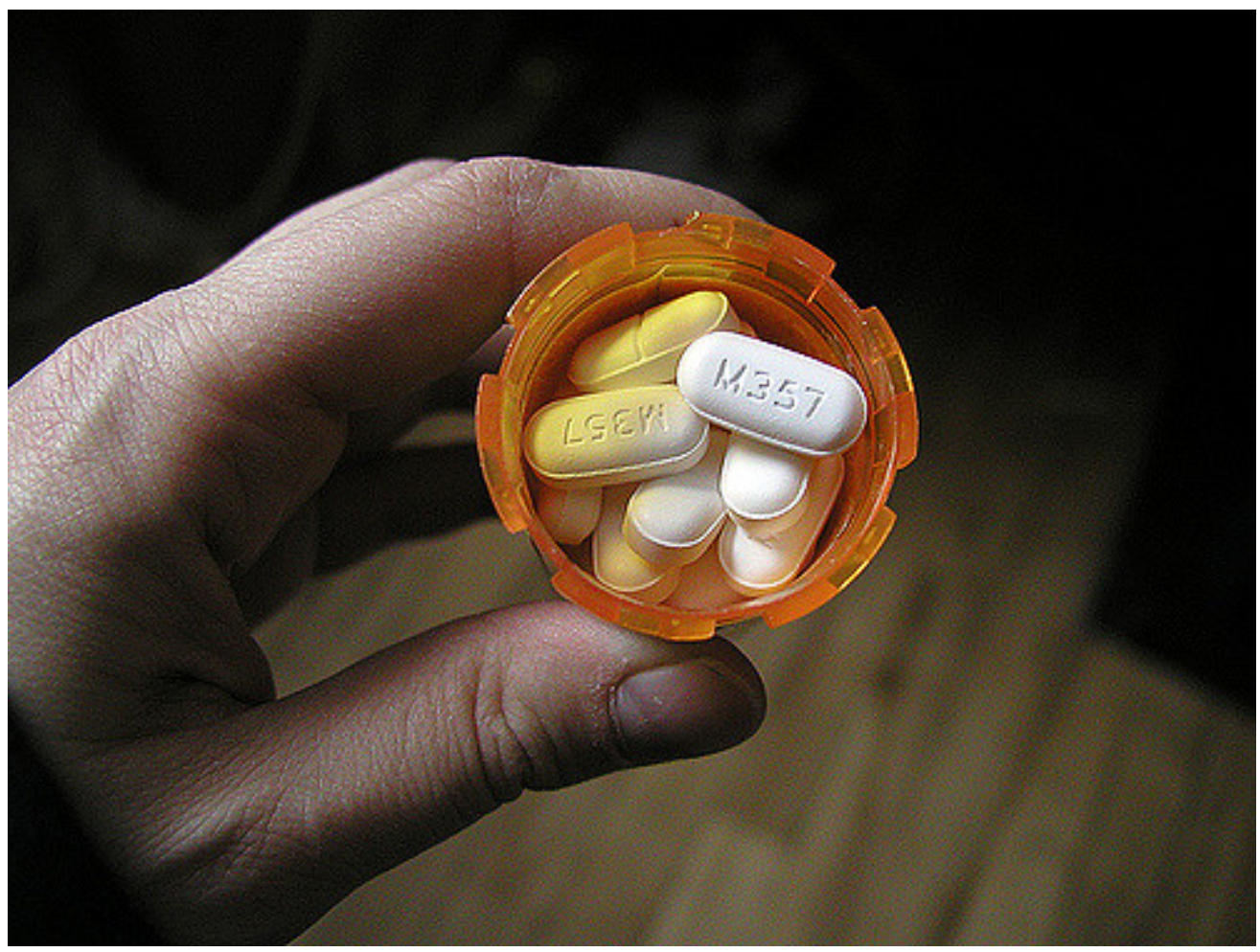

Many prescription drug abusers use drugs obtained from their own prescriptions or from prescriptions of friends or relatives.

sharyn morrow - the husband's vicodin - CC BY-NC-ND 2.0.

Most prescription drug abusers have their own prescriptions or obtain their drugs from friends, acquaintances, or relatives who have their own prescriptions. Whatever the source, some of these prescriptions are obtained legitimately — for actual medical conditions — and then abused, and some are obtained after feigning a medical condition. Many experts fault physicians for overprescribing painkillers and other prescription drugs.

Prescription drug abuse is thought to be growing for two reasons (National Institute on Drug Abuse, 2005). First, physicians' prescriptions for painkillers and other drugs continue to rise, creating a greater supply of prescription drugs that can be abused. Second, online pharmacies and pain clinics have made it easier to obtain prescription drugs, with or without an actual prescription.

The Note 7.14 “Applying Social Research” box discusses the roots of adolescent prescription drug abuse in family and school factors. The importance of these factors reinforces the sociological view that the origins of drug use often lie beyond the individual and in the social environment.

\section{Applying Social Research}

\section{Prescription Drug Abuse by Adolescents}

Despite the importance of prescription drug abuse, social science research on its causes is relatively sparse. In one of the first studies to examine the social origins of adolescent prescription drug abuse, sociologist Jason A. Ford analyzed data on adolescents in the national survey conducted by the Substance Abuse and Mental Health Services Administration that is discussed elsewhere in this chapter. Drawing on the large body of work that attributes drug use in part to weak 
social bonds, Ford reasoned that prescription drug abuse should be higher among adolescents who have weaker bonds to their parents and also weaker bonds to their schools.

For his measure of parental bonds, Ford used several questions that asked adolescents about their relationship with their parents, including whether parents feel proud of them and praise them for doing a good job, and whether their parents help them with their homework and limit their time out with friends on a school night. For his measure of school bonds, he used several questions that asked adolescents such things as whether they liked going to school and whether they found their schooling meaningful and important. His measure of prescription drug abuse relied on the adolescents' selfreports of whether they had used any prescription drug for nonmedical purposes in the past year.

Controlling for gender, race, and other factors, Ford found support for his hypotheses: prescription drug abuse was higher among adolescents with weaker bonds to their parents and also weaker bonds to their schools.

These results have important implications for efforts to reduce prescription drug abuse by adolescents. They suggest that efforts by our society to strengthen families and to improve our schools may well have a significant, beneficial sideeffect: lower prescription drug abuse by adolescents.

Source: Ford, 2009

\section{Key Takeaways}

- The distinction between legal drugs and illegal drugs has no logical basis; legal drugs cause much more harm than illegal drugs.

- Alcohol and tobacco kill more than 500,000 Americans annually. Binge drinking on campuses results in accidents and assaults involving several hundred thousand college students annually.

- Marijuana is by far the most commonly used illegal drug. The low prevalence of other illegal drugs still amounts to millions of people using these drugs annually.

\section{For Your Review}

1. Do you agree or disagree that the distinction between legal drugs and illegal drugs is not logical? Explain your answer.

2. Do you agree that binge drinking is a problem that campuses should address, or do you think that it's a relatively harmless activity that lets students have some fun? Explain your answer.

\section{References}

Alateen. (2011). Am I a peacemaker or a creator of chaos. Alateen Talk. Retrieved from http[0]://www.alanon.org/alateen-talk.

American Academy of Child and Adolescent Psychiatry. (2006). Children of alcoholics. Retrieved October 4, 2011, from http://www.aacap.org/galleries/FactsForFamilies/17 children of alchoholics.pdf. 
American Medical Association. (2004). Alcohol industry 101: Its structure \& organization. Chicago, IL: Author.

Beckett, K., \& Herbert, S. (2008). The consequences and costs of marijuana prohibition. Seattle, WA: American Civil Liberties Union of Washington State.

Brandt, A. (2009). The cigarette century: The rise, fall, and deadly persistence of the product that defined America. New York, NY: Basic Books.

Center for Science in the Public Interest. (2008). Binge drinking on college campuses. Retrieved September 20, 2011, from http://www.cspinet.org/booze/collfact1.htm.

Centers for Disease Control and Prevention. (2011). Economic facts about US tobacco production and use. Retrieved September 20, 2011, from http://www.cdc.gov/tobacco/data statistics/fact sheets/economics/ econ facts/.

Distilled Spirits Council of the United States. (2011). Economic contribution of alcohol beverage industry. Retrieved September 19, 2011, from http://www.discus.org/pdf/ATT2 Economic Contribution.pdf.

Drug Policy Alliance. (2011). Marijuana facts. Retrieved September 22, 2011, from http://www.drugpolicy.org/ facts/drug-facts/marijuana-facts.

Faupel, C. E., Horowitz, A. M., \& Weaver., G. S. (2010). The sociology of American drug use. New York, NY: Oxford University Press.

Felson, R. B., Teasdale, B., \& Burchfield, K. B. (2008). The influence of being under the influence. Journal of Research in Crime \& Delinquency, 45(2), 119-141.

Ford, J. A. (2009). Nonmedical Prescription Drug Use Among Adolescents: The Influence of Bonds to Family and School. Youth \& Society, 40(3), 336-352.

Frech, E. J., \& Go, M. F. (2009). Treatment and Chemoprevention of NSAID-associated Gastrointestinal Complications. Therapeutics and Clinical Risk Management, 5, 65-73.

Gardner, A. (2010, May 3). Report: Alcohol Companies go online to lure young drinkers. USA Today. Retrieved from http://www.usatoday.com/news/health/index.

Goode, E. (2008). Drugs in American society (7th ed.). New York, NY: McGraw Hill.

Hanson, G. R., Venturelli, P. J., \& Fleckenstein, A. E. (2012). Drugs and society (11th ed.). Burlington, MA: Jones \& Bartlett.

Harvard School of Public Health. (2012). Alcohol: Balancing risks and benefits. Retrieved March 30, 2012, from http://www.hsph.harvard.edu/nutritionsource/what-should-you-eat/alcohol-full-story/index.html.

James, S. D. (2008, September 10). Children of alcoholics forced into adulthood. abcnews.com. Retrieved from http://abcnews.go.com/Health/story?id=5770753\&page=5770751.

Jernigan, D. H. (2009). The global alcohol industry: An overview [Supplmental material]. Addiction, 104, 6-12. 
King, B., Dube, S., Kaufmann, R., Shaw, L., \& Pechacek, T. (2011). Vital signs: Current cigarette smoking among adults aged $\geq 18$ years-United States, 2005-2010. Morbidity and Mortality Weekly Report, 60(35), 1207-1212.

Kleiman, M. A. R., Caulkins, J. P., \& Hawken, A. (2011). Drugs and drug policy: What everyone needs to know. New York, NY: Oxford University Press.

Martin, T. W. (2011, September 6). Fewer Americans are smoking, and those who do puff less. The Wall Street Journal. Retrieved from http://blogs.wsj.com/health/2011/2009/2006/fewer-americans-are-smoking-andthose-who-do-puff-less/.

Mokdad, A. H., Marks, J. S., Stroup, D. F., \& Gerberding, J. L. (2004). Actual causes of death in the United States, 2000. Journal of the American Medical Association, 291(10), 1238-1245.

National Center on Addiction and Substance Abuse. (2007). Wasting the best and the brightest: Substance abuse at America's colleges and universities. New York, NY: Author.

National Institute on Drug Abuse. (2005). Prescription drugs: Abuse and addiction. Washington, DC: Author.

National Institute on Drug Abuse. (2010). InfoFacts: Marijuana. Retrieved September 22, 2011, from http://www.nida.nih.gov/infofacts/marijuana.html.

National Institute on Drug Abuse. (2011). Cocaine: Abuse and addiction. Retrieved September 27, 2011, from http://www.nida.nih.gov/researchreports/cocaine/effects.html.

National Institutes of Health. (2011). NIH study finds hospitalizations increase for alcohol and drug overdoses. Retrieved September 21, 2011, from http://www.nih.gov/news/health/sep2011/niaaa-20.htm.

Smith, A. (2011, June 9). Alcohol Sales Thrive in Hard Times. CNN. Retrieved from http://money.cnn.com.

Substance Abuse and Mental Health Services Administration. (2008). Underage alcohol use among full-time college students. Retrieved September 20, 2011, from http://oas.samhsa.gov/2k6/college/collegeUnderage.htm.

US Department of Agriculture. (2011). Food CPI and expenditures: Table 1. Retrieved September 19, 2011, from http://www.ers.usda.gov/Briefing/CPIFoodAndExpenditures/Data/Expenditures tables/table1.htm.

Zuger, A. (2011, June 14). A general in the drug war. New York Times. p. D1. 


\subsection{Social Patterning of Drug Use}

\section{Learning Objectives}

1. Outline the nature of gender differences in drug use.

2. Understand whether racial and ethnic differences in drug use exist.

3. Explain whether education and religiosity are related to drug use.

It is a sociological truism that our sociodemographic backgrounds-gender, race and ethnicity, social class, and so forth-influence many of our behaviors and attitudes. Drug use is no different. By examining the social patterning of drug use, we can see which kinds of people, in terms of their sociodemographic backgrounds, are more or less at risk for using drugs. And by understanding these sociodemographic differences, we begin to understand why some people are more likely than others to use drugs. Our examination of these differences will rely heavily on data from the SAMHSA survey discussed earlier and focus on past-month differences in alcohol, tobacco, and illegal drug use (all illegal drugs combined).

\section{Gender}

In the study of crime and deviance, gender is an important predictor: Males are more likely than females to commit the more serious forms of crime and deviance, such as homicide, robbery, and burglary. This pattern generally holds true for drug use of various types. Figure 7.2 "Gender and Prevalence of Alcohol, Tobacco, and Illegal Drug Use, Ages 26 and Older, 2010 (Percentage Using in Past Month)” shows that men are more likely than women to use alcohol, tobacco, and illegal drugs. In related data, men are also more than twice as likely as women to engage in binge drinking (30.7 percent compared to 13.8 percent) and heavy drinking (9.7 percent compared to 2.8 percent) as defined earlier.

Figure 7.2 Gender and Prevalence of Alcohol, Tobacco, and Illegal Drug Use, Ages 26 and Older, 2010 (Percentage Using in Past Month) 


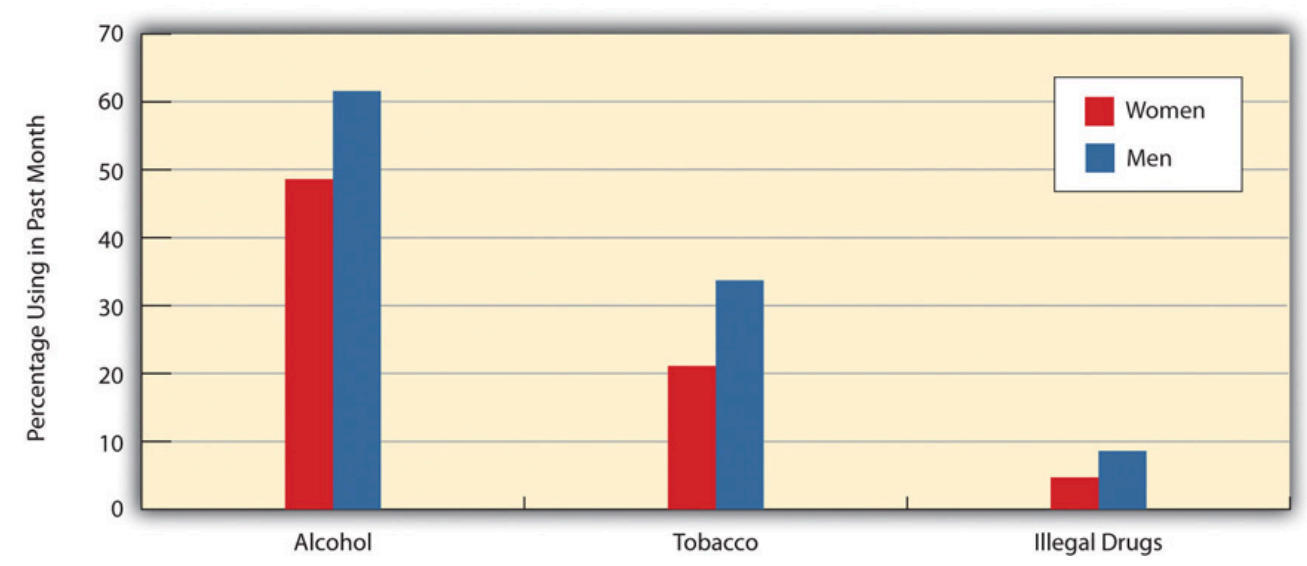

Source: Substance Abuse and Mental Health Services Administration. (2011). Results from the 2010 national survey on drug use and health: Summary of national findings. Rockville, MD: Author.

Why do these gender differences exist? A common thread underlines gender differences in criminal behavior and in drug use of various kinds, and that is masculinity (Lindsey, 2011). Compared to girls, boys are raised to be more active, assertive, and daring, and to be less concerned about the effects of their behavior on others. As they grow older, these traits make them more likely to use drugs and also to commit various types of crimes. Ironically, the way that most parents raise their sons helps make their sons more likely than their daughters to drink, smoke, and use illegal drugs once they reach adolescence and in the many decades of their adulthood.

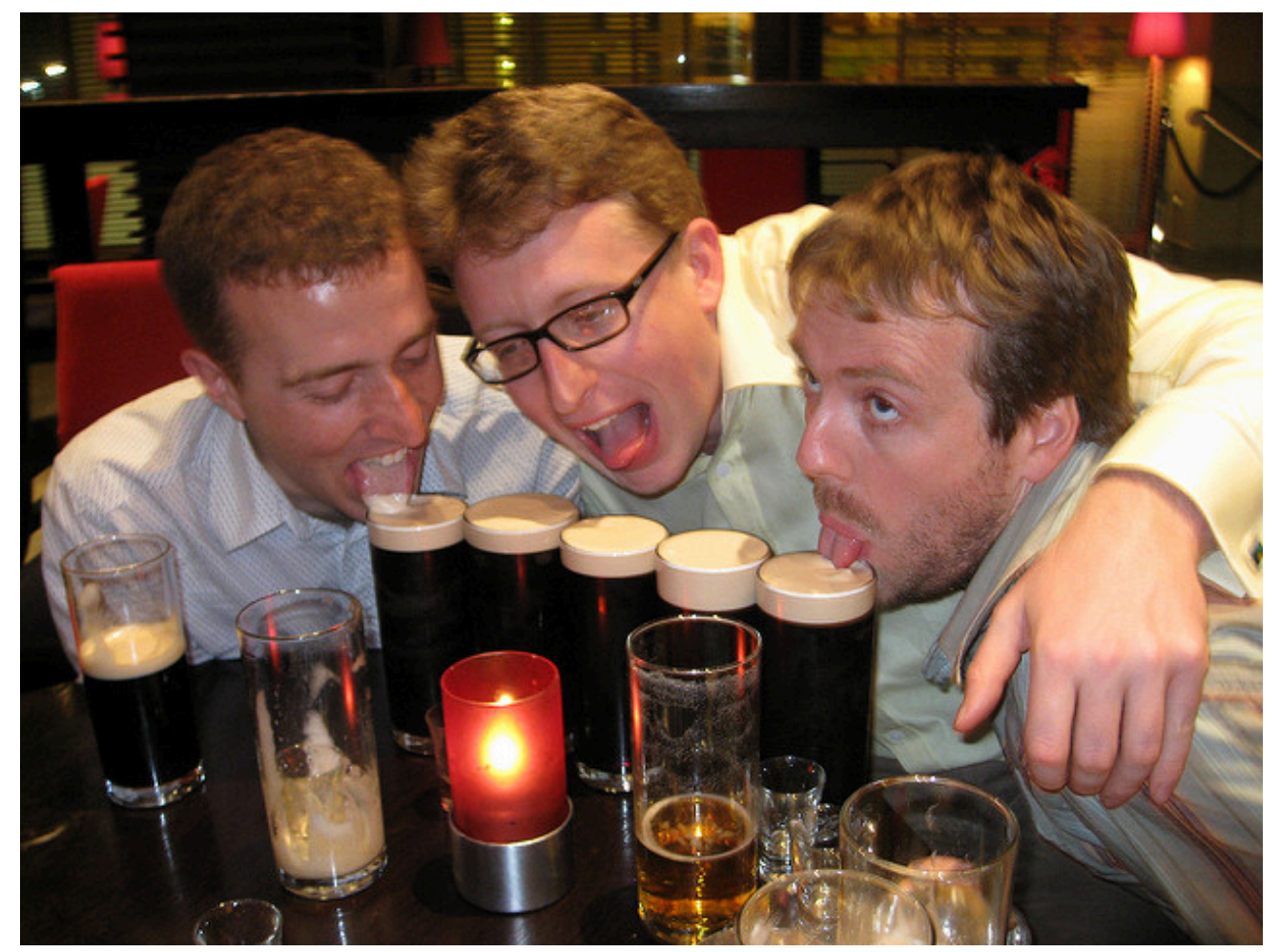

On the average, males drink alcohol more often and more heavily than females, and they are also more likely to use other types of drugs. 
In an important exception to the general gender difference just discussed, females are more likely than males to use prescription drugs for nonmedical reasons (Ford, 2009). The reasons for this counterintuitive finding are unclear, but scholars speculate that because girls and women obtain more prescription drugs than do boys and men, their greater nonmedical use of prescription drugs reflects the fact that they have more access to these drugs in the first place.

\section{Race and Ethnicity}

Racial and ethnic differences in drug use of various types exist to some extent but are less clear-cut than the gender differences we just examined (see Figure 7.3 "Race/Ethnicity and Prevalence of Alcohol, Tobacco, and Illegal Drug Use, Ages 26 and Older, 2010 (Percentage Using in Past Month)”). For alcohol use, whites have the highest rate of drinking, and Native Americans, despite the popular image that they have alcohol problems, have the lowest rate. For tobacco use, Native Americans have the highest rate of use, and Asians have the lowest rate. For illegal drugs, Native Americans again have the highest rate of use, and Hispanics have the lowest rate. Note that African Americans have roughly the same illegal drug use rate as whites, and have lower rates of alcohol and tobacco use than whites do. Although many people believe that African Americans are more likely than whites to use drugs, research data show that this belief is a myth.

Figure 7.3 Race/Ethnicity and Prevalence of Alcohol, Tobacco, and Illegal Drug Use, Ages 26 and Older, 2010 (Percentage Using in Past Month)

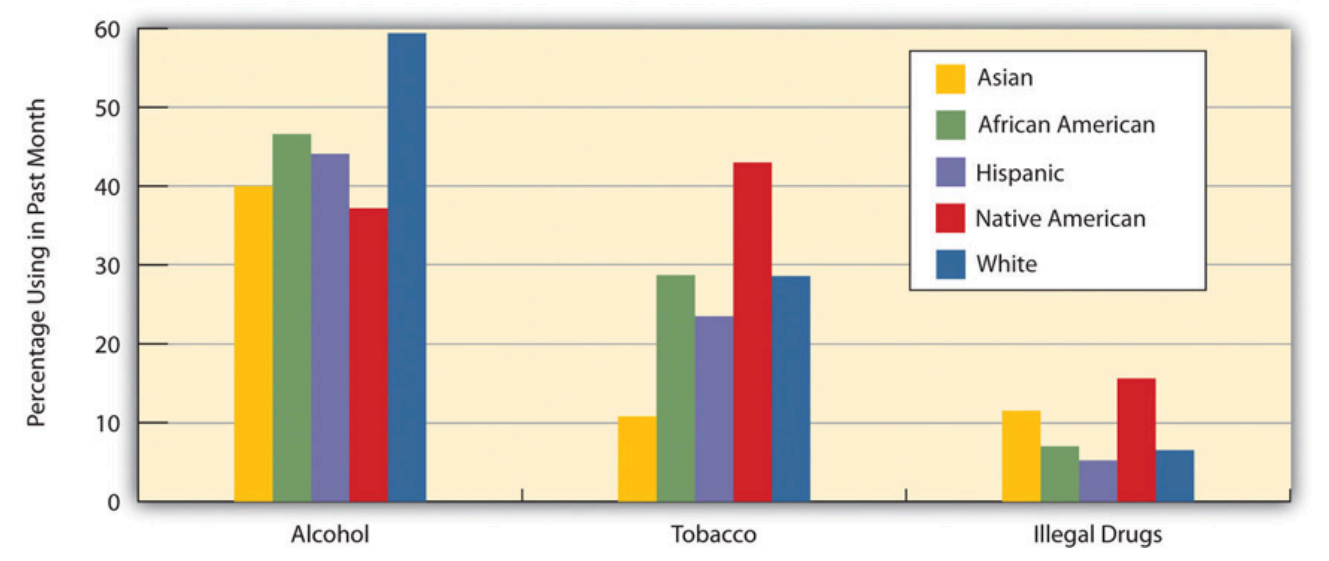

Source: Substance Abuse and Mental Health Services Administration. (2011). Results from the 2010 national survey on drug use and health: Summary of national findings. Rockville, MD: Author.

The illegal drugs category includes many types of drugs. We do not have space to illustrate racial/ethnic differences in the use of each of these drugs, but we will examine differences in marijuana and cocaine (including crack) use. Figure 7.4 "Race/Ethnicity and Prevalence of Marijuana and Cocaine Use, Ages 26 and Older, 2010 (Percentage Using in Lifetime)" shows these differences for lifetime use. Despite some minor differences, African Americans, Native Americans, and whites have the highest lifetime use of marijuana, while Asians and Hispanics have the lowest use. Turning to cocaine, Native Americans have the highest lifetime use, and Asians have the lowest use. Note again that African Americans have a lower rate of lifetime use than whites; this racial difference 
will be relevant for our discussion toward the end of the chapter of the racial impact of the legal war on drugs since the 1970s.

Figure 7.4 Race/Ethnicity and Prevalence of Marijuana and Cocaine Use, Ages 26 and Older, 2010 (Percentage Using in Lifetime)

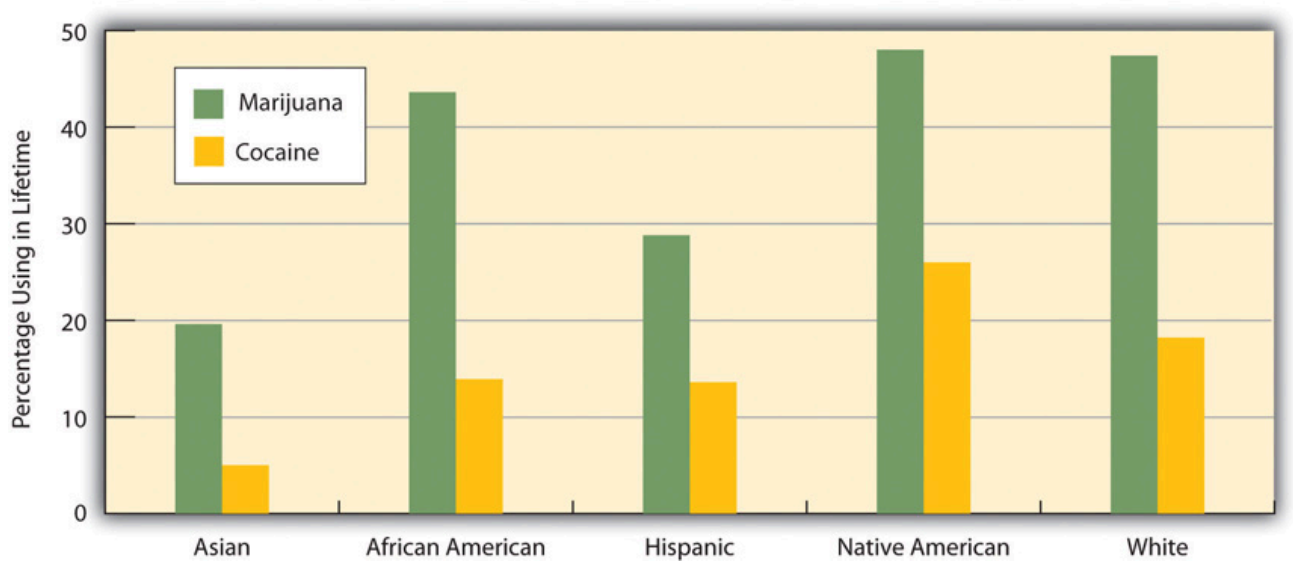

Source: Substance Abuse and Mental Health Services Administration. (2011). Results from the 2010 national survey on drug use and health: Summary of national findings. Rockville, MD: Author.

\section{Education}

Education differences in drug use depend on the type of drug (see Figure 7.5 "Education and Prevalence of Alcohol, Tobacco, and Illegal Drug Use, Ages 26 and Older, 2010 (Percentage Using in Past Month)”). For alcohol, higher levels of education are associated with a higher likelihood of drinking. One possible reason for this association is that people with lower levels of education are more likely to be religious, and people who are religious are less likely to drink. For tobacco, higher levels of education are associated with lower levels of tobacco use. In particular, college graduates are much less likely to use tobacco than people without a college degree. For illegal drugs, there is no clear association between education and use of these drugs, although college graduates report the lowest past-month use.

Figure 7.5 Education and Prevalence of Alcohol, Tobacco, and Illegal Drug Use, Ages 26 and Older, 2010 (Percentage Using in Past Month)

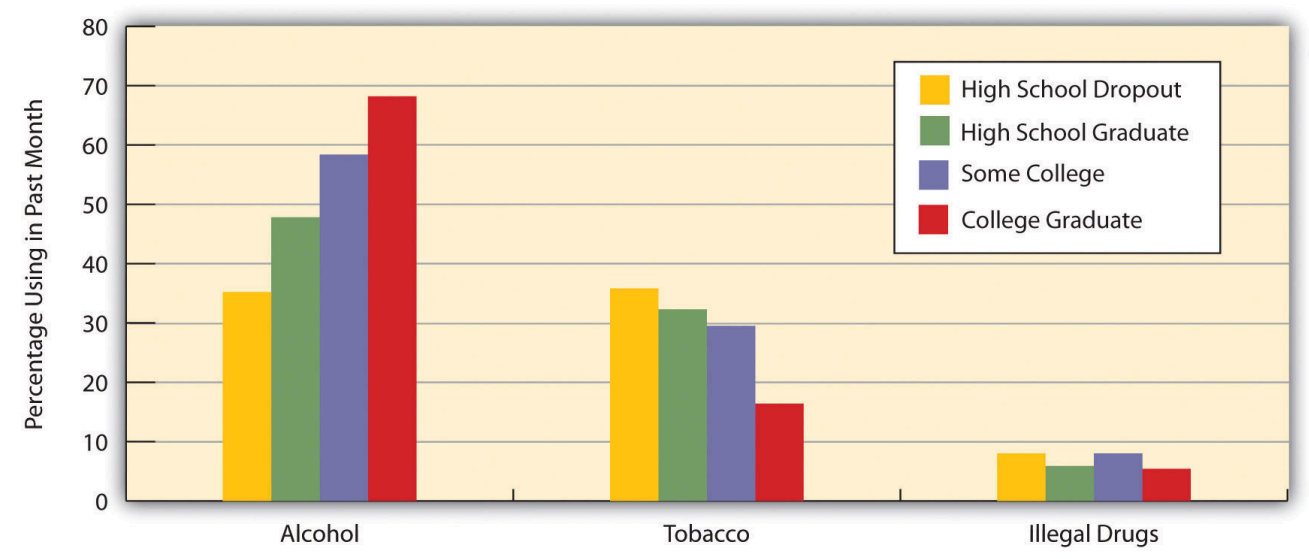


Source: Substance Abuse and Mental Health Services Administration. (2011). Results from the 2010 national survey on drug use and health: Summary of national findings. Rockville, MD: Author.

\section{Region of Country}

The regions of the United States differ in many attitudes and behaviors, and one of these behaviors is drug use (see Figure 7.6 "Region of Country and Prevalence of Alcohol, Tobacco, and Illegal Drug Use, Ages 26 and Older, 2010 (Percentage Using in Past Month)”). The regional differences are not large, but the South has lowest rate of alcohol use, in part reflecting the fact that it is the most religious region in the nation. The South and Midwest have the highest rates of tobacco use, while the West has the lowest rate, befitting its image as a "healthy" region. However, the West also has the highest rate of illegal drug use, although its use is only slightly higher than the other regions' use.

Figure 7.6 Region of Country and Prevalence of Alcohol, Tobacco, and Illegal Drug Use, Ages 26 and Older, 2010 (Percentage Using

in Past Month)

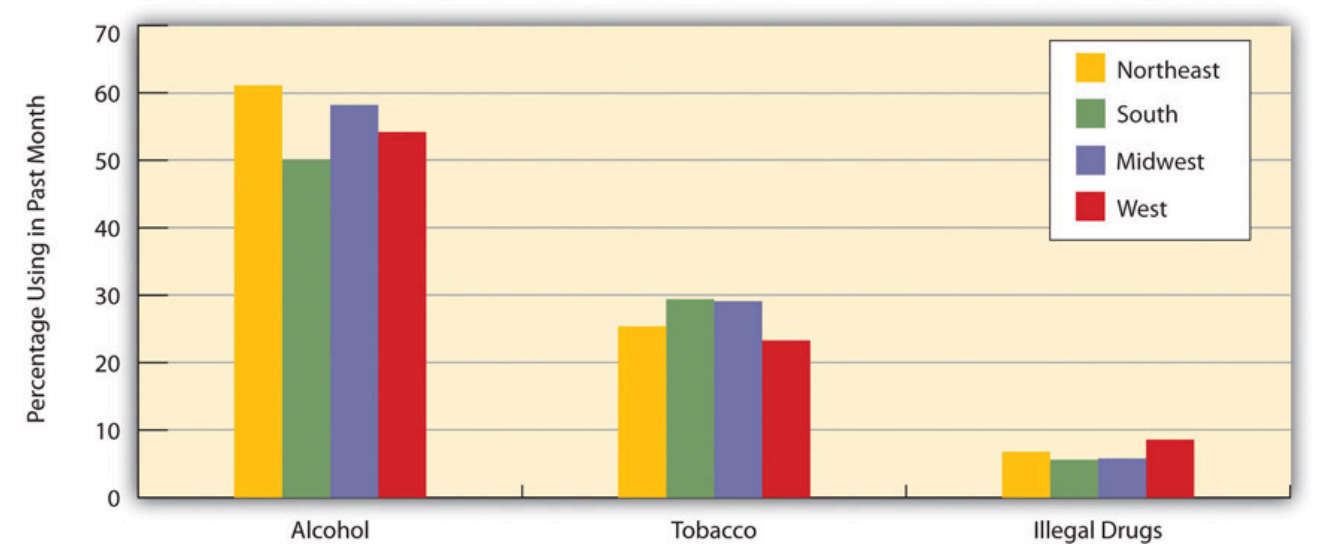

Source: Substance Abuse and Mental Health Services Administration. (2011). Results from the 2010 national survey on drug use and health: Summary of national findings. Rockville, MD: Author.

\section{Religiosity}

A growing number of studies finds that religiosity—how religious someone is — affects how often people use various drugs: The more religious people are, the lower their drug use; conversely, the less religious they are, the higher their drug use (Desmond, Soper, \& Purpura, 2009). We can see evidence of this relationship in Figure 7.7 "Religiosity and Drinking among Youths Ages 17-18 (Percentage Saying They Drank Alcohol on Only 0-2 Days in the Past Year)", which presents data for a nationwide sample of youths ages 17-18. Those who say religion is important in their lives report less drinking (i.e., on only 0-2 days in the past year) than those who say religion is unimportant in their lives. 


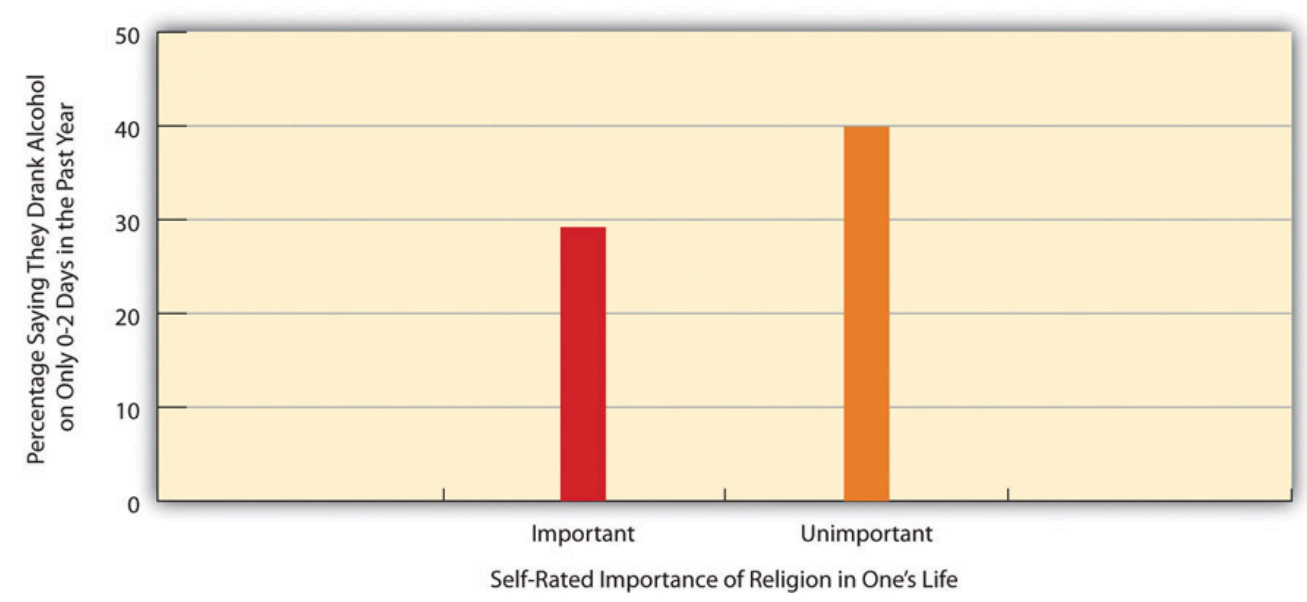

Source: National Longitudinal Study of Adolescent Health, Wave I. (2012). Retrieved from http://www.icpsr.umich.edu/cgi-bin/ SDA/DSDR/hsda?dsdr+21600-0001.

\section{Key Takeaways}

- Drug use is socially patterned: Aspects of our sociodemographic backgrounds affect our likelihood of using various drugs.

- Perhaps the clearest social pattern involves gender, with males more likely than females to use and abuse alcohol, tobacco, and illegal drugs.

- Despite common beliefs, the rate of illegal drug use is lower for African Americans than for whites.

\section{For Your Review}

1. The text discusses five social patterns of drug use: gender, race/ethnicity, education, region of country, and religiosity. Taking into account these five sets of patterns, write a short essay in which you use this information to understand your own level of use (or nonuse) of alcohol, tobacco, and illegal drugs.

2. Did it surprise you to read that illegal drug use is lower among African Americans than among whites? Why or why not?

\section{References}

Desmond, S. A., Soper, S. E., \& Purpura, D. J. (2009). Religiosity, moral beliefs, and delinquency: Does the effect of religiosity on delinquency depend on moral beliefs? Sociological Spectrum, 29, 51-71.

Ford, J. A. (2009). Nonmedical prescription drug use among adolescents: The influence of bonds to family and school. Youth \& Society, 40(3), 336-352. 
299 Social Problems

Lindsey, L. L. (2011). Gender roles: A sociological perspective (5th ed.). Upper Saddle River, NJ: Prentice Hall. 


\subsection{Explaining Drug Use}

\section{Learning Objectives}

1. Understand the possible biological origins of drug addiction.

2. Explain why longitudinal research on personality traits and drug use is important.

3. Outline the aspects of the social environment that may influence drug use.

To know how to reduce drug use, we must first know what explains it. The major explanations for drug use come from the fields of biology, psychology, and sociology.

\section{Biological Explanations}

In looking at drug use, the field of biology focuses on two related major questions. First, how and why do drugs affect a person's behavior, mood, perception, and other qualities? Second, what biological factors explain why some people are more likely than others to use drugs?

Regarding the first question, the field of biology has an excellent understanding of how drugs work. The details of this understanding are beyond the scope of this chapter, but they involve how drugs affect areas in the brain and the neurotransmitters that cause a particular drug's effects. For example, cocaine produces euphoria and other positive emotions in part because it first produces an accumulation of dopamine, a neurotransmitter linked to feelings of pleasure and enjoyment. 


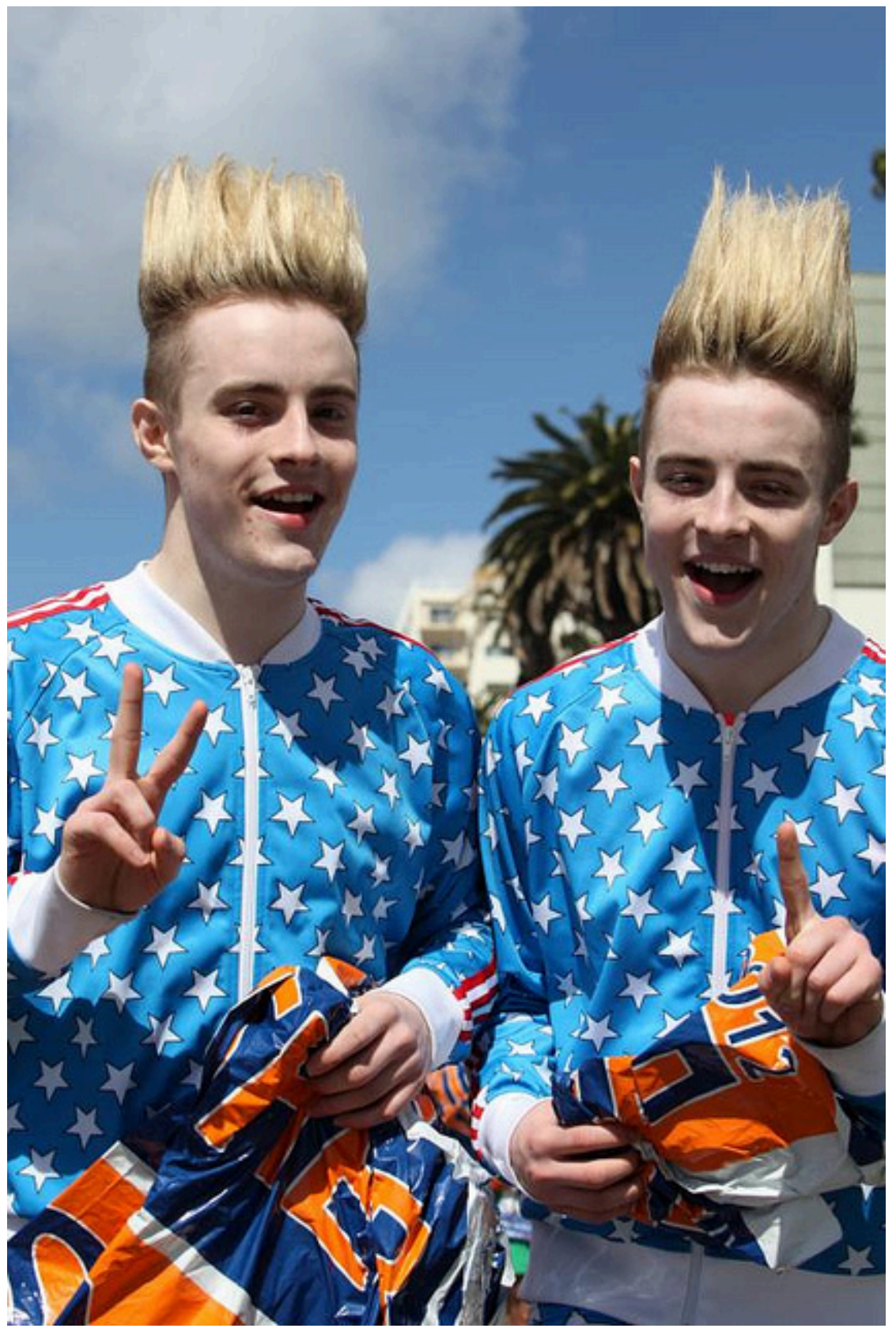

Research on identical twins suggests that alcoholism has a genetic basis.

Michael Dorausch - Identical Twins Jedward - CC BY-SA 2.0.

Regarding the second question, biological research is more speculative, but it assumes that some people are particularly vulnerable to the effects of drugs. These people are more likely to experience very intense effects and to become physiologically and/or psychologically addicted to a particular drug. To the extent this process occurs, the people in question are assumed to have a biological predisposition for drug addiction that is thought to be a genetic predisposition.

Most research on genetic predisposition has focused on alcohol and alcoholism (Hanson et al., 2012). Studies of twins find that identical twins are more likely than fraternal twins (who are not genetically identical) to both have alcohol problems or not to have them. In addition, studies of children of alcoholic parents who are adopted by 
nonalcoholic parents find that these children are more likely than those born to nonalcoholic parents to develop alcohol problems themselves. Although a genetic predisposition for alcoholism might exist for reasons not yet well understood, there is not enough similar research on other types of drug addiction to assume that a genetic predisposition exists for these types. Many nonbiological factors also explain the use of, and addiction to, alcohol and other drugs. We now turn to these factors.

\section{Psychological Explanations}

Psychological explanations join biological explanations in focusing on why certain individuals are more likely than others to use drugs and to be addicted to drugs (Hanson et al., 2012). Some popular psychological explanations center on personality differences between drug users and nonusers. These explanations assume that users have personality traits that predispose them to drug use. These traits include low self-esteem and low selfconfidence, low trust in others, and a need for thrills and stimulation. In effect, drug users have inadequate personalities, or personality defects, that make them prone to drug use, and once they start using drugs, their personality problems multiply.

One problem with research on personality explanations is methodological: If we find personality differences between drug users and nonusers, should we conclude that personality problems cause drug use, or is it possible that drug use causes personality problems? Most of the research on personality and drug use cannot answer this question adequately, since it studies drug users and nonusers at one point in time (cross-sectional research). To answer this question adequately, longitudinal research, which examines the same people over time, is necessary. Among initial drug abstainers at Time 1, if those with the personality traits mentioned earlier turn out to be more likely than those without the traits to be using drugs at Time 2, then we can infer that personality problems affect drug use rather than the reverse. Longitudinal research on personality and drug use that studies adolescents and college students does indeed find this causal sequence (Sher, Bartholow, \& Wood, 2000). However, some scholars still question the importance of personality factors for drug use and addiction (Goode, 2012). They say these factors have only a small effect, if that, and they cite research questioning whether personality differences between users and nonusers in fact exist (Feldman, Boyer, Kumar, \& Prout, 2011).

Other psychological explanations are based on the classic concept from behavioral psychology of operant conditioning - the idea that people and animals are more likely to engage in a behavior when they are rewarded, or reinforced, for it. These explanations assume that people use drugs because drugs are positive reinforcers in two respects. First, drugs provide pleasurable effects themselves and thus provide direct reinforcement. Second, drug use often is communal: People frequently use drugs (alcohol is certainly a prime example, but so are many other drugs) with other people, and they enjoy this type of social activity. In this manner, drug use provides indirect reinforcement.

\section{Sociological Explanations}

Sociological explanations emphasize the importance of certain aspects of the social environment-social structure, social bonds to family and school, social interaction, and culture — or drug use, depending on the type 
of drug. For drugs like heroin and crack that tend to be used mostly in large urban areas, the social structure, or, to be more precise, social inequality, certainly seems to matter. As sociologist Elliott Currie (1994, p. 3) has observed, the use of these drugs by urban residents, most of them poor and of color, reflects the impact of poverty and racial inequality: 'Serious drug use is not evenly distributed: it runs 'along the fault lines of our society.' It is concentrated among some groups and not others, and has been for at least half a century.” This fact helps explain why heroin use grew in the inner cities during the 1960s, as these areas remained poor even as the US economy was growing. Inner-city youths were attracted to heroin because its physiological effects helped them forget about their situation and also because the heroin subculture-using an illegal drug with friends, buying the drug from dealers, and so forth — was an exciting alternative to the bleakness of their daily lives. Crack became popular in inner cities during the 1980s for the same reasons.

Social bonds to families and schools also make a difference. Adolescents with weak bonds to their families and schools, as measured by such factors as the closeness they feel to their parents and teachers, are more likely to use drugs of various types than adolescents with stronger bonds to their families and schools. Their weaker bonds prompt them to be less likely to accept conventional norms and more likely to use drugs and engage in other delinquent behavior.

Regarding social interaction, sociologists emphasize that peer influences greatly influence one's likelihood of using alcohol, tobacco, and a host of other drugs (Hanson et al., 2012). Much and probably most drug use begins during adolescence, when peer influences are especially important. When our friends during this stage of life are drinking, smoking, or using other drugs, many of us want to fit in with the crowd and thus use one of these drugs ourselves. In a related explanation, sociologists also emphasize that society’s “drug culture” matters for drug use. For example, because we have a culture that so favors alcohol, many people drink alcohol. And because we have a drug culture in general, it is no surprise, sociologically speaking, that drug use of many types is so common.

To the extent that social inequality, social interaction, and a drug culture matter for drug use, sociologists say, it is a mistake to view most drug use as stemming from an individual's biological or psychological problems. Although these problems do play a role for some individuals' use of some drugs, drug use as a whole stems to a large degree from the social environment and must be understood as a social problem, and not just as an individual problem.

Beyond these general explanations of why people use drugs, sociological discussions of drug use reflect the three sociological perspectives introduced in Chapter 1 "Understanding Social Problems"-functionalism, conflict theory, and symbolic interactionism—as we shall now discuss. Table 7.6 "Theory Snapshot" summarizes this discussion.

Table 7.6 Theory Snapshot 


\begin{tabular}{|c|c|}
\hline $\begin{array}{l}\text { Theoretical } \\
\text { perspective }\end{array}$ & Contributions to understanding of drug use \\
\hline Functionalism & $\begin{array}{l}\text { Drug use is functional for several parties in society. It provides drug users the various positive } \\
\text { physiological effects that drugs have; it provides the sellers of legal or illegal drugs a source of income; } \\
\text { and it provides jobs for the criminal justice system and the various other parties that deal with drug use. } \\
\text { At the same time, both legal drugs and illegal drugs contribute to dysfunctions in society. }\end{array}$ \\
\hline $\begin{array}{l}\text { Conflict } \\
\text { theory }\end{array}$ & $\begin{array}{l}\text { Much drug use in poor urban areas results from the poverty, racial inequality, and other conditions } \\
\text { affecting people in these locations. Racial and ethnic prejudice and inequality help determine why some } \\
\text { drugs are illegal as well as the legal penalties for these drugs. The large multinational corporations that } \\
\text { market and sell alcohol, tobacco, and other legal drugs play a powerful role in the popularity of these } \\
\text { drugs and lobby Congress to minimize regulation of these drugs. }\end{array}$ \\
\hline $\begin{array}{l}\text { Symbolic } \\
\text { interactionism }\end{array}$ & $\begin{array}{l}\text { Drug use arises from an individual's interaction with people who engage in drug use. From this type of } \\
\text { social interaction, an individual learns how to use a drug and also learns various attitudes that justify drug } \\
\text { use and define the effects of a drug as effects that are enjoyable. }\end{array}$ \\
\hline
\end{tabular}

\section{Functionalism}

Recall that functionalist theory emphasizes the need for social stability, the functions that different aspects of society serve for society's well-being, and the threats (or dysfunctions) to society's well-being posed by certain aspects of society. In line with this theory, sociologists emphasize that drug use may actually be functional for several members of society. For the people who use legal or illegal drugs, drug use is functional because it provides them the various positive physiological effects that drugs have. For the people who sell legal or illegal drugs, drug use is functional because it provides them a major source of income. Illegal drug use is even functional for the criminal justice system, as it helps provide jobs for the police, court officials, and prison workers who deal with illegal drugs. Legal and illegal drugs also provide jobs for the social service agencies and other organizations and individuals whose work focuses on helping people addicted to a drug. At the same time, drugs, whether legal or illegal, have the many dysfunctions for society that this chapter discussed earlier, and this fact must not be forgotten as we acknowledge the functions of drugs.

\section{Conflict Theory}

Conflict theory stresses the negative effects of social inequality and the efforts of the elites at the top of society's hierarchy to maintain their position. This theory helps us understand drugs and drug use in at least three respects. First, and as noted just earlier, much drug use in poor urban areas results from the poverty, racial inequality, and other conditions affecting people in these locations. They turn to illegal drugs partly to feel better about their situation, and partly because the illegal drug market is a potentially great source of income that does not require even a high school degree.

Second, conflict theory emphasizes that racial and ethnic prejudice and inequality help determine why some drugs are illegal as well as the criminal penalties for these drugs. For example, the penalties for crack are much harsher, gram for gram, than those for powder cocaine, even though the two drugs are pharmacologically identical. Crack users are primarily poor African Americans in urban areas, while powder cocaine users are primarily whites, many of them at least fairly wealthy. These facts prompt many observers to say that the harsher penalties 
for crack are racially biased (Tonry, 2011). Other evidence for this argument of conflict theory is seen in the history of the illegality of opium, cocaine, and marijuana. As we discussed earlier, racial and ethnic prejudice played an important role in why these common drugs in the nineteenth century became illegal: prejudice against Chinese immigrants for opium, prejudice against African Americans for cocaine, and prejudice against Mexican Americans for marijuana.

Third, conflict theory emphasizes the huge influence that multinational corporations have in the marketing and sale of the legal drugs - alcohol, tobacco, and many prescription drugs - that often have harmful individual and societal consequences. To maximize their profits, these companies do their best, as noted earlier, to convince Americans and people in other nations to use their products. They also spend billions of dollars to lobby Congress. As also mentioned earlier, the tobacco industry hid for years evidence of the deadly effects of its products. All these efforts illustrate conflict theory's critical view of the role that corporations play in today's society.

\section{Symbolic Interactionism}

Symbolic interactionism focuses on the interaction of individuals and on how they interpret their interaction. Given this focus, symbolic interactionism views social problems as arising from the interaction of individuals. As such, it understands drug use as a behavior arising from an individual's interaction with people who engage in drug use. From this type of social interaction, an individual learns how to use a drug and also learns various attitudes that justify drug use and define the effects of a drug as effects that are enjoyable.

A study of drug use that reflects this approach is Howard S. Becker's (1953) classic article, "Becoming a Marihuana User.” Becker wrote that someone usually begins smoking marijuana in the presence of friends who are experienced marijuana users. This social interaction, he argued, is critical for new users to wish to continue using marijuana. To want to do so, they must learn three behaviors or perceptions from the experienced users who are "turning them on" to marijuana use. First, new users must learn how to smoke a joint (marijuana cigarette) by deeply inhaling marijuana smoke and holding in the smoke before exhaling. Second, they must perceive that the effects they feel after smoking enough marijuana (spatial distortion, hunger pangs, short-term memory loss) signify that they are stoned (under the influence of marijuana); their friends typically tell them that if they are feeling these effects, they are indeed stoned. Third, they must learn to define these effects as pleasurable; if people suddenly experience spatial distortion, intense hunger, and memory loss, they might very well worry they are having huge problems! To prevent this from happening, their friends say things to them such as, "Doesn't that feel great!” This and similar comments help reassure the new users that the potentially worrisome effects they are experiencing are not only bad ones but in fact very enjoyable ones.

\section{Key Takeaways}

- Biological theories assume that some people are especially vulnerable to drug addiction for genetic reasons.

- A popular set of psychological theories assumes that drug addiction results from certain personality traits and problems.

- Sociological theories attribute drug use to various aspects of the social environment, including peer 
influences, weak social bonds, and the larger drug culture.

\section{For Your Review}

1. When you think about the reasons for drug use and addiction, do you think biological factors, psychological factors, or the social environment play the most important role? Explain you answer.

2. Write a brief essay in which you discuss a time when your friends influenced you, or someone else you know, to use a legal or illegal drug.

\section{References}

Becker, H. S. (1953). Becoming a Marihuana User. American Journal of Sociology, 59, 235-242.

Currie, E. (1994). Reckoning: Drugs, the cities, and the American future. New York, NY: Hill and Wang.

Feldman, M., Boyer, B., Kumar, V. K., \& Prout, M. (2011). Personality, drug preference, drug use, and drug availability. Journal of Drug Education, 41(1), 45-63.

Goode, E. (2012). Drugs in American society (8th ed.). New York, NY: McGraw-Hill.

Hanson, G. R., Venturelli, P. J., \& Fleckenstein, A. E. (2012). Drugs and society (11th ed.). Burlington, MA: Jones \& Bartlett.

Sher, K. J., Bartholow, B. D., \& Wood, M. D. (2000). Personality and substance use disorders: A prospective study. Journal of Consulting and Clinical Psychology, 68, 818-829.

Tonry, M. (2011). Punishing race: A continuing American dilemma. New York, NY: Oxford University Press. 


\subsection{Drug Policy and the War on Illegal Drugs}

\section{Learning Objectives}

1. Explain whether the DARE program is effective.

2. Outline the goals and examples of a harm reduction approach to drug use.

3. List the problems arising from the current legal war on illegal drugs.

For many decades, the United States has used several strategies to try to deal with drugs. These strategies generally fall into four categories: treatment, prevention, harm reduction, and, for certain drugs, criminalization and the use of the criminal justice system, or, as we will call it, the war on illegal drugs. We now turn to these strategies.

\section{Treatment}

Treatment programs are intended for people who already are using drugs, perceive they have a drug problem, and want to reduce or eliminate their drug use. This strategy is probably familiar to most readers, even if they have not used drugs themselves or at least have not had the benefit of a treatment program. Treatment programs often involve a group setting, but many drug users also receive individual treatment from a psychiatrist, psychologist, or drug counselor. Perhaps the most famous treatment program is Alcoholics Anonymous, a program that involves alcoholics meeting in a group setting, acknowledging their drinking problem and its effects on family members and other loved ones, and listening to each other talk about their situations. Other group settings are residential settings, sometimes called detox units. In these settings, people check themselves into an institution and stay there for several weeks until they and the professionals who treat them are satisfied. Perhaps the most famous residential treatment program is the Betty Ford Center in Rancho Mirage, California; this center was established by and named after an acknowledged alcoholic who was the wife of President Gerald Ford. 


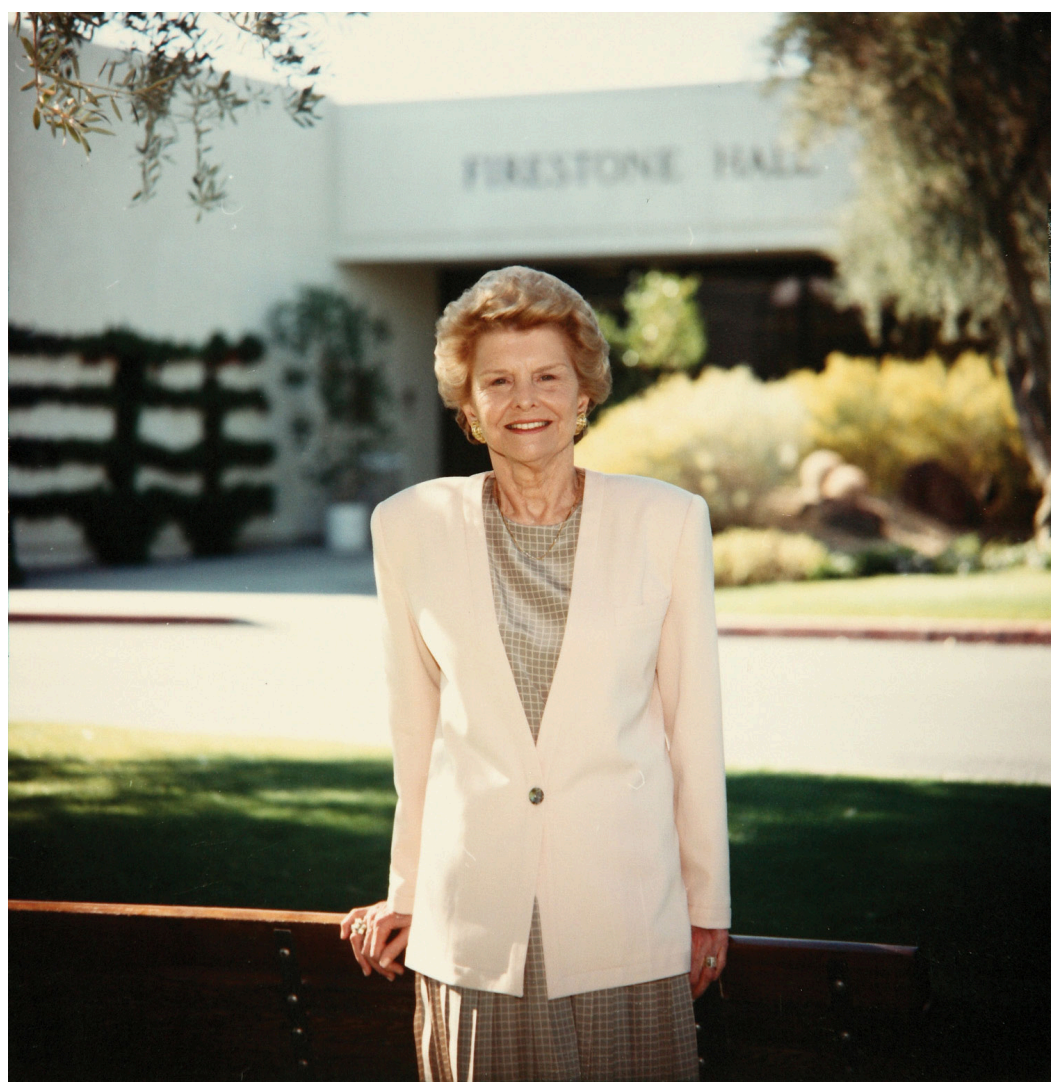

The Betty Ford Center is a residential detox unit for people with alcohol and other drug problems.

Image courtesy of Betty Ford Center, http://commons.wikimedia.org/wiki/File:BETTYFORD.jpg.

In addition to or in conjunction with group treatment programs, individual treatment for drug addiction may involve the use of "good" drugs designed to help wean addicts off the drug to which they are addicted. For example, nicotine gum, patches, and other products are designed to help cigarette smokers stop smoking.

The various forms of treatment can be very effective for some addicts and less effective or not effective at all for other addicts; most treatment programs have a high failure rate (Goode, 2012). A sociological perspective suggests that however effective treatment might be for some people, the origins of drug use ultimately lie in the larger society — its social structure, social interaction, and the drug culture — and that these roots must be addressed for serious reductions in drug use to occur.

\section{Prevention}

Because it is always best to try to prevent a problem before it begins, an important strategy to deal with drug use involves prevention. The major prevention strategies involve drug education or drug testing (Faupel et al., 2010). Many education-based prevention programs focus on children and adolescents. This focus reflects the fact that use of most drugs begins during adolescence, and that if adolescents do not begin using drugs during this period of their lives, they are much less likely to do so when they become adults. Some education strategies follow what is called an informational model: they involve public-service advertising, the distribution of drug pamphlets in 
medical offices, and other such efforts. Several studies question the effectiveness of strategies based on this model (Faupel et al., 2010).

Other education programs take place in the secondary school system and on college campuses. The most famous such program is almost certainly DARE (Drug Abuse Resistance Education), which involves police officers speaking to middle-school children. DARE programs have been carried out in more than 7,000 schools across the nation. However, several studies find that DARE programs do not generally reduce subsequent drug use among the children who attend them compared to children who do not attend them (Faupel et al., 2010).

Drug testing is very common in today's society, and you may well have been required to have a drug test as part of an application for a job, involvement in a school sport, or other activity. At least half of US workplaces now perform required drug tests. Drug testing is expensive, and many critics say it is not cost-effective in view of the low prevalence of illegal drug use in the United States (Faupel et al., 2010).

\section{Harm Reduction}

A third strategy involves harm reduction. As this term implies, this strategy attempts to minimize the harm caused by drugs. It recognizes that many people will use drugs despite efforts to prevent or persuade them from doing so and despite any punishment they might receive for using illegal drugs. Our nation is currently using a harm reduction approach with regard to alcohol and tobacco. It recognizes that tens of millions of people use these products, and designated-driving programs and other efforts try to minimize the considerable harm these two drugs cause.

A specific harm reduction strategy with regard to illegal drugs is the provision of clean, sterile needles for people who inject themselves with heroin, cocaine/crack, or other drugs. Many of these users share needles, and this sharing spreads HIV, hepatitis, and other diseases. If they have a supply to sterile needles, the reasoning goes, the transmission of these diseases will be reduced even if use of the drugs with the aid of the needles does not reduce. Critics say the provision of sterile needles in effect says that drug use is OK and may even encourage drug use. Proponents reply that needle-based drug use will occur whether or not sterile needles are provided, and that the provision of sterile needles does more good than harm. Other nations have adopted this type of harm reduction much more extensively than the United States.

Another harm reduction strategy involves the use of drug courts, which began in the 1990s and now number more than 2,500 across the United States. In these courts, drug offenders who have been arrested and found guilty are sentenced to drug treatment and counseling rather than to jail or prison. Evaluation studies show that the courts save much money compared to imprisoning drug offenders and that they are more effective than imprisonment in reducing the offenders' drug habit (Stinchcomb, 2010).

\section{People Making a Difference}

Law Enforcement against Prohibition 
Law Enforcement Against Prohibition (LEAP) is an organization of current and former police and other criminal justice professionals, including prosecutors, judges, and FBI agents, who advocate for the legalization of illegal drugs. Because many of these professionals were on the front lines in the war against drugs and often put their lives in danger, their views about drug policy cannot be dismissed lightly.

One of their members is MacKenzie Allen, a 65-year-old deputy sheriff who worked in Los Angeles and Seattle, including time as an undercover agent who bought illegal drugs and made countless arrests for drug offenses. Although Allen strongly disapproves of drug use, his many years in law enforcement led him to realize that the drug problem is best understood as a public health problem, not a legal problem. He notes that the United States has lowered cigarette use through public education and without outlawing cigarettes. "Can you imagine the mayhem had we outlawed cigarettes?” he writes. "Can you envision the 'cigarette cartels' and the bloodbath that would follow? Yet, thanks to a public awareness campaign we’ve made a huge dent in tobacco use without arresting a single cigarette smoker.”

Allen adds that most of the problems associated with illegal drug use are actually the result of the laws against drugs. These laws create a huge illegal market, much of it involving violent cartels, he says, that promises strong profits for the manufacturers and sellers of illegal drugs. He is also critical of other aspects of the war on drugs:

If the colloquial definition of insanity is doing the same thing over and over, expecting a different result, what does that say about our "War on Drugs"? We've been pursuing this strategy for forty years. It has cost a trillion taxpayer dollars, thousands of lives (both law enforcement and civilians) and destroyed hundreds of thousands more by incarceration. Moreover, it undermines the safety of our communities by overcrowding our jails and prisons, forcing them to give early release to truly violent offenders.

Another LEAP member is Joseph D. McNamara, the former police chief of San Jose, California. McNamara also criticizes the violence resulting from the laws against drugs. "Like an increasing number of law enforcers," he writes specifically about marijuana, "I have learned that most bad things about marijuana-especially the violence made inevitable by an obscenely profitable black market—are caused by the prohibition, not by the plant.” He continues, "Al Capone and his rivals made machine-gun battles a staple of 1920s city street life when they fought to control the illegal alcohol market. No one today shoots up the local neighborhood to compete in the beer market...How much did the [Mexican] cartels make last year dealing in Budweiser, Corona or Dos Equis? Legalization would seriously cripple their operations.”

As these statements indicate, the legal war on drugs has had many costs. It is difficult to know what to do about illegal drugs, but in bringing these costs to the attention of elected officials and the American public, Law Enforcement Against Prohibition is making a difference. For further information about LEAP, visit copssaylegalizedrugs.com.

Sources: Allen, 2001; Law Enforcement Against Prohibition, 2011; McNamara, 2010

\section{The War on Illegal Drugs}

The most controversial drug strategy involves the criminalization of many drugs and the use of the police and the rest of the criminal justice system to apprehend and punish the users, manufacturers, and sellers of illegal drugs. As the brief history of drug use at the beginning of this chapter indicated, the United States has banned certain drugs since the late nineteenth century, and it accelerated this effort during the 1970s and 1980s as concern grew about heroin, crack, and other drugs.

In judging the war on illegal drugs, two considerations should be kept in mind (Meier \& Geis, 2007). One consideration is the philosophical question of the extent to which the government in a free society should outlaw behaviors that may be harmful even if people (let's assume we are talking about legal adults) want to engage in them. Americans do all kinds of things that may harm themselves and that may directly or indirectly harm other people. For example, many Americans eat high amounts of candy, ice cream, potato chips, hamburgers, and other 
"fat food" that causes obesity, great harm to individual health, premature death and bereavement, and tens of billions of dollars in health costs and lost productivity annually. Although obesity almost certainly causes more harm overall than illegal drugs, no one is about to say that the use of "fat food" should be banned or restricted, although some schools and workplaces have removed candy and soda machines. Americans also engage in many other activities that can be very harmful, including downhill skiing, contact sports, skydiving, and any number of other activities, but no one is about to say that we should be prohibited from engaging in these efforts. Where is the logic, then, in allowing all these behaviors and in not allowing the use of certain drugs? A philosophical argument can be made that all drug use should, in fact, be allowed in a free society (Husak, 2002), and perhaps this is an issue that you and your classmates will want to discuss.

The second consideration is the social science question of whether laws against drugs do more good than harm, or more harm than good. In a rational society, if a law or policy does more good than harm, then we should have the law or policy. However, if it does more harm than good, however much good it might do, then we should not have it, because the harm outweighs the good.

In considering this issue, critics of drug laws say they do much more harm than good, and they often cite Prohibition as an example of this dynamic. Prohibition was repealed because our society decided it was doing much more harm than good and was thus a "triumphant failure," as one author has called this period of our history (Okrent, 2011, p. 67). Prohibition caused several harms: (1) the rise of organized crime to earn illegal profits from the manufacture, distribution, and sale of alcohol; (2) the violence and murder among organized crime gangs that fought each other over drug "turf"; (3) the wounding and death of innocent bystanders from gunfights between organized crime gangs; (4) the wounding and murder of police officers who enforced Prohibition; (5) rampant corruption among police officers and political officials who took money from organized crime to ignore violations of Prohibition; and (6) the expenditure of much time, money, and energy by the criminal justice system to enforce Prohibition.

Prohibition did reduce drinking and the violence associated with drinking. But some scholars say that the organized crime violence caused by Prohibition was so common and deadly that the homicide rate grew during Prohibition rather than lessening (Jensen, 2000), though other scholars dispute this finding (Owens, 2011). In yet another problem, many people during Prohibition became sick and/or died from drinking tainted liquor. Because alcohol was no longer regulated, illegal alcohol often contained, by accident or design, dangerous substances. As an example, 15,000 people in the Midwest became sick with a severe neurological problem after drinking an illegal alcohol laced with a paint thinner chemical (Genzlinger, 2011).

Critics of today's war on illegal drugs say that it has reproduced the same problems that Prohibition produced. Among these problems are the following:

- Drug gangs and individual drug sellers engage in deadly fights with each other and also kill or wound police officers and other law enforcement personnel who fight the war on drugs.

- Many innocent bystanders, including children, are wounded or killed by stray bullets.

- Many police officers take bribes to ignore drug law violations and/or sell drugs confiscated from dealers.

- The criminal justice system and other agencies spend much time, money, and energy in the war against illegal drugs, just as they did during Prohibition. Enforcing drug laws costs about $\$ 50$ billion annually 
(McVay, n.d.). Police and other law enforcement personnel make more than 1.6 million arrests for drug offenses annually, including about 850,000 arrests for marijuana possession (Federal Bureau of Investigation, 2011). Some 500,000 people are in prison or jail for drug offenses.

- The drug war has focused disproportionately on African Americans and Latinos and greatly increased their numbers who have gone to jail or prison. Even though illegal drug use is more common among whites than among blacks, the arrest rate for drug offenses is ten times higher for African Americans than the rate for whites (Blow, 2011). Partly because of the drug war, about one-third of young African American men have prison records.

- Most of the 17,000 annual deaths from illegal drug use stem from the fact that the drugs are illegal. Because they are illegal, they may contain dangerous substances that can be fatal, just as in Prohibition. In addition, some illegal drug users overdose because they underestimate the purity of a drug.

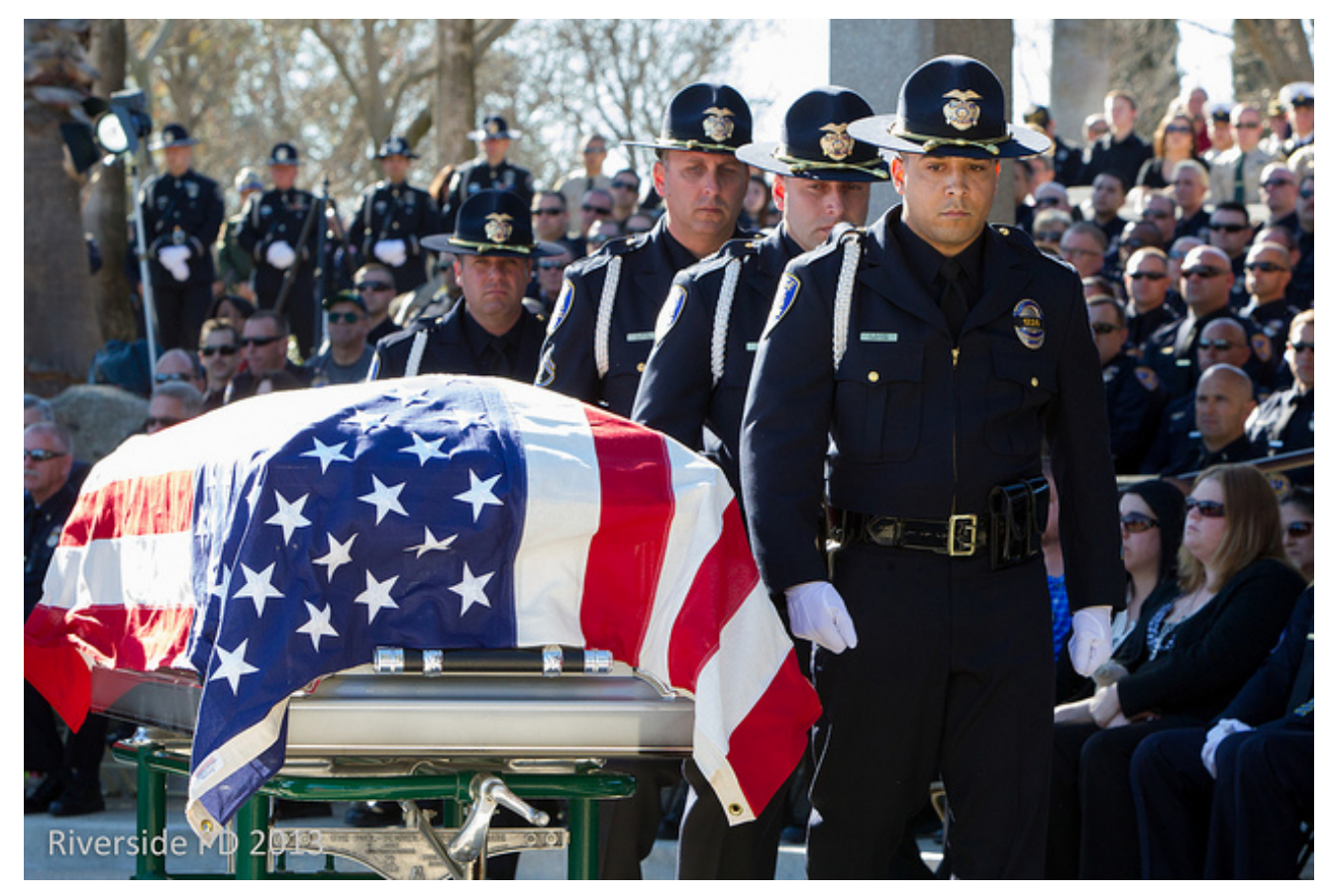

One of the harms associated with the war on drugs is that police officers die in the line of duty when they are killed by drug sellers or users.

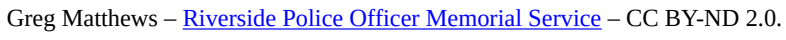

Because of all these problems, drug law critics say, the United States should legalize marijuana, the most benign illegal drug, and seriously consider legalizing some or all other illegal drugs.

Proponents of the drug war reply that if drugs were legalized or decriminalized (still against the law, but violations would be treated like traffic offenses), many more people would use the newly legal drugs, and the problems these drugs cause would increase. Responding to this argument, drug law critics say it is not at all certain that drug use would increase if drugs were legalized. To support their view, they cite two pieces of evidence.

First, illegal drugs are relatively easy to obtain and use without fear of arrest. If people have decided not to use 
illegal drugs now, it is unlikely they will use them if the drugs were legalized. Support for this argument comes from national data on high school seniors (Johnston, O’Malley, Bachman, \& Schulenberg, 2011). In 2010, 82 percent of seniors said they could easily obtain marijuana, and 35.5 percent said they could easily obtain cocaine. Despite these numbers, only 35 percent had used marijuana in the past year, and only 3 percent had used cocaine in the past year.

Second, marijuana use in the United States decreased in the 1970s and 1980s after several states decriminalized it. As we noted earlier, marijuana use also declined in the Netherlands after they decriminalized the drug in the 1970s. Moreover, even though use of marijuana is legal in the Netherlands, its rate of marijuana use is no higher than the rate of marijuana use in the United States (Drug Policy Alliance, 2012). In another international comparison, Portugal decriminalized possession of all drugs in 2001; after it did so, teenage drug use declined (see Note 7.28 “Lessons from Other Societies”).

At this point, it is impossible to know how much, if at all, the use of illegal drugs would rise if they were legalized. Critics of the drug war say that even if the use of drugs did rise, the benefits of legalizing or decriminalizing them would still outweigh the disadvantages (Feiling, 2010).

\section{Lessons from Other Societies}

What Happened after the Netherlands and Portugal Decriminalized Drugs?

As the United States ponders its drug policy, the experience of the Netherlands and Portugal provides some provocative lessons.

The Netherlands decriminalized drugs in 1976. Under the Netherlands' policy, although criminal penalties remain for possessing hard drugs (cocaine, heroin, etc.) and large quantities of marijuana, drug users are not normally arrested for possessing drugs, but they must receive drug treatment if they are arrested for another reason. Drug sellers are not normally arrested for selling small amounts of drugs, but they may be arrested for selling them in large. Marijuana use in the Netherlands dropped in the immediate years after it was decriminalized. Although it increased somewhat since then, as in some other nations, it remains much lower than the US rate. According to the Netherlands Ministry of Foreign Affairs, 23 percent of Dutch residents ages 15-64 have used cannabis at least once in their lives, compared to 40 percent of Americans ages 12 and older (2005 figures). Dutch use of cocaine and heroin also remains much lower than American use. Reflecting the Netherlands' experience, most of the nations in Western Europe have also decriminalized marijuana possession and use, and their rates of marijuana use also remain lower than the US rate.

In 2001, Portugal became the first European nation to remove all criminal penalties for drug possession. Portugal took this step because it reasoned that fear of arrest keeps drug addicts from seeking help and because it recognized that drug treatment costs far less than imprisonment. Anyone convicted of drug possession is sent for drug treatment, but the person may refuse treatment without any penalty.

In the first five years after Portugal decriminalized all drug possession, teenaged illegal drug use declined, new HIV infections from sharing needles declined, and the prison population also declined. Meanwhile, the number of drug addicts receiving treatment increased by 41 percent. A researcher who reported these trends commented, "Judging by every metric, decriminalization in Portugal has been a resounding success. It has enabled the Portuguese government to manage and control the drug problem far better than virtually every other Western country does.” A Portuguese drug official agreed, "The impact [of drugs] in the life of families and our society is much lower than it was before decriminalization," and noted that police are now freer to spend more time and energy on high-level dealers. Adult drug use in Portugal has risen slightly since 2001, but so has adult drug use in other European nations that did not decriminalize drugs. Portugal's increase has not been higher than these other nations' increase.

Although the Netherlands, Portugal, and other Western European nations certainly differ from the United States in many 
ways, their experience strongly suggests that decriminalization of drugs may cause much more good than harm. If so, the United States has important lessons to learn from their experiences.

Sources: Hughes \& Stevens, 2010; Netherlands Ministry of Foreign Affairs, 2008; Reinarman \& Hendrien, 2004; Szaalavitz, 2009; Tracey \& Jahromi, 2010

\section{Key Takeaways}

- To deal with drugs, the United States has used several strategies, including treatment, prevention, harm reduction, and the legal war on illegal drugs.

- According to its critics, the war on illegal drugs has done much more harm than good and in this respect is repeating the example of Prohibition.

\section{For Your Review}

1. Do you think the United States should make sterile needles and syringes freely available to people who are addicted to drugs that are injected? Why or why not?

2. Do you agree or disagree that the war on illegal drugs is doing more harm than good? Explain your answer.

\section{References}

Allen, M. (2011, February 23). Why this cop asked the President about legalizing drugs. Huffington Post. Retrieved from http://www.huffingtonpost.com/mackenzie-allen/why-this-cop-asked-the-pr b 827338.html.

Blow, C. M. (2011, June 11). Drug bust. New York Times, p. A21.

Drug Policy Alliance. (2012). Drug policy around the world: The Netherlands. Retrieved from http://www.drugpolicy.org/facts/drug-facts/marijuana-facts\#medical.

Faupel, C. E., Horowitz, A. M., \& Weaver., G. S. (2010). The sociology of American drug use. New York, NY: Oxford University Press.

Federal Bureau of Investigation. (2011). Crime in the United States, 2010. Washington, DC: Author.

Genzlinger, N. (2011, October 1). Bellying up to the time when America went dry. New York Times, p. C1.

Goode, E. (2012). Drugs in American society (8th ed.). New York, NY: McGraw-Hill.

Hughes, C. E., \& Stevens, A. (2010). What can we learn from the Portuguese decriminalization of illicit drugs? British Journal of Criminology, 50(6), 999-1022. 
Husak, D. (2002). Legalize this! The case for decriminalizing drugs. New York, NY: Verso Books.

Jensen, G. F. (2000). Prohibition, alcohol, and murder: Untangling counterveiling mechanisms. Homicide Studies, 4, 18-36.

Johnston, L. D., O’Malley, P. M., Bachman, J. G., \& Schulenberg, J. E. (2011). Monitoring the future. National results on adolescent drug use: Overview of key findings, 2010 Ann Arbor, MI: Institute for Social Research.

Law Enforcement Against Prohibition. (2011). Ending the Drug War: A Dream Deferred. Medford, MA: Author.

McNamara, J. D. (2010, July 25). Legalize pot, former San Jose police chief says. San Francisco Chronicle. Retrieved from http://www.sfgate.com/cgi-bin/article.cgi?f=/c/a/2010/07/25/IN1K1EGQRJ.DTL.

McVay, D. A. (n.d.). Drug War Facts (6th ed.). Retrieved from http://www.drugwarfacts.org/cms.

Meier, R. F., \& Geis, G. (2007). Criminal justice and moral issues. New York, NY: Oxford University Press.

Netherlands Ministry of Foreign Affairs. (2008). FAQ drugs: A guide to drug policy. Retrieved from http://www.minbuza.nl.

Okrent, D. (2011). Last call: The rise and fall of prohibition. New York, NY: Scribner.

Owens, E. G. (2011, October 2). The (not so) roaring '20s. New York Times, p. SR12.

Reinarman, C., Cohen, P. D. A., \& Hendrien, K. L. (2004). The limited relevance of drug policy: Cannabis in Amsterdam and in San Francisco. American Journal of Public Health, 94, 836-842.

Stinchcomb, J. B. (2010). Drug courts: Conceptual foundation, empirical findings, and policy implications. Drugs: Education, Prevention \& Policy, 17(2), 148-167.

Szaalavitz, M. (2009, April 20). Drugs in Portugal: Did decriminalization work? Time. Retrieved from http://www.time.com/time/health/article/0,8599,1893946,1893900.html.

Tracey, M., \& Jahromi, N. (2010, December 15). Importing the Portuguese model of drug reform. The Nation. Retrieved from http://www.thenation.com/article/157124/importing-portuguese-model-drug-reform. 


\subsection{Addressing the Drug Problem and Reducing Drug Use}

\section{Learning Objectives}

1. Explain the problems associated with arresting hundreds of thousands of people for drug possession.

2. List any three specific measures that may help deal with the drug problem.

As you may have already noticed and will notice again, the other chapters in this book usually present a fairly optimistic assessment when they discuss prospects for addressing the social problem discussed in each chapter. They point to the experience of other nations that do a good job of addressing the social problem, they cite social science evidence that points to solutions for addressing the problem, and they generally say that the United States could address the problem if it had the wisdom to approach it appropriately and to spend sufficient sums of money.

This chapter will not end with an optimistic assessment for addressing the drug problem. The reason for this lack of optimism is that what's past is prologue: People have enthusiastically used drugs since prehistoric times and show no signs of reducing their drug use. Many and perhaps most scholars think the legal war on drugs has had little, if any, impact on drug use (Walker, 2011), and many scholars recognize that this war brought with it the many disadvantages cited in the previous section. As Kleiman et al. (2011, p. xvi) observe, "Our current drug policies allow avoidable harm by their ineffectiveness and create needless suffering by their excesses.”

A growing number of people in the political world agree. In 2011, the Global Commission on Drug Policy issued a major report on the world's antidrug efforts. The commission comprised nineteen members, including a former United Nations secretary general, a former US secretary of state, a former chair of the US Federal Reserve, and former presidents or prime ministers of Brazil, Colombia, Greece, Mexico, and Switzerland. The commission's report called for a drastic rethinking of current drug policy: "The global war on drugs has failed, with devastating consequences for individuals and societies around the world...Fundamental reforms in national and global drug control policies are urgently needed” (Global Commission on Drug Policy, 2011, p. 3). Decriminalization and even legalization of illegal drugs should be seriously considered, the report concluded.

Given this backdrop, many drug experts question whether our current drug policies make sense. They add that the best approach our society could take would be to expand the prevention, treatment, and harm reduction approaches discussed earlier; because drugs will always be with us, our society should do what it can to minimize the many harms that drugs cause. Thus drug education prevention and drug treatment programs should be expanded, sterile needles should be made available for drug addicts who inject their drugs, and drug courts should be used for a greater number of drug offenders.

Beyond these approaches, some experts say marijuana use should be decriminalized and that decriminalization of other drugs should be seriously considered. If marijuana were not only decriminalized but also legalized and taxed, it is estimated that this new tax revenue would amount to $\$ 8.7$ billion annually and that about $\$ 8.7$ billion 
annually would also be saved in reduced law enforcement costs, for a total of more than $\$ 17$ billion in new funds that could be used for drug prevention, drug treatment, and other needs (Kristof, 2010). Many Americans agree with these experts: In a 2011 Gallup poll, 50 percent of the public favored legalizing marijuana, while 46 percent opposed legalizing it (Graves, 2011).

More generally, these experts say, it makes little sense to arrest more than 1.3 million people each year for drug possession and to put many of them in jail or prison. We do not arrest and imprison alcoholics and cigarette smokers; instead we try to offer them various kinds of help, and we should do the same for people who are addicted to other kinds of drugs. If arrest and imprisonment must continue, these measures should be reserved for sellers of large quantities of illegal drugs, not for the people who use the drugs or for those who sell only small quantities. When low-level drug dealers are imprisoned, they are simply replaced on the street by new dealers. Providing low-level dealers with alternative sentencing would reduce the number of imprisoned dealers over time by several hundred thousand annually without making illegal drugs more available.

In addition to all these measures, several other steps might well reduce certain kinds of drug use or at least reduce the harm that both drugs and our current drug policies cause (Kleiman et al., 2011). These steps include the following:

1. Providing legally prescribed heroin and/or substitute opiates, including methadone, for heroin addicts. This provision has proven effective in several other nations.

2. Encouraging primary care physicians and other health-care providers to screen more carefully for substance abuse.

3. Basing drug sentencing less on the quantity of illegal drugs sold and more on the level of violence in which some drug sellers engage.

4. Abandoning DARE. According to Kleiman et al. (2011, p. 201), "the continued dominance in schoolbased drug education of DARE - a program that has never been shown to actually reduce drug use - is a scandal.” They instead recommend school-based programs that help children develop self-control and prosocial behavior, as these programs have also been shown to reduce children's subsequent drug use.

5. Following the psychological principle of operant conditioning by providing drug addicts small cash payments for clean drug tests, as these rewards have been shown to be effective.

6. Fully reintegrating former drug dealers and recovering drug addicts into society. They should have full access to public housing, educational loans, and other benefits, and they should be allowed to vote in states that now do not let them vote.

7. Raising alcohol taxes. According to Kleiman et al. (2011), tripling the alcohol tax would especially reduce drinking by heavy drinkers and by minors, and it would reduce the number of homicides by 1,000 annually and the number of motor vehicle accidents by 2,000 annually. The new tax money could also help fund alcohol treatment and prevention programs. "In the entire field of drug-abuse control,” Kleiman et al. (2011, p. 204) write, "there is no bargain as attractive as a higher alcohol tax.”

8. Prohibiting alcohol sales to anyone who has engaged in drunk driving or who has committed violence under the influence of alcohol. For this ban to work, everyone who wants to buy alcohol would have to show an ID, and those prohibited from buying alcohol would have that indicated on 
their ID. This ban would certainly be unpopular among the many drinkers who drink responsibly, but it would reduce the great harm that alcohol causes.

9. Allowing marijuana users to grow their own cannabis or to buy it from small growers. This would reduce the sales of cannabis, and thus its profits, from the organized crime groups and the Mexican cartels that now provide much of the marijuana used in the United States.

10. Raising the cigarette tax. Some states already have high cigarette taxes, but several states have low cigarette taxes. Raising the taxes in the low-tax states would reduce cigarette smoking in these states. The new tax revenue could be used to fund treatment programs that help reduce smoking.

\section{Key Takeaways}

- Critics of the war on drugs say that people who use illegal drugs should be treated, not arrested, just as people who use alcohol and tobacco are treated, if they seek treatment, rather than arrested.

- Specific measures that could help address the drug problem include providing legally prescribed heroin or substitute opiates for heroin addicts and raising the alcohol tax.

\section{For Your Review}

1. Do you think that alcohol taxes should be raised? Why or why not?

2. Do you favor decriminalization of marijuana? Explain your answer.

\section{References}

Global Commission on Drug Policy. (2011). War on drugs: Report of the Global Commission on Drug Policy. Rio de Janeiro, Brazil: Author.

Graves, L. (2011, October 18). Marijuana legalization receives 50 percent support in new poll. Huffington Post. Retrieved from http://www.huffingtonpost.com/2011/2010/2017/support-for-marijuana-legalization-at-alltime-high_n 1016461.html?utm source =DailyBrief\&utm campaign=1101811\&utm medium=email\&utm content=NewsEntry \&utm term=Daily\%1016420Brief.

Kleiman, M. A. R., Caulkins, J. P., \& Hawken, A. (2011). Drugs and drug policy: What everyone needs to know. New York, NY: Oxford University Press.

Kristof, N. D. (2010, October 28). End the war on pot. New York Times, p. A33. 
319 Social Problems

Walker, S. (2011). Sense and nonsense about crime, drugs, and communities: A Policy guide (7th ed.). Belmont, CA: Wadsworth. 


\subsection{End-of-Chapter Material}

\section{Summary}

1. Humans have used drugs of various types since prehistoric times. Alcohol has been a common drug in the United States since the colonial period, and opium, marijuana, and heroin were common legal drugs in the late nineteenth century.

2. The distinction between legal and illegal drugs lacks a logical basis. Alcohol and tobacco kill many more people than all illegal drugs combined.

3. The use of several drugs is socially patterned. Males are more likely than females to use drugs, and religious people are less likely to use them than those who are less religious. The differences that race/ethnicity, education, and region of country make for drug use depends on the type of drug.

4. Biological theories assume that drug addiction results from a genetic predisposition, while psychological theories attribute drug use to certain personality traits and to positive reinforcement.

5. Sociological theories attribute drug use to peer and cultural influences. A sociological perspective suggests that the ultimate roots of drug use lie in the social environment rather than inside the individual.

6. Major approaches to dealing with drugs include treatment, prevention, harm reduction, and the use of the criminal justice system for illegal drugs. Critics of the war on drugs say that it does more harm than good, and they urge that serious consideration be given to decriminalizing marijuana and perhaps other drugs.

\section{Using What You Know}

A college friend of yours seems to drink a lot most nights and even goes to class some mornings hung over. You've become so concerned that you've suggested to your friend when you've been out for the evening to just have a couple drinks. Your friend has just laughed you off. What, if anything, do you do?

\section{What You Can Do}

To help deal with the societal and individual problems caused by alcohol and other drugs, you may wish to do any of the following:

1. Volunteer for a local agency that helps teenagers or adults who have a problem with alcohol or other drugs.

2. Start or join in efforts on your campus to encourage responsible drinking.

3. Start a group to encourage your state to raise taxes on alcohol and cigarettes. 


\section{Chapter 8: Crime and Criminal Justice}

\section{Social Problems in the News}

"Wilson St. Residents Stunned by Shooting," the headline said. A shooting of a toddler in Chattanooga, TN, left a neighbor afraid. At 9:45 p.m. on a Friday night, someone walked up to an apartment and fired a gun through a window. One bullet struck the toddler in the leg, and another bullet struck a 20-year-old male with him in the hand. A neighbor across the hallway heard the shots and later told a reporter, "It scared me, my heart was beating, my hands were shaking. I was nervous and scared, is the baby going to survive. I was stuck on my bed and I was like what am I supposed to do, go see who is at my door or if I open it I might get shot at. I'm worrying about the baby, that's all I'm worrying about." Because the 20-year-old victim was a known gang member, police suspected that the incident was related to a drive-by gang shooting that occurred earlier in the evening.

Source: Boatwright, 2011

As this poignant account reminds us, many people across the nation live in fear of crime, and you may know several people, perhaps including yourself, who have been victims of a crime. The study of crime bears directly on this book's theme of continuity and change: Crime seems to have always been with us, yet sound social science research points to many programs and policies with great promise for reducing crime if only our nation would undertake them. We begin with some conceptual issues in understanding crime before turning to the types of crime, explanations for crime, and some aspects of the criminal justice system.

\section{References}

Boatwright, M. (2011, March 5). Wilson St. residents stunned by shooting. WRCB-TV. Retrieved from http://www.wrcbtv.com/Global/story.asp?S=14194540. 


\subsection{The Problem of Crime}

\section{Learning Objectives}

1. Understand the extent of public concern about crime.

2. Explain how the news media contribute to myths about crime.

3. Describe how crime in the United States is measured.

Put most simply, crime is behavior that is prohibited by the criminal law because it is considered especially harmful or offensive. This simple definition, however, raises many questions:

- Who decides what is offensive or harmful?

- Are some harmful behaviors not considered crimes, and are some crimes not that harmful?

- Are some people more likely than others to be considered criminals because of their gender, race and ethnicity, social class, age, or other aspect of their social backgrounds?

These questions lie at the heart of the sociological study of deviance, of which crime is a special type. Deviance is behavior that violates social norms and arouses strong social disapproval. This definition reflects the common sociological view that deviance is not a quality of a behavior itself but rather the result of what other people think about the behavior. This view is reflected in an often-cited quote from sociologist Howard S. Becker (1963, p. 9), who wrote several decades ago that "deviance is not a quality of the act the person commits, but rather a consequence of the application by others of rules or sanctions to an 'offender.' The deviant is one to whom that label has been successfully applied; deviant behavior is behavior that people so label.”

This definition reminds us that some harmful behaviors, such as white-collar crime, may not be considered deviant and fail to result in severe legal punishment, perhaps because wealthy individuals perform them. It also reminds us that some less harmful behaviors, such as prostitution, may be considered very deviant because the public deems the behavior immoral and because poor people engage in them. As these possibilities suggest, the application of a criminal label to an offender is problematic: People arrested and/or convicted of a crime may not have engaged in a very harmful behavior or even in the behavior of which they are suspected, and people with no criminal record have in fact engaged in harmful and even criminal behavior.

\section{Public Concern about Crime}

The American public is clearly concerned about crime. Two-thirds of the public said in a 2011 Gallup poll that crime had risen from the previous year. More than a third, 38 percent, said they would be "afraid to walk alone at night” within one mile of their residence; this figure translates to more than 86 million adults. In the same poll, 
47 percent (or about 114 million adults) said they worry about their homes being burglarized, and 44 percent said they worry about thefts of or from their motor vehicles. Corresponding figures for other crimes were: experiencing identity theft, 67 percent; getting mugged, 34 percent; getting attacked while driving your car, 19 percent; being sexually assaulted, 22 percent (including 37 percent of women); and getting murdered, 20 percent (among the lowest figures in this list, but one that still amounts to 42 million adults worrying about being murdered).

Although the public is concerned about crime, at least some of this concern might exceed what the facts about crime would justify. For example, although most of the public, as we just noted, thinks the crime rate has been rising, this rate has actually been declining since the early 1990s. And although one-fifth of the public worries about getting murdered, homicides comprise less than one-tenth of 1 percent of all violent and property crime (street crime); only about 7 of every 100,000 Americans, or 0.007 percent, are murdered every year; homicide does not rank among the top ten causes of death (which include heart disease and cancer); and the number of homicides is much lower than the number of deaths from harmful behavior by corporations (such as pollution or unsafe products and workplaces). Crime is indeed a real problem, but public concern about crime may be higher than the facts warrant.

\section{Media Myths}

To the extent this is true, news media coverage of crime may be partly responsible (Robinson, 2011). For example, if the television news and newspapers suddenly have several stories about a few sensational crimes, public concern about crime may jump, even though crime in general has not risen at all. Similarly, the news media have increased their crime coverage even when crime is falling, as happened during the early 1990s when the major US television networks more than doubled their nightly news stories about crime even though crime had been declining (Freeman, 1994).

The news media, in fact, distort the amount and nature of crime in several ways (Surette, 2011). First, they overdramatize crime by reporting it in many news stories. Crime dominates news coverage in many newspapers and television newscasts, and, as just noted, the media may devote much coverage to a few sensational crimes and create the false impression that a "crime wave" is occurring when the crime rate may even be declining.

Second, the media devote particularly heavy coverage to violent crime, reflecting the common saying that "if it bleeds, it leads.” For example, more than 25 percent of the crime stories on evening newscasts and in newspapers concern homicide, even though homicide comprises less than 1 percent of all crime (Feld, 2003). Similarly, the vast majority of crime stories feature violent crime, even though violent crime comprises only about 12-14 percent of all street crimes combined. Media attention to violent crime thus gives the public the false impression that most crime is violent when in fact most crime involves a theft of some sort (property crime). 


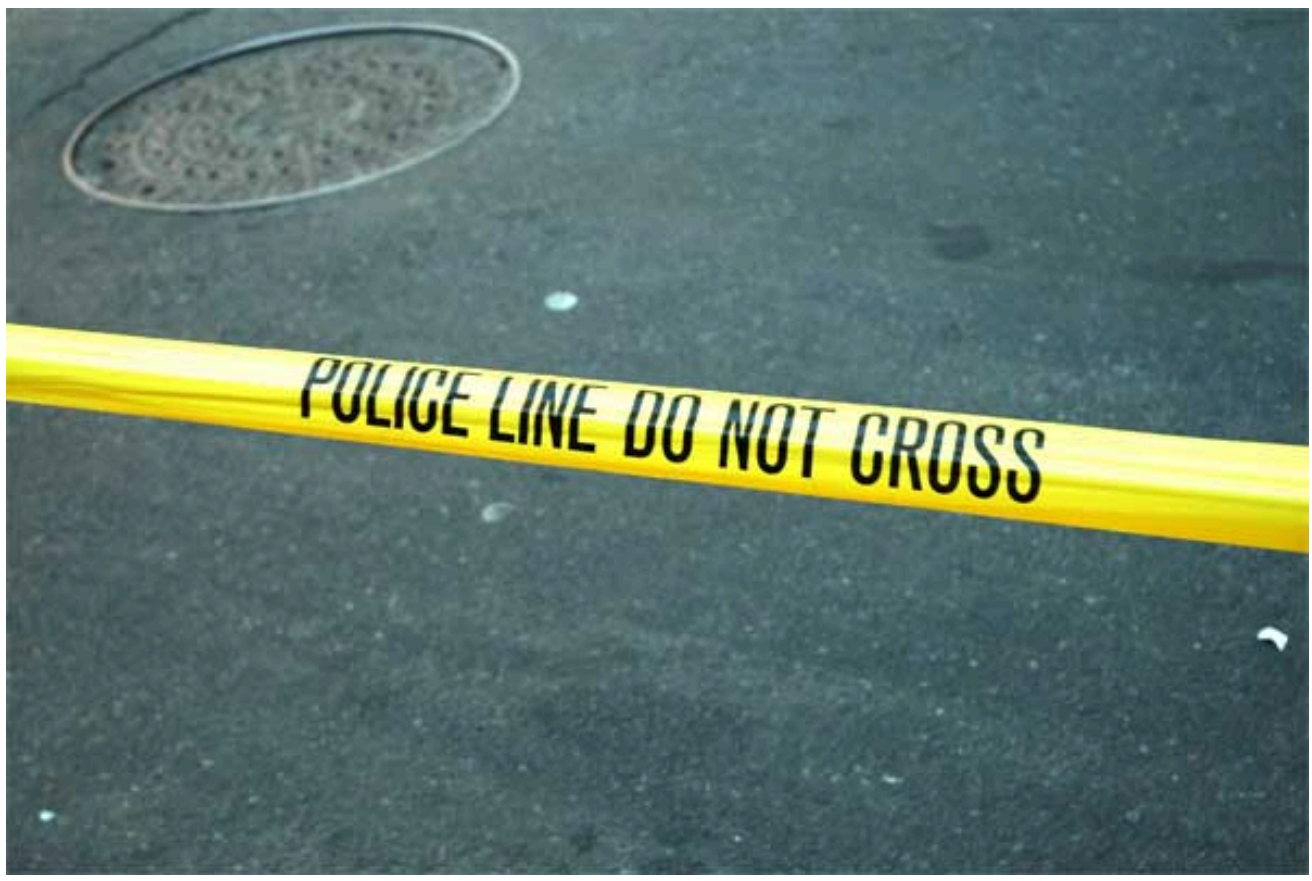

The news media feature violent crime, even though violent crime comprises only a small portion of all crime.

Darla Hueske - $\underline{\text { did not cross }}$ - CC BY-ND 2.0.

Third, the media tend to highlight crimes committed by African Americans or other people of color and crimes with white victims. A greater percentage of crime stories involve people of color as offenders than is true in arrest statistics. A greater percentage of crime stories also involve whites as victims than is actually true, and newspaper stories of white-victim crimes are longer than those of black-victim crimes. Crimes in which African Americans are the offenders and whites are the victims also receive disproportionate media coverage even though most crimes involve offenders and victims of the same race. In all these ways, the news media exaggerate the extent to which people of color commit crimes and the extent to which whites are victims of crimes.

Fourth, the media also tend to highlight crimes committed by youths. In one study of thousands of local newscast stories, about two-thirds of the stories about violence depicted youthful offenders, even though teenagers commit only about 14-16 percent of violent crime (Jackson, 1997). In a related problem, media stories involving teenagers are much more likely to show them committing crime or other antisocial acts than committing good deeds or other positive behavior. In these ways, the news media convey a false impression that leads the public to believe both that youths commit much of our violent crime and that youth violence has been rising even though it has actually declined since the early 1990s.

\section{Measuring Crime}

It is surprisingly difficult to know how much crime occurs. Crime is not like the weather, when we all can see whether it is raining, snowing, or sunny. Usually when crime occurs, only the criminal and the victim, and sometimes an occasional witness, know about it. We thus have an incomplete picture of the crime problem, but 
because of various data sources we still have a pretty good understanding of how much crime exists and of who is most likely to commit it and be victimized by it.

The government's primary source of crime data is the Uniform Crime Reports (UCR), published annually by the Federal Bureau of Investigation. The FBI gathers its data from police departments around the country who tell the FBI about crimes that have come to their attention. The police also tell the FBI whether someone is arrested for the crime and, if so, the person's age, gender, and race. The FBI gathers all these UCR data and reports them in an annual volume called Crime in the United States (Federal Bureau of Investigation, 2011).

Most UCR data concern the so-called Part I Crimes, eight felonies that the FBI considers the most serious. Four of these are violent crimes-homicide, rape, aggravated assault, and robbery-and four are property crimes_burglary, larceny (e.g., shoplifting, pick-pocketing, purse-snatching), motor vehicle theft, and arson.

According to the FBI, 1,246,248 violent crimes and 9,082,887 property crimes occurred in 2010, for a total of about 10.3 million. This is the nation's official crime count, and by any standard it is a lot of crime. However, this number is much lower than it should be because more than half of all crime victims do not report their crimes to the police, and the police thus do not know about them. These unreported crimes represent "hidden" crimes or, as they are often called, the dark figure of crime. Thus the true crime problem is much greater than suggested by the UCR.

This underreporting of crime represents a major problem for the UCR's validity. Several other problems exist. First, the UCR excludes white-collar crimes and thus diverts attention away from their harm. Second, police practices affect the number of crimes listed in the UCR. For example, the police do not record every report they hear from a citizen as a crime. Sometimes they do not have the time to do so, and sometimes they do not believe the citizen. If they do not record the report, the FBI does not count it as a crime. If the police start recording more reports or fail to record even more reports, the official crime rate will rise or fall, respectively, even though the actual number of crimes has not changed. This fact has led to crime-reporting scandals during the past two decades, as police departments in several major cities failed to record many crimes or downgraded others (e.g., calling a rape a simple assault) in an apparent effort to make it appear as if the crime rate were falling (Hart, 2004). In a third problem, if crime victims become more or less likely to report their crimes to the police (e.g., the advent of the 911 emergency number may have increased calls to the police), the official crime rate will again change, even if the actual number of crimes has not.

To get a more accurate picture of crime, the federal government began in the early 1970s to administer a survey, now called the National Crime Victimization Survey (NCVS), to tens of thousands of randomly selected US households. People in the households are asked whether they or their residence has been the victim of several different types of crimes in the past half year. Their responses are then extrapolated to the entire US population to yield fairly accurate estimates of the actual number of crimes occurring in the nation. These estimates are thought to be more accurate than the UCR's figures, even if it is true that victims sometimes might not want to tell NCVS interviewers what happened to them (Catalano, 2006).

Table 8.1 "Number of Crimes: Uniform Crime Reports (UCR) and National Crime Victimization Survey (NCVS), 2010" lists the number of street crimes as reported by the UCR and estimated by NCVS. Note that these two crime sources do not measure exactly the crimes. For example, the NCVS excludes commercial crimes such as shoplifting, while the UCR includes them. The NCVS also includes simple assaults (where someone receives only 
a minor injury), while the UCR excludes them. These differences notwithstanding, we can still see that the NCVS estimates about 1.8 times as many crimes as the UCR reports to us. The dark figure of crime is large indeed.

Table 8.1 Number of Crimes: Uniform Crime Reports (UCR) and National Crime Victimization Survey (NCVS), 2010

\begin{tabular}{|l|l|l|}
\hline & UCR & NCVS \\
\hline Violent crime & $1,246,248$ & $3,817,380$ \\
\hline Property crime & $9,082,887$ & $14,908,330$ \\
\hline Total & $10,329,135$ & $18,725,710$ \\
\hline
\end{tabular}

Source: Maguire, K. (Ed.). (2011). Sourcebook of criminal justice statistics. Retrieved from http://www.albany.edu/sourcebook/toc 3.html.

A third source of crime information is the self-report survey. Here subjects, usually adolescents, indicate on an anonymous questionnaire whether and how often they committed various offenses in, say, the past year. Typically, they also answer questions about their family relationships, school performance, and other aspects of their backgrounds. Self-report studies have yielded valuable information about delinquency and explanations of crime. Like the NCVS, they underscore how much crime is committed that does not come to the attention of the police.

\section{Key Takeaways}

- Much of the American public is concerned about crime, and many people worry about becoming a victim of various types of crime.

- The news media overdramatize the nature and amount of crime, and they give more attention to crimes involving African Americans and Latinos as offenders and whites as victims.

- The nation's major source of crime data is the Uniform Crime Reports (UCR). However, many people do not report their crimes to the police, and police practices affect the number of "official" crimes reported by the UCR.

\section{For Your Review}

1. Why do you think so many Americans are afraid of crime even though the crime rate has greatly declined since the early 1990s?

2. Why is it difficult to measure crime accurately? Why is the measurement of crime by the FBI inaccurate?

\section{References}

Becker, H. S. (1963). Outsiders: Studies in the sociology of deviance. New York, NY: Free Press. 
Catalano, S. M. (2006). The measurement of crime: Victim reporting and police recording. New York, NY: LFB Scholarly.

Federal Bureau of Investigation. (2011). Crime in the United States, 2010. Washington, DC: Author.

Feld, B. C. (2003). The politics of race and juvenile justice: The "due process revolution" and the conservative reaction. Justice Quarterly, 20, 765-800.

Freeman, M. (1994, March 14). Networks doubled crime coverage in '93, despite flat violence levels in US society. Mediaweek, 4, p. 4.

Hart, A. (2004, February 21). Report finds Atlanta police cut figures on crimes. New York Times, p. A1.

Jackson, D. Z. (1997, September 10). No wonder we're afraid of youths. The Boston Globe, p. A15.

Robinson, M. B. (2011). Media coverage of crime and criminal justice. Durham, NC: Carolina Academic Press.

Surette, R. (2011). Media, crime, and criminal justice: Images, realities, and policies (4th ed.). Belmont, CA: Wadsworth. 


\subsection{Types of Crime}

\section{Learning Objectives}

1. Describe the major aspects of homicide.

2. Discuss evidence indicating that white-collar crime is more serious than street crime.

3. Explain the major issues raised by the concept of consensual crime.

Many types of crime exist. Criminologists commonly group crimes into several major categories: (1) violent crime; (2) property crime; (3) white-collar crime; (4) organized crime; and (5) consensual or victimless crime. Within each category, many more specific crimes exist. For example, violent crime includes homicide, aggravated and simple assault, rape and sexual assault, and robbery, while property crime includes burglary, larceny, motor vehicle theft, and arson. Because a full discussion of the many types of crime would take several chapters or even an entire book or more, we highlight here the most important dimensions of the major categories of crime and the issues they raise for public safety and crime control.

\section{Violent Crime}

Even if, as our earlier discussion indicated, the news media exaggerate the problem of violent crime, it remains true that violent crime plagues many communities around the country and is the type of crime that most concerns Americans. The news story that began this chapter reminds us that violent crime is all too real for too many people; it traps some people inside their homes and makes others afraid to let their children play outside or even to walk to school. Rape and sexual assault are a common concern for many women and leads them to be more fearful of being victimized than men: In the 2011 Gallup poll mentioned earlier, 37 percent of women said they worried about being sexually assaulted, compared to only 6 percent of men (see Figure 8.1 "Gender and Worry about Being Sexually Assaulted (Percentage Saying They Worry "Frequently” or "Occasionally”)”). 


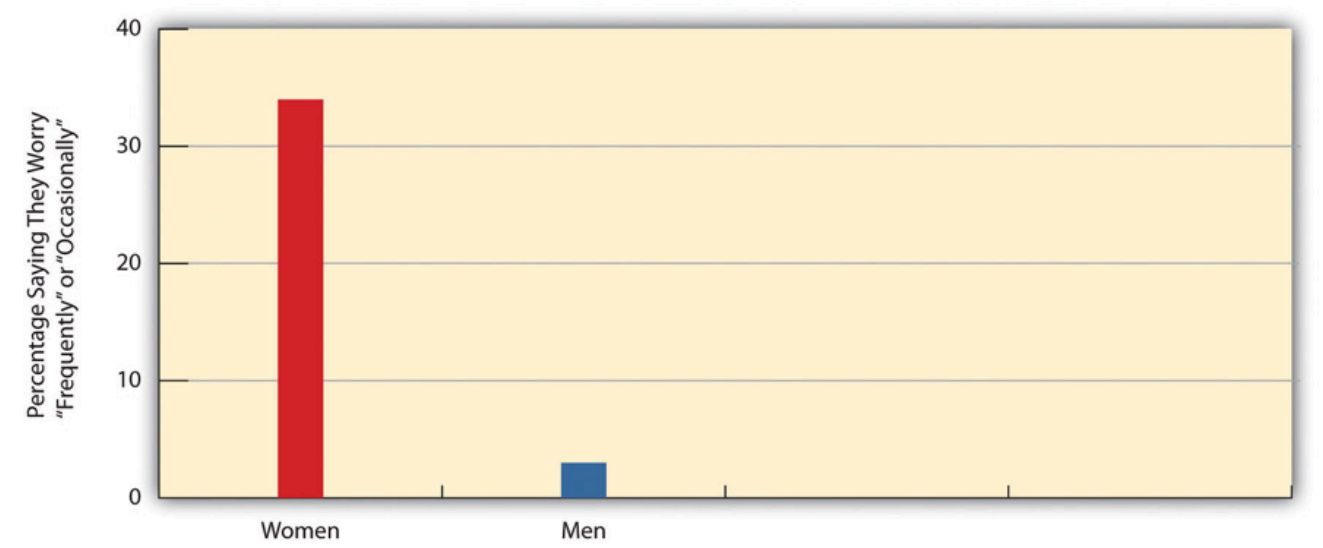

Source: Data from Maguire, K. (Ed.). (2011). Sourcebook of criminal justice statistics. Retrieved from http://www.albany.edu/ sourcebook.

Research on violent crime tends to focus on homicide and on rape and sexual assault. Homicide, of course, is considered the most serious crime because it involves the taking of a human life. As well, homicide data are considered more accurate than those for other crimes because most homicides come to the attention of the police and are more likely than other crimes to lead to an arrest. For its part, the focus on rape and sexual assault reflects the contemporary women's movement's interest in these related crimes beginning in the 1970s and the corresponding interest of criminologists, both female and male, in the criminal victimization of women.

Certain aspects of homicide are worth noting. First, although some homicides are premeditated, most in fact are relatively spontaneous and the result of intense emotions like anger, hatred, or jealousy (Fox, Levin, \& Quinet, 2012). Two people may begin arguing for any number of reasons, and things escalate. A fight may then ensue that results in a fatal injury, but one of the antagonists may also pick up a weapon and use it. About 25-50 percent of all homicides are victim-precipitated, meaning that the eventual victim is the one who starts the argument or the first one to escalate it once it has begun.

Second, and related to the first aspect, most homicide offenders and victims knew each other before the homicide occurred. Indeed, about three-fourths of all homicides involve nonstrangers, and only one-fourth involve strangers. Intimate partners (spouses, ex-spouses, and current and former partners) and other relatives commit almost 30 percent of all homicides (Messner, Deane, \& Beaulieu, 2002). Thus although fear of a deadly attack by a stranger dominates the American consciousness, we in fact are much more likely on average to be killed by someone we know than by someone we do not know. 


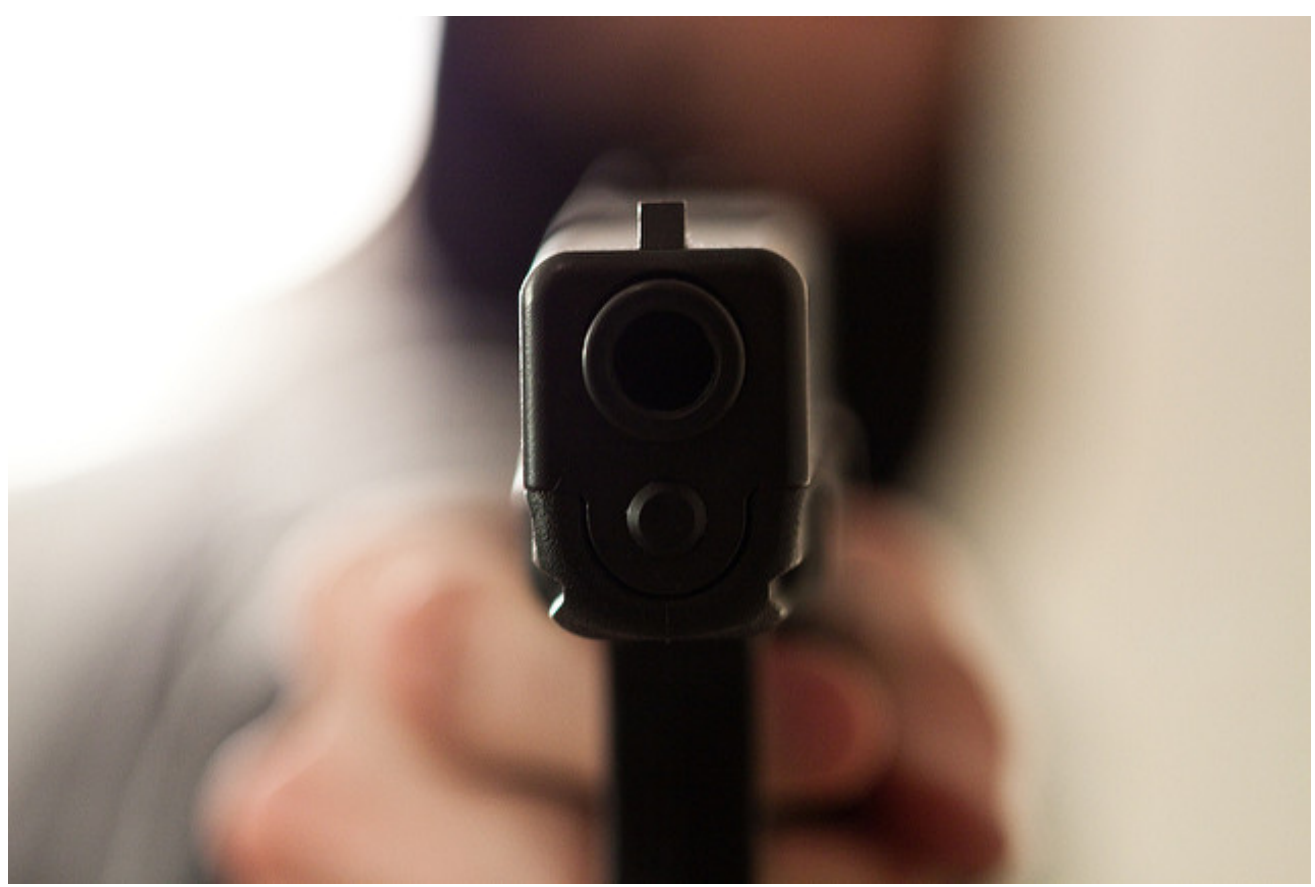

About two-thirds of homicides involve firearms, and half involve a handgun.

Geoffery Fairchild - The Robbery - CC BY 2.0.

Third, about two-thirds of homicides involve firearms. To be a bit more precise, just over half involve a handgun, and the remaining firearm-related homicides involve a shotgun, rifle, or another undetermined firearm. Combining these first three aspects, then, the most typical homicide involves nonstrangers who have an argument that escalates and then results in the use of deadly force when one of the antagonists uses a handgun.

Fourth, most homicides (as most violent crime in general) are intraracial, meaning that they occur within the same race; the offender and victim are of the same race. For single offender/single victim homicides where the race of both parties is known, about 90 percent of African American victims are killed by African American offenders, and about 83 percent of white victims are killed by white offenders (Federal Bureau of Investigation, 2011). Although whites fear victimization by African Americans more than by whites, whites in fact are much more likely to be killed by other whites than by African Americans. While African Americans do commit about half of all homicides, most of their victims are also African American.

Fifth, males commit about 90 percent of all homicides and females commit only 10 percent. As we discuss in Section 3.1 "Racial and Ethnic Inequality: A Historical Prelude", males are much more likely than women to commit most forms of crime, and this is especially true for homicide and other violent crime.

Sixth, the homicide rate is much higher in large cities than in small towns. In 2010, the homicide rate (number of homicides per 100,000 population) in cities with a population at or over 250,000 was 10.0 percent, compared to only 2.5 percent in towns with a population between 10,000 and 24,999 (see Figure 8.2 "Population Size and Homicide Rate, 2010"). Thus the risk for homicide is four times greater in large cities than in small towns. While most people in large cities certainly do not die from homicide, where we live still makes a difference in our chances of being victimized by homicide and other crime. 


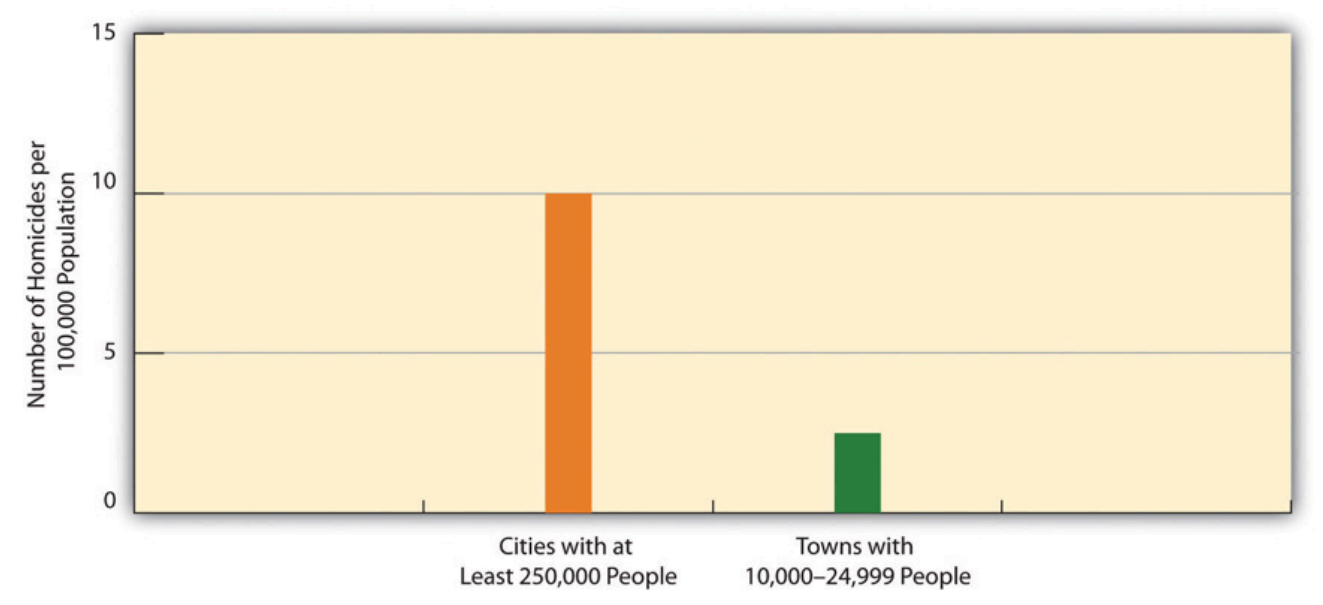

Source: Data from Federal Bureau of Investigation. (2011). Crime in the United States, 2010. Washington, DC: Author.

Finally, the homicide rate rose in the late 1980s and peaked during the early 1990s before declining sharply until the early 2000s and then leveling off and declining a bit further since then. Although debate continues over why the homicide rate declined during the 1990s, many criminologists attribute the decline to a strong economy, an ebbing of gang wars over drug trafficking, and a decline of people in the 15-25 age group that commits a disproportionate amount of crime (Blumstein \& Wallman, 2006). Some observers believe rising imprisonment rates also made a difference, and we return to this issue later in this chapter.

Rape and sexual assault were included in Chapter 4 "Gender Inequality”'s discussion of violence against women as a serious manifestation of gender inequality. As that chapter noted, it is estimated that one-third of women on the planet have been raped or sexually assaulted, beaten, or physically abused in some other way (Heise, Ellseberg, \& Gottemoeller, 1999). While it is tempting to conclude that such violence is much more common in poor nations than in a wealthy nation like the United States, we saw in Chapter 4 "Gender Inequality" that violence against women is common in this nation as well. Like homicide, about three-fourths of all rapes and sexual assaults involve individuals who know each other, not strangers.

\section{Property Crime}

As noted earlier, the major property crimes are burglary, larceny, motor vehicle theft, and arson. These crimes are quite common in the United States and other nations and, as Table 8.1 "Number of Crimes: Uniform Crime Reports (UCR) and National Crime Victimization Survey (NCVS), 2010” indicated, millions occur annually in this country. Many Americans have installed burglar alarms and other security measures in their homes and similar devices in their cars and SUVs. While property crime by definition does not involve physical harm, it still makes us concerned, in part because it touches so many of us. Although property crime has in fact declined along with violent crime since the early 1990s, it still is considered a major component of the crime problem, because it is so common and produces losses of billions of dollars annually.

Much property crime can be understood in terms of the roles and social networks of property criminals. In this regard, many scholars distinguish between amateur theft and professional theft. Most property offenders are amateur offenders: They are young and unskilled in the ways of crime, and the amount they gain from any single 
theft is relatively small. They also do not plan their crimes and instead commit them when they see an opportunity for quick illegal gain. In contrast, professional property offenders tend to be older and quite skilled in the ways of crime, and the amount they gain from any single theft is relatively large. Not surprisingly, they often plan their crimes well in advance. The so-called cat burglar, someone who scales tall buildings to steal jewels, expensive artwork, or large sums of money, is perhaps the prototypical example of the professional property criminals. Many professional thieves learn how to do their crimes from other professional thieves, and in this sense they are mentored by the latter just as students are mentored by professors, and young workers by older workers.

\section{White-Collar Crime}

If you were asked to picture a criminal in your mind, what image would you be likely to think of first: a scruffy young male with a scowl or sneer on his face, or a handsome, middle-aged man dressed in a three-piece business suit? No doubt the former image would come to mind first, if only because violent crime and property crime dominate newspaper headlines and television newscasts and because many of us have been victims of violent or property crime. Yet white-collar crime is arguably much more harmful than street crime, both in terms of economic loss and of physical injury, illness, and even death.

What exactly is white-collar crime? The most famous definition comes from Edwin Sutherland (1949, p. 9), a sociologist who coined the term in the 1940s and defined it as "a crime committed by a person of respectability and high social status in the course of his occupation." Sutherland examined the behavior of the seventy largest US corporations and found that they had violated the law hundreds of times among them. Several had engaged in crimes during either World War I or II; they provided defective weapons and spoiled food to US troops and even sold weapons to Germany and other nations the United States was fighting.

Although white-collar crime as studied today includes auto shop repair fraud and employee theft by cashiers, bookkeepers, and other employees of relatively low status, most research follows Sutherland's definition in focusing on crime committed by people of "respectability and high social status.” Thus much of the study of white-collar crime today focuses on fraud by physicians, attorneys, and other professionals and on illegal behavior by executives of corporations designed to protect or improve corporate profits (corporate crime).

In the study of professional fraud, health-care fraud stands out for its extent and cost (Rosoff, Pontell, \& Tillman, 2010). Health-care fraud is thought to amount to more than $\$ 100$ billion per year, compared to less than $\$ 20$ billion for all property crime combined. For example, some physicians bill Medicare and private insurance for services that patients do not really need and may never receive. Medical supply companies sometimes furnish substandard equipment. To compensate for the economic loss it incurs, health-care fraud drives up medical expenses and insurance costs. In this sense, it steals from the public even though no one ever breaks into your house or robs you at gunpoint.

Although health-care and other professional fraud are serious, corporate crime dwarfs all other forms of whitecollar crime in the economic loss it incurs and in the death, injury, and illness it causes. Corporate financial crime involves such activities as fraud, price fixing, and false advertising. The Enron scandal in 2001 involved an energy corporation whose chief executives exaggerated profits. After their fraud and Enron's more dire financial state were finally revealed, the company's stock plummeted and it finally went bankrupt. Its thousands of workers lost 
their jobs and pensions, and investors in its stock lost billions of dollars. Several other major corporations engaged in (or strongly suspected of doing so) accounting fraud during the late 1990s and early 2000s, but Enron was merely the most notorious example of widespread scandal that marked this period.

While corporate financial crime and corruption have cost the nation untold billions of dollars in this and earlier decades, corporate violence-actions by corporations that kill or maim people or leave them ill —is even more scandalous. The victims of corporate violence include corporate employees, consumers of corporate goods, and the public as a whole. Annual deaths from corporate violence exceed the number of deaths from homicide, and illness and injury from corporate violence affect an untold number of people every year.

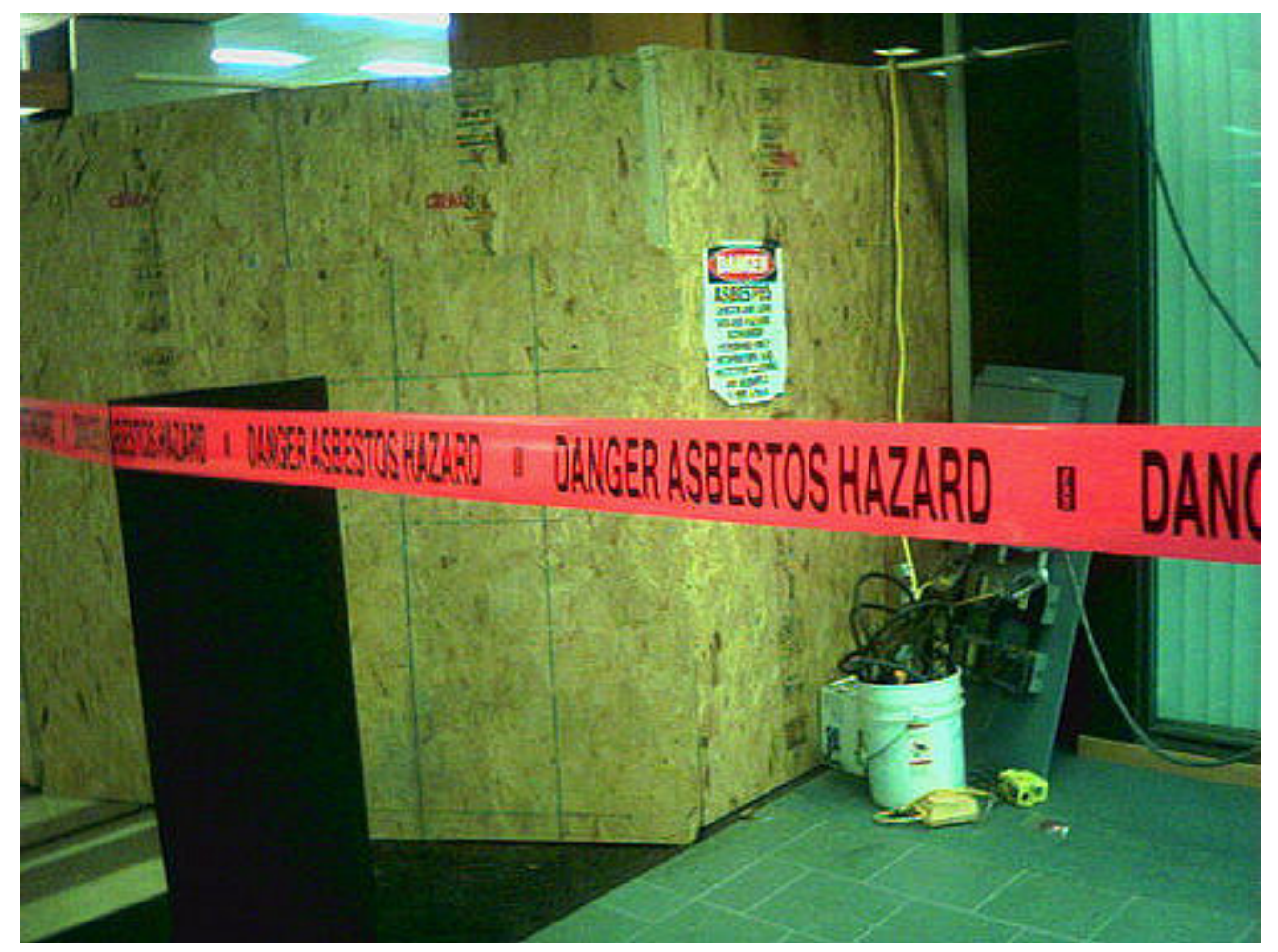

The asbestos industry learned in the 1930s that asbestos was a major health hazard, but it kept this discovery a secret for more than three decades.

Aaron Suggs - $\underline{\text { Asbestos }}-$ CC BY 2.0.

Employees of corporations suffer from unsafe workplaces in which workers are exposed to hazardous conditions and chemicals because their companies fail to take adequate measures to reduce or eliminate this exposure. Such exposure may result in illness, and exposure over many years can result in death. According to a recent estimate, more than 50,000 people die each year from workplace exposure (American Federation of Labor and Congress of Industrial Organizations [AFL-CIO], 2010), a figure about three times greater than the number of annual homicides. About 1,500 coal miners die each year from black lung disease, which results from the breathing of coal dust; many and perhaps most of these deaths would be preventable if coal mining companies took adequate safety measures (G. Harris, 1998). In another example, the asbestos industry learned during the 1930s that exposure to asbestos could cause fatal lung disease and cancer. Despite this knowledge, asbestos companies hid evidence of this hazard for more than three decades: They allowed their workers to continue to work with asbestos and marketed asbestos as a fire retardant that was widely installed in schools and other buildings. More than 
200,000 asbestos workers and members of the public either have already died or are expected to die from asbestos exposure; most or all of these deaths could have been prevented if the asbestos industry had acted responsibly when it first discovered it was manufacturing a dangerous product (Lilienfeld, 1991).

Unsafe products also kill or maim consumers. One of the most notorious examples of deaths from an unsafe product involved the Ford Pinto, a car first sold in the early 1970s that was vulnerable to fire and explosion when hit from behind in a minor rear-end collision (Cullen, Maakestad, \& Cavender, 2006). Ford knew before the Pinto went on the market that its gas tank was unusually vulnerable in a rear-end collision and determined it would take about \$11 per car to fix the problem. It then did a cost-benefit analysis to determine whether it would cost more to fix the problem or instead to settle lawsuits after Pinto drivers and passengers died or were burned and injured in rear-end collisions. This analysis indicated that Ford would save about $\$ 87$ million if it did not fix the problem and instead paid out compensation after Pinto drivers and passengers died or got burned. Because Ford made this decision, about five hundred people eventually died in Pinto rear-end collisions and many others were burned.

The toll of white-collar crime, both financial and violent, is difficult to estimate, but by all accounts it exceeds the economic loss and death and injury from all street crime combined. White-collar crime is thought to involve an annual economic loss of more than $\$ 700$ billion annually from corporate fraud, professional fraud, employee theft, and tax evasion and an annual toll of at least 100,000 deaths from workplace-related illness or injury, unsafe products, and preventable environmental pollution. These figures compare to an economic loss of less than \$20 billion from property crime and a death toll of about 17,000 from homicide (Barkan, 2012). By any measure, the toll of white-collar crime dwarfs the toll of street crime, even though the latter worries us much more than whitecollar crime. Despite the harm that white-collar crime causes, the typical corporate criminal receives much more lenient punishment, if any, than the typical street criminal (Rosoff et al., 2010).

\section{Organized Crime}

Organized crime refers to criminal activity by groups or organizations whose major purpose for existing is to commit such crime. When we hear the term "organized crime," we almost automatically think of the so-called Mafia, vividly portrayed in the Godfather movies and other films, that comprises several highly organized and hierarchical Italian American "families.” Although Italian Americans have certainly been involved in organized crime in the United States, so have Irish Americans, Jews, African Americans, and other ethnicities over the years. The emphasis on Italian domination of organized crime overlooks these other involvements and diverts attention from the actual roots of organized crime.

What are these roots? Simply put, organized crime exists and even thrives because it provides goods and/or services that the public demands. Organized crime flourished during the 1920s because it was all too ready and willing to provide an illegal product, alcohol, that the pubic continued to demand even after Prohibition began. Today, organized crime earns its considerable money from products and services such as illegal drugs, prostitution, pornography, loan sharking, and gambling. It also began long ago to branch out into legal activities such as trash hauling and the vending industry.

Government efforts against organized crime since the 1920s have focused on arrest, prosecution, and other law-enforcement strategies. Organized crime has certainly continued despite these efforts. This fact leads some 
scholars to emphasize the need to reduce public demand for the goods and services that organized crime provides. However, other scholars say that reducing this demand is probably a futile or mostly futile task, and they instead urge consideration of legalizing at least some of the illegal products and services (e.g., drugs and prostitution) that organized crime provides. Doing so, they argue, would weaken the influence of organized crime.

\section{Consensual Crime}

Consensual crime (also called victimless crime) refers to behaviors in which people engage voluntarily and willingly even though these behaviors violate the law. Illegal drug use, discussed in Chapter 7 "Alcohol and Other Drugs”, is a major form of consensual crime; other forms include prostitution, gambling, and pornography. People who use illegal drugs, who hire themselves out as prostitutes or employ the services of a prostitute, who gamble illegally, and who use pornography are all doing so because they want to. These behaviors are not entirely victimless, as illegal drug users, for example, may harm themselves and others, and that is why the term consensual crime is often preferred over victimless crime. As just discussed, organized crime provides some of the illegal products and services that compose consensual crime, but these products and services certainly come from sources other than organized crime.

This issue aside, the existence of consensual crime raises two related questions that we first encountered in Chapter 7 "Alcohol and Other Drugs". First, to what degree should the government ban behaviors that people willingly commit and that generally do not have unwilling victims? Second, do government attempts to ban such behaviors do more good than harm or more harm than good? Chapter 7 "Alcohol and Other Drugs"'s discussion of these questions focused on illegal drugs, and in particular on the problems caused by laws against certain drugs, but similar problems arise from laws against other types of consensual crime. For example, laws against prostitution enable pimps to control prostitutes and help ensure the transmission of sexual diseases because condoms are not regularly used.

Critics of consensual crime laws say we are now in a new prohibition and that our laws against illegal drugs, prostitution, and certain forms of gambling are causing the same problems now that the ban on alcohol did during the 1920s and, more generally, cause more harm than good. Proponents of these laws respond that the laws are still necessary as an expression of society's moral values and as a means, however imperfect, of reducing involvement in harmful behaviors.

\section{Key Takeaways}

- Most homicides are committed for relatively emotional, spontaneous reasons and between people who knew each other beforehand.

- White-collar crime involves more death, injury, and economic loss than street crime, but the punishment of white-collar crime is relatively weak.

- Consensual crime raises two related issues: (a) To what extent should the government prohibit people from engaging in behavior in which there are no unwilling victims, and (b) do laws against consensual crime do more good than harm or more harm than good? 


\section{For Your Review}

1. If homicide is a relatively emotional, spontaneous crime, what does that imply for efforts to use harsh legal punishment, including the death penalty, to deter people from committing homicide?

2. Do you think consensual crimes should be made legal? Why or why not?

\section{References}

American Federation of Labor and Congress of Industrial Organizations (AFL-CIO). (2010). Death on the job: The toll of neglect. Washington, DC: Author.

Barkan, S. E. (2012). Criminology: A sociological understanding (5th ed.). Upper Saddle River, NJ: Prentice Hall.

Blumstein, A., \& Wallman, J. (Eds.). (2006). The crime drop in America (2nd ed.). Cambridge: Cambridge University Press.

Federal Bureau of Investigation. (2011). Crime in the United States, 2010. Washington, DC: Federal Author.

Fox, J. A., Levin, J., \& Quinet, K. (2012). The will to kill: Making sense of senseless murder. Upper Saddle River, NJ: Prentice Hall.

Harris, G. (1998, April 19). Despite laws, hundreds are killed by black lung. The Courier-Journal (Louisville, $K Y)$, p. A1.

Heise, L., Ellseberg, M., \& Gottemoeller, M. (1999). Ending violence against women. Population Reports, 27(4), $1-44$.

Cullen, F. T., Maakestad, W. J., \& Cavender, G. (2006). Corporate crime under attack: The fight to criminalize business violence. Cincinnati, $\mathrm{OH}$ : Anderson.

Lilienfeld, D. E. (1991). The silence: The asbestos industry and early occupational cancer research—a case study. American Journal of Public Health, 81, 791-800.

Messner, S. F., Deane, G., \& Beaulieu, M. (2002). A log-multiplicative association model for allocating homicides with unknown victim-offender relationships. Criminology, 40, 457-479.

Rosoff, S. M., Pontell, H. N., \& Tillman, R. (2010). Profit without honor: White collar crime and the looting of America (5th ed.). Upper Saddle River, NJ: Prentice Hall.

Sutherland, E. H. (1949). White collar crime. New York, NY: Holt, Rinehart, and Winston. 


\subsection{Who Commits Crime?}

\section{Learning Objectives}

1. Explain why males commit more crime than females.

2. Discuss whether social class differences exist in crime rates.

3. Discuss whether racial/ethnic differences exist in crime rates.

While people from all walks of life commit street crime, some people are still more likely than others to break the law because of their social backgrounds. These social backgrounds include their gender, age, social class, urban/ rural residence, and race and ethnicity. Despite their inaccuracies, the three data sources discussed in the first section of this chapter all provide a similar picture of what kinds of people, in terms of their social backgrounds, are more or less likely to commit street crime. We briefly discuss each background in turn.

\section{Gender}

Simply put, males commit much more crime than females. In UCR data, men comprise about 81 percent of all arrests for violent crime and about 63 percent of all arrests for property crime. (See Figure 8.3 "Gender and Arrest (Percentage of All Arrests)”.) In the NCVS, victims report that males commit most of the violent crimes they experienced, and self-report studies find that males far outpace females in the commission of serious street offenses. When it comes to breaking the law, crime is a man's world.

Figure 8.3 Gender and Arrest (Percentage of All Arrests)

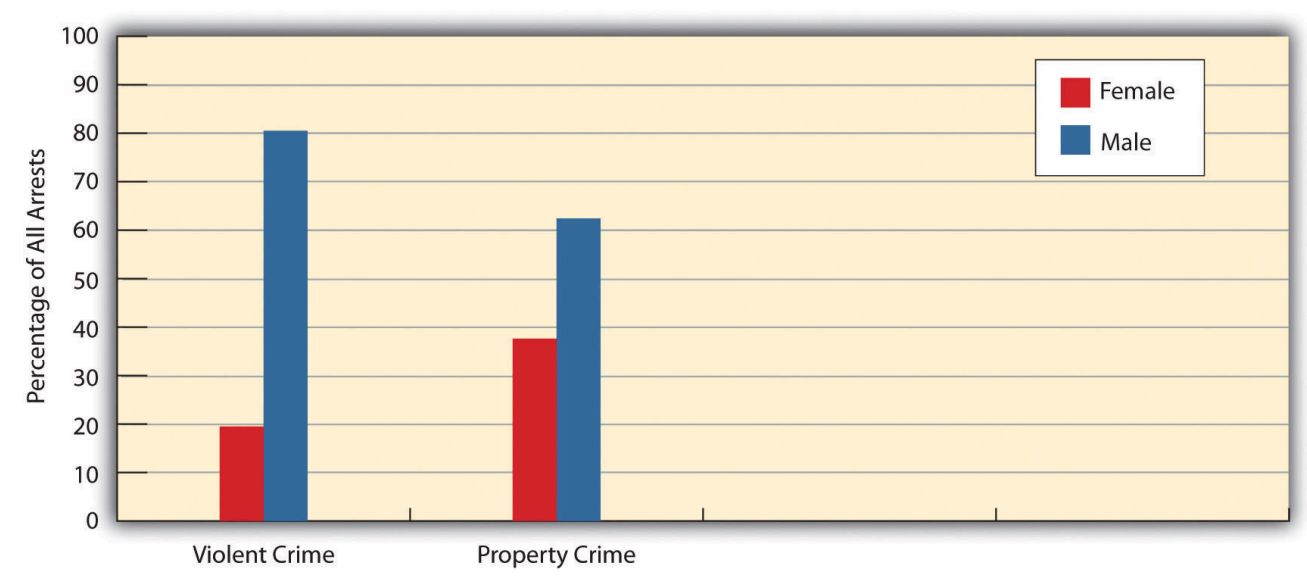

Source: Data from Federal Bureau of Investigation. (2011). Crime in the United States, 2010. Washington, DC: Author. 
The key question is why such a large gender difference exists. Some scholars attribute this difference to biological differences between the sexes, but most criminologists attribute it to sociological factors. One of these is gender role socialization: Despite greater recognition of gender roles, we continue to raise our boys to be assertive and aggressive, while we raise our girls to be gentle and nurturing (Lindsey, 2011). Such gender socialization has many effects, and one of these is a large gender difference in criminal behavior. A second factor is opportunity. Studies find that parents watch their daughters more closely than they watch their sons, who are allowed to stay out later at night and thus have more opportunity to break the law.

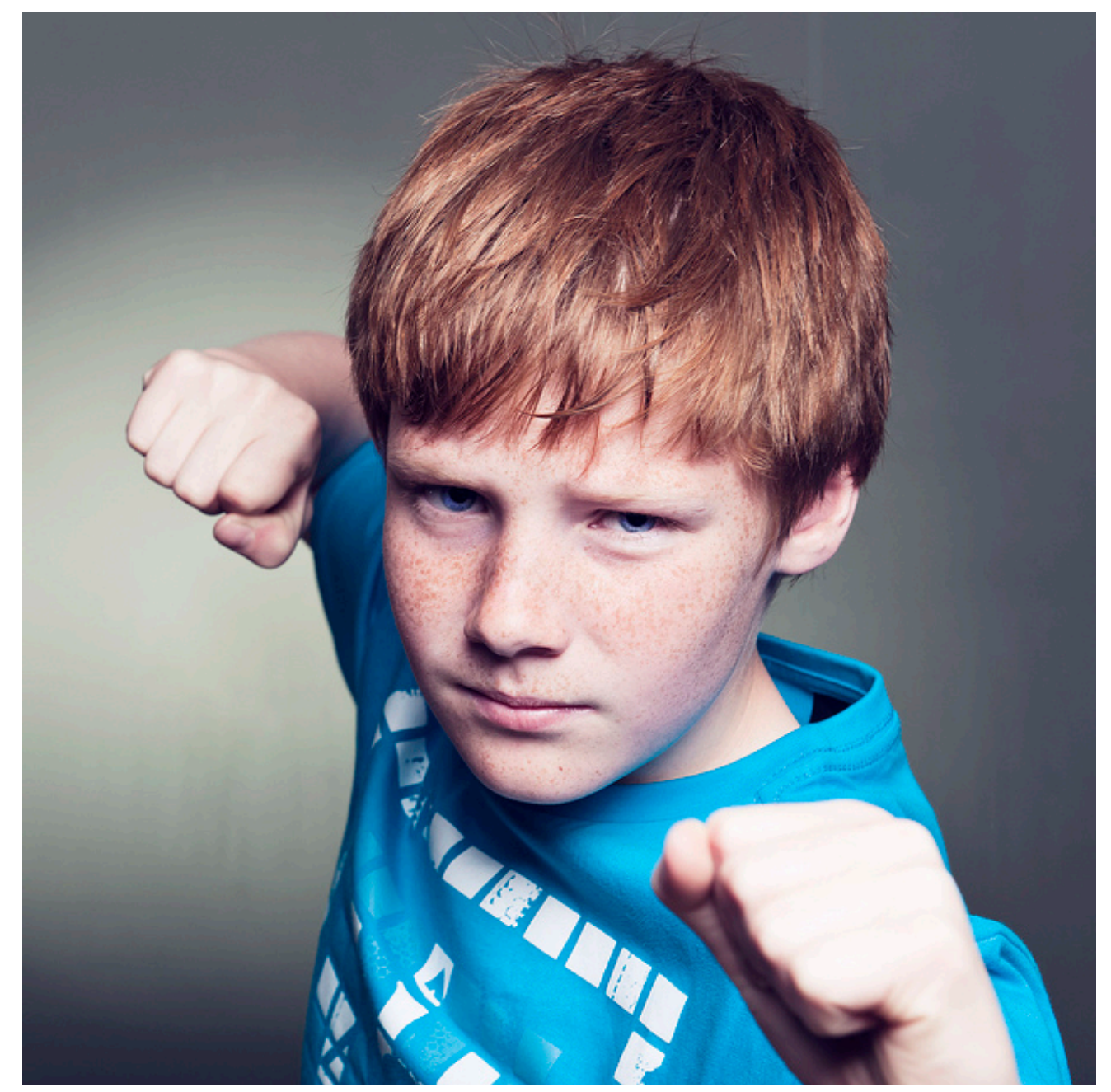

Males have higher crime rates than females. An important reason for this gender difference is that boys are socialized to be assertive and aggressive, while girls are socialized to be gentle and nurturing.

Philippe Put - $\underline{\text { Fight }}$ - CC BY 2.0.

\section{Age}

Age also makes a difference in criminal behavior: Offending rates are highest in the late teens and early twenties and decline thereafter. Accordingly, people in the 15-24 age range account for about 40 percent of all arrests even though they comprise only about 14 percent of the population. 
Several factors again seem to account for this pattern (Shoemaker, 2010). First, peer relationships matter more during this time of one's life than later, and peers are also more likely during this period than later to be offenders themselves. For both reasons, our peer relationships during our teens and early twenties are more likely than those in our later years to draw us into crime. Second, adolescents and young adults are more likely than older adults to lack full-time jobs; for this reason, they are more likely to need money and thus to commit offenses to obtain money and other possessions. Third, as we age out of our early twenties, our ties to conventional society increase: Many people marry, have children, and begin full-time employment, though not necessarily in that order. These events and bonds increase our stakes in conformity, to use some social science jargon, and thus reduce our desire to break the law (Laub, Sampson, \& Sweeten, 2006).

\section{Social Class}

Findings on social class differences in crime are less clear than they are for gender or age differences. Arrests statistics and much research indicate that poor people are much more likely than wealthier people to commit street crime. However, some scholars attribute the greater arrests of poor people to social class bias against them. Despite this possibility, most criminologists would probably agree that social class differences in criminal offending are "unmistakable” (Harris \& Shaw, 2000, p. 138). Reflecting this conclusion, one sociologist has even noted, with tongue only partly in cheek, that social scientists know they should not "stroll the streets at night in certain parts of town or even to park there" and that areas of cities that frighten them are "not upper-income neighborhoods" (Stark, 1987, p. 894). Thus social class does seem to be associated with street crime, with poor individuals doing more than their fair share.

Explanations of this relationship center on the effects of poverty, which, as the next section will discuss further, is said to produce anger, frustration, and economic need and to be associated with a need for respect and with poor parenting skills and other problems that make children more likely to commit antisocial behavior when they reach adolescence and beyond. These effects combine to lead poor people to be more likely than wealthier people to commit street crime, even if it is true that most poor people do not commit street crime at all.

Although the poor are more likely than the wealthy to commit street crime, it is also true that the wealthy are much more likely than the poor to commit white-collar crime, which, as argued earlier, can be much more harmful than street crime. If we consider both street crime and white-collar crime, then there does not appear to be a social class-crime relationship, since the poor have higher rates of the former and the wealthy have higher rates of the latter.

\section{Urban versus Rural Residence}

Where we live also makes a difference for our likelihood of committing crime. We saw earlier that big cities have a much higher homicide rate than small towns. This trend exists for violent crime and property crime more generally. Urban areas have high crime rates in part because they are poor, but poverty by itself does not completely explain the urban-rural difference in crime, since many rural areas are poor as well. A key factor that explains the higher crime rates of urban areas is their greater population density (Stark 1987). When many people 
live close together, they come into contact with one another more often. This fact means that teenagers and young adults have more peers to influence them to commit crime, and it also means that potential criminals have more targets (people and homes) for their criminal activity. Urban areas also have many bars, convenience stores, and other businesses that can become targets for potential criminals, and bars, taverns, and other settings for drinking can obviously become settings where tempers flare and violence ensues.

\section{Race and Ethnicity}

In discussing who commits crime, any discussion of race and ethnicity is bound to arouse controversy because of the possibility of racial and ethnic stereotyping. But if we can say that men and younger people have relatively high crime rates without necessarily sounding biased against individuals who are male or younger, then it should be possible to acknowledge that certain racial and ethnic groups have higher crime rates without sounding biased against them.

Keeping this in mind, race and ethnicity do seem to be related to criminal offending. In particular, much research finds that African Americans and Latinos have higher rates of street crime than non-Latino whites. For example, although African Americans comprise about 13 percent of the US population, they account for about 39 percent of all arrests for violent crime (see Figure 8.4 "Race and Arrest for Violent Crime (Percentage of All Violent Crime Arrests)").

Figure 8.4 Race and Arrest for Violent Crime (Percentage of All Violent Crime Arrests)

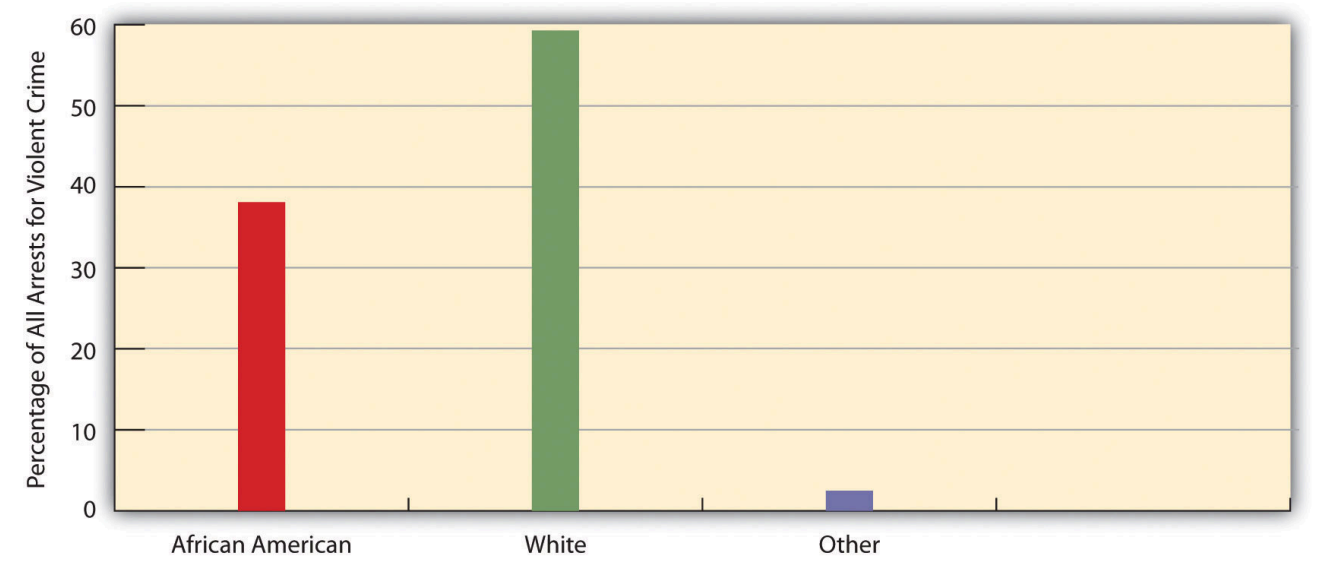

Source: Data from Federal Bureau of Investigation. (2011). Crime in the United States, 2010. Washington, DC: Author.

Latinos also have higher crime rates than non-Latino whites, but lower rates than those for African Americans. Although racial and ethnic bias by the criminal justice system may account for some of these racial/ethnic differences in offending, most criminologists agree that such differences do in fact exist for serious street crimes (Walker, Spohn, \& DeLone, 2012).

Why do these differences exist? A racist explanation would attribute them to biological inferiority of the groups, African Americans and Latinos, with the relatively high rates of offending. Such explanations were popular several generations ago but fortunately lost favor as time passed and attitudes changed. Today, scholars attribute racial/ethnic differences in offending to several sociological factors (Unnever \& Gabbidon, 2011). First, African 
Americans and Latinos are much poorer than whites on the average, and poverty contributes to higher crime rates. Second, they are also more likely to live in urban areas, which, as we have seen, also contribute to higher crime rates. Third, the racial and ethnic discrimination they experience leads to anger and frustration that in turn can promote criminal behavior. Although there is less research on Native Americans' criminality, they, too, appear to have higher crime rates than whites because of their much greater poverty and experience of racial discrimination (McCarthy \& Hagan, 2003).

In appreciating racial/ethnic differences in street crime rates, it is important to keep in mind that whites commit most white-collar crime, and especially corporate crime, as it is white people who lead and manage our many corporations. Just as social class affects the type of crime that people do, so do race and ethnicity. Wealthy, white people commit much crime, but it is white-collar crime they tend to commit, not street crime.

\section{Key Takeaways}

- Males commit more street crime than females, in part because of gender role socialization that helps make males more assertive and aggressive.

- Young people commit a disproportionate amount of street crime, in part because of the influence of their peers and their lack of stakes in conformity.

- The disproportionate involvement of African Americans and Latinos in street crime arises largely from their poverty and urban residence.

\section{For Your Review}

1. If we say that males commit more crime than females, does that imply that we are prejudiced against males? Why or why not?

2. Write a brief essay that outlines social class and racial/ethnic differences in street crime and explains the reasons for these differences.

\section{References}

Harris, A. R., \& Shaw, J. A. W. (2000). Looking for patterns: Race, class, and crime. In J. F.Sheley (Ed.), Criminology: A contemporary handbook (3rd ed., pp. 129-163). Belmont, CA: Wadsworth.

Laub, J. H., Sampson, R. J., \& Sweeten, G. A. (2006). Assessing Sampson and Laub’s life-course theory of crime. In F. T. Cullen (Ed.), Taking stock: The status of criminological theory (Vol. 15, pp. 313-333). New Brunswick, NJ: Transaction.

Lindsey, L. L. (2011). Gender roles: A sociological perspective (5th ed.). Upper Saddle River, NJ: Prentice Hall. McCarthy, B., \& Hagan, J. (2003). Sanction effects, violence, and native North American street youth. In D. 
F. Hawkins (Ed.), Violent crime: Assessing race and ethnic differences (pp. 117-137). Cambridge: Cambridge University Press.

Shoemaker, D. J. (2010). Theories of delinquency: An examination of explanations of delinquent behavior (6th ed.). New York, NY: Oxford University Press.

Stark, R. (1987). Deviant places: A theory of the ecology of crime. Criminology, 25, 893-911.

Unnever, J. D., \& Gabbidon, S. L. (2011). A theory of African American offending: Race, racism, and crime. New York, NY: Routledge.

Walker, S., Spohn, C., \& DeLone, M. (2012). The color of justice: Race, ethnicity, and crime in America (5th ed.). Belmont, CA: Wadsworth. 


\subsection{Explaining Crime}

\section{Learning Objectives}

1. Understand social structure theories of crime.

2. Explain the social bonding theory of crime.

3. Describe the general assumptions of conflict theories of crime.

If we want to be able to reduce crime, we must first understand why it occurs. Sociologists generally discount explanations rooted in the individual biology or psychology of criminal offenders. While a few offenders may suffer from biological defects or psychological problems that lead them to commit crime, most do not. Further, biological and psychological explanations cannot adequately explain the social patterning of crime discussed earlier: why higher crime rates are associated with certain locations and social backgrounds. For example, if California has a higher crime rate than Maine, and the United States has a higher crime rate than Canada, it would sound silly to say that Californians and Americans have more biological and psychological problems than Mainers and Canadians, respectively. Biological and psychological explanations also cannot easily explain why crime rates rise and fall, nor do they lend themselves to practical solutions for reducing crime.

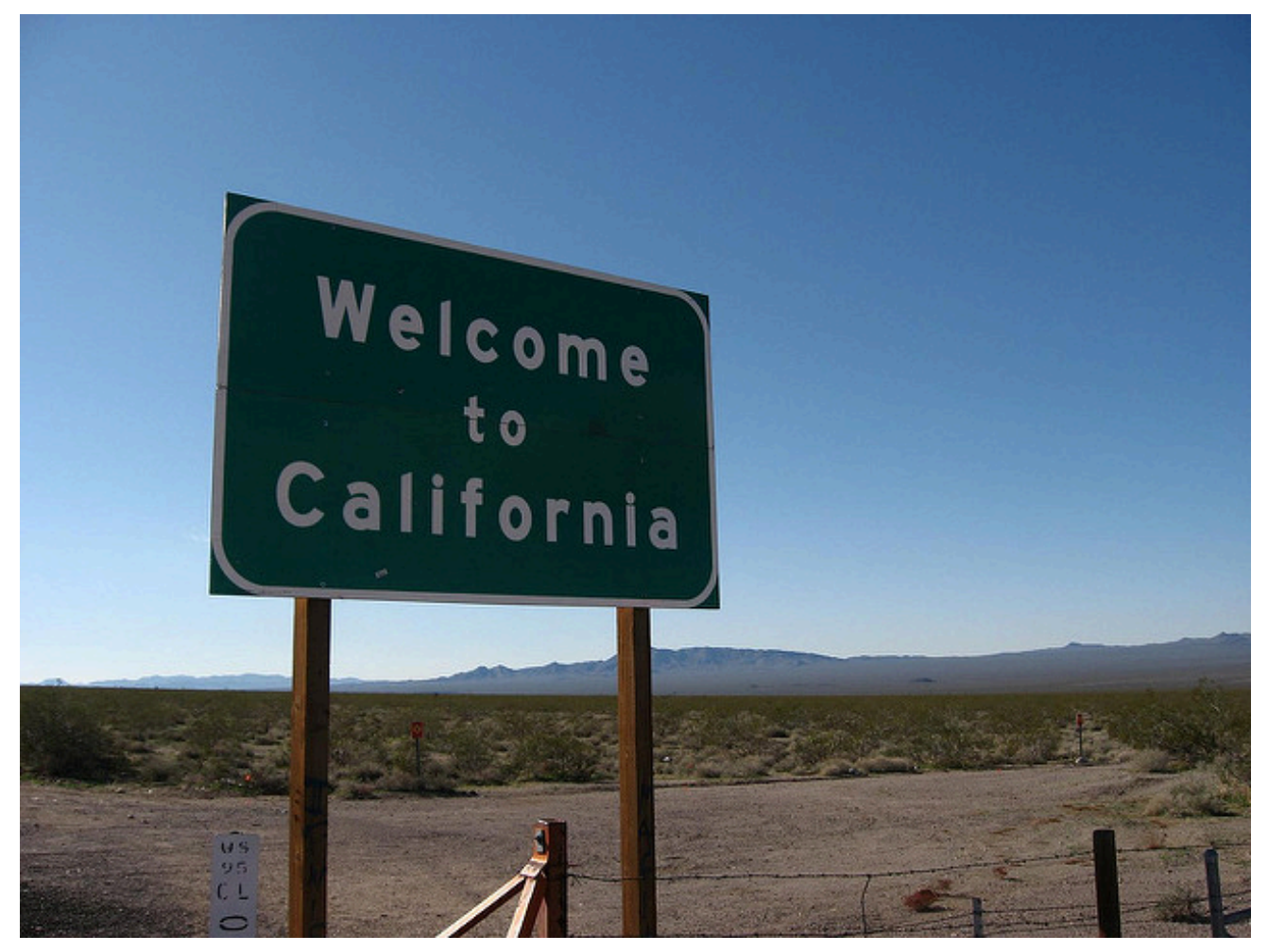


California has a higher crime rate than many other states, but it is difficult to argue that Californians have more biological or

psychological problems than the residents of other states.

Ken Lund - Welcome to California, Nevada-California Border, U.S. 95 - CC BY-SA 2.0.

In contrast, sociological explanations do help understand the social patterning of crime and changes in crime rates, and they also lend themselves to possible solutions for reducing crime. A brief discussion of these explanations follows, and a summary appears in Table 8.2 "Sociological Explanations of Crime".

Table 8.2 Sociological Explanations of Crime

\begin{tabular}{|c|c|c|}
\hline $\begin{array}{l}\text { Major } \\
\text { perspective }\end{array}$ & $\begin{array}{l}\text { Related } \\
\text { explanation }\end{array}$ & Summary of explanation \\
\hline \multirow[t]{2}{*}{$\begin{array}{l}\text { Functional } \\
\text { (social } \\
\text { structure } \\
\text { theories) }\end{array}$} & $\begin{array}{l}\text { Social } \\
\text { disorganization }\end{array}$ & $\begin{array}{l}\text { Certain social characteristics of urban neighborhoods contribute to high crime rates. } \\
\text { These characteristics include poverty, dilapidation, population density, and population } \\
\text { turnover. }\end{array}$ \\
\hline & Anomie & $\begin{array}{l}\text { According to Robert Merton, crime by the poor results from a gap between the cultural } \\
\text { emphasis on economic success and the inability to achieve such success through the } \\
\text { legitimate means of working. }\end{array}$ \\
\hline \multirow[t]{3}{*}{$\begin{array}{l}\text { Interactionist } \\
\text { (social } \\
\text { process } \\
\text { theories) }\end{array}$} & $\begin{array}{l}\text { Differential } \\
\text { association }\end{array}$ & $\begin{array}{l}\text { Edwin } \mathrm{H} \text {. Sutherland argued that criminal behavior is learned by interacting with close } \\
\text { friends who teach us how to commit various crimes and also the values, motives, and } \\
\text { rationalizations we need to adopt in order to justify breaking the law. }\end{array}$ \\
\hline & Social bonding & $\begin{array}{l}\text { Travis Hirschi wrote that delinquency results from weak bonds to conventional social } \\
\text { institutions, such as families and schools. }\end{array}$ \\
\hline & Labeling & $\begin{array}{l}\text { Deviance and crime result from being officially labeled; arrest and imprisonment } \\
\text { increase the likelihood of reoffending. }\end{array}$ \\
\hline \multirow[t]{3}{*}{$\begin{array}{l}\text { Conflict } \\
\text { (conflict } \\
\text { theories) }\end{array}$} & Group conflict & $\begin{array}{l}\text { Criminal law is shaped by the conflict among the various social groups in society that } \\
\text { exist because of differences in race and ethnicity, social class, religion, and other factors. }\end{array}$ \\
\hline & Radical & $\begin{array}{l}\text { The wealthy try to use the law and criminal justice system to reinforce their power and to } \\
\text { keep the poor and people of color at the bottom of society. }\end{array}$ \\
\hline & Feminist & $\begin{array}{l}\text { Gender plays an important role in the following areas: (1) the reasons girls and women } \\
\text { commit crime; (2) the reasons female crime is lower than male crime; (3) the } \\
\text { victimization of girls and women by rape, sexual assault, and domestic violence; and (4) } \\
\text { the experience of women professionals and offenders in the criminal justice system. }\end{array}$ \\
\hline
\end{tabular}

\section{The Functional Perspective: Social Structure Theories}

Social structure theories all stress that crime results from the breakdown of society's norms and social organization and in this sense fall under the functional perspective outlined in Chapter 1 "Understanding Social Problems". They trace the roots of crime to problems in the society itself rather than to biological or psychological problems inside individuals. By doing so, they suggest the need to address society's social structure in order to reduce crime. Several social structure theories exist. 


\section{Social Disorganization Theory}

A popular explanation is social disorganization theory. This approach originated primarily in the work of Clifford R. Shaw and Henry D. McKay (1942), two social scientists at the University of Chicago who studied that city's delinquency rates during the first three decades of the twentieth century. During this time, the ethnic composition of Chicago changed considerably, as the city's inner zones were first occupied by English, German, and Irish immigrants, and then by Eastern European immigrants, and then by African Americans who moved there from southern states. Shaw and McKay found that the inner zones of Chicago consistently had the highest delinquency rates regardless of which ethnic group lived there, and they also found that the ethnic groups' delinquency rates declined as they moved to outer areas of Chicago. To explain these related patterns, Shaw and McKay reasoned that the inner zones of Chicago suffered from social disorganization: A weakening of social institutions such as the family, school, and religion that in turn weakens the strength of social bonds and norms and the effectiveness of socialization. Research today confirms that crime rates are highest in neighborhoods with several kinds of structural problems, including high rates of residential mobility, population density, poverty, and single-parent families (Mazerolle, Wickes, \& McBroom, 2010).

\section{Anomie Theory}

Another popular explanation is anomie theory, first formulated by Robert K. Merton (1938) in a classic article. Writing just after the Great Depression, Merton focused on the effects of poverty in a nation like the United States that places so much emphasis on economic success. With this strong cultural value, wrote Merton, the poor who do not achieve the American dream feel especially frustrated. They have several ways or adaptations of responding to their situation (see Table 8.3 “Anomie Theory”).

Table 8.3 Anomie Theory

\begin{tabular}{|l|l|l|}
\hline & \multicolumn{2}{|l|}{ Goal of economic success } \\
\hline Value of working & Accept & Reject \\
\hline Accept & Conformity & Ritualism \\
\hline Reject & Innovation & Retreatism \\
\hline
\end{tabular}

First, said Merton, they may continue to accept the goal of economic success and also the value of working at a job to achieve such success; Merton labeled this adaptation conformity. Second, they may continue to favor economic success but reject the value of working and instead use new, illegitimate means, for example theft, of gaining money and possessions; Merton labeled this adaptation innovation. Third, they may abandon hope of economic success but continue to work anyway because work has become a habit. Merton labeled this adaptation ritualism. Finally, they may reject both the goal of economic success and the means of working to achieve such success and withdraw from society either by turning to drugs or by becoming hobos; Merton labeled this adaptation retreatism. He also listed a fifth adaptation, which he called rebellion, to characterize a response in which people 
reject economic success and working and work to bring about a new society with new values and a new economic system.

Merton's theory was very influential for many years but eventually lost popularity, partly because many crimes, such as assault and rape, are not committed for the economic motive that his theory assumed, and partly because many people use drugs and alcohol without dropping out of society, as his retreatism category assumed. In recent years, however, scholars have rediscovered and adapted his theory, and it has regained favor as new attention is being paid to the frustration resulting from poverty and other strains in one's life that in turn may produce criminal behavior (Miller, Schreck, \& Tewksbury, 2011).

\section{The Interactionist Perspective: Social Process Theories}

Social process theories all stress that crime results from the social interaction of individuals with other people, particularly their friends and family, and thus fall under the interactionist perspective outlined in Chapter 1 "Understanding Social Problems". They trace the roots of crime to the influence that our friends and family have on us and to the meanings and perceptions we derive from their views and expectations. By doing so, they indicate the need to address the peer and family context as a promising way to reduce crime.

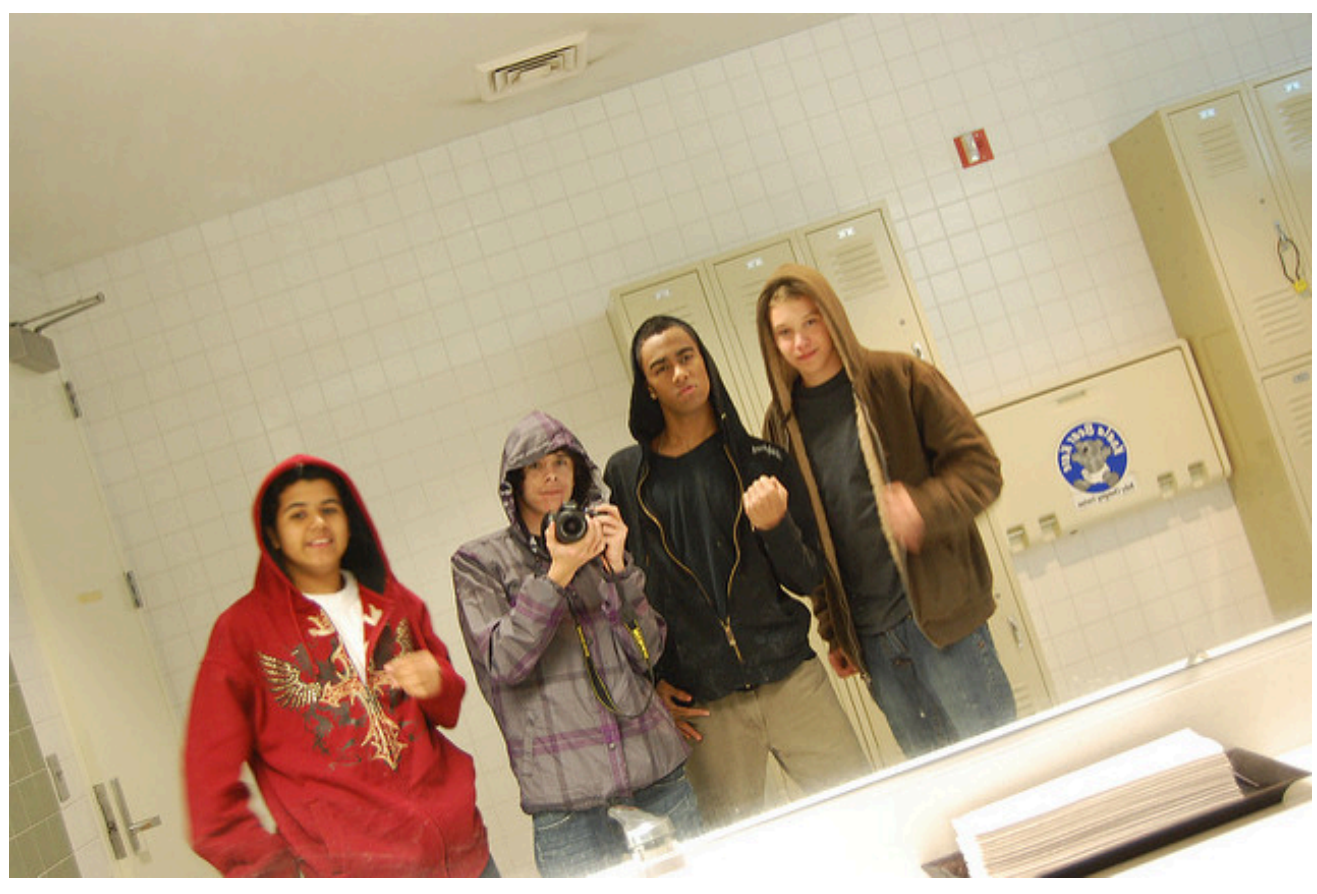

Social process theories stress that crime results from social interaction. In particular, our friends influence our likelihood of committing crime or not committing crime. 


\section{Differential Association Theory}

One of the most famous criminological theories is differential association theory, first formulated at about the same time as Merton's anomie theory by Edwin H. Sutherland and published in its final form in an edition of a criminology text he wrote (Sutherland, 1947). Sutherland rejected the idea, fashionable at the time, that crime had strong biological roots and instead said it grew out of interaction with others. Specifically, he wrote that adolescents and other individuals learn that it is acceptable to commit crime and also how to commit crime from their interaction with their close friends. Adolescents become delinquent if they acquire more and stronger attitudes in favor of breaking the law than attitudes opposed to breaking the law. As Sutherland put it, "A person becomes delinquent because of an excess of definitions favorable to the violation of law over definitions unfavorable to the violation of law." Crime and delinquency, then, result from a very normal social process, social interaction. Adolescents are more or less at risk for delinquency partly depending on who their friends are and what their friends do or don't do.

Many scholars today consider peer influences to be among the most important contributors to delinquency and other misbehavior (Akers \& Sellers, 2009). One problem with differential association theory is that it does not explain behavior, like rape, that is usually committed by a lone offender and that is generally the result of attitudes learned from one's close friends.

\section{Social Bonding Theory}

In a 1969 book, Causes of Delinquency, Travis Hirschi (1969) asked not what prompts people to commit crime, but rather what keeps them from committing crime. This question was prompted by his view that human nature is basically selfish and that it is society's task to tame this selfishness. He wrote that an adolescent's bonds to society, and specifically the bonds to family and school, help keep the adolescent from breaking the law.

Hirschi identified several types of social bonds, but generally thought that the closer adolescents feel to their family and teachers, the more they value their parents' beliefs and school values, and the more time they spend with their families and on school activities, the less likely they are to be delinquent. Turning that around, they are more likely to be delinquent if they feel more distant from their parents and teachers, if they place less value on their family's and school's values, and if they spend less time with these two very important social institutions in their lives.

Hirschi's social bonding theory attracted immediate attention and is one of the most popular and influential theories in criminology today. It highlighted the importance of families and schools for delinquency and stimulated much research on their influence. Much of this research has focused on the relationship between parents and children. When this relationship is warm and harmonious and when children respect their parents' values and parents treat their children firmly but fairly, children are less likely to commit antisocial behavior during childhood and delinquency during adolescence. Schools also matter: Students who do well in school and are very involved in extracurricular activities are less likely than other students to engage in delinquency (Bohm \& Vogel, 2011). 


\section{Children and Our Future}

\section{Saving Children from a Life of Crime}

Millions of children around the nation live in circumstances that put them at risk for a childhood, adolescence, and adulthood filled with antisocial behavior, delinquency, and crime, respectively. Although most of these children in fact will not suffer this fate, many of their peers will experience these outcomes. These circumstances thus must be addressed to save these children from a life of crime. As social scientists Brandon C. Welsh and David P. Farrington observe, "Convincing research evidence exists to support a policy of saving children from a life of crime by intervening early in childhood to tackle key risk factors."

What are these risk factors? They include being born to a teenaged, single mother; living in poverty or near poverty; attending poor, dilapidated schools; and living in high-crime urban areas. As should be evident, these risk factors are all related, as most children born to teenaged, single mothers live in poverty or near poverty, and many such children live in high-crime urban areas.

What can be done to help save such children from a life of crime? Ideally, our nation would lift them and their families entirely out of poverty with employment and social payment policies. Although this sort of national policy will not occur in the foreseeable future, a growing amount of rigorous social science evaluation evidence points to several effective programs and policies that can still help at-risk children. These include (1) at the individual level, certain types of preschool programs and social skills training programs; (2) at the family level, home visiting by trained professionals and parenting training programs; and (3) at the school and community levels, certain types of after-school and community-mentoring programs in which local adults spend time with children at risk for delinquency and other problems.

As Welsh and Farrington note, "Early prevention is by no means a panacea. But it does represent an integral part of any plan to reduce the nation's crime rate.” They add that several other Western democracies have national agencies devoted to improving behavioral and other outcomes among those nations' children, and they call for the United States to establish a similar national agency, the National Council on Early Prevention, as part of a nationwide strategy to prevent delinquency and other antisocial behaviors among American youth.

Sources: Piquero, Farrington, Welsh, Tremblay, \& Jennings, 2009; Welsh \& Farrington, 2007

Another social institution, religion, has also been the subject of research. An increasing number of studies are finding that religious involvement seemingly helps keep adolescents from using alcohol and other drugs (see Chapter 7 “Alcohol and Other Drugs"), from engaging in frequent sexual activity, and from engaging in delinquency generally (Desmond, Soper, \& Purpura, 2009). Fewer studies of religiosity and criminality during adulthood exist, but one investigation found an association between greater religiosity and fewer sexual partners among never-married adults (Barkan, 2006).

\section{Labeling Theory}

Our criminal justice system is based on the idea that the prospect of quick arrest and harsh punishment should deter criminal behavior. Labeling theory has the opposite idea, as it assumes that labeling someone as a criminal or deviant, which arrest and imprisonment certainly do, makes the person more likely to continue to offend. This result occurs, argues the theory, because the labeling process gives someone a negative self-image, reduces the potential for employment, and makes it difficult to have friendships with law-abiding individuals. 


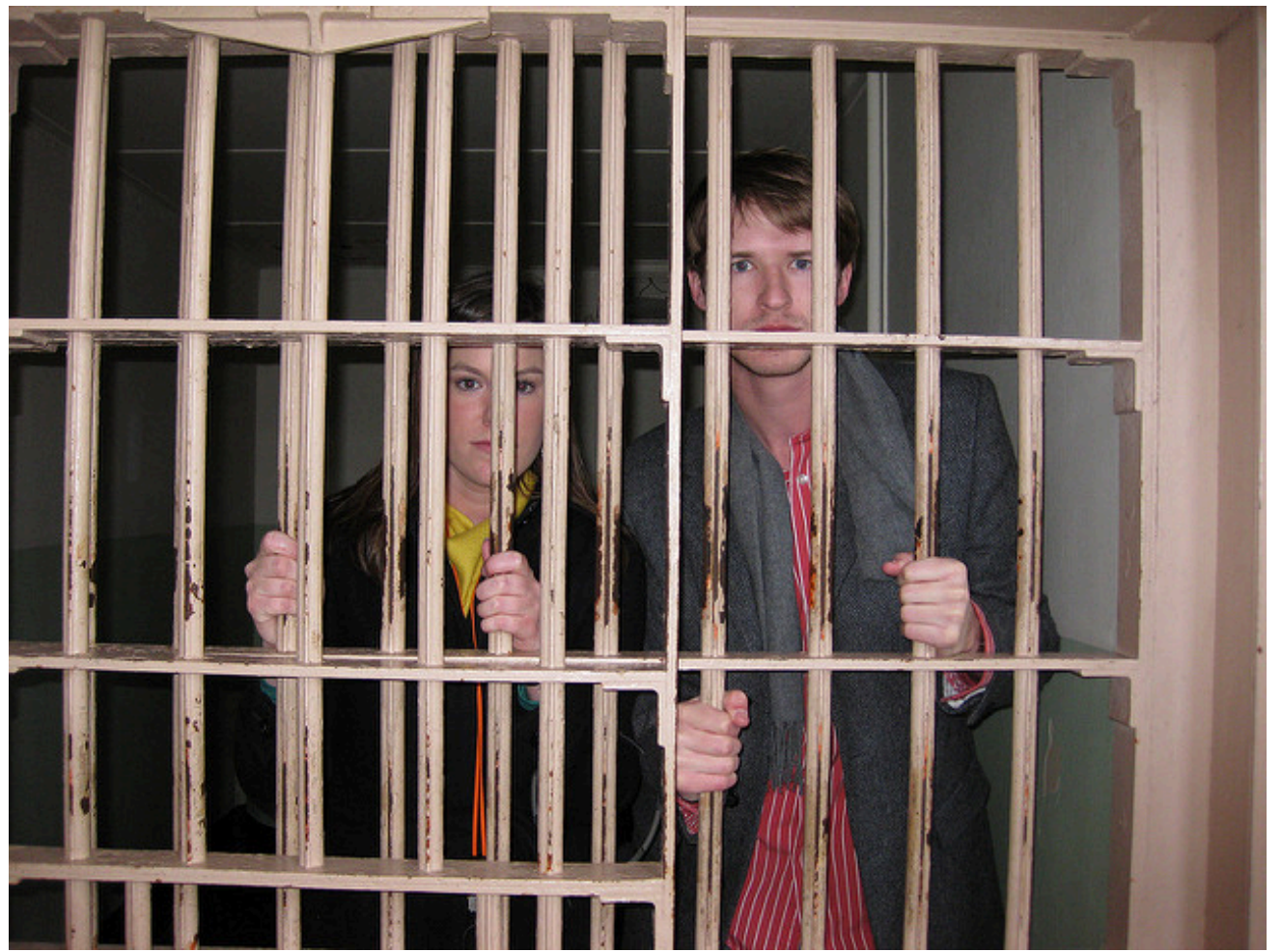

When this man is released from prison, he will probably face difficulties in finding a job and starting friendships with law-abiding people. These difficulties will make him more likely to commit new crimes.

Derek Key - Jailbirds - CC BY 2.0.

Suppose, for example, that you were just released from prison after serving a five-year term for armed robbery. When you apply for a job and list your prison term on the application, how likely are you to get hired? If you are at a bar and meet someone who interests you and then tell the person where you were for the previous five years, what are the chances that the conversation will continue? Faced with bleak job prospects and a dearth of people who want to spend time with you, what are your alternatives? Might you not succumb to the temptation to hang out with other offenders and even to commit new crime yourself?

Although research findings are not unanimous, several studies do find that arrest and imprisonment increase future offending, as labeling theory assumes (Nagin, Cullen, \& Jonson, 2009). To the extent this undesired consequence occurs, efforts to stem juvenile and adult crime through harsher punishment may sometimes have the opposite result from their intention.

\section{The Conflict Perspective}

Several related theories fall under the conflict perspective outlined in Chapter 1 "Understanding Social Problems". Although they all have something to say about why people commit crime, their major focus is on the use and misuse of the criminal law and criminal justice system to deal with crime. Three branches of the conflict perspective exist in the study of crime and criminal justice. 
The first branch is called group conflict theory, which assumes that criminal law is shaped by the conflict among the various social groups in society that exist because of differences in race and ethnicity, social class, religion, and other factors. Given that these groups compete for power and influence, the groups with more power and influence try to pass laws that ban behaviors in which subordinate groups tend to engage, and they try to use the criminal justice system to suppress subordinate group members. A widely cited historical example of this view is Prohibition, which was the result of years of effort by temperance advocates, most of them from white, Anglo-Saxon, rural, and Protestant backgrounds, to ban the manufacture, sale, and use of alcohol. Although these advocates thought alcohol use was a sin and incurred great social costs, their hostility toward alcohol was also motivated by their hostility toward the types of people back then who tended to use alcohol: poor, urban, Catholic immigrants. Temperance advocates' use of legal means to ban alcohol was, in effect, a "symbolic crusade” against people toward whom these advocates held prejudicial attitudes (Gusfield, 1963).

The second branch of the conflict perspective is called radical theory. Radical theory makes the same general assumptions as group conflict theory about the use of criminal law and criminal justice, but with one key difference: It highlights the importance of (economic) social class more than the importance of religion, ethnicity, and other social group characteristics. In this way, radical theory evokes the basic views of Karl Marx on the exploitation and oppression of the poor and working class by the ruling class (Lynch \& Michalowski, 2006).

An early but still influential radical explanation of crime was presented by Dutch criminologist Willem Bonger (1916). Bonger blamed the high US crime rate on its economic system, capitalism. As an economic system, he said, capitalism emphasizes the pursuit of profit. Yet, if someone gains profit, someone else is losing it. This emphasis on self-gain, he said, creates an egoistic culture in which people look out for themselves and are ready and even willing to act in a way that disadvantages other people. Amid such a culture, he said, crime is an inevitable outcome. Bonger thought crime would be lower in socialist societies because they place more emphasis on the welfare of one's group than on individual success.

Feminist approaches comprise the third branch of the conflict perspective on the study of crime and criminal justice. Several such approaches exist, but they generally focus on at least one of four areas: (1) the reasons girls and women commit crime; (2) the reasons female crime is lower than male crime; (3) the victimization of girls and women by rape, sexual assault, and domestic violence; and (4) the experience of women professionals and offenders in the criminal justice system.

Regarding the first area, the research generally finds that girls and women commit crime for the same reasons that boys and men commit crime: poverty, parental upbringing, and so forth. But it also finds that both women and men "do gender" when they commit crime. That is, they commit crime according to gender roles, at least to some extent. Thus one study found that women robbers tend to rob other women and not to use a gun when they do so (J. Miller \& Brunson, 2000).

In addressing the second area, on why female crime is less common than male crime, scholars often cite two reasons discussed earlier: gender role socialization and gender-based differences in parental supervision. One additional reason derives from social bonding theory: Girls feel closer to their parents than boys do, and thus are less delinquent (Lanctôt \& Blanc, 2002). 


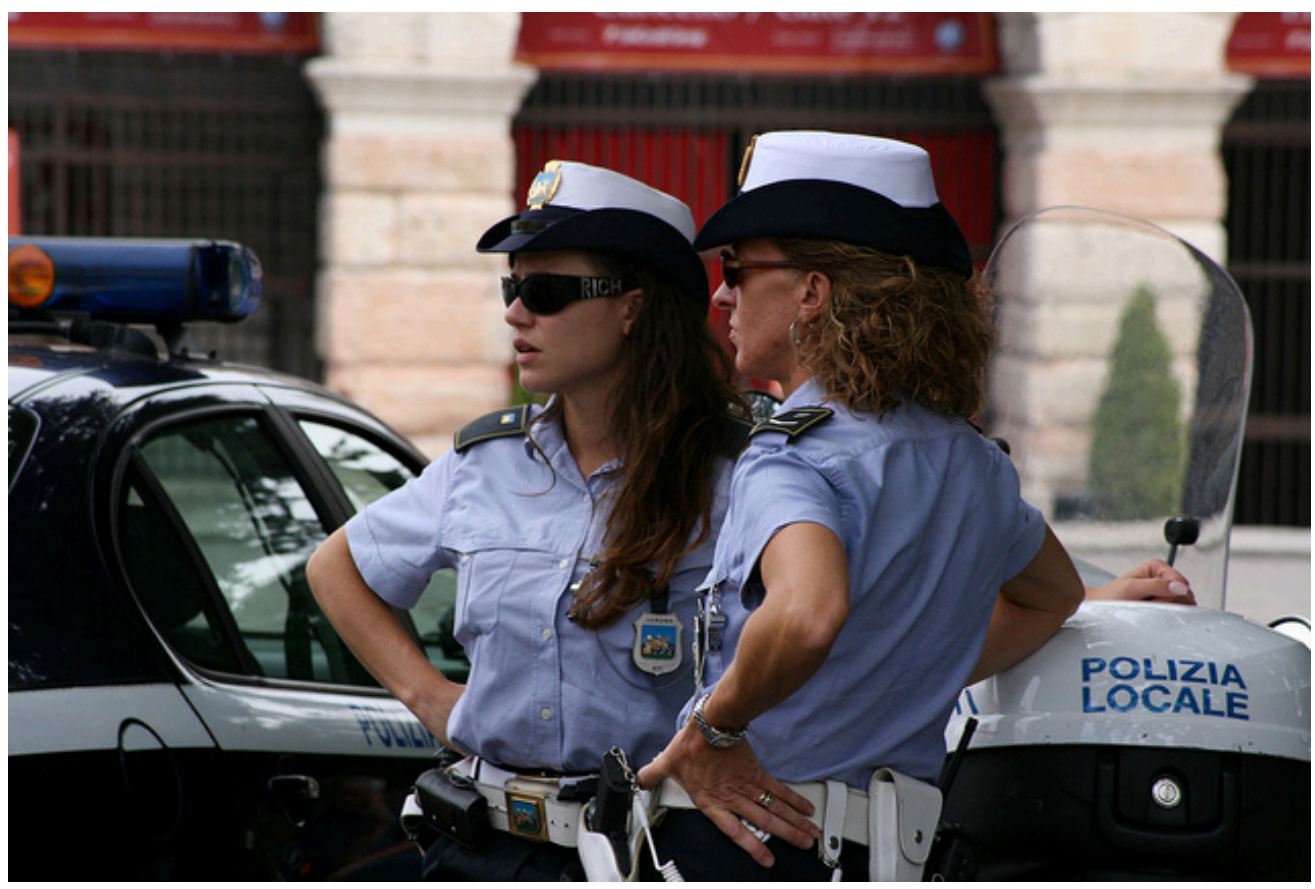

One important area of feminist-inspired work on crime and criminal justice involves studies of women police officers.

Joery Bruijntjes - Polizia Locale - CC BY-NC 2.0.

We have already commented on the victimization of women from rape, sexual assault, and domestic violence, but the study of this topic began with work by feminist criminologists during the 1970s. Since that time, innumerable works have addressed this type of victimization, which is also thought to contribute to girls' delinquency and, more generally, female drug and alcohol abuse (Chesney-Lind \& Jones, 2010).

The final area for feminist work addresses women professionals and offenders in the criminal justice system. This body of research certainly goes beyond the scope of this book, but it documents the many blatant and subtle forms of discrimination that women face as police, attorneys, judges, prison guards, and other professionals (Muraskin, 2012). A primary task of research on women offenders is to determine how they fare in the criminal justice system compared to male offenders. Studies tend to find that females receive somewhat more lenient treatment than males for serious offenses and somewhat harsher treatment for minor offenses, although some studies conclude that gender does not make too much of a difference one way or the other (Chesney-Lind \& Pasko, 2004).

\section{Key Takeaways}

- Social structure theories stress that crime results from economic and other problems in how society is structured and from poverty and other problems in neighborhoods.

- Interactionist theories stress that crime results from our interaction with family members, peers, and other people, and from labeling by the criminal justice system.

- Conflict theories stress that social groups with power and influence try to use the law and criminal justice system to maintain their power and to keep other groups at the bottom of society. 


\section{For Your Review}

1. What are any two criminogenic (crime-causing) social or physical characteristics of urban neighborhoods?

2. According to labeling theory, why are arrest and imprisonment sometimes counterproductive?

\section{References}

Akers, R. L., \& Sellers, C. S. (2009). Criminological theories: Introduction, evaluation, and application (5th ed.). New York, NY: Oxford University Press.

Barkan, S. E. (2006). Religiosity and premarital sex during adulthood. Journal for the Scientific Study of Religion, 45, 407-417.

Bohm, R. M., \& Vogel, B. (2011). A primer on crime and delinquency theory (3rd ed.). Belmont, CA: Wadsworth.

Bonger, W. (1916). Criminality and economic conditions (H. P. Horton, Trans.). Boston, MA: Little, Brown.

Chesney-Lind, M., \& Jones, N. (Eds.). (2010). Fighting for girls: New perspectives on gender and violence. Albany, NY: State University of New York Press.

Chesney-Lind, M., \& Pasko, L. (2004). The female offender: Girls, women, and crime (2nd ed.). Thousand Oaks, CA: Sage Publications.

Desmond, S. A., Soper, S. E., \& Purpura, D. J. (2009). Religiosity, moral beliefs, and delinquency: Does the effect of religiosity on delinquency depend on moral beliefs? Sociological Spectrum, 29, 51-71.

Gusfield, J. R. (1963). Symbolic crusade: Status politics and the American temperance movement. Urbana, IL: University of Illinois Press.

Hirschi, T. (1969). Causes of delinquency. Berkeley, CA: University of California Press.

Lanctôt, N., \& Blanc, M. L. (2002). Explaining deviance by adolescent females. Crime and Justice: A Review of Research, 29, 113-202.

Lynch, M. J., \& Michalowski, R. J. (2006). Primer in radical criminology: Critical perspectives on crime, power and identity (4th ed.). Monsey, NY: Criminal Justice Press.

Mazerolle, L., Wickes, R., \& McBroom, J. (2010). Community variations in violence: The role of social ties and collective efficacy in comparative context. Journal of Research in Crime and Delinquency, 47(1), 3-30.

Merton, R. K. (1938). Social structure and anomie. American Sociological Review, 3, 672-682. 
Miller, J. M., Schreck, C. J., \& Tewksbury, R. (2011). Criminological theory: A brief introduction (3rd ed.). Upper Saddle River, NJ: Prentice Hall.

Miller, J., \& Brunson, R. K. (2000). Gender dynamics in youth gangs: A comparison of males' and females’ accounts. Justice Quarterly, 17, 419-448.

Muraskin, R. (Ed.). (2012). Women and justice: It’s a crime (5th ed.). Upper Saddle River, NJ: Prentice Hall.

Nagin, D. S., Cullen, F. T., \& Jonson, C. L. (2009). Imprisonment and reoffending. Crime and Justice: A Review of Research, 38, 115-200.

Piquero, A. R., Farrington, D. P., Welsh, B. C., Tremblay, R., \& Jennings, W. (2009). Effects of early family/parent training programs on antisocial behavior and delinquency. Journal of Experimental Criminology 5, 83-120.

Shaw, C. R., \& McKay, H. D. (1942). Juvenile delinquency and urban areas. Chicago, IL: University of Chicago Press.

Sutherland, E. H. (1947). Principles of criminology (4th ed.). Philadelphia, PA: J. P. Lippincott.

Welsh, B. C., \& Farrington, D. P. (2007). Save children from a life of crime. Criminology \& Public Policy, 6(4), 871-879. 


\subsection{The Criminal Justice System}

\section{Learning Objectives}

1. Describe what is meant by the "working personality" of the police.

2. Discuss the quality of legal representation of criminal defendants.

3. Explain whether incarceration reduces crime in an effective and cost-efficient manner.

The criminal justice system in a democracy like the United States faces two major tasks: (1) keeping the public safe by apprehending criminals and, ideally, reducing crime; and (2) doing so while protecting individual freedom from the abuse of power by law enforcement agents and other government officials. Having a criminal justice system that protects individual rights and liberties is a key feature that distinguishes a democracy from a dictatorship.

How well does the US criminal justice system work in both respects? How well does it control and reduce crime, and how well does it observe individual rights and not treat people differently based on their social class, race and ethnicity, gender, and other social characteristics? What are other problems in our criminal justice system? Once again, whole books have been written about these topics, and we have space here to discuss only some of this rich literature.

\section{Police}

The police are our first line of defense against crime and criminals and for that reason are often called "the thin blue line.” Police officers realize that their lives may be in danger at any time, and they also often interact with suspects and other citizens whose hostility toward the police is quite evident. For these reasons, officers typically develop a working personality that, in response to the danger and hostility police face, tends to be authoritarian and suspicious (Skolnick, 1994). Indeed, it is not too far-fetched to say that police-citizen relations are characterized by mutual hostility and suspicion (Dempsey \& Forst, 2012).

Two aspects of police behavior are especially relevant for a textbook on social problems. The first is police corruption. No one knows for sure how much police corruption occurs, but low-level corruption (e.g., accepting small bribes and stealing things from stores while on patrol) is thought to be fairly common, while high-level corruption (e.g., accepting large bribes and confiscating and then selling illegal drugs) is thought to be far from rare. In one study involving trained researchers who rode around in police cars, more than one-fifth of the officers being observed committed some corruption (Reiss, 1980). Several notorious police scandals have called attention to rampant corruption amid some police forces. One scandal more than three decades ago involved New York City officer Frank Serpico, whose story was later documented in a best-selling book (Maas, 1973) and in a tension- 
filled film starring Al Pacino. After Serpico reported high-level corruption to his superiors, other officers plotted to have him murdered and almost succeeded. A more recent scandal involved the so-called Rampart Division in Los Angeles and involved dozens of officers who beat and shot suspects, stole drugs and money, and lied at the trials of the people they arrested (Glover \& Lait, 2000).

The other relevant behavior is police brutality or, to use a less provocative term, the use of undue (also called unjustified or excessive) force by police. Police, of course, are permitted and even expected to use physical force when necessary to subdue suspects. Given the context of police work noted earlier (feelings of danger and suspicion) and the strong emotions at work in any encounter between police and suspects, it is inevitable that some police will go beyond the bounds of appropriate force and commit brutality. An important question is how much police brutality occurs. In a recent national survey, about 1 percent of US residents who had had an encounter with the police in 2008 believed that excessive force was used against them (Eith \& Durose, 2011). This is a low figure in percentage terms, but still translates to 417,000 people who may have been victims of police brutality in one year.

How well do the police prevent crime? To answer this question, let us be clear what it is asking. The relevant question is not whether having the police we do have keeps us safer than having no police at all. Rather, the relevant question is whether hiring more police or making some specific change in police practice would lower the crime rate. The evidence on this issue is complex, but certain conclusions are in order.

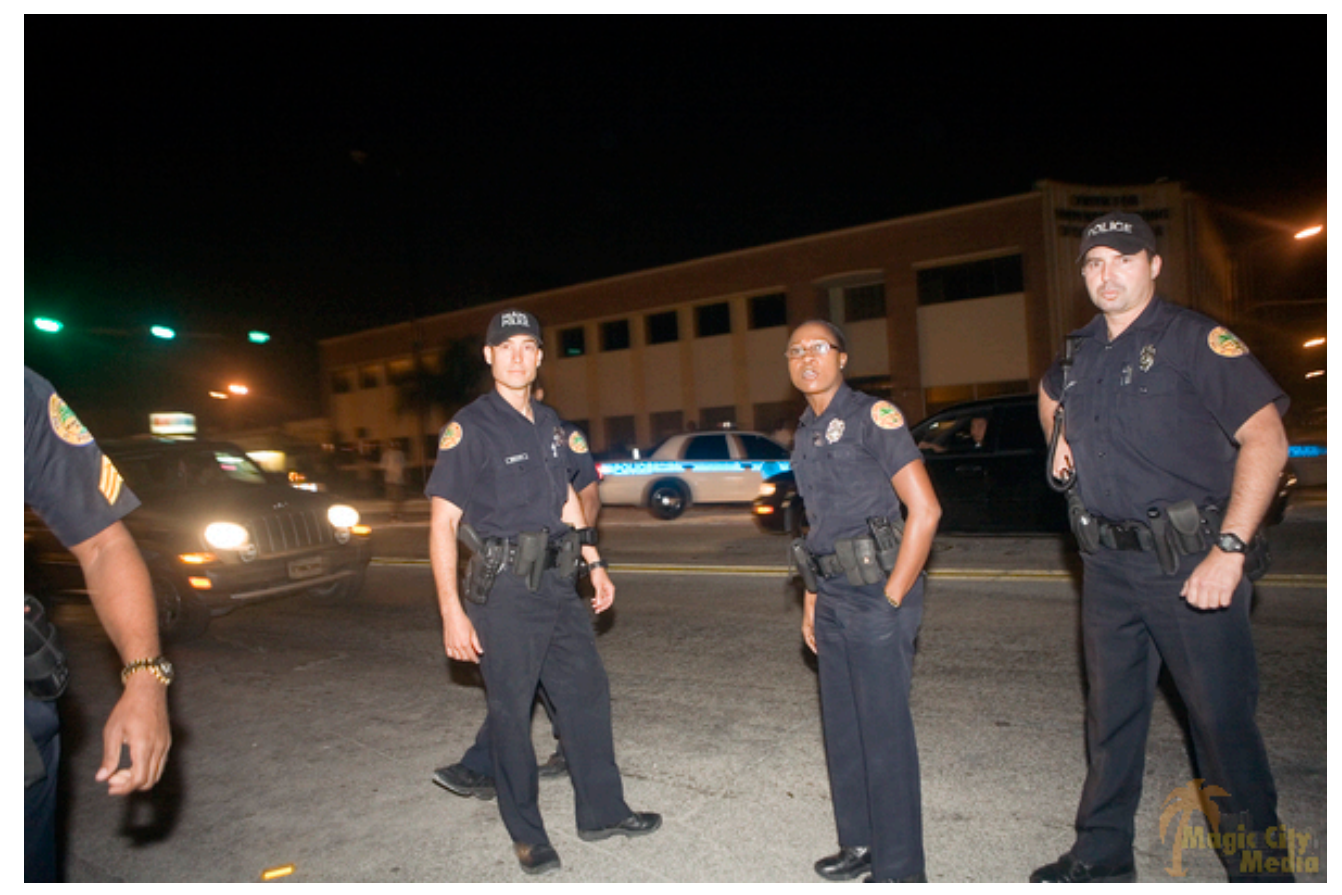

In terms of crime reduction, the ways in which police are deployed matter more than the actual number of police.

Joery Bruijntjes - Polizia Locale - CC BY-NC 2.0.

First, simply adding more officers to a city's existing police force will probably not reduce crime, or will reduce it only to a very small degree and at great expense (Walker, 2011). Several reasons may explain why additional police produce small or no reductions in crime. Much violence takes place indoors or in other locations far from police purview, and practical increases in police numbers still would not yield numbers high enough to guarantee 
a police presence in every public location where crime might happen. Because criminals typically think they can commit a crime with impunity if no police are around, the hiring of additional police is not likely to deter them.

Additional police may not matter, but how police are deployed does matter. In this regard, a second conclusion from the policing and crime literature is that directed patrol involving the consistent deployment of large numbers of police in high-crime areas ("hot spots”) can reduce crime significantly (Mastrofski, Weisburd, \& Braga, 2010). Crackdowns - in which the police flood a high crime and drug neighborhood, make a lot of arrests, and then leave-have at most a short-term effect, with crime and drug use eventually returning to their previous levels or simply becoming displaced to other neighborhoods.

\section{Criminal Courts}

In the US legal system, suspects and defendants enjoy certain rights and protections guaranteed by the Constitution and Bill of Rights and provided in various Supreme Court rulings since these documents were written some 220 years ago. Although these rights and protections do exist and again help distinguish our democratic government from authoritarian regimes, in reality the criminal courts often fail to achieve the high standards by which they should be judged. Justice Denied (Downie, 1972) and Injustice for All (Strick, 1978) were the titles of two popular critiques of the courts written about four decades ago, and these titles continue to apply to the criminal courts today.

A basic problem is the lack of adequate counsel for the poor. Wealthy defendants can afford the best attorneys and get what they pay for: excellent legal defense. An oft-cited example here is O. J. Simpson, the former football star and television and film celebrity who was arrested and tried during the mid-1990s for allegedly killing his ex-wife and one of her friends (Barkan, 1996). Simpson hired a "dream team" of nationally famous attorneys and other experts, including private investigators, to defend him at an eventual cost of some \$10 million. A jury acquitted him, but a poor defendant in similar circumstances almost undoubtedly would have been found guilty and perhaps received a death sentence.

Almost all criminal defendants are poor or near poor. Although they enjoy the right to free legal counsel, in practice they receive ineffective counsel or virtually no counsel at all. The poor are defended by public defenders or by court-appointed private counsel, and either type of attorney simply has far too many cases in any time period to handle adequately. Many poor defendants see their attorneys for the first time just moments before a hearing before the judge. Because of their heavy caseloads, the defense attorneys do not have the time to consider the complexities of any one case, and most defendants end up pleading guilty.

A 2006 report by a New York state judicial commission reflected these problems (Hakim, 2006, p. B1). The report concluded that "local governments were falling well short of constitutional requirements in providing legal representation to the poor," according to a news story. Some New York attorneys, the report found, had an average yearly caseload of 1,000 misdemeanors and 175 felonies. The report also found that many poor defendants in 1,300 towns and villages throughout the state received no legal representation at all. The judge who headed the commission called the situation "a serious crisis."

Another problem is plea bargaining, in which a defendant agrees to plead guilty, usually in return for a reduced sentence. Under our system of justice, criminal defendants are entitled to a trial by jury if they want one. In reality, 
however, most defendants plead guilty, and criminal trials are very rare: Fewer than 3 percent of felony cases go to trial. Prosecutors favor plea bargains because they help ensure convictions while saving the time and expense of jury trials, while defendants favor plea bargains because they help ensure a lower sentence than they might receive if they exercised their right to have a jury trial and then were found guilty. However, this practice in effect means that defendants are punished if they do exercise their right to have a trial. Critics of this aspect say that defendants are being coerced into pleading guilty even when they have a good chance of winning a not guilty verdict if their case went to trial (Oppel, 2011).

\section{The Problem of Prisons}

The United States now houses more than 1.5 million people in state and federal prisons and more than 750,000 in local jails. This total of about 2.3 million people behind bars is about double the 1990 number and yields an incarceration rate that is by far the highest rate of any Western democracy. This high rate is troubling, and so is the racial composition of American prisoners. More than 60 percent of all state and federal prisoners are African American or Latino, even though these two groups comprise only about 30 percent of the national population. As Chapter 7 “Alcohol and Other Drugs” noted, African Americans and Latinos have been arrested and imprisoned for drug offenses far out of proportion to their actual use of illegal drugs. This racial/ethnic disparity has contributed to what law professor Michelle Alexander (2010) terms the "new Jim Crow" of mass incarceration. Reflecting her concern, about one of every three young African American males are under correctional supervision (in jail or prison or on probation or parole).

The corrections system costs the nation more than $\$ 75$ billion annually. What does the expenditure of this huge sum accomplish? It would be reassuring to know that the high US incarceration rate keeps the nation safe and even helps reduce the crime rate, and it is certainly true that the crime rate would be much higher if we had no prisons at all. However, many criminologists think the surge in imprisonment during the last few decades has not helped reduce the crime rate at all or at least in a cost-efficient manner (Durlauf \& Nagin, 2011). Greater crime declines would be produced, many criminologists say, if equivalent funds were instead spent on crime prevention programs instead of on incarceration (Welsh \& Farrington, 2007), a point returned to in Section 8.6 "Reducing Crime”.

Criminologists also worry that prison may be a breeding ground for crime because rehabilitation programs such as vocational training and drug and alcohol counseling are lacking and because prison conditions are substandard. They note that more than 700,000 inmates are released from prison every year and come back into their communities ill equipped to resume a normal life. There they face a lack of job opportunities (how many employers want to hire an ex-con?) and a lack of friendships with law-abiding individuals, as our earlier discussion of labeling theory indicated. Partly for these reasons, imprisonment ironically may increase the likelihood of future offending (Durlauf \& Nagin, 2011).

Living conditions behind bars merit further discussion. A common belief of Americans is that many prisons and jails are like country clubs, with exercise rooms and expensive video and audio equipment abounding. However, this belief is a myth. Although some minimum-security federal prisons may have clean, adequate facilities, state prisons and local jails are typically squalid places. As one critique summarized the situation, "Behind the walls, prisoners are likely to find cramped living conditions, poor ventilation, poor plumbing, substandard heating 
and cooling, unsanitary conditions, limited private possessions, restricted visitation rights, constant noise, and a complete lack of privacy” (Kappeler \& Potter, 2005, p. 293).

Some Americans probably feel that criminals deserve to live amid overcrowding and squalid living conditions, while many Americans are probably at least not very bothered by this situation. But this situation increases the odds that inmates will leave prison and jail as more of a threat to public safety than when they were first incarcerated. Treating inmates humanely would be an important step toward successful reentry into mainstream society.

\section{People Making a Difference}

\section{Making a Difference in the Lives of Ex-Cons}

The text notes that more than 600,000 inmates are released from prison every year. Many of them are burdened with drug, alcohol, and other problems and face bleak prospects for employment, friendships, and stable lives, in general. Since 1967, The Fortune Society has been making a difference in the lives of ex-convicts in and near New York City.

The Fortune Society's website (http://www.fortunesociety.org) describes the group’s mission: “The Fortune Society is a nonprofit social service and advocacy, founded in 1967, whose mission is to support successful reentry from prison and promote alternatives to incarceration, thus strengthening the fabric of our communities." About 70 percent of its more than 190 employees are ex-prisoners and/or have histories of substance abuse or homelessness. It is fair to say that The Fortune Society was working on prisoner reentry long before scholars discovered the problem in the late 1990s and early 2000s.

The group's president, JoAnne Page, described its halfway house where inmates stay for up to two months after their release from prisons: "This is what we do. We bring people home safely. There's a point when the crime happened. The sentence was served, and the rehabilitation must begin. We look at a human being as much more than the worst they ever did." Recalling that many of her relatives died in the Holocaust, Page added, "What my family experience did was to make me want to be somebody who fights institutions that damage people and who makes the world a little safer. Prisons are savage institutions."

In addition to its halfway house, the Fortune Society provides many other services for inmates, ex-inmates, and offenders who are put on probation in lieu of incarceration. It regularly offers drug and alcohol counseling, family services, adult education and career development programs, and classes in anger management, parenting skills, and health care. One of its most novel programs is Miss Betty's Practical Cooking and Nutrition Class, an eight-week course for ex-inmates who are young fathers. While a first reaction might be to scoff at such a class, a Fortune counselor pointed to its benefits after conceding her own immediate reaction. "When I found out about the cooking classes, I thought, 'So they're going to learn to cook, so what?' What's that going to do? But it's building self-esteem. For most of these guys, they're in a city, they've grown up on Kool-Aid and a bag of chips. This is building structure. They're at the point where they have really accomplished something...They're learning manners. You really can change patterns.”

One ex-convict that Fortune helped was 22-year-old Candice Ellison, who spent more than two years in prison for assault. After not finding a job despite applying to several dozen jobs over a six-month span, she turned in desperation to The Fortune Society for help. Fortune bought her interview clothes and advised her on how to talk about her prison record with potential employers. Commending the help she received, she noted, "Some of my high school friends say it's not that hard to get a job, but for people like me with a criminal background, it's like 20 times harder."

The Fortune Society has received national recognition for its efforts. Two federal agencies, the Department of Justice and the Department of Housing and Urban Development, have featured The Fortune Society as a model program for helping ex-inmates. The Urban Institute featured this model in a video it developed about prisoner reentry programs. And in 2005, the American Society of Criminology presented the Society its President's Award for "Distinguished Contributions to the Cause of Justice." These and other examples of the national recognition won by The Fortune Society indicate that for more than four decades it has indeed been making a difference.

Sources: Bellafante, 2005; Greenhouse, 2011; Richardson, 2004 


\section{Focus on the Death Penalty}

The death penalty is perhaps the most controversial issue in the criminal justice system today. The United States is the only Western democracy that sentences common criminals to death, as other democracies decided decades ago that civilized nations should not execute anyone, even if the person took a human life. About two-thirds of Americans in national surveys favor the death penalty, with their reasons including the need for retribution ("an eye for an eye”), deterrence of potential murderers, and lower expenditure of public funds compared to a lifetime sentence. Social science evidence is irrelevant to the retribution argument, which is a matter for philosophy and theology, but it is relevant to many other aspects of the death debate. Taken together, the evidence on all these aspects yields a powerful case against the death penalty (Death Penalty Information Center, 2011).

First, capital punishment does not deter homicide: Almost all studies on this issue fail to find a deterrent effect. An important reason for this stems from the nature of homicide. As discussed earlier, it is a relatively spontaneous, emotional crime. Most people who murder do not sit down beforehand to calculate their chances of being arrested, convicted, and executed. Instead they lash out. Premeditated murders do exist, but the people who commit them do not think they will get caught and so, once again, are not deterred by the potential for execution.

Second, the death penalty is racially discriminatory. While some studies find that African Americans are more likely than whites who commit similar homicides to receive the death penalty, the clearest evidence for racial discrimination involves the race of the victim: Homicides with white victims are more likely than those with African American victims to result in a death sentence (Paternoster \& Brame, 2008). Although this difference is not intended, it suggests that the criminal justice system values white lives more than African American lives.

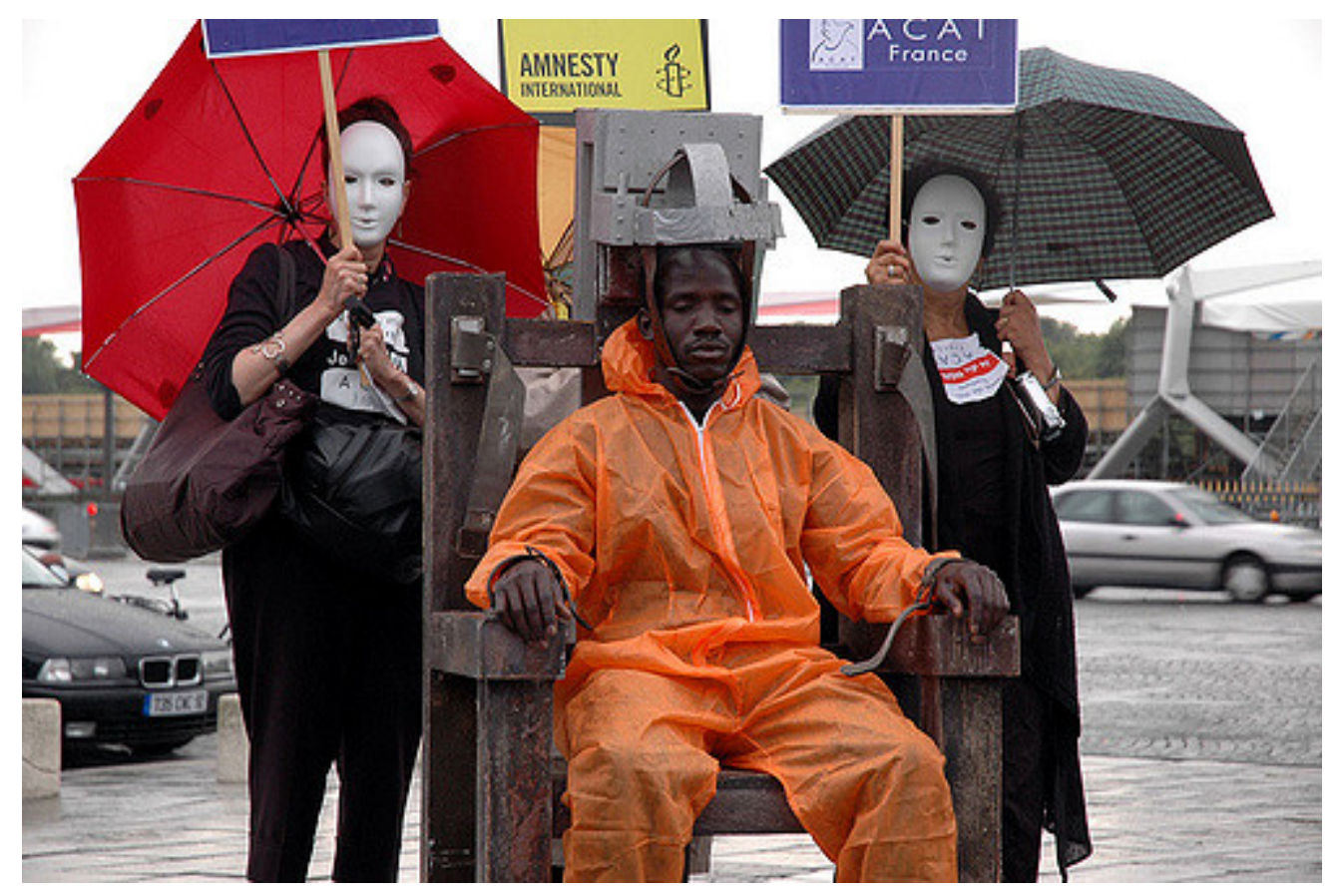

The death penalty is racially discriminatory and does not deter homicide.

Thomas Hawk - Miami Police - CC BY-NC 2.0. 
Third, many people have been mistakenly convicted of capital offenses, raising the possibility of wrongful executions. Sometimes defendants are convicted out of honest errors, and sometimes they are convicted because the police and/or prosecution fabricated evidence or engaged in other legal misconduct. Whatever their source, wrongful convictions of capital offenses raise the ugly possibility that a defendant will be executed even though he was actually innocent of any capital crime. During the past four decades, more than 130 people have been released from death row after DNA or other evidence cast serious doubt on their guilt. In March 2011, Illinois abolished capital punishment, partly because of concern over the possibility of wrongful executions. As the Illinois governor summarized his reasons for signing the legislative bill to abolish the death penalty, "Since our experience has shown that there is no way to design a perfect death penalty system, free from the numerous flaws that can lead to wrongful convictions or discriminatory treatment, I have concluded that the proper course of action is to abolish it” (Schwartz \& Fitzsimmons, 2011:A18).

Fourth, executions are expensive. Keeping a murderer in prison for life costs about $\$ 1$ million in current dollars (say 40 years at $\$ 25,000$ per year), while the average death sentence costs the state about $\$ 2$ million to $\$ 3$ million in legal expenses.

This diverse body of evidence leads most criminologists to oppose the death penalty. In 1989, the American Society of Criminology adopted this official policy position on capital punishment: "Be it resolved that because social science research has demonstrated the death penalty to be racist in application and social science research has found no consistent evidence of crime deterrence through execution, The American Society of Criminology publicly condemns this form of punishment, and urges its members to use their professional skills in legislatures and courts to seek a speedy abolition of this form of punishment.”

\section{Key Takeaways}

- Partly because the police often fear for their lives, they tend to have a "working personality" that is authoritarian and suspicious. Police corruption and use of undue force remain significant problems in many police departments.

- Although criminal defendants have the right to counsel, the legal representation of such defendants, most of whom are poor or near poor, is very inadequate.

- Prisons are squalid places, and incarceration has not been shown to reduce crime in an effective or costefficient manner.

- Most criminologists agree that capital punishment does not deter homicide, and they worry about racial discrimination in the use of the death penalty and about the possibility of wrongful executions.

\section{For Your Review}

1. Have you ever had an encounter with a police officer? If so, how would you describe the officer's personality? Was it similar to what is described in the text?

2. The text argues that improvement in prison conditions would help reduce the probability of reoffending after inmates leave prison. Do you agree or disagree with this statement? Explain your answer. 


\section{References}

Alexander, M. (2010). The new Jim Crow: Mass incarceration in the age of colorblindness. New York, NY: New Press.

Barkan, S. E. (1996). The social science significance of the O. J. Simpson case. In G. Barak (Ed.), Representing O. J.: Murder, criminal justice and mass culture (pp. 36-42). Albany, NY: Harrow and Heston.

Bellafante, G. (2005, March 9). Recipe for a second chance. New York Times, p. F1.

Death Penalty Information Center. (2011). Facts about the death penalty. Washington, DC: Author. Retrieved from http://www.deathpenaltyinfo.org/documents/FactSheet.pdf.

Dempsey, J. S., \& Forst, L. S. (2012). An introduction to policing (6th ed.). Belmont, CA: Cengage Learning.

Downie, L., Jr. (1972). Justice denied: The case for reform of the courts. Baltimore, MD: Penguin Books.

Durlauf, S. N., \& Nagin, D. S. (2011). Imprisonment and crime: Can both be reduced? Criminology \& Public Policy, 10, 13-54.

Eith, C., \& Durose, M. R. (2011). Contacts between police and the public, 2008. Washington, DC: Bureau of Justice Statistics.

Glover, S., \& Lait, M. (2000, February 10). Police in secret group broke law routinely, transcripts say. The Los Angeles Times, p. A1.

Greenhouse, S. (2011, January 25). States help ex-inmates find jobs. New York Times, p. B1.

Hakim, D. (2006, June 29). Judge urges state control of legal aid for the poor. New York Times, p. B1.

Kappeler, V. E., \& Potter, G. W. (2005). The mythology of crime and criminal justice (4th ed.). Prospect Heights, IL: Waveland Press.

Maas, P. (1973). Serpico. New York, NY: Viking Press.

Mastrofski, S. D., Weisburd, D., \& Braga, A. A. (2010). Rethinking policing: The policy implications of hot spots of crime. In N. A. Frost, J. D. Freilich \& T. R. Clear (Eds.), Contemporary issues in criminal justice policy (pp. 251-264). Belmont, CA: Wadsworth.

Oppel, R. A., Jr. (2011, September 26). Sentencing shift gives new leverage to prosecutors. New York Times, p. A1.

Paternoster, R., \& Brame, R. (2008). Reassessing race disparities in Maryland capital cases. Criminology, 46, 971-1007.

Reiss, A. J., Jr. (1980). Officer violations of the law. In R. J. Lundman (Ed.), Police behavior: A sociological perspective (pp. 253-272). New York, NY: Oxford University Press. 
Richardson, L. (2004, July 13). Defending the despised, and loving to do so. New York Times, p. B2.

Schwartz, J., \& Fitzsimmons, E. G. (2011, March 10). Illinois governor signs capital punishment ban. New York Times, p. A18.

Skolnick, J. H. (1994). Justice without trial: Law enforcement in democratic society (3rd ed.). New York, NY: Macmillan.

Strick, A. (1978). Injustice for all. New York, NY: Penguin.

Walker, S. (2011). Sense and nonsense about crime, drugs, and communities: A policy guide (7th ed.). Belmont, CA: Wadsworth.

Welsh, B. C., \& Farrington, D. P. (Eds.). (2007). Preventing Crime: What works for children, offenders, victims and places. New York, NY: Springer. 


\subsection{Reducing Crime}

\section{Learning Objective}

1. Describe five strategies that criminologists have proposed to reduce crime.

During the last few decades, the United States has used a get-tough approach to fight crime. This approach has involved longer prison terms and the building of many more prisons and jails. As noted earlier, scholars doubt that this surge in imprisonment has achieved significant crime reduction at an affordable cost, and they worry that it may be leading to greater problems in the future as hundreds of thousands of prison inmates are released back into their communities every year.

Many of these scholars favor an approach to crime borrowed from the field of public health. In the areas of health and medicine, a public health approach tries to treat people who are already ill, but it especially focuses on preventing disease and illness before they begin. While physicians try to help people who already have cancer, medical researchers constantly search for the causes of cancer so that they can try to prevent it before it affects anyone. This model is increasingly being applied to criminal behavior, and criminologists have advanced several ideas that, if implemented with sufficient funds and serious purpose, hold great potential for achieving significant, cost-effective reductions in crime (Barlow \& Decker, 2010; Frost, Freilich, \& Clear, 2010; Lab, 2010). Many of their strategies rest on the huge body of theory and research on the factors underlying crime in the United States, which we had space only to touch on earlier, while other proposals call for criminal justice reforms. We highlight some of these many strategies here.

\section{Applying Social Research}

“Three Strikes” Laws Strike Out

The get-tough approach highlighted in the text has involved, among other things, mandatory minimum sentencing, in which judges are required to give convicted offenders a minimum prison term, often several years long, rather than a shorter sentence or probation.

Beginning in the 1990s, one of the most publicized types of mandatory sentencing has been the "three strikes and you're out" policy that mandates an extremely long sentence-at least twenty-five years - and sometimes life imprisonment for offenders convicted of a third (or, in some states, a second) felony. The intent of these laws, enacted by about half the states and the federal government, is to reduce crime by keeping dangerous offenders behind bars for many years and by deterring potential offenders from committing crime (general deterrence). Sufficient time since the first three strikes laws were passed has elapsed to enable criminologists to assess whether they have, in fact, reduced crime.

Studies of this issue find that three strikes laws do not reduce serious crime and, in fact, may even increase the number of homicides. Several studies have focused on California, where tens of thousands of offenders have been sentenced under the state's three strikes law passed in 1994. Almost all these studies conclude that California's law did not reduce subsequent crime or did so by only a negligible amount. A few studies also have examined nationwide samples of city 
and state crime rates in the states that adopted three strikes laws and in the states that did not do so. These studies also fail to find that three strikes laws have reduced crime. As one of these studies, by three criminologists from the University of Alabama at Birmingham, concludes, "Consistent with other studies, ours finds no credible statistical evidence that passage of three strikes laws reduces crime by deterring potential criminals or incapacitating repeat offenders.” The national studies even find that three strikes laws have increased the number of homicides. This latter finding is certainly an unintended consequence of these laws and may stem from decisions by felons facing a third strike to kill witnesses so as to avoid life imprisonment.

In retrospect, it is not very surprising that three strikes laws do not work as intended. Many criminals simply do not think they will get caught and thus are not likely to be deterred by increased penalties. Many are also under the influence of drugs and/or alcohol at the time of their offense, making it even less likely they will worry about being caught. In addition, many three strikes offenders tend to be older (because they are being sentenced for their third felony, not just their first) and thus are already "aging out” beyond the high-crime age group, 15-25. Thus three strikes laws target offenders whose criminality is already declining because they are getting older.

In addition to the increase in homicides, research has identified other problems produced by three strikes laws. Because three strikes defendants do not want a life term, some choose a jury trial instead of pleading guilty. Jury trials are expensive and slow compared to guilty pleas and thus cost the prosecution both money and time. In another problem, the additional years that three strikes offenders spend in prison are costing the states millions of dollars in yearly imprisonment costs and in health-care costs as these offenders reach their elderly years.

As should be clear, the body of three strikes research has important policy implications, as noted by the University of Alabama at Birmingham scholars: "(P)olicy makers should reconsider the costs and benefits associated with three strikes laws” (p. 235). Three strikes laws do not lower crime and in fact increase homicides, and they have forced the states to spend large sums of money on courts and prisons. The three strikes research strongly suggests that three strikes laws should be eliminated.

Sources: Kovandzic, Sloan, \& Vieraitis, 2004; Walker, 2011

A first strategy involves serious national efforts to reduce poverty and to improve neighborhood living conditions. It is true that most poor people do not commit crime, but it is also true that most street crime is committed by the poor or near poor for reasons discussed earlier. Efforts that create decent-paying jobs for the poor, enhance their vocational and educational opportunities, and improve their neighborhood living conditions should all help reduce poverty and its attendant problems and thus to reduce crime (Currie, 2011).

A second strategy involves changes in how American parents raise their boys. To the extent that the large gender difference in serious crime stems from male socialization patterns, changes in male socialization should help reduce crime (Collier, 2004). This will certainly not happen any time soon, but if American parents can begin to raise their boys to be less aggressive and less dominating, they will help reduce the nation's crime rate. As two feminist criminologists have noted, "A large price is paid for structures of male domination and for the very qualities that drive men to be successful, to control others, and to wield uncompromising power....Gender differences in crime suggest that crime may not be so normal after all. Such differences challenge us to see that in the lives of women, men have a great deal more to learn” (Daly \& Chesney-Lind, 1988, p. 527).

\section{Lessons from Other Societies}

\section{Preventing Crime and Treating Prisoners in Western Europe}

The text suggests the get-tough approach that the United States has been using to reduce crime has not worked in a costeffective manner and has led to other problems, including a flood of inmates returning to their communities every year. 
In fighting crime, the United States has much to learn from Western Europe. In contrast to the US get-tough approach, Western European nations tend to use a public health model that comprises two components. The first is a focus on crime prevention that uses early childhood intervention programs and other preventive measures to address the roots of crime and other childhood and family problems. The second is a criminal justice policy that involves sentencing defendants and treating prisoners in a manner more likely to rehabilitate offenders and reduce their repeat offending than the more punitive approach in the United States.

The overall Western European approach to offenders is guided by the belief that imprisonment should be reserved for the most dangerous violent offenders, and that probation, community service, and other forms of community corrections should be used for other offenders. Because violent offenders comprise only a small proportion of all offenders, the Western European approach saves a great deal of money while still protecting public safety.

The experience of Denmark and the Netherlands is illustrative. Like the United States, Denmark had to deal with rapidly growing crime rates during the 1960s. Whereas the United States responded with the get-tough approach involving longer and more certain prison terms and the construction of more and more prisons, Denmark took the opposite approach: It adopted shorter prison terms for violent offenders and used the funds saved from the reduced prison costs to expand community corrections for property offenders. Finland and the Netherlands have also adopted a similar approach that favors community corrections and relatively short prison terms for violent offenders over the get-tough approach the United States adopted.

All these nations save great sums of money in prison costs and other criminal justice expenses because they chose not to adopt the US get-tough approach, yet their rates of serious violent crime lag behind the US rates. Although these nations obviously differ from the United States, the advantages of their approach should be kept in mind as the United States evaluates its get-tough policies. There may be much to learn from their less punitive approach to crime: While the United States got tough, perhaps they got sensible.

Sources: Dammer \& Albanese, 2011; Waller \& Welsh, 2007

A third and very important strategy involves expansion of early childhood intervention (ECI) programs and nutrition services for poor mothers and their children, as the Note 8.28 "Children and Our Future” box discussed earlier. ECI programs generally involve visits by social workers, nurses, or other professionals to young, poor mothers shortly after they give birth, as these mother's children are often at high risk for later behavioral problems (Welsh \& Farrington, 2007). These visits may be daily or weekly and last for several months, and they involve parenting instruction and training in other life skills. These programs have been shown to be very successful in reducing childhood and adolescent misbehavior in a cost-effective manner (Greenwood, 2006). In the same vein, nutrition services would also reduce the risk of neurological impairment among newborns and young children and thus their likelihood of developing later behavioral problems.

A fourth strategy calls for a national effort to improve the nation's schools and schooling. This effort would involve replacing large, older, and dilapidated schoolhouses with smaller, nicer, and better equipped ones. For many reasons, this effort should help improve student academic achievement and school commitment and thus lower delinquent and later criminal behavior.

A final set of strategies involves changes in the criminal justice system that should help reduce repeat offending and save much money that could be used to fund the ECI programs and other efforts just outlined. Placing nonviolent property and drug offenders in community corrections (e.g., probation, daytime supervision) would reduce the number of prison and jail inmates by hundreds of thousands annually without endangering Americans' safety and save billions of dollars in prison costs (Jacobson, 2006). These funds could also be used to improve prison and jail vocational and educational programming and drug and alcohol services, all of which are seriously underfunded. If properly funded, such programs and services hold great promise for rehabilitating many inmates 
(Cullen, 2007). Elimination of the death penalty would also save much money while also eliminating the possibility of wrongful executions.

This is not a complete list of strategies, but it does suggest the kinds of efforts that would help address the roots of crime and, in the long run, help to reduce it. Although the United States may not be interested in pursuing this crime-prevention approach, strategies like the ones just mentioned would in the long run be more likely than our current get-tough approach to create a safer society and at the same time save us billions of dollars annually.

Note that none of these proposals addresses white-collar crime, which should not be neglected in a discussion of reducing the nation's crime problem. One reason white-collar crime is so common is that the laws against it are weakly enforced; more consistent enforcement of these laws should help reduce white-collar crime, as would the greater use of imprisonment for convicted white-collar criminals (Rosoff et al., 2010).

\section{Key Takeaways}

- The get-tough approach has not been shown to reduce crime in an effective and cost-efficient manner. A sociological explanation of crime thus suggests the need to focus more resources on the social roots of crime in order to prevent crime from happening in the first place.

- Strategies suggested by criminologists to reduce crime include (a) reducing poverty and improving neighborhood living conditions, (b) changing male socialization patterns, (c) expanding early childhood intervention programs, (d) improving schools and schooling, and (e) reducing the use of incarceration for drug and property offenders.

\section{For Your Review}

1. The text notes that social science research has not shown the get-tough approach to be effective or costefficient. If this is true, why do you think this approach has been so popular in the United States since the 1970s?

2. Of the five strategies outlined in the text to reduce crime, which one strategy do you think would be most effective if it were implemented with adequate funding? Explain your answer.

\section{References}

Barlow, H. D., \& Decker, S. H. (Eds.). (2010). Criminology and public policy: Putting theory to work. Philadelphia, PA: Temple Univeristy Press.

Collier, R. (2004). Masculinities and crime: Rethinking the “man question”? In C. Sumner (Ed.), The Blackwell companion to criminology (pp. 285-308). Oxford, United Kingdom: Blackwell.

Cullen, F. T. (2007). Make rehabilitation corrections’ guiding paradigm. Criminology \& Public Policy, 6(4), 717-727. 
Currie, E. (2011). On the pitfalls of spurious prudence. Criminology \& Public Policy, 10, 109-114.

Daly, K., \& Chesney-Lind, M. (1988). Feminism and criminology. Justice Quarterly, 5, 497-538.

Dammer, H. R., \& Albanese, J. S. (2011). Comparative criminal justice systems (4th ed.). Belmont, CA: Wadsworth

Frost, N. A., Freilich, J. D., \& Clear, T. R. (Eds.). (2010). Contemporary issues in criminal justice policy: Policy proposals from the American society of criminology conference. Belmont, CA: Wadsworth.

Greenwood, P. W. (2006). Changing lives: Delinquency prevention as crime-control policy. Chicago, IL: University of Chicago Press.

Jacobson, M. (2006). Reversing the punitive turn: The Limits and promise of current research. Criminology \& Public Policy, 5, 277-284.

Kovandzic, T. V., Sloan, J. J., III, \& Vieraitis, L. M. (2004). “Striking out” as crime reduction policy: The impact of “three strikes” laws on crime rates in US cities. Justice Quarterly, 21, 207-239.

Lab, S. P. (2010). Crime prevention: Approaches, practices and evaluations (7th ed.). Cincinnati, OH: Anderson.

Rosoff, S. M., Pontell, H. N., \& Tillman, R. (2010). Profit without honor: White collar crime and the looting of America (5th ed.). Upper Saddle River, NJ: Prentice Hall.

Walker, S. (2011). Sense and nonsense about crime, drugs, and communities: A policy guide (7th ed.). Belmont, CA: Wadsworth.

Waller, I., \& Welsh, B. C. (2007). Reducing crime by harnessing international best practices. In D. S. Eitzen (Ed.), Solutions to social problems: Lessons from other societies (pp. 208-216). Boston, MA: Allyn \& Bacon.

Welsh, B. C., \& Farrington, D. P. (2007). Save children from a life of crime. Criminology \& Public Policy, 6(4), 871-879. 


\subsection{End-of-Chapter Material}

\section{Summary}

1. Crime is a major concern for many Americans. More than one-third fear walking alone at night in their neighborhoods, and even larger percentages worry about specific types of crimes. News media coverage of crime contributes to these fears. The media overdramatize crime by covering so much of it and by giving especially heavy attention to violent crime even though most crime is not violent. In other problems, the news media disproportionately depict young people and people of color as offenders and whites as victims.

2. The nation's major source of crime statistics is the FBI's Uniform Crime Reports (UCR). Because many people do not tell the police about crimes they have experienced, the UCR underestimates the actual level of crime in the United States. It is also subject to changes in police reporting practices and in particular to deliberate efforts by police to downplay the amount of crime. To help correct these problems, the National Crime Victimization Survey (NCVS) measures crime every year in a national survey that asks residents to report their criminal victimization. The NCVS is thought to yield a more accurate estimate of crime than the UCR, and it also provides much information on the circumstances under which victimization occurs. Selfreport surveys, typically given to adolescents, are a final form of crime measurement and provide much information on the adolescents' social backgrounds and thus on the context of their offending.

3. The major categories of crime are violent crime, property crime, white-collar crime, and consensual crime. Much violent crime is relatively spontaneous and emotional, and a surprising amount involves victims and offenders who knew each other before the violent act occurred. Despite popular perceptions, most violent crime is also intraracial. A major distinction in the understanding of property crime is that between professional thieves, who are very skilled and steal valuable possessions or large sums of money, and amateur thieves, who are unskilled and whose theft is petty by comparison. Corporate crime and other kinds of white-collar crime arguably cost the nation more than street crime in economic loss, health problems, and death; corporate violence involves unsafe working conditions, unsafe products, and environmental pollution. Consensual crime, such as illegal drug use and prostitution, raises two important questions: (1) Which consensual but potentially harmful behaviors should the state ban and which should it not ban, and (2) does banning such behaviors do more harm than good or more good than harm?

4. Crime is socially patterned. Males commit more serious crimes than females. African Americans and Latinos have higher crime rates than whites, poor people have higher crime rates than the wealthy, and youths in their teens and early twenties have higher crime rates than older people. In addition, crime is higher in urban areas than in rural areas.

5. Many sociological theories of criminal behavior exist. Social structure theories highlight poverty and weakened social institutions as important factors underlying crime. Social process theories stress the importance of peer relationships, social bonding, and social reaction. Conflict theories call attention to the possible use of the legal system to punish behavior by subordinate groups, while feminist theories examine gender differences in criminality, the victimization of women by rape, sexual assault, and domestic violence, and the experiences of women professionals and offenders in the criminal justice system.

6. The criminal justice system costs tens of billions of dollars annually, yet scholars question the potential of this system to reduce crime. How police are deployed seems a more important factor regarding their potential for crime reduction than the actual numbers of police. The surge in imprisonment of the last few decades may have accounted for a relatively small drop in crime, but whatever reduction it has achieved has not been cost-effective, and hundreds of thousands of prison inmates are now returning every year to their communities. Several problems also exist in the criminal justice system itself. Police corruption and brutality remain serious concerns, while indigent defendants receive inadequate legal representation or none 
at all. Despite public perceptions, prisons and jails are squalid places, and rape and other violence are daily concerns.

7. The United States is the only Western democracy to use the death penalty for common criminals. Social science evidence finds that the death penalty does not deter homicide, is racially discriminatory, may involve wrongful convictions, and costs considerably more than life imprisonment.

8. Many proposals for reducing crime derive from sociological evidence. These proposals aim to reduce poverty and improve neighborhood living conditions; to change male socialization patterns; to expand early childhood intervention programs and nutrition services; to improve the nation's schools and schooling; and to reduce the number of prison inmates by placing nonviolent property and drug offenders in community corrections. The funds saved by this last proposal could be used to improve prison and jail rehabilitation programming.

\section{Using What You Know}

Suppose you are the Democratic Party Governor of a midsized state and that you are up for reelection in two years. You were a political science major in college but had a sociology minor with a focus in criminal justice. The crime rate in your state has risen slightly since you took office, and there is growing sentiment in the state's major newspapers and from the Republican Party opposition in the state legislature to lengthen prison terms for serious crime and to build two more prisons for the greater number of prisoners that will be expected. Because of your studies in college, you are skeptical that this approach will reduce crime, and you recognize it will cost millions of dollars. But you also realize that your opponents and some members of the news media are beginning to say that you are soft on crime. What do you do?

\section{What You Can Do}

To help deal with the problem of crime, you may wish to do any of the following:

1. Volunteer at an agency that helps troubled teenagers.

2. Volunteer with an organization that helps ex-offenders.

3. Work for an organization that provides early childhood intervention services for at-risk children. 


\section{Chapter 9: Sexual Behavior}

\section{Social Problems in the News}

“More Texas Schools Teach Safe Sex with Abstinence," the headline said. Across Texas, sex education in the public schools typically emphasizes the need for abstinence and ignores the concept of safe sex. But in the western Texas town of Midland, school officials decided to include safe sex into the school district's sex education curriculum for the seventh and eighth grades after several years of rising teen pregnancies, with 172 students pregnant in 2010. A school official said, "These are girls as young as 13 that are pregnant; some of them are on their second pregnancies."

In what is called an "abstinence-plus" approach, the new curriculum continues to urge students to wait to have sex, but it also teaches them about birth control and condoms. A consultant at the University of Texas who was advising the Midland school system scoffed at the idea that teaching teenagers about safe sex encourages them to have sex: "I can assure you kids aren't getting aroused when they see a condom." She added that teenagers hear about and see a lot of sex on television and the Internet and hear about it from their friends. Given this backdrop, she said, it is important that they get accurate information about sex: "The more you know about your body, how to make better decisions and choices, the better decisions that adolescents make," she said, adding, "The more we demystify it, the more we talk about it, the better."

The school official was optimistic that the new curriculum would reduce teen pregnancies, but she was realistic about the difficulty of the problem. "I would love to be able say [it is] going to be 100-percent effective, we're going to turn this thing around," she said. "What we are going to do is impact children to make better choices in regard to sexual integrity. And that would potentially be delaying sexual activity. We're not going to stop teenagers from having sex. I wish we could, but we're not going to."

Source: Smith, 2011

This news story reminds us that sexual behavior is often cause for concern and the basis for certain social problems. It should come as no surprise that social scientists study many aspects of sexual behavior and have provided a good deal of insight on sexual issues. This chapter discusses the social scientific evidence for various types of sexual behavior and issues relating to them: teenage sex and pregnancy, abortion, prostitution, and pornography. Although people often have strong views about these issues, we will see that the social scientific evidence sometimes challenges the views that many people hold.

\section{References}

Smith, M. (2011, September 16). More Texas schools teach safe sex with abstinence. The Texas Tribune. Retrieved from http://www.texastribune.org/texas-education/public-education/condoms-safe-sex-appear-more-texas-sexeducation/. 


\subsection{An Overview of Heterosexuality}

\section{Learning Objectives}

1. Explain what happened as a result of the sexual revolution.

2. Describe current views on sexual behavior.

3. Understand the prevalence of certain sexual behaviors today.

Because Chapter 5 "Sexual Orientation and Inequality" discussed sexual orientation and inequality, this chapter's discussion of sexual behavior focuses almost entirely on issues concerning heterosexual sex. To provide a backdrop for these issues, we first provide an overview of heterosexual behavior and views about such behavior.

\section{The Sexual Revolution: Changing Attitudes and Changing Behavior}

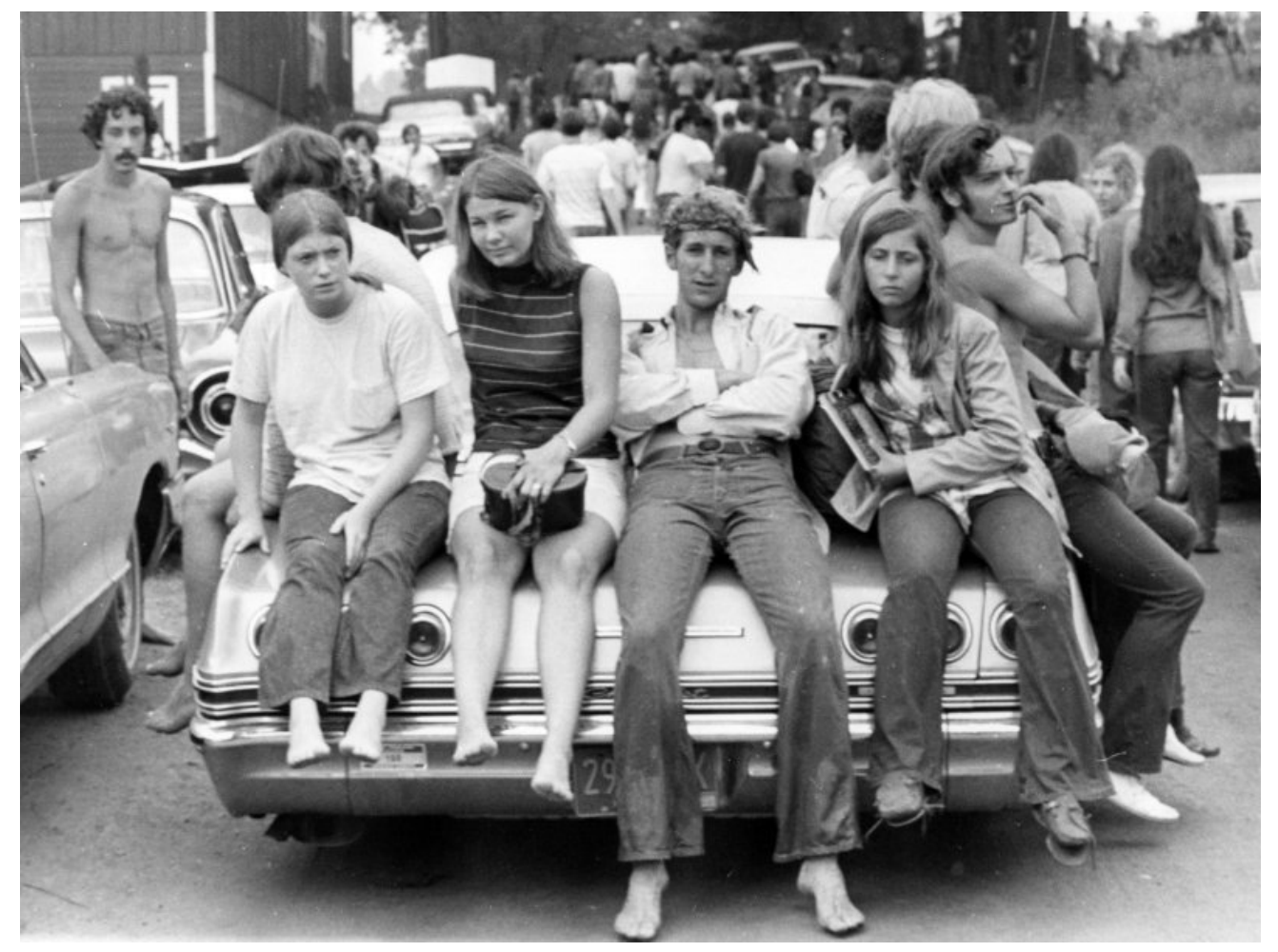

The youth counterculture of the 1960s emphasized that sexual intercourse need not be delayed until marriage. Their views helped fuel the so-called sexual revolution. 
The 1960s were a time of major change in the United States. The Southern civil rights movement and Vietnam antiwar movements shook the nation, and the women's rights, gay rights, and environmental movements began. Another major change was the sexual revolution, which saw a substantial change in many aspects of Americans' sexual behavior and in how they thought about sex. Thanks in large part to the introduction of the birth control pill, women became freer to have sex without fear of pregnancy. The hippies of the youth counterculture of the 1960s emphasized free love, the idea that sexual intercourse and other forms of sex need not be delayed until marriage, and a popular slogan heard during the Vietnam antiwar movement was "make love, not war.” A highlight (or lowlight, depending on one's view) of the era was the Summer of Love in 1967, when tens of thousands of young people gathered in the Haight-Ashbury neighborhood of San Francisco to do drugs, have sex, and engage in other counterculture activities. The appearance of HIV and AIDS during the 1980s reversed some of the trends of the sexual revolution, as people became more concerned about the consequences of unprotected sex, but the effects of this revolution largely remain: Many more people now have sex before marriage than before the 1960s, and views about certain sexual behaviors have become less conservative since the 1960s and 1970s (Harding \& Jencks, 2003).

We can see evidence of changing views about sex in data from the General Social Survey (GSS), which has been administered nationally since the early 1970s. One of the questions the GSS asks is about premarital sex: “There's been a lot of discussion about the way morals and attitudes about sex are changing in this country. If a man and woman have sex relations before marriage, do you think it is always wrong, almost always wrong, wrong only sometimes, or not wrong at all?” In 1972, only 27.2 percent of the public replied it was "not wrong at all,” but by 2010, this percentage almost doubled to 53.1 percent (see Figure 9.1 "Change in Views about Premarital Sex (Percentage Saying Premarital Sex Is “Not Wrong at All”)”).

Figure 9.1 Change in Views about Premarital Sex (Percentage Saying Premarital Sex Is “Not Wrong at All”)

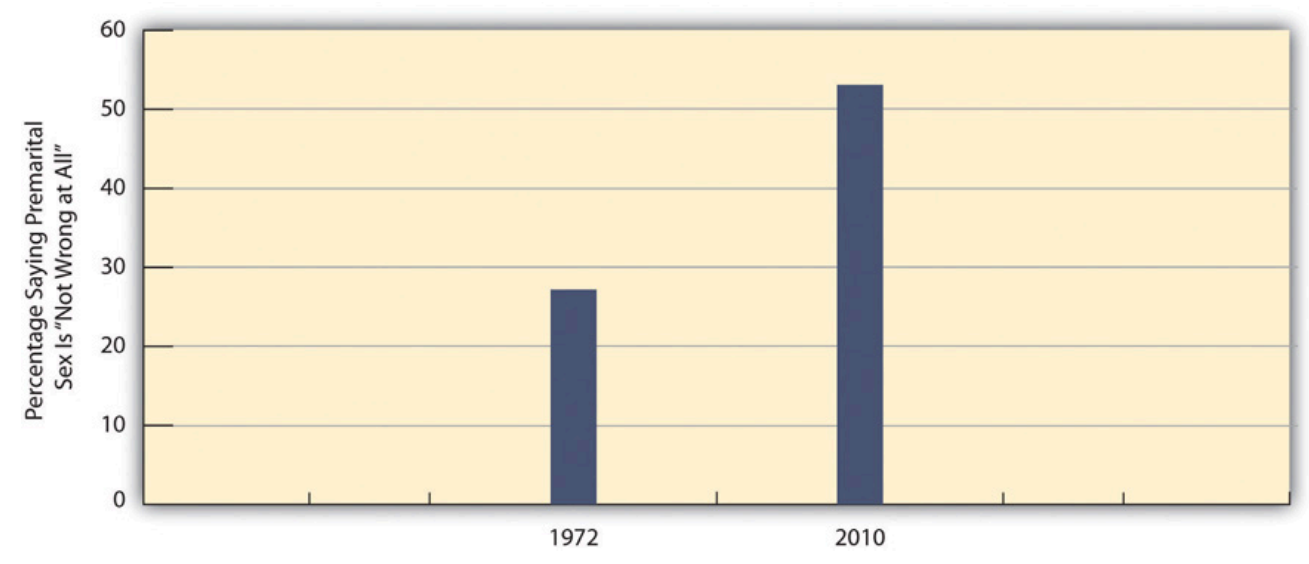

Source: Data from General Social Surveys. (1972 and 2010). Retrieved from http://sda.berkeley.edu/cgi-bin/hsda?harcsda+gss10.

On two other issues, extramarital sex and sex between teenagers, views have not changed from a generation ago. Very few Americans today, fewer than 5 percent, think that either type of sexual behavior is "not wrong at all," and very few thought they were not wrong a generation ago when the GSS asked about these two behaviors. As all these trend data indicate, the sexual revolution changed certain sexual attitudes but did not affect other attitudes. In this respect, then, the sexual revolution was only partly revolutionary.

Certain changes in sexual behavior also occurred as part of the sexual revolution. In particular, many more people 
began having sex before age 18 during and after the 1960s than before the 1960s and, in a related trend, to have more sexual partners before age 18 (Laumann, Gagnon, Michael, \& Michaels, 1994). We can see evidence of the former trend in national survey data reported in Table 9.1 "Percentage Who Had Heterosexual Sex before Age 18”, which shows the percentage of people born in different decades (birth cohorts) who had sex before age 18. Among women, less than one-third of those in the 1933-1942 and 1943-1952 birth cohorts (who would all have reached age 18 before the sexual revolution) had sex before age 18. These low figures jumped to 47.6 percent for those in the 1953-1962 birth cohort (who became teenagers in the 1960s and 1970s, during the sexual revolution) and then grew further to 58.2 percent in the next birth cohort. In a twenty-year span, then, women became 28.2 percent more likely (= $58.2-30.0$ ) to have sex before age 18. Men, too, became more likely to have sex before age 18 , though at a slightly smaller rate of increase, 18.8 percent $(=61.3-42.5)$ over the thirty-year span shown in the table. In related figures, only 30 percent of teenaged girls in 1972 were sexually experienced; by 1988, this figure had jumped to 51 percent (Martinez, Copen, \& Abma, 2011). The remarkable increase in teenage sex for both females and males since the 1960s has had important repercussions down to the present, as we shall see in the section on teenage sex and pregnancy later in this chapter.

Table 9.1 Percentage Who Had Heterosexual Sex before Age 18

\begin{tabular}{|l|l|l|l|l|}
\hline Birth cohort & $\mathbf{1 9 3 3 - 1 9 4 2}$ & $\mathbf{1 9 4 3 - 1 9 5 2}$ & $\mathbf{1 9 5 3 - 1 9 6 2}$ & $\mathbf{1 9 6 3 - 1 9 7 4}$ \\
\hline Women & 32.2 & 30.0 & 47.6 & 58.2 \\
\hline Men & 42.5 & 47.9 & 56.8 & 61.3 \\
\hline
\end{tabular}

Source: Laumann, E. O., Gagnon, J. H., Michael, R. T., \& Michaels, S. (1994). The social organization of sexuality. (p. 328) Chicago, IL: University of Chicago Press.

\section{Heterosexuality Today: Attitudes and Behavior}

Americans' attitudes today about heterosexual behavior are very diverse. On some issues, Americans are fairly united, either in a more tolerant and accepting direction or in a less tolerant and unaccepting direction. On other issues, Americans are fairly divided, with large numbers of people feeling one way and large numbers feeling another way. The American public is probably even more diverse in its sexual behavior: Some people have a lot of sex and engage in a variety of sexual activities, while other people have less sex and limit their sexual activity to vaginal intercourse. To gain a sense of what Americans are thinking and doing in the area of heterosexual activity, national surveys provide some important evidence.

\section{Attitudes}

As noted earlier, the GSS asks respondents to indicate their views on several types of heterosexual behavior and issues related to this behavior. We'll first look again at their views about sexual behavior that we examined earlier in the discussion about the sexual revolution. This time we will focus on the percentage who say the behaviors 
are wrong (“always wrong," “almost always wrong,” or "sometimes wrong”) (see Figure 9.2 "Views on Sexual Behavior (Percentage Saying the Behavior Is Wrong)”).

Figure 9.2 Views on Sexual Behavior (Percentage Saying the Behavior Is Wrong)

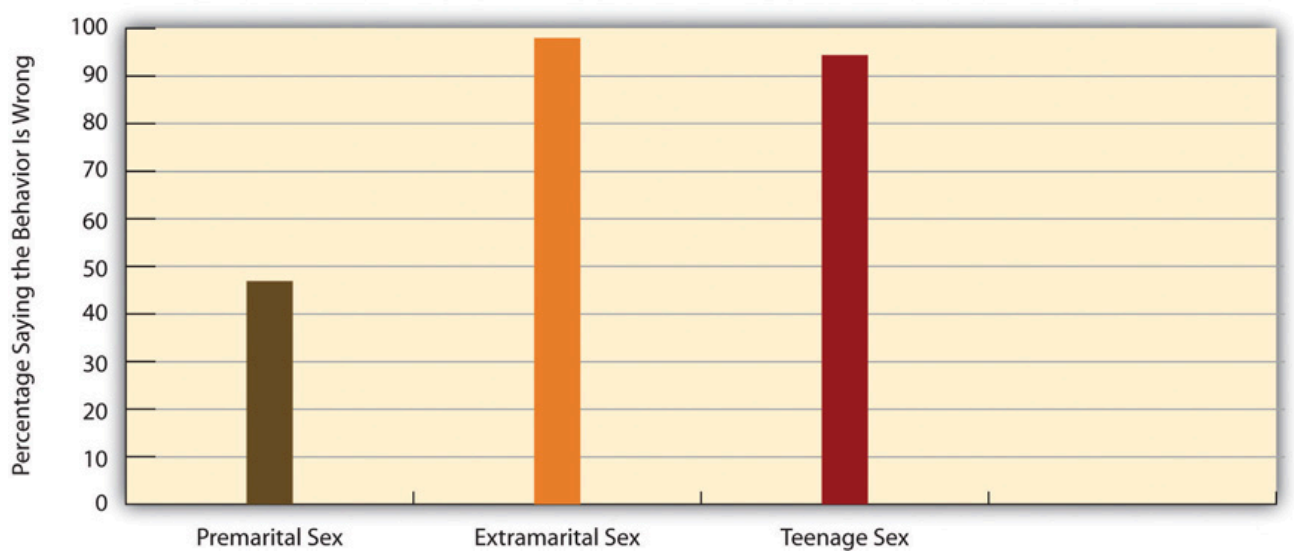

Source: Data from General Social Survey. (2010). Retrieved from http://sda.berkeley.edu/cgi-bin/hsda?harcsda+gss10.

Figure 9.2 "Views on Sexual Behavior (Percentage Saying the Behavior Is Wrong)" shows that Americans almost unanimously think that adultery (extramarital sex) and teenage sex are wrong, but that they are fairly evenly split on whether premarital sex is wrong, with 47 percent saying it is wrong and the remainder, 53 percent, saying it is not wrong at all.

Certain aspects of our social backgrounds predict our views about premarital sex. In particular, women, older people, and those who are more religious are more likely than their counterparts to disapprove of it. We see evidence of these trends in Figure 9.3 "Correlates of Disapproval of Premarital Sex (Percentage Saying Premarital Sex between a Woman and a Man Is Wrong)", which focuses on the percentage of GSS respondents who say that premarital sex is wrong (always wrong, almost always wrong, or sometimes wrong). Gender and age are moderately related to views about premarital sex, while religiosity is strongly related to these views. 

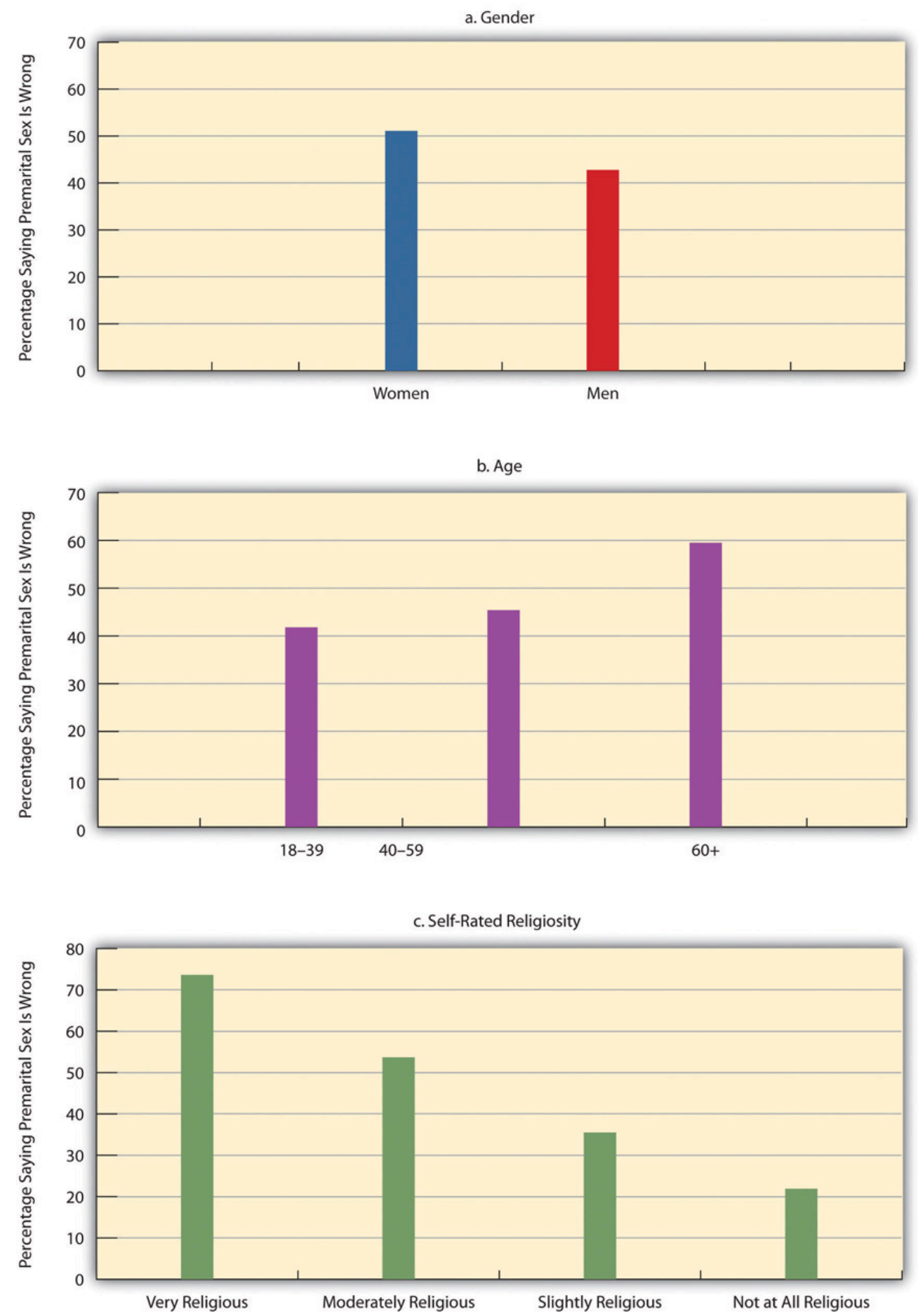

Source: Data from General Social Survey. (2010). Retrieved from http://sda.berkeley.edu/cgi-bin/hsda?harcsda+gss10.

\section{Behavior}

A good understanding of Americans' sexual behaviors comes from the 2006-2008 National Survey of Family Growth (NSFG), which was administered to 13,459 Americans ages 15-44 nationwide. Although this survey 
omits people older than 44, it still yields valuable information about people in their prime reproductive years. Chapter 5 "Sexual Orientation and Inequality" on sexual orientation also used some NSFG data.

Table 9.2 "Lifetime Prevalence of Sexual Behaviors, Ages 15-24*” reports some NSFG gender-based data on several kinds of sexual behaviors for young people ages 15-24. Although many people think that males are much more sexually active than females, the data in Table 9.2 "Lifetime Prevalence of Sexual Behaviors, Ages 15-24*" show that the gender differences in heterosexual contact are practically nonexistent. Reflecting a conclusion from Chapter 5 "Sexual Orientation and Inequality"'s discussion of sexual orientation, however, females are more likely than males to have had same-sex sexual contact. In one other gender difference not reported in the table, males (17.6 percent) are more likely than females (9.4 percent) to have at least two heterosexual partners in the past year. In this specific sexual activity, then, males are indeed more active than females.

Table 9.2 Lifetime Prevalence of Sexual Behaviors, Ages 15-24*

\begin{tabular}{|l|l|l|}
\hline & Females & Males \\
\hline No sexual contact & 28.6 & 27.2 \\
\hline Any opposite-sex contact & 70.1 & 71.7 \\
\hline Any opposite-sex contact: vaginal intercourse & 65.1 & 62.9 \\
\hline Any opposite-sex contact: gave or received oral sex & 62.6 & 64.0 \\
\hline Any opposite-sex contact: anal sex & 20.2 & 20.9 \\
\hline Any same-sex behavior & 13.4 & 4.0 \\
\hline * Percentage engaging in behavior at least once & & \\
\hline
\end{tabular}

Source: Chandra, A., Mosher, W. D., Copen, C., \& Sionean, C. (2011). Sexual behavior, sexual attraction, and sexual identity in the United States: Data from the 2006-2008 national survey of family growth (National Health Statistics Reports: Number 36). Hyattsville, MD: National Center for Health Statistics. 


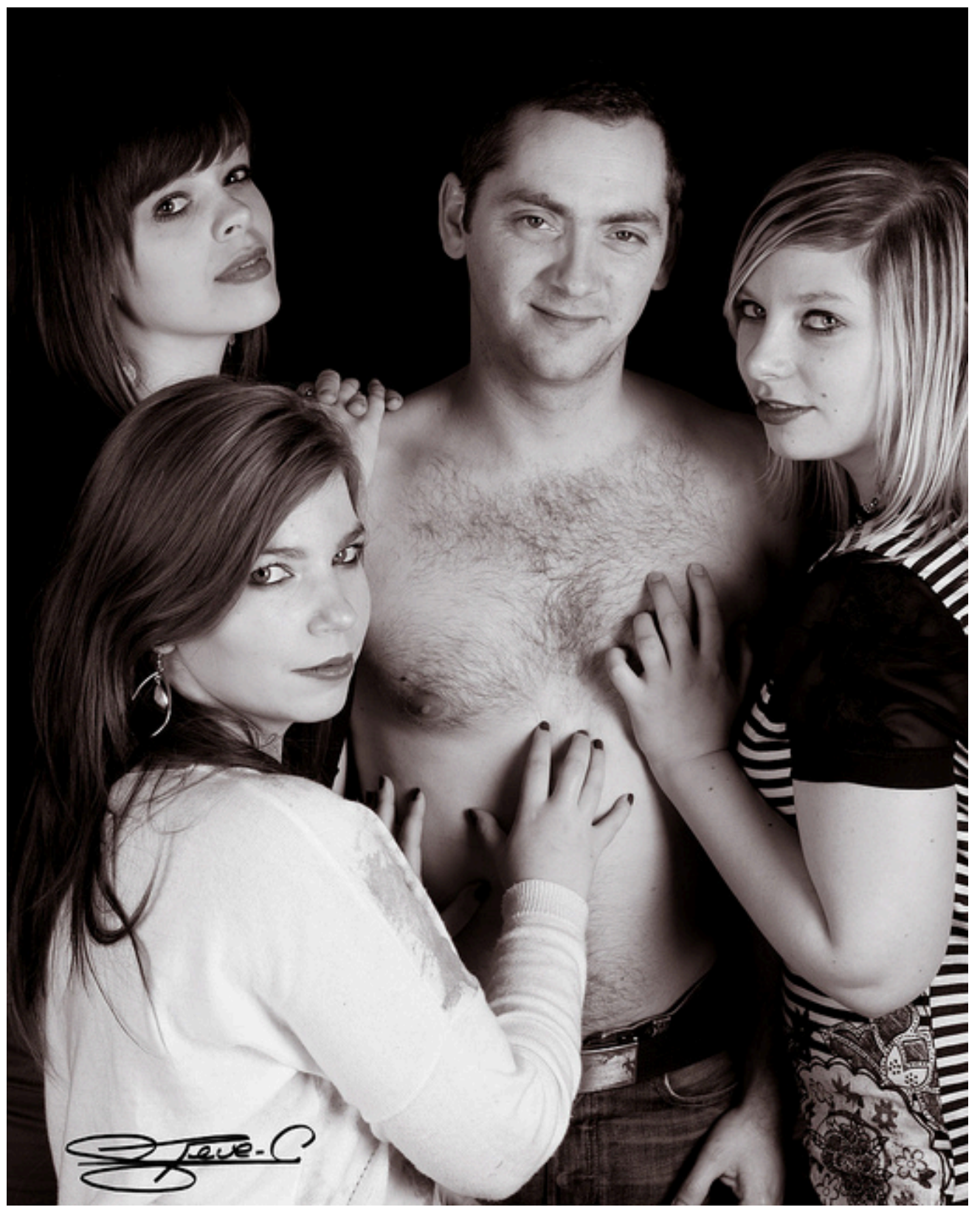

Although women and men in the United States are equally sexually active, unmarried men tend to have more sexual partners than unmarried women.

Steve C Et tant pis pour les jaloux ! - CC BY 2.0.

We saw earlier that higher degrees of religiosity are strongly associated with greater disapproval of premarital sex. Does this mean that religiosity should also be associated with a lower likelihood of actually engaging in premarital sex? The answer is clearly yes, as many studies of adolescents find that those who are more religious are more likely to still be virgins and, if they have had sex, more likely to have had fewer sexual partners (Regenerus, 2007). Survey data on adults yield a similar finding: Among all never-married adults in the GSS, those who are more religious are also more likely to have had fewer sexual partners (Barkan, 2006). We see evidence of this relationship in Table 9.3 "Self-Rated Religiosity and Number of Sexual Partners in Past Five Years among NeverMarried Adults Ages 18-39 (\%)”, which shows that among never-married adults ages 18-39, those who are very 
religious are more likely to have had no sexual partners in the past five years and, if they have had any partners, to have had fewer partners. Although it is hypothetically possible that not having sexual partners leads someone to become more religious, it is much more likely that being very religious reduces the number of sexual partners that never-married adults have.

Table 9.3 Self-Rated Religiosity and Number of Sexual Partners in Past Five Years among Never-Married Adults Ages 18-39 (\%)

\begin{tabular}{|l|l|l|l|}
\hline Number of sexual partners & Very religious & Moderately religious & Slightly religious or not at all religious \\
\hline 0 & 31.1 & 7.6 & 9.2 \\
\hline 1 & 29.5 & 29.6 & 21.6 \\
\hline 2 or more & 39.4 & 62.8 & 69.2 \\
\hline
\end{tabular}

Source: Data from General Social Surveys. (2006-2010). Retrieved from http://sda.berkeley.edu/cgi-bin/hsda?harcsda+gss10.

\section{Key Takeaways}

- The sexual revolution liberalized some views about sexual behavior and increased participation in some forms of sexual behavior, particularly premarital sex.

- Gender, age, and religiosity predict attitudes about premarital sex.

- There are little or no gender differences today in the prevalence of various heterosexual behaviors, but men are more likely than women to have had at least two sex partners in the past year.

\section{For Your Review}

1. Do you think the sexual revolution was a good thing or a bad thing? Explain your answer.

2. Did it surprise you to learn that women and men are equally sexually active today? Why or why not?

\section{References}

Barkan, S. E. (2006). Religiosity and premarital sex during adulthood. Journal for the Scientific Study of Religion, 45, 407-417.

Harding, D. J., \& Jencks, C. (2003). Changing attitudes toward premarital sex. Public Opinion Quarterly, 67(2), 211-226.

Laumann, E. O., Gagnon, J. H., Michael, R. T., \& Michaels, S. (1994). The social organization of sexuality. Chicago, IL: University of Chicago Press. 
Martinez, G., Copen, C. E., \& Abma, J. C. (2011). Teenagers in the United States: Sexual activity, contraceptive use, and childbearing, 2006-2010 national survey of family growth. Vital and Health Statistics, 23(31), 1-35.

Regenerus, M. D. (2007). Forbidden fruit: Sex \& religion in the lives of American teenagers. New York, NY: Oxford Univeristy Press. 


\subsection{Teenage Sex and Pregnancy}

\section{Learning Objectives}

1. Describe how many teenagers have had sex.

2. List several problems associated with teenage pregnancy and birth.

3. Discuss how to reduce teenage pregnancy and help teenage mothers.

We saw earlier that the percentage of teenagers who have sex greatly increased during the 1960s and 1970s. Regardless of what one thinks about premarital sex, this increase had at least two important practical consequences: It greatly increased the risk of teenage pregnancy, and it greatly increased the risk of getting HIV and other sexually transmitted diseases (STDs). For these and other reasons, teenage sex rightly arouses much concern. This section examines trends in teenage sex and pregnancy, the reasons for these trends, and possible measures for reducing teenage pregnancy. As part of this examination, it also discusses sexually transmitted disease, which affects sexually active teens but also sexually active people beyond their teen years.

\section{Teenage Sexual Activity}

As noted earlier, teenagers are much more sexually active today than they were before the sexual revolution. About 43 percent of never-married teens ages 15-19 of both sexes have had sexual intercourse (Martinez et al., 2011); this percentage represents a drop from its highest point, in 1988, of 51 percent for females and of 60 percent for males. About three-fourths of girls in today's sexually experienced group and 85 percent of boys in this group use contraception, most often a condom, the first time they ever have sex. In their most recent act of sexual intercourse, almost 86 percent of girls and 93 percent of boys used contraception, again most often a condom.

The birth rate for females aged 15-19 in 2009 was 39.1 births per 1,000 females. This rate represented a substantial decline from the early 1990s, when the rate reached a peak of almost 60. However, it was still twice as high as Canada's rate and much higher yet than other Western democracies (see Figure 9.4 "Teenage Birth Rates in Selected Western Democracies (Number of Annual Births per 1,000 Women Aged 15-19)”). 


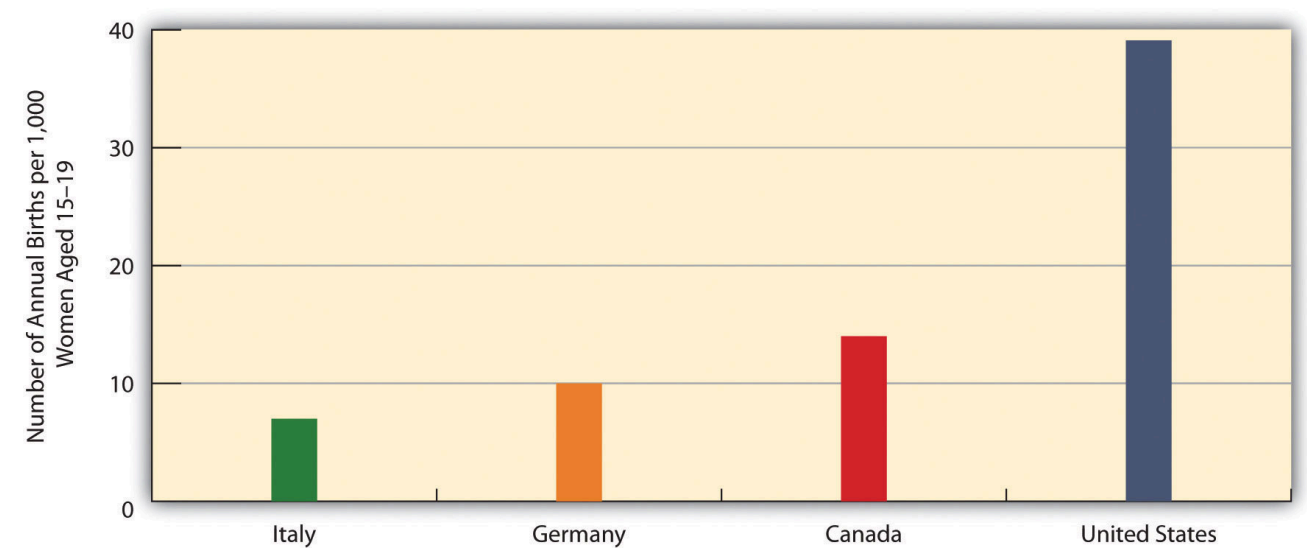

Source: Data from Martinez, G., Copen, C. E., \& Abma, J. C. (2011). Teenagers in the United States: Sexual activity, contraceptive use, and childbearing, 2006-2010 national survey of family growth. Vital and Health Statistics, 23(31), 1-35.

If 43 percent of teens have had sexual intercourse, that means the majority of teens, 57 percent, have never had intercourse. It is interesting to examine their reasons for still being virgins. Table 9.4 "Main Reason Given for Never Having Sexual Intercourse, Ages 15-19 (\%)" shows the relevant data. The top reason for both sexes is religion and morals, followed by concern about a possible pregnancy and not having found the right person with whom to have sex.

Table 9.4 Main Reason Given for Never Having Sexual Intercourse, Ages 15-19 (\%)

\begin{tabular}{|l|l|l|}
\hline & Females & Males \\
\hline Against religion or morals & 38 & 31 \\
\hline Don't want to get (a female) pregnant & 19 & 25 \\
\hline Haven't found the right person yet & 17 & 21 \\
\hline Don't want to get an STD & 7 & 10 \\
\hline In a relationship, but waiting for the right time & 7 & 5 \\
\hline Other reason & 12 & 8 \\
\hline
\end{tabular}

Source: Martinez, G., Copen, C. E., \& Abma, J. C. (2011). Teenagers in the United States: Sexual activity, contraceptive use, and childbearing, 2006-2010 national survey of family growth. Vital and Health Statistics, 23(31), 1-35.

\section{The Problem of Teenage Pregnancy}

Most teenage pregnancies and births are unplanned and are part of a more general problem for all women in their childbearing years. About one-half of all pregnancies in the United States, or more than 3 million pregnancies annually, are unplanned. Approximately 40 percent of these unplanned pregnancies end in abortion, and about 10 percent end by miscarriage. Putting all these numbers together, about 1.6 million live births happen each year as a result of unplanned pregnancies (National Campaign to Prevent Teen and Unplanned Pregnancy, 2011). The cost 
of medical services for unplanned pregnancies and for the infants that are born from many of them cost the nation more than $\$ 11$ billion annually (Gold, 2011).

About one-fifth of all unplanned pregnancies, or almost 700,000 annually, occur to teenagers; another 50,000 teenage pregnancies are planned. These two figures add to 750,000 teenage pregnancies annually, with some 400,000 births resulting from these pregnancies (Kost, Henshaw, \& Carlin, 2010). Altogether, about 18 percent of women, or one of every six females, become teen mothers, and in several southern and southwestern states this percentage is as high as 25-30 percent (Perper \& Manlove, 2009).

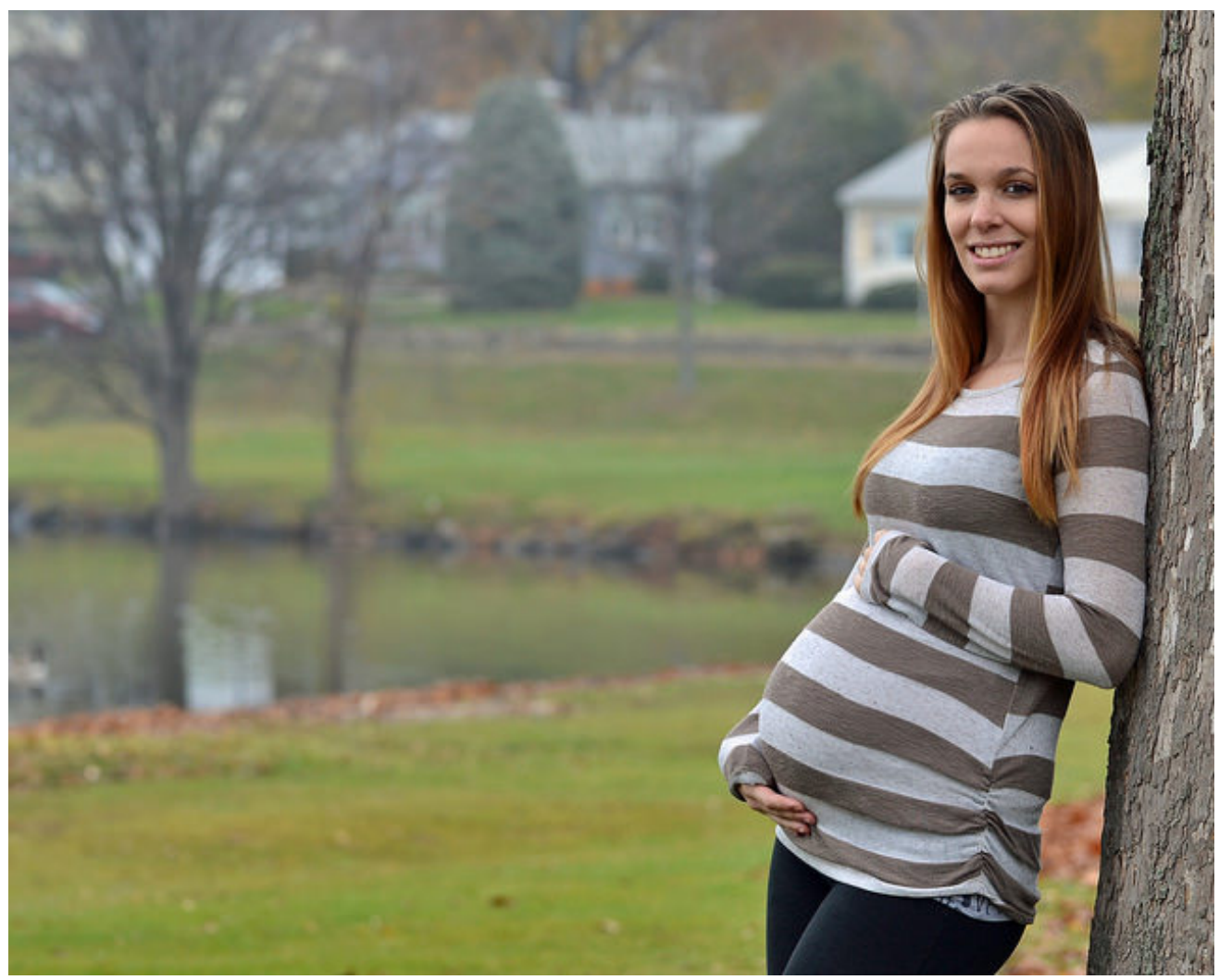

About 18 percent of teenaged girls become mothers. In several southern and southwestern states, this percentage is as high as $25-30$ percent.

bradfordst219 - CC BY 2.0.

Although teenaged pregnancies (and births from these pregnancies) are far from the majority of all pregnancies, unplanned or planned, they pose special problems (American College of Obstetricians and Gynecologists, 2011; Anderson, 2011). On the individual level, pregnant teenagers are more at risk than older pregnant women for high blood pressure and anemia, and they are also more likely to experience early labor, premature birth, and low birth weight. In addition, because teenagers are more likely than adults to have STDs, pregnant teenagers are more likely than older pregnant women to have an STD while they are pregnant, either because they already had an STD when they conceived or because they contract an STD from having sex during pregnancy.

Many pregnant teenagers decide to drop out of school. If they stay in school, they often must deal with the embarrassment of being pregnant, and the physical and emotional difficulties accompanying their teenage pregnancy can affect their school performance. Once the baby is born, child care typically becomes an enormous 
problem, whether or not the new mother is in school. Because pregnant teenagers disproportionately come from families that are poor or near poor, they have few financial resources and often have weak social support networks, either before or after the baby is born (Andrews \& Moore, 2011).

At the societal level, teenage pregnancy and motherhood are very costly in at least two important respects. First, because pregnancy and childbirth complications are more common among teenagers, their health-care expenses during and after pregnancy and childbirth are often higher than the expenses incurred by older women. Medicaid, the federal government's national health plan for poor families, often covers much of these expenses, and the premiums that private health insurance companies charge are higher than otherwise because of their expenses when they insure the families of pregnant teenagers.

Second, the children of teenage mothers are at risk for several kinds of behavioral and developmental problems. The Note 9.7 "Children and Our Future” box discusses these problems further.

\section{Children and Our Future}

Kids Having Kids: The Children of Teenage Mothers

Teenage mothers (ages 15-19) are often unprepared emotionally or practically to raise a child. They often have poor parenting skills and, for example, do not take the time to read daily to their children and otherwise stimulate their cognitive development. They are also less likely than older mothers to provide proper emotional support for their children. In addition, the stress they experience as very young mothers puts them at risk for neglecting or abusing their children. The fact that teenage mothers tend to come from low-income families and continue to live in poverty or near poverty after they become mothers compounds all these problems.

For all these reasons, the children of teenage mothers are at greater risk for several kinds of problems. These problems include impaired neurological development, behavioral problems, and poor school performance.

In particular, when compared to children born to older mothers, the children of teen mothers have lower cognitive scores on the average when they start kindergarten, and they continue to have lower math, reading, and vocabulary test scores as they grow older. These problems persist into their own adolescence, as they are less likely than children of older mothers to graduate from high school. Children of teen mothers are also somewhat more likely to have chronic health problems during childhood and adolescence. When the children of teenage mothers become adolescents, they are also more at risk for delinquency and drug use and to have a prison record by the time they reach young adulthood.

The teenage pregnancy and birth rates in the United States are by far the highest of all Western democracies. The problems that children of teen mothers experience underscore the need for our nation to do everything possible to prevent teenage pregnancy.

Sources: Andrews \& Moore, 2011; Hoffman \& Maynard, 2008

\section{Trends in Teenage Pregnancy}

The bad news is that there are far too many teenage pregnancies. The good news is that the rate of teenage pregnancy has declined rather dramatically since the early 1990 s.

The teenage pregnancy rate is commonly expressed as the annual number of pregnancies per 1,000 women aged 15-19. In 2006, this rate was 71.5, equal to 7.15 percent of all women in this age bracket (Kost et al., 2010). Because many women in this age group either have never had sex or have not had sex in the past year, it is 
instructive to consider the pregnancy rate among women ages 15-19 who are sexually active. In 2006, this rate was 152.8 per 1,000 , equal to 15.28 percent of all sexually active women in this age group.

As high as these rates are, and they are much higher than the rates in other Western democracies, the US teenage pregnancy rate is much lower now than it was in the early 1990s. Figure 9.5 "Pregnancy Rates for US Women Aged 15-19, 1972-2006 (Number of Pregnancies per 1,000 Women Aged 15-19)” displays this dramatic trend. Teenage pregnancy reached a peak rate of 116.9 in 1990 before falling rather steadily to its 2006 rate of 71.5, a much lower rate than existed during the early 1970s. Reflecting the decline in teenage pregnancy, teenage births, as noted earlier, also reached a record low of 39.1 births per 1,000 women ages 15-19 in 2009, as compared to its peak rate of 61.8 in 1991. Despite this dramatic decline, the US teenage birth rate remains the highest of all Western democracies. Experts attribute the decline in teenage pregnancy and birth mostly to increased contraceptive use (stemming from a combination of increased sex education in the schools and increased provision of contraceptives to teenagers) and, to a smaller extent, to reduced sexual activity among some teenagers (Kost et al., 2010).

Figure 9.5 Pregnancy Rates for US Women Aged 15-19, 1972-2006 (Number of Pregnancies per 1,000 Women Aged 15-19)

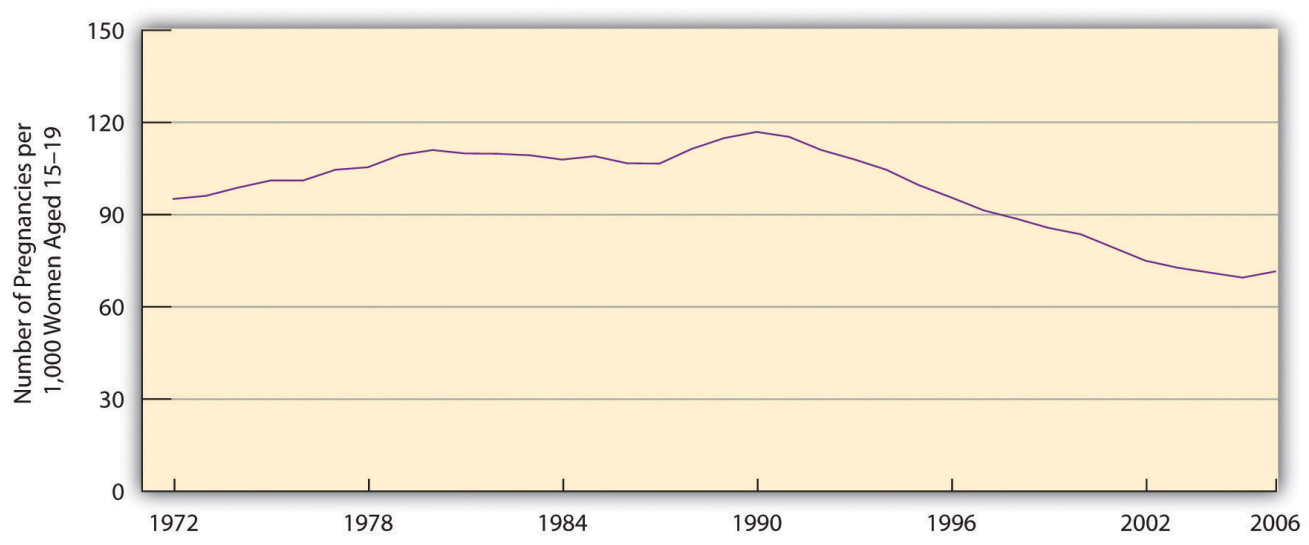

Source: Data from Kost, K., Henshaw, S., \& Carlin, L. (2010). US teenage pregnancies, births and abortions: National and state trends and trends by race and ethnicity, 2010. New York, NY: Guttmacher Institute.

\section{Correlates of Teenage Pregnancy}

We have already noted that teenagers from poor or near-poor families are at greater risk for becoming pregnant. In addition to social class, two other important correlates of teenage pregnancy are race/ethnicity and geography.

Figure 9.6 "Race/Ethnicity and Teenage Pregnancy, 2006 (Number of Pregnancies per 1,000 Women Aged 15-19)” displays the racial/ethnic differences for teenage pregnancy, which are rather large. The pregnancy rates for black and Hispanic teenagers are almost three times greater than the rates for non-Hispanic whites.

Figure 9.6 Race/Ethnicity and Teenage Pregnancy, 2006 (Number of Pregnancies per 1,000 Women Aged 15-19) 


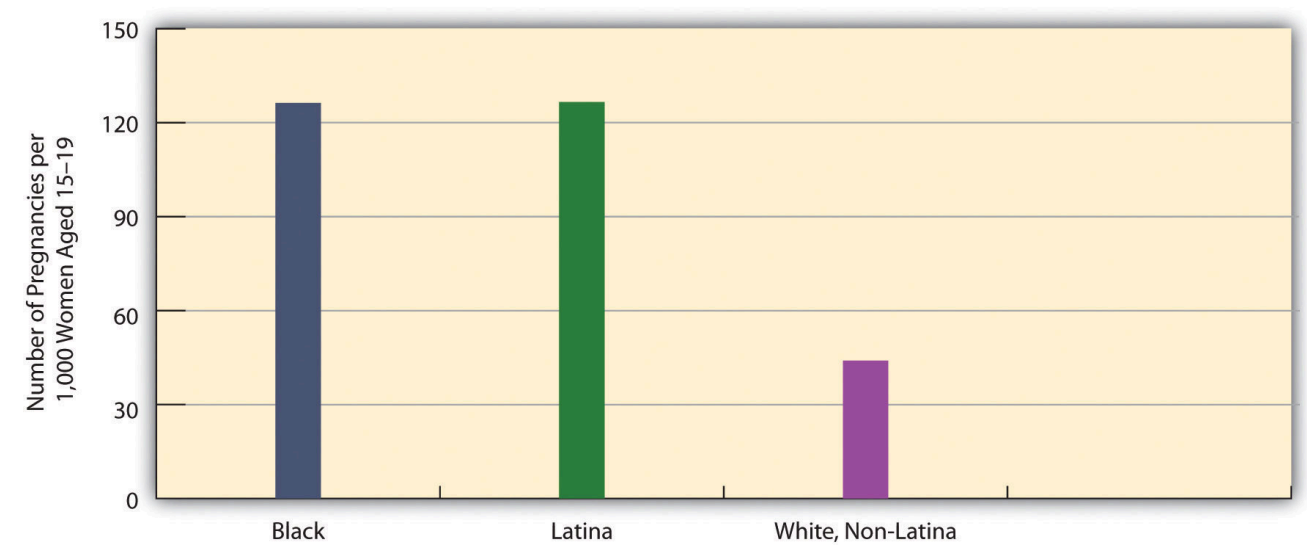

Source: Data from Kost, K., Henshaw, S., \& Carlin, L. (2010). US teenage pregnancies, births and abortions: National and state trends and trends by race and ethnicity, 2010. New York, NY: Guttmacher Institute.

Large differences also exist in teenage pregnancy rates by state and the regions of the country into which the states fall. In general, the South has a higher teenage pregnancy rate than the rest of the nation (see Figure 9.7 “Teenage Pregnancy Rates in the United States, 2005 (Number of Pregnancies per 1,000 Women Aged 15-19)”), although there are individual differences by state. The South's generally higher rate stems largely from its higher poverty rate and racial/ethnic composition. As the opening news story on Texas indicates, sex education programs emphasizing safe sex are also less common in Southern states than in many other states. The same difference holds for the provision of contraceptives by Planned Parenthood and other agencies and organizations. The lack of these two important pregnancy-prevention measures probably also contributes to the South's higher teenage pregnancy rate.

Figure 9.7 Teenage Pregnancy Rates in the United States, 2005 (Number of Pregnancies per 1,000 Women Aged 15-19)

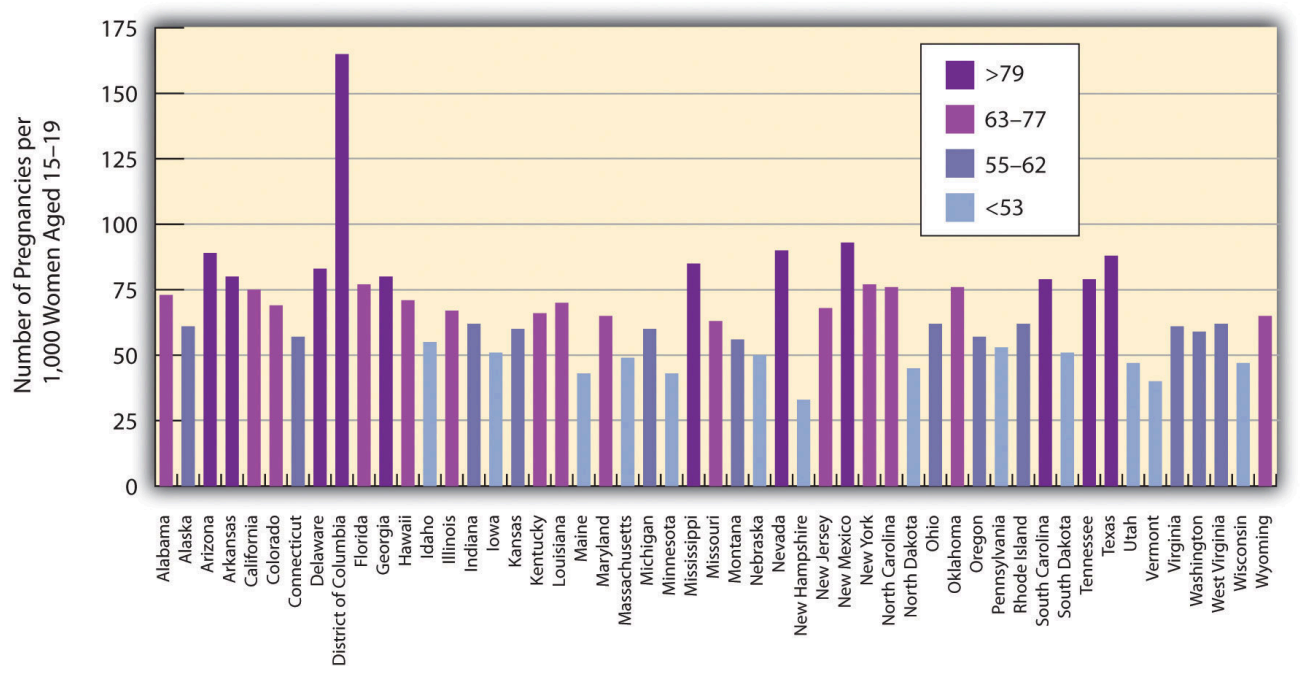

Source: Data from Kost, K., Henshaw, S., \& Carlin, L. (2010). US teenage pregnancies, births and abortions: National and state trends and trends by race and ethnicity, 2010. New York, NY: Guttmacher Institute. 


\section{Sexually Transmitted Diseases}

In addition to pregnancy and birth, another problem associated with teenage sexual activity is the transmission of sexually transmitted diseases (STDs). This is a problem during the teenage years, but it is even more of a problem during young adulthood, when sexual activity is greater than during adolescence (Wildsmith, Schelar, Peterson, \& Manlove, 2010). The STD rate in the United States is higher than in most other Western democracies. Almost 19 million new cases of STDs are diagnosed annually, and more than 65 million Americans have an incurable STD such as herpes. Although teens and young adults ages 15-24 compose only one-fourth of sexually active people, they account for one-half of all new STDs. Despite this fact, most young adults who test positive for an STD did not believe they were at risk for getting an STD (Wildsmith et al., 2010).

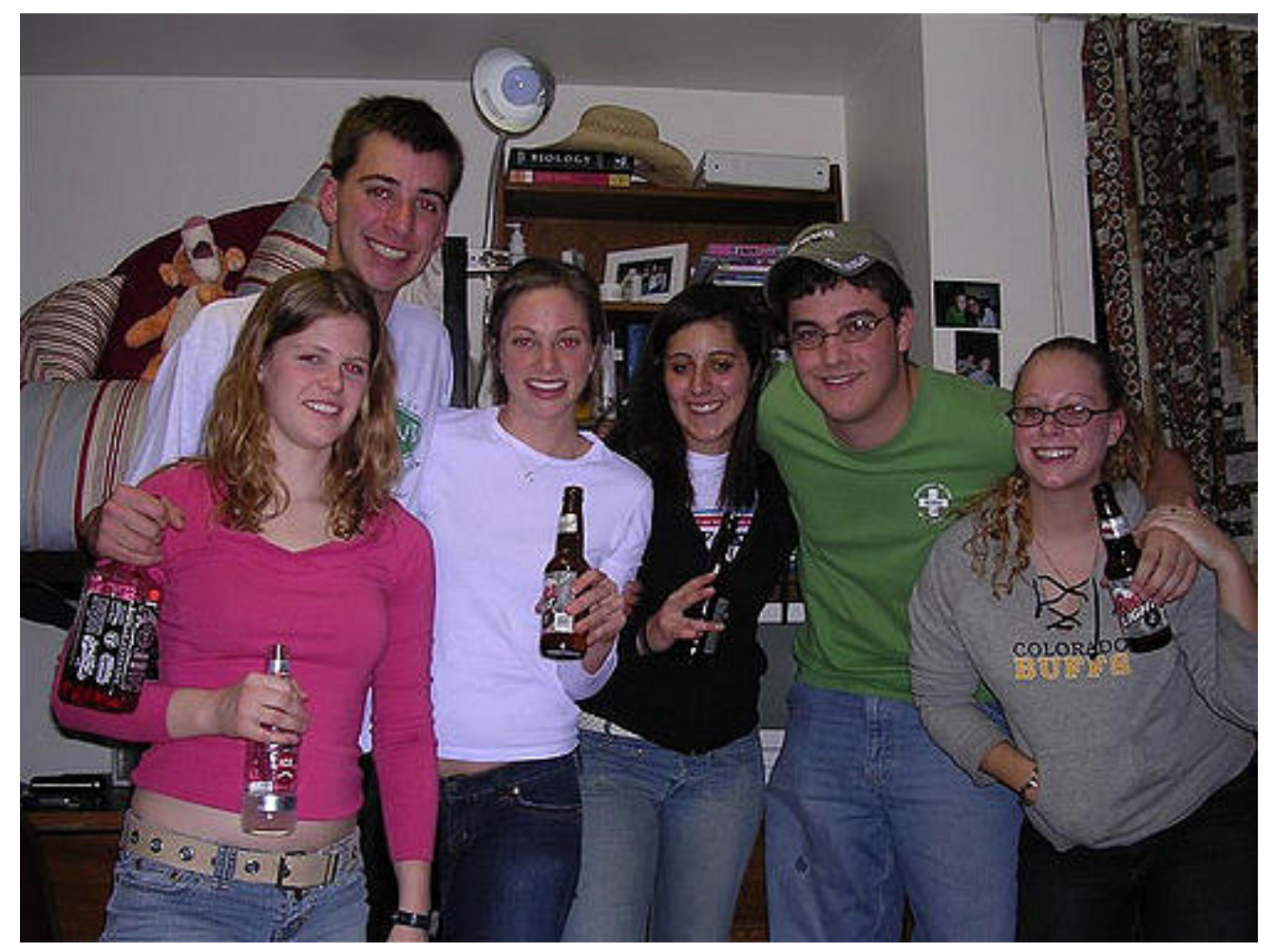

Teens and young adults ages 15-24 compose one-fourth of all sexually active people, but they account for one-half of new sexually transmitted diseases.

Brian Rosner - New Friends at CU - CC BY 2.0.

In any one year, 15 percent of young adults ages 18 and 26 have an STD. This figure masks a significant gender difference: 20 percent of young women have had an STD in the past year, compared to 10 percent of young men. It also masks important racial/ethnic differences: 34 percent of young African Americans have had an STD in the past year, compared to 10 percent of Asians, 15 percent of Hispanics, and 10 percent of whites.

Three types of sexual behaviors increase the risk of transmitting or contracting an STD: having sex with at least three partners during the past year, having a sex partner with a known STD, and not using a condom regularly. About 17 percent of sexually active young adults have had at least three partners during the past year, and 8 percent have had a partner with a known STD. Three-fourths of unmarried sexually active young adults do not 
use a condom regularly. Combining all these risk factors, 39 percent have engaged in one risk factor in the past year, 14 percent have engaged in at least two risk factors, and the remainder, 48 percent, have engaged in no risk factors (Wildsmith et al., 2010).

\section{Reducing Teenage Pregnancy and Helping Teenage Mothers}

Teenage pregnancies cannot occur in either of these two situations: (1) Teenagers do not have sex, or (2) they use effective contraception if they do have sex. If we could wave a magic wand or turn the clock back to before the 1960s, it might be possible to greatly reduce the number of teenagers who have sex, but that day is long past. Teenage sex increased during the 1960s and 1970s and, despite some slight declines after HIV and AIDS became a worldwide problem during the 1980s and 1990s, remains much more frequent than before the sexual revolution. Most sexual behavior researchers believe that pleas for abstinence, as well as sex education programs that focus solely or almost entirely on abstinence, do not help to reduce teen sex and pregnancy (Ball \& Moore, 2008).

If this is true, they say, then the best strategy is to use a harm reduction approach. We first encountered this term in Chapter 7 "Alcohol and Other Drugs"'s discussion of illegal drugs. A harm reduction approach recognizes that because certain types of harmful behavior are inevitable, our society should do its best to minimize the various kinds of harm that these various behaviors generate. In regard to teenage sex and pregnancy, a harm reduction approach has two goals: (1) to help reduce the risk for pregnancy among sexually active teens and (2) to help teenage mothers and their children.

\section{Reducing Pregnancy}

To achieve the first goal, parents, sex education classes, family planning clinics, youth development programs, and other parties must continue to emphasize the importance of waiting to have sex but also the need for teenagers to use contraception if they are sexually active. In addition, effective contraception (birth control pills, other hormonal control, and also condoms, which protect against STDs) must be made available for teenagers at little or no cost. Studies indicate that these two contraception strategies do not lead to more teenage sex, and they also indicate that consistent contraceptive use greatly reduces the risk of teenage pregnancy. As one writer has summarized these studies' conclusions, “Contraceptives no more cause sex than umbrellas cause rain...When contraception is unavailable, the likely consequences is not less sex, but more pregnancy” (Kristof, 2011, p. A31).

\section{People Making a Difference}

Helping Teenagers Reduce the Risk of Pregnancy

The Metro Council for Teen Potential (MCTP) is a membership coalition in Rochester, New York, that "promotes a comprehensive community-wide approach to foster youth assets and youth health," according to its website. To do so, MCTP provides various kinds of information to its member agencies and organizations, including the latest data on pregnancy and other problems facing teens and the latest information on the "best practices" to use to help teens. It has also developed a youth curriculum and media campaign aimed at informing youths about risky behaviors, sexuality, and 
other aspects of their lives. Its member groups include the Rochester School District and youth development organizations throughout Rochester.

An important focus of MCTP's efforts is teen pregnancy, and MCTP has received substantial funding from the US Centers for Disease Control and Prevention to formulate and implement strategies to prevent teen pregnancies. Its website includes results from a random survey of Rochester-area teens about their sexual behavior, views about teen pregnancy, substance use, and other behaviors and attitudes. The website also includes some basic data on Rochester teens' sexual experiences. For example, the 2006 teen birth rate in Rochester was 76 births per 1,000 girls ages 15-19; this rate was much higher than the US rate of 42 and the New York state rate of 26.

MCTP supports several initiatives in Rochester that focus on teenage sexuality and pregnancy. One set of programs called CONECTS provides a variety of teenage pregnancy prevention strategies through such subcontractors as the YWCA. Another program, In-Control, provides reproductive health care and education through Planned Parenthood. A third program, Family Talk, involves workshops that aim to help parents of teens talk more effectively with their children about sexuality and substance abuse.

For these and other efforts, MCTP has won the Organizational Award from the Youth Services Quality Council for the high quality of its work for youths and their families. In helping to reduce teen pregnancy and address other problems facing teenagers in Rochester, the Metro Council for Teen Potential is making a difference. For further information, visit its website at http://www.metrocouncil.us.

In this regard, a recent report of the Guttmacher Institute called contraception a "proven, cost-effective strategy" (Gold, 2011, p. 7). It added, "Contraception is almost universally accepted as a way to reduce the risk of unintended pregnancy...Contraceptive use reduces the risk of unintended pregnancy significantly, and consistent contraceptive use virtually eliminates it.” The report noted that government-funded family planning agencies prevent 2 million unintended pregnancies annually by providing contraception to 9 million young and lowincome women each year. Because most of the women who would have these prevented pregnancies would be eligible for Medicaid, the Medicaid savings from these prevented pregnancies amount to about \$7 billion annually. An expansion of family planning services would almost certainly be an effective strategy for reducing teenage pregnancies as well as unplanned pregnancies among older women.

Another strategy to prevent teenage pregnancy involves the use of early childhood intervention (ECI) programs. Many such programs exist, but they generally involve visits by social workers, nurses, and other professionals to the homes of children who are at risk for neurological, emotional, and/or behavioral problems during their first several years and also as they grow into adolescents and young adults (Kahn \& Moore, 2010). It might sound like a stereotype, but these children are disproportionately born to single, teenage mothers and/or to slightly older parents who live in poverty or near poverty. Long-term evaluation studies show that the best of these programs reduce the likelihood that the very young children they help will become pregnant or have children of their own after they become teenagers (Ball \& Moore, 2008). In effect, helping young children today helps prevent teenage pregnancy tomorrow.

\section{Helping Teen Mothers}

Because teen pregnancies occur despite the best prevention efforts, the second goal of a harm reduction approach is to help teens during their pregnancy and after childbirth. This strategy has the immediate aim of providing practical and emotional support for these very young mothers; it also has the longer-term aims of reducing repeat pregnancies and births and of preventing developmental and behavior problems among their children. 
To achieve these aims, ECI programs have again been shown to be helpful (Ball \& Moore, 2008). Another type of program to help teen mothers involves the use of second-chance homes, which are maternity group homes for unmarried teen mothers (Andrews \& Moore, 2011). One of the many sad facts of teenage motherhood is that teen mothers often have nowhere to live. A teen mother's parent(s) may refuse to let her and her infant live with them, either because they are angry at her pregnancy or because they simply do not have the room or financial means to house and take care of a baby. Or a pregnant teen may decide to leave her parents' home because of the parents' anger or because they refuse to let her continue seeing the child's father. In another possibility, a teen mother may begin living with the father, but these unions are typically unstable and often end, again leaving her and her child without a home. As well, many teen mothers were runaways from home before they became pregnant or were living in foster care. Because of all these situations, many teen mothers find themselves without a place to live.

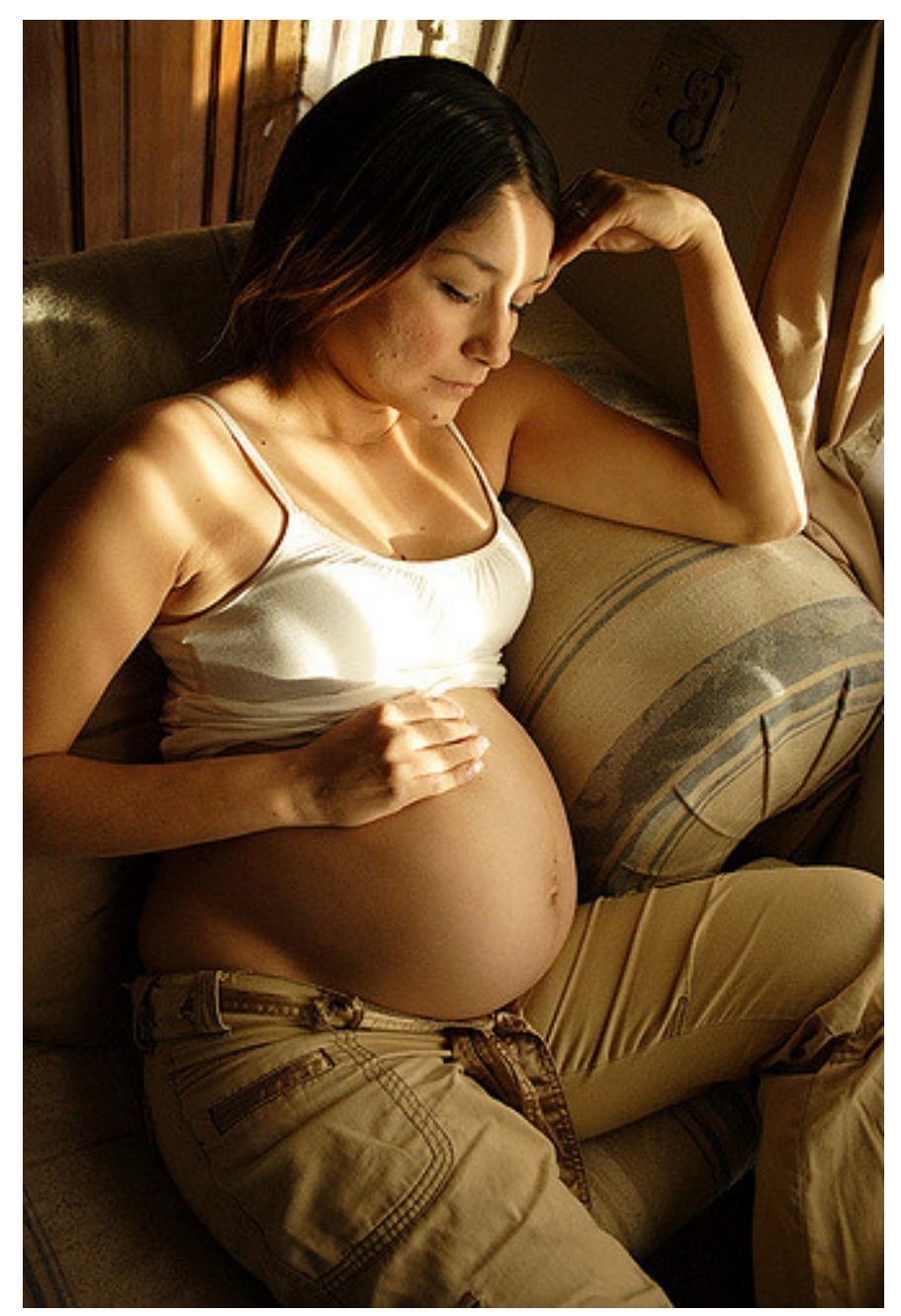

Second-chance homes provide many kinds of services for pregnant teenagers and teen mothers, many of whom are unable to continue living with their own parents.

Teresa Rodríguez - cynthea y kabeer jr - CC BY-ND 2.0.

In second-chance homes (which, depending on the program, are in reality one large house, a set of apartments, or a network of houses), mothers and children (as well as pregnant teens) receive shelter and food, but they also receive important services, such as childrearing help, educational and vocational counseling and training, family planning 
counseling, and parenting classes. Although rigorous evaluation studies do not yet exist of the effectiveness of second-chance homes, they do seem to offer a valuable resource for teen mothers and their children (Andrews \& Moore, 2011).

\section{Addressing Poverty}

A final strategy for addressing the problem of teenage sex and pregnancy is to address a more general societal condition that helps produce teenage sex and pregnancy. This condition is poverty. As noted earlier, children who grow up in poor families and in disadvantaged neighborhoods - those with high rates of poverty, unemployment, high school dropouts, and so forth—are more likely to have sex earlier as teens and to become pregnant (Harding, 2003; Scott, Steward-Streng, Barry, \& Manlove, 2011). Efforts that reduce poverty (see Chapter 2 "Poverty") and improve the conditions of disadvantaged neighborhoods will also reduce the collateral effects of poverty, including teenage pregnancy.

\section{Key Takeaways}

- The United States has the highest rates of teenage pregnancy and birth of all Western democracies. However, these rates have declined substantially from the early 1990s.

- Pregnancies and births among teenagers incur higher health-care costs than those among older women. In addition, children of teenage mothers are at risk for several kinds of developmental, cognitive, and behavioral problems.

- A key strategy to reduce teenage pregnancies involves the provision and use of effective contraception at little or no cost. A key strategy to help teen mothers and their children involves second-chance homes and early childhood intervention programs.

\section{For Your Review}

1. Imagine that you became a parent at age 17. How would your life have been different from what it is now?

2. Many sexually active teenagers do not use contraception regularly. Why do you think they do not use it more often? 


\subsection{Abortion}

\section{Learning Objectives}

1. Summarize the history of abortion and abortion law in the United States.

2. Explain why there are regional differences in abortion rates.

3. Describe some of the correlates of views on abortion.

A major consequence of unplanned pregnancy, during or after the teen years, is abortion. As noted earlier, about 40 percent of all unplanned pregnancies are terminated by an abortion. The more we can reduce unplanned pregnancies through the various strategies just discussed, the fewer abortions we will have. This section presents some additional information on abortion while acknowledging the incredibly strong passions that abortion raises on both sides of the issue. Many people believe that abortion represents a woman's right to control her own body, while many other people believe that abortion is murder. We will not review these arguments, which should be very familiar by now, but we will look at the history of abortion and present some public opinion data about abortion and public health data on its prevalence. We end with a brief discussion of abortion policy.

\section{A Brief History of Abortion}

Like drug use discussed in Chapter 7 "Alcohol and Other Drugs" and prostitution discussed later in this chapter, abortion has a very long history. In fact, sex historians Vern Bullough and Bonnie Bullough (1977, p. 92) note that abortion has "been widely practiced since the beginning of recorded history.” Although early Christianity regarded abortion as murder, there was no general agreement regarding how old the fetus must be for an abortion to be considered murder. During the Middle Ages, most religious scholars thought abortion was not murder unless quickening (when a woman begins to feel the fetus moving) had occurred, which is usually about four to five months into a pregnancy. In a notable development, Pope Pius IX declared in 1869 that abortion was murder no matter how young the fetus was, and that remains the current belief of the Catholic Church.

During the nineteenth century, many countries passed new laws that banned abortion, and most US states did so as well. Bullough and Bullough (1977, p. 111) say that these new laws were intended to protect pregnant women from unskilled abortionists, but that the laws backfired because "desperate women turned to illegal practitioners." Many illegal abortion providers were simply unskilled to perform abortions, but even doctors and midwives who provided abortions illegally did not have access to hospitals or medical clinics if something went wrong. After antibiotics came into use during the twentieth century, illegal abortion providers also did not have access to these miracle drugs and thus could not treat infections that occurred after they performed their abortions. By the early 1960s, the only legal abortions in most states were those done to save the mother's life, with about 8,000 such therapeutic abortions performed annually. 
In addition to these legal abortions, an estimated 400,000-650,000 illegal abortions were also being performed annually by the early 1960s. For the reasons just given, these abortions were often risky procedures and resulted in a "very high maternal mortality rate” (Bullough \& Bullough, 1977, p. 112). In plain English, many women died from illegal abortions.

The sheer number of illegal abortions and maternal death and health complications helped ignite a new abortion rights movement. This movement also believed that women have the right to control their own bodies without government interference. By 1970, sixteen states had legalized abortion or had made abortions easier to receive under certain circumstances. Some courts began to rule that laws against abortion violated women's constitutional right to privacy. Finally, the US Supreme Court supported legal abortion in its famous and controversial 1973 decision, Roe v. Wade. This decision allowed all abortions during the first trimester (a roughly three-month period of pregnancy) and permitted states to regulate abortion during the second trimester to protect the mother's health, but states could still not prohibit abortion during this trimester. For the remaining trimester, states were allowed to prohibit abortion except when the mother's life or health was at stake.

The legalization of abortion by the Roe decision was controversial from the beginning and remains controversial today (see Note 9.14 “Applying Social Research”). Amid all this controversy, it is important to keep in mind that the Roe decision protected the health and lives of many pregnant women. As the Guttmacher Institute (Cohen, 2009, p. 2) explains, “The United States legalized abortion nationwide in 1973, in part because of the clear evidence that restrictive laws were not ending abortion but were exacting a significant public health toll, notably on lower-income women who could not travel or pay for safe services. Almost immediately afterward, pregnancyrelated deaths and hospitalizations due to complications of unsafe abortion effectively ended. The United States was not the first country and has been far from the last to recognize this relationship and move to liberalize its law.”

\section{Applying Social Research}

\section{The Abortion and Crime Rate Controversy}

In 2001, two scholars published an article on abortion and crime rates. The article concluded that the legalization of abortion after the Supreme Court's Roe v. Wade decision in 1973 lowered the crime rate two decades later. They reasoned that the Roe decision increased the number of abortions among poor teenagers, whose children are at risk for delinquency and crime when they reach adolescence and young adulthood. Because the increased number of abortions meant that these children were never born, the crime rate in the late 1980s and 1990s was lower than it would have been because of the Roe decision.

This article set off a firestorm of controversy, with people on both sides of the abortion debate appalled at the implication that abortions should be promoted to lower the crime rate many years later. The article also set off a wave of social science research to determine the validity of the article's conclusion.

The research that has been published in the decade since this controversial article has yielded mixed results. Some studies have found that legal abortion did lower the crime rate; other studies have found that it did not lower the crime rate; and some studies have even found that it raised the crime rate. Even if abortion might have lowered the crime rate during the 1990s, most criminologists think that the crime rate decline during that decade mostly stemmed from other reasons, including more effective policing and a thriving economy.

It remains highly debatable whether any possible crime-reducing effect of abortion is a relevant factor for the debate over legal abortion. Regardless of its possible relevance, however, the social science research on this issue is so equivocal that it is premature to assume that abortion does, in fact, lower the crime rate. 
Sources: Chamlin, Myer, \& Sanders, 2008; Donohue \& Levitt, 2001; Kahane, Paton, \& Simmons, 2008

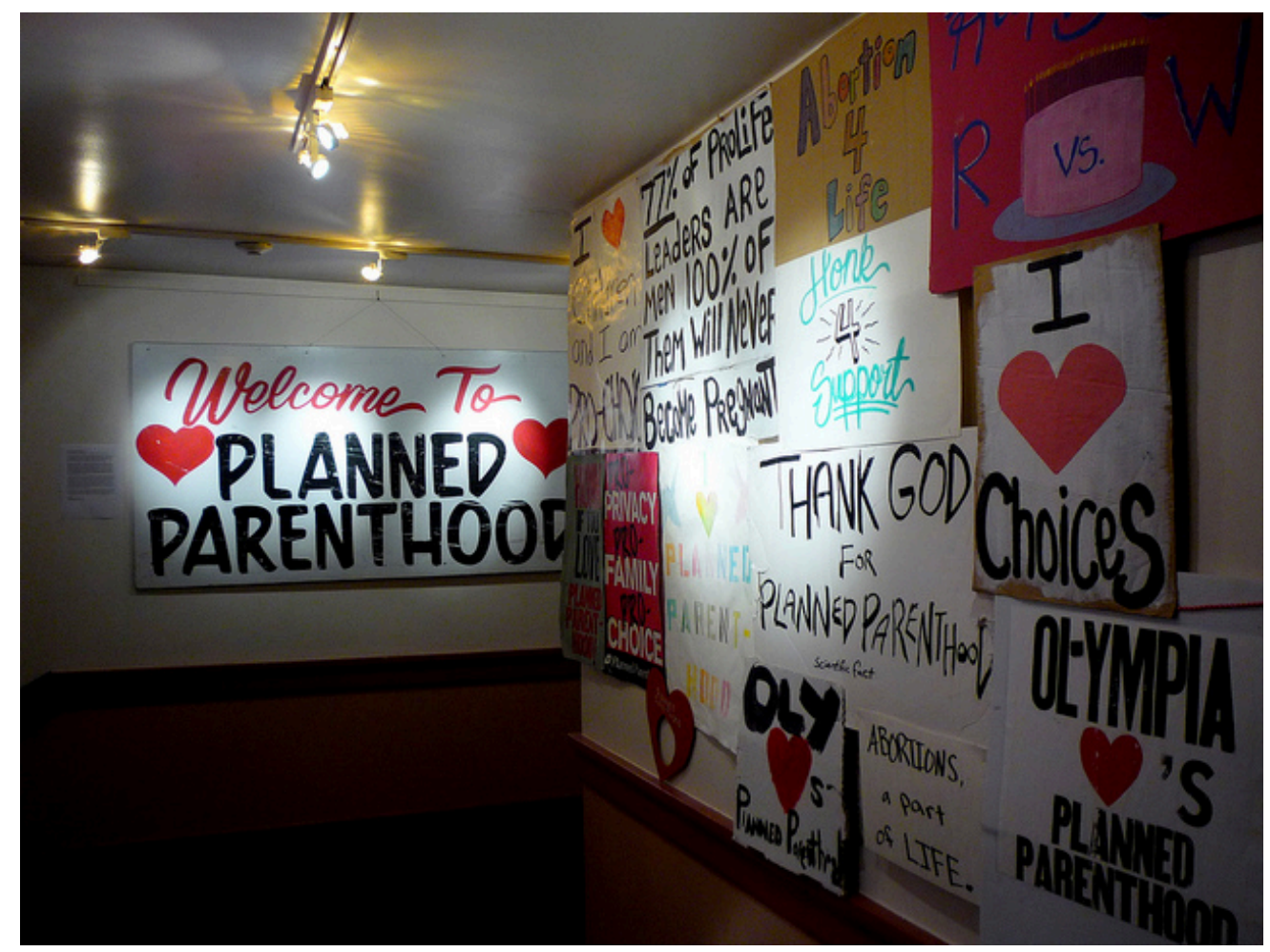

The legalization of abortion in the United States after the 1973 Roe v. Wade decision of the Supreme Court reduced the number of unsafe abortions.

Jason Taellious - Support Planned Parenthood Sign Art - CC BY-SA 2.0.

Despite the fact that Roe $v$. Wade ended the health risks of unsafe abortions, access to abortion has weakened in the years since this case was decided in 1973. In a 1992 ruling, Planned Parenthood v. Casey, the Supreme Court weakened Roe by ruling that states could ban abortions after the fetus became viable at twenty-two or twenty-three weeks, which is before the end of the second trimester. This ruling also allowed states to require a twenty-four-hour waiting period, the signing of an informed consent form, and the signing of a parental consent form for minors. Various acts by Congress have also made it more difficult to receive an abortion. In particular, Congressional legislation in 1976 banned Medicaid funding of abortions.

Many states have passed various measures to make it more difficult for a woman to get an abortion. As of March 2012, these selected measures were in effect (Guttmacher Institute, 2012):

- Thirty-two states prohibit the use of state funds for abortions unless the woman's life is in danger or the pregnancy resulted from rape or incest.

- Nineteen states require that a woman receive counseling before an abortion that includes information on one or more of the following topics: the ability of a fetus to feel pain, mental health consequences following an abortion, the availability of ultrasound, or the claimed link between abortion and breast cancer. 
- Twenty-six states require a waiting period between receiving counseling and receiving an abortion.

- Twenty-six states require consent from one or both parents for a minor to receive an abortion, and fifteen states require that one or both parents be notified; included in these numbers are four states that require both consent and notification.

- Two states require a woman to have an ultrasound before having an abortion.

\section{Abortion Data}

Some basic facts about the number of abortions in the United States are essential for a complete understanding of the abortion issue. (Data are for 2008 and come from Jones \& Kooistra, 2011). Perhaps the most important fact is that about 1.2 million abortions occur annually in the United States, down from a peak of 1.6 million abortions in 1990. This decrease is thought to stem from a drop in unwanted pregnancies (see earlier discussion) and from a decline in facilities that provide abortions because of harassment from abortion opponents and reduced public funding. About 90 percent of abortions are done during the first trimester (approximately twelve weeks).

The abortion rate (number of abortions per 1,000 women ages 15-44) differs by region (2008 data) and is highest in the Northeast and lowest in the Midwest (see Figure 9.8 "Regional Differences in Abortion Rates, 2008”). It should be noted, however, that there is much variation within each region. In the West, for example, the abortion rate is 27.6 in California but only 0.9 in Wyoming.

Figure 9.8 Regional Differences in Abortion Rates, 2008

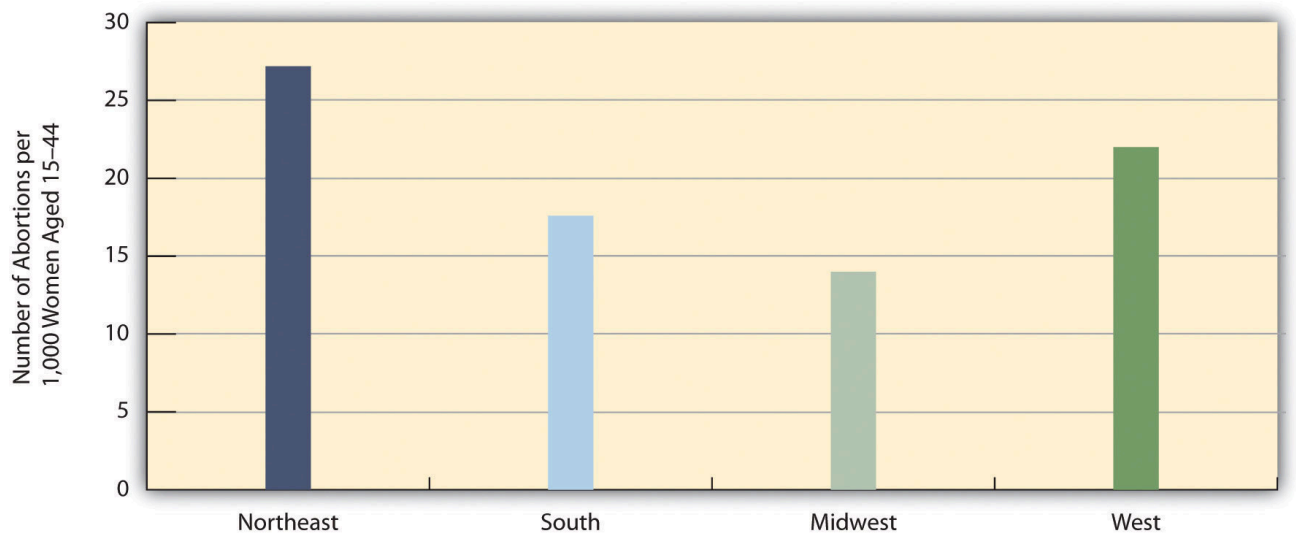

Source: Data from Jones, R. K., \& Kooistra, K. (2011). Abortion incidence and access to services in the United States, 2008.

Perspectives on Sexual and Reproductive Health, 43, 41-50.

These regional and state differences greatly reflect the presence or absence of nearby abortion providers. In many parts of the nation, it is very difficult and even practically impossible for women to get an abortion. Only 13 percent of the more than 3,000 counties in the United States have an abortion provider; one-third of women of childbearing age (15-44) live in the 87 percent of counties that lack any abortion providers (Jones \& Kooistra, 2011). These women must travel relatively long distances to a provider and may lack the money or transportation to do so. The percentage of women ages 15-44 in counties with no provider reflects the regional abortion rates in Figure 9.8 "Regional Differences in Abortion Rates, 2008”. In the Midwest, 52 percent of these women live 
in counties without a provider. Comparable figures for the other regions are: Northeast, 18 percent; South, 47 percent; and West, 13 percent. About half of all women in the Midwest and South, then, live in counties without an abortion provider.

\section{Public Views about Abortion}

People tend to hold very strong views about abortion, and the news media regularly report on rallies and other events carried out by both sides of the abortion controversy. This news coverage obscures an important fact about public opinion on abortion: The public largely supports abortions that occur under certain circumstances, while it is divided over abortions that occur under other circumstances. On some types of abortions, then, there is a strong public consensus in a favor of abortion, while on other types of abortions there is much disagreement.

The circumstances for which the public largely supports abortions are those where the physical health of the mother is at stake, where the pregnancy resulted from a rape or act of incest, or where the baby is likely to have a serious defect. The circumstances for which the public is divided on abortion are those where a woman wants an abortion for any other reason, including her wish not to have any more children.

We see evidence of these two patterns of abortion opinion in data from the GSS. The GSS regularly asks a series of questions that begin with the following statement: "Please tell me whether or not you think it should be possible for a pregnant woman to obtain a legal abortion if...” After this initial statement, the question lists a circumstance or reason for an abortion. These scenarios are as follows: (a) The woman's own health is seriously endangered by the pregnancy; (b) she became pregnant as a result of rape; (c) there is a strong chance of serious defect in the baby; (d) she is married and does not want any more children; (e) the family has a very low income and cannot afford any more children; (f) she is not married and does not want to marry the man; and (g) the woman wants it for any reason.

As Figure 9.9 "Support for Legal Abortion (Percentage Saying a Woman Should Be Able to Obtain a Legal Abortion for Each Circumstance)" shows, strong majorities of the public support a legal abortion for the first three scenarios: the women's health is endangered, the pregnancy resulted from a rape; or the baby is likely to have a serious defect. On the other hand, only 40-50 percent of the public support a legal abortion for the remaining scenarios: a married woman does not want more children, the family cannot afford more children, an unmarried woman does not want to marry; or a woman wants an abortion for any reason. 


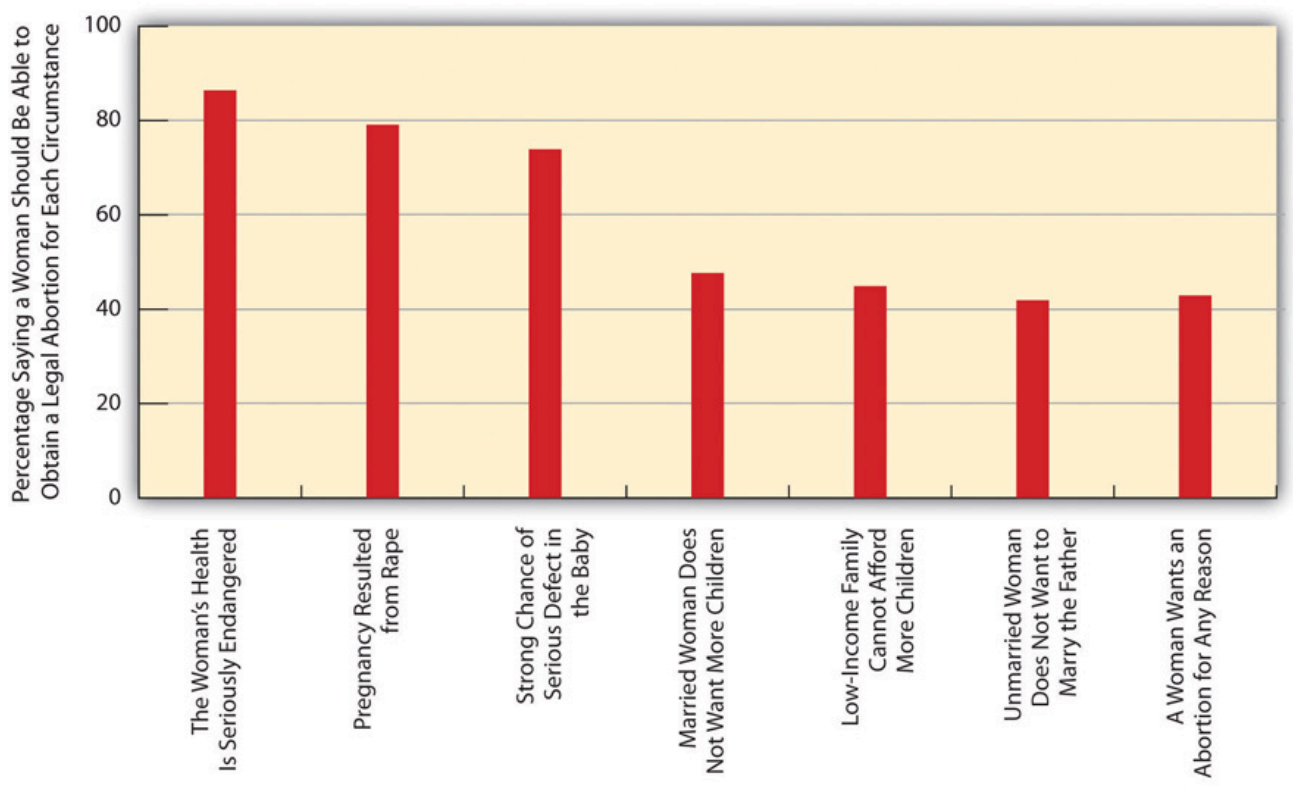

Source: Data from General Social Survey. (2010). Retrieved from http://sda.berkeley.edu/cgi-bin/hsda?harcsda+gss10.

\section{Correlates of Public Views}

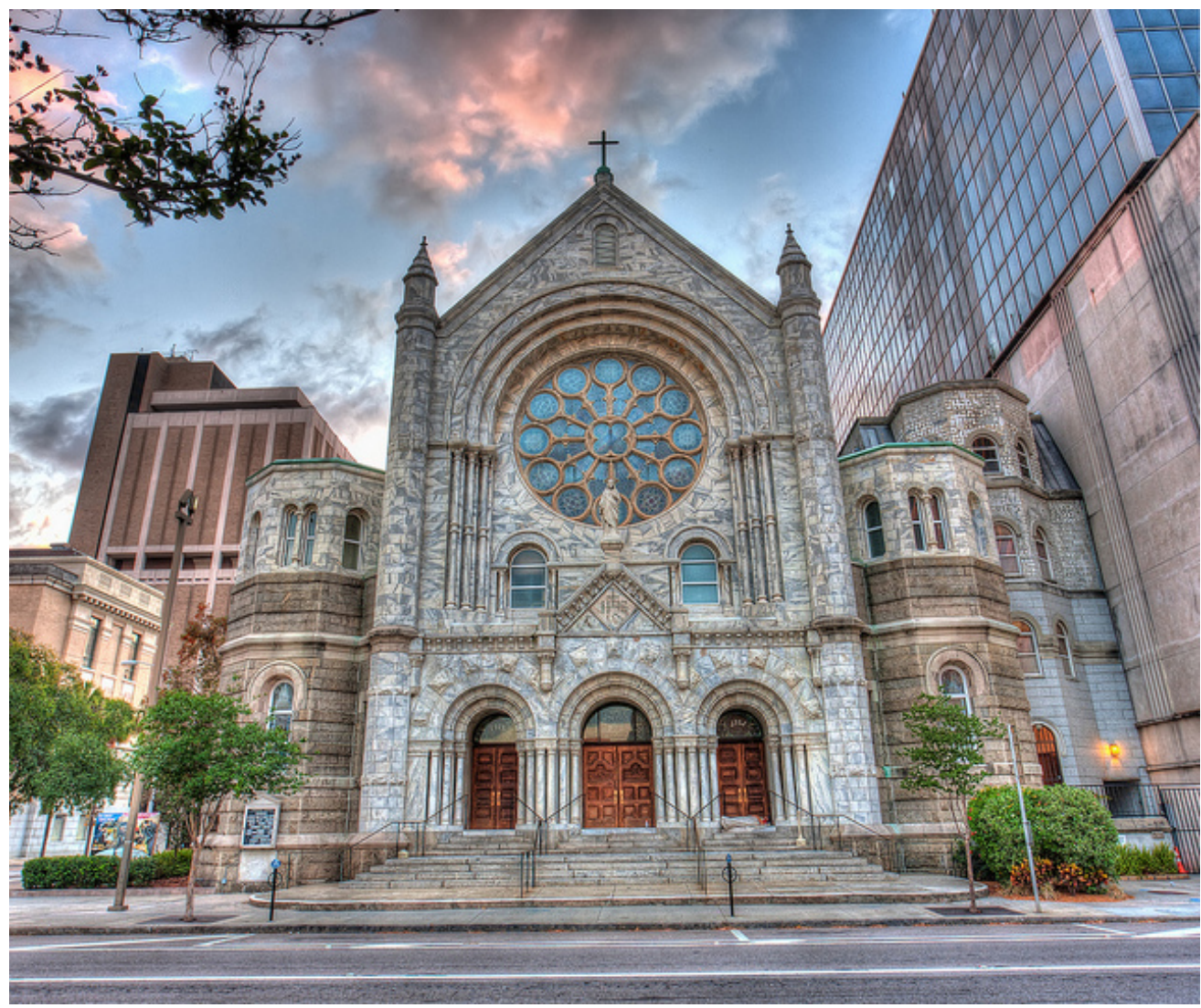


Although the Catholic Church is a leading opponent of legal abortions, Catholics are not more likely than Protestants to oppose legal

abortion.

Matthew Paulson - Sacred Heart Catholic Church - CC BY-NC-ND 2.0.

Reflecting the sociological principle that our social backgrounds influence our attitudes and behaviors, several aspects of people's social backgrounds are associated with their views on abortion. We can illustrate this by using the GSS question that asks whether respondents support a legal abortion "for any reason." In the entire GSS sample, about 43 percent support legal abortion for any reason; using a common term for people who favor legal abortion, they are entirely pro-choice.

You have probably heard many times that people who are religious tend to oppose abortion rights much more than people who are less religious. Using the GSS “for any reason” item, we would thus expect that very religious people would be much less likely than other people to favor abortion for any reason. Figure 9.10 "Self-Rated Religiosity and Support for Legal Abortion for Any Reason (\%)” shows this is indeed the case. People who say they are not religious are almost four times more likely than those who are very religious to support a legal abortion for any reason.

Figure 9.10 Self-Rated Religiosity and Support for Legal Abortion for Any Reason (\%)

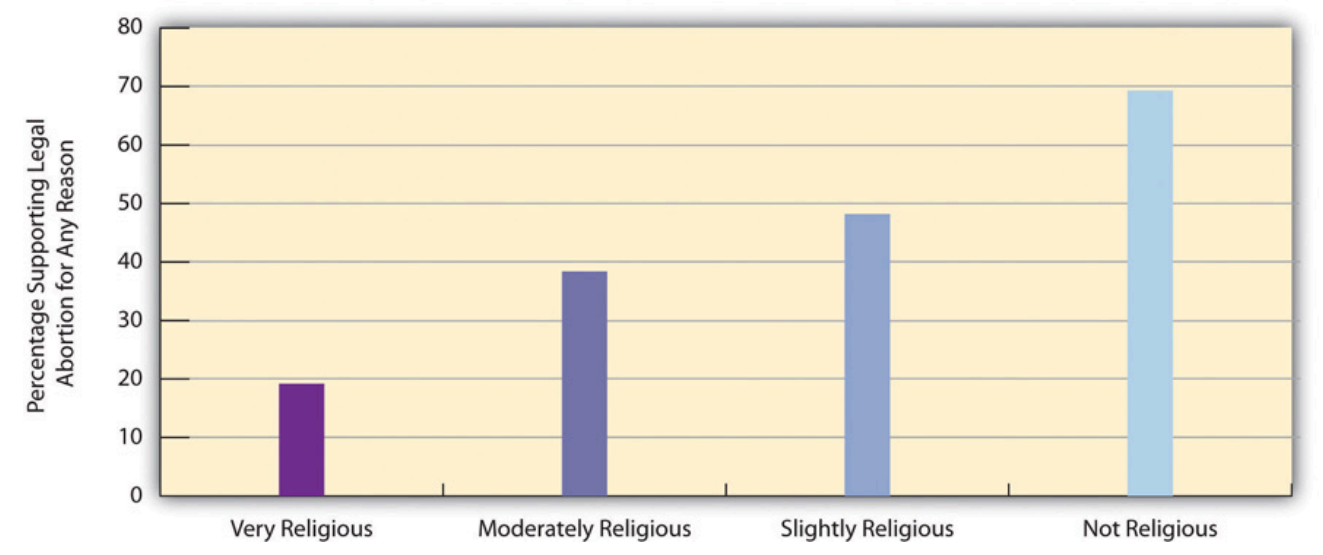

Source: Data from General Social Survey. (2010). Retrieved from http://sda.berkeley.edu/cgi-bin/hsda?harcsda+gss10.

You have probably also heard many times that the Catholic Church is a leading opponent of legal abortion. Does this mean that Catholics themselves are less likely than Protestants to support legal abortion for any reason? The answer to this question is no: Figure 9.11 "Religious Preference and Support for Legal Abortion for Any Reason (\%)” shows that Catholics and Protestants are about equally likely to favor legal abortion for any reason, with Jews and people with no religious preference about twice as likely to favor it. 


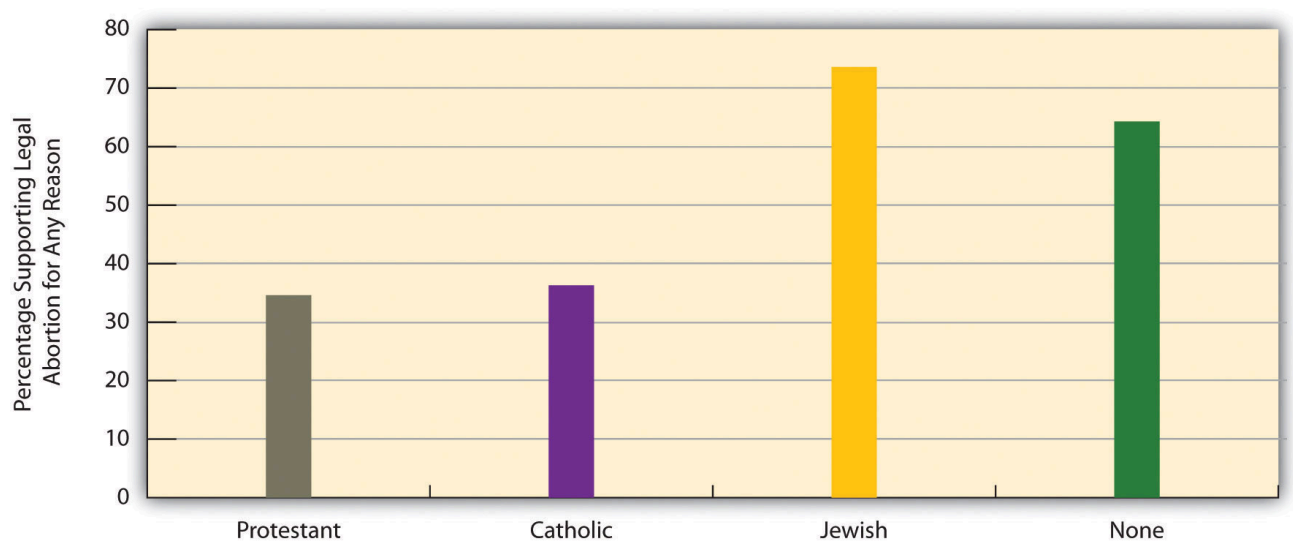

Source: Data from General Social Surveys. (2008-2010). Retrieved from http://sda.berkeley.edu/cgi-bin/hsda?harcsda+gss10.

It might make sense to think that women are more likely than men to favor legal abortion. However, there is no gender difference in this regard. As Figure 9.12 "Gender and Support for Legal Abortion for Any Reason (\%)" shows, women are in fact slightly less likely than men to favor legal abortion, although the difference shown in the figure is too small to be statistically significant.

Figure 9.12 Gender and Support for Legal Abortion for Any Reason (\%)

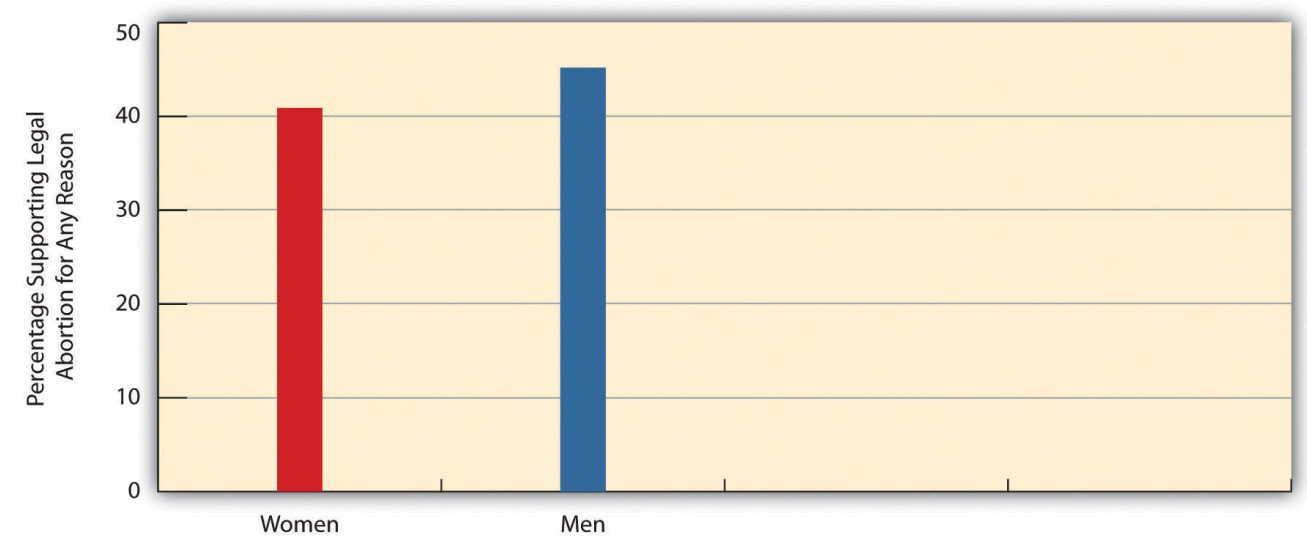

Source: Data from General Social Survey. (2010). Retrieved from http://sda.berkeley.edu/cgi-bin/hsda?harcsda+gss10.

Three other aspects of our social backgrounds are rather strongly associated with abortion views: education, our political views, and region of country. People with college degrees are much more likely than those with lower education levels to support legal abortion for any reason (Figure 9.13 "Education and Support for Legal Abortion for Any Reason (\%)"); liberals are twice as likely as conservatives to favor legal abortion (Figure 9.14 "SelfDescribed Political Views and Support for Legal Abortion for Any Reason (\%)”); and people in the Northeast and West are more likely to favor legal abortion than people in the South and Midwest. 


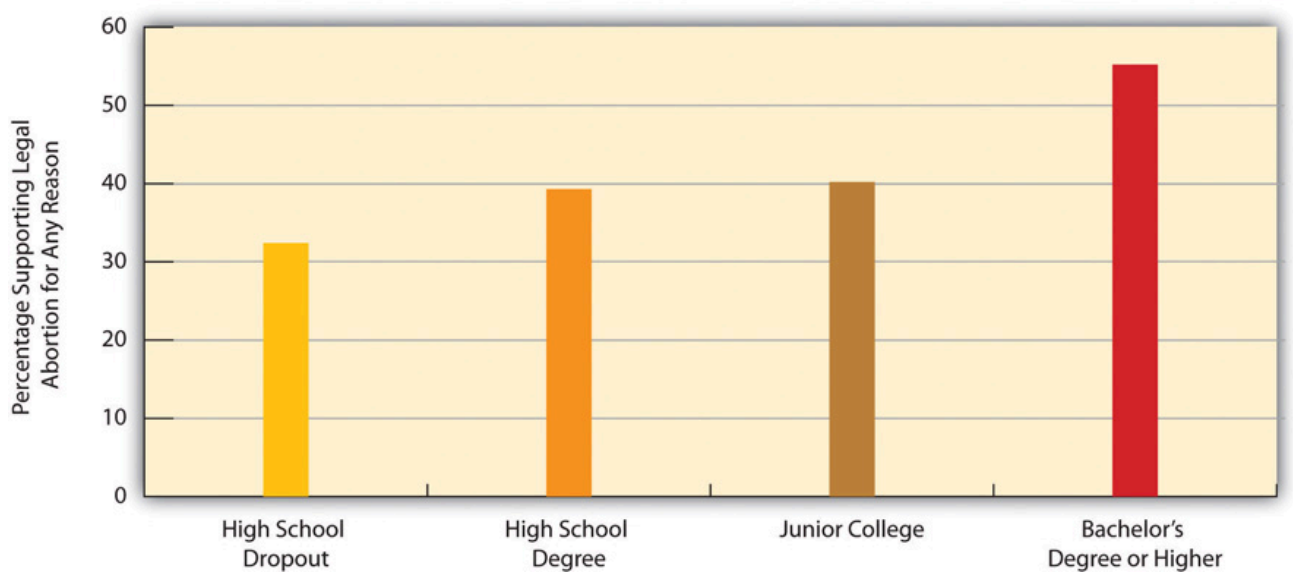

Source: Data from General Social Survey. (2010). Retrieved from http://sda.berkeley.edu/cgi-bin/hsda?harcsda+gss10.

Figure 9.14 Self-Described Political Views and Support for Legal Abortion for Any Reason (\%)

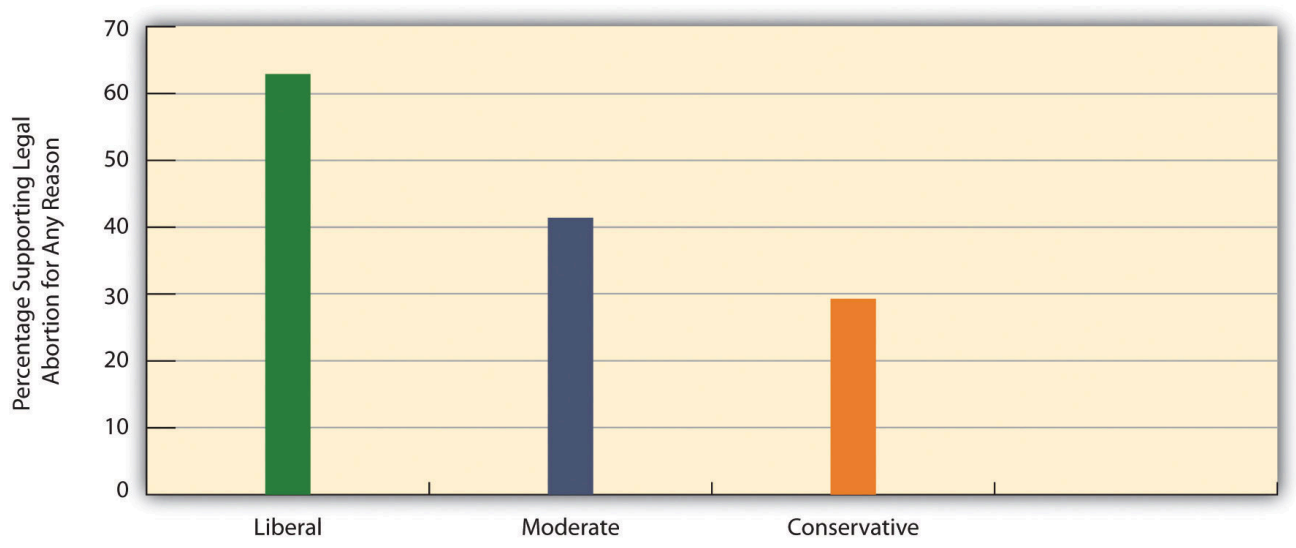

Source: Data from General Social Survey. (2010). Retrieved from http://sda.berkeley.edu/cgi-bin/hsda?harcsda+gss10.

Figure 9.15 Region and Support for Legal Abortion for Any Reason (\%)

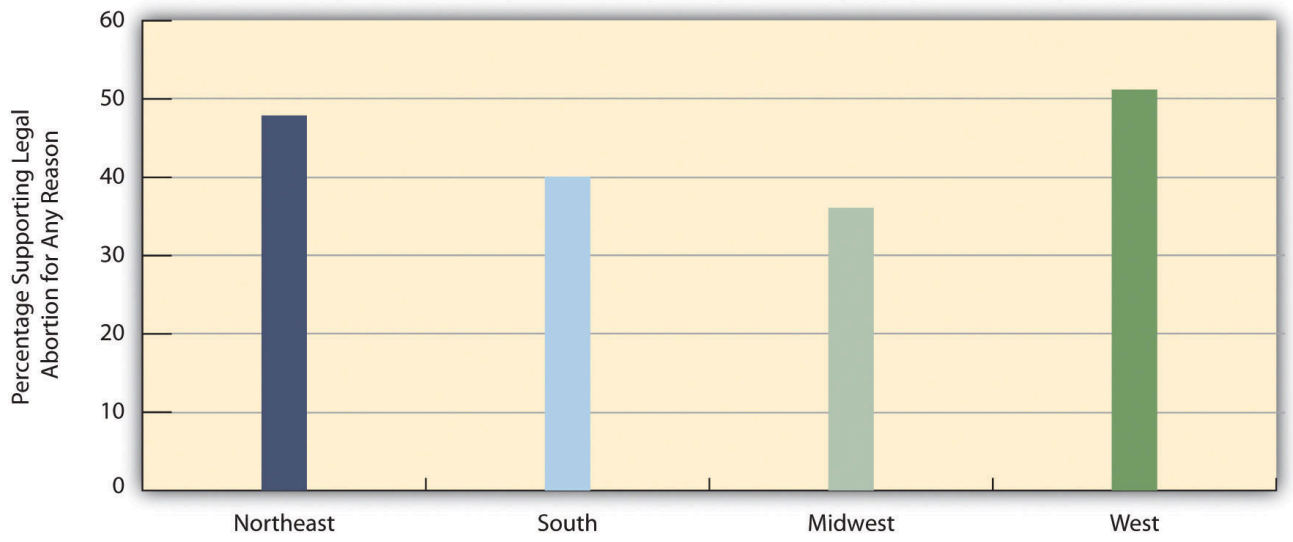

Source: Data from General Social Survey. (2010). Retrieved from http://sda.berkeley.edu/cgi-bin/hsda?harcsda+gss10. 


\section{Reducing Abortions and Making Them Safe}

No one likes abortions. Abortion rights opponents liken them to murder, and abortion rights proponents are certainly not gleeful when abortions occur. Rather, they recognize that abortions will occur whether they are legal or illegal, and they think that legal abortion protects women from the dangers of illegal abortions and recognizes women's right to control their own bodies. As President Bill Clinton and Secretary of State Hillary Clinton have summarized the view of abortion rights proponents in various speeches during the past two decades, abortion should be safe, legal, and rare.

Chapter 7 "Alcohol and Other Drugs"'s discussion of illegal drugs emphasized that "what's past is prologue”: Because drugs have been used since prehistoric times, it is no surprise that illegal drug use remains common today even despite possible arrest and punishment. The long history of abortion suggests that "what's past is prologue" is again a relevant theme for this particular behavior. Since the beginning of recorded history, women have tried to end their pregnancies. Whatever we might think of abortion, the fact remains that many women will continue to try to end their pregnancies whether abortion is legal or whether it is illegal. As with teenage pregnancy and the use of illegal drugs, a harm reduction approach to abortion again makes sense in view of this basic fact, as we shall now explain.

Around the world, the rate of abortion is generally unrelated to whether it is legal or illegal. Laws against abortions thus do not reduce abortions, but they do cause another very serious problem (Barot, 2011). When abortion is illegal, women either must have an abortion from an unskilled provider in unhygienic conditions, or they may try to induce their own abortion by inserting an object into their uterus or by ingesting a toxic substance. Not surprisingly, all these illegal abortions are very risky and can lead to many complications, including severe bleeding, serious infection, or organ damage, any of which can be fatal. Unsafe abortion around the world is one of the top three reasons for maternal mortality, along with childbirth-related infection and hemorrhaging. For abortion to be safe, then, it must be legal. Making abortion illegal does not make abortions disappear, but it does make them dangerous.

Both sides of the abortion debate want to see abortions reduced. How then can this goal be achieved? The most promising strategy is to reduce unintended pregnancies, as discussed in the previous section on teenage pregnancy, through the consistent use of effective contraception. The reason for this strategy is simple: Almost all abortions result from unintended pregnancies, and if we can reduce unintended pregnancies, we will reduce the number of abortions. As the Guttmacher Institute (Barot, 2011, p. 24) explains, "Extensive research shows that behind almost every abortion is an unintended pregnancy, and the most effective way to prevent unintended pregnancy is through correct and consistent use of contraceptives.”

Ironically, the religious opponents and politically conservative opponents of abortion also tend to be opposed to sex education that emphasizes safe sex and, as well, to providing contraceptives at no cost or low cost to sexually active teenagers and young adults. During the past few years, many state governments led by conservative governors and/or state legislatures have reduced or eliminated funding for Planned Parenthood and other family planning agencies whose clients are largely low-income women (Pollitt, 2011; Tan, 2011).

These funding cuts and other efforts to reduce contraceptive counseling and provision have two consequences. First, they help ensure that many more unwanted babies are born, at a cost of roughly $\$ 10,000$ in medical delivery 
costs for each baby and thousands of dollars more in the societal problems (discussed in the teenage pregnancy section) associated with unwanted births to poor mothers. In 2011, Texas reduced family planning funds by $\$ 73$ million annually, despite estimates that this reduction would result in 20,000 additional births annually that would involve \$200 million in medical delivery costs.

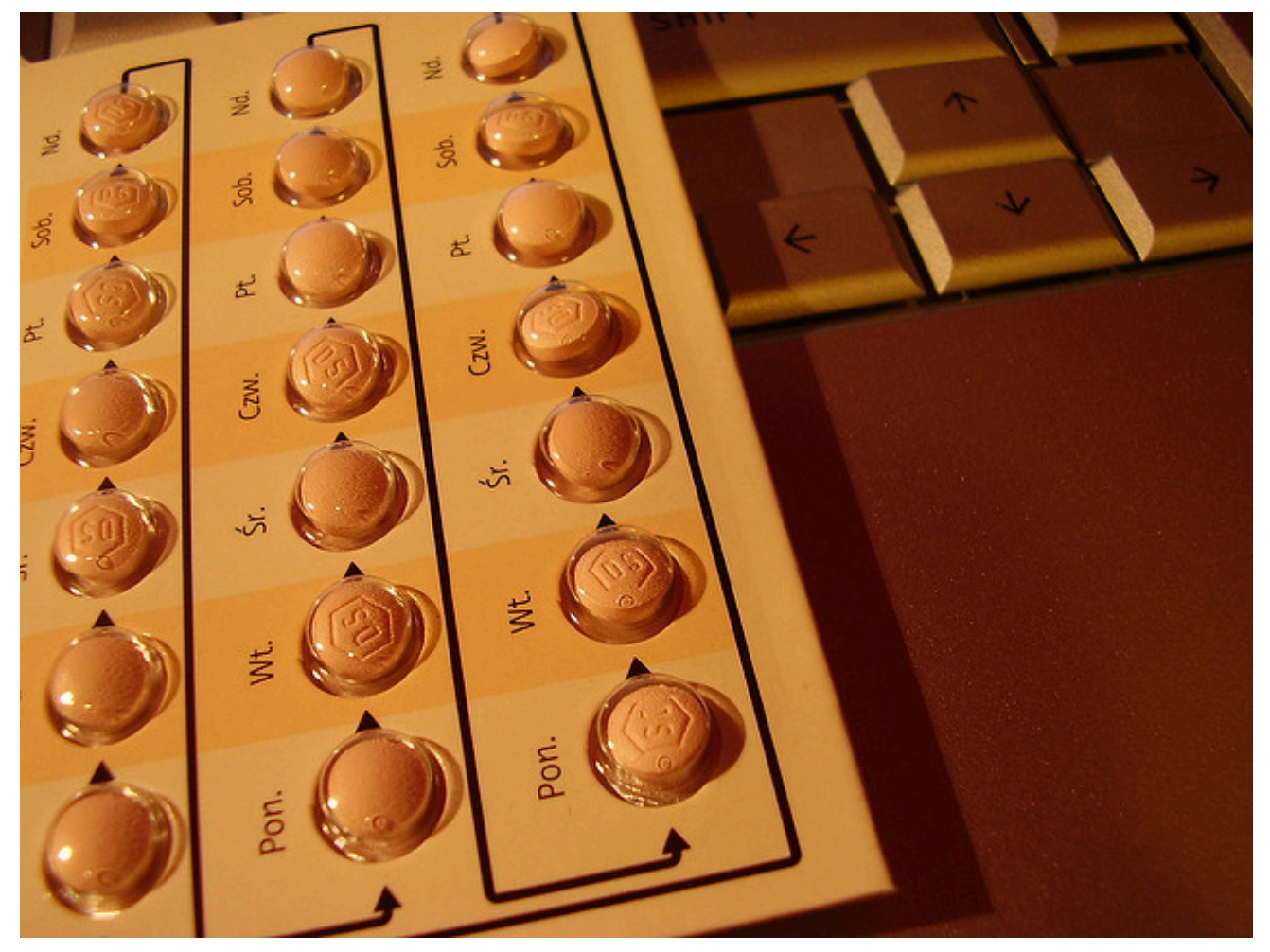

Efforts to reduce contraceptive counseling and the use of contraceptives help increase the number of unplanned pregnancies and, in turn, the number of abortions.

anqa - contraceptive pills - CC BY-NC 2.0.

Second, these efforts also help ensure that more unintended pregnancies and thus more abortions will occur. If, as the Guttmacher Institute reminds us, almost all abortions result from unintended pregnancies, then any efforts by political and religious forces that make it less likely that sexually active people use contraception ironically help increase the number of abortions. Because abortion opponents want to reduce abortions, they should favor additional funding for family planning agencies and for other efforts that increase contraceptive use.

A few numbers indicate the seriousness of the problem. The federal program that funds family planning centers is Title X of the Public Health Services Act. Centers funded by Title X provide contraceptive services and other services to about 4.7 million women annually. The Guttmacher Institute (2011) estimates that these services help prevent 973,000 unintended pregnancies. These pregnancies would have resulted in 433,000 unplanned births and 406,000 abortions. If efforts that have been attempted in Congress to reduce or eliminate Title X funding succeed, these pregnancies and abortions would occur.

Beyond these considerations, it is also important that public funds be available to pay for abortions by low-income women. As noted earlier, Medicaid funding cannot be used for abortions that are not meant to protect the mother's health or to end a pregnancy from rape or incest, and about two-thirds of the states have eliminated state funding 
for these abortions. Because only a small proportion of women are poor enough to be covered by Medicaid, restoring Medicaid coverage for all abortions would increase the number of abortions by only 2.5 percent (Gold, 2010).

Although people on both sides of the abortion debate have sincere, strongly held views, a dispassionate analysis based on the discussion in this section leads to the following conclusions. First, if we want abortions to be rare, efforts to promote safe sex and the consistent use of effective contraception must be applauded and funded, not condemned and unfunded. Second, abortions will occur whether or not they are legal; recognizing this fact, if we want abortions to be safe, they must be legal, and restrictions on access to them should be removed.

\section{Key Takeaways}

- Abortion continues to be one of the most controversial issues in the United States. Many states have implemented laws and policies that make it difficult to obtain abortions.

- Several aspects of our social backgrounds predict views on legal abortion. In particular, religiosity is associated with opposition to legal abortion, while education is associated with approval of legal abortion.

- To reduce the number of abortions, it is necessary to reduce unwanted pregnancies. To ensure that abortions will be safe, they must be legal.

\section{For Your Review}

1. Do you favor or oppose legal abortion? Does your answer depend on the reasons for which a woman desires an abortion? Write an essay in which you explain your answer.

2. A major principle of sociology is that social backgrounds influence attitudes and behavior. Write an essay in which you illustrate this principle with regard to attitudes about abortion.

\section{References}

Barot, S. (2011). Unsafe abortion: The missing link in global efforts to improve maternal health. Guttmacher Policy Review, 14(2), 24-28.

Bullough, V. L., \& Bullough, B. (1977). Sin, sickness, and sanity: A history of sexual attitudes. New York, NY: New American Library.

Chamlin, M. B., Myer, A. J., \& Sanders, B. A. (2008). Abortion as crime control: A cautionary tale. Criminal Justice Policy Review, 19(2), 135-152.

Cohen, S. A. (2009). Facts and consequences: Legality, incidence and safety of abortion worldwide. Guttmacher Policy Review, 12(4), 2-6. 
Donohue, J. J., \& Levitt, S. D. (2001). The impact of legalized abortion on crime. Quarterly Journal of Economics, 116, 379-420.

Gold, R. B. (2010). Insurance coverage and abortion incidence: Information and misinformation. Guttmacher Policy Review, 13(4), 7-10.

Guttmacher Institute. (2012). An overview of abortion laws. Retrieved on March 31, 2012 at http://www.guttmacher.org/statecenter/spibs/spib OAL.pdf.

Guttmacher Institute. (2011). Title X-supported family planning services nationally and in each state. Retrieved November 4, 2011, from http://www.guttmacher.org/media/inthenews/2011/02/16/index.html.

Jones, R. K., \& Kooistra, K. (2011). Abortion incidence and access to services in the United States, 2008. Perspectives on Sexual and Reproductive Health, 43, 41-50.

Kahane, L. H., Paton, D., \& Simmons, R. (2008). The abortion-crime link: Evidence from England and Wales. Economica, 75(1), 1-21.

Pollitt, K. (2011, October 5). Ban birth control? They wouldn't dare... The Nation. Retrieved from http://www.thenation.com/article/163808/ban-birth-control-they-wouldnt-dare?rel=emailNation.

Tan, T. (2011, October 16). Planned Parenthood struggles after state budget cuts. New York Times, p. A29. 


\subsection{Prostitution}

\section{Learning Objectives}

1. Summarize the history of prostitution in the United States.

2. List the reasons that lead many people to dislike prostitution.

3. Explain the problems that streetwalkers experience and why these problems occur.

Prostitution, the selling of sexual services, is yet another controversial sexual behavior. Many people, and especially those with conservative, religious views, believe prostitution is immoral because it involves sex for money, and they consider prostitution a sign of society's moral decay. Many feminists believe that prostitution is degrading to women and provides a context in which prostitutes are robbed, beaten, and/or raped. These two groups of people might agree on little else, but they both hold strong negative views about prostitution. Regardless of their other beliefs, many people also worry that prostitution spreads STDs. All these groups think prostitution should remain illegal, and they generally prefer stricter enforcement of laws against prostitution.

Other people also do not like prostitution, but they believe that the laws against prostitution do more harm than good. They think that legalizing prostitution would reduce the various harms prostitution causes, and they believe that views about the immorality of prostitution should not prevent our society from dealing more wisely with it than it does now.

This section presents a short history of prostitution before turning to the various types of prostitution, reasons for prostitution, and policy issues about how best to deal with this particular sexual behavior. Because most prostitution involves female prostitutes and male customers, our discussion will largely focus on this form.

\section{History of Prostitution}

Often called the world's oldest profession, prostitution has been common since ancient times (Ringdal, 2004). In ancient Mesopotamia, priests had sex with prostitutes. Ancient Greece featured legal brothels (houses of prostitution) that serviced political leaders and common men alike. Prostitution was also common in ancient Rome, and in the Old Testament it was "accepted as a more or less necessary fact of life and it was more or less expected that many men would turn to prostitutes” (Bullough \& Bullough, 1977, pp. 137-138). During the Middle Ages and through the nineteenth century, prostitution was tolerated as a necessary evil, as legal brothels operated in much of Europe and were an important source of tax revenue. As the dangers of venereal disease became known, some cities shut down their brothels, but other cities required regular medical exams of their brothels' prostitutes. 
Prostitution was also common in the United States through the nineteenth century (Bullough \& Bullough, 1987). Poor women became prostitutes because it provided a source of income at a time when they had few other options for jobs. Some prostitutes worked for themselves on streets and in hotels and other establishments, and other prostitutes worked in legal brothels in many US cities. During the Civil War, prostitutes found many customers among the soldiers of the Union and the Confederacy; the term hooker for prostitute comes from their relations with soldiers commanded by Union general Joseph Hooker. After the Civil War, camps of prostitutes would set up at railroad construction sites. When the railroad workers would visit the camps at night, they hung their red signal lamps outside the prostitutes' tents so they could be found if there was a railroad emergency. The term "red-light district” for a prostitution area originated in the red glow that resulted from this practice.

Many US cities had legal brothels into the early 1900s. Beginning in about 1910, however, religious groups and other parties increasingly spoke out about the immorality of prostitution, and in addition claimed that middle-class girls were increasingly becoming prostitutes. Their efforts succeeded in shutting down legal brothels nationwide. Some illegal brothels continued, and among their number was a San Francisco brothel run during the 1940s by a madam (brothel manager and/or owner) named Sally Stanford. Her clientele included many leading politicians and businessmen of San Francisco and nearby areas. Like other earlier brothels, Stanford's brothel required regular medical exams of her employees to help prevent the spread of venereal diseases (Stanford, 1966). Despite or perhaps because of her fame from being a madam, Stanford was later elected mayor of Sausalito, a town across the bay from San Francisco.

\section{Prostitution in the United States Today}

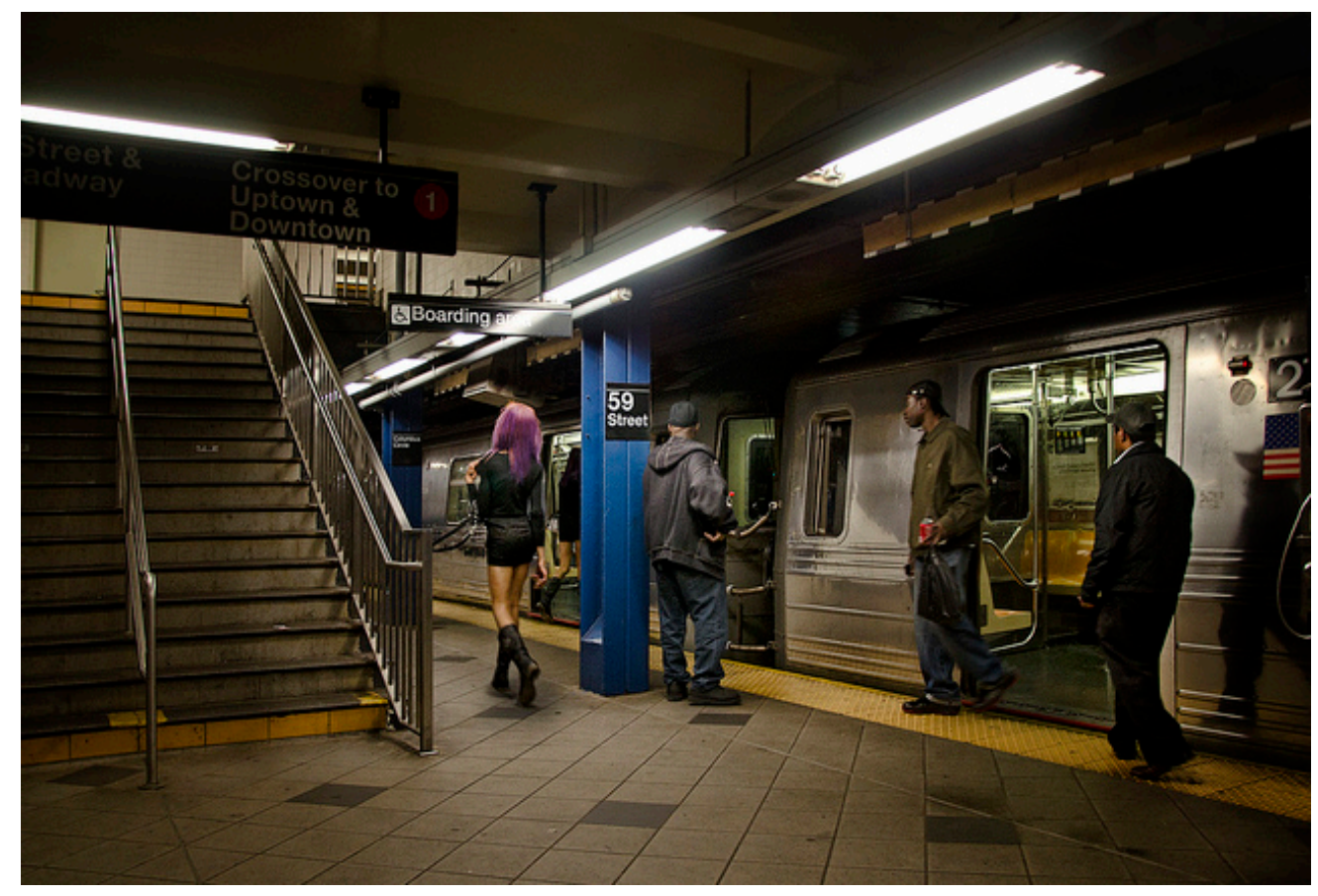

Estimates of the number of prostitutes in the United States range widely between 70,000 and 500,000. Streetwalkers comprise about one-fifth of all prostitutes.

Eric Parker - Prostitute 3 am - CC BY-NC 2.0. 
No one really knows how many prostitutes we now have. Prostitutes are not eager to be studied, and because their work is illegal, the federal government does not compile statistics on their numbers as it does for physicians, plumbers, teachers, and hundreds of other legal occupations. One well-analyzed estimate put the number of female prostitutes at 70,000 and further concluded that they engage in an average of 700 acts of prostitution with male customers annually, or almost 50 million acts of prostitution overall each year (Brewer et al., 2000). However, other estimates put the number of prostitutes as high as 500,000, with many of these prostitutes working part-time, whether or not they also work in a legal occupation (Clinard \& Meier, 2011).

Regardless of the actual number, prostitution is very common. The GSS asks, "Thinking about the time since your $18^{\text {th }}$ birthday, have you ever had sex with a person you paid or who paid you for sex?” In 2010, 11.9 percent of men and 1.7 percent of women answered "yes" to this question. These figures translate to about 13.5 million men 18 and older who have engaged in prostitution, usually as the customer, and 2.1 million women.

In 2010, police and other law enforcement agents made almost 63,000 arrests for prostitution and commercialized vice (Federal Bureau of Investigation, 2011). Most of these arrests were of prostitutes, but some were of customers. Women accounted for almost 69 percent of the arrests in this entire category.

\section{Types of Prostitutes}

Several types of prostitutes exist. At the bottom of the prostitution "hierarchy" are streetwalkers (also called street prostitutes), who typically find their customers, or are found by their customers, somewhere on a street. They then have a quick act of sex in the customer's car, in an alleyway or other secluded spot, or in a cheap hotel. Although streetwalkers are the subjects in most studies of prostitutes, they in fact compose only about one-fifth of all prostitutes (Weitzer, 2012).

The remaining 80 percent of prostitutes generally work indoors. Call girls work as independent operators in their homes or fairly fancy hotels and charge a lot of money for their services, which include sex but also talking and dining. Their clients are typically businessmen or other wealthy individuals. Many call girls earn between \$200 and \$500 per hour, and some earn between \$1,000 and \$6,000 per hour or per session (Weitzer, 2009). Escorts work for escort agencies, which often advertise heavily in phone books and on the Internet. They may operate out of an apartment rented by their agency or come to a client's hotel room or other location. Although they may actually act as an escort to a dinner or show, typically their services include sexual acts. They, too, are generally well paid for their work, but do not earn nearly as much as call girls because they have to give at least 30 percent of their earnings to their agency.

Call girls and escorts rank at the top of the prostitution hierarchy (Weitzer, 2009). Below them, but above streetwalkers, are three other types of prostitutes. Brothel workers, as the name implies, are prostitutes who work in brothels. The only legal brothels in the United States today are found in several rural counties in Nevada, which legalized prostitution in these counties in 1971. Workers in these brothels pay income tax. Because their employers require regular health exams and condom use, the risk of sexually transmitted disease in Nevada's brothels is low. Massage parlor workers, as their name also implies, work in massage parlors. Many massage parlors, of course, involve no prostitution at all, and are entirely legal. However, some massage parlors are in fact fronts for prostitution, where the prostitute masturbates a man and brings him to what is often termed a "happy 
ending.” A final category of prostitution involves prostitutes who work in bars, casinos, or similar establishments (bar or casino workers). They make contact with a customer in these settings and then have sex with them elsewhere.

The lives and welfare of streetwalkers are much worse than those of the five types of indoor workers just listed. As sociologist Ronald Weitzer (2012, p. 212) observes, "Many of the problems associated with 'prostitution' are actually concentrated in street prostitution and much less evident in the indoor sector.” In particular, many streetwalkers are exploited or abused by pimps, use heroin or other drugs, and are raped, robbed, and/or beaten by their clients. A good number of streetwalkers also began their prostitution careers as runaway teenagers and were abused as children.

In contrast, indoor workers begin their trade when they were older and are less likely to have been abused as children. Their working conditions are much better than those for streetwalkers, they are less likely to be addicted to drugs and to have STDs, they are better paid, and they are much less likely to be victimized by their clients. Studies that compare indoor prostitutes with nonprostitutes find that they have similar levels of self-esteem, physical health, and mental health. Many indoor prostitutes even report a rise in self-esteem after they begin their indoor work (Weitzer, 2012).

\section{Explaining Prostitution}

By definition, prostitution involves the selling of sex. This means that money is the key feature of prostitution. As such, money is also the major motivation for women who become prostitutes, as most of them come from low-income backgrounds. For indoor workers, and especially call girls, prostitution is a potentially well-paying occupation. Streetwalkers hardly get rich from prostitution and suffer the many problems listed earlier, but prostitution still provides them a source of income that they are unlikely to receive through legal occupations because they have few marketable job skills.

Despite this financial motivation, most women do not become prostitutes, and scholars have tried to understand why some women do so. Because prostitutes are not eager to be studied, as noted earlier, we do not yet have studies of random samples of prostitutes, and probably never will have such studies. As also noted earlier, most studies of prostitutes involve streetwalkers, even though they compose only about 20 percent of all prostitutes. Several of these studies cite high rates of child abuse in the backgrounds of streetwalkers, but other studies find that their rates of child abuse are similar to those of women from similar sociodemographic backgrounds who are not prostitutes (Weitzer, 2009). Although some studies find certain psychological problems among streetwalkers, it is unclear whether these problems existed before they became streetwalkers or developed (as is very possible) after they became streetwalkers. Methodologically, the best way to clarify this causal question would be to randomly assign young women to become prostitutes or not to become prostitutes, and then to study what happens to their psychological health afterward. For many reasons, this type of study would be highly unethical and will never be done. In the absence of studies of this type, it is difficult to determine what exactly prompts some women to become prostitutes. 


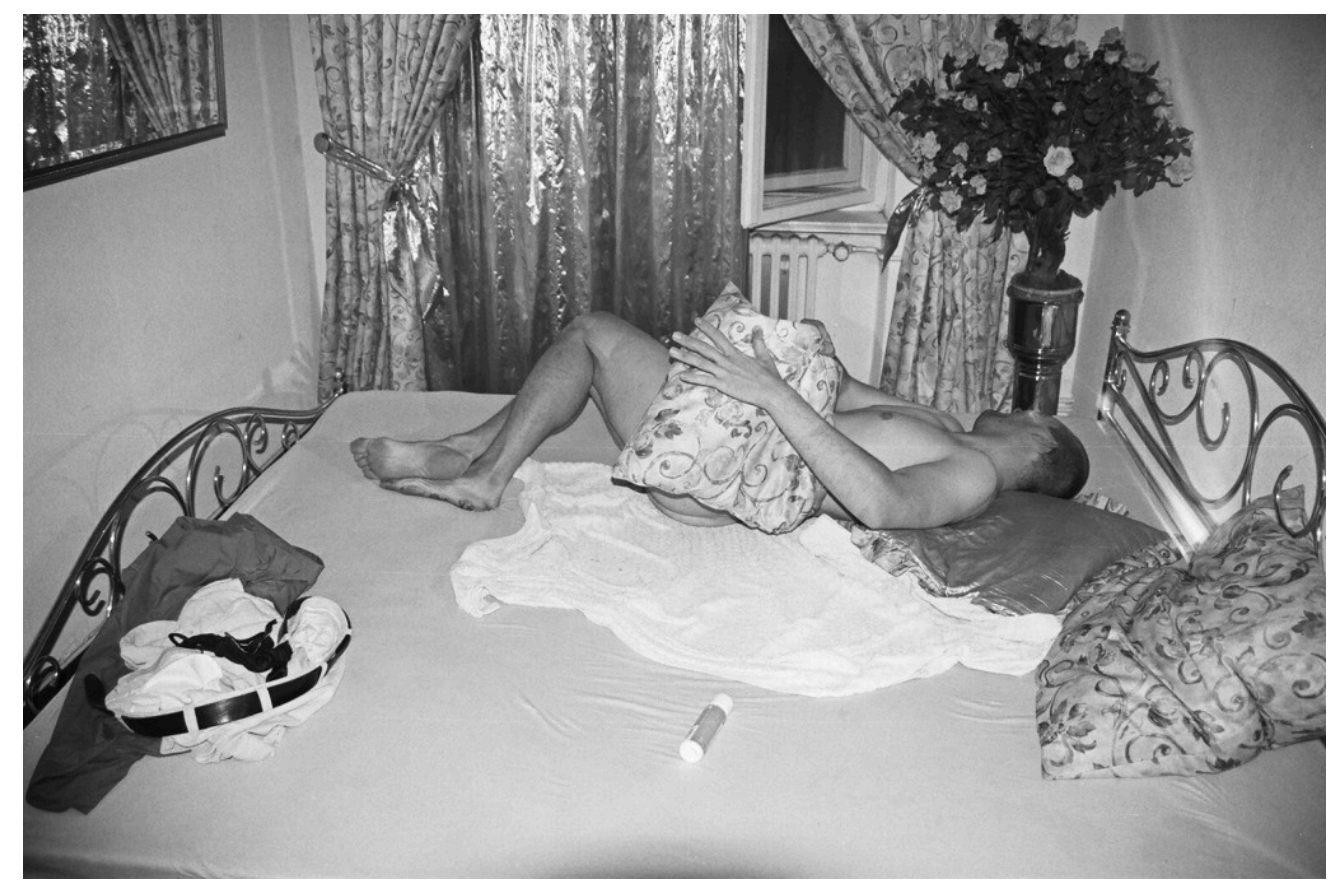

Customers of prostitutes tend to come from the same kinds of social backgrounds as do noncustomers. They have certain motivations for wanting to be with a prostitute, but many noncustomers have the same motivations yet still do not pay for prostitution.

Wikimedia Commons - CC BY-SA 2.5.

\section{Customers}

There is an old saying that "it takes two to tango.” Prostitution obviously cannot occur unless a customer wants to pay for the services of a prostitute. Despite this essential fact of prostitution, there are very few studies of why men choose to become customers. The implicit message from this lack of studies is that it is normal for men to have sex with a prostitute but abnormal for women to charge these men for this sex. The few studies we do have do not find any substantial differences between customers and noncustomers (Weitzer, 2009). Just as men come from various social backgrounds, so do the men who choose to have sex with a prostitute.

Customers do have certain motivations for choosing to pay for prostitution (Weitzer, 2009). These motivations include (1) the desire to have sex with someone with a certain physical appearance (age, race, body type); (2) the lack of a sexual partner or dissatisfaction with a sexual partner, including a desire to have unconventional sex that the partner does not share; (3) the thrill of having sex with a prostitute; and (4) the desire to have sex without having to make an emotional commitment. Although one or more of these motivations may be necessary for a man's decision to seek prostitution, they do not entirely explain this decision. For example, many men may not have a sexual partner or may be dissatisfied with a partner they do have, but they still do not decide to pay for a prostitute. 


\section{Sociological Perspectives}

Beyond explaining why individual women and men are more likely than others to pay for sex or to receive pay for sex, the three sociological perspectives outlined in Chapter 1 "Understanding Social Problems"-functionalist theory, conflict theory, and symbolic interactionism—offer more general insights on prostitution. Table 9.5 "Theory Snapshot" provides a summary of these insights.

Table 9.5 Theory Snapshot

\begin{tabular}{|c|c|}
\hline $\begin{array}{l}\text { Theoretical } \\
\text { perspective }\end{array}$ & Contributions to understanding prostitution \\
\hline Functionalism & $\begin{array}{l}\text { Prostitution is functional for several parties in society. It provides prostitutes a source of income, and it } \\
\text { provides a sexual alternative for men who lack a sexual partner or are dissatisfied with their current sexual } \\
\text { partner. According to Kingsley Davis, prostitution also helps keep the divorce rate lower than it would be } \\
\text { if prostitution did not exist. }\end{array}$ \\
\hline $\begin{array}{l}\text { Conflict } \\
\text { theory }\end{array}$ & $\begin{array}{l}\text { Prostitution arises from women's poverty in a patriarchal society. It also reflects the continuing cultural } \\
\text { treatment of women as sex objects who exist for men's pleasure. }\end{array}$ \\
\hline $\begin{array}{l}\text { Symbolic } \\
\text { interactionism }\end{array}$ & $\begin{array}{l}\text { Prostitutes and their customers have various understandings of their behavior that help them justify why } \\
\text { they engage in this behavior. Many prostitutes believe they are performing an important service for their } \\
\text { customers, and this belief is perhaps more common among indoor prostitutes than among street } \\
\text { prostitutes. }\end{array}$ \\
\hline
\end{tabular}

According to functionalist theory, prostitution exists because it serves several important functions for society generally and for certain people in society. As we have already mentioned, it provides a source of income for many women who otherwise might be jobless, and it provides a sexual alternative for men with the motivations listed earlier. Almost eight decades ago, sociologist Kingsley Davis (1937) wrote that prostitution even lowers the divorce rate. He reasoned that many married men are unhappy with their sex life with their wives. If they do not think this situation can improve, some men start an affair with another woman and may fall in love with that woman, threatening these men's marriages. Other men turn to a prostitute. Because prostitution is generally impersonal, these men do not fall in love with their prostitutes, and their marriages are not threatened. Without prostitution, then, more men would have affairs, and more divorces would result. Although Davis's hypothesis is provocative, there are no adequate studies to test it.

According to conflict theory, prostitution reflects the economic inequality in society. Many poor women feel compelled to become prostitutes because of their lack of money; because wealthier women have many other sources of income, the idea of becoming a prostitute is something they never have to consider. Sad but interesting historical support for this view comes from an increase in prostitution in the second half of the nineteenth century. Many women lost husbands and boyfriends in the war and were left penniless. Lacking formal education and living in a society that at the time offered few job opportunities to women, many of these bereaved women were forced to turn to prostitution to feed their families and themselves. As American cities grew rapidly during the last decades of the nineteenth century, thousands of immigrant women and other poor women also turned to prostitution as a needed source of income (Rosen, 1983). This late nineteenth-century increase in prostitution, then, occurred because of women's poverty.

According to the feminist version of conflict theory, prostitution results not only from women's poverty but also 
from society's patriarchal culture that still views men as the dominant figure in heterosexual relationships and that still treats women as "sex objects" who exist for men's pleasure (Barry, 1996). In such a culture, it is no surprise and even inevitable that men will want to pay for sex with a woman and that women will be willing to be paid for sex. In this feminist view, the oppression and exploitation that prostitution inherently involves reflects the more general oppression and exploitation of women in the larger society.

Symbolic interactionism moves away from these larger issues to examine the everyday understandings that prostitutes and their customers have about their behavior. These understandings help both prostitutes and customers justify their behavior. Many prostitutes, for example, believe they are performing an important service for the men who pay them. Indoor prostitutes are perhaps especially likely to feel they are helping their customers by providing them not only sex but also companionship (Weitzer, 2009). A woman who owned a massage parlor named "The Classic Touch" echoed this view. Her business employed fourteen women who masturbated their customers and offered a senior citizen discount. The owner reasoned that her employees were performing an important service: "We have many senior citizens and handicapped people. We have some men who are impotent and others who are divorced or in bad marriages. This is a safe, AIDS-free environment...that helps marriages. Husbands come in here and get a stress release and then they are able to go home and take on more. These are men who aren’t in bars picking up strange women” (Ordway, 1995, p. 1).

\section{Dealing with Prostitution}

With prostitution, past is once again prologue. It has existed since ancient times, and it has continued throughout the United States long since prostitution was banned by the United States in 1920. The legal brothels that now exist in rural counties in Nevada are the exception in this nation, not the rule. Yet prostitution is common outside of Nevada, and thousands of arrests occur nationwide for it.

As with illegal drugs (see Chapter 7 "Alcohol and Other Drugs"), as we think about how to deal with prostitution, we should consider both a philosophical question and a social science question (Meier \& Geis, 2007). The philosophical question is whether two people should be allowed to engage in a behavior, in this case prostitution, in which both want to participate. Many people may dislike this behavior for various reasons, but is that sufficient justification for the behavior to be banned if both people (let's assume they are legal adults) want to engage in it? In this regard, and without at all meaning to equate prostitution with same-sex sexual behavior, an analogy with homosexuality is worth considering. Homosexual sex used to be illegal because many people thought it was immoral. When the US Supreme Court finally invalidated all laws against homosexual sex in its 2003 case, Lawrence v. Texas, the majority opinion declared that "the fact that a State's governing majority has traditionally viewed a particular practice as immoral is not a sufficient reason for upholding a law prohibiting the practice.” It further asserted, "The petitioners are entitled to respect for their private lives. The State cannot demean their existence or control their destiny by making their private sexual conduct a crime. Their right to liberty under the Due Process Clause gives them the full right to engage in their conduct without intervention of the government.” Although the majority opinion specifically said its decision did not apply to prostitution, a reasonable argument may be made that respect for privacy of consensual sexual conduct also means that prostitution, too, should be legal.

Here it may be argued that prostitution still victimizes and objectifies women even if they want to engage in 
it. This is a reasonable argument, but there are many occupations that victimize employees, either because the occupations are dangerous (such as coal mining and construction work) or because the job requirements objectify women as sex objects (such as fashion modeling and cheerleading). Because hardly anyone would say these occupations should be illegal, is it logical to say that prostitution should be illegal? Former US Surgeon General Joycelyn Elders thinks it makes no sense to ban prostitution simply because it objectifies women: "Why are we so upset about sex workers selling sexual acts to consenting adults?” she asks. "We say that they are selling their bodies, but how different is that from what athletes do? They're selling their bodies. Models? They're selling their bodies. Actors? They're selling their bodies” (McCaslin, 1999, p. A8).

The social science question concerning laws against prostitution is whether these laws do more good than harm, or more harm than good. If they do more good than harm, they should be maintained and even strengthened; if they do more harm than good, they should be repealed. A growing number of scholars believe that the laws against prostitution do more harm than good, and they say that the best way to deal with prostitution might be to legalize and regulate it (Weitzer, 2011).

Proponents of legalization argue as follows. Although many people cite the horrible lives of many streetwalkers as a major reason for their support of laws against prostitution, these laws ironically cause the problems that streetwalkers experience (Weitzer, 2011). When US prostitution was legal a century ago in brothels across the nation, brothel prostitutes were safer than streetwalkers are now. Prostitutes working today in Nevada's legal brothels are safer than streetwalkers. Whatever we might think of their behavior, legal brothel workers are relatively safe from being robbed, beaten, or raped, and their required regular medical exams leave them relatively free of sexually transmitted disease. The health problems and criminal victimization that many streetwalkers experience happen because their behavior is illegal, and legalizing and regulating prostitution would reduce these problems (Weitzer, 2011).

In this regard, legalization of prostitution is yet another harm reduction approach to a social problem. As Weitzer (2012, p. 227) observes, "Research suggests that, under the right conditions, legal prostitution can be organized in a way that increases workers' health, safety, and job satisfaction. Mandatory condom use and other safe-sex practices are typical in legal brothels, and the workers face much lower risk of abuse from customers.”

Legalization of prostitution would also yield a considerable amount of tax revenue, as is now true in Nevada. Let's assume that 50 million acts of prostitution occur annually in the United States, to cite our earlier estimate that is probably too low, and that each of these acts costs an average \$30. Putting these numbers together, prostitutes receive $\$ 1.5$ billion annually in income. If they paid about one-third of this amount (admittedly a rough estimate) in payroll taxes, the revenue of state and federal governments would increase by $\$ 500$ million. Because the tens of thousands of arrests for prostitution and commercialized vice annually would reduce significantly if prostitution were legalized, the considerable financial savings from this reduction could be used for other pursuits.

Legalizing prostitution would add the United States to the lengthy list of other Western democracies that have already legalized it. Although their models of legalization vary, the available evidence indicates that legalizing prostitution does, in fact, reduce the many problems now associated with illegal prostitution (see Note 9.25 "Lessons from Other Societies"). 


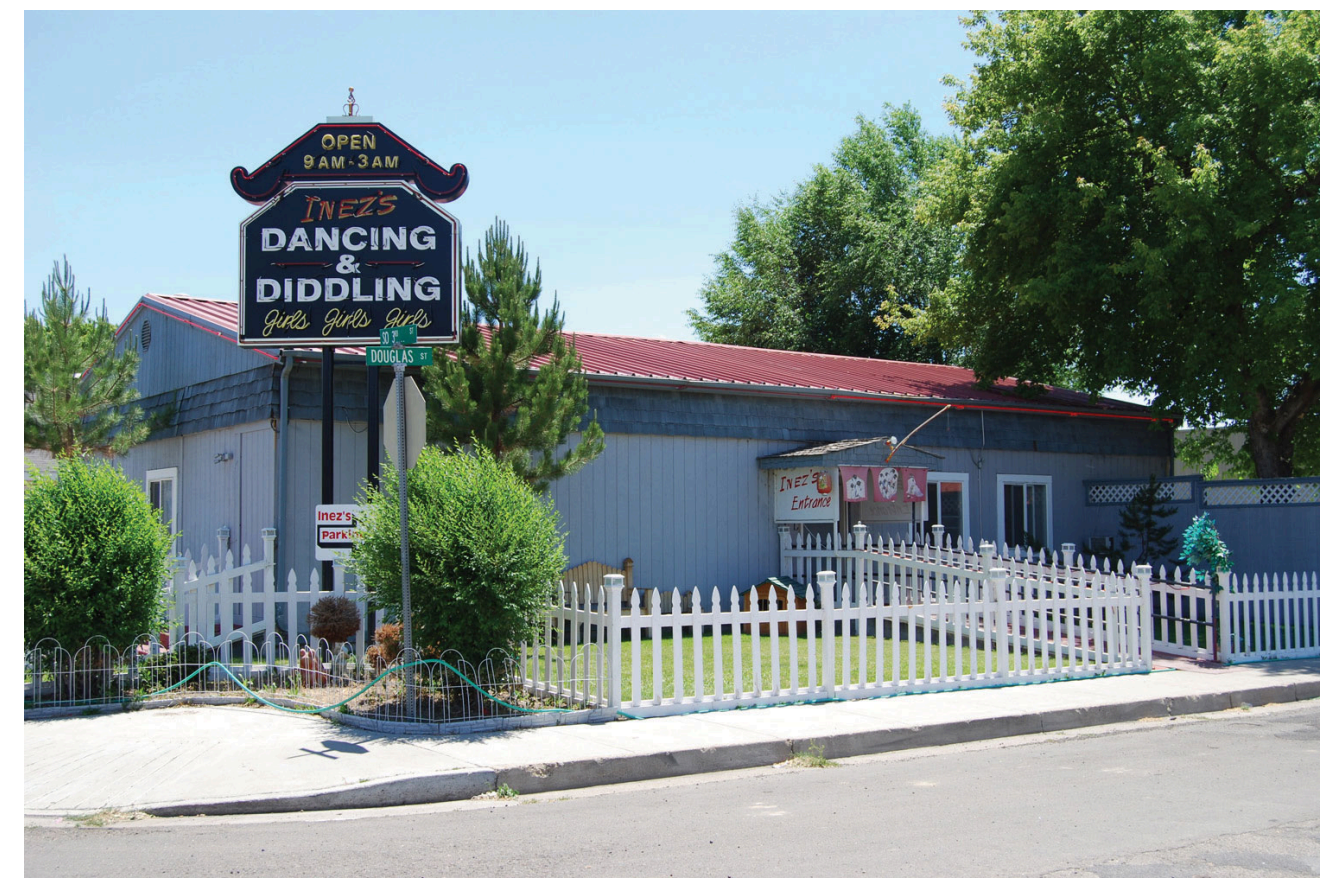

Workers in legal brothels are relatively safe from victimization by customers and from the risk of incurring and transmitting sexual diseases.

\section{Lessons from Other Societies}

\section{Legal Brothels in Other Western Democracies}

In many other Western democracies, prostitution is legal to varying degrees that depend on the specific nation. In some nations, streetwalking is permitted, but in other nations, only brothels are permitted.

The legal brothel model is what the United States had a century ago and has today only in rural Nevada. As in Nevada, other nations that permit legal brothels usually require regular health exams and the use of condoms to prevent the transmission of sexual diseases. They also license the brothels so that the brothels must fulfill various standards, including the safe-sex practices just mentioned, to receive a license. In addition, brothels must pay taxes on their revenues, and brothel workers must pay taxes on their incomes.

As in rural Nevada, brothel workers in these other nations are unlikely to be abused by their customers. A major reason for their relative safety is that they work indoors and that any abuse by customers might be heard or witnessed by someone else inside the brothel. In addition, brothels in many nations have implemented certain measures to ensure workers' safety, including the provision of panic buttons, the use of listening devices, and screening of customers when they enter the brothel.

A report by the Ministry of Justice in the Netherlands, where legal brothels operate, has concluded that most brothel workers say that they feel safe. A government report in New Zealand, which legalized prostitution in 2003, concluded that legalization made it more likely that prostitutes report any problems to the police and also increased their selfesteem because their behavior was now legal. A government commission in Australia that evaluated legal brothels in the northeastern state of Queensland concluded, "There is no doubt that licensed brothels provide the safest working environment for sex workers in Queensland...Legal brothels now powering in Queensland provide a sustainable model for a healthy, crime-free, and safe legal licensed brothel industry.”

Assessing all these nations' experiences, sociologist Ronald Weitzer concluded that "legal prostitution, while no 
panacea, is not inherently dangerous and can be structured to minimize risks and empower workers.” The United States, then, has much to learn from the other Western democracies that have legalized prostitution.

Sources: Weitzer, 2009, 2012

\section{Key Takeaways}

- Prostitution has existed since ancient times and continues to be common today around the world. The United States had legal brothels before 1920, and legal brothels are found today in rural counties in Nevada.

- Many people oppose prostitution because they feel it is immoral or because they feel it degrades and victimizes women. Because prostitution usually involves consensual behavior, some scholars say it should not be illegal in a society that values a right to privacy.

- Some scholars also say that laws against prostitution do more harm than good and in particular account for the various problems that streetwalkers experience.

\section{For Your Review}

1. Do you think prostitution should become legal and regulated? Why or why not?

2. The major difference between prostitution and sex resulting from a casual pickup involves whether money is exchanged. Write an essay in which you first take the "pro" side on the following debate question, and then take the "con” side: that prostitution is worse than sex from a casual pickup.

\section{References}

Barry, K. (1996). The prostitution of sexuality. New York, NY: New York University Press.

Brewer, D. D., Potterat, J. J., Garrett, S. B., Muth, S. Q., John M. Roberts, J., Kasprzyk, D., et al. (2000). Prostitution and the sex discrepancy in reported number of sexual partners. Proceedings of the National Academy of Sciences, 97, 12385-12388.

Bullough, V. L., \& Bullough, B. (1977). Sin, sickness, and sanity: A history of sexual attitudes. New York, NY: New American Library.

Bullough, V. L., \& Bullough, B. (1987). Women and prostitution: A social history. Buffalo, NY: Prometheus.

Clinard, M. B., \& Meier, R. F. (2011). Sociology of deviant behavior (14th ed.). Fort Worth, TX: Harcourt Brace.

Davis, K. (1937). The sociology of prostitution. American Sociological Review, 2, 744-755.

Federal Bureau of Investigation. (2011). Crime in the United States, 2010. Washington, DC: Author. 
McCaslin, J. (1999, October 13). Vaginal politics. Washington Times, p. A8.

Meier, R. F., \& Geis, G. (2007). Criminal justice and moral issues. New York, NY: Oxford University Press.

Ordway, R. (1995, May 26). Relaxation spas perplex officials. The Bangor Daily News, p. 1.

Ringdal, N. J. (2004). Love for sale: A world history of prostitution (R. Daly, Trans.). New York, NY: Grove Press.

Rosen, R. (1983). The lost sisterhood: Prostitution in America, 1900-1918. Baltimore, MD: Johns Hopkins Univesity Press.

Stanford, S. (1966). The lady of the house. New York, NY: G. P. Putnam.

Weitzer, R. (2009). Sociology of sex work. Annual Review of Sociology, 35(0360-0572, 0360-0572), 213-234.

Weitzer, R. (2011). Legalizing prostitution: From illicit vice to lawful business. New York, NY: New York University Press.

Weitzer, R. (2012). Prostitution: Facts and fictions. In D. Hartmann \& C. Uggen (Eds.), The Contexts reader (pp. 223-230). New York, NY: W. W. Norton. 


\subsection{Pornography}

\section{Learning Objectives}

1. Explain why pornography is difficult to define.

2. Describe evidence indicating that pornography is popular.

3. Discuss whether pornography contributes to violence against women.

Pornography may be defined as printed or visual materials that are sexually explicit and that are intended to arouse sexual excitement rather than artistic appreciation. This definition is fine as far as it goes, but it does raise many questions that underscore the difficulty of dealing with prostitution. For example, how "explicit” must a printed or visual material be for it to be explicit? Is a picture of a woman in a skimpy negligee explicit, or must she be fully unclothed? If a woman in a photo is wearing an evening gown that is very low-cut, is that explicit? If a young male gets aroused by seeing her cleavage, does that make the photo of her pornographic? If two people on network television are obviously beginning to have consensual sex just before a commercial begins (this is network television, after all), is that explicit and arousing enough to constitute pornography? If you answered no to this last question, what if some viewers did find this short portrayal of consensual sex to be explicit and arousing? Is their reaction enough for us to have to conclude that the scene they saw was indeed pornographic? How many people in fact have to find a printed or visual material explicit and arousing for it to be considered pornographic?

These questions suggest that it is not very easy to define pornography after all. Back in the 1950s, young males in the United States would leaf through National Geographic magazine to peek at photos of native women who were partially nude. Those photos, of course, were not put there to excite boys across the country; instead they were there simply to depict native people in their natural habitat. Another magazine began about the same time that also contained photos of nude women. Its name was Playboy, and its photos obviously had a much different purpose: to excite teenage boys and older men alike. Other, more graphic magazines grew in its wake, and today television shows and PG-13 and R-rated movies show more nudity and sex than were ever imaginable in the days when National Geographic was a boy's secret pleasure. Beyond these movies and television shows, a powerful pornography industry now exists on the Internet, in porn stores, and elsewhere. Although Playboy quickly became very controversial, it is considered tame compared to what else is now available.

If things as different as National Geographic, Playboy, R-rated movies, and hard-core pornography show nudity and can be sexually arousing, what, then, should be considered pornography? Are at least some of the tamer pictures in Playboy really that different from the great paintings in art history that depict nude women? This question is not necessarily meant to defend Playboy; rather, it is meant to have you think about what exactly is and is not pornography and what, if anything, our society can and should do about it.

However we define pornography, sexually explicit materials, along with drugs, prostitution, and abortion, have 
been common since ancient times (Bullough \& Bullough, 1977). Archeologists have uncovered sexually explicit drawings, pottery, and other artifacts from China, Greece, Japan, Persia, Peru, and other locations; these artifacts depict sexual organs and sexual behavior. Sexually explicit material appears in much writing left from ancient Greece and ancient Rome. "Vast quantities of material dealing with sex” (Bullough \& Bullough, 1977, p. 161) remain from medieval Europe. The huge amount of pornography that exists today represents a centuries-old tradition.

\section{Public Opinion about Pornography}

Many people oppose pornography, but two very different groups have been especially outspoken over the years, as has been true about prostitution. One of these groups consists of religious organizations and individuals who condemn pornography as a violation of religious values and as an offense to society's moral order. The other group consists of feminists who condemn pornography for its sexual objectification of women and especially condemn the hard-core pornography that glorifies horrible sexual violence against women. Many feminists also charge that pornography promotes rape by reinforcing the cultural myths discussed earlier. As one writer put it in a famous phrase some thirty years ago, "Pornography is the theory, and rape the practice” (Morgan, 1980, p. 139).

The GSS asks, "Which of these statements comes closest to your feelings about pornography laws: (1) There should be laws against the distribution of pornography whatever the age; (2) There should be laws against the distribution of pornography to persons under 18; or (3) There should be no laws forbidding the distribution of pornography.” In 2010, about 31 percent of the public thought that pornography should be illegal for everyone, and 65 percent thought it should be illegal for people under 18; only 4 percent thought there should be no laws against pornography. Adding the last two percentages together, though, 69 percent thought pornography should be legal for everyone 18 and older.

Certain aspects of our social backgrounds predict our views about pornography laws. Two of the strongest predictors are gender and religiosity. Focusing on the percentage who favor laws against pornography regardless of age, there is a strong gender difference in this view (see Figure 9.16 "Gender and Support for Laws against Pornography Regardless of Age (\%)”), with women more than twice as likely than men to favor these laws. Religiosity also predicts support for pornography laws regardless of age: People who consider themselves very religious are five times more likely than those who consider themselves not religious to favor these laws (see Figure 9.17 “Self-Rated Religiosity and Support for Laws against Pornography Regardless of Age (\%)”). 


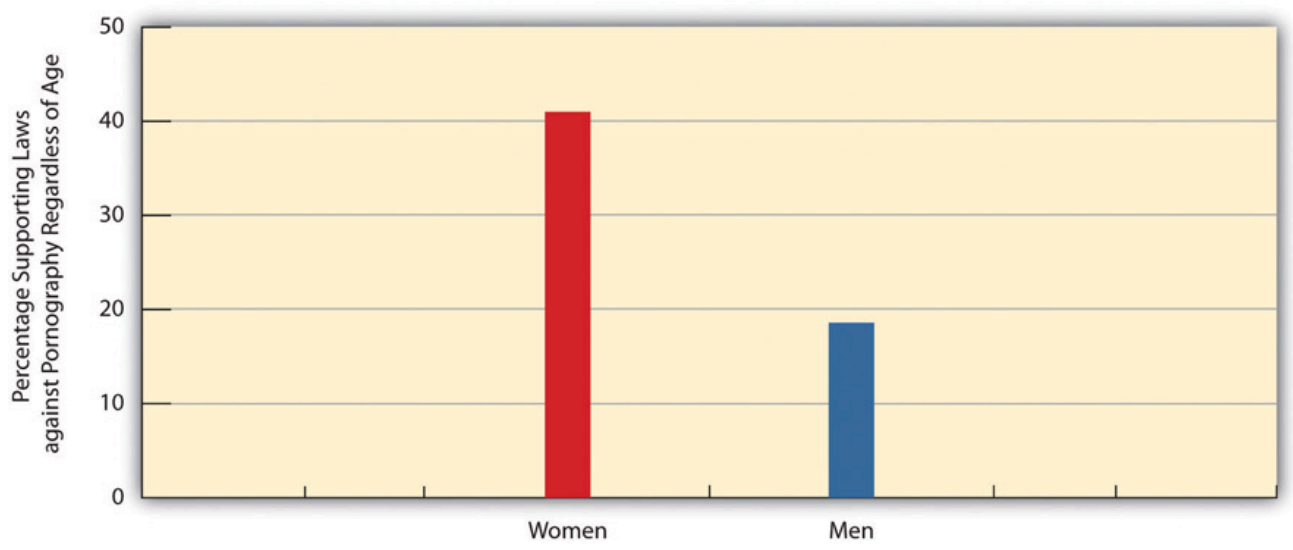

Source: Data from General Social Survey. (2010). Retrieved from http://sda.berkeley.edu/cgi-bin/hsda?harcsda+gss10.

Figure 9.17 Self-Rated Religiosity and Support for Laws against Pornography Regardless of Age (\%)

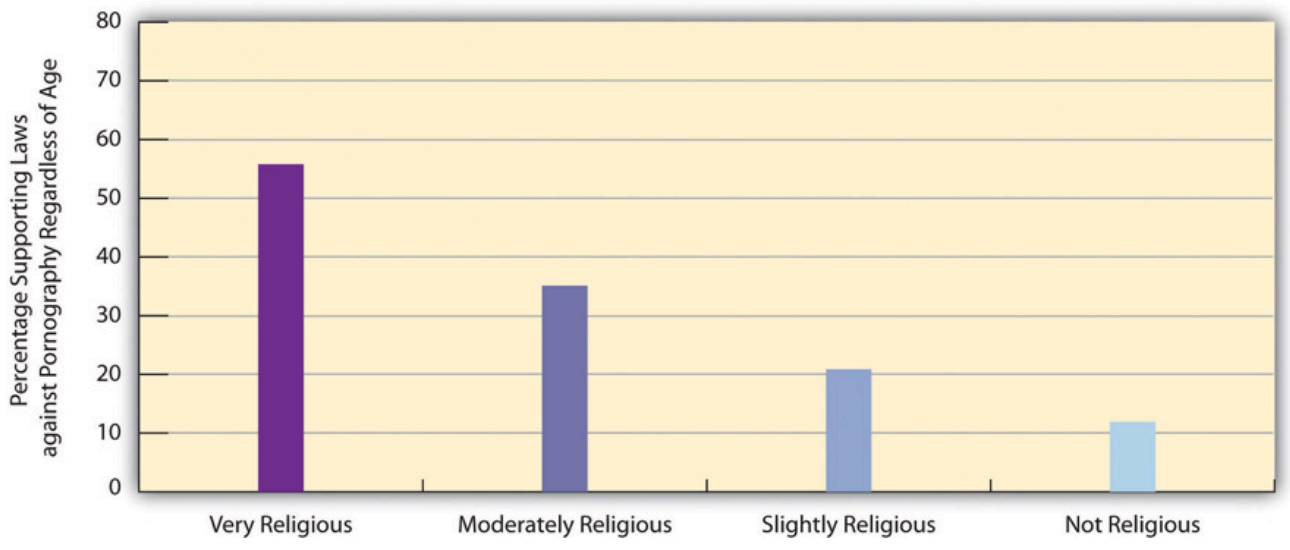

Source: Data from General Social Survey. (2010). Retrieved from http://sda.berkeley.edu/cgi-bin/hsda?harcsda+gss10.

\section{The Popularity of Pornography}

Pornography is so widespread and easy to access on the Internet and elsewhere that many people must be viewing it, reading it, and in general "using" it. Various data and estimates for the United States support this assumption (Diamond, 2009; Family Safe Media, 2011). For example, pornography revenues amount to more than $\$ 13$ billion annually (from the sale and rental of adult DVDs, the viewing of pornographic Internet sites, the purchase of adult videos on cable and in hotel rooms, payments for phone sex, visits in exotic dance clubs, the purchase of sexually explicit novelties, and subscriptions to and the purchase of sexually explicit magazines). An estimated 12 percent of all websites are pornographic. In addition, about 40 percent of Americans visit pornographic sites on the Internet at least monthly, and, according to the GSS, one-fourth of Americans, or almost 60 million adults, have seen an X-rated movie in the past year.

We saw earlier that gender and religiosity predict views about pornography laws. As you might expect, they also predict X-rated movie viewing. Men are more than twice as likely as women to have seen an X-rated movie in the past year (see Figure 9.18 "Gender and Viewing of X-Rated Movie in Past Year (Percentage Seeing a Movie 
at Least Once)"), while very religious people are only about one-third as likely as those who are not religious to have seen an X-rated movie.

Figure 9.18 Gender and Viewing of X-Rated Movie in Past Year (Percentage Seeing a Movie at Least Once)

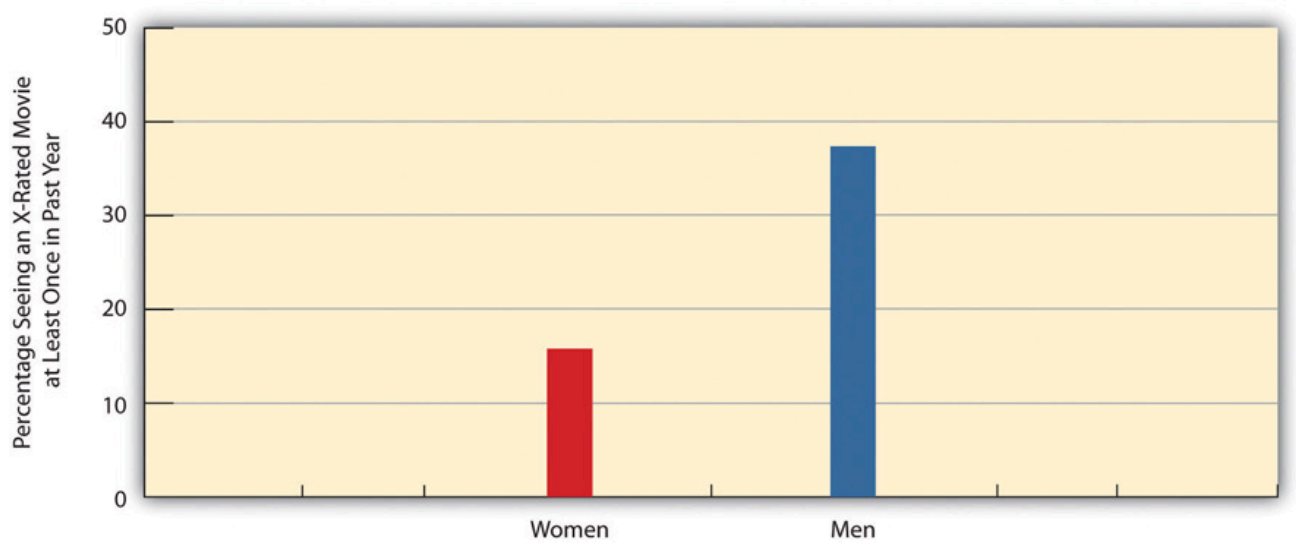

Source: Data from General Social Survey. (2010). Retrieved from http://sda.berkeley.edu/cgi-bin/hsda?harcsda+gss10.

Figure 9.19 Self-Rated Religiosity and Viewing of X-Rated Movie in Past Year (Percentage Seeing a Movie at Least Once)

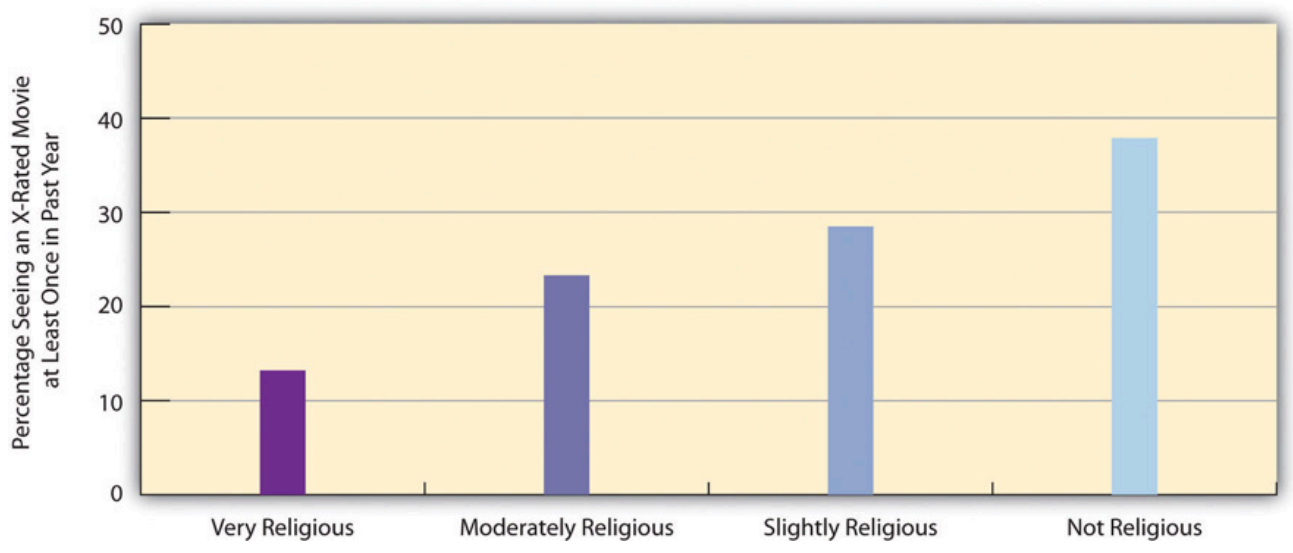

Source: Data from General Social Survey. (2010). Retrieved from http://sda.berkeley.edu/cgi-bin/hsda?harcsda+gss10.

\section{Effects of Pornography}

Many feminists and other people oppose pornography because they believe it causes rape or other violence against women. This belief raises an important question: To what extent does pornography in fact cause such violence? The fairest answer might be that we do not really know. Many scholars believe pornography does cause violence against women, but other scholars conclude that pornography does not have this effect and may even help reduce sexual violence by providing a sexual outlet for men (Diamond, 2009; Weitzer, 2011).

These divergent views reflect the complexity of the evidence from studies of pornography. Many studies do conclude that pornography causes rape. For example, male students who watch violent pornography in experiments later exhibit more hostile attitudes toward women than those watching consensual sex or nonsexual 
interaction. However, it remains doubtful that viewing pornography in real life has a longer-term effect that lasts beyond the laboratory setting, and several experimental studies do not even find any short-term effects. In other types of research, rape rates have not risen in the US states that have made their pornography laws more lenient, and states' rape rates are not related to their circulation rates of pornographic magazines. Further, rape rates have declined sharply since the early 1990s even though pornography is much more widely available now than back then thanks to the Internet and other technologies.

A recent review of the research on pornography and rape concluded that pornography does not increase rape (Ferguson \& Hartley, 2009, p. 323):

Evidence for a causal relationship between exposure to pornography and sexual aggression is slim and may, at certain times, have been exaggerated by politicians, pressure groups and some social scientists. Some of the debate has focused on violent pornography, but evidence of any negative effects is inconsistent, and violent pornography is comparatively rare in the real world. Victimization rates for rape in the United States demonstrate an inverse relationship between pornography consumption and rape rates. Data from other nations have suggested similar relationships...It is concluded that it is time to discard the hypothesis that pornography contributes to increased sexual assault behavior.

\section{Dealing with Pornography}

Whatever pornography is or is not, many people find it disgusting, but many other people are more tolerant of it. In our discussion of prostitution, we examined the issue of whether it is proper for a democracy to ban a consensual behavior simply or mostly because many people consider it immoral. The same question may be asked about pornography (to be more precise, pornography that does not involve children), especially because it does not appear to cause violence against women. Even if it did cause such violence, efforts to stop it raise important issues of freedom of speech and censorship. In a free society, civil liberties advocates say, we must proceed very cautiously. Once we ban some forms of pornography, they ask, where do we stop (Strossen, 2000).

This issue aside, much of what we call pornography still degrades women by depicting them as objects that exist for men's sexual pleasure and by portraying them as legitimate targets of men's sexual violence. These images should be troubling for any society that values gender equality. The extent of pornography in the United States may, for better or worse, reflect our historical commitment to freedom of speech, but it may also reflect our lack of commitment to full equality between women and men. Even if, as we have seen, the survey evidence shows growing disapproval of traditional gender roles, the persistence of pornography shows that our society has a long way to go toward viewing women as equally human as men.

\section{Key Takeaways}

- Pornography is notoriously difficult to define. Just as beauty is in the eyes of the beholder, to quote the old saying, so is pornography.

- Pornography is a major industry in the United States and around the world and accounts for about $\$ 13$ billon 
in US revenues annually.

- A growing conclusion from the research evidence is that pornography does not lead to violence against women. In addition to this consideration, laws against pornography raise questions of freedom of speech.

\section{For Your Review}

1. Do you think all pornography should be legal for people age eighteen and older? Why or why not?

2. In your opinion, does pornography promote violence against women? Explain your answer.

\section{References}

Bullough, V. L., \& Bullough, B. (1977). Sin, sickness, and sanity: A history of sexual attitudes. New York, NY: New American Library.

Diamond, M. (2009). Pornography, public acceptance and sex related crime: A review. International Journal of Law \& Psychiatry, 32(5), 304-314.

Family Safe Media. (2011). Pornography statistics. Retrieved October 23, 2011, from http://www.familysafemedia.com/pornography statistics.html.

Ferguson, C. J., \& Hartley, R. D. (2009). The pleasure is momentary...the expense damnable?: The influence of pornography on rape and sexual assault. Aggression \& Violent Behavior, 14(5), 323-329.

Morgan, R. (1980). Theory and practice: Pornography and rape. In L. Lederer (Ed.), Take Back the Night (pp. 134-140). New York, NY: William Morrow.

Strossen, N. (2000). Defending pornography: Free speech, sex, and the fight for women's rights. New York, NY: New York University Press.

Weitzer, R. (2011). Review essay: Pornography's effects: The need for solid evidence. [Book review]. Violence Against Women, 17(5), 666-675. 


\subsection{End-of-Chapter Material}

\section{Summary}

1. The sexual revolution of the 1960s and 1970s involved changes in Americans' attitudes on certain sexual issues and an increase in premarital sex.

2. Although teenagers are more sexually active today than before the sexual revolution, teenage pregnancy and birth rates have declined sharply since the early 1990s. Teenage pregnancy and birth cause several problems for the teenage mother and for society as a whole.

3. To reduce teenage pregnancy further, the United States should expand publically funded family planning programs and increase the provision of contraceptives at little or no cost.

4. Abortion has been common since ancient times and remains one of the most controversial issues in the United States. Since the US Supreme Court's Roe v. Wade decision legalized all abortions during the first two trimesters, subsequent court rulings and various state actions have made abortions more difficult to obtain. Abortion rates differ by region of the nation and reflect the presence or absence of abortion providers.

5. Around the world, abortion rates do not depend on whether abortion is legal or illegal, and they occur in great numbers even when they are illegal. For abortions to be as safe as possible, they must be legal.

6. Prostitution has also been common since ancient times. Until the second decade of the twentieth century it was legal in much of the United States in the form of legal brothels.

7. Streetwalkers comprise about one-fifth of all prostitutes. Compared to indoor prostitutes, they are more likely to be victims of violence and to obtain and transmit sexual diseases.

8. When prostitution is legal, prostitutes fare much better than when prostitution is illegal. The problems that streetwalkers experience generally stem from the fact that their behavior is illegal.

9. Pornography has also been around since ancient times. It does not appear to cause sexual violence against women, and efforts to ban it raise freedom of speech issues.

\section{Using What You Know}

A friend of yours has become pregnant after a casual sexual encounter. She is in the second semester of her junior year and was planning to graduate in fifteen months and go on to get a master's degree in a business school. She confides in you that she is considering an abortion and wants your advice on what she should do. What do you tell her?

\section{What You Can Do}

To help deal with the sexual behavior problems discussed in this chapter, you may wish to do any of the following: 
1. Volunteer for a local agency that helps pregnant teenagers.

2. Start or join in efforts on your campus to encourage safe sex.

3. Volunteer at a family planning agency. 


\section{Chapter 10: The Changing Family}

\section{Social Problems in the News}

"Help for Domestic Violence Victims Declining,” the headline said. In Georgia, donations and other financial assistance to battered women's shelters were dwindling because of the faltering economy. This decreased funding was forcing the shelters to cut back their hours and lay off employees. As Meg Rogers, the head of a shelter with a six-month waiting list explained, "We are having to make some very tough decisions."

Reflecting her experience, shelters in Georgia had to turn away more than 2,600 women and their children in the past year because of lack of space. Many women had to return to the men who were abusing them. This situation troubled Rogers. "I think their safety is being compromised," she said. "They may go to the abuser's family even if they don't go back to the abuser." A domestic violence survivor also worried about their fate and said she owed her own life to a women's shelter: "I love them to this day and I'm alive because of them."

Source: Simmons, 2011

Once upon a time, domestic violence did not exist, or so the popular television shows of the 1950s would have had us believe. Neither did single-parent households, gay couples, interracial couples, mothers working outside the home, heterosexual spouses deciding not to have children, or other family forms and situations that are increasingly common today. Domestic violence existed, of course, but it was not something that television shows and other popular media back then depicted. The other family forms and situations also existed to some degree but have become much more common today. 


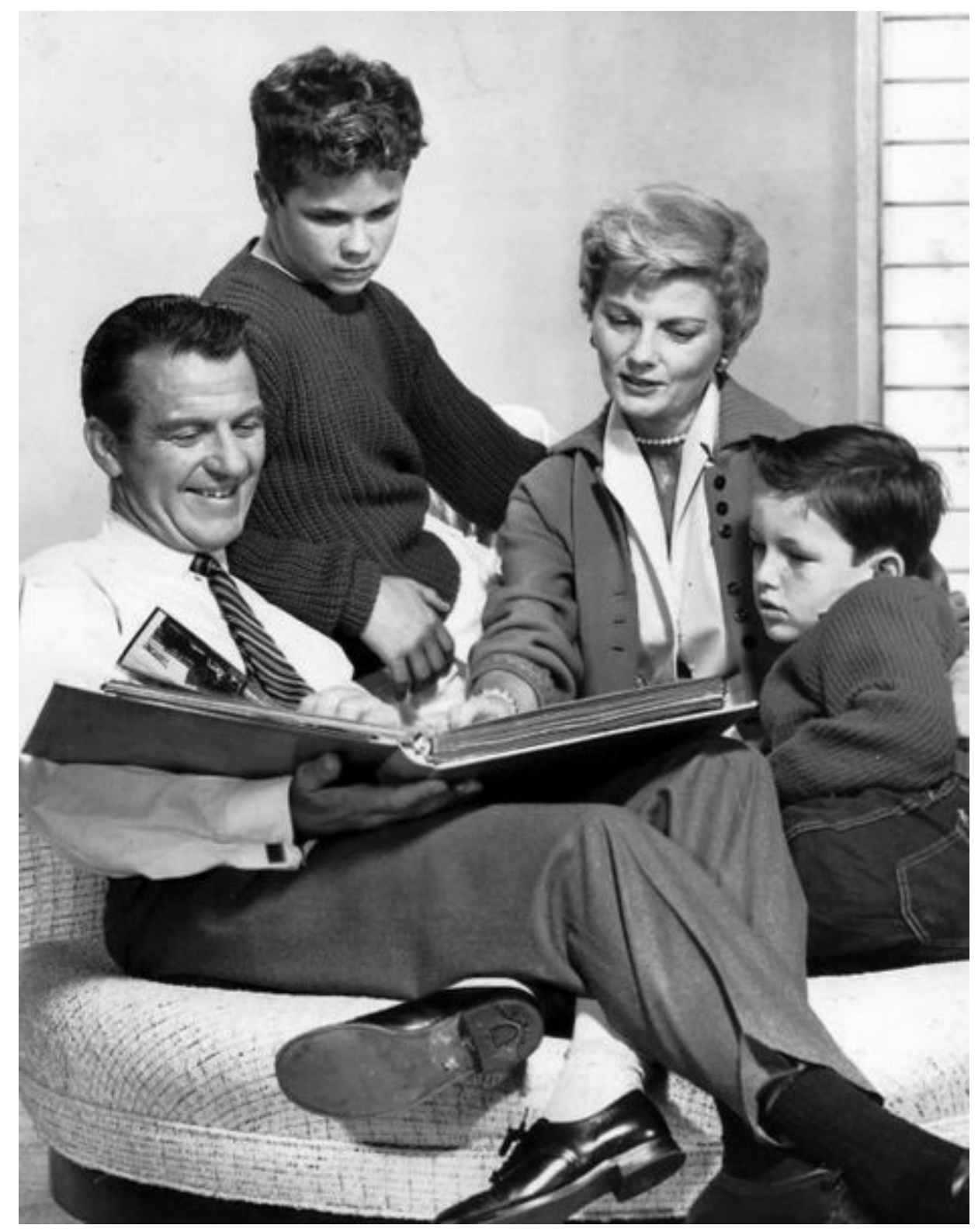

Families shown in today's television shows are very different from the traditional family depicted in popular television shows of the 1950s. Television families from the 1950s consisted of two heterosexual parents, with the father working outside the home and the mother staying at home with two or more wholesome children.

The Bees Knees Daily - Cast photo of the Cleaver Family from "Leave It To Beaver" - CC BY-NC-SA 2.0.

The 1950s gave us Leave It to Beaver and other television shows that depicted loving, happy, “traditional” families living in the suburbs. The father worked outside the home, the mother stayed at home to take care of the kids and do housework, and their children were wholesome youngsters who rarely got into trouble and certainly did not use drugs or have sex. Today we have ABC's Modern Family, which features one traditional family (two heterosexual parents and their three children) and two nontraditional families (one with an older white man and a younger Latina woman and her child, and another with two gay men and their adopted child). Many other television shows today and in recent decades have featured divorced couples or individuals, domestic violence, and teenagers doing drugs or committing crime. 
In the real world, we hear that parents are too busy working at their jobs to raise their kids properly. We hear of domestic violence as in the story from Georgia at the start of this chapter. We hear of kids living without fathers, because their parents are divorced or never were married in the first place. We hear of young people having babies, using drugs, and committing violence. We hear that the breakdown of the nuclear family, the entrance of women into the labor force, and the growth of single-parent households are responsible for these problems. Some observers urge women to work only part-time or not at all so they can spend more time with their children. Some yearn wistfully for a return to the 1950s, when everything seemed so much easier and better. Children had what they needed back then: one parent to earn the money, and another parent to take care of them full time until they started kindergarten, when this parent would be there for them when they came home from school.

Families have indeed changed, but this yearning for the 1950s falls into what historian Stephanie Coontz (2000) calls the "nostalgia trap." The 1950s television shows did depict what some families were like back then, but they failed to show what many other families were like. Moreover, the changes in families since that time have probably not had all the harmful effects that many observers allege. Historical and cross-cultural evidence even suggests that the Leave It to Beaver-style family of the 1950s was a relatively recent and atypical phenomenon and that many other types of families can thrive just as well as the 1950s television families did.

This chapter expands on these points and looks at today's families and the changes they have undergone. It also examines some of the controversies and problems now surrounding families and relationships.

\section{References}

Coontz, S. (2000). The way we never were: American families and the nostalgia trap. New York, NY: Basic Books.

Simmons, A. (2011, October 29). Help for domestic violence victims declining. The Atlanta Journal-Constitution. Retrieved from http://www.ajc.com/news/crime/help-for-domestic-violence-1212373.html. 


\subsection{Overview of the Family}

\section{Learning Objectives}

1. Describe why many children throughout history have not lived in a nuclear family.

2. Understand the status of the nuclear family in the United States since the colonial period.

3. Describe the major marriage and family arrangements in the United States today.

A family is a group of two or more people who are related by blood, marriage, adoption, or a mutual commitment and who care for one another. Defined in this way, the family is universal or nearly universal: Some form of the family has existed in every society, or nearly every society, that we know about (Starbuck, 2010). Yet it is also true that many types of families have existed, and the cross-cultural and historical record indicates that these different forms of the family can all "work": They provide practical and emotional support for their members and they socialize their children.

It is important to keep this last statement in mind, because Americans until the last few decades thought of only one type of family, and that is the nuclear family: A married heterosexual couple and their young children living by themselves under one roof. The nuclear family has existed in most societies with which scholars are familiar. An extended family, which consists of parents, their children, and other relatives, has a nuclear family at its core and was quite common in prehistoric societies. Many one-parent families begin as (two-parent) nuclear families that dissolve upon divorce or separation or, more rarely, the death of one of the parents. In recent decades, oneparent families have become more common in the United States because of divorce and births out of wedlock, but they were actually very common throughout most of human history because many spouses died early in life and because many babies were born out of wedlock. 


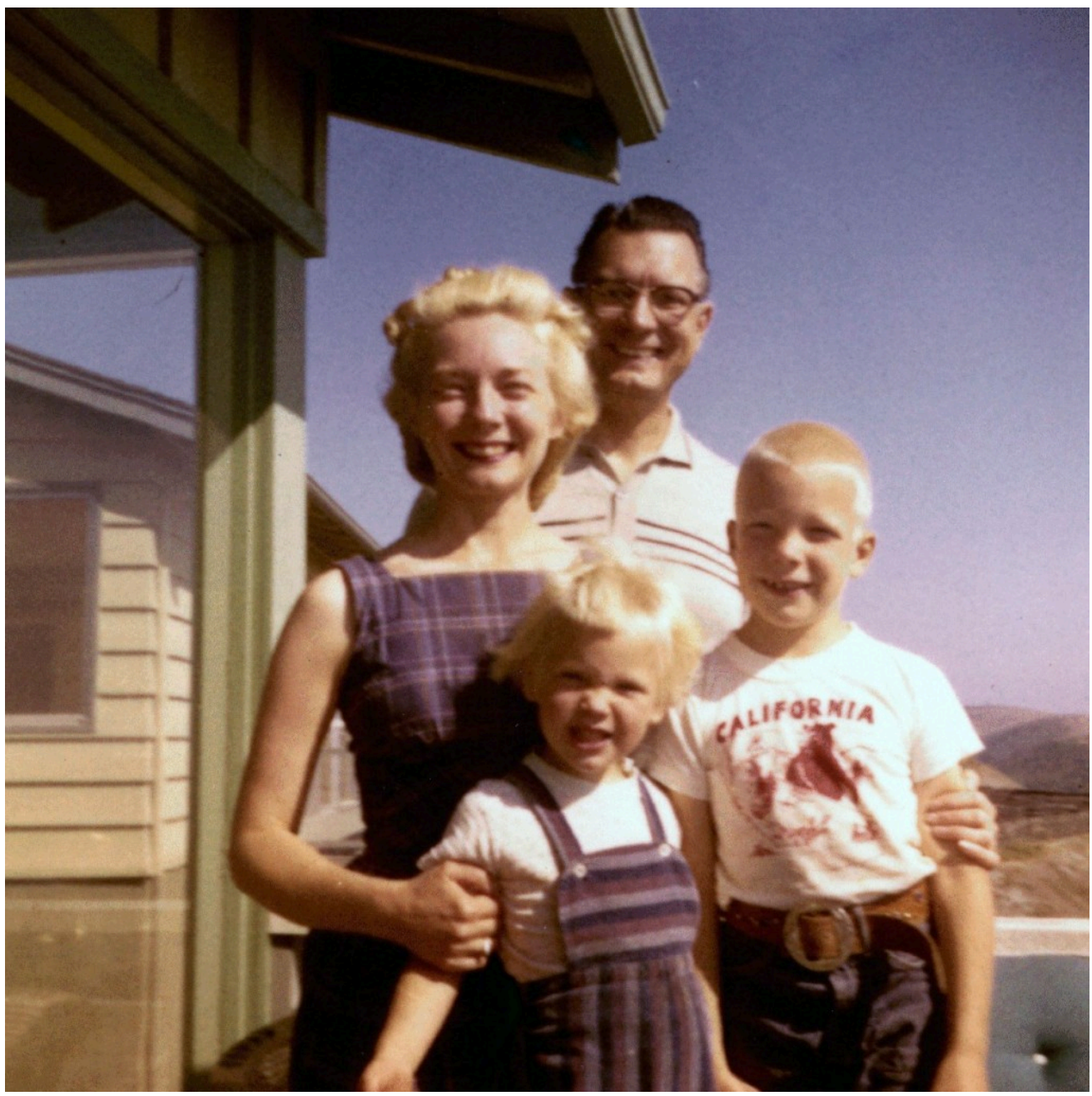

Although the nuclear family is a common family arrangement today, historically many children lived with only one parent because spouses died early and many babies were born out of wedlock.

Wikimedia Commons - CC BY 2.0.

Although many prehistoric societies featured nuclear families, a few societies studied by anthropologists have not had them. In these societies, a father does not live with a woman after she has his child and sees them either irregularly or not at all. Despite the absence of a father and the lack of a nuclear family, this type of family arrangement seems to have worked well in these societies. In particular, children are cared for and grow up to be productive members of their societies (Smith, 1996).

These examples do not invalidate the fact that nuclear families are almost universal. But they do indicate that the functions of the nuclear family can be achieved through other family arrangements. If that is true, perhaps the oft-cited concern over the "breakdown" of the 1950s-style nuclear family in modern America is at least somewhat undeserved. As indicated by the examples just given, children can and do thrive without two parents. To say this is meant neither to extol divorce, births out of wedlock, and fatherless families nor to minimize the problems they may involve. Rather, it is meant simply to indicate that the nuclear family is not the only viable form of family organization (Seccombe, 2012).

In fact, although nuclear families remain the norm in most societies, in practice they are something of a historical 
rarity: Until about a century ago, many spouses died by their mid-forties, and many babies were born out of wedlock. In medieval Europe, for example, people died early from disease, malnutrition, and other problems. One consequence of early mortality was that many children could expect to outlive at least one of their parents and thus essentially were raised in one-parent families or in stepfamilies (Gottlieb, 1993).

During the American colonial period, different family types abounded, and the nuclear family was by no means the only type (Coontz, 1995). Nomadic Native American groups had relatively small nuclear families, while nonnomadic groups had larger extended families. Because nuclear families among African Americans slaves were difficult to achieve, slaves adapted by developing extended families, adopting orphans, and taking in other people not related by blood or marriage. Many European parents of colonial children died because average life expectancy was only 45 years. The one-third to one-half of children who outlived at least one of their parents lived in stepfamilies or with just their surviving parent. Mothers were so busy working the land and doing other tasks that they devoted relatively little time to child care, which instead was entrusted to older children or servants.

Moving much forward in US history, an important change in American families occurred during the 1940s after World War II ended. As men came home after serving in the military in Europe and Japan, books, magazines, and newspapers exhorted women to have babies, and babies they did have: People got married at younger ages and the birth rate soared, resulting in the now famous baby boom generation. Meanwhile, divorce rates dropped. The national economy thrived as auto and other factory jobs multiplied, and many families for the first time could dream of owning their own homes. Suburbs sprang up, and many families moved to them. Many families during the 1950s did indeed fit the Leave It to Beaver model of the breadwinner-homemaker suburban nuclear family. Following the Depression of the 1930s and the war of the 1940s, the 1950s seemed an almost idyllic decade.

Even so, less than 60 percent of American children during the 1950s lived in breadwinner-homemaker nuclear families. Moreover, many lived in poverty, as the poverty rate then was almost twice as high as it is today. Teenage pregnancy rates were about twice as high as today. Although not publicized back then, alcoholism and violence in families were common. Historians have found that many women in this era were unhappy with their homemaker

roles, Mrs. Cleaver (Beaver's mother) to the contrary, suffering from what Betty Friedan (1963) famously called the "feminine mystique."

During the 1960s and 1970s, women began to enter the labor force. They did so to increase their families' incomes and to achieve greater self-fulfillment. More than 60 percent of married women with children under 6 years of age are now in the labor force, compared to less than 19 percent in 1960. At about the same time, divorce rates increased for several reasons that we examine later in this chapter. Changes in the American family had begun, and along with them various controversies and problems.

\section{Marriage and the Family in the United States Today}

In the United States today, marriage remains an important institution. Only about 27 percent of all adults (18 or older) have never been married, 56 percent are currently married, 10 percent are divorced, and 6 percent are widowed (see Figure 10.1 "Marital Status of the US Population 18 Years of Age or Older, 2010"). Thus 72 percent of American adults have been married, whether or not they are currently married. Because more than half of the never-married people are under 30, it is fair to say that many of them will be getting married sometime in the 
future. When we look just at people aged 45-54, about 87 percent are currently married or had been married at some point in their lives. In a 2010 poll, only 5 percent of Americans under age 30 said they did not want to get married (Luscombe, 2010). These figures all indicate that marriage continues to be an important ideal in American life, even if not all marriages succeed. As one sociologist has said, "Getting married is a way to show family and friends that you have a successful personal life. It’s like the ultimate merit badge” (Luscombe, 2010).

Although marriage remains an important institution, two recent trends do suggest that its importance is declining for some segments of the population (Cohn, Passel, Wang, \& Livingston, 2011). First, although 71 percent of adults have been married, this figure represents a drop from 85 percent in 1960. Second, education greatly affects whether we marry and stay married, and marriage is less common among people without a college degree.

Figure 10.1 Marital Status of the US Population 18 Years of Age or Older, 2010

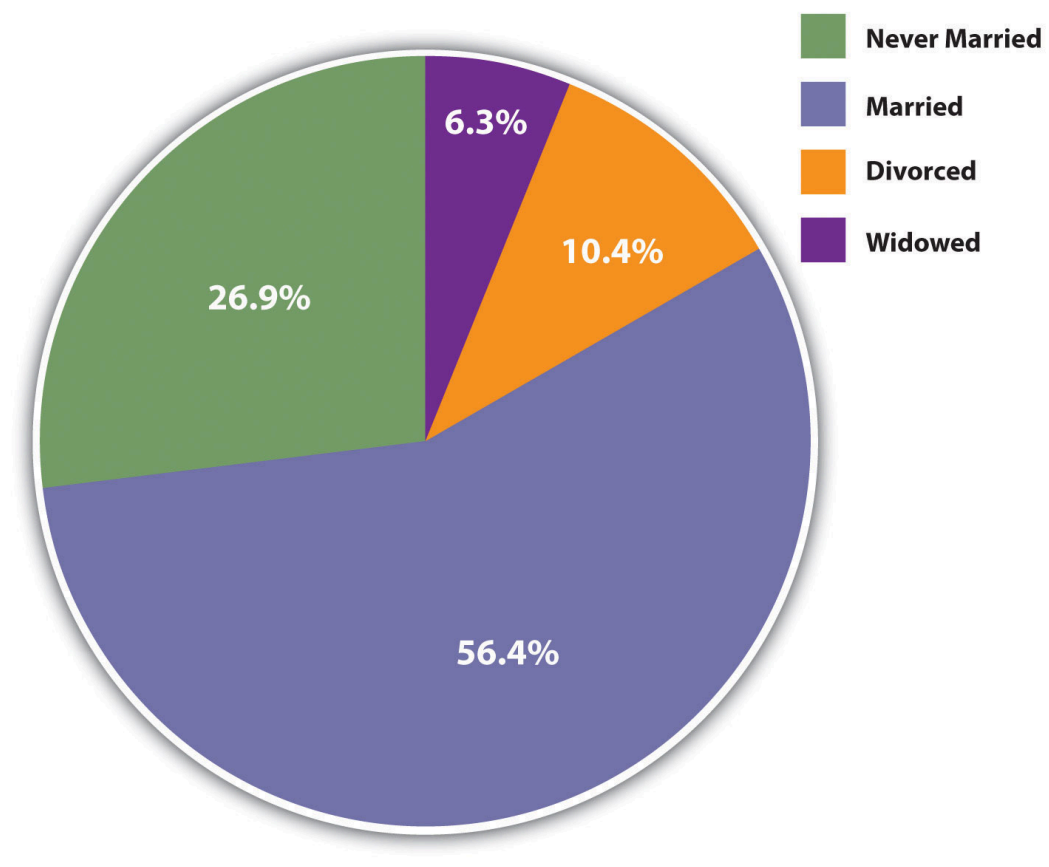

Source: Data from US Census Bureau. (2012). Statistical abstract of the United States: 2012. Washington,

DC: US Government Printing Office. Retrieved from http://www.census.gov/compendia/statab.

Recent figures provide striking evidence of this relationship. Almost two-thirds (64 percent) of college graduates are currently married, compared to less than half (47 percent) of high school graduates and high school dropouts combined. People with no more than a high school degree are less likely than college graduates to marry at all, and they are more likely to get divorced, as we shall discuss again later, if they do marry.

This difference in marriage rates worsens the financial situation that people with lower education already face. As one observer noted, “As marriage increasingly becomes a phenomenon of the better-off and better-educated, the incomes of two-earner married couples diverge more from those of struggling single adults” (Marcus, 2011). One of the many consequences of this education gap in marriage is that the children of one-parent households are less likely than those of two-parent households to graduate high school and to attend college. In this manner, a parent's low education helps to perpetuate low education among the parent's children. 


\section{The United States Compared to Other Democracies}

In several ways, the United States differs from other Western democracies in its view of marriage and in its behavior involving marriage and other intimate relationships (Cherlin, 2010; Hull, Meier, \& Ortyl, 2012). First, Americans place more emphasis than their Western counterparts on the ideal of romantic love as a basis for marriage and other intimate relationships and on the cultural importance of marriage. Second, the United States has higher rates of marriage than other Western nations. Third, the United States also has higher rates of divorce than other Western nations; for example, 42 percent of American marriages end in divorce after fifteen years, compared to only 8 percent in Italy and Spain. Fourth, Americans are much more likely than other Western citizens to remarry once they are divorced, to cohabit in short-term relationships, and, in general, to move from one intimate relationship to another, a practice called serial monogamy. This practice leads to instability that can have negative impacts on any children that may be involved and also on the adults involved.

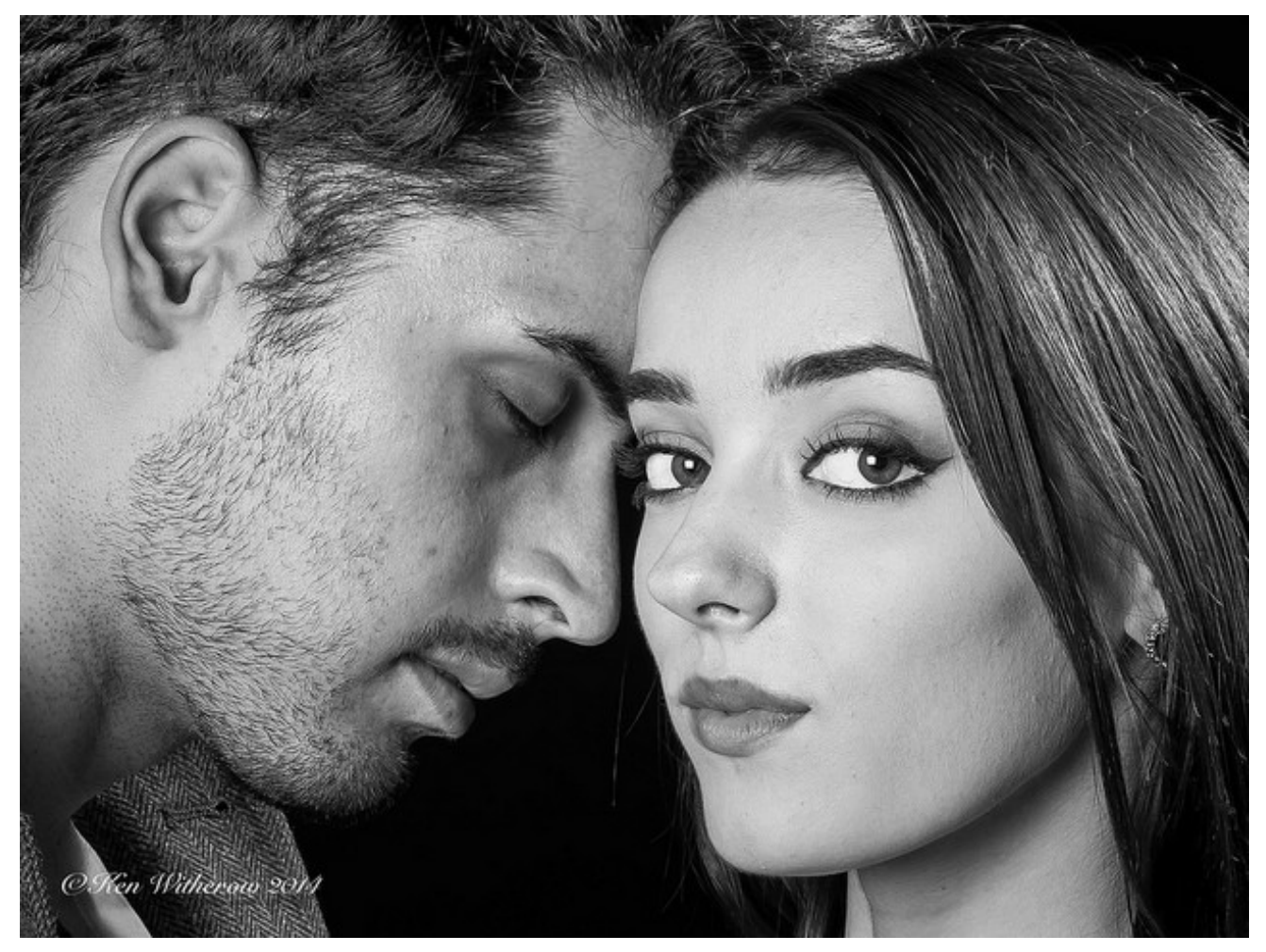

Americans place more emphasis than Europeans on the ideal of romantic love as the basis for marriage. This emphasis helps account for why the United States has a higher divorce rate than many European nations.

Ken Witherow - Digimem Studio Photo Shoot - CC BY 2.0.

The US emphasis on romantic love helps account for its high rates of marriage, divorce, and serial monogamy. It leads people to want to be in an intimate relationship, marital or cohabiting. Then when couples get married because they are in love, many quickly find that passionate romantic love can quickly fade; because their expectations of romantic love were so high, they become more disenchanted once this happens and unhappy in their marriage. As sociologist Andrew J. Cherlin (2010, p. 4) observes, “Americans are conflicted about lifelong marriage: they value the stability and security of marriage, but they tend to believe that individuals who are 
unhappy with their marriages should be allowed to end them." Still, the ideal of romantic love persists even after divorce, leading to remarriage and/or other intimate relationships.

\section{Children and Families}

The United States has about 36 million families with children under 18. About 70 percent of these are marriedcouple families, while 30 percent (up from about 14 percent in the 1950s) are one-parent families. Most of these latter families are headed by the mother (see Figure 10.2 "Family Households with Children under 18 Years of Age, 2010”).

Figure 10.2 Family Households with Children under 18 Years of Age, 2010

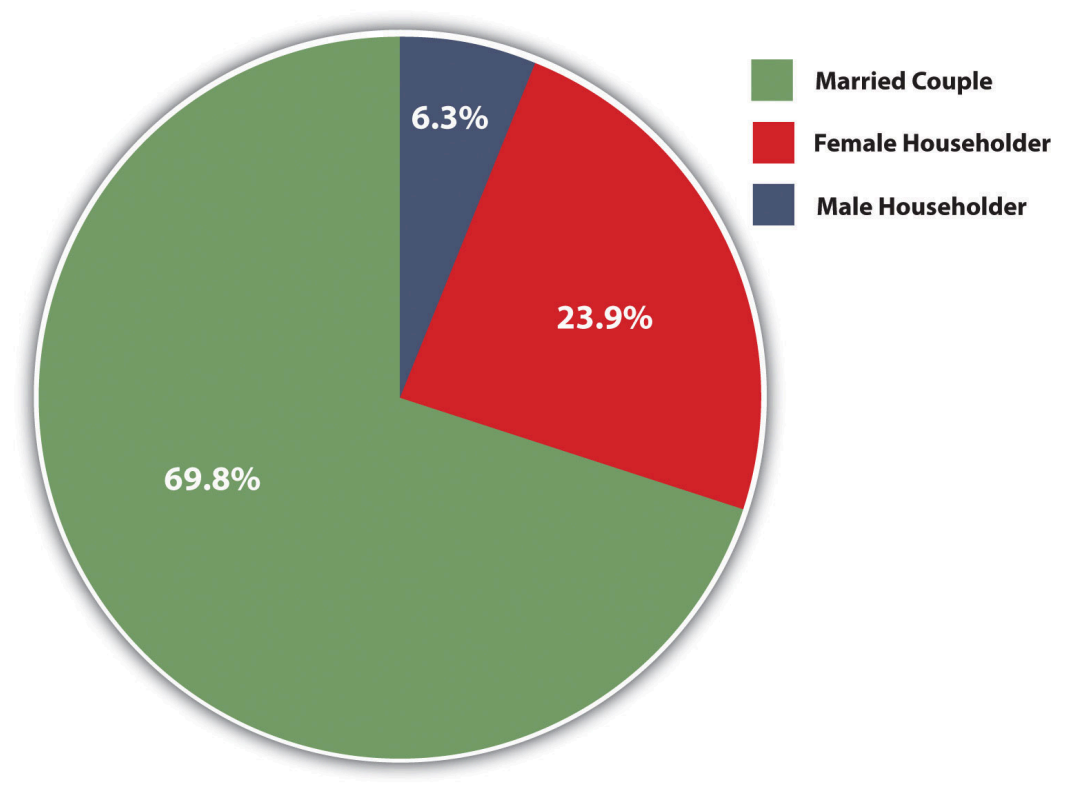

Source: Data from US Census Bureau. (2012). Statistical abstract of the United States: 2012. Washington,

DC: US Government Printing Office. Retrieved from http://www.census.gov/compendia/statab.

The proportion of families with children under 18 that have only one parent varies significantly by race and ethnicity: Latino and African American families are more likely than white and Asian American households to have only one parent (see Figure 10.3 "Race, Ethnicity, and Percentage of Family Groups with Only One Parent, 2010”). Similarly, whereas 30 percent of all children do not live with both their biological parents, this figure, too, varies by race and ethnicity: about 61 percent of African American children, 15 percent of Asian children, 33 percent of Latino children, and 23 percent of non-Latino white children. 


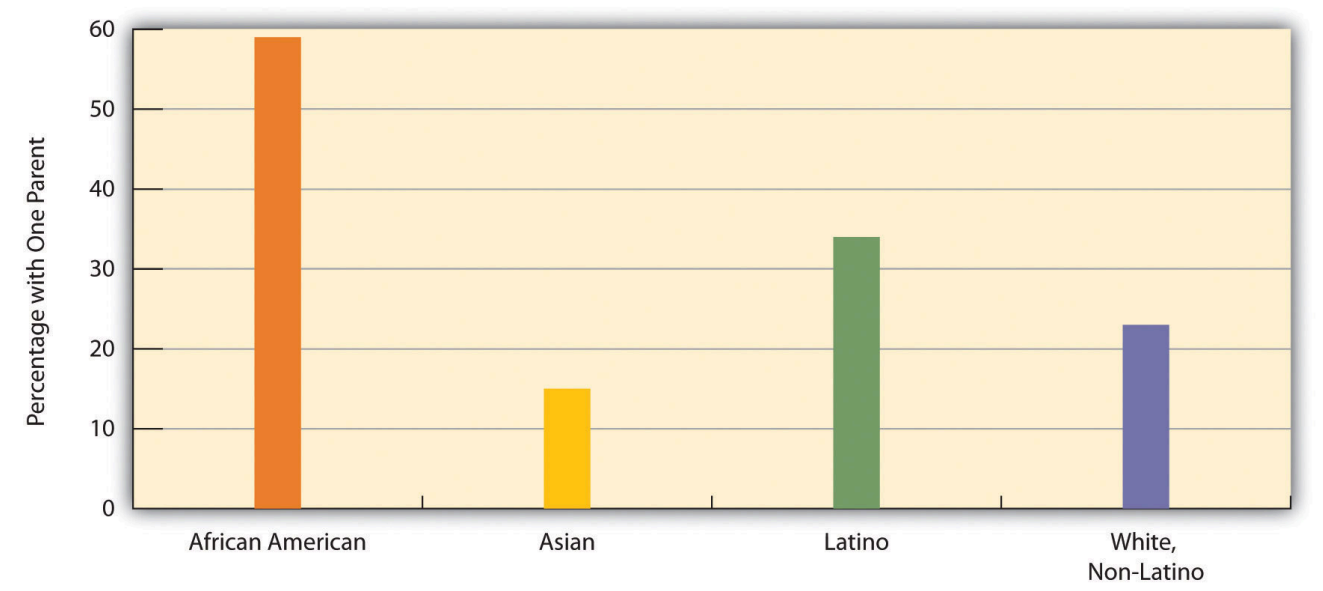

Source: Data from US Census Bureau. (2012). Statistical abstract of the United States: 2012. Washington, DC: US Government Printing Office. Retrieved from http://www.census.gov/compendia/statab.

We will discuss several other issues affecting children later in this chapter. But before we move on, it is worth noting that children, despite all the joy and fulfillment they so often bring to parents, also tend to reduce parents' emotional well-being. As a recent review summarized the evidence, "Parents in the United States experience depression and emotional distress more often than their childless adult counterparts. Parents of young children report far more depression, emotional distress and other negative emotions than non-parents, and parents of grown children have no better well-being than adults who never had children” (Simon, 2008, p. 41).

Children have these effects because raising them can be both stressful and expensive. Depending on household income, the average child costs parents between $\$ 134,000$ and $\$ 270,000$ from birth until age 18. College education obviously can cost tens of thousands of dollars beyond that. Robin W. Simon (2008) argues that American parents' stress would be reduced if the government provided better and more affordable day care and after-school options, flexible work schedules, and tax credits for various parenting costs. She also thinks that the expectations Americans have of the joy of parenthood are unrealistically positive and that parental stress would be reduced if expectations became more realistic.

\section{Key Takeaways}

- Although the nuclear family has been very common, many children throughout history have not lived in a nuclear family, in part because a parent would die at an early age.

- Most Americans eventually marry. This fact means that marriage remains an important ideal in American life, even if not all marriages succeed.

- About 30 percent of children live with only one parent, almost always their mother. 


\section{For Your Review}

1. Write a brief essay in which you describe the advantages and disadvantages of the 1950s-type nuclear family in which the father works outside the home and the mother stays at home.

2. The text notes that most people eventually marry. In view of the fact that so many marriages end in divorce, why do you think that so many people continue to marry?

3. Some of the children who live only with their mothers were born out of wedlock. Do you think the parents should have married for the sake of their child? Why or why not?

\section{References}

Cherlin, A. J. (2010). The marriage-go-round: The state of marriage and the family in America today. New York, NY: Vintage.

Cohn, D., Passel J., Wang, W., \& Livingston, G. (2011). Barely half of US adults are married-a record low. Washington, DC: Pew Research Center.

Coontz, S. (1995, summer). The way we weren't: The myth and reality of the “traditional” family. National Forum: The Phi Kappa Phi Journal, 11-14.

Friedan, B. (1963). The feminine mystique. New York, NY: W. W. Norton.

Gottlieb, B. (1993). The family in the Western world from the black death to the industrial age. New York, NY: Oxford University Press.

Hull, K. E., Meier, A., \& Ortyl, T. (2012). The changing landscape of love and marriage. In D. Hartmann \& C. Uggen (Eds.), The contexts reader (2nd ed., pp. 56-63). New York, NY: W. W. Norton.

Luscombe, B. (2010, November 18). Who needs marriage? A changing institution. Time. Retrieved from http://www.time.com/time/magazine/article/0,9171,2032116,2032100.html.

Marcus, R. (2011, December 18). The marriage gap presents a real cost. The Washington Post. Retrieved from http://www.washingtonpost.com/opinions/the-marriage-gap-presents-a-real-cost/2011/12/16/ gIQAz24DzO story.html?hpid=z3.

Seccombe, K. (2012). Families and their social worlds (2nd ed.). Upper Saddle River, NJ: Pearson.

Simon, R. W. (2008). The joys of parenthood, reconsidered. Contexts, 7(2), 40-45.

Smith, R. T. (1996). The matrifocal family: Power, pluralism, and politics. New York, NY: Routledge.

Starbuck, G. H. (2010). Families in context (2nd ed.). Boulder, CO: Paradigm. 


\subsection{Sociological Perspectives on the Family}

\section{Learning Objective}

1. Summarize understandings of the family as presented by functional, conflict, and social interactionist theories.

Sociological views on today's families and their problems generally fall into the functional, conflict, and social interactionist approaches introduced in Chapter 1 "Understanding Social Problems". Let's review these views, which are summarized in Table 10.1 "Theory Snapshot”.

Table 10.1 Theory Snapshot

\begin{tabular}{|l|l|}
$\begin{array}{l}\text { Theoretical } \\
\text { perspective }\end{array}$ & Major assumptions \\
\hline Functionalism & $\begin{array}{l}\text { The family performs several essential functions for society. It socializes children, it provides emotional } \\
\text { and practical support for its members, it helps regulate sexual activity and sexual reproduction, and it } \\
\text { provides its members with a social identity. Family problems stem from sudden or far-reaching changes in } \\
\text { the family’s structure or processes; these problems threaten the family’s stability and weaken society. }\end{array}$ \\
\hline $\begin{array}{l}\text { Conflict } \\
\text { theory }\end{array}$ & $\begin{array}{l}\text { The family contributes to social inequality by reinforcing economic inequality and by reinforcing } \\
\text { patriarchy. Family problems stem from economic inequality and from patriarchal ideology. The family } \\
\text { can also be a source of conflict, including physical violence and emotional cruelty, for its own members. }\end{array}$ \\
\hline $\begin{array}{l}\text { Symbolic } \\
\text { interactionism }\end{array}$ & $\begin{array}{l}\text { The interaction of family members and intimate couples involves shared understandings of their } \\
\text { situations. Wives and husbands have different styles of communication, and social class affects the } \\
\text { expectations that spouses have of their marriages and of each other. Family problems stem from different } \\
\text { understandings and expectations that spouses have of their marriage. }\end{array}$ \\
\hline
\end{tabular}

\section{Social Functions of the Family}

Recall that the functional perspective emphasizes that social institutions perform several important functions to help preserve social stability and otherwise keep a society working. A functional understanding of the family thus stresses the ways in which the family as a social institution helps make society possible. As such, the family performs several important functions.

First, the family is the primary unit for socializing children. No society is possible without adequate socialization of its young. In most societies, the family is the major unit in which socialization happens. Parents, siblings, and, if the family is extended rather than nuclear, other relatives all help socialize children from the time they are born. 


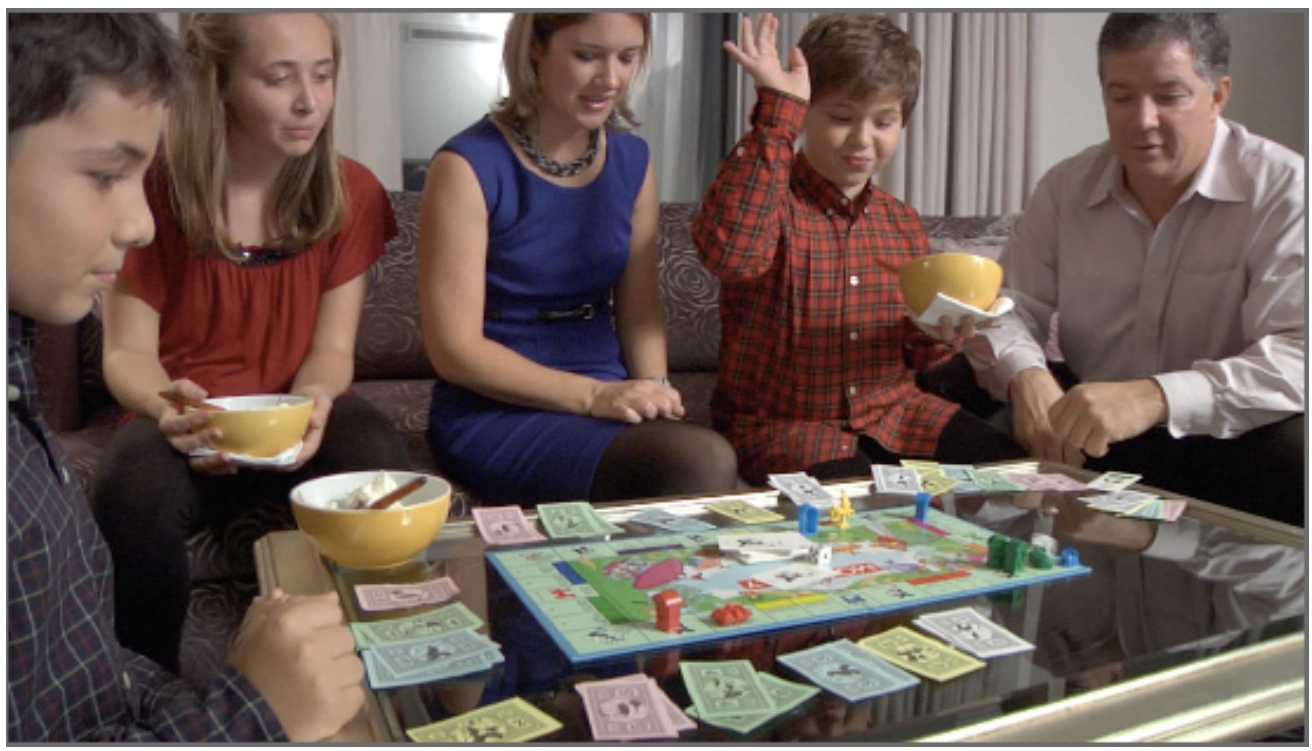

One of the most important functions of the family is the socialization of children. In most societies the family is the major unit through

which socialization occurs.

Colleen Kelly - Kids Playing Monopoly Chicago - CC BY 2.0.

Second, the family is ideally a major source of practical and emotional support for its members. It provides them food, clothing, shelter, and other essentials, and it also provides them love, comfort, and help in times of emotional distress, and other types of support.

Third, the family helps regulate sexual activity and sexual reproduction. All societies have norms governing with whom and how often a person should have sex. The family is the major unit for teaching these norms and the major unit through which sexual reproduction occurs. One reason for this is to ensure that infants have adequate emotional and practical care when they are born.

Fourth, the family provides its members with a social identity. Children are born into their parents' social class, race and ethnicity, religion, and so forth. Some children have advantages throughout life because of the social identity they acquire from their parents, while others face many obstacles because the social class or race/ethnicity into which they are born is at the bottom of the social hierarchy.

Beyond discussing the family's functions, the functional perspective on the family maintains that sudden or farreaching changes in conventional family structure and processes threaten the family's stability and thus that of society. For example, most sociology and marriage-and-family textbooks during the 1950s maintained that the male breadwinner-female homemaker nuclear family was the best arrangement for children, as it provided for a family's economic and child-rearing needs. Any shift in this arrangement, they warned, would harm children and, by extension, the family as a social institution and even society itself. Textbooks no longer contain this warning, but many conservative observers continue to worry about the impact on children of working mothers and oneparent families. We return to their concerns shortly. 


\section{The Family and Conflict}

Conflict theorists agree that the family serves the important functions just listed, but they also point to problems within the family that the functional perspective minimizes or overlooks altogether.

First, the family as a social institution contributes to social inequality. Because families pass along their wealth to their children, and because families differ greatly in the amount of wealth they have, the family helps reinforce existing inequality. As it developed through the centuries, and especially during industrialization, the family also became more and more of a patriarchal unit (since men made money working in factories while women stayed home), helping to reinforce men's status at the top of the social hierarchy.

Second, the family can also be a source of conflict for its own members. Although the functional perspective assumes the family provides its members emotional comfort and support, many families do just the opposite and are far from the harmonious, happy groups depicted in the 1950s television shows. Instead, they argue, shout, and use emotional cruelty and physical violence. We return to family violence later in this chapter.

The conflict perspective emphasizes that many of the problems we see in today's families stem from economic inequality and from patriarchy. The problems that many families experience reflect the fact that they live in poverty or near poverty. Money does not always bring happiness, but a dire lack of money produces stress and other difficulties that impair a family's functioning and relationships. The Note 10.9 "Applying Social Research" box discusses other ways in which social class influences the family.

Conflict within a family also stems from patriarchy. Husbands usually earn more money than wives, and many men continue to feel that they are the head of their families. When women resist this old-fashioned notion, spousal conflict occurs.

\section{Applying Social Research}

\section{Social Class and the Family}

A growing amount of social science research documents social class differences in how well a family functions: the quality of its relationships and the cognitive, psychological, and social development of its children. This focus reflects the fact that what happens during the first months and years of life may have profound effects on how well a newborn prospers during childhood, adolescence, and beyond. To the extent this is true, the social class differences that have been found have troublesome implications.

According to sociologist Frank E. Furstenberg Jr., “steep differences exist across social classes” in mothers’ prenatal experiences, such as the quality of their diet and health care, as well as in the health care that their infants receive. As a result, he says, "children enter the world endowed unequally." This inequality worsens after they are born for several reasons.

First, low-income families are much more likely to experience negative events, such as death, poor health, unemployment, divorce, and criminal victimization. When these negative events do occur, says Furstenberg, "social class affects a family's ability to cushion their blow...Life is simply harder and more brutish at the bottom." These negative events produce great amounts of stress; as Chapter 2 "Poverty" discussed, this stress in turn causes children to experience various developmental problems.

Second, low-income parents are much less likely to read and speak regularly to their infants and young children, who 
thus are slower to develop cognitive and reading skills; this problem in turn impairs their school performance when they enter elementary school.

Third, low-income parents are also less able to expose their children to cultural experiences (e.g., museum visits) outside the home, to develop their talents in the arts and other areas, and to otherwise be involved in the many nonschool activities that are important for a child's development. In contrast, wealthier parents keep their children very busy in these activities in a pattern that sociologist Annette Lareau calls concerted cultivation. These children's involvement in these activities provides them various life skills that help enhance their performance in school and later in the workplace.

Fourth, low-income children grow up in low-income neighborhoods, which often have inadequate schools and many other problems, including toxins such as lead paint, that impair a child's development. In contrast, says Furstenberg, children from wealthier families "are very likely to attend better schools and live in better neighborhoods. It is as if the playing field for families is tilted in ways that are barely visible to the naked eye.”

Fifth, low-income families are less able to afford to send a child to college, and they are more likely to lack the social contacts that wealthier parents can use to help their child get a good job after college.

For all these reasons, social class profoundly shapes how children fare from conception through early adulthood and beyond. Because this body of research documents many negative consequences of living in a low-income family, it reinforces the need for wide-ranging efforts to help such families.

Sources: Bandy, Andrews, \& Moore, 2012; Furstenberg, 2010; Lareau, 2010

\section{Families and Social Interaction}

Social interactionist perspectives on the family examine how family members and intimate couples interact on a daily basis and arrive at shared understandings of their situations. Studies grounded in social interactionism give us a keen understanding of how and why families operate the way they do.

Some studies, for example, focus on how husbands and wives communicate and the degree to which they communicate successfully (Tannen, 2001). A classic study by Mirra Komarovsky (1964) found that wives in bluecollar marriages liked to talk with their husbands about problems they were having, while husbands tended to be quiet when problems occurred. Such gender differences are less common in middle-class families, where men are better educated and more emotionally expressive than their working-class counterparts, but gender differences in communication still exist in these families. Another classic study by Lillian Rubin (1976) found that wives in middle-class families say that ideal husbands are ones who communicate well and share their feelings, while wives in working-class families are more apt to say that ideal husbands are ones who do not drink too much and who go to work every day.

According to the symbolic interactionist perspective, family problems often stem from the different understandings, perceptions, and expectations that spouses have of their marriage and of their family. When these differences become too extreme and the spouses cannot reconcile their disagreements, spousal conflict and possibly divorce may occur (Kaufman \& Taniguchi, 2006). 


\section{Key Takeaways}

- The family ideally serves several functions for society. It socializes children, provides practical and emotional support for its members, regulates sexual reproduction, and provides its members with a social identity.

- Reflecting conflict theory's emphases, the family may also produce several problems. In particular, it may contribute for several reasons to social inequality, and it may subject its members to violence, arguments, and other forms of conflict.

- Social interactionist understandings of the family emphasize how family members interact on a daily basis. In this regard, several studies find that husbands and wives communicate differently in certain ways that sometimes impede effective communication.

\section{For Your Review}

1. As you think how best to understand the family, do you favor the views and assumptions of functional theory, conflict theory, or social interactionist theory? Explain your answer.

2. Do you think the family continues to serve the function of regulating sexual behavior and sexual reproduction? Why or why not?

\section{References}

Bandy, T., Andrews, K.M., \& Moore, K.A. (2012). Disadvantaged families and child outcomes: The importance of emotional support for mothers. Washington, DC: Child Trends.

Furstenberg, F. E., Jr. (2010). Diverging development: The not-so-invisible hand of social class in the United States. In B. J. Risman (Ed.), Families as they really are (pp. 276-294). New York, NY: W. W. Norton.

Kaufman, G., \& Taniguchi, H. (2006). Gender and marital happiness in later life. Journal of Family Issues, 27(6), 735-757.

Komarovsky, M. (1964). Blue-collar marriage. New York, NY: Random House.

Lareau, A. (2010). Unequal childhoods: Inequalities in the rhythms of daily life. In B. J. Risman (Ed.), Families as they really are (pp. 295-298). New York: W. W. Norton.

Rubin, L. B. (1976). Worlds of pain: Life in the working-class family. New York, NY: Basic Books.

Tannen, D. (2001). You just don't understand: Women and men in conversation. New York, NY: Quill. 


\subsection{Changes and Problems in American Families}

\section{Learning Objectives}

1. Discuss why the US divorce rate rose during the 1960s and 1970s and summarize the major individual-level factors accounting for divorce today.

2. Describe the effects of divorce for spouses and children.

3. Summarize the evidence on how children fare when their mothers work outside the home.

4. Describe the extent of family violence and explain why it occurs.

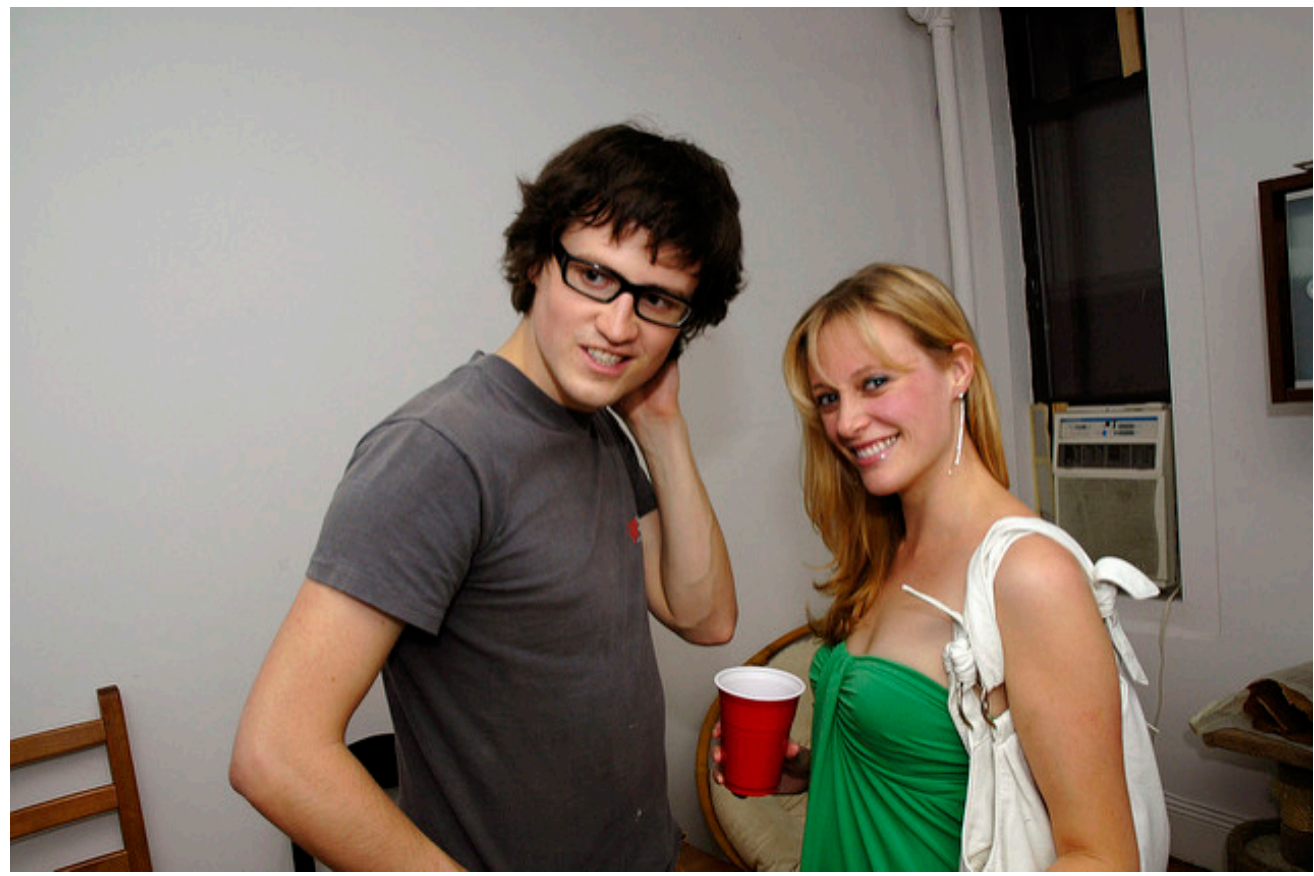

According to the census, roughly 6 million opposite-sex couples are currently cohabiting in the United States. The average cohabitation lasts less than two years.

Amit Gupta - CC BY-NC 2.0.

American families have undergone many changes since the 1950s. Scholars, politicians, and the public have strong and often conflicting views on the reasons for these changes and on their consequences. We now look at some of the most important issues affecting US families through the lens of the latest social scientific evidence. Because Chapter 5 "Sexual Orientation and Inequality" on sexual orientation and inequality discussed same-sex marriage and families, please refer back to that chapter for material on this very important topic. 


\section{Cohabitation}

Some people who are not currently married nonetheless cohabit, or live together, with someone of the opposite sex in a romantic relationship. The census reports that about 6 million opposite-sex couples are currently cohabiting; these couples constitute about 10 percent of all opposite-sex couples (married plus unmarried) who live together. The average cohabitation lasts less than two years and ends when the couple either splits up or gets married; about half of cohabiting couples do marry, and half split up. More than half of people in their twenties and thirties have cohabited, and roughly one-fourth of this age group is currently cohabiting (Brown, 2005). Roughly 55 percent of cohabiting couples have no biological children, about 45 percent live with a biological child of one of the partners, and 21 percent live with their own biological child. (These figures add to more than 100 percent because many couples live with their own child and a child of a partner.) About 5 percent of children live with biological parents who are cohabiting.

Interestingly, many studies find that married couples who have cohabited with each other before getting married are more likely to divorce than married couples who did not cohabit (Jose, O’Leary, \& Moyer, 2010). As sociologist Susan L Brown (2005, p. 34) notes, this apparent consequence is ironic: "The primary reason people cohabit is to test their relationship's viability for marriage. Sorting out bad relationships through cohabitation is how many people think they can avoid divorce. Yet living together before marriage actually increases a couple's risk of divorce.” Two reasons may account for this result. First, cohabitation may change the relationship between a couple and increase the chance they will divorce if they get married anyway. Second, individuals who are willing to live together without being married may not be very committed to the idea of marriage and thus may be more willing to divorce if they are unhappy in their eventual marriage.

Recent research compares the psychological well-being of cohabiting and married adults and also the behavior of children whose biological parent or parents are cohabiting rather than married (Apel \& Kaukinen, 2008; Brown, 2005). On average, married adults are happier and otherwise have greater psychological well-being than cohabiting adults, while the latter, in turn, fare better psychologically than adults not living with anyone. Research has not yet clarified the reasons for these differences, but it seems that people with the greatest psychological and economic well-being are most likely to marry. If this is true, it is not the state of being married per se that accounts for the difference in well-being between married and cohabiting couples, but rather the extent of wellbeing that affects decisions to marry or not marry. Another difference between cohabitation and marriage concerns relationship violence. Among young adults (aged 18-28), this type of violence is more common among cohabiting couples than among married or dating couples. The reasons for this difference remain unknown but may again reflect differences in the types of people who choose to cohabit (Brown \& Bulanda, 2008).

The children of cohabiting parents tend to exhibit lower well-being of various types than those of married parents: They are more likely to engage in delinquency and other antisocial behavior, and they have lower academic performance and worse emotional adjustment. The reasons for these differences remain to be clarified but may again stem from the types of people who choose to cohabit rather than marry. 


\section{Divorce and Single-Parent Households}

The US divorce rate has risen since the early 1900s, with several peaks and valleys, and is now the highest in the industrial world. It rose sharply during the Great Depression and World War II, probably because of the economic distress of the former and the family disruption caused by the latter, and fell sharply after the war as the economy thrived and as marriage and family were proclaimed as patriotic ideals. It dropped a bit more during the 1950s before rising sharply through the 1960s and 1970s (Cherlin, 2009). The divorce rate has since declined somewhat (see Figure 10.4 "Number of Divorces per 1,000 Married Women Aged 15 or Older, 1960-2009”) and today is only slightly higher than its peak at the end of World War II. Still, the best estimates say that 40-50 percent of all new marriages will one day end in divorce (Teachman, 2008). The surprising announcement in June 2010 of the separation of former vice president $\mathrm{Al}$ Gore and his wife, Tipper, was a poignant reminder that divorce is a common outcome of many marriages.

Figure 10.4 Number of Divorces per 1,000 Married Women Aged 15 or Older, 1960-2009

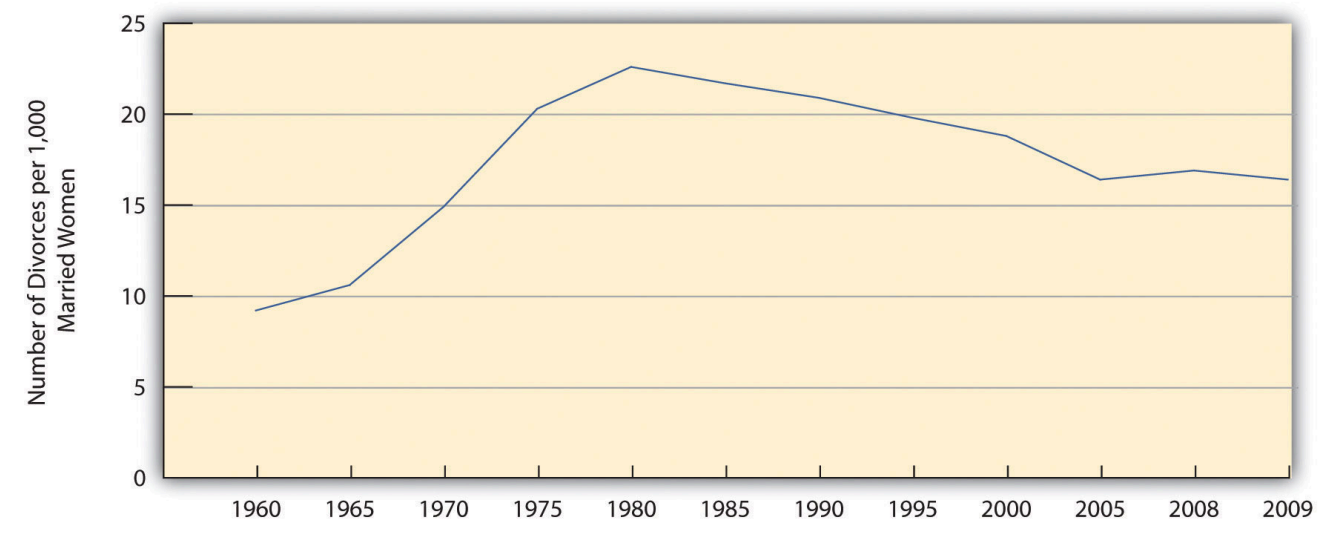

Source: Data from Wilcox, W. B. (Ed.). (2010). The state of our unions, 2010: Marriage in America. Charlottesville, VA: National Marriage Project.

\section{Reasons for Divorce}

We cannot be certain about why the divorce rate rose so much during the 1960s and 1970s, but we can rule out two oft-cited causes. First, there is little reason to believe that marriages became any less happy during this period. We do not have good data to compare marriages then and now, but the best guess is that marital satisfaction did not decline after the 1950s ended. What did change was that people after the 1950s became more willing to seek divorces in marriages that were already unhappy.

Second, although the contemporary women's movement is sometimes blamed for the divorce rate by making women think marriage is an oppressive institution, the trends in Figure 10.4 "Number of Divorces per 1,000 Married Women Aged 15 or Older, 1960-2009”' suggest this blame is misplaced. The women's movement emerged in the late 1960s and was capturing headlines by the early 1970s. Although the divorce rate obviously rose after that time, it also started rising several years before the women's movement emerged and captured headlines. If the divorce rate began rising before the women's movement started, it is illogical to blame the 
women's movement. Instead, other structural and cultural forces must have been at work, just as they were at other times in the last century, as just noted, when the divorce rate rose and fell.

Why, then, did divorce increase during the 1960s and 1970s? One reason is the increasing economic independence of women. As women entered the labor force in the 1960s and 1970s, they became more economically independent of their husbands, even if their jobs typically paid less than their husbands' jobs. When women in unhappy marriages do become more economically independent, they are more able to afford to get divorced than when they have to rely entirely on their husbands' earnings (Hiedemann, Suhomlinova, \& O’Rand, 1998). When both spouses work outside the home, moreover, it is more difficult to juggle the many demands of family life, and family life can be more stressful. Such stress can reduce marital happiness and make divorce more likely. Spouses may also have less time for each other when both are working outside the home, making it more difficult to deal with problems they may be having.

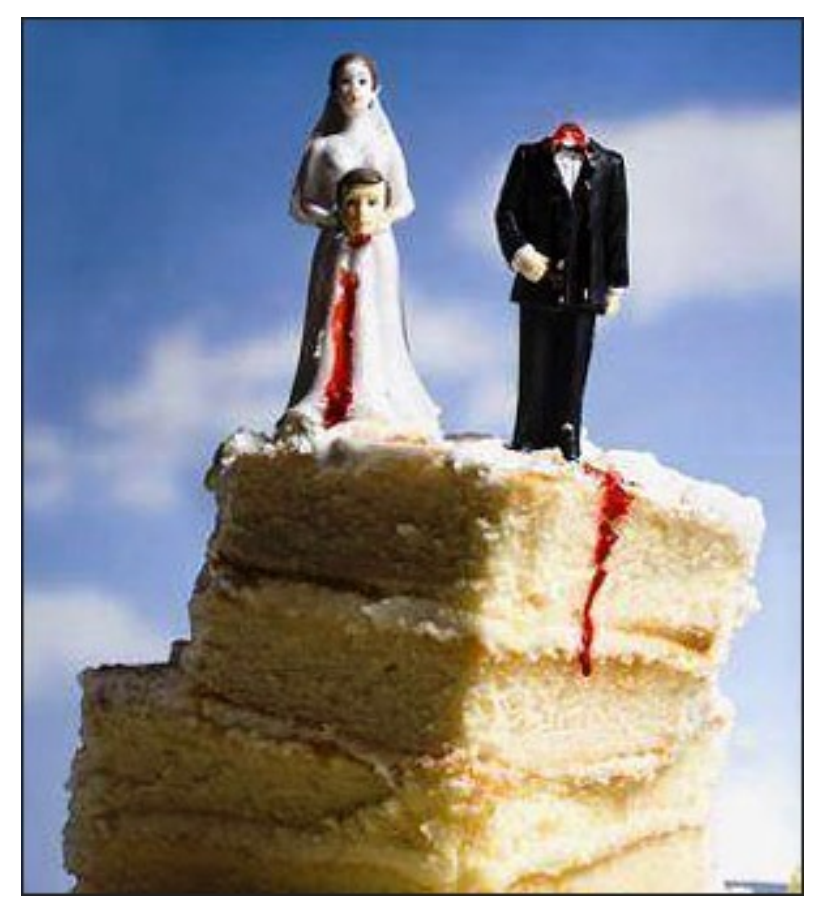

Disapproval of divorce has declined since the 1950s, and divorce is now considered a normal if unfortunate part of life.

John C Bullas BSc MSc PhD MCIHT MIAT - Divorce Cakes a 005 - CC BYNC-ND 2.0.

It is also true that disapproval of divorce has declined since the 1950s, even if negative views of it still remain (Cherlin, 2009). Not too long ago, divorce was considered a terrible thing; now it is considered a normal if unfortunate part of life. We no longer say a bad marriage should continue for the sake of the children. When New York Governor Nelson Rockefeller ran for president in the early 1960s, the fact that he had been divorced hurt his popularity, but when California Governor Ronald Reagan ran for president less than two decades later, the fact that he had been divorced was hardly noted. Many presidential candidates and other politicians today have been divorced. But is the growing acceptability of divorce a cause of the rising divorce rate, or is it the result of the rising divorce rate? Or is it both a cause and a result? This important causal order question is difficult to resolve. 
Another reason divorce rose during the 1960s and 1970s may be that divorces became easier to obtain legally. In the past, most states required couples to prove that one or both had committed actions such as mental cruelty, adultery, or other such behaviors in order to get divorced. Today almost all states have no-fault divorce laws that allow a couple to divorce if they say their marriage has failed from irreconcilable differences. Because divorce has become easier and less expensive to obtain, more divorces occur. But are no-fault divorce laws a cause or result of the post-1950s rise in the divorce rate? The divorce rate increase preceded the establishment of most states' no-fault laws, but it is probably also true that the laws helped make additional divorces more possible. Thus nofault divorce laws are probably one reason for the rising divorce rate after the 1950s, but only one reason (Kneip \& Bauer, 2009).

We have just looked at possible reasons for divorce rate trends, but we can also examine the reasons why certain marriages are more or less likely to end in divorce within a given time period. Although, as noted earlier, 40-50 percent of all new marriages will probably end in divorce, it is also true that some marriages are more likely to end than others. Family scholars identify several correlates of divorce (Clarke-Stewart \& Brentano, 2006; Wilcox, 2010). An important one is age at marriage: Teenagers who get married are much more likely to get divorced than people who marry well into their twenties or beyond, partly because they have financial difficulties and are not yet emotionally mature. A second correlate of divorce is social class: People who are poor and have less formal education at the time of their marriage are much more likely to get divorced than people who begin their marriages in economic comfort and with higher levels of education.

\section{Effects of Divorce and Single-Parent Households}

Much research exists on the effects of divorce on spouses and their children, and scholars often disagree on what these effects are. One thing is clear: Divorce plunges many women into poverty or near-poverty (Gadalla, 2008; Wilcox, 2010). Many have been working only part time or not at all outside the home, and divorce takes away their husband's economic support. Even women working full time often have trouble making ends meet, because many are in low-paying jobs. One-parent families headed by a woman for any reason are much poorer (\$32,031 in 2010 median annual income) than those headed by a man $(\$ 49,718)$. Meanwhile, the median income of married-couple families is much higher $(\$ 72,751)$. Almost 32 percent of all single-parent families headed by women are officially poor, compared to only about 16 percent of single-parent families headed by men and 6 percent of married-couple families (DeNavas-Walt, Proctor, \& Smith, 2011).

Although the economic consequences of divorce seem clear, what are the psychological consequences for husbands, wives, and their children? Are they better off if a divorce occurs, worse off, or about the same?

\section{Effects on Spouses}

The research evidence for spouses is very conflicting. Many studies find that divorced spouses are, on average, less happy and have poorer mental health after their divorce, but some studies find that happiness and mental health often improve after divorce (Cherlin, 2009; Waite, Luo, \& Lewin, 2009). The postdivorce time period that is studied may affect what results are found: For some people psychological well-being may decline in the 
immediate aftermath of a divorce, given how difficult the divorce process often is, but rise over the next few years. The contentiousness of the marriage also matters. Some marriages ending in divorce have been filled with hostility, conflict, and sometimes violence, while other marriages ending in divorce have not been very contentious at all, even if they have failed. Individuals seem to fare better psychologically after ending a very contentious marriage but fare worse after ending a less contentious marriage (Amato \& Hohmann-Marriott, 2007).

\section{Effects on Children}

What about the children? Parents used to stay together "for the sake of the children," thinking that divorce would cause their children more harm than good. Studies of this issue generally find that children in divorced families are indeed more likely, on average, to do worse in school, to use drugs and alcohol and suffer other behavioral problems, and to experience emotional distress and other psychological problems (Wilcox, 2010). The trauma of the divorce and the difficulties that single parents encounter in caring for and disciplining children are thought to account for these effects.

However, two considerations suggest that children of divorce may fare worse for reasons other than divorce trauma and the resulting single-parent situation. First, most children whose parents divorce end up living with their mothers. As we just noted, many divorced women and their children live in poverty or near poverty. To the extent that these children fare worse in many ways, their mothers' low incomes may be a contributing factor. Studies of this issue find that divorced mothers' low incomes do, in fact, help explain some of the difficulties that their children experience (Demo \& Fine, 2010). Divorce trauma and single-parenthood still matter for children's well-being in many of these studies, but the worsened financial situation of divorced women and their children also makes a difference.

Second, it is possible that children do worse after a divorce because of the parental conflict that led to the divorce, not because of the divorce itself. It is well known that the quality of the relationship between a child's parents affects the child's behavior and emotional well-being (Moore, Kinghorn, \& Bandy, 2011). This fact raises the possibility that children may fare better if their parents end a troubled marriage than if their parents stay married. Recent studies have investigated this issue, and their findings generally mirror the evidence for spouses just cited: Children generally fare better if their parents end a highly contentious marriage, but they fare worse if their parents end a marriage that has not been highly contentious (Hull et al., 2012). As one researcher summarizes this new body of research, "All these new studies have discovered the same thing: The average impact of divorce in society at large is to neither increase nor decrease the behavior problems of children. They suggest that divorce, in and of itself, is not the cause of the elevated behavior problems we see in children of divorce” (Li, 2010, p. 174). Commenting on divorces from highly contentious marriages, sociologist Virginia E. Rutter (2010, p. 169) bluntly concludes, "There are times and situations when divorce is beneficial to the people who divorce and to their children.”

\section{Fathers and Children}

Recall that most children whose parents are not married, either because they divorced or because they never were 
married, live with their mothers. Another factor that affects how children in these situations fare is the closeness of the child-father relationship. Whether or not children live with their fathers, they fare better in many respects when they have an emotionally close relationship with their fathers. This type of relationship is certainly more possible when they live with their fathers, and this is a reason that children who live with both their parents fare better on average than children who live only with their mother. However, some children who do live with their fathers are less close to them than some children who live apart from their fathers.

Recent research by sociologist Alan Booth and colleagues (Booth, Scott, \& King, 2010) found that the former children fare worse than the latter children. As Booth et al. (2010, p. 600) summarize this result, "We find that adolescents who are close to their nonresident fathers report higher self-esteem, less delinquency, and fewer depressive symptoms than adolescents who live with a father with whom they are not close. It appears that adolescents benefit more from a close bond to a nonresident father than a weak bond to a resident father." To the extent this is true, they add, "youth are not always better off in two-parent families.” In fact, children who are not close to a father with whom they live have lower self-esteem than children who are not close to a father with whom they do not live. Overall, though, children fare best when they live with fathers with whom they have a close relationship: "It does not appear that strong affection alone can overcome the problems associated with father absence from the child's residence.”

\section{Marriage and Well-Being}

Is marriage good for people? This is the flip side of the question we have just addressed on whether divorce is bad for people. Are people better off if they get married? Or are they better off if they stay single?

In 1972, sociologist Jessie Bernard (1972) famously said that every marriage includes a "her marriage" and a "his marriage.” By this she meant that husbands and wives view and define their marriages differently. When spouses from the same marriage are interviewed, they disagree on such things as how often they should have sex, how often they actually do have sex, and who does various household tasks. Women do most of the housework and child care, while men are freer to work and do other things outside the home. Citing various studies, she said that marriage is better for men than for women. Married women, she said, have poorer mental health than unmarried women, while married men have better mental health than unmarried men. In short, she said that marriage was good for men but bad for women. 


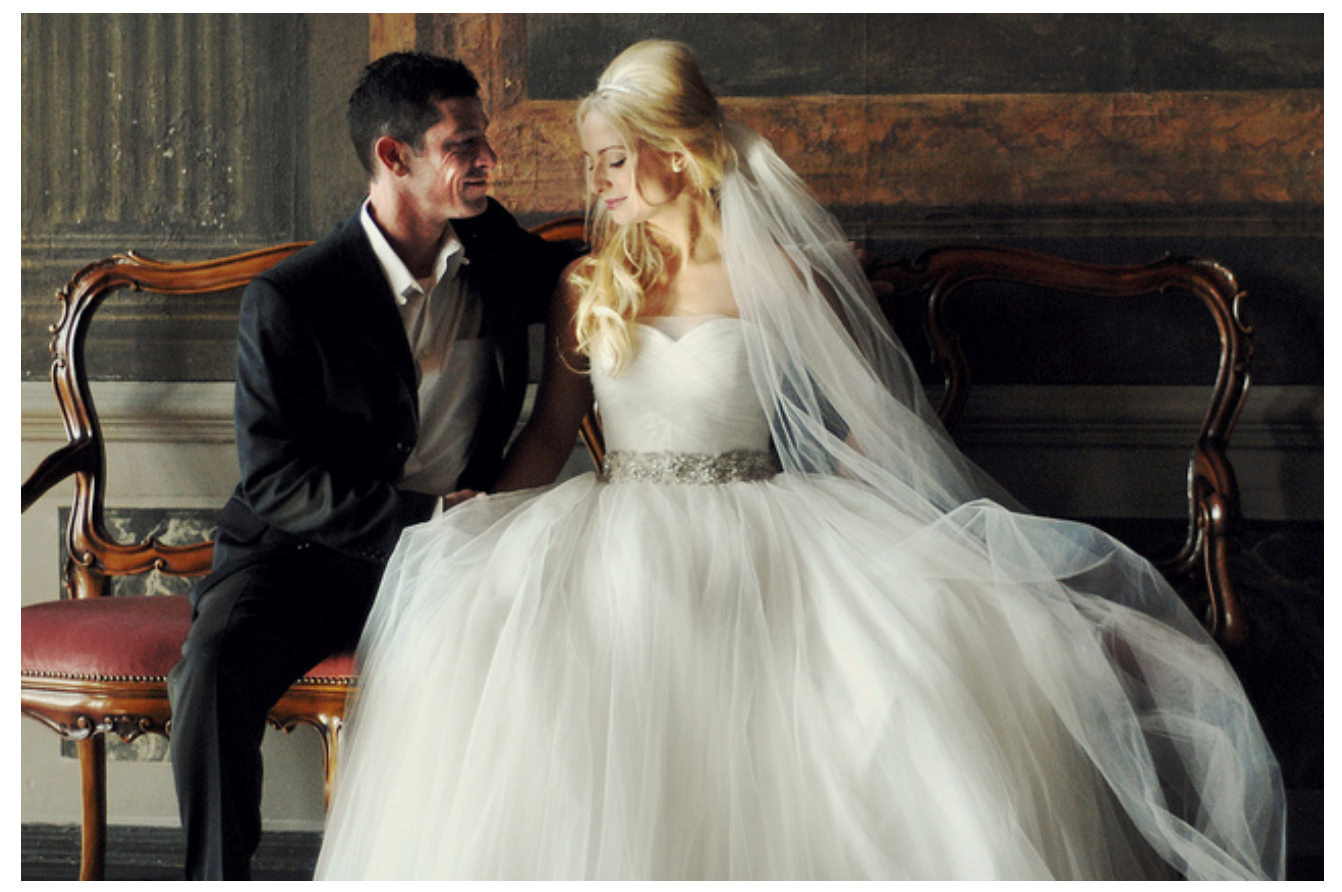

Married people are generally happier than unmarried people and score higher on other measures of psychological well-being.

Silvia Sala - CC BY-NC-ND 2.0.

Critics later said that Bernard misinterpreted her data on women and that married women are also better off than unmarried women (Glenn, 1997). Recent research generally finds that marriage does benefit both sexes: Married people, women and men alike, are generally happier than unmarried people (whether never married, divorced, or widowed), score better on other measures of psychological well-being, are physically healthier, have better sex lives, and have lower death rates (Waite et al., 2009; Wilcox, 2010). There is even evidence that marriage helps keep men from committing crime (Theobald \& Farrington, 2011)! Marriage has these benefits for several reasons, including the emotional and practical support spouses give each other, their greater financial resources compared to those of unmarried people, and the sense of obligation they have toward each other.

Three issues qualify the general conclusion that marriage is beneficial (Frech \& Williams, 2007). First, it would be more accurate to say that good marriages are beneficial, because bad marriages certainly are not, and stressful marriages can impair physical and mental health (Parker-Pope, 2010). Second, although marriage is generally beneficial, its benefits seem greater for older adults than for younger adults, for whites than for African Americans, and for individuals who were psychologically depressed before marriage than for those who were not depressed. Third, psychologically happy and healthy people may be the ones who get married in the first place and are less apt to get divorced once they do marry. If so, marriage does not promote psychological well-being; rather, psychological well-being promotes marriage. Research testing this selectivity hypothesis finds that both processes occur: Psychologically healthy people are more apt to get and stay married, but marriage also promotes psychological well-being. 


\section{Working Mothers and Day Care}

As noted earlier, women are now much more likely to be working outside the home than a few decades ago. This is true for both married and unmarried women and also for women with and without children. As women have entered the labor force, the question of who takes care of the children has prompted much debate and controversy. Many observers say young children suffer if they do not have a parent, implicitly their mother, taking care of them full-time until they start school and being there every day when they get home from school. The public is divided on the issue of more mothers working outside the home: 21 percent say this trend is "a good thing for society"; 37 percent say it is "a bad thing for society”; and 46 percent say it “doesn’t make much difference” (Morin, 2010). What does research say about how young children fare if their mothers work? (Notice that no one seems to worry that fathers work!)

Early studies compared the degree of attachment shown to their mothers by children in day care and that shown by children who stay at home with their mothers. In one type of study, children were put in a laboratory room with their mothers and observed as the mothers left and returned. The day-care kids usually treated their mothers' departure and returning casually and acted as if they did not care that their mothers were leaving or returning. In contrast the stay-at-home kids acted very upset when their mothers left and seemed much happier and even relieved when they returned. Several researchers concluded that these findings indicated that day-care children lacked sufficient emotional attachment to their mothers (Schwartz, 1983). However, other researchers reached a very different conclusion: The day-care children's apparent nonchalance when their mothers left and returned simply reflected the fact that they always saw her leave and return every day when they went to day care. The lack of concern over her behavior showed only that they were more independent and self-confident than the stayat-home children, who were fearful when their mothers left, and not that they were less attached to their mothers (Coontz, 1997).

More recent research has compared stay-at-home children and day-care children starting with infancy, with some of the most notable studies using data from a large study funded by the National Institute of Child Health and Human Development, a branch of the National Institutes of Health (Rabin, 2008). This research finds that daycare children exhibit better cognitive skills (reading and arithmetic) than stay-at-home children but are also slightly more likely to engage in aggressive behavior that is well within the normal range of children's behavior. This research has also yielded two other conclusions. First, the quality of parenting and other factors such as parent's education and income matter much more for children's cognitive and social development than whether or not they are in day care. Second, to the extent that day care is beneficial for children, it is high-quality day care that is beneficial, as low-quality day care can be harmful. 


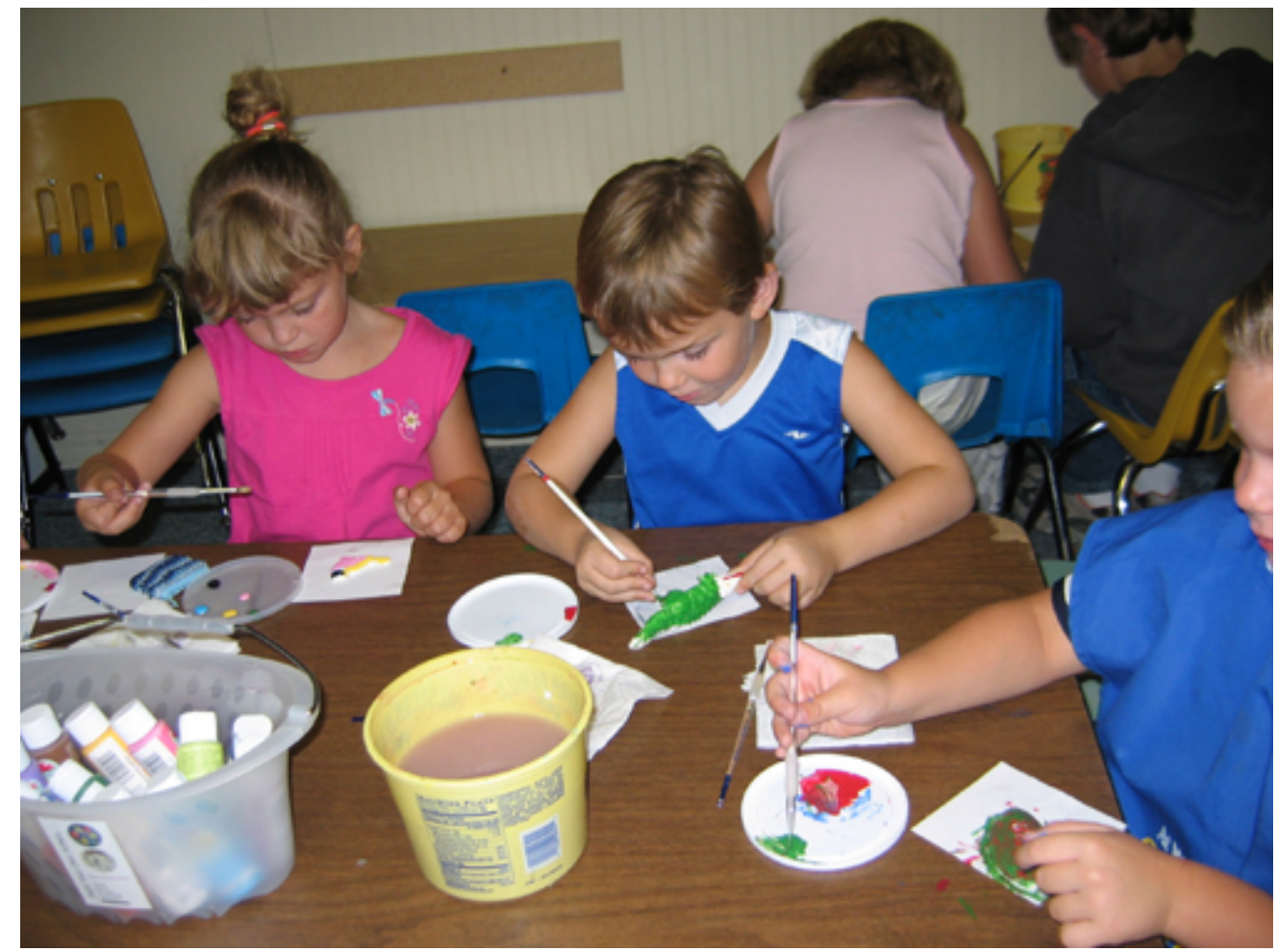

Children in day care exhibit better cognitive skills than stay-at-home children but are also slightly more likely to engage in aggressive behavior that is within the normal range of children's behavior.

njxw - Daycare - CC BY-NC-ND 2.0.

This latter conclusion is an important finding, because many day-care settings in the United States are not high quality. Unfortunately, many parents who use day care cannot afford high-quality care, which can cost hundreds of dollars monthly. This problem reflects the fact that the United States lags far behind other Western democracies in providing subsidies for day care (see Note 10.21 "Lessons from Other Societies" later in this chapter). Because working women are certainly here to stay and because high-quality day care seems at least as good for children as full-time care by a parent, it is essential that the United States make good day care available and affordable.

Affordable child care is especially essential for low-income parents. After the United States plunged into economic recession in 2008, many states reduced their subsidies for child care. As a result, many low-income parents who wanted to continue working or to start a job could not afford to do so because child care can be very expensive: For a family living below the poverty line, child care comprises one-third of the family budget on the average. As the head of a California organization that advocates for working parents explained, "You can't expect a family with young children to get on their feet and get jobs without child care” (Goodman, 2010, p. A1).

\section{Racial and Ethnic Diversity in Marriages and Families}

Marriages and families in the United States exhibit a fair amount of racial and ethnic diversity, as we saw earlier in this chapter. Children are more likely to live with only one parent among Latino and especially African American families than among white and Asian American families. Moreover, African American, Latino, and 
Native American children and their families are especially likely to live in poverty. As a result, they are at much greater risk for the many problems that children in poverty experience (see Chapter 2 "Poverty").

Beyond these cold facts lie other racial and ethnic differences in family life (Wright, Mindel, Tran, \& Habenstein, 2012). Studies of Latino and Asian American families find they have especially strong family bonds and loyalty. Extended families in both groups and among Native Americans are common, and these extended families have proven a valuable shield against the problems all three groups face because of their race/ethnicity and poverty.

The status of the African American family has been the source of much controversy for several decades. Perhaps the major reason for this controversy is the large number of African American children living in single-parent households: Whereas 41 percent of all births are to unmarried women (up from 28 percent in 1990), such births account for 72 percent of all births to African American women (see Figure 10.5 "Percentage of Births to Unmarried Mothers, by Race/Ethnicity 2010”).

Figure 10.5 Percentage of Births to Unmarried Mothers, by Race/Ethnicity 2010

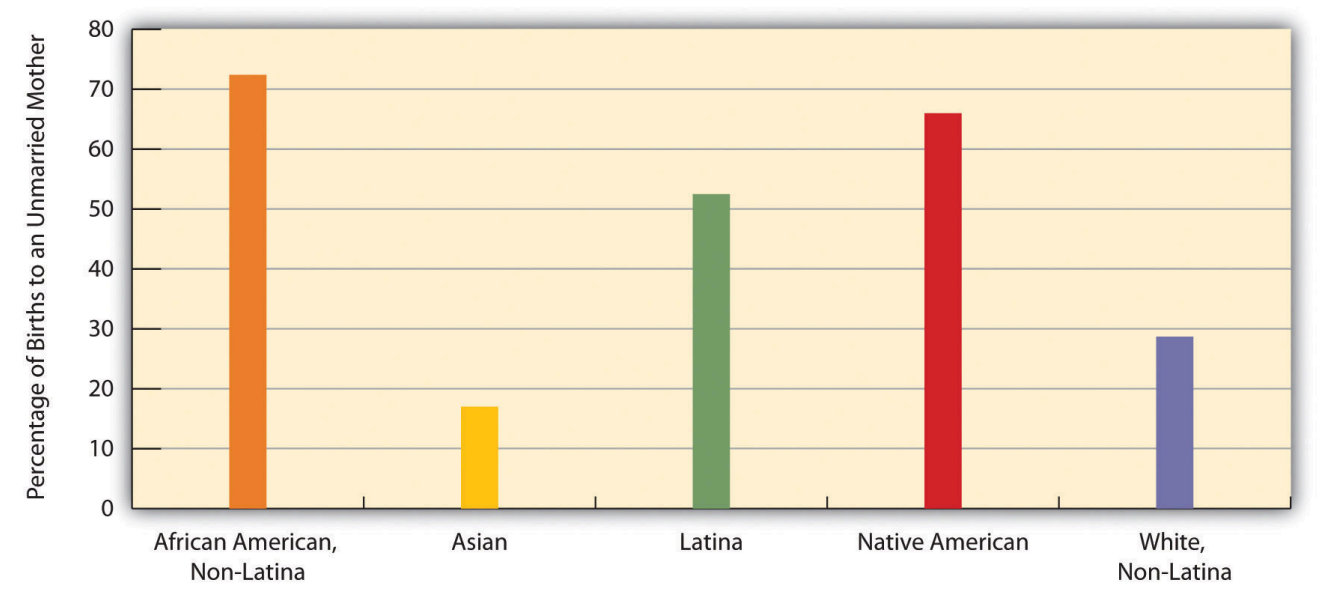

Source: Data from US Census Bureau. (2012). Statistical abstract of the United States: 2012. Washington, DC: US Government Printing Office. Retrieved from http://www.census.gov/compendia/statab.

Many scholars attribute the high number of fatherless families among African Americans to the forcible separation of families during slavery and to the fact that so many young black males today are unemployed, in prison or jail, or facing other problems (Patterson, 1998). Some observers say this high number of fatherless families in turn contributes to African Americans' poverty, crime, and other problems (Haskins, 2009). But other observers argue that this blame is misplaced to at least some extent. Extended families and strong female-headed households in the African American community, they say, have compensated for the absence of fathers (Willie \& Reddick, 2010). The problems African Americans face, they add, stem to a large degree from their experience of racism, segregated neighborhoods, lack of job opportunities, and other structural difficulties (Sampson, 2009). Even if fatherless families contribute to these problems, these scholars say, these other factors play a larger role.

\section{Family Violence}

Although family violence has received much attention since the 1970s, families were violent long before scholars 
began studying family violence and the public began hearing about it. We can divide family violence into two types: violence against intimates (spouses, live-in partners, boyfriends, or girlfriends) and violence against children. (Violence against elders also occurs and was discussed in Chapter 6 “Aging and Ageism”.)

\section{Violence against Intimates}

Intimates commit violence against each other in many ways: they can hit with their fists, slap with an open hand, throw an object, push or shove, or use or threaten to use a weapon. When all these acts and others are combined, we find that much intimate violence occurs. While we can never be certain of the exact number of intimates who are attacked, the US Department of Justice estimates from its National Crime Victimization Survey (NCVS) that about 509,000 acts of violence (2010 data) are committed annually by one intimate against another intimate; 80 percent of these acts are committed by men against women (Truman, 2011). Another national survey about a decade ago found that 22 percent of US women had been physically assaulted by a spouse or partner at some point in their lives (Tjaden \& Thoennes, 1998). This figure, if still true, translates to more than 20 million women today. A national survey of Canadian women found that 29 percent had been attacked by a spouse or partner (Randall \& Haskell, 1995). Taken together, these different figures all indicate that intimate partner violence is very common and affects millions of people.

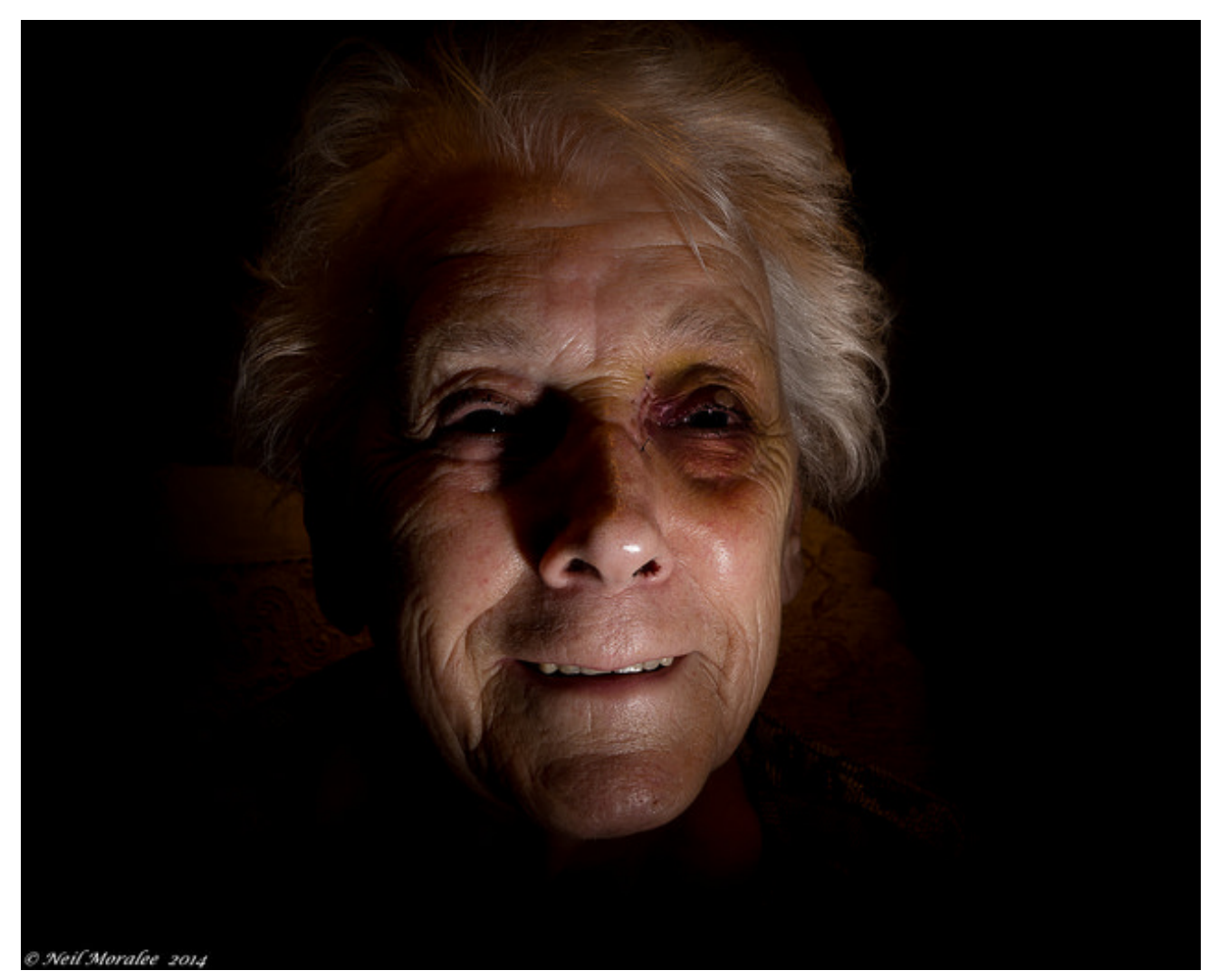

According to some estimates, about one-fifth of US women have been assaulted by a spouse or partner at least once in their lives.

Neil Moralee - Not Defeated. - CC BY 2.0.

Some observers claim that husbands are just as likely as wives to be beaten by a spouse, and there is evidence 
that husbands experience an act of violence from their wives about as often as wives do from their husbands. Yet this "gender equivalence" argument has been roundly criticized. Although women do commit violence against husbands and boyfriends, their violence is less serious (e.g., a slap compared to using a fist) and usually in selfdefense to their husbands' violence. And although some studies find an equal number of violent acts committed by husbands and wives, other studies find much more violence committed by husbands (Johnson, 2006).

Why do men hit their wives, partners, and girlfriends? As with rape (see Chapter 4 "Gender Inequality"), sociologists answer this question by citing both structural and cultural factors. Structurally, women are the subordinate gender in a patriarchal society and, as such, are more likely to be victims of violence, whether it is rape or intimate violence. Intimate violence is more common in poor families, and economic inequality thus may lead men to take out their frustration over their poverty on their wives and girlfriends (Martin, Vieraitis, \& Britto, 2006).

Cultural myths also help explain why men hit their wives and girlfriends (Gosselin, 2010). Many men continue to believe that their wives should not only love and honor them but also obey them, as the traditional marriage vow says. If they view their wives in this way, it becomes that much easier to hit them. In another myth, many people ask why women do not leave home if the hitting they suffer is really that bad; the implication is that the hitting cannot be that bad because they do not leave home. This reasoning ignores the fact that many women do try to leave home, which often angers their husbands and ironically puts the women more at risk for being hit, or they do not leave home because they have nowhere to go (Kim \& Gray, 2008). As the news story that began this chapter discussed, battered women's shelters are still few in number and can accommodate a woman and her children for only two or three weeks. Many battered women also have little money of their own and simply cannot afford to leave home. The belief that battering cannot be that bad if women hit by their husbands do not leave home ignores all these factors and is thus a myth that reinforces spousal violence against women. (See Note 10.15 "People Making a Difference" for a profile of the woman who started the first women's shelter.)

\section{People Making a Difference}

The Founder of the First Battered Women's Shelter

Sandra Ramos deserves our thanks because she founded the first known shelter for battered women in North America back in the late 1970s.

Her life changed one night in 1970 when she was only 28 years old and working as a waitress at a jazz club. One night a woman from her church in New Jersey came to her home seeking refuge from a man who was abusing her. Ramos took in the woman and her children and soon did the same with other abused women and their children. Within a few months, twenty-two women and children were living inside her house. "It was kind of chaotic," recalls Maria, 47, the oldest of Ramos's three children. "It was a small house; we didn't have a lot of room. But she reaches out to people she sees suffering. She does everything in her power to help them."

When authorities threatened to arrest Ramos if she did not remove all these people from her home, she conducted sit-ins and engaged in other actions to call attention to the women's plight. She eventually won county funding to start the first women's shelter.

Today Ramos leads a New Jersey nonprofit organization, Strengthen Our Sisters, that operates several shelters and halfway houses for battered women. Her first shelter and these later ones have housed thousands of women and children since the late 1970s, and at any one time today they house about 180 women and their children.

One woman whom Ramos helped was Geraldine Wright, who was born in the Dominican Republic. Wright says she 
owes Ramos a great debt. "Sandy makes you feel like, OK, you're going through this, but it's going to get better," she says. "One of the best things I did for myself and my children was come to the shelter. She helped me feel strong, which I usually wasn't. She helped me get a job here at the shelter so that I could find a place and pay the rent.”

Since that first woman knocked on her door in 1970, Sandra Ramos has worked unceasingly for the rights and welfare of abused women. She has fittingly been called "one of the nation's most well-known and tireless advocates on behalf of battered women.” For more than forty years, Sandra Ramos has made a considerable difference.

Source: Llorente, 2009

\section{Child Abuse}

Child abuse takes many forms. Children can be physically or sexually assaulted, and they may also suffer from emotional abuse and practical neglect. Whatever form it takes, child abuse is a serious national problem.

It is especially difficult to know how much child abuse occurs. Infants obviously cannot talk, and toddlers and older children who are abused usually do not tell anyone about the abuse. They might not define it as abuse, they might be scared to tell on their parents, they might blame themselves for being abused, or they might not know whom they could talk to about their abuse. Whatever the reason, they usually remain silent, thus making it very difficult to know how much abuse takes place. 


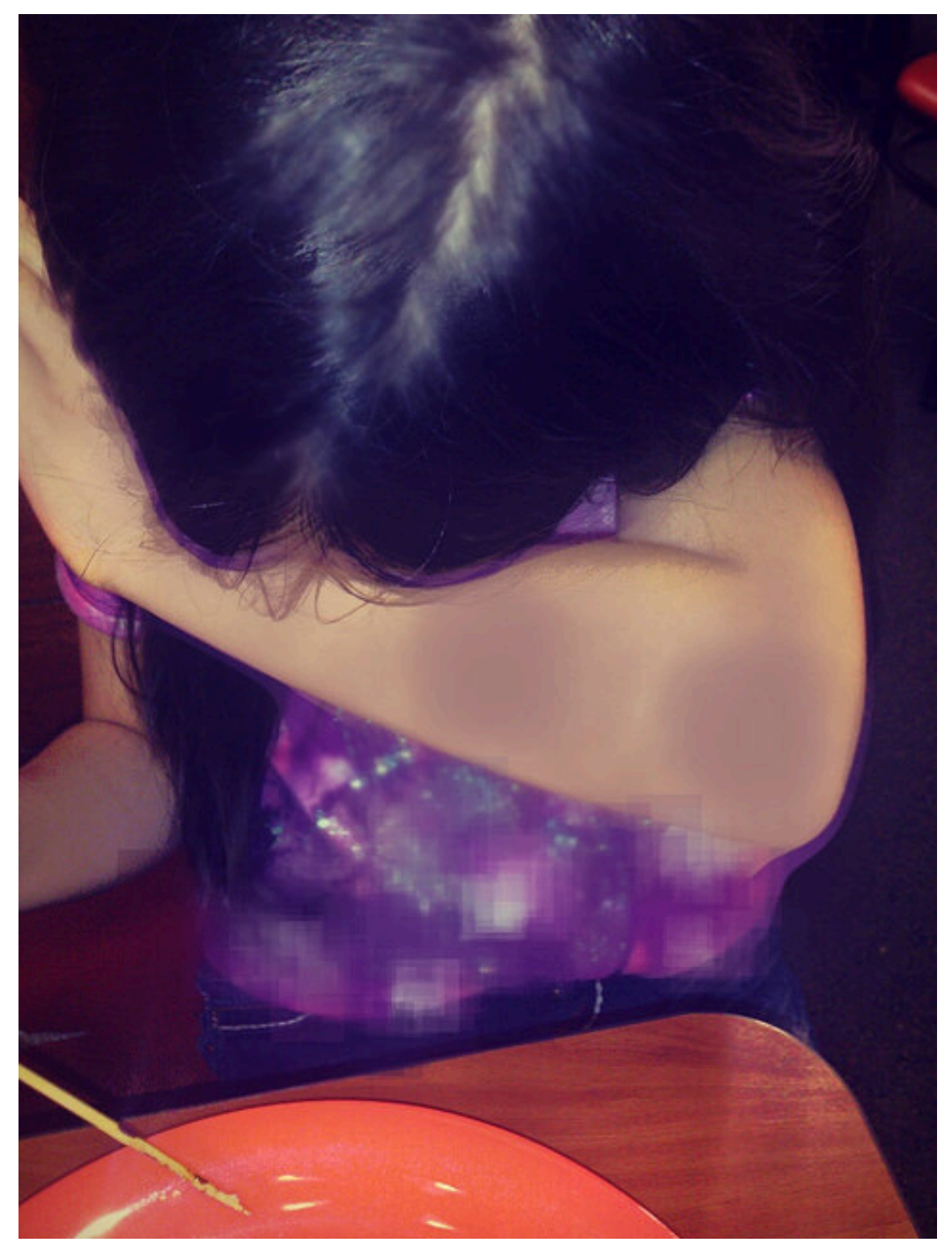

Government data estimate that about 800,000 children are abused or neglected each year. Because most children do not report their abuse or neglect, the actual number is probably much higher.

Jane Fox - Child Abuse mental - CC BY-ND 2.0.

Using information from child protective agencies throughout the country, the US Department of Health and Human Services estimates that almost 800,000 children (2008 data) are victims of child abuse and neglect annually (Administration on Children Youth and Families, 2010). This figure includes some 122,000 cases of physical abuse; 69,000 cases of sexual abuse; 539,000 cases of neglect; 55,000 cases of psychological maltreatment; and 17,000 cases of medical neglect. The total figure represents about 1 percent of all children under the age of 18. Obviously this is just the tip of the iceberg, as many cases of child abuse never become known. A 1994 Gallup poll asked adult respondents about physical abuse they suffered as children. Twelve percent said they had been abused (punched, kicked, or choked), yielding an estimate of 23 million adults in the United States who were physically abused as children (D. W. Moore, 1994). Some studies estimate that about 25 percent of girls and 10 percent of boys are sexually abused at least once before turning 18 (Garbarino, 1989). In a study of a random sample of women in Toronto, Canada, 42 percent said they had been sexually abused before 
turning 16 (Randall \& Haskell, 1995). Whatever the true figure is, most child abuse is committed by parents, stepparents, and other people the children know, not by strangers.

\section{Children and Our Future}

\section{Is Spanking a Good Idea?}

As the text discusses, spanking underlies many episodes of child abuse. Nonetheless, many Americans approve of spanking. In the 2010 General Social Survey, 69 percent of respondents agreed that "it is sometimes necessary to discipline a child with a good, hard, spanking." Reflecting this "spare the rod and spoil the child" belief, most parents have spanked their children. National survey evidence finds that two-thirds of parents of toddlers ages 19-35 months have spanked their child at least once, and one-fourth spank their child sometimes or often.

The reason that many people approve of spanking and that many parents spank is clear: They believe that spanking will teach a child a lesson and improve a child's behavior and/or attitude. However, most child and parenting experts believe the opposite is true. When children are spanked, they say, and especially when they are spanked regularly, they are more likely to misbehave as a result. If so, spanking ironically produces the opposite result from what a parent intends.

Spanking has this effect for several reasons. First, it teaches children that they should behave to avoid being punished. This lesson makes children more likely to misbehave if they think they will not get caught, as they'd not learn to behave for its own sake. Second, spanking also teaches children that it is OK to hit someone to solve an interpersonal dispute and even to hit someone if you love her or him, because that is what spanking is all about. Third, children who are spanked may come to resent their parents and thus be more likely to misbehave because their bond with their parents weakens.

This harmful effect of spanking is especially likely when spanking is frequent. As Alan Kazin, a former president of the American Psychological Association (APA) explains, "Corporal punishment has really serious side effects. Children who are hit become more aggressive.” When spanking is rare, this effect may or may not occur, according to research on this issue, but this research also finds that other forms of discipline are as effective as a rare spanking in teaching a child to behave. This fact leads Kazin to say that even rare spanking should be avoided. "It suppresses [misbehavior] momentarily. But you haven’t really changed its probability of occurring. Physical punishment is not needed to change behavior. It's just not needed."

Sources: Berlin et al., 2009; Harder, 2007; Park, 2010; Regalado, Sareen, Inkelas, Wissow, \& Halfon, 2004

Why does child abuse occur? Structurally speaking, children are another powerless group and, as such, are easy targets of violence. Moreover, the best evidence indicates that child abuse is more common in poorer families. The stress these families suffer from their poverty is thought to be a major reason for the child abuse occurring within them (Gosselin, 2010). As with spousal violence, then, economic inequality is partly to blame for child abuse. Cultural values and practices also matter. In a nation where spanking is common, it is inevitable that physical child abuse will occur, because there is a very thin line between a hard spanking and physical abuse: Not everyone defines a good, hard spanking in the same way. As two family violence scholars once noted, “Although most physical punishment [of children] does not turn into physical abuse, most physical abuse begins as ordinary physical punishment” (Wauchope \& Straus, 1990, p. 147). (See Note 10.17 “Children and Our Future” for a further discussion of spanking.)

Abused children are much more likely than children who are not abused to end up with various developmental, psychological, and behavioral problems throughout their life course. In particular, they are more likely to be aggressive, to use alcohol and other drugs, to be anxious and depressed, and to get divorced if they marry (Trickett, Noll, \& Putnam, 2011). 


\section{Key Takeaways}

- The divorce rate rose for several reasons during the 1960s and 1970s but has generally leveled off since then.

- Divorce often lowers the psychological well-being of spouses and their children, but the consequences of divorce also depend on the level of contention in the marriage that has ended.

- Despite continuing controversy over the welfare of children whose mothers work outside the home, research indicates that children in high-quality day care fare better in cognitive development than those who stay at home.

- Violence between intimates is fairly common and stems from gender inequality, income inequality, and several cultural myths that minimize the harm that intimate violence causes.

- At least 800,000 children are abused or neglected each year in the United States. Because most abused children do not report the abuse, the number of cases of abuse and neglect is undoubtedly much higher.

\section{For Your Review}

1. Think of someone you know (either yourself, a relative, or a friend) whose parents are divorced. Write a brief essay in which you discuss how the divorce affected this person.

2. Do you think it is ever acceptable for a spouse to slap or hit another spouse? Why or why not?

\section{References}

Administration on Children Youth and Families. (2010). Child maltreatment 2008. Washington, DC: US Department of Health and Human Services.

Amato, P. R., \& Hohmann-Marriott, B. (2007). A comparison of high- and low-distress marriages that end in divorce. Journal of Marriage \& Family, 69(3), 621-638.

Apel, R., \& Kaukinen, C. (2008). On the relationship between family structure and antisocial behavior: Parental cohabitation and blended households. Criminology, 46(1), 35-70.

Berlin, L. J., Ispa, J. M., Fine, M. A., Malone, P. S., Brooks-Gunn, J., Brady-Smith, C., et al. (2009). Correlates and consequences of spanking and verbal punishment for low-income white, African American, and Mexican American toddlers. Child Development, 80(5), 1403-1420.

Bernard, J. (1972). The future of marriage. New York, NY: Bantam.

Booth, A., Scott, M. E., \& King, V. (2010). Father residence and adolescent problem behavior: Are youth always better off in two-parent families? Journal of Family Issues, 31(5), 585-605. 
Brown, S. L. (2005). How cohabitation is reshaping American families. Contexts, 4(3), 33-37.

Brown, S. L., \& Bulanda, J. R. (2008). Relationship violence in young adulthood: A comparison of daters, cohabitors, and marrieds. Social Science Research, 37(1), 73-87.

Cherlin, A. J. (2009). The origins of the ambivalent acceptance of divorce. Journal of Marriage \& Family, 71(2), 226-229.

Clarke-Stewart, A., \& Brentano, C. (2006). Divorce: Causes and consequences. New Haven, CT: Yale University Press.

Coontz, S. (1997). The way we really are: Coming to terms with America's changing families. New York, NY: Basic Books.

Demo, D. H., \& Fine, M. A. (2010). Beyond the average divorce. Thousand Oaks, CA: Sage Publications.

DeNavas-Walt, C., Proctor, B. D., \& Smith, J. C. (2011). Income, poverty, and health insurance coverage in the United States: 2010 (Current Population Reports, P60-239). Washington, DC: US Census Bureau.

Frech, A., \& Williams, K. (2007). Depression and the psychological benefits of entering marriage. Journal of Health and Social Behavior, 48, 149-163.

Gadalla, T. M. (2008). Gender differences in poverty rates after marital dissolution: A longitudinal study. Journal of Divorce \& Remarriage, 49(3/4), 225-238.

Garbarino, J. (1989). The incidence and prevalence of child maltreatment. In L. Ohlin \& M. Tonry (Eds.), Family violence (Vol. 11, pp. 219-261). Chicago, IL: University of Chicago Press.

Glenn, N. D. (1997). A Critique of twenty family and marriage and the family textbooks. Family Relations, 46, 197-208.

Goodman, P. S. (2010, May 24). Cuts to child care subsidy thwart more job seekers. New York Times, p. A1.

Gosselin, D. K. (2010). Heavy hands: An introduction to the crimes of family violence (4th ed.). Upper Saddle River, NJ: Prentice Hall.

Harder, B. (2007, February 19). Spanking: When parents lift their hands. Los Angeles Times. Retrieved from http://articles.latimes.com/2007/feb/19/health/he-spanking19.

Haskins, R. (2009). Moynihan was right: Now what? The Annals of the American Academy of Political and Social Science, 621, 281-314.

Hiedemann, B., Suhomlinova, O., \& O’Rand, A. M. (1998). Economic independence, economic status, and empty nest in midlife marital disruption. Journal of Marriage and the Family, 60, 219-231.

Hull, K. E., Meier, A., \& Ortyl, T. (2012). The changing landscape of love and marriage. In D. Hartmann \& C. Uggen (Eds.), The contexts reader (2nd ed., pp. 56-63). New York, NY: W. W. Norton. 
Johnson, M. P. (2006). Conflict and control: Gender symmetry and asymmetry in domestic violence. Violence Against Women, 12, 1003-1018.

Jose, A., O’Leary, K. D., \& Moyer, A. (2010). Does premarital cohabitation predict subsequent marital stability and marital quality? A meta-analysis. Journal of Marriage \& Family, 72(1), 105-116.

Kim, J., \& Gray, K. A. (2008). Leave or stay? Battered women's decision after intimate partner violence. Journal of Interpersonal Violence, 23(10), 1465-1482.

Kneip, T., \& Bauer, G. (2009). Did unilateral divorce laws raise divorce rates in Western Europe? Journal of Marriage \& Family, 71(3), 592-607.

Li, J.-C. A. (2010). Briefing paper: The impact of divorce on children’s behavior problems. In B. J. Risman (Ed.), Families as they really are (pp. 173-177). New York, NY: W. W. Norton.

Llorente, E. (2009). Strengthening her sisters. Retrieved November 2, 2011, from http://www.aarp.org/givingback/volunteering/info-10-2009/strengthening_her_sisters.html.

Martin, K., Vieraitis, L. M., \& Britto, S. (2006). Gender equality and women's absolute status: A test of the feminist models of rape. Violence Against Women, 12, 321-339.

Moore, D. W. (1994, May). One in seven Americans victim of child abuse. The Gallup Poll Monthly, 18-22.

Moore, K. A., Kinghorn, A., \& Bandy, T. (2011). Parental relationship quality and child outcomes across subgroups. Washington, DC: Child Trends.

Morin, R. (2010). The public renders a split verdict on changes in family structure. Washington, DC: Pew Research Center.

Park, A. (2010). The long-term effects of spanking. Time International (Atlantic Edition), 175(18), 95-95.

Parker-Pope, T. (2010, April 18). Is marriage good for your health? The New York Times Sunday Magazine, p. MM46.

Patterson, O. (1998). Rituals of blood: Consequences of slavery in two American centuries. Washington, DC: Civitas/CounterPoint.

Rabin, R. C. (2008, September 15). A consensus about day care: Quality counts. New York Times, p. A1.

Randall, M., \& Haskell, L. (1995). Sexual violence in women's lives: Findings from the Women’s Safety Project, a community-based survey. Violence Against Women, 1, 6-31.

Regalado, M., Sareen, H., Inkelas, M., Wissow, L. S., \& Halfon, N. (2004). Parents’ discipline of young children: Results from the national survey of early childhood health. Pediatrics, 113, 1952-1958.

Rutter, V. E. (2010). The case for divorce. In B. J. Risman (Ed.), Families as they really are (pp. 159-169). New York, NY: W. W. Norton. 
Sampson, R. J. (2009). Racial stratification and the durable tangle of neighborhood inequality. The Annals of the American Academy of Political and Social Science, 621, 260-280.

Schwartz, P. (1983). Length of day-care attendance and attachment behavior in eighteen-month-old infants. Child Development, 54, 1073-1078.

Teachman, J. (2008). Complex life course patterns and the risk of divorce in second marriages. Journal of Marriage \& Family, 70(2), 294-305.

Theobald, D., \& Farrington, D. P. (2011). Why do the crime-reducing effects of marriage vary with age? British Journal of Criminology, 51(1), 136-158.

Tjaden, P., \& Thoennes, N. (1998). Prevalence, incidence, and consequences of violence against women: Findings from the national violence against women survey. Washington, DC: US Department of Justice.

Trickett, P. K., Noll, J. G., \& Putnam, F. W. (2011). The impact of sexual abuse on female development: Lessons from a multigenerational, longitudinal research study. Development and Psychopathology, 23(2), 453-476.

Truman, J. L. (2011). Criminal victimization, 2010. Washington, DC: Bureau of Justice Statistics.

Waite, L. J., Luo, Y., \& Lewin, A. C. (2009). Marital happiness and marital stability: Consequences for psychological well-being. Social Science Research, 38(1), 201-212

Wauchope, B., \& Straus, M. A. (1990). Physical punishment and physical abuse of American children: Incidence rates by age, gender, and occupational class. In M. A. Straus \& R. J. Gelles (Eds.), Physical violence in American families: Risk factors and adaptations to violence in 8,145 families (pp. 133-148). New Brunswick, NJ: Transaction Books.

Wilcox, W. B. (Ed.). (2010). The state of our unions 2010: Marriage in America. Charlottesville, VA: National Marriage Project.

Willie, C. V., \& Reddick, R. J. (2010). A new look at black families (6th ed.). Lanham, MD: Rowman \& Littlefield. Wright, R. H., Jr., Mindel, C. H., Tran, T. V., \& Habenstein, R. W. (Eds.). (2012). Ethnic families in America: Patterns and variations (5th ed.). Upper Saddle River, NJ: Pearson. 


\subsection{Families in the Future}

\section{Learning Objective}

1. Understand the implications of social science theory and research for how to address family problems.

As perhaps our most important social institution, the family seems to arouse strong passions from almost everyone. Sociological theory and research, along with research from the other social sciences, have important implications for how our society should address the various family issues discussed in this chapter.

One set of implications concerns the many children and families living in poverty. The households in which they live are mostly headed by women, and the majority of these households are the result of divorce. The programs and policies outlined in Chapter 2 "Poverty" are certainly relevant for any efforts to help these families. These efforts include, but are not limited to, increased government financial support, subsidies for child care, vocational training and financial aid for schooling for women who wish to return to the labor force or to increase their wages, early childhood visitation and intervention programs, and increases in programs providing nutrition and medical care to poor women and their children (Cherlin, 2009). In all these efforts, the United States has much to learn from the nations of Western Europe (see Note 10.21 “Lessons from Other Societies”).

\section{Lessons from Other Societies}

Putting Families First: Helping Families in Western Europe

The nations of Western Europe make a much greater effort than the United States to help families with young children. According to sociologist James W. Russell, these nations believe that taking care of their children is a communal responsibility because "society as a whole benefits from having children adequately reared. Children grow up to take over the responsibilities of maintaining the survival of the society. They will also be available to provide needed services to both their own parents and aging adults who did not raise their own children. An aging adult who did not have children may need the services of a younger doctor who was raised by someone else.” In contrast, says Russell, the United States tends to believe that families need to be self-reliant and should not expect very much help from the government. This difference in philosophy leads Western European nations to provide much more support than the United States for families with young children.

This support takes several forms whose nature and extent vary among the Western European nations. Most of the nations, for example, provide at least four months of paid maternity leave after the birth of a child; in contrast, the United States guarantees only three months of unpaid leave, and only for employees who work for companies that employ at least fifty people. Many European nations also provide paid parental leave after the maternity leave benefits expire; the Untied States does not provide this benefit. In Sweden, parents share 450 days of paid leave to care for a new child.

In another striking difference from the United States, all European nations have a family allowance program, which provides cash payments to parents for every child they have after their first child. The intent here is to not only help these families, but also to encourage them to have children to help counter declining birth rates in Europe. 
A third very important difference is that European nations provide free or heavily subsidized child care of generally high quality to enable parents to work outside the home. For example, France provides free child care for children ages 2-6 and pays 75 percent of the cost of child care for children under 2.

In these and other ways, the nations of Western Europe help their families with young children and thus their societies as a whole. The United States has much to learn from their example.

Sources: Russell, 2011; Shahmehri, 2007

Another issue and set of implications from social science research concern family violence. To the extent that much violence against intimates and children is rooted in the frustration and stress accompanying poverty, efforts that reduce poverty will also reduce family violence. And to the extent that gender inequality helps explain violence against women, continuing and strengthening efforts to reduce gender inequality should also reduce violence against intimates, as most of this violence is directed by men against women. Further, if, as many scholars believe, the violent nature of masculinity helps account for violence men commit against their wives and girlfriends, then efforts to change male gender-role socialization should also help.

Turning to child abuse, because so much child abuse remains unknown to child protective authorities, it is difficult to reduce its seriousness and extent. However, certain steps might still help. Because child abuse seems more common among poorer families, then efforts that reduce poverty should also reduce child abuse. The home visitation programs that help poor children also help reduce child abuse. Although, as noted earlier, approval of spanking is deeply rooted in our culture, a national educational campaign to warn about the dangers of spanking, including its promotion of children's misbehavior, may eventually reduce the use of spanking and thus the incidence of child physical abuse.

Divorce is a final issue for which research by sociologists and other scholars is relevant. Much evidence suggests that divorce from low-conflict marriages has negative consequences for spouses and children, and some evidence suggests that these consequences arise not from the divorce itself but rather from the conflict preceding the divorce and the poverty into which many newly single-parent households are plunged. There is also evidence that spouses and children fare better after a divorce from a highly contentious marriage. Efforts to help preserve marriages should certainly continue, but these efforts should proceed cautiously or not proceed at all for the marriages that are highly contentious. To the extent that marital conflict partly arises from financial difficulties, once again government efforts that help reduce poverty should also help preserve marriages.

\section{Key Takeaways}

- Efforts to help children and families living in poverty or near poverty should be expanded.

- Efforts to help preserve marriages should proceed cautiously or not at all for highly contentious marriages. 


\section{For Your Review}

1. Why do you think the United States lags behind other democracies in efforts to help families?

2. What do you think is the single most important policy or action that our government should take to help America's families?

\section{References}

Cherlin, A. J. (2009). The origins of the ambivalent acceptance of divorce. Journal of Marriage \& Family, 71(2), 226-229.

Russell, J. W. (2011). Double standard: Social policy in Europe and the United States (2nd ed.). Lanham, MD: Rowman \& Littlefield.

Shahmehri, B. (2007). More than welcome: Families come first in Sweden. In J. H. Skolnick \& E. Currie (Eds.), Crisis in American institutions (13th ed., pp. 204-209). Boston: Allyn \& Bacon. 


\subsection{End-of-Chapter Material}

\section{Summary}

1. As a social institution, the family is a universal or near-universal phenomenon. Yet historical and crosscultural records indicate that many types of families and family arrangements exist now and have existed in the past. Although the nuclear family has been the norm in many societies, in practice its use has been less common than many people think. Many societies have favored extended families, and in early times children could expect, because of the death of a parent or births out of wedlock, to live at least some part of their childhood with only one parent.

2. Almost one-third of American children live in one-parent families; this percentage varies by race and ethnicity. Some research finds that parents experience more stress and lower psychological well-being than nonparents.

3. Sociological perspectives on the family fall into the more general functional, conflict, and social interactionist approaches guiding sociological thought. Functional theory emphasizes the several functions that families serve for society, including the socialization of children and the economic and practical support of family members. Conflict theory emphasizes the ways in which nuclear families contribute to ongoing gender, class, and race inequality, while social interactionist approaches examine family communication and interaction to make sense of family life.

4. Scholars continue to debate the consequences of divorce and single-parent households for women, men, and their children. Several studies find that divorce and single parenting in and of themselves do not have the dire consequences for children that many observers assume. The low income of single-parent households, and not the absence of a second parent, seems to account for many of the problems that children in such households do experience. Women and children seem to fare better when a highly contentious marriage ends.

5. Despite ongoing concern over the effect on children of day care instead of full-time care by one parent, recent research finds that children in high-quality day care are not worse off than their stay-at-home counterparts. Some studies find that day-care children are more independent and self-confident than children who stay at home and that they perform better on various tests of cognitive ability.

6. Racial and ethnic diversity marks American family life. Controversy also continues to exist over the high number of fatherless families in the African American community. Many observers blame many of the problems African Americans face on their comparative lack of two-parent households, but other observers say this blame is misplaced.

7. Family violence affects millions of spouses and children yearly. Structural and cultural factors help account for the high amount of intimate violence and child abuse. Despite claims to the contrary, the best evidence indicates that women are much more at risk than men for violence by spouses and partners.

\section{Using What You Know}

You're working for a medium-sized corporation and have become friendly with one of your coworkers, Susan. One day she shows up at work with some bruises on the right side of her face. She looks upset, and when you ask her what 
happened, Susan replies that she slipped on the stairs at home and took a nasty fall. You suspect that her husband hit her and that she's not telling the truth about how she got hurt. What, if anything, do you say or do?

\section{What You Can Do}

To help deal with the family problems discussed in this chapter, you may wish to do any of the following:

1. Volunteer at a day-care center.

2. Volunteer at a battered women's shelter.

3. Start or join a group on your campus that addresses dating violence. 


\section{Chapter 11: Schools and Education}

\section{Social Problems in the News}

"Baltimore Students Lead Rally for Better School Facilities,” the headline said. On a crisp fall day, some 240 students, teachers, and parents held a rally at City Hall in Baltimore, Maryland, to call for massive improvements in the city's deteriorating schools. According to the news article, students displayed photos of decaying conditions in their schools and "spoke of horrific learning conditions: roaches, rodents, decaying roofs, rotting walls, sewage overflows, and inadequate heating and cooling systems." A high school senior said, "It's not that the teachers aren't the best, because they are, and it's not that the students are misbehaving. That's not it. We have buildings that you can't do anything with.” The president of Baltimore’s City Council agreed. "We owe it to our students to have state-of-the-art schools," he said. "Our school buildings are conducive to our kids' learning. If they go into school buildings that don't have running water, where bathrooms aren’t functioning properly, with outdated furniture and no books in the library, then what do we expect from our kids?”

Source: Burris, 2011

Charles Dickens's majestic novel, A Tale of Two Cities, begins with this unforgettable passage: "It was the best of times, it was the worst of times, it was the age of wisdom, it was the age of foolishness, it was the epoch of belief, it was the epoch of incredulity, it was the season of Light, it was the season of Darkness, it was the spring of hope, it was the winter of despair, we had everything before us, we had nothing before us, we were all going direct to heaven, we were all going direct the other way."

These words are timeless, and they certainly apply to the US education system today. In many ways it is the best of systems, but in many ways it is also the worst of systems. It teaches wisdom, but its many problems smack of foolishness. It fills many people with hope, but it also fills many people with despair. Some students have everything before them, but many also have nothing before them. In the wealthiest nation on the face of the earth, students in one of America's largest cities, Baltimore, attend schools filled with roaches and rodents and reeking of sewage. They are hardly alone, as students in cities across the nation could easily speak of similar ills. If Dickens were alive today, he might well look at our schools and conclude that "we were all going direct the other way."

Education is one of our most important social institutions. Youngsters and adolescents spend most of their weekday waking hours in school, doing homework, or participating in extracurricular activities, and many then go on to college. People everywhere care deeply about what happens in our nation's schools, and issues about the schools ignite passions across the political spectrum. Yet, as the opening news story about Baltimore's schools illustrates, many schools are poorly equipped to prepare their students for the complex needs of today's world.

This chapter's discussion of education begins with an overview of education in the United States and then turns to sociological perspectives on education. The remainder of the chapter discusses education in today's society. This discussion highlights education as a source and consequence of various social inequalities and examines several key issues affecting the nation's schools and the education of its children. 
465 Social Problems

\section{References}

Burris, J. (2011, November 3). Baltimore students lead rally for better school facilities. The Baltimore Sun. Retrieved from http://articles.baltimoresun.com/2011-11-03/news/bs-md-ci-rally-facilities-20111103_1_schoolbuildings-baltimore-students-city-schools. 


\subsection{An Overview of Education in the United States}

\section{Learning Objectives}

1. Explain why compulsory education arose during the nineteenth century.

2. Summarize social class, gender, and racial and ethnic differences in educational attainment.

3. Describe the impact that education has on income.

4. Explain how the US education system ranks internationally.

Education is the social institution through which a society teaches its members the skills, knowledge, norms, and values they need to learn to become good, productive members of their society. As this definition makes clear, education is an important part of socialization. Education is both formal and informal. Formal education is often referred to as schooling, and as this term implies, it occurs in schools under teachers, principals, and other specially trained professionals. Informal education may occur almost anywhere, but for young children it has traditionally occurred primarily in the home, with their parents as their instructors. Day care has become an increasingly popular venue in industrial societies for young children's instruction, and education from the early years of life is thus more formal than it used to be.

Education in early America was only rarely formal. During the colonial period, the Puritans in what is now Massachusetts required parents to teach their children to read and also required larger towns to have an elementary school, where children learned reading, writing, and religion. In general, though, schooling was not required in the colonies, and only about 10 percent of colonial children, usually just the wealthiest, went to school, although others became apprentices (Urban \& Wagoner, 2008).

To help unify the nation after the Revolutionary War, textbooks were written to standardize spelling and pronunciation and to instill patriotism and religious beliefs in students. At the same time, these textbooks included negative stereotypes of Native Americans and certain immigrant groups. The children going to school continued primarily to be those from wealthy families. By the mid-1800s, a call for free, compulsory education had begun, and compulsory education became widespread by the end of the century. This was an important development, as children from all social classes could now receive a free, formal education. Compulsory education was intended to further national unity and to teach immigrants “American” values. It also arose because of industrialization, as an industrial economy demanded reading, writing, and math skills much more than an agricultural economy had.

Free, compulsory education, of course, applied only to primary and secondary schools. Until the mid-1900s, very few people went to college, and those who did typically came from fairly wealthy families. After World War II, however, college enrollments soared, and today more people are attending college than ever before, even though college attendance is still related to social class, as we shall discuss shortly.

An important theme emerges from this brief history: Until very recently in the record of history, formal schooling 
was restricted to wealthy males. This means that boys who were not white and rich were excluded from formal schooling, as were virtually all girls, whose education was supposed to take place informally at home. Today, as we will see, race, ethnicity, social class, and, to some extent, gender continue to affect both educational achievement and the amount of learning occurring in schools.

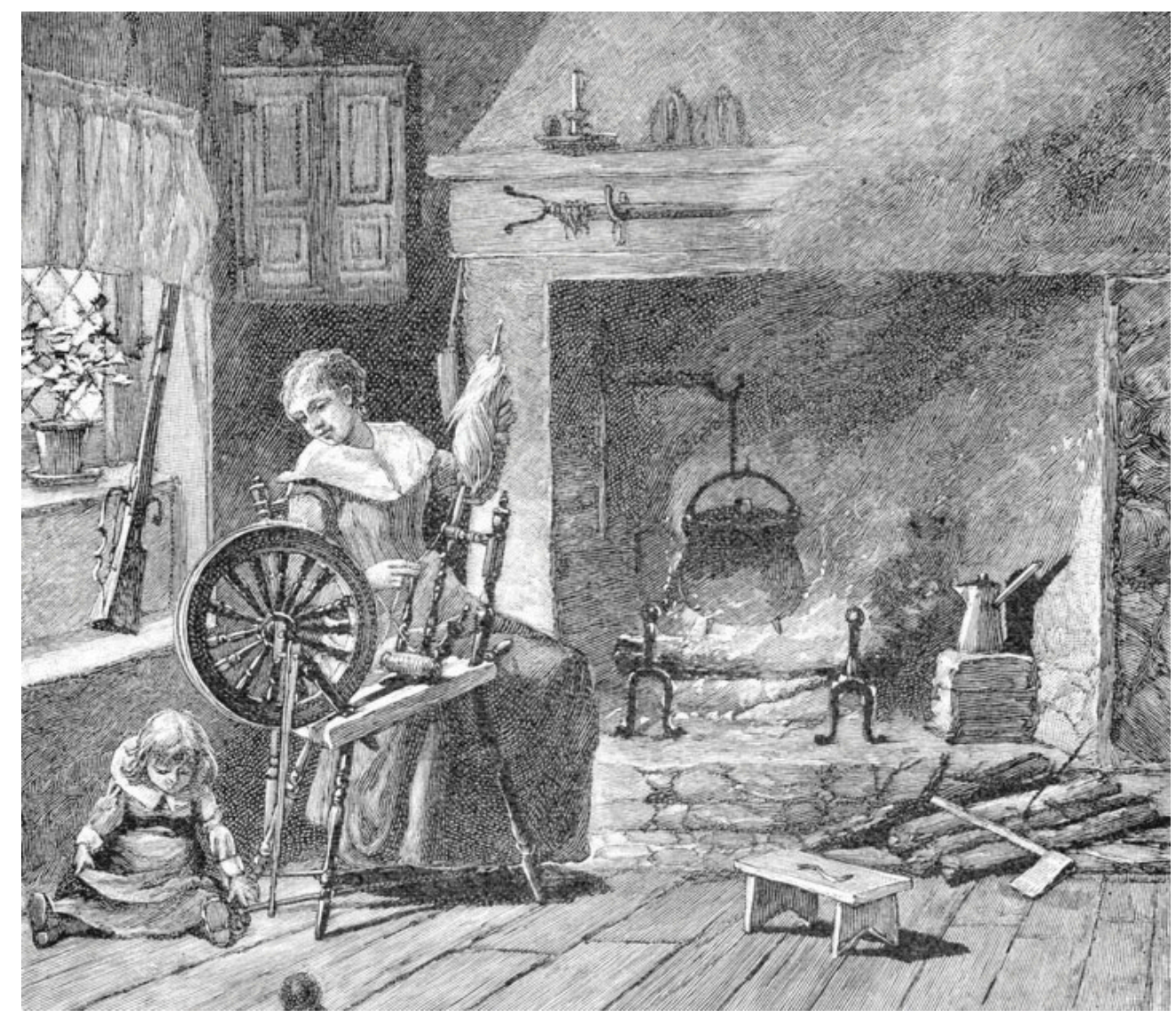

In colonial America, only about 10 percent of children went to school, and these children tended to come from wealthy families. After the Revolutionary War, new textbooks helped standardize spelling and pronunciation and promote patriotism and religious beliefs, but these textbooks also included negative stereotypes of Native Americans.

Wikimedia Commons - public domian.

\section{Education in the United States Today}

Education in the United States is a massive social institution involving millions of people and billions of dollars. More than 75 million people, almost one-fourth of the US population, attend school at all levels. This number includes 40 million in grades pre-K through eighth grade, 16 million in high school, and 20 million in college (including graduate and professional school). They attend some 132,000 elementary and secondary schools and about 4,200 two-year and four-year colleges and universities and are taught by about 4.8 million teachers and professors (US Census Bureau, 2012). 


\section{Correlates of Educational Attainment}

About 65 percent of US high school graduates enroll in college the following fall. This is a very high figure by international standards, as college in many other industrial nations is reserved for the very small percentage of the population who pass rigorous entrance exams. They are the best of the brightest in their nations, whereas higher education in the United States is open to all who graduate high school. Even though that is true, our chances of achieving a college degree are greatly determined at birth, as social class and race and ethnicity substantially affect who goes to college. They affect whether students drop out of high school, in which case they do not go on to college; they affect the chances of getting good grades in school and good scores on college entrance exams; they affect whether a family can afford to send its children to college; and they affect the chances of staying in college and obtaining a degree versus dropping out. For all these reasons, educational attainment—how far one gets in school—depends heavily on family income and race/ethnicity (Tavernise, 2012). Family income, in fact, makes a much larger difference in educational attainment than it did during the 1960s.

\section{Family Income and Race/Ethnicity}

Government data readily show the effects of family income and race/ethnicity on educational attainment. Let's first look at how race and ethnicity affect the likelihood of dropping out of high school. Figure 11.1 "Race, Ethnicity, and High School Dropout Rate, Persons Ages 16-24, 2009 (Percentage Not Enrolled in School and without a High School Degree)" shows the percentage of people ages 16-24 who are not enrolled in school and who have not received a high school degree. The dropout rate is highest for Latinos and Native Americans and lowest for Asians and whites.

Figure 11.1 Race, Ethnicity, and High School Dropout Rate, Persons Ages 16-24, 2009 (Percentage Not Enrolled in School and without a High School Degree)

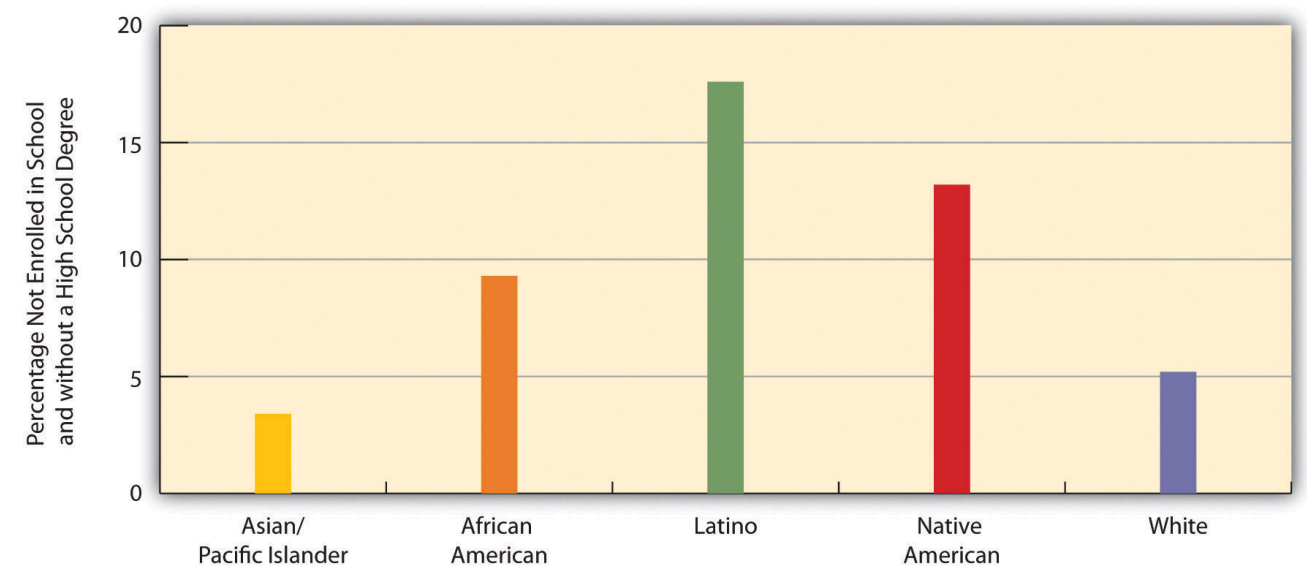

Source: Aud, S., Hussar, W., Kena, G., Bianco, K., Frohlich, L., Kemp, J., et al. (2011). The condition of education 2011. Washington,

DC: National Center for Education Statistics.

Now let's look at how family income affects the likelihood of attending college, a second benchmark of educational attainment. Figure 11.2 "Family Income and Percentage of High School Graduates Who Attend 
College Immediately after Graduation, 2009” shows the relationship between family income and the percentage of high school graduates who enroll in college immediately following graduation: Students from families in the highest income bracket are more likely than those in the lowest bracket to attend college. This “income gap” in college entry has become larger in recent decades (Bailey \& Dynarski, 2011).

Figure 11.2 Family Income and Percentage of High School Graduates Who Attend College Immediately after Graduation, 2009

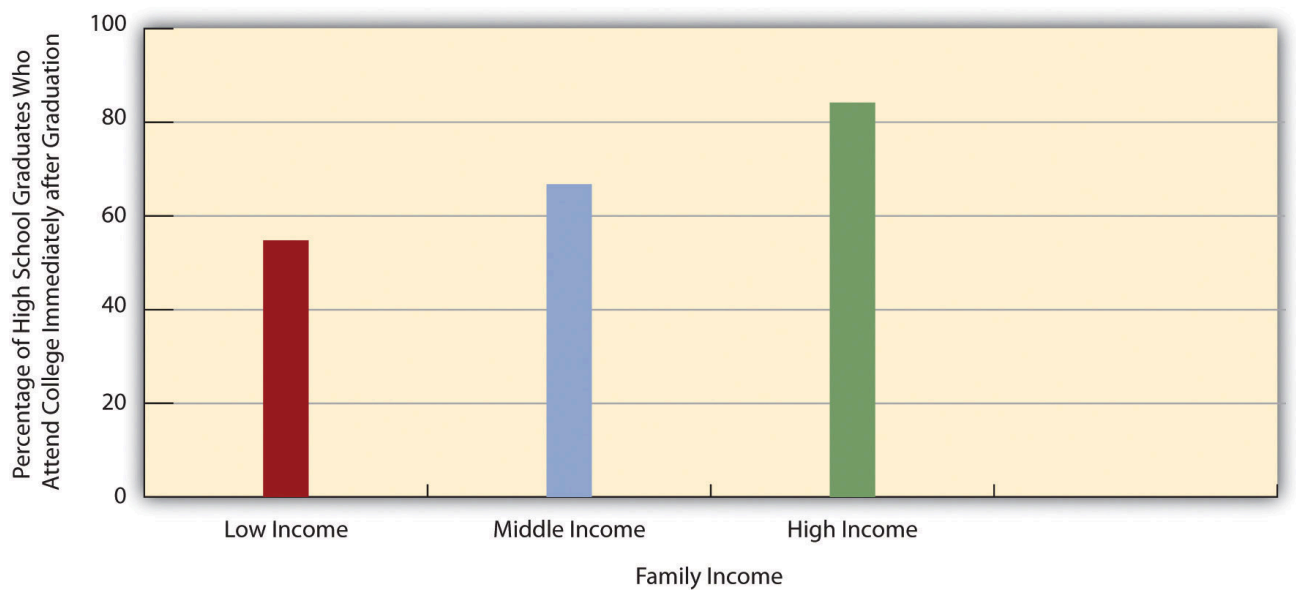

Source: Aud, S., Hussar, W., Kena, G., Bianco, K., Frohlich, L., Kemp, J., et al. (2011). The condition of education 2011. Washington, DC: National Center for Education Statistics.

Finally, let's examine how race and ethnicity affect the likelihood of obtaining a college degree, a third benchmark of educational attainment. Figure 11.3 "Race, Ethnicity, and Percentage of Persons Ages 25 or Older with a FourYear College Degree, 2010" shows the relationship between race/ethnicity and the percentage of persons 25 or older who have a bachelor's or master's degree. This relationship is quite strong, with African Americans and Latinos least likely to have a degree, and whites and especially Asians/Pacific Islanders most likely to have a degree.

Figure 11.3 Race, Ethnicity, and Percentage of Persons Ages 25 or Older with a Four-Year College Degree, 2010

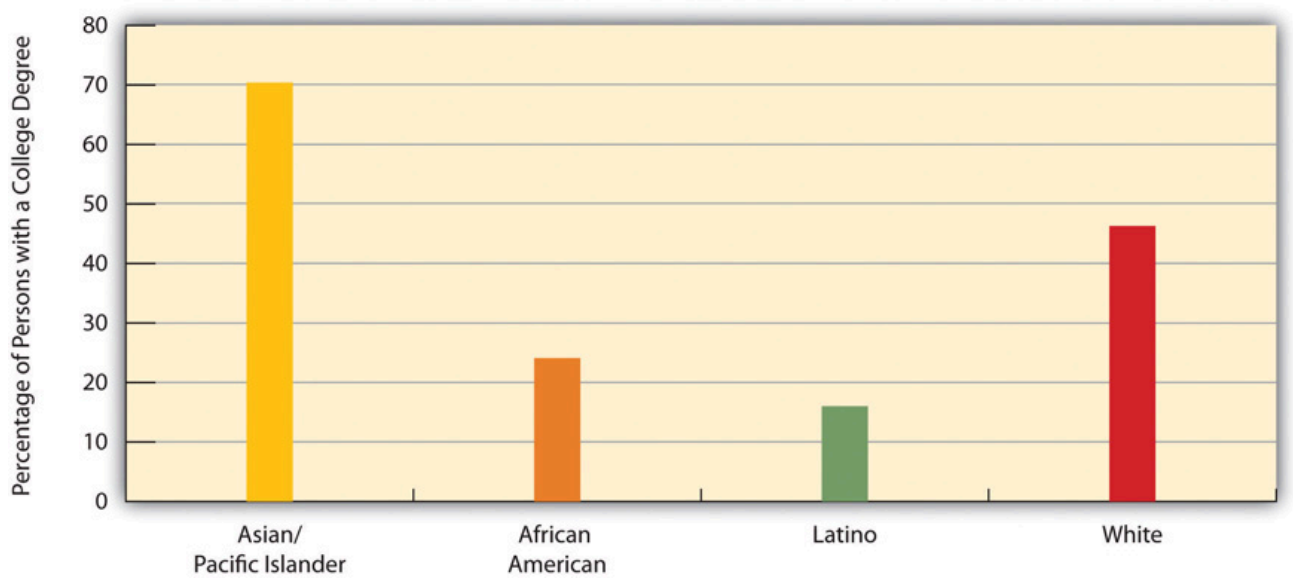

Source: Aud, S., Hussar, W., Kena, G., Bianco, K., Frohlich, L., Kemp, J., et al. (2011). The condition of education 2011. Washington, DC: National Center for Education Statistics. 


\section{Explaining the Racial/Ethnic Gap in Educational Attainment}

Why do African Americans and Latinos have lower educational attainment? Four factors are commonly cited: (a) the underfunded and otherwise inadequate schools that children in both groups often attend; (b) the higher poverty of their families and lower education of their parents that often leave children ill prepared for school even before they enter kindergarten; (c) racial discrimination; and (d) the fact that African American and Latino families are especially likely to live in very poor neighborhoods (Ballantine \& Hammack, 2012; Yeung \& Pfeiffer, 2009).

The last two factors, racial discrimination and residence in high-poverty neighborhoods, need additional explanation. At least three forms of racial discrimination impair educational attainment (Mickelson, 2003). The first form involves tracking. As we discuss later, students tracked into vocational or general curricula tend to learn less and have lower educational attainment than those tracked into a faster-learning, academic curriculum. Because students of color are more likely to be tracked "down” rather than "up," their school performance and educational attainment suffer.

The second form of racial discrimination involves school discipline. As we also discuss later, students of color are more likely than white students to be suspended, expelled, or otherwise disciplined for similar types of misbehavior. Because such discipline again reduces school performance and educational attainment, this form of discrimination helps explain the lower attainment of African American and Latino students.

The third form involves teachers' expectations of students. As our later discussion of the symbolic interactionist perspective on education examines further, teachers' expectations of students affect how much students learn. Research finds that teachers have lower expectations for their African American and Latino students, and that these expectations help to lower how much these students learn.

Turning to residence in high-poverty neighborhoods, it may be apparent that poor neighborhoods have lower educational attainment because they have inadequate schools, but poor neighborhoods matter for reasons beyond their schools' quality (Kirk \& Sampson, 2011; Wodtke, Harding, \& Elwert, 2011). First, because many adults in these neighborhoods are high school dropouts and/or unemployed, children in these neighborhoods lack adult role models for educational attainment. Second, poor neighborhoods tend to be racially and ethnically segregated. Latino children in these neighborhoods are less likely to speak English well because they lack native Englishspeaking friends, and African American children are more likely to speak "black English" than conventional English; both language problems impede school success.

Third, poor neighborhoods have higher rates of violence and other deviant behaviors than wealthier neighborhoods. Children in these neighborhoods thus are more likely to experience high levels of stress, to engage in these behaviors themselves (which reduces their attention and commitment to their schooling), and to be victims of violence (which increases their stress and can impair their neurological development). Crime in these neighborhoods also tends to reduce teacher commitment and parental involvement in their children's schooling. Finally, poor neighborhoods are more likely to have environmental problems such as air pollution and toxic levels of lead paint; these problems lead to asthma and other health problems among children (as well as adults), which impairs the children's ability to learn and do well in school.

For all these reasons, then, children in poor neighborhoods are at much greater risk for lower educational 
attainment. As a recent study of this risk concluded, "Sustained exposure to disadvantaged neighborhoods...throughout the entire childhood life course has a devastating impact on the chances of graduating from high school” (Wodtke et al., 2011, p. 731). If these neighborhoods are not improved, the study continued, "concentrated neighborhood poverty will likely continue to hamper the development of future generations of children” (Wodtke et al., 2011, p. 733).

\section{Gender}

Gender also affects educational attainment. If we do not take age into account, slightly more men than women have a college degree: 30.3 percent of men and 29.6 percent of women. This difference reflects the fact that women were less likely than men in earlier generations to go to college. But today there is a gender difference in the other direction: Women now earn more than 57 percent of all bachelor's degrees, up from just 35 percent in 1960 (see Figure 11.4 “Percentage of All Bachelor’s Degrees Received by Women, 1960-2009”). This difference reflects the fact that females are more likely than males to graduate high school, to attend college after high school graduation, and to obtain a degree after starting college (Bailey \& Dynarski, 2011).

Figure 11.4 Percentage of All Bachelor’s Degrees Received by Women, 1960-2009

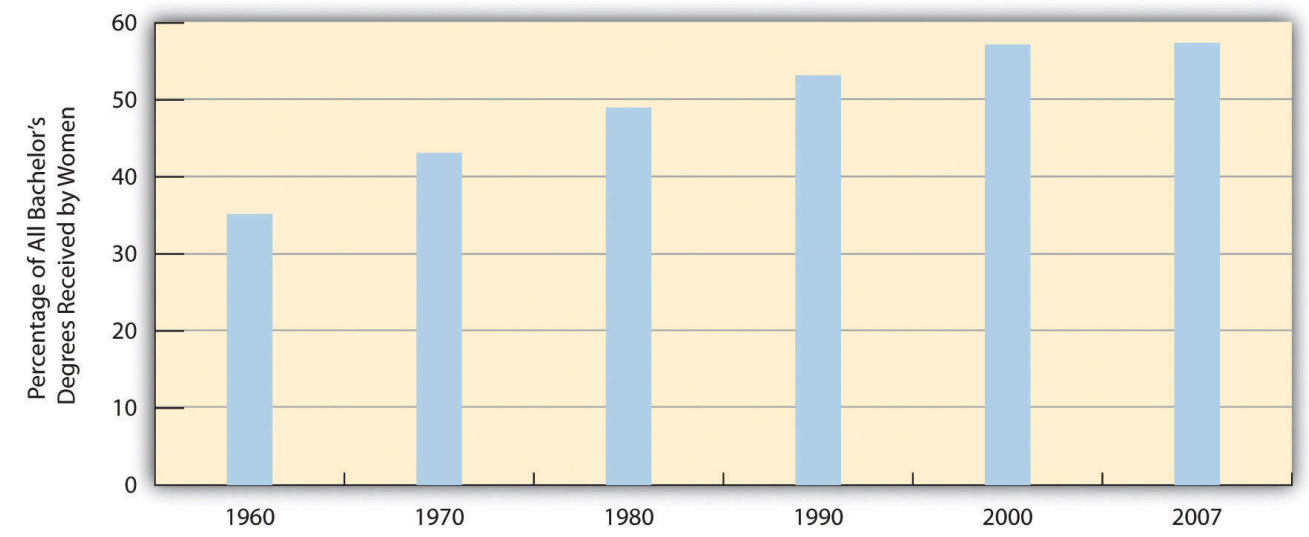

Source: Data from US Census Bureau. (2012). Statistical abstract of the United States: 2012. Washington, DC: US Government Printing Office. Retrieved from http://www.census.gov/compendia/statab.

\section{Impact of Education on Income}




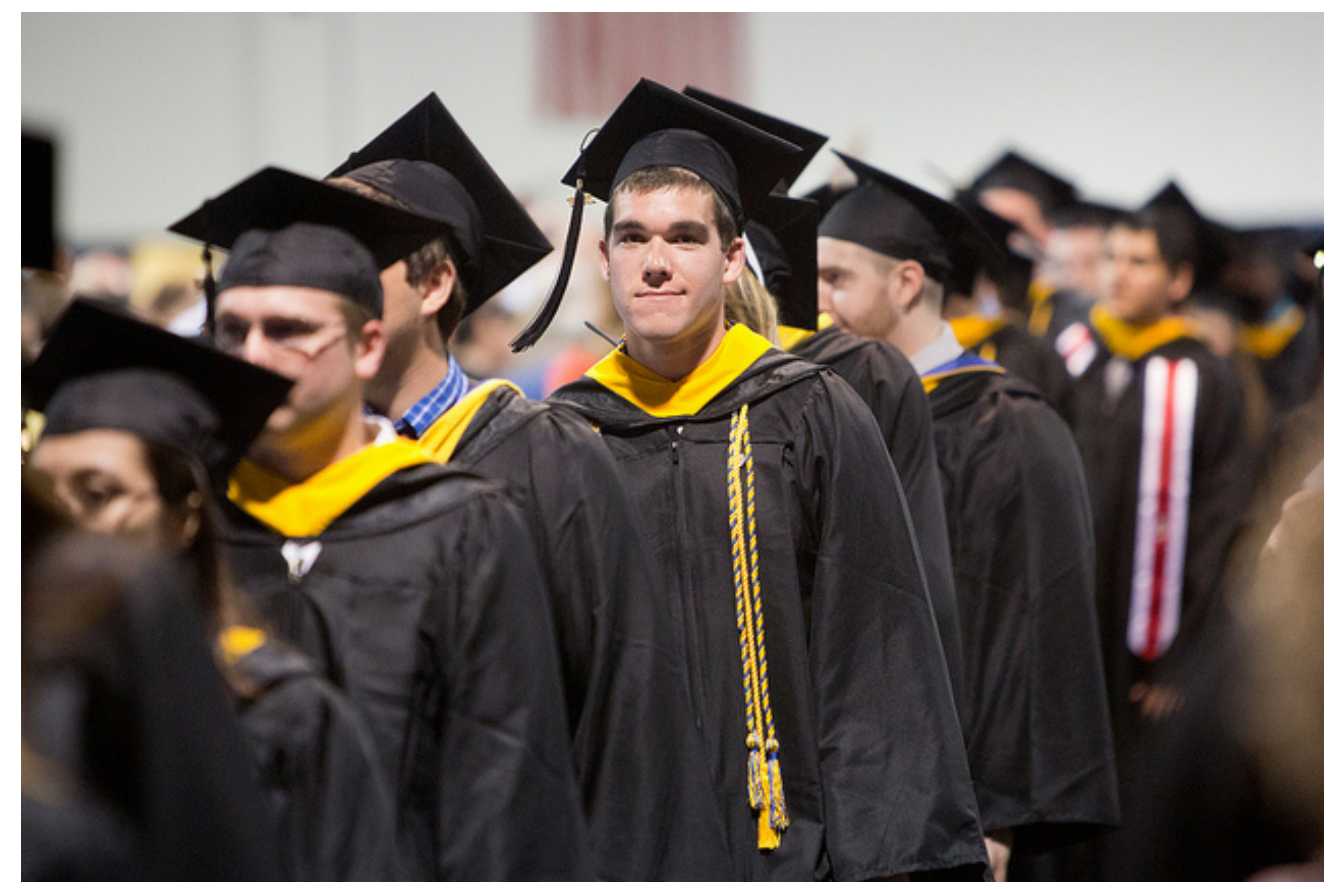

On the average, college graduates have much higher annual earnings than high school graduates. How much does this consequence affect why you decided to go to college?

Merrimack College - $\underline{\text { Commencement } 2012}$ - CC BY-NC-ND 2.0.

Have you ever applied for a job that required a high school degree? Are you going to college in part because you realize you will need a college degree for a higher-paying job? As these questions imply, the United States is a credential society (Collins, 1979). This means at least two things. First, a high school or college degree (or beyond) indicates that a person has acquired the needed knowledge and skills for various jobs. Second, a degree at some level is a requirement for most jobs. As you know full well, a college degree today is a virtual requirement for a decent-paying job. The ante has been upped considerably over the years: In earlier generations, a high school degree, if even that, was all that was needed, if only because so few people graduated from high school to begin with. With so many people graduating from high school today, a high school degree is not worth as much. Then too, today’s society increasingly requires skills and knowledge that only a college education brings.

A credential society also means that people with more formal education achieve higher incomes. Annual earnings are indeed much higher for people with more education (see Figure 11.5 "Educational Attainment and Median Annual Earnings, Ages 25-34, 2009”). As earlier chapters indicated, gender and race/ethnicity affect the payoff we get from our education, but education itself still makes a huge difference for our incomes. 


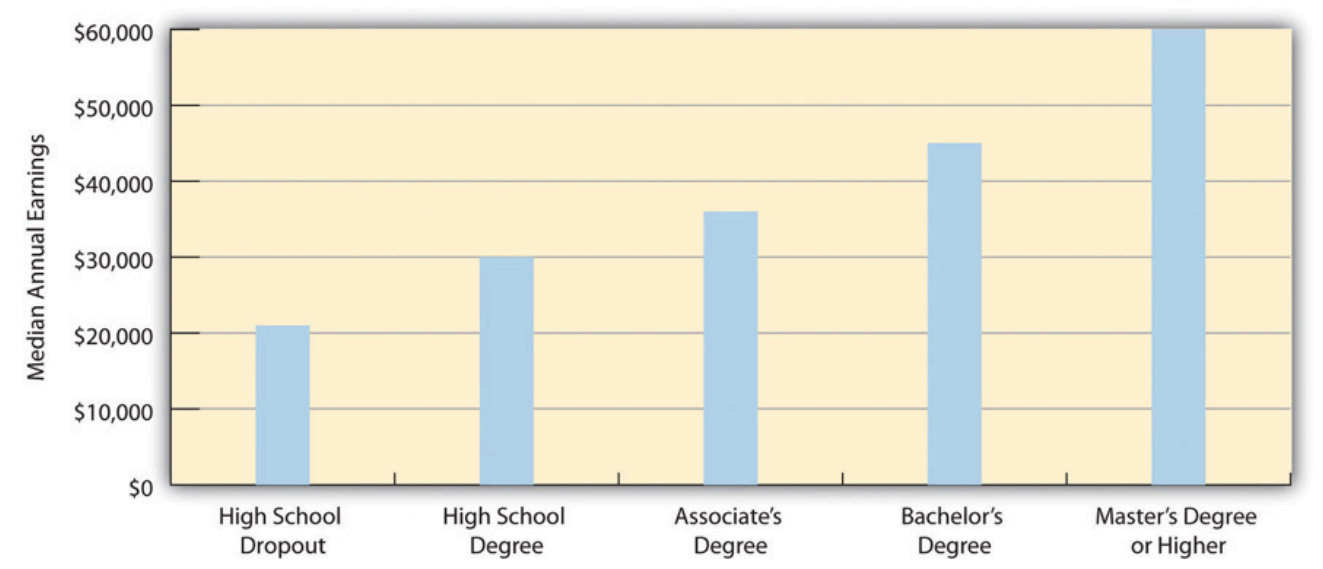

Source: Aud, S., Hussar, W., Kena, G., Bianco, K., Frohlich, L., Kemp, J., et al. (2011). The condition of education 2011. Washington,

DC: National Center for Education Statistics.

\section{Impact of Education on Mortality}

Beyond income, education also affects at what age people tend to die. Simply put, people with higher levels of education tend to die later in life, and those with lower levels tend to die earlier (Miech, Pampel, Kim, \& Rogers, 2011). The reasons for this disparity are complex, but two reasons stand out. First, more highly educated people are less likely to smoke and engage in other unhealthy activities, and they are more likely to exercise and to engage in other healthy activities and also to eat healthy diets. Second, they have better access to high-quality health care.

\section{How the US Education System Compares Internationally}

The United States has many of the top colleges and universities and secondary schools in the world, and many of the top professors and teachers. In these respects, the US education system is "the best of systems." But in other respects, it is "the worst of systems." When we compare educational attainment in the United States to that in the world's other democracies, the United States lags behind its international peers.

Differences in the educational systems of the world's democracies make exact comparisons difficult, but one basic measure of educational attainment is the percentage of a nation's population that has graduated high school. A widely cited comparison involves the industrial nations that are members of the Organisation for Economic Cooperation and Development (OECD). Of the twenty-eight nations for which OECD has high school graduation data, the United States ranks only twenty-first, with a graduation rate of 76 percent (Organisation for Economic Co-operation and Development, 2011). In contrast, several nations, including Finland, Ireland, Norway, Portugal, Switzerland, and the United Kingdom have graduation rates of at least 90 percent. If we limit the comparison to the OECD nations that compose the world's wealthy democracies (see Chapter 2 "Poverty") to which the United States is most appropriately compared, the United States ranks only thirteenth out of sixteen such nations.

OECD also collects and publishes data on proficiency in mathematics, reading, and science among 15-year-olds in its member nations (Organisation for Economic Co-operation and Development, 2010). In reading and science, 
the United States ranks only at the average for all OECD nations, while the US score for mathematics ranks below the OECD average. Compared to their counterparts in other industrial nations, then, American 15-year-olds are only average or below average for these three important areas of study. Taking into account high school graduation rates and these proficiency rankings, the United States is far from the world leader in the quality of education. The Note 11.8 "Lessons from Other Societies" box examines what the United States might learn from the sterling example of Finland's education system.

\section{Lessons from Other Societies}

\section{Successful Schooling in Finland}

Finland is widely regarded as having perhaps the top elementary and secondary education system in the world. Its model of education offers several important lessons for US education. As a recent analysis of Finland's schools put it, "The country's achievements in education have other nations doing their homework."

To understand the lessons to be learned from Finland, we should go back several decades to the 1970s, when Finland's education system was below par, with its students scoring below the international average in mathematics and science. Moreover, urban schools in Finland outranked rural schools, and wealthy students performed much better than lowincome students. Today, Finnish students rank at the top in international testing, and low-income students do almost as well as wealthy students.

Finland's education system ranks so highly today because it took several measures to improve its education system. First, and perhaps most important, Finland raised teachers' salaries, required all teachers to have a three-year master's degree, and paid all costs, including a living stipend, for the graduate education needed to achieve this degree. These changes helped to greatly increase the number of teachers, especially the number of highly qualified teachers, and Finland now has more teachers for every 1,000 residents than does the United States. Unlike the United States, teaching is considered a highly prestigious profession in Finland, and the application process to become a teacher is very competitive. The college graduates who apply for one of Finland's eight graduate programs in teaching typically rank in the top 10 percent of their class, and only 5-15 percent of their applications are accepted. A leading Finnish educator observed, "It's more difficult getting into teacher education than law or medicine." In contrast, US students who become teachers tend to have lower SAT scores than those who enter other professions, they only need a four-year degree, and their average salaries are lower than other professionals with a similar level of education.

Second, Finland revamped its curriculum to emphasize critical thinking skills, reduced the importance of scores on standardized tests and then eliminated standardized testing altogether, and eliminated academic tracking before tenth grade. Unlike the United States, Finland no longer ranks students, teachers, or schools according to scores on standardized tests because these tests are no longer given.

Third, Finland built many more schools to enable the average school to have fewer students. Today the typical school has fewer than three hundred students, and class sizes are smaller than those found in the United States.

Fourth, Finland increased funding of its schools so that its schools are now well maintained and well equipped. Whereas many US schools are decrepit, Finnish schools are decidedly in good repair.

Finally, Finland provided free medical and dental care for children and their families and expanded other types of social services, including three years of paid maternity leave and subsidized day care, as the country realized that children's health and home environment play critical roles in their educational achievement.

These and other changes helped propel Finland's education system to a leading position among the world's industrial nations. As the United States ponders how best to improve its own education system, it may have much to learn from Finland's approach to how children should learn.

Sources: Abrams, 2011; Anderson, 2011; Eggers \& Calegari, 2011; Hancock, 2011; Ravitch, 2012; Sahlberg, 2011 


\section{Key Takeaways}

- Until very recently in the record of history, formal schooling was restricted to wealthy males.

- Students from low-income backgrounds tend to have lower educational attainment than students from wealthier backgrounds.

- African Americans and Latinos tend to have lower educational attainment than non-Latino whites and Asians.

- Gender influences educational attainment in a complex fashion; older women have lower educational attainment than older men, but younger women have greater educational attainment than younger men.

- The United States ranks behind many other industrial nations in the quality of the education its citizens receive.

\section{For Your Review}

1. Do you think the government should take steps to try to reduce racial and ethnic differences in education, or do you think it should take a hands-off approach? Explain your answer.

2. Should the government require that children receive a formal education, as it now does, or should it be up to parents to decide whether their children should receive a formal education? Explain your answer.

\section{References}

Abrams, S. E. (2011, January 28). The children must play: What the United States could learn from Finland about education reform. The New Republic. Retrieved from http://www.tnr.com/article/politics/82329/education-reformFinland-US.

Anderson, J. (2011, December 13). From Finland, an intriguing school-reform model. New York Times, p. A33.

Bailey, M. J., \& Dynarski, S. (2011). Gains and gaps: Changing inequality in US college entry and completion. Ann Arbor, MI: Population Studies Center.

Ballantine, J. H., \& Hammack, F. M. (2012). The sociology of education: A systematic analysis (7th ed.). Upper Saddle River, NJ: Prentice Hall.

Collins, R. (1979). The credential society: An historical sociology of education and stratification. New York, NY: Academic Press.

Eggers, D., \& Calegari, N. C. (2011, May 1). The high cost of low teacher salaries. New York Times, p. WK12.

Hancock, L. (2011, September). Why are Finland's schools successful? Smithsonian. Retrieved from 
http://www.smithsonianmag.com/people-places/Why-Are-Finlands-Schools-

Successful.html?c=y\&story=fullstory.

Kirk, D. S., \& Sampson, R. J. (2011). Crime and the production of safe schools. In G. J. Duncan \& R. J. Murnane (Eds.), Whither opportunity?: Rising inequality, schools, and children's life chances (pp. 397-418). New York, NY: Russell Sage Foundation.

Mickelson, R. A. (2003). When are racial disparities in education the result of racial discrimination? A social science perspective. Teachers College Record, 105, pp. 1052-1086.

Miech, R., Pampel, F., Kim, J., \& Rogers, R. G. (2011). Education and mortality: The role of widening and narrowing disparities. American Sociological Review, 76, 913-934.

Organisation for Economic Co-operation and Development. (2011). How many students finish secondary education? Retrieved November 10, 2011, from http://www.oecd.org/dataoecd/62/3/48630687.pdf.

Organisation for Economic Co-operation and Development. (2010). PISA 2009 results: What students know and can do-Student performance in reading, mathematics and science (Vol. 1). Paris, France: Author.

Ravitch, D. (2012, March 8). Schools we can envy. The New York Review of Books. Retrieved from http://www.nybooks.com/articles/archives/2012/mar/08/schools-we-can-envy/.

Sahlberg, P. (2011). Finnish lessons: What can the world learn from educational change in Finland? New York, NY: Teachers College Press.

Tavernise, S. (2012, February 10). Education gap grows between rich and poor, studies say. New York Times, p. A1.

Urban, W. J., \& Wagoner, J. L., Jr. (2008). American education: A history (4th ed.). New York, NY: Routledge.

US Census Bureau. (2012). Statistical abstract of the United States: 2012. Washington, DC: US Government Printing Office. Retrieved from http://www.census.gov/compendia/statab.

Wodtke, G. T., Harding, D. J., \& Elwert, F. (2011). Neighborhood effects in temporal perspective: The impact of long-term exposure to concentrated disadvantage on high school graduation. American Sociological Review, 76(5), 713-736.

Yeung, W.-J. J., \& Pfeiffer, K. M. (2009). The black-white test score gap and early home environment. Social Science Research, 38(2), 412-437. 


\subsection{Sociological Perspectives on Education}

\section{Learning Objectives}

1. List the major functions of education.

2. Explain the problems that conflict theory sees in education.

3. Describe how symbolic interactionism understands education.

The major sociological perspectives on education fall nicely into the functional, conflict, and symbolic interactionist approaches (Ballantine \& Hammack, 2012). Table 11.1 "Theory Snapshot” summarizes what these approaches say.

Table 11.1 Theory Snapshot

\begin{tabular}{|l|l|}
$\begin{array}{l}\text { Theoretical } \\
\text { perspective }\end{array}$ & Major assumptions \\
\hline Functionalism & $\begin{array}{l}\text { Education serves several functions for society. These include (a) socialization, (b) social integration, (c) } \\
\text { social placement, and (d) social and cultural innovation. Latent functions include child care, the } \\
\text { establishment of peer relationships, and lowering unemployment by keeping high school students out of } \\
\text { the full-time labor force. Problems in the educational institution harm society because all these functions } \\
\text { cannot be completely fulfilled. }\end{array}$ \\
\hline $\begin{array}{l}\text { Conflict } \\
\text { theory }\end{array}$ & $\begin{array}{l}\text { Education promotes social inequality through the use of tracking and standardized testing and the impact } \\
\text { of its “hidden curriculum.” Schools differ widely in their funding and learning conditions, and this type of } \\
\text { inequality leads to learning disparities that reinforce social inequality. }\end{array}$ \\
\hline $\begin{array}{l}\text { Symbolic } \\
\text { interactionism }\end{array}$ & $\begin{array}{l}\text { This perspective focuses on social interaction in the classroom, on the playground, and in other school } \\
\text { venues. Specific research finds that social interaction in schools affects the development of gender roles } \\
\text { and that teachers' expectations of pupils' intellectual abilities affect how much pupils learn. Certain } \\
\text { educational problems have their basis in social interaction and expectations. }\end{array}$ \\
\hline
\end{tabular}

\section{The Functions of Education}

Functional theory stresses the functions that education serves in fulfilling a society's various needs. Perhaps the most important function of education is socialization. If children are to learn the norms, values, and skills they need to function in society, then education is a primary vehicle for such learning. Schools teach the three Rs (reading, 'riting, 'rithmetic), as we all know, but they also teach many of the society's norms and values. In the United States, these norms and values include respect for authority, patriotism (remember the Pledge of Allegiance?), punctuality, and competition (for grades and sports victories).

A second function of education is social integration. For a society to work, functionalists say, people must 
subscribe to a common set of beliefs and values. As we saw, the development of such common views was a goal of the system of free, compulsory education that developed in the nineteenth century. Thousands of immigrant children in the United States today are learning English, US history, and other subjects that help prepare them for the workforce and integrate them into American life.

A third function of education is social placement. Beginning in grade school, students are identified by teachers and other school officials either as bright and motivated or as less bright and even educationally challenged. Depending on how they are identified, children are taught at the level that is thought to suit them best. In this way, they are presumably prepared for their later station in life. Whether this process works as well as it should is an important issue, and we explore it further when we discuss school tracking later in this chapter.

Social and cultural innovation is a fourth function of education. Our scientists cannot make important scientific discoveries and our artists and thinkers cannot come up with great works of art, poetry, and prose unless they have first been educated in the many subjects they need to know for their chosen path.

Figure 11.6 The Functions of Education

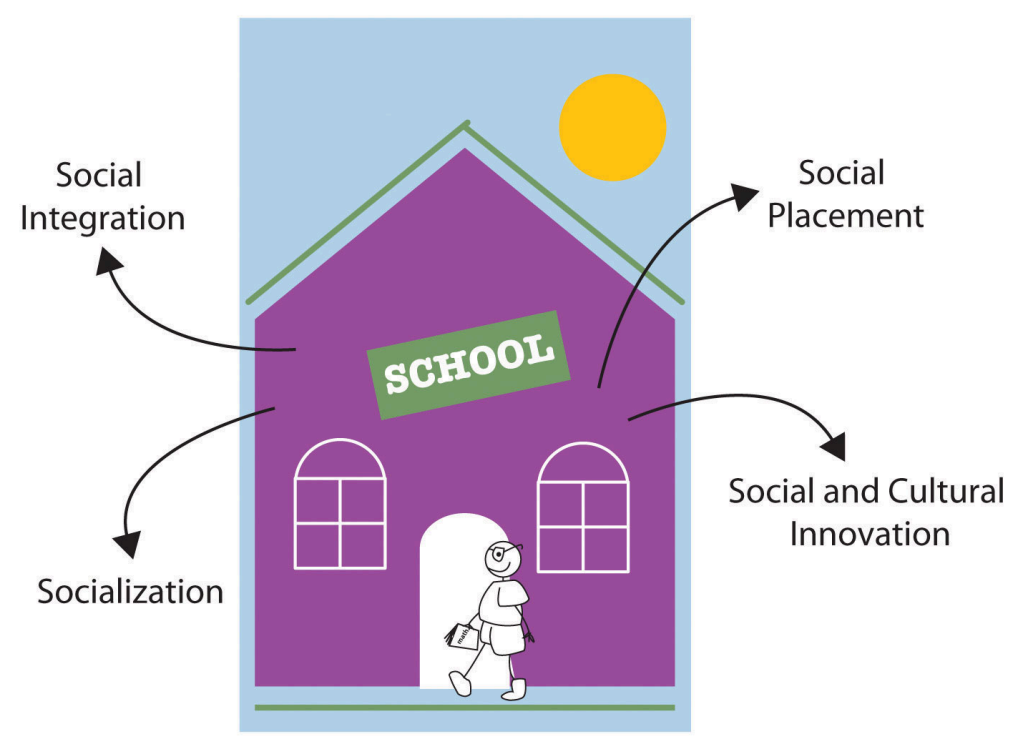

Schools ideally perform many important functions in modern society. These include socialization, social

integration, social placement, and social and cultural innovation.

Education also involves several latent functions, functions that are by-products of going to school and receiving an education rather than a direct effect of the education itself. One of these is child care: Once a child starts kindergarten and then first grade, for several hours a day the child is taken care of for free. The establishment of peer relationships is another latent function of schooling. Most of us met many of our friends while we were in school at whatever grade level, and some of those friendships endure the rest of our lives. A final latent function of education is that it keeps millions of high school students out of the full-time labor force. This fact keeps the unemployment rate lower than it would be if they were in the labor force.

Because education serves so many manifest and latent functions for society, problems in schooling ultimately 
harm society. For education to serve its many functions, various kinds of reforms are needed to make our schools and the process of education as effective as possible.

\section{Education and Inequality}

Conflict theory does not dispute the functions just described. However, it does give some of them a different slant by emphasizing how education also perpetuates social inequality (Ballantine \& Hammack, 2012). One example of this process involves the function of social placement. When most schools begin tracking their students in grade school, the students thought by their teachers to be bright are placed in the faster tracks (especially in reading and arithmetic), while the slower students are placed in the slower tracks; in high school, three common tracks are the college track, vocational track, and general track.

Such tracking does have its advantages; it helps ensure that bright students learn as much as their abilities allow them, and it helps ensure that slower students are not taught over their heads. But conflict theorists say that tracking also helps perpetuate social inequality by locking students into faster and lower tracks. Worse yet, several studies show that students' social class and race and ethnicity affect the track into which they are placed, even though their intellectual abilities and potential should be the only things that matter: White, middle-class students are more likely to be tracked "up," while poorer students and students of color are more likely to be tracked "down." Once they are tracked, students learn more if they are tracked up and less if they are tracked down. The latter tend to lose self-esteem and begin to think they have little academic ability and thus do worse in school because they were tracked down. In this way, tracking is thought to be good for those tracked up and bad for those tracked down. Conflict theorists thus say that tracking perpetuates social inequality based on social class and race and ethnicity (Ansalone, 2010).

Conflict theorists add that standardized tests are culturally biased and thus also help perpetuate social inequality (Grodsky, Warren, \& Felts, 2008). According to this criticism, these tests favor white, middle-class students whose socioeconomic status and other aspects of their backgrounds have afforded them various experiences that help them answer questions on the tests.

A third critique of conflict theory involves the quality of schools. As we will see later in this chapter, US schools differ mightily in their resources, learning conditions, and other aspects, all of which affect how much students can learn in them. Simply put, schools are unequal, and their very inequality helps perpetuate inequality in the larger society. Children going to the worst schools in urban areas face many more obstacles to their learning than those going to well-funded schools in suburban areas. Their lack of learning helps ensure they remain trapped in poverty and its related problems.

In a fourth critique, conflict theorists say that schooling teaches a hidden curriculum, by which they mean a set of values and beliefs that support the status quo, including the existing social hierarchy (Booher-Jennings, 2008). Although no one plots this behind closed doors, our schoolchildren learn patriotic values and respect for authority from the books they read and from various classroom activities.

A final critique is historical and concerns the rise of free, compulsory education during the nineteenth century (Cole, 2008). Because compulsory schooling began in part to prevent immigrants' values from corrupting “American” values, conflict theorists see its origins as smacking of ethnocentrism (the belief that one’s own group 
is superior to another group). They also criticize its intention to teach workers the skills they needed for the new industrial economy. Because most workers were very poor in this economy, these critics say, compulsory education served the interests of the upper/capitalist class much more than it served the interests of workers.

\section{Symbolic Interactionism and School Behavior}

Symbolic interactionist studies of education examine social interaction in the classroom, on the playground, and in other school venues. These studies help us understand what happens in the schools themselves, but they also help us understand how what occurs in school is relevant for the larger society. Some studies, for example, show how children's playground activities reinforce gender-role socialization. Girls tend to play more cooperative games, while boys play more competitive sports (Thorne, 1993) (see Chapter 4 “Gender Inequality”).

\section{Applying Social Research}

Assessing the Impact of Small Class Size

Do elementary school students fare better if their classes have fewer students rather than more students? It is not easy to answer this important question, because any differences found between students in small classes and those in larger classes might not necessarily reflect class size. Rather, they may reflect other factors. For example, perhaps the most motivated, educated parents ask that their child be placed in a smaller class and that their school goes along with this request. Perhaps teachers with more experience favor smaller classes and are able to have their principals assign them to these classes, while new teachers are assigned larger classes. These and other possibilities mean that any differences found between the two class sizes might reflect the qualities and skills of students and/or teachers in these classes, and not class size itself.

For this reason, the ideal study of class size would involve random assignment of both students and teachers to classes of different size. (Recall that Chapter 1 "Understanding Social Problems" discusses the benefits of random assignment.) Fortunately, a notable study of this type exists.

The study, named Project STAR (Student/Teacher Achievement Ratio), began in Tennessee in 1985 and involved 79 public schools and 11,600 students and 1,330 teachers who were all randomly assigned to either a smaller class (13-17 students) or a larger class (22-25 students). The random assignment began when the students entered kindergarten and lasted through third grade; in fourth grade, the experiment ended, and all the students were placed into the larger class size. The students are now in their early thirties, and many aspects of their educational and personal lives have been followed since the study began.

Some of the more notable findings of this multiyear study include the following:

- While in grades $\mathrm{K}-3$, students in the smaller classes had higher average scores on standardized tests.

- Students who had been in the smaller classes continued to have higher average test scores in grades 4-7.

- Students who had been in the smaller classes were more likely to complete high school and also to attend college.

- Students who had been in the smaller classes were less likely to be arrested during adolescence.

- Students who had been in the smaller classes were more likely in their twenties to be married and to live in wealthier neighborhoods.

- White girls who had been in the smaller classes were less likely to have a teenage birth than white girls who had been in the larger classes.

Why did small class size have these benefits? Two reasons seem likely. First, in a smaller class, there are fewer students 
to disrupt the class by talking, fighting, or otherwise taking up the teacher's time. More learning can thus occur in smaller classes. Second, kindergarten teachers are better able to teach noncognitive skills (cooperating, listening, sitting still) in smaller classes, and these skills can have an impact many years later.

Regardless of the reasons, it was the experimental design of Project STAR that enabled its findings to be attributed to class size rather than to other factors. Because small class size does seem to help in many ways, the United States should try to reduce class size in order to improve student performance and later life outcomes.

Sources: Chetty et al., 2011; Schanzenbach, 2006

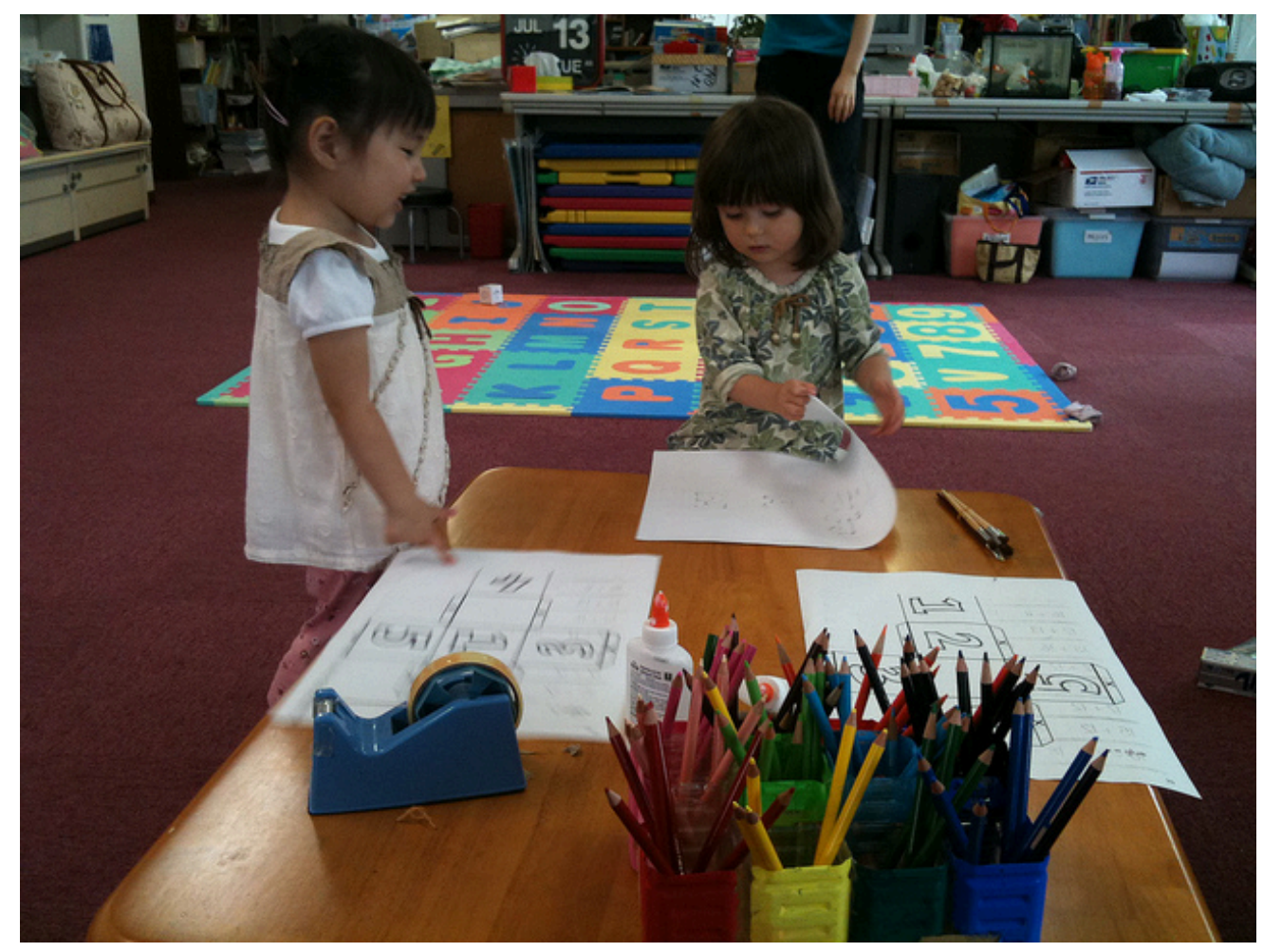

Research guided by the symbolic interactionist perspective suggests that teachers' expectations may influence how much their students learn. When teachers expect little of their students, their students tend to learn less.

ijiwaru jimbo - Pre-school colour pack - CC BY-NC-ND 2.0.

Another body of research shows that teachers' views about students can affect how much the students learn. When teachers think students are smart, they tend to spend more time with these students, to call on them, and to praise them when they give the right answer. Not surprisingly, these students learn more because of their teachers' behavior. But when teachers think students are less bright, they tend to spend less time with these students and to act in a way that leads them to learn less. Robert Rosenthal and Lenore Jacobson (1968) conducted a classic study of this phenomenon. They tested a group of students at the beginning of the school year and told their teachers which students were bright and which were not. They then tested the students again at the end of the school year. Not surprisingly, the bright students had learned more during the year than the less bright ones. But it turned out that the researchers had randomly decided which students would be designated bright and less bright. Because the "bright" students learned more during the school year without actually being brighter at the beginning, their teachers' behavior must have been the reason. In fact, their teachers did spend more time with them and praised 
them more often than was true for the "less bright" students. This process helps us understand why tracking is bad for the students tracked down.

Other research in the symbolic interactionist tradition focuses on how teachers treat girls and boys. Many studies find that teachers call on and praise boys more often (Jones \& Dindia, 2004). Teachers do not do this consciously, but their behavior nonetheless sends an implicit message to girls that math and science are not for them and that they are not suited to do well in these subjects. This body of research has stimulated efforts to educate teachers about the ways in which they may unwittingly send these messages and about strategies they could use to promote greater interest and achievement by girls in math and science (Battey, Kafai, Nixon, \& Kao, 2007).

\section{Key Takeaways}

- According to the functional perspective, education helps socialize children and prepare them for their eventual entrance into the larger society as adults.

- The conflict perspective emphasizes that education reinforces inequality in the larger society.

- The symbolic interactionist perspective focuses on social interaction in the classroom, on school playgrounds, and at other school-related venues. Social interaction contributes to gender-role socialization, and teachers' expectations may affect their students’ performance.

\section{For Your Review}

1. Review how the functionalist, conflict, and symbolic interactionist perspectives understand and explain education. Which of these three approaches do you most prefer? Why?

\section{References}

Ansalone, G. (2010). Tracking: Educational differentiation or defective strategy. Educational Research Quarterly, 34(2), 3-17.

Ballantine, J. H., \& Hammack, F. M. (2012). The sociology of education: A systematic analysis (7th ed.). Upper Saddle River, NJ: Prentice Hall.

Battey, D., Kafai, Y., Nixon, A. S., \& Kao, L. L. (2007). Professional development for teachers on gender equity in the sciences: Initiating the conversation. Teachers College Record, 109(1), 221-243.

Booher-Jennings, J. (2008). Learning to label: Socialisation, gender, and the hidden curriculum of high-stakes testing. British Journal of Sociology of Education, 29, 149-160.

Chetty, R., Friedman, J. N., Hilger, N., Saez, E., Schanzenbach, D. W., \& Yagan, D. (2011). How does your 
kindergarten classroom affect your earnings? Evidence from Project STAR. Quarterly Journal of Economics, 126, 1593-1660.

Cole, M. (2008). Marxism and educational theory: Origins and issues. New York, NY: Routledge.

Grodsky, E., Warren, J. R., \& Felts, E. (2008). Testing and social stratification in American education. Annual Review of Sociology, 34(1), 385-404.

Jones, S. M., \& Dindia, K. (2004). A meta-analystic perspective on sex equity in the classroom. Review of Educational Research, 74, 443-471.

Rosenthal, R., \& Jacobson, L. (1968). Pygmalion in the classroom. New York, NY: Holt.

Schanzenbach, D. W. (2006). What have researchers learned from Project STAR? (Harris School Working Paper-Series 06.06).

Thorne, B. (1993). Gender play: Girls and boys in school. New Brunswick, NJ: Rutgers University Press. 


\subsection{Issues and Problems in Elementary and Secondary Education}

\section{Learning Objectives}

1. Describe how schooling in the United States helps perpetuate social inequality.

2. Explain the difference between de jure segregation and de facto segregation.

3. Summarize the evidence on the effectiveness of single-sex education.

4. Describe the extent of school violence and the controversy over zero-tolerance policies.

5. Discuss how and why social inequality in the larger society manifests itself in higher education.

The elementary (K-8) and secondary (9-12) education system today faces many issues and problems of interest not just to educators and families but also to sociologists and other social scientists. We cannot discuss all these issues here, but we will highlight some of the most interesting and important.

\section{Schools and Inequality}

Earlier we mentioned that schools differ greatly in their funding, their conditions, and other aspects. Noted author and education critic Jonathan Kozol refers to these differences as "savage inequalities," to quote the title of one of his books (Kozol, 1991). Kozol's concern over inequality in the schools stemmed from his experience as a young teacher in a public elementary school in a Boston inner-city neighborhood in the 1960s. Kozol was shocked to see that his school was literally falling apart. The building itself was decrepit, with plaster falling off the walls and bathrooms and other facilities substandard. Classes were large, and the school was so overcrowded that Kozol's fourth-grade class had to meet in an auditorium, which it shared with another class, the school choir, and, for a time, a group of students practicing for the Christmas play. Kozol's observations led to the writing of his first award-winning book, Death at an Early Age (Kozol, 1967).

Kozol (1991) later traveled around the United States and systematically compared public schools in several cities' inner-city neighborhoods to those in the cities' suburbs. Everywhere he went, he found great discrepancies in school spending and in the quality of instruction. In schools in Camden, New Jersey, for example, spending per pupil was less than half the amount spent in the nearby, much wealthier town of Princeton. Chicago and New York City schools spent only about half the amount that some of the schools in nearby suburbs spent.

These numbers were reflected in other differences Kozol found when he visited city and suburban schools. In East St. Louis, Illinois, where most of the residents are poor and almost all are African American, schools had to shut down once because of sewage backups. The high school's science labs were thirty to fifty years out of date when Kozol visited them; the biology lab had no dissecting kits. A history teacher had 110 students but only twenty-six textbooks, some of which were missing their first one hundred pages. At one of the city's junior high 
schools, many window frames lacked any glass, and the hallways were dark because light bulbs were missing or not working. Visitors could smell urinals one hundred feet from the bathroom.

Contrast these conditions with those Kozol observed in suburban schools. A high school in a Chicago suburb had seven gyms and an Olympic-sized swimming pool. Students there could take classes in seven foreign languages. A suburban New Jersey high school offered fourteen AP courses, fencing, golf, ice hockey, and lacrosse, and the school district there had ten music teachers and an extensive music program.

From his observations, Kozol concluded that the United States is shortchanging its children in poor rural and urban areas. As we saw in Chapter 2 "Poverty", poor children start out in life with many strikes against them. The schools they attend compound their problems and help ensure that the American ideal of equal opportunity for all remains just that—an ideal—rather than a reality. As Kozol (1991, p. 233) observed, “All our children ought to be allowed a stake in the enormous richness of America. Whether they were born to poor white Appalachians or to wealthy Texans, to poor black people in the Bronx or to rich people in Manhasset or Winnetka, they are all quite wonderful and innocent when they are small. We soil them needlessly.”

Although the book in which Kozol reported these conditions was published more than twenty years ago, ample evidence (including the news story about Baltimore's schools that began this chapter) shows these conditions persist today. A recent news report discussed public schools in Washington, DC. More than 75 percent of the schools in the city had a leaking roof at the time the report was published, and 87 percent had electrical problems, some of which involved shocks or sparks. Most of the schools' cafeterias—85 percent-had health violations, including peeling paint near food and rodent and roach infestation. Thousands of requests for building repairs, including 1,100 labeled "urgent” or “dangerous," had been waiting more than a year to be addressed. More than one-third of the schools had a mouse infestation, and in one elementary school, there were so many mice that the students gave them names and drew their pictures. An official with the city's school system said, "I don't know if anybody knows the magnitude of problems at D.C. public schools. It's mind-boggling” (Keating \& Haynes, 2007).

Large funding differences in the nation’s schools also endure. In Philadelphia, Pennsylvania, for example, annual per-pupil expenditure was \$10,878 in 2010; in nearby suburban Lower Merion Township, it was \$21,110, or 95 percent higher than Philadelphia’s expenditure (Federal Education Budget Project, 2012).

Teacher salaries are related to these funding differences. Salaries in urban schools in low-income neighborhoods are markedly lower than those in schools in wealthier neighborhoods (Dillon, 2011). As a result, teachers at the low-income schools tend to be inexperienced teachers just out of college. All things equal, they are less likely than their counterparts at wealthier schools to be effective teachers. 


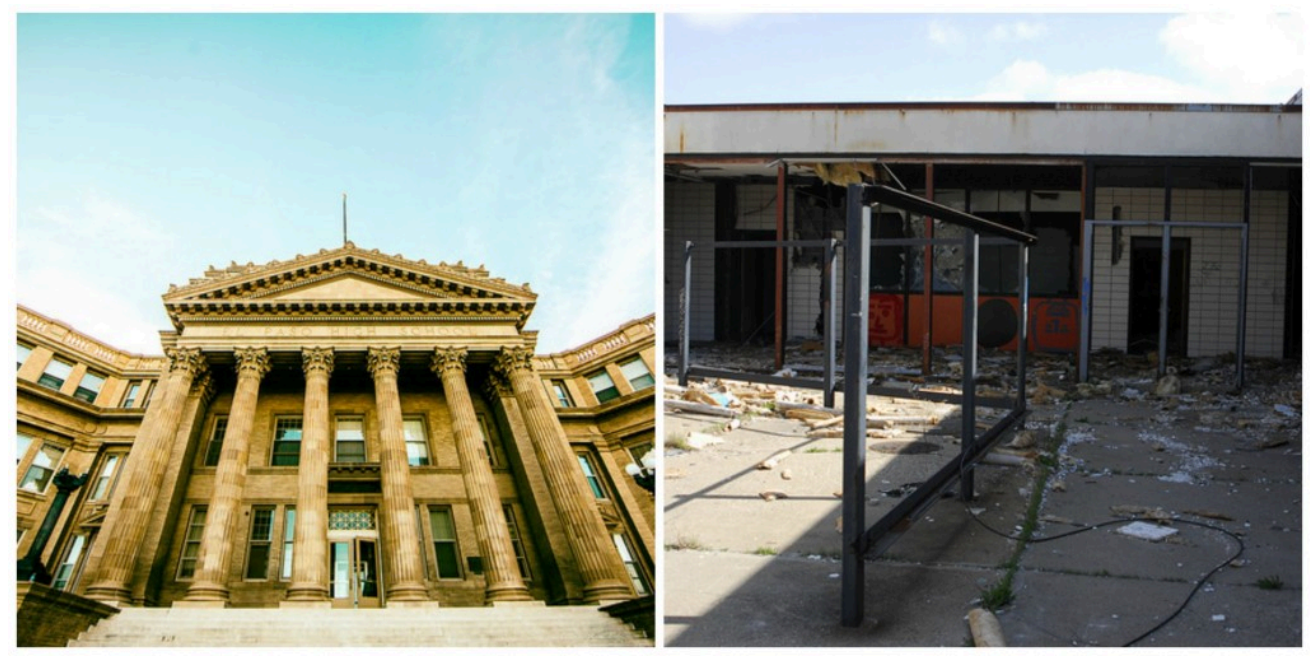

Jonathan Kozol has written movingly of "savage inequalities” in American schools arising from large differences in their funding and

in the condition of their physical facilities.

Thomas Hawk - El Paso High School - CC BY-NC 2.0; Nitram242 - Detroit School - CC BY 2.0.

\section{People Making a Difference}

Teaching Young Students about Science and Conservation

Since 1999, the Ocean Discovery Institute (ODI) has taught more than 40,000 public school students in a low-income San Diego neighborhood about the ocean and the environment. Most of the students are Latino, and a growing number are recent immigrants from Southeast Asia and East Africa. By learning about ocean science, the students also learn something about geology, physics, and other sciences. ODI's program has grown over the years, and it now services more than 5,000 students annually in ten schools. To accomplish its mission, ODI engages in several kinds of activities.

First, ODI instructors teach hands-on marine science activities to students in grades 3-6. They also consult closely with the schools' teachers about the science curriculum taught in the schools.

Second, ODI runs an after-school program in which they provide marine science-based lessons as well as academic, social, and college-entry support to approximately sixty students in grades 6-12.

Third, ODI takes about twenty high school students every summer to the Sea of Cortez in Baja California, Mexico, for an intensive five-week research experience at a field research station. Before they do so, they are trained for several weeks in laboratory and field research procedures, and they also learn how to swim and snorkel. After they arrive at the field research station, they divide into three research teams; each team works on a different project under the guidance of ODI instructors and university and government scientists. A recent project, which won an award from the World Wildlife Fund, has focused on reducing the number of sea turtles that are accidentally caught in fishing nets.

The instruction provided by ODI has changed the lives of many students. Perhaps most notably, about 80 percent of the students who have participated in the after-school or summer program have attended a four-year college or university (with almost all declaring a major in one of the sciences), compared to less than one-third of students in their schools who have not participated in these programs. One summer program student, whose parents were deported by the government, recalls the experience fondly: "I have learned to become independent, and I pushed myself to try new things. Now I know I can overcome barriers and take chances...I am prepared to overcome challenges and follow my dreams.”

In 2011, ODI was one of three organizations that received the Presidential Award for Excellence in Science, Mathematics, and Engineering Mentoring. Several ODI officials and students traveled to the White House to take part in various events and accept the award from President Obama. As this award attests, the Ocean Discovery Institute is 
making a striking difference in the lives of low-income San Diego students. For further information, visit http://www.oceandiscoveryinstitute.org. (Full disclosure: The author's son works for ODI.)

Source: Ocean Discovery Institute, 2011

\section{School Segregation}

A related issue to school inequality is school racial segregation. Before 1954, schools in the South were racially segregated by law (de jure segregation). Communities and states had laws that dictated which schools white children attended and which schools African American children attended. Schools were either all white or all African American, and, inevitably, white schools were much better funded than African American schools. Then in 1954, the US Supreme Court outlawed de jure school segregation in its famous Brown v. Board of Education decision. Southern school districts fought this decision with legal machinations, and de jure school segregation did not really end in the South until the civil rights movement won its major victories a decade later.

Meanwhile, northern schools were also segregated; decades after the Brown decision, they have become even more segregated. School segregation in the North stemmed, both then and now, not from the law but from neighborhood residential patterns. Because children usually go to schools near their homes, if adjacent neighborhoods are all white or all African American, then the schools for these neighborhoods will also be all white or all African American, or mostly so. This type of segregation is called de facto segregation.

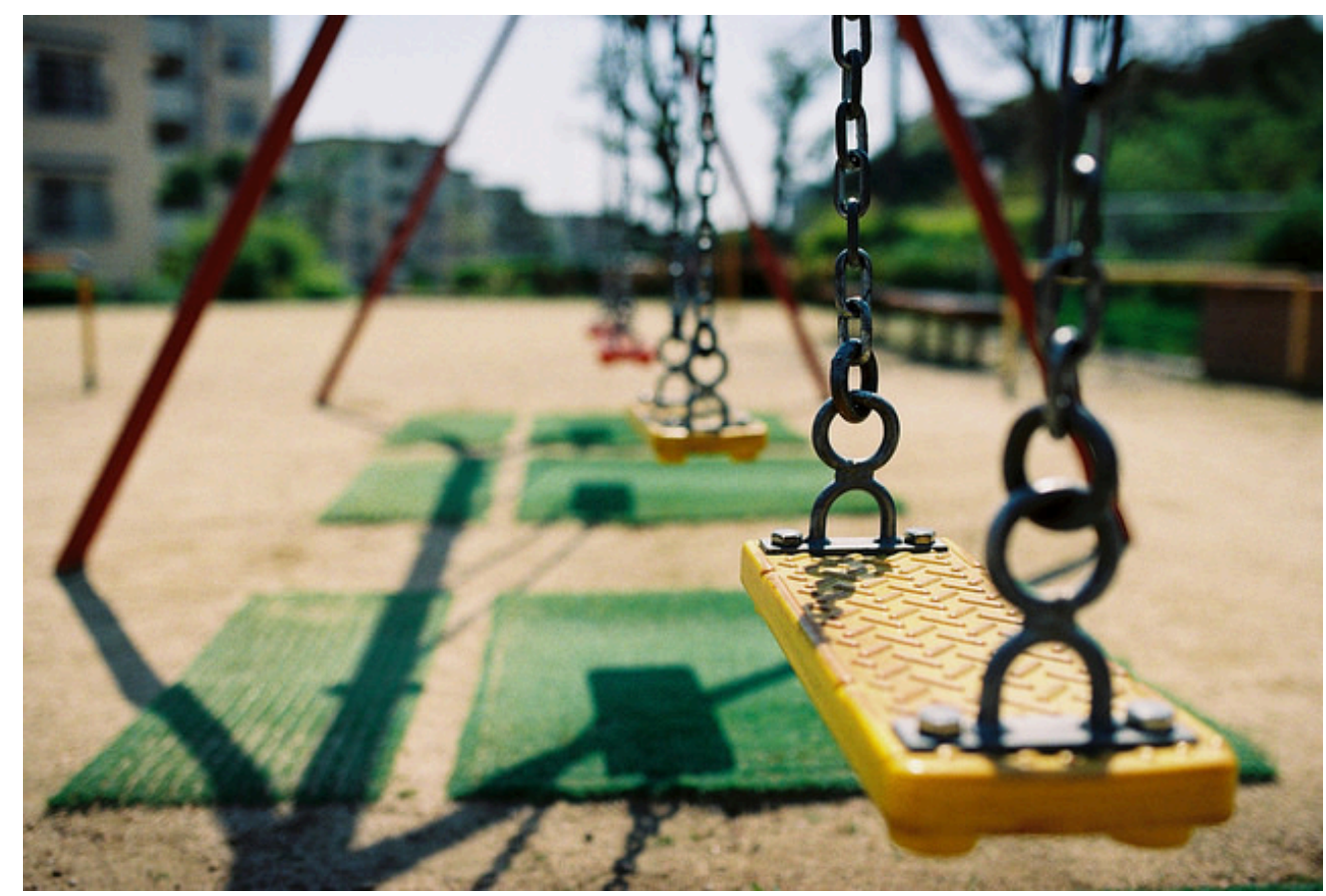

Many children today attend schools that are racially segregated because of neighborhood residential patterns.

halfrain - $\underline{\text { Swings }}$ - CC BY-SA 2.0.

Today many children continue to go to schools that are segregated because of neighborhood residential patterns, 
a situation that Kozol (2005) calls “apartheid schooling.” About 40 percent of African American and Latino children attend schools that are very segregated (at least 90 percent of their students are of color); this level of segregation is higher than it was four decades ago. Although such segregation is legal, it still results in schools that are all African American and/or all Latino and that suffer severely from lack of funding, poor physical facilities, and poorly paid teachers (Orfield, Siegel-Hawley, \& Kucsera, 2011).

During the 1960s and 1970s, states, municipalities, and federal courts tried to reduce de facto segregation by busing urban African American children to suburban white schools and, less often, by busing white suburban children to African American urban schools. Busing inflamed passions as perhaps few other issues did during those decades (Lukas, 1985). White parents opposed it because they did not want their children bused to urban schools, where, they feared, the children would be unsafe and receive an inferior education. The racial prejudice that many white parents shared heightened their concerns over these issues. African American parents were more likely to see the need for busing, but they, too, wondered about its merits, especially because it was their children who were bused most often and faced racial hostility when they entered formerly all-white schools.

As one possible solution to reduce school segregation, some cities have established magnet schools, schools for high-achieving students of all races to which the students and their families apply for admission (Vopat, 2011). Although these schools do help some students whose families are poor and of color, their impact on school segregation has been minimal because the number of magnet schools is low and because they are open only to the very best students who, by definition, are also few in number. Some critics also say that magnet schools siphon needed resources from public school systems and that their reliance on standardized tests makes it difficult for African American and Latino students to gain admission.

\section{School Choice: Education Vouchers and Charter Schools}

Children who attend a public school ordinarily attend the school that is designated for the neighborhood in which they live, and they and their parents normally have little choice in the matter. One of the most popular but also controversial components of the school reform movement today is school choice, in which parents and their children, primarily from low-income families in urban areas, receive public funds to attend a school different from their neighborhood's school. School choice has two components. The first component involves education vouchers, which parents can use as tuition at private or parochial (religious) schools. The second component involves charter schools, which are public schools (because public funds pay for students' tuition) built and operated by for-profit companies. Students normally apply for admission to these schools; sometimes they are accepted based on their merit and potential, and sometimes they are accepted by lottery. Both components have strong advocates and fierce critics. We examine each component in turn.

\section{Education Vouchers}

Advocates of school choice programs involving education vouchers say they give low-income families an option for high-quality education they otherwise would be unable to afford. These programs, the advocates add, also help improve the public schools by forcing them to compete for students with their private and parochial counterparts. 
In order to keep a large number of parents from using vouchers to send their children to the latter schools, public schools have to upgrade their facilities, improve their instruction, and undertake other steps to make their brand of education an attractive alternative. In this way, school choice advocates argue, vouchers have a "competitive impact" that forces public schools to make themselves more attractive to prospective students (National Conference of State Legislatures, 2011).

Critics of school choice programs say they harm the public schools by decreasing their enrollments and therefore their funding. Public schools do not have the money now to compete with private and parochial ones, nor will they have the money to compete with them if vouchers become more widespread. Critics also worry that voucher programs will lead to a "brain drain" of the most academically motivated children and families from low-income schools (Crone, 2011).

Because school choice programs and school voucher systems are still relatively new, scholars have not yet had time to assess whether they improve their students' academic achievement. Some studies do find small improvements, but methodological problems make it difficult to reach any firm conclusions at this point (DeLuca \& Dayton, 2009). Although there is also little research on the impact of school choice programs on funding and other aspects of public school systems, some evidence does indicate a negative impact. In Milwaukee, for example, enrollment decline from the use of vouchers cost the school system \$26 million in state aid during the 1990s, forcing a rise in property taxes to replace the lost funds. Because the students who left the Milwaukee school system came from most of its 157 public schools, only a few left any one school, diluting the voucher system's competitive impact. Thus although school choice programs may give some families alternatives to public schools, they might not have the competitive impact on public schools that their advocates claim, and they may cost public school systems state aid (Cooper, 1999).

\section{Charter Schools}

About 5,000 charter schools operate across the nation, with about 3 percent of American children attending them. Charter schools and their proponents claim that students fare better in these schools than in conventional public schools because of the charter schools' rigorous teaching methods, strong expectations for good behavior, small classrooms, and other advantages (National Alliance for Public Charter Schools, 2012).

Critics say charter schools incur the same problems that education vouchers incur: They take some of the brightest students from a city's conventional public schools and lead to lower funding for these schools (Ravitch, 2010; Rosenfeld, 2012). Critics also cite research findings that charter schools do not in fact deliver the strong academic performance claimed by their advocates. For example, a study that compared test scores at charter schools in sixteen states with those at public schools found that the charter schools did worse overall: 17 percent of charter schools had better scores than public schools, 46 percent had scores similar to those of public schools, and 37 percent had lower scores (Center for Research on Education Outcomes, 2009).

Even when charter school test scores are higher, there is the methodological problem that students are not randomly assigned to attend a charter school (Basile, 2010). It is thus possible that the students and parents who apply to charter schools are more highly motivated than those who do not. If so, the higher test scores found in some charter schools may reflect the motivation of the students attending these schools, and not necessarily 
the schools' teaching methods. It is also true that charter schools do not usually enroll students who know little English (because their parents are immigrants) and students with disabilities or other problems. All such students often face difficulties in doing well in school. This is yet another possible reason that a small number of charter schools outperform public schools. Despite the popularity of charter schools, then, the academic case for them remains to be proven.

\section{Single-Sex Schools and Classes}

Before the late 1960s and early 1970s, many colleges and universities, including several highly selective campuses, were single-sex institutions. Since that time, almost all the male colleges and many of the female colleges have gone coed. A few women's colleges still remain, as their administrators and alumnae say that women can achieve much more in a women's college than in a coed institution. The issue of single-sex institutions has been more muted at the secondary school level, as most public schools have been coeducational since the advent of free, compulsory education during the nineteenth century. However, several private schools were singlesex ones from their outset, and many of these remain today. Still, the trend throughout the educational world was toward coeducation.

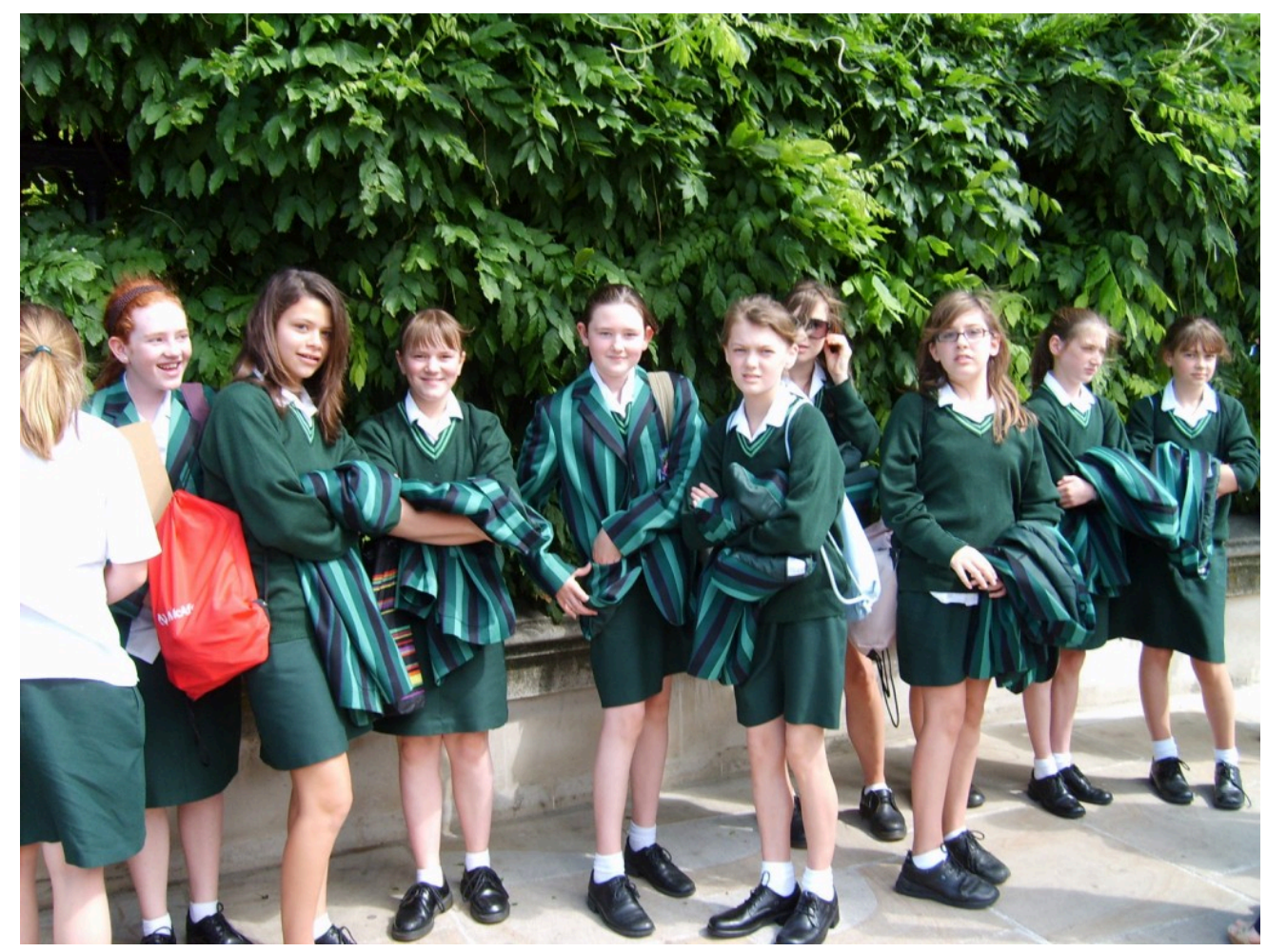

Single-sex schools and classes have become more popular for several reasons. The research so far indicates that single-sex education may be beneficial in certain respects for the students experiencing it.

Wikimedia Commons - CC BY 3.0.

Since the 1990s, however, some education specialists have argued that single-sex secondary schools, or at least single-sex classes, might make sense for girls or for boys. In response, single-sex classes and single-sex schools 
have arisen in at least seventeen US cities. The argument for single-sex learning for girls rests on the same reasons advanced by advocates for women's colleges: Girls can do better academically, and perhaps especially in math and science classes, when they are by themselves. The argument for boys rests on a different set of reasons (National Association for Single Sex Public Education, 2011). Boys in classes with girls are more likely to act "macho" and thus to engage in disruptive behavior; in single-sex classes, boys thus behave better and are more committed to their studies. They also feel freer to exhibit an interest in music, the arts, and other subjects not usually thought of as "macho" topics. Furthermore, because the best students in coed schools are often girls, many boys tend to devalue academic success in coed settings and are more likely to value it in single-sex settings. Finally, in a boysonly setting, teachers can use examples and certain teaching techniques that boys may find especially interesting, such as the use of snakes to teach biology. To the extent that single-sex education may benefit boys for any of these reasons, these benefits are often thought to be highest for boys from families living in poverty or near poverty.

What does the research evidence say about single-sex schooling's benefits? A review of several dozen studies concluded that the results of single-sex schooling are mixed overall but that there are slightly more favorable outcomes for single-sex schools compared to coeducational schools (US Department of Education, 2005). However, the review noted that methodological problems limited the value of the studies it examined. For example, none of the studies involved random assignment of students to single-sex or coeducational schooling. Further, all the studies involved high school students and a majority involved students in Catholic schools. This limited scope prompted the call for additional studies of younger students and those in public schools.

Another review of the research evidence was more critical of single-sex schooling (Halpern et al., 2011). This review concluded that such schooling does not benefit girls or boys and in fact does them harm by reinforcing gender-role stereotypes. Boys in all-boy classes become more aggressive, the review said, and girls in all-girl classes become more feminine. The review also argued that single-sex schooling is based on a faulty, outdated understanding of how girls and boys learn and function. Drawing on this review and other evidence, two critics of single-sex education recently concluded, "So there is a veritable mountain of evidence, growing every day, that the single-sex classroom is not a magic bullet to save American education. And scant evidence that it heightens the academic achievement of girls and boys” (Barnett \& Rivers, 2012).

\section{Children and Our Future}

The Importance of Preschool and Summer Learning Programs for Low-Income Children

The first few years of life are absolutely critical for a child's neurological and cognitive development. What happens, or doesn't happen, before ages 5 and 6 can have lifelong consequences for a child's educational attainment, adolescent behavior, and adult employment and family life. However, as this chapter and previous chapters emphasize, low-income children face many kinds of obstacles during this critical phase of their lives. Among other problems, their families are often filled with stressful life events that impair their physical and mental health and neurological development, and their parents read and talk to them much less on the average than wealthier parents do. These difficulties in turn lower their school performance and educational attainment, with negative repercussions continuing into adulthood.

To counteract these problems and enhance low-income children's ability to do well in school, two types of programs have been repeatedly shown to be very helpful and even essential. The first is preschool, a general term for semiformal early learning programs that take place roughly between ages 3 and 5 . As the name of the famous Head Start program implies, preschool is meant to help prepare low-income children for kindergarten and beyond. Depending on the program, preschool involves group instruction and play for children, developmental and health screening, and other 
components. Many European nations have high-quality preschool programs that are free or heavily subsidized, but these programs are, by comparison, much less prevalent in the United States and often more costly for parents.

Preschool in the United States has been shown to have positive benefits that extend well into adulthood. For example, children who participate in Head Start and certain other programs are more likely years later to graduate high school and attend college. They also tend to have higher salaries in their twenties, and they are less likely to engage in delinquency and crime.

The second program involves summer learning. Educators have discovered that summer is an important time for children's learning. During the summer, children from middle-class and wealthier families tend to read books, attend summer camp and/or engage in other group activities, and travel with their parents. When they return to school in September, their reading and math skills are higher than when the summer began. In contrast, low-income children are much less likely to have these types of summer experiences, and those who benefitted from school lunch programs during the academic year often go hungry. As a result, their reading and math skills are lower when they return to school than when the summer began.

In response to this discovery, many summer learning programs have been established. They generally last from four to eight weeks and are held at schools, campgrounds, community centers, or other locations. Although these programs are still relatively new and not yet thoroughly studied, a recent review concluded that they "can be effective and are likely to have positive impacts when they engage students in learning activities that are hands-on, enjoyable, and have realworld applications.”

Preschool programs help children in the short and long term, and summer programs appear to have the same potential. Their expansion in the United States would benefit many aspects of American society. Because their economic benefits outweigh their economic costs, they are a "no-brainer" for comprehensive social reform efforts.

Sources: Child Trends, 2011; Downey \& Gibbs, 2012; Garces, Thomas, \& Currie, 2003; Reynolds, Temple, Ou, Arteaga, \& White, 2011; Terzian \& Moore, 2009

\section{School Violence}

The issue of school violence won major headlines during the 1990s, when many children, teachers, and other individuals died in the nation's schools. From 1992 until 1999, 248 students, teachers, and other people died from violent acts (including suicide) on school property, during travel to and from school, or at a school-related event, for an average of about thirty-five violent deaths per year (Zuckoff, 1999).

Several of these deaths occurred in mass shootings. In just a few examples, in December 1997, a student in a Kentucky high school shot and killed three students in a before-school prayer group. In March 1998, two middle school students in Arkansas pulled a fire alarm to evacuate their school and then shot and killed four students and one teacher as they emerged. Two months later, an Oregon high school student killed his parents and then went to his school cafeteria, where he killed two students and wounded twenty-two others. Against this backdrop, the infamous April 1999 school shootings at Columbine High School in Littleton, Colorado, where two students murdered twelve other students and one teacher before killing themselves, seemed like the last straw. Within days, school after school across the nation installed metal detectors, located police at building entrances and in hallways, and began questioning or suspending students joking about committing violence. People everywhere wondered why the schools were becoming so violent and what could be done about it. A newspaper headline summarized their concern: “fear is spread around nation” (Zuckoff, 1999).

Fortunately, school violence has declined since the 1990s, with fewer students and other people dying in the nation's schools or being physically attacked. As this trend indicates, the risk of school violence should not 
be exaggerated: Statistically speaking, schools are very safe, especially in regard to fatal violence. Two kinds of statistics illustrate this point. First, less than 1 percent of all homicides involving school-aged children take place in or near school; virtually all children's homicides occur in or near a child's home. Second, an average of seventeen students are killed at school yearly; because about 56 million students attend US elementary and secondary schools, the chances are less than one in 3 million that a student will be killed at school. The annual rate of other serious school violence (rape and sexual assault, aggravated assault, and robbery) is only three crimes per one hundred students; although this is still three too many, it does indicate that 97 percent of students do not suffer these crimes (National Center for Injury Prevention and Control, 2010).

Eric Harris and Dylan Klebold killed thirteen people at Columbine High School in 1999 before killing themselves. Their massacre led people across the nation to question why violence was occurring in the schools and to wonder what could be done to reduce it.

Read more about it at; http://en.wikipedia.org/wiki/File:Eric harris dylan_klebold.jpg.

\section{Bullying}

Bullying is another problem in the nation's elementary and secondary schools and is often considered a specific type of school violence. However, bullying can take many forms, such as taunting, that do not involve the use or threat of physical violence. As such, we consider bullying here as a separate problem while acknowledging its close relation to school violence.

First it will be helpful to define bullying. A common definition in the research literature is that bullying involves "physical and verbal attacks and harassment directed at a victim(s) by one student or a group of students over an extensive period of time” (Moon, Hwang, \& McCluskey, 2011). Another definition is also helpful: "The use of one's strength or popularity to injure, threaten or embarrass another person on purpose” (St. George, 2011). As these definitions suggest, bullying can be physical in nature (violence such as shoving and punching), verbal (teasing, taunting, and name calling), and social (spreading rumors, breaking up friendships, deliberately excluding someone from an activity). An additional form of bullying that has emerged in the last decade or so is cyberbullying. As its name implies, cyberbullying involves the use of the Internet, cell phones and smartphones, and other digital technologies to bully others (e.g., rumors can be spread via Facebook) (US Department of Health and Human Services, 2012).

Bullying is a serious problem for at least two reasons. First, bullying is a common occurrence. About one-third of students report being victimized by some form of bullying during the school year; this rate of victimization is much higher than the 3 percent rate of victimization for school violence mentioned in the previous section (National Center for Injury Prevention and Control, 2010).

Second, bullying can have serious consequences (Adams \& Lawrence, 2011). Students who are bullied often experience psychological problems that can last into adulthood; these problems include anxiety, depression, loneliness, sleeplessness, and suicidal thoughts. Their physical health may also suffer. Their school performance (grades, attendance, and participation in school activities) may also decline. In addition, bullying victims 
sometimes respond by lashing out in violence; many of the mass school shootings of the 1990s were committed by male students who had been bullied.

A tragic example of bullying's effects occurred in September 2011, when a 14-year-old boy in western New York, Jamey Rodemeyer, killed himself after being bullied by classmates because he was gay. Much of the bullying involved homophobic taunts on a social media site Jamey used, including comments such as "JAMIE IS STUPID, GAY, FAT ANND UGLY. HE MUST DIE!” and “I wouldn’t care if you died. No one would. So just do it: It would make everyone WAY more happier!" A week before he died, Jamey wrote on his site, "I always say how bullied I am, but no one listens. What do I have to do so people will listen to me?” (Tan, 2011).

\section{School Discipline and Racial Discrimination}

To reduce school violence and bullying, many school districts have adopted strict policies that specify harsh punishments. A common policy involves zero-tolerance for weapons; this type of policy calls for automatic suspension or expulsion of a student who has anything resembling a weapon for any reason. However, this policy is often applied too rigidly. In one example, a 6-year-old boy in Delaware excitedly took his new camping utensil-a combination of knife, fork, and spoon—-from Cub Scouts to school to use at lunch. He was suspended for having a knife and ordered to spend forty-five days in reform school. His mother said her son certainly posed no threat to anyone at school, but school officials replied that their policy had to be strictly enforced because it is difficult to determine who actually poses a threat from who does not (Urbina, 2009). In another case, a ninth grader took a knife and cigarette lighter away from a student who had used them to threaten a fellow classmate. The ninth grader was suspended for the rest of the school year for possessing a weapon, even though he had them only because he was protecting his classmate. According to a news story about this case, the school's reaction was “vigilance to a fault” (Walker, 2010, p. A12).

Zero-tolerance or other very strict policies are also in place in many schools for offenses such as drug use and possession, fighting, and classroom disruption. However well intended these policies may be, the research evidence suggests that they are ineffective in deterring the behavior they are meant to prevent, and may even be counterproductive. As one review of this evidence puts it, "It is not clear that zero tolerance policies are succeeding in improving school safety. In fact, some evidence...suggests that these policies actually may have an adverse effect on student academic and behavioral outcomes” (Boccanfuso \& Kuhfeld, 2011, p. 1). When students are suspended, their grades may suffer, and their commitment to schooling may lower; these problems in turn increase their likelihood of engaging in delinquency. The expelled students find it difficult to get back into a school and eventually achieve a high school degree. Their behavior, too, may become more unlawful as a result, and they also are more likely to face unemployment and low-paying jobs. Zero-tolerance school discipline thus seems to do much more harm than good.

In addition to deterrence, another reason for the adoption of strict discipline policies has been to avoid the racial discrimination that occurs when school officials have discretion in deciding which students should be suspended or expelled (Skiba \& Rausch, 2006). In school districts with such discretion, African American students with weapons or "near weapons" (such as a small penknife) are more likely than white students with the same objects to be punished in this manner. However, a growing body of research finds that African American and Latino students are still more likely than white students to be suspended or expelled for similar misbehaviors (having a 
weapon, fighting, cursing a teacher, etc.) even in school districts with very strict discipline (Welch \& Payne, 2010; Lewin, 2012). School discipline, then, is often racially discriminatory.

\section{Key Takeaways}

- Schools in America are unequal: They differ greatly in the extent of their funding, in the quality of their physical facilities, and in other respects. Jonathan Kozol calls these differences "savage inequalities."

- Single-sex education at the secondary level has become more popular. Preliminary evidence indicates that this form of education may be beneficial for several reasons, but more evidence on this issue is needed.

- Although school violence has declined since the 1990s, it continues to concern many Americans. Bullying at school is a common problem and can lead to more serious violence by the children who are bullied.

- School choice programs are popular but also controversial. Charter schools on the average do no better than public schools, and sometimes worse.

\section{For Your Review}

1. If you were the principal of a middle school, would you favor or oppose single-sex classes? Explain your answer.

2. Do you favor or oppose school vouchers? Why?

\section{References}

Adams, F. D., \& Lawrence, G. J. (2011). Bullying victims: The effects last into college. American Secondary Education, 40(1), 4-13.

Barnett, R. C., \& Rivers, C. (2012, February 17). Why science doesn't support single-sex classes. Education Week. Retrieved from http://www.edweek.org/ew/articles/2012/02/17/ 21barnett.h31.html?tkn=XNPFPP3DSaPBokSRePilYv9tz\%2FsDy4SQ5jGa\&cmp=ENL -EU-VIEWS1.

Basile, M. (2010). False impression: How a widely cited study vastly overstates the benefits of charter schools. New York, NY: Century Foundation.

Boccanfuso, C., \& Kuhfeld, M. (2011). Multiple responses, promising results: Evidence-based, nonpunitive alternatives to zero tolerance. Washington, DC: Child Trends.

Center for Research on Education Outcomes. (2009). Multiple choice: Charter school performance in 16 states. Stanford, CA: Author.

Child Trends. (2011). Research-based responses to key questions about the 2010 Head Start impact study. Washington, DC: Author. 
Cooper, K. J. (1999, June 25). Under vouchers, status quo rules. The Washington Post, p. A3.

Crone, J. A. (2011). How can we solve our social problems? (2nd ed.). Thousand Oaks, CA: Pine Forge Press.

DeLuca, S., \& Dayton, E. (2009). Switching social contexts: The effects of housing mobility and school choice programs on youth outcomes. Annual Review of Sociology, 35(1), 457-491.

Dillon, S. (2011, December 1). Districts pay less in poor schools, report says. New York Times, p. A29.

Downey, D. B., \& Gibbs, B. G. (2012). How schools really matter. In D. Hartmann \& C. Uggen (Eds.), The Contexts Reader (2nd ed., pp. 80-86). New York, NY: W. W. Norton.

Federal Education Budget Project. (2012). K-12: Pennsylvania. Retrieved January 2, 2012, from http://febp.newamerica.net/k12/PA.

Garces, E., Thomas, D., \& Currie, J. (2003). Longer-term effects of Head Start. Santa Monica, CA: RAND Corporation.

Halpern, D. F., Eliot, L., Bigler, R. S., Fabes, R. A., Hanish, L. D., Hyde, J., et al. (2011). The pseudoscience of single-sex schooling. Science, 333, 1706-1707.

Keating, D., \& Haynes, V. D. (2007, June 10). Can DC schools be fixed? The Washington Post, p. A1.

Kozol, J. (1967). Death at an early age: The destruction of the hearts and minds of negro children in the Boston public schools. Boston, MA: Houghton Mifflin.

Kozol, J. (1991). Savage inequalities: Children in America’s schools. New York, NY: Crown.

Kozol, J. (2005). The shame of the nation: The restoration of apartheid schooling in America. New York, NY: Crown.

Lewin, T. (2012, March 6). Black students face more discipline, study suggests. New York Times, p. A11.

Lukas, J. A. (1985). Common ground: A turbulent decade in the lives of three American families. New York, NY: Knopf.

Moon, B., Hwang, H.-W., \& McCluskey, J. D. (2011). Causes of school bullying: Empirical test of a general theory of crime, differential association theory, and general strain theory. Crime \& Delinquency, 57, 849-877.

National Alliance for Public Charter Schools. (2012). Why charter schools? Retrieved January 11, 2012, from http://www.publiccharters.org/About-Charter-Schools/Why-Charter-Schools003F.aspx.

National Association for Single Sex Public Education. (2011). Advantages for boys. Retrieved January 2, 2012, from http://www.singlesexschools.org/advantages-forboys.htm.

National Center for Injury Prevention and Control. (2010). Understanding school violence fact sheet. Washington, DC: Centers for Disease Control and Prevention. 
National Conference of State Legislatures. (2011). Publicly funded school voucher programs. Retrieved January 2, 2012, from http://www.ncsl.org/default.aspx?tabid=12942.

Ocean Discovery Institute. (2011). Believe: A PEN in the classroom anthology. San Diego, CA: Author.

Orfield, G., Siegel-Hawley, G., \& Kucsera, J. (2011). Divided we fail: Segregated and unequal schools in the Southland. Los Angeles, CA: Civil Rights Project.

Ravitch, D. (2010, March 8). Why I changed my mnd about school reform. The Wall Street Journal. Retrieved from http://online.wsj.com/article/SB10001424052748704869304575109443305343962.html.

Reynolds, A. J., Temple, J. A., Ou, S.-R., Arteaga, I. A., \& White, B. A. B. (2011, July 15). School-based early childhood education and age-28 well-being: Effects by timing, dosage, and subgroups. Science, 360-364.

Rosenfeld, L. (2012, March 16). How charter schools can hurt. New York Times. Retrieved from http://www.nytimes.com/2012/03/17/opinion/how-charter-schools-can-hurt.html?emc=tnt\&tntemail0=y.

Skiba, R. J., \& Rausch, M. K. (2006). Zero tolerance, suspension, and expulsion: Questions of equity and effectiveness. In C. M. Evertson \& C. S. Weinstein (Eds.), Handbook of classroom management: Research, practice, and contemporary issues (pp. 1063-1089). Mahwah, NJ: Lawrence Erlbaum Associates.

St. George, D. (2011, September 5). Bullying linked to lower school achievement. The Washington Post. Retrieved from http://www.washingtonpost.com/local/education/bullying-linked-to-lower-school-achievement/ 2011/09/01/gIQArmQw4J_story.html.

Tan, S. (2011, September 20). Teenager struggled with bullying before taking his life. The Buffalo News. Retrieved from http://www.buffalonews.com/city/schools/article563538.ece.

Terzian, M., \& Moore, K. A. (2009). What works for summer learning programs for low-income children and youth: Preliminary lessons from experimental evaluations of social interventions. Washington, DC: Child Trends.

Urbina, I. (2009, October 11). It’s a fork, it’s a spoon, it’s a...weapon? New York Times, p. A1.

US Department of Education. (2005). Single-sex versus secondary schooling: A systematic review. Washington, DC: Office of Planning, Evaluation and Policy Development.

US Department of Health and Human Services. (2012). What is bullying? Retrieved January 5, 2012, from http://www.stopbullying.gov/topics/what is bullying/index.html.

Vopat, M. C. (2011). Magnet schools, innate talent, and social justice. Theory and Research in Education, 9, 59-72.

Walker, A. (2010, January 23). Vigilance to a fault. The Boston Globe, p. A12.

Welch, K., \& Payne, A. A. (2010). Racial threat and punitive school discipline. Social Problems, 57(1), $25-48$.

Zuckoff, M. (1999, May 21). Fear is spread around nation. The Boston Globe, p. A1. 


\subsection{Issues and Problems in Higher Education}

\section{Learning Objectives}

1. Explain why certain college students flounder.

2. Describe what is meant by legacy admissions and summarize the criticism of this policy.

3. List any two factors that affect college and university graduation rates.

4. Describe the extent of physical and sexual violence on the nation's campuses.

The issues and problems discussed so far in this chapter concern elementary and secondary schools in view of their critical importance for tens of millions of children and for the nation's social and economic well-being. However, higher education has its own issues and problems. Once again, we do not have space to discuss all these matters, but we will examine some of the most interesting and important. (Recall that Chapter 7 "Alcohol and Other Drugs” discussed alcohol abuse on campus, a very significant higher education problem.)

\section{Cost}

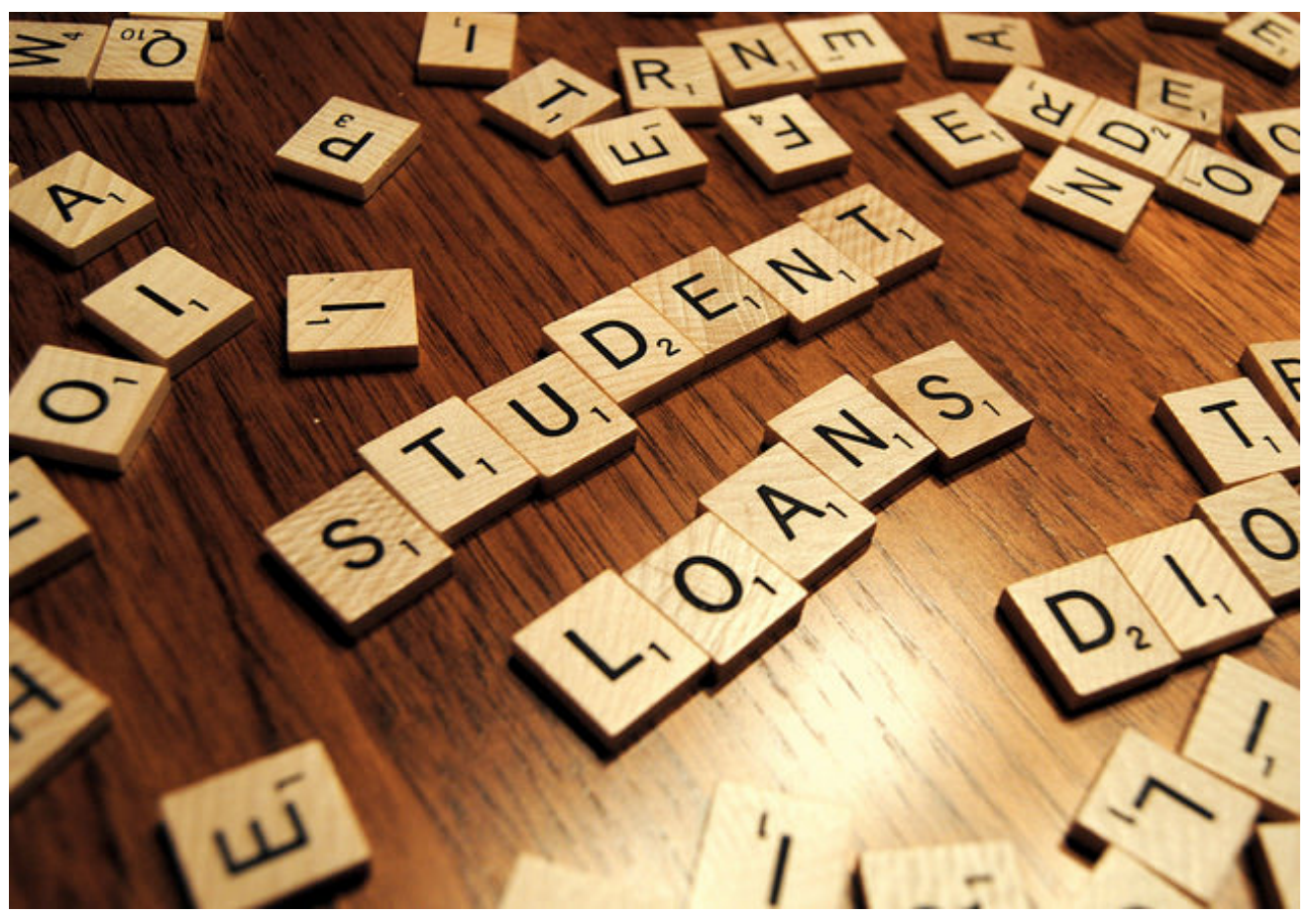

Higher education can cost students and their parents tens of thousands of dollars per year. This expense prevents many students from going to college and puts many students and parents into considerable debt. 
Perhaps the most important issue is that higher education, at least at four-year institutions, is quite expensive and can cost tens of thousands of dollars per year. This figure varies by the type of college or university, as private institutions cost much more than public institutions (for in-state students). According to the College Board (2012), only 44 percent of all students attend a four-year institution whose annual tuition and fees amount to less than $\$ 9,000$. That means that more than half of students attend an institution whose annual tuition and fees are $\$ 9,000$ or more; this cost averages more than $\$ 28,500$ at private colleges and universities and exceeds $\$ 36,000$ at many of these institutions. Tuition and fees average $\$ 8,244$ at public four-year institutions. Room and board expenses for on-campus students at four-year institutions range from about $\$ 8,000$ to $\$ 14,000$, and books and supplies average at least an additional $\$ 1,168$ for students who do not have the opportunity to read free or low-cost textbooks such as this one.

Combining these figures, students at the least expensive four-year institutions might have bills that total $\$ 17,000$ to $\$ 20,000$ annually, and those at the most expensive private institutions have bills that exceed $\$ 50,000$. Scholarships and other financial aid reduce these costs for many students. Private institutions actually collect only about 67 percent of their published tuition and fees because of the aid they hand out, and public institutions collect only about 82 percent (Stripling, 2010). However, many students who receive aid may still have bills totaling thousands of dollars annually and graduate with huge loans to repay. At two-year public institutions, annual tuition and fees average almost $\$ 3,000$; these colleges are more affordable but nonetheless can be very costly for their students and their families.

In view of all these figures, it should come as no surprise that many students graduate in debt. Of all the college students who graduated in 2010, roughly two-thirds had to take out loans to pay for their various expenses. These students graduated with an average debt of $\$ 25,250$ (Pope, 2011), which can certainly take many years to pay off.

\section{Floundering Students}

Although college is often said to be the best time of one's life, many students have difficulties during their college years. These students are called floundering students. Homesickness during the first semester on campus is common, but a number of students have difficulties beyond homesickness. According to psychiatry professor David Leibow, who has studied troubled students, many floundering students mistakenly believe that they are the only ones who are floundering, and many fail to tell their parents or friends about their problems (Golden, 2010). The major cause of floundering, says Leibow, is academic difficulties; other causes include homesickness, relationship problems, family problems including family conflict and the serious illness or death of a family member, personal illness, and financial difficulties.

An estimated 10 percent of students annually seek psychological counseling on their college campus, primarily for depression, anxiety, and relationship problems (Epstein, 2010). About one-third of college students overall have sought counseling by the time they graduate or leave school for other reasons, and 7 percent say they have considered suicide before or after entering college (Sieben, 2011). Many students who seek counseling are given medications to treat their symptoms. Leibow says these medications are often helpful but worries that they are overprescribed. Three reasons underlie his concern. First, although the students given these medications 
may have problems, often the problems are a normal part of growing into adulthood and not serious enough to justify medication. Second, some of these medications can have serious side effects. Third, students who take medications may be less motivated to address the underlying reasons for their problems.

\section{Social Class and Race in Admissions}

We saw earlier in this chapter that African American, Latino, and low-income students are less likely to attend college. And when low-income students do attend college, they are much more likely to attend lower-ranking institutions than very selective campuses. At the very top colleges and universities, 74 percent of new students come from the wealthiest one-fourth of US households, and only 3 percent come from the poorest one-fourth of households (Krugman, 2012).

These facts raise important questions about the lack of diversity in college admissions and campus life. $\underline{\text { Chapter }}$ 3 "Racial and Ethnic Inequality" discussed the debate over racially based affirmative action in higher education. Reflecting this debate, some states have passed laws prohibiting the use of race and ethnicity in admissions to public colleges and universities. One such state was California, where voters approved this type of prohibition in 1996. During the first year after this ban took effect, the number of African American and Latino students admitted to the University of California system dropped by about 25 percent and by 50 percent at the system's two most selective campuses in Berkeley and Los Angeles (UCLA). According to the head of the University of California system, "If we had affirmative action as one of our tools, we'd do somewhat better for Hispanics, and we’d probably do significantly better for African-Americans” (Pérez-Peña, 2012).

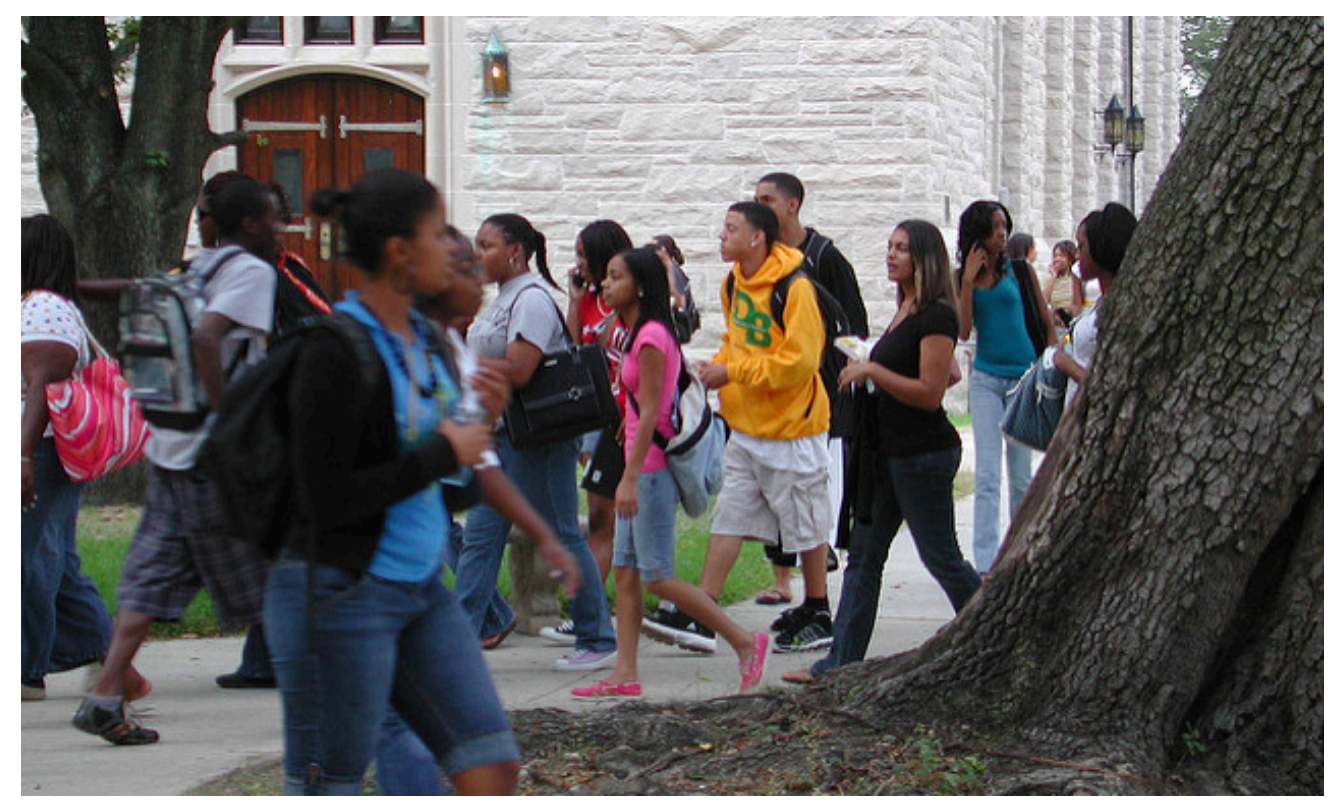

Although colleges and universities are making a greater effort to attract and retain low-income students and students of color, these students remain greatly underrepresented at institutions of higher education.

Bart Everson - $\underline{\text { Students }}$ - CC BY 2.0.

In three states with bans on affirmative action, California, Florida, and Texas, public universities automatically 
admit the top students in every high school. Because many of their high schools are predominantly African American or Latino, this strategy has helped counter their bans on affirmative action. However, because many more high schools in these states are mostly Latino rather than African American, the strategy has proven more beneficial for Latino admissions than for African American admissions (Pérez-Peña, 2012).

Partly because affirmative action is so controversial, attention has begun to focus on the low numbers of lowincome students at many colleges and universities, and especially at the more selective institutions as ranked by US News \& World Report and other sources. Many education scholars and policymakers feel that increasing the number of low-income students would not only help these students but also increase campus diversity along the lines of socioeconomic status and race/ethnicity (since students of color are more likely to be from lowincome backgrounds). Efforts to increase the number of low-income students, these experts add, would avoid the controversy that has surrounded affirmative action.

In response to this new attention to social class, colleges and universities have begun to increase their efforts to attract and retain low-income students, which a recent news report called "one of the most underrepresented minority groups at many four-year colleges” (Schmidt, 2010). The dean of admissions and financial aid at Harvard University summarized these efforts as follows: "I honestly cannot think of any admissions person I know who is not looking - as sort of a major criteria [sic] of how well their year went-at how well they did in attracting people of different economic backgrounds” (Schmidt, 2010).

As part of their strategy to attract and retain low-income students, Harvard and other selective institutions are now providing financial aid to cover all or most of the students' expenses. Despite these efforts, however, the US higher education system has become more stratified by social class in recent decades: The richest students now occupy a greater percentage of the enrollment at the most selective institutions than in the past, while the poorest students occupy a greater percentage of the enrollment at the least selective four-year institutions and at community colleges (Schmidt, 2010).

\section{Legacy Admissions}

At highly selective colleges and universities, the policy of legacy admissions makes it easier for certain wealthy students to gain admission. Under this policy, students who are daughters or sons (or other relatives) of graduates of the institution are given preference in admissions. Because their parents are very likely to be wealthy, a legacy admissions policy in effect amounts to what critics call "affirmative action for the rich" (Kahlenberg, 2010). According to recent research, being a child of an alumna or alumnus of one of these institutions increases one's chances of admission by forty-five percentage points (Kahlenberg, 2011). Thus if a nonlegacy applicant with certain qualifications would ordinarily have a 40 percent chance of being admitted, a legacy applicant with the same qualifications would have an 85 percent chance of being admitted. Critics say legacy admissions give an unfair advantage to wealthy students and use up valuable spots that should go to more qualified students from more varied socioeconomic backgrounds. As one critic puts it, "It's fundamentally unfair because it's a preference that advantages the already advantaged. It has nothing to do with the individual merit of the applicant” (Lewin, 2010, p. A12). 


\section{Graduation Rates}

For the sake of students and of their colleges and universities, it is important that as many students as possible go on to earn their diplomas. However, only 57 percent of students at four-year institutions graduate within six years. This figure varies by type of institution. At the highly selective private institutions, 80-90 percent or more of students typically graduate within six years, while at many public institutions, the graduate rate is about 50 percent. Academic and financial difficulties and other problems explain why so many students fail to graduate (Gonzalez, 2010).

The 57 percent overall rate masks a racial/ethnic difference in graduation rates: While 60 percent of white students graduate within six years, only 49 percent of Latino students and 40 percent of African American students graduate. At some institutions, the graduation rates of Latino and African American students match those of whites, thanks in large part to exceptional efforts by these institutions to help students of color. As one expert on this issue explains, "What colleges do for students of color powerfully impacts the futures of these young people and that of our nation" (Gonzalez, 2010). Another expert placed this issue into a larger context: "For both moral and economic reasons, colleges need to ensure that their institutions work better for all the students they serve" (Stephens, 2010).

In this regard, it is important to note that the graduation rate of low-income students from four-year institutions is much lower than the graduation rate of wealthier students (Luhby, 2011). In fact, students with high test scores and low-income parents are less likely to graduate than students with low test scores and high-income parents (Krugman, 2012).

Low-income students drop out at higher rates because of academic and financial difficulties and family problems. Their academic and financial difficulties are intertwined. Low-income students often have to work many hours per week during the academic year to be able to pay their bills. Because their work schedules reduce the time they have for studying, their grades may suffer. This general problem has been made worse by cutbacks in federal grants to low-income students that began during the 1980s. These cutbacks forced low-income students to rely increasingly on loans, which have to be repaid. This fact leads some to work more hours during the academic year to limit the loans they must take out, and their increased work schedule again may affect their grades.

Low-income students face additional difficulties beyond the financial (Berg, 2010). Their writing and comprehension skills upon entering college are often weaker than those of wealthier students. If they are firstgeneration college students (meaning that neither parent went to college), they often have problems adjusting to campus life and living amid students from much more advantaged backgrounds.

\section{Campus Violence}

Earlier we discussed violence in the elementary and secondary schools. Violence can also happen on college and university campuses, although shootings are very rare. However, three recent examples illustrate that students and faculty are not immune from gun violence. In April 2012, a former student lined up and then shot and killed seven people and wounded three others at Oikos University in Oakland, California. In February 2010, Amy Bishop, a 
biology professor at the University of Alabama in Huntsville who had recently been denied tenure, allegedly shot and killed three faculty at a department meeting and wounded three others. Almost three years earlier, a student at Virginia Tech went on a shooting rampage and killed thirty-two students and faculty before killing himself.

Other types of violence are more common on the nation's campuses. Chapter 4 "Gender Inequality" noted that an estimated 20-30 percent of women students have been raped or sexually assaulted (including attempts), usually by a male student who was an acquaintance, friend, or intimate partner. Beyond rape and sexual assault, students are also sometimes assaulted or robbed. Federal victimization data show that about 6 percent of college students are victims of at least one act of all these types of violence annually (Baum \& Klaus, 2005). Because there are about 20 million students in college, this 6 percent figure translates to about 1.2 million annual violent victimizations at US colleges and universities. It is important to note that the 6 percent rate masks a significant gender difference: 8 percent of male students experience at least one act of violence annually, compared to about 4 percent of female students. Male students are thus twice as likely as female students to be victimized by violence. For just rape and sexual assault, though, female students are much more likely than male students to be victimized.

Many colleges and universities have been accused of not taking rape and sexual assault seriously in what one news report called a "struggle for justice” for campus rape victims (Lipka, 2011; Shapiro, 2010). This criticism takes two forms. First, campuses ignore many reports of rape and sexual assault altogether. Second, they hand out weak or no discipline in cases when they do heed reports. One student's account of her university's lack of followup to her alleged rape illustrates this criticism. "It was as if they were going above and beyond to ensure nothing would be done in my case," the woman later recalled. "I felt extremely disappointed to know that the institution in charge of ensuring my safety did not recognize the massive distress the sexual assault caused me. Furthermore, I was disappointed that when I sought justice through their system, I was treated with hostility and disrespect. I was clearly not believed, and was often blamed for what had happened” (Webley, 2011).

\section{Key Takeaways}

- The cost of higher education and other problems make it difficult for low-income students and students of color to enter college and to stay in college once admitted.

- Many college students have academic and personal problems that lead them to flounder and to seek psychological counseling.

- Many campuses continue to lack racial and social class diversity, and affirmative action remains very controversial.

- Physical and sexual violence is a general problem on the nation's campuses. At least one-fifth of college women are raped or sexually assaulted.

\section{For Your Review}

1. If you were the director of admissions at a university, what steps would you take to increase the number of applications from low-income students?

2. Do you think alcohol use is to blame for most campus violence, or are there other important factors at work? 
Explain your answer.

\section{References}

Baum, K., \& Klaus, P. (2005). Violent victimization of college students, 1995-2002. Washington, DC: Bureau of Justice Statistics.

Berg, G. A. (2010). Low-income students and the perpetuation of inequality: Higher education in America. Burlington, VT: Ashgate.

College Board, The. (2012). What it costs to go to college. Retrieved from http://www.collegeboard.com/student/ pay/add-it-up/4494.html.

Epstein, J. (2010, May 4). Stability in student mental health. Inside Higher Ed. Retrived from http://www.insidehighered.com/news/2010/2005/2004/counseling.

Golden, S. (2010, September 15). When college is not the best time. Inside Higher Ed. Retrieved from http://www.insidehighered.com/news/2010/2009/2015/leibow.

Gonzalez, J. (2010, August 9). Reports highlight disparities in graduation rates among white and minority students. The Chronicle of Higher Education. Retrieved from http://chronicle.com/article/Reports-HighlightDisparities/123857.

Kahlenberg, R. (2011, January 6). Do legacy preferences count more than race? The Chronicle of Higher Education. Retrieved from http://chronicle.com/blogs/innovations/do-legacy-preferences-count-more-than-race/ $\underline{28294}$.

Kahlenberg, R. D. (Ed.). (2010). Affirmative action for the rich: Legacy preferences in college admissions. New York, NY: Century Foundation.

Krugman, P. (2012, January 9). America’s unlevel field. New York Times, p. A19.

Lewin, T. (2010, January 9). Study finds family connections give big advantage in college admissions. New York Times, p. A12.

Lipka, S. (2011, March 20). Colleges face conflicting pressures in dealing with cases of sexual assault. The Chronicle of Higher Education. Retrieved from http://chronicle.com/article/Colleges-Face-Conflicting/126818/.

Luhby, T. (2011, November 28). College graduation rates: Income really matters. CNN Money. Retrieved from http://money.cnn.com/2011/11/21/news/economy/income_college/index.htm.

Pérez-Peña, R. (2012, April 2). To enroll more minority students, colleges work around the courts. New York Times, p. A9. 
Pope, J. (2011, November 3). Average student loan debt: \$25,250. The Huffington Post. Retrieved from http://www.huffingtonpost.com/2011/2011/2003/average-student-debt-2525_n_1073335.html.

Schmidt, P. (2010, September 19). In push for diversity, colleges pay attention to socioeconomic class. The Chronicle of Higher Education. Retrieved from http://chronicle.com/article/Socioeconomic-Class-Gains/ 124446/?key=TjgnJ124441E124444aHZGM124443hiaT124448TZzgHPSRqZR124448jY124443A YPn124440pbl124449WFQ\%124443D\%124443D.

Shapiro, J. (2010, February 24). Campus rape victims: A struggle for justice. National Public Radio. Retrieved from http://www.npr.org/templates/story/story.php?storyId=124001493.

Sieben, L. (2011, March 14). Nearly a third of college students have had mental-health counseling, study finds. The Chronicle of Higher Education. Retrieved from http://chronicle.com/article/Nearly-a-Third-of-College/ $\underline{126726 .}$.

Stephens, L. (2010). Reports reveal colleges with the biggest, smallest gaps in minority graduation rates in the US. Washington, DC: The Education Trust.

Stripling, J. (2010, September 15). Refining aid choices. Inside Higher Ed. Retrieved from http://www.insidehighered.com/news/2010/2009/2015/discounting.

Webley, K. (2011, April 18). It's not just Yale: Are colleges doing enough to combat sexual violence? Time. Retrieved from http://www.time.com/time/nation/article/0,8599,2065849-2065841,2065800.html. 


\subsection{Improving Schools and Education}

\section{Learning Objectives}

1. Understand how helpful good schooling can be to improve the lives of low-income children.

2. Discuss the importance of good teachers.

3. List any three strategies that will improve the education of low-income students.

This concluding section focuses mostly on elementary and secondary education, given its critical importance for young people's development. As we consider how to improve the nation's schools, and especially how to improve outcomes for low-income students and students of color, we need to keep in mind an important consideration: Good schooling can make an important difference for these students, and good teachers can greatly help lowincome students (Chetty et al., 2011). However, a large body of research demonstrates that students' family and neighborhood backgrounds actually matter much more than the quality of schooling for their school performance (Downey \& Gibbs, 2012; Ladd \& Fiske, 2011). Good schooling, then, can only go so far in overcoming the many strikes that low-income students and those of color have against them even before they enter kindergarten and the problems they continue to experience thereafter. As one education writer observes,

Let's be realistic: Teachers aren't miracle workers. There's only so much they can do to address problems that troubled students bring to class every day, including neglect, abuse, and unaddressed medical and mental health issues. The obvious and subtle ways that poverty inhibits a child's ability to learn—from hearing, visual and dental problems to higher asthma rates to diminished verbal interaction in the home-have been well-documented.

So let's seek to improve the state of families. Attacking schools and teachers makes everyone feel like a reformer, but the problems begin long before a child steps through the schoolhouse door. (Farhi, 2011)

\section{Teachers and School Reform}

This understanding of low-income students' school performance has important implications for school-reform efforts. For example, if good schooling cannot ordinarily be expected to have a large impact on poor students' lives, this fact calls into question certain aspects of the "No Child Left Behind" movement of the last decade. This movement, begun by the federal government, uses students' scores on standardized tests to assess the quality of their schools. Perhaps inevitably, the subsequent growth in standardized testing has meant that teachers' performance ratings have become increasingly tied to their students' standardized test scores. However, because students' test scores reflect their socioeconomic backgrounds and other nonschool factors much more than the quality of their schooling, these scores are not a good measure of teachers' performance. As one education specialist summarizes this situation, "Of all the goals of the education reform movement, none is more elusive 
than developing an objective model to assess teachers. Studies have shown that over time, test scores do not provide a consistent means of separating good from bad instructors. Test scores are an inadequate proxy for quality because too many factors outside the teachers' control can influence student performance from year to year-or even from classroom to classroom during the same year” (Russell, 2011, p. WK12).

\section{The Need for More General Social Reform}

The importance of students' family and neighborhood backgrounds has a significant implication beyond the issue of teacher assessment: To improve low-income students' school performance, our society must address the problems of poverty and racial/ethnic inequality. As two sociologists argue this point, "If we are serious about improving American children's school performance, we will need to take a broader view of education policy. In addition to school reform, we must also aim to improve children's lives where they spend the vast majority of their time-with their families and in their neighborhoods" (Downey and Gibbs, 2012, p. 85). Chapter 2 "Poverty" and Chapter 3 "Racial and Ethnic Inequality" discussed strategies to reduce poverty and racial/ethnic inequality; these strategies would also help improve the school performance of low-income students and those of color.

\section{A School Reform Agenda}

Despite the need to address poverty and racial inequality, it remains true that schools with decaying buildings, uncommitted teachers, and other problems cannot be expected to produce students with even adequate levels of academic achievement. It is thus critical, says poverty expert Mark Robert Rank (2004, p. 208), to do everything possible to provide a quality education to the nation's poor children: "To deny children the fundamental right to a decent education is both morally wrong and bad social policy. It flies in the face of the American concept of equality of opportunity...Countless studies have documented the immediate and lingering effects of disparate educational outcomes on later life. Improving public education for low-income children is absolutely essential.”

In short, good schools and good teachers do matter. In particular, good elementary- and middle-school teachers have been shown to have a lifelong impact on their students: students with good teachers are more likely years later to have lower teenage pregnancy rates and higher college attendance rates, and they are also more likely to have higher salaries in adulthood (Lowrey, 2012).

Education experts urge several measures to improve the nation's schools and the education of American children (Madland \& Bunker, 2011; Rokosa, 2011; Rothstein, 2010; Smerdon \& Borman, 2009). These measures include the following:

- Have smaller schools and smaller classrooms.

- Provide more funding for schools, especially those in low-income neighborhoods.

- Repair decaying school buildings.

- Increase teachers’ pay to attract more highly qualified applicants.

- Hold teachers more accountable for their students’ learning, while recognizing the obstacles that 
teachers of low-income students must overcome.

- Expand early childhood (preschool) education.

On the national level, these steps will cost billions of dollars, but this expenditure promises to have a significant payoff by saving money in the long run and reducing crime, health problems, and other social ills.

As the United States tries to improve its schools, it is also important to attend to the emotional and physical health needs of low-income children (Lowe, 2011). Because of the many problems these children experience in their families and neighborhoods, including alcohol and drug abuse, hunger, illness, marital conflict, and violence, their emotional and physical health may often suffer. They cannot be expected to do well in school unless they are in good health in both respects. For this reason, many schools are now partnering with community health organizations and other agencies to address the emotional and physical health needs of schoolchildren, often by establishing well-staffed and well-equipped health centers inside the schools. Another effort involves recess (yes, recess!), as evidence indicates that children are healthier and better behaved if they go out for recess for a sufficient amount of time.

In a related issue, it is also important for the nation to try to improve parenting skills if it hopes to improve the educational performance and attainment of low-income students (Roksa \& Potter, 2011). As Chapter 10 "The Changing Family” discussed, low-income parents are less likely to read and talk with their young children, and this problem impairs their children's cognitive and neurological development. Home visits and other efforts by professionals to encourage parents of infants and toddlers to engage in these activities regularly hold potential for improving their children's ability to learn and do well in school.

School violence and bullying are two other problems that must also be addressed. Several of the steps just outlined should reduce school violence, but other measures should also help. One example involves antibullying programs, which include regular parent meetings, strengthened playground supervision, and appropriate discipline when warranted. Research indicates that these programs reduce bullying by 20-23 percent on the average (Farrington \& Ttofi, 2009). Any reduction in bullying should in turn help reduce the likelihood of school massacres like Columbine, because, as noted earlier, many of the students committing these massacres had been humiliated and bullied by other students. More generally, because the roots of school violence are also similar to the roots of youth violence outside the schools, measures that reduce youth violence should also reduce school violence. As discussed in previous chapters, such measures include early childhood prevention programs for youths at risk for developmental and behavioral problems, parenting training programs, and policies that provide income and jobs for families living in poverty.

At the level of higher education, our discussion highlighted the fact that social inequality in the larger society also plays out in colleges and universities. The higher dropout rates for low-income students and for students of color in turn contribute to more social inequality. Colleges and universities need to do everything possible to admit these students and then to help them once they are admitted, as they face many obstacles and difficulties that white students from more advantaged backgrounds are much less likely to encounter. 


\section{Key Takeaways}

- Good schooling can be very helpful for low-income students, but these students' socioeconomic backgrounds have more impact than schooling on their futures.

- For this reason, more general social reform must accompany effective school reform.

- Several strategies, including smaller classes and better-paid teachers, will help improve the learning of lowincome students.

\section{For Your Review}

1. Write a short essay in which you outline what a school's superintendent might do to improve the learning of the school district's elementary school students.

2. Why do you think the United States has not more vigorously pursued the school reform agenda outlined in this section?

\section{References}

Chetty, R., Friedman, J. N., Hilger, N., Saez, E., Schanzenbach, D. W., \& Yagan, D. (2011). How does your kindergarten classroom affect your earnings? Evidence from Project STAR. Quarterly Journal of Economics, 126, 1593-1660.

Downey, D. B., \& Gibbs, B. G. (2012). How schools really matter. In D. Hartmann \& C. Uggen (Eds.), The Contexts Reader (2nd ed., pp. 80-86). New York, NY: W. W. Norton.

Farhi, P. (2011, May 20). Five myths about America's schools. The Washington Post. Retrieved from http://www.washingtonpost.com/opinions/.

Farrington, D. P., \& Ttofi, M. M. (2009). Reducing school bullying: Evidence-based implications for policy. Crime and Justice: A Review of Research, 39, 281-345.

Ladd, H. F., \& Fiske, E. B. (2011, December 12). Class matters. Why won’t we admit it? New York Times, p. A23.

Lowe, J. I. (2011, January 13). To boost learning, start with emotional health. Education Week. Retrieved from http://www.edweek.org/ew/articles/2011/12/07/13lowe_ep.h31.html.

Lowrey, A. (2012, January 6). Big study links good teachers to lasting gain. New York Times, p. A1.

Madland, D., \& Bunker, N. (2011). Middle-class societies invest more in public education: A stronger middle class is associated with higher levels of spending on education. Washington, DC: Center for American Progress. 
Rank, M. R. (2004). One nation, underprivileged: Why American poverty affects us all. New York, NY: Oxford University Press.

Rokosa, J. (2011). Fighting the war on poverty with early childhood education. Retrieved January 7, 2012, from http://www.americanprogress.org/issues/2011/10/poverty early childhood education.html.

Roksa, J., \& Potter, D. (2011). Parenting and academic achievement: Intergenerational transmission of educational advantage. Sociology of Education, 84, 299-321.

Rothstein, R. (2010). How to fix our schools. Retrieved January 11, 2012, from http://www.epi.org/publication/ ib286/.

Russell, H. B. (2011, May 1). A new measure for classroom quality. New York Times, p. WK12.

Smerdon, B. A., \& Borman, K. M. (Eds.). (2009). Saving America's high schools. Washington, DC: Urban Institute Press. 


\subsection{End-of-Chapter Material}

\section{Summary}

1. Education is both formal and informal. Formal education occurs in schools under specially trained teachers, while informal education takes place primarily in the home, with parents as instructors.

2. In the early nineteenth century in the United States, a movement for free, compulsory education began. Reasons for interest in such education included the perceived needs to unify the country, to "Americanize" immigrants, and to give members of the working class the skills, knowledge, and discipline they needed to be productive workers.

3. In the United States, social class, race and ethnicity, and gender all affect educational attainment. Poor people end up with less schooling than middle- and upper-class people, and African Americans and Latinos have lower educational attainment than whites and Asian Americans. Although women had less schooling than men in the past, today they are more likely to graduate from high school and to attend college.

4. Education in the United States has a significant impact on two areas. One is income: the higher the education, the higher the income. The second is attitudes: the higher the education, the greater the tolerance for nontraditional behaviors and viewpoints.

5. Sociological perspectives on education fall into the functionalist, conflict, and symbolic interactionist approaches discussed in earlier chapters. Functional theory stresses the functions education serves for society, including socialization, social placement, social integration, and social and cultural innovation. Conflict theory stresses that education perpetuates and reinforces existing social inequality for several reasons, including the use of tracking and inequality in schooling between rich and poor communities. Symbolic interactionism emphasizes the social interaction that's part of schooling and calls attention to the ways in which the treatment of students as smart or dull can affect how much they end up learning.

6. Several issues and problems affect education in the United States today. Many schools are decrepit and lack sufficient books and equipment, and many are also segregated by race and ethnicity. Increasing interest in school choice has led to controversy over whether the government should provide aid to parents to send their children to private and parochial schools. Additional controversy surrounds the issue of single-sex schools for girls. Finally, school violence is an issue of continuing concern; however, the vast majority of schools are very safe for their students, teachers, and other personnel. Bullying is more common, with about one-third of students bullied every year.

7. At the level of higher education, students of color and those from low-income backgrounds are less likely to attend college at all, and if they do attend, they are less likely to graduate.

\section{Using What You Know}

You are the principal of a middle school in a poor urban neighborhood. Your classrooms lack basic supplies, your roof often leaks, and an ominous odor often arises from your school's water system. You have appealed many times to the school district for additional funds to deal with all these problems, but these funds have not been provided. What, if anything, do you do next? 


\section{What You Can Do}

To help deal with the education problems discussed in this chapter, you may wish to do any of the following:

1. Volunteer to tutor students at a local school or after-school program.

2. If your college or university has low numbers of low-income students, establish a student group to encourage your school to admit more such students.

3. Start or join a group on your campus to call attention to the need for responsible alcohol use, as drinking is associated with much campus violence. 


\section{Chapter 12: Work and the Economy}

\section{Social Problems in the News}

"White-Collar Workers Join Crowds Straining Food Banks," the headline said. Amid the nation's continuing faltering economy, middle-class families across the United States who had lost their jobs were being forced to get free food at food pantries. One woman, who lost her job as a consultant, said her family’s savings had dwindled to less than \$200. "Without the network of food pantries around us, I don't know how we would have eaten," she said. As more middleclass workers were turning to the food pantries, the pantries' donations had fallen. As one food pantry official put it, "We're seeing many faces from the middle class who had been donors who now need support from our food bank. Right now, our donations are softer than we would like them to be.” Meanwhile, a survey of college-educated New York residents found that 30 percent said they had trouble affording food.

Source: Cole, 2012

One of the most momentous events of the twentieth century was the Great Depression, which engulfed the United States in 1929 and spread to the rest of the world, lasting almost a decade. Millions were thrown out of work, and bread lines became common. In the United States, a socialist movement gained momentum for a time as many workers blamed US industry and capitalism for their unemployment.

The Depression involved the failing of the economy. The economy also failed in the United States beginning in late 2007, when the country entered what has been called the Great Recession. Although the recession has officially ended, the jobless rate remains much higher than before the recession. The news article that began this chapter provides just a small illustration of the millions of lives that have been affected.

This chapter examines the many problems related to work and the economy in the United States today. It also examines the related issues of economic inequality and economic mobility. As we shall see, the United States has a mediocre record in both these areas when compared to other wealthy democracies.

\section{References}

Cole, P. (2012, January 11). White-collar workers join crowd straining food banks. Bloomberg.com. Retrieved from $\quad$ http://www.bloomberg.com/news/2012-01-11/mercedes-owners-ph-d-holders-join-swelling-crowdstraining-soup-kitchens.html. 


\subsection{Overview of the Economy}

\section{Learning Objectives}

1. Describe the three sectors of the economy.

2. Distinguish the two major economic systems in the world today.

3. Discuss the advantages and disadvantages of capitalism and socialism.

When we hear the term economy, it is usually in the context of how the economy "is doing": Is inflation soaring or under control? Is the economy growing or shrinking? Is unemployment rising, declining, or remaining stable? Are new college graduates finding jobs easily or not? All these questions concern the economy, but sociologists define economy more broadly as the social institution that organizes the production, distribution, and consumption of a society's goods and services. Defined in this way, the economy touches us all. Keep in mind that the economy is not the same as government, which is the social institution through which power is distributed and exercised. Economy and government are social institutions that are certainly intertwined, but conceptually they are distinct.

The economy is composed of three sectors. The primary sector is the part of the economy that takes and uses raw materials directly from the natural environment. Its activities include agriculture, fishing, forestry, and mining. The secondary sector of the economy transforms raw materials into finished products and is essentially the manufacturing industry. Finally, the tertiary sector is the part of the economy that provides services rather than products; its activities include clerical work, health care, teaching, and information technology services.

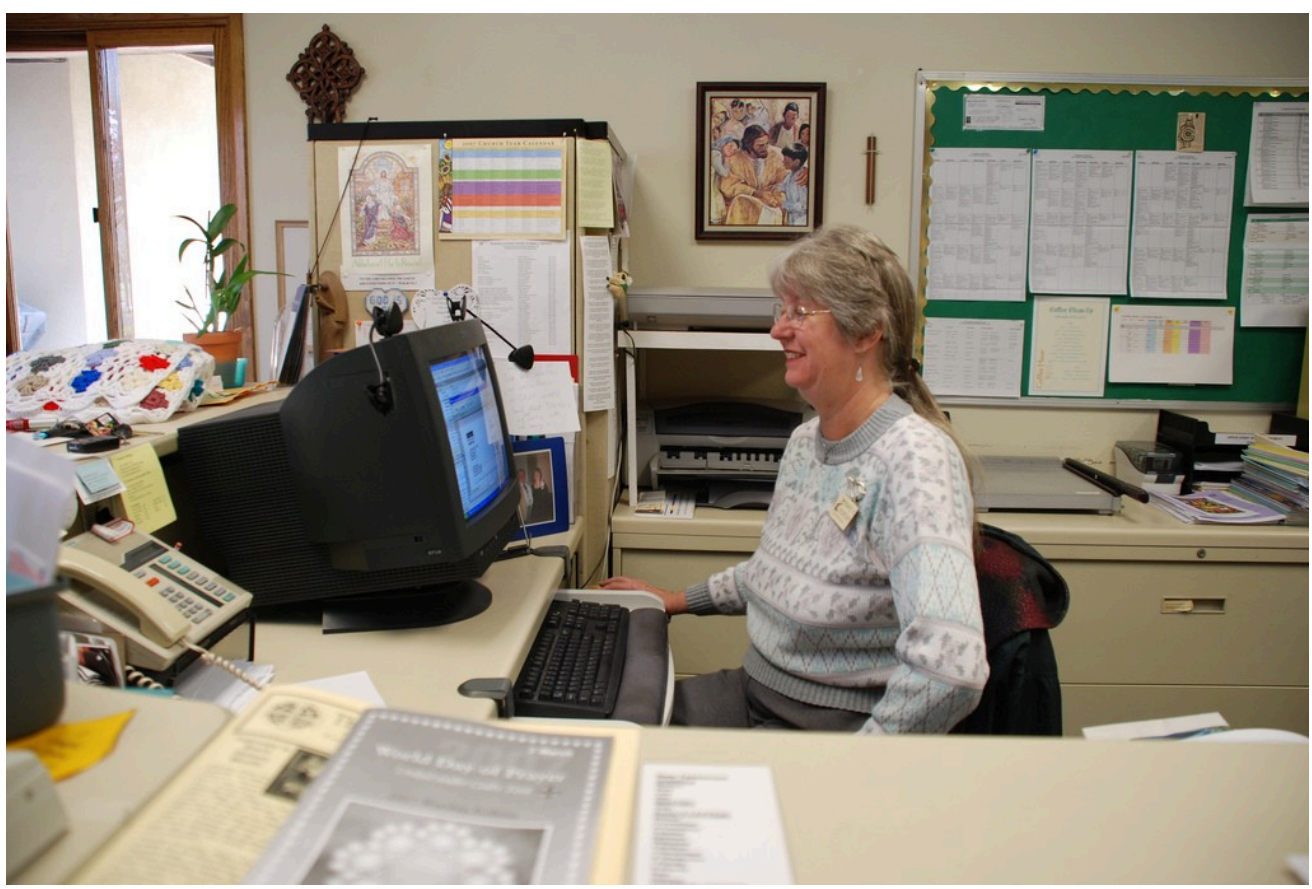


Clerical work and other occupations that provide services rather than products constitute the tertiary sector in the economy.

Wikimedia Commons - CC BY 2.0.

Societies differ in many ways, but they all have to produce, distribute, and consume goods and services. How this happens depends on which sectors of the economy are most important. This latter variable in turn depends heavily on the level of a society's development. Generally speaking, the less developed a society's economy, the more important its primary sector; the more developed a society's economy, the more important its tertiary sector. As societies developed economically over the centuries, the primary sector became less important and the tertiary sector became more important. The primary sector was certainly the only sector in the hunting-and-gathering societies that existed thousands of years ago, while the tertiary sector dominates much of the economy in today's wealthiest democracies.

\section{Types of Economic Systems}

The two major economic systems in modern societies are capitalism and socialism. In practice, no one society is purely capitalist or socialist, so it is helpful to think of capitalism and socialism as lying on opposite ends of a continuum. Societies' economies mix elements of both capitalism and socialism but do so in varying degrees, so that some societies lean toward the capitalist end of the continuum, while other societies lean toward the socialist end. For example, the United States is a capitalist nation, but the government still regulates many industries to varying degrees. The industries usually would prefer less regulation, while their critics usually prefer more regulation. The degree of such regulation was the point of controversy after the failure of banks and other financial institutions in 2008 and 2009. Let’s see how capitalism and socialism differ.

\section{Capitalism}

Capitalism is an economic system in which the means of production are privately owned. By means of production, we mean everything - land, tools, technology, and so forth - that is needed to produce goods and services. As outlined by famed Scottish philosopher Adam Smith (1723-1790), widely considered the founder of modern economics, the most important goal of capitalism is the pursuit of personal profit (Smith, 1776/1910). As individuals seek to maximize their own wealth, society as a whole is said to benefit. Goods get produced, services are rendered, people pay for the goods and services they need and desire, and the economy and society as a whole prosper. 


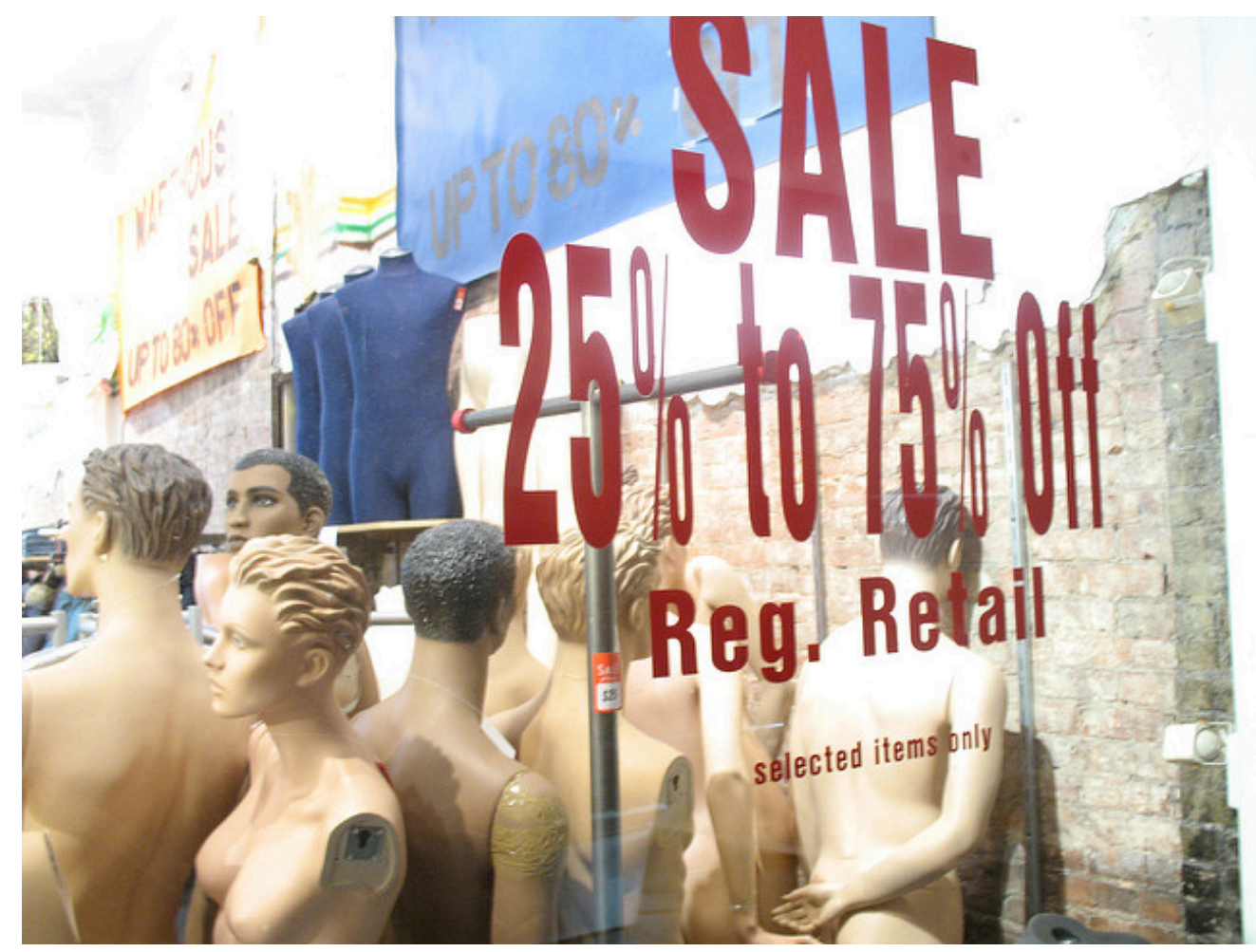

One important hallmark of capitalism is competition for profit. This competition is thought to help ensure the best products at the lowest prices, as companies will ordinarily try to keep their prices as low as possible to attract buyers and maximize their sales.

Consumerist Dot Com - sale window - CC BY 2.0.

As people pursue personal profit under capitalism, they compete with each other for the greatest profits. Businesses try to attract more demand for their products in many ways, including lowering prices, creating better products, and advertising how wonderful their products are. In capitalist theory, such competition helps ensure the best products at the lowest prices, again benefiting society as a whole. Such competition also helps ensure that no single party controls an entire market. According to Smith, the competition that characterizes capitalism should be left to operate on its own, free of government intervention or control. For this reason, capitalism is often referred to as laissez-faire (French for "leave alone") capitalism, and terms to describe capitalism include the freeenterprise system and the free market.

The hallmarks of capitalism, then, are private ownership of the means of production, the pursuit of profit, competition for profit, and the lack of government intervention in this competition.

\section{Socialism}

The features of socialism are the opposite of those just listed for capitalism and were spelled out most famously by Karl Marx. Socialism is an economic system in which the means of production are collectively owned, usually by the government. Whereas the United States has several airlines that are owned by airline corporations, a socialist society might have one government-owned airline. 
The most important goal of socialism is not the pursuit of personal profit but rather work for the collective good: The needs of society are considered more important than the needs of the individual. Because of this view, individuals do not compete with each other for profit; instead they work together for the good of everyone. If under capitalism the government is supposed to let the economy alone, under socialism the government controls the economy.

The ideal outcome of socialism, said Marx, would be a truly classless or communist society. In such a society all members are equal, and stratification does not exist. Obviously Marx's vision of a communist society was never fulfilled, and nations that called themselves communist departed drastically from his vision of communism.

Recall that societies can be ranked on a continuum ranging from mostly capitalist to mostly socialist. At one end of the continuum, we have societies characterized by a relatively free market, and at the other end we have those characterized by strict government regulation of the economy. Figure 12.1 "Capitalism and Socialism across the Globe” depicts the nations of the world along this continuum. Capitalist nations are found primarily in North America and Western Europe but also exist in other parts of the world.

Figure 12.1 Capitalism and Socialism across the Globe

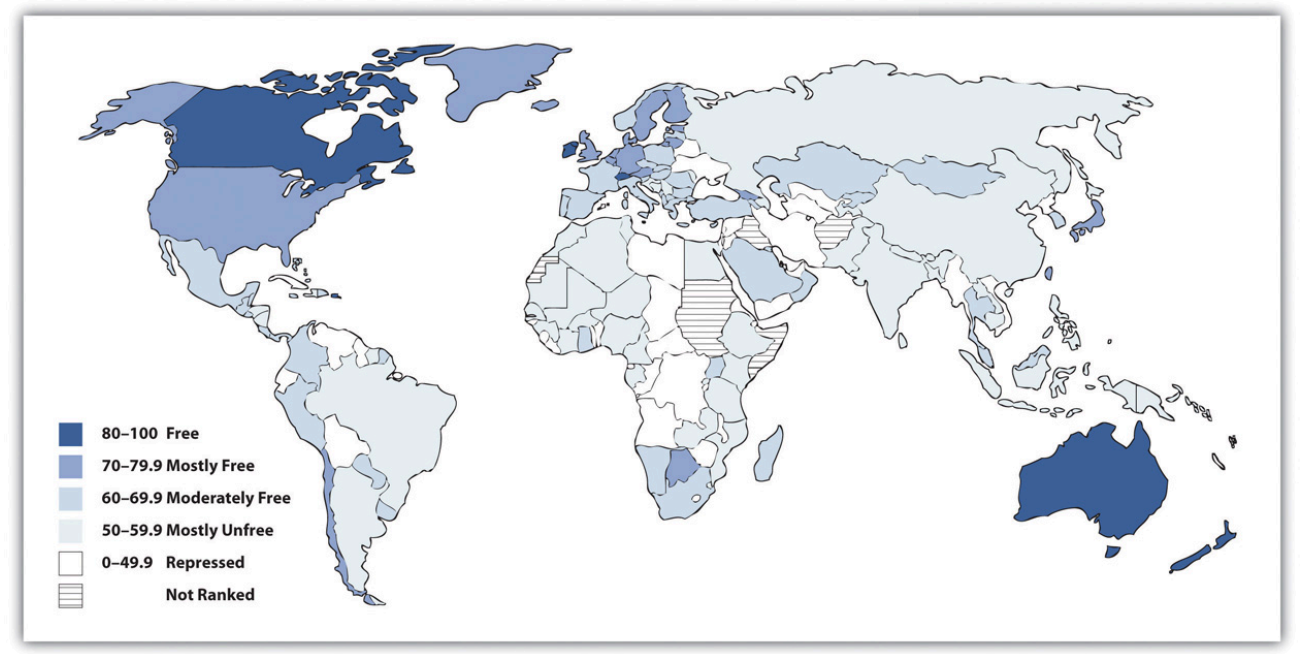

Source: Adapted from The Heritage Foundation. (2010). Distribution of economic freedom. Retrieved from http://www.heritage.org/ index/pdf/2010/Index2010_map.pdf.

\section{Comparing Capitalism and Socialism}

People have debated the relative merits of capitalism and socialism at least since the time of Marx (Bowles, 2012; Cohen, 2009). Compared to socialism, capitalism has several advantages. It produces greater economic growth and productivity, at least in part because it provides more incentives (i.e., profit) for economic innovation. It also is often characterized by greater political freedom in the form of civil rights and liberties. As an economic system, capitalism seems to lend itself to personal freedom: Because its hallmarks include the private ownership of the means of production and the individual pursuit of profit, there is much more emphasis in capitalist societies on the 
needs and desires of the individual and less emphasis on the need for government intervention in economic and social affairs.

Yet capitalism also has its drawbacks. There is much more economic inequality in capitalism than in socialism. Although capitalism produces economic growth, not all segments of capitalism share this growth equally, and there is a much greater difference between the rich and poor than under socialism. People can become very rich in capitalist nations, but they can also remain quite poor.

Another possible drawback depends on whether you prefer competition or cooperation. It is often said that important values in the United States include competition and individualism, both of which arguably reflect this nation's capitalist system. Children in the United States are raised with more of an individual orientation than children in socialist societies, who learn that the needs of their society are more important than the needs of the individual. Whereas US children learn to compete with each other for good grades, success in sports, and other goals, children in socialist societies learn to cooperate to achieve tasks.

More generally, capitalism is said by its critics to encourage selfish and even greedy behavior: If individuals try to maximize their profit, they do so at the expense of others. In competition, someone has to lose. A company's ultimate aim, and one that is generally lauded, is to maximize its profits by driving another company out of the market altogether. If so, that company succeeds even if some other party is hurting. The small mom-and-pop grocery stores, drugstores, and hardware stores are almost a thing of the past, as big-box stores open their doors and drive their competition out of business. To its critics, then, capitalism encourages harmful behavior, and there are many losers in capitalism. Yet it is precisely this type of behavior that is taught in business schools.

As a business columnist recently summarized these problems of capitalism,

Why does one have to be a Democrat or a liberal to complain bout the way business gets done? Like most Americans, I am OK with the notion that free-market capitalism produces winners and losers. What I don't like is that it also produces liars, cheaters, swindlers, self-dealing narcissists, overleveraged idiots and reckless egomaniacs out to abuse their economic power and take unfair advantage of hard-working people.

I don’t complain about fraud, abuse and folly because I am antibusiness or anticapitalist... What free-market capitalism hasn’t yet figured out is what to do with all its losers. At this point in the economic cycle, they are piling up like used tires: debtsacked college kids who can’t get jobs, foreclosed homeowners, failed small-business owners, pink-slipped employees, [and] millions suddenly ejected from the middle class. (Lewis, 2012, p. C3)

\section{Democratic Socialism}




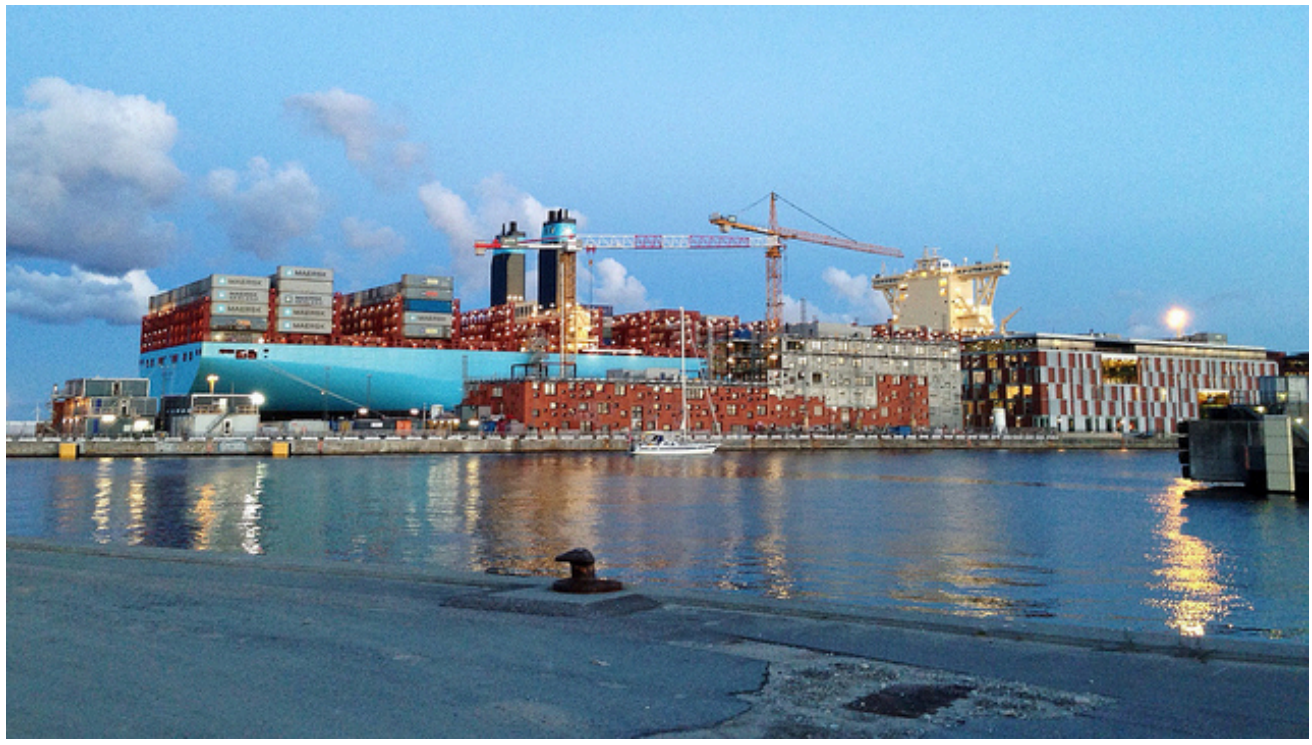

The economies of Denmark, pictured here, and several other Western European nations feature a combination of capitalism and socialism that is called democratic socialism. In these economies, the government owns important industries, but private property and political freedom remain widespread.

bobthemagicdragon - Majestic - CC BY-NC-ND 2.0.

Some nations combine elements of both capitalism and socialism and are called social democracies, while their combination of capitalism and socialism is called democratic socialism. In these nations, which include Denmark, Sweden, and several other Western European nations, the government owns several important industries, but much property remains in private hands, and political freedom is widespread. The governments in these nations have extensive programs to help the poor and other people in need. Although these nations have high tax rates to help finance their social programs, their experience indicates it is very possible to combine the best features of capitalism and socialism while avoiding their faults (Russell, 2011) (see Note 12.10 "Lessons from Other Societies").

\section{Lessons from Other Societies}

\section{Democratic Socialism in Scandinavia}

The five Scandinavian nations, also called the Nordic nations, are Denmark, Finland, Iceland, Norway, and Sweden. These nations differ in many ways, but they also share many similarities. In particular, they are all social democracies, as their governments own important industries while their citizens enjoy much political freedom. Each nation has the three branches of government with which most people are familiar-executive, judicial, and legislative-and each nation has a national parliament to which people are elected by proportional representation.

Social democracies like the Scandinavian nations are often called controlled capitalist market economies. The word controlled here conveys the idea that their governments either own industries or heavily regulate industries they do not own. A key feature of these social democracies' economies is that inequality in wealth and income is not generally tolerated. Employers, employees, and political officials are accustomed to working closely to ensure that poverty and its related problems are addressed as much as possible and in as cooperative a manner as possible.

Underlying this so-called social welfare model is a commitment to universalism. All citizens, regardless of their socioeconomic status or family situation, receive various services, such as child care and universal health care, that are 
free or heavily subsidized. To support this massive provision of benefits, the Scandinavian nations have very high taxes that their citizens generally accept as normal and necessary.

The Scandinavian nations rank at or near the top in international comparisons of health, education, economic wellbeing, and other measures of quality of life. The Scandinavian experience of social democracy teaches us that it is very possible to have a political and economic model that combines the best features of capitalism and socialism while retaining the political freedom that citizens expect in a democracy.

Sources: Russell, 2011; Sejersted, 2011

\section{The US Labor Force}

We now turn from a general discussion of economic systems to some basic facts on the labor force in the world's leading capitalist nation, the United States. The civilian labor force in the United States consists of all noninstitutionalized civilians 16 years of age or older who work for pay or are looking for work. The civilian labor force (hereafter labor force) consists of about 154 million people, or almost two-thirds of the population, including about 71 percent of men and 58 percent of women (Bureau of Labor Statistics, 2012).

Of those who are currently employed, approximately 2.4 million people work in the agricultural sector, and a much larger number, 138 million, work in nonagricultural industries. Of the latter number, 109 million work in private industry, 21 million work in government, and almost 9 million are self-employed. Most of the currently employed work full-time, but more than 26 million work only part-time. Of this number, 69 percent work parttime for noneconomic reasons; for example, they have childcare or other family obligations, or they are in school. Another 31 percent work part-time for economic reasons: They are unable to find a full-time job, or they may have lost a full-time job because of the faltering economy.

Approximately 87 million Americans ages 16 and older are not in the labor force. Of this number, 93 percent do not desire a job. Most of these individuals are retired, disabled, or taking care of children and/or other family members. Of the 7 percent who would like a job but are still not in the labor force, most have dropped out of the labor force (stopped looking for a job) because they have become discouraged after previously looking for work but not finding a job.

Some 5 percent of currently employed people have two or more jobs at any one time. This percentage translates to about 7 million individuals. It varies slightly by gender: 5.3 percent of employed women have at least two jobs, compared to 4.7 percent of employed men.

Chapter 4 "Gender Inequality” noted that women’s labor force participation soared during the last few decades. This general increase is even steeper for married women with children under 6 years of age: In 2009, almost 62 percent of such women were in the labor force, compared to less than 19 percent in 1960 (US Census Bureau, 2012), a threefold difference (see Figure 12.2 "Labor Force Participation Rate of Married Women with Children Younger than 6 Years of Age, 1960-2007”).

Figure 12.2 Labor Force Participation Rate of Married Women with Children Younger than 6 Years of Age, 1960-2007 


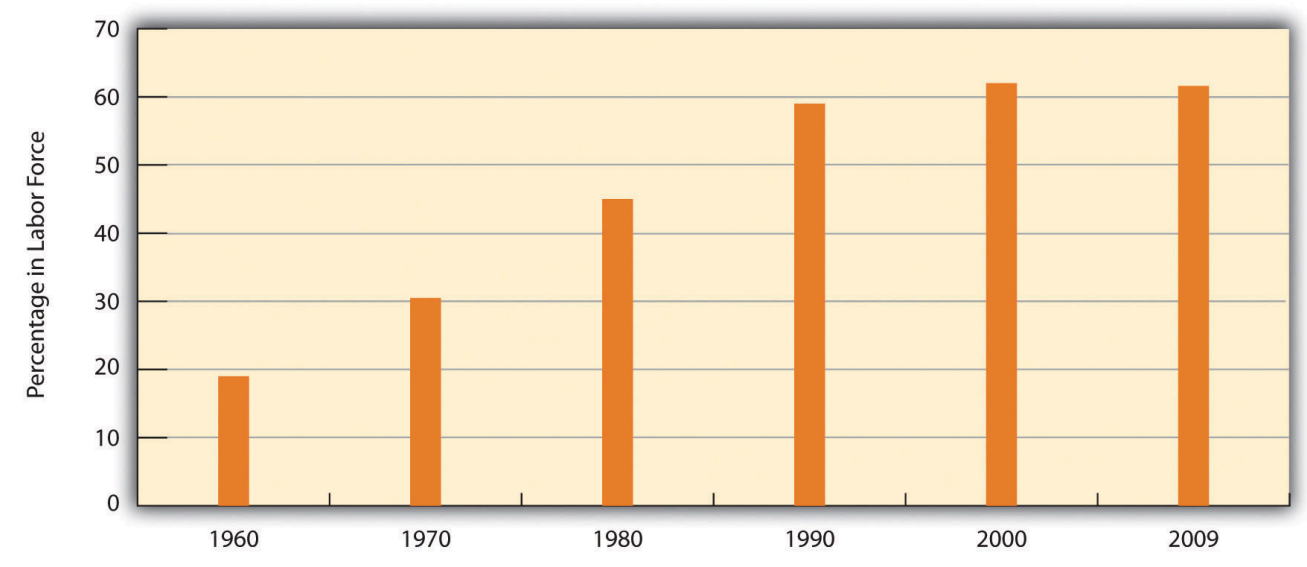

Source: Data from US Census Bureau. (2012). Statistical abstract of the United States: 2012. Washington, DC: US Government Printing Office. Retrieved from http://www.census.gov/compendia/statab.

\section{Key Takeaways}

- The economy is the social institution that organizes the production, distribution, and consumption of a society's goods and services. It consists of three sectors: the primary sector, the secondary sector, and the tertiary sector.

- The two major economic systems in modern societies are capitalism and socialism. In practice, most societies have economies that mix elements of both systems but that lean toward one end of the capitalism-socialism continuum.

- Social democracies combine elements of both capitalism and socialism. They have achieved high economic growth while maintaining political freedom and personal liberty.

\section{For Your Review}

1. In what ways might capitalism be a better economic system than socialism? In what ways might socialism be a better economic system than capitalism?

2. Write a brief essay in which you discuss the values capitalism and socialism seem to develop among the people who live under either type of economic system.

\section{References}

Bowles, P. (2012). Capitalism. New York, NY: Longman.

Bureau of Labor Statistics. (2012). 2012 employment and earnings online. Washington, DC: Author. Retrieved from http://www.bls.gov/opub/ee/home.htm.

Cohen, G. A. (2009). Why not socialism? Princeton, NJ: Princeton University Press. 
Lewis, A. (2012, January 14-15). Occupy Mitt Romney! Bangor Daily News, p. C3.

Russell, J. W. (2011). Double standard: Social policy in Europe and the United States (2nd ed.). Lanham, MD: Rowman \& Littlefield.

Sejersted, F. (2011). The age of social democracy: Norway and Sweden in the twentieth century (R. Daly, Trans.). Princeton, NJ: Princeton University Press.

Smith, A. (1910). The wealth of nations. (Original work published 1776). London, United Kingdom: University Paperbacks.

US Census Bureau. (2012). Statistical abstract of the United States: 2012. Washington, DC: US Government Printing Office. Retrieved from http://www.census.gov/compendia/statab. 


\subsection{Sociological Perspectives on Work and the Economy}

\section{Learning Objectives}

1. List any two functions of work and the economy as emphasized by functionalism.

2. Summarize conflict theory's critique of work and the economy.

3. Explain the overall approach of symbolic interactionism to understanding work and the economy.

The three sociological perspectives examined in earlier chapters continue to offer insights that help us understand the economy, including the nature of work on which any economy rests. Table 12.1 "Theory Snapshot" summarizes these insights.

Table 12.1 Theory Snapshot

\begin{tabular}{|l|l|}
$\begin{array}{l}\text { Theoretical } \\
\text { perspective }\end{array}$ & Major assumptions \\
\hline Functionalism & $\begin{array}{l}\text { Work and the economy serve several functions for society. The economy makes society possible by } \\
\text { providing the goods and services it needs. Work gives people an income and also provides them some } \\
\text { self-fulfillment and part of their identity. }\end{array}$ \\
\hline $\begin{array}{l}\text { Conflict } \\
\text { theory }\end{array}$ & $\begin{array}{l}\text { Control of the economy enables the economic elite to maintain their position at the top of society and to } \\
\text { keep those at the bottom in their place. Work is often alienating, and the workplace is often a site for } \\
\text { sexual harassment and other problems. }\end{array}$ \\
\hline $\begin{array}{l}\text { Symbolic } \\
\text { interactionism }\end{array}$ & $\begin{array}{l}\text { This perspective focuses on social interaction in the workplace, on how employees respond to problems in } \\
\text { their workplaces, and on how they perceive the work they do. }\end{array}$ \\
\hline
\end{tabular}

\section{Functionalism}

Recall that the functionalist perspective highlights the many functions that social institutions serve for society. Accordingly, this perspective paints a positive picture of work and the economy by pointing to their many benefits.

The economy's major function is also an absolutely essential function: the provision of goods and services. Because the economy provides the goods and services that any society needs, the economy makes a society possible. As we saw earlier, capitalist and socialist societies provide goods and services in different ways, and each type of economy has its advantages and disadvantages. Regardless of the relative merits of capitalism and socialism, however, both a capitalist economy and socialist economy make possible the societies in which they are found.

Many high school students have summer jobs or after-school jobs. Whether or not they go to college, most people 
work for pay once they reach adulthood. Some work full-time until they retire, some alternate full-time work and part-time work, and some may start out with a job but drop out of the labor force to raise their children. Regardless of these various work patterns, the most important function that most people derive from working is their paycheck. Simply put, work provides the income that most people need for food, clothing, shelter, and other essential needs in today's society.

But work has important, nonmaterial functions beyond helping us pay the bills. Many people consider their job part of their overall identity, just as the college students reading this book consider being a student as part of their current identity. As we enter adulthood, we are not just a spouse, partner, parent, or child of our parents; we are also an accountant, banker, claims adjuster, day care worker, elementary school teacher, financial consultant, garage door installer, and so forth. The job we have helps provide us with a sense of who we are, or, to put it another way, a sense of our identity.

Especially if we enjoy our jobs, work can also give us a sense of self-fulfillment, self-confidence, and self-esteem. These psychological effects combine to form yet another important function of work.

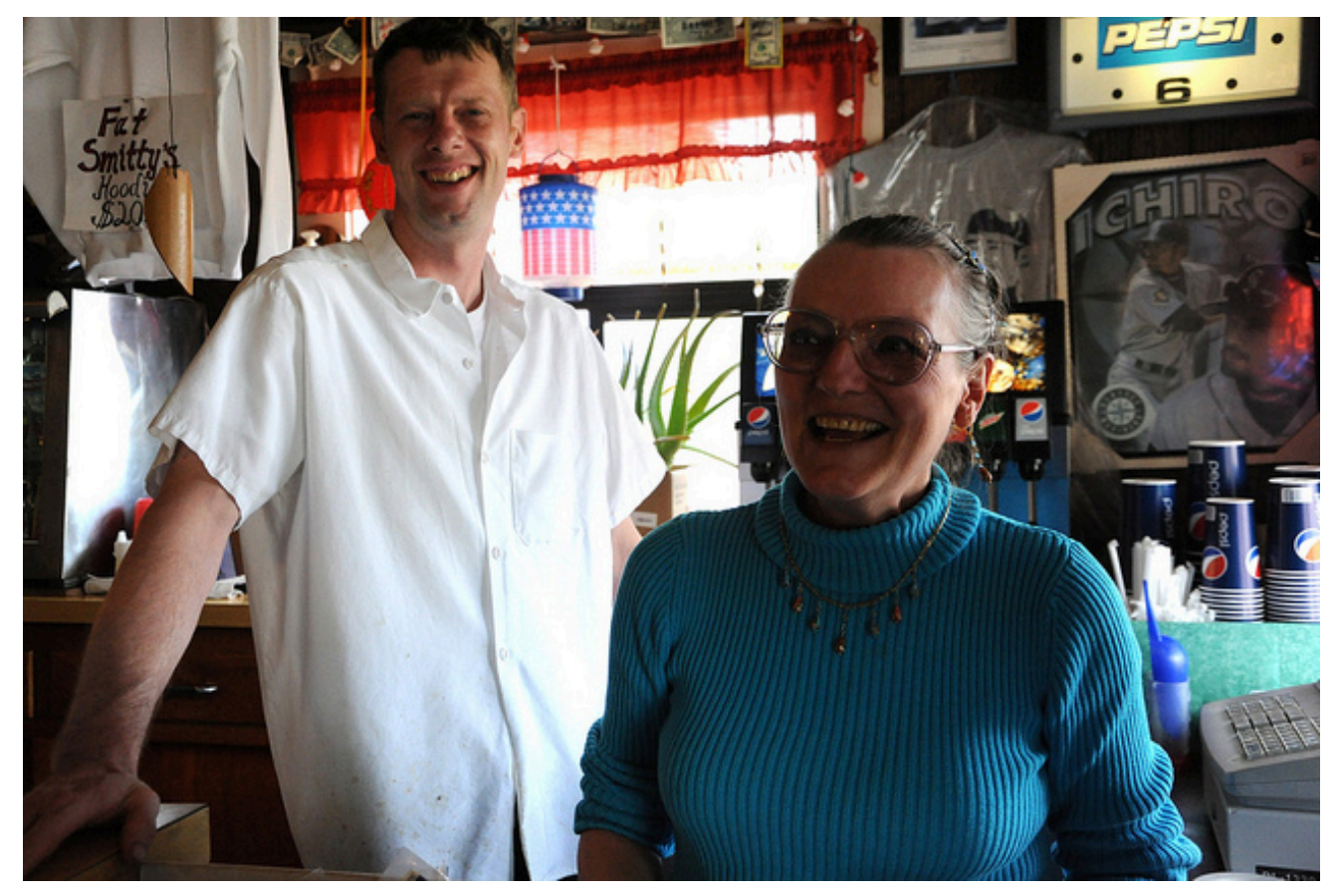

An important function of work is that it provides a context for coworker friendships. Many people have friends whom they met in their workplaces or through their work.

Wonderlane - $\underline{\text { Co-workers laughing at Fat Smitty's }}$ - CC BY 2.0.

A third function is friendships. Many people have friends and acquaintances whom they met at their workplaces or at least through their work (McGuire, 2007). Coworkers discuss all kinds of topics with each other, including personal matters, sports, and political affairs, and they often will invite other coworkers over to their homes or go out with them to a movie or a restaurant. These friendships are yet another benefit that work often provides.

The nonmaterial benefits that work provides for many people are important and should not be discounted. Although this is speculative, many wealthy people no longer need to work but continue to work because of these 
nonmaterial benefits. National survey data support the importance of work's nonmaterial benefits in this regard. In the 2010 General Social Survey (GSS), respondents in the labor force were asked, "If you were to get enough money to live as comfortably as you would like for the rest of your life, would you continue to work or would you stop working?” More than two-thirds (68.7 percent) of these respondents replied that they would indeed continue working.

\section{Conflict Theory}

Conflict theory's views of work and the economy largely derive from the writings of Karl Marx and Friedrich Engels during the nineteenth century. As Chapter 1 "Understanding Social Problems" discussed, Marx and Engels sharply criticized capitalism as an economic system that inherently oppresses workers. In their view, the bourgeoisie, or ruling class, owns the means of production, while the proletariat, or working class, does not own the means of production. The bourgeoisie uses its wealth, power, and influence to oppress and exploit the proletariat.

Although today's conflict theorists are not necessarily Marxists, they nonetheless criticize many aspects of capitalism, and the earlier discussion of the disadvantages of capitalism reflects their views. They also criticize how large companies treat their workers. As just one example, they call attention to the fact that many companies maintain dangerous workplaces that result in injury, illness, and/or death for tens of thousands of workers annually. We return to this particular problem later in this chapter.

Conflict theorists also point out that the workplace is a setting for sexual harassment, which was discussed in Chapter 4 "Gender Inequality". Although work can and does bring the many benefits assumed by functionalist theory, work can also be a source of great distress for the hundreds of thousands of women and men who are sexually harassed every year.

Marx also wrote that work in a capitalist society is inherently alienating. This is so, he said, because workers do not design the products they build, because factory work (which was the dominant mode of production in Marx's time) involves boring and repetitive tasks, and because workers are treated by their employers as mere commodities to be hired and fired at will. Reflecting Marx's views, conflict theory today also points to the alienating nature of work.

Following up on this concern, social scientists have tried to determine the extent of worker alienation and job satisfaction, as well as the correlates of these two attitudes (Mauno, Kinnunen, \& Feldt, 2012). They generally find that American workers like their jobs much more than Marx anticipated but also that the extent to which they like their jobs depends on the income their jobs bring, the degree of autonomy they enjoy in their jobs, and other factors. In the 2010 GSS, 88 percent of respondents said they are "very" or "somewhat" satisfied with the work they do, and only 12 percent said they were dissatisfied. This latter figure is probably much lower than Marx would have predicted for a capitalist society like the United States. One possible reason for this low amount of job dissatisfaction, and one that Marx did not foresee, is the number of workplace friendships as described earlier. Such friendships can lead workers to like their jobs more than they otherwise would and help overcome the alienation they might feel without the friendships. 


\section{Symbolic Interactionism}

Recall that symbolic interactionism focuses on the interaction of individuals and on how they interpret their interaction. In line with this "micro" focus, many scholars have generated rich descriptions of how certain workplaces' behaviors and understandings are "negotiated" and of how certain kinds of workers view aspects of their work and interpret the meaning of their work. Numerous studies of this type exist of police officers, prostitutes, attorneys, nurses and physicians, teachers, and a variety of other occupations. Most of these studies are based on intensive interviews of people in these occupations. Taken together, they provide a sensitive portrait of why people enter these various jobs and careers, what they like and dislike about their jobs, how they interact with other people in their workplaces, and a host of other issues.

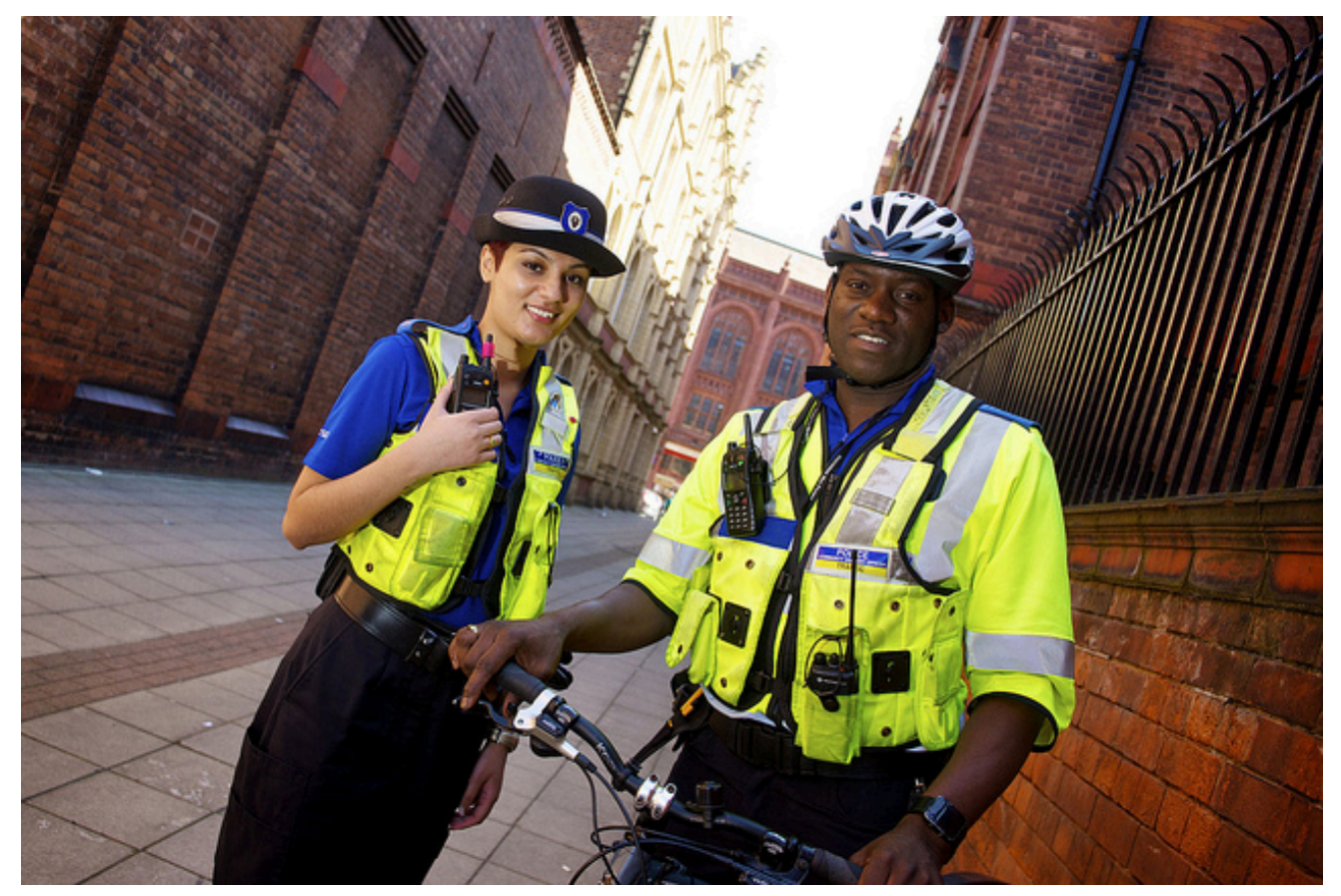

Studies of police officers' behavior and perceptions provide an excellent example of the symbolic interactionist understanding of work. According to Jonathan Rubinstein, an important goal of officers is to maintain the respect of other officers.

West Midlands Police - Day 4 - PCSOs on Patrol in Birmingham - CC BY-SA 2.0.

A classic study of the workplace grounded in the symbolic interactionist tradition was sociologist Joan Emerson's (1970) study of gynecological exams. At the time Emerson wrote her study, most gynecologists were men. Because they are necessarily viewing and touching their women patients' genitals, they have to ensure their patients do not think their doctor is behaving in a sexual manner. For this to happen, Emerson wrote, (male) gynecologists take pains to appear as medical professionals rather than as men interested in having sex or aroused by what they were seeing and feeling. In this way, they "define the situation” as a professional encounter rather than as a sexual encounter.

Male gynecologists use several strategies to appear as professionals, according to Emerson. For example, they have a (female) nurse present during the exam to help the patient feel comfortable. They also certainly avoid saying anything that might suggest they are sexually aroused. More generally, gynecologists and nurses always 
act in a nonchalant, matter-of-fact manner, which sends the patient an implicit message: "In the medical world the pelvic area is like any other part of the body; its private and sexual connotations are left behind when you enter the hospital” (Emerson, 1970, p. 78). In all these ways, gynecological exams are defined only as medical encounters, and patients are helped to feel as comfortable as possible under rather uncomfortable circumstances.

In another classic study grounded in the symbolic interactionist tradition, Jonathan Rubinstein (1993) spent a year riding around and otherwise interacting with police officers in Philadelphia. He later wrote compellingly about police officers' constant fear for their safety, about how they try to control suspects and other threatening people without drawing their guns, about how they interact with each other and with their superiors, and many other matters. In one passage, he wrote about how officers (he interviewed policemen) try to win and keep the respect of other officers: “A patrolman must learn to avoid any appearance or incompetency if he hopes to maintain the respect of his colleagues. Every man must go to considerable lengths to cover up any weakness or error that might reflect poorly on his competence” (Rubinstein, 1993, p. 105). Thus officers learn to record dispatchers' information promptly and accurately, and they avoid remarks that question the competence of other officers.

\section{Key Takeaways}

- Functionalism emphasizes the importance of the economy for any society, and the income and selffulfillment that work often provides.

- Conflict theory highlights the control of the economy by the economic elite, the alienation of work, and various problems in the workplace.

- Symbolic interactionism focuses on interaction in the workplace and how workers perceive many aspects of their work and workplace interaction.

\section{For Your Review}

1. Which of the three major sociological approaches to understanding work and the economy do you most prefer? Why?

2. Write a brief essay in which you use a symbolic interactionist approach to understand some aspect of a job you have held or hold now.

\section{References}

Emerson, J. P. (1970). Behavior in private places: Sustaining definitions of reality in gynecological examinations. In H. P. Dreitzel (Ed.), Recent sociology (Vol. 2, pp. 74-97). New York, NY: Collier.

Mauno, S., Kinnunen, U., \& Feldt, T. (2012). Work-family culture and job satisfaction: Does gender and parenting status alter the relationship? Community, Work \& Family, 15(1), 101-129. 
McGuire, G. M. (2007). Intimate work: A typology of the social support that workers provide to their network members. Work and Occupations, 34, 125-147.

Rubinstein, J. (1993). City police. New York, NY: Farrar, Straus \& Giroux. 


\subsection{Problems in Work and the Economy}

\section{Learning Objectives}

1. Outline recent trends in jobs and wages.

2. Discuss the effects of unemployment.

3. Summarize the problems associated with increasing economic inequality.

The economy and the quality and quantity of work certainly affect the lives of all Americans. At the same time, work and the economy give rise to many kinds of problems that also affect millions of Americans. This section examines several of these problems.

\section{The Loss of Jobs and Wages}

Because the American economy greatly weakened as the nation went into a deep recession in late 2007, it should come as no surprise that millions of jobs have been lost during the past half-decade and that wages have declined for many Americans. Yet long before the recession began, certain ominous trends in the American economy were evident. These trends involved a general loss of jobs in many sectors of the American economy and stagnating wages.

These trends partly reflected the fact that the United States has joined other industrial nations in moving into a postindustrial economy. In a postindustrial economy, information technology and service jobs replace the machines and manufacturing jobs that are hallmarks of an industrial economy. If physical prowess and skill with one's hands were prerequisites for many industrial jobs, mental prowess and communication skills are prerequisites for postindustrial jobs.

This move to a postindustrial economy has been a mixed blessing for many Americans. The information age has obvious benefits too numerous to mention, but there has also been a cost to the many workers whom postindustrialization and the globalization of the economy have left behind. Since the 1980s, many manufacturing companies moved their plants from US cities to sites in the developing world in Asia and elsewhere, a problem called capital flight. Along with the faltering economy, these trends have helped fuel a loss of 5.5 million manufacturing jobs from the American economy since 2000 (Hall, 2011).

A related problem is outsourcing, in which US companies hire workers overseas for customer care, billing services, and other jobs that Americans used to do. China, India, and the Philippines, which have skilled workforces relatively fluent in English, are the primary nations to which US companies outsource their work. According to projections, some 3.4 million jobs will have been lost by 2015 because of outsourcing (Levine, 
2012). Many call centers employ workers in India, and when you call up a computer company or some other business for technical help, you might very well talk with an Indian. Because these call centers have cost Americans jobs and also because Americans and Indians often have trouble understanding each other's accents, outsourcing has been very controversial since it became popular in the early 2000s.

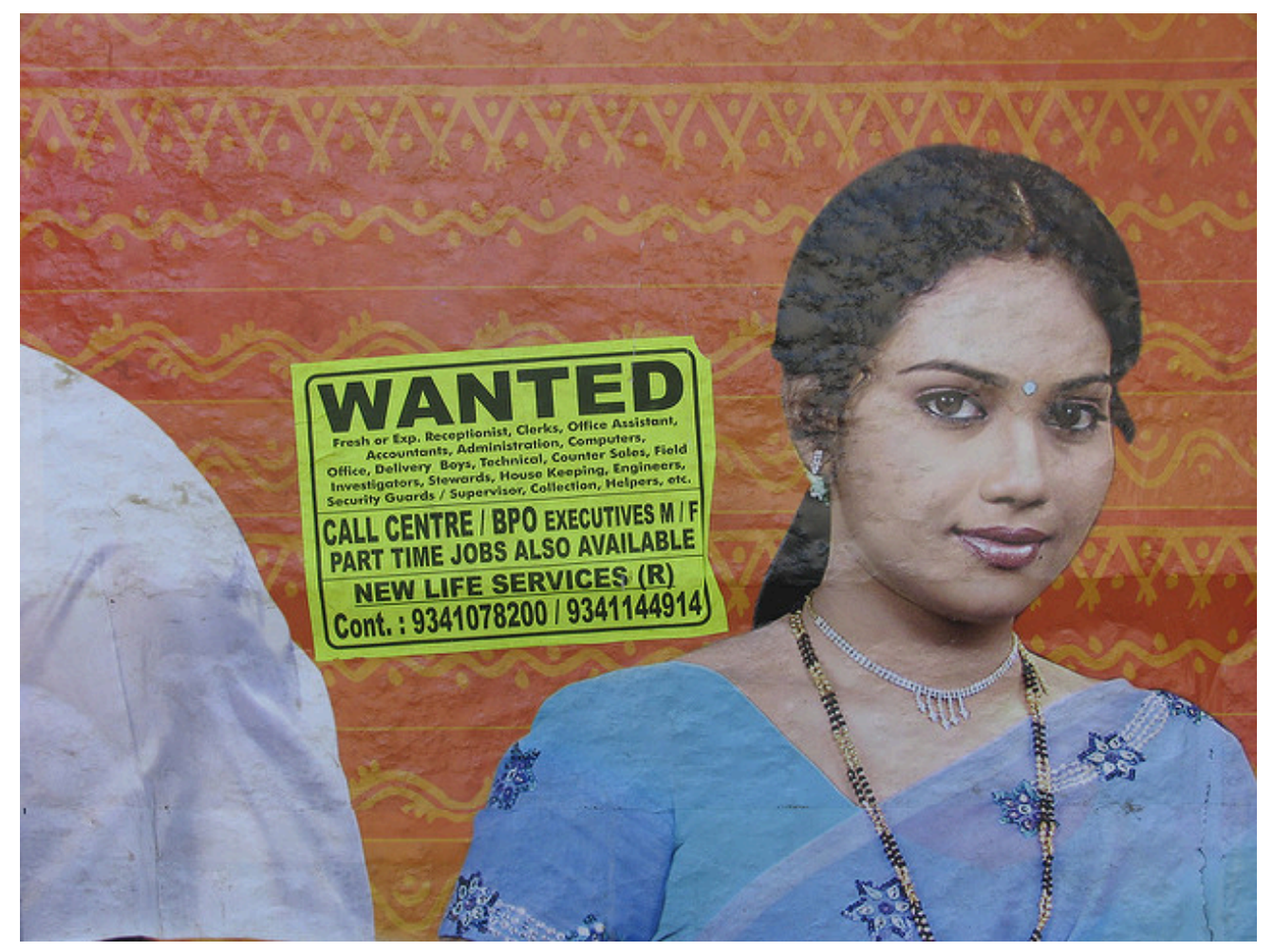

Many American jobs have been lost because of outsourcing to other countries.

Paul Keller - wanted - CC BY 2.0.

All these problems reflect a more general shift in the United States from goods-producing jobs to service jobs. Although some of these service jobs, such as many in the financial and computer industries, are high paying, many are in low-wage occupations, such as restaurant and clerical work, that pay less than the goods-producing jobs they replaced. Partly as a result, the average hourly wage (in 2009 dollars) in the United States for workers (excluding managers and supervisors) rose by only one dollar from \$17.46 in 1979 to \$18.63 in 2009. This change represented an increase of just 0.2 percent per year during that three-decade span, as workers’ wages have essentially stagnated during the last three decades (Economic Policy Institute, 2012).

Wage changes in recent years also depend on what social class someone is in. While the average compensation of chief executive officers (CEOs) of large corporations grew by 167 percent from 1989 to 2007, the average compensation of the typical worker grew by only 10 percent (Mishel, Bernstein, \& Shierholz, 2009). Another way of understanding this disparity is perhaps more striking. In 1965, the average compensation of CEOs was twentyfour times greater than that of the typical worker; in 2009, their compensation was 185 times greater than that of the typical worker (Economic Policy Institute, 2012). These figures reflect growing economic inequality in the United States, a problem we further examine later in this chapter. 


\section{The Decline of Labor Unions}

One of the most important developments accompanying industrialization in the nineteenth century was the rise of labor unions and their conflict with management over wages and working conditions (Dubofsky \& Dulles, 2010). The pay that workers received was quite low, and the conditions in which they worked were often miserable. The typical employee worked at least ten hours a day for six or seven days a week, with almost no overtime pay and no paid vacations or holidays. To improve wages and working conditions, many labor unions were founded after the Civil War, only to meet determined opposition from companies, the government, and the courts. Companies told each other which workers were suspected of being union members, and these workers were then prevented from getting jobs. Strikers were often arrested for violating laws prohibiting strikes. When juries began finding them not guilty, employers turned to asking judges for injunctions that prohibited strikes. Workers who then went on strike were held in contempt of court by the judge as juries were kept out of the process.

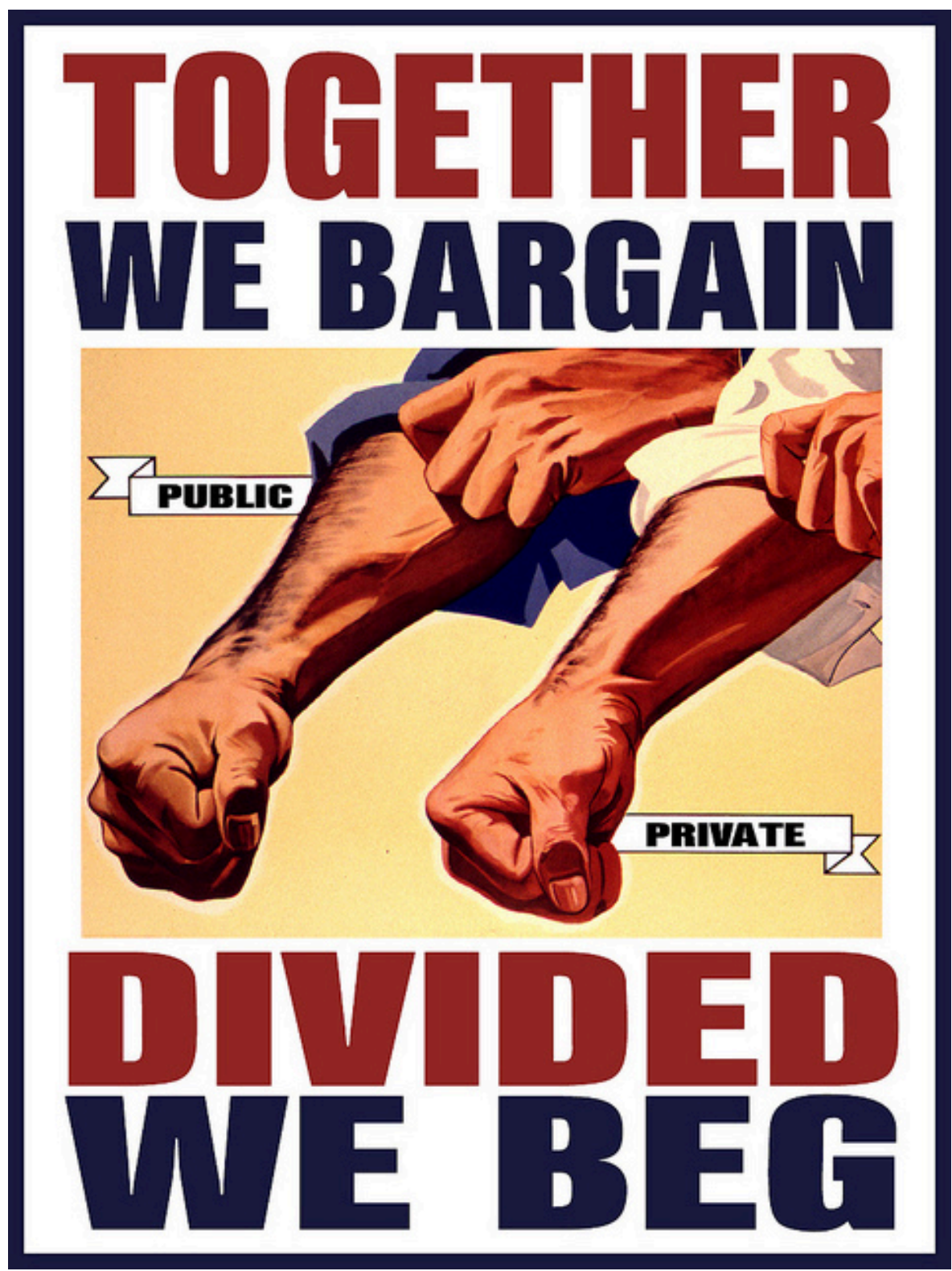


From the 1870s through the 1930s, labor unions fought companies over issues such as low wages and substandard

working conditions.

DonkeyHotey - Together We Bargain - CC BY 2.0.

Labor strife also marked the Great Depression, when masses of people blamed business leaders for their economic plight. Huge sit-ins and other labor protests occurred at auto plants in Detroit. In response, the Congress passed several laws that gave workers a minimum wage, the right to join unions, a maximum-hour workweek, and other rights that Americans now take for granted.

Today labor unions have lost some of their influence, especially as postindustrialization has supplanted the industrial economy and as the United States has lost much of its manufacturing base. Four decades ago, about one-fourth of all private-sector nonagricultural workers belonged to labor unions. By 1985 this figure had dropped to 14.6 percent, and today it stands at only 7.2 percent (Hirsch \& Macpherson, 2011). In response, labor unions have intensified their efforts to increase their membership, only to find that US labor laws are filled with loopholes that allow companies to prevent their workers from forming a union. For example, after a company's workers vote to join a union, companies can appeal the vote, and it can take several years for courts to order the company to recognize the union. In the meantime, the low wages, substandard working conditions, and other factors that motivated workers to want to join a union are allowed to continue.

Just as the growth of unions during the late nineteenth and early twentieth centuries helped to raise workers' wages, the decline of unions has lowered wages. Two reasons explain this decline (Mishel et al., 2009). First, union workers earn about 14 percent more than nonunion workers (controlling for experience, education, occupation, and other factors), a phenomenon known as the union wage premium. Because fewer workers are now in unions than four decades ago, they are less likely to benefit from this premium. Second, as unions have declined, there has been less pressure on nonunion employers to raise their wages to match union wages.

Because the union wage premium is greater for African Americans and Latinos than for whites, the wage decline caused by the decline of unions has probably been steeper for those two groups than for whites. It is also true that union workers are more likely than nonunion workers to be covered by employer-paid health insurance and also to have lower health premiums and deductibles. The decline of unions has thus meant that the average worker today is less likely to have employer-paid health insurance and, if they do, more likely to have higher premiums and deductibles.

\section{Unemployment}

Unemployment is a fact of life. There will always be people laid off or fired, who voluntarily quit their jobs, or who just graduated school and are still looking for work. But most unemployed people are involuntarily unemployed, and for them the financial and psychological consequences can be devastating, as we saw in the news story that began this chapter.

Unemployment rates rise and fall with the economy, and the national unemployment rate was as high as 10.2 percent in October 2009 amid the Great Recession that began almost two years earlier. It was still 8.3 percent in February 2012, amounting to almost 13 million people. But whether unemployment is high or low, it always 
varies by race and ethnicity, with African American and Latino unemployment rates much higher than the white rate (see Figure 12.3 "Race, Ethnicity, and Unemployment Rate, February 2012”). Unemployment is also higher for younger people than for older people. In February 2012, 23.8 percent of all teenagers in the labor force (aged 16-19) were unemployed, a figure three times higher than that for adults. The unemployment rate for African Americans in this age group was a very high 34.7 percent, twice as high as the 21.3 percent figure for whites in this age group (Bureau of Labor Statistics, 2012).

Figure 12.3 Race, Ethnicity, and Unemployment Rate, February 2012

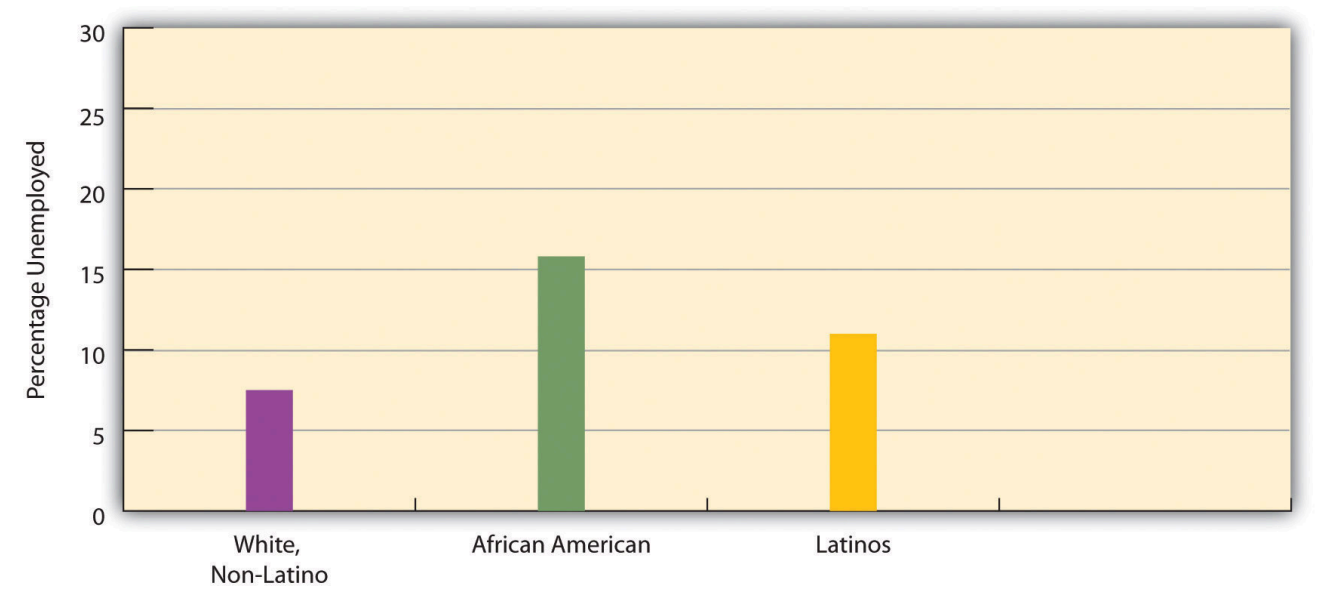

Source: Bureau of Labor Statistics (2012). Employment \& earnings online. Retrieved from http://www.bls.gov/opub/ee/home.htm.

Unemployment figures are misleading in an important respect, as they do not include people who are underemployed. Underemployment includes the unemployed and also two other types of people: (a) those who are working part-time but who want to work full-time-the so-called marginally attached, and (b) those who have stopped looking for work because they have not been able to find a job. Many economists think that underemployment provides a more accurate measure than unemployment of the number of people with employment problems.

For example, in December 2011, when the unemployment rate was 8.5 percent and 13 million people were officially unemployed, the underemployment rate was 15.2 percent, equal to 23.8 million people (Shierholz, 2012). These figures are almost twice as high as the official unemployment figures. Reflecting the racial/ethnic disparity in unemployment, 24.4 percent of African American workers and 22.3 percent of Latino workers were underemployed, compared to only 12.5 percent of white workers. Reflecting on the great amount of underemployment during the Great Recession, one economist commented, "When you combine the long-term unemployed with those who are dropping out and those who are working part time because they can’t find anything else, it is just far beyond anything we’ve seen in the job market since the 1930s” (Herbert, 2010, p. A25).

We have just seen that unemployment rises when the economy falters and that race and ethnicity affect the probability of being unemployed. These two facts provide evidence supporting the sociological imagination (see Chapter 1 "Understanding Social Problems"). As C. Wright Mills (1959) emphasized in his original discussion of this concept, unemployment is best viewed more as a public issue than as a personal trouble. When so many people are unemployed during an economic recession and when there is such striking evidence of higher unemployment rates among the persons of color who have the least opportunity for the education and training 
needed to obtain and keep a job, it is evident that high unemployment rates reflect a public issue rather than just a collection of public troubles.

Several kinds of problems make it difficult for people of color to be hired into jobs and thus contribute to the racial/ethnic disparity in unemployment. The Para 12.142 box discusses these problems.

\section{Applying Social Research}

Race, Ethnicity, and Employment

As the text discusses, people of color are more likely than whites to be unemployed or underemployed. While a relative lack of education helps explain these higher rates for people of color, other kinds of problems are also apparent.

One problem is racial discrimination on the part of employers, regardless of how conscious employers are of their discriminatory behavior. Chapter 4 "Gender Inequality" recounted a study by sociologist Devah Pager (2003), who had young white and African American men apply independently in person for various jobs in Milwaukee. These men wore the same type of clothing and reported similar levels of education and other qualifications. Some said they had a criminal record, while others said they had not committed any crimes. In striking evidence of racial discrimination in hiring, African American applicants without a criminal record were hired at the same low rate as white applicants with a criminal record.

Pager and sociologists Bruce Western and Bart Bonikowski also investigated racial discrimination in another field experiment in New York City (Pager, Bonikowski, \& Western, 2009). They had white, African American, and Latino "testers," all of them "well-spoken, clean-cut young men” (p. 781), apply in person to low-level service jobs (e.g., retail sales and delivery drivers) requiring no more than a high school education; all the testers had similar (hypothetical) qualifications. Almost one-third (31 percent) of white testers received a call back or job offer, compared to only 25.2 percent of Latino testers and 15.2 percent of African American testers. The researchers concluded that their findings "add to a large research program demonstrating the continuing contribution of discrimination to racial inequality in the post-civil rights era” (p. 794).

Other kinds of evidence also reveal racial discrimination in hiring. Two scholars sent job applications in response to help-wanted ads in Boston and Chicago (Bertrand \& Mullainathan, 2003). They randomly assigned the applications to feature either a "white-sounding” name (e.g., Emily or Greg) or an “African American-sounding” name (e.g., Jamal and Lakisha). White names received 50 percent more callbacks than African American names for job interviews.

Racial differences in access to the informal networks that are often so important in finding a job also contribute to the racial/ethnic disparity in employment. In a study using data from a nationwide survey of a random sample of Americans, sociologist Steve McDonald and colleagues found that people of color and women are less likely than white males to receive informal word of vacant, high-level supervisory positions (McDonald, Nan, \& Ao, 2009).

As these studies indicate, research by sociologists and other social scientists reveals that race and ethnicity continue to make a difference in employment prospects for Americans. This body of research reveals clear evidence of discrimination, conscious or unconscious, in hiring and also of racial/ethnic differences in access to the informal networks that are often so important for hiring. By uncovering this evidence, these studies underscore the need to address discrimination, access to informal networks, and other factors that contribute to racial and ethnic disparities in employment.

\section{The Impact of Unemployment}

Although the news article that began this chapter gave us a moving account of unemployed people at food banks, survey data also provide harsh evidence of the social and psychological effects of being unemployed. In July 2010, the Pew Research Center issued a report based on a survey of 810 adults who were currently unemployed or 
had been unemployed since the Great Recession began in December 2007 and 1,093 people who had never been unemployed during the recession (Morin \& Kochhar, 2010). The report's title, Lost Income, Lost Friends—and Loss of Self-Respect, summarized its major findings.

Of those who had been unemployed for at least six months (long-term unemployment), 44 percent said that the recession had caused "major changes" in their lives, versus only 20 percent of those who had never been unemployed. More than half of the long-term unemployed said their family income had declined, and more than 40 percent said that their family relations had been strained and that they had lost contact with close friends. In another finding, 38 percent said they had "lost some self-respect” from being unemployed. One-third said they were finding it difficult to pay their rent or mortgage, compared to only 16 percent of those who had never been unemployed during the recession. Half had borrowed money from family or friends to pay bills, versus only 18 percent of the never unemployed. Of all the people who had been unemployed, almost half had experienced sleep difficulties, and 5 percent had experienced drug or alcohol problems. All these numbers paint a distressing picture of the social and psychological impact of unemployment during the Great Recession that began in late 2007.

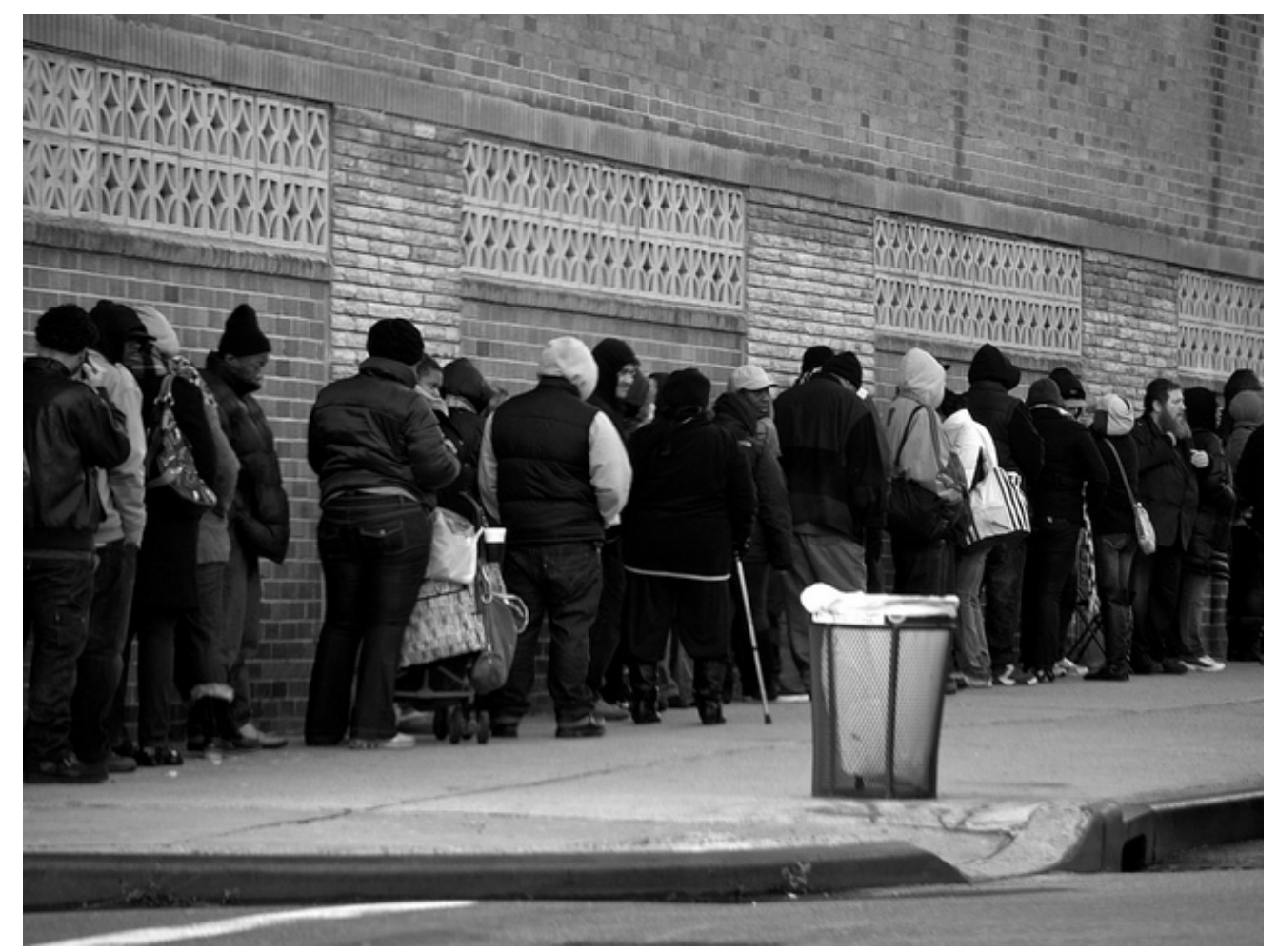

Unemployment lines were all too common in recent years. Long-term unemployment often causes various social and psychological difficulties.

Rawle C. Jackman - The line of hope... - CC BY-NC-ND 2.0.

Unemployment also has a significant impact on children whose parent or parents are unemployed. The Note 12.21 "Children and Our Future" box discusses this impact. 


\section{Children and Our Future}

The Hidden Casualties of Unemployment

As unemployment soared in the wake of the Great Recession that began in 2007, many more children lived in a household where a parent had become unemployed. By early 2010, 11 percent of American children, or 8.1 million children overall, had an unemployed parent. Just slightly more than two years earlier, this number had been much smaller, 4.8 million. In just over two years, then, the number of children with an unemployed parent grew by two-thirds.

After their parents became unemployed, these children began to suffer various psychological effects. One news report summarized this psychological impact as follows: "For many families across the country, the greatest damage inflicted by this recession has not necessarily been financial, but emotional and psychological. Children, especially, have become hidden casualties, often absorbing more than their parents are fully aware of. Several academic studies have linked parental job loss - especially that of fathers - to adverse impacts in areas like school performance and self-esteem.”

The emotional and psychological effects for children occur for at least two reasons. First, unemployed parents tend to experience extra stress and to become withdrawn. Second, married parents and unmarried partners often experience interpersonal conflict when one of them becomes unemployed. Both of these consequences of unemployment in turn affect children in a household where at least one parent is unemployed.

Children have suffered in other ways from the rise in unemployment. More children have become homeless as their households fell into poverty. In addition, children of an unemployed parent are more likely to repeat a grade or, if they are adolescents, to drop out of school. Child abuse has probably also increased in families where a parent became unemployed.

In view of all these consequences for the children of the unemployed, the United States should do everything possible to put parents and other adults back to work and to help the children of unemployed parents deal with the devastating effects of the Great Recession.

Sources: Lovell \& Isaacs, 2010; Luo, 2009

\section{Corporations}

One of the most important but controversial features of modern capitalism is the corporation, a formal organization that has a legal existence, including the right to sign contracts, that is separate from that of its members. 


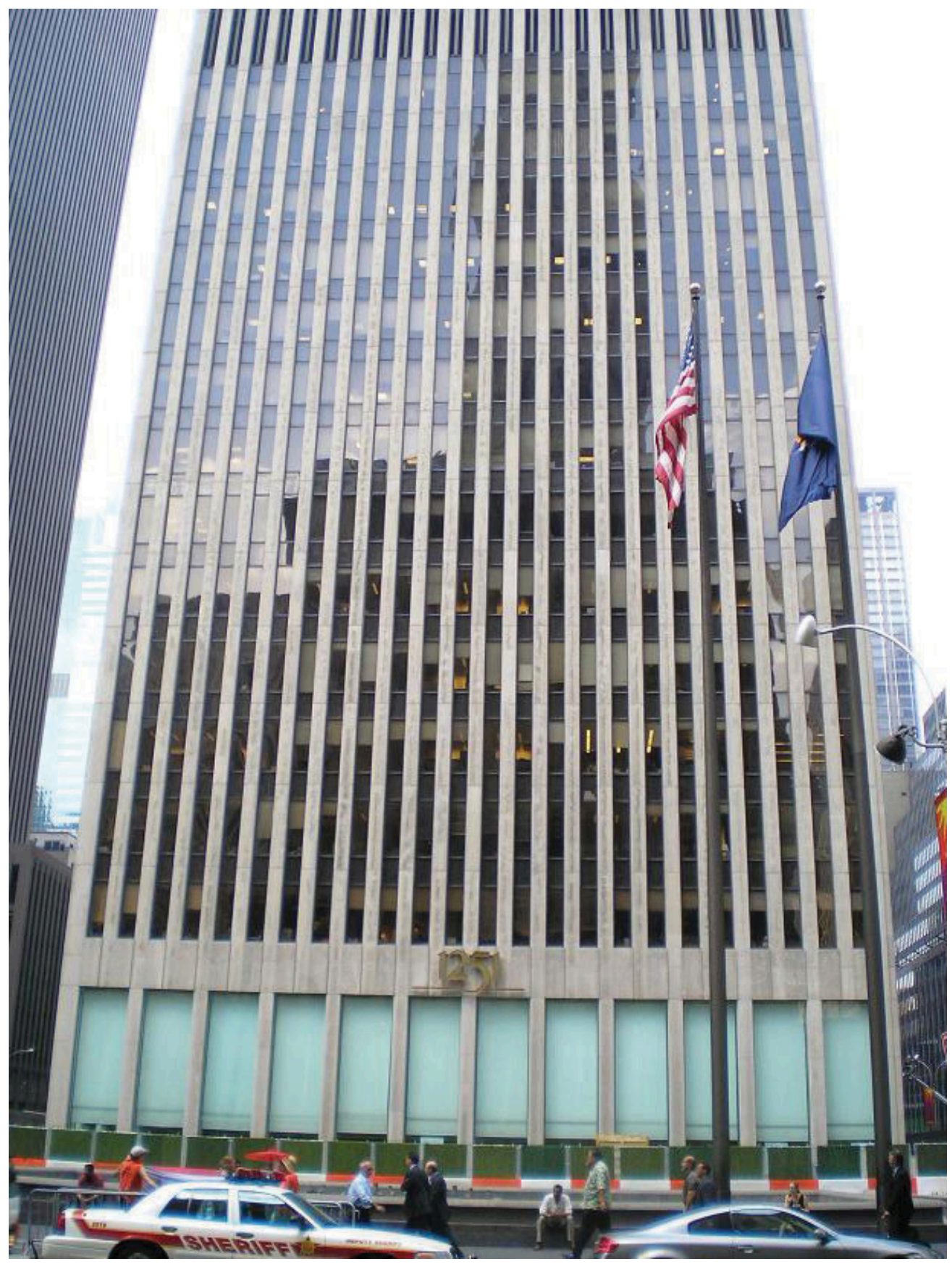

Corporations such as Exxon dominate the US economy. They employ thousands of workers, and their assets total many trillions of dollars.

Wikimedia Commons - CC BY-SA 2.5 .

Adam Smith, the founder of capitalism, envisioned that individuals would own the means of production and compete for profit, and this is the model the United States followed in its early stage of industrialization. After the Civil War, however, corporations quickly replaced individuals and their families as the owners of the means of production and as the competitors for profit. As corporations grew following the Civil War, they quickly tried to control their markets by, for example, buying up competitors and driving others out of business. To do so, they engaged in bribery, kickbacks, and complex financial schemes of dubious ethics. They also established factories 
and other workplaces with squalid conditions. Their shady financial practices won their chief executives the name "robber barons" and led the federal government to pass the Sherman Antitrust Act of 1890 designed to prohibit restraint of trade that raised prices (Hillstrom \& Hillstrom, 2005).

More than a century later, corporations have increased in both number and size. Although several million US corporations exist, most are fairly small. Each of the largest five hundred, however, has an annual revenue exceeding $\$ 4.3$ billion (2011 data) and employs thousands of workers. Their total assets run into the trillions of dollars (Fortune, 2011). It is no exaggeration to say they control the nation's economy, as together they produce most of the US private sector output, employ millions of people, and have revenues equal to most of the US gross domestic product. In many ways, the size and influence of corporations stifle the competition that is one of the hallmarks of capitalism. For example, several markets, including that for breakfast cereals, are controlled by four or fewer corporations. This control reduces competition because it reduces the number of products and competitors, and it thus raises prices to the public (Parenti, 2011).

The last few decades have seen the proliferation and rise of the multinational corporation, a corporation with headquarters in one nation but with factories and other operations in many other nations (Wettstein, 2009). Multinational corporations centered in the United States and their foreign affiliates have more than \$17 trillion in assets and employ more than 31 million people (US Census Bureau, 2012). The assets of the largest multinational corporations exceed those of many of the world's nations. Often their foreign operations are in poor nations, whose low wages make them attractive sites for multinational corporation expansion. Many multinational employees in these nations work in sweatshops at very low pay and amid substandard living conditions. Critics of this practice say multinationals not only mistreat workers in poor nations but also exploit these nations' natural resources. In contrast, defenders of the practice say multinationals are bringing jobs to poor nations and helping them achieve economic growth. As this debate illustrates, the dominance of multinational corporations will certainly continue to spark controversy.

As we first discussed in Chapter 8 "Crime and Criminal Justice", another controversial aspect of corporations is the white-collar crime in which they engage (Rosoff, Pontell, \& Tillman, 2010). Price fixing by corporations costs the US public some $\$ 60$ billion annually (Simon, 2008). Workplace-related illnesses and injuries that could have been prevented if companies had safe workplaces kill about 50,000 workers each year (American Federation of Labor and Congress of Industrial Organizations, 2011). An estimated 10,000 US residents die annually from unsafe products, including contaminated food (Consumer Product Safety Commission, 2010; Young, 2010). All in all, corporate lawbreaking and neglect probably result in almost 100,000 deaths annually and cost the public more than $\$ 400$ billion (Barkan, 2012).

In sum, corporations are the dominant actors in today's economy. They provide most of our products and many of our services and employ millions of people. It is impossible to imagine a modern industrial system without corporations. Yet they often stifle competition, break the law, and, according to their critics, exploit people and natural resources in developing nations.

\section{Economic Inequality}

In 2011, the Occupy Wall Street movement gave national attention to economic inequality by emphasizing the 
differences between the " $1 \%$ " and the "99\%." Proclaiming "We are the $99 \%$," they decried the concentration of wealth in the richest of the rich and the growing inequality of the last few decades. (See Note 12.24 "People Making a Difference”.) The issue of economic inequality merits further attention here.

\section{People Making a Difference}

\section{Occupy Wall Street}

Before 2011, economic inequality in the United States certainly existed and in fact had increased greatly since the 1970s. However, although economic inequality was a topic of concern to social scientists, it was not a topic of concern to the general news media. Because the news media generally ignored economic inequality, it was also not a topic of concern to the general public.

That all changed beginning on September 17, 2011, when hundreds of people calling themselves "Occupy Wall Street" marched through the financial district in New York City before dozens encamped overnight and for weeks to come. Occupy Wall Street took these actions to protest the role of major banks and corporations in the economic collapse of 2007 and 2008 and to call attention to their dominance over the political process. Within weeks, similar Occupy encampments had spread to more than one hundred cities in the United States and hundreds more across the globe. "We are the 99\%," they said again and again, as "occupy" became a verb heard repeatedly throughout the United States.

By winter, almost all Occupy encampments had ended either because of legal crackdowns or because of the weather conditions. By that time, however, the Occupy protesters had won news media attention everywhere. In a December 2011 poll by the Pew Research Center, 44 percent of Americans supported the Occupy Wall Street movement, while 35 percent opposed it. Almost half (48 percent) said they agreed with the concerns raised by the movement, compared to 30 percent who said they disagreed with these concerns. In the same poll, 61 percent said the US economic system "unfairly favors the wealthy," while 36 percent said it was fair to all Americans. In a related area, 77 percent said "there is too much power in the hands of a few rich people and corporations." In all these items, there was a notable difference by political party preference. For example, 91 percent of Democrats agreed that a few rich people and corporations have too much power, compared to 80 percent of Independents and only 53 percent of Republicans.

Regardless of these political differences, Occupy Wall Street succeeded in bringing economic inequality and related issues into the national limelight. In just a few short months in 2011, it made a momentous difference.

Sources: Pew Research Center, 2011; vanden Heuvel, 2012

Let's start by defining economic inequality, which refers to the extent of the economic difference between the rich and the poor. Because most societies are stratified, there will always be some people who are richer or poorer than others, but the key question is how much richer or poorer they are. When the gap between them is large, we say that much economic inequality exists; when the gap between them is small, we say that relatively little economic inequality exists.

Considered in this light, the United States has a very large degree of economic inequality. A common way to examine inequality is to rank the nation's families by income from lowest to highest and then to divide this distribution into fifths. Thus we have the poorest fifth of the nation's families (or the 20 percent of families with the lowest family incomes), a second fifth with somewhat higher incomes, and so on until we reach the richest fifth of families, or the 20 percent with the highest incomes. We then can see what percentage each fifth has of the nation's entire income. Figure 12.4 "Share of National Income Going to Income Fifths, 2010" shows such a calculation for the United States. The poorest fifth enjoys only 3.3 percent of the nation's income, while the richest fifth enjoys 50.2 percent. Another way of saying this is that the richest 20 percent of the population have as much income as the remaining 80 percent of the population. 
Figure 12.4 Share of National Income Going to Income Fifths, 2010

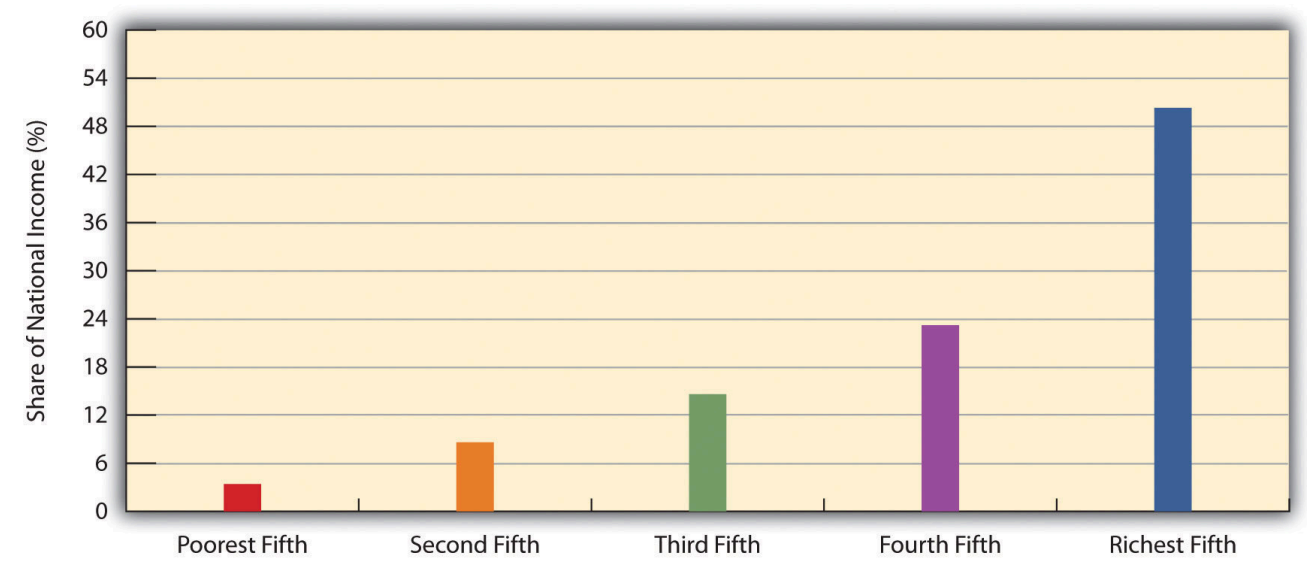

Source: Data from US Census Bureau. (2012). Statistical abstract of the United States: 2012. Washington, DC: US Government Printing Office. Retrieved from http://www.census.gov/compendia/statab.

This degree of inequality is the largest in the industrialized world. Figure 12.5 "Income Inequality around the World" compares the inequality among several industrialized nations by dividing the median income of households in the ninetieth percentile (meaning they have more income than 90 percent of all households) by the median income of households in the tenth percentile (meaning they have more income than only 10 percent of all households); the higher this resulting ninetieth percentile/tenth percentile ratio, the greater a nation's inequality. The ratio for the United States far exceeds that for any other nation.

Figure 12.5 Income Inequality around the World

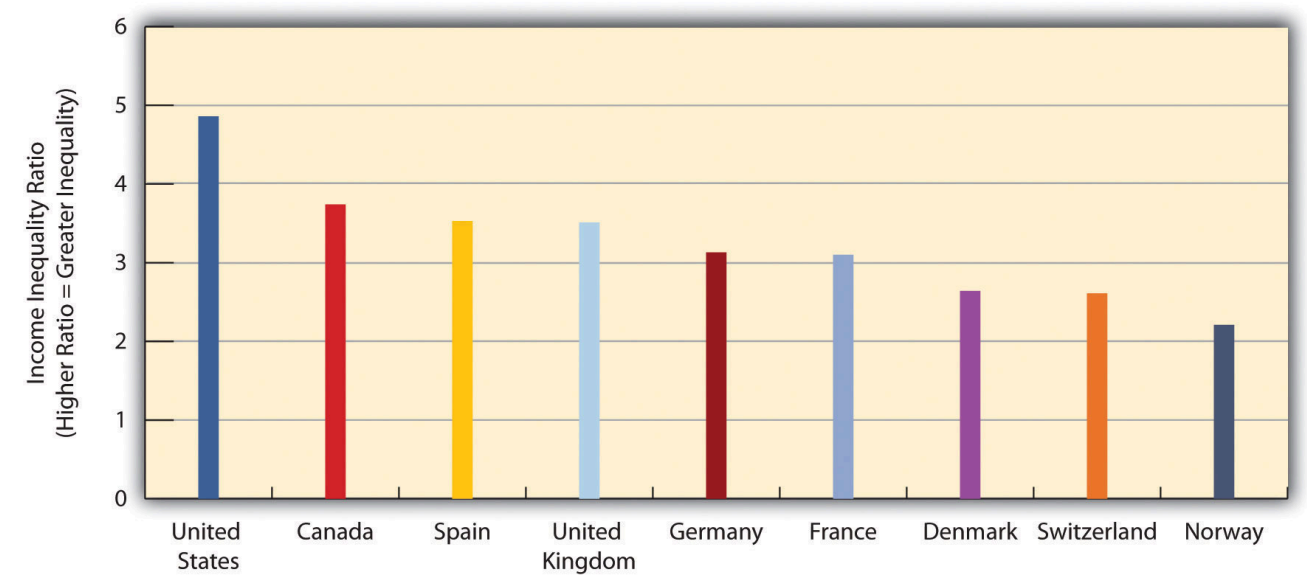

Ratio of median income of richest 10 percent in each nation to that of poorest 10 percent.

Source: Data from Mishel, L., Bernstein, J., \& Shierholz, H. (2009). The state of working America 2008/2009. Ithaca, NY: ILR Press.

\section{The Role of Tax Policy}

Economic inequality in the United States has increased during the last three decades. The loss of manufacturing 
jobs and unions accounts for some of this increase. However, a primary reason for the rising inequality has been tax policy. More specifically, the federal government has implemented steep cuts in the highest tax rates for income from salaries and wages and especially in tax rates for income from dividends and capital gains (Hacker \& Pierson, 2011). This latter cut is especially important because dividends and capital gains account for a much larger share of the income of wealthy families than the income of ordinary families. To be more specific, dividends and capital gains account for only 0.7 percent of the income of the bottom four-fifths of the nation's families, but for 18.8 percent of the income of the top fifth, 38.2 percent of the top 1 percent, and a striking 51.9 percent of the top 0.1 percent (Hungerford, 2011). In a related statistic, three-fourths of all capital gains are received by the top 1 percent (Krugman, 2012). Relative to its national wealth, the United States is the lowest-taxed industrial democracy in the world (Leonhardt, 2012).

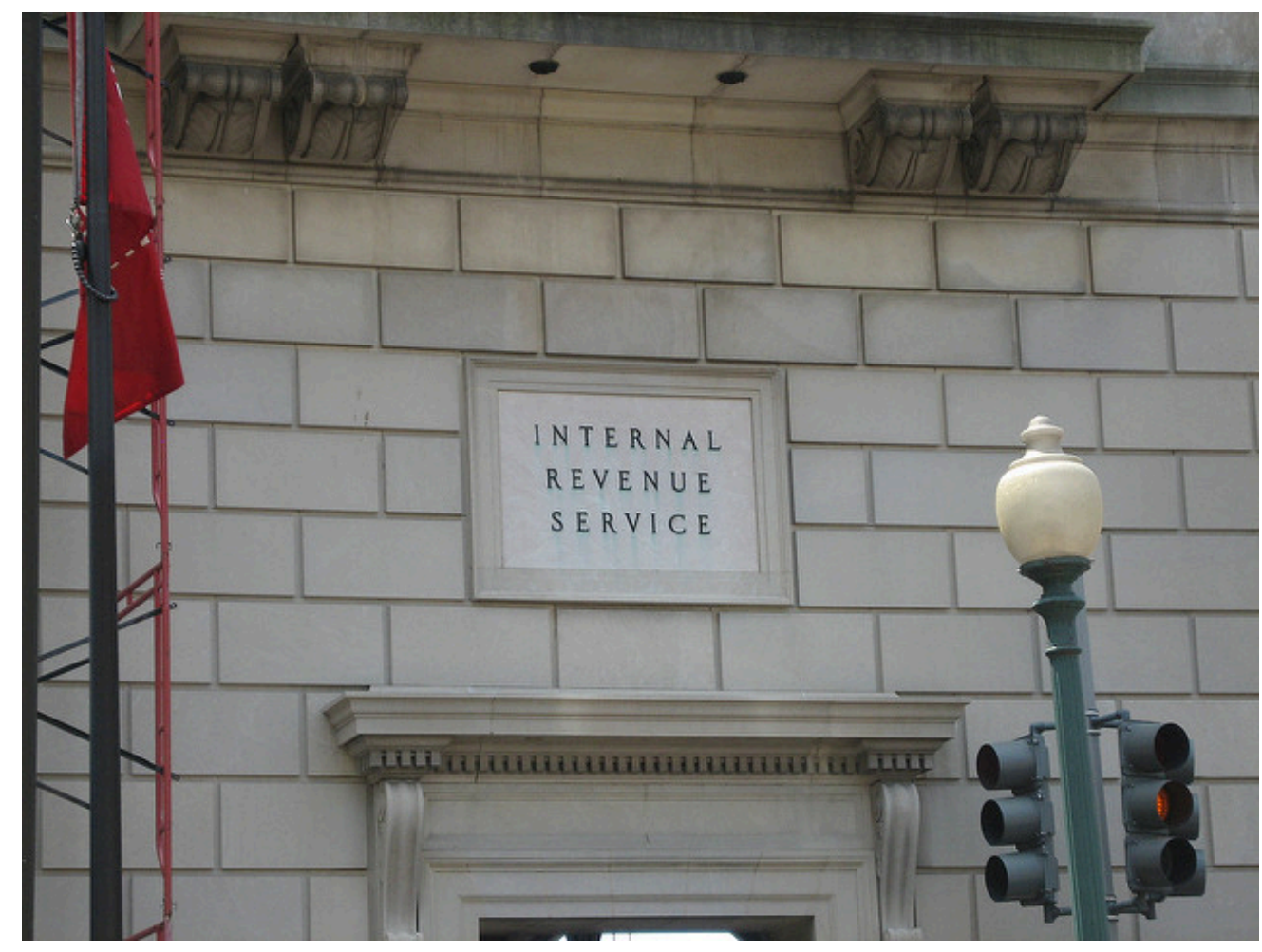

Tax rates for the very wealthy have declined dramatically since the 1970s. This decline has helped fuel a rise in economic inequality.

Martin Haesemeyer - The Internal Revenue Service - CC BY-NC-ND 2.0.

Keep this context in mind as we note that tax cuts in 2003 lowered the tax rate for dividends and capital gains from 28 percent to 15 percent. Meanwhile, the top tax rate for income from salaries and wages is 35 percent. Thus many very wealthy families and individuals pay a lower percentage of their income in taxes than many middle- and upper-middle-class families do because so much of the wealthy families' income is from dividends and capital gains. In fact, the four hundred wealthiest families and individuals in the country pay only about 18 percent of their income in federal tax (Krugman, 2012). As the director of Citizens for Tax Justice explained, "The low taxes on capital gains and dividends are why people who make a ton of money, which is largely from investment income, do awfully well. The Warren Buffetts, the hedge fund managers - they pay really low tax rates” (Confessore, Kocieniewski, \& Parker, 2011, p. A1). This fact prompts a critical question from Paul 
Krugman, winner of the Nobel Prize in economics: "Is there a good reason why the rich should bear a startlingly light tax burden?” His answer: “Such low taxes on the very rich are indefensible” (Krugman, 2012, p. A27).

The lowering of tax rates has helped make the nation's wealthiest families even wealthier. After adjusting for inflation, their after-tax income grew by a much greater amount than that for the poorest families from 1979 to 2007. Income grew by only 18 percent for the poorest fifth but by 65 percent for the wealthiest fifth (excluding the top 1 percent), and it also grew by a whopping 275 percent for families in the top 1 percent (Congressional Budget Office, 2011). As a result, economic inequality increased. Figure 12.6 "Growth of Economic Inequality in the United States (Percentage Share of Total National Income)" shows that wealthiest 1 percent now have a much larger share of the nation's total posttax income than they did in 1979, while the poorest fifth have a lower share. As the saying goes, the rich get richer, and the poor get poorer.

Figure 12.6 Growth of Economic Inequality in the United States (Percentage Share of Total National Income)

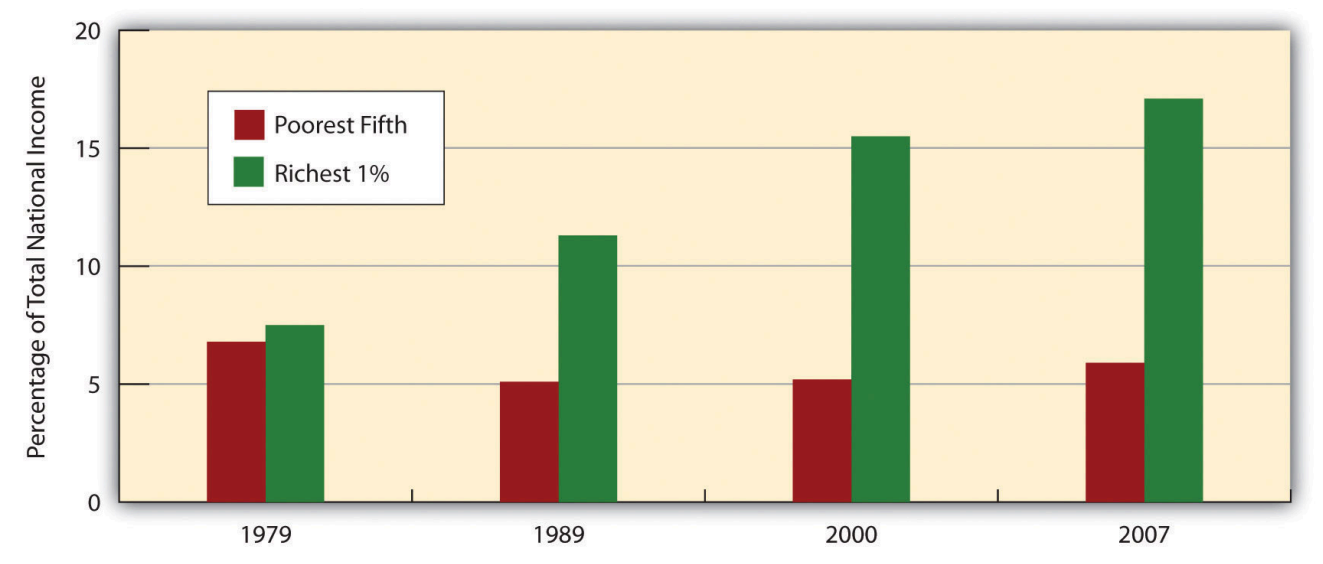

Source: Economic Policy Institute. (2011). Share of total income by income fifths and a breakdown of the top 20\%. The State of working America. Washington, DC: Economic Policy Institute. Retrieved from http://stateofworkingamerica.org/charts/householdincome-shares-1979-2007.

\section{The Impact of Economic Inequality}

Why should we care if economic inequality has increased and if the United States has the highest degree of inequality of all industrial democracies? One answer is that it is a matter of fairness. The United States is not only the wealthiest nation in the world; it is also a nation that historically has stressed that everyone is created equal and that everyone has an equal opportunity to pursue the "American dream" by becoming economically successful. Against this backdrop, a high degree of economic inequality is simply "un-American” and unfair.

Beyond this rather philosophical critique are more practical considerations. First, a high degree of economic inequality is strongly associated with a high degree of poverty and near poverty: If the rich are getting richer, there is normally less wealth to "go around," and the poor get poorer. For the same reason, high economic inequality is also associated with a shrinking of the middle class. In the United States, as both poverty (and near poverty) and wealth have increased, the size of the middle class has reduced, as the chair of the Council of Economic Advisers has emphasized (Krueger, 2012). 
Second, a high degree of economic inequality is also associated with low economic mobility (the movement of people up or down the socioeconomic ladder) (Krueger, 2012). As noted earlier, the United States is the most economically unequal of all industrial democracies. It also has lower economic mobility: Americans born into poverty or near poverty are less likely than their counterparts in other democracies to be able to move up the socioeconomic ladder (DeParle, 2012).

Next, high economic inequality may slow economic growth. This possible effect occurs for at least three reasons (Krueger, 2012). First, the wealthy tend to save their money rather than spend it. Second, a shrinking middle class means there is less spending by the middle class to stimulate the economy. Third, workers' morale is likely to be lower in a society with higher economic inequality, and their lower morale decreases their productivity. As the chair of the Council of Economic Advisers has stated, "The evidence suggests that a growing middle class is good for the economy, and that a more fair distribution of income would hasten economic growth. Businesses would benefit from restoring more fairness to the economy by having more middle class customers, more stable markets, and improved employee morale and productivity” (Krueger, 2012).

Finally, many social scientists consider nations with high degrees of economic inequality to be "unhealthy societies," to quote the title of a book on this issue (Wilkinson, 1996). Economic inequality is thought to undermine social cohesion and increase polarization, and also to cause other problems (Barash, 2012; Wilkinson \& Pickett, 2011). Among the world's industrial nations, higher degrees of economic inequality are associated with worse physical and mental health, lower life expectancy, and higher rates of violent crime. High economic inequality, then, is a matter not only of fairness but also of life and death.

\section{Tax Evasion}

Another significant problem in the American economy is tax evasion. The Internal Revenue Service (IRS) periodically estimates the amount of tax evasion and derives a figure it calls the tax gap: the difference between what Americans owe in federal taxes and what they actually pay. Much of the annual tax gap results from the failure of professionals such as physicians and attorneys to report self-employment income and from the claiming of false deductions by wealthy individuals and families (Braithwaite, 2009).

In January 2012, the IRS released its estimate of the tax gap for 2006. The initial tax gap was \$450 billion. After payment of late taxes and certain enforcement efforts, this gap was reduced to $\$ 385$ billion, still an astronomical figure; tax evasion by corporations amounted for about $\$ 70$ billion of this amount. The total tax gap is about twenty times greater than the annual economic loss from property crimes such as burglary and motor vehicle theft. In 2006, the federal budget deficit was $\$ 248$ billion. If everyone had paid the taxes they owed, there would have been no deficit at all, and the federal government in fact would have had a surplus of $\$ 137$ billion (Pizzigati, 2012).

Despite the huge problem of tax evasion, budget cuts in 2011 weakened the ability of the IRS to enforce the tax code. In 2012, the IRS had 3,000 fewer employees working in enforcement than it had in 2010 (Pizzigati, 2012).

\section{Crime in the Workplace}




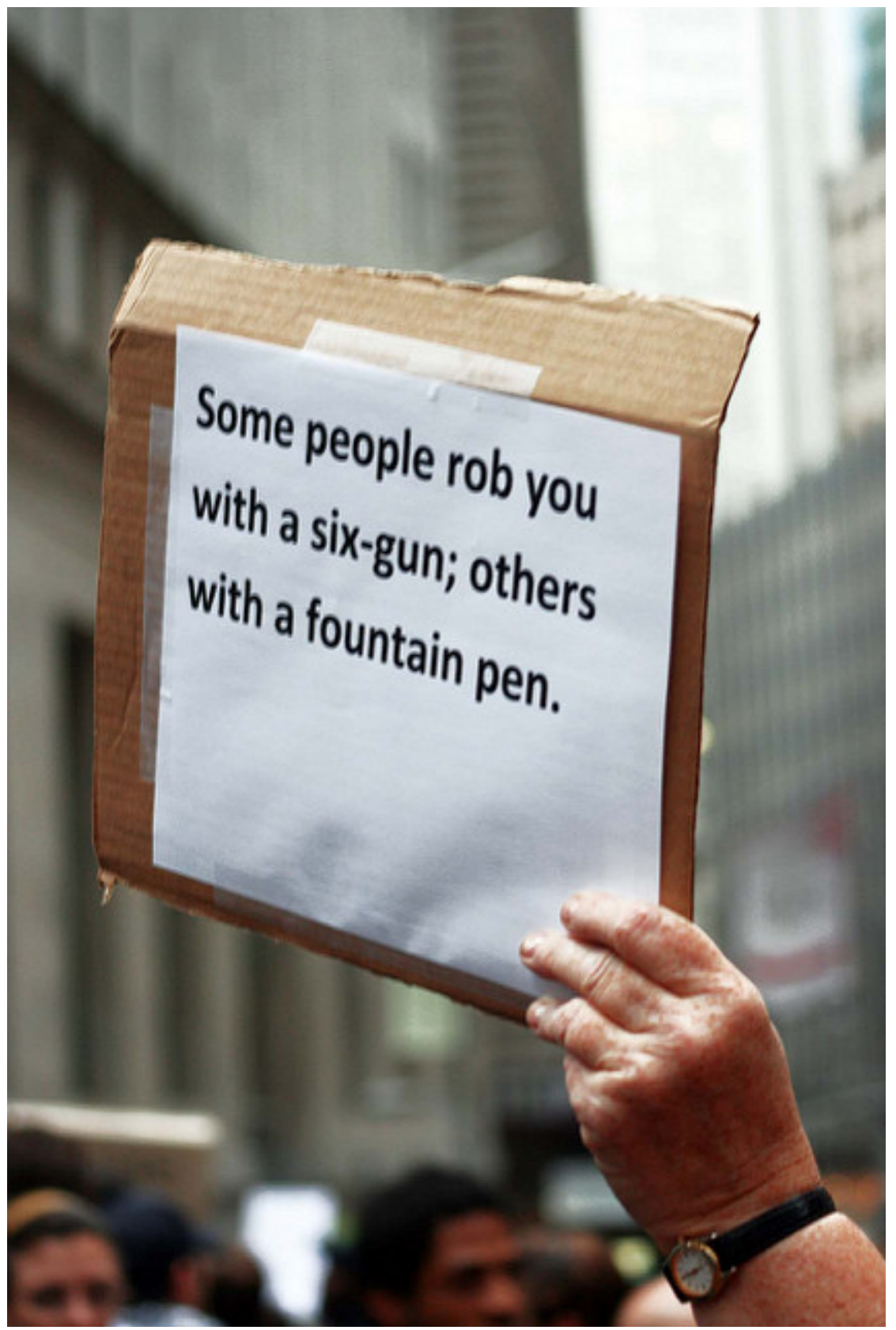

Employee theft costs about $\$ 19.5$ billion annually. Workers' dissatisfaction with various aspects of their jobs is a major reason for this form of theft.

A. Golden - the US\$ 3 TRILLION HEIST - CC BY-NC-ND 2.0.

An unfortunate fact about work in the United States is crime in the workplace, which is the last problem in work and the economy that we will examine. Two major types of such crime exist: employee theft and workplace violence. 


\section{Employee Theft}

Employee theft takes two forms: pilferage and embezzlement. Pilferage involves the stealing of goods, while embezzlement involves the stealing of money in its various dimensions (cash, electronic transactions, etc.). Whichever form it takes, employee theft is so common that is has been called a "widespread, pervasive, and costly form of crime” (Langton, Piquero, \& Hollinger, 2006, p. 539). It is estimated that about 75 percent of employees steal at least once from their employers and that the annual amount of employee theft is $\$ 19.5$ billion (National Retail Federation, 2007).

Employee theft occurs for many reasons, but a common reason is worker dissatisfaction with various aspects of their job. They may think their wages or salaries are too low, they may feel they have been treated unfairly by their employer, and so forth. As the estimates of the amount of employee theft suggest, this form of theft is not condemned by many people, and, indeed, many workplaces have informal norms that approve of certain forms of theft-for example, it is OK to steal inexpensive objects such as (depending on the workplace) utensils, food, pencils and pens, or toilet paper. Not surprisingly, embezzlement is often more costly to an employer than pilferage; although it can involve just a few dollars from a cash register, it can also involve hundreds of thousands or millions of dollars acquired through more sophisticated means.

When we think of employee theft, we probably usually think of theft by blue-collar or lower white-collar employees. However, physicians, attorneys, and other professionals also steal from their patients/clients or from the government, even if their form of theft is often much more complex and sophisticated than what the term "employee theft" may usually imply. Attorneys may bill their clients for work that was never done, and physicians may bill Medicare or private insurance for patients they never saw or for procedures that were never performed. We call this form of "employee” theft professional fraud. Fraud by physicians and other health-care professionals (including nursing homes and medical testing laboratories) is thought to amount to \$100 billion every year (Rosoff et al., 2010), a figure that far exceeds the $\$ 19.5$ billion in "conventional” employee theft and the similar figure lost to property crime (robbery, burglary, larceny, and motor vehicle theft).

\section{Workplace Violence}

In January 2012, a lumber company employee in North Carolina entered the company's warehouse armed with a twelve-gauge shotgun. He shot and killed three coworkers and critically wounded another coworker. He then returned home, shot himself in the head, and later died at a hospital. A news report described the gunman as a “disgruntled” employee (Muskal, 2012). 


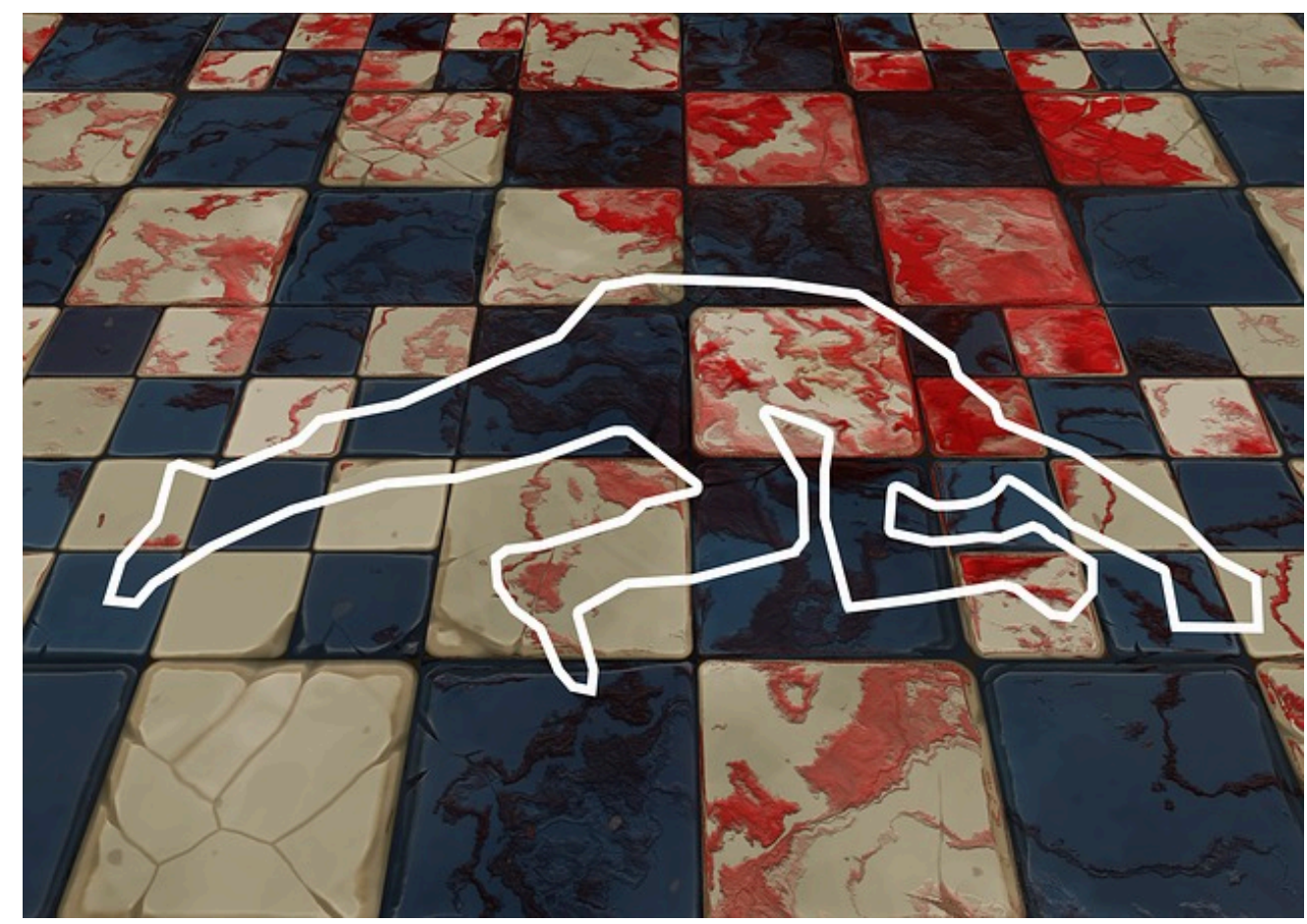

About five hundred homicides occur at workplaces every year. The majority of these homicides result from robberies, not from the actions of disgruntled workers.

Pixabay - CC0 Public Domain.

Many people die or are injured by acts of violence at their workplaces every year in the United States. In 2008, 517 people were slain at their workplaces, according to the US Bureau of Labor Statistics. As disturbing as this number was, it represented a sharp drop from the numbers that prevailed a decade earlier, when 1,080 workplace homicides occurred in 1994. From 2003 through 2008, an average of 497 workplace homicides occurred every year (Needleman, 2010).

In terms of who is involved and the reasons for their involvement, three kinds of workplace homicides are the most common. The first and by far the most common type is homicide as the result of robbery. This category includes the many store clerks, gas station attendants, taxi drivers, and other employees who are slain during a robbery, as well as police who are killed as they try to stop a robbery or apprehend the offender. The second category is homicide committed as an act of domestic violence; in this type, the offender, almost always a man, seeks out his wife or girlfriend (or ex-wife or ex-girlfriend) at her workplace and kills her. The third category involves disgruntled workers, such as the North Carolina lumber employee just discussed, who kill one or more people at their workplace whom they blame for problems the killers have been having. Although this type of homicide is the type that the phrase "workplace violence" or "workplace killings" usually brings to mind, it is actually the least common of the three types listed here (Fox, 2010).

\section{Key Takeaways}

- The move to a postindustrial economy has resulted in a loss of jobs and wages in the United States, thanks 
in part to capital flight and outsourcing.

- Unemployment soared after the Great Recession that began in late 2007. Joblessness has significant consequences for the financial and psychological well-being of the millions of people who are unemployed.

- Economic inequality has greatly increased since the 1970s, thanks in large part to changes in the tax code that favored the wealthy.

- Corporations often engage in white-collar crime that costs hundreds of billions of dollars annually and results in tens of thousands of deaths.

\section{For Your Review}

1. Write a brief essay in which you discuss the benefits and disadvantages of corporations in modern society.

2. Write a brief essay in which you summarize the problems associated with increasing economic inequality.

3. Fewer workers belong to labor unions now than just a few decades ago. Do you think this is a good development or a bad development? Explain your answer.

4. Think of a job you now have or your most recent job if you are currently not employed. On a scale of 1 (very dissatisfied) to 10 (very satisfied), how satisfied are you (were you) with your job? Explain why you have (had) this level of satisfaction.

\section{References}

American Federation of Labor and Congress of Industrial Organizations. (2011). Death on the job: The toll of neglect. Washington, DC: Author.

Barash, D. (2012, January 13). The wanton wages of income inequality. The Chronicle of Higher Education. Retrieved from http://chronicle.com/blogs/brainstorm/the-wages-of-inequality/ 43020?sid=pm\&utm source=pm\&utm medium=en.

Barkan, S. E. (2012). Criminology: A sociological understanding (5th ed.). Upper Saddle River, NJ: Prentice Hall.

Bertrand, M., \& Mullainathan, S. (2003). Are Emily and Greg more employable than Lakisha and Jamal? A field experiment on labor market discrimination (Working Paper No. 9873). Cambridge, MA: National Bureau of Economic Research. Retrieved from http://papers.nber.org/papers/w9873.pdf.

Braithwaite, V. (2009). Tax evasion. In M. Tonry (Ed.), The Oxford handbook of crime and public policy (pp. 381-405). New York, NY: Oxford University Press.

Bureau of Labor Statistics. (2012). 2012 employment and earnings online. Washington, DC: Bureau of Labor Statistics. Retrieved from http://www.bls.gov/opub/ee/home.htm. 
Confessore, N., Kocieniewski, D., \& Parker, A. (2011, January 18). Romney shares some tax data; critics pounce. New York Times, p. A1.

Congressional Budget Office. (2011). Trends in the distribution of household income between 1979 and 2007. Retrieved from http://www.cbo.gov/ftpdocs/124xx/doc12485/WebSummary.pdf.

DeParle, J. (2012, January 5). Harder for Americans to rise from lower rungs. New York Times, p. A1.

Dubofsky, M., \& Dulles, F. R. (2010). Labor in America: A history (8th ed.). Wheeling, IL: Harlan Davidson.

Economic Policy Institute. (2012). The state of working America. Retrieved January 17, 2012, from http://stateofworkingamerica.org.

Fortune. (2011). Fortune 500. Retrieved January 14, 2012, from http://money.cnn.com/magazines/fortune/ fortune500/2011/full list.

Fox, J. A. (2010). Workplace homicide: What is the risk? Retrieved from http://boston.com/community/blogs/ crime punishment/2010/08/workplace homicide the risks.html.

Hacker, J. S., \& Pierson, P. (2011). Winner-take-all politics: How Washington made the rich richer-and turned its back on the middle class. New York, NY: Simon \& Schuster.

Hall, D. (2011, November 3). As the manufacturing sector goes, so goes America? Retrieved January 16, 2012, from http://www.epi.org/blog/manufacturing-sector-american-economy.

Herbert, B. (2010, August 10). The horror show. New York Times, p. A25.

Hillstrom, K., \& Hillstrom, L. C. (Eds.). (2005). The industrial revolution in America. Santa Barbara, CA: ABCCLIO.

Hirsch, B., \& Macpherson, D. (2011). Union membership and coverage database from the CPS. Retrieved from http://unionstats.com.

Hungerford, T. L. (2011). Changes in the distribution of income among tax filers between 1996 and 2006: The role of labor income, capital income, and tax policy. Washington, DC: Congressional Research Service.

Krueger, A. B. (2012). The rise and consequences of inequality in the United States. Retrieved January 19, 2012, from http://www.americanprogress.org/events/2012/01/pdf/krueger.pdf.

Krugman, P. (2012, January 20). Taxes at the top. New York Times, p. A27.

Langton, L., Piquero, N. L., \& Hollinger, R. C. (2006). An empirical test of the relationship between employee theft and low self-control. Deviant Behavior, 27, 537-565.

Leonhardt, D. (2012, January 20). Why taxes aren’t as high as they seem. New York Times, p. A15.

Levine, L. (2012). Offshoring (or offshore outsourcing) and job loss among US workers (CRS Report RL32292). 
549 Social Problems

Retrieved January 17, 2012, from http://forbes.house.gov/UploadedFiles/CRS Offshoring and Job_Loss Among_U S Workers.pdf.

Lovell, P., \& Isaacs, J. B. (2010). Families of the recession: Unemployed parents \& their children. Washington, DC: Brookings Institution.

Luo, M. (2009, November 12). Job woes exacting a toll on family life. New York Times, p. A1.

McDonald, S., Nan, L., \& Ao, D. (2009). Networks of opportunity: Gender, race, and job leads. Social Problems, 56(3), 385-402.

Mills, C. W. (1959). The sociological imagination. London, United Kingdom: Oxford University Press.

Mishel, L., Bernstein, J., \& Shierholz, H. (2009). The state of working America 2008/2009. Ithaca, NY: ILR Press.

Morin, R., \& Kochhar, R. (2010). Lost income, lost friends-and loss of self-respect: The impact of long-term unemployment. Washington, DC: Pew Research Center.

Muskal, M. (2012). Man Shoots 4 Co-Workers, Killing 3, Authorities Say. Los Angeles times, January 12, A12.

National Retail Federation. (2007, June 11). Retail losses hit $\$ 41.6$ billion last year, according to national retail security survey [Press release]. Retrieved from http://www.nrf.com/ modules.php?name=News\&op=viewlive\&sp id=318.

Needleman, S. E. (2010, August 10). When violence strikes the workplace. The Wall Street Journal. Retrieved from

http://online.wsj.com/article/

$\underline{\text { SB10001424052748704164904575421560153438240.html?mod=googlenews wsj. }}$

Pager, D. (2003). The mark of a criminal record. American Journal of Sociology, 108, 937-975.

Pager, D., Bonikowski, B., \& Western, B. (2009). Discrimination in a low-wage labor market: A field experiment. American Sociological Review, 74(5), 777-799.

Parenti, M. (2011). Democracy for the few (9th ed.). Belmont, CA: Wadsworth.

Pizzigati, S. (2012). Law and order 24/7, except at tax time. Retrieved January 14, 2012, from http://toomuchonline.org/tax-gap-law-and-order.

Rosoff, S. M., Pontell, H. N., \& Tillman, R. (2010). Profit without honor: White collar crime and the looting of America (5th ed.). Upper Saddle River, NJ: Prentice Hall.

Shierholz, H. (2012, January 6). A solid step in the right direction for the labor market. Retrieved January 17, 2012, from http://www.epi.org/publication/december-2011-jobs-picture.

Simon, D. R. (2008). Elite deviance (9th ed.). Boston, MA: Allyn and Bacon.

US Census Bureau. (2012). Statistical abstract of the United States: 2012. Washington, DC: US Government Printing Office. Retrieved from http://www.census.gov/compendia/statab. 
US Consumer Product Safety Commission. (2010, April 15). 2010 annual report to the president and the Congress. Washington, DC: Author.

vanden Heuvel, K. (2012, January 26) The occupy effect. The Nation. Retrieved from http://www.thenation.com/ blog/165883/occupy-effect?rel=emailNation.

Wettstein, F. (2009). Multinational corporations and global justice: Human rights obligations of a quasigovernmental institution. Stanford, CA: Stanford Business Books.

Wilkinson, R. G. (1996). Unhealthy societies: The afflictions of inequality. New York, NY: Routledge.

Wilkinson, R., \& Pickett, K. (2011). The spirit level: Why greater equality makes societies stronger. New York, NY: Bloomsbury Press.

Young, S. (2010, April 15). E. coli cases down in 2009, CDC says. CNN Health. Retrieved from http://articles.cnn.com/2010-04-15/health/foodborne.illness.cdc 1 foodnet-cases-of-e-coli-hemolytic-uremicsyndrome? s= PM:HEALTH. 


\subsection{Improving Work and the Economy}

\section{Learning Objective}

1. Understand several types of social reform for improving work and the economy.

This chapter has discussed problems related to work and the economy. Critics of capitalism say many of these and other problems arise from the nature of capitalism. According to this way of thinking, capitalism as an economic system emphasizes competition and thus a "winner takes all” mentality. In this kind of system, there are many losers, and there is also unbridled greed for ever greater wealth. Further, because there is relatively little government regulation in the free-market system that is a hallmark of capitalism, large corporations are left relatively free to engage in behavior that advances their profits but that also stifles competition, harms the environment, and causes other social ills. Regardless of the merits of this general critique, capitalism is not about to disappear. Any improvement in work and the economy, then, must stem from social reforms based on sound social research. This chapter's discussion points to several important problems that must be addressed.

One problem is racial and ethnic discrimination in hiring and employment. Several kinds of studies, but especially field experiments involving job applicants who are similar except for their race and ethnicity, provide powerful evidence of continuing discrimination despite federal and state laws banning it. This evidence certainly suggests the need for stronger enforcement of existing laws against racial and ethnic bias in employment and for public education campaigns to alert workers to signs of this type of discrimination.

A second problem concerns worker morale. Economic inequality and a faltering economy continue to threaten to undermine worker morale and hence worker productivity. Individual employers can do little about these two fundamental problems in the larger economy, but they can do something about worker morale. In this regard, this chapter discussed the importance of coworker friendships for workers' satisfaction with their jobs and for their more general individual well-being. In view of this importance, employers and employees alike should make special efforts to promote coworker friendships. Because work is such an important part of most people's lives, these efforts should prove beneficial for many reasons. Employers should also take other measures to improve worker morale, including improvements in wages and working conditions.

A third problem is unemployment. Sociologists, psychologists, and other scholars have documented the social and emotional consequences of unemployment. The effects of unemployment go far beyond the loss of money. Revealed by much research, these consequences sometimes seem forgotten in national debates over whether to extend unemployment insurance benefits. But unemployment does have a human face, and it is essential to provide monetary benefits and other kinds of help for the unemployed.

A fourth problem is corporate misbehavior. As this chapter discussed, corporations are essential to the US economy but also cause great harm. It is not an exaggeration to say that corporate crime is rampant and that it 
goes largely unpunished. Stricter federal and state oversight of and sanctions against corporate misbehavior are needed.

A fifth problem is economic inequality. The degree of inequality has grown during the past few decades, thanks in large part to changes in the tax codes that greatly favored the wealthy. Restoring tax rates to their standards before the 1980s would help to lessen economic inequality and thus help lessen the problems arising from this type of inequality. In a related area, although the official federal tax rate for corporate profits is 35 percent, many corporations pay a much lower percentage than this because of various loopholes and shelters in the federal tax code. From 2009 to 2011, 280 corporations paid an average of only 18.5 percent of their profits in federal taxes, and 30 of these corporations paid no federal tax during this period (Kocieniewski, 2011). The corporations' effective tax rate was lower than that of corporations in many other democracies. For the ten-year period beginning 2002, General Electric paid only 2.3 percent of its profits in federal taxes (Eichler, 2012). Ending the loopholes and shelters that corporations enjoy will help greatly to increase federal revenue. As the advocacy group Citizens for Tax Justice observes, "Closing the loopholes will have real benefits, including a fairer tax system, reduced federal budget deficits and more resources to improve our roads, bridges and schools-things that are really important for economic development here in the United States” (Kocieniewski, 2011, p. B1).

More generally, it is worth noting a recommendation of many observers concerning the federal government's role in the economy. These observers say the government must take a more active role in improving the national infrastructure, job training, and research and development, and in more generally providing incentives for large corporations to invest their resources in job creation. In this regard, they cite the recent experience of Germany, which has recovered faster than the United States from the worldwide recession (Jacobs, 2012).

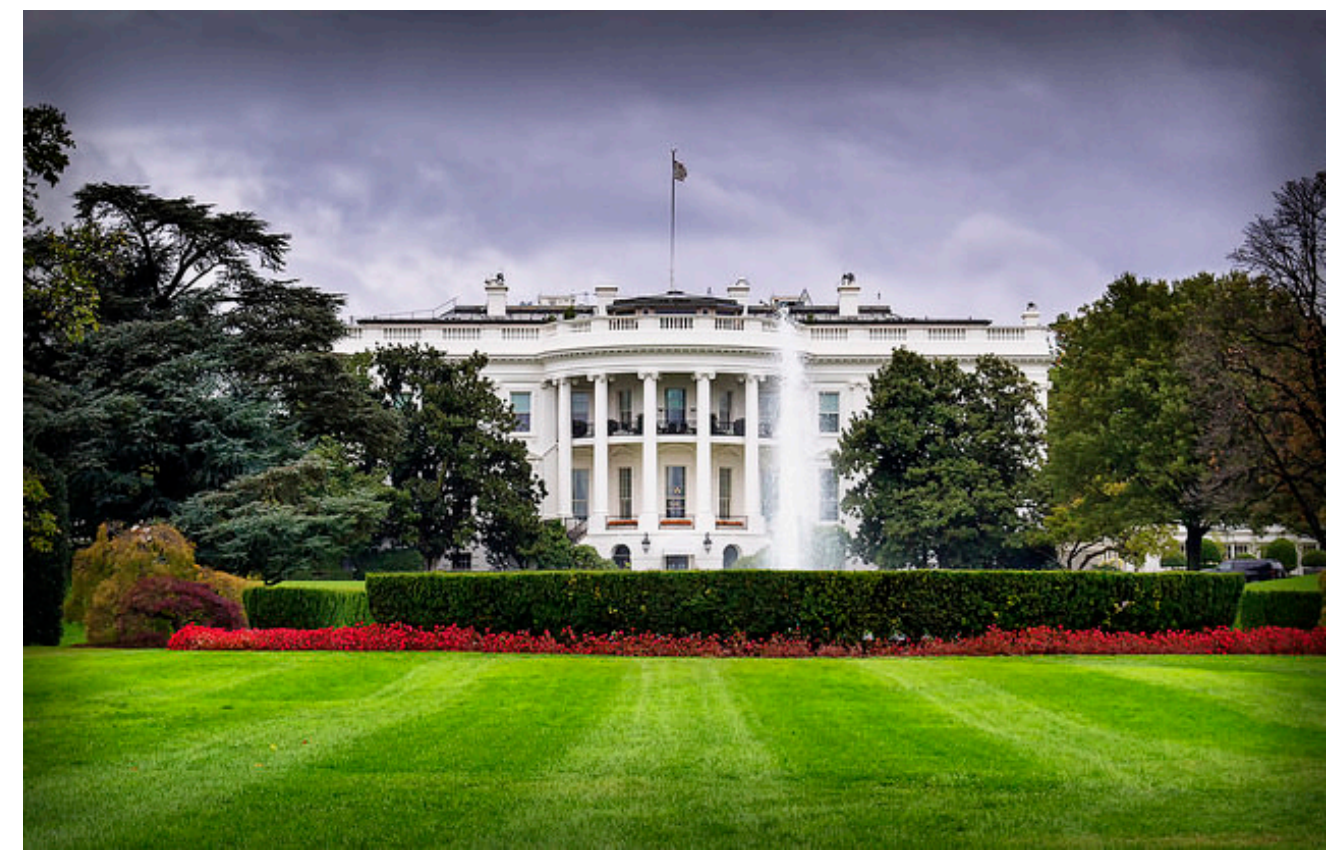

To improve the economy and create many jobs, many observers say the federal government needs to follow the example of Western

Europe by expanding its role in the economy.

Diego Cambiaso - White House - CC BY-SA 2.0.

Germany had this success, these observers say, because it undertook several labor market policies. In particular, 
Germany provided more generous unemployment benefits than found in the United States (including unemployment compensation in return for working shorter hours, which avoided layoffs), and it provided businesses incentives for employment training and subsidies and incentives to hire the unemployed. Other nations have also eased the effects of the recession because their governments have played this type of active role, one that is much more active than found in the United States. The experience of Germany and of several other nations strongly suggests that "government policy and investment can play a vital role in providing incentives for the private sector,” as one journalist put it (Zakaria, 2012). If so, the US federal government would do well to follow the example of Germany and other nations.

In this regard, a comprehensive approach involving job-creation funding is essential (Fieldhouse and Thiess, 2011). This approach would involve federal funding and/or budgetary policy reform in the following areas: (1) funding for the renovation of schools, improvement in transportation, and improvements in other components of the national infrastructure; (2) funding for the hiring of thousands of teachers, child care workers, and community service workers; and (3) expansion of unemployment insurance benefits, both to help the families of the unemployed and to give them money that they will spend to help stimulate the economy.

Taken together, these measures promise to create millions of jobs. Because these jobs would stimulate the economy and increase tax revenue, these measures would help to pay for themselves. Additional funding for these measures would come from raising tax rates on the very wealthy, as discussed earlier, and from other types of tax reform, including ending tax loopholes for the oil and gas industry and implementing a "financial speculation tax" (Fieldhouse \& Thiess, 2011). This last type of tax reform would involve a small tax on all stock transactions, with a 0.5 percent tax raising about $\$ 80$ billion annually (Bivens, 2011).

More generally, recall that the social democracies of Scandinavia have combined democratic freedom and economic prosperity. Although there are certainly no signs that the United States is about to follow their example, our nation also has much to learn from these societies as it considers how best to rebuild its economy and to help the millions of people who are unemployed or underemployed.

\section{Key Takeaways}

- Certain social reforms are necessary to improve aspects of work and the economy.

- Returning tax codes to their rates before the 1980s will help lessen economic inequality.

- Stricter federal and state oversight of corporate behavior is needed to help address corporate crime.

- A greater investment of federal funding in job creation and the raising of taxes for the very wealthy is necessary to create jobs while stimulating the economy.

\section{For Your Review}

1. Write a brief essay that summarizes any three strategies for improving work and the economy.

2. To what extent, if any, do you think capitalism is to blame for the problems in work and the economy 
discussed in this chapter? Explain your answer.

\section{References}

Bivens, J. (2011). Truly shared sacrifice includes Wall Street. Retrieved from http://www.epi.org/blog/sharedsacrifice-wall-street-financial-speculation-tax.

Eichler, A. (2012, February 27). General Electric tax rate 2.3 percent over decade, report finds. The Huffington Post. Retrieved from http://www.huffingtonpost.com/2012/02/27/general-electric-tax-rate n 1305196.html.

Fieldhouse, A., \& Thiess, R. (2011). The Restore the American Dream for the 99\% Act: An analysis of jobcreation provisions. Washington, DC: Economic Policy Institute.

Jacobs, E. (2012). Growth through innovation: Lessons for the United States from the German labor market miracle. Washington, DC: Brookings Institution.

Kocieniewski, D. (2011, November 3). Biggest public firms paid little US tax, study says. New York Times, p. B1.

Zakaria, F. (2012, January 18). The economic lessons the rest of the world could teach us. The Washington Post. Retrieved from http://www.washingtonpost.com/opinions/the-economic-lessons-the-rest-of-the-world-couldteach-us/2012/01/18/gIQAfSuG9P story.html. 


\subsection{End-of-Chapter Material}

\section{Summary}

1. Capitalism and socialism are the two primary types of economic systems in the world today. Capitalism involves private ownership, the pursuit of profit, and competition for profit, while socialism involves the collective ownership of goods and resources and efforts for the common good. Several nations practice democratic socialism, which is meant to combine the best of capitalism and socialism.

2. According to functionalism, the economy makes society possible by providing essential goods and services, while work gives people income and self-fulfillment. According to conflict theory, work is alienating, and the economic elite uses its control of the economy to maintain their elite position. Symbolic interactionism focuses on social interaction in the workplace and on how they perceive the work they do.

3. Problems in work and the economy include the following: (a) the loss of jobs and wages; (b) the decline of labor unions; (c) unemployment; (d) corporate misbehavior; (e) rising economic inequality; (f) tax evasion; and (g) workplace crime.

4. Social reforms based on sound social science research are needed to improve work and the economy. Two important reforms would involve stricter enforcement of laws against racial discrimination in hiring and employment and of penalties for corporate crime.

\section{Using What You Know}

You graduated from college a year ago and have begun working in sales for an electronics company. You've become good friends with a coworker, with whom you often "hang out" at bars and the occasional party. However, one day you notice this coworker pocketing a smartphone, and you realize that a theft is occurring. What, if anything, do you do? Explain your answer.

\section{What You Can Do}

To help deal with the work and economy problems discussed in this chapter, you may wish to do any of the following:

1. Start or join a group that tries to educate the public about economic inequality.

2. Assist a local labor union in its efforts to have safer workplaces. 


\section{Chapter 13: Health and Health Care}

\section{Social Problems in the News}

"More Columbus Kids Living in Poverty," the headline said. New data from the Ohio Department of Education showed that three-fourths of schoolchildren in Columbus, Ohio, live in poverty or near poverty and qualify for federally subsidized school lunch. Ten years earlier, only about 58 percent of Columbus children qualified. According to the news report, "Childhood poverty directly impacts children's health. Children living in poverty are less likely to receive needed medical care, more likely to have health problems such as asthma, more likely to be overweight, among other health problems."

Source: Lietz, 2012

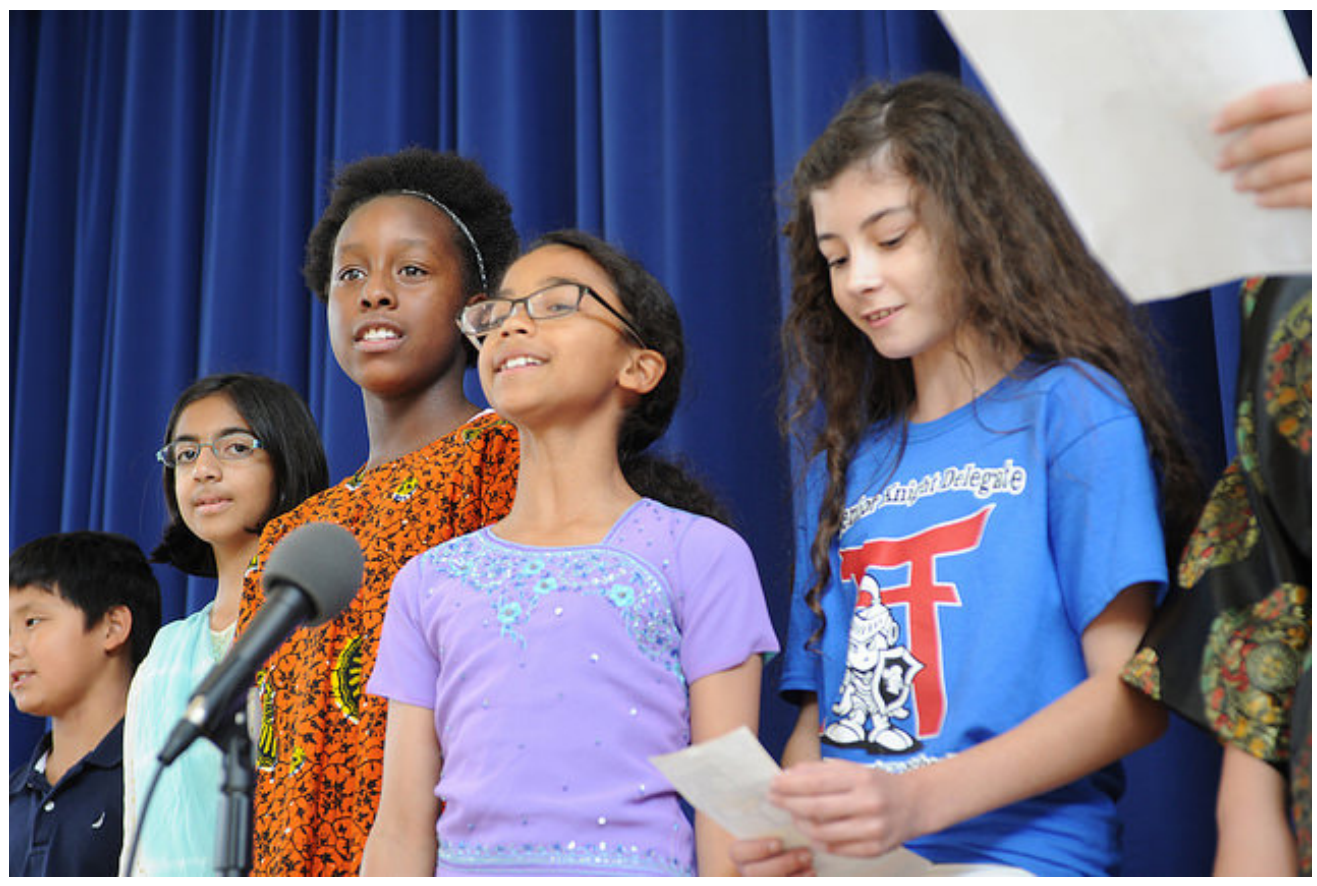

A sociological approach emphasizes that our social class, race and ethnicity, and gender, among other aspects of our social backgrounds, influence our levels of health and illness.

U.S. Army Garrison Japan - Arnn students celebrate diversity; weeklong recognition - CC BY-NC-ND 2.0.

This news story reminds us that social class is linked to health and illness, and it illustrates just one of the many ways in which health and health care are urgent problems in our society. Accordingly, this chapter examines these problems. Its discussion is based on the common sociological view that health and illness are not just medical problems but social problems.

Unlike physicians, sociologists and other public health scholars do not try to understand why any one person 
becomes ill. Instead, they typically examine rates of illness to explain why people from certain social backgrounds are more likely than those from others to become sick. Here, as we will see, our social backgrounds_our social class, race and ethnicity, and gender-make a critical difference.

The fact that our social backgrounds affect our health may be difficult for many of us to accept. We all know someone who has died from a serious illness or currently suffers from one. There is always a medical cause of this person's illness, and physicians do their best to try to cure it and prevent it from recurring. Sometimes they succeed; sometimes they fail. Whether someone suffers a serious illness is often simply a matter of bad luck or bad genes: We can do everything right and still become ill. In saying that our social backgrounds affect our health, sociologists do not deny any of these possibilities. They simply remind us that our social backgrounds also play an important role (Cockerham, 2012).

With this basic understanding in mind, we now turn to sociological perspectives on health and health care.

\section{References}

Cockerham, W. C. (2012). Medical sociology (12th ed.). Upper Saddle River, NJ: Prentice Hall.

Lietz, J. (2012, January 17). More Columbus kids living in poverty. Examiner.com. Retrieved from http://www.examiner.com/children-s-health-in-columbus/more-columbus-kids-living-poverty. 


\subsection{Sociological Perspectives on Health and Health Care}

\section{Learning Objective}

1. List the assumptions of the functionalist, conflict, and symbolic interactionist perspectives on health and medicine.

Before discussing these perspectives, we must first define three key concepts-health, medicine, and health care - that lie at the heart of their explanations and of this chapter's discussion. Health refers to the extent of a person's physical, mental, and social well-being. As this definition suggests, health is a multidimensional concept. Although the three dimensions of health just listed often affect each other, it is possible for someone to be in good physical health and poor mental health, or vice versa. Medicine refers to the social institution that seeks to prevent, diagnose, and treat illness and to promote health in its various dimensions. This social institution in the United States is vast, to put it mildly, and involves more than 11 million people (physicians, nurses, dentists, therapists, medical records technicians, and many other occupations). Finally, health care refers to the provision of medical services to prevent, diagnose, and treat health problems.

With these definitions in mind, we now turn to sociological explanations of health and health care. As usual, the major sociological perspectives that we have discussed throughout this book offer different types of explanations, but together they provide us with a more comprehensive understanding than any one approach can do by itself. Table 13.1 "Theory Snapshot” summarizes what they say.

Table 13.1 Theory Snapshot

\begin{tabular}{|l|l|l|l|l}
$\begin{array}{l}\text { Theoretical } \\
\text { perspective }\end{array}$ & Major assumptions \\
\hline Functionalism & $\begin{array}{l}\text { Good health and effective medical care are essential for the smooth functioning of society. Patients must } \\
\text { perform the "sick role" in order to be perceived as legitimately ill and to be exempt from their normal } \\
\text { obligations. The physician-patient relationship is hierarchical: The physician provides instructions, and } \\
\text { the patient needs to follow them. }\end{array}$ \\
\hline $\begin{array}{l}\text { Conflict } \\
\text { theory }\end{array}$ & $\begin{array}{l}\text { Social inequality characterizes the quality of health and the quality of health care. People from } \\
\text { disadvantaged social backgrounds are more likely to become ill and to receive inadequate health care. } \\
\text { Partly to increase their incomes, physicians have tried to control the practice of medicine and to define } \\
\text { social problems as medical problems. }\end{array}$ \\
\hline $\begin{array}{l}\text { Symbolic } \\
\text { interactionism }\end{array}$ & $\begin{array}{l}\text { Health and illness are social constructions: Physical and mental conditions have little or no objective } \\
\text { reality but instead are considered healthy or ill conditions only if they are defined as such by a society. } \\
\text { Physicians "manage the situation" to display their authority and medical knowledge. }\end{array}$ \\
\hline
\end{tabular}




\section{The Functionalist Approach}

As conceived by Talcott Parsons (1951), the functionalist perspective emphasizes that good health and effective medical care are essential for a society's ability to function. Ill health impairs our ability to perform our roles in society, and if too many people are unhealthy, society's functioning and stability suffer. This was especially true for premature death, said Parsons, because it prevents individuals from fully carrying out all their social roles and thus represents a "poor return" to society for the various costs of pregnancy, birth, child care, and socialization of the individual who ends up dying early. Poor medical care is likewise dysfunctional for society, as people who are ill face greater difficulty in becoming healthy and people who are healthy are more likely to become ill.

For a person to be considered legitimately sick, said Parsons, several expectations must be met. He referred to these expectations as the sick role. First, sick people should not be perceived as having caused their own health problem. If we eat high-fat food, become obese, and have a heart attack, we evoke less sympathy than if we had practiced good nutrition and maintained a proper weight. If someone is driving drunk and smashes into a tree, there is much less sympathy than if the driver had been sober and skidded off the road in icy weather.

Second, sick people must want to get well. If they do not want to get well or, worse yet, are perceived as faking their illness or malingering after becoming healthier, they are no longer considered legitimately ill by the people who know them or, more generally, by society itself.

Third, sick people are expected to have their illness confirmed by a physician or other health-care professional and to follow the professional's instructions in order to become well. If a sick person fails to do so, she or he again loses the right to perform the sick role.

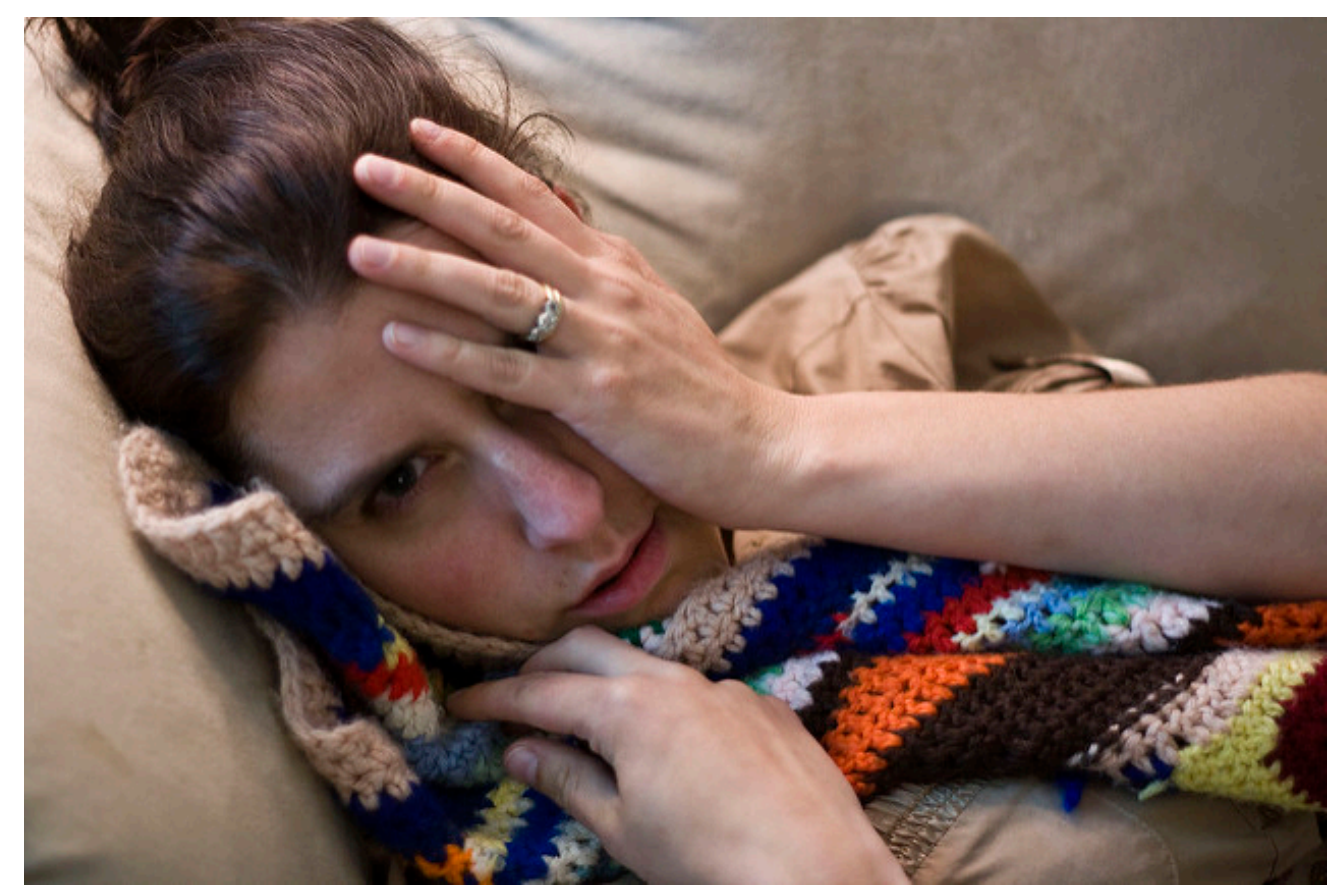

Talcott Parsons wrote that for a person to be perceived as legitimately ill, several expectations, called the sick role, must be met. These expectations include the perception that the person did not cause her or his own health problem. 
If all these expectations are met, said Parsons, sick people are treated as sick by their family, their friends, and other people they know, and they become exempt from their normal obligations to all these people. Sometimes they are even told to stay in bed when they want to remain active.

Physicians also have a role to perform, said Parsons. First and foremost, they have to diagnose the person's illness, decide how to treat it, and help the person become well. To do so, they need the cooperation of the patient, who must answer the physician's questions accurately and follow the physician's instructions. Parsons thus viewed the physician-patient relationship as hierarchical: the physician gives the orders (or, more accurately, provides advice and instructions), and the patient follows them.

Parsons was certainly right in emphasizing the importance of individuals' good health for society's health, but his perspective has been criticized for several reasons. First, his idea of the sick role applies more to acute (shortterm) illness than to chronic (long-term) illness. Although much of his discussion implies a person temporarily enters a sick role and leaves it soon after following adequate medical care, people with chronic illnesses can be locked into a sick role for a very long time or even permanently. Second, Parsons's discussion ignores the fact, mentioned earlier, that our social backgrounds affect the likelihood of becoming ill and the quality of medical care we receive. Third, Parsons wrote approvingly of the hierarchy implicit in the physician-patient relationship. Many experts say today that patients need to reduce this hierarchy by asking more questions of their physicians and by taking a more active role in maintaining their health. To the extent that physicians do not always provide the best medical care, the hierarchy that Parsons favored is at least partly to blame.

\section{The Conflict Approach}

The conflict approach emphasizes inequality in the quality of health and of health-care delivery (Weitz, 2013). As noted earlier, the quality of health and health care differs greatly around the world and within the United States. Society's inequities along social class, race and ethnicity, and gender lines are reproduced in our health and health care. People from disadvantaged social backgrounds are more likely to become ill, and once they do become ill, inadequate health care makes it more difficult for them to become well. As we will see, the evidence of disparities in health and health care is vast and dramatic.

The conflict approach also critiques efforts by physicians over the decades to control the practice of medicine and to define various social problems as medical ones. Physicians' motivation for doing so has been both good and bad. On the good side, they have believed they are the most qualified professionals to diagnose problems and to treat people who have these problems. On the negative side, they have also recognized that their financial status will improve if they succeed in characterizing social problems as medical problems and in monopolizing the treatment of these problems. Once these problems become "medicalized," their possible social roots and thus potential solutions are neglected.

Several examples illustrate conflict theory's criticism. Alternative medicine is becoming increasingly popular, but so has criticism of it by the medical establishment. Physicians may honestly feel that medical alternatives are inadequate, ineffective, or even dangerous, but they also recognize that the use of these alternatives is financially 
harmful to their own practices. Eating disorders also illustrate conflict theory's criticism. Many of the women and girls who have eating disorders receive help from a physician, a psychiatrist, a psychologist, or another healthcare professional. Although this care is often very helpful, the definition of eating disorders as a medical problem nonetheless provides a good source of income for the professionals who treat it and obscures its cultural roots in society's standard of beauty for women (Whitehead \& Kurz, 2008).

Obstetrical care provides another example. In most of human history, midwives or their equivalent were the people who helped pregnant women deliver their babies. In the nineteenth century, physicians claimed they were better trained than midwives and won legislation giving them authority to deliver babies. They may have honestly felt that midwives were inadequately trained, but they also fully recognized that obstetrical care would be quite lucrative (Ehrenreich \& English, 2005).

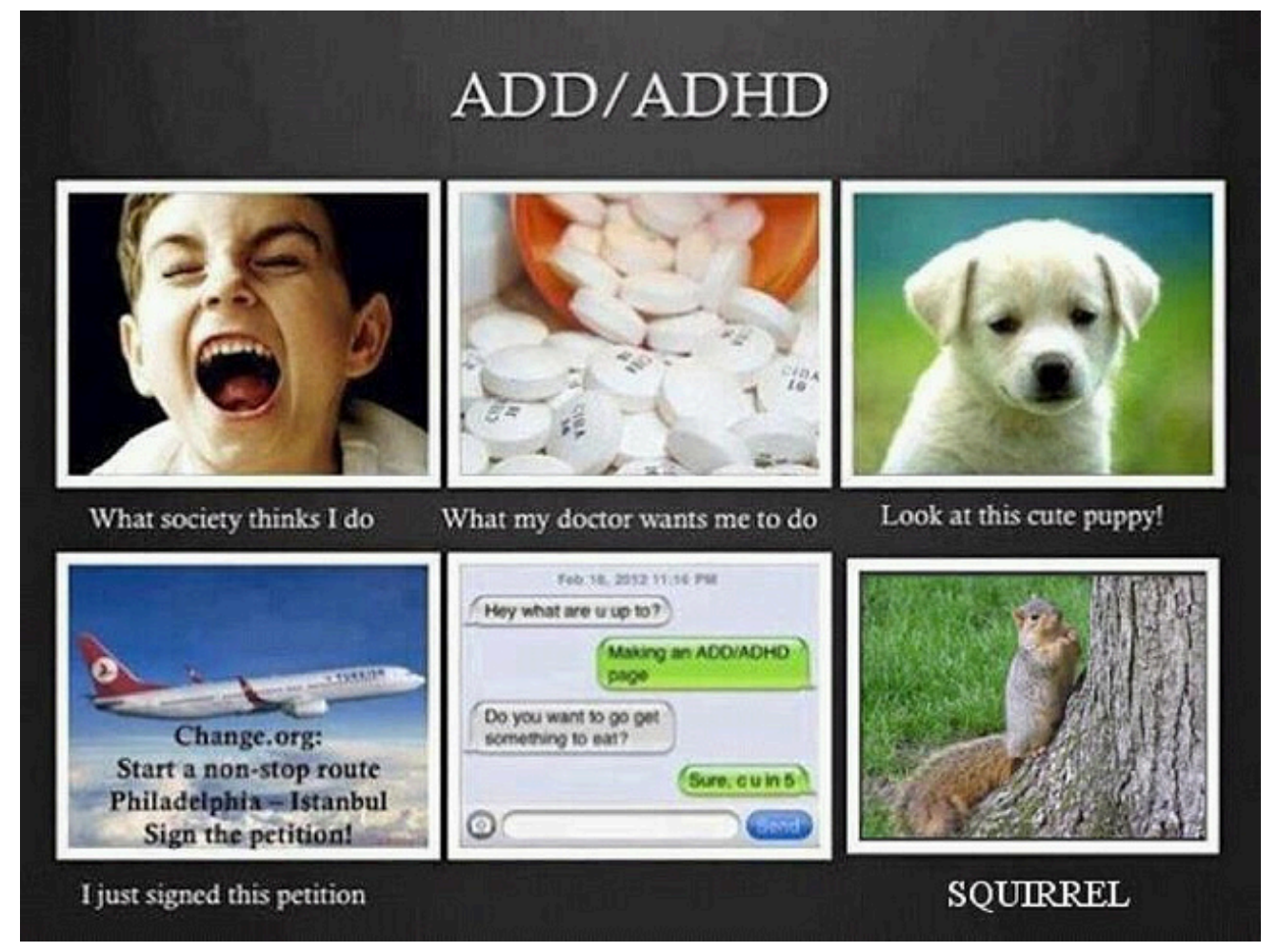

According to conflict theory, physicians have often sought to define various social problems as medical problems. An example is the development of the diagnosis of ADHD, or attention deficit/hyperactivity disorder.

birgerking - What I Really Do... ADD/ADHD - CC BY 2.0.

In a final example, many hyperactive children are now diagnosed with ADHD, or attention deficit/hyperactivity disorder. A generation or more ago, they would have been considered merely as overly active. After Ritalin, a drug that reduces hyperactivity, was developed, their behavior came to be considered a medical problem and the ADHD diagnosis was increasingly applied, and tens of thousands of children went to physicians' offices and were given Ritalin or similar drugs. The definition of their behavior as a medical problem was very lucrative for physicians and for the company that developed Ritalin, and it also obscured the possible roots of their behavior in inadequate parenting, stultifying schools, or even gender socialization, as most hyperactive kids are boys (Conrad, 2008; Rao \& Seaton, 2010). 
Critics say the conflict approach's assessment of health and medicine is overly harsh and its criticism of physicians' motivation far too cynical. Scientific medicine has greatly improved the health of people around the world. Although physicians are certainly motivated, as many people are, by economic considerations, their efforts to extend their scope into previously nonmedical areas also stem from honest beliefs that people's health and lives will improve if these efforts succeed. Certainly there is some truth in this criticism of the conflict approach, but the evidence of inequality in health and medicine and of the negative aspects of the medical establishment's motivation for extending its reach remains compelling.

\section{The Symbolic Interactionist Approach}

The symbolic interactionist approach emphasizes that health and illness are social constructions. This means that various physical and mental conditions have little or no objective reality but instead are considered healthy or ill conditions only if they are defined as such by a society and its members (Buckser, 2009; Lorber \& Moore, 2002). The ADHD example just discussed also illustrates symbolic interactionist theory's concerns, as a behavior that was not previously considered an illness came to be defined as one after the development of Ritalin. In another example first discussed in Chapter 7 "Alcohol and Other Drugs", in the late 1800s opium use was quite common in the United States, as opium derivatives were included in all sorts of over-the-counter products. Opium use was considered neither a major health nor legal problem. That changed by the end of the century, as prejudice against Chinese Americans led to the banning of the opium dens (similar to today's bars) they frequented, and calls for the banning of opium led to federal legislation early in the twentieth century that banned most opium products except by prescription (Musto, 2002).

In a more current example, an attempt to redefine obesity is now under way in the United States. Obesity is a known health risk, but a "fat pride” or "fat acceptance” movement composed mainly of heavy individuals is arguing that obesity's health risks are exaggerated and calling attention to society's discrimination against overweight people. Although such discrimination is certainly unfortunate, critics say the movement is going too far in trying to minimize obesity's risks (Diamond, 2011).

The symbolic interactionist approach has also provided important studies of the interaction between patients and health-care professionals. Consciously or not, physicians "manage the situation" to display their authority and medical knowledge. Patients usually have to wait a long time for the physician to show up, and the physician is often in a white lab coat; the physician is also often addressed as "Doctor," while patients are often called by their first name. Physicians typically use complex medical terms to describe a patient's illness instead of the more simple terms used by laypeople and the patients themselves.

Management of the situation is perhaps especially important during a gynecological exam, as first discussed in Chapter 12 "Work and the Economy". When the physician is a man, this situation is fraught with potential embarrassment and uneasiness because a man is examining and touching a woman's genital area. Under these circumstances, the physician must act in a purely professional manner. He must indicate no personal interest in the woman's body and must instead treat the exam no differently from any other type of exam. To further "desex" the situation and reduce any potential uneasiness, a female nurse is often present during the exam.

Critics fault the symbolic interactionist approach for implying that no illnesses have objective reality. Many 
serious health conditions do exist and put people at risk for their health regardless of what they or their society thinks. Critics also say the approach neglects the effects of social inequality for health and illness. Despite these possible faults, the symbolic interactionist approach reminds us that health and illness do have a subjective as well as an objective reality.

\section{Key Takeaways}

- A sociological understanding emphasizes the influence of people's social backgrounds on the quality of their health and health care. A society's culture and social structure also affect health and health care.

- The functionalist approach emphasizes that good health and effective health care are essential for a society's ability to function, and it views the physician-patient relationship as hierarchical.

- The conflict approach emphasizes inequality in the quality of health and in the quality of health care.

- The interactionist approach emphasizes that health and illness are social constructions; physical and mental conditions have little or no objective reality but instead are considered healthy or ill conditions only if they are defined as such by a society and its members.

\section{For Your Review}

1. Which approach—functionalist, conflict, or symbolic interactionist—do you most favor regarding how you understand health and health care? Explain your answer.

2. Think of the last time you visited a physician or another health-care professional. In what ways did this person come across as an authority figure possessing medical knowledge? In formulating your answer, think about the person's clothing, body position and body language, and other aspects of nonverbal communication.

\section{References}

Buckser, A. (2009). Institutions, agency, and illness in the making of Tourette syndrome. Human Organization, 68(3), 293-306.

Conrad, P. (2008). The medicalization of society: On the transformation of human conditions into treatable disorders. Baltimore, MD: Johns Hopkins University Press.

Diamond, A. (2011). Acceptance of fat as the norm is a cause for concern. Nursing Standard, 25(38), $28-28$.

Lorber, J., \& Moore, L. J. (2002). Gender and the social construction of illness (2nd ed.). Lanham, MD: Rowman \& Littlefield.

Musto, D. F. (Ed.). (2002). Drugs in America: A documentary history. New York, NY: New York University Press.

Parsons, T. (1951). The social system. New York, NY: Free Press. 
Rao, A., \& Seaton, M. (2010). The way of boys: Promoting the social and emotional development of young boys. New York, NY: Harper Paperbacks.

Weitz, R. (2013). The sociology of health, illness, and health care: A critical approach (6th ed.). Thousand Oaks, CA: Wadsworth.

Whitehead, K., \& Kurz, T. (2008). Saints, sinners and standards of femininity: Discursive constructions of anorexia nervosa and obesity in women’s magazines. Journal of Gender Studies, 17, 345-358. 


\subsection{Global Aspects of Health and Health Care}

\section{Learning Objectives}

1. Describe how the nations of the world differ in important indicators of health and illness.

2. Explain the health-care model found in industrial nations other than the United States.

As we have seen in previous chapters, understanding what happens in other societies helps us to understand what happens in our own society. This section's discussion of health and health care across the globe, then, helps shed some light on what is good and bad about US health and medicine.

\section{International Disparities in Health and IIIness}

The nations of the world differ dramatically in the quality of their health and health care. The poorest nations suffer terribly. Their people suffer from poor nutrition, unsafe water, inadequate sanitation, rampant disease, and inadequate health care. One disease they suffer from is AIDS. Some 34 million people worldwide have HIV/ AIDS, and two-thirds of these live in sub-Saharan Africa. Almost two million people, most of them from this region, died in 2010 from HIV/AIDS (World Health Organization, 2011). All these health problems produce high rates of infant mortality and maternal mortality and high death rates. For all these reasons, people in the poorest nations have shorter life spans than those in the richest nations.

A few health indicators should indicate the depth of the problem. Figure 13.1 "Infant Mortality for LowIncome, Lower-Middle-Income, Higher-Middle-Income, and High-Income Nations, 2010” compares an important indicator, infant mortality (number of deaths before age 1 per 1,000 live births) for nations grouped into four income categories. The striking contrast between the two groups provides dramatic evidence of the health problems poor nations face. When, as Figure 13.1 "Infant Mortality for Low-Income, Lower-Middle-Income, Higher-Middle-Income, and High-Income Nations, 2010” indicates, 70 children in the poorest nations die before their first birthday for every 1,000 live births (equivalent to 7 out of 100), the poor nations have serious problems indeed.

Figure 13.1 Infant Mortality for Low-Income, Lower-Middle-Income, Higher-Middle-Income, and High-Income Nations, 2010 


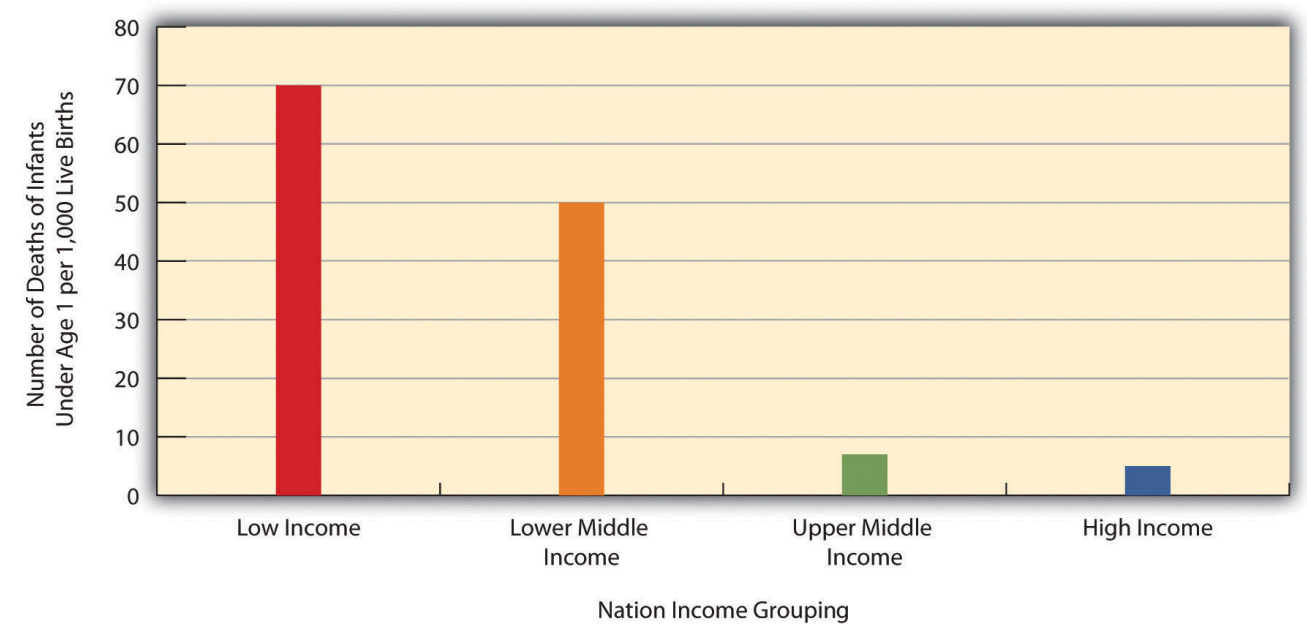

Source: Data from World Bank. (2012). World databank. Retrieved from http://databank.worldbank.org/ddp/home.do?Step=1\&id=4.

Figure 13.2 "Percentage of Population with Access to Adequate Sanitation Facilities, 2008" shows how the world differs in access to adequate sanitation facilities (i.e., the removal of human waste from the physical environment, as by toilets). Whereas this percentage is at least 98 percent in the wealthy nations of North America, Western Europe, Australia, and New Zealand, it is less than 33 percent in many poor nations in Africa and Asia.

Figure 13.2 Percentage of Population with Access to Adequate Sanitation Facilities, 2008

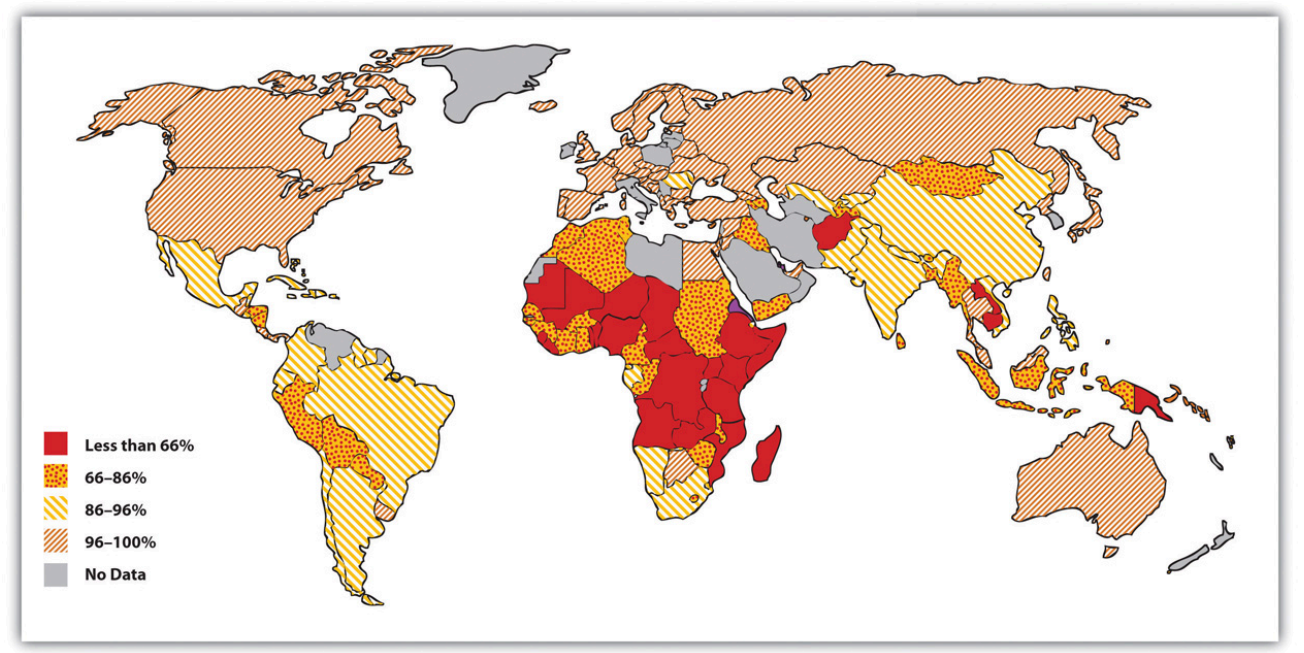

Source: Adapted from World Bank. (2010). Improved sanitation facilities (\% of population with access). Retrieved from http://www.worldbank.org. 


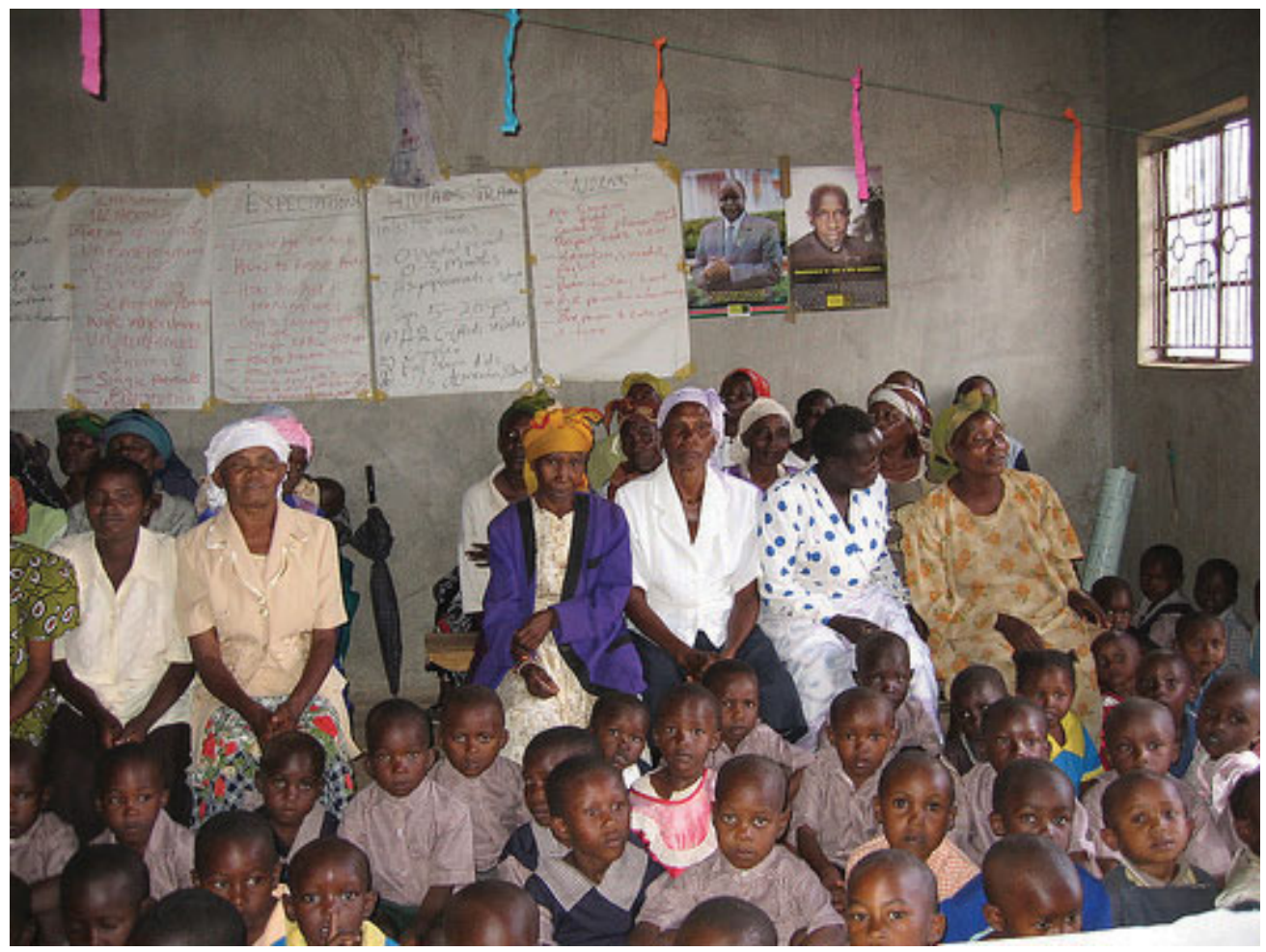

Two-thirds of the 33 million people worldwide who have HIV/AIDS live in sub-Saharan Africa. This terrible fact illustrates just one of the many health problems that people in poor nations suffer.

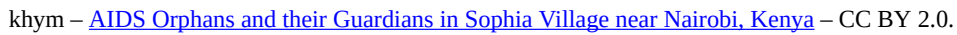

Life expectancy is another important measure of a nation's health and is very relevant for understanding worldwide disparities in health and health care. Figure 13.3 "Average Life Expectancy across the Globe (Years)" illustrates these disparities. Not surprisingly, the global differences in this map are similar to those for adequate sanitation in the map depicted in Figure 13.2 "Percentage of Population with Access to Adequate Sanitation Facilities, 2008”. North America, Western Europe, Australia, and New Zealand have much longer life expectancies (75 years and higher) than Africa and Asia, where some nations have expectancies below 50 years. The society we live in can affect our life span by more than a quarter of a century.

Figure 13.3 Average Life Expectancy across the Globe (Years) 


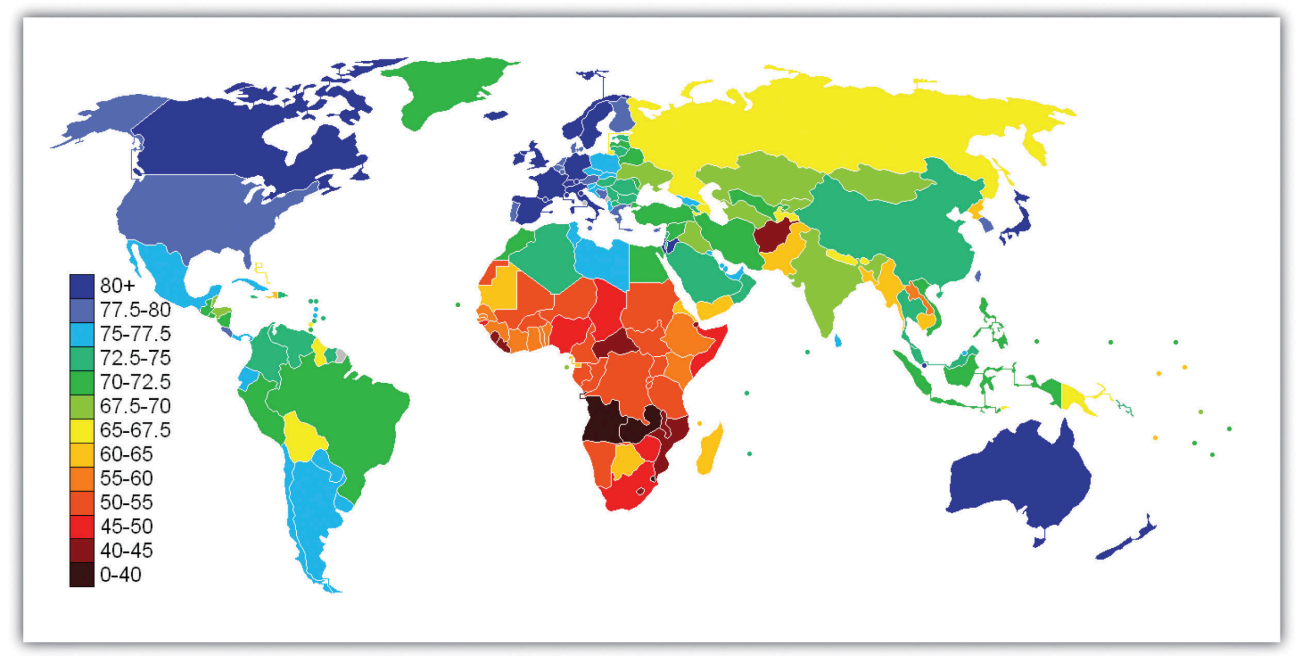

Source: Adapted from http://en.wikipedia.org/wiki/File:Life_Expectancy_2011_Estimates_CIA_World_Factbook.png.

\section{Health Care in Industrial Nations}

Industrial nations throughout the world, with the notable exception of the United States, provide their citizens with some form of national health care and national health insurance (Russell, 2011). Although their healthcare systems differ in several respects, their governments pay all or most of the costs for health care, drugs, and other health needs. In Denmark, for example, the government provides free medical care and hospitalization for the entire population and pays for some medications and some dental care. In France, the government pays for some of the medical, hospitalization, and medication costs for most people and all these expenses for the poor, unemployed, and children under the age of 10. In Great Britain, the National Health Service pays most medical costs for the population, including medical care, hospitalization, prescriptions, dental care, and eyeglasses. In Canada, the National Health Insurance system also pays for most medical costs. Patients do not even receive bills from their physicians, who instead are paid by the government.

Although these national health insurance programs are not perfect-for example, people sometimes must wait for elective surgery and some other procedures - they are commonly credited with reducing infant mortality, extending life expectancy, and, more generally, for enabling their citizenries to have relatively good health. Their populations are generally healthier than Americans, even though health-care spending is much higher per capita in the United States than in these other nations. In all these respects, these national health insurance systems offer several advantages over the health-care model found in the United States (Reid, 2010) (see Note 13.11 "Lessons from Other Societies”).

\section{Lessons from Other Societies}

National Health Care in Wealthy Democracies

As the text discusses, industrial nations other than the United States provide free or low-cost health care to their citizens in what is known as national (or universal) health insurance and national health care. Although the United States spends 
more per capita than these nations on health care, it generally ranks much lower than they do on important health indicators. Of twenty-four wealthy democracies from North America, Western Europe, and certain other parts of the world (Australia, Japan, New Zealand; the exact number of nations varies slightly by indicator), the United States has the lowest life expectancy, the highest infant mortality, and the highest rates of obesity, adult diabetes, and HIV and AIDS. It ranks only twenty-first in mortality from heart disease and only tenth in breast cancer mortality rate. The United States also ranks twenty-second for annual doctor consultations per capita and among the highest for hospital admissions for various conditions, such as respiratory disease, that are avoidable with adequate primary and outpatient care. According to policy analyst Lawrence Mishel and colleagues, the conclusion from these international comparisons is inescapable: “Although the United States spends more on health care than other countries with similar per capita income and populations, it has worse health outcomes, on average...Compared to the United States, other countries are more committed to the health and well-being of their citizens through more-universal coverage and morecomprehensive health care systems.”

Because of Canada's proximity, many studies compare health and health-care indicators between the United States and Canada. A recent review summarized the evidence: “Although studies' findings go in both directions, the bulk of the research finds higher quality of care in Canada.”

Surveys of random samples of citizens in several nations provide additional evidence of the advantages of the type of health care found outside the United States and the disadvantages of the US system. In surveys in 2007 of US residents and those of six other nations (Australia, Canada, Germany, the Netherlands, New Zealand, and the United Kingdom), Americans ranked highest in the percentage uninsured (16 percent in the United States compared to 0-2 percent elsewhere), highest in the percentage that did not receive needed medical care during the last year because of costs, and highest by far in the percentage that had "serious problems" in paying medical bills in the past year.

A fair conclusion from all the evidence is that US health lags behind that found in other wealthy nations because the latter provide free or low-cost national health care to their citizens and the United States does not. If so, the United States has much to learn from their example. Because the health-care reform achieved in the United States in 2009 and 2010 did not include a national health-care model, the United States will likely continue to lag behind other democracies in the quality of health and health care. At the same time, the cost of health care will certainly continue to be much higher in the United States than in other Western nations, in part because the United States uses a fee-for-service model in which many physicians are paid for every procedure they do rather than the set salary that some other nations feature.

Sources: Docteur \& Berenson, 2009; Mishel, Bernstein, \& Shierholz, 2009; Organisation for Economic Co-operation and Development, 2011; Schoen et al., 2007

\section{Key Takeaways}

- The world's nations differ dramatically in the quality of their health and health care. People in poor nations suffer from many health problems, and poor nations have very high rates of infant mortality and maternal mortality.

- Except for the United States, industrial nations have national health-care systems and national health insurance. Their health-care models help their citizens to have relatively good health at affordable levels.

\section{For Your Review}

1. What do you think should be done to help improve the health of poor nations? What role should the United States play in any efforts in this regard?

2. Do you think the United States should move toward the national health insurance model found in other 
Western nations? Why or why not?

\section{References}

Docteur, E., \& Berenson, R. A. (2009). How does the quality of US health care compare internationally? Washington, DC: Urban Institute Press.

Mishel, L., Bernstein, J., \& Shierholz, H. (2009). The state of working America 2008/2009. Ithaca, NY: ILR Press.

Organisation for Economic Co-operation and Development. (2011). Health at a glance 2011: OECD indicators. Paris, France: Author.

Reid, T. R. (2010). The healing of America: A global quest for better, cheaper, and fairer health care. New York, NY: Penguin Press.

Russell, J. W. (2011). Double standard: Social policy in Europe and the United States (2nd ed.). Lanham, MD: Rowman \& Littlefield.

Schoen, C., Osborn, R., Doty, M. M., Bishop, M., Peugh, J., \& Murukutla, N. (2007). Toward higher-performance health systems: Adults' health care experiences in seven countries, 2007. Health Affairs 26(6), w717-w734.

World Health Organization. (2011). Global response: Epidemic update and health sector progress towards universal access. Retrieved from http://www.who.int/hiv/en/index.html. 


\subsection{Problems of Health in the United States}

\section{Learning Objectives}

1. Describe how and why social class, race and ethnicity, and gender affect physical health and health care in the United States.

2. Summarize the differences that social class, race and ethnicity, and gender make for mental health.

When we examine health and health care in the United States, there is both good news and bad news. The good news is considerable. Health has improved steadily over the last century, thanks in large part to better public sanitation and the discovery of antibiotics. Illnesses and diseases such as pneumonia and polio that used to kill or debilitate people are either unknown today or treatable by modern drugs. Other medical discoveries and advances have also reduced the extent and seriousness of major illnesses, including many types of cancer, and have prolonged our lives.

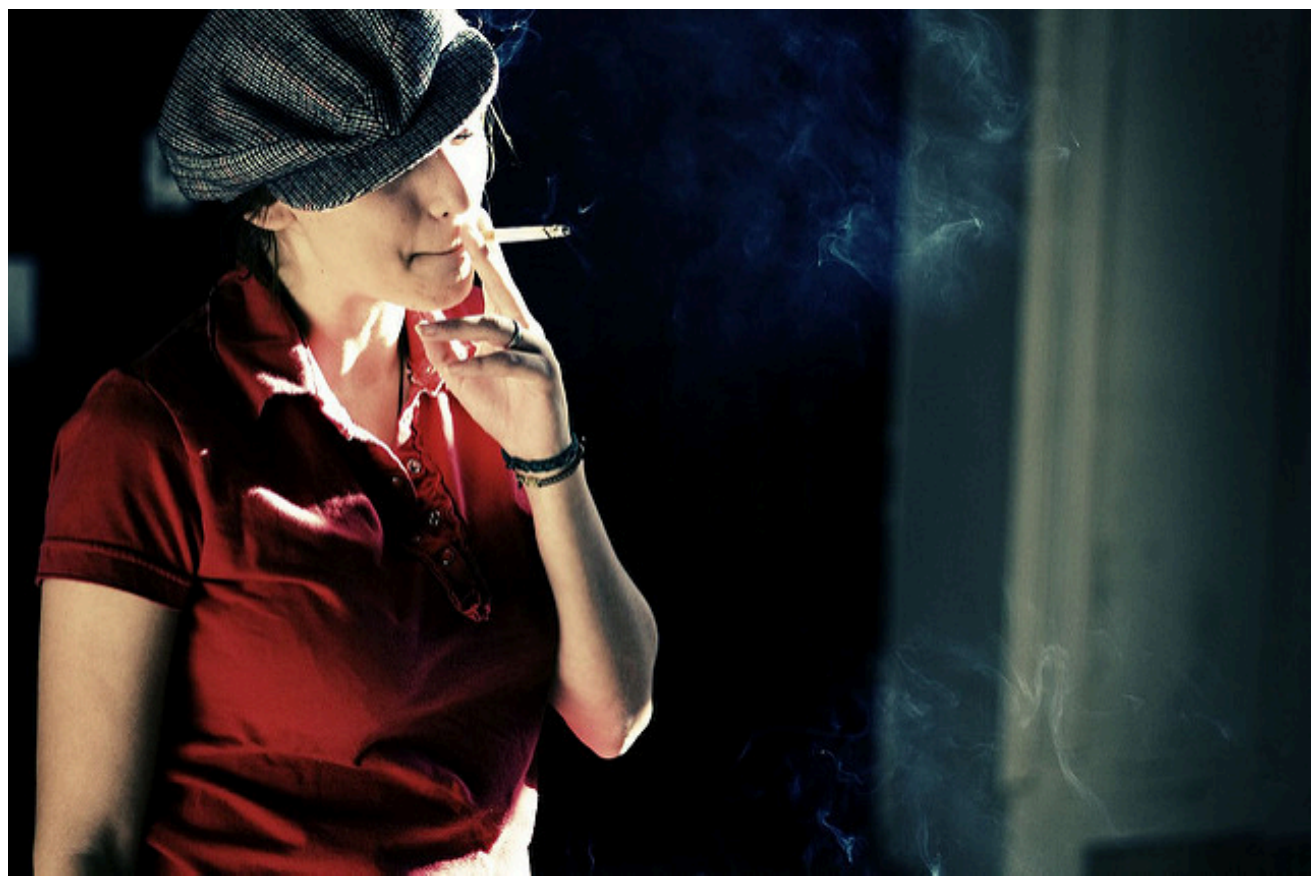

Cigarette smoking in the United States has declined considerably since the 1960s.

Xava du - smoke souls - CC BY-NC-ND 2.0.

Because of these and other factors, the US average life expectancy climbed from about 47 years in 1900 to about 78 years in 2010. Similarly, infant mortality dropped dramatically in the last half-century from 29.2 infant deaths per 1,000 live births in 1950 to only 6.75 in 2007 (see Figure 13.4 "Infant Deaths per 1,000 Live Births, United 
States, 1950-2007”). Cigarette smoking declined from 51 percent for males and 34 percent for females in 1965 to 23 percent and 18 percent, respectively, in 2009 (National Center for Health Statistics, 2011). In another area, various policies during the past three decades have dramatically reduced levels of lead in young children's blood: 88 percent of children had unsafe levels in the mid-1970s, compared to less than 2 percent three decades later (Centers for Disease Control and Prevention, 2007).

Figure 13.4 Infant Deaths per 1,000 Live Births, United States, 1950-2007

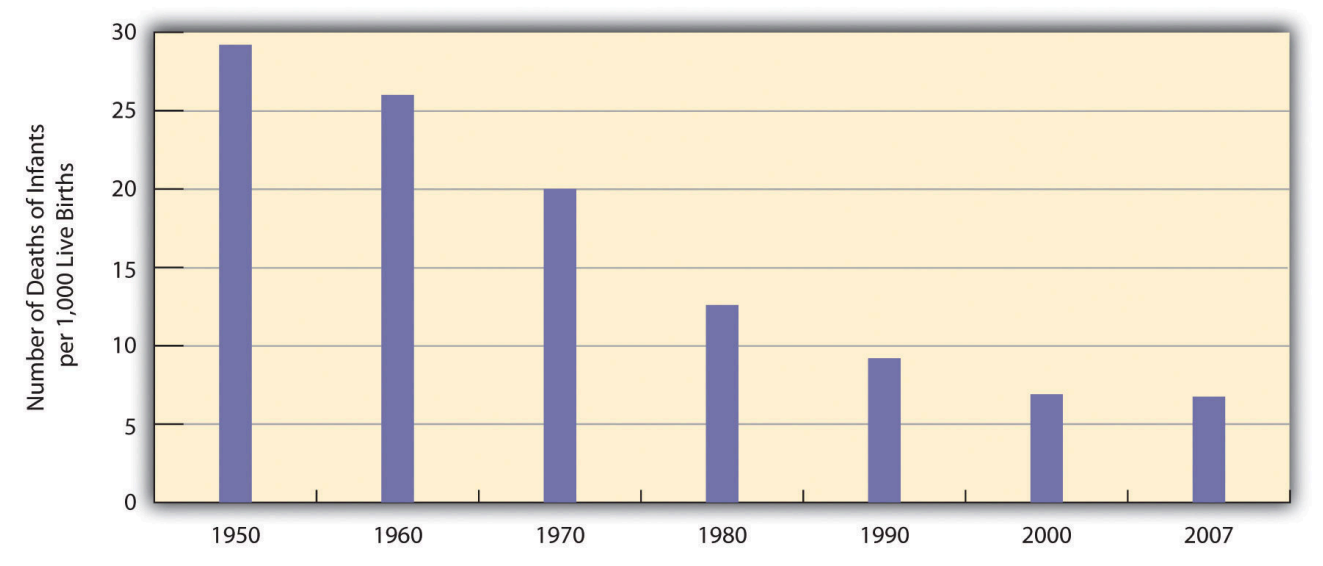

Source: Data from National Center for Health Statistics. (2011). Health, United States, 2010. Hyattsville, MD: Centers for Disease Control and Prevention.

\section{The Poor Status of American Health}

Unfortunately, the bad news is also considerable. Despite all the gains just mentioned, the United States lags behind most other wealthy democracies in several health indicators, as we have seen, even though it is the wealthiest nation in the world. Moreover, 14.5 percent of US households and almost 49 million Americans are "food insecure" (lacking sufficient money for adequate food and nutrition) at least part of the year; more than one-fifth of all children live in such households (Coleman-Jensen, Nord, Andrews, \& Carlson, 2011). More than 8 percent of all infants are born at low birth weight (under 5.5 pounds), putting them at risk for long-term health problems; this figure has risen steadily since the late 1980s and is higher than the 1970 rate (National Center for Health Statistics, 2011). In other areas, childhood rates of obesity, asthma, and some other chronic conditions are on the rise, with about one-third of children considered obese or overweight (Van Cleave, Gortmaker, \& Perrin, 2010). Clearly the United States still has a long way to go in improving the nation's health.

There is also bad news in the social distribution of health. Health problems in the United States are more often found among the poor, among people from certain racial and ethnic backgrounds, and, depending on the problem, among women or men. Social epidemiology refers to the study of how health and illness vary by sociodemographic characteristics, with such variations called health disparities. When we examine social epidemiology in the United States, we see that many health disparities exist. In this way, health and illness both reflect and reinforce society's social inequalities. We now turn to the most important health disparities, starting with physical health and then mental health. 


\section{Health Disparities: Physical Health}

\section{Social Class}

Not only do the poor have less money, but they also have much worse health, as the news story that began this chapter illustrated. There is growing recognition in the government and in medical and academic communities that social class makes a huge difference when it comes to health and illness (Centers for Disease Control and Prevention, 2011).

Many types of health indicators illustrate the social class-health link in the United States. In an annual survey conducted by the government, people are asked to indicate the quality of their health. As Figure 13.5 "Family Income and Self-Reported Health (Percentage of People 18 or Over Saying Health Is Only Fair or Poor), 2009” shows, poor people are much more likely than those with higher incomes to say their health is only fair or poor. These self-reports of health are subjective indicators, and it is possible that not everyone interprets "fair" or "poor" health in the same way. But objective indicators of actual health also indicate a strong social class-health link (National Center for Health Statistics, 2011).

Figure 13.5 Family Income and Self-Reported Health (Percentage of People 18 or Over Saying Health Is Only Fair or Poor), 2009

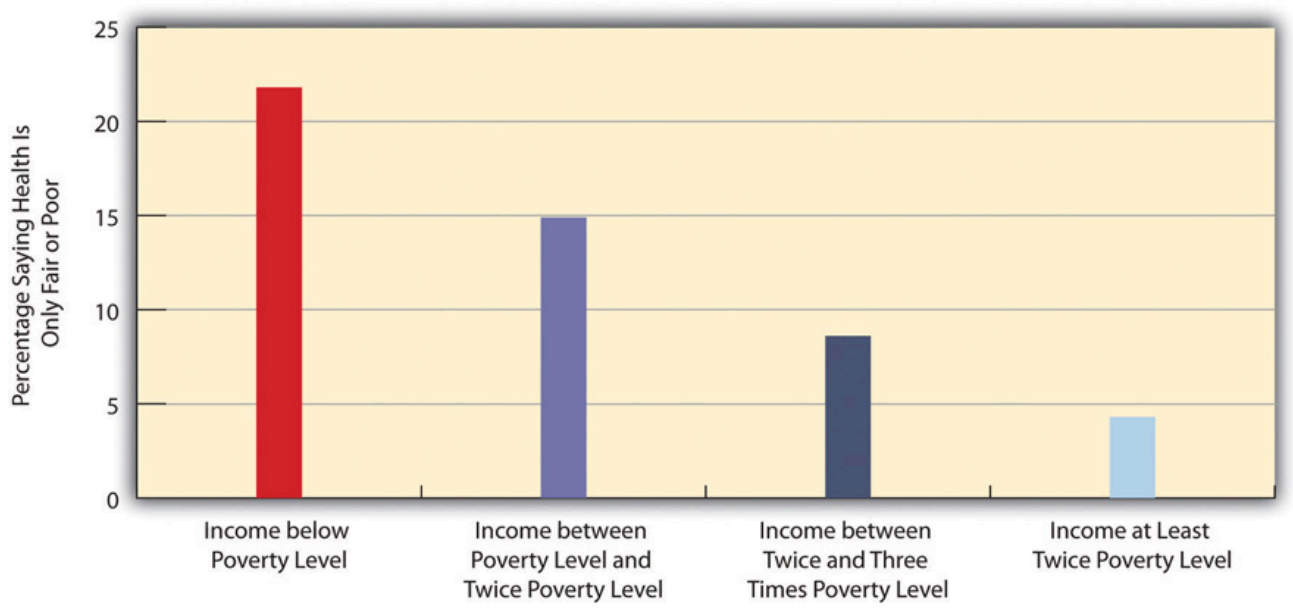

Source: Data from National Center for Health Statistics. (2011). Health, United States, 2010. Hyattsville, MD: Centers for Disease Control and Prevention.

\section{Children and Our Future}

The Poor Health of Poor Children

When we consider health disparities, some of the most unsettling evidence involves children. As a recent report by the Robert Wood Johnson Foundation concluded, "The data illustrate a consistent and striking pattern of incremental improvements in health with increasing levels of family income and educational attainment: As family income and levels of education rise, health improves. In almost every state, shortfalls in health are greatest among children in the 
poorest or least educated households, but even middle-class children are less healthy than children with greater advantages.”

Some government data illustrate the difference that poverty makes for the nation's children:

- Children of poor mothers are more than twice as likely as children born to wealthier mothers to be born with low birth weight.

- By the age of 9 months, poor children are already more likely to exhibit poor health and lower cognitive and socioemotional development.

- By age 3, poor children are two-thirds more likely to have asthma than children whose families' incomes are more than 150 percent of the poverty line.

- Based on their parents' reports, poor children are almost five times more likely (33 percent compared to 7 percent) to be in less than very good health (i.e., their parents rated their children's health as poor, fair, or good rather than as very good or excellent).

In these and other ways, children in low-income families are more likely than children in wealthier families to have more health problems, many of which last into adolescence and adulthood. Poor children's poor health thus makes a critical difference throughout their lives. As sociologist Steven A. Haas and colleagues observe, “A growing body of work demonstrates that those who experience poor health early in life go on to complete less schooling, hold less prestigious jobs, and earn less than their healthier childhood peers.”

One reason for the poor health of poor children is that their families are more likely to experience many kinds of stress (see Chapter 2 "Poverty"). Another reason is that their families are more likely to experience food insecurity and, if they are urban, to live in neighborhoods with higher levels of lead and pollution. Low-income children also tend to watch television more often than wealthier children and for this and other reasons to be less physically active; their relative lack of physical activity is yet another reason for their worse health. Finally, their parents are much more likely than wealthier parents to smoke cigarettes; the secondhand smoke they inhale impairs their health.

The clear evidence of poverty's effects on the health of poor children underscores the need of the United States to do everything possible to minimize these effects. Any money spent to reduce these effects will pay for itself many times over throughout these children's lifetimes: They will have fewer health problems as they grow up, costing the United States much less in health care, and be better able to do well in school and to have higher incomes as adults. In both the short run and long run, then, improving the health of poor children will also improve the economic and social health of the whole nation.

Sources: Haas, Glymour, \& Berkman, 2011; Kaplan, 2009; Murphey, Mackintosh, \& McCoy-Roth, 2011; Robert Wood Johnson Foundation, 2008

For example, poor adults are also at much greater risk for many health problems, including heart disease, diabetes, arthritis, and some types of cancer. Rates of high blood pressure, serious heart conditions, and diabetes are at least twice as high for middle-aged adults with family incomes below the poverty level than for those with incomes at least twice the poverty level. All these social class differences in health contribute to a striking difference in life expectancy, with Americans whose family incomes are more than four times the federal poverty level expected to live 6.5 years longer than those living in poverty (Kaplan, 2009).

Several reasons account for the social class-health link (Pampel, Krueger, \& Denney, 2010). One reason is stress, which, as Chapter 2 "Poverty" explained, is higher for people with low incomes because of unemployment, problems in paying for the necessities of life, and a sense of little control over what happens to them. Stress in turn damages health because it impairs the immune system and other bodily processes.

A second reason is that poor people live in conditions, including crowded, dilapidated housing with poor 
sanitation, that are bad for their health and especially that of their children. Although these conditions have improved markedly in the United States over the last few decades, they continue for many of the poor.

Another reason for the poor's worse health is their lack of access to adequate health care. As is well known, many poor people lack medical insurance and in other respects have inadequate health care. These problems make it more likely they will become ill in the first place and more difficult for them to become well because they cannot afford to visit a physician or to receive other health care. Still, social class disparities in health exist even in countries that provide free national health care, a fact that underscores the importance of the other reasons discussed here for the social class-health link (Elo, 2009).

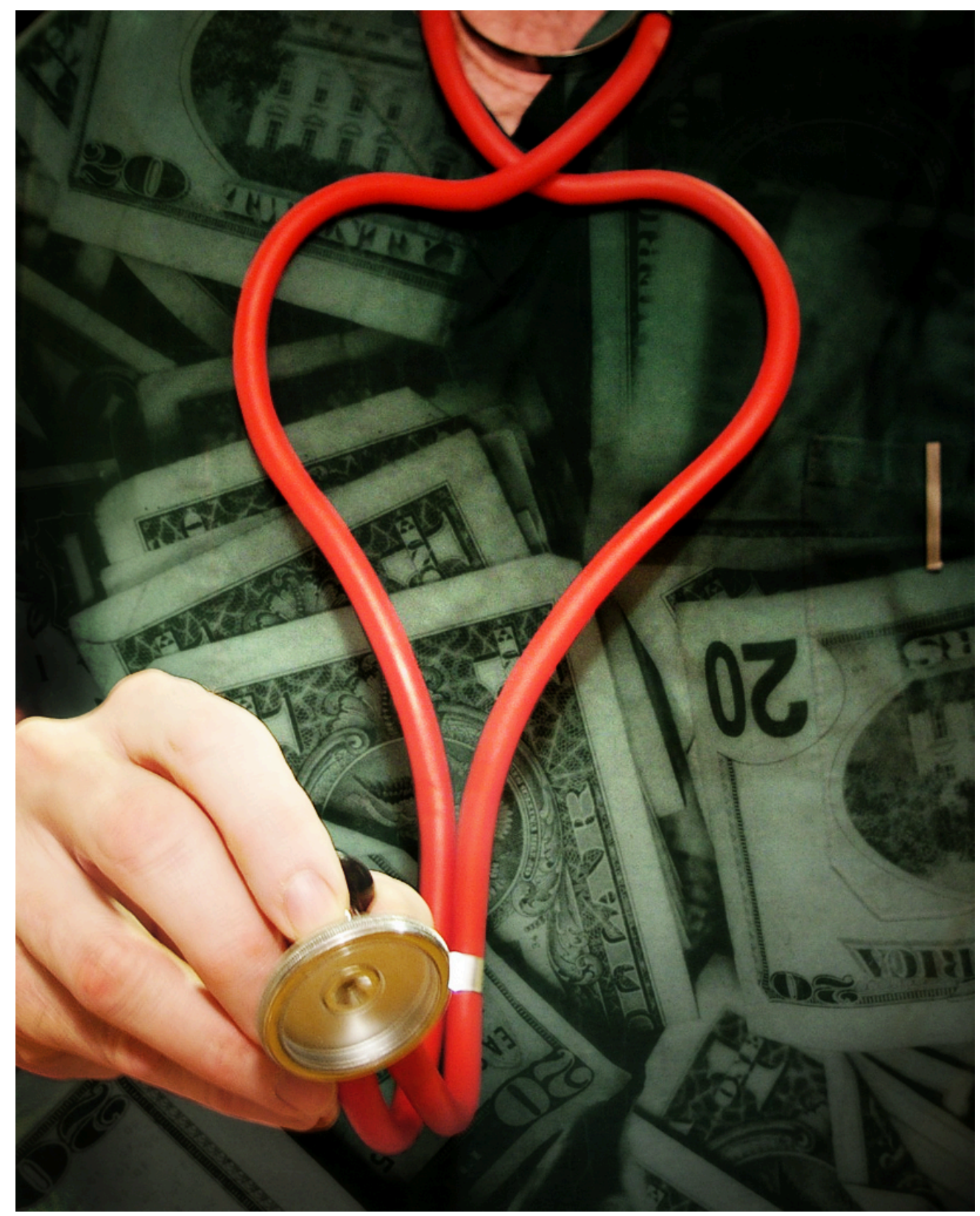

Many people who are poor or near poor lack medical insurance and in other ways have inadequate health care. These problems make it more likely they will become ill and, once ill, less likely they will become well. 


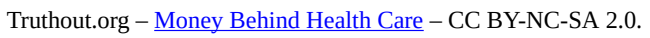

A fourth reason is a lack of education, which, in ways not yet well understood, leads poor people to be unaware or unconcerned about risk factors for health and to have a fatalistic attitude that promotes unhealthy behaviors and reluctance to heed medical advice (Elo, 2009). In one study of whether smokers quit smoking after a heart attack, only 10 percent of heart attack patients without a high school degree quit smoking, compared to almost 90 percent of those with a college degree (Wray, Herzog, Willis, \& Wallace, 1998).

A final reason for the poor health of poor people is unhealthy lifestyles, as just implied. Although it might sound like a stereotype, poor people are more likely to smoke, to eat high-fat food, to avoid exercise, to be overweight, and, more generally, not to do what they need to do (or to do what they should not be doing) to be healthy (Pampel et al., 2010). Scholars continue to debate whether unhealthy lifestyles are more important in explaining poor people's poor health than the other factors just discussed. Regardless of the proper mix of reasons, the fact remains that the poor have worse health.

\section{Race and Ethnicity}

Health differences also exist when we examine the effects of race and ethnicity, and they are literally a matter of life and death. We can see this when we compare life expectancies for whites and African Americans born in 2006 (Table 13.2 "US Life Expectancy at Birth for People Born in 2007”). When we do not take gender into account, African Americans can expect to live about five fewer years than whites. Among men, they can expect to live almost six fewer years, and among women, four fewer years.

Table 13.2 US Life Expectancy at Birth for People Born in 2007

\begin{tabular}{|l|l|l|}
\hline \multirow{2}{*}{ African American } & Both sexes & $\mathbf{7 3 . 6}$ \\
\cline { 2 - 3 } & Men & 70.0 \\
\cline { 2 - 3 } & Women & 76.8 \\
\hline \multirow{2}{*}{ White } & Both sexes & $\mathbf{7 8 . 4}$ \\
\hline & Men & 75.9 \\
\hline & Women & 80.8 \\
\hline
\end{tabular}

Source: Data from National Center for Health Statistics. (2011). Health, United States, 2010. Hyattsville, MD: Centers for Disease Control and Prevention.

At the beginning of the life course, infant mortality also varies by race and ethnicity (Table 13.3 "Mother's Race/Ethnicity and US Infant Mortality, 2006 (Number of Infant Deaths per 1,000 Live Births)”), with African American infants more than twice as likely as white infants to die before their first birthday. Infant mortality among Native Americans is almost 1.5 times the white rate, while that for Latinos is about the same (although the Puerto Rican rate is also higher, at 8.0), and Asians a bit lower. In a related indicator, maternal mortality (from complications of pregnancy or childbirth) stands at 8.1 maternal deaths for every 100,000 live births for 
non-Latina white women, 7.2 for Latina women, and a troubling 23.8 for African American women. Maternal mortality for African American women is thus about three times greater than that for the other two groups.

Table 13.3 Mother’s Race/Ethnicity and US Infant Mortality, 2006 (Number of Infant Deaths per 1,000 Live Births)

\begin{tabular}{|l|l|}
\hline African American & 12.9 \\
\hline Asian or Pacific Islander & 4.5 \\
\hline Latina & 5.4 \\
\hline Central and South American & 4.5 \\
\hline Cuban & 5.1 \\
\hline Mexican & 5.3 \\
\hline Puerto Rican & 8.0 \\
\hline Native American & 8.3 \\
\hline White & 5.6 \\
\hline
\end{tabular}

Source: Data from National Center for Health Statistics. (2011). Health, United States, 2010. Hyattsville, MD: Centers for Disease Control and Prevention.

In other indicators, African Americans are more likely than whites to die from heart disease, although the white rate of such deaths is higher than the rates of Asians, Latinos, and Native Americans. African Americans are also more likely than whites to be overweight and to suffer from asthma, diabetes, high blood pressure, and several types of cancer. Latinos and Native Americans have higher rates than whites of several illnesses and conditions, including diabetes.

Commenting on all these disparities in health, a former head of the US Department of Health and Human Services said a decade ago, "We have been—and remain — two nations: one majority, one minority — separated by the quality of our health” (Penn et al., 2000, p. 102). The examples just discussed certainly indicate that her statement is still true today.

Why do such large racial and ethnic disparities in health exist? To a large degree, they reflect the high poverty rates for African Americans, Latinos, and Native Americans compared to those for whites. In addition, inadequate medical care is perhaps a special problem for people of color, thanks to unconscious racial bias among health-care professionals that affects the quality of care that people of color receive (see discussion later in this chapter).

An additional reason for racial disparities in health is diet. Many of the foods that have long been part of African American culture are high in fat. Partly as a result, African Americans are much more likely than whites to have heart disease and high blood pressure and to die from these conditions (Parra-Medina et al., 2010). In contrast, first-generation Latinos tend to have diets consisting of beans, grains, and other low-fat foods, preventing health problems stemming from their poverty from being even worse. But as the years go by and they adopt the typical American's eating habits, their diets tend to worsen, and their health worsens as well (Pérez-Escamilla, 2009).

In a significant finding, African Americans tend to have worse health than whites even among those with the same 
incomes. Several reasons explain this racial gap. One is the extra stress that African Americans of all incomes face because they live in a society that is still racially prejudiced and discriminatory (Bratter \& Gorman, 2011). In this regard, studies find that African Americans and Latinos who have experienced the most racial discrimination in their daily lives tend to have worse physical health (Lee \& Ferraro, 2009). Some middle-class African Americans may also have grown up in poor families and incurred health problems in childhood that continue to affect them. As a former US surgeon general once explained, "You're never dealing with a person just today. You're dealing with everything they've been exposed to throughout their lives. Does it ever end? Our hypothesis is that it never ends” (Meckler, 1998, p. 4A).

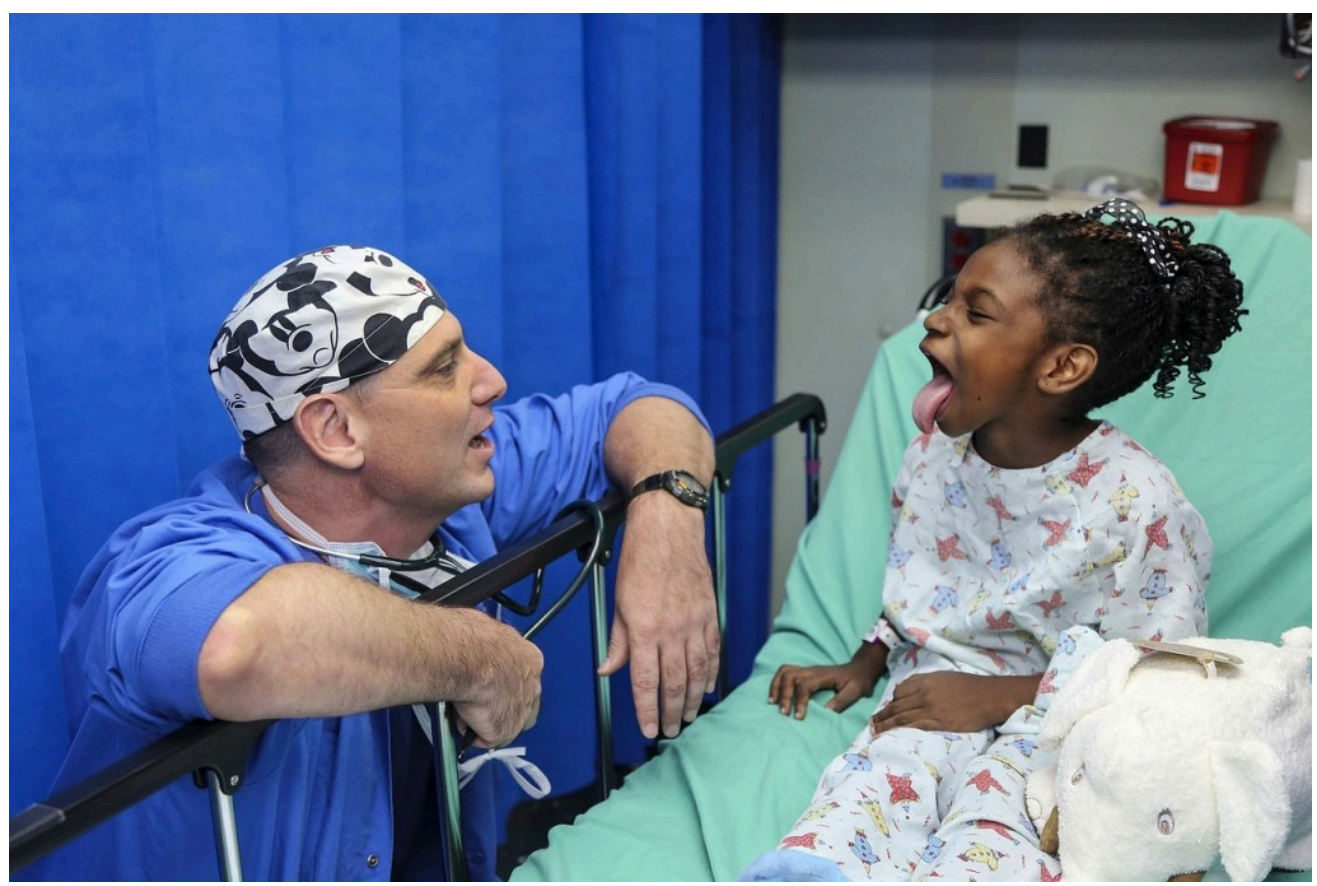

African Americans have worse health than whites, even when people with the same incomes are compared. One reason for this racial gap is the continuing racial discrimination that African Americans experience and the stress that accompanies this experience.

Pixabay - CC0 Public Domain.

To some degree, racial differences in health may also have a biological basis. For example, African American men appear to have higher levels of a certain growth protein that may promote prostate cancer; African American smokers may absorb more nicotine than white smokers; and differences in the ways African Americans' blood vessels react may render them more susceptible to hypertension and heart disease (Meckler, 1998; Ricker \& Bird, 2005). Because alleged biological differences have been used as the basis for racism, and because race is best thought of as a social construction rather than a biological concept (see Chapter 3 "Racial and Ethnic Inequality"), we must be very careful in acknowledging such differences (Frank, 2007). However, if they do indeed exist, they may help explain at least some of the racial gap in health.

A final factor contributing to racial differences in health is physical location: poor people of color are more likely to live in urban areas and in other locations that are unhealthy places because of air and water pollution, hazardous waste, and other environmental problems (Walker, 2011). This problem is termed environmental racism (Michney, 2011). One example of this problem is found in the so-called Cancer Alley on a long stretch of the Mississippi 
River in Louisiana populated mostly by African Americans; 80 percent of these residents live within three miles of a polluting industrial facility (Cernansky, 2011).

\section{Gender}

The evidence on gender and health is both complex and fascinating. Women outlive men by more than six years, and, as Table 13.2 "US Life Expectancy at Birth for People Born in 2007" showed, the gender difference in longevity persists across racial categories. At the same time, women have worse health than men in many areas. For example, they are more likely to suffer from migraine headaches, osteoporosis, and immune diseases such as lupus and rheumatoid arthritis. Women thus have more health problems than men do even though they outlive men-a situation commonly known as the morbidity paradox (Gorman \& Read, 2006). Why, then, do women outlive men? Conversely, why do men die earlier than women? The obvious answer is that men have more lifethreatening diseases, such as heart disease and emphysema, than women, but that raises the question of why this is so.

Several reasons explain the gender gap in longevity. One might be biological, as women's estrogen and other sexlinked biological differences may make them less susceptible to heart disease and other life-threatening illnesses, even as they render them more vulnerable to some of the health problems already listed (Kuller, 2010). A second reason is that men lead more unhealthy lifestyles than women because of differences in gender socialization. For example, men are more likely than women to smoke, to drink heavily, and to drive recklessly. All such behaviors make men more vulnerable than women to life-threatening illnesses and injuries. Men are also more likely than women to hold jobs in workplaces filled with environmental and safety hazards that kill thousands of people-most of them men-annually.

A final reason is men's reluctance to discuss and seek help for their medical problems, owing to their masculine socialization into being "strong, silent types." Just as men do not like to ask for directions, as the common wisdom goes, so do they not like to ask for medical help. As one physician put it, “I’ve often said men don’t come in for checkups because they have a big $S$ tattooed on their chests; they think they're Superman” (Guttman, 1999, p. 10).

Studies find that men are less likely than women to tell anyone when they have a health problem and to seek help from a health-care professional (Emmers-Sommer et al., 2009). When both sexes do visit a physician, men ask fewer questions than women do. In one study, the average man asked no more than two questions, while the average woman asked at least six. Because patients who ask more questions get more information and recover their health more quickly, men's silence in the exam room may contribute to their shorter longevity (Foreman, 1999). Interestingly, the development of erectile dysfunction drugs like Viagra may have helped improve men's health, as men have had to see a physician to obtain prescriptions for these drugs when otherwise they would not have seen a physician (Guttman, 1999).

We have just discussed why men die sooner than women, which is one of the two gender differences that constitute the morbidity paradox. The other gender difference concerns why women have more nonfatal health problems than men. Several reasons explain this difference (Read \& Gorman, 2010). 


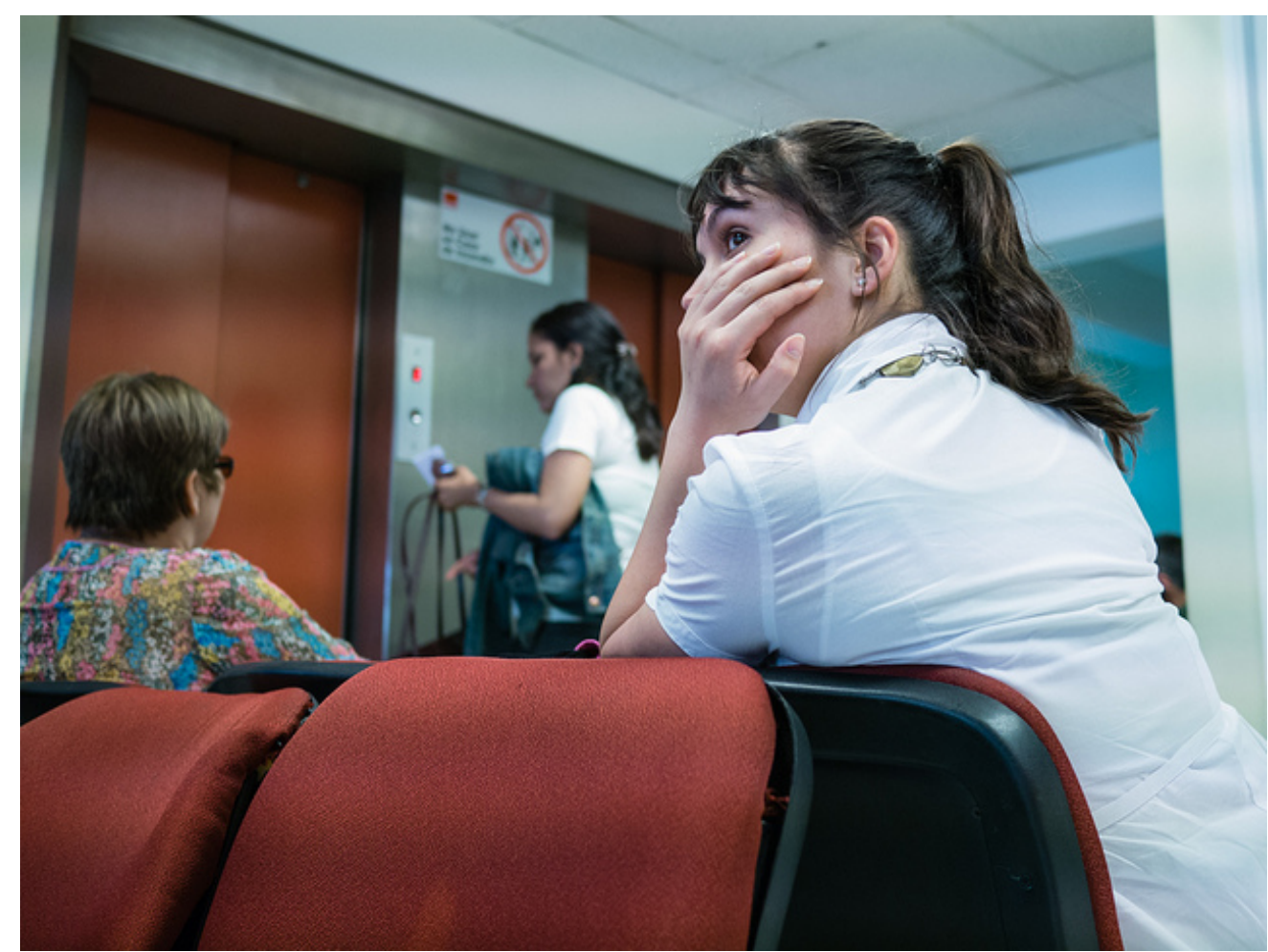

Women more than men tend to have more health problems that are not life threatening. Two reasons for this gender difference are gender inequality in the larger society and the stress accompanying women's traditional caregiving role in the family.

Francisco Osorio - CL Society 287: Waiting for a doctor - CC BY 2.0.

One reason arises from the fact that women outlive men. Because women are thus more likely than men to be in their senior years, they are also more likely to develop the many health problems associated with old age. This suggests that studies that control for age (by comparing older women with older men, middle-aged women with middle-aged men, and so forth) should report fewer gender differences in health than those that do not control for age, and this is indeed true.

However, women still tend to have worse health than men even when age is taken into account. Medical sociologists attribute this gender difference to the gender inequality in the larger society (Read \& Gorman, 2010). For example, women are poorer overall than men, as they are more likely to work only part-time and in lowpaying jobs even if they work full time. As discussed earlier in this chapter, poverty is a risk factor for health problems. Women's worse health, then, is partly due to their greater likelihood of living in poverty or near poverty. Because of their gender, women also are more likely than men to experience stressful events in their everyday lives, such as caring for a child or an aging parent. Their increased stress impairs the immune systems and thus worsens their health. It also is an important cause of their greater likelihood of depression and the various physical health problems (weakened immune systems, higher blood pressure, lack of exercise) that depression often causes. Finally, women experience discrimination in their everyday lives because of our society's sexism, and (as is also true for people of color) this discrimination is thought to produce stress and thus poorer physical health (Landry \& Mercurio, 2009). 


\section{Health Disparities: Mental Health}

Health consists of mental well-being as well as physical well-being, and people can suffer mental health problems in addition to physical health problems. Scholars disagree over whether mental illness is real or, instead, a social construction. The predominant view in psychiatry, of course, is that people do have actual problems in their mental and emotional functioning and that these problems are best characterized as mental illnesses or mental disorders and should be treated by medical professionals (McNally, 2011). But other scholars say mental illness is a social construction or a "myth" (Szasz, 2010). In their view, all kinds of people sometimes act oddly, but only a few are labeled as mentally ill. If someone says she or he hears the voice of an angel, we ordinarily attribute their perceptions to their religious views and consider them religious, not mentally ill. But if someone instead insists that men from Mars have been in touch, we are more apt to think there is something mentally wrong with that person. Mental illness thus is not real but rather is the reaction of others to problems they perceive in someone's behavior.

This intellectual debate notwithstanding, many people do suffer serious mental and emotional problems, such as severe mood swings and depression, that interfere with their everyday functioning and social interaction. Sociologists and other researchers have investigated the social epidemiology of these problems. Several generalizations seem warranted from their research regarding disparities in mental health (Cockerham, 2011).

\section{Social Class}

First, social class affects the incidence of mental illness. To be more specific, poor people exhibit more mental health problems than richer people: They are more likely to suffer from schizophrenia, serious depression, and other problems. A major reason for this link is the stress of living in poverty and the many living conditions associated with it. One interesting causal question here is whether poverty leads to mental illness or mental illness leads to poverty. Although there is evidence of both causal paths, most scholars believe that poverty contributes to mental illness more than the reverse (Warren, 2009). 


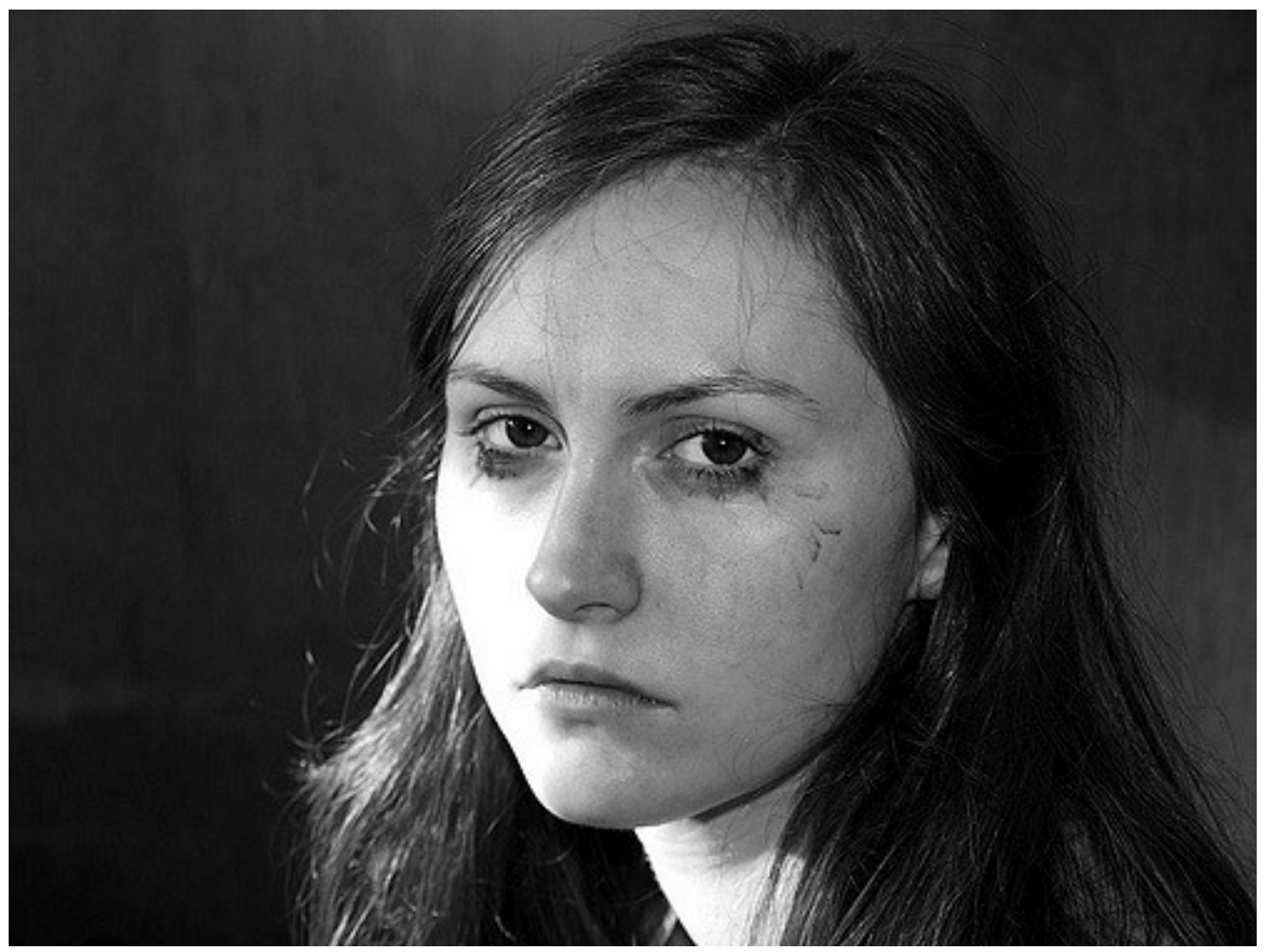

Women are more likely than men to be seriously depressed. Sociologists attribute this gender difference partly to gender socialization that leads women to keep problems inside themselves while encouraging men to express their problems outwardly.

Jessica B - Week Five - Face of depression... - CC BY-NC-ND 2.0.

\section{Race and Ethnicity}

Second, there is no clear connection between race/ethnicity and mental illness, as evidence on this issue is mixed: Although many studies find higher rates of mental disorder among people of color, some studies find similar rates to whites' rates (Mossakowski, 2008). These mixed results are somewhat surprising because several racial/ethnic groups are poorer than whites and more likely to experience everyday discrimination, and for these reasons should exhibit more frequent symptoms of mental and emotional problems. Despite the mixed results, a fair conclusion from the most recent research is that African Americans and Latinos are more likely than whites to exhibit signs of mental distress (Jang, Chiriboga, Kim, \& Phillips, 2008; Mossakowski, 2008).

\section{Gender}

Third, gender is related to mental illness but in complex ways, as the nature of this relationship depends on the type of mental disorder. Women have higher rates of manic-depressive disorders than men and are more likely to be seriously depressed, but men have higher rates of antisocial personality disorders that lead them to be a threat to others (Kort-Butler, 2009). Although some medical researchers trace these differences to sex-linked biological differences, sociologists attribute them to differences in gender socialization that lead women to keep problems 
inside themselves while encouraging men to express their problems outwardly, as through violence. To the extent that women have higher levels of depression and other mental health problems, the factors that account for their poorer physical health, including their higher rates of poverty and stress and rates of everyday discrimination, are thought to also account for their poorer mental health (Read \& Gorman, 2010).

\section{Key Takeaways}

- Social class, race and ethnicity, and gender all influence the quality of health in the United States. Health problems are more common among people from low-income backgrounds and among people of color. Women are more likely than men to have health problems that are not life threatening.

- Although debate continues over whether mental illness is a social construction, many people do suffer mental health problems. The social epidemiology for mental health and illness resembles that for physical health and illness, with social class, race/ethnicity, and gender disparities existing.

- The private insurance model in the United States incurs huge administrative costs and results in more than 50 million people lacking health insurance.

\section{For Your Review}

1. In thinking about the health problems of individuals from low-income backgrounds, some people blame lack of access to adequate health care for these problems, while other people blame unhealthy lifestyles practiced by low-income individuals. Where do you stand on this debate? Explain your answer.

2. Write a brief essay in which you present a sociological explanation of the higher rate of depression found among women than among men.

\section{References}

Bratter, J. L., \& Gorman, B. K. (2011). Is discrimination an equal opportunity risk? Racial experiences, socioeconomic status, and health status among black and white adults. Journal of Health and Social Behavior, 52, 365-382.

Centers for Disease Control and Prevention. (2007). Interpreting and managing blood lead levels $<10 \mu \mathrm{g} / \mathrm{dL}$ in children and reducing childhood exposures to lead: Recommendations of CDC's advisory committee on childhood lead poisoning prevention. MMWR (Morbidity and Mortality Weekly Report), 56(RR-8), 1-16.

Centers for Disease Control and Prevention. (2011). CDC health disparities and inequalities report-United States, 2011. Morbidity and Mortality Weekly Report, 60, 1-114.

Cernansky, R. (2011, February 8). Cancer alley: Big industry \& bigger illness along Mississippi River. Retrieved from http://www.treehugger.com/corporate-responsibility/cancer-alley-big-industry-bigger-illness-alongmississippi-river.html. 
Cockerham, W. C. (2011). Sociology of mental disorder (8th ed.). Upper Saddle River, NJ: Prentice Hall.

Coleman-Jensen, A., Nord, M., Andrews, M., \& Carlson, S. (2011). Household food security in the United States in 2010. Washington, DC: US Department of Agriculture.

Elo, I. T. (2009). Social class differentials in health and mortality: Patterns and explanations in comparative perspective. Annual Review of Sociology, 35, 553-572.

Emmers-Sommer, T. M., Nebel, S., Allison, M.-L., Cannella, M. L., Cartmill, D., Ewing, S., et al. (2009). Patientprovider communication about sexual health: The relationship with gender, age, gender-stereotypical beliefs, and perceptions of communication inappropriateness. Sex Roles: A Journal of Research, 60, 9-10.

Foreman, J. (1999, June 14). A vist most men would rather not make. The Boston Globe, p. C1.

Frank, R. (2007). What to make of it? The (Re)emergence of a biological conceptualization of race in health disparities research. Social Science \& Medicine, 64(10), 1977-1983.

Gorman, B. K., \& Read, J. G. (2006). Gender disparities in adult health: An examination of three measures of morbidity. Journal of Health and Social Behavior, 47(2), 95-110.

Guttman, M. (1999, June 11-13). Why more men are finally going to the doctor. USA Weekend, p. 10.

Haas, S. A., Glymour, M., \& Berkman, L. F. (2011). Childhood health and labor market inequality over the life course. Journal of Health and Social Behavior, 52, 298-313.

Jang, Y., Chiriboga, D. A., Kim, G., \& Phillips, K. (2008). Depressive symptoms in four racial and ethnic groups: The survey of older Floridians (SOF). Research on Aging, 30(4), 488-502.

Kaplan, G. A. (2009). The poor pay more: Poverty's high cost to health. Princeton, NJ: Robert Wood Johnson Foundation.

Kort-Butler, L. A. (2009). Coping styles and sex differences in depressive symptoms and delinquent behavior. Journal of Youth and Adolescence, 38(1), 122-136.

Kuller, L. H. (2010). Cardiovascular disease is preventable among women. Expert Review of Cardiovascular Therapy, 8(2), 175-187.

Landry, L. J., \& Mercurio, A. E. (2009). Discrimination and women's mental health: The mediating role of control. Sex Roles: A Journal of Research, 61, 3-4.

Lee, M.-A., \& Ferraro, K. F. (2009). Perceived discrimination and health among Puerto Rican and Mexican Americans: Buffering effect of the lazo matrimonial? Social Science \& Medicine, 68, 1966-1974.

McNally, R. J. (2011). What is mental illness? Cambridge, MA: Belknap Press.

Meckler, L. (1998, November 27). Health gap between races persists. Ocala Star-Banner, p. 4A. 
Michney, T. M. (2011). White civic visions versus black suburban aspirations: Cleveland's Garden Valley urban renewal project. Journal of Planning History, 10(4), 282-309.

Mossakowski, K. N. (2008). Dissecting the influence of race, ethnicity, and socioeconomic status on mental health in young adulthood. Research on Aging, 30(6), 649-671.

Murphey, D., Mackintosh, B., \& McCoy-Roth, M. (2011). Early childhood policy focus: Health eating and physical activity. Early Childhood Highlights, 2(3), 1-9.

National Center for Health Statistics. (2011). Health, United States, 2010. Hyattsville, MD: Centers for Disease Control and Prevention.

Pampel, F. C., Krueger, P. M., \& Denney, J. T. (2010). Socioeconomic disparities in health behaviors. Annual Review of Sociology, 36, 349-370.

Parra-Medina, D., Wilcox, S., Wilson, D. K., Addy, C. L., Felton, G., \& Poston, M. B. (2010). Heart healthy and ethnically relevant (HHER) lifestyle trial for improving diet and physical activity in underserved African American women. Contemporary Clinical Trials, 31(1), 92-104.

Penn, N. E., Kramer, J., Skinner, J. F., Velasquez, R. J., Yee, B. W. K., Arellano, L. M., et al. (2000). Health practices and health-care systems among cultural groups. In R. M. Eisler \& M. Hersen (Eds.), Handbook of gender, culture, and health (pp. 101-132). New York, NY: Routledge.

Pérez-Escamilla, R. (2009). Dietary quality among Latinos: Is acculturation making us sick? Journal of the American Dietetic Association, 109(6), 988-991.

Read, J. G., \& Gorman, B. M. (2010). Gender and health inequality. Annual Review of Sociology, 36, 371-386.

Ricker, P. P., \& Bird, C. E. (2005). Rethinking gender differences in health: Why we need to integrate social and biological perspectives. Journals of Gerontology Series B, 60, S40-S47.

Robert Wood Johnson Foundation. (2008). America's health starts with healthy children: How do states compare? Princeton, NJ: Author.

Szasz, T. S. (2010). The myth of mental illness: Foundations of a theory of personal conduct. New York, NY: Harper Perennial.

Van Cleave, J., Gortmaker, S. L., \& Perrin, J. M. (2010). Dynamics of obesity and chronic health conditions among children and youth. JAMA, 303(7), 623-630.

Walker, A. K. (2011, November 20). Where you live can help determine your health, studies say. Bangor Daily News. Retrieved from http://bangordailynews.com/2011/11/20/health/where-you-live-can-help-determineyour-health-studies-say.

Warren, J. R. (2009). Socioeconomic status and health across the life course: A test of the social causation and health selection hypotheses. Social Forces, 87(4), 2125-2153. 
Wray, L. A., Herzog, A. R., Willis, R. J., \& Wallace, R. B. (1998). The impact of education and heart attack on smoking cessation among middle-aged adults. Journal of Health and Social Behavior, 39, 271-294. 


\subsection{Problems of Health Care in the United States}

\section{Learning Objectives}

1. Summarize the problems associated with the model of private insurance that characterizes the US health system.

2. Explain how and why mistakes and infections occur in hospitals.

3. Describe any two other problems in US health care other than the lack of health insurance.

As the continuing debate over health care in the United States reminds us, the practice of medicine raises many important issues about its cost and quality. We now turn to some of these issues.

\section{Private Health Insurance and the Lack of Insurance}

Medicine in the United States is big business. Expenditures for health care, health research, and other health items and services have risen sharply in recent decades, having increased tenfold since 1980, and now costs the nation more than \$2.6 trillion annually (see Figure 13.6 "US Health-Care Expenditure, 1980-2010 (in Billions of Dollars)"). This translates to the largest figure per capita in the industrial world. Despite this expenditure, the United States lags behind many other industrial nations in several important health indicators, as we have already seen. Why is this so?

Figure 13.6 US Health-Care Expenditure, 1980-2010 (in Billions of Dollars)

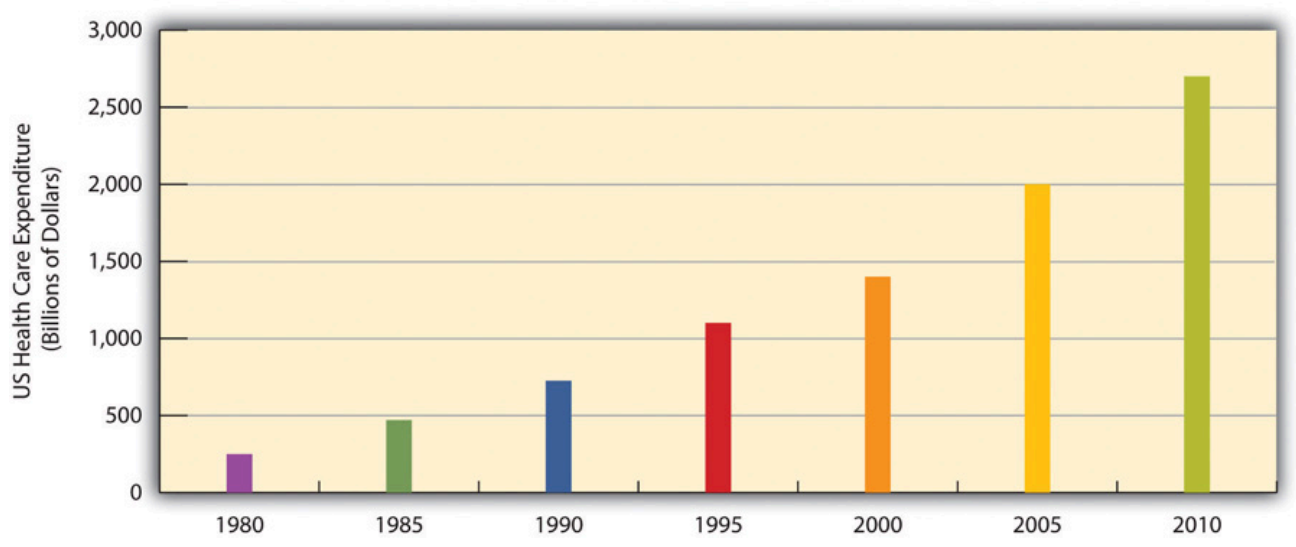

Source: Data from US Census Bureau. (2010). Statistical abstract of the United States: 2010. Washington, DC: US Government Printing Office. Retrieved from http://www.census.gov/compendia/statab.

An important reason is the US system of private health insurance. As discussed earlier, other Western nations 
have national systems of health care and health insurance. In stark contrast to these nations, the United States relies largely on a direct-fee system, in which patients under 65 (those 65 and older are covered by Medicare) are expected to pay for medical costs themselves, aided by private health insurance, usually through one's employer. Table 13.4 "Health Insurance Coverage in the United States, 2010" shows the percentages of Americans who have health insurance from different sources or who are not insured at all. (All figures are from the period before the implementation of the major health-care reform package was passed by the federal government in early 2010.) Adding together the top two figures in the table, 54 percent of Americans have private insurance, either through their employers or from their own resources. About 29 percent have some form of public insurance (Medicaid, Medicare, other public), and 16 percent are uninsured. This final percentage amounts to almost 50 million Americans, including 8 million children, who lack health insurance.

Table 13.4 Health Insurance Coverage in the United States, 2010

\begin{tabular}{|l|l|}
\hline Source of coverage & Percentage of people with this coverage \\
\hline Employer & $49 \%$ \\
\hline Individual & $5 \%$ \\
\hline Medicaid & $16 \%$ \\
\hline Medicare & $12 \%$ \\
\hline Other public & $1 \%$ \\
\hline Uninsured & $16 \%$ \\
\hline
\end{tabular}

Source: Data from Kaiser Family Foundation. (2012). Kaiser state health facts. Retrieved from http://www.statehealthfacts.org.

Their lack of health insurance has deadly consequences because they are less likely to receive preventive health care and care for various conditions and illnesses. For example, because uninsured Americans are less likely than those with private insurance to receive cancer screenings, they are more likely to be diagnosed with more advanced cancer rather than an earlier stage of cancer (Halpern et al., 2008). It is estimated that 45,000 people die each year because they do not have health insurance (Wilper et al., 2009). The Note 13.22 “Applying Social Research" box discusses a very informative real-life experiment on the difference that health insurance makes for people's health.

\section{Applying Social Research}

Experimental Evidence on the Importance of Health Insurance

As the text discusses, studies show that Americans without health insurance are at greater risk for a variety of illnesses and life-threatening conditions. Although this research evidence is compelling, uninsured Americans may differ from insured Americans in other ways that also put their health at risk. For example, perhaps people who do not buy health insurance may be less concerned about their health and thus less likely to take good care of themselves. Because many studies have not controlled for all such differences, experimental evidence would be more conclusive (see Chapter 1 "Understanding Social Problems").

For this reason, the results of a fascinating real-life experiment in Oregon were very significant. In 2008, Oregon 
decided to expand its Medicaid coverage. Because it could not accommodate all the poor Oregonians who were otherwise uninsured, it had them apply for Medicaid by lottery. Researchers then compared the subsequent health of the Oregonians who ended up on Medicaid with that of Oregonians who remained uninsured. Because the two groups resulted from random assignment (the lottery), it is reasonable to conclude that any later differences between them must have stemmed from the presence or absence of Medicaid coverage.

Although this study is ongoing, initial results obtained a year after it began showed that Medicaid coverage had already made quite a difference. Compared to the uninsured "control” group, the newly insured Oregonians rated themselves happier and in better health and reported fewer sick days from work. They were also 50 percent more likely to have seen a primary care doctor in the year since they received coverage, and women were 60 percent more likely to have had a mammogram. In another effect, they were much less likely to report having had to borrow money or not pay other bills because of medical expenses.

A news report summarized these benefits of the new Medicaid coverage: "[The researchers] found that Medicaid's impact on health, happiness, and general well-being is enormous, and delivered at relatively low cost: Low-income Oregonians whose names were selected by lottery to apply for Medicaid availed themselves of more treatment and preventive care than those who remained excluded from government health insurance. After a year with insurance, the Medicaid lottery winners were happier, healthier, and under less financial strain.”

Because of this study's experimental design, it “represents the best evidence we've got," according to the news report, of the benefits of health insurance coverage. As researchers continue to study the two groups in the years ahead and begin to collect data on blood pressure, cardiovascular health, and other objective indicators of health, they will add to our knowledge of the effects of health insurance coverage.

Sources: Baicker \& Finkelstein, 2011; Fisman, 2011

Although 29 percent of Americans do have public insurance, this percentage and the coverage provided by this insurance do not begin to match the coverage enjoyed by the rest of the industrial world. Although Medicare pays some medical costs for the elderly, we saw in Chapter 6 "Aging and Ageism” that its coverage is hardly adequate, as many people must pay hundreds or even thousands of dollars in premiums, deductibles, coinsurance, and copayments. The other government program, Medicaid, pays some health-care costs for the poor, but many low-income families are not poor enough to receive Medicaid. Eligibility standards for Medicaid vary from one state to another, and a family poor enough in one state to receive Medicaid might not be considered poor enough in another state. The State Children's Health Insurance Program (SCHIP), begun in 1997 for children from lowincome families, has helped somewhat, but it, too, fails to cover many low-income children. Largely for these reasons, about two-thirds of uninsured Americans come from low-income families.

Not surprisingly, the 16 percent uninsured rate varies by race and ethnicity (see Figure 13.7 "Race, Ethnicity, and Lack of Health Insurance, 2008 (Percentage of People under Age 65 with No Insurance)”). Among people under 65 and thus not eligible for Medicare, the uninsured rate rises to almost 22 percent of the African American population and 32 percent of the Latino population. Moreover, 45 percent of adults under 65 who live in official poverty lack health insurance, compared to only 6 percent of higher-income adults (those with incomes higher than four times the poverty level). Almost one-fifth of poor children have no health insurance, compared to only 3 percent of children in higher-income families (Kaiser Family Foundation, 2012). As discussed earlier, the lack of health insurance among the poor and people of color is a significant reason for their poorer health. 


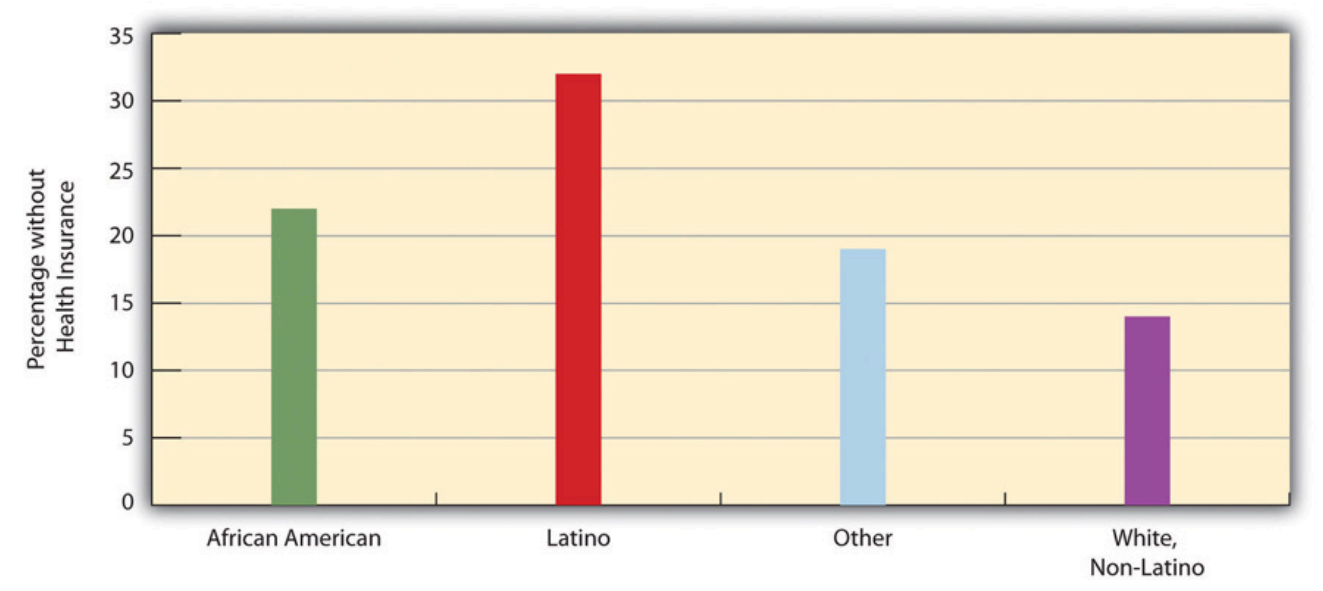

Source: Data from Kaiser Family Foundation. (2012). Kaiser state health facts. Retrieved from http://www.statehealthfacts.org.

\section{The High Cost of Health Care}

As noted earlier, the United States spends much more money per capita on health care than any other industrial nation. The US per capita health expenditure was $\$ 7,960$ in 2009 , the latest year for which data were available at the time of this writing. This figure was about 50 percent higher than that for the next two highest-spending countries, Norway and Switzerland; 80 percent higher than Canada's expenditure; twice as high as Frances's expenditure; and 2.3 times higher than the United Kingdom's expenditure (Organisation for Economic Cooperation and Development, 2011). The huge expenditure by the United States might be justified if the quality of health and of health care in this nation outranked that in its peer nations. As we have seen, however, the United States lags behind many of its peer nations in several indicators of health and health care quality. If the United States spends far more than its peer nations on health care yet still lags behind them in many indicators, an inescapable conclusion is that the United States is spending much more than it should be spending.

Why is US spending on health care so high? Although this is a complex issue, two reasons stand out (Boffey, 2012). First, administrative costs for health care in the United States are the highest in the industrial world. Because so much of US health insurance is private, billing and record-keeping tasks are immense, and "hordes of clerks and accountants [are] needed to deal with insurance paperwork," according to one observer (Boffey, 2012, p. SR12). Billing and other administrative tasks cost about \$360 billion annually, or 14 percent of all US healthcare costs (Emanuel, 2011). These tasks are unnecessarily cumbersome and fail to take advantage of electronic technologies that would make them much more efficient.

Second, the United States relies on a fee for service model for private insurance. Under this model, physicians, hospitals, and health care professionals and business are relatively free to charge whatever they want for their services. In the other industrial nations, government regulations keep prices lower. This basic difference between the United States and its peer nations helps explain why the cost of health care services in the United States is so much higher than in its peer nations. Simply put, US physicians and hospitals charge much more for their services than do their counterparts in other industrial nations (Klein, 2012). And because physicians are paid for every service they perform, they have an incentive to perform more diagnostic tests and other procedures than necessary. As one economic writer recently said, “The more they do, the more they earn” (Samuelson, 2011). 
A few examples illustrate the higher cost of medical procedures in the United States compared to other nations. To keep things simple, we will compare the United States with just Canada (see Figure 13.8 "Average Cost of Selected Medical Procedures and Services”). The average US appendectomy costs $\$ 13,123$, compared to $\$ 3,810$ in Canada; the average US hip replacement costs $\$ 34,354$, compared to $\$ 10,753$ in Canada; the average US normal childbirth costs $\$ 8,435$, compared to $\$ 2,667$ in Canada; and the average US bypass surgery costs $\$ 59,770$, compared to \$22,212 in Canada. The costs of diagnostic tests also differ dramatically between the two nations. For example, a head CT scan costs an average of \$464 in the United States, compared to only \$65 in Canada, and an MRI scan costs and average of \$1,009 in the United States, compared to only \$304 in Canada (International Federation of Health Plans, 2010).

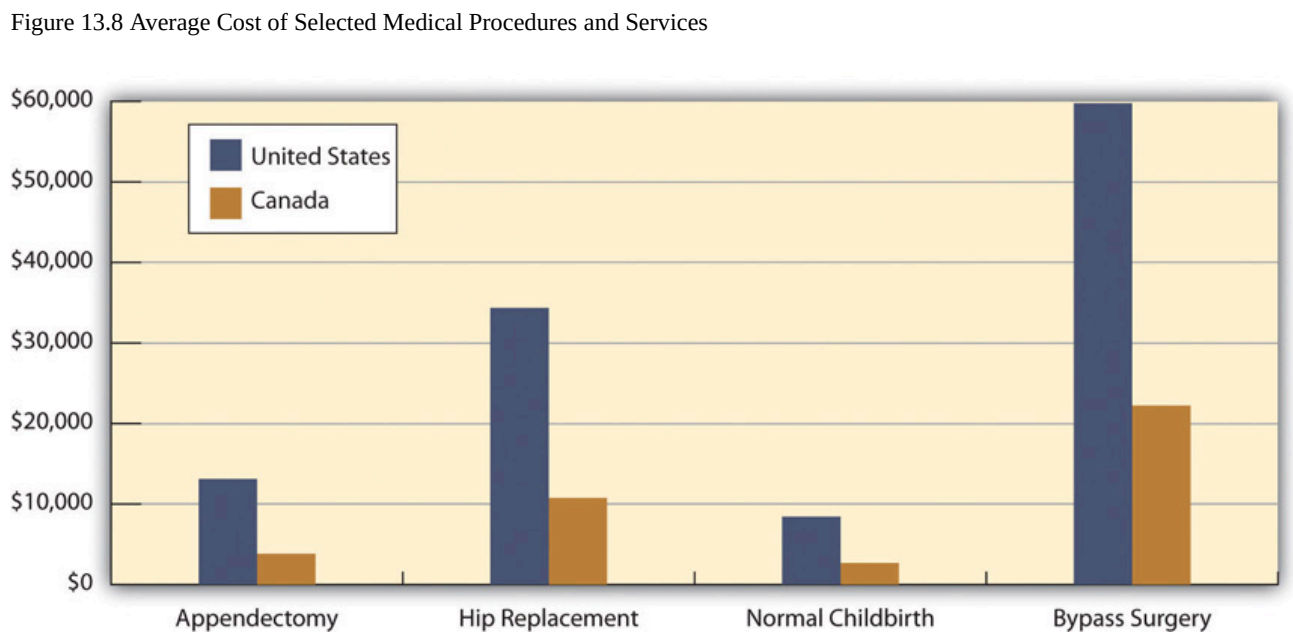

Source: Boffey, P. M. (2012, January 22). The money traps in US health care. New York Times, p. SR12.

\section{Managed Care and HMOs}

To many critics, a disturbing development in the US health-care system has been the establishment of health maintenance organizations, or HMOs, which typically enroll their subscribers through their workplaces. HMOs are prepaid health plans with designated providers, meaning that patients must visit a physician employed by the HMO or included on the HMO's approved list of physicians. If their physician is not approved by the HMO, they have to either see an approved physician or see their own without insurance coverage. Popular with employers because they are less expensive than traditional private insurance, HMOs have grown rapidly in the last three decades and now enroll more than 70 million Americans (see Figure 13.9 "Growth of Health Maintenance Organizations (HMOs), 1980-2007 (Millions of Enrollees)”). 


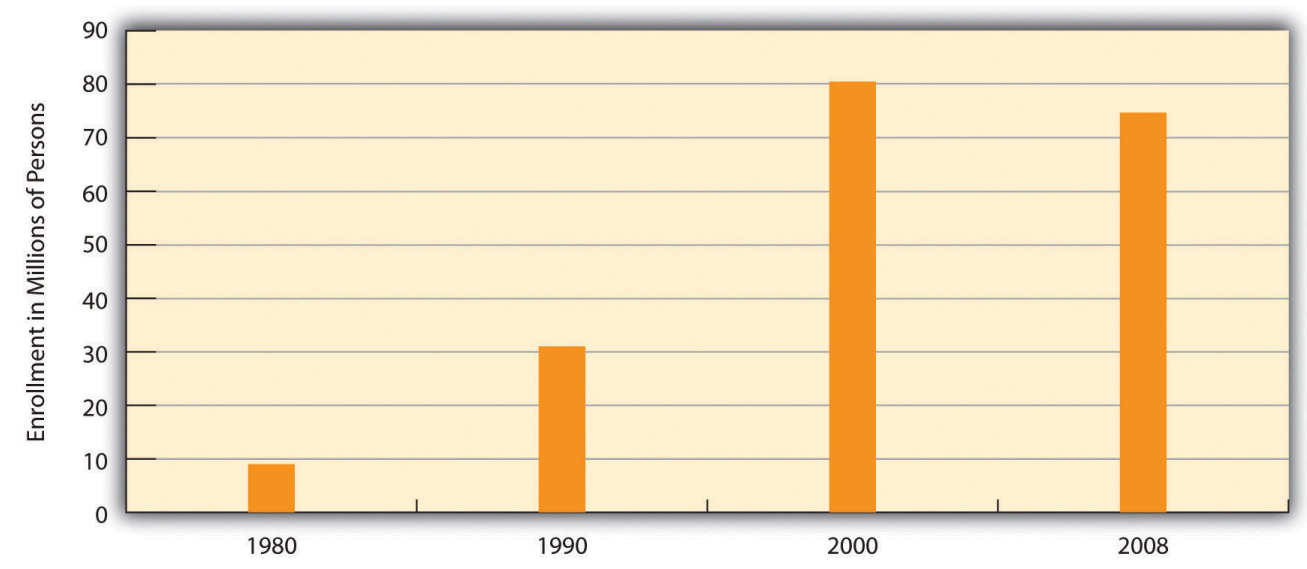

Source: Data from US Census Bureau. (2012). Statistical abstract of the United States: 2012. Washington, DC: US Government Printing Office. Retrieved from http://www.census.gov/compendia/statab.

Although HMOs have become popular, their managed care is also very controversial for at least two reasons (Kronick, 2009). The first is the HMOs' restrictions just noted on the choice of physicians and other health-care providers. Families who have long seen a family physician but whose employer now enrolls them in an HMO sometimes find they have to see another physician or risk going without coverage. In some HMOs, patients have no guarantee that they can see the same physician at every visit. Instead, they see whichever physician is assigned to them at each visit. Critics of HMOs argue that this practice prevents physicians and patients from getting to know each other, reduces patients' trust in their physician, and may for these reasons impair patient health.

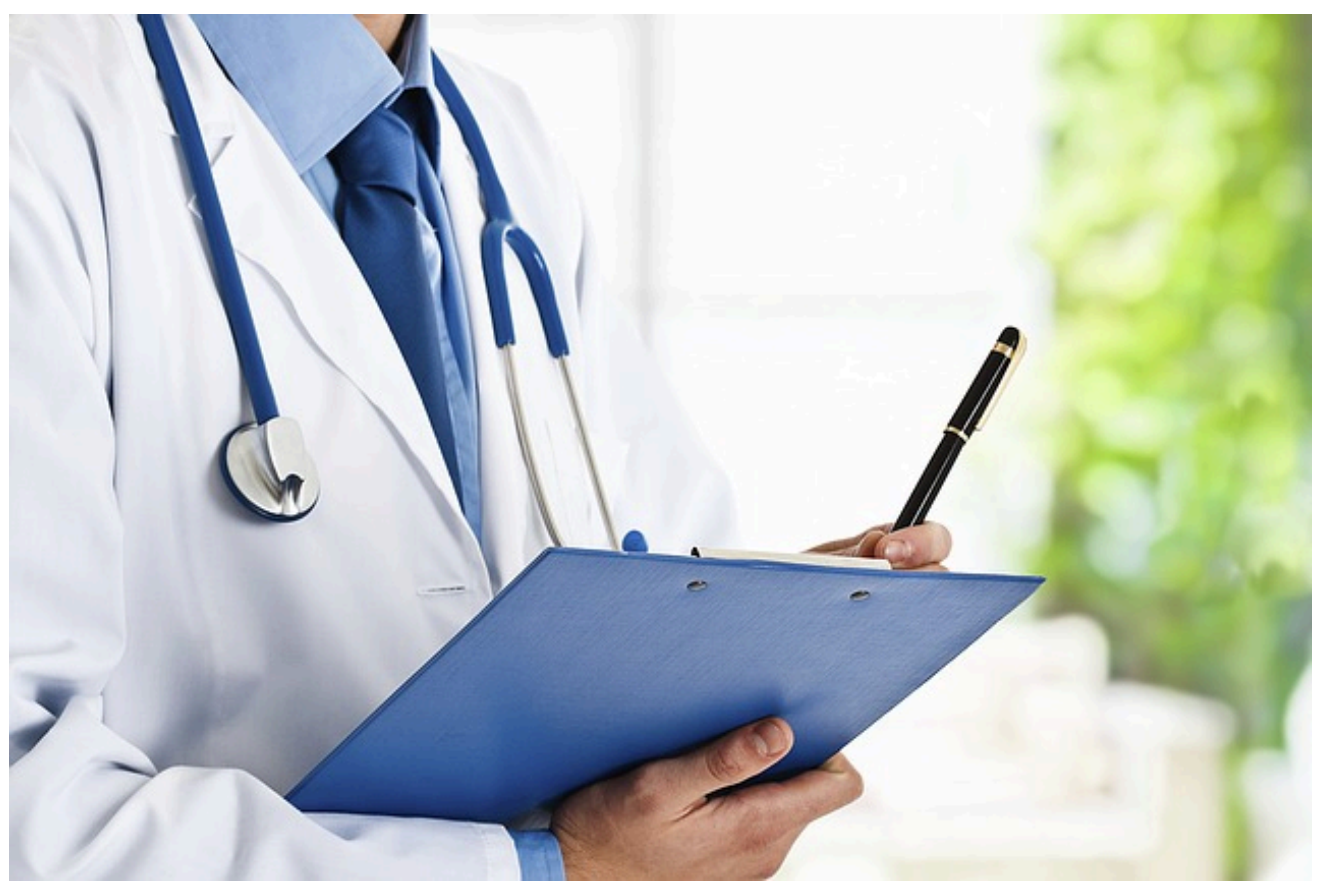

The managed care that HMOs provide is controversial for several reasons. These reasons include restrictions on the choice of physicians and especially on the types of medical exams and procedures that patients may undergo. 
The second reason for the managed-care controversy is perhaps more important. HMOs often restrict the types of medical exams and procedures patients may undergo, a problem called denial of care, and limit their choice of prescription drugs to those approved by the HMO, even if their physicians think that another, typically more expensive drug would be more effective. HMOs claim that these restrictions are necessary to keep medical costs down and do not harm patients.

\section{Racial and Gender Bias in Health Care}

Another problem in the US medical practice is apparent racial and gender bias in health care. Racial bias seems fairly common; as Chapter 3 "Racial and Ethnic Inequality" discussed, African Americans are less likely than whites with the same health problems to receive various medical procedures (Samal, Lipsitz, \& Hicks, 2012). Gender bias also appears to affect the quality of health care (Read \& Gorman, 2010). Research that examines either actual cases or hypothetical cases posed to physicians finds that women are less likely than men with similar health problems to be recommended for various procedures, medications, and diagnostic tests, including cardiac catheterization, lipid-lowering medication, kidney dialysis or transplant, and knee replacement for osteoarthritis (Borkhoff et al., 2008).

\section{Other Problems in the Quality of Care}

Other problems in the quality of medical care also put patients unnecessarily at risk. We examine three of these here:

1. Sleep deprivation among health-care professionals. As you might know, many physicians get very little sleep. Studies have found that the performance of surgeons and medical residents who go without sleep is seriously impaired (Institute of Medicine, 2008). One study found that surgeons who go without sleep for twenty-four hours have their performance impaired as much as a drunk driver. Surgeons who stayed awake all night made 20 percent more errors in simulated surgery than those who slept normally and took 14 percent longer to complete the surgery (Wen, 1998).

2. Shortage of physicians and nurses. Another problem is a shortage of physicians and nurses (Mangan, 2011). This is a general problem around the country, but even more of a problem in two different settings. The first such setting is hospital emergency rooms. Because emergency room work is difficult and relatively low paying, many specialist physicians do not volunteer for it. Many emergency rooms thus lack an adequate number of specialists, resulting in potentially inadequate emergency care for many patients.

Rural areas are the second setting in which a shortage of physicians and nurses is a severe problem. As discussed further in Chapter 14 "Urban and Rural Problems", many rural residents lack convenient access to hospitals, health care professionals, and ambulances and other emergency care. This lack of access contributes to various health problems in rural areas.

3. Mistakes by hospitals. Partly because of sleep deprivation and the shortage of health-care 
professionals, hundreds of thousands of hospital patients each year suffer from mistakes made by hospital personnel. They receive the wrong diagnosis, are given the wrong drug, have a procedure done on them that was really intended for someone else, or incur a bacterial infection.

An estimated one-third of all hospital patients experience one or more of these mistakes (Moisse, 2011). These and other mistakes are thought to kill almost 200,000 patients per year, or almost 2 million every decade (Crowley \& Nalder, 2009). Despite this serious problem, a government report found that hospital employees fail to report more than 80 percent of hospital mistakes, and that most hospitals in which mistakes were reported nonetheless failed to change their policies or practices (Salahi, 2012).

A related problem is the lack of hand washing in hospitals. The failure of physicians, nurses, and other hospital employees to wash their hands regularly is the major source of hospital-based infections. About 5 percent of all hospital patients, or 2 million patients annually, acquire an infection. These infections kill 100,000 people every year and raise the annual cost of health care by $\$ 30$ billion to $\$ 40$ billion (Rosenberg, 2011).

\section{Medical Ethics and Medical Fraud}

A final set of problems concerns questions of medical ethics and outright medical fraud. Many types of healthcare providers, including physicians, dentists, medical equipment companies, and nursing homes, engage in many types of health-care fraud. In a common type of fraud, they sometimes bill Medicare, Medicaid, and private insurance companies for exams or tests that were never done and even make up "ghost patients” who never existed or bill for patients who were dead by the time they were allegedly treated. In just one example, a group of New York physicians billed their state’s Medicaid program for over \$1.3 million for 50,000 psychotherapy sessions that never occurred. All types of health-care fraud combined are estimated to cost about $\$ 100$ billion per year (Kavilanz, 2010).

Other practices are legal but ethically questionable. Sometimes physicians refer their patients for tests to a laboratory that they own or in which they have invested. They are more likely to refer patients for tests when they have a financial interest in the lab to which the patients are sent. This practice, called self-referral, is legal but does raise questions of whether the tests are in the patient's best interests or instead in the physician's best interests (Shreibati \& Baker, 2011).

In another practice, physicians have asked hundreds of thousands of their patients to take part in drug trials. The physicians may receive more than $\$ 1,000$ for each patient they sign up, but the patients are not told about these payments. Characterizing these trials, two reporters said that "patients have become commodities, bought and traded by testing companies and physicians" and said that it "injects the interests of a giant industry into the delicate physician-patient relationship, usually without the patient realizing it” (Eichenwald \& Kolata, 1999; Galewitz, 2009). These trials raise obvious conflicts of interest for the physicians, who may recommend their patients do something that might not be good for them but would be good for the physicians' finances. 


\section{Key Takeaways}

- The US health-care model relies on a direct-fee system and private health insurance. This model has been criticized for contributing to high health-care costs, high rates of uninsured individuals, and high rates of health problems in comparison to the situation in other Western nations.

- Other problems in US health care include the restrictive practices associated with managed care, racial/ ethnic and gender bias in health-care delivery, hospital errors, and medical fraud.

\section{For Your Review}

1. Do you know anyone, including yourself or anyone in your family, who lacks health insurance? If so, do you think the lack of health insurance has contributed to any health problems? Write a brief essay in which you discuss the evidence for your conclusion.

2. Critics of managed care say that it overly restricts important tests and procedures that patients need to have, while proponents of managed care say that these restrictions are necessary to keep health-care costs in check. What is your view of managed care?

\section{References}

Baicker, K., \& Finkelstein, A. (2011). The effects of Medicaid coverage-learning from the Oregon experiment. New England Journal of Medicine, 365(8), 683-685.

Boffey, P. M. (2012, January 22). The money traps in US health care. New York Times, p. SR12.

Borkhoff, C. M., Hawker, G. A., Kreder, H. J., Glazier, R. H., Mahomed, N. N., \& Wright, J. G. (2008). The effect of patients' sex on physicians' recommendations for total knee arthroplasty. Canadian Medical Association Journal, 178(6), 681-687.

Crowley, C. F., \& Nalder, E. (2009, August 9). Secrecy shields medical mishaps from public view. San Francisco Chronicle, p. A1.

Eichenwald, K., \& Kolata, G. (1999, May 16). Drug trials hide conflicts for doctors. New York Times, p. A1.

Emanuel, E. J. (2011, November 12). Billions wasted on billing. New York Times. Retrieved from http://opinionator.blogs.nytimes.com/2011/2011/2012/billions-wasted-on-billing/?ref=opinion.

Fisman, R. (2011, July 7). Does health coverage make people healthier? Slate.com. Retrieved from http://www.slate.com/articles/business/the dismal_science/2011/07/ does health coverage make people healthier.html.

Galewitz, P. (2009, February 22). Cutting-edge option: Doctors paid by drugmakers, but say trials not about 
money. Palm Beach Post. Retrieved from http://www.mdmediaconnection.com/ printmedia.php\#!prettyPhoto[iframe2]/0/.

Halpern, M. T., Ward, E. M., Pavluck, A. L., Schrag, N. M., Bian, J., \& Chen, A. Y. (2008). Association of insurance status and ethnicity with cancer stage at diagnosis for 12 cancer sites: A retrospective analysis. The Lancet Oncology, 9(3), 221-231.

Institute of Medicine. (2008). Resident duty hours: Enhancing sleep, supervision, and safety. Washington, DC: National Academies Press.

International Federation of Health Plans. (2010). 2010 comparative price report: Medical and hospital fees by country. London, United Kingdom: Author.

Kaiser Family Foundation. (2012). State health facts. Retrieved from http://www.statehealthfacts.org.

Kavilanz, P. (2010, January 13). Health care: A "gold mine” for fraudsters. CNN Money. Retrieved from http://money.cnn.com/2010/01/13/news/economy/health_care fraud.

Klein, E. (2012, March 2). High health-care costs: It's all in the pricing. The Washington Post. Retrieved from http://www.washingtonpost.com/business/high-health-care-costs-its-all-in-the-pricing/2012/02/28/ gIQAtbhimR story.html.

Kronick, R. (2009). Medicare and HMOs-The Search for Accountability. New England Journal of Medicine, 360, 2048-2050.

Mangan, K. (2011). Proposals to cut federal deficit would worsen physician shortage, medical groups warn. Chronicle of Higher Education, 58(6), A17-A17.

Moisse, K. (2011, April 7). Hospital errors common and underreported. ABCnews.com. Retrieved from http://abcnews.go.com/Health/hospital-errors-common-underreported-study/ story?id=13310733\#.TxxeY13310732NSRye.

Organisation for Economic Co-operation and Development. (2011). Health at a glance 2011: OECD indicators. Paris, France: Author.

Read, J. G., \& Gorman, B. M. (2010). Gender and health inequality. Annual Review of Sociology, 36, 371-386.

Rosenberg, T. (2011, April 25). Better hand-washing through technology. New York Times. Retrived from http://opinionator.blogs.nytimes.com/2011/2004/2025/better-hand-washing-through-technology.

Salahi, L. (2012, January 6). Report: Hospital errors often unreported. ABCnews.com. Retrieved from http://abcnews.go.com/Health/Wellness/hospital-staff-report-hospital-errors/ story?id=15308019\#.TxxfKWNSRyd.

Samal, L., Lipsitz, S. R., \& Hicks, L. S. (2012). Impact of electronic health records on racial and ethnic disparities in blood pressure control at US primary care visits. Archives of Internal Medicine, 172(1), 75-76.

Samuelson, R. J. (2011, November 28). A grim diagnosis for our ailing health care system. The Washington Post. 
Retrieved from http://www.washingtonpost.com/opinions/a-grim-diagnosis-for-our-ailing-us-health-care-system/ 2011/11/25/gIQARdgm2N story.html.

Shreibati, J. B., \& Baker, L. C. (2011). The relationship between low back magnetic resonance imaging, surgery, and spending: Impact of physician self-referral status. Health Services Research, 46(5), 1362-1381.

Wen, P. (1998, February 9). Tired surgeons perform as if drunk, study says. The Boston Globe, p. A9.

Wilper, A. P., Woolhandler, S., Lasser, K. E., McCormick, D., Bor, D. H., \& Himmelstein, D. U. (2009). Health insurance and mortality in US adults. American Journal of Public Health, 99(12), 1-7. 


\subsection{Improving Health and Health Care}

\section{Learning Objectives}

1. Explain how the United States could improve the quality of health and health care.

2. List strategies that will improve global health.

The US health-care system, despite the recent health-care reform legislation and medical advances that used to be only a dream, still has a long way to go before affordable and high-quality health care is available to all. With the health of so many people at stake, the United States needs to make every effort to achieve this essential goal. How might we achieve this goal?

We have seen throughout this chapter that social class, race and ethnicity, and gender all play a profound role in the quality of health and health care. People from low-income backgrounds have higher rates of physical and mental illness because of the stress and other factors associated with living with little money and also because of their lack of access to adequate health care. Partly because they tend to be poorer and partly because of the discrimination they experience in their daily lives and in the health-care system, people of color also have higher rates of physical and mental illness. Findings on gender are more complex, but women have higher rates than men of nonfatal physical illness and of depression and other mental illness, and they experience lower quality of health care for certain conditions.

To improve health and health care in the United States, then, the importance of social class, race and ethnicity, and gender must be addressed. Efforts, as outlined in earlier chapters, that reduce poverty and racial/ethnic and gender inequality should also improve the physical and mental health of those currently at risk because of their low incomes, race or ethnicity, and/or gender, as public health experts recognize (Bradley \& Taylor, 2011). At the same time, special efforts must be made to ensure that these millions of individuals receive the best health care possible within the existing system of social inequality. 


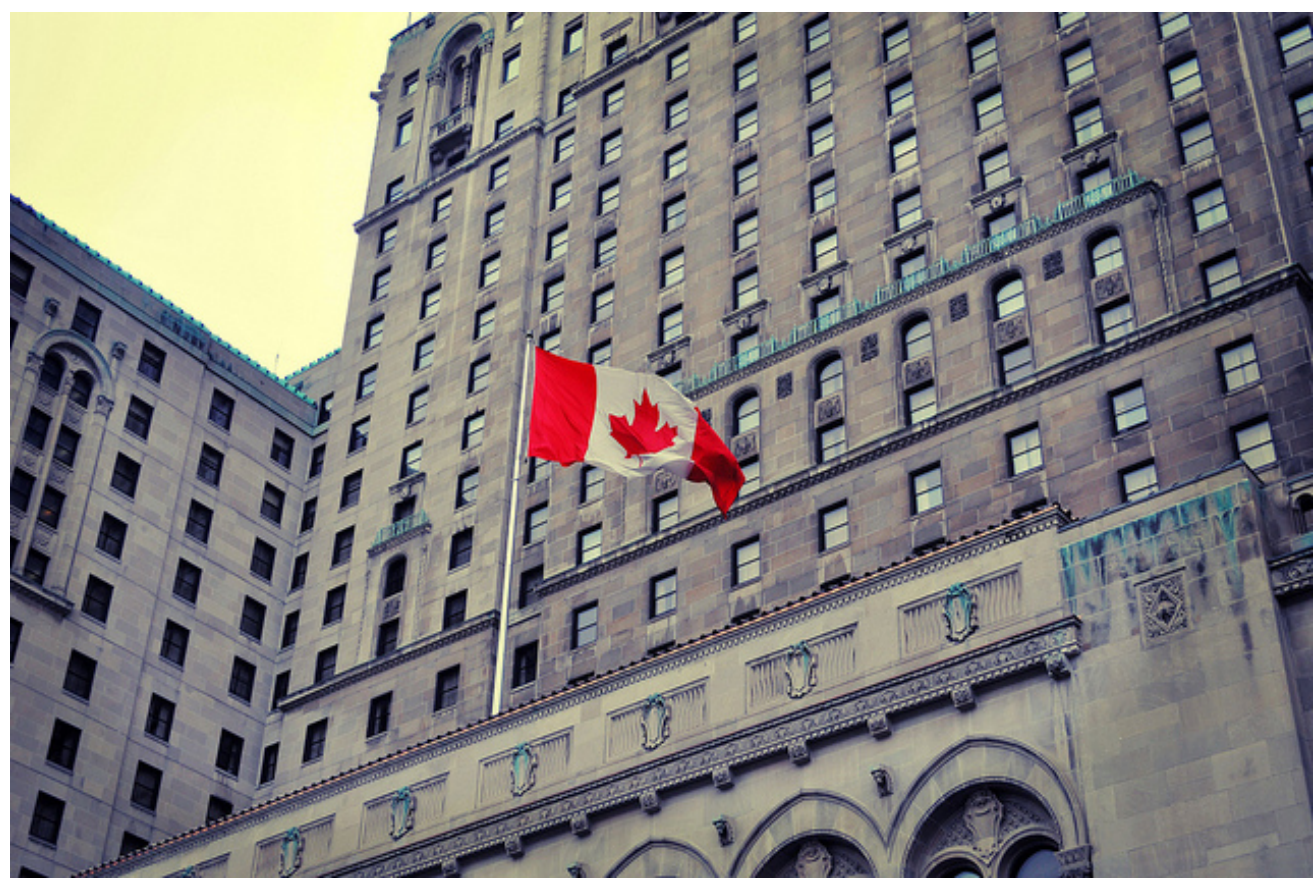

Canada and other wealthy nations have national health-care systems that provide models for the United States to follow.

Samuel Auguste - $\underline{\text { Au Canada }}$ - CC BY-NC-ND 2.0.

In this regard, the national health-care and health insurance systems of Canada, the United Kingdom, and many other Western nations provide models for the United States. As discussed in this chapter, these nations provide better health care to their citizens in many ways and at a lower cost than that incurred under the US model of private insurance. Their models are not perfect, but a government-funded and government-run singlepayer system — or "Medicare for all," as it has been called—shows great promise for improving the health and health care of all Americans. We in effect have single-payer-that is, government-funded —systems for police, firefighters, education, public libraries, and even the postal service, proponents of national health insurance say, and they add that Medicare, a government-funded program, is largely successful (Kristof, 2009). The US government also runs a preventive care and hospital system for military veterans through the Department of Veterans Affairs (VA); this system has been called "one of the best-performing and most cost-effective elements in the American medical establishment” (Kristof, 2009, p. A31). According to a study by the Rand Corporation, "If other health care providers followed the V.A.'s lead, it would be a major step toward improving the quality of care across the U.S. health care system” (Kristof, 2009, p. A31).

These models all indicate that national health insurance and the single-payer system for health care found in many other democracies could also succeed in the United States. As one single-payer proponent observed, "A public role in health care shouldn’t be any scarier or more repugnant than a public fire department” (Kristof, 2009, p. A31). (The Note 13.28 "People Making a Difference" box highlights a national physicians group that advocates for a single-payer system.) 


\section{People Making a Difference}

Physicians in Favor of National Health Insurance

Physicians for a National Health Program (PNHP) is a national organization of some 18,000 physicians who support a single-payer system of national health insurance in the United States. They advocate for this goal through the PNHP's website and through a variety of advocacy efforts. These efforts include writing articles for medical and public health journal; writing op-ed columns for newspapers; and making educational materials available to members of the public who wish to contact their members of Congress. PNHP members also appear on local and national television news shows and coordinate and speak at public health forums. PNHP has local chapters and allied groups in more than forty states and the District of Columbia.

According to PNHP, a single-payer system would greatly reduce the billing, paperwork, and other administrative costs of the private insurance model that now dominates the US health care system. These costs, PNHP says, account for onethird of US health expenditures; if the United States were to adopt a national single-payer system, administrative costs would be reduced by $\$ 400$ billion. PNHP also emphasizes that more than 50 million Americans are now uninsured and many others are underinsured. A national single-payer system would cover virtually the entire population.

An important reason for the high administrative costs of US health care, PNHP explains, is the fact that private insurance companies are for-profit companies. Because their goal is to make a profit, they advertise and engage in various marketing activities, and their CEOs and other executives receive extremely high salaries and other compensation. A single-payer system would eliminate all these problems.

By calling attention to the many problems in the current US health model and by advocating for a national single-payer system, Physicians for a National Health Program is helping to make a difference. For more information, visit http://www.pnhp.org.

Short of adopting national health insurance, other efforts to improve health and health care are certainly essential. One such effort would include an expansion of measures that fall broadly into what the field of public health calls preventive care. This approach recognizes that the best approach to health and health care is to prevent illness and disease before they begin. One facet of this approach focuses on the unhealthy behaviors and lifestyles, including lack of exercise, obesity, and smoking, characteristic of millions of Americans. Although the United States has public education campaigns and other initiatives on these risk factors, more could still be done. Another facet of this approach focuses on early childhood in general but especially on early childhood among low-income families. As this chapter has emphasized beginning with the Note 13.1 "Social Problems in the News" story, many health problems begin very early in childhood and even in the womb. Home visitation and nutrition assistance programs must be expanded across the country to address these problems.

Another effort must focus on the high cost of health care. We saw earlier that the US fee-for-service model, in which hospitals and physicians largely set the prices for their services, contributes greatly to the high cost of health care in the United States. Related to this model, physicians are paid for each patient they see, rather than receiving a set salary, as teachers, firefighters, police officers, and most other occupations that service large numbers of people receive. Yet there are some outstanding hospitals, such as the Mayo Clinic in Minnesota and the Cleveland Clinic in Ohio, where physicians do work on salary rather than charging for each patient or for each surgery; costs per patient at these hospitals tend to be lower (Gawande, Berwick, Fisher, \& McClellan, 2009). Moving toward this model would help lower health-care costs. The greater use of electronic systems for patient records and billing and for communication among physicians would also reduce costs. So would the elimination of many diagnostic tests and medical procedures and surgeries that research has shown to be unnecessary and that may cost at least \$200 billion annually (Weinberger, 2011). 
Another strategy that would reduce health care costs would be the adoption of "integrated care," also called "high touch medicine" (Emanuel, 2011). In this model, teams of health care professionals (nurses, pharmacists, physicians) coordinate care for the chronically ill patients (10 percent of the population) who account for twothirds of all health care costs. This integrated care involves extensive communication among the members of a patient's team with the patient and any caregivers, home visits by nurses to check on the patient, and other components. The goal is to help the patients take better care of themselves so that they do not become sicker and need (additional) hospital or emergency room care. Because hospital and emergency room care is so expensive, the prevention of hospital and emergency room visits through integrated care yields a significant savings in health care costs. If integrated care became the norm around the country, it is estimated that its adoption would save more than $\$ 80$ billion annually.

It is also essential to reduce medical errors in hospitals and to raise the rate of hand washing. Many hospitals have adopted strict protocols, such as frequent washing of hands and the use of checklists before surgeries, to reduce infection and errors, but many hospitals have also failed to adopt these protocols. Their failure to do so is a hidden national scandal that kills thousands of people annually.

What can be done to improve world health? Because the poorest nations have the poorest health, it is essential that the wealthy nations provide them the money, equipment, and other resources they need to improve their health and health care. The residents of these nations also need to be given the resources they need to undertake proper sanitation and other good health practices. In this regard, organizations like the World Health Organization have been instrumental in documenting the dire status of health in the poor nations and in promoting efforts to help them, and groups like Doctors Without Borders have been instrumental in bringing health-care professionals and medical care to poor nations. Ultimately, however, these nations' poor health is just one of the consequences of the global inequality examined in Chapter 2 "Poverty". Until these nations' economic circumstances and high rates of illiteracy improve dramatically, their health status will remain a serious problem.

\section{Key Takeaways}

- Effective health care reform must address social class, racial and ethnic, and gender inequalities in health and health care.

- National health insurance involving a single-payer system would improve many aspects of health and health care in the United States.

- In the absence of national health insurance, several types of changes could still help to reduce health care costs.

\section{For Your Review}

1. Do you favor or oppose national health insurance for the United States? Explain your answer.

2. Why do you think the United States remains the only industrial nation without national health insurance? 


\section{References}

Bradley, E. H., \& Taylor, L. (2011, December 9). To fix health, help the poor. New York Times, p. A39.

Emanuel, E. J. (2011, November 16). Saving by the bundle. New York Times. Retrieved from http://opinionator.blogs.nytimes.com/2011/2011/2016/saving-by-the-bundle.

Gawande, A., Berwick, D., Fisher, E., \& McClellan, M. (2009, August 13). 10 steps to better health care. New York Times, p. A27.

Kristof, N. D. (2009, September 3). Health care that works. New York Times, p. A31.

Weinberger, S. (2011, June 9). Pointless tests drive medical costs skyward: Doctors have to grapple with diagnostic overkill. Philly.com. Retrieved from http://articles.philly.com/2011-06-09/news/29638875_1_ct-scantesting-health-care-system. 


\subsection{End-of-Chapter Material}

\section{Summary}

1. A sociological approach emphasizes the relationship between health, medicine, and society. In particular, our social backgrounds influence our health and access to health care.

2. Sociological perspectives on health and illness fall into the functional, conflict, and interactionist approaches encountered in previous chapters. The functional view emphasizes the importance of health for a society's stability and the roles that people play when they are sick. The conflict view stresses inequality in the quality of health and health-care delivery and efforts by physicians to monopolize the practice of medicine to increase their profits. According to the interactionist view, health and illness are social constructions subject to people's and society's interpretations. The interactionist view also studies how medical professionals and patients interact and the way professionals manage understandings of such interaction.

3. Health and the quality of health care differ widely around the world and reflect global inequality. The earth's poorest nations have extremely high rates of infant mortality and life-threatening diseases such as AIDS and very low life expectancy.

4. The United States lags behind most other industrial nations in important health indicators such as infant mortality and life expectancy. Moreover, serious disparities exist within the United States in the social distribution of health, as evidenced by the study of social epidemiology.

5. Social class, race and ethnicity, and gender all affect the quality of health. The health of poor people is worse than that of the nonpoor. African Americans, Hispanics, and Native Americans all fare worse than whites on many health indicators, in large part because of their poverty and history of discrimination. Women fare worse than men on several heath indicators, but men have lower life expectancies because of their higher rates of certain life-threatening illnesses.

6. Health care in the United States today faces several problems. The United States is alone among the world's industrial nations in not offering universal national health insurance; its absence is thought to help account for the country's low ranking in the industrial world on major health indicators. Managed care has also come under criticism for restricting coverage of important medical procedures and prescription medicines. Racial and gender bias in health care is another problem that has adverse effects on the nation's health. Other quality-of-care problems include tired physicians, a lack of emergency room physicians, and numerous mistakes made in hospitals.

\section{Using What You Know}

You have been working for two months as a volunteer in a hospital in or near your hometown. Your duties include bringing food to patients, talking with them, and otherwise helping them to feel comfortable. However, you have noticed that many of the physicians and nurses you have seen coming into patients' rooms do not wash their hands, and you doubt that they washed their hands immediately before entering the rooms. What, if anything, do you do? Explain your answer. 


\section{What You Can Do}

To help deal with the health and health-care problems discussed in this chapter, you may wish to do any of the following:

1. Volunteer at a local hospital or health clinic.

2. Start a group on your campus to advocate for national health insurance, or join an existing group in the nearby community.

3. Volunteer for a local agency that tries to address the health-care needs of low-income children and their families. 


\section{Chapter 14: Urban and Rural Problems}

\section{Social Problems in the News}

"Downtown Decay Poses Problem for Community,” the headline said. The downtown district of Charleston, South Carolina, has some of the most beautiful older homes in the country, but it also has its share of dilapidated housing. According to the news article, "There are two distinct sides to downtown Charleston, the postcard perfect homes and the crumbling, rundown houses. Dilapidated buildings near the crosstown aren't just eyesores, they're becoming safety hazards.” A neighborhood activist criticized city officials for ignoring the problem of rundown, dangerous houses. "It's out of sight, out of mind," he said. Ignoring this problem "wouldn't happen in the tourist areas," he added, "but why should it happen in the community where people live and work every day?"

Source: Davenport, 2012.

America's cities are centers of culture, innovation, fine dining, world-class medical research, high finance, and so many other hallmarks. Yet, as this news story from Charleston reminds us, our cities also have dilapidated housing and many other problems. So do the nation's rural areas. This chapter examines urban and rural problems in the United States.

We will see that many of these problems reflect those that earlier chapters discussed. But we will also see that some problems are worse in cities precisely because they are cities (and therefore are crowded with traffic and many buildings and people). And we'll see that some problems are worse in rural areas precisely because they are rural (and therefore are isolated with long distances to travel). These defining features of cities and rural areas, respectively, should be kept in mind as we examine the problems occurring in these two important settings for American life.

\section{References}

Davenport, M. (2012, January 11). Downtown decay poses problem for community. WCSC TV. Retrieved from http://www.live5news.com/story/16501227/downtown-decay-poses-problem-for-community. 


\subsection{A Brief History of Urbanization}

\section{Learning Objectives}

1. Discuss the health problems that resulted when cities developed.

2. Explain why urbanization grew in the United States during the nineteenth century.

3. List the problems poor nations face as their cities grow even larger.

One of the most significant changes over the centuries has been urbanization, or the shift from rural areas to large cities. Urbanization has had important consequences for many aspects of social, political, and economic life (Kleniewski \& Thomas, 2011).

The earliest cities developed in ancient times after the rise of horticultural and pastoral societies made it possible for people to stay in one place instead of having to move around to find food. Because ancient cities had no sanitation facilities, people typically left their garbage and human waste in the city streets or just outside the city wall (which most cities had for protection from possible enemies). This poor sanitation led to rampant disease and high death rates. Some cities eventually developed better sanitation procedures, including, in Rome, a sewer system. Still, the world remained largely rural until the industrialization of the nineteenth century. We return to industrialization shortly.

During the American colonial period, cities along the eastern seaboard were the centers of commerce and politics. Boston, New York, and Philadelphia were the three largest cities in population size. Yet they were tiny in comparison to their size today. In 1790, the year after George Washington became the first president of the new nation, New York’s population was only 33,131; Philadelphia’s was 28,522; and Boston's was 18,230 (Gibson, 1998). Today, of course, cities of this size are called small towns. New York's population is vastly higher, at about 8.2 million; Philadelphia's is 1.5 million; and Boston’s is 618, 000.

US cities became more numerous and much larger during the nineteenth century because of two trends. The first was immigration, as waves of immigrants from Ireland and then Italy and other nations began coming to the United States during the 1820s. The second was industrialization, as people moved to live near factories and other sites of industrial production. These two trends were momentous: People crowded together as never before, and they crowded into living conditions that were often squalid. Lack of sanitation continued to cause rampant disease, and death rates from cholera, typhoid, and other illnesses were high. 


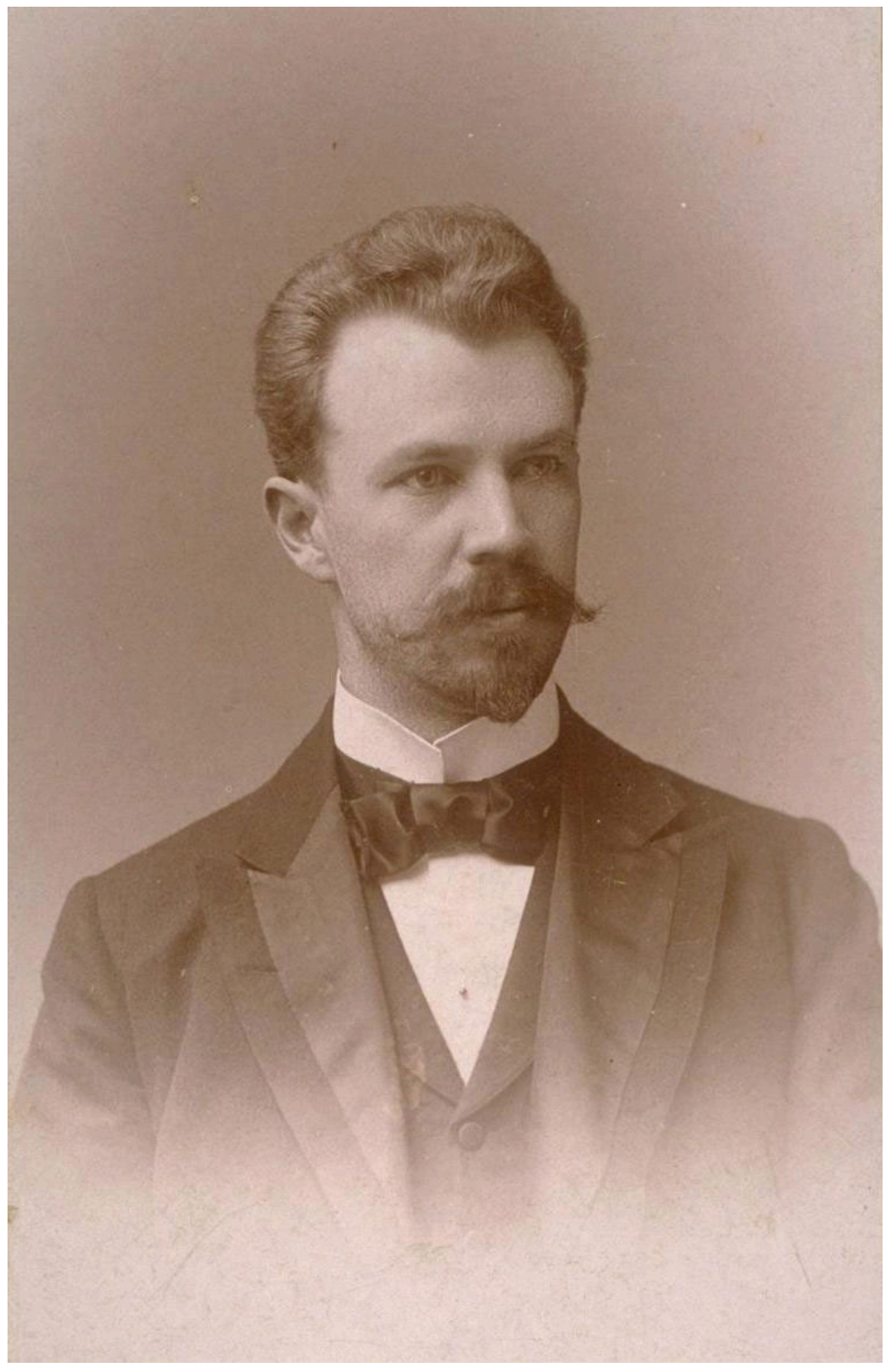

Muckraker Lincoln Steffens wrote a classic work, The Shame of the Cities, that criticized the municipal corruption characterizing many US cities at the turn of the twentieth century.

Crime also became a significant problem, as did riots and other mob violence beginning in the 1830s. This type of mass violence was so common that the 1830s have been called the "turbulent era" (Feldberg, 1980). Most of this mass violence was committed by native-born whites against African Americans, Catholics, and immigrants. Native whites resented their presence and were deeply prejudiced against them. During the three decades beginning in 1830, almost three-fourths of US cities with populations above 20,000 had at least one riot. This wave of mass violence in the nation's cities led Abraham Lincoln to lament, "Accounts of outrages committed by mobs form the everyday news of the times... Whatever their causes be, it is common to the whole country” (Barkan \& Snowden, 2008, p. 34). 
American cities grew even more rapidly after the Civil War as both industrialization and immigration continued. By the early years of the twentieth century, US cities on the East Coast were almost unimaginably crowded, and their living conditions continued to be wretched for many of their residents. Their city governments, police forces, and business worlds were also notoriously corrupt. In 1904, Lincoln Steffens, a renowned "muckraking” journalist, published his classic work, The Shame of the Cities (Steffens, 1904), which was a collection of six articles he had written for McClure's Magazine. In this book, Steffens used biting prose to attack the municipal corruption of the times in Chicago, Philadelphia, St. Louis, and other cities. In the original articles that compose the book, he named names: He listed by name people who gave and received bribes and those who were corrupt in other ways. A decade earlier, another muckraker, Jacob Riis, had published How the Other Half Lives: Studies among the Tenements of New York (Riis, 1890), a book of searing photographs of poverty in the largest US city. The books by Steffens and Riis remain as vivid reminders of what cities were like a century ago, and perhaps are still like today in some respects.

As Americans moved west after the Civil War and during the twentieth century, western cities appeared almost overnight and expanded the pace of urbanization. Continued industrialization, immigration, and general population growth further increased the number and size of US cities. Internal migration had a similar impact, as waves of African Americans moved from the South to Chicago and other northern cities.

Figure 14.1 Populations of Chicago, New York, and Los Angeles, 1790-2010

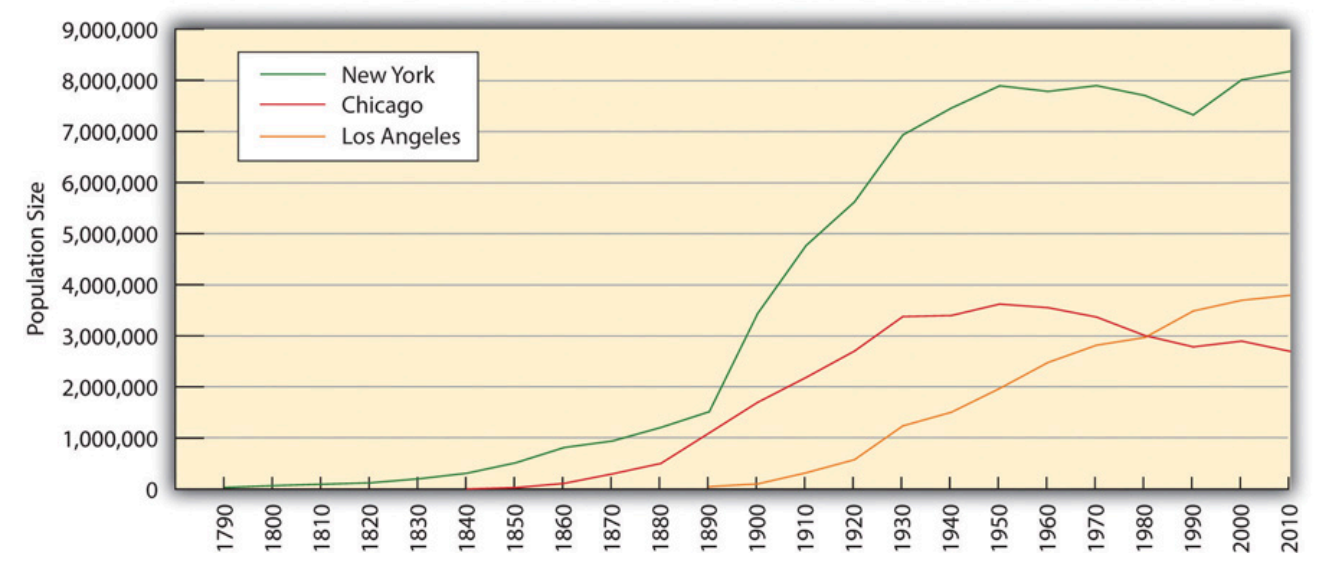

Note: New York annexed Brooklyn in 1898; therefore, New York’s population beginning in 1900 includes Brooklyn’s population.

Sources: Gibson, C. (1998). Population of the 100 largest cities and other urban places in the United States: 1790-1990. Washington, DC: US Census Bureau; US Census Bureau. (2012). Statistical abstract of the United States: 2012. Washington, DC: US Government Printing Office. Retrieved from http://www.census.gov/compendia/statab.

Figure 14.1 "Populations of Chicago, New York, and Los Angeles, 1790-2010" depicts the growth of Chicago, New York, and Los Angeles from 1790 to 2010. Chicago and Los Angeles first appear in the graph when they began to rank in the largest one hundred cities.

Note that the populations of New York and Chicago show some decline after 1950. This decline reflects two other trends affecting cities in the past half-century: (1) the movement of people from cities to suburbs; and (2) the movement of Americans from northern cities to southern and southwestern cities. Reflecting this second trend, and also reflecting increases in immigration from Mexico and Asia, southern and southwestern cities have grown rapidly during the past few decades. For example, during the 1970-2010 period, the populations of Albuquerque, 
New Mexico, and Phoenix, Arizona, more than doubled, while the populations of Cleveland, Ohio, and Detroit, Michigan, both fell by about half (see Figure 14.2 "Population Change from 1970 to 2010 for Selected Cities").

Figure 14.2 Population Change from 1970 to 2010 for Selected Cities

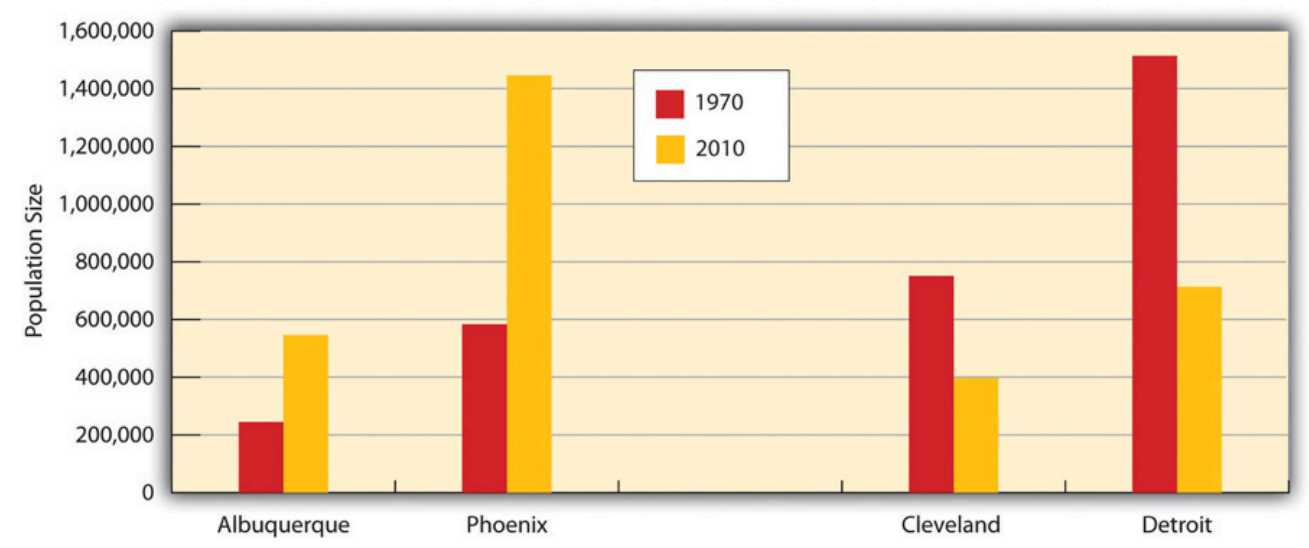

Source: US Census Bureau. (2012). Statistical abstract of the United States: 2012. Washington, DC: US Government Printing Office. Retrieved from http://www.census.gov/ compendia/statab.

This trend in urbanization aside, the fact remains that the United States has become much more urbanized since its formation. Today, more than three-fourths of the US population lives in an urban area (defined generally as an incorporated territory with a population of at least 2,500), and less than one-fourth lives in a rural area. As Figure 14.3 "Urbanization in the United States (Percentage Living in Urban Areas)" shows, the degree of urbanization rose steadily through the nineteenth and twentieth centuries before slowing down by the end of the last century.

Figure 14.3 Urbanization in the United States (Percentage Living in Urban Areas)

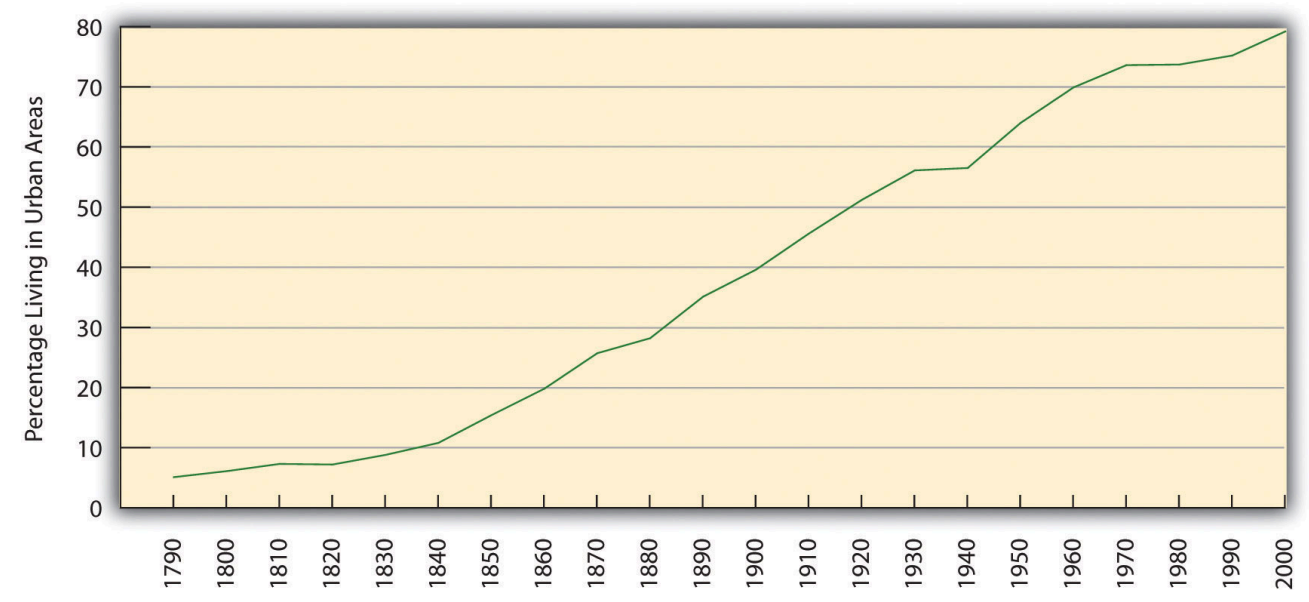

Sources: http://www.census.gov/population/www/censusdata/files/table-4.pdf; http://www.fhwa.dot.gov/planning/census_issues/archives/metropolitan_planning/cps2k.cfm.

\section{Global Urbanization}

If the United States has urbanized during the last two centuries, so has much of the rest of the world. Only 3 percent of the world's population lived in urban areas in 1800. By a century later in 1900, 14 percent of the world's 
population lived in urban areas, and twelve cities had populations over 1 million. Just a half-century later in 1950, the world's urban population had doubled to 30 percent, and the number of cities over 1 million grew six times to eighty-three cities.

Today, more than half the world's population lives in urban areas, and the number of cities over 1 million stands at more than four hundred. By 2030, almost two-thirds of the world's population is projected to live in urban areas. The number of megacities — cities with populations over 10 million-rose from three in 1975 to sixteen in 2000, and is expected to reach twenty-seven by 2025 (Population Reference Bureau, 2012).

Despite all this growth, the degree of urbanization still varies around the world (see Figure 14.4 "Percentage of World Population Living in Urban Areas"). In general, wealthy nations are more urban than poor nations, thanks in large part to the latter's rural economies. Still, urbanization in poor nations is proceeding rapidly. Most megacities are now in, and will continue to be in, nations that are relatively poor or desperately poor. The number of urban residents in these nations will increase greatly in the years ahead as people there move to urban areas and as their populations continue to grow through natural fertility. Fertility is a special problem in this regard for two reasons. First, women in poor nations have high fertility rates. Second, poor nations have very high proportions of young people, and these high rates mean that many births occur because of the large number of women in their childbearing years.

Figure 14.4 Percentage of World Population Living in Urban Areas

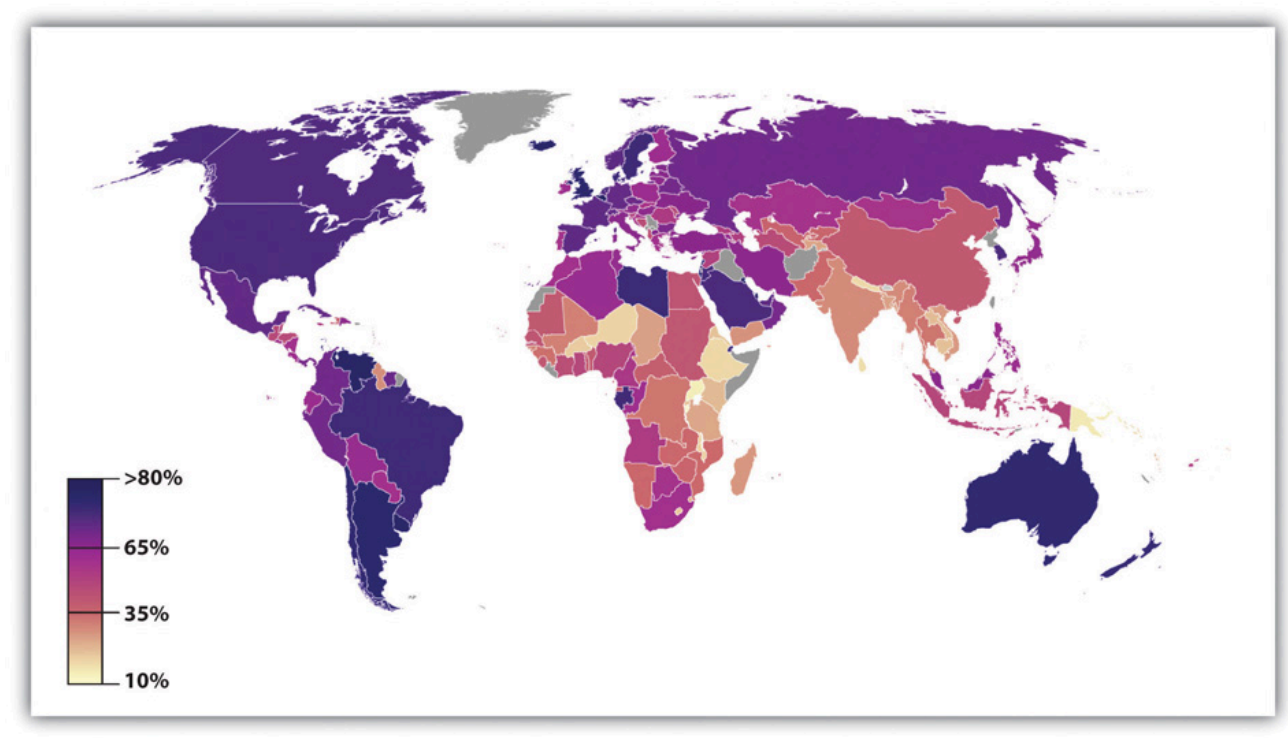

Source: Adapted from http://en.wikipedia.org/wiki/File:Urban_population_in_2005_world_map.PNG.

Rapid urbanization poses both opportunities and challenges for poor nations. The opportunities are many. Jobs are more plentiful in cities than in rural areas and incomes are higher, and services such as health care and schooling are easier to deliver because people are living more closely together. In another advantage, women in poor nations generally fare better in cities than in rural areas in terms of education and employment possibilities (United Nations Population Fund, 2011). 


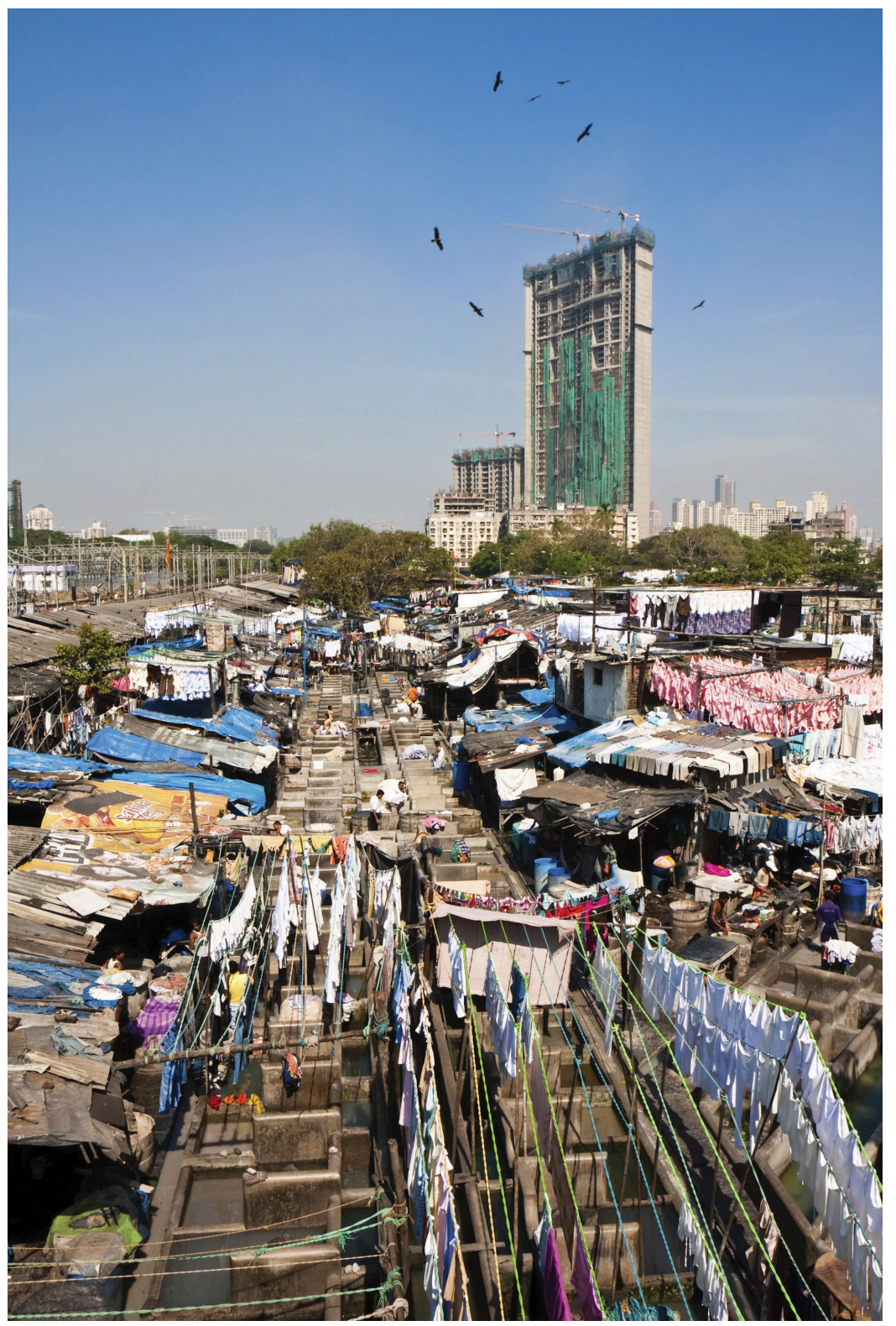

In large cities in poor nations, as this scene illustrates, many people live in deep poverty and lack clean

water and sanitation.

Wikimedia Commons - CC BY-SA 3.0.

But there are also many challenges. In the large cities of poor nations, homeless children live in the streets as beggars, and many people lack necessities and conveniences that urban dwellers in industrial nations take for granted. As the United Nations Population Fund (2007) warns, "One billion people live in urban slums, which are typically overcrowded, polluted and dangerous, and lack basic services such as clean water and sanitation.” The rapid urbanization of poor nations will compound the many problems these nations already have, just as the rapid urbanization in the industrial world more than a century ago led to the disease and other problems discussed earlier. As cities grow rapidly in poor nations, moreover, these nations' poverty makes them ill equipped to meet the challenges of urbanization. Helping these nations meet the needs of their cities remains a major challenge for the world community in the years ahead. In this regard, the United Nations Population Fund (2007) urges 
particular attention to housing: "Addressing the housing needs of the poor will be critical. A roof and an address in a habitable area are the first step to a better life. Improving access to basic social and health services, including reproductive health care, for poor people in urban slums is also critical to breaking the cycle of poverty.”

Life in the megacity of Mumbai (formerly called Bombay) in India illustrates many of the problems facing large cities in poor nations. Mumbai's population exceeds 12.4 million, with another 8 million living in the greater metropolitan area; this total of more than 20 million ranks Mumbai's metropolitan population as the fourth highest in the world. An author who grew up in Mumbai calls his city an "urban catastrophe." He continued, "Bombay is the future of urban civilization on the planet. God help us" (Kotkin, 2011). A recent news story illustrated his bleak assessment with this description of life in Mumbai: "The majority of Mumbai's population now lives in slums, up from one-sixth in 1971—a statistic that reflects a lack of decent affordable housing, even for those gainfully employed. Congested, overcrowded, and polluted, Mumbai has become a difficult place to live. The life expectancy of a Mumbaikar is now seven years shorter than an average Indian's, a remarkable statistic in a country still populated by poor villagers with little or no access to health care” (Kotkin, 2011).

\section{Key Takeaways}

- US cities grew rapidly during the nineteenth century because of industrialization and immigration.

- The United States is now a heavily urbanized society, whereas it was largely a rural society just a century ago.

- Urbanization poses special challenges for poor nations, which are ill equipped to address the many problems associated with urbanization.

\section{For Your Review}

1. Write an essay in which you discuss the advantages and disadvantages of urbanization.

2. If you had your preference, would you want to live in a large city, small city or town, or rural area? Explain your answer.

\section{References}

Barkan, S. E., \& Snowden, L. L. (2008). Collective violence. Cornwall-on-Hudson, NY: Sloan.

Feldberg, M. (1980). The turbulent era: Riot and disorder in Jacksonian America. New York, NY: Oxford University Press.

Gibson, C. (1998). Population of the 100 largest cities and other urban places in the United States: 1790-1990. Washington, DC: US Census Bureau. 
Kleniewski, N., \& Thomas, A. R. (2011). Cities, change, and conflict (4th ed.). Belmont, CA: Wadsworth.

Kotkin, J. (2011). A leg up: World's largest cities no longer homes of upward mobility. Retrieved January 29, 2012, from http://www.newgeography.com/content/002051-a-leg-up-worlds-largest-cities-no-longer-homesupward-mobility.

Population Reference Bureau. (2012). Human population: Urbanization. Retrieved from http://www.prb.org/ Educators/TeachersGuides/HumanPopulation/Urbanization.aspx.

Riis, J. (1890). How the other half lives: Studies among the tenements of New York. New York. NY: Charles Scribner's Sons.

Steffens, L. (1904). The shame of the cities. New York, NY: McClure, Phillips.

United Nations Population Fund. (2007). Linking population, poverty, and development. Urbanization: A majority in cities. Retrieved from http://www.unfpa.org/pds/urbanization.htm.

United Nations Population Fund. (2011). The State of World Population 2011. Retrieved from http://foweb.unfpa.org/SWP2011/reports/EN-SWOP2011-FINAL.pdf. 


\subsection{Sociological Perspectives on Urbanization}

\section{Learning Objective}

1. List the assumptions of the three major sociological perspectives concerning urbanization.

Once again the three major sociological perspectives offer important but varying insights to help us understand urbanization. Table 14.1 “Theory Snapshot” summarizes their assumptions.

Table 14.1 Theory Snapshot

\begin{tabular}{|l|l|}
$\begin{array}{l}\text { Theoretical } \\
\text { perspective }\end{array}$ & Major assumptions \\
\hline Functionalism & $\begin{array}{l}\text { Cities serve many important functions for society but also have their dysfunctions. Functionalist theorists } \\
\text { differ on the relative merits and disadvantages of urban life, and in particular on the degree to which a } \\
\text { sense of community and social bonding exists within cities. }\end{array}$ \\
\hline $\begin{array}{l}\text { Conflict } \\
\text { theory }\end{array}$ & $\begin{array}{l}\text { Cities are run by political and economic elites that use their resources to enrich their positions and to take } \\
\text { resources from the poor and people of color. The diversity of social backgrounds found in cities } \\
\text { contributes to conflict over norms and values. }\end{array}$ \\
\hline $\begin{array}{l}\text { Symbolic } \\
\text { interactionism }\end{array}$ & $\begin{array}{l}\text { City residents differ in their types of interaction and perceptions of urban life. Cities are not chaotic places } \\
\text { but rather locations in which strong norms and values exist. }\end{array}$ \\
\hline
\end{tabular}

\section{Functionalism}

A basic debate within the functionalist perspective centers on the relative merits of cities and urbanization: In what ways and to what extent are cities useful (functional) for society, and in what ways and to what extent are cities disadvantageous and even harmful (dysfunctional) for society? Put more simply, are cities good or bad?

In essence, there is no one answer to this question, because cities are too complex for a simple answer. Cities are both good and bad. They are sites of creativity, high culture, population diversity, and excitement, but they are also sites of crime, impersonality, and other problems.

Since sociologists began studying urbanization in the early years of the discipline, an important question has been the degree to which cities are impersonal and alienating for their residents. In 1887, German sociologist Ferdinand Tönnies (1887/1963) raised this question when he wrote about the changes that occurred as societies changed from small, rural, and traditional cultures to larger, urban, and industrial settings. He said that a sense of community, or Gemeinschaft, characterizes traditional societies. In these societies, family, kin, and community ties are quite strong, with people caring for each other and looking out for one another. As societies grew and industrialized and 
as people moved to cities, he wrote, social ties weakened and became more impersonal. Tönnies called this type of society a Gesellschaft, and he was quite critical of this development. He lamented the loss in urban societies of close social bonds and of a strong sense of community, and he feared that a sense of rootlessness in these societies begins to replace the feeling of stability and steadiness characteristic of small, rural societies.

One of the key founders of sociology, French scholar Émile Durkheim, was more positive than Tönnies about the nature of cities and urbanized societies. He certainly appreciated the social bonds and community feeling, which he called mechanical solidarity, characteristic of small, rural societies. However, he also thought that these societies stifled individual freedom and that social ties still exist in larger, urban societies. He called these latter ties organic solidarity, which he said stems from the division of labor. When there is a division of labor, he wrote, everyone has to depend on everyone else to perform their jobs. This interdependence of roles creases a solidarity that retains much of the bonding and sense of community found in small, rural societies (Durkheim, 1893/1933).

Contemporary research tends to emphasize that strong social bonds do exist in cities (Guest, Cover, Matsueda, \& Kubrin, 2006). Although cities can be anonymous (think of the mass of people walking by each other on a busy street in the downtown area of a large city), many city residents live in neighborhoods where people do know each other, associate with each other, and look out for each other. In these neighborhoods, a sense of community and strong social bonds do, in fact, exist.

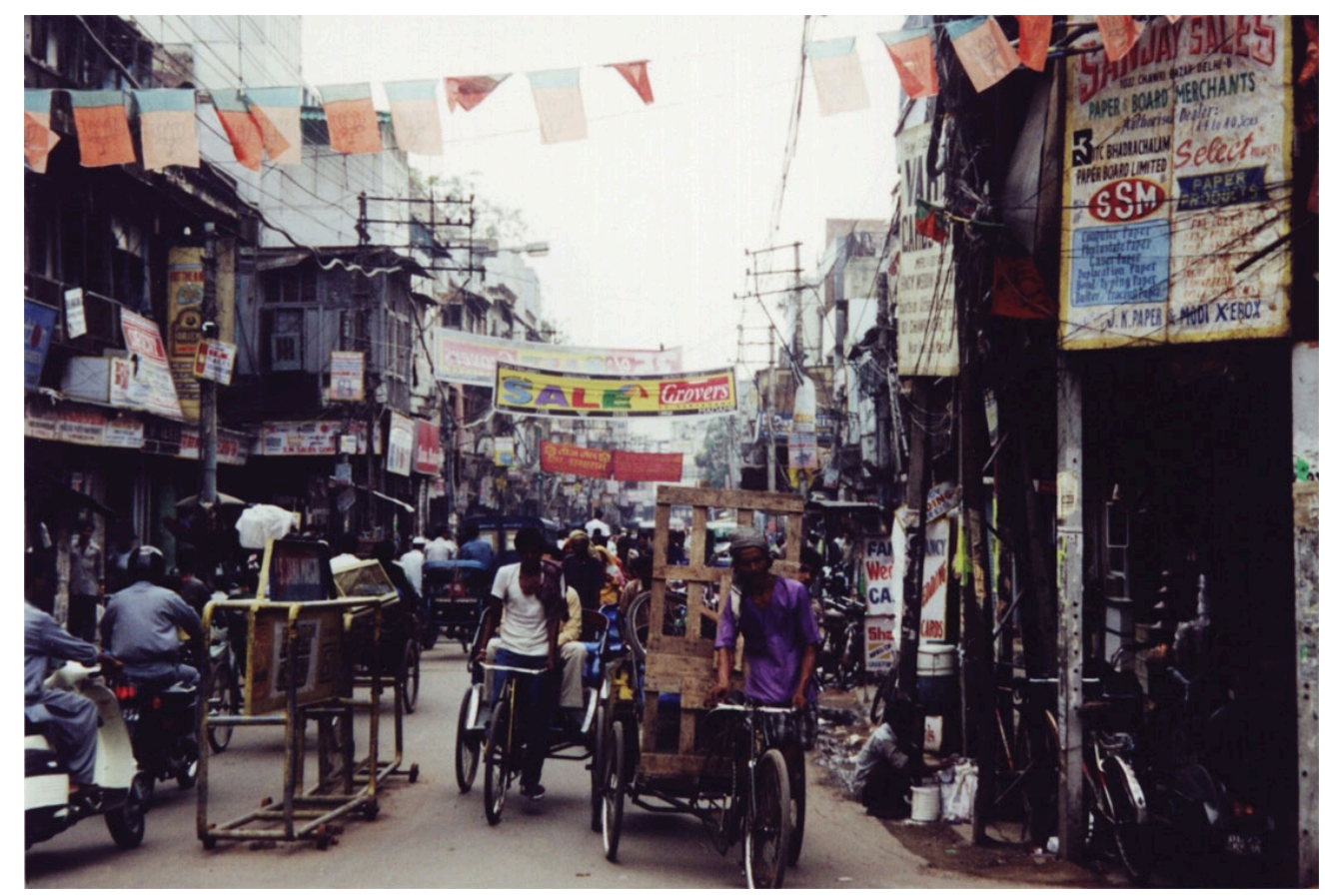

In many urban neighborhoods, people are friendly with each other and feel a strong sense of community.

Wikimedia Commons - CC BY 3.0.

In 1938, University of Chicago sociologist Louis Wirth wrote a very influential essay, "Urbanism as a Way of Life,” in which he took both a positive and a negative view of cities (Wirth, 1938). He agreed with Tönnies that cities have a weaker sense of community and weaker social bonds than do rural areas. But he also agreed with Durkheim that cities generate more creativity and greater tolerance for new ways of thinking. In particular, he said that urban residents are more tolerant than rural residents of nontraditional attitudes, behaviors, and lifestyles, in 
part because they are much more exposed than rural residents to these nontraditional ways. Supporting Wirth's hypothesis, contemporary research finds that urban residents indeed hold more tolerant views on several kinds of issues (Moore \& Ovadia, 2006).

An example of the greater tolerance of urban residents (and thus the lower tolerance of rural residents) appears in Figure 14.5 "Urban/Rural Residence and Belief That Premarital Sex Is "Always Wrong” (\%)", which depicts the percentage of Americans in the nation's twelve largest metropolitan areas and in its rural areas who say that premarital sex is "always wrong." Rural residents are twice as likely as urban residents to feel this way.

Figure 14.5 Urban/Rural Residence and Belief That Premarital Sex Is “Always Wrong” (\%)

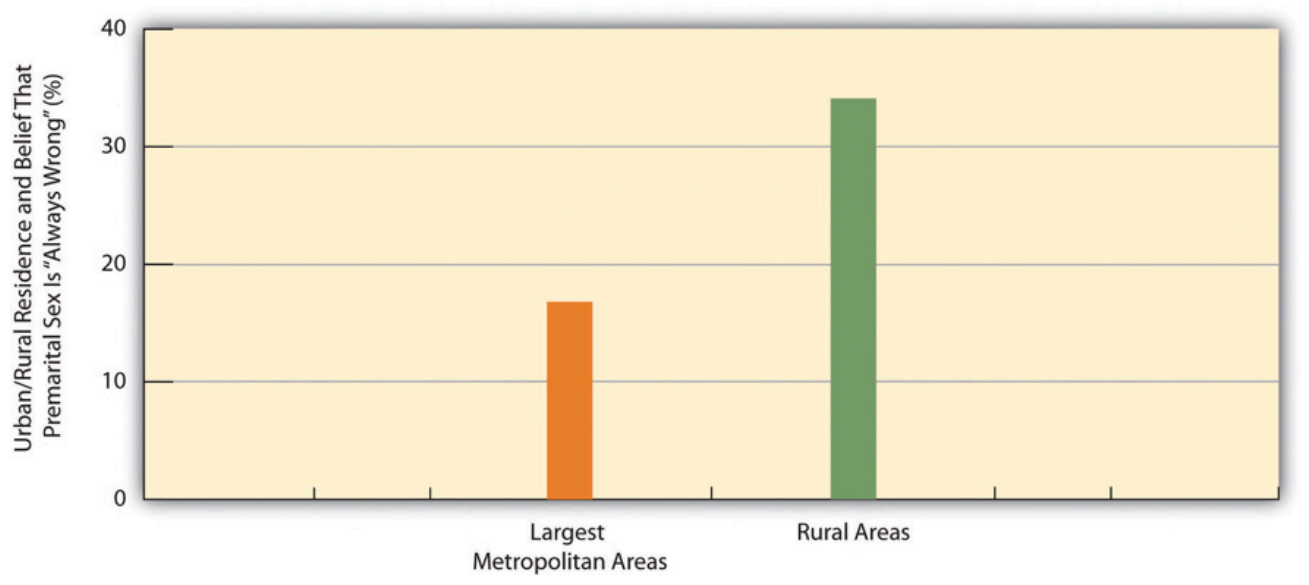

Source: Data from General Social Survey. (2010). Retrieved from http://sda.berkeley.edu/cgi-bin/hsda?harcsda+gss10.

\section{Conflict Theory}

We just saw that functionalism has mixed views about the benefits and disadvantages of cities and urban life and thus of urbanization. In contrast to this ambivalence, conflict theory's views are uniformly critical. In this regard, recall from Chapter 1 "Understanding Social Problems" that conflict theory assumes a basic conflict between society's "haves" and "have-nots," or between the economic and political elites and the poor and people of color. This type of conflict, says conflict theory, manifests itself especially in the nation's cities, in which the "haves" and "have-nots" live very different lives. On the one hand, the rich in American cities live in luxurious apartments and work in high-rise corporate buildings, and they dine at the finest restaurants and shop at the most expensive stores. On the other hand, the poor and people of color live in dilapidated housing and can often barely make ends meet.

Beyond this basic disparity of city life, conflict theorists add that the diverse backgrounds and interests of city residents often lead to conflict because some residents' beliefs and practices clash with those of other residents. In one of the earliest statements of this position, sociologist Thorsten Sellin (1938), who was writing during an era of mass immigration into American cities of people from other nations, said that crime is the result of "culture conflict." In particular, he wrote that crime by immigrants often results from the clash of their traditional ways of thinking and acting with the norms of American society. As one example, he wrote that a father in New Jersey who had emigrated from Sicily killed a teenage boy who had slept with his daughter. The father was surprised 
when he was arrested by local police, because in the traditional Sicilian culture a man was permitted and even expected to defend his family's honor by acting as the father did!

More recent applications of conflict theory to urbanization emphasize the importance of political economy, or the interaction of political and economic institutions and processes. In this way of thinking, political and economic elites in a city (bankers, real estate investors, politicians, and others) collaborate to advance their respective interests. Thus urban development often takes the form of displacing poor urban residents from their homes so that condominiums, high-rise banks and other corporate buildings, posh shopping malls, or other buildings favoring the rich can be built. More generally, these elites treat cities as settings for the growth of their wealth and power, rather than as settings where real people live, go to school, work at a job, and have friends and acquaintances. Sociologists John Logan and Harvey Molotch use the term growth machine ideology to characterize the view of the city that guides these elites’ policies and practices (Logan \& Molotch, 2007).

\section{Symbolic Interactionism}

Consistent with the overall approach of symbolic interactionism, scholars of the city who take this approach focus on the nature of urban residents' interaction with each other, the reasons for their patterns of interaction, and their perceptions of various aspects of urban life. Their work has yielded many rich, vivid descriptions of the urban life. Many and probably most of these accounts have concerned the lives of the poor and of people of color. The late Elliott Liebow wrote two of the most famous accounts. The first of these two was his majestic Tally's Corner (Liebow, 1967), which depicted the lives of African American men who "hung around" a particular street corner in a large city. His second account was Tell Them Who I Am: The Lives of Homeless Women (Liebow, 1993), which, as its title implies, depicted the lives of urban homeless women. Yet another classic account is William Foote Whyte’s (1943) Street Corner Society, which examined leadership in a street gang in Chicago, Illinois.

These and other accounts all depict cities as places where various norms and values prevail, in contrast to views of cities that depict them as wild, chaotic places. Building on these more positive accounts, recent work by sociologist Elijah Anderson emphasizes that most poor urban residents are “decent” (as they call themselves), law-abiding people who strongly disapprove of the crime and drug use in their neighborhoods (Anderson, 2000). He also emphasizes that cities are filled with parks and other public settings in which people from different racial and socioeconomic backgrounds gather every day and interact in various ways that help foster interracial understanding. Anderson calls these settings "cosmopolitan canopies," and says they "offer a respite from the lingering tensions of urban life and an opportunity for diverse peoples to come together...Through personal observation, they may come casually to appreciate one another's differences and empathize with the other in a spirit of humanity" (Anderson, 2011, pp. xiv-xv). In this manner, writes Anderson, people from different races can at least partly overcome the racial tensions that afflict many American cities.

\section{Types of Urban Residents}

Other work in the symbolic interactionist tradition seeks to understand the different lifestyles of city residents. 
Sociologist Herbert Gans (1982) authored a classic typology of urban residents based on their differing lifestyles and experiences. Gans identified five types of city residents.

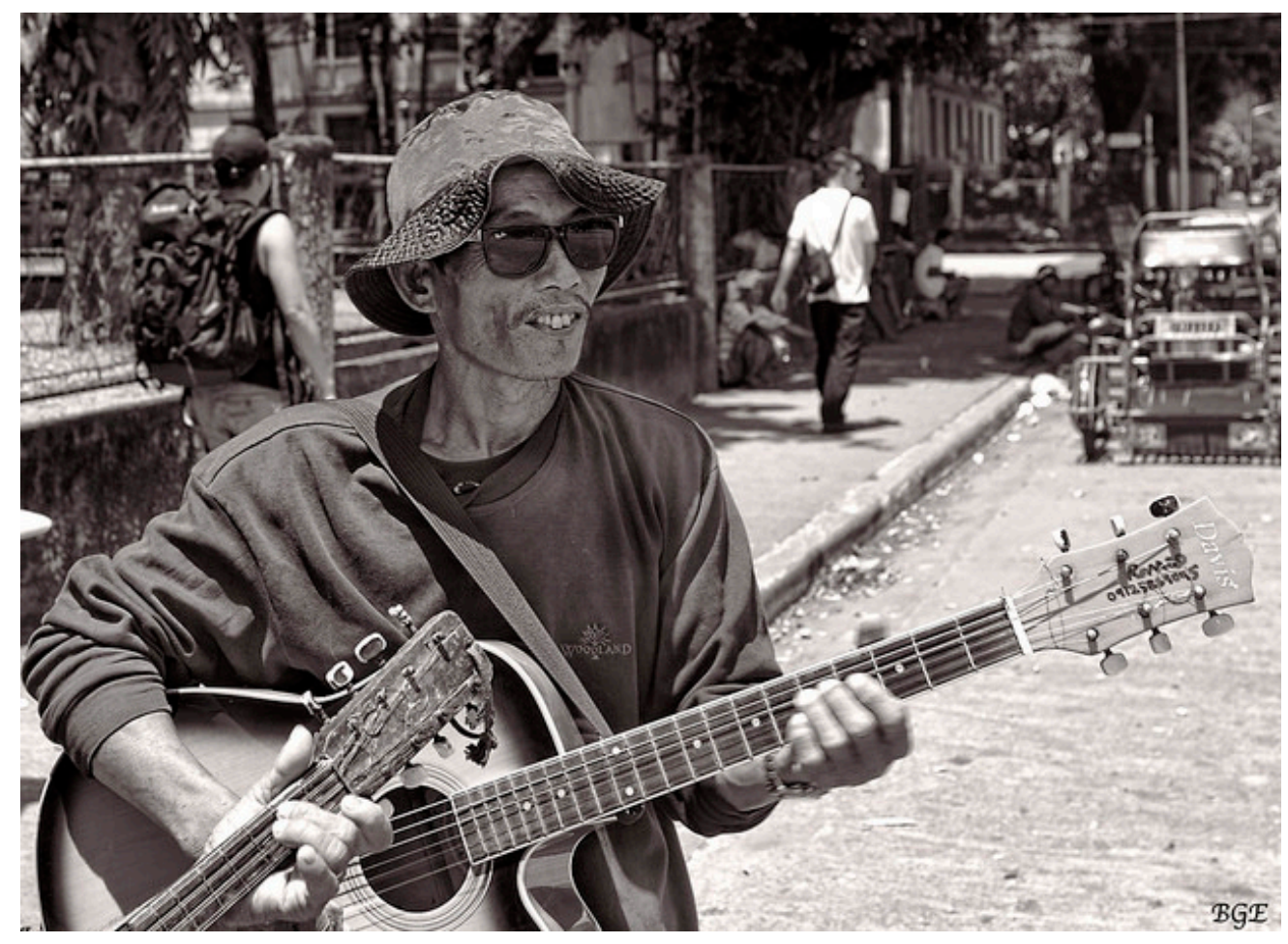

Herbert Gans identified several types of city residents. One of these types is the cosmopolites, who include students, writers, musicians, and intellectuals, all of whom live in a city because of its cultural attractions and other amenities.

Brian Evans - $\underline{\text { Street Musician }}$ - CC BY-ND 2.0.

The first type is cosmopolites. These are people who live in a city because of its cultural attractions, restaurants, and other features of the best that a city has to offer. Cosmopolites include students, writers, musicians, and intellectuals. Unmarried and childless individuals and couples are the second type; they live in a city to be near their jobs and to enjoy the various kinds of entertainment found in most cities. If and when they marry or have children, respectively, many migrate to the suburbs to raise their families. The third type is ethnic villagers, who are recent immigrants and members of various ethnic groups who live among each other in certain neighborhoods. These neighborhoods tend to have strong social bonds and more generally a strong sense of community. Gans wrote that all these three types generally find the city inviting rather than alienating and have positive experiences far more often than negative ones.

In contrast, two final types of residents find the city alienating and experience a low quality of life. The first of these two types, and the fourth overall, is the deprived. These are people with low levels of formal education who live in poverty or near poverty and are unemployed, are underemployed, or work at low wages. They live in neighborhoods filled with trash, broken windows, and other signs of disorder. They commit high rates of crime and also have high rates of victimization by crime. The final type is the trapped. These are residents who, as their name implies, might wish to leave their neighborhoods but are unable to do so for several reasons: they may be alcoholics or drug addicts, they may be elderly and disabled, or they may be jobless and cannot afford to move to a better area. 
In thinking about this typology, it is important to keep in mind that city residents' social backgrounds—-their social class, race/ethnicity, gender, age, and sexual orientation—all influence the kind of lifestyle they tend to adopt and thus the type of resident they are according to the typology. As earlier chapters documented, these dimensions of our social backgrounds often yield many kinds of social inequalities, and the quality of life that city residents enjoy depends heavily on these dimensions. For example, residents who are white and wealthy have the money and access to enjoy the best that cities have to offer, while those who are poor and of color typically experience the worst aspects of city life. Because of fear of rape and sexual assault, women often feel more constrained than men from traveling freely throughout a city and being out late at night; older people also often feel more constrained because of physical limitations and fear of muggings; and gays and lesbians are still subject to physical assaults stemming from homophobia. The type of resident we are, then, in terms of our sociodemographic profile affects what we experience in the city and whether that experience is positive or negative.

\section{Key Takeaways}

- Functionalism offers both a positive and a negative view of urbanization. Functionalist sociologists differ on the degree of social solidarity that exists in cities.

- According to conflict theory, economic and political elites use their resources to develop cities in a way that benefits them. The diverse social backgrounds of urban residents also contribute to certain types of conflict.

- According to symbolic interactionism, social inequality based on social class, race/ethnicity, gender, age, and sexual orientation affects the quality of urban experiences. In addition to differences in their sociodemographic profiles, city residents differ in other ways. Herbert Gans identified several types of urban dwellers: cosmopolites, unmarried and childless, ethnic villagers, deprived, and trapped.

\section{For Your Review}

1. Write an essay that summarizes the assumptions of any two of the major sociological perspectives on urbanization.

2. Which of the three perspectives makes the most sense to you? Why?

\section{References}

Anderson, E. (2000). Code of the street: Decency, violence, and the moral life of the inner city. New York, NY: W. W. Norton.

Anderson, E. (2011). The cosmopolitan canopy: Race and civility in everyday life. New York, NY: W. W. Norton.

Durkheim, É. (1933). The division of labor in society. London, United Kingdom: Free Press. (Original work published 1893). 
Gans, H. J. (1982). The urban villagers: Group and class in the life of Italian-Americans (Updated and expanded ed.). New York, NY: Free Press.

Guest, A. M., Cover, J. K., Matsueda, R. L., \& Kubrin, C. E. (2006). Neighborhood context and neighboring ties. City \& Community, 5(4), 363-385.

Liebow, E. (1993). Tell them who I am: The lives of homeless women. New York, NY: Free Press.

Logan, J. R., \& Molotch, H. L. (2007). Urban fortunes: The political economy of place (2nd ed.). Berkeley, CA: University of California Press.

Moore, L. M., \& Ovadia, S. (2006). Accounting for spatial variation in tolerance: The effects of education and religion. Social Forces, 84(4), 2205-2222.

Sellin, T. (1938). Culture conflict and crime (No. Bulletin 41): New York, NY: Social Science Research Council. Tönnies, F. (1963). Community and society. New York, NY: Harper and Row. (Original work published 1887).

Whyte, W. F. (1943). Street corner society: The social structure of an Italian slum. Chicago, IL: University of Chicago Press.

Wirth, L. (1938). Urbanism as a way of life. American Journal of Sociology, 44, 3-24. 


\subsection{Problems of Urban Life}

\section{Learning Objectives}

1. Discuss any three problems of urban life.

2. Provide an example of a problem that specifically arises from the fact that cities consist, by definition, of large numbers of people living in a relatively small space.

Life in US cities today is certainly complex. On the one hand, many US cities are vibrant places, filled with museums and other cultural attractions, nightclubs, theaters, and restaurants and populated by people from many walks of life and from varied racial and ethnic and national backgrounds. Many college graduates flock to cities, not only for their employment opportunities but also for their many activities and the sheer excitement of living in a metropolis.

On the other hand, many US cities are also filled with abject poverty, filthy and dilapidated housing, high crime rates, traffic gridlock, and dirty air. Many Americans would live nowhere but a city, and many would live anywhere but a city. Cities arouse strong opinions, pro and con, because there are many things both to like and to dislike about cities.

By definition, cities consist of very large numbers of people living in a relatively small amount of space. Some of these people have a good deal of money, but many people, and in some cities most people, have very little money. Cities must provide many kinds of services for all their residents, and certain additional services for their poorer residents. These basic facts of city life make for common sets of problems affecting cities throughout the nation, albeit to varying degrees, with some cities less able than others to address these problems. This section examines several of these problems.

\section{Fiscal Problems}

One evident problem is fiscal: Cities typically have serious difficulties in paying for basic services such as policing, public education, trash removal, street maintenance, and snow removal (at least in cold climates), and in providing certain services for their residents who are poor or disabled or who have other conditions. The fiscal difficulties that cities routinely face became even more serious with the onset of the nation's deep recession in late 2007, as the term fiscal crisis was used again and again to describe the harsh financial realities that cities continued to face even after the recession officially ended in mid-2009 (McNichol, 2009).

In early 2012, almost three years after the United States officially emerged from the recession, this fiscal crisis persisted. The mayor of Syracuse, New York, announced that her city faced a budget deficit of \$16 million and called its fiscal problems "staggering” (Knauss, 2012). Mayors in Rhode Island told their governor that their cities 
need fiscal aid from the state to prevent them from having to declare bankruptcy. One of the mayors said, "We all have the same issues. Something has to be done this year. We cannot have a study commission. We cannot say 'we'll wait until 2013 or 2014.' This is do or die” (Klepper, 2012). Detroit, Michigan, was in danger of running out of money altogether and being taken over by its state government. The member of the US House of Representatives who represents Detroit said he was seeking aid from the federal government: "Bottom line, I'm asking for federal aid to avoid massive layoffs, especially for our public safety workers. That's what we actually need to attract businesses here who create jobs. We need safe streets and we need good schools” (Oosting, 2012).

In response to financial problems in these and other cities across the nation, the US Conference of Mayors urged Congress in early 2012 to provide several kinds of aid to cities, including low-interest loans for local rail and road projects and funding for housing and job training for low-income residents (United States Conference of Mayors, 2012).

\section{Applying Social Research}

\section{Urban Neighborhoods and Poor Health}

Social scientists have long thought that poor urban neighborhoods pose, in and of themselves, significant health risks for their residents. These neighborhoods lack supermarkets with fresh fruits and vegetables, and they lack safe parks and other settings for exercise. They are also neighborhoods with high crime rates and thus much stress. For all these reasons, they should impair the physical health of their residents. Reflecting this argument, the residents of poor urban neighborhoods do, in fact, exhibit significant health problems compared to the residents of wealthier neighborhoods.

Although this argument might sound compelling, the residents of poor and wealthier neighborhoods might differ in other ways that affects their respective health. For example, people living in wealthier neighborhoods are generally more educated and more conscious of taking care of their health. If their health then is better than that of their counterparts in poor neighborhoods, it is difficult to know how much the neighborhood setting itself plays a role in the health of residents.

For this reason, a recent study of a real-life experiment provided compelling evidence of the importance of the quality of a neighborhood for one's health. In the 1990s, the federal government conducted an experiment in which 1,800 poor urban women were randomly selected and, with their permission, assigned to move from their neighborhoods to wealthier neighborhoods. The women were studied a decade after they moved. In particular, they were weighed and had their blood checked for evidence of diabetes. Their results were then compared to women in their original neighborhoods who were not selected to move away. The women who did move away ended up with somewhat lower rates of diabetes and obesity than those who stayed behind.

The experimental design of this study allowed the researchers to conclude that the change in neighborhoods was the reason for their improvement in these two health measures. Reflecting this conclusion, the secretary of the US Department of Housing and Urban Development said, "This study proves that concentrated poverty is not only bad policy, it's bad for your health.” A news report observed that the results of this study "offered some of the strongest support yet for the idea that where you live can significantly affect your overall health, especially if your home is in a low-income area."

The results of this experimental study underscore the need to improve the living conditions of poor urban neighborhoods, as these conditions affect many life outcomes of the adults and children who live in them.

Sources: Ludwig et al., 2011; Stobbe, 2011 


\section{Crowding}

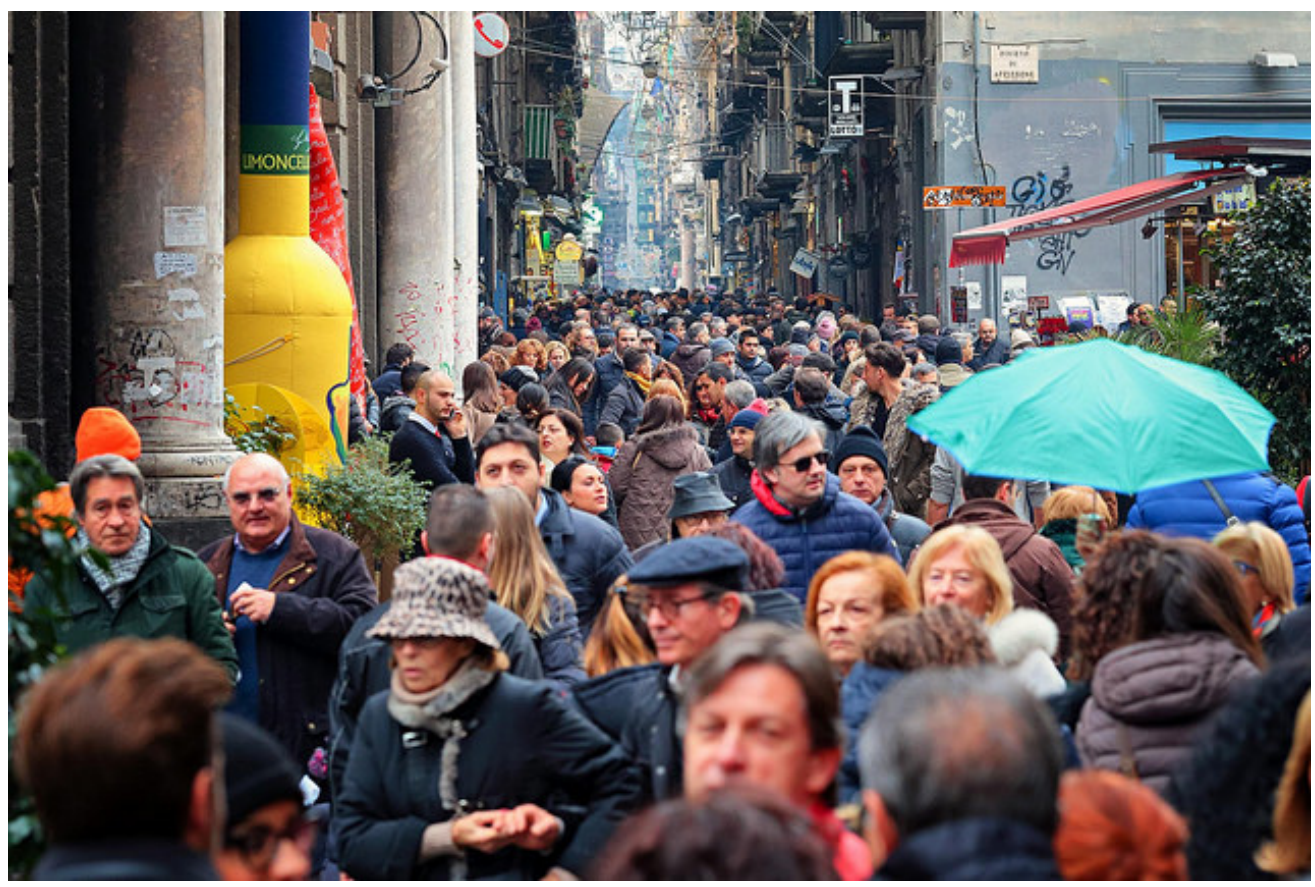

Cities experience many kinds of problems, and crowding is one of them. People who live amid crowding are more likely to experience stress and depression and to engage in aggressive behavior or be victimized by it.

Stròlic Furlàn - Davide Gambino - Lots of people - CC BY-ND 2.0.

Another problem is crowding. Cities are crowded in at least two ways. The first involves residential crowding: large numbers of people living in a small amount of space. City streets are filled with apartment buildings, condominiums, row houses, and other types of housing, and many people live on any one city block. Residential crowding is perhaps the defining feature of any large city. In this regard, let's compare the Manhattan borough of New York City with the state of Idaho. Roughly 1.6 million people live in each location. However, in Manhattan they are packed into only about 24 square miles, while in Idaho they live within 84,000 square miles. Manhattan's population density, the number of people per square mile, is 68,000 people per square mile; Idaho's population density is only about 19 people per square mile. Population density in Manhattan is thus 3,579 times $(68,000 \div$ 19) greater than in Idaho.

New York is incredibly crowded, but other cities are also very crowded. Chicago's population density, for example, exceeds 12,200 persons per square mile, while even a smaller city like Cincinnati (population 331,000) has a population density of 4,700 persons per square mile. Even a much smaller city like Ames, Iowa (population 51,000 ) has a population density of 2,360 persons per square mile. Population density in the small city of Ames is still 124 times greater than in the entire state of Idaho. Residential crowding is thus very high in almost any city in the United States compared to a rural area.

The second type of crowding is household crowding: Dwelling units in cities (apartments and houses) are typically small because of lack of space, and much smaller overall than houses in suburbs or rural areas. This forces many 
people to live in close quarters within a particular dwelling unit, especially if they are low-income individuals or families.

Some research finds that either type of crowding produces higher levels of stress, depression, aggression and crime. Here an interesting gender difference may exist (Regoeczi, 2008): Household crowding may produce depression in women but not men, and aggression in men but not women.

Although crowding of both types is a problem, then, there is little that cities can do to reduce crowding. This fact underscores the need to undertake other efforts that might address the various consequences of residential and household crowding. In this regard, Chapter 8 "Crime and Criminal Justice" outlined several efforts to help reduce crime and delinquency.

\section{Housing}

A third problem involves housing. Here there are several related issues. Much urban housing is substandard, as this chapter's opening news story illustrated, and characterized by such problems as broken windows, malfunctioning heating systems, peeling lead paint, and insect infestation.

At the same time, adequate housing is not affordable for many city residents, as housing prices in cities can be very high, and usually higher than in rural areas, and the residents' incomes are typically very low. Cities thus have a great need for adequate, affordable housing. According to the US Department of Housing and Urban Development (2012), housing is affordable when a household pays no more than 30 percent of its annual income on housing. Low-income households that must spend more than this benchmark may be unable to afford clothing, food, health care, and transportation. Yet 12 million US households pay more than half their annual incomes for housing.

Another housing issue concerns racial segregation. Although federal law prohibits segregated housing, cities across the country are nonetheless highly segregated by race, with many neighborhoods all or mostly African American. In a widely cited book, sociologists Douglas S. Massey and Nancy A. Denton (1993) termed this situation "American apartheid." They said that these segregated neighborhoods result from a combination of several factors, including (a) "white flight” into suburbs, (b) informal—and often illegal—racially discriminatory actions that make it difficult for African Americans to move into white neighborhoods (such as real estate agents falsely telling black couples that no houses are available in a particular neighborhood), and (c) a general lack of income and other resources that makes it very difficult for African Americans to move from segregated neighborhoods.

Massey and Denton argued that residential segregation worsens the general circumstances in which many urban African Americans live. Several reasons account for this effect. As whites flee to the suburbs, the people left behind are much poorer. The tax base of cities suffers accordingly, and along with it the quality of city schools, human services, and other social functions. All these problems help keep the crime rate high and perhaps even raise it further. Because segregated neighborhoods are poor and crime ridden, businesses do not want to invest in them, and employment opportunities are meager. This fact worsens conditions in segregated neighborhoods even further. Consequently, concluded Massey and Denton, racial segregation helps to keep very poor people living in deep poverty and decaying neighborhoods. 
Other research supports this conclusion. As a review of the research evidence summarized this situation, "Whether voluntary or involuntary, living in racially segregated neighborhoods has serious implications for the present and future mobility opportunities of those who are excluded from desirable areas. Where we live affects our proximity to good job opportunities, educational quality, and safety from crime (both as victim and as perpetrator), as well as the quality of our social networks” (Charles, 2003, pp. 167-168).

Against this pessimistic backdrop, it is worth noting that neighborhood segregation in US cities is somewhat less extensive now than four decades ago, thanks in part to fair-housing legislation enacted during the 1960s (Roberts, 2012). Despite this bit of progress, racial discrimination in the housing market continues (see Chapter 3 "Racial and Ethnic Inequality"), and most African Americans still live in neighborhoods that are heavily populated by African Americans and hence racially segregated (Logan \& Stults, 2011). One demographer summarizes this "good news, bad news" situation as follows: “There is now very much more black-white neighborhood integration than 40 years ago. Those of us who worked on segregation in the 1960s never anticipated such declines. Nevertheless, blacks remain considerably more segregated from whites than do Hispanics or Asians” (Roberts, 2012, p. A13).

To improve the socioeconomic status and living circumstances of African Americans, then, it is critical that residential segregation be reduced. Although Latinos live in segregated neighborhoods to a smaller degree, reducing segregation would also help their circumstances.

\section{Children and Our Future}

The Plight of Homeless Children

The faltering economy and wave of home foreclosures of the past few years resulted in what has been called a "national surge" of homeless children. The number of children who are homeless at least part of the year now reaches more than 1.6 million annually, equal to more than 2 percent of all American children. Because of their circumstances, they are at greater risk than their housed peers for hunger, asthma and other chronic health conditions, and stress and emotional problems.

They are at also greater risk for poor school performance. Amid the surge in children's homelessness, the nation's schools marshaled their resources to help their homeless children. An official with a private charity that helps poor families pointed out the obvious problem: "It's hard enough going to school and growing up, but these kids also have to worry where they'll be staying that night and whether they'll eat. We see 8-year-olds telling Mom not to worry, don't cry."

School districts began sending special buses to homeless shelters, motels, and other settings for homeless children and their parents so that the children could continue attending their regular school. They also assigned social workers to help homeless families and other personnel to bring them school supplies, to drive them to look at shelters where they could live, and to perform other tasks. Federal legislation in fact requires schools to take extra measures to help homeless children, but school superintendents say that the federal government has not provided them the necessary funds to carry out the intent of the legislation. This lack of funding adds to their school districts' already dire financial situation.

Charity Crowell, age 9, was just one of the hundreds of thousands of homeless children the schools were trying to help. During the semester her family became homeless, her grades fell to C's from her usual high standard. One reason was that she had trouble staying awake in class. She explained why: "I couldn't go to sleep, I was worried about all the stuff."

Another homeless student, Destiny Corfee, age 11, became homeless after her parents lost both their jobs and then their house and had to move into their van. The family then parked the van at a Wal-Mart so that their children could go into 
the store and clean themselves before they went to school. Recalling life in the van, Destiny said, "I was embarrassed that maybe one of my friends might see me. I don’t want anybody to know that I was actually in there.”

Sources: Bassuk, Murphy, Coupe, Kenney, \& Beach, 2011; Eckholm, 2009; Pelley, 2011

\section{Homelessness}

A related problem to housing is homelessness. In cities throughout the United States, men, women, and children live in the streets, abandoned vehicles or houses, cheap motels, or trailers, or living in someone else's home temporarily. In cities with cold climates, homelessness can be life-threatening during the winter. But regardless of climate, the homeless are in a dire situation. Some research finds that one-third of the homeless are victims of violence or theft during the year; this rate of victimization is four times higher than that in the general population (Wenzel, Leake, \& Gelberg, 2001). Homeless shelters provide some relief against crime, hunger, and the many other problems arising from homelessness, but too few shelters exist to meet the demand, and those that do exist are underfunded.

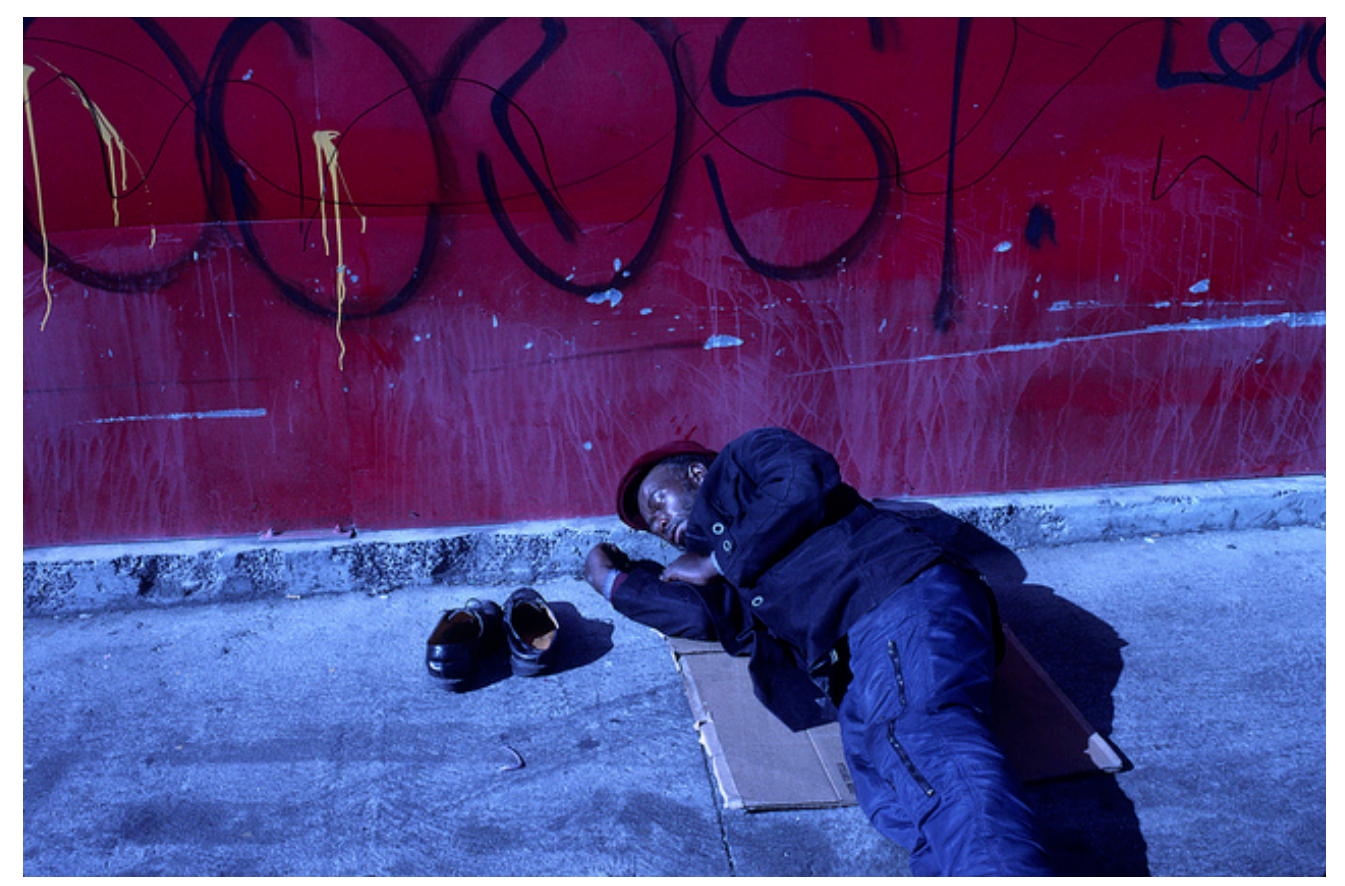

Homelessness is a major problem in many cities. The federal government estimates that 650,000 Americans are homeless on any given night.

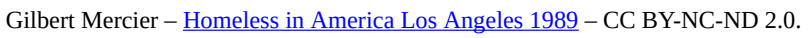

As should be clear, the problem of homelessness cannot be understood from the problem of poverty (see Chapter $\underline{2}$ "Poverty"). Wealthy families that lose their homes, as after a fire, usually can expect to find suitable temporary lodging and have their homeowners' insurance pay for a new home (Lee, Tyler, \& Wright, 2010). Poor families who can no longer pay their rent or mortgage payments face eviction and homelessness from which they find it difficult to recover. 
It is rather difficult to determine the actual number of homeless persons (Lee et al., 2010). For example, if a family is living literally in the streets, we would all agree they are homeless. But if they are living in an abandoned building or in a cheap motel, should they be considered homeless? Even with an adequate definition of homelessness, it is difficult to actually count the number of homeless persons because it is very difficult to find them all. For example, if researchers count all the homeless people who use all the shelters in a city within a given time period, they still fail to count the homeless people who do not come to a shelter.

Keeping these definition and measurement problems in mind, it is nonetheless worth noting that the federal government estimates 650,000 Americans to be homeless on any given night, and 1.6 million to use a shelter or other transitional housing annually (Lee et al., 2010). Because people move in and out of homelessness, the number of people who are homeless at least part of the year is undoubtedly much higher. National survey evidence suggests that 14 percent of Americans have been homeless at least once in their lives, a figure much higher than that in most European nations (Lee et al., 2010).

The US Conference of Mayors (2011) compiled information on homelessness in twenty-nine cities across the country. This large study yielded the following profile of homeless adults:

- $26 \%$ with severe mental illness

- $16 \%$ physically disabled

- $15 \%$ employed

- $13 \%$ victims of domestic violence

- $13 \%$ military veterans

- $4 \%$ HIV positive

As this profile suggests, the homeless population is at much greater risk for a variety of physical and mental health problems and other difficulties (Lee et al., 2010). In particular, they are much more likely than housed Americans to experience hunger and food insecurity, and they are up to twenty times more likely to suffer from chronic illnesses such as hepatitis, high blood pressure, tuberculosis, and vascular disease. On the average, homeless adults die by their midfifties, about twenty years shorter than the average life span of housed adults.

\section{Traffic and Transportation}

A fifth problem of city life is traffic and transportation. For better or worse, a fact of city life that arises from the defining feature of cities - many people living in a relatively small area-is that many people need to travel to get to work or school and to visit stores, museums, and any number of other leisure-time settings. Someone living in a rural area is probably able to drive ten miles to work in no longer than twenty minutes, but someone living in an urban area may easily take an hour or longer to travel the same distance after crawling along in traffic and stopping at light after light, or sitting and crawling along in long miles of traffic on an urban highway. 


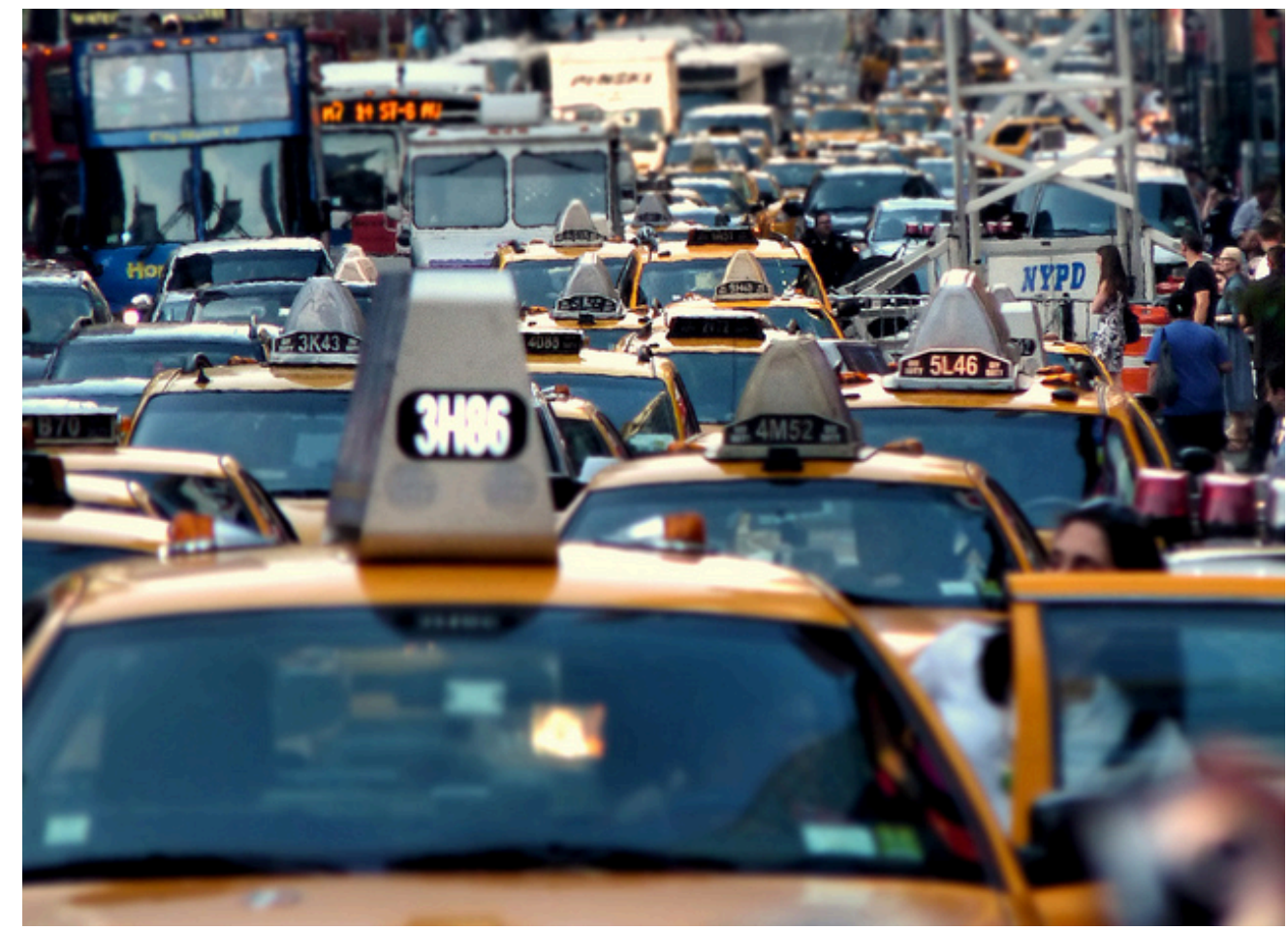

Traffic is a major problem in cities. The great number of motor vehicles in a relatively small space often leads to gridlock and contributes greatly to air pollution.

joiseyshowaa - World Class Traffic Jam 2 - CC BY-SA 2.0.

One manifestation of the traffic problem in cities is traffic gridlock, when traffic in all directions is barely moving or not moving at all. Gridlock occurs in urban areas, not rural ones, because of the sheer volume of traffic and the sheer number of intersections controlled by traffic lights or stop signs. Some cities have better public transportation than others, but congested traffic and time-consuming commuting are problems that urban residents experience every day (see Note 14.19 “Lessons from Other Societies”).

\section{Lessons from Other Societies}

Making Drivers Miserable to Reduce Traffic Congestion

One of the costs of urbanization and modern life is traffic. Urban streets and highways are clogged with motor vehicles, and two major consequences of so much traffic are air pollution and tens of thousands of deaths and injuries from vehicular accidents. To reduce city traffic, many European cities are trying to make driving so burdensome that commuters and other drivers will seek other forms of transportation. As a recent news story summarized this trend, these cities are "creating environments openly hostile to cars. The methods vary, but the mission is clear: to make car use expensive and just plain miserable enough to tilt drivers toward more environmentally friendly modes of transportation."

For example, Copenhagen, Munich, and Vienna have banned cars on many streets. Barcelona and Paris have replaced car lanes with bicycle lanes. London and Stockholm now require drivers entering their downtowns to pay a heavy toll charge. Many German cities restrict parts of their downtowns to cars that meet certain limits on carbon dioxide emission. Other European cities have sharply limited the number of parking spaces at shopping malls and other areas, and they have also eliminated on-street parking. 
This European strategy to relieve traffic congestion differs greatly from the strategy the United States uses. As a European environmental official explained this difference, "In the United States, there has been much more of a tendency to adapt cities to accommodate driving. Here there has been more movement to make cities more livable for people, to get cities relatively free of cars.”

Zurich, the largest city in Switzerland, has made special efforts to "torment drivers," said the news story, in the hope that drivers will seek other modes of transportation. For example, it added more traffic lights to cause more traffic delays, and it shortened the length of green lights and lengthened red lights. It also banned cars in one of its busiest downtown areas and elsewhere imposed speed limits of just a few miles an hour so that pedestrians are free to cross the street whenever they want. Although store owners in Zurich worried that they would lose business after their streets were closed to traffic, that effect has not happened because pedestrian traffic increased.

Observing traffic inching through hundreds of pedestrians and bicyclists, a Zurich traffic official was happy. "Driving is a stop-and-go experience," he said. "That's what we like! Our goal is to reconquer public space for pedestrians, not to make it easy for drivers."

In contrast, most American cities have tried to make it easier for drivers through such measures as synchronizing green lights and developing apps to help drivers find parking. However, these measures do not reduce the number of cars and do little to relieve traffic congestion. Instead, they tend to make it more likely that people will want to drive in the downtown areas. In contrast, Europe has tried to relieve traffic congestion by reducing the number of cars. Its model offers more potential for reducing the pollution and other problems caused by traffic, and it is one that the United States should adopt.

Source: Rosenthal, 2011

To help reduce traffic congestion, cities long ago developed various means of public transportation: buses, subways, and light rail. Some cities have better public transportation than other cities; Los Angeles has a notoriously bad reputation for the quality of its public transportation. Yet residents of cities with relatively good public transportation still experience severe traffic congestion, long commutes, and related problems: It is estimated that the average Chicago commuter spends seventy hours per year just sitting in traffic jams (Greenfield, 2011). Public transportation is sometimes faster than commuting by car or SUV but can still be very time consuming. People who take a bus or other public transportation can easily spend an hour or more, depending on how far they have to travel and the quality of their city's transportation system, traveling to a bus or train station, waiting for their transportation, making any necessary connections, and then traveling to their workplace.

One consequence of traffic congestion is stress. As one mental health expert observed, "Commuters can experience greater stress than fighter pilots in battle” (Greenfield, 2011). Another consequence is huge financial costs. Sitting in traffic wastes both time and fuel. The Texas Transportation Institute (TTI), perhaps the leading scholarly unit for the study of traffic problems, estimates that traffic congestion costs the nation \$115 billion annually in wasted time and fuel, or $\$ 713$ for every auto commuter. Traffic congestion wastes 4.8 billion hours and 1.9 billion gallons of gasoline annually, an amount that would fill more than 200,000 gasoline tank trucks (Schrank, Lomax, \& Eisele, 2011). To relieve traffic congestion, TTI recommends significant investments of public funds in public transportation and more efficient designs in private and public transportation systems such as the greater use of electronic toll taking and better timing of traffic lights to increase traffic flow.

\section{Air Pollution}

Traffic congestion and the sheer amount of traffic in cities also contribute mightily to air pollution, which we 
consider here as a separate urban problem. Traffic creates pollution from motor vehicles' exhaust systems, and some cities have factories and other enterprises that also pollute. As a result, air quality in cities is substandard.

This poor air quality has significant health consequences, as it produces higher rates of respiratory and heart disease and higher mortality rates in cities (Stylianou \& Nicolich, 2009). Because even fairly low levels of air pollution can have these health effects (Brunekreef, 2011), cities are unhealthy places and even deadly places for many people.

Both to increase their "carbon footprint" and to get some exercise, many urban residents bicycle in traffic to and from work or bicycle during their leisure time. Ironically, doing so subjects them to air pollution from the traffic surrounding them. This pollution has been shown to impair their cardiovascular and respiratory functioning (Weichenthal et al., 2011).

Because people of color disproportionately live in cities, urban air pollution affects them more than it affects white people. As Chapter 13 "Health and Health Care" noted, this disparity is part of the larger problem of environmental racism. Cities are bad in many ways for their residents, and the air pollution of cities is bad for the health of their residents, who are overwhelmingly people of color in many cities.

If urban residents in general suffer health consequences from air pollution, these consequences are particularly serious and more common among children. Air pollution increases their rates of asthma and other respiratory diseases (Patel et al., 2011). These health problems in turn affect their school performance and can have other lifelong consequences.

\section{Mental Health Problems}

Our earlier discussions of crowding and of traffic congestion indicated that stress is one of the most important consequences of these two urban problems. Stress in turn impairs the mental health of urban residents. Much research finds that urban residents have worse mental health than rural residents. In particular, they have much higher levels of mood and anxiety disorders and of schizophrenia (Lederbogen et al., 2011).

\section{Public Education}

Yet another issue for cities is the state of their public education. As Chapter 11 "Schools and Education" emphasized, many city schools are housed in old buildings that, like much city housing, are falling apart. City schools are notoriously underfunded and lack current textbooks, adequate science equipment, and other instructional materials.

\section{People Making a Difference}

Working to Achieve Social Justice 
Nancy Radner has been a tireless advocate for the homeless and for social justice more generally. From 2006 to 2012 , she served as the head of the Chicago Alliance to End Homelessness, which works with eighty-four homeless service agencies and manages more than \$50 million in state and federal funding for homeless services. The Alliance also gathers and distributes various kinds of information on homelessness and coordinates political, educational, and public relations events to increase understanding of homelessness.

Before joining the Chicago Alliance, Radner was a program officer at the Corporation for Supportive Housing, a national organization that engages in many kinds of efforts aimed at helping the homeless and other low-income individuals find affordable housing. She also served as a staff attorney at the Legal Assistance Foundation of Chicago, where she specialized in housing law.

In 2012, Radner left the Chicago Alliance for another social justice position when she joined the Ounce of Prevention Fund as director of Illinois policy. The Ounce, as this Illinois organization calls itself, advocates for early childhood education and other programs and policies aimed at helping low-income children.

Many people who receive a law degree from a top law school, as Radner did, take a job in a large law firm or with a large corporation and spend their careers helping the wealthy. Instead, Radner chose to use her legal knowledge to help achieve social justice for the poor. She once said of her efforts to end homelessness, "People call us starry-eyed dreamers. But I actually say we're steely-eyed realists because ending homelessness is not hard. We know exactly how to do it. And what we're trying to do is create the political will to get it fully done. We can't prevent people from losing their housing. But what we can do is ensure that if that happens that there's a system in place to get them out of homelessness really quickly.”

In working her entire career to help the poor and homeless, Nancy Radner has helped make a difference.

Sources: Kapos, 2012; Schorsch, 2010

\section{Crime}

When many people think about the disadvantages of city life, they probably think about crime, a problem mentioned several times already in this chapter. Their fears are well grounded. Simply put, cities have much higher rates of violent and property crime than do small towns or rural areas (see Figure 14.6 “Crime Rates in Large Cities and Rural Counties, 2010 (Number of Crimes per 100,000 Residents)”). For example, the violent crime rate (number of crimes per 100,000 residents) in 2010 was almost four times higher in the nation's largest cities than in its rural counties, while the property crime rate was more than twice as high.

Figure 14.6 Crime Rates in Large Cities and Rural Counties, 2010 (Number of Crimes per 100,000 Residents)

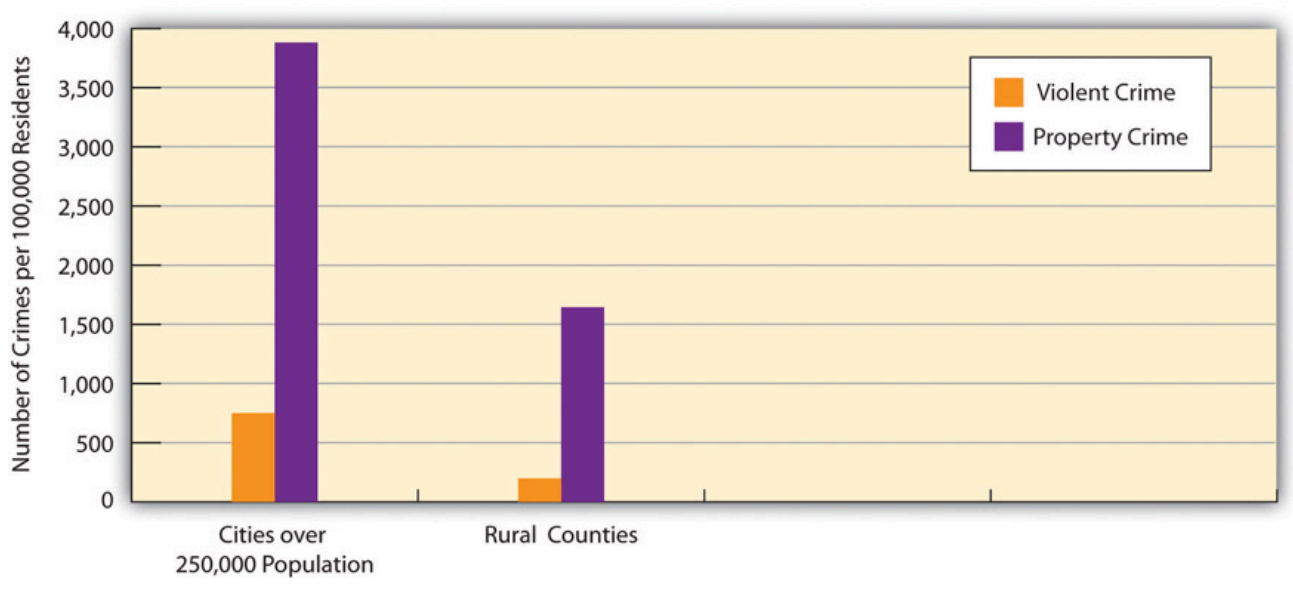


Why are city crime rates much higher? Because crime rates take the number of people into account, the answer is not simply that cities have more people than rural areas. Nor is the answer simply that cities have higher poverty than rural areas, because rural areas in fact have higher poverty overall, as we discuss later in this chapter. Rather, an important answer is that cities have higher residential crowding (or higher population density) and also more household crowding, as we saw earlier.

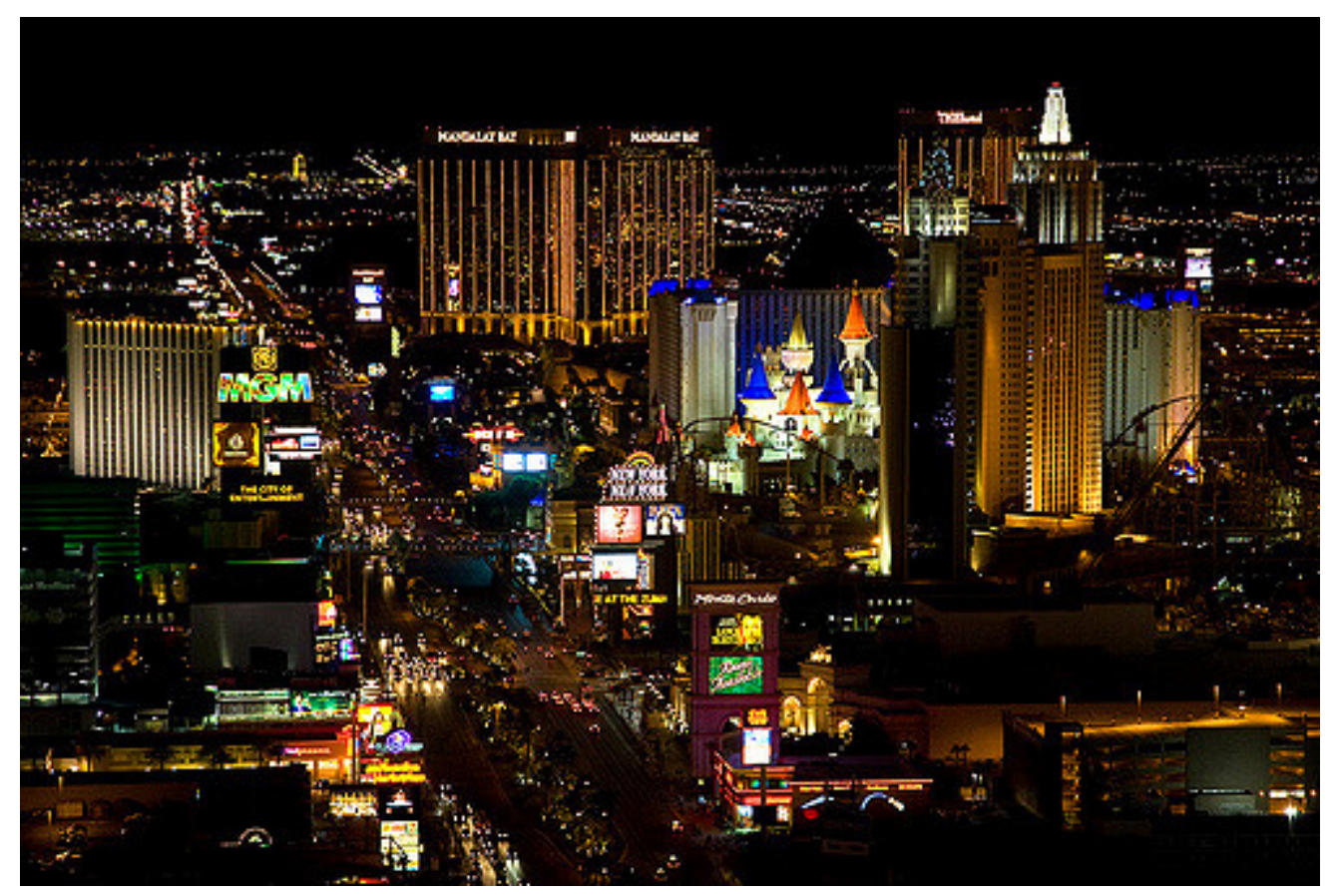

Crime rates are higher in cities in part because the great numbers of urban residents provide many potential targets for criminals.

James Marvin Phelps - Las Vegas Boulevard - CC BY-NC 2.0.

Several reasons explain why higher residential crowding produces higher crime rates. Consider violent crime. For a violent crime to occur, it takes two people to tangle, so to speak. Criminals cannot kill, rob, or assault someone unless there is a "someone" to assault. In a city, there are many potential targets of violence all crowded together into a relatively small space, and thus many potential targets for criminals. In a rural area, potential targets are spread across miles, and a robber can go a long time without ever seeing a potential victim. Many assaults are also committed not by hardened criminals but by people (usually men) who get angry because of some perceived insult. In a city, there is a much greater chance for interaction to occur where someone might feel insulted, simply because there are so many people living within a small space and bars and other venues for them to congregate. A thousand people living on one city block are more likely to encounter each other than a thousand people living across thirty square miles in a rural area. Because there is more opportunity in a city for insults and other problems to occur that lead to violence, more violence occurs.

Cities also have more crowded households than rural areas, as we saw earlier, and these also make a difference for at least two reasons (Stark, 1987). Crowded households are more stressful, and people who experience stress are more likely to be aggressive. Further, people (and perhaps especially young people) who live in crowded households often find they need to "get outside” to be away from the stress of the household and to 
have some "elbow room" and privacy. But once outside, they are that much more likely to interact with other people. Because, as we just noted, social interaction is a prerequisite for violence, household crowding indirectly contributes to violence for this reason.

Residential crowding and household crowding thus combine to produce higher crime rates in cities than in urban areas. City neighborhoods differ in their degree of both types of crowding, and those that have higher crowding rates should have higher crime rates, all else equal. In sociologist Rodney Stark's (1987) term, these neighborhoods are deviant places because their structural features, such as crowding, almost automatically contribute to higher crime rates regardless of who is living in these neighborhoods.

Another structural feature of cities helps to explain why they have a higher property crime rate than rural areas. Burglars obviously cannot burglarize a home unless there is a nearby home to burglarize. In cities, there are many homes to serve as potential targets for burglars; in rural areas, these homes are far and few between. Similarly, if someone wants to shoplift in a store or break into a store overnight, they can more easily do so in an urban area, where there are many stores, than in a rural area, where the landscape is filled with trees or fields rather than Walmarts or Best Buys.

Although Stark (1987) coined the term deviant places to refer to urban neighborhoods that had certain features that contribute to high crime rates, his term can also refer to cities themselves. For the reasons just discussed, cities are inevitably much more likely than rural areas to be deviant places. The defining feature of a city-large numbers of people living in a small area-guarantees that cities will have higher crime rates than rural areas. Cities are deviant places precisely because they are cities.

\section{Key Takeaways}

- Major issues and problems confronting US cities today include those involving fiscal difficulties, crowding, housing, traffic, pollution, public education, and crime.

- Several of these problems stem directly from the fact that cities involve large numbers of people living in a relatively small amount of space.

\section{For Your Review}

1. If you were to work for a mayor of a large city to help address one specific problem in that city, which problem would you prefer to work on? Why?

2. Americans often seem to blame city residents for many of the problems affecting US cities today, including low academic achievement and rundown conditions in city schools and crime in the streets. Do you think it is fair to blame city residents for these problems, or are there other reasons for them? Explain your answer. 


\section{References}

Bassuk, E., Murphy, C., Coupe, N. T., Kenney, R. R., \& Beach, C. A. (2011, September 6). America's youngest outcasts 2010. Needham, MA: National Center on Family Homelessness.

Brunekreef, B. (2011). Air pollution and health: Evidence, thresholds, standards. Air Quality \& Climate Change, 45(3), 35-37.

Charles, C. Z. (2003). The dynamics of racial residential segregation. Annual Review of Sociology, 29, 167-207.

Eckholm, E. (2009). Surge in homeless pupils strains schools. New York Times, p. A1.

Greenfield, B. (2011, September 23). America's most stressful cities. Forbes. Retrieved from http://www.forbes.com/sites/bethgreenfield/2011/09/23/americas-most-stressful-cities.

Kapos, S. (2012, January 31). Nancy Radner leaves poverty group's top job to direct policy at Ounce of Prevention. Chicago Business. Retrieved from http://www.chicagobusiness.com/article/20120131/BLOGS03/ $\underline{120139929 / n a n c y-r a d n e r-l e a v e s-p o v e r t y-g r o u p s-t o p-j o b-t o-d i r e c t-p o l i c y-a t-o u n c e-o f-p r e v e n t i o n . ~}$

Klepper, D. (2012, January 5). RI Gov., mayors say state must help cities now. The Boston Globe. Retrieved from $\quad$ http://www.boston.com/news/local/rhode island/articles/2012/01/05/ ri gov mayors say state must help cities now.

Knauss, T. (2012, January 26). Former Lt. Gov. Richard Ravitch to advise Syracuse on finances, Mayor Stephanie Miner says. The Post-Standard. Retrieved from http://www.syracuse.com/news/index.ssf/2012/01/ former lt gov richard ravitch.html.

Lederbogen, F., Kirsch, P., Haddad, L., Streit, F., Tost, H., Schuch, P., et al. (2011). City living and urban upbringing affect neural social stress processing in humans. Nature, 474(7352), 498-501.

Lee, B. A., Tyler, K. A., \& Wright, J. D. (2010). The new homelessness revisited. Annual Review of Sociology, 36, 501-521.

Logan, J. R., \& Stults, B. J. (2011). The persistence of segregation in the metropolis: New findings from the 2010 census. Retrieved from http://www.s4.brown.edu/us2010/Data/Report/report2.pdf.

Ludwig, J., Sanbonmatsu, L., Gennetian, L., Adam, E., Duncan, G. J., Katz, L. F., et al. (2011). Neighborhoods, obesity, and diabetes - a randomized social experiment. New England Journal of Medicine, 365(16), 1509-1519.

Massey, D. S., \& Denton, N. A. (1993). American apartheid: Segregation and the making of the underclass. Cambridge, MA: Harvard University Press.

McNichol, D. A. (2009, May 1). Revenue loss putting cities in fiscal vise. New York Times, p. NJ1.

Oosting, J. (2012, January 30). Rep. Hansen Clarke talks with president on Air Force One, seeks emergency aid for Detroit. Mlive.com. Retrieved from http://www.mlive.com/news/detroit/index.ssf/2012/01/ rep hansen clarke talks with p.html. 
Patel, M. M., Quinn, J. W., Jung, K. H., Hoepner, L., Diaz, D., Perzanowski, M., et al. (2011). Traffic density and stationary sources of air pollution associated with wheeze, asthma, and immunoglobulin E from birth to age 5 years among New York City children. Environmental Research, 111(8), 1222-1229.

Regoeczi, W. C. (2008). Crowding in context: An examination of the differential responses of men and women to high-density living environments. Journal of Health and Social Behavior, 49, 254-268.

Roberts, S. (2012, January 31). Study of census results finds that residential segregation is down sharply. New York Times, p. A13.

Rosenthal, E. (2011, June 27). Across Europe, irking drivers is urban policy. New York Times, A1.

Schorsch, K. (2010, October 17). Alliance sees a path to ending homelessness. Chicago Tribune. Retrieved from http://articles.chicagotribune.com/2010-10-17/news/ct-met-holiday-giving-chicago-allianc20101017 1 endhomelessness-nancy-radner- homeless-system.

Schrank, D., Lomax, T., \& Eisele, B. (2011). 2011 urban mobility report. College Station, TX: Texas Transportation Institute.

Stark, R. (1987). Deviant places: A theory of the ecology of crime. Criminology, 25, 893-911.

Stobbe, M. (2011, October 20). Decade-long study links living in low-income neighborhoods to poor health. The Boston Globe, p. A15.

Stylianou, M., \& Nicolich, M. J. (2009). Cumulative effects and threshold levels in air pollution mortality: Data analysis of nine large US cities using the NMMAPS dataset. Environmental Pollution, 157, 2216-2213.

US Conference of Mayors. (2011). Hunger and homelessness survey: A status report on hunger and homelessness in America's cities. Washington, DC: Author.

US Conference of Mayors. (2012, January 24). Statement by US Conference of Mayors president Los Angeles Mayor Antonio Villaraigosa in reaction to President Obama's State of the Union address. Retrived from http://www.usmayors.org/pressreleases/uploads/2012/0124-statement-sotu.pdf.

US Department of Housing and Urban Development. (2012). Affordable housing. Retrieved Janaury 31, 2012, from http://www.hud.gov/offices/cpd/affordablehousing.

Weichenthal, S., Kulka, R., Dubeau, A., Martin, C., Wang, D., \& Dales, R. (2011). Traffic-related air pollution and acute changes in heart rate variability and respiratory function in urban cyclists. Environmental Health Perspectives, 119(10), 1373-1378.

Wenzel, S. L., Leake, B. D., \& Gelberg, L. (2001). Risk factors for major violence among homeless women. Journal of Interpersonal Violence, 16, 739-752. 


\subsection{Problems of Rural Life}

\section{Learning Objectives}

1. List three positive aspects of rural life in the United States.

2. Describe two problems of rural life in the United States.

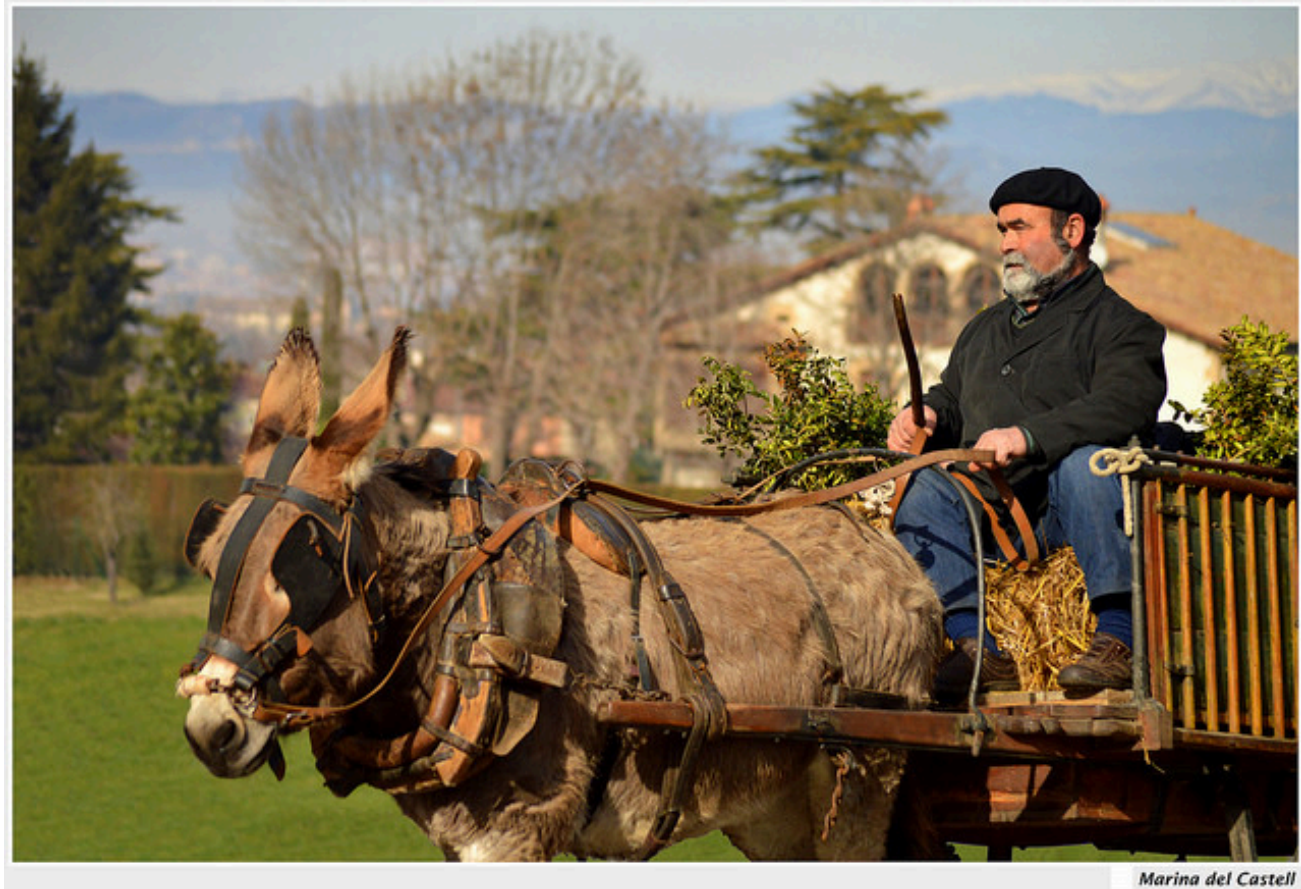

Rural areas can be beautiful and relaxing, but they also must confront important challenges. These problems include a lack of public transportation, human services, and medical professionals and facilities.

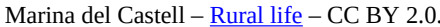

About one-fourth of the US population and more than 40 percent of the world population live in rural areas. As the previous section demonstrated, a dual view of cities exists: they have many advantages, but they also have many disadvantages. This dual view also applies to rural areas, but it does so in a sort of mirror image: The advantages of cities are often disadvantages for rural areas, and the disadvantages of cities are often advantages for rural areas.

On the positive side, and focusing on the United States, rural areas feature much more open space and less crowding. Their violent and property crime rates are much lower than those in large cities, as we have seen. The air is cleaner because there is less traffic and fewer factories and other facilities that emit pollution. Life in rural areas is thought to be slower paced, resulting in lower levels of anxiety and a greater sense of relaxation. For these and other reasons, rural residents exhibit better mental health on the average than do urban residents. 
On the negative side, rural areas are often poor and lack the services, employment opportunities, and leisure activities that cities have. Teens often complain of boredom, and drug and alcohol use can be high (Johnson et al., 2008). Public transportation is often lacking, making it difficult for people without motor vehicles, who tend to have low incomes, to get to workplaces, stores, and other venues (Brown, 2008). Rural residents with motor vehicles often must still travel long distances to shop, to visit a doctor, to go to work, and to do any number of other activities. Many rural areas in the United States lack high-speed broadband, a necessity in today's economy. As a result, their economic development is impaired (Whitacre, 2010). All these challenges contribute to special problems in rural areas. We now examine some of these problems.

\section{Rural Health}

As Chapter 13 "Health and Health Care" noted, rural areas often lack sufficient numbers of health care professionals, hospitals, and medical clinics. The National Rural Health Association (2012) points out that although one-fourth of the US population is rural, only one-tenth of physicians practice in rural areas. Urban areas have 134 physician specialists for every 100,000 residents, but rural areas have less than one-third this number.

Compounding these shortages are other problems. The first is that the small hospitals typical of rural areas generally lack high-quality care and equipment. A patient who needs heart bypass surgery, brain surgery, or other types of complex medical care is likely to have travel to an urban hospital far away.

The second problem is the long distances that ambulances and patients must travel. Because ambulances and other emergency vehicles must travel so far, rural residents with emergencies receive medical attention more slowly than their urban counterparts. The long distances that people must travel make it more difficult for patients with health problems to receive medical care. For example, a rural cancer patient who needs chemotherapy or radiation might have to travel two to three hours in each direction to receive treatment. Travel distances in rural areas also mean that rural residents are less likely than urban residents to receive preventive services such as physical examinations; screenings for breast cancer, cervical cancer, and colorectal cancer; and vaccinations for various illnesses and diseases.

In yet another problem, rural areas are also much more likely than urban areas to lack mental health care, drug abuse counseling and programs, and other services related to physical and mental health.

For all these reasons, rural residents are more at risk than urban residents for certain health problems, including mortality. For example, only one-third of all motor vehicle accidents happen in rural areas, but two-thirds of all deaths from such accidents occur in rural areas. These problems help explain why rural residents are more likely than urban residents to report being in only fair or poor health in government surveys (Bennett, Olatosi, \& Probst, 2009).

An additional health problem in rural areas arises from the age profile of their populations. Compared to urban areas, rural areas have an "aging population,” or a greater percentage of adults aged 65 and older. This fact adds to the health-care problems that rural areas must address. 


\section{Rural Schools and Education}

The discussion of education in Chapter 11 "Schools and Education" focused mostly on urban schools. Many of the problems discussed there also apply to rural schools. However, rural schools often face hurdles that urban and suburban schools are much less likely to encounter (Center for Rural Policy and Development, 2009).

First, because rural areas have been losing population, they have been experiencing declining school enrollment and school closings. When a school does close, teachers and other school employees have lost their jobs, and students have to rather suddenly attend a new school that is usually farther from their home than their former school.

Second, rural populations are generally older than urban populations, as mentioned earlier, and have a greater percentage of retired adults. Therefore, rural areas' per-capita income and sales tax revenue are lower than that for urban and suburban areas, and this lower revenue makes the funding of public schools more challenging.

Third, rural families live relatively far from the public schools, and the schools are relatively far from each other. As a result, rural school districts have considerable expenses for transporting children to and from school, afterschool athletic events, and other activities.

Finally, it is often difficult to recruit and retain quality teachers in rural areas. This problem has forced some rural school districts to offer hiring bonuses or housing assistance to staff their schools.

\section{Rural Poverty}

Although many US cities have high poverty rates, the poverty rate is actually somewhat higher overall in rural areas than in urban areas. In 2010, 16.5 percent of rural residents were classified as officially poor, compared to 14.9 percent of urban residents. However, the poverty rate in the nation's largest cities was higher yet at 19.7 percent. The number of poor rural residents was almost 8 million, while the number of poor urban residents (reflecting the fact that most Americans live in urban areas) was almost 36 million (DeNavas-Walt, Proctor, \& Smith, 2011).

Rural poverty is thought to be more persistent than urban poverty because of the factors that contribute to its high rate. These factors include the out-migration of young, highly skilled workers; the lack of industrial jobs that typically have been higher paying than agricultural jobs; and limited opportunities for the high-paying jobs of the information age. Biotech companies, electronics companies, and other symbols of the information age are hardly ever found in the nation's rural areas. Instead, they locate themselves in or near urban areas, in which are found the universities, masses of people, and other necessary aspects these companies need to succeed.

Compounding the general problem of poverty, rural areas are also more likely than nonrural areas to lack human services programs to help the poor, disabled, elderly, and other people in need of aid (National Advisory Committee on Rural Health and Human Services, 2011). Because rural towns are so small, they often cannot afford services such as soup kitchens, homeless shelters, and Meals on Wheels, and thus must rely on services located in other towns. Yet rural towns are often far from each other, making it difficult and expensive for rural 
residents to obtain the services they need. For example, a Meals on Wheels program in an urban area may travel just a few miles and serve dozens of people, while it may have to travel more than one hundred miles in a rural area and serve only a few people. Adding to this problem is the strong sense in many rural areas that individuals should be strong enough to fend for themselves and not accept government help. Even when services are available, some people who need them decline to take advantage of them because of pride and shame.

\section{Domestic Violence}

One of the sad facts of rural life is domestic violence. This form of violence is certainly common in urban areas, but the defining feature of rural areas — a relatively low number of people living in a relatively broad area—creates several problems for victims of domestic violence, most of them women (DeKeseredy \& Schwartz, 2009).

For example, these women often find it difficult to get help and/or to leave their abusers wherever they live. However, it is often even more difficult for rural women to do so. Rural police may be unenlightened about domestic violence and may even know the abuser; for either reason, they may not consider his violence a crime, and abused women may be that much more reluctant to tell the police about their abuse.

Another problem concerns the availability of battered women's shelters, which provide invaluable services for abused women and any children they might have. These shelters tend to be found in cities, which still do not have nearly enough shelters. Rural areas generally lack shelters, and any shelters that exist are often long distances from the homes of abused women. In rural areas, abused women are also more likely than their urban counterparts to lack neighbors and friends to whom they can turn for support, or at least to live farther from these individuals. For all these reasons, rural women who experience domestic violence face a problem that has been called "dangerous exits” (DeKeseredy \& Schwartz, 2009).

\section{Key Takeaways}

- Like cities, rural areas also have their advantages and disadvantages. They can be beautiful, relaxing places in which to live, but they also lack many of the cultural advantages and other amenities that cities feature.

- Rural areas are characterized by sparse populations and long distances that people must travel. These conditions make it difficult to provide adequate public transportation and various kinds of human services. The poverty of many rural areas aggravates these problems.

\section{For Your Review}

1. If you had your choice, would you want to live in a large city, medium-sized city, small town, or rural area? Explain your answer.

2. Americans often seem to blame city residents for many of the problems affecting US cities today, including low academic achievement, rundown conditions in city schools, and crime in the streets. Do you think it is fair to blame city residents for these problems, or are there other reasons for them? Explain your answer. 


\section{References}

Bennett, K. J., Olatosi, B., \& Probst, J. C. (2009). Health disparities: A rural-urban chartbook. Columbia, SC: South Carolina Rural Health Research Center.

Brown, D. M. (2008). Public transportation on the move in rural America. Washington, DC: Economic Research Service.

Center for Rural Policy and Development. (2009). A region apart: A look at challenges and strategies for rural K-12 schools. Saint Peter, MN: Center for Rural Policy and Development.

DeKeseredy, W. S., \& Schwartz, M. D. (2009). Dangerous exits: Escaping abusive relationships in rural America. New Brunswick, NJ: Rutgers University Press.

DeNavas-Walt, C., Proctor, B. D., \& Smith, J. C. (2011). Income, poverty, and health insurance coverage in the United States: 2010 (Current Population Reports, P60-239). Washington, DC: US Census Bureau.

Johnson, A. O., Mink, M. D., Harun, N., Moore, C. G., Martin, A. B., \& Bennett, K. J. (2008). Violence and drug use in rural teens: National prevalence estimates from the 2003 youth risk behavior survey. Journal of School Health, 78(10), 554-561.

National Advisory Committee on Rural Health and Human Services. (2011). The 2011 report to the secretary: Rural health and human services issues. Washington, DC: US Department of Health and Human Services.

National Rural Health Association. (2012). What's different about rural health care? Retrieved from http://www.ruralhealthweb.org/go/left/about-rural-health.

Whitacre, B. E. (2010). The diffusion of Internet technologies to rural communities: A portrait of broadband supply and demand. American Behavioral Scientist, 53, 1283-1303. 


\subsection{Improving Urban and Rural Life}

\section{Learning Objective}

1. Explain the value of a sociological perspective for addressing urban housing and crowding problems.

Many urban problems are not, strictly speaking, sociological or other social science problems. For example, traffic congestion is arguably more of an engineering issue than a sociological issue, even if traffic congestion has many social consequences. Other urban problems are problems discussed in previous chapters that disproportionately affect urban areas. For example, crime is more common in urban areas than elsewhere, and racial and ethnic inequality is much more of an issue in urban areas than rural areas because of the concentration of people of color in our cities. Previous chapters have discussed such problems in some detail, and the strategies suggested in those chapters need not be discussed again here.

Still other urban issues exist that this chapter was the first to present. Two of these involve crowding and housing. Cities are certainly crowded, and some parts of cities are especially crowded. Housing is expensive, and many urban residents live in dilapidated, substandard housing. Here again a sociological perspective offers some insight, as it reminds us that these problems are intimately related to inequalities of social class, race and ethnicity, and gender. Although it is critical to provide adequate, affordable housing to city residents, it is also important to remember that these various social inequalities affect who is in most need of such housing. Ultimately, strategies aimed at providing affordable housing will not succeed unless they recognize the importance of these social inequalities and unless other efforts reduce or eliminate these inequalities. Racial residential segregation also remains a serious problem in our nation's urban centers, and sociologists have repeatedly shown that residential segregation contributes to many of the problems that urban African Americans experience. Reducing such segregation must be a fundamental goal of any strategy to help American cities.

Although traffic congestion is largely an engineering issue, engineers do not operate in a social vacuum. People will be more likely to drive in a city when it is easier for them to drive, and less likely to drive when it is more difficult for them to drive. As the Note 14.19 "Lessons from Other Societies" box illustrated, European cities have done much more than US cities to reduce traffic congestion and thus improve air quality in their cities. Americans may resist the measures the European nations have taken, but the success of these measures suggests that the United States should also use them to deal with the many problems associated with traffic congestion.

Certain problems discussed in previous chapters are also more urgent in rural areas. In particular, the isolation and long distances of rural areas poses special challenges for the provision of adequate health care and for addressing the needs of victims of domestic violence. Ironically, some of the very features that make rural areas so attractive to many people also make them difficult settings for other people. In view of this context, it is essential that public transportation in rural areas be expanded, and that the many types of medical care and social and legal services commonly found in urban areas also be expanded. Although rural residents undoubtedly do not expect to find 
the range of care and services available to their urban counterparts, they should not have to suffer from a lack of adequate care and services.

\section{Key Takeaways}

- Many of the problems of urban and rural life were addressed in earlier chapters. The strategies discussed in these chapters to address these problems thus also apply to the problems examined in this chapter.

- Many urban problems are associated with poverty and racial discrimination. Reducing these problems should help relieve urban problems.

- The characteristics of rural areas that often make them so appealing also lead to certain problems that are especially urgent in rural areas.

\section{For Your Review}

1. How do you think American cities should try, if at all, to reduce traffic congestion?

2. Are urban problems worse than rural problems, or are rural problems worse than urban problems? Explain your answer. 


\subsection{End-of-Chapter Material}

\section{Summary}

1. Urbanization is a consequence of population growth. Cities first developed in ancient times after the rise of horticultural and pastoral societies and "took off" during the Industrial Revolution as people moved to be near factories. Urbanization led to many social changes then and continues today to affect society.

2. Functionalism, conflict theory, and symbolic interactionism offer varied understandings of urbanization. Functionalists have a mixed view of urbanization, while conflict theorists hold a negative view.

3. Cities face many problems, several of which reflect the fact that cities feature large numbers of people living within a relatively small space. Among the most serious of these problems are residential crowding, substandard and racially segregated housing, heavy traffic and great amounts of air pollution, and high crime rates.

4. Rural areas face many challenges that result from their sparse populations and the great distances that people must often travel. Among other problems, rural areas have a lack of economic opportunities in today's information age and a general lack of various kinds of human services.

\section{Using What You Know}

After graduating from college, you are now working as an entry-level assistant to the mayor of a medium-sized city. You are aware that many city residents are unhappy with the quality of housing in their neighborhoods. The mayor thinks the city has little, if any, money to help improve the city's housing, and also thinks that the housing problem is not nearly as bad as the city's residents seem to think. The mayor asks your opinion about this issue. Based on what you have learned in this chapter and perhaps in other coursework and reading, what do you tell the mayor?

\section{What You Can Do}

To help deal with the urban and rural problems discussed in this chapter, you may wish to do any of the following:

1. Volunteer at a social service agency in your community.

2. Start or join a Habitat for Humanity or other group that builds homes for low-income families.

3. Attend local city council meetings to learn about budgetary issues so that you will be in a more knowledgeable position to help your community. 


\section{Chapter 15: Population and the Environment}

\section{Social Problems in the News}

"India's Air the World's Unhealthiest,” the headline said. A study by researchers at Columbia and Yale Universities ranked India as having the worst air pollution on the planet. India's levels of one component of air pollution, fine particulate matter, were almost five times higher than the safe level for humans. The head of an Indian environmental organization attributed her country's air problem to its numbers of motor vehicles. Although India has fewer vehicles per capita than wealthy nations, its vehicles are very polluting, and it still has a very high number of vehicles because of its huge population. Adding that India has very weak emission standards, she called for stronger standards: "We need to take big steps or the problem will overwhelm us.”

Source: Timmons \& Vyawahare, 2012

This news story reminds us that air pollution is a worldwide problem. The story also reminds us that a major reason for India's air pollution problem is its sheer population size, as India ranks second in the world with 1.2 billion people, just behind China. As India’s example suggests, population and environmental problems are often intertwined.

This chapter examines problems such as food scarcity and climate change associated with population growth and the environment. We will see that these problems raise complex issues without easy solutions, but we will also see that these are urgent problems that must be addressed. Indeed, it is no exaggeration to say that the fate of the earth depends on adequate solutions to these problems.

\section{References}

Timmons, H., \& Vyawahare, M. (2012, February 1). India’s air the world's unhealthiest, study says. New York Times. Retrieved from http://india.blogs.nytimes.com/2012/2002/2001/indias-air-the-worlds-unhealthiest-studysays. 


\subsection{Sociological Perspectives on Population and the Environment}

\section{Learning Objective}

1. Understand the perspectives that functionalism, conflict theory, and symbolic interactionism offer on population and the environment.

As usual, the major sociological perspectives offer insights that help us understand issues relating to population growth and to the environment. Table 15.1 "Theory Snapshot” summarizes their assumptions.

Table 15.1 Theory Snapshot

\begin{tabular}{|l|l|}
$\begin{array}{l}\text { Theoretical } \\
\text { perspective }\end{array}$ & Major assumptions \\
\hline Functionalism & $\begin{array}{l}\text { Population and the environment affect each other. Normal population growth is essential for any society, } \\
\text { but population growth that is too great or too little leads to various problems. Environmental problems are } \\
\text { to be expected in an industrial society, but severe environmental problems are dysfunctional. }\end{array}$ \\
\hline $\begin{array}{l}\text { Conflict } \\
\text { theory }\end{array}$ & $\begin{array}{l}\text { Population growth is not a serious problem because the world has sufficient food and other resources, all } \\
\text { of which must be more equitably distributed. The practices of multinational corporations and weak } \\
\text { regulation of these practices account for many environmental problems. }\end{array}$ \\
\hline $\begin{array}{l}\text { Symbolic } \\
\text { interactionism }\end{array}$ & $\begin{array}{l}\text { People have certain perceptions and understandings of population and environmental issues. Their social } \\
\text { backgrounds affect these perceptions, which are important to appreciate if population and environmental } \\
\text { problems are to be addressed. }\end{array}$ \\
\hline
\end{tabular}

\section{Functionalism}

Functionalism considers population growth and its various components (birth, death, and migration) as normal and essential processes for any society. A society certainly cannot survive if it loses members, but it can thrive only if it grows so that it can meet future challenges. Functionalism also considers pollution and other environmental problems to be an inevitable consequence of today's society, but it assumes that environmental problems that are too severe are certainly dysfunctional for society.

The reasons for the importance of population growth depend on the type of a society's economy. For example, agricultural and other nonindustrial societies need high birth rates to counteract their high death rates. Industrial societies have lower death rates, but they still need to be able to hire younger workers as older workers retire, while new industries need to be able to count on hiring enough young workers with the skills and knowledge these industries require. However, population growth that is too rapid and severe can be dysfunctional for a 
society. Such growth creates crowding and can use up valuable resources such as food, and it can also harm the environment.

As this discussion suggests, functionalism emphasizes how the population and environment affect each other. Population growth leads to certain environmental problems, as we shall see, while environmental problems have important consequences for the populations for whole nations and even the world. At the same time, several industrial nations today actually do not have enough population growth to provide sufficient numbers of younger workers to replace retiring workers and to maintain their tax bases. While too much population growth causes many problems, then, too little population growth also causes problems.

\section{Conflict Theory}

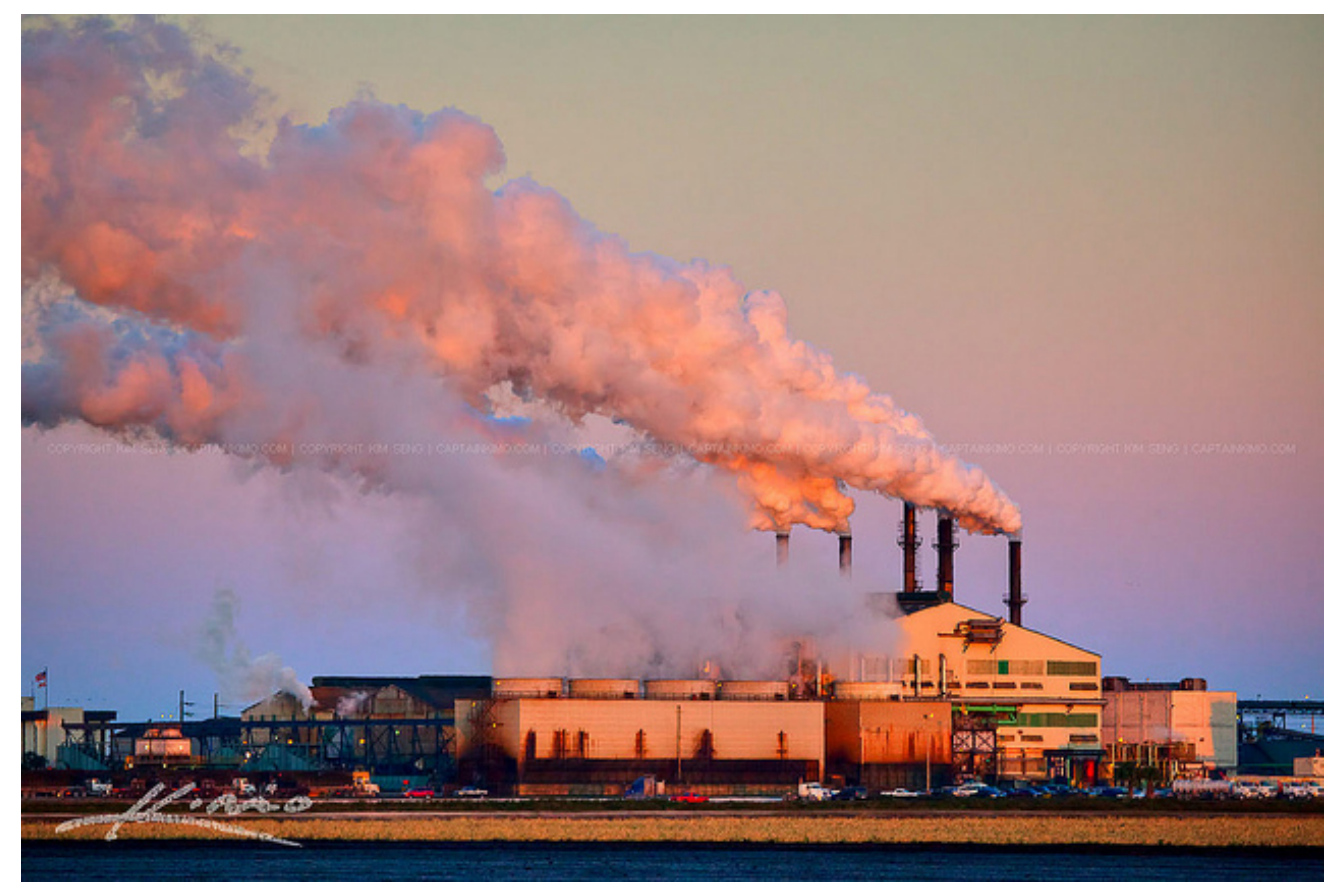

Conflict theory blames many environmental problems on pollution by multinational corporations that occurs because of weak regulations and a failure to enforce the regulations that do exist.

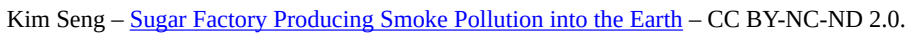

Conflict theory does not consider population growth to be a serious problem. Instead, it assumes that the earth has enough food and other resources to meet the needs of its growing population. To the extent that food shortages and other problems meeting these needs exist, these problems reflect decisions by economic and political elites in poor nations to deprive their peoples of food and other resources; they also reflect operations by multinational corporations that deprive these nations of their natural resources. If population growth is a problem, then, it is a problem not because there is a lack of food and other resources, but rather because these resources are not distributed fairly. To the extent this is true, efforts to satisfy the world's need for food and other resources should focus on distributing these resources more equitably rather than on limiting population growth. 
At the same time, conflict theory recognizes that many poor nations still have population growth that is more than desirable. The theory blames this growth on the failure of these nations' governments to make contraceptives readily available and to do everything possible to increase women's education and independence (which both reduce their birth rates).

In regard to a particular population issue we will discuss (immigration), conflict theory emphasizes the role played by racial and ethnic prejudice in popular views on immigration. It generally favors loosening restrictions on immigration into the United States and making it possible for undocumented immigrants to become US citizens if they so desire.

Conflict theory also assumes that the world's environmental problems are not inevitable and instead arise from two related sources. First, multinational corporations engage in practices that pollute the air, water, and ground. Second, the United States and other governments fail to have strong regulations to limit corporate pollution, and they fail to adequately enforce the regulations they do have.

\section{Symbolic Interactionism}

Symbolic interactionism offers four kinds of understandings of population and environmental problems. First, it seeks to understand why people engage or do not engage in activities related to population growth and other problems (e.g., the use of contraception) and to environmental problems (e.g., recycling). In order to address population growth and environmental problems, it is important to understand why people become involved, or fail to become involved, in various activities related to these problems.

Second, it emphasizes people's perceptions of population and environmental problems. To the extent that public attitudes play a key role in the persistence of these problems, it is important to know the reasons for public views on these problems so that efforts to address the problems may be better focused.

Next, symbolic interactionism assumes that population and environmental problems are to some extent social constructions (see Chapter 1 "Understanding Social Problems"), as these problems do not come to be considered social problems unless sufficient numbers of people and/or influential organizations in the public and private sectors recognize them as problems. For example, lead was a serious health problem long before the US government banned it in paint in 1977 and in gasoline in 1990. As early as the first few years of the twentieth century, scientists were calling attention to the toxic properties of lead paint and more generally of lead itself. Still, lead was added to gasoline in 1922 to raise octane levels. Despite growing evidence over the next few decades of lead's toxic qualities, various industries continued to say that lead was safe for the general public (Michaels, 2008). The banning of lead was ultimately due to the efforts of environmental groups and to the fact that the growing amount of scientific evidence of lead's dangers became overwhelming

Finally, symbolic interactionism emphasizes that people from different social backgrounds and from different cultures may have different understandings of population issues and of environmental issues. For example, someone who grows up in a rural area may consider even a small city to be incredibly crowded, while someone who grows up in a large city may consider a small city to be too tiny and lacking in museums, restaurants, and other amenities that large cities offer. 


\section{Key Takeaways}

- Functionalism recognizes the problems arising from population growth that is too rapid, but disagrees on the extent to which overpopulation is a serious problem.

- Conflict theory attributes world hunger to inequalities in the distribution of food rather than to overpopulation.

- Symbolic interactionism considers people’s perceptions and activities regarding population (e.g., contraception) and the environment.

\section{For Your Review}

1. Which of the three major perspectives—functionalism, conflict theory, or symbolic interactionism—seems to have the best approach in how it understands population and environmental issues? Explain your answer.

\section{References}

Michaels, D. (2008). Doubt is their product: How industry's assault on science threatens your health. New York, NY Oxford University Press. 


\subsection{Population}

\section{Learning Objectives}

1. Describe the central concepts of the study of demography.

2. Understand demographic transition theory and how it compares with the views of Thomas Malthus.

3. Explain why some experts feel that world hunger does not result from overpopulation.

4. Provide examples of how US history is marked by anti-immigrant prejudice.

Population change often has weighty consequences throughout a society. As we think about population change, we usually think about and worry about population growth, but population decline is also a concern. Consider the experience of Michigan (Dzwonkowski, 2010). Like several other northern states, Michigan has lost population during the past few decades. Its birth rate has declined by 21 percent from 1990, and elementary school populations dropped as a result. Several schools lost so many students that they had to close, and others are in danger of closing. In addition, many more people have been moving out of Michigan than moving in. Because many of those moving out are young, college-educated adults, they take with them hundreds of millions of dollars in paychecks away from Michigan's economy and tax revenue base. They also leave behind empty houses and apartments that help depress the state's real estate market. Because of the loss of younger residents from the declining birth rate and out-migration, Michigan's population has become older on the average. This shift means that there is now a greater percentage of residents in their older years who need state services.

Among other consequences, then, Michigan's population decline has affected its economy, educational system, and services for its older residents. While Michigan and other states are shrinking, states in the southern and western regions of the nation are growing, with their large cities becoming even larger. This population growth also has consequences. For example, schools become more crowded, pressuring communities to hire more teachers and either enlarge existing schools or build new ones. The population growth also strains hospitals, social services, and many other sectors of society.

This brief discussion of US cities underscores the various problems arising from population growth and decline. These are not just American problems, as they play out across the world. The remainder of this section introduces the study of population and then examines population problems in greater depth.

\section{The Study of Population}

We have commented that population change is an important source of other changes in society. The study of population is so significant that it occupies a special subfield within sociology called demography. To be more 
precise, demography is the study of changes in the size and composition of population. It encompasses several concepts: fertility and birth rates, mortality and death rates, and migration. Let's look at each of these briefly.

\section{Fertility and Birth Rates}

Fertility refers to the number of live births. Demographers use several measures of fertility. One measure is the crude birth rate, or the number of live births for every 1,000 people in a population in a given year. We call this a "crude" birth rate because the population component consists of the total population, not just the number of women or even the number of women of childbearing age (commonly considered 15-44 years).

A second measure is the general fertility rate (also just called the fertility rate or birth rate), or the number of live births per 1,000 women aged 15-44 (i.e., of childbearing age). The US general fertility rate for 2010 was about 64.7 (i.e., 64.7 births per 1,000 women aged 15-44) (Sutton \& Hamilton, 2011).

A third measure is the total fertility rate, or the number of children an average woman is expected to have in her lifetime (taking into account that some women have more children and some women have fewer or no children). This measure often appears in the news media and is more easily understood by the public than either of the first two measures. In 2010, the US total fertility rate was about 1.93 (or 1,930 births for every 1,000 women) (Hamilton, Martin, \& Ventura, 2011).

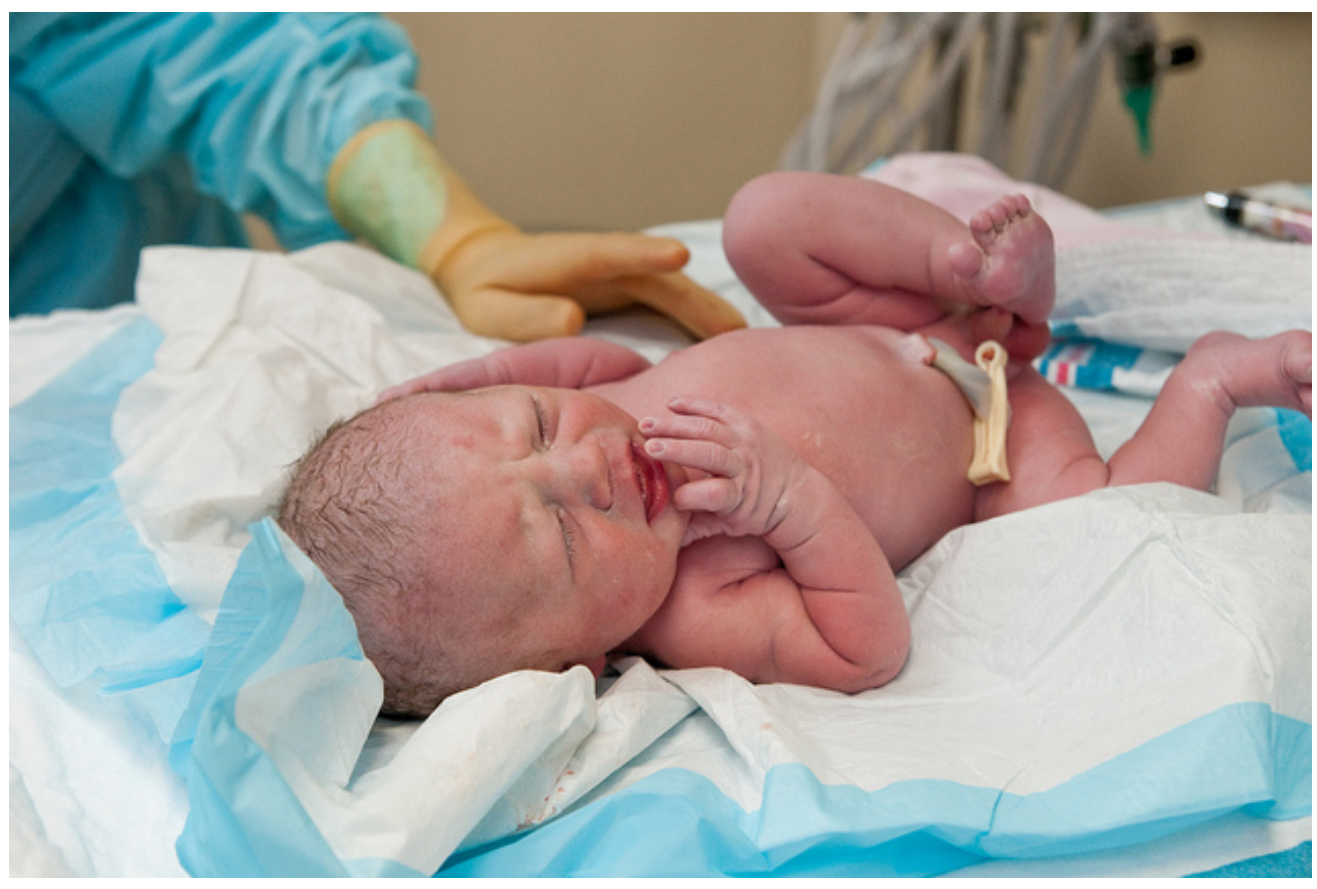

Demographers use several measures of fertility. The general fertility rate refers to the number of live births per 1,000 women aged 15-44. The US general fertility rate is about 65.5 .

Daniel - Delivery - CC BY-NC-ND 2.0.

As Figure 15.1 "US General Fertility Rate, 1920-2010" indicates, the US general fertility rate has changed a lot since 1920, dropping from 101 (per 1,000 women aged 15-44) in 1920 to 70 in 1935, during the Great Depression, 
before rising afterward until 1955. (Note the very sharp increase from 1945 to 1955, as the post-World War II baby boom began.) The fertility rate then fell steadily after 1960 until the 1970s but has remained rather steady since then, fluctuating only slightly between 65 and 70 per 1,000 women aged 15-44.

Figure 15.1 US General Fertility Rate, 1920-2010

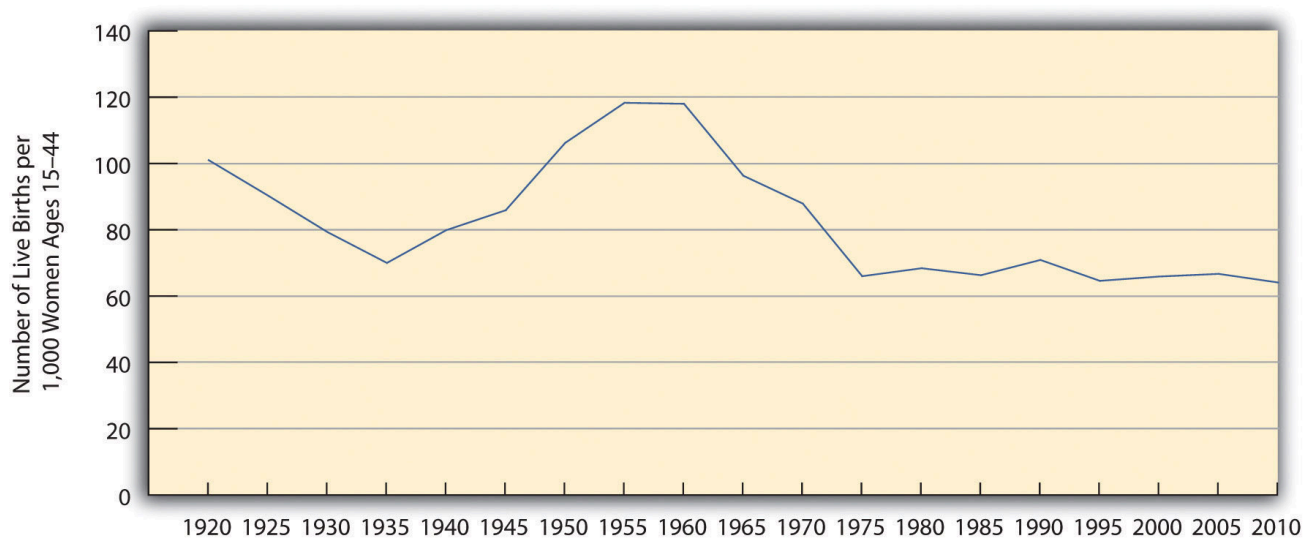

Sources: Data from Hamilton, B. E., Martin, J. A., \& Ventura, S. J. (2011). Births: Preliminary data for 2010. National Vital Statistics

Reports, 60(2), 1-13; Martin, J. A., Hamilton, B. E., Sutton, P. D., Ventura, S. J., Menacker, F., Kirmeyer, S., \& Mathews, T. J. (2009). Births: Final data for 2006. National Vital Statistics Reports, 57(7), 1-102; US Census Bureau. (1951). Statistical abstract of the United States: 1951. Washington, DC: US Government Printing Office.

Fertility rates differ around the world and are especially high in poor nations (see Figure 15.2 "Crude Birth Rates around the World, 2008 (Number of Births per 1,000 Population)”). Demographers identify several reasons for these high rates (Weeks, 2012).

Figure 15.2 Crude Birth Rates around the World, 2008 (Number of Births per 1,000 Population)

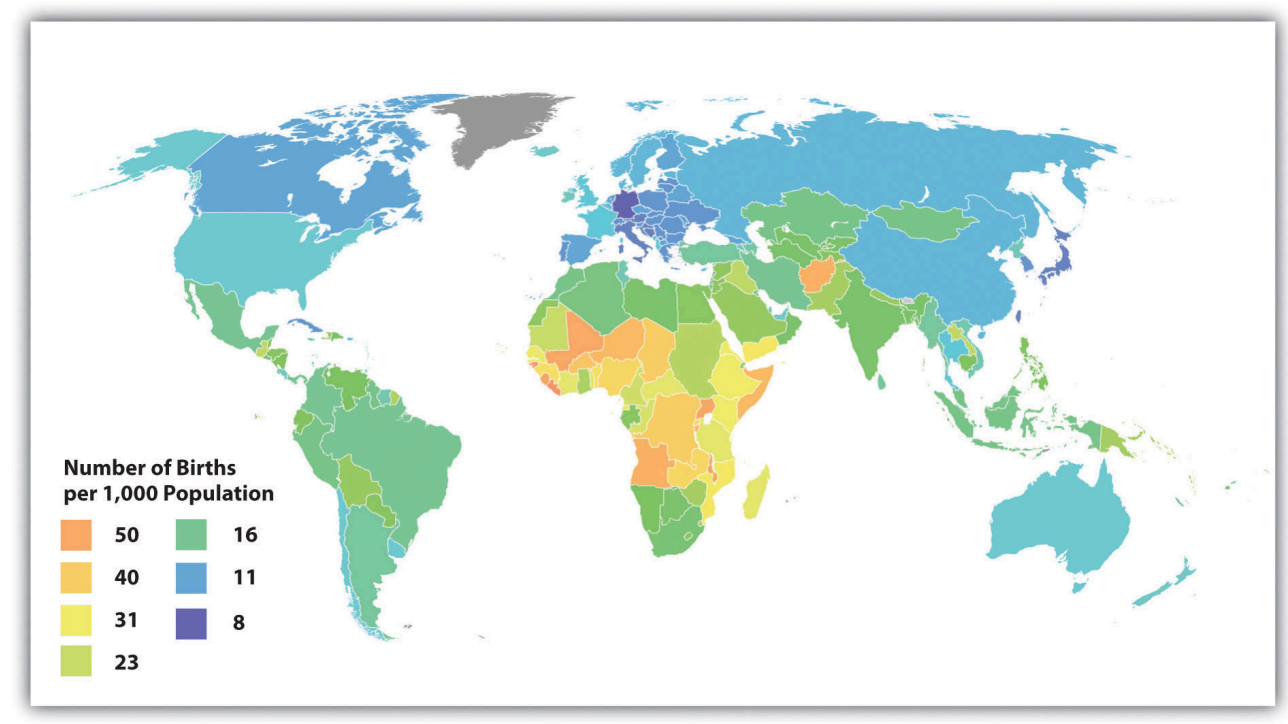

Source: Adapted from http://en.wikipedia.org/wiki/File:Birth rate figures for countries.PNG.

First, poor nations are usually agricultural ones. In agricultural societies, children are an important economic 
resource, as a family will be more productive if it has more children. This means that families will ordinarily try to have as many children as possible. Second, infant and child mortality rates are high in these nations. Because parents realize that one or more of their children may die before adulthood, they have more children to make up for the anticipated deaths.

A third reason is that many parents in low-income nations prefer sons to daughters, and, if a daughter is born, they try again for a son. Fourth, traditional gender roles are often very strong in poor nations, and these roles include the belief that women should be wives and mothers above all. With this ideology in place, it is not surprising that women will have several children. Finally, contraception is uncommon in poor nations. Without contraception, many more pregnancies and births certainly occur. For all these reasons, then, fertility is much higher in poor nations than in rich nations.

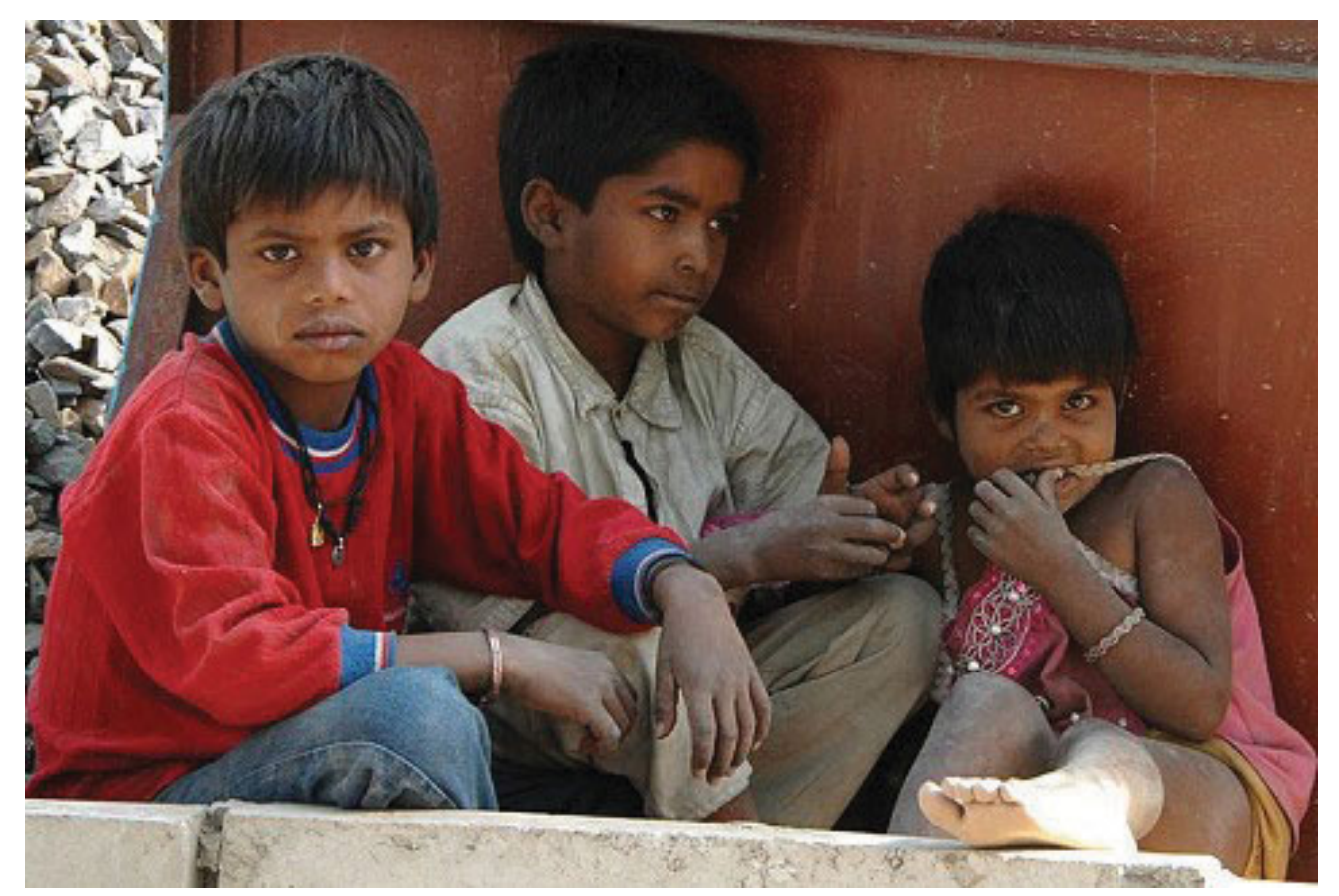

Poor nations have higher birth rates for several reasons. One reason is the agricultural economies typical of these nations. In these economies, children are an important economic resource, and families will ordinarily try to have as many children as possible.

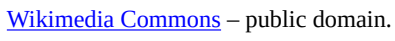

\section{Mortality and Death Rates}

Mortality is the flip side of fertility and refers to the number of deaths. Demographers measure it with the crude death rate, the number of deaths for every 1,000 people in a population in a given year. We call this a "crude" death rate because the population component consists of the total population and does not take its age distribution into account. All things equal, a society with a higher proportion of older people should have a higher crude death rate. Demographers often calculate age-adjusted death rates that adjust for a population's age distribution. 


\section{Migration}

Another important demographic concept is migration, the movement of people into and out of specific regions. Since the dawn of human history, people have migrated in search of a better life, and many have been forced to migrate by ethnic conflict or the slave trade.

Several classifications of migration exist. When people move into a region, we call it in-migration, or immigration; when they move out of a region, we call it out-migration, or emigration. The in-migration rate is the number of people moving into a region for every 1,000 people in the region, while the out-migration rate is the number of people moving from the region for every 1,000 people. The difference between the two is the net migration rate (in-migration minus out-migration). Recalling our earlier discussion. Michigan has had a net migration of less than zero, as its out-migration has exceeded its in-migration.

Migration can also be either domestic or international in scope. Domestic migration happens within a country's national borders, as when retired people from the northeastern United States move to Florida or the Southwest. International migration happens across national borders. When international immigration is heavy, the effect on population growth and other aspects of national life can be significant, as can increased prejudice against the new immigrants. Domestic migration can also have a large impact. The great migration of African Americans from the South into northern cities during the first half of the twentieth century changed many aspects of those cities' lives (Wilkerson, 2011). Meanwhile, the movement during the past few decades of northerners into the South and Southwest also had quite an impact: The housing market initially exploded, for example, and traffic increased.

\section{Population Growth and Decline}

Now that you are familiar with some basic demographic concepts, we can discuss population change in more detail. Three of the factors just discussed determine changes in population size: fertility (crude birth rate), mortality (crude death rate), and net migration. The natural growth rate is simply the difference between the crude birth rate and the crude death rate. The US natural growth rate is about 0.6 percent (or 6 per 1,000 people) per year. When immigration is also taken into account, the total population growth rate has been almost 1.0 percent per year (Rosenberg, 2012).

Figure 15.3 “International Annual Population Growth Rates (\%), 2005-2010” depicts the annual population growth rate (including both natural growth and net migration) of all the nations in the world. Note that many African nations are growing by at least 3 percent per year or more, while most European nations are growing by much less than 1 percent or are even losing population, as discussed earlier. Overall, the world population is growing by about 80 million people annually (Population Reference Bureau, 2012).

Figure 15.3 International Annual Population Growth Rates (\%), 2005-2010 


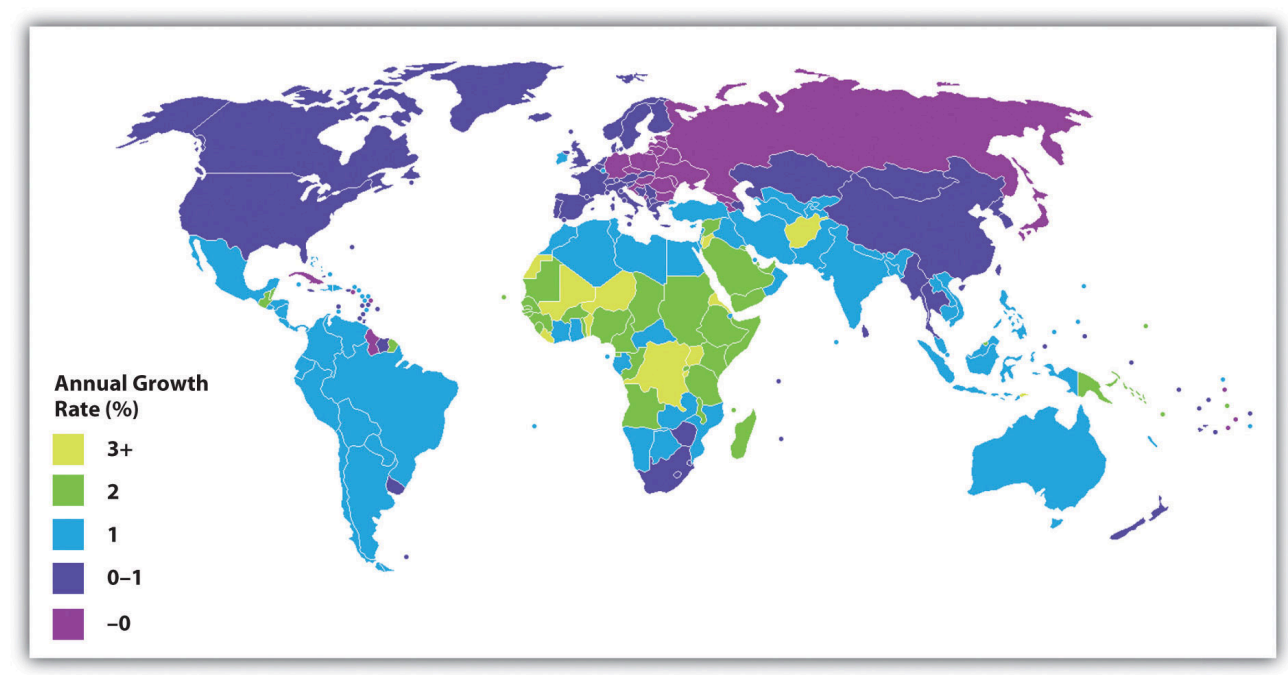

Source: Adapted from http://lt.wikipedia.org/wiki/Vaizdas:Population_growth_rate_world_2005-2010_UN.PNG.

To determine how long it takes for a nation to double its population size, divide the number 70 by its population growth rate. For example, if a nation has an annual growth rate of 3 percent, it takes about 23.3 years $(70 \div 3)$ for that nation's population size to double. As you can see from the map in Figure 15.3 "International Annual Population Growth Rates (\%), 2005-2010”, several nations will see their population size double in this time span if their annual growth continues at its present rate. For these nations, population growth will be a serious problem if food and other resources are not adequately distributed.

Demographers use their knowledge of fertility, mortality, and migration trends to make projections about population growth and decline several decades into the future. Coupled with our knowledge of past population sizes, these projections allow us to understand population trends over many generations. One clear pattern emerges from the study of population growth. When a society is small, population growth is slow because there are relatively few adults to procreate. But as the number of people grows over time, so does the number of adults. More and more procreation thus occurs every single generation, and population growth then soars in a virtual explosion.

We saw evidence of this pattern when we looked at world population growth. When agricultural societies developed some 12,000 years ago, only about 8 million people occupied the planet. This number had reached about 300 million about 2,100 years ago, and by the fifteenth century it was still only about 500 million. It finally reached 1 billion by about 1850; by 1950, only a century later, it had doubled to 2 billion. Just fifty years later, it tripled to more than 6.8 billion, and it is projected to reach more than 9 billion by 2050 (see Figure 15.4 "Total World Population, 1950-2050”) and 10 billion by 2100 (Gillis \& Dugger, 2011). 

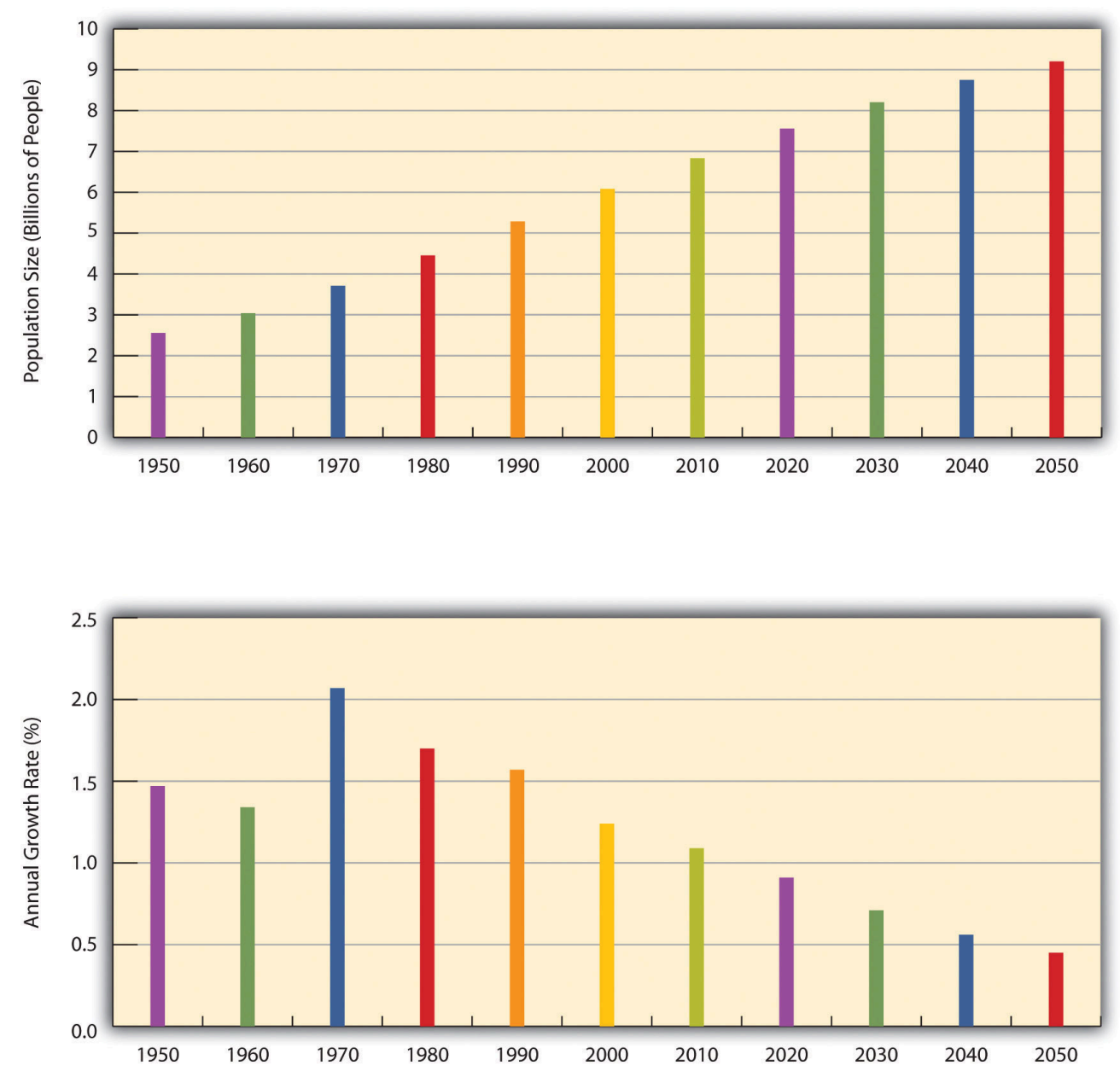

Source: Data from US Census Bureau. (2012). Statistical abstract of the United States: 2012. Washington, DC: US Government Printing Office. Retrieved from http://www.census.gov/compendia/statab.

Eventually, however, population growth begins to level off after exploding, as explained by demographic transition theory, discussed later. We see this in the bottom half of Figure 15.4 "Total World Population, 1950-2050", which shows the average annual growth rate for the world's population. This rate has declined over the last few decades and is projected to further decline over the next four decades. This means that while the world's population will continue to grow during the foreseeable future, it will grow by a smaller rate as time goes by. As Figure 15.3 “International Annual Population Growth Rates (\%), 2005-2010” suggested, the growth that does occur will be concentrated in the poor nations in Africa and some other parts of the world. Still, even in these nations the average number of children a woman has in her lifetime dropped from six a generation ago to about three today.

Past and projected sizes of the US population appear in Figure 15.5 "Past and Projected Size of the US Population, 1950-2050 (in Millions)”. The US population is expected to number about 440 million people by 2050. 


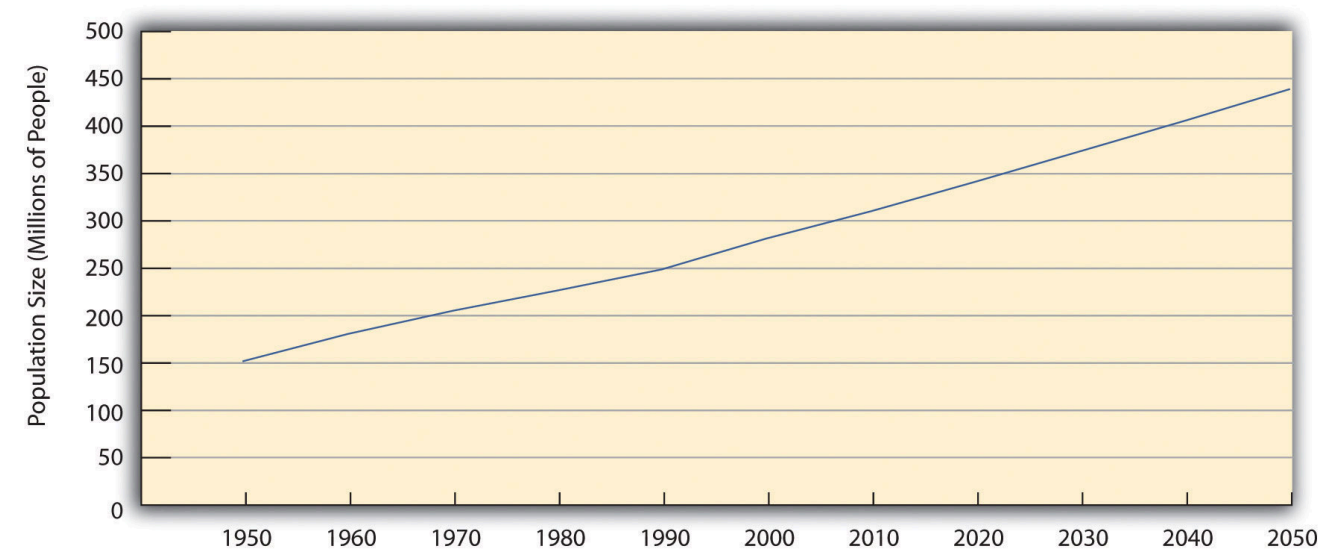

Source: Data from US Census Bureau. (2012). Statistical abstract of the United States: 2012. Washington, DC: US Government Printing Office. Retrieved from http://www.census.gov/compendia/statab.

\section{Views of Population Growth}

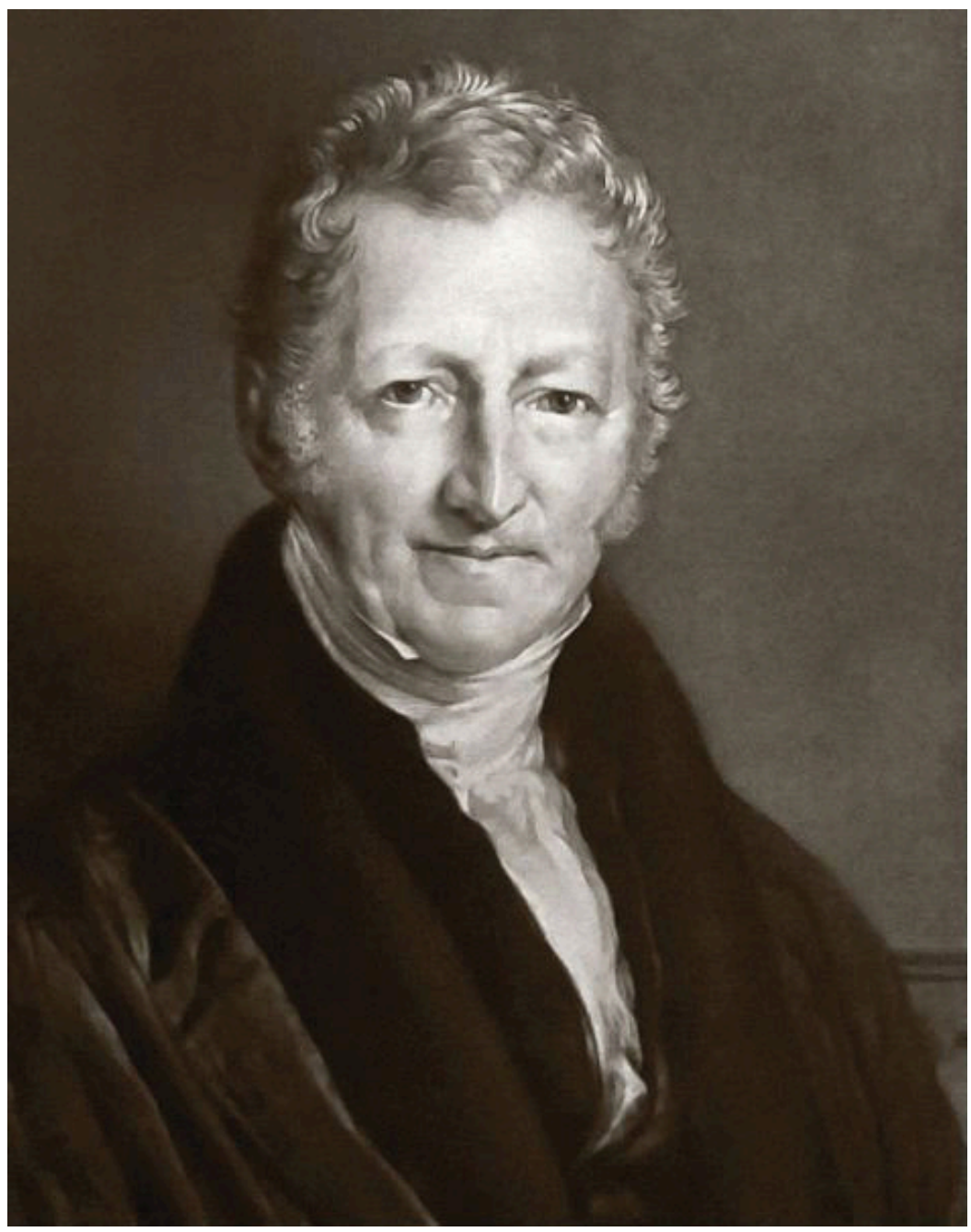


Thomas Malthus, an English economist who lived about two hundred years ago, wrote that population

increases geometrically while food production increases only arithmetically. These understandings led him

to predict mass starvation.

Wikimedia Commons - public domain.

The numbers just discussed show that the size of the United States and world populations has increased tremendously in just a few centuries. Not surprisingly, people during this time have worried about population growth and specifically overpopulation. One of the first to warn about population growth was Thomas Malthus (1766-1834), an English economist, who said that population increases geometrically (2, 4, 8, 16, 32, 64, 128, $256,512,1024 \ldots$.. If you expand this list of numbers, you will see that they soon become overwhelmingly large in just a few more "generations." Malthus (1798/1926) said that food production increases only arithmetically $(1,2,3,4,5,6 \ldots)$ and thus could not hope to keep up with the population increase, and he predicted that mass starvation would be the dire result.

During the 1970s, population growth became a major issue in the United States and some other nations. Zero population growth, or ZPG, was a slogan often heard. There was much concern over the rapidly growing population in the United States and, especially, around the world, and there was fear that our "small planet" could not support massive increases in the number of people (Ehrlich, 1969). Some of the most dire predictions of the time warned of serious food shortages by the end of the century.

Fortunately, Malthus and ZPG advocates were wrong to some degree. Although population levels have certainly soared, the projections in Figure 15.4 "Total World Population, 1950-2050" show the rate of increase is slowing. Among other factors, the development of more effective contraception, especially the birth control pill, has limited population growth in the industrial world and, increasingly, in poorer nations. Food production has also increased by a much greater amount than Malthus and ZPG advocates predicted.

\section{The Debate over Overpopulation}

Many experts continue to be concerned about overpopulation, as they feel it is directly responsible for the hunger and malnutrition that plague hundreds of millions of people in poor nations (Gillis, 2011). One expert expressed this concern: "Every billion more people makes life more difficult for everybody-it's as simple as that. Is it the end of the world? No. Can we feed 10 billion people? Probably. But we obviously would be better off with a smaller population” (Gillis \& Dugger, 2011, p. A1). Recognizing this problem, India has begun giving cash bonuses to poor, rural married couples, who typically have high fertility rates, to wait to have children, and it has intensified its encouragement of contraception (Yardley, 2010). 


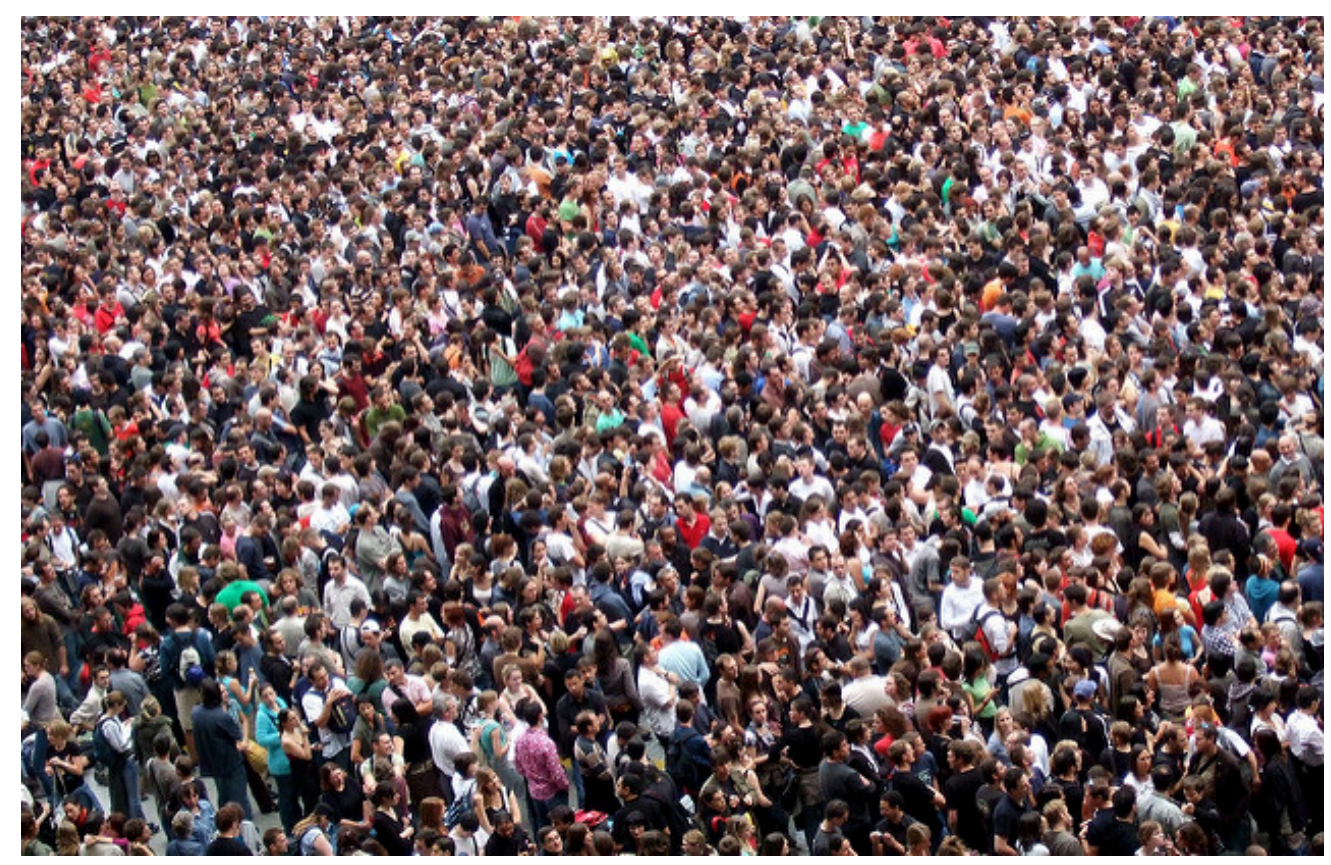

Calls during the 1970s for zero population growth (ZPG) population control stemmed from concern that the planet was becoming overpopulated and that food and other resources would soon be too meager to support the world's population.

James Cridland - Crowd - CC BY 2.0.

However, other experts say the world's resources remain sufficient and minimize the problem of overpopulation. They acknowledge that widespread hunger in Africa and other regions does exist. However, they attribute this problem not to overpopulation and lack of food but rather to problems in distributing the sufficient amount of food that does in fact exist. As an official for Oxfam International explained, “Today's major problems in the food system are not fundamentally about supply keeping up with demand, but more about how food gets from fields and on to forks" (2011). The official added that enough grain (cereal and soy) exists to easily feed the world, but that one-third of cereal and 90 percent of soy feed livestock instead. Moving away from a meat-laden Western diet would thus make much more grain available for the world's hungry poor.

Sociologists Stephen J. Scanlan and colleagues add that food scarcity results from inequalities in food distribution rather than from overpopulation: "[Food] scarcity is largely a myth. On a per capita basis, food is more plentiful today than any other time in human history...Even in times of localized production shortfalls or regional famines there has long been a global food surplus...A good deal of thinking and research in sociology...suggests that world hunger has less to do with the shortage of food than with a shortage of affordable or accessible food. Sociologists have found that social inequalities, distribution systems, and other economic and political factors create barriers to food access” (Scanlan, Jenkins, \& Peterson, 2010, p. 35).

This sociological view has important implications for how the world should try to reduce global hunger. International organizations such as the World Bank and several United Nations agencies have long believed that hunger is due to food scarcity, and this belief underlies the typical approaches to reducing world hunger that focus on increasing food supplies with new technologies and developing more efficient methods of delivering food. But if food scarcity is not a problem, then other approaches are necessary. According to Scanlan et al., these approaches involve reducing the social inequalities that limit poor nations' access to food. 
As an example of one such inequality, Scanlan et al. point out that poor nations lack the funds to import the abundant food that does exist. These nations' poverty, then, is one inequality that leads to world hunger, but gender and ethnic inequalities are also responsible. Nations with higher rates of gender inequality and ethnic inequality have higher rates of hunger. In view of this fact, the authors emphasize that improvements in gender and ethnic equality are necessary to reduce global hunger: "International attention to food security should therefore shift from increasing food supply to regulating armed conflict, improving human rights, and promoting gender equity throughout the world-factors that reduce barriers to access and empower populations throughout the world to benefit from their food entitlements” (Scanlan et al., 2010, p. 39).

\section{Demographic Transition Theory}

As we consider whether overpopulation is the threat that Malthus and contemporary concerned scientists have considered it to be, it is important to appreciate demographic transition theory, mentioned earlier. This theory links population growth to the level of technological development across three stages of social evolution and suggests that this growth slows considerably as nations become more industrialized.

In the first stage, coinciding with preindustrial societies, the birth rate and death rate are both high. The birth rate is high because of the lack of contraception and the several other reasons cited earlier for high fertility rates, and the death rate is high because of disease, poor nutrition, lack of modern medicine, and other problems. These two high rates cancel each other out, and little population growth occurs.

In the second stage, coinciding with the development of industrial societies, the birth rate remains fairly high, owing to the lack of contraception and a continuing belief in the value of large families, but the death rate drops because of several factors, including increased food production, better sanitation, and improved medicine. Because the birth rate remains high but the death rate drops, population growth takes off dramatically.

In the third stage, the death rate remains low, but the birth rate finally drops as families begin to realize that large numbers of children in an industrial economy are more of a burden than an asset. Another reason for the drop is the availability of effective contraception. As a result, population growth slows, and, as we saw earlier, it has become quite low or even gone into a decline in several industrial nations.

Demographic transition theory, then, gives us more reason to be cautiously optimistic regarding the threat of overpopulation: As poor nations continue to modernize-much as industrial nations did two hundred years ago- their population growth rates should start to decline.

Still, population growth rates in poor nations continue to be high, and, as already mentioned, gender and ethnic inequality helps allow rampant hunger to persist. Hundreds of thousands of women die in poor nations each year during pregnancy and childbirth. Reduced fertility would save their lives, in part because their bodies would be healthier if their pregnancies were spaced farther apart (Schultz, 2008). Although world population growth is slowing, then, it is still growing too rapidly in poor nations. To reduce it further, more extensive family planning programs are needed, as is economic development in general: Women who are better educated and have more money tend to have lower fertility. 


\section{Population Decline and Pronatalism}

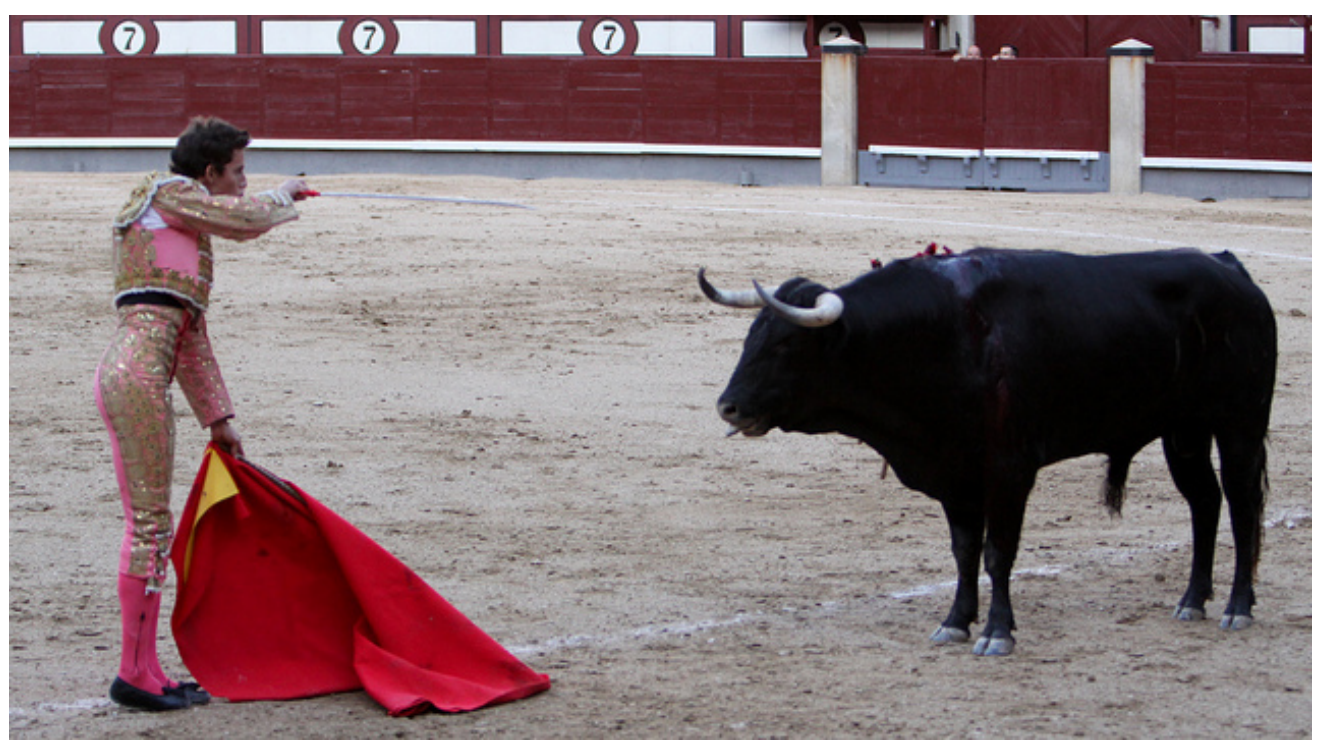

Spain is one of several European nations that have been experiencing a population decline because of lower birth rates. Like some other nations, Spain has adopted pronatalist policies to encourage people to have more children; it provides $€ 2,500$, about $\$ 3,400$, for each child.

paul.hartrick - $\underline{\text { Spain-477 }}$ - CC BY-NC 2.0.

If population growth remains a problem in poor nations, population decline is a problem in some industrial nations. As noted earlier, some nations are even experiencing population declines, while several more are projected to have population declines by 2050 (Brooks, 2012). For a country to maintain its population, the average woman needs to have 2.1 children, the replacement level for population stability. But several industrial nations, not including the United States, are below this level. Increased birth control is one reason for their lower fertility rates but so are decisions by women to stay in school longer, to go to work right after their schooling ends, and to postpone having their first child.

Ironically, these nations' population declines have begun to concern demographers and policymakers (Haartsen \& Venhorst, 2010). Because people in many industrial nations are living longer while the birth rate drops, these nations are increasingly having a greater proportion of older people and a smaller proportion of younger people. In several European nations, there are more people 61 or older than 19 or younger. As this trend continues, it will become increasingly difficult to take care of the health and income needs of so many older persons, and there may be too few younger people to fill the many jobs and provide the many services that an industrial society demands. The smaller labor force may also mean that governments will have fewer income tax dollars to provide these services.

To deal with these problems, several governments have initiated pronatalist policies aimed at encouraging women to have more children. In particular, they provide generous child-care subsidies, tax incentives, and flexible work schedules designed to make it easier to bear and raise children, and some even provide couples outright cash payments when they have an additional child. Russia in some cases provides the equivalent of about $\$ 9,000$ for each child beyond the first, while Spain provides $€ 2,500$ (equivalent to about $\$ 3,400$ ) for each child (Haub, 2009). 


\section{Two Other Problems Related to Population Growth}

As we saw, population experts debate the degree to which population growth contributes to global poverty and hunger. But there is little debate that population growth contributes to two other global problems.

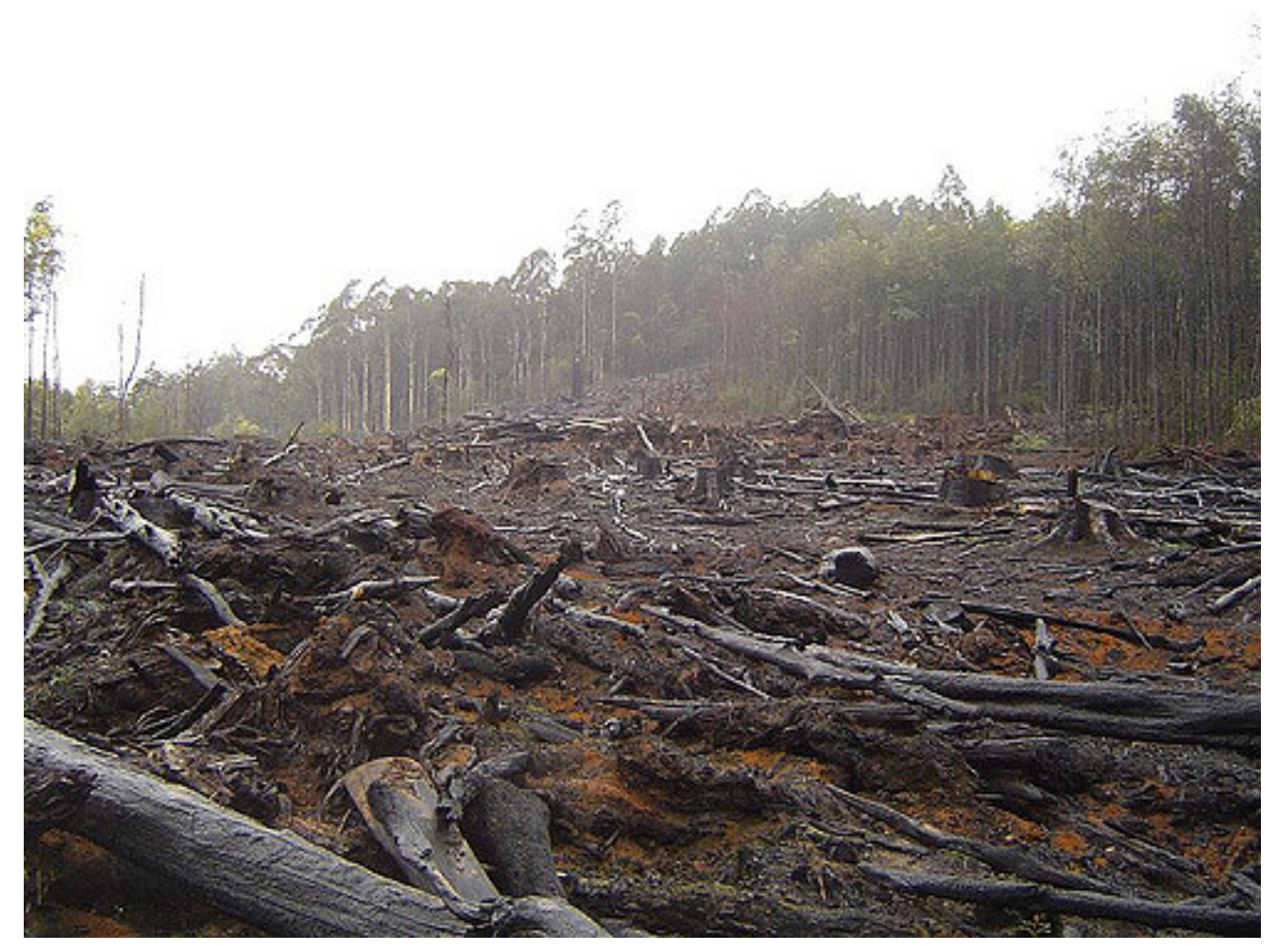

Population growth causes many environmental problems, one of which is deforestation.

crustmania - Deforestation - CC BY 2.0.

One of these problems concerns the environment. Population growth in both wealthy and poor nations has damaged the environment in many ways (Walsh, 2011). As the news story that opens this chapter illustrated, countries with large numbers of people drive many motor vehicles that pollute the air, and these countries engage in many other practices of the industrial era that pollute the air, water, and ground. Further, as populations have expanded over the centuries, they have cut down many trees and deforested many regions across the globe. This deforestation ruins animal habitats and helps to contribute to global warming because trees help remove carbon dioxide from the atmosphere and release oxygen into the atmosphere.

Another problem is interpersonal conflict in general and armed conflict in particular. As populations grow, they need more and more food, water, and other resources. When these resources have become too scarce over the centuries, many societies have decided to take resources from other societies "by any means necessary," as the old saying goes, meaning the use of force (Gleditsch \& Theisen, 2010).

Population growth thus helps to create armed conflict between societies, but it also helps to generate conflict within a single society. As a society grows, people begin to compete for resources. This competition has often led to hostility of many types, including interpersonal violence. As we shall discuss shortly, the history of immigration 
in the United States illustrates this dynamic. As the number of immigrants grew rapidly in various historical eras, native-born whites perceived threats to their jobs, land, and other resources and responded with mob violence.

\section{Immigration}

Recall that migration generally and immigration specifically are central concepts in the study of population. As just indicated, immigration is also a source of great controversy in the United States and in many other countries. This controversy is perhaps almost inevitable, as increasing numbers of immigrants can affect many aspects of a society: crowding in its cities, increasing enrollments in its schools, having enough jobs for everyone who wants to work, and so forth. However, the fact that immigration can cause these complications does not begin to justify the prejudice and hostility that have routinely greeted immigrants into the United States and elsewhere.

The history of the United States is filled with prejudice and hostility of this type. Starting with the Pilgrims, this nation was settled by immigrants who came to these shores seeking political and religious freedom and economic opportunity. Despite these origins, when great waves of immigrants came to the United States beginning in the nineteenth century, they were hardly greeted with open arms (Roediger, 2006). During the first half of this century, some 3 million Irish immigrants, most of them Catholic, moved to the United States. Because these immigrants were not Anglo-Saxon Protestants, native-born whites (most of whom were Anglo-Saxon Protestants) deeply disliked them and even considered them to be a different race from white. During the 1850s, the so-called KnowNothing Party, composed of native-born whites, was openly hostile to Irish immigrants and would engage in mob violence against them, with many murders occurring. Later waves of immigrants from Italian, Polish, and Jewish backgrounds also were not considered fully white and subject to employment discrimination and other ethnic prejudice and hostility.

Beginning with the California gold rush of 1849 and continuing after the Civil War, great numbers of Chinese immigrants came to the United States and helped to build the nation's railroads and performed other important roles. They, too, were greeted hostilely by native-born whites who feared the Chinese were taking away their jobs (Pfaelzer, 2008). As the national economy worsened during the 1870s, riots against the Chinese occurred in western cities. In more than three hundred cities and towns, whites went into Chinese neighborhoods, burned them down, and murdered some Chinese residents while forcing the remainder to leave town. Congress finally outlawed Chinese immigration in 1882, with this ban lasting for almost a century.

During the 1930s, rising numbers of Mexican Americans in the western United States led to similar hostility (Daniels, 2002). The fact that this decade was the time of the Great Depression deepened whites' concerns that Mexican immigrants were taking away their jobs. White-owned newspapers falsely claimed that these immigrants posed a violent threat to white Americans, and that their supposed violence was made more likely by their use of marijuana. It is estimated that at least 500,000 Mexicans returned to their native country, either because they were

forcibly deported or because they returned there themselves under great pressure.

\section{Immigration Today}

Immigration continues to be a major concern for many Americans today, whose concern centers mostly on 
Mexican immigrants even though they are less than a majority of all immigrants. According to political scientist Victoria M. DeFrancesco Soto (2012), this focus stems from racial prejudice: "Let's call a spade a spade. Opposition to immigration is not a concern rooted in personal economic concerns. Neither is it a concern having to do with state's rights. Anti-immigrant sentiment isn't even about immigrants as a whole. As rigorous social scientific research shows, opposition to immigration is closely linked to the negative racial animus toward one very specific group, Latinos.”

As we try to make sense of immigration and of immigration policy, some basic facts are worth appreciating. The number of immigrants greatly increased two or three decades ago, but the number of illegal immigrants entering the United States now is very small compared to just a decade ago (Myers, 2012). Foreign-born residents composed 12.9 percent of the US population in 2010, or 40 million immigrants overall, compared to only 7.9 percent in 1990 (Immigration Policy Center, 2012). Almost one-third of immigrants are Mexican, while onefourth are Asian. Most of the remainder come from the Caribbean, Central America, and South America. Slightly more than half of all foreign-born residents come from Mexico or one of the other Latin American nations. Almost 40 percent of Latinos and two-thirds of Asians in the United States are foreign-born.

Almost three-fourths of immigrants are naturalized US citizens, legal residents, or legal temporary migrants. Slightly more than one-fourth, 28 percent, or about 11 million people, are illegal residents. About 60 percent, or almost 7 million, of these residents are Mexican. Approximately 4.5 million children born in the United States, who are thus citizens, have at least one parent who is an unauthorized immigrant.

Unauthorized immigrants compose more than 5 percent of the US labor force, a number equivalent to 8 million workers. Households headed by unauthorized immigrants paid an estimated $\$ 11.2$ billion in state and federal taxes in 2010. According to the Immigration Policy Center (2012), if all unauthorized immigrants somehow left the United States, the US economy would suffer an annual loss of 2.8 million jobs, \$552 billion in economic activity, and $\$ 245$ billion in gross domestic product (GDP).

As these labor and economic figures make clear, illegal immigrants form an important component of the US economy. In another fact that may surprise immigration opponents, many studies also find that immigrants, both legal and illegal, have lower crime rates than nonimmigrants (Wadsworth, 2010). These low rates are thought to stem from immigrants' stable families, strong churches, and high numbers of small businesses that make for stable neighborhoods. Ironically, as immigrants stay longer in the United States, the crime rates of their children, and then those of their children's children, become higher. As immigrant families stay longer in the United States, then, their crime rates tend to rise, in part because they become “Americanized” (Sampson, 2008).

\section{Efforts to Limit Immigration}

Although immigrants strengthen the US economy and have low crime rates, much of the public is opposed to immigration. In the 2010 General Social Survey (GSS), half the respondents said that the number of immigrants to the United States should be reduced by "a little” or “a lot," and only about 14 percent said this number should be increased. In a 2011 CNN poll, one-third of the public said it is "somewhat" or "very" unsympathetic toward illegal immigrants and their families. In the same poll, more than half the public favored building a sevenhundred-mile fence along the border with Mexico (PollingReport.com, 2012). 
In recent years, many states enacted strict laws regarding immigrants, including the denial of schooling and various social services to unauthorized immigrant families. Arizona, Georgia, and Alabama enacted some of the most restrictive legislation.

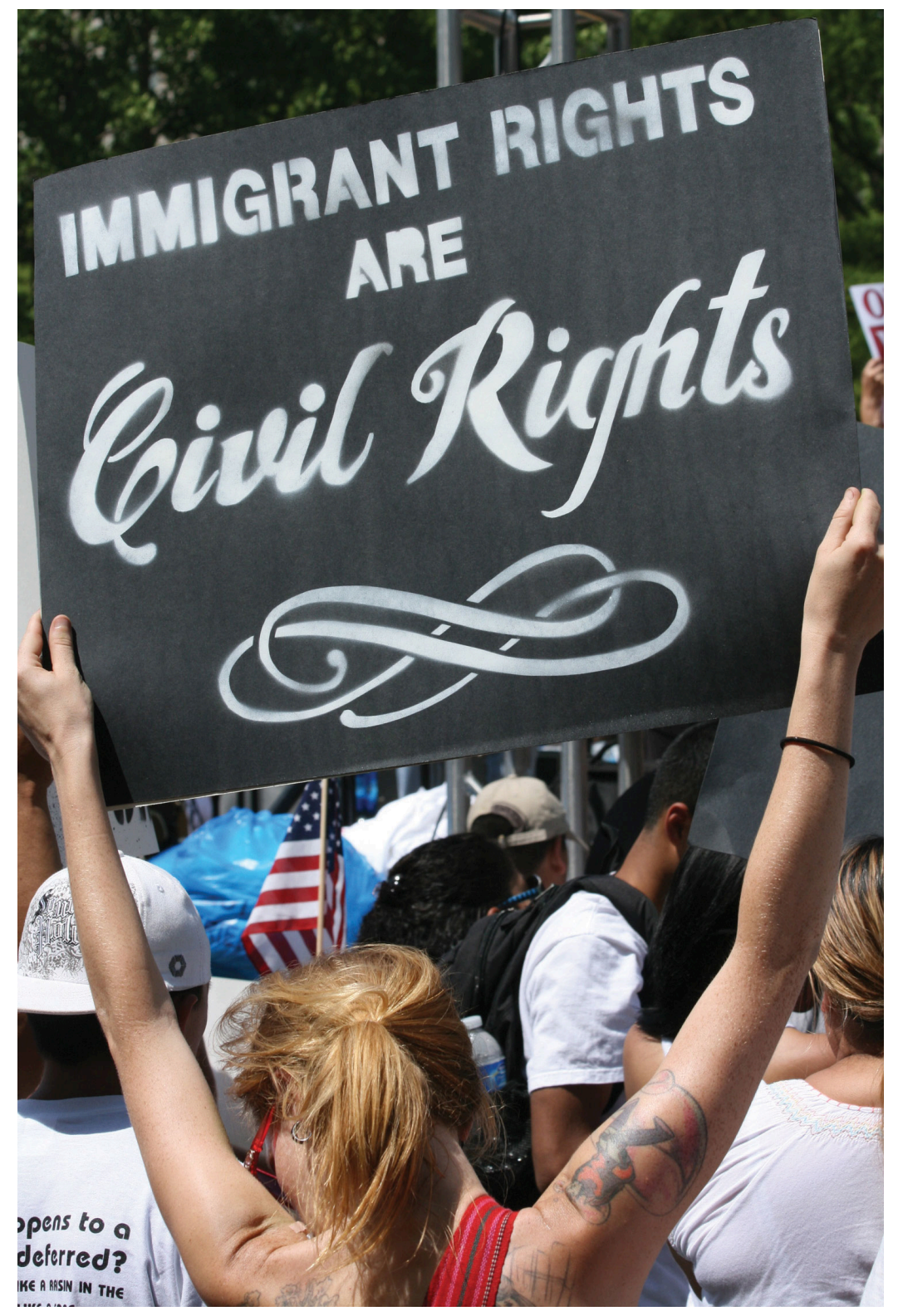

Arizona is one of several states that have enacted very restrictive laws regarding immigration.

Nevele Osteog - Immigration Reform Leaders Arrested in Washington DC - CC BY 2.0.

Arizona's law, passed in 2010, made failing to carry immigration documents a crime and required the police to question and detain anyone they suspected of being an illegal immigrant. Previously, these restrictions had been the sole province of the federal government. Critics charged this new law would lead to ethnic and racial profiling, as only people who looked Mexican would be stopped by police for suspicion of being illegal (Archibold, 2010). They also noted that the new law caused an economic loss of \$250 million during the first year after its enactment from a loss in conference and convention business in Arizona (Brown, 2011). 
Georgia’s law, enacted in 2011, allowed police to demand immigration documents from criminal suspects and to hold suspects who do not provide documentation for deportation by federal officials. The law also made it more difficult to hire workers without proper documentation, increased the penalties for businesses that hire these workers, and provided penalties for people who house or transport unauthorized immigrants. Georgia's Chamber of Commerce worried about the law's economic impact, and in particular was concerned that the law would reduce tourism. Reports estimated that if the law forced all unauthorized workers to leave Georgia, the state's agricultural industry would lose up to $\$ 1$ billion annually, since unauthorized workers form the bulk of the Georgia’s farm labor force (Berman, 2011).

Alabama's law, enacted in 2011, also allowed police to detain people suspected of being unauthorized immigrants. In addition, it required schools to record the immigration status of all students and also required people seeking a driver's license to prove that they were US citizens. The law led to very long lines to renew driver's licenses, and, because immigrant migrant workers left the state, many crops went unharvested on the state's farms. Business leaders feared the law would harm the state's economy, a fear that was heightened when a German executive at Mercedes-Benz was detained by police (Ott, 2012).

Several months after the Alabama law took effect, a study by a University of Alabama economist concluded that it had forced at least 40,000 and perhaps as many as 80,000 unauthorized workers to leave the state (Lee, 2012). The exit of so many workers caused an estimated annual loss to Alabama’s GDP of at least \$2 billion, a loss in state and state revenue from income and sales taxes of at least \$57 million, and a loss in local sales tax revenue of at least $\$ 20$ million.

\section{Self-Deportation}

Many critics of immigration hope these and other laws and practices will make life so difficult for unauthorized immigrants that they engage in self-deportation by returning to Mexico or their other native countries. According to the Immigration Policy Center (2012), however, there is little evidence that self-deportation actually occurs. A major reason for this fact is that two-thirds of unauthorized adult immigrants have been in the United States for at least ten years, and almost half are parents of children born in the United States (who, as mentioned earlier, are thus US citizens). These adults and their children therefore have established roots in American soil and simply want to stay in the United States.

\section{Detention}

The federal government has the responsibility for detaining and deporting unauthorized immigrants. The number of immigrants detained every year exceeds 360,000, with an average detention length of almost three months; more than 1,000 individuals are detained for over a year. At a cost of more than $\$ 60,000$ per detainee, the annual cost of this detention system exceeds $\$ 21$ billion. Most detainees are in custody for technical violations of immigrant laws, such as overstaying a visa, rather than for serious criminal behavior. As such, they do not pose a public danger.

Debate continues over the extent to which the government should carry out deportation, but critics and even 
immigration judges decry the conditions under which illegal immigrants are detained (Semple, 2011). They say that detainees are denied basic due process rights, such as the right to have a court-appointed attorney. More than four-fifths have no legal representation at all, and those who do receive legal assistance often receive incompetent assistance.

\section{Immigrants and Domestic Violence}

Another immigration issue concerns battered women who are immigrants (Constable, 2012). When women are beaten or otherwise abused by their husbands or boyfriends, it is often difficult for them to leave their abusers (see Chapter 10 "The Changing Family"). But abused immigrant women face a special problem in this regard. Because often they are allowed to live in the United States only because their husbands are legal residents or citizens, they fear deportation if they go to the police and their husband is deported. Other abused immigrant women who are in the United States illegally similarly fear they will be deported if they go to the police. Fortunately, federal law now allows abused immigrant women to apply for legal residency, but many women are not aware of this possibility.

Although our discussion of immigration has painted a critical portrait of many aspects of US immigration policy, the United States actually ranks fairly high among the world's nations in how it treats its immigrants. The Note 15.17 "Lessons from Other Societies" box discusses this international comparison in greater detail.

\section{Lessons from Other Societies}

The Status of Legal Immigrants in Western Democracies

The Migrant Integration Policy Index (MIPEX) is an effort of the British Council and the Migration Policy Group, an international consortium. This index ranks the United States, Canada, and twenty-eight European nations on the extent to which legal immigrants are integrated into each nation's political and economic life and on the path to full citizenship. It also ranks the extent to which each nation has antidiscrimination laws to protect immigrants. Overall, MIPEX consists of 148 policy indicators.

In the latest (2011) MIPEX report, the United States ranked ninth out of the thirty-one states on this index; Sweden ranked first, followed by Portugal and Canada. Summarizing one of the effort's major findings, a news report observed that "strong U.S. antidiscrimination laws protect immigrants and guarantee them equal rights and opportunities, a model for immigration rules elsewhere.” MIPEX also ranked the United States highly on legal immigrants' opportunities for employment, for education, and for reuniting with family members.

At the same time, the MIPEX report noted that the United States denies many immigrants several federal benefits and imposes large fees for certain immigration procedures. It also asserted that US immigration laws are unnecessarily complex and that visa availability is too limited. The relatively lower scores that the United States enjoyed in all these areas led it to lag behind the eight nations that scored higher on the index.

Reacting to the MIPEX report, the director of the Immigration Policy Center in Washington, DC, said the United States would benefit from improving its efforts to integrate immigrants, for example by better helping them learn English, and she warned that federal and state budget cuts threatened to lower the US ranking.

Although the United States, then, ranks fairly high among the world's democracies in the status of its legal immigrants, the higher status enjoyed by immigrants in Canada and some other democracies points to directions the United States should follow to improve its ranking and create a better climate for its immigrants.

Sources: Huddleston \& Niessen, 2011; Restrepo, 2011 


\section{Key Takeaways}

- To understand changes in the size and composition of population, demographers use several concepts, including fertility and birth rates, mortality and death rates, and migration.

- Although overpopulation remains a serious concern, many experts say the world's food supply is sufficient providing that it is distributed efficiently and equitably.

- Although illegal immigration to the United States has dwindled and immigrants are faring well overall, many Americans are concerned about immigration, and several states have passed very restrictive laws concerning immigration.

\section{For Your Review}

1. How concerned are you about population growth and overpopulation? Explain your answer in a brief essay.

2. Before you began reading this chapter, did you think that food scarcity was the major reason for world hunger today? Why do you think a belief in food scarcity is so common among Americans?

3. Do you think nations with low birth rates should provide incentives for women to have more babies? Why or why not?

4. If immigrants seem to be faring fairly well in the United States, as the text explains, why do you think so many Americans have negative attitudes about immigration and immigrants? Explain your answer.

\section{References}

Archibold, R. C. (2010, April 24). Arizona enacts stringent law on immigration. New York Times, p. A1.

Berman, J. (2011, November 28). Georgia immigration law could have dire consequences for state's economy: Study. The Huffington Post. Retrieved from http://www.huffingtonpost.com/2011/2010/2005/georgiaimmigration-law-economy n_995889.html.

Brooks, D. (2012, March 13). The population implosion. New York Times, p. A25.

Brown, R. (2011, May 14). Georgia gives police added power to seek out illegal immigrants. New York Times, p. A12.

Constable, P. (2012, February 8). For battered immigrant women, fear of deportation becomes abusers' weapon, but 2 laws can overcome that. The Washington Post. Retrieved from http://www.washingtonpost.com/local/forbattered-immigrant-women-fear-of-deportation-becomes-abusers-weapon/2012/01/30/gIQAZCx3zQ story.html.

Daniels, R. (2002). Coming to America: A history of immigration and ethnicity in American life. New York, NY: Harper Perennial. 
DeFrancesco Soto, V. M. (2012, February 24). Anti-immigrant rhetoric is anti-Latino. The Nation. Retrieved from http://www.thenation.com/blog/166442/anti-immigrant-rhetoric-anti-latino.

Dzwonkowski, R. (2010, September 19). New leaders can’t shrink from Michigan realities. Detroit Free Press, p. 2A.

Ehrlich, P. R. (1969). The population bomb. San Francisco, CA: Sierra Club.

Gillis, J. (2011, June 5). A warm planet struggles to feed itself. New York Times, p. A1.

Gillis, J., \& Dugger, C. W. (2011, May 4). UN forecasts 10.1 million by century’s end. New York Times, p. A1.

Gleditsch, N. P., \& Theisen, O. M. (2010). Resources, the environment and conflict. In M. D. Cavelty \& V. Mauer (Eds.), The Routledge handbook of security studies (pp. 221-232). New York, NY: Routledge.

Haartsen, T., \& Venhorst, V. (2010). Planning for decline: Anticipating on population decline in the Netherlands. Tijdschrift voor Economische en Sociale Geografie (Journal of Economic \& Social Geography), 101(2), $218-227$.

Hamilton, B. E., Martin, J. A., \& Ventura, S. J. (2011). Births: Preliminary data for 2010. National Vital Statistics Reports, 60(2), 1-14.

Haub, C. (2009). Birth rates rising in some low birth-rate countries. Washington, DC: Population Reference Bureau. Retrieved from http://www.prb.org/Articles/2009/fallingbirthrates.aspx.

Huddleston, T., \& Niessen, J. (2011). Migrant integration policy index III. Brussels, Belgium: British Council and Migration Policy Group.

Immigration Policy Center. (2012). Strength in diversity: The economic and political power of immigrants, Latinos, and Asians. Washington, DC: Author.

Immigration Policy Center. (2012). The real meaning of “self-deportation.” Washington, DC: Author.

King, R. (2011, June 1). Global food crisis: The challenge of changing diets. The Guardian. Retrieved from http://www.guardian.co.uk/global-development/poverty-matters/2011/jun/01/global-food-crisis-changing-diets.

Lee, M. J. (2012, February 1). Alabama immigration law costs $\$ 11$ billion, study shows. Politico. Retrieved from http://www.politico.com/news/stories/0212/72308.html.

Malthus, T. R. (1926). First essay on population. London, United Kingdom: Macmillan. (Oringal work published 1798).

Myers, D. (2012, January 12). The next immigration challenge. New York Times, p. A27.

Ott, T. (2012, February 7). Alabama’s immigration law may get a second look. National Public Radio. Retrived from http://www.npr.org/2012/2002/2007/146490508/alabamas-immigration-law-may-get-a-second-look.

Pfaelzer, J. (2008). Driven out: The forgotten war against Chinese Americans. Berkeley, CA: University of California Press. 
PollingReport.com. (2012). Immigration. Retrieved February 8, 2012, from http://www.pollingreport.com/ immigration.htm.

Population Reference Bureau. (2012). World population growth, 1950-2050. Retrieved February 4, 2012, from http://www.prb.org/Educators/TeachersGuides/HumanPopulation/PopulationGrowth.aspx.

Restrepo, M. (2011, March 1). International study points out US immigration policy successes, failures. The American Independent. Retrieved from http://www.americanindependent.com/171724/international-study-pointsout-u-s-immigration-policy-successes-failures.

Roediger, D. R. (2006). Working toward whiteness: How America’s immigrants became white. New York, NY: Basic Books.

Rosenberg, M. (2012). Population growth rates. Retrieved from http://geography.about.com/od/ populationgeography/a/populationgrow.htm.

Sampson, R. J. (2008). Rethinking crime and immigration. Contexts, 7(2), 28-33.

Scanlan, S. J., Jenkins, J. C., \& Peterson, L. (2010). The scarcity fallacy. Contexts, 9(1), 34-39.

Semple, K. (2011, December 19). In a study, judges express a bleak view of lawyers representing immigrants. New York Times, p. A24.

Sutton, P. D., \& Hamilton, B. E. (2011). Recent trends in births and fertility rates through 2010. Washington, DC: Centers for Disease Control and Prevention.

Wadsworth, T. (2010). Is immigration responsible for the crime drop? An assessment of the influence of immigration on changes in violent crime between 1990 and 2000. Social Science Quarterly, 91, 531-553.

Walsh, B. (2011, October 26). Why the real victim of overpopulation will be the environment. Time. Retrieved from http://www.time.com/time/specials/packages/article/0,28804,2097720_2097782 2097814,00.html.

Weeks, J. R. (2012). Population: An introduction to concepts and issues (11th ed.). Belmont, CA: Wadsworth.

Wilkerson, I. (2011). The warmth of other suns: The epic story of America's great migration New York, NY: Vintage Books.

Yardley, J. (2010, August 22). India tries using cash bonuses to slow birthrates. New York Times, p. A8. 


\subsection{The Environment}

\section{Learning Objectives}

1. List two reasons that make the environment an appropriate topic for sociologists to study.

2. Describe two of the environmental problems facing the world today.

3. Describe what is meant by the assertion that environmental problems are human problems.

4. Explain the concepts of environmental inequality and environmental racism.

5. Understand the various environmental problems that exist today.

At first glance, the environment does not seem to be a sociological topic. The natural and physical environment is something that geologists, meteorologists, oceanographers, and other scientists should be studying, not sociologists. Yet we have just discussed how the environment is affected by population growth, and that certainly sounds like a sociological discussion. In fact, the environment is very much a sociological topic for several reasons.

First, our worst environmental problems are the result of human activity, and this activity, like many human behaviors, is a proper topic for sociological study. This textbook has discussed many behaviors: racist behavior, sexist behavior, criminal behavior, sexual behavior, and others. Just as these behaviors are worthy of sociological study, so are the behaviors that harm (or try to improve) the environment.

Second, environmental problems have a significant impact on people, as do the many other social problems that sociologists study. We see the clearest evidence of this impact when a major hurricane, an earthquake, or another natural disaster strikes. In January 2010, for example, a devastating earthquake struck Haiti and killed more than 250,000 people, or about 2.5 percent of that nation's population. The effects of these natural disasters on the economy and society of Haiti will certainly also be felt for many years to come. 


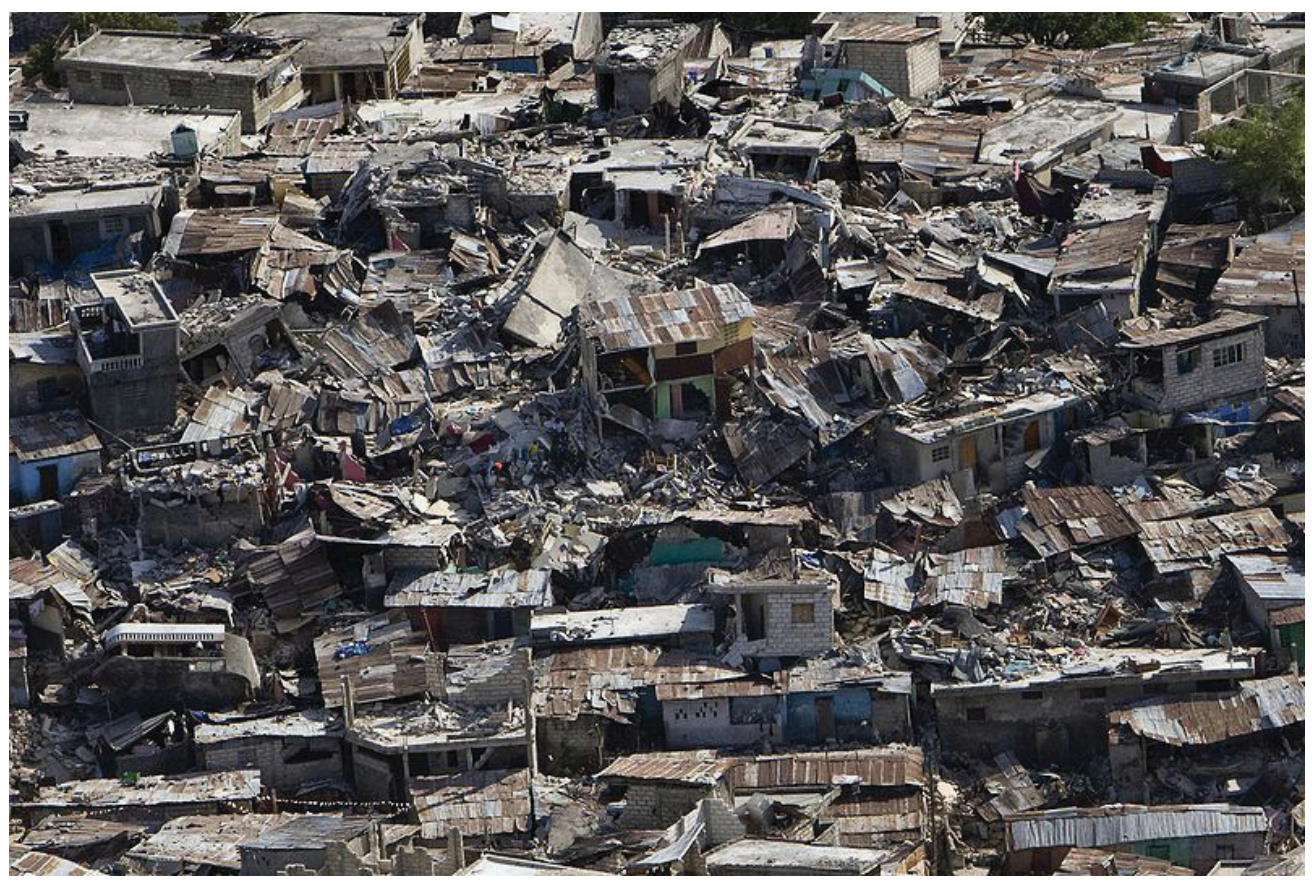

As is evident in this photo taken in the aftermath of the 2010 earthquake that devastated Haiti, changes in the natural environment can lead to profound changes in a society. Environmental changes are one of the many sources of social change.

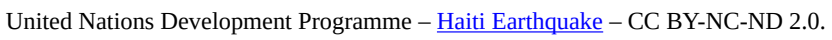

Slower changes in the environment can also have a large social impact. As noted earlier, industrialization and population growth have increased the pollution of our air, water, and ground. Climate change, a larger environmental problem, has also been relatively slow in arriving but threatens the whole planet in ways that climate change researchers have documented and will no doubt be examining for the rest of our lifetimes and beyond. We return to these two environmental problems shortly.

A third reason the environment is a sociological topic is a bit more complex: Solutions to our environmental problems require changes in economic and environmental policies, and the potential implementation and impact of these changes depends heavily on social and political factors. In the United States, for example, the two major political parties, corporate lobbyists, and environmental organizations regularly battle over attempts to strengthen environmental regulations.

A fourth reason is that many environmental problems reflect and illustrate social inequality based on social class and on race and ethnicity: As with many problems in our society, the poor and people of color often fare worse when it comes to the environment. We return to this theme later in our discussion of environmental racism.

Fifth, efforts to improve the environment, often called the environmental movement, constitute a social movement and, as such, are again worthy of sociological study. Sociologists and other social scientists have conducted many studies of why people join the environmental movement and of the impact of this movement. 


\section{Environmental Sociology}

All these reasons suggest that the environment is quite fittingly a sociological topic, and one on which sociologists should have important insights. In fact, so many sociologists study the environment that their collective study makes up a subfield in sociology called environmental sociology, which refers simply to the sociological study of the environment. More specifically, environmental sociology is the study of the interaction between human behavior and the natural and physical environment. According to a report by the American Sociological Association, environmental sociology "has provided important insights” (Nagel, Dietz, \& Broadbent, 2010, p. 13) into such areas as public opinion about the environment, the influence of values on people's environmental behavior, and inequality in the impact of environmental problems on communities and individuals.

Environmental sociology assumes "that humans are part of the environment and that the environment and society can only be fully understood in relation to each other” (McCarthy \& King, 2009, p. 1). Because humans are responsible for the world's environmental problems, humans have both the ability and the responsibility to address these problems. As sociologists Leslie King and Deborah McCarthy (2009, p. ix) assert, "We both strongly believe that humans have come to a turning point in terms of our destruction of ecological resources and endangerment of human health. A daily look at the major newspapers points, without fail, to worsening environmental problems...Humans created these problems and we have the power to resolve them. Naturally, the longer we wait, the more devastating the problems will become; and the more we ignore the sociological dimensions of environmental decline the more our proposed solutions will fail.”

Environmental sociologists emphasize two important dimensions of the relationship between society and the environment: (a) the impact of human activity and decision making and (b) the existence and consequences of environmental inequality and environmental racism. We now turn to these two dimensions.

\section{Human Activity and Decision Making}

Perhaps more than anything else, environmental sociologists emphasize that environmental problems are the result of human decisions and activities that harm the environment. Masses of individuals acting independently of each other make decisions and engage in activities that harm the environment, as when we leave lights on, keep our homes too warm in the winter or too cool in the summer, and drive motor vehicles that get low gas mileage. Corporations, government agencies, and other organizations also make decisions and engage in practices that greatly harm the environment. Sometimes individuals and organizations know full well that their activities are harming the environment, and sometimes they just act carelessly without much thought about the possible environmental harm of their actions. Still, the environment is harmed whether or not individuals, corporations, and governments intend to harm it.

A major example of the environmental harm caused by human activity was the British Petroleum (BP) oil spill that began in April 2010 when an oil rig leased by BP exploded in the Gulf of Mexico and eventually released almost 5 million barrels of oil (about 200 million gallons) into the ocean. Congressional investigators later concluded that BP had made a series of decisions that "increased the danger of a catastrophic well," including a decision to save money by using an inferior casing for the well that made an explosion more likely. A news report paraphrased 
the investigators as concluding that "some of the decisions appeared to violate industry guidelines and were made despite warnings from BP’s own employees and outside contractors” (Fountain, 2010, p. A1).

Sociologists McCarthy and King (2009) cite several other environmental accidents that stemmed from reckless decision making and natural disasters in which human decisions accelerated the harm that occurred. One accident occurred in Bhopal, India, in 1984, when a Union Carbide pesticide plant leaked forty tons of deadly gas. Between 3,000 and 16,000 people died immediately and another half million suffered permanent illnesses or injuries. A contributing factor for the leak was Union Carbide's decision to save money by violating safety standards in the construction and management of the plant.

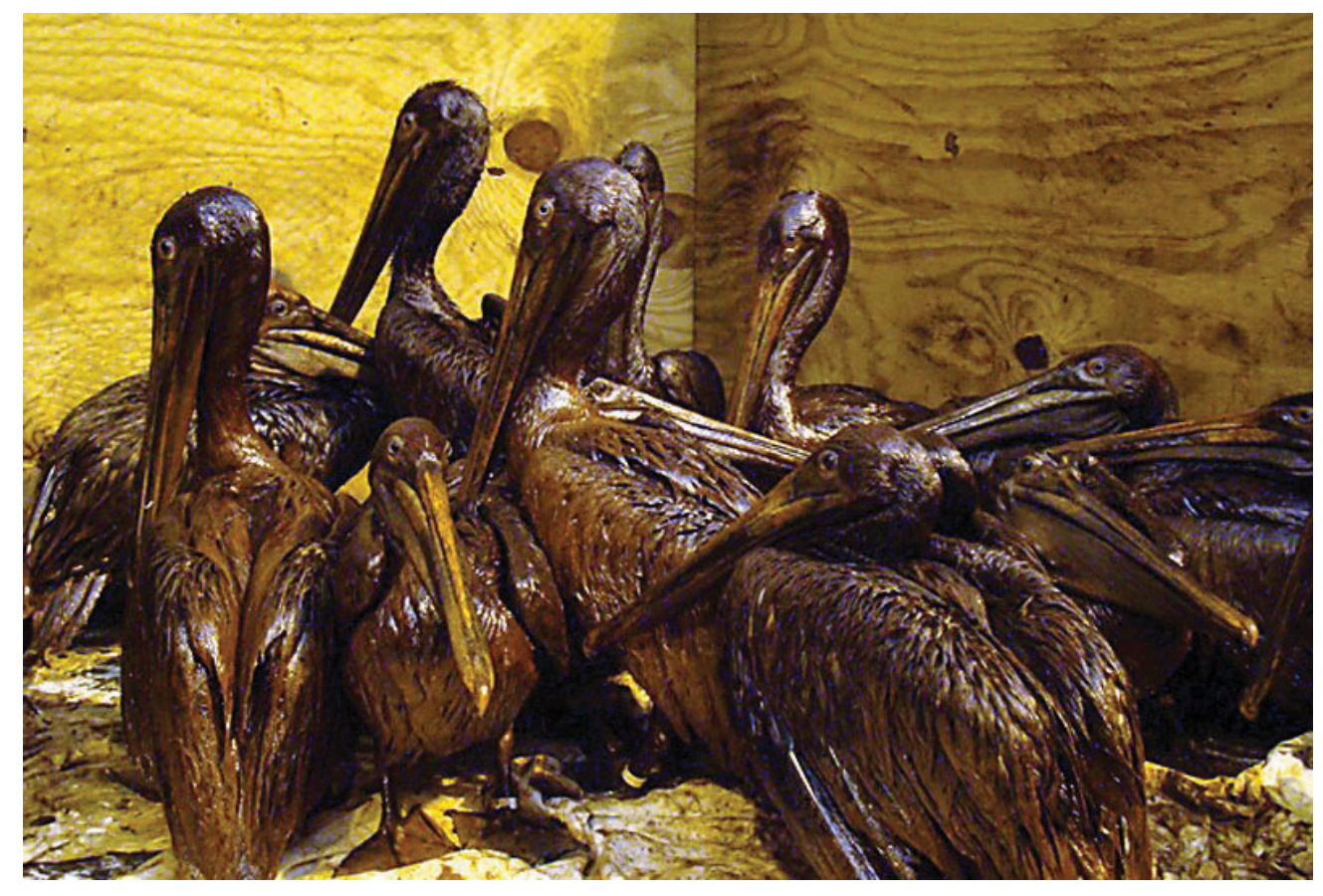

The April 2010 BP oil spill occurred after BP made several decisions that may have increased the possibility of a catastrophic explosion of the well.

International Bird Rescue Research Center - Gulf Oiled Pelicans June 3, 2010 - CC BY 2.0.

A second preventable accident was the 1989 Exxon Valdez oil tanker disaster, in which the tanker hit ground off the coast of Alaska and released 11 million gallons of oil into Prince William Sound. Among other consequences, the spill killed hundreds of thousands of birds and marine animals and almost destroyed the local fishing and seafood industries. The immediate cause of the accident was that the ship's captain was an alcoholic and left the bridge in the hands of an unlicensed third mate after drinking five double vodkas in the hours before the crash occurred. Exxon officials knew of his alcoholism but let him command the ship anyway. Also, if the ship had had a double hull (one hull inside the other), it might not have cracked on impact or at least would have released less oil, but Exxon and the rest of the oil industry had successfully lobbied Congress not to require stronger hulls.

Hurricane Katrina was a more recent environmental disaster in which human decision making resulted in a great deal of preventable damage. After Katrina hit the Gulf Coast and especially New Orleans in August 2005, the resulting wind and flooding killed more than 1,800 people and left more than 700,000 homeless. McCarthy and King (2009, p. 4) attribute much of this damage to human decision making: "While hurricanes are typically 
considered 'natural disasters,' Katrina's extreme consequences must be considered the result of social and political failures.” Long before Katrina hit, it was well known that a major flood could easily breach New Orleans levees and have a devastating impact. Despite this knowledge, US, state, and local officials did nothing over the years to strengthen or rebuild the levees. In addition, coastal land that would have protected New Orleans had been lost over time to commercial and residential development. In short, the flooding after Katrina was a human disaster, not a natural disaster.

\section{Environmental Inequality and Environmental Racism}

A second emphasis of environmental sociology is environmental inequality and the related concept of environmental racism. Environmental inequality (also called environmental injustice) refers to the fact that lowincome people and people of color are disproportionately likely to experience various environmental problems, while environmental racism refers just to the greater likelihood of people of color to experience these problems (Walker, 2012). The term environmental justice refers to scholarship on environmental inequality and racism and to public policy efforts and activism aimed at reducing these forms of inequality and racism. The Note 15.25 “Applying Social Research” box discusses some very significant scholarship on environmental racism.

\section{Applying Social Research}

Environmental Racism in the Land of Cotton

During the 1970s, people began to voice concern about the environment in the United States and across the planet. As research on the environment grew by leaps and bounds, some scholars and activists began to focus on environmental inequality in general and on environmental racism in particular. During the 1980s and 1990s, their research and activism spawned the environmental justice movement that has since shed important light on environmental inequality and racism and helped reduce these problems.

Research by sociologists played a key role in the beginning of the environmental justice movement and continues to play a key role today. Robert D. Bullard of Clark Atlanta University stands out among these sociologists for the impact of his early work in the 1980s on environmental racism in the South and for his continuing scholarship since then. He has been called "the father of environmental justice" and was named by Newsweek as one of the thirteen most influential environmental leaders of the twentieth century, along with environmental writer Rachel Carson, former vice president $\mathrm{Al}$ Gore, and ten others.

Bullard's first research project on environmental racism began in the late 1970s after his wife, an attorney, filed a lawsuit on behalf of black residents in Atlanta who were fighting the placement of a landfill in their neighborhood. To collect data for the lawsuit, Bullard studied the placement of landfills in other areas. He found that every city-owned landfill in Houston was in a black neighborhood, even though African Americans amounted to only one-fourth of Houston residents at the time. He also found that three out of four privately owned landfills were in black neighborhoods, as were six of the eight city-owned incinerators. He extended his research to other locations and later recalled what he discovered: "Without a doubt, it was a form of apartheid where whites were making decisions and black people and brown people and people of color, including Native Americans on reservations, had no seat at the table."

In 1990, Bullard published his findings in his book Dumping in Dixie: Race, Class, and Environmental Quality. This book described the systematic placement in several Southern states of toxic waste sites, landfills, and chemical plants in communities largely populated by low-income residents and/or African Americans. Dumping in Dixie was the first book to examine environmental racism and is widely credited with helping advance the environmental justice movement. It received some notable awards, including the Conservation Achievement Award from the National Wildlife Federation. 
More recently, Bullard, along with other sociologists and scholars from other disciplines, has documented the impact of race and poverty on the experience of New Orleans residents affected by the flooding after Hurricane Katrina. As in many other cities, African Americans and other low-income people largely resided in the lower elevations in New Orleans, and whites and higher-income people largely resided in the higher elevations. The flooding naturally had a much greater impact on the lower elevations and thus on African Americans and the poor. After the flood, African Americans seeking new housing in various real estate markets were more likely than whites to be told that no housing was available.

Bullard's early work alerted the nation to environmental racism and helped motivate the Environmental Protection Agency in the 1990s to begin paying attention to it. His various research efforts are an outstanding example of how social research can increase understanding of a significant social problem.

Sources: Bullard, 1990; Bullard \& Wright, 2009; Dicum, 2006

According to the American Sociological Association report mentioned earlier, the emphasis of environmental sociology on environmental inequality reflects the emphasis that the larger discipline of sociology places on social inequality: "A central finding of sociology is that unequal power dynamics shape patterns of social mobility and access to social, political, and economic resources” (Nagel et al., 2010, p. 17). The report adds that global climate change will have its greatest effects on the poorest nations: "Many of the countries least responsible for the rise in greenhouse gases will be most likely to feel its impacts in changes in weather, sea levels, health care costs, and economic hardships” (Nagel et al., 2010, p. 17).

Examples of environmental racism and inequality abound. Almost all the hazardous waste sites we discuss later in this chapter are located in or near neighborhoods and communities that are largely populated by low-income people and people of color. When factories dump dangerous chemicals into rivers and lakes, the people living nearby are very likely to be low-income and of color. Around the world, the people most affected by climate change and other environmental problems are those in poor nations and, even within those nations, those who are poorer rather than those who are wealthier.

Some evidence shows that although low-income people are especially likely to be exposed to environmental problems, this exposure is even more likely if they are people of color than if they are white. As a review of this evidence concluded, "It would be fair to summarize this body of work as showing that the poor and especially the nonwhite poor bear a disproportionate burden of exposure to suboptimal, unhealthy environmental conditions in the United States. Moreover, the more researchers scrutinize environmental exposure and health data for racial and income inequalities, the stronger the evidence becomes that grave and widespread environmental injustices have occurred throughout the United States” (Evans \& Kantrowitz, 2002, p. 323).

As should be apparent from the discussion in this section, the existence of environmental inequality and environmental racism shows that social inequality in the larger society exposes some people much more than others to environmental dangers. This insight is one of the most important contributions of environmental sociology. 


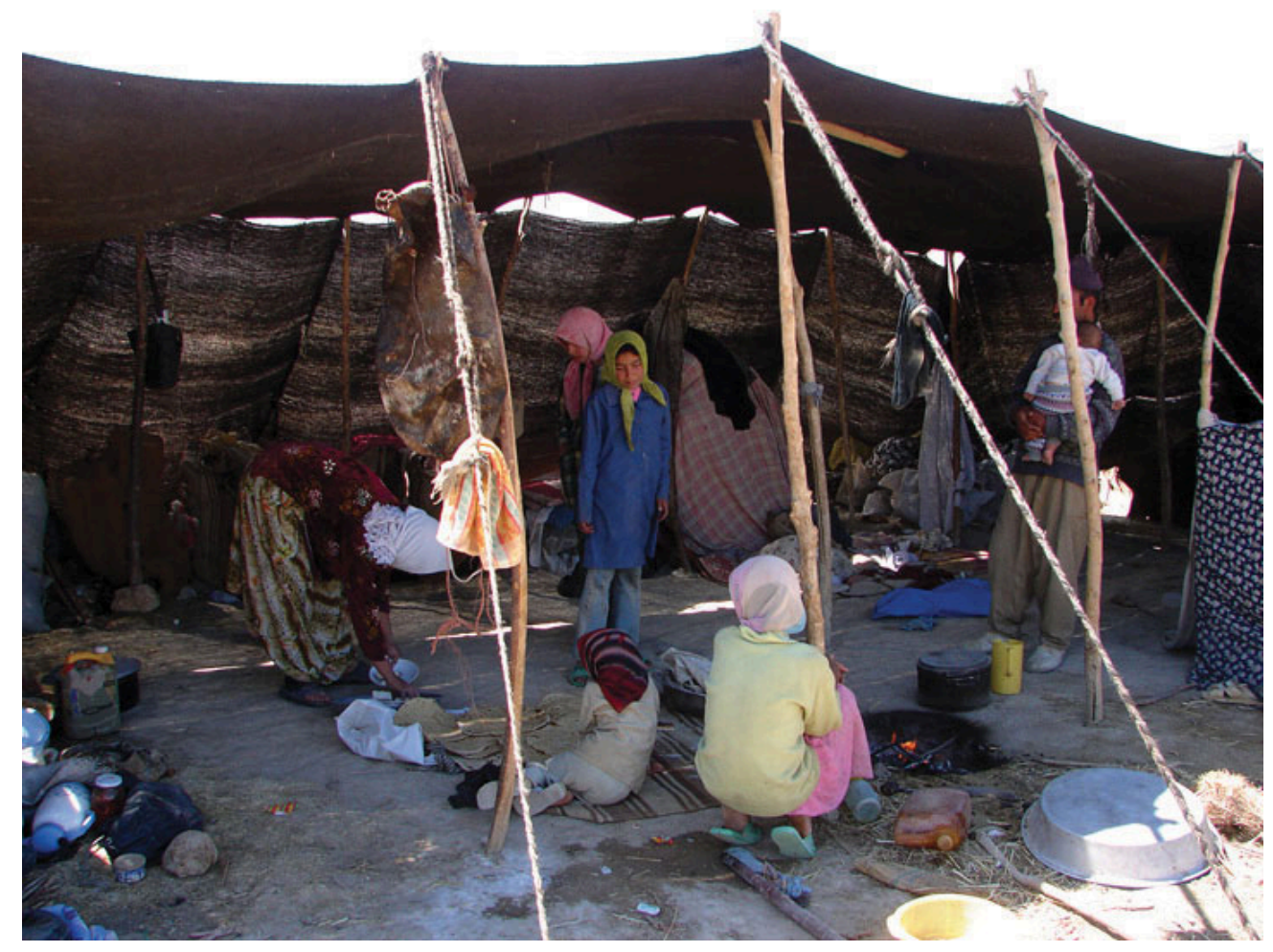

Global climate change is very likely to have its greatest impact on people in the poorest nations, even though these nations are the least responsible for greenhouse gases.

Hamed Saber - The Nomad's Simple Life - CC BY 2.0.

\section{Environmental Problems}

To say that the world is in peril environmentally might sound extreme, but the world is in fact in peril. An overview of environmental problems will indicate the extent and seriousness of this problem. 


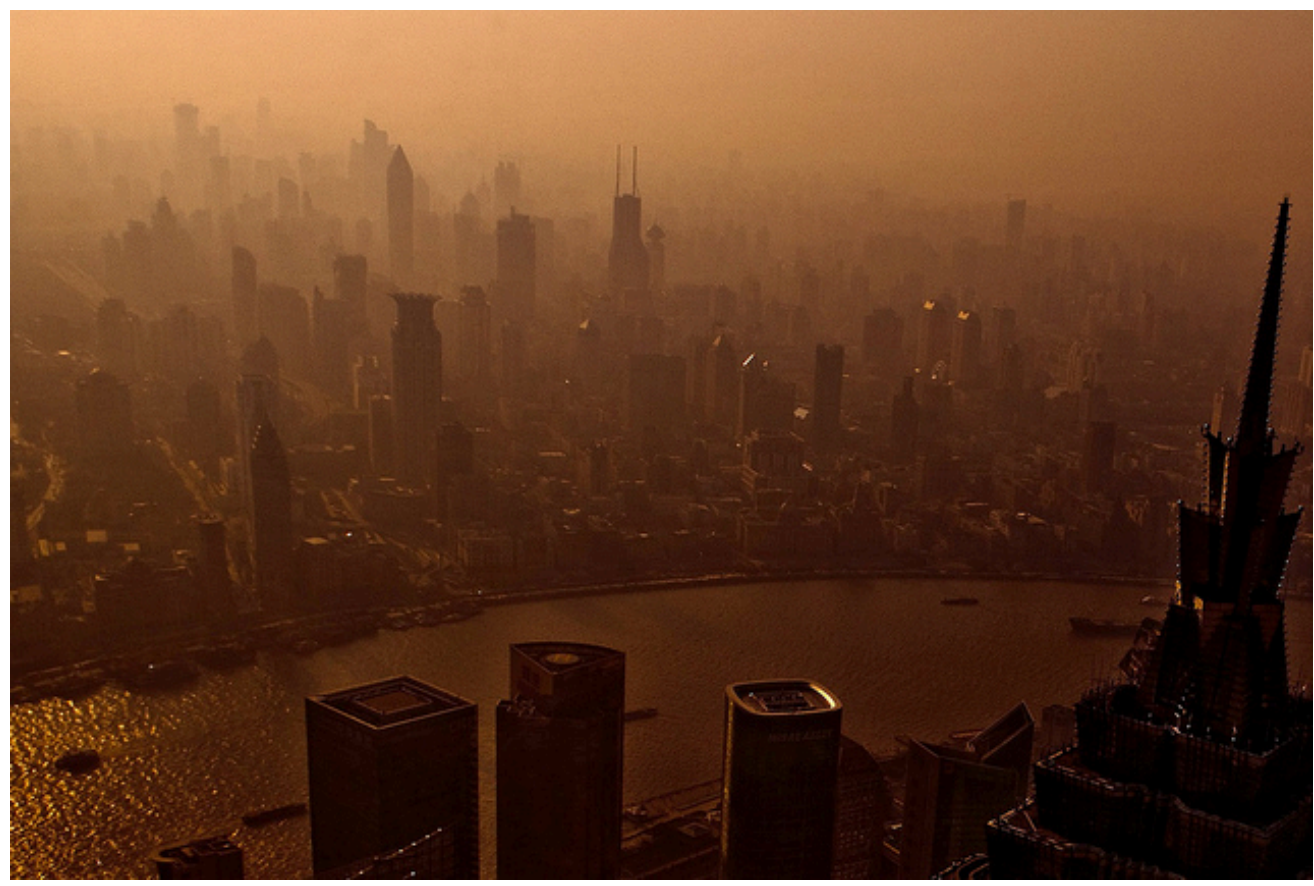

Air pollution probably kills thousands of Americans every year and 2 million people across the planet.

Lei Han - Shanghai - CC BY-NC-ND 2.0.

\section{Air Pollution}

Estimates of the annual number of US deaths from air pollution range from a low of 10,000 to a high of 60,000 (Reiman \& Leighton, 2010). The worldwide toll is much greater, and the World Health Organization (2011) estimates that 1.3 million people across the globe die every year from air pollution.

These deaths stem from the health conditions that air pollution causes, including heart disease, lung cancer, and respiratory disease such as asthma. Most air pollution stems from the burning of fossil fuels such as oil, gas, and coal. This problem occurs not only in the wealthy industrial nations but also in the nations of the developing world; countries such as China and India have some of the worst air pollution. In developing nations, mortality rates of people in cities with high levels of particulate matter (carbon, nitrates, sulfates, and other particles) are 15-50 percent higher than the mortality rates of those in cleaner cities. In European countries, air pollution is estimated to reduce average life expectancy by 8.6 months. The World Health Organization (2011) does not exaggerate when it declares that air pollution "is a major environmental health problem affecting everyone in developed and developing countries alike.”

Pollution of many types especially harms children's health. The Note 15.26 “Children and Our Future” box discusses this harm in greater detail. 


\section{Children and Our Future}

Children and Environmental Health Hazards

As we consider environmental problems, we must not forget the world's children, who are at special risk for environmental health problems precisely because they are children. Their bodies and brains grow rapidly, and they breathe in more air per pound of body weight than adults do. They also absorb substances, including toxic substances from their gastrointestinal tract faster than adults do.

These and other physiological differences all put children at greater risk than adults for harm from environmental health hazards. Children's behavior also puts them at greater risk. For example, no adult of normal intelligence would eat paint chips found on the floor, but a young child can easily do so. Children also play on lawns, playgrounds, and other areas in which pesticides are often used, and this type of activity again gives them greater exposure. Young children also put their hands in their mouths regularly, and any toxins on their hands are thereby ingested.

Poverty compounds all these problems. Poor children are more likely to live in houses with lead paint, in neighborhoods with higher levels of air pollution, and in neighborhoods near to hazardous waste sites. Poor children of color are especially at risk for these environmental problems.

Three of the greatest environmental health hazards for children are lead, pesticides, and air pollution. Lead can cause brain and nervous system damage, hearing problems, and delayed growth among other effects; pesticides can cause various problems in the immune, neurological, and respiratory systems; and air pollution can cause asthma and respiratory illnesses. All these health problems can have lifelong consequences.

Unfortunately, certain environmentally induced health problems for children are becoming more common. For example, US children's asthma cases have increased by more than 40 percent since 1980, and more than four hundred American children now have asthma. Two types of childhood cancer thought to stem at least partly from environmental hazards have also increased during the past two decades: acute lymphocytic by 10 percent and brain tumors by 30 percent.

It should be evident from this overview that environmental health hazards pose a serious danger for children in the United States and the rest of the world. Because children are our future, this danger underscores the need to do everything possible to improve the environment.

Source: Children’s Environmental Health Network, 2009

\section{Global Climate Change}

The burning of fossil fuels also contributes to global climate change, often called global warming, thanks to the oft-discussed greenhouse effect caused by the trapping of gases in the atmosphere that is turning the earth warmer, with a rise of almost $1^{\circ} \mathrm{C}$ during the past century. In addition to affecting the ecology of the earth's polar regions and ocean levels throughout the planet, climate change threatens to produce a host of other problems, including increased disease transmitted via food and water, malnutrition resulting from decreased agricultural production and drought, a higher incidence of hurricanes and other weather disasters, and extinction of several species (Gillis \& Foster, 2012; Zimmer, 2011). All these problems have been producing, and will continue to produce, higher mortality rates across the planet. The World Health Organization (2010) estimates that climate change causes more than 140,000 excess deaths worldwide annually. 


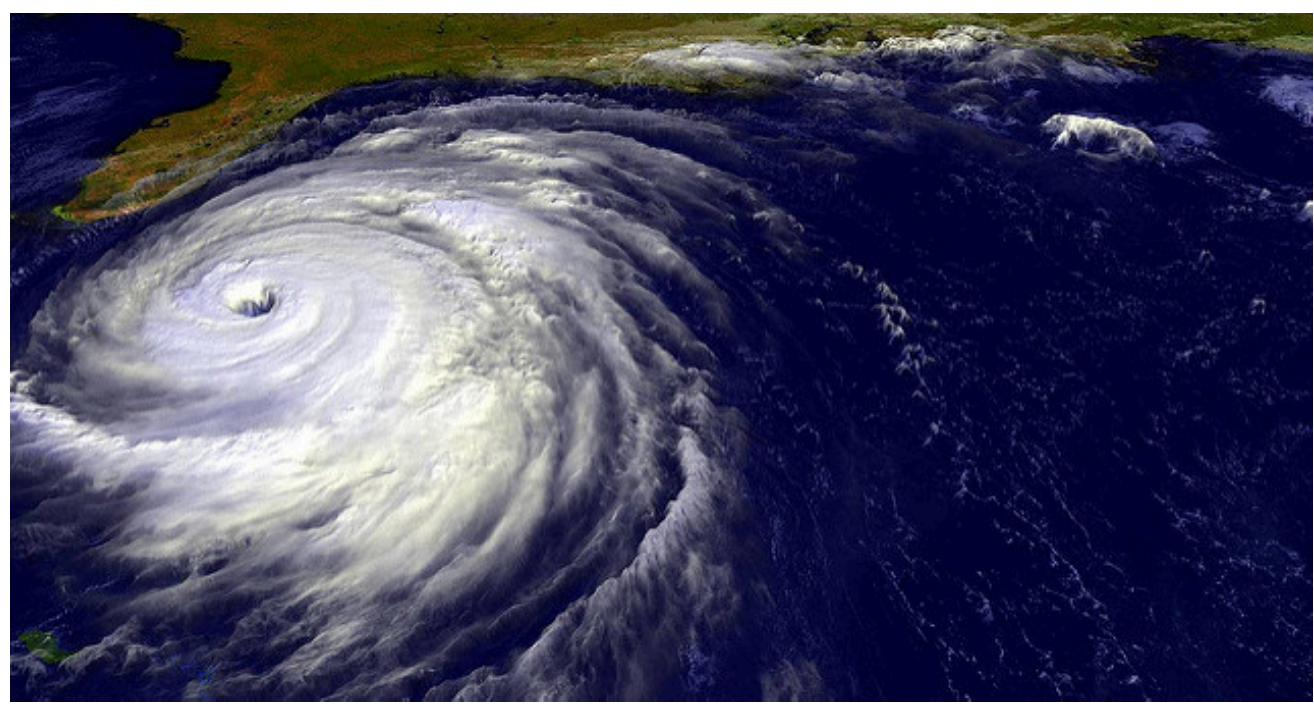

Climate change is causing many problems, including weather disasters such as the one depicted here.

kakela - Hurricane Jeanne - CC BY-NC-ND 2.0.

Another problem caused by climate change may be interpersonal violence and armed conflict (Agnew, 2012; Fisman \& Miguel, 2010; Kristof, 2008), already discussed as a consequence of population growth. Historically, when unusual weather events have caused drought, flooding, or other problems, violence and armed conflict have resulted. For example, witch-burnings in medieval Europe accelerated when extremely cold weather ruined crops and witches were blamed for the problem. Economic problems from declining farm values are thought to have increased the lynchings of African Americans in the US South. As crops fail from global warming and reduced rainfall in the years ahead, African populations may plunge into civil war: According to an Oxford University economist, having a drought increases by 50 percent the chance that an African nation will have a civil war a year later (Kristof, 2008).

As we consider climate change, it is important to keep in mind certain inequalities mentioned earlier (McNall, 2011). First, the world's richest nations contribute more than their fair share to climate change. The United States, Canada, France, Germany, and the United Kingdom compose 15 percent of the world's population but are responsible for half of the planet's carbon dioxide emissions. Second, the effects of climate change are more severe for poor nations than for rich nations. Africans, for example, are much less able than Americans to deal with the effects of drought, weather disasters, and the other problems caused by climate change.

Although almost all climate scientists believe that climate change is a serious problem and stems from human behavior, 28 percent of Americans in a November 2011 poll responded "no" when asked, "Is there solid evidence the earth is warming?” Another 18 percent said solid evidence does exist but that global warming is occurring because of "natural patterns" rather than "human activity." Only 38 percent agreed with climate scientists' belief that global warming exists and that it arises from human activity (Pew Research Center, 2011).

Overall, 63 percent of respondents agreed that solid evidence of global warming exists (leaving aside the question of why it is occurring). This figure differed sharply by political party preference, however: Whereas 77 percent of Democrats said solid evidence exists, only 43 percent of Republicans and 63 percent of Independents shared this 
opinion. Similarly, whereas 55 percent of Democrats said global warming is a "very serious” problem, only 14 percent of Republicans and 39 percent of Independents felt this way (Pew Research Center, 2011).

\section{Water Pollution and Inadequate Sanitation}

Water quality is also a serious problem. Drinking water is often unsafe because of poor sanitation procedures for human waste in poor nations and because of industrial discharge into lakes, rivers, and streams in wealthy nations. Inadequate sanitation and unsafe drinking water cause parasitic infections and diseases such as diarrhea, malaria, cholera, intestinal worms, typhoid, and hepatitis A. The World Health Organization estimates that unsafe drinking water and inadequate sanitation cause the following number of annual deaths worldwide: (a) 2.5 million deaths from diarrhea, including 1.4 million child deaths from diarrhea; (b) 500,000 deaths from malaria; and (c) 860,000 child deaths from malnutrition. At least 200 million more people annually suffer at least one of these serious diseases due to inadequate sanitation and unsafe drinking water (Cameron, Hunter, Jagals, \& Pond, 2011; Prüss-Üstün, Bos, Gore, \& Bartram, 2008).

\section{Nuclear Power}

Nuclear power has been an environmental controversy at least since the 1970s. Proponents of nuclear power say it is a cleaner energy than fossil fuels such as oil and coal and does not contribute to global warming. Opponents of nuclear power counter that nuclear waste is highly dangerous no matter how it is disposed, and they fear meltdowns that can result if nuclear power plant cores overheat and release large amounts of radioactive gases into the atmosphere.

The most serious nuclear plant disaster involved the Chernobyl plant in Ukraine in 1986. Chernobyl's core exploded and released radioactive gases into the atmosphere that eventually spread throughout Europe. The amount of radiation released was four hundred times greater than the amount released by the atomic bomb that devastated Hiroshima at the end of World War II. About five-dozen people (Chernobyl workers or nearby residents) soon died because of the disaster. Because radiation can cause cancer and other health problems that take years to develop, scientists have studied the health effects of the Chernobyl disaster for the last quartercentury. According to the United Nations Scientific Committee of the Effects of Atomic Radiation (UNSCEAR), an estimated 27,000 additional cancer deaths worldwide will eventually result from the Chernobyl disaster (Gronlund, 2011).

Seven years earlier in March 1979, a nuclear disaster almost occurred in the United States at the Three Mile Island plant in central Pennsylvania. A series of technological and human failures allowed the plant's core to overheat to almost disastrous levels. The nation held its breath for several days while officials sought to bring the problem under control. During this time, some 140,000 people living within twenty miles of the plant were evacuated. The near disaster severely weakened enthusiasm for nuclear power in the United States, and the number of new nuclear plants dropped sharply in the ensuing two decades (Fischer, 1997).

Japan was the site of the worst nuclear disaster since Chernobyl in March 2011, when an earthquake and tsunami seriously damaged a nuclear plant in the Fukushima region, 155 miles north of Tokyo. More than 80,000 residents 
had to be evacuated because of the massive release of radioactive gases and water, and they remained far from their homes a year later as high levels of radiation continued to be found in the evacuated area. A news report on the anniversary of the disaster described the desolation that remained: "What's most striking about Japan's nuclear exclusion zone is what you don't see. There are no people, few cars, no sign of life, aside from the occasional livestock wandering empty roads. Areas once home to 80,000 people are now ghost towns, frozen in time. Homes ravaged from the powerful earthquake that shook this region nearly a year ago remain virtually untouched. Collapsed roofs still block narrow streets. Cracked roads make for a bumpy ride” (Fujita, 2012). It will take at least thirty years to fully decommission the damaged reactors at Fukushima. The news report said, "This nuclear wasteland may not be livable for decades” (Fujita, 2012).

In February 2012, the US Nuclear Regulatory Commission (NRC) issued a study that said the risk from nuclear power accidents in the United States was “very small.” If an accident should occur, the NRC concluded, plant operators would have time to cool down reactor cores and prevent or reduce the emission of radiation (DiSavino, 2012). However, the Union of Concerned Scientists (UCS) is more concerned about this risk (Union of Concerned Scientists, 2011). It says that several US reactors are of the same design as the Fukushima reactors and thus potentially at risk for a similar outcome if damaged by an earthquake. According to the UCS, "If [these reactors] were confronted with a similar challenge, it would be foolish to assume the outcome would not also be similar." It adds that although earthquakes can cause fires at reactors, US plants routinely violate fire protection standards. A news report on the similarities between US nuclear power plants and the Fukushima plant reached a similar conclusion, noting that US nuclear power plants "share some or all of the risk factors that played a role at Fukushima” (Zeller, 2011).

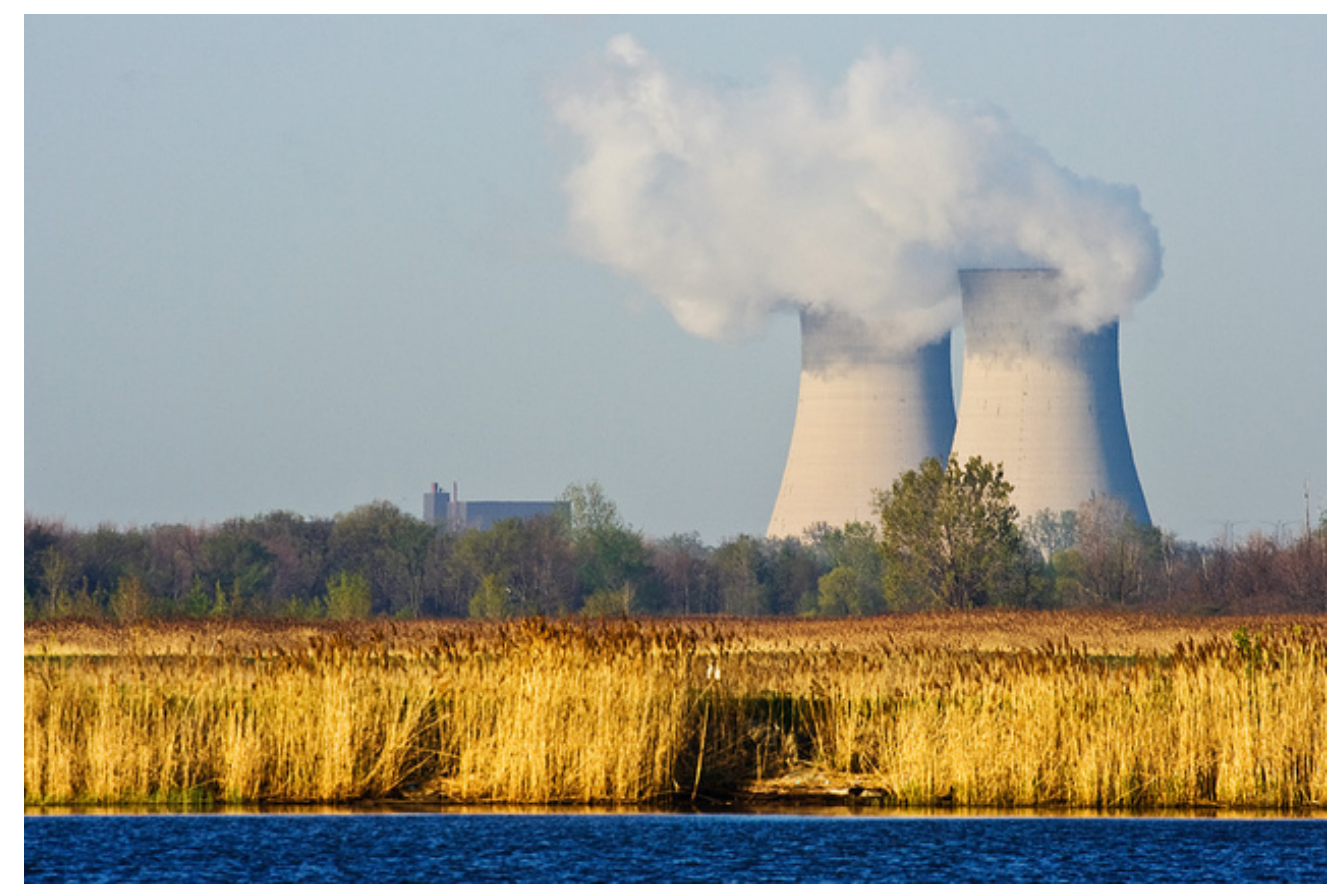

Critics say many US nuclear plants lack adequate protection against several kinds of dangers.

James Marvin Phelps - Nuclear Wetlands - CC BY-NC 2.0.

As this conclusion implies, nuclear power critics say NRC oversight of the nuclear industry is too lax. A 2011 investigation by the Associated Press (AP) yielded support for this criticism (Donn, 2011). The AP found that 
the NRC has been "working closely with the nuclear power industry to keep the nation's aging reactors operating within safety standards by repeatedly weakening those standards or simply failing to enforce them.” The report continued, "Time after time, officials at the [NRC] have decided that original regulations were too strict, arguing that safety margins could be eased without peril.” For example, when certain valves at nuclear plants leaked, the NRC revised its regulations to permit more leakage. Also, when cracking of steam generator tubes allowed radiation to leak, standards on tubing strength were weakened. And when reactors began to violate temperature standards, the NRC almost doubled the permitted temperatures. The investigation found "thousands" of problems in aging reactors that it said the NRC have simply ignored, and it concluded that a "cozy relationship" exists between the NRC and the nuclear industry.

A retired NRC engineer interviewed by the AP agreed that his former employer too often accommodated the nuclear industry by concluding that existing regulations are overly stringent. "That's what they say for everything, whether that’s the case or not,” the engineer said. "They say 'We have all this built-in conservatism.””

\section{Ground Pollution and Hazardous Waste}

Pollution of the air and water is an environmental danger, as we saw earlier, but so is pollution of the ground from hazardous waste. Hazardous wastes are unwanted materials or byproducts that are potentially toxic. If discarded improperly, they enter the ground and/or bodies of water and eventually make their way into the bodies of humans and other animals and/or harm natural vegetation.

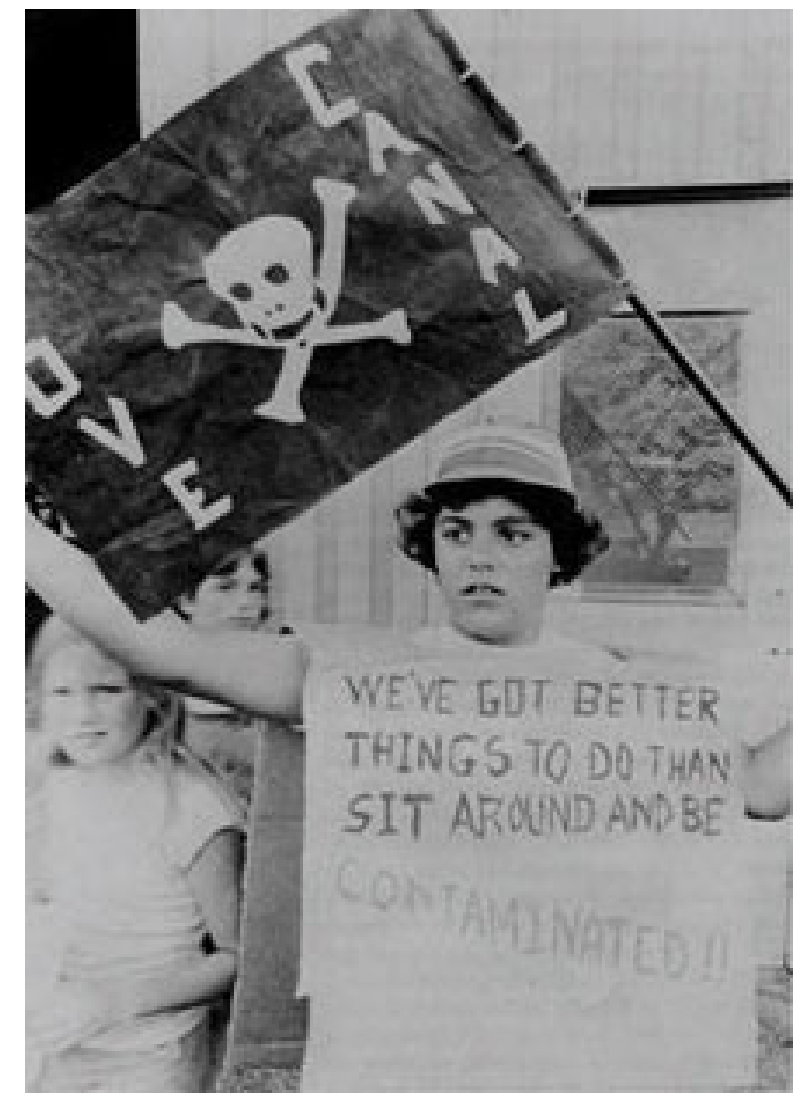


Love Canal, an area in Niagara Falls, New York, was the site of chemical dumping that led to many birth defects and other health

problems.

Wikimedia Commons - public domain.

Two major sources of hazardous waste exist: (1) commercial products such as pesticides, cleaning fluids, and certain paints, batteries, and electronics and (2) byproducts of industrial operations such as solvents and wastewater. Hazardous waste enters the environment through the careless actions of homeowners and other consumers, and also through the careless actions of major manufacturing corporations. It can cause birth defects, various chronic illnesses and conditions, and eventual death.

Sometimes companies have dumped so much hazardous waste into a specific location that they create hazardous waste sites. These sites are defined as parcels of land and water that have been contaminated by the dumping of dangerous chemicals into the ground by factories and other industrial operations. The most famous (or rather, infamous) hazardous waste site in the United States is undoubtedly Love Canal, an area in a corner of Niagara Falls, New York. During the 1940s and 1950s, a chemical company dumped 20,000 tons of toxic chemicals into the canal and then filled it in with dirt and sold it for development to the local school board. A school and more than eight hundred homes, many of them low income, were later built just near the site. The chemicals eventually leached into the groundwater, yards, and basements of the homes, reportedly causing birth defects and other health problems. (See Note 15.27 “People Making a Difference”.)

\section{People Making a Difference}

\section{In Praise of Two Heroic Women}

In the annals of activism against hazardous waste dumping, two women stand out for their contributions.

One was Lois Gibbs, who led a movement of residents of Love Canal to call attention to the dumping of hazardous waste in their neighborhood, as just discussed in the text. Gibbs had never been politically active before 1978, when evidence of the dumping first came to light. After reading a newspaper article about the dumping, she began a petition to shut down a local school that was next to the dump site. Her efforts generated a good deal of publicity and prompted state officials to perform environmental tests in the homes near the site. Two years later the federal government authorized funding to relocate 660 families from the dangerous area. Gibbs later wrote, "It will take a massive effort to move society from corporate domination, in which industry's rights to pollute and damage health and the environment supersede the public's right to live, work, and play in safety. This is a political fight. The science is already there, showing that people's health is at risk. To win, we will need to keep building the movement, networking with one another, planning, strategizing, and moving forward. Our children's futures, and those of their unborn children, are at stake."

The second woman was Erin Brockovich, the subject of a 2000 film of that name starring Julia Roberts. Brockovich also was not politically active before she discovered hazardous waste dumping while she was working as a legal assistant for a small California law firm. As part of her work on a real estate case, she uncovered evidence that Pacific Gas \& Electric had been dumping a toxic industrial solvent for thirty years into the water supply of the small town of Hinkley. Her investigation led to a lawsuit that ended in 1996 with the awarding of \$333 million in damages to several hundred Hinkley residents.

Both Lois Gibbs and Erin Brockovich have remained active on behalf of environmental safety in the years since their celebrated initial efforts. They are two heroic women who have made a very significant difference.

Sources: Brockovich, 2010; Gibbs, 1998 
The Superfund program of the US Environmental Protection Agency (EPA), begun about thirty years ago, monitors and cleans up hazardous waste sites throughout the country. Since its inception, the Superfund program has identified and taken steps to address more than 1,300 hazardous waste sites. About 11 million people live within one mile of one of these sites.

\section{Oceans}

The world's oceans are at peril for several reasons, with "potentially dire impacts for hundreds of millions of people across the planet," according to a news report (ScienceDaily, 2010). A major reason is that overfishing of fish and mammals has dramatically reduced the supply of certain ocean animals. This reduction certainly makes it difficult for people to eat certain fishes at restaurants or buy them at supermarkets, but a far more important problem concerns the ocean food chain (Weise, 2011). As the supply of various ocean animals has dwindled, the food supply for the larger ocean animals that eat these smaller animals has declined, putting the larger animals at risk. And as the number of these larger animals has declined, other animals that prey on these larger animals have had to turn to other food sources or not have enough to eat. This chain reaction in the ocean food chain has serious consequences for the ocean's ecosystem.

One example of this chain reaction involves killer whales and sea otters in the ocean off of western Alaska (Weise, 2011). Killer whales eat many things, but sea lions and harbor seals form a key part of their diet. However, the supply of these ocean mammals in western Alaska and elsewhere has decreased because of human overfishing of their prey fish species. In response, killer whales have been eating more sea otters, causing a 90 percent decline in the number of sea otters in western Alaska. Because sea otters eat sea urchins, the loss of sea otters in turn has increased the number of sea urchins there. And because sea urchins consume kelp beds, kelp beds there are disappearing, removing a significant source of food for other ocean life (Estes et al., 2011).

Another example of the ocean chain reaction concerns whales themselves. The whaling industry that began about 1,000 years ago and then intensified during the eighteenth century severely reduced the number of whales and made right whales almost extinct. In southern oceans, whale feces are an important source of nutrients for very small animals and plankton. As the whale population in these oceans has declined over the centuries, these animals and plankton that are essential for the ocean's ecosystem have suffered immeasurable losses (Weise, 2011).

Bycatch. In addition to overfishing, bycatch, or the unintentional catching and killing of fish, marine mammals, sea turtles, and seabirds while other fish are being caught, also endangers hundreds of ocean species and further contributes to the chain reaction we have described. The US National Oceanic and Atmospheric Administration (2012) says that bycatch "can have significant social, environmental, and economic impacts.” It costs the fishing industry much time and money, it threatens many ocean species, and it endangers the ocean's ecosystem.

A familiar bycatch example to many Americans is the accidental catching and killing of dolphins when tuna are being caught by large fishing nets. A less familiar example involves sea turtles. These animals' numbers have declined so steeply in recent decades that six of the seven species of sea turtles are in danger of extinction. The major reason for this danger is bycatch from shrimp trawl nets and other types of fishing. This bycatch has killed millions of sea turtles since 1990 (Viegas, 2010).

Climate change. Other ocean problems stem from climate change. The oceans' coral reefs are among the most 
colorful and beautiful sights in the world. More important, they are an essential source of nutrients for the oceans' ecosystem and a major source of protein for 500 million people. They help protect shorelines from natural disasters such as tsunamis, and they attract tens of billions of dollars in tourism.

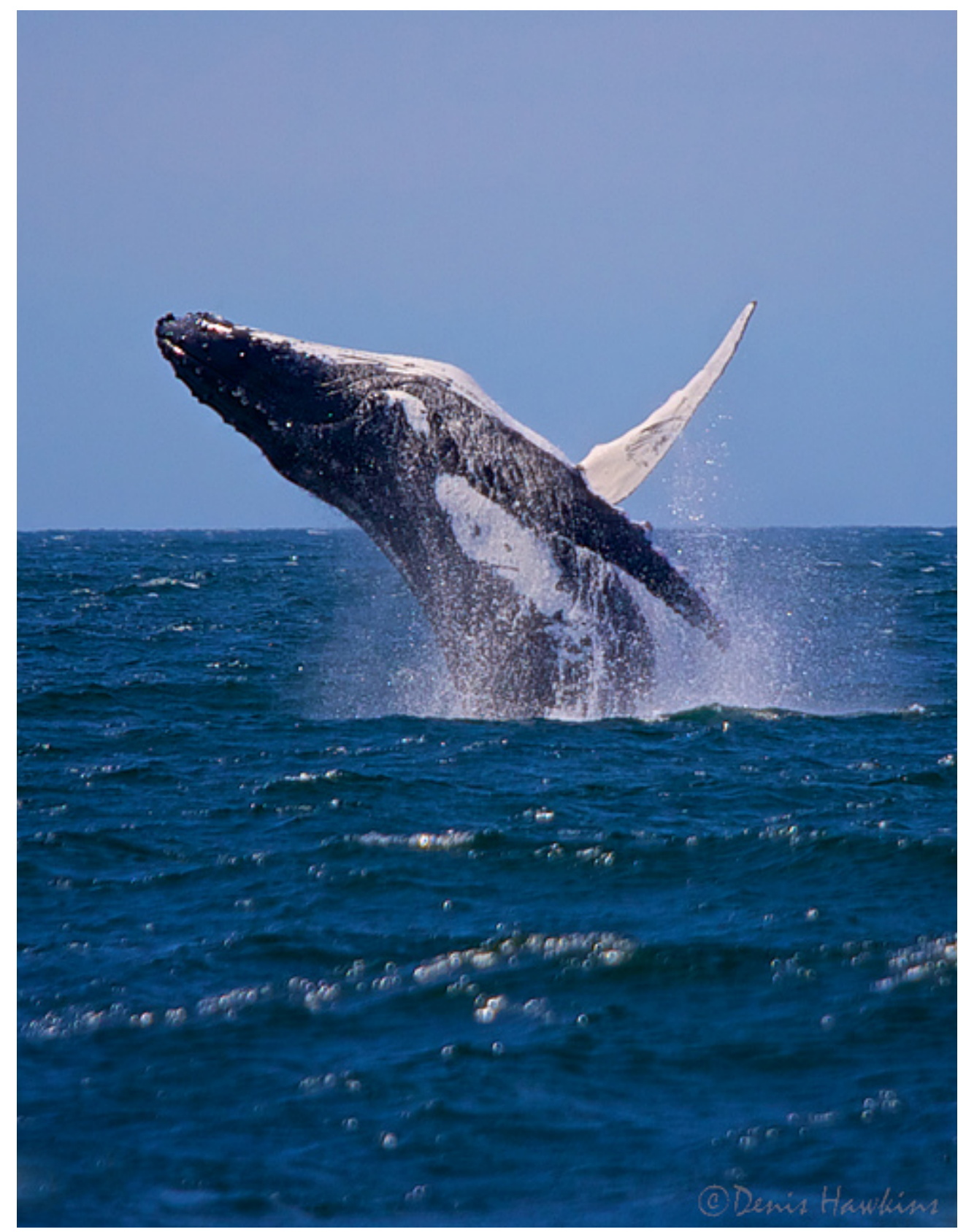

The decline of the whale population due to the whaling industry threatens the world's supply of plankton and other very small marine animals.

Denis Hawkins - Whale breaching at Jervis Bay - CC BY-ND 2.0.

Despite all these benefits, coral reefs have long been endangered by overfishing, tourism, and coastal development, among other factors. Scientists have now found that climate change is also harming coral reefs (Rudolf, 2011). The global warming arising from climate change is overheating coral reefs throughout the world. This overheating in turn causes the reefs to expel the algae they consume for food; the algae are also responsible 
for the reefs' bright colors. The reefs then turn pale and die, and their deaths add to the ocean's food chain problem already discussed. Scientists estimate that three-fourths of the earth's reefs are at risk from global warming, and that one-fifth of all reefs have already been destroyed. They further estimate that almost all reefs will be at risk by 2050.

Global warming will continue to be a main culprit in this regard, but so will increasing acidity, yet another problem arising from climate change. As carbon dioxide is released into the atmosphere, much of it falls into the ocean. This lowers the oceans' $\mathrm{pH}$ level and turns the oceans more acidic. This increasing acidity destroys coral reefs and also poses a risk to commercial species such as clams, lobsters, and mussels.

An additional ocean problem stemming from climate change is rising sea levels (Daley, 2011). Global warming has caused polar ice caps to melt and the seas to rise. This problem means that storm surges during severe weather are becoming an ever-greater problem. Even without storm surges, much coastal land has already been lost to rising ocean levels. Despite these problems, many coastal communities have failed to build adequate barriers that would minimize damage from ocean flooding.

\section{Food}

This chapter discussed food shortages earlier as a population problem, but food can also be an environmental hazard. Simply put, food is often unsafe to eat. In 2011, at least 31 Europeans died from a rare strain of E. coli, a deadly bacterium, and more than 3,000 became very ill; the culprit was contaminated bean sprouts (CNN, 2011). According to the Centers for Disease Control and Prevention, 325,000 Americans are hospitalized annually because of illnesses contracted from contaminated food, and 5,000 Americans die each year from these illnesses (Kristof, 2011).

The deadly bacteria at fault often result from improper handling and other activities related to growing livestock and processing food. But they also result from the fact that livestock are routinely given antibiotics to keep them healthy despite the crowded and often dirty conditions in which they live. However, this wide use of antibiotics allows bacteria resistant to antibiotics to grow. When humans contract illnesses from these bacteria, antibiotics do not relieve the illnesses (Kristof, 2012).

One journalist pointed out the obvious problem: "We would never think of trying to keep our children healthy by adding antibiotics to school water fountains, because we know this would breed antibiotic-resistant bacteria. It's unconscionable that Big Ag [Big Agriculture] does something similar for livestock" (Kristof, 2011, p. WK10). A member of the US House of Representatives who is also a microbiologist agreed: "These statistics tell the tale of an industry that is rampantly misusing antibiotics in an attempt to cover up filthy, unsanitary living conditions among animals. As they feed antibiotics to animals to keep them healthy, they are making our families sicker by spreading these deadly strains of bacteria” (Kristof, 2011, p. WK10). 


\section{Key Takeaways}

- Environmental problems are largely the result of human behavior and human decision making. Changes in human activity and decision making are thus necessary to improve the environment.

- Environmental inequality and environmental racism are significant issues. Within the United States and around the world, environmental problems are more often found where poor people and people of color reside.

- Air pollution, global climate change, water pollution and inadequate sanitation, and hazardous waste are major environmental problems that threaten the planet.

\section{For Your Review}

1. Pretend you are on a debate team and that your team is asked to argue in favor of the following resolution: Be it resolved, that air and water pollution is primarily the result of reckless human behavior rather than natural environmental changes. Using evidence from the text, write a two-minute speech (about three hundred words) in favor of the resolution.

2. How much of the environmental racism that exists do you think is intentional? Explain your answer.

3. List one thing you did yesterday that was good for the environment and one thing that was bad for the environment.

\section{References}

Agnew, R. (2012). Dire forecast: A theoretical model of the impact of climate change on crime. Theoretical Criminology, 16, 21-42.

Brockovich, E. (2010). Erin Brockovich biography. Retrieved February 8, 2012, from http://www.brockovich.com/mystory.html.

Bullard, R. D. (1990). Dumping in Dixie: Race, class, and environmental quality. Boulder, CO: Westview Press.

Bullard, R. D., \& Wright, B. (2009). Race, place, and the environment in post-Katrina New Orleans. In R. D. Bullard \& B. Wright (Eds.), Race, place, and environmental justice after hurricane Katrina: Struggles to reclaim, rebuild, and revitalize New Orleans and the Gulf Coast (pp. 19-48). Boulder, CO: Westview Press.

Cameron, J., Hunter, P., Jagals, P., \& Pond, K. (Eds.). (2011). Valuing water, valuing livelihoods. London, United Kingdom: World Health Organization.

Children's Environmental Health Network. (2009). An introduction to children's environmental health. Retrieved February 8, 2012, from http://www.cehn.org/introduction childrens environmental health.

CNN. (2011, June 10). E. coli death toll rises to 31; sprouts traced to trash in home. CNN World. Retrieved 
from

http://articles.cnn.com/2011-06-10/world/europe.e.coli_1_coli-outbreak-sprouts-germanhealth? s=PM:WORLD.

Daley, B. (2011, April 3). Fighting a losing battle with the sea. Boston.com. Retrieved from http://www.boston.com/news/science/articles/2011/04/03/fighting a losing battle with the sea.

Dicum, G. (2006, March 14). Meet Robert Bullard, the father of environmental justice. Grist Magazine. Retrieved from http://www.grist.org/article/dicum.

DiSavino, S. (2012, February 1). Nuclear accidents pose little risk to health: NRC. Reuters. Retrieved from http://www.reuters.com/article/2012/02/01/us-utilities-nuclear-accidentstudy-idUSTRE8101ZA20120201.

Donn, J. (2011, June 20). As nuclear plants age, NRC loosens safety regulations. The Boston Globe, p. A2.

Estes, J. A., Terborgh, J., Brashares, J. S., Power, M. E., Berger, J., Bond, W. J., et al. (2011). Trophic downgrading of planet Earth. Science, 333(6040), 301-306.

Evans, G. W., \& Kantrowitz, E. (2002). Socioeconomic status and health: The potential role of environmental risk exposure. Annual Review of Public Health, 23(1), 303.

Fischer, D. (1997). History of the International Atomic Energy Agency: The first forty years. Vienna, Austria: Internatinal Atomic Energy Agency.

Fisman, R., \& Miguel, E. (2010). Economic gangsters: Corruption, violence, and the poverty of nations. Princeton, NJ: Princeton University Press.

Fountain, H. (2010, June 15). Documents show risky decisions before BP blowout. New York Times, p. A1.

Fujita, A. (2012, February 6). Japan's nuclear exclusion zone shows few signs of life. ABC News. Retrieved from $\quad$ http://abcnews.go.com/International/fukushimas-nuclear-exclusion-zone-shows-signs-life/ story?id=15521091\#.TzFSXONSRyc.

Gibbs, L. M. (1998). Learning from Love Canal: A 20th anniversary retrospective. Retrieved February 8, 2012, from http://arts.envirolink.org/arts and activism/LoisGibbs.html.

Gillis, J., \& Foster, J. M. (2012, March 29). Weather runs hot and cold, so scientists look to the ice. New York Times, p. A1.

Gronlund, L. (2011). How many cancers did Chernobyl really cause?-updated version. Cambridge, MA: Union of Concerned Scientists.

King, L., \& McCarthy, D. (Eds.). (2009). Environmental sociology: From analysis to action (2nd ed.). Lanham, MD: Rowman \& Littlefield.

Kristof, N. (2012, April 5). Arsenic in our chicken? New York Times, p. A23.

Kristof, N. D. (2008, April 13). Extended forecast: Bloodshed. New York Times. Retrieved from http://www.nytimes.com/2008/04/13/opinion/13kristof.html. 
Kristof, N. D. (2011, June 12). When food kills. New York Times, p. WK10.

McCarthy, D., \& King, L. (2009). Introduction: Environmental problems require social solutions. In L. King \& D. McCarthy (Eds.), Environmental Sociology: From Analysis to Action (2nd ed., pp. 1-22). Lanham, MD: Rowman \& Littlefield.

McNall, S. G. (2011). Rapid climate change: Causes, consequences, and solutions. New York, NY: Routledge.

Nagel, J., Dietz, T., \& Broadbent, J. (Eds.). (2010). Workshop on sociological perspectives on global climate change. Washington, DC: National Science Foundation.

National Oceanic and Atmospheric Administration. (2012). National bycatch program. Retrieved February 13, 2012, from http://www.nmfs.noaa.gov/by catch/index.htm.

Pew Research Center. (2011). Modest rise in number saying there is "solid evidence" of global warming. Washington, DC: Author.

Prüss-Üstün, A., Bos, R., Gore, F., \& Bartram, J. (2008). Safer water, better health: Costs, benefits, and sustainability of interventions to protect and promote health. Geneva, Switzerland: World Health Organization.

Reiman, J., \& Leighton, P. (2010). The rich get richer and the poor get prison: Ideology, class, and criminal justice (9th ed.). Upper Saddle River, NJ: Prentice Hall.

Rudolf, J. C. (2011, June 5). Under the sea, coral reefs in peril. New York Times, p. WK3.

ScienceDaily. (2010, June 19). Ocean changes may have dire impact on people. ScienceDaily. Retrieved from http://www.sciencedaily.com/releases/2010/06/100618103558.htm.

Union of Concerned Scientists. (2011). Nuclear reactor crisis in Japan FAQs. Retrieved from http://www.ucsusa.org/nuclear_power/nuclear_power_risk/safety/nuclear-reactor-crisis-faq.html\#us-plant-risk.

Viegas, J. (2010, April 6). Millions of sea turtles captured, killed by fisheries. Discovery News. Retrieved from http://news.discovery.com/animals/turtles-bycatch-fishing.html.

Walker, G. (2012). Environmental justice: Concepts, evidence, and politics. New York, NY: Routledge.

Weise, E. (2011, July 15). Predator loss can start food-chain reaction. USA Today, p. 9A.

World Health Organization. (2011). Air quality and health. Retrieved from http://www.who.int/mediacentre/ factsheets/fs313/en/index.html.

World Health Organization. (2010). Climate change and health. Retrieved from http://www.who.int/mediacentre/ factsheets/fs266/en/index.html.

Zeller, T., Jr. (2011, March 14). US nuclear plants have same risks, and backups, as Japan counterparts. New York Times, p. A10.

Zimmer, C. (2011, April 5). Multitude of species face climate threat. New York Times, p. D1. 


\subsection{Addressing Population Problems and Improving the Environment}

\section{Learning Objectives}

1. Outline sociological-based strategies that should help address population issues.

2. List sociological-based strategies and other efforts that should help improve environmental problems.

The topics of population and the environment raise many issues within the United States and across the globe for which a sociological perspective is very relevant. We address a few of these issues here.

\section{Population}

We saw earlier that experts disagree over how concerned we should be generally about global population growth, and especially about the degree to which overpopulation is responsible for world hunger. Still, almost everyone would agree that world hunger is a matter of the most serious concern, even if they do not agree on why world hunger is so serious and so persistent. Both across the globe and within the United States, children and adults go hungry every day, and millions starve in the poorest nations in Africa and Asia.

As our earlier discussion indicated, many experts believe it is a mistake to blame world hunger on a scarcity of food. Instead, they attribute world hunger to various inequalities in access to, and in the distribution of, what is actually a sufficient amount of food to feed the world's people. To effectively reduce world hunger, inequalities across the globe and within the United States based on income, ethnicity, and gender must be addressed; some ways of doing so have been offered in previous chapters.

Population growth in poor nations has slowed but remains a significant problem. Their poverty, low educational levels, and rural settings all contribute to high birth rates. More effective contraception is needed to reduce their population growth, and the United Nations and other international bodies must bolster their efforts, with the aid of increased funding from rich nations, to provide contraception to poor nations. But contraceptive efforts will not be sufficient by themselves. Rather, it is also necessary to raise these nations' economic circumstances and educational levels, as birth rates are lower in nations that are wealthier and more educated. In particular, efforts that raise women's educational levels are especially important if contraceptive use is to increase. In all these respects, we once again see the importance of a sociological perspective centering on the significance of socioeconomic inequality. 


\section{The Environment}

Environmental problems cannot be fully understood without appreciating their social context. In this regard, we discussed two major emphases of environmental sociology. First, environmental problems are largely the result of human decision making and activity and thus preventable. Second, environmental problems disproportionately affect the poor and people of color.

These two insights have important implications for how to improve our environment. Simply put, we must change the behaviors and decisions of individuals, businesses, and other organizations that harm the environment, and we must do everything possible to lessen the extra environmental harm that the poor and people of color experience. Many environmental scholars and activists believe that these efforts need to focus on the corporations whose industrial activities are often so damaging to the air, water, and land.

Beyond these general approaches to improving the environment, there are many strategies and policies that the United States and other nations could and should undertake to help the environment. Although a full discussion of these lies beyond the scope of this chapter, environmental experts recommend a number of actions for the United States to undertake (Lever-Tracy, 2011; Madrid, 2010; McNall, 2011). These include the following:

1. Establish mandatory electricity and natural gas reduction targets for utilities.

2. Expand renewable energy (wind and sun) by setting a national standard of 25 percent of energy to come from renewable sources by 2025.

3. Reduce deforestation by increasing the use of sustainable building materials and passing legislation to protect forests.

4. Reduce the use of fossil fuels by several measures, including higher fuel economy standards for motor vehicles, closing down older coal-fired power plants, and establishing a cap-and-trade system involving large payments by companies for carbon emissions to encourage them to reduce these emissions.

5. In cities, increase mass transit and develop more bicycle lanes and develop more efficient ways of using electricity and water. 


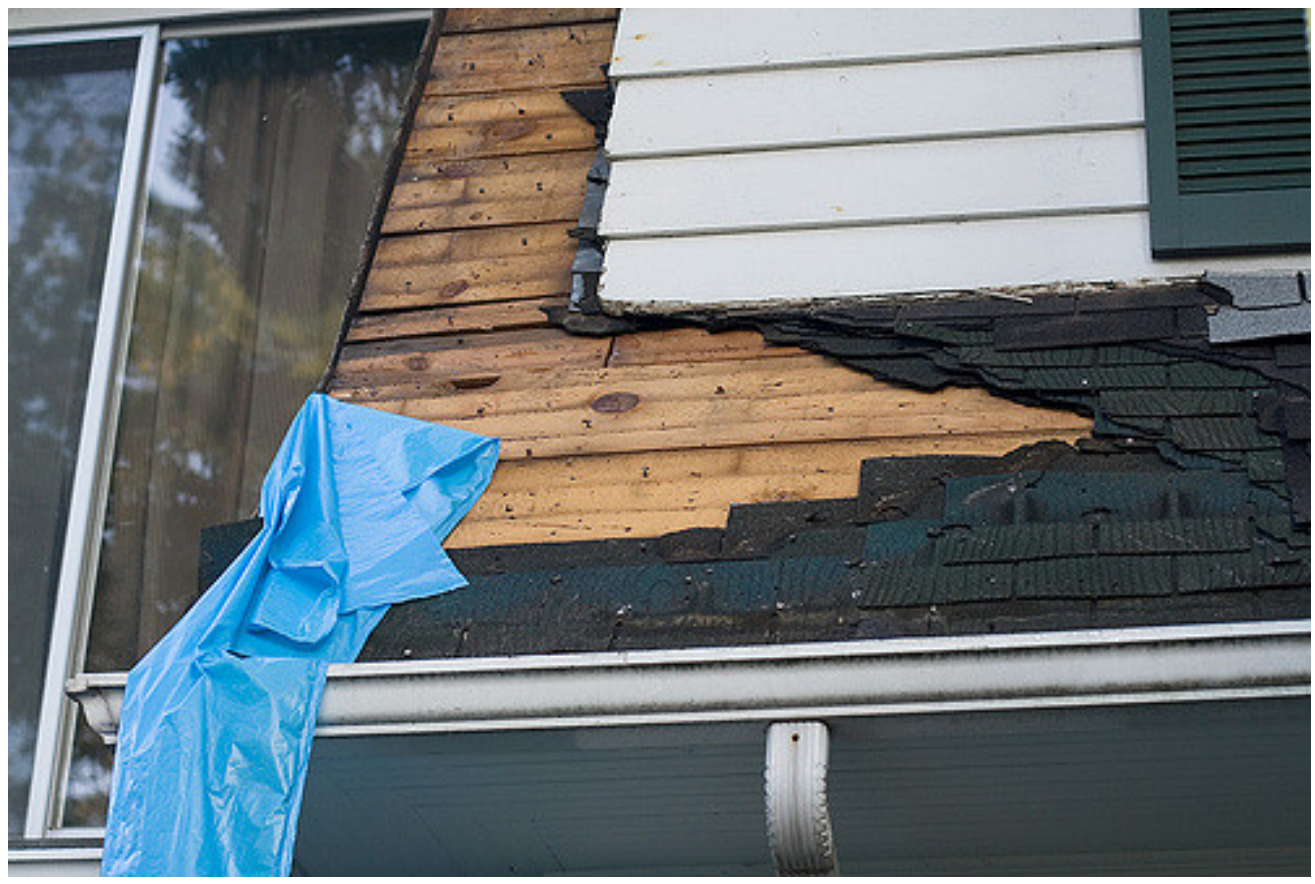

If the rooftops of houses were painted white or covered with light-colored shingles, atmospheric temperatures would reduce.

Ben Zibble - $\underline{\text { Shingles upon shingles }}$ - CC BY-NC-ND 2.0.

Another strategy is perhaps delightfully simple: turn rooftops and paved surfaces white! In many US cities, roofs of houses, high-rises, and other buildings are covered with dark asphalt shingles. Dark surfaces trap heat from the sun and promote higher air temperatures. Painting roofs white or using white shingles to reflect the sun's heat would reduce these temperatures and help offset the effects of global warming (Levinson et al., 2010; Lomborg, 2010). A similar offset would occur from changing the color of our streets. Many roads in cities and other areas are composed of dark asphalt; using a lighter material would also help reduce air temperature and counter global warming. If these measures reduced air temperature in warm cities, less air conditioning would be needed. In turn, electricity use and carbon dioxide emissions would also decline.

To repeat what was said at the outset of this chapter, it is no exaggeration to say that the fate of our planet depends on the successful implementation of these and other strategies and policies. Because, as sociology emphasizes, the environmental problems that confront the world are the result of human activity, changes in human activity are necessary to save the environment.

\section{Key Takeaways}

- Efforts to address population issues should focus on the various inequalities that lead to both overpopulation and food scarcity.

- Efforts to improve the environment should keep in mind the greater environmental harm that the poor and people of color suffer. 


\section{For Your Review}

1. If you had a million dollars to spend to address one population problem, would you use it to provide contraception, or would you use it to improve the distribution of food? Explain your answer.

2. Which one of the environmental problems discussed in the text concerns you the most? Why?

\section{References}

Lever-Tracy, C. (2011). Confronting climate change. New York, NY: Routledge.

Levinson, R., Akbari, H., Berdahl, P., Wood, K., Skilton, W., \& Petersheim, J. (2010). A novel technique for the production of cool colored concrete tile and asphalt shingle roofing products. Solar Energy Materials \& Solar Cells, 94(6), 946-954.

Lomborg, B. (2010, November 17). Cost-effective ways to address climate change. The Washington Post. Retrieved from http://www.washingtonpost.com/wp-dyn/content/article/2010/11/16/AR2010111604973.html.

Madrid, J. (2010). From a "green farce" to a green future: Refuting false claims about immigrants and the environment. Washington, DC: Center for American Progress.

McNall, S. G. (2011). Rapid climate change: Causes, consequences, and solutions. New York, NY: Routledge. 


\subsection{End-of-Chapter Material}

\section{Summary}

1. Functionalism stresses the value of normal changes in population growth and the environment, but recognizes that certain population and environmental problems are dysfunctional. Conflict theory stresses that world hunger stems from lack of access to food, not from overpopulation, and it blames multinational corporations for environmental problems. Symbolic interactionism emphasizes people's activities and perceptions in regard to population and the environment.

2. Demography is the study of population. It encompasses three central concepts-fertility, mortality, and migration - which together determine population growth.

3. The world's population is growing by about 80 million people annually. Population growth is greatest in the low-income nations of Africa and other regions, while in several industrial nations it is declining.

4. Thomas Malthus predicted that the earth's population would greatly exceed the world's food supply. Although his prediction did not come true, hunger remains a serious problem around the world. Food supply is generally ample thanks to improved technology, but the distribution of food is inadequate in low-income nations.

5. Demographic transition theory helps explain why population growth did not continue to rise as much as Malthus predicted. As societies become more technologically advanced, first death rates and then birth rates decline, leading eventually to little population growth.

6. US history is filled with prejudice against immigrants. Immigrants today contribute in many ways to the American economy and have relatively low crime rates. Despite these facts, many people are opposed to immigration, and many states have passed laws to restrict benefits and movement for immigrants.

7. Environmental sociology is the sociological study of the environment. One major emphasis of environmental sociology is that environmental problems are largely the result of human activity and human decision making. A second major emphasis is that environmental problems disproportionately affect lowincome people and people of color. These effects are called environmental inequality and environmental racism, respectively.

8. Environmental problems include climate change, air and water pollution, and hazardous waste. Children are particularly vulnerable to the health effects of environmental problems.

\section{Using What You Know}

You are in your second year in the accounting division of a large company that operates a factory on the main river in a small town. One day you notice some financial documents. These documents suggest to you that your company has been dumping a toxic solvent into the river rather than having it collected and taken to a safe site. Having had an environmental sociology course in college, you are very concerned about this possible problem, but you are not certain that the dumping is in fact occurring, and you also do not want to lose your job. Do you take any action related to your new suspicion of the possible dumping, or do you remain silent? Explain your answer. 


\section{What You Can Do}

To help deal with the population and environmental problems discussed in this chapter, you may wish to do any of the following:

1. Contribute money to a national environmental organization or join a local environmental group in your activity.

2. Start an organization on your campus to deal with world hunger.

3. Organize speaker series on your campus to various environmental topics. 


\section{Chapter 16: War and Terrorism}

\section{Social Problems in the News}

"War Crimes Haunt Iraq Vet,” the headline said. In the early 2000s, John Milton, a pseudonym, joined the Army and was sent to Iraq. There he served as a medic but was also armed. At age 21, he and five other soldiers were driving one day back from a beer run when a small bomb hit their vehicles. One of the soldiers died instantly, but the others survived and shot the bomber. As the bomber was lying on the ground and needing medical attention, the soldiers began to punch and kick him. Instead of tending to the bomber's injuries, Milton fatally shot him in the head.

In the years since his military service ended, Milton's war crime has haunted him. He continues to have nightmares and cannot get rid of his guilt. He talked with a psychiatrist at a Veterans Administration hospital, but that did not help because the psychiatrist “didn’t understand what [he] was talking about.” Before he entered the Army, Milton said, he "used to love being around people, but no more." He was thinking of moving from his home in New Jersey to a quieter, emptier state like Montana or Wyoming.

Milton also remembered being ordered to euthanize wounded but treatable Iraqi soldiers, yet another war crime. After he did so several times, he decided he could no longer in good conscience follow those orders. He recalled, "I can still see every one of their faces, individually, exactly what they looked like that day.”

Source: Bykofsky, 2012

Great war novels like The Red Badge of Courage and War and Peace highlight the heroism and horror that both occur on the battlefield. This news story likewise reminds us that war, however heroic, is also horrible. Atrocities happen; soldiers are killed or wounded, physically and/or mentally; and civilians suffer and die. As Sydney H. Schanberg (2005, p. 1), a former New York Times reporter who covered the US wars in Vietnam and Cambodia, has bluntly observed, “'History,' Hegel said, 'is a slaughterhouse.’ And war is how the slaughter is carried out.”

For much of human history, people considered war a necessary evil that was often waged for noble reasons. World War II, for example, was what we now call "the good war," fought to end Hitler's attempt to conquer much of the world. Millions died on the battlefield, in cities bombed by planes, and in concentration camps before Hitler and his allies were finally defeated.

About two decades after World War II ended, the United States began fighting another war meant to save the world for democracy, but this war was very different from the one against Hitler. This war was fought in Vietnam, and however a noble effort World War II might have been, the Vietnam War was just as ignoble to its critics. It was a war, some said, not to save the world for democracy but to help extend America's power where it did not belong. The war's severest critics called it an act of genocide against Asians. If the World War II generation grew up with a patriotic love for their nation, the Vietnam War generation grew up with much more cynicism about their government and about the military.

Ironically, that generation's concern about the military was shared by none other than President Dwight D. Eisenhower, who warned about the dangers of what he called the military-industrial complex - the friendly interplay of the military, the defense industry, and political leaders - in his farewell presidential address 
(Ledbetter, 2011). Eisenhower himself had been a member of the military-industrial complex, having served as a five-star general and supreme commander of the Allied forces in Europe during World War II before becoming president. His military experience made him no fan of warfare; as he once observed, "I hate war as only a soldier who has lived it can, only as one who has seen its brutality, its futility, its stupidity." He also feared that the military-industrial complex was becoming too powerful and gaining "unwarranted influence” over American life as it acted for its own interests and not necessarily for those of the nation as a whole. He warned that the "potential for the disastrous rise of misplaced power exists and will persist” (Eisenhower, 1960).

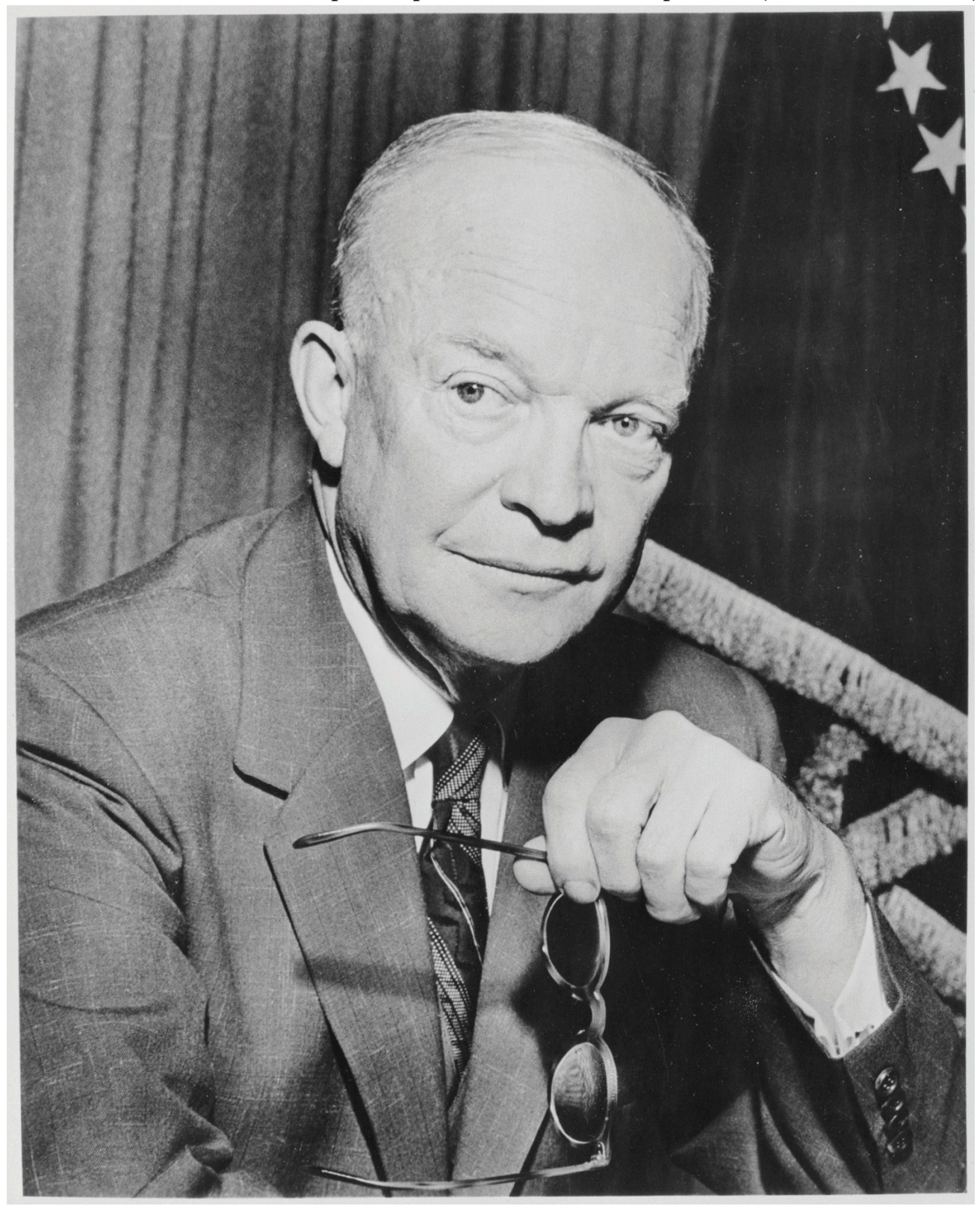

President Dwight D. Eisenhower warned about what he called the "unwarranted influence” of the military-industrial complex.

Wikimedia Commons - public domain.

Eisenhower's fears about the military-industrial complex reflected his more general concern about militarism, or an overemphasis on military policy and spending, which he thought was costing the nation far too much money. In 
a remarkable and now famous statement made early in his presidency, Eisenhower (1960, p. A1) declared, "Every gun that is made, every warship launched, every rocket fired, signifies in the final sense, a theft from those who hunger and are not fed, those who are cold and are not clothed. This world in arms is not spending money alone. It is spending the sweat of its laborers, the genius of its scientists, the hopes of its children. This is not a way of life at all in any true sense. Under the clouds of war, it is humanity hanging on a cross of iron.”

Eisenhower's concerns are even more valid today. As the United States and other governments spend hundreds of billions of dollars annually on their militaries, mass death and destruction from war beyond what Eisenhower could have ever imagined are a major concern, and serious social needs go unmet. It is probably trite to say that war profoundly affects societies, but that is precisely why war and the threat of war are considered perhaps the most pressing social problem of our times and a threat to the entire planet.

Terrorism also profoundly affects societies. Yet most Americans probably did not consider terrorism a social problem before September 11, 2001, when, as has often been said, the world changed. On that terrible day, terrorists drove two passenger jets into the World Trade Center in New York and another into the Pentagon; a fourth plane apparently headed for a Washington, DC, target crashed in central Pennsylvania when brave passengers fought back. The shock of the 3,000 deaths that resulted continues to haunt us even as we have become accustomed to homeland security measures in our airports and elsewhere that would have seemed inconceivable a generation ago.

Against this horrific backdrop of the modern era, this chapter examines war and terrorism as the final social problems discussed in this book. As forms of armed conflict that aim to defeat an opponent, war and terrorism have been part of the human experience for thousands of years. However, their manifestation in the contemporary era is particularly frightening, thanks to ever more powerful weapons, such as nuclear arms, that threaten human existence. We consider their causes, dynamics, and consequences before discussing certain actions and policies that might conceivably reduce these threats to peaceful societies and human existence.

\section{References}

Bykofsky, S. (2012, February 10). War crimes haunt Iraq vet. Philadelphia Daily News. Retrieved from http://www.philly.com/philly/news/20120210 Stu Bykofsky War crimes haunt Iraq vet.html.

Eisenhower, D. D. (1960). Farewell Speech. New York Times, A1.

Eisenhower, D. D. (1960). Public papers of the presidents of the United States: Dwight D. Eisenhower. Washington, DC: US Government Printing Office.

Ledbetter, J. (2011). Unwarranted influence: Dwight D. Eisenhower and the military-industrial complex. New Haven, CT: Yale University Press.

Schanberg, S. H. (2005, May 10). Not a pretty picture. The Village Voice, p. 1. 


\subsection{Sociological Perspectives on War and Terrorism}

\section{Learning Objective}

1. Summarize the key assumptions and emphases of the functionalist, conflict, and symbolic interactionist perspectives on war and terrorism.

The three major sociological perspectives offer some very different understandings of war and terrorism. You might agree with some of their assumptions and disagree with other assumptions, but together they capture the major dimensions of these two forms of armed conflict. Table 16.1 "Theory Snapshot" summarizes these assumptions.

Table 16.1 Theory Snapshot

\begin{tabular}{|l|l|}
$\begin{array}{l}\text { Theoretical } \\
\text { perspective }\end{array}$ & Major assumptions \\
\hline Functionalism & $\begin{array}{l}\text { War and terrorism serve several important functions. For example, they increase social solidarity as a } \\
\text { society unites to defeat a perceived enemy. Some wars have also helped preserve freedom and democracy. }\end{array}$ \\
\hline $\begin{array}{l}\text { Conflict } \\
\text { theory }\end{array}$ & $\begin{array}{l}\text { War and militarism primarily advance the interests of the military-industrial complex and take billions of } \\
\text { dollars from unmet social needs. }\end{array}$ \\
\hline $\begin{array}{l}\text { Symbolic } \\
\text { interactionism }\end{array}$ & $\begin{array}{l}\text { Symbols such as the flag play an important role in marshaling support for war. Definitions of several } \\
\text { concepts also play an important role in public opinion regarding war and terrorism. }\end{array}$ \\
\hline
\end{tabular}

\section{Functionalism}

Recall that functionalism emphasizes the usefulness of certain behaviors and social institutions for many aspects of society. One of functionalism's most important insights is that social problems might actually be useful in this way, however many difficulties they might otherwise cause. To use an example from Chapter 1 "Understanding Social Problems”, crime certainly causes many problems, but it also creates hundreds of thousands of jobs in law enforcement, courts and corrections, home security, and other sectors of the economy that deal with crime.

In this spirit, functionalism similarly emphasizes the ways in which war and terrorism are useful for society, however horrible they are in so many other ways. Perhaps the first sociologist to make this point for war was Robert E. Park, the 1925 president of the American Sociological Association (which was then called the American Sociological Society - a name that was later changed because of its acronym!). In January 1941, less than a year before the bombing of Pearl Harbor, Park published an influential essay called "The Social Function of War: Observations and Notes,” in a leading sociology journal (Park, 1941). 
Park's essay outlined several functions of war. First, war helps resolve international disputes over matters such as territorial boundaries and religious and other ideologies. No matter what one might think of war, historically it has resolved disputes between nations, with the winner of the war winning the dispute. Even though very few people would say that war is a preferred method for resolving a dispute, it still has performed this function.

Second, war generates a stronger sense of social bonding and solidarity within the societies that are at war. Having a common enemy, people within a society at war "come together" with a shared purpose and feel more united and patriotic than before. This dynamic is called the external conflict/internal cohesion process (Markides \& Cohn, 1982). Although Park did not discuss terrorism, this form of armed conflict can also create social solidarity. In the days and weeks after 9/11, Americans came together as one people, and the president of France famously said, "We are all Americans."

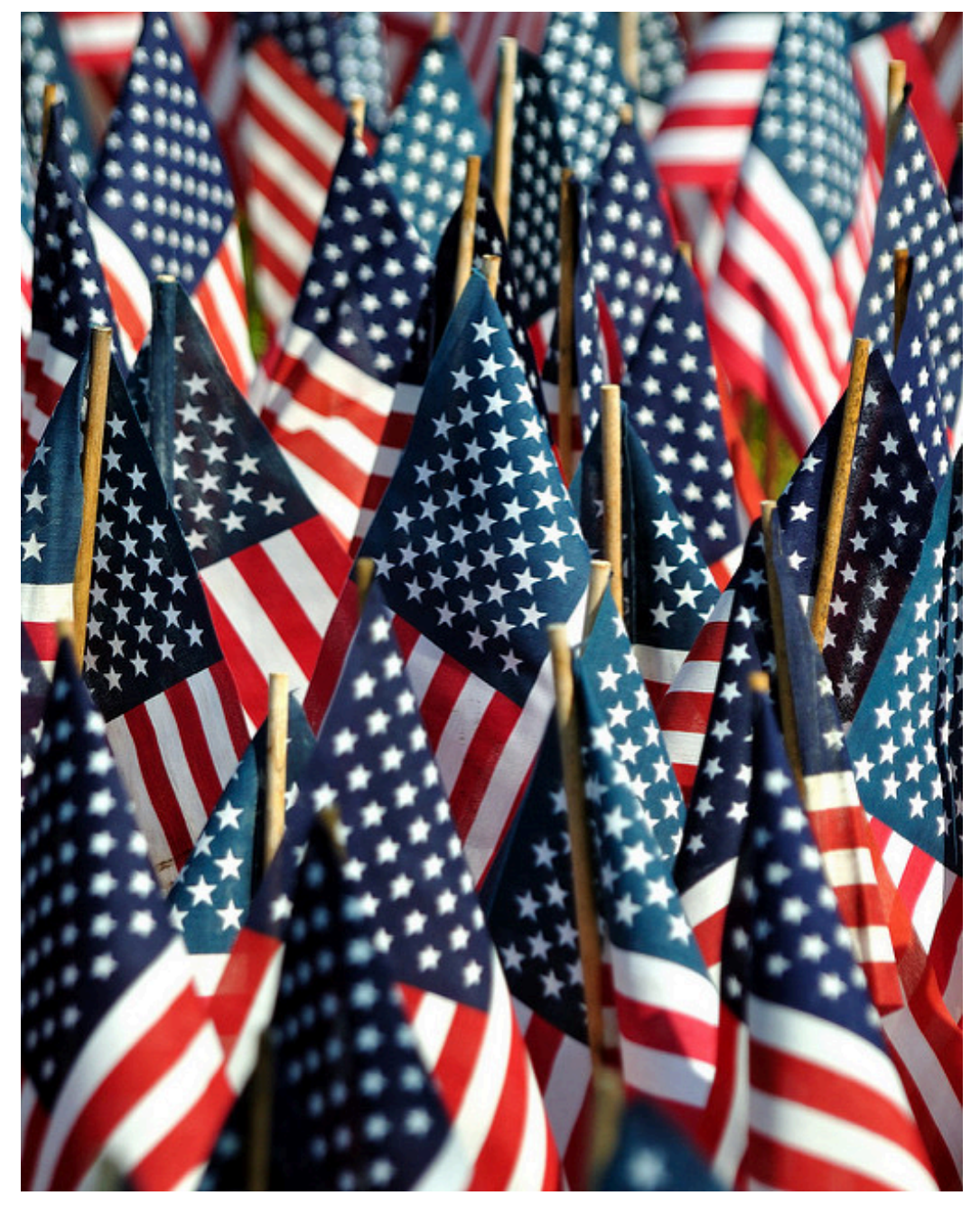

War generates a sense of social cohesion among the people in a society that is at war.

Glenn Harper - Flags - CC BY-NC-ND 2.0.

Third, wars many centuries ago, such as those in which ancient Rome in essence formed and grew from conquering various tribes, led to the development of the nation-state as a political institution. As these tribes came under the rule of nation-states, their separate tribal identities weakened as they gradually identified themselves as one people belonging to their nation-state; Park (p. 569) referred to this process as "the coming-together and 
integration of races and peoples.” Moreover, the size and resources of these nation-states allowed them to generate scientific, cultural, and political advances that played an important role in world history. War, then, indirectly contributed to these advances. Although nation-states still might have eventually developed even without war, their development was accelerated by war.

Other functions of war can also be cited. Some wars, including the American colonists' war against England and the Allies' war against Hitler and Japan, have helped maintain and establish freedom and democracy. In the past and also today, war and military service have also provided important opportunities for jobs and career advancement for people of color and women. Related to this, the US military provides millions of jobs annually and is a ready form of employment for people who only have a high school education. More generally, the military and the defense industry are certainly important components of the US economy, and military spending in some eras has helped stimulate the US economy. In perhaps the most notable example of this effect, spending for World War II is commonly credited with helping to lift the United States out of the Great Depression (Shiller, 2012).

In a final function, weapons research and other types of military research have contributed to scientific and technological development in general. For example, military research played a key role in the early development of the Internet.

\section{Conflict Theory}

Conflict theory's perspective on war and the military is decidedly more negative than that of functionalism. There are actually many different views within conflict theory about war and the military, but three related views stand out. The first view echoes President Eisenhower's concern over the power and influence of the militaryindustrial complex. According to conflict theory, the United States spends so much on the military and even goes to war because military officials, defense contractors, and political leaders work hand-in-hand in a rather cozy relationship. Although they may profess that their actions are meant to keep the nation safe, their ultimate goal is to enhance their political power and financial well-being.

The most famous critique of the military-industrial complex from a conflict theorist is undoubtedly that of sociologist C. Wright Mills in his book The Power Elite (1956). According to Mills, the power elite is composed of government, big business, and the military, which together constitute a ruling class that controls society and works for its own interests, not for the interests of the citizenry. Members of the power elite, Mills said, see each other socially and serve together on the boards of directors of corporations, charitable organizations, and other bodies. When cabinet members, senators, and top generals and other military officials retire, they often become corporate executives; military officials in particular join defense contractors. Conversely, corporate executives often become cabinet members and other key political appointees, and defense industry executives often end up in the Pentagon. This circulation of the elites creates a rather cozy relationship that helps ensure their dominance over American life and in particular ensures that the military-industrial complex has an untold influence over economic and foreign policy.

A more recent critique of the military-industrial complex and foreign policy by sociologist Mark C. Worrell (2011, p. 51) bluntly stresses the role played by the desire for corporate profits: "War is business and it is profitable... What we learned in the aftermath of World War II is that mass destruction is great for corporate 
profits...War is driven by corporate profits and corporations drive politics.” According to Worrell and other contemporary critics of what they call the warfare state, the United States now has a permanent war economy. In their view, the war on terrorism after 9/11 and the wars in Iraq and Afghanistan "have only deepened the trend toward ever more concentrated state, corporate, and military power in a society that ostensibly embraces democratic values” (Boggs, 2011, p. ix).

The second view of conflict theory concerns imperialism, or the use of military power and other means to extend a nation's influence and control over other nations. This view, held by the more radical proponents of conflict theory, argues that war and other military ventures by the United States are done for the sake of imperialism rather than for noble goals such as the preservation and extension of democracy. In this view, the United States wages war and engages in other military actions to gain access to oil and other resources of other societies, with the ultimate aim of enriching multinational corporations and other parties. The characterization does not hold true for World War II, conflict theorists concede, but they argue it holds true for many and perhaps most other US wars and military actions, historically and today. In their view, the wars in Iraq and Afghanistan in particular were fought under false pretenses to maintain adequate oil supply and more generally to extend America's military and economic influence around the world (Worrell, 2011).

A third view of conflict theory criticizes the size of the military budget and emphasizes the billions of dollars it takes from social needs such as poverty and climate change. As sociologist Carl Boggs (2011, p. 17) argues, "The war economy, for its part, devours roughly one trillion dollars in material, technological, and human resources yearly..., ensuring a pattern of waste, destruction, uneven development, eroded public infrastructures, and decimated social programs. Decaying American cities have become a supreme legacy of the warfare system." We return to this issue later in this chapter.

\section{Symbolic Interactionism}

Symbolic interactionist writing on war features several emphases. One theme concerns the perceptions and experiences of people involved in war: soldiers, civilians, and others. There are many moving accounts, for example, both real and fictitious, of soldiers' life on the battlefield and after they come home from war. 


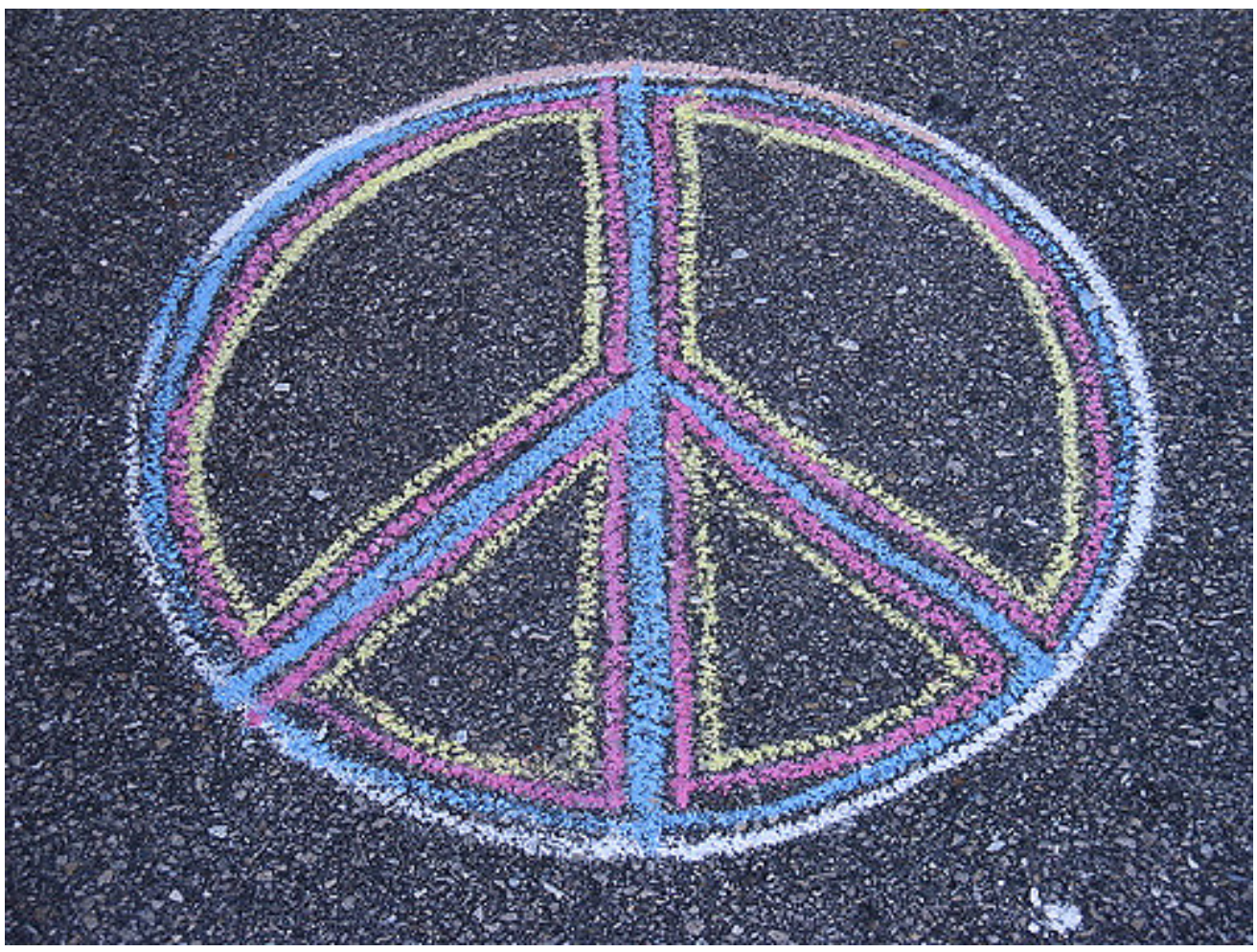

Source: Clip art: http://www.homemade-preschool.com/image-files/peace-sign-black.png.

A second emphasis concerns the use of symbols to marshal support for war or protest against war. Symbols such as the flag evoke feelings of patriotism, perhaps especially when a nation is at war. The president and other politicians typically display a flag when they give major speeches, and it would be unthinkable for a flag not to be showing when the speech is about war or the threat of war. During the Vietnam War, protesters sometimes flew the US flag upside-down (the international symbol of distress) to show their hatred of the war, and some protesters also burned the flag — an act that is almost guaranteed to provoke outrage and hostility from onlookers.

Other symbols can also be important. When the United States invaded Iraq in March 2003, millions of Americans put magnetic yellow ribbons on their cars, SUVs, and pickup trucks to show their support for the troops. The largest manufacturer of the ribbons sold more than one million monthly a year after the war began. However, sales slipped as support for the war declined, and four years after the war numbered only 4,000 monthly (Ward, 2007). Another ubiquitous symbol during the Vietnam War was the so-called international peace symbol (see Figure 16.1 "International Peace Symbol"), originally designed in the late 1950s to symbolize concern over nuclear weapons. Vietnam War protesters wore this symbol on their clothing, and many put peace symbol decals on their motor vehicles, book bags, and other possessions.

A third emphasis of symbolic interactionism concerns how concepts related to war and terrorism come to be defined in ways that advance the goals of various parties. For example, a key goal of the military in basic training is to convince trainees that people they may face on the battlefield are the enemy and, as such, an appropriate target for killing. Related to this goal is the need to convince trainees that when they kill an enemy soldier, the killing is a justified killing and not murder. Similarly, the military often refers to civilian deaths or wounding as collateral damage in a conscious or unconscious attempt to minimize public horror at civilian casualties.

Another definitional issue concerns terrorism. As we shall discuss later, the definition of terrorism is very 
subjective, as actions that some people might regard as terrorism might be regarded by other people as freedom fighting or some other much more positive term than terrorism.

With this theoretical background in mind, we now turn to several issues and problems of war and terrorism.

\section{Key Takeaways}

- War and terrorism serve several functions, including the creation of social solidarity.

- According to conflict theory, war advances the interests of the military-industrial complex, while militarism takes money away from unmet social needs.

- Symbolic interactionism emphasizes the importance of symbols in support for war and terrorism and the experience of civilians and veterans as victims of war.

\section{For Your Review}

1. Which one of the three perspectives on war and terrorism do you most favor? Why?

2. Why do you think the flag has so much symbolic importance in American society?

\section{References}

Boggs, C. (2011). Empire versus democracy: The triumph of corporate and military power. New York, NY: Routledge.

Markides, K. C., \& Cohn, S. F. (1982). External conflict/internal cohesion: A reevaluation of an old theory. American Sociological Review, 47, 88-98.

Mills, C. W. (1956). The power elite. New York, NY: Oxford University Press.

Park, R. E. (1941). The social function of war: Observations and notes. American Journal of Sociology, 46, 551-570.

Shiller, R. J. (2012, January 15). Spend, spend, spend. It’s the American way. New York Times, BU3.

Ward, A. (2007, March 2). Yellow ribbons dwindle with war support. The Financial Times. Retrieved from http://www.ft.com/intl/cms/s/0/4793da48-c8f7-11db-9f7b-000b5df10621.html\#axzz1uqyZTxHR.

Worrell, M. P. (2011). Why nations go to war: A sociology of military conflict. New York, NY: Routledge. 


\subsection{War}

\section{Learning Objectives}

1. Explain why war is best understood as a social phenomenon and why nations go to war.

2. Outline both sides to the debate over the size of the US military budget.

3. List the types of problems that military veterans often face.

War is "sustained armed conflict" that causes "large-scale loss of life or extreme material destruction" (Worrell, 2011, p. 1). Wars occur both between nations and within nations, when two or more factions engage in armed conflict. War between nations is called international war, while war within nations is called civil war.

\section{The World at War}

More than 100 million soldiers and civilians are estimated to have died during the international and civil wars of the twentieth century (Leitenberg, 2006). Although this is almost an unimaginable number, there is cause for some hope, even as there is also cause for despair.

The hope arises from historical evidence that the number of international wars, civil wars, and other types of armed conflict has in fact declined over the centuries, with the number in the past half-century much smaller than in centuries past (Pinker, 2012). Reflecting this decline, a smaller percentage of the world's population died in armed conflict during the past century than in earlier eras.

To illustrate this trend, compare two periods of history (Pinker, 2012). The first is the thirteenth century, when the Mongol Empire under the initial leadership of Genghis Khan became an empire in Asia and Eastern Europe through wars and conquest in which it killed 40 million people. The second period is 1939-1945, when World War II killed 55 million people. Although 55 million is more than 40 million, the world's population in the thirteenth century was only one-seventh its population during the World War II period. A quick calculation shows that about 11 percent of the world's population died from the Mongolian wars, while 2 percent died from World War II. In terms of the risk of dying in war, then, the Mongolian wars were five times more deadly than World War II. 


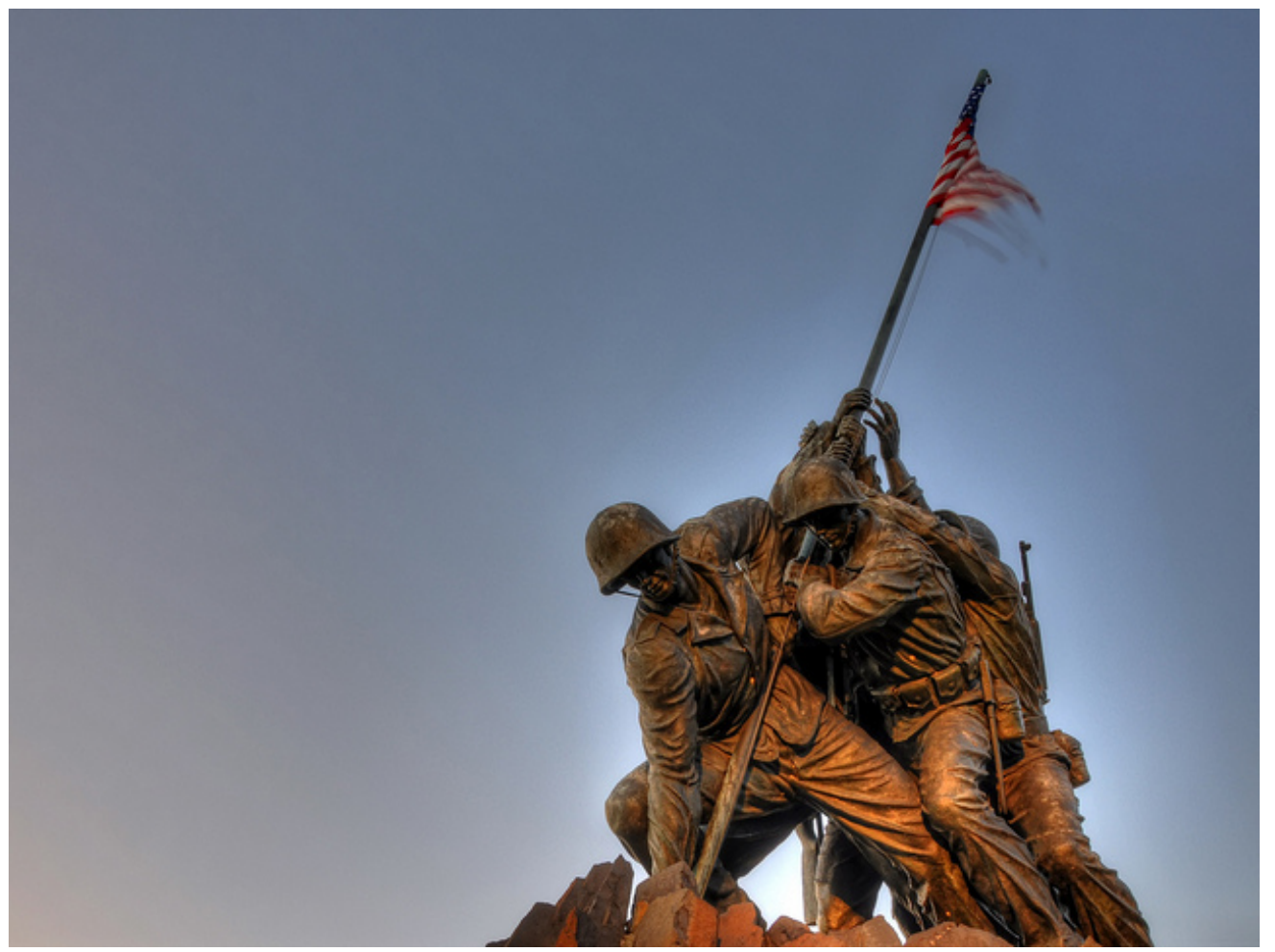

Although World War II killed an estimated 55 million people, a smaller percentage of the world's population died in armed conflict during the twentieth century than in earlier eras.

Reid Kasprowicz - A Flag for the Fallen - CC BY-NC-ND 2.0.

Looking further back in world history, the death rate in prehistoric times from tribal warfare was extremely high. If this high rate had held true during the twentieth century, 2 billion people would have died in twentieth-century wars rather than the 100 million who did die (Pinker, 2012). Although wars, other armed conflicts, terrorism, and genocide certainly continue, and 100 million is a terribly high number of deaths, the world overall is in fact more peaceful now than in the past.

That is the good news and the cause for hope. The cause for despair is twofold. First, war, terrorism, genocide, and other armed conflicts do continue. Even if they are less frequent and less deadly than in the past, that is of little comfort to the tens of millions of people around the world during the past century who died or otherwise suffered in war and other armed conflict and who live in fear today of becoming a victim of armed conflict.

Second, the world today is a much more dangerous place than in the past because of the existence of nuclear weapons. The thirteenth-century Mongolians killed their 40 million with battleaxes and other crude weapons; the World War II deaths resulted from gunfire and conventional bombs. At the end of that war, however, the nuclear age began when the United States dropped two atomic weapons on Japan that killed tens of thousands instantly and tens of thousands more from radiation exposure.

Those two weapons were tiny in both number and size compared to nuclear weapons today. More than 20,000 nuclear warheads now exist; 4,800 are operational and almost 2,000 (held by the United States and Russia) are on high alert, ready to be used at any time (Federation of American Scientists, 2011). Each of these warheads is an average of at least twenty times more powerful than each of the atomic bombs that decimated Japan. The Union 
of Concerned Scientists (2009) summarizes their danger bluntly: "Nuclear weapons remain the greatest and most immediate threat to human civilization.” However more peaceful the world is today, it could easily end at any moment.

\section{The United States at War}

If we say the history of the United States has been written in war, that is not too much of an exaggeration. The United States, of course, began with the colonial war against England. The American Civil War, also called the War Between the States, then tore it apart less than a century later. Between 1861 and 1865, at least 618,000 and perhaps as many as 750,000 soldiers in both the Union and the Confederacy died on the battlefield or from disease. The minimum estimate almost matches the number of American deaths in all the other wars the United States has fought, and the maximum estimate greatly exceeds this number (see Table 16.2 "US Participation in Major Wars").

Table 16.2 US Participation in Major Wars

\begin{tabular}{|l|l|l|l|}
\hline War & Number of troops & Troop deaths & Troops wounded \\
\hline Revolutionary War & $184,000-250,000$ & 4,435 & 6,188 \\
\hline War of 1812 & 286,730 & 2,260 & 4,505 \\
\hline Mexican War & 78,218 & 13,283 & 4,152 \\
\hline Civil War & $3,867,500$ & $618,222-750,000$ & 412,175 \\
\hline Spanish-American War & 306,760 & 2,446 & 1,662 \\
\hline World War I & $4,734,991$ & 116,516 & 204,002 \\
\hline World War II & $16,112,566$ & 405,399 & 671,846 \\
\hline Korean War & $5,720,000$ & 36,574 & 103,284 \\
\hline Vietnam War & $8,744,000$ & 58,209 & 153,303 \\
\hline Persian Gulf War & $2,225,000$ & 382 & 467 \\
\hline Iraq and Afghanistan Wars & $2,333,972$ & 6,251 & 47,566 \\
\hline Note: Deaths are from combat, disease, and other causes. & \\
\hline
\end{tabular}

Sources: Fischer, H. (2005). American war and military operations casualties: Lists and statistics. Retrieved from http://www.history.navy.mil/ library/online/american\%20war\%20casualty.htm; $\quad$ http://web.archive.org/web/20070711050249/http://www.cwc.lsu.edu/other/stats/ warcost.htm; Hacker, J. D. (2011, September 20). New York Times. Retrieved from http://opinionator.blogs.nytimes.com/2011/09/20/ recounting-the-dead; US Department of Defense. (2012, May 18). Operation Iraqi Freedom (OIF), Operation New Dawn (OND), and Operation Enduring Freedom (OEF) U.S. Casualty Status. Retrieved from http://www.defense.gov/news/casualty.pdf (accessed February 16, 2012); Martinez, L. (2011, November 11). US veterans: By the numbers. ABC News. Retrieved from http://abcnews.go.com/Politics/usveterans-numbers/story?id=14928136\#1. 
The United States has been at war in one-fifth of the years it has existed (Bumiller, 2010). Between the end of the colonial period and 1993, the US military was involved in at least 234 declared wars, undeclared wars, or other situations abroad involving actual or potential armed conflict (Collier, 1993). Since 1993, US armed forces have waged war in Iraq and in Afghanistan and also joined international military operations in such countries as Bosnia, Herzegovina, and Libya. By any measure, then, the US military has played a fundamental role, for better or worse, in the nation's foreign affairs historically and also today. Supporters of this role say the military has both protected and advanced the political and economic interests of the United States, while critics, as we have seen, charge that the military has been an instrument of imperialism.

\section{Explaining War}

The enormity of war has long stimulated scholarly interest in why humans wage war (Levy \& Thompson, 2010). A popular explanation for war derives from evolutionary biology. According to this argument, war is part of our genetic heritage because the humans who survived tens of thousands of years ago were those who were most able, by virtue of their temperament and physicality, to take needed resources from other humans they attacked and to defend themselves from attackers. In this manner, a genetic tendency for physical aggression and warfare developed and thus still exists today. In support of this evolutionary argument, some scientists note that chimpanzees and other primates also engage in group aggression against others of their species (Wrangham, 2004).

However, other scientists dispute the evolutionary explanation for several reasons (Begley, 2009). First, the human brain is far more advanced than the brains of other primates, and genetic instincts that might drive these primates' behavior do not necessarily drive human behavior. Second, many societies studied by anthropologists have been very peaceful, suggesting that a tendency to warfare is more cultural than biological. Third, most people are not violent, and most soldiers have to be resocialized (in boot camp or its equivalent) to overcome their deep moral convictions against killing. If warlike tendencies were part of human genetic heritage, these convictions would not exist. 


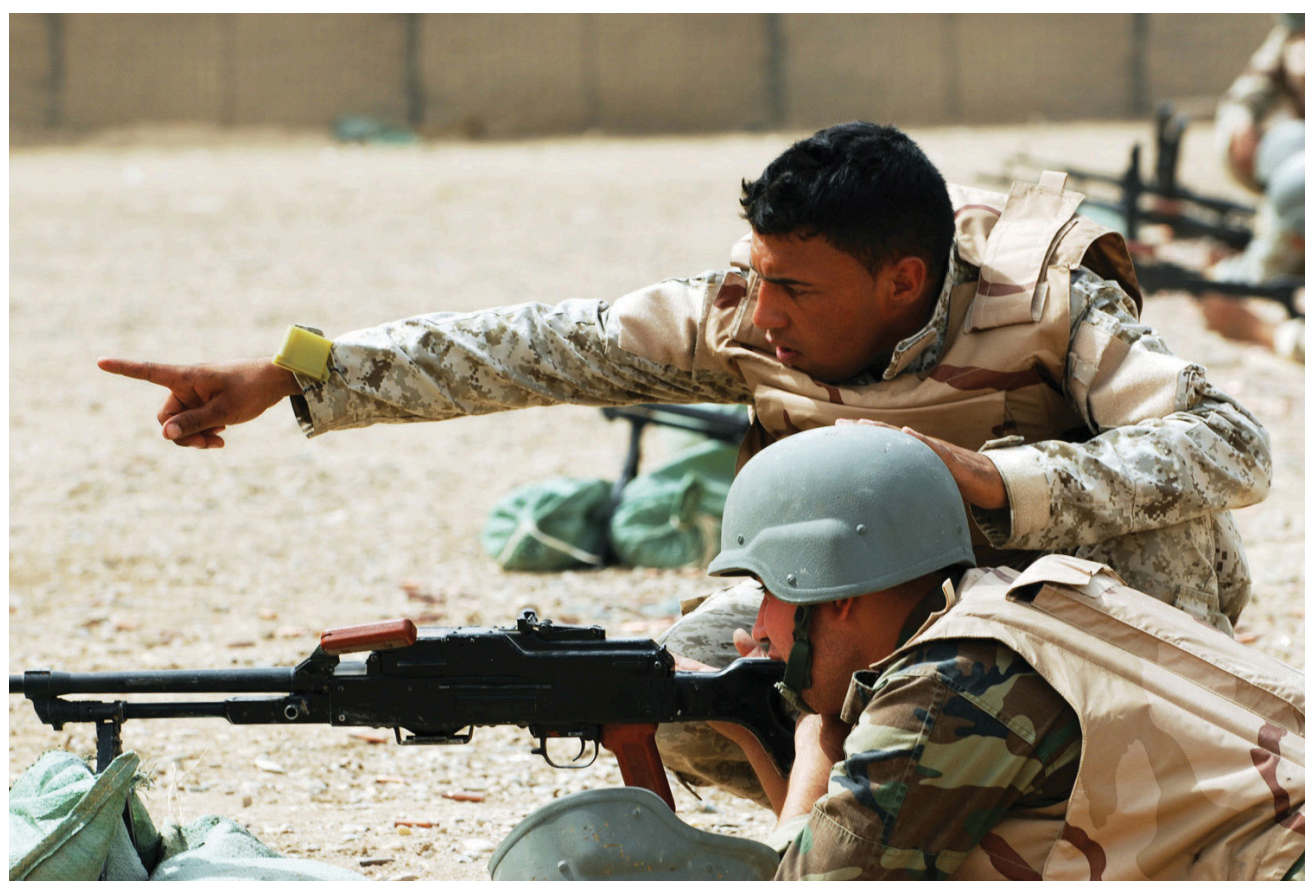

Scholars have attempted to explain why human beings wage war. A popular explanation comes from the field of evolutionary biology and claims that a tendency toward warfare is hardwired into our genetic heritage because it conferred certain evolutionary advantages.

Image courtesy of Sgt. Joshua Risner, US Army, http://commons.wikimedia.org/wiki/File:US Army 51817 BAGHDAD _Iraqi_Soldiers,_with_the_6th_IA_Division, familiarize_themselves_with_their_targets_and_prepare_ for a PKC machine gun range at Combat Outpost 402, here, Sept. 28. In addition to marksmanship.jpg.

\section{War as a Social Phenomenon}

If warfare is not biological in origin, then it is best understood as a social phenomenon, one that has its roots in the decisions of political and military officials. Sometimes, as with the US entrance into World War II after Pearl Harbor, these decisions are sincere and based on a perceived necessity to defend a nation's people and resources, and sometimes these decisions are based on cynicism and deceit (Solomon, 2006).

A prime example of this latter dynamic is the Vietnam War. The 1964 Gulf of Tonkin Resolution, in which Congress authorized President Lyndon Johnson to wage an undeclared war in Vietnam, was passed after North Vietnamese torpedo boats allegedly attacked US ships. However, later investigation revealed that the attack never occurred and that the White House lied to Congress and the American people (Wells, 1994). Four decades later, questions of deceit were again raised after the United States began the war against Iraq because of its alleged possession of weapons of mass destruction. These weapons were never found, and critics charged that the White House had fabricated and exaggerated evidence of the weapons in order to win public and congressional support for the war (Danner, 2006). 


\section{Population Change and Environmental Change}

Although war is a social phenomenon arising from decisions of political and military officials, other phenomena can make it more likely that these officials will decide to go to war. These more basic causes of war include population change and environmental change. As Chapter 15 "Population and the Environment" discussed, population growth may lead to armed conflict of various types, including war, because growing populations need more food, water, and other resources. History shows that when these resources become too scarce within a society, that society is more likely to go to war to wrest these resources from another society (Gleditsch \& Theisen, 2010).

Chapter 15 "Population and the Environment" also discussed environmental change as a source of armed conflict, including war (Fisman \& Miguel, 2010). Recall that when weather disasters and other environmental changes cause drought and other problems, crops and other resources become scarcer. Historically, this scarcity has again motivated societies to go to war.

\section{Ideology and Prejudice}

Nations also go to war for ideological reasons: they have certain belief systems that lead them to hold prejudice and other hostile feelings toward nations with different belief systems. Religion is a very important ideology in this regard. Historically and also today, nations in the Middle East and elsewhere have gone to war or are otherwise in conflict because of religious differences. Although the causes of World War II are complex, Hitler's effort to conquer much of Europe stemmed at least partly from his belief that Aryans (Germans and other Europeans with blond hair and blue eyes) were a superior species and non-Aryans were an inferior species (Bess, 2008).

\section{Civilians: The Casualties of War}

Table 16.2 "US Participation in Major Wars" listed the hundreds of thousands of troop deaths in American wars. The nation rightly grieved these deaths when they occurred and built monuments, such as the Korean and Vietnam veterans memorials in Washington, DC, that list the names of the dead.

John Tirman, director of the Center for International Studies at the Massachusetts Institute of Technology, worries that Americans have neglected the civilian victims of war. He applauds the Korean and Vietnam memorials in Washington, but he laments that "neither mentions the people of those countries who perished in the conflicts" (Tirman, 2012, p. B01). "When it comes to our wars overseas," he adds, "concern for the victims is limited to U.S. troops.”

Tirman notes that approximately 6 million civilians and soldiers died in the Korean, Vietnam/Indochina, Iraq, and Afghanistan wars. Most of these victims were civilians, and most of these civilian deaths were the result of actions by the United States and its allies. These deaths stemmed from bombs and other weapons that went astray, from orders by military and political leaders to drop millions upon millions of bombs on civilian areas, and sometimes 
from atrocities committed by US personnel. In World War II, Tirman adds, the United States dropped two atomic bombs that killed tens of thousands of civilians, and it joined its allies in the carpet bombing of German and Japanese cities that also killed hundreds of thousands.

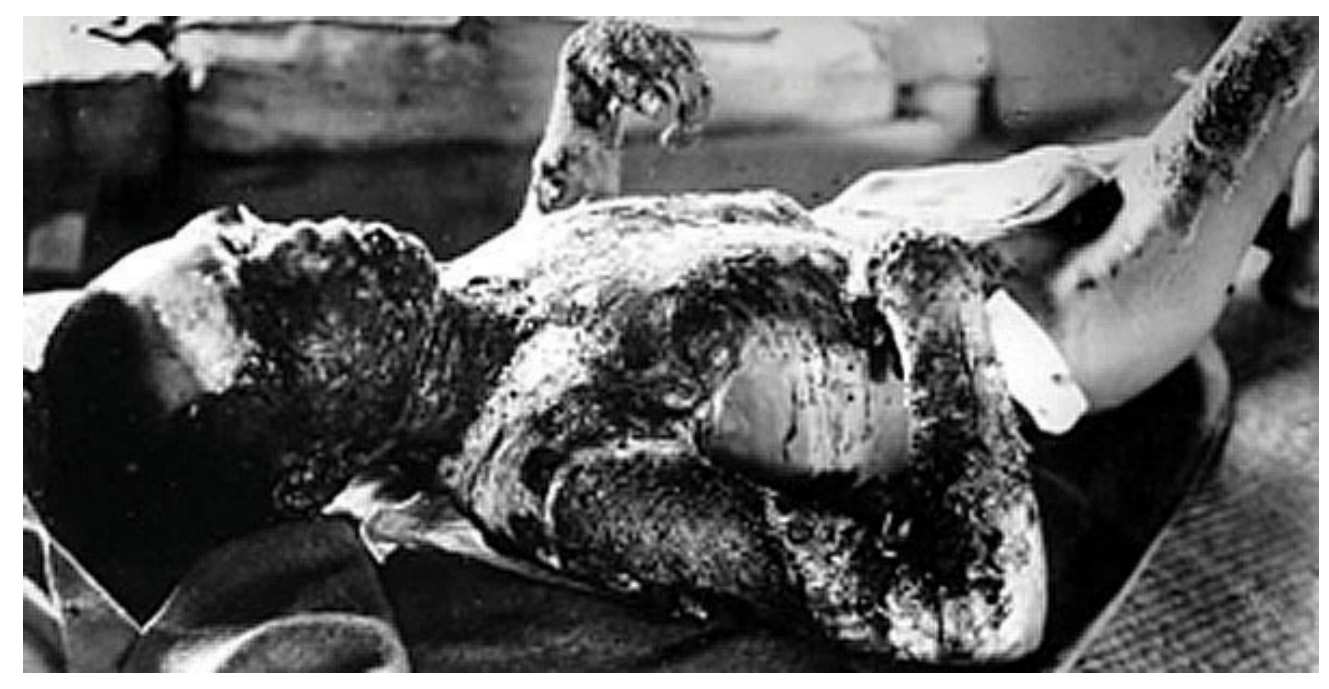

The two atomic bombs dropped by the United States over Japan during World War II killed tens of thousands of civilians. Scholar John Tirman worries that Americans have generally ignored the civilian victims of US wars.

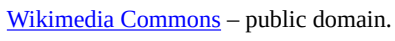

Tirman (2012) acknowledges that the carpet bombing, atomic bombing, and other actions in World War II that killed hundreds of thousands of civilians may have had strategic purposes, and the morality of these actions remains hotly debated today. But he also notes that the Korean and Vietnam wars included many atrocities committed by American troops against civilians. To be blunt, American troops simply shot untold hundreds of Korean and Vietnamese civilians in cold blood.

Tirman describes one Korean incident in which machine gun fire from US warplanes killed about one hundred civilian refugees who were resting on a road. The remaining several hundred refugees hid and were shot at for three days by US ground soldiers. Tirman (2012, p. 107) writes, "Surviving Koreans from the onslaught described in detail the chaotic panic they experienced; having believed the Americans were protecting them, they then saw the U.S. troops fire indiscriminately at men, women, and children at the scene.” At the end of the three days, about four hundred civilians lay dead.

In Vietnam, Tirman writes, American troops and planes routinely razed villages to the ground, killing villagers indiscriminately, and then evacuated any survivors. Once they were evacuated, their villages were designated "free fire zones," and then often bombed indiscriminately once again, killing any villagers who managed to remain in these zones despite the evacuations. All these killings were outright slaughter.

In one example of what Tirman (2011, p. 153) calls a typical massacre, US soldiers arrived at a village that had just been bombed and ordered surviving residents to gather at the center of the town. After they did so, US ground troops shot them and left a pile of dead bodies that included twenty-one children. As this brief discussion indicates, although the massacre of 347 Vietnamese at the hamlet of My Lai is undoubtedly the Vietnam massacre 
that is best known (and perhaps the only known) to the American public, massacres were far from rare and in fact were rather common.

A central part of US military strategy in Vietnam involved destroying rice fields and the rest of the countryside to make it difficult for the Vietcong forces to engage in guerrilla warfare. To do so, it routinely deployed chemical weapons such as Agent Orange (dioxin, a known carcinogen), napalm, and white phosphorous. Planes sprayed and bombed these chemicals. These actions did destroy the countryside, but they also destroyed humans. The Note 16.13 "Children and Our Future" box discusses this problem in greater detail.

\section{Children and Our Future}

"Napalm Sticks to Kids"

This book has emphasized that children are often the innocent victims of various social problems from the time they are born, with important consequences for their futures. There are also many innocent victims in wartime, but when children are victims, our hearts especially go out to them. The Vietnam War marked a time when many Americans became concerned about children's suffering during wartime. A key focus of their concern was the use of napalm.

Napalm is a very flammable jellylike substance made out of gasoline, soap, and white phosphorous. Napalm bombs were used in World War II to set fire to cities, military bunkers, and other targets. When napalm ends up on human skin, it causes incredibly severe pain and burns down to the bone, with death often resulting. Because napalm is very sticky, it is almost impossible to wipe off or remove with water once it does end up on skin.

Bombs containing napalm made by Dow Chemical were routinely used by the US military and its South Vietnamese allies during the Vietnam War to defoliate the countryside and to attack various targets. Some 400,000 tons of napalm were used altogether. When a napalm bomb explodes, it ignites an enormous fireball that burns everything in its path. Inevitably, Vietnamese civilians were in the path of the fireballs generated by the US and South Vietnamese militaries. An unknown number of civilians were burned severely or, if they were lucky, died. Many antiwar protests in the United States focused on the civilian suffering from napalm. Protesters at Dow Chemical's New York office carried signs that said, "Napalm Burns Babies, Dow Makes Money.”

One of these civilians was a 9-year-old girl named Phan Thi Kim Phuc. An Associated Press photo of her running naked and screaming with burns after her village was napalmed was one of the most memorable photos of that war. Although she survived, it took seventeen surgeries to turn her whole again.

A poem about napalm, reportedly written by members of the US First Air Cavalry, surfaced during the war. Some verses follow. 
We shoot the sick, the young, the lame, We do our best to kill and maim,

Because the kills all count the same, Napalm sticks to kids.

Ox cart rolling down the road, Peasants with a heavy load,

They're all V.C. when the bombs explode, Napalm sticks to kids.

A baby sucking on his mother's $t * t$, Children cowering in a pit,

Dow Chemical doesn't give a s!\#t, Napalm sticks to kids.

Blues out on a road recon, See some children with their mom, What the hell, let's drop the bomb, Napalm sticks to kids.

Flying low across the trees,

Pilots doing what they please,

Dropping frags on refugees,

Napalm sticks to kids.

They're in good shape for the shape they're in, But, God I wonder how they can win, With Napalm running down their skin, Napalm sticks to kids.

Drop some napalm on the barn, It won't do too much harm, Just burn off a leg or arm, Napalm sticks to kids. 


\section{Veterans: The Casualties of War}

The attention just given to civilians should in no way obscure or minimize the fact that veterans are also casualties of war. The Korean and Vietnam veterans' memorials in the nation's capital and so many other memorials across the nation remind us of the hundreds of thousands of brave men and women who have died serving their country. But veterans are casualties in other ways, as the news story that began this chapter made clear. They suffer terrible physical and mental wounds that can maim them for life (Dao, 2012).

Veterans of the Vietnam War came back to a nation that often did not greet them as heroes. Many came back addicted to heroin and other drugs, many were unemployed, and many became homeless. Many veterans of the wars in Iraq and Afghanistan have also come back home with these problems. Their unemployment rate was 13.1 percent in December 2011, compared to only 8.5 percent for the general public; the unemployment rate for veterans ages 20-24 was near 30 percent (Dewan, 2011; Zornick, 2012). Many veterans are experiencing posttraumatic stress disorder (PTSD), marked by nightmares, panic attacks, and other symptoms (Dao, 2012). Veterans with PTSD often end up with problems in their marriages or other relationships and are more likely to commit violence against their spouses or partners. When these problems occur, they may ironically worsen the psychological state of these veterans.

A related problem is suicide. For every 100,000 Iraq and Afghanistan veterans who receive health care from the Veterans Administration, 38 have killed themselves. The suicide rate of the general population is only 11.3 deaths per 100,000 population. The suicide rate of Iraq and Afghanistan veterans is thus more than three times higher than that of the general public (Martinez \& Bingham, 2011).

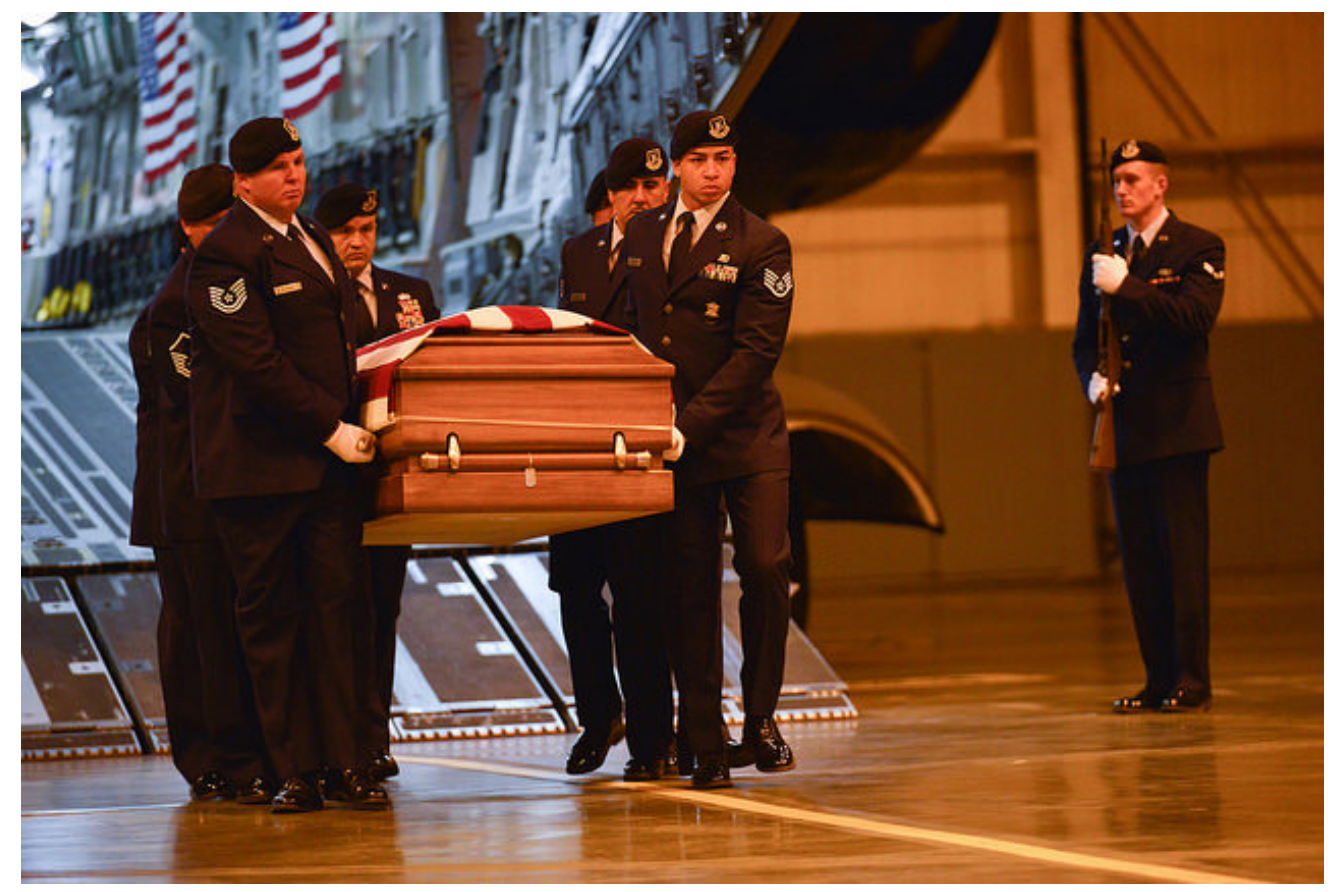


Veterans of the Iraq and Afghanistan War have a higher suicide rate than that of the general public.

The National Guard - New York National Guard - CC BY 2.0.

Evidence from a national survey of Iraq and Afghanistan veterans underscores the problems they face (Pew Research Center, 2011). Almost half said their family relations were strained and that they often felt irritable or angry; 44 percent said they had problems reentering civilian life; and 37 percent said they had suffered from PTSD.

One Iraq veteran with these problems is Tom Marcum, who came home with a brain injury, PTSD, and fits of violence and short-term memory loss. His wife April had to quit her teaching job to take care of him, and their life savings slowly dwindled. April missed the man she used to know: "The biggest loss is the loss of the man I married. His body's here, but his mind is not here anymore. I see glimpses of him, but he's not who he was” (Einhorn, 2011, p. A12).

As the Marcums' situation indicates, spouses and other family members of veterans also are casualties of war. Indeed, the Marcums' situation is far from rare among the families of the 2 million veterans of the Iraq and Afghanistan wars. As a news report summarized these families' experience, “Ms. Marcum has joined a growing community of spouses, parents and partners who, confronted with damaged loved ones returning from war who can no longer do for themselves, drop most everything in their own lives to care for them. Jobs, hobbies, friends, even parental obligations to young children fall by the wayside. Families go through savings and older parents dip into retirement funds” (Einhorn, 2011, p. A12).

Families of deployed troops also face many difficulties. There is the natural fear that loved ones will never return from their overseas involvement in armed conflict. This fear can take a psychological toll on all members of these families, but perhaps especially on children. One teenager recalled the tensions that arose when his father was in Iraq: "I was in eighth grade when my dad deployed to Iraq. A kid walked up to me and said, 'Your dad's a baby killer.' I didn’t handle that well. We both wound up suspended for that one” (Ashton, 2011).

A recent study found that adolescents with a deployed parent are more likely than those with civilian parents to feel depressed and suicidal. They are also more likely to engage in drug use and binge drinking. Reflecting on these findings, an author of the study said, "It's really time to focus on the children that are left behind" (Ashton, 2011).

\section{Rape and Sexual Assault}

Women veterans face a special problem that most male veterans do not have to fear. That problem is rape, as at least one-fifth and perhaps as many as 84 percent of all military service are raped or sexually assaulted (including sexual harassment) by other military personnel (Turchik \& Wilson, 2010). In 2010, more than 19,000 US military personnel, most of them women, were raped or sexually assaulted (Stalsburg, 2011). Only about one-seventh of these victims reported their rapes and sexual assaults. Of these reported cases, only one-fifth went to trial, and only half of these defendants were convicted. As these numbers make clear, military personnel who commit rape and sexual assault almost always avoid any punishment. 


\section{Applying Social Research}

Determining the Prevalence of Rape and Sexual Assault in the Military

As the text discusses, most military women who are raped or sexually assaulted do not report these crimes to military authorities. As a result, reported rapes and sexual assaults compose only a very small percentage of all military rapes and sexual assaults. To get a more accurate estimate of how many such crimes occur, sound social research is necessary.

Despite this need, research on sexual assault in the military was scant before the early 2000s. This type of research accelerated, however, after several scandals involving sexual assault and harassment occurred during the 1990s on military bases and at military academies. The primary mode of research involved survey questionnaires given anonymously to samples, many of them random, of military members. The samples are almost entirely of women, given their higher risk of being sexually assaulted.

In these surveys, between 10 percent and 33 percent of women report being raped (including attempts) while they were serving in the military. When sexual assaults and sexual harassment are added to the crimes mentioned to respondents, between 22 percent and 84 percent of women report being raped, sexually assaulted, and/or sexually harassed while serving. Very few studies include men in their surveys, but one study reported a 3 percent rate of sexual assault victimization for men while they were in the military.

One major problem in this research literature is that different studies use different definitions and measures of sexual assault. Regardless of these problems, this growing body of research documents how often rape and sexual assault in the military occur. It also documents the psychological and health effects of military sexual assault (MSA). These effects are similar to those for civilians, and include anxiety, depression, PTSD, poorer physical health, and poorer job performance (in this case, their military duties).

In shedding light on the prevalence of military rape and sexual assault and on the many negative effects of these crimes, social science research has performed an important service. Future research will no doubt build on existing studies to further illuminate this significant problem.

Source: Turchik \& Wilson, 2010

Women veterans who are raped or sexually assaulted often suffer PTSD. In fact, rape and sexual assault are the leading cause of PTSD among women veterans, while combat trauma is the leading cause of PTSD among male veterans. Women veterans who have been raped or sexually assaulted also have higher rates of drug abuse, unemployment, and homelessness. One veteran recalled being gang raped by her drill sergeant and four other soldiers, who then broke several bones in her body and urinated on her. Several years later, she was still having many health problems and could not forget what happened to her. She also refused to display the American flag, saying, "When I looked at the American flag, I used to see red, white, and blue. Now, all I see is blood" (Herdy \& Moffeit, 2004, p. 4).

In addition to psychological and physiological trauma, rape and sexual assault impose huge economic costs on the military because of medical expenses for helping survivors and for prosecuting their rapists. Health care expenses for survivors amount to almost \$1 billion annually, and the cost of prosecution amounts to \$19 million annually (Stalsburg, 2011).

Women veterans say that when they do report rape and sexual assault, military officials typically either blame them for what happened, ignore the crime altogether, or give the offender a very mild punishment such as not being allowed to leave a military base for a short period. When one woman who was raped by two soldiers in Iraq told her commander, he threatened her with a charge of adultery because she was married (Speier, 2012). 


\section{Helping American Veterans}

After World War II, the GI Bill helped millions of veterans to go to college and otherwise readjust to civilian life. But many observers say that the United States has neglected the veterans of later wars. Although education benefits and many other services for veterans exist, the nation needs to do much more to help veterans, these observers say (Baker, 2012; Shusman, 2012).

The high unemployment rate of the Iraq and Afghanistan veterans has made this need even more urgent. As one business writer put it, "Collectively, it is our patriotic responsibility to help our nation's servicemen and women thrive in today’s economy” (Gerber, 2012). Advocates for veterans with severe physical or cognitive problems also urge the government to greatly expand its very small program of monthly cash payments to these veterans' families to help replace their lost incomes (Einhorn, 2011).

As this brief discussion suggests, US veterans have many unmet needs. Our nation's failure to meet their needs is shameful.

\section{Other Impacts of War}

When we think of the impact of war, the consequences for civilians and veterans as just discussed come most readily to mind. But not all civilians are affected equally. One of the many sad truisms of war is that its impact on a society is greatest when the war takes place within the society's boundaries. For example, the Iraq war that began in 2003 involved two countries more than any others, the United States and Iraq. Because it took place in Iraq, many more Iraqis than Americans died or were wounded, and the war certainly affected Iraqi society-its infrastructure, economy, natural resources, and so forth-far more than it affected American society. Most Americans continued to live their normal lives, whereas most Iraqis had to struggle to survive the many ravages of war.

War also has impact beyond the consequences for civilians and veterans. As historians and political scientists have often described, wars have a significant economic and political impact. Many examples of this impact exist, but one well-known example involves the defeat of Germany in World War I, which led to a worsening economy during the next decade that in turn helped fuel the rise of Hitler.

War can also change a nation's political structure in obvious ways, as when the winning nation forces a new political system and leadership on the losing nation. Other political and economic changes brought by war are less obvious. World War I again provides an interesting example of such changes. Before the war, violent labor strikes were common in Britain and other European nations. When the war began, a sort of truce developed between management and labor, as workers wanted to appear patriotic by supporting the war effort and hoped that they would win important labor rights for doing so. Although the truce later dissolved and labor-management conflict resumed, labor eventually won some limited rights thanks partly to its support for the war. As a historian summarized this connection, "By the end of the war, labor's wartime mobilization and participation had increased its relative power within European societies. As a result, and despite the fact that endeavors to reward labor for its 
wartime cooperation were, in general, provisional, partial, and half-hearted, it was nonetheless the case that labor achieved some real gains” (Halperin, 2004, p. 155).

Other types of less obvious social changes have also resulted from various wars. For example, the deaths of so many soldiers during the American Civil War left many wives and mothers without their family's major breadwinner. Their poverty forced many of these women to turn to prostitution to earn an income, resulting in a rise in prostitution after the war (Rafter, 1990). Some eighty years later, the involvement of African Americans in the US armed forces during World War II helped begin the racial desegregation of the military. This change is widely credited with helping spur the hopes of southern African Americans that racial desegregation would someday occur in their hometowns (McKeeby, 2008).

\section{Militarism and the US Military Budget}

As discussed earlier, President Eisenhower eloquently warned about the influence of the US military and the size of the military budget. The defense industry remains a powerful force in the US economy six decades after Eisenhower issued his warning, and US military spending continues unabated. In 2011, military spending (defense outlays by the Department of Defense and certain other agencies; outlays include costs for the Iraq and Afghanistan wars) according to the government was approximately $\$ 768$ billion. Defense outlays rose by 85 percent beyond inflation between 2000 and 2011.

\section{Clarifying the Military Budget}

As large as it is, the $\$ 768$ billion just cited as the "official” figure for the US military budget is misleading in at least two ways. First, it excludes several military-related costs such as veterans' benefits and interest on the national debt from past military spending. When these costs are taken into account, the total 2011 military budget ranged between an estimated \$1.2 trillion and \$1.4 trillion (Friends Committee on National Legislation, 2012; War Resisters League, 2012). 


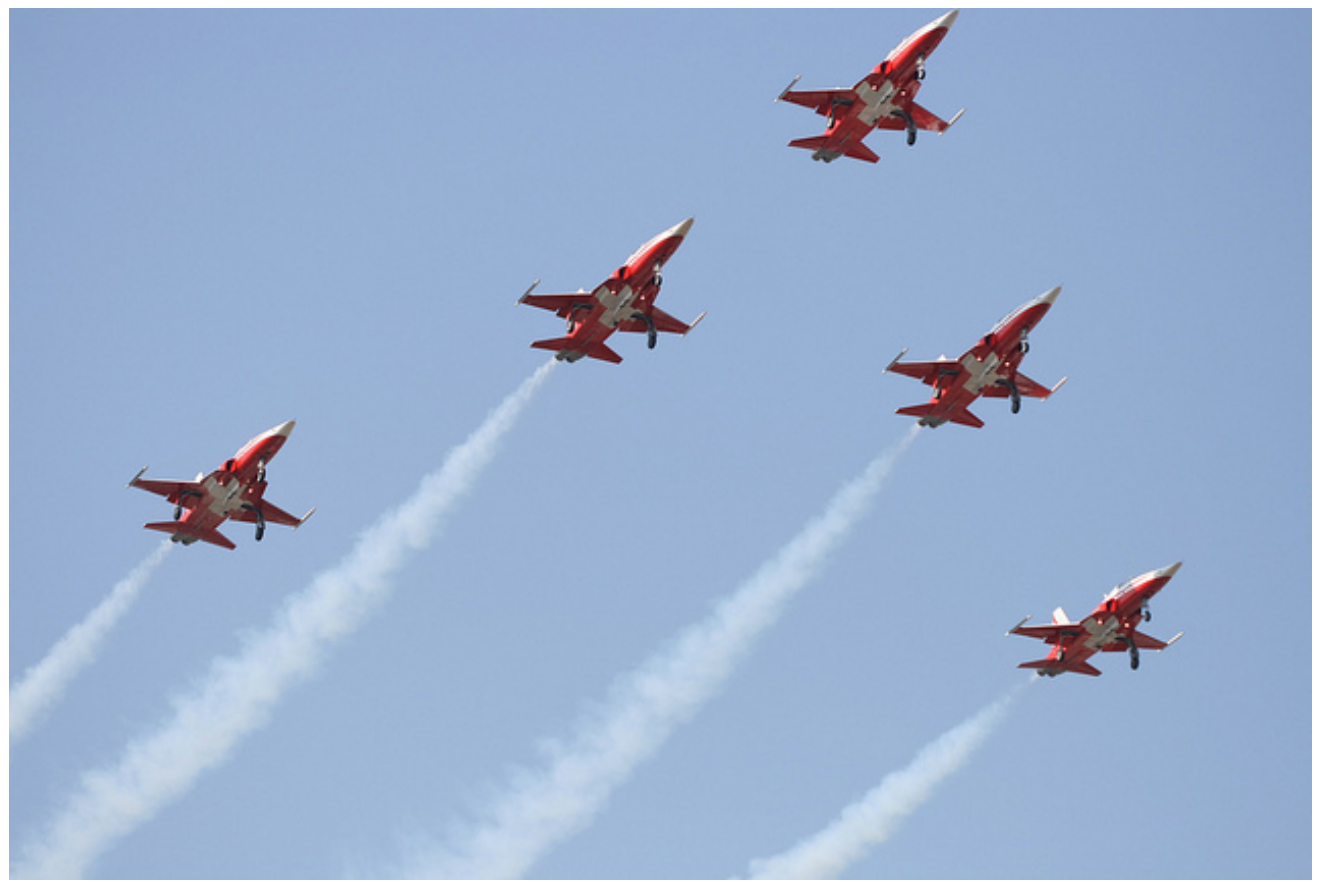

Jeremy Seitz $-\underline{\text { Swiss Jets }}$ - CC BY 2.0.

Second, the government states that defense outlays accounted for almost 20 percent of federal spending in 2011 (US Census Bureau, 2012). However, the calculation for this statement excludes the additional military expenses just discussed, and it uses a misleading measure of federal spending. This latter fact needs some explanation. Federal spending includes both mandatory and discretionary spending. As its name implies, mandatory spending is required by various laws and includes such things as Social Security, Medicare and Medicaid, and interest payments on the national debt. Much of these mandatory expenses are funded by trust funds, such as Social Security taxes, which are raised and spent separately from income taxes. Discretionary spending involves the money the president and Congress must decide how to spend each year and includes federal income tax dollars only. Critics of the military budget argue that it is more accurate to cite its share of discretionary spending rather than its share of all federal spending (i.e., mandatory plus discretionary).

Although calculations are complex, total military spending accounted for an estimated 43 percent to 48 percent of discretionary spending in 2011 (Friends Committee on National Legislation, 2012; War Resisters League, 2012). To put that another way, between 43 percent and 48 percent of all federal income tax dollars were used for military expenditures that year. This percentage range is much higher than the 20 percent share of federal spending cited by the government solely for defense outlays.

\section{The US Military Budget in International Perspective}

However it is calculated, the US military budget is by far the highest in the world and in fact accounts for 43 percent of the world's military spending. In 2010, the US official military budget (defense outlays only) was \$698 billion. China ranked a distant second at $\$ 119$ billion, followed by the United Kingdom at $\$ 60$ billion and France at $\$ 49$ billion (see Figure 16.3 “International Military Spending, 2010”). 


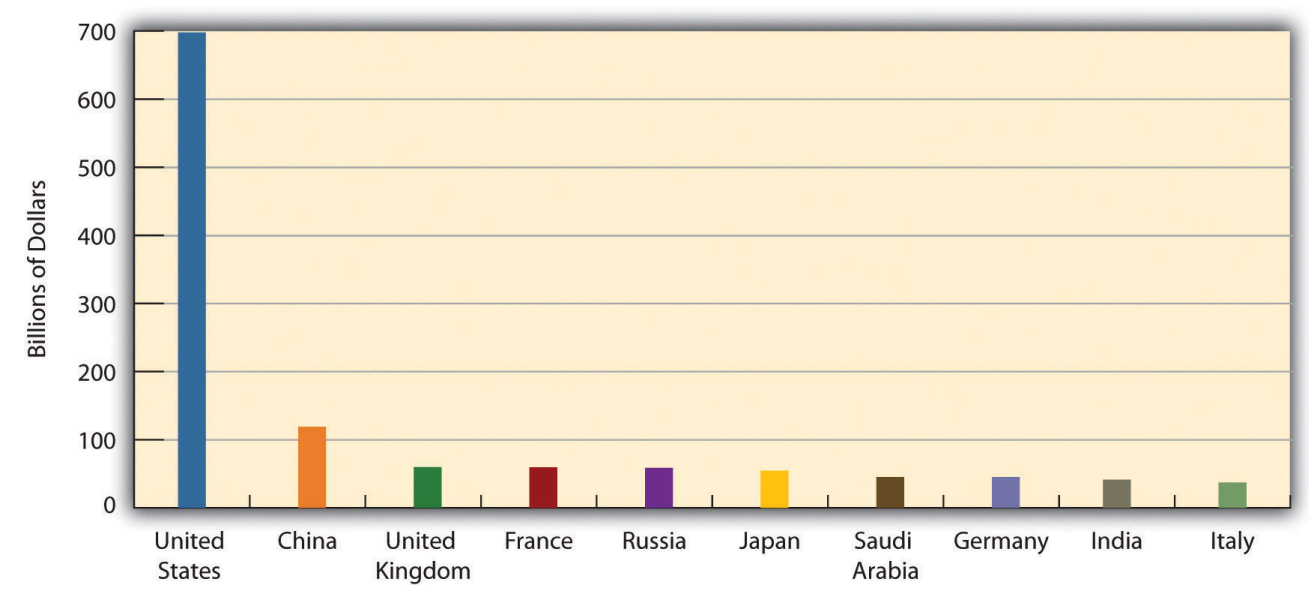

Wikimedia Commons - public domain.

\section{Lessons from Other Societies}

\section{Guns or Butter?}

"Guns versus butter" is a macroeconomics phrase that illustrates the dilemma that nations face in deciding their spending priorities. The more they spend on their military (guns), the less they can spend on food for their poor and other domestic needs (butter).

In making this very important decision, Europe has chosen butter over guns. The wealthy European countries that compose the bulk of the Organization for Economic Cooperation and Development (OECD), an international consortium, spend 2.5 percent of their total economy (gross domestic product, or GDP) on their militaries. In contrast, the United States spends 5.1 percent of its economy on its base military budget, which does not include costs for veterans' benefits, for the Iraq and Afghanistan wars, and military spending that falls outside the Pentagon's budget.

The European nations' decisions to limit their military spending allows more spending for social needs. As a result, observes one economics writer, most Europeans have "universal health care, deeply subsidized education (including free university tuition in many countries), modern infrastructure, good mass transit, and far less poverty" than the United States has. Perhaps worse, the United States ranks last among the world's twenty wealthiest democracies in life expectancy and infant mortality and also ranks worst in the risk of dying before age 60. In addition, half of American children need food stamps at some time before becoming adults, while this problem is far rarer in Europe.

Compared to Europe, then, the United States has chosen guns over butter, leaving far less money for its social needs. As an economics writer wryly noted, "So remember to take pride in American power, and remember that it comes at a very high price.” In making this classic macroeconomics decision, the United States has much to learn from the wealthy nations of Europe.

Source: Holland, 2011

\section{US Arms Exports}

Another dimension of militarism involves arms exports by both the US government and US military contractors. Combining data on both types of exports, the United States sent $\$ 12.2$ billion in arms deliveries to other nations in 2010. This figure ranked the highest in the world and constituted almost 35 percent of all world arms 
exports. Russia ranked second with $\$ 5.3$ billion in arms deliveries, while Germany ranked third with $\$ 2.6$ billion (Grimmett, 2011). Most arms exports from the United States and other exporters go to developing nations. Critics say these exports help fuel the worldwide arms race and international discord. They add that the exports often go to nations ruled by dictators, who then use them to threaten their own people (Feinstein, 2011; Shah, 2011).

\section{"A Theft from Those Who Hunger and Are Not Fed"}

Oscar Arias, a former president of Costa Rica and a winner of the Nobel Peace Prize, echoed these famous words from President Eisenhower when he wrote a decade ago that US military spending took money away from important domestic needs. "Americans are hurt," he warned, "when the defense budget squanders money that could be used to repair schools or to guarantee universal health care” (Arias, 1999, p. A19).

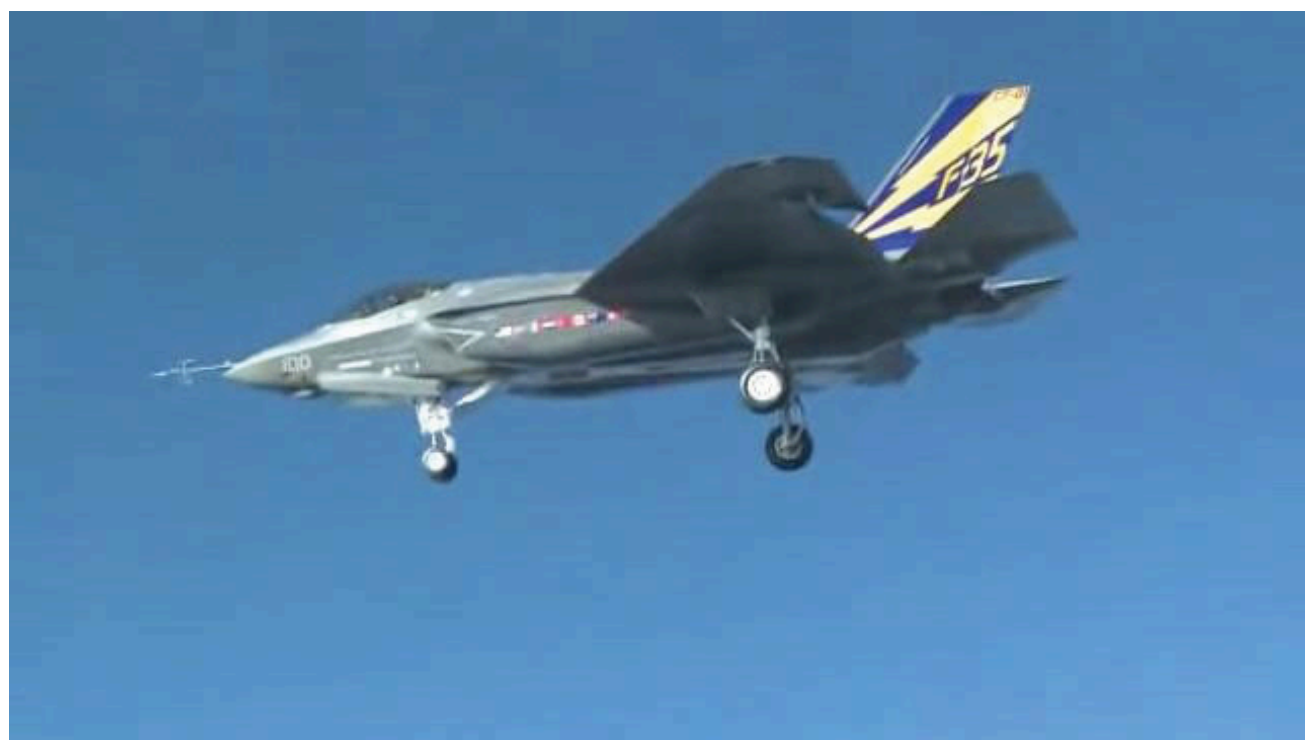

The \$300 million cost of each F-35 fighter aircraft could pay for the salaries of 10,000 new teachers.

Source: “First F-35C Flight," Wikipedia, Last modified on November 20, 2011, http://commons.wikimedia.org/wiki/ File:First_F-35C_Flight.ogv.

Since Arias wrote these words, the United States has spent more than \$5.5 trillion on defense outlays in constant dollars (see Figure 16.3 “International Military Spending, 2010”), including \$1.3 trillion on the wars in Iraq and Afghanistan. Cost equivalencies illustrate what is lost when so much money is spent on the military, especially on weapons systems that do not work and are not needed.

For example, the F-35 fighter aircraft has been plagued with "management problems, huge cost-overruns, [and] substantial performance shortfalls,” according to a recent news report (Kaplan, 2012). Each F-35 costs about \$300 million. This same sum could be used to pay the salaries of 10,000 new teachers earning $\$ 30,000$ per year or to build twenty elementary schools at a cost of \$15 million each. In another example, the Navy is designing a new series of nuclear submarines, with construction planned to start in 2019. The Navy plans to purchase twelve of these submarines. Each submarine is projected to cost more than \$8 billion to build and another \$21 billion in constant dollars in operation and maintenance costs over its lifetime (Castelli, 2012). This \$29 billion sum for 
each submarine during its lifetime could provide 5.8 million scholarships worth \$5,000 each to low- and middleincome high school students to help them pay for college.

The wars in Iraq and Afghanistan provide additional examples of "a theft from those who hunger and are not fed.” These wars cost the United States about \$1.3 trillion through 2012, for an average of more than \$100 billion annually (Harrison, 2012). This same yearly amount could have paid for one year’s worth (California cost figures) of all of the following (National Priorities Project, 2012):

- 146,000 police officers

- 9.5 million children receiving low-income health care (Medicaid)

- 1.7 million students receiving full-tuition scholarships at state universities

- 1.6 million Head Start slots for children

- 179,000 elementary school teachers

- 162,000 firefighters

- 2.5 million Pell Grants of \$5,550 each

All these figures demonstrate that war and preparation for war indeed have a heavy human cost, not only in the numbers of dead and wounded, but also in the diversion of funds from important social functions and needs.

\section{The Debate over the Size of the Military Budget}

This diversion of funds is unfortunate, but it might still be necessary if the high level of US military spending is needed to ensure the nation's security. Experts disagree over this issue. Some think the United States needs to maintain and in fact increase its level of military spending, even with the Cold War long ended, to replace aging weapons systems, to meet the threat posed by terrorists and by "rogue" nations such as Iran, and to respond to various other trouble spots around the world. Military spending is good for workers, they add, because it creates jobs, and it also contributes to technological development (Boot, 2012; England, 2012; McKeon, 2012).

Other experts echo President Eisenhower's concern over the size of the military budget (Bacevich, 2011; Korb, Rothman, \& Hoffman, 2012; Lochhead, 2012; Wheeler, 2009). Noting that the military budget today exceeds the average budget during the Cold War, they think military spending is far higher than it needs to be to ensure the nation's defense with the Soviet Union no longer a threat. They say the United States could safely decrease its nuclear and conventional weapons arsenals without at all endangering national security. They also say that the stationing of some 300,000 American troops on 865 military bases abroad at the time of this writing, including 81,000 troops in Europe and 220,000 in other nations, is hardly needed to ensure the nation's defense. As one scholar said of the military bases, "It makes as much sense for the Pentagon to hold onto 227 military bases in Germany as it would for the post office to maintain a fleet of horses and buggies” (vanden Heuvel, 2011).

These experts say the military budget is bloated for at least four reasons. First, the defense industry is very effective at lobbying Congress for increased military spending, with the cozy relationship among members of the military-industrial complex helping to ensure the effectiveness of this lobbying. Second, members of Congress 
fear being labeled "weak on defense" if they try to reduce the military budget or do not agree to new weapons systems requested by the Pentagon. Regarding this fear, former US senator and presidential candidate George McGovern (2011, p. 47), a decorated World War II hero, writes, "We need to end the false choice between a bloated budget and a weak spine.”

Third, and helping to explain the success of this lobbying, military spending provides jobs and income to the home districts of members of Congress. Fourth, military waste in the form of cost overruns from poor accounting and other management failures is rampant. As just one example of such waste, a 2011 federal audit found that cost overruns over the prior two years had added at least $\$ 70$ billion to projected costs of various weapons systems (Drew, 2011). A major reason for this problem was that the Pentagon had begun building these systems before their designs had been completely tested.

Critics also argue that military spending actually produces fewer jobs than spending in other sectors (Ledbetter, 2011). According to a recent estimate, $\$ 1$ billion spent by the Pentagon creates 11,200 jobs, but the same $\$ 1$ billion spent in other sectors would create 16,800 clean energy jobs, 17,200 health-care jobs, and 26,700 education jobs (Pollin \& Garrett-Peltier, 2011). To quote the title of a recent report, military spending is "a poor job creator" (Hartung, 2012). This report concluded that "the more money we spend on unneeded weapons programs, the more layoffs there will be of police officers, firefighters, teachers, and other workers whose jobs are funded directly or indirectly by federal spending."

As this overview of the debate over military spending indicates, the military remains a hot topic more than two decades after the Cold War ended following the demise of the Soviet Union. As we move further into the twenty-first century, the issue of military spending will present a major challenge for US political and economic institutions to address in a way that meets America's international and domestic interests.

\section{Key Takeaways}

- War is a social phenomenon in which a mixture of motives underlies decisions to go to war.

- War has significant impacts, but perhaps most of all on civilians and veterans.

- US military spending amounts to more than $\$ 1$ trillion annually.

- Critics of the military budget say that the billions of dollars spent on weapons and other military needs would be better spent on domestic needs such as schools and day care.

\section{For Your Review}

1. Do you think the US military budget should be increased, be reduced, or stay about the same? Explain your answer.

2. What do you think is the worst problem that veterans have faced in returning from the wars in Iraq and Afghanistan? Why? 


\section{References}

Arias, O. (1999). Stopping America’s most lethal export. New York Times, June 23, p. A19.

Ashton, A. (2011, July 22). Children of deployed troops struggle, study finds. Bangor Daily News. Retrieved from http://bangordailynews.com/2011/07/22/health/children-of-deployed-troops-struggle-researchers-find.

Bacevich, A. (2011). Washington rules: America's path to permanent war. New York, NY: Metropolitan Books.

Baker, L. (2012, February 18). A concerted effort needed to help homeless veterans. The Times-Leader. Retrieved from $\quad$ http://www.timesleader.com/stories/A-concerted-effort-needed-to-help-homeless-veteransCOMMENTARY-STATE-SENLISA-

BAKER,89325?search filter=A+concerted+effort+needed+to+help+homeless +veterans \&town id=1\&sub type $=$ stories.

Begley, S. (2009, June 29). Don’t blame the caveman. Newsweek, 52-62.

Bess, M. (2008). Choices under fire: Moral dimensions of World War II. New York, NY: Vintage Books.

Boot, M. (2012). Slashing America's defense: A suicidal trajectory. Retrieved February 20, 2012, from http://www.cfr.org/defense-policy-and-budget/slashing-americas-defense-suicidal-trajectory/p26989.

Bumiller, E. (2010, July 25). The war: A trillion can be cheap. New York Times, p. WK3.

Castelli, C. J. (2012, February 17). DOD: New nuclear subs will cost $\$ 347$ billion to acquire, operate. InsideDefense.com NewsStand. Retrieved from http://defensenewsstand.com/NewsStand-General/The-INSIDERFree-Article/dod-new-nuclear-subs-will-cost-347-billion-to-acquire-operate/menu-id-720.html.

Collier, E. C. (1993). Instances of use of United States forces abroad, 1798-1993. Retrieved from http://www.history.navy.mil/wars/foabroad.htm.

Danner, M. (2006). The secret way to war: The Downing Street memo and the Iraq War's buried history. New York, NY: New York Review of Books.

Dao, J. (2012, January 2). Acting out war's inner wounds. New York Times, p. A1.

Dewan, S. (2011, December 18). As wars end, young veterans return to scant jobs. New York Times, p. A1.

Drew, C. (2011, March 30). Audit of Pentagon spending finds $\$ 70$ billion in waste. New York Times, p. B4.

Einhorn, C. (2011, September 28). Looking after the soldier, back home and damaged. New York Times, p. A12.

England, G. (2012, February 5). Military preparedness does not come cheap. The Washington Post. Retrieved from http://www.washingtonpost.com/opinions/military-preparedness-does-not-come-cheap/2012/02/05/ gIQA5PLfsQ story.html. 
Federation of American Scientists. (2011). Status of world nuclear forces. Retrieved February 16, 2012, from http://www.fas.org/programs/ssp/nukes/nuclearweapons/nukestatus.html.

Feinstein, A. (2011). The shadow world: Inside the global arms trade. New York, NY: Farrar, Straus and Giroux.

Fisman, R., \& Miguel, E. (2010). Economic gangsters: Corruption, violence, and the poverty of nations. Princeton, NJ: Princeton University Press.

Friends Committee on National Legislation. (2012). Where do our income tax dollars go. Retrieved from http://fcnl.org/assets/flyer/taxchart11.pdf.

Gerber, S. (2012, February 7). Why we should help veterans start their own businesses. Time. Retrieved from http://business.time.com/2012/02/07/why-we-should-help-veterans-start-their-own-businesses/.

Gleditsch, N. P., \& Theisen, O. M. (2010). Resources, the environment, and conflict. In M. D. Cavelty \& V. Mauer (Eds.), The Routledge handbook of security studies (pp. 221-232). New York, NY: Routledge.

Grimmett, R. E. (2011). Conventional arms transfers to developing nations, 2003-2010. Washington, DC: Congressional Research Service.

Halperin, S. (2004). War and social change in modern Europe: The great transformation revisited. Cambridge, United Kingdom: Cambridge University Press.

Harrison, T. (2012). Analysis of the FY2012 defense budget. Washington, DC: Center for Strategic and Budgetary Assessments.

Hartung, W. D. (2012). Military spending: A poor job creator. Washington, DC: Center for International Policy.

Herdy, A., \& Moffeit, M. (2004). Betrayal in the Ranks. Retrieved from http://www.denverpost.com/Stories/ 0,0,36\%257E30137\%257E,00.html.

Holland, J. (2011, June 17). Are we giant suckers? While the US blows money on the military, Europe spends dough on social programs. AlterNet. Retrieved from http://www.alternet.org/world/151337/ are we giant suckers while the us blows money on the military, europe

spends dough on social_programs.

Kaplan, F. (2012, February 13). What happened to a leaner, meaner military. Slate. Retrieved from http://www.slate.com/articles/news and_politics/war_stories/2012/

02/ 2013 pentagon budget why so much spending on big war weapons .html.

Korb, L. J., Rothman, A., \& Hoffman, M. (2012). The fiscal year 2013 defense budget: A report card. Washington, DC: Center for American Progress.

Ledbetter, J. (2011). Unwarranted Influence: Dwight D. Eisenhower and the military-industrial complex. New Haven, CT: Yale University Press.

Leitenberg, M. (2006). Deaths in wars and conflicts in the 20th century. Ithaca, NY: Cornell University Peace Studies Program. 
Levy, J. S., \& Thompson, W. R. (2010). Causes of war. Malden, MA: Wiley-Blackwell.

Lochhead, C. (2012, February 14). Obama's defense cuts are a drop in the bucket. San Francisco Chronicle, p. A6.

Martinez, L., \& Bingham, A. (2011, November 11). US veterans: By the numbers. ABC News. Retrieved from http://abcnews.go.com/Politics/us-veterans-numbers/story?id=14928136\#14928131.

McGovern, G. (2011). What it means to be a democrat. New York, NY: Penguin.

McKeeby, D. (2008, February 25). End of US military segregation set stage for rights movement. America.gov. Retrieved from http:/www.america.gov/st/diversity-english/2008/February/ 20080225120859liameruoy0.9820215.html.

McKeon, H. P. B. (2012, January 12). Obama's damaging blow to our military. The Washington Post. Retrieved from http://www.washingtonpost.com/opinions/obamas-damaging-blow-to-our-military/2012/01/12/ gIQA3eMhuP story.html.

National Priorities Project. (2012). Trade-offs. Retrieved February 16, 2012, from http://costofwar.com/en/ tradeoffs/state/CA/program/11/tradeoff/0.

Pew Research Center. (2011). War and sacrifice in the post-9/11 era. Washington, DC: Author.

Pinker, S. (2012). The better angels of our nature: Why violence has declined. New York, NY: Penguin.

Pollin, R., \& Garrett-Peltier, H. (2011). The US employment effects of military and domestic spending priorities: 2011 update. Amherst, MA: Political Economy Research Institutes.

Rafter, N. H. (1990). Partial justice: Women, prisons, and social control. New Brunswick, NJ: Transaction.

Shah, A. (2011). Arms trade: A major cause of suffering. Retrieved February 17, 2012, from http://www.globalissues.org/issue/73/arms-trade-a-major-cause-of-suffering.

Shusman, B. (2012, February 18). Public, private organizations work to help thousands of homeless veterans in NY. Voice of America News. Retrieved from http://www.voanews.com/english/news/usa/Public-PrivateOrganizations-Work-to-Help-Thousands-of-Homeless-Veterans-in-NY- 139520143.html.

Solomon, N. (2006). War made easy: How presidents and pundits keep spinning us to death. Hoboken, NJ: Wiley. Speier, J. (2012, February 8). Victims of military rape deserve justice. CNN.com. Retrieved http://www.cnn.com/. Stalsburg, B. L. (2011). Rape, sexual assault, and sexual harassment in the military: The quick facts. Retrieved February 18, 2012, from http://servicewomen.org/wp-content/uploads/2012/03/Rape-Sexual-Assault-and-SexualHarassment-in-the-Military.pdf.

Tirman, J. (2011). The deaths of others: The fate of civilians in America's wars. New York, NY: Oxford University Press. 
Tirman, J. (2012, January 8). Do we care when civilians die in war? The Washington Post, p. B01.

Turchik, J. A., \& Wilson, S. M. (2010). Sexual assault in the US military: A review of the literature and recommendations for the future. Aggression and Violent Behavior, 15, 267-277.

Union of Concerned Scientists. (2009). Nuclear weapons overview. Retrieved February 16, 2012, from http://www.ucsusa.org/nuclear weapons and global security/nuclear weapons/technical issues/nuclearweapons-overview.html.

US Census Bureau. (2012). Statistical abstract of the United States: 2012. Washington, DC: US Government Printing Office. Retrieved from http://www.census.gov/compendia/statab.

vanden Heuvel, K. (2011, June 13). Around the globe, US military bases generate resentment, not security. The Nation. Retrieved from http://www.thenation.com/blog/161378/around-globe-us-military-bases-generateresentment-not-security.

Vietnam Veterans Against the War. (1971). A.I.D.E. napalm sticks to kids. Retrieved February 20, 2012, from http://www.vvaw.org/veteran/article/?id=823.

War Resisters League. (2012). Where your income tax money really goes. Retrieved from https://www.warresisters.org/sites/default/files/FY2012piechart-color.pdf.

Wells, T. (1994). The war within: America’s battle over Vietnam. Berkeley, CA: University of California Press.

Wheeler, W. T. (2009). America's defense meltdown: Pentagon reform for President Obama and the new Congress Stanford, CA: Stanford University Press.

Worrell, M. P. (2011). Why nations go to war: A sociology of military conflict. New York, NY: Routledge.

Wrangham, R. W. (2004). Killer species. Daedalus, 133(4), 25-35.

Zornick, G. (2012, January 6). Job numbers are up, but veterans are left behind. The Nation. Retrieved from http://www.thenation.com/blog/165487/job-numbers-are-veterans-are-left-behind. 


\subsection{Terrorism}

\section{Learning Objectives}

1. Explain why terrorism is difficult to define.

2. List the major types of terrorism.

3. Evaluate the law enforcement and structural-reform approaches for dealing with terrorism.

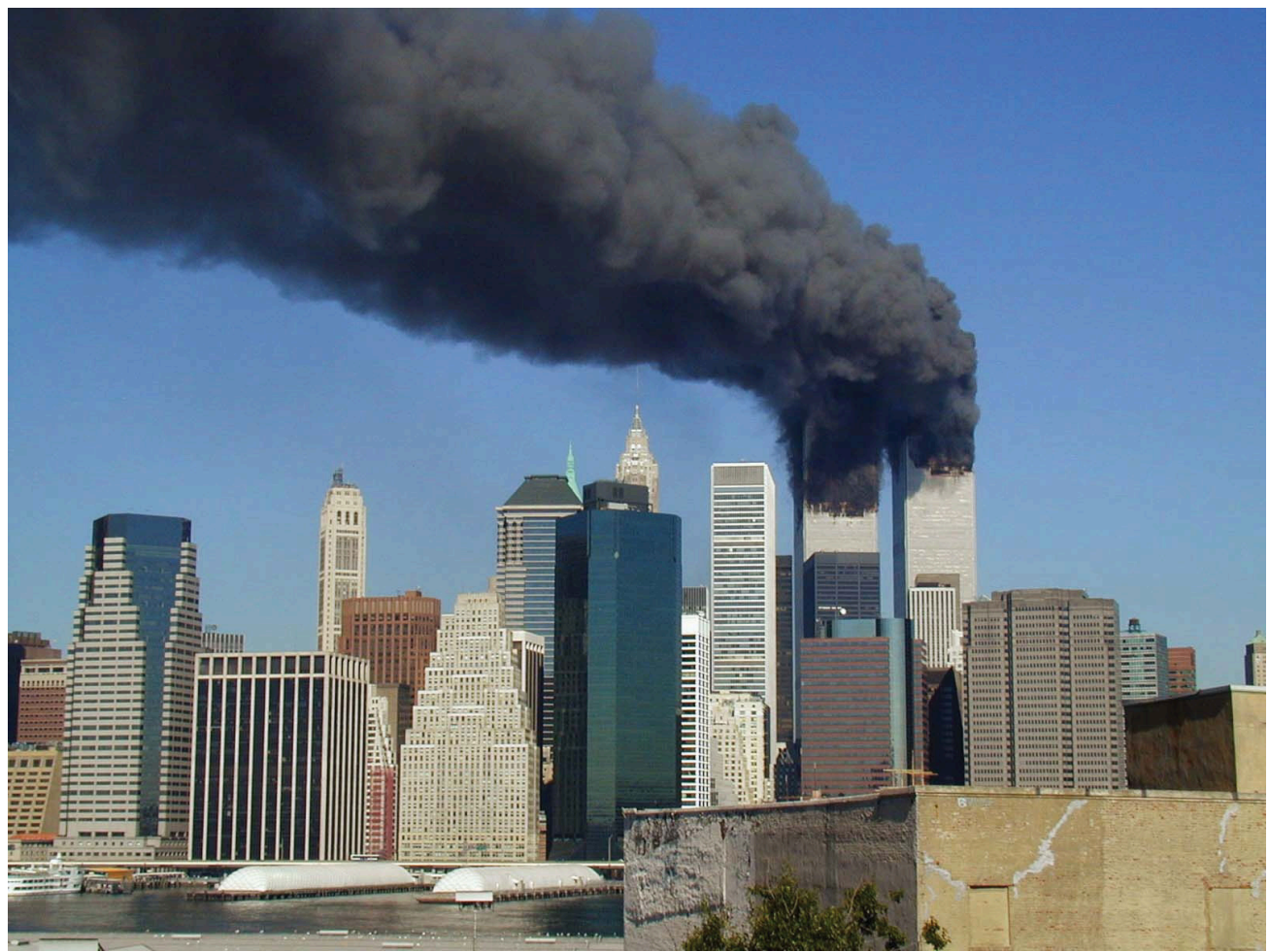

The 9/11 attacks spawned an immense national security network and prompted the expenditure of more than $\$ 3$ trillion on the war against terrorism.

Michael Foran - 9/11 WTC 32 - CC BY-NC-SA 2.0.

Terrorism is hardly a new phenomenon, but Americans became horrifyingly familiar with it on September 11, 2001. The 9/11 attacks remain in the nation's consciousness, and many readers may know someone who died on that terrible day. The attacks also spawned a vast national security network that now reaches into almost every aspect of American life. This network is so secretive, so huge, and so expensive that no one really knows precisely how large it is or how much it costs (Priest \& Arkin, 2010). However, it is thought to include 1,200 government organizations, 1,900 private companies, and almost 900,000 people with security clearances (Applebaum, 2011). The United States has spent an estimated \$3 trillion since 9/11 on the war on terrorism, including more than \$1 
trillion on the wars in Iraq and Afghanistan whose relevance for terrorism has been sharply questioned. Questions of how best to deal with terrorism continue to be debated, and there are few, if any, easy answers to these questions.

Not surprisingly, sociologists and other scholars have written many articles and books about terrorism. This section draws on their work to discuss the definition of terrorism, the major types of terrorism, explanations for terrorism, and strategies for dealing with terrorism. An understanding of all these issues is essential to make sense of the concern and controversy about terrorism that exists throughout the world today.

\section{Defining Terrorism}

There is an old saying that “one person's freedom fighter is another person's terrorist.” This saying indicates some of the problems in defining terrorism precisely. Some years ago, the Irish Republican Army (IRA) waged a campaign of terrorism against the British government and its people as part of its effort to drive the British out of Northern Ireland. Many people in Northern Ireland and elsewhere hailed IRA members as freedom fighters, while many other people condemned them as cowardly terrorists. Although most of the world labeled the 9/11 attacks as terrorism, some individuals applauded them as acts of heroism. These examples indicate that there is only a thin line, if any, between terrorism on the one hand and freedom fighting and heroism on the other hand. Just as beauty is in the eyes of the beholder, so is terrorism. The same type of action is either terrorism or freedom fighting, depending on who is characterizing the action.

Although dozens of definitions of terrorism exist, most take into account what are widely regarded as the three defining features of terrorism: (a) the use of violence; (b) the goal of making people afraid; and (c) the desire for political, social, economic, and/or cultural change. A popular definition by political scientist Ted Robert Gurr (1989, p. 201) captures these features: "The use of unexpected violence to intimidate or coerce people in the pursuit of political or social objectives.”

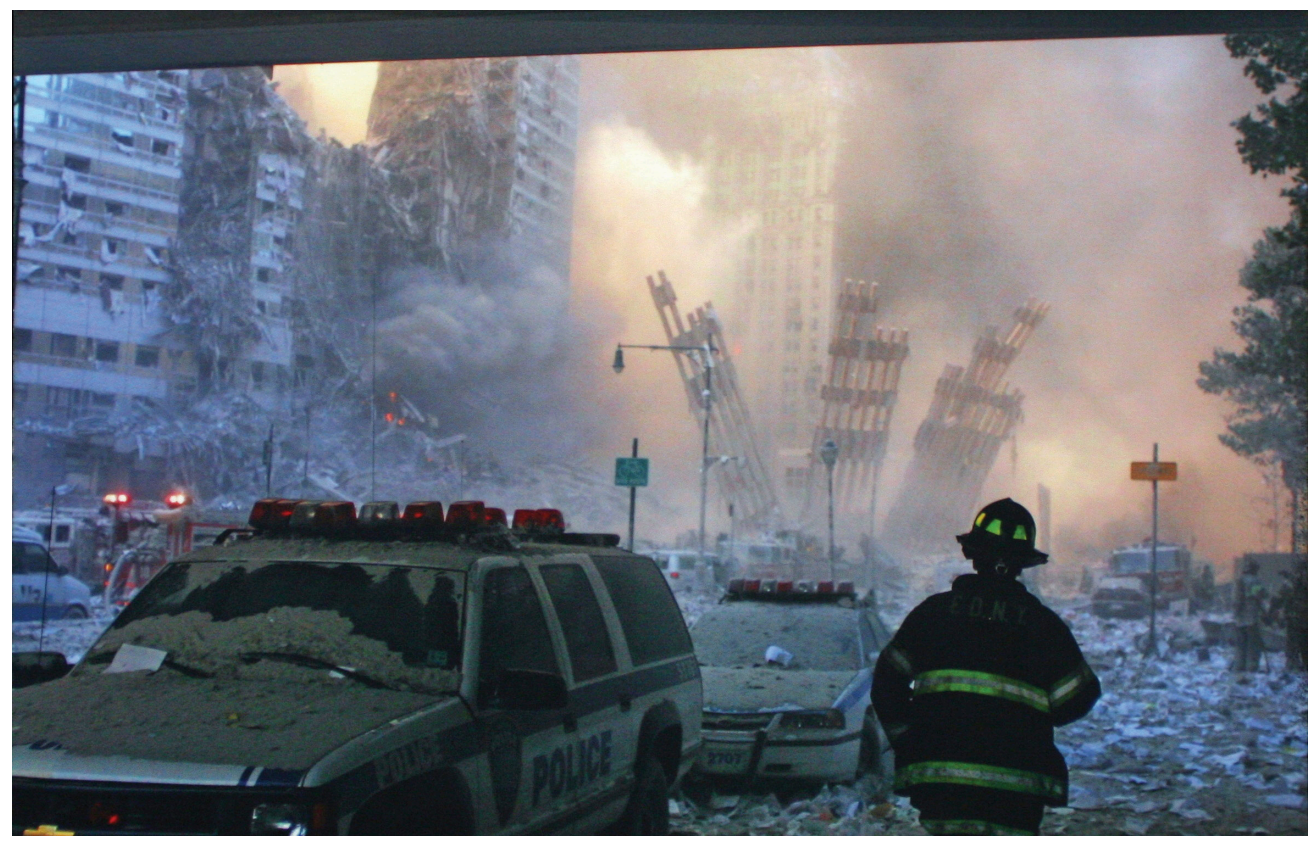


As the attacks on 9/11 remind us, terrorism involves the use of indiscriminate violence to instill fear in a population and thereby win

certain political, economic, or social objectives.

Cliff - September 11th, 2011 - CC BY 2.0.

\section{Types of Terrorism}

When we think about this definition, 9/11 certainly comes to mind, but there are, in fact, several kinds of terrorism-based on the identity of the actors and targets of terrorism-to which this definition applies. A typology of terrorism, again by Gurr (1989), is popular: (a) vigilante terrorism, (b) insurgent terrorism, (c) transnational (or international) terrorism, and (d) state terrorism. Table 16.3 "Types of Terrorism” summarizes these four types.

Table 16.3 Types of Terrorism

\begin{tabular}{|l|l|}
\hline $\begin{array}{l}\text { Vigilante } \\
\text { terrorism }\end{array}$ & Violence committed by private citizens against other private citizens. \\
\hline $\begin{array}{l}\text { Insurgent } \\
\text { terrorism }\end{array}$ & $\begin{array}{l}\text { Violence committed by private citizens against their own government or against businesses and } \\
\text { institutions seen as representing the "establishment." }\end{array}$ \\
\hline $\begin{array}{l}\text { Transnational } \\
\text { terrorism }\end{array}$ & Violence committed by citizens of one nation against targets in another nation. \\
\hline State terrorism & Violence committed by a government against its own citizens. \\
\hline
\end{tabular}

Vigilante terrorism is committed by private citizens against other private citizens. Sometimes the motivation is racial, ethnic, religious, or other hatred, and sometimes the motivation is to resist social change. The violence of racist groups like the Ku Klux Klan was vigilante terrorism, as was the violence used by white Europeans against Native Americans from the 1600s through the 1800s. What we now call "hate crime" is a contemporary example of vigilante terrorism.

Insurgent terrorism is committed by private citizens against their own government or against businesses and institutions seen as representing the "establishment." Insurgent terrorism is committed by both left-wing groups and right-wing groups and thus has no political connotation. US history is filled with insurgent terrorism, starting with some of the actions the colonists waged against British forces before and during the American Revolution, when "the meanest and most squalid sort of violence was put to the service of revolutionary ideals and objectives" (Brown, 1989, p. 25). An example here is tarring and feathering: hot tar and then feathers were smeared over the unclothed bodies of Tories. Some of the labor violence committed after the Civil War also falls under the category of insurgent terrorism, as does some of the violence committed by left-wing groups during the 1960s and 1970s. A relatively recent example of right-wing insurgent terrorism is the infamous 1995 bombing of the federal building in Oklahoma City by Timothy McVeigh and Terry Nichols that killed 168 people.

Transnational terrorism is committed by the citizens of one nation against targets in another nation. This is the type that has most concerned Americans at least since 9/11, yet 9/11 was not the first time Americans had been killed by international terrorism. A decade earlier, a truck bombing at the World Trade Center killed six people 
and injured more than 1,000 others. In 1988, 189 Americans were among the 259 passengers and crew who died when a plane bound for New York exploded over Lockerbie, Scotland; agents from Libya were widely thought to have planted the bomb. Despite all these American deaths, transnational terrorism has actually been much more common in several other nations: London, Madrid, and various cities in the Middle East have often been the targets of international terrorists.

State terrorism involves violence by a government that is meant to frighten its own citizens and thereby stifle their dissent. State terrorism may involve mass murder, assassinations, and torture. Whatever its form, state terrorism has killed and injured more people than all the other kinds of terrorism combined (Gareau, 2010). Genocide, of course is the most deadly type of state terrorism, but state terrorism also occurs on a smaller scale. As just one example, the violent response of Southern white law enforcement officers to the civil rights protests of the 1960s amounted to state terrorism, as officers murdered or beat hundreds of activists during this period. Although state terrorism is usually linked to authoritarian regimes, many observers say the US government also engaged in state terror during the nineteenth century, when US troops killed thousands of Native Americans (D. A. Brown, 2009).

\section{Explaining Terrorism}

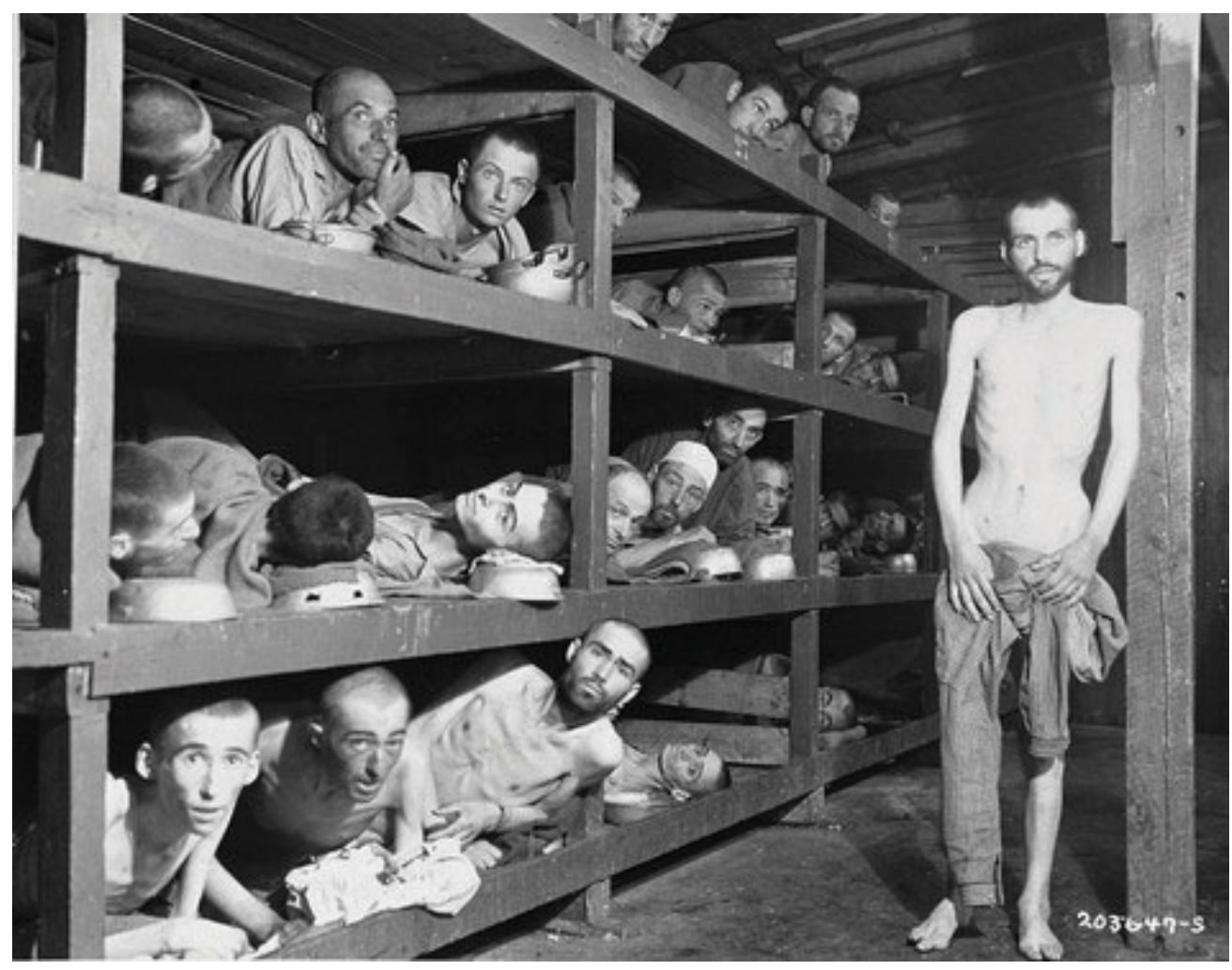

Genocide is the most deadly type of state terrorism. The Nazi holocaust killed some 6 million Jews and 6 million other people.

Wikimedia Commons - CC BY 2.0.

Why does terrorism occur? It is easy to assume that terrorists must have psychological problems that lead them to have sadistic personalities, and that they are simply acting irrationally and impulsively. However, most researchers 
agree that terrorists are psychologically normal despite their murderous violence and, in fact, are little different from other types of individuals who use violence for political ends. As one scholar observed, "Most terrorists are no more or less fanatical than the young men who charged into Union cannon fire at Gettysburg or those who parachuted behind German lines into France. They are no more or less cruel and coldblooded than the Resistance fighters who executed Nazi officials and collaborators in Europe, or the American GI's ordered to ‘pacify’ Vietnamese villages” (Rubenstein, 1987, p. 5).

Contemporary terrorists tend to come from well-to-do families and to be well-educated themselves; ironically, their social backgrounds are much more advantaged in these respects than are those of common street criminals, despite the violence they commit.

If terrorism cannot be said to stem from individuals’ psychological problems, then what are its roots? In answering this question, many scholars say that terrorism has structural roots. In this view, terrorism is a rational response, no matter how horrible it may be, to perceived grievances regarding economic, social, and/or political conditions (White, 2012). The heads of the US 9/11 Commission, which examined the terrorist attacks of that day, reflected this view in the following assessment: "We face a rising tide of radicalization and rage in the Muslim world-a trend to which our own actions have contributed. The enduring threat is not Osama bin Laden but young Muslims with no jobs and no hope, who are angry with their own governments and increasingly see the United States as an enemy of Islam” (Kean \& Hamilton, 2007, p. B1). As this assessment indicates, structural conditions do not justify terrorism, of course, but they do help explain why some individuals decide to commit it.

\section{The Impact of Terrorism}

The major impact of terrorism is apparent from its definition, which emphasizes public fear and intimidation. Terrorism can work, or so terrorists believe, precisely because it instills fear and intimidation. Anyone who might have happened to be in or near New York City on 9/11 will always remember how terrified the local populace was to hear of the attacks and the fears that remained with them for the days and weeks that followed. 


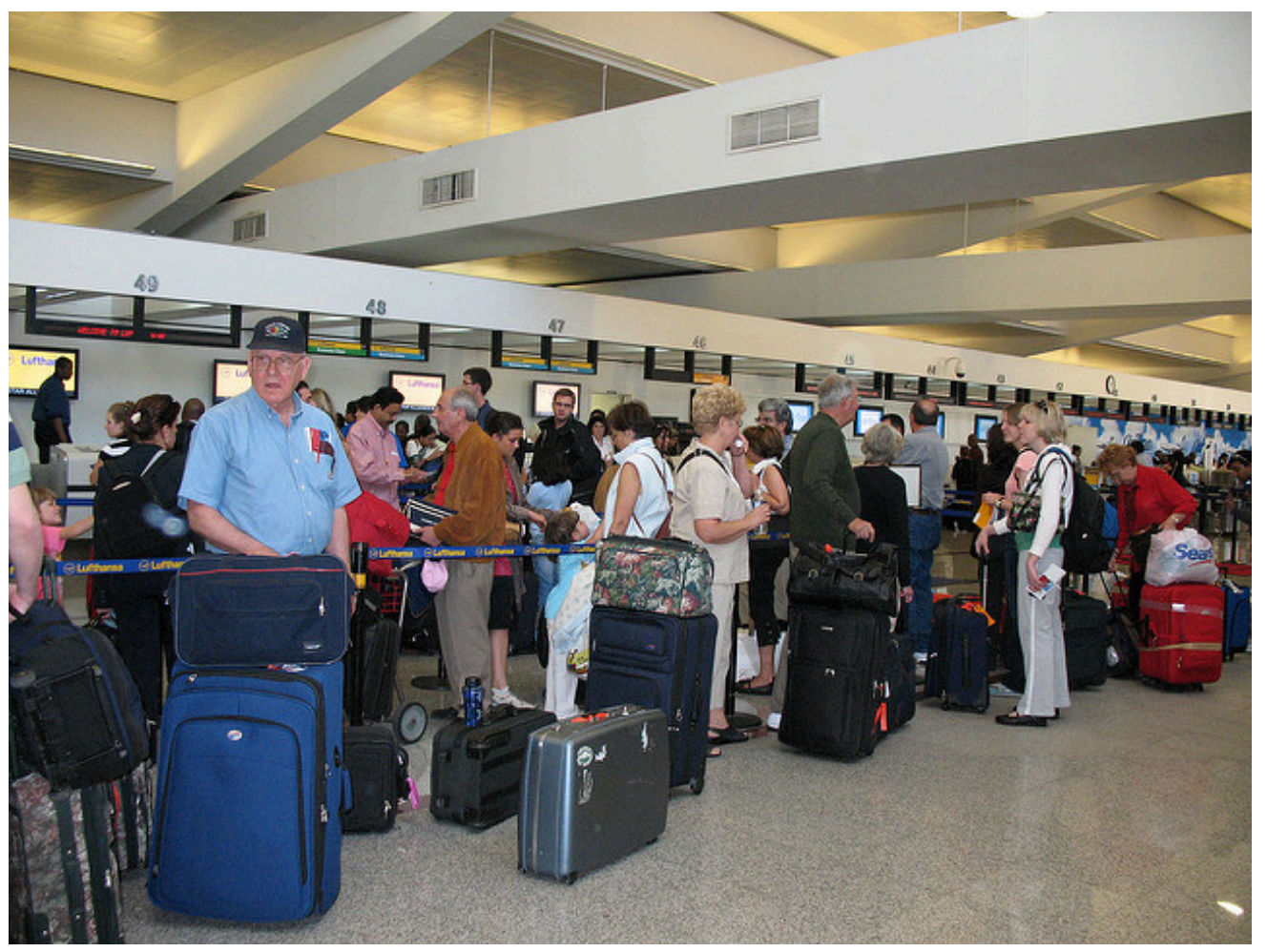

Hardly anyone likes standing in the long airport security lines that are a result of the $9 / 11$ attacks. Some experts say that certain airport security measures are an unneeded response to these attacks.

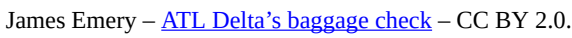

Another significant impact of terrorism is the response to it. As mentioned earlier, the 9/11 attacks led the United States to develop an immense national security network that defies description and expense, as well as the Patriot Act and other measures that some say threaten civil liberties; to start the wars in Iraq and Afghanistan; and to spend more than \$3 trillion in just one decade on homeland security and the war against terrorism. Airport security increased, and Americans have grown accustomed to having to take off their shoes, display their liquids and gels in containers limited to three ounces, and stand in long security lines as they try to catch their planes.

People critical of these effects say that the "terrorists won," and, for better or worse, they may be correct. As one columnist wrote on the tenth anniversary of 9/11, "And yet, 10 years after 9/11, it's clear that the 'war on terror' was far too narrow a prism through which to see the planet. And the price we paid to fight it was far too high" (Applebaum, 2011, p. A17). In this columnist's opinion, the war on terror imposed huge domestic costs on the United States; it diverted US attention away from important issues regarding China, Latin America, and Africa; it aligned the United States with authoritarian regimes in the Middle East even though their authoritarianism helps inspire Islamic terrorism; and it diverted attention away from the need to invest in the American infrastructure: schools, roads, bridges, and medical and other research. In short, the columnist concluded, "in making Islamic terrorism our central priority — at times our only priority—we ignored the economic, environmental and political concerns of the rest of the globe. Worse, we pushed aside our economic, environmental and political problems until they became too great to be ignored” (Applebaum, 2011, p. A17).

To critics like this columnist, the threat to Americans of terrorism is “over-hyped” (Holland, 2011b). They acknowledge the 9/11 tragedy and the real fears of Americans, but they also point out that in the years since 
9/11, the number of Americans killed in car accidents, by air pollution, by homicide, or even by dog bites or lightning strikes has greatly exceeded the number of Americans killed by terrorism. They add that the threat is overhyped because defense industry lobbyists profit from overhyping it and because politicians do not wish to be seen as "weak on terror." And they also worry that the war on terror has been motivated by and also contributed to prejudice against Muslims (Kurzman, 2011).

\section{Key Takeaways}

- Terrorism involves the use of intimidating violence to achieve political ends. Whether a given act of violence is perceived as terrorism or as freedom fighting often depends on whether someone approves of the goal of the violence.

- Several types of terrorism exist. The 9/11 attacks fall into the transnational terrorism category.

\section{For Your Review}

1. Do you think the US response to the $9 / 11$ attacks has been appropriate, or do you think it has been too overdone? Explain your answer.

2. Do you agree with the view that structural problems help explain Middle Eastern terrorism? Why or why not?

\section{References}

Applebaum, A. (2011, September 2). The price we paid for the war on terror. The Washington Post, p. A17.

Brown, D. A. (2009). Bury my heart at Wounded Knee: An Indian history of the American west. New York, NY: Sterling Innovation.

Brown, R. M. (1989). Historical patterns of violence. In T. R. Gurr (Ed.), Violence in America: Protest, rebellion, reform (Vol. 2, pp. 23-61). Newbury Park, CA: Sage Publications.

Gareau, F. H. (2010). State terrorism and the United States: From counterinsurgency to the war on terrorism. Atlanta, GA: Clarity Press.

Gurr, T. R. (1989). Political terrorism: Historical antecedents and contemporary trends. In T. R. Gurr (Ed.), Violence in America: Protest, rebellion, reform (Vol. 2, pp. 201-230). Newbury Park, CA: Sage Publications.

Holland, J. (2011, September 14). How fearmongering over terrorism is endangering American communities. AlterNet. $\quad$ Retrieved from http://www.alternet.org/story/152403/ how fearmongering over terrorism is skewing our priorities and putting us all at risk ?page=entire. 
Kean, T. H., \& Hamilton, L. H. (2007, September 9). Are we safer today? The Washington Post, p. B1.

Kurzman, C. (2011, July 31). Where are all the Islamic terrorists? The Chronicle of Higher Education. Retrieved from http://chronicle.com/article/Where-Are-All-the-Islamic/ $\underline{128443 / \text { ?sid }=\text { cr\&utm source }=\text { cr\&utm medium }=\text { en. }}$.

Priest, D., \& Arkin, W. M. (2010, July 20). A hidden world, growing beyond control. The Washington Post, p. A1. Rubenstein, R. E. (1987). Alchemists of revolution: Terrorism in the modern world. New York, NY: Basic Books. White, J. R. (2012). Terrorism and homeland security: An introduction (7th ed.). Belmont, CA: Wadsworth. 


\subsection{Preventing War and Stopping Terrorism}

\section{Learning Objectives}

1. Outline approaches that show promise for preventing war.

2. Understand the differences between the law enforcement and structural-reform approaches to preventing terrorism.

War has existed since prehistoric times, and terrorism goes back at least to the days of the Old Testament (e.g., when Samson brought down the temple of the Philistines in an act of suicide that also killed scores of Philistines). Given their long histories, war and terrorism are not easy to prevent. However, theory and research by sociologists and other social scientists point to several avenues that may ultimately help make the world more peaceful.

\section{Preventing War}

The usual strategies suggested by political scientists and international relations experts to prevent war include arms control and diplomacy. Approaches to arms control and diplomacy vary in their actual and potential effectiveness. The historical and research literatures on these approaches are vast (Daase \& Meier, 2012; Garcia, 2012) and beyond the scope of this chapter. Regardless of the specific approaches taken, suffice it here to say that arms control and diplomacy will always remain essential strategies to prevent war, especially in the nuclear age when humanity is only minutes away from possible destruction.

Beyond these two essential strategies, the roots of war must also be addressed. As discussed earlier, war is a social, not biological, phenomenon and arises from decisions by political and military leaders to go to war. There is ample evidence that deceit accompanies many of these decisions, as leaders go to many wars for less than noble purposes. To the extent this is true, citizens must always be ready to question any rationales given for war, and a free press in a democracy must exercise eternal vigilance in reporting on these rationales. According to critics, the press and the public were far too acquiescent in the decision to go to war in Iraq in 2003, just as they had been acquiescent a generation earlier when the Vietnam War began being waged (Solomon, 2006). To prevent war, then, the press and the public must always be ready to question assumptions about the necessity of war. The same readiness should occur in regard to militarism and the size of the military budget.

In this regard, history shows that social movements can help prevent or end armament and war and limit the unchecked use of military power once war has begun (Breyman, 2001; Staggenborg, 2010). While activism is no guarantee of success, responsible nonviolent protest against war and militarism provides an important vehicle for preventing war or for more quickly ending a war once it has begun. 


\title{
People Making a Difference
}

\author{
Speaking Truth to Power
}

The American Friends Service Committee (AFSC) is a Quaker organization that has long worked for peace and social justice. Its national office is in Philadelphia, Pennsylvania, and it has local offices in more than thirty other US cities and also in more than a dozen other nations.

AFSC was established in 1917 to help conscientious objectors serve their country in nonmilitary ways during World War I. After that war ended with the defeat of Germany and Austria, AFSC provided food to thousands of German and Austrian children. It helped Jewish refugees after Hitler came to power, and sent various forms of aid to Japan after World War II ended. During the 1960s, it provided nonviolence training for civil rights activists and took a leading role in the movement to end the Vietnam War. Since the 1960s, AFSC has provided various types of help to immigrants, migrant workers, prisoners, and other "have-not” groups in need of social justice. It also works to achieve nonviolent conflict resolution in urban communities and spoke out against plans to begin war in Iraq in 2003.

In 1947, AFSC and its British counterpart won the Nobel Peace Prize for their aid to hungry children and other Europeans during and after World Wars I and II. The Nobel committee proclaimed in part, "The Quakers have shown us that it is possible to carry into action something which is deeply rooted in the minds of many: sympathy with others; the desire to help others... without regard to nationality or race; feelings which, when carried into deeds, must provide the foundations of a lasting peace.”

For almost a century, the American Friends Service Committee has been active in many ways to achieve a more just, peaceable world. It deserves the world's thanks for helping to make a difference. For further information, visit http://www.afsc.org.

As we think about how to prevent war, we must not forget two important types of changes that create pressures for war: population change and environmental change. Effective efforts to reduce population growth in the areas of the world where it is far too rapid will yield many benefits, but one of these is a lower likelihood that certain societies will go to war. Effective efforts to address climate change will also yield many benefits, and one of these is also a lower likelihood of war and ethnic conflict in certain parts of the world.

Finally, efforts to prevent war must keep in mind the fact that ideological differences and prejudice sometimes motivate decisions to go to war. It might sound rather idealistic to say that governments and their citizenries should respect ideological differences and not be prejudiced toward people who hold different religious or other ideologies or have different ethnic backgrounds. However, any efforts by international bodies, such as the United Nations, to achieve greater understanding along these lines will limit the potential for war and other armed conflict. The same potential holds true for efforts to increase educational attainment within the United States and other industrial nations but especially within poor nations. Because prejudice generally declines as education increases, measures that raise educational attainment promise to reduce the potential for armed conflict in addition to the other benefits of increased education.

In addition to these various strategies to prevent war, it is also vital to reduce the size of the US military budget. Defense analysts who think this budget is too high have proposed specific cuts in weapons systems that are not needed and in military personnel at home and abroad who are not needed (Arquilla \& Fogelson-Lubliner, 2011; Knight, 2011; Sustainable Defense Task Force, 2010). Making these cuts would save the nation from $\$ 100$ billion to $\$ 150$ billion annually without at all endangering national security. This large sum could then be spent to help meet the nation's many unmet domestic needs. 


\section{Stopping Terrorism}

Because of 9/11 and other transnational terrorism, most analyses of "stopping terrorism" focus on this specific type. Traditional efforts to stop transnational terrorism take two forms (White, 2012). The first strategy involves attempts to capture known terrorists and to destroy their camps and facilities and is commonly called a law enforcement or military approach. The second strategy stems from the recognition of the structural roots of terrorism just described and is often called a structural-reform approach. Each approach has many advocates among terrorism experts, and each approach has many critics.

Law enforcement and military efforts have been known to weaken terrorist forces, but terrorist groups have persisted despite these measures. Worse yet, these measures may ironically inspire terrorists to commit further terrorism and increase public support for their cause. Critics also worry that the military approach endangers civil liberties, as the debate over the US response to terrorism since 9/11 so vividly illustrates (Cole \& Lobel, 2007). This debate took an interesting turn in late 2010 amid the increasing use of airport scanners that generate body images. Many people criticized the scanning as an invasion of privacy, and they also criticized the invasiveness of the "pat-down" searches that were used for people who chose not to be scanned (Reinberg, 2010).

In view of all these problems, many terrorism experts instead favor the structural-reform approach, which they say can reduce terrorism by improving or eliminating the conditions that give rise to the discontent that leads individuals to commit terrorism. Here again the assessment of the heads of the 9/11 Commission illustrates this view: "We must use all the tools of U.S. power-including foreign aid, educational assistance and vigorous public diplomacy that emphasizes scholarship, libraries and exchange programs - to shape a Middle East and a Muslim world that are less hostile to our interests and values. America's long-term security relies on being viewed not as a threat but as a source of opportunity and hope” (Kean \& Hamilton, 2007, p. B1).

Although there are no easy solutions to transnational terrorism, then, efforts to stop this form of terrorism must not neglect its structural roots. As long as these roots persist, new terrorists will come along to replace any terrorists who are captured or killed. Such recognition of the ultimate causes of transnational terrorism is thus essential for the creation of a more peaceable world.

\section{Key Takeaways}

- Arms control and diplomacy remain essential strategies for stopping war, but the roots of war must also be addressed.

- The law enforcement/military approach to countering terrorism may weaken terrorist groups, but it also may increase their will to fight and popular support for their cause and endanger civil liberties.

\section{For Your Review}

1. Do you think deceit was involved in the decision of the United States to go to war against Iraq in 2003? 
Why or why not?

2. Which means of countering terrorism do you prefer more, the law enforcement/military approach or the structural-reform approach? Explain your answer.

\section{References}

Arquilla, J., \& Fogelson-Lubliner. (2011, March 13). The Pentagon’s biggest boondoggles. New York Times, p. WK12.

Breyman, S. (2001). Why movements matter: The west German peace movement and US arms control policy. Albany, NY: State University of New York Press.

Cole, D., \& Lobel, J. (2007). Less safe, less free: Why America is losing the war on terror. New York, NY: New Press.

Daase, C., \& Meier, O. (Eds.). (2012). Arms control in the 21st century: Between coercion and cooperation. New York, NY: Routledge.

Garcia, D. (2012). Disarmament diplomacy and human security: Regimes, norms, and moral progress in international relations. New York, NY: Routledge.

Kean, T. H., \& Hamilton, L. H. (2007, September 9). Are we safer today? The Washington Post, p. B1.

Knight, C. (2011). Strategic adjustment to sustain the force: A survey of current proposals. Cambridge, MA: Project on Defense Alternatives.

Reinberg, S. (2010, November 23). Airport body scanners safe, experts say. Bloomberg Businessweek. Retrieved from http://www.businessweek.com.

Solomon, N. (2006). War made easy: How presidents and pundits keep spinning us to death Hoboken, NJ: Wiley. Staggenborg, S. (2010). Social movements. New York, NY: Oxford University Press.

Sustainable Defense Task Force. (2010). Debt, deficits, \& defense: A way forward. Cambridge, MA: Project on Defense Alternatives.

White, J. R. (2012). Terrorism and homeland security: An introduction (7th ed.). Belmont, CA: Wadsworth. 


\subsection{End-of-Chapter Material}

\section{Summary}

1. President Eisenhower warned of the dangers of a high military budget and the militarism of the United States.

2. War actually serves several functions according to functional theory, but conflict theory emphasizes the many problems war causes and the role played in militarism by the military-industrial complex. Symbolic interactionism focuses on the experiences of soldiers and civilians in the military and in wartime and on their perceptions of war and the military.

3. War is best regarded as a social phenomenon rather than a biological phenomenon. Decisions to go to war are sometimes based on noble reasons, but they also involve deceit and prejudice.

4. Civilians and veterans are both victims of war. Civilian deaths in war are almost inevitable, and atrocities are far from rare. American veterans are at greater risk for PTSD, unemployment, and several other problems that also affect their families.

5. The United States has the highest military budget by far in the world. Debate continues over the size of this budget; critics say that the United States would have a higher quality of life if the military budget were reduced and the saved dollars spent on unmet social needs.

6. Terrorism is best regarded as rational behavior committed for political reasons rather than as psychologically abnormal behavior. The US response to the $9 / 11$ attacks has cost hundreds of billions of dollars, and critics say that the war on terrorism has both exaggerated the threat of terrorism and diverted attention and funds from unmet social needs.

\section{Using What You Know}

You are a key aide to a US senator who has been asked to participate in a university forum on the size of the US military budget. The senator asks you to write a memo for her that summarizes the arguments on both sides of debate on the military budget and that also indicates your own view of what position the senator should take on this debate. What position will you recommend to the senator? Explain your answer in detail.

\section{What You Can Do}

To help deal with the problems of war and terrorism discussed in this chapter, you may wish to do any of the following:

1. Educate yourself about the military budget and publish a pamphlet on the web and/or in print that critically examines the size of this budget.

2. Form or join a peace group on your campus or in the surrounding community that calls attention to the various problems related to the military that were discussed in this chapter. 
3. Because prejudice against Muslims increased after $9 / 11$, form or join a group in your campus or surrounding community that seeks to improve relations between Muslims and non-Muslims. 


\section{Supplementary materials}

Power Point slides and discussion questions and topics are available. These materials were written by Dr. Antoinette Aizon (antoinette.aizon@scccd.edu), a psychology and sociology professor at Reedley College. These supplementary materials are made available through a CC BY-NS-SA 4.0 license.

Social Problems: Continuity and Change supplementary materials 